Quality of

Surface Waters of the United States,

1967

Parts 3 and 4. Ohio River Basin and St. Lawrence River Basin

GEOLOGICAL SURVEY WATER-SUPPLY PAPER 2012

Prepared in cooperation with the States of Alabama, Georgia, Illinois, Indiana, Kentucky, Maryland, Michigan, New York, North Carolina, Ohio, Pennsylvania, Tennessee, Virginia, West Virginia, Wisconsin, and with other agencies

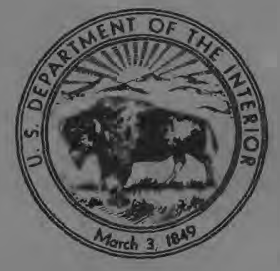




\section{Quality of}

Surface Waters of the

\section{United States,}

1967

Parts 3 and 4. Ohio River Basin and St. Lawrence River Basin

Prepared in cooperation with the States of Alabama, Georgia, Illinois, Indiana, Kentucky, Maryland, Michigan, New York, North Carolina, Ohio, Pennsylvania, Tennessee, Virginia, West Virginia, Wisconsin, and with other agencies

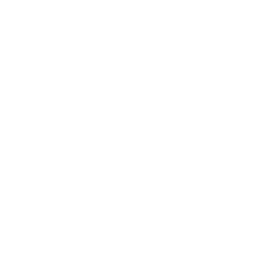




\section{UNITED STATES DEPARTMENT OF THE INTEFIOR}

ROGERS C. B. MORTON, Secretary

\section{GEOLOGICAL SURVEY}

W. A. Radlinski, Acting Director

Library of Congress catalog card No. GS 43-68

For sale by the Superintendent of Documents, U.S. Government Prirting Office Washington, D.C. 20402 - Price $\$ 2.45$ (paper cover)

Stock Number 2401-1200 


\section{PREFACE}

This report was prepared by the U.S. Geological Survey in cooperation with the States of Alabama, Georgia, Illinois, Indiana, Kentucky, Maryland, Michigan, New York, North Carolina, C'io, Pennsylvania, Tennessee, Virginia, West Virginia, Wiscorsin, and with other agencies, by personnel of the Water Resources Division, E. L. Hendricks, chief hydrologist, G. W. Whetstone, assistant chief hydrologist for Scientific Publications and Data Management, under the general direction of G. A. Billingsley, chief, Reports Section, and B. A. Anderson, chief, Data Reports Unit.

The data were collected under the supervision of district chiefs of the Water Resources Division as follows:

A. D. Ash. Lansing, Mich.

N. H. Beamer...........................Harrisburg, Pa. W. L. Broadhurst....................... Tuscaloosa, Ala.

A. N. Cameron...........................Atlanta, Ga.

J. H. Cragwall, Jr......................Nashville, Tenn.

J. W. Gambrell..............................Richmond, Va. W. C. Griffin..............................Charleston, W. Va. M. D. Hale.......................... Indianapolis, Ind. R. C. Heath.................................Raleigh, N. C. C. L. R. Holt, Jr...........................Madison, Wis. W. D. Mitchell...........................Champaign, Ill. J. J. Molloy.................................Columbus, Ohio G. G. Parker....................................Albany, N. Y. F. F. Schrader.........................Louisville, Ky. W. F. White.............................Parkville, Md. 


\section{CONTENTS}

Preface........................ III

List of Water-Quality stations, in downstream order, for which records are published.... VII

Introduction ....................... 1

Collection and examination of data.......... 4

Chemical quality................... 5

Temperature.................... 5

Sediment..................... 6

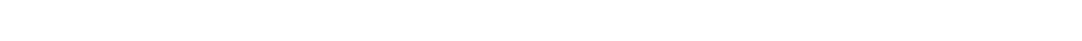

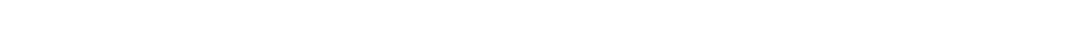

Mineral constituents in solution........... 11

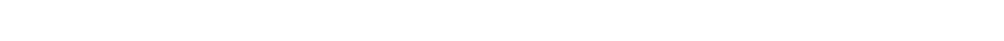

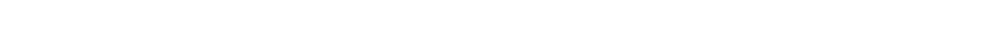

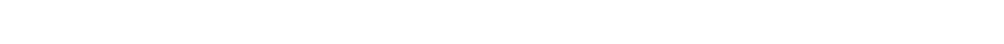

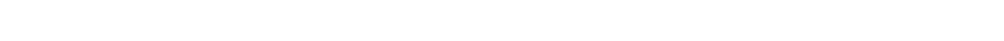

Calcium....................... 12

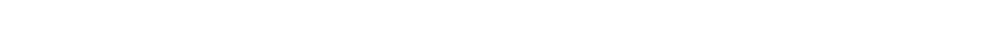

Strontium...................... 12

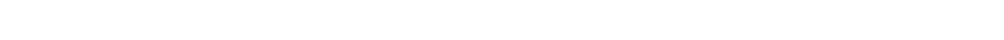

Lithium....................... 13

Bicarbonate, carbonate and hydroxide....... 13

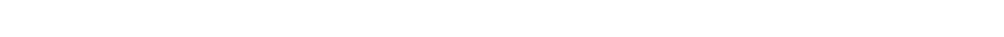

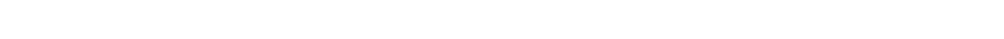

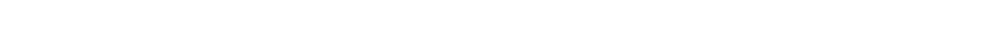

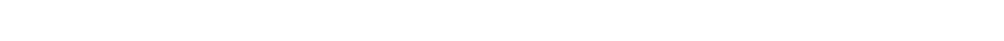

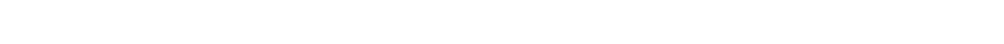

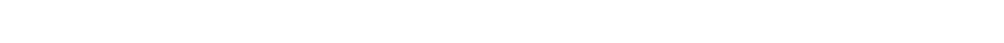

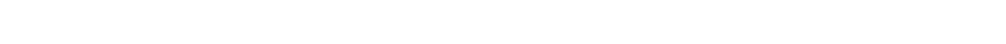

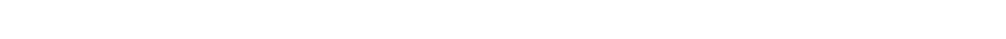

Nickel and cobalt................. 15

Copper...................... 16

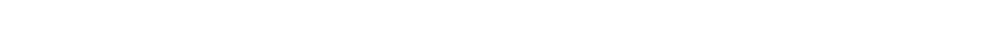

Zinc......................... 17

Barium. .................... 17

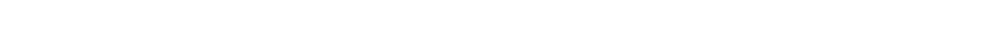

Iodide........................ 17

Properties and characteristics of water...... 18

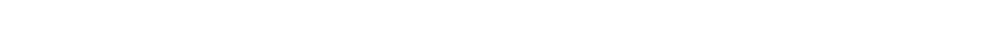

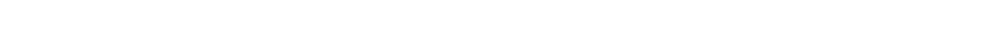

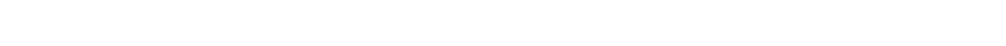

Specific conductance.................. 20 
Composition of surface waters--Continued

Properties and characteristics of water--Continued

Hydrogen-ion concentration............

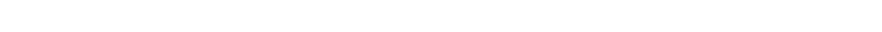

Oxygen consumed.

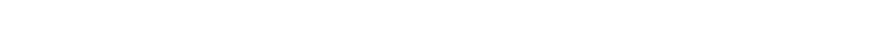

Biochemical oxygen demand............ 21

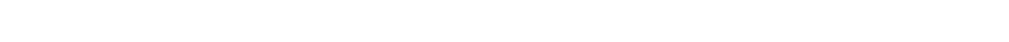

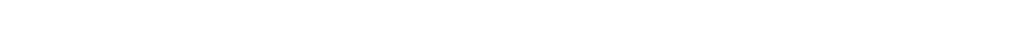

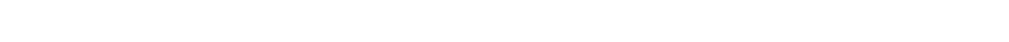

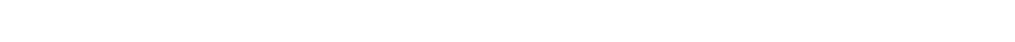

Sediment....................... 24

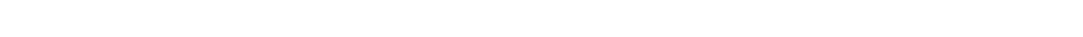

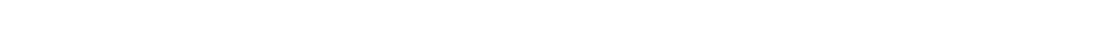

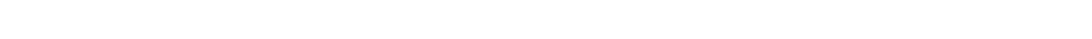

Division of work.................... 29

Literature cited.................... 31

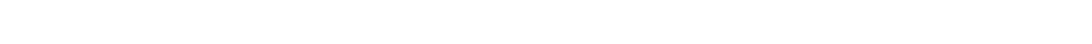

\section{$\overline{\text { ILLUSTRATION }}$}

Figure 1. Map of the United States showing basins covered by the six water-supply papers on quality of surface waters in 1967. 


\section{WATER-QUALITY STATIONS, IN DOWNSTREAM ORDER, FOR WHICH RECORDS ARE PUBLISHED}

[Letters after station name designate type of data: (c) chemical, (t) water temperature, (s) sediment]

OHIO RIVER BASIN

Allegheny River (head of Ohio River) below reservoir, near Kinzua, $\mathrm{Pa}$. (ct).........

Page

Allegheny River near Kinzua, Pa. (ct)............ 36 CONEWANGO CREEK BASIN

Conewango Creek at Waterboro, N.Y. (c)....... CLARION RIVER BASIN

Clarion River:

Toms Run at Cooksburg, Pa. (c)...........

Allegheny River at Kittanning, $\mathrm{Pa}$ ( $(\mathrm{ct}) \ldots \ldots \ldots \ldots$ KI SKIM INETAS RIVER BASIN

Stony Creek (head of Kiskiminetas River):

Conemaugh River (continuation of Stony Creek)

at Seward, $\mathrm{Pa} .(\mathrm{ct}) \ldots \ldots \ldots \ldots \ldots \ldots \ldots . . . . .$.

Kiskiminetas River at Leechburg (Vandergrift),

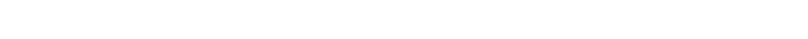

Allegheny River at Oakmont, $\mathrm{Pa}$ ( $(\mathrm{ct}) \ldots \ldots \ldots \ldots \ldots$

MONONGAHELA RIVER BASI N

Tygart Valley River (head of Monongahela

River) at Elkins, w. Va. (t)..........

Roaring Creek at Norton, W. Va. (ts)........

Grassy Run at Norton, w. Va. (ts)..........

Monongahela River at lock and dam 8, at Point

Marion, Pa. (ct).................... 58

Cheat River at Lake Lynn, $\mathrm{Pa} .(\mathrm{t}) \ldots \ldots . . . . . .61$

Youghiogheny River at Friendsville, Md. (t). 62

Casselman River at Grantsville, Md. (c)... 63

Monongahela River at South Pittsburg, $\mathrm{Pa}$.

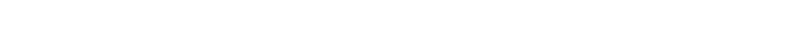

64

BEAVER RIVER BASIN

Mahoning River (head of Beaver River):

West Branch Mahoning River near Ravenna,

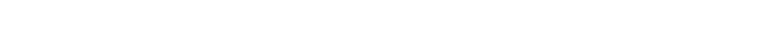

Mahoning River at Leavittsburg, Ohio (ct).....

Mahoning River at Lowellville, Ohio (ct)......

Mahoning River at Ohio-Pennsylvania State

69

71

line, below Lowellville, Ohio (ct)...... 73

Ohio River at Stratton, Ohio (ct)........... 77

MUSK INGUM RIVER BASI N

Muskingum River:

Walhounding River:

Killbuck Creek at Killbuck, Ohio (ts)..... 
OHIO RIVER BASIN--Continued

MUSKINGUM RIVER BASIN--Continued

Muskingum River:--Continued

Wills Creek:

Salt Fork at mouth, near Cambridge,

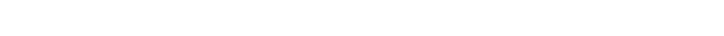

Muskingum River at Dresden, Ohio (ts).........

Licking River near Newark, Ohio ( $t) \ldots . . . . .$.

Licking River below Dillon Dam, near Dillon

Falls, Ohio $(t) \ldots \ldots \ldots \ldots \ldots \ldots \ldots \ldots . . . . .$.

Muskingum River at Philo, Ohio (ct)..........

Muskingum River near Beverly, Ohio (ct).......

HOCKING RIVER BASIN

Hocking River below Athens, Ohio (ct)........ KANAWHA RIVER BASIN

New River at Glen Lyn, Va. (ct).............. 100

New River at Bluestone Dam, W. Va. ( $t) \ldots \ldots \ldots . . .101$

Greenbrier River:

Knapp Creek at Marlinton, W. Va. (t)...... 102

Kanawha River at Cabin Creek, w. Va. ( $t$...... 103

Elk River at Sutton, $W$. Va. (t)............. 104

Elk River near Frametown, $w$. Va. ( $t) \ldots \ldots \ldots . .105$

Elk River at Clay, w. Va. (t).............. 106

Elk River at Queen Shoals, W. Va. $(t) \ldots \ldots . . .107$

Kanawha River at Charleston, $w$. Va. ( $t$....... 108

Kanawha River at Winfield Dam, at Winfield, W. Va. (ct)....................... 109

RACCOON CREEK BASIN

Raccoon. Creek at Adamsville, Ohio (ct)........ BIG SANDY RIVER BASIN

Levisa Fork (head of Big Sandy River):

Russell Fork at Elkhorn City, Ky. (t).......

Johns Creek near Van Lear, Ky. (t).........

Levisa Fork at Paintsville, Ky (ts).........

Tug Fork at Kermit, w. Va. $(t) \ldots . . . \ldots \ldots . .$. TYGARTS CREEK BASIN

Tygarts Creek near Greenup, Ky. (ts)........ SCIOTO RIVER BASIN

Scioto River:

Olentangy River:

Whets tone Creek near Ashley, Ohio (c).....

olentangy River near Worthington, Ohio $(t) \ldots$ Big Walnut Creek:

Alum Creek at Africa, Ohio (ct)...........

Scioto River below Shadehill, Ohio (ct).......

Deer Creek at Williamsport, Ohio (ct)....... 136

Scioto River at Chillicothe, Ohio (ct)........ 139

Paint Creek near Bourneville, ohio (ct)..... 142

Scioto River at Higby, Ohio (cts)............. 146

Scioto River at Lucasville, ohio (ct).......... 152

UPPER TWIN CREEK BASIN

Upper Twin Creek at McGaw, Ohio (cs).........

LITTLE MIAMI RIVER BASIN

Little Miami River:

East Fork Little Miami River at Perintown,

Ohio (ct)...................... 
LICKING RIVER BASIN

Licking River at Farmers, Ky. ( $t s) \ldots \ldots \ldots \ldots \ldots$

Licking River at McKinneysburg, Ky. (cts).....

South Fork Licking River at Cynthiana, Ky.

(t) ..........................

168

GREAT MIAMI RIVER BASIN

Great Miami River at Troy, Ohio (c)..........

Great Miami River near Taylorsville Dam, at

Taylorsville, Ohio (c)............... 170

Stillwater River at Pleasant Hili, Ohio (s). 172

Stillwater River at Englewood, Ohio (c)..... 176

Mad River at Eagle City, Ohio (ts)......... 178

Mad River near Dayton, Ohio (c) ............... 181

Great Miami River at West Carroliton, Ohio (c) 183

Great Miami River near Miamisburg, Ohio (ct).. 185

Twin Creek at Germantown, Ohio (c)......... 190

Great Miami River at Middletown, Ohio (c)..... 191

Great Miami River near Middletown, Ohio (c)... 193

Great Miami River at Hamilton, Ohio (t)....... 195

Great Miami River near Hamil ton, Ohio (c)..... 196

Great Miami River at New Bal timore, Ohio (ct). 198

Great Miami River at Elizabe thtown, Ohio (ct). 201

Ohio River at Markland Dam, near Warsaw, Ky.

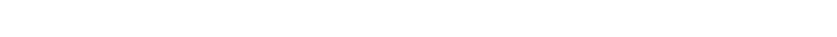

KENTUCKY RIVER BASIN

North Fork Kentucky River:

Car $r$ Fork near Sassafras, Ky. (t)..........

North Fork Kentucky River at Hazard, Ky. (ct).

Dix River at Dix Dam, near Burgin, Ky. (t)..

Kentucky River at lock 4 , at Frankfort, Ky.

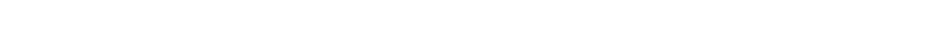

Eagle Creek at Glencoe, Ky. (ts)...........

SALT RIVER BASIN

Salt River at Shepherdsville, Ky. (c)........

Rolling Fork near Boston, Ky. (t).......... GREEN RIVER BASIN

Green River near Campbellsville, Ky. ( $t$ )......

Green River near Greensburg, Ky. (c).........

Little Barren River near Monroe, Ky. (c)....

Green River at Munfordville, Ky. (cts)........

Green River at Mammoth Cave, Ky. (c)..........

Wet Prong Buffalo Creek near Mammoth Cave,

$\mathrm{Ky} .(\mathrm{cs}) \ldots \ldots \ldots \ldots \ldots \ldots \ldots \ldots \ldots \ldots \ldots \ldots$

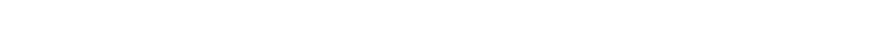

Barren River near Finney, Ky. (t)...........

Barren River at Bowling Green, Ky. (ct).....

Rough River at Rough River Dam, near Falis

$$
\text { of Rough, } \mathrm{Ky} .(\mathrm{t}) \ldots \ldots \ldots \ldots \ldots \ldots \ldots \ldots \ldots
$$

205

211

213

216

222

226

227

Rough River at Dundee, Ky. (t)............

WABASH RIVER BASIN

Wabash River at Huntington, Ind. $(t) \ldots \ldots \ldots \ldots$

Wabash River at Lafayette, Ind. (ts)..........

Big Raccoon Creek near Fincastle, Ind. ( $t s)$.

White River near Noblesville, Ind. (t)......

White River at Noblesville, Ind. (t)........ 
OHIO RIVER BASIN--Continued

WABASH RIVER BASIN--Conti nued

Wabash River--Continued

White River near Nora, Ind. (t)..........

White River near Centerton, Ind. ( $t s) \ldots \ldots$.

East Fork White River at Seymour, Ind. $(t \dot{s})$

Salt Creek near Har rodsburg, Ind. ( $t) \ldots$

White River at Petersburg, Ind. (t)....... TRADEWATE R RIVER BASIN

Tradewater River at Olney, Ky. (cts)......... CUMBERLAND RIVER BASIN

Yellow Creek near Middlesboro, Ky. (c)...... Cumberland River at Barbourville, Ky. ( $t$ )..... Cumberland River near Burkesville, Ky. (ct)... TENNESSEE RIVER BASIN

French Broad River (head of Tennessee River)

at Rosman, N.C. (c)..................

French Broad River at Blantyre, N.C. (c)......

French Broad River at Bent Creek, N.C. (c)....

French Broad River at Asheville, N.C. (c).....

French Broad River at Marshall, N.C. (ct)..... French Broad River at Hot Springs, N.C. (c)... Pigeon River at Canton, N.C. (c)...........

Pigeon River near Hepco, N.C. (c)...........

Cataloochee Creek near Cataloochee, N.C.

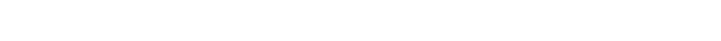

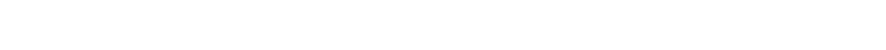
North Toe River:

South Toe River near Celo, N.C. (ct)......

Holston River:

Beech Creek at Kepler, Tenn. (ct).........

Holston River near Rogersville, Tenn. (t)...

Little River above Townsend, Tenn. (ct).....

Tucka segee River at Dillsboro, N.C. (c)...

Tuckasegee River at Bryson City, N.C. (c).

Little Tennessee River below Chilhowee Dam,

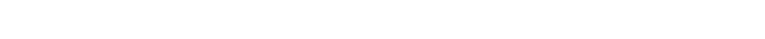

Tellico River at Teliico Piains, Tenn. (

Clinch River at Speers Ferry, Va. ( $t) \ldots . .$. .

Powell River near Jonesville, Va. ( $\mathrm{t}) \ldots .$. .

Bullrun Creek near Halls Crossroads,

Tenn. $(t) \ldots \ldots \ldots \ldots \ldots \ldots \ldots \ldots . . \ldots$

291

292

293

294

295

296

297

298

Poplar Creek:

East Fork Poplar Creek near Oak Ridge, Tenn. $(t) \ldots \ldots \ldots \ldots \ldots \ldots \ldots \ldots$

Emory River:

Crab Orchard Creek near Deermont, Tenn. (ct)

Hiwassee River:

Valley River at Tomotla, N.C. (ct)....... 303

Toccoa River near Dial, Ga. (t).......... 305

Sequatchie River near Whitwell, Tenn. ( $t) \ldots 306$

Flint River near Chase, Ala. 
OHIO RIVER BASIN--Conti nued

TENNESSEE RIVER BASIN--Conti nued

Tennessee River--Continued

Flint River--Conti nued

Elk River:

Richland Creek near Pulaski, Tenn. (ct).

Page

Bear Creek near Hackl eburg, Ala. (ct)....... 308

Cedar Creek near Pleasant Site, Ala. ( $t)$.. 310

Little Bear Creek near Halltown, Ala. $(t)$

Bear Creek at Bishop, Ala. ( $t) \ldots \ldots \ldots \ldots \ldots \ldots$ 312

313

Duck River:

Piney River at Vernon, Tenn. (ct)........ 314

Buffalo River near Flat Woods, Tenn. (ct).

Tennessee River at Kentucky Dam, near

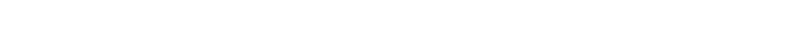

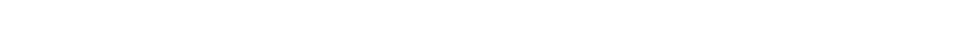

Ohio River at lock and dam 53, near Grand Chain,

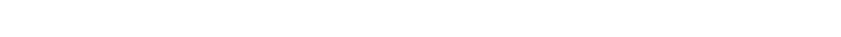
Analyses of samples collected at low flow on streams in the Ohio River basin in Ohio...

Pesticide analyses of streams in the Ohio River

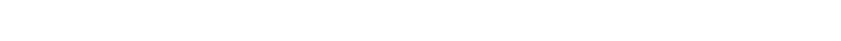
Miscellaneous analyses of 1 akes and streams in Ohio River basin................... ₹35 Records available for water temperatures....... 383

ST. LAWRENCE RIVER BASIN

STREAMS TRIBUTARY TO LAKE SUPERIOR

Washington Creek at Windigo, Mich. (ct)....... STREAMS TRIBUTARY TO LAKE MICHIGAN

Black River near Garnet, Mich. (t).......... Middle Branch Escanaba River:

Black River near Republic, Mich. (ct)....... Middle Branch Escanaba River near Ishpeming, Mich. (t) ......................

Schweitzer Creek near Palmer, Mich. (t)..... Ford River near Hyde, Mich. (t)............. Brule River:

Peshekee River near Champion, Mich. ( $t) \ldots . .$.

Michagamme River near Witch Lake, Mich, (cts) Menominee River:

Pine River :

Popple River near Fence, Wis. (cts).......

Sturgeon River near Foster City, Mich. ( $t$ )

Grand River near Eaton Rapids, Mich. ( $t) \ldots . .$. Grand River at Lansing, Mich. $(t) \ldots . . . \ldots . .$. Grand River at Portland, Mich. $(t) \ldots \ldots \ldots \ldots \ldots$ Muskegon River at Evart, Mich. (t)...........

Little Muskegon River near Morley, Mich. ( $t$ ) Manistee River near Grayling, Mich. (t)....... Pine River near Luther, Mich. (s)........... Silver Creek near Luther, Mich. (s)......... Pine River near Wellston, Mich. (s)......... Little Manistee River near Freesoil, Mich. 
ST. LAWRENCE RIVER BASIN--Con tinued

STREAMS TRIBUTARY TO LAKE MICHIGAN--Continued

Page

Boardman River near Mayfield, Mich. (t)....... 418

Jordan River near East Jordan, Mich. ( $t$....... 419

STREAMS TRIBUTARY TO LAKE HURON

Burt Lake (head of Cheboygan River):

Sturgeon River near Wolverine, Mich. ( $t) \ldots$.

Au Sable River at Grayling, Mich. (t)......... 421

South Branch Au Sable River near Luzerne,

Rifle River:

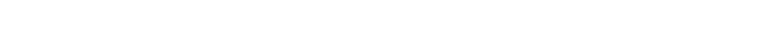

422

Houghton Creek near Lupton, Mich. (t).......

Rifle River at "The Ranch," near Lupton, Mich.

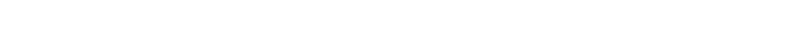

Prior Creek near Seikirk, Mich. $(t) \ldots \ldots \ldots$

Rifle River at Selkirk, Mich. (t)...........

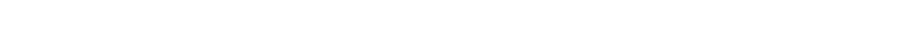

Shiawassee River at Byron, Mich. (t)..........

Shiawassee River at Owosso, Mich. (s).........

Cass River at Frankenmuth, Mich. (s)....... STREAMS TRIBUTARY TO ST. CLAIR RIVER

Black River near Fargo, Mich. (s)........... STREAMS TRIBUTARY TO LAKE ST. CLAIR

Clinton River near Drayton plains, Mich. (t)..

Clinton River near Fraser, Mich. (s)......... STREAMS TRIBUTARY TO LAKE ERIE

River Raisin near Monroe, Mich. (ts).........

Maumee River (continuation of St. Joseph River):

St. Marys River near Fort Wayne, Ind. ( $t r)$.. Maumee River at Defiance, Ohio (ct).......... Auglaize River at Cloverdale, Ohio (ct).....

Auglaize River near Defiance, Ohio (ct).....

Maumee River at Waterville, Ohio (cts)........

Maumee River at Toledo Overseas Terminal dcok, at Toledo, Ohio (c)..................

Maumee River at mouth, at U.S. Coast Guard Station, at Toledo, Ohio (ct).........

Maumee River at Center $C$. and $O$. Railroad dock, at Toledo, Ohio (c).............

Sandusky River below Fremont, Ohio (ct).......

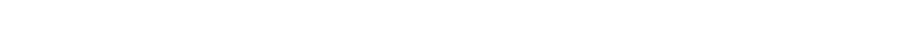

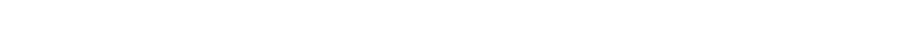

Cuyahoga River at Independence, Ohio (cts)....

Cuyahoga River at Dupont intake in Cleveland, Ohio (c).........................

Cuyahoga River at West Third Street Bridge, Cleveland, Ohio (ct).................

Cuyahoga River at Center street Bridge in Cleveland, Ohio (ct).

Grand River at Painesville, ohio (ct) $\ldots . . .$.

Buffalo Creek at Gardenvilie, N.Y. (c)......... 
ST. LAWRENCE RIVER BASIN--Continued

STREAMS TRIBUTARY TO LAKE ONTARIO--Continued

Genesee River--Continued

Canaseraga Creek near Canaseraga, N.Y. (t)..

Page

Genesee River at Driving Park Avenue,

Rochester, N.Y. (t) ............... 5no

Seneca River at Baldwinsvilie, N.Y. (t)....... 501

West Branch Fish Creek at Blossvale, N. Y.

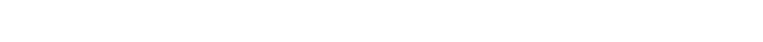

East Branch Fish Creek at Taberg, N.Y.(ct) Oneida Lake:

Oneida Creek at Oneida, N.Y. (c) ......... 505

Canaseraga Creek near Lakeport, N.Y. (c).. 506 Cowaselon Creek at Onion town, N.Y. (c).. 507

Chittenango Creek:

Limestone Creek:

Butternut Creek near Jamesville, N.Y.

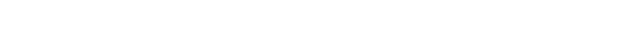

Chittenango Creek at Bridgeport, $\hat{N}_{.} \mathrm{Y}_{\text {. (c). }}$.

Scriba Creek near Constantia, N.Y. (ct)... Oneida Lake, USGS Station No.9, N.Y. (c)... Oneida Lake, USGS Station No. 10, N.Y. (c).. Oneida Lake, USGS Station No. 8, N.Y. (c)... Oneida Lake, USGS Station No. 11, N.Y. (c).. Oneida Lake, USGS Station No. 12, N.Y. (c).. Oneida Lake, USGS Station No. 13, N.Y. (c)... Oneida Lake, USGS Station No. 14, N.Y. (c)... Oneida Lake, USGS Station No. 15, N.Y. (c)... Oneida Lake, USGS Station No. 16, N.Y. (c)... Oneida Lake, USGS Station No. 18, N.Y. (c)... Oneida Lake, USGS Station No. 19, N.Y. (c).. Oneida Lake, USGS Station No. 17, N.Y. (c).. Oneida Lake, USGS Station No. 20, N.Y. (c).. Oneida Lake, USGS Station No. 21, N.Y. (c).. Oneida Lake, USGS Station No. 22, N.Y. (c).. Oneida River below dam, at Caughdenoy,

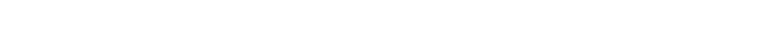

\section{Black River:}

Independence River at Donnattsburg, $N . Y .(t)$

Beaver River at Moshier Falls, N.Y. ( $t) \ldots .$. .

Black River at Water town, N.Y. (ct).......... 502 503 506

Lake Champlain (head of Richelieu River):

Bouquet River at Willsboro, N.Y. (c).......

Chemical quality of lakes in Oakland County,

Mich.........................

Chemical-Quality investigation of Cold Water

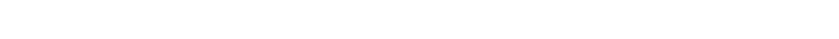


XIV WATER-QUALITY STATIONS, IN DOWNSTREAM ORDER

ST. LAWRENCE RIVER BASIN--Continued

Pesticide analyses of Streams in st. Lawrence

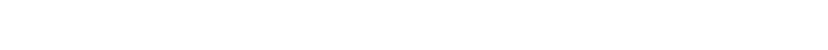

Page

Miscellaneous analyses of lakes and streams in

St. Lawrence River basin.............. 546

Index.............................. 571 


\title{
QUALITY OF SURFACE WATERS OF THE UNITED STATES, 1967
}

\author{
PARTS 3 and 4
}

\section{INTRODUCTION}

The quality-of-water investigations of the United States Geological Survey are concerned with chemical and physical characteristics of the surface and ground water supplies of the Nation. Most of the investigations carried on in cooperation with Stat $\epsilon$ and Federal agencies deal with the amounts of matter in solutior and in suspension in streams.

The records of chemical analysis, suspended sediment, and temperature of surface waters given in this volume serve as a basis for determining the suitability of waters for various uses. The flow and water quality of a stream are related to variations in rainfall and other forms of precipitation. In general, lower concentrations of dissolved solids may be expected during periods of high flow than during periods of low flow. Conversely, the suspended solids in some streams may change materially with relatively small variations in flow, whereas for other streams the quality of the water may remain relatively uniform throughout large ranges in discharge.

The Geological Survey has published annual records of chemical quality, water temperature, and suspended sediment since 1941. The records prior to 1948 were published each year in a single volume for the entire country, and in two volumes in 1948 and in 1949. From 1950 to 1958, the records were publisted in 4 volumes; from 1959 to 1963 in 5 volumes; and since 1S 54 in 6 volumes. The drainage basins covered by the six volumes are shown in Figure 1. The shaded area in Figure 1 represents the section of the country covered in this volume for the water year 1967 (October 1, 1966 to September 30, 1967).

To meet interim requirements, water-quality records have been released by the Geological Survey in annual reports, beginning with the 1964 water year, by State. These reports are entitled, "Water Resources Data for (State), Part 2. Water Q rality 
Records." Distribution of these reports is limited and primarily for local needs. Any revisions or corrections fount necessary to the records published in these annual State repor's have been made and published in this volume without reference.

The records herein are listed by drainage basins in a downstream direction along the main stream. All stations on a tributary entering above a mainstream station are listed before that station. A station on a tributary that enters between two mainstream stations is listed between them. A similar order is followed in listing stations on first rank, second ran', and other ranks of tributaries. In the list of water-quality stations in the front of this volume, the rank of the tributaries is indicated by an indention. Each indention represents one rank.

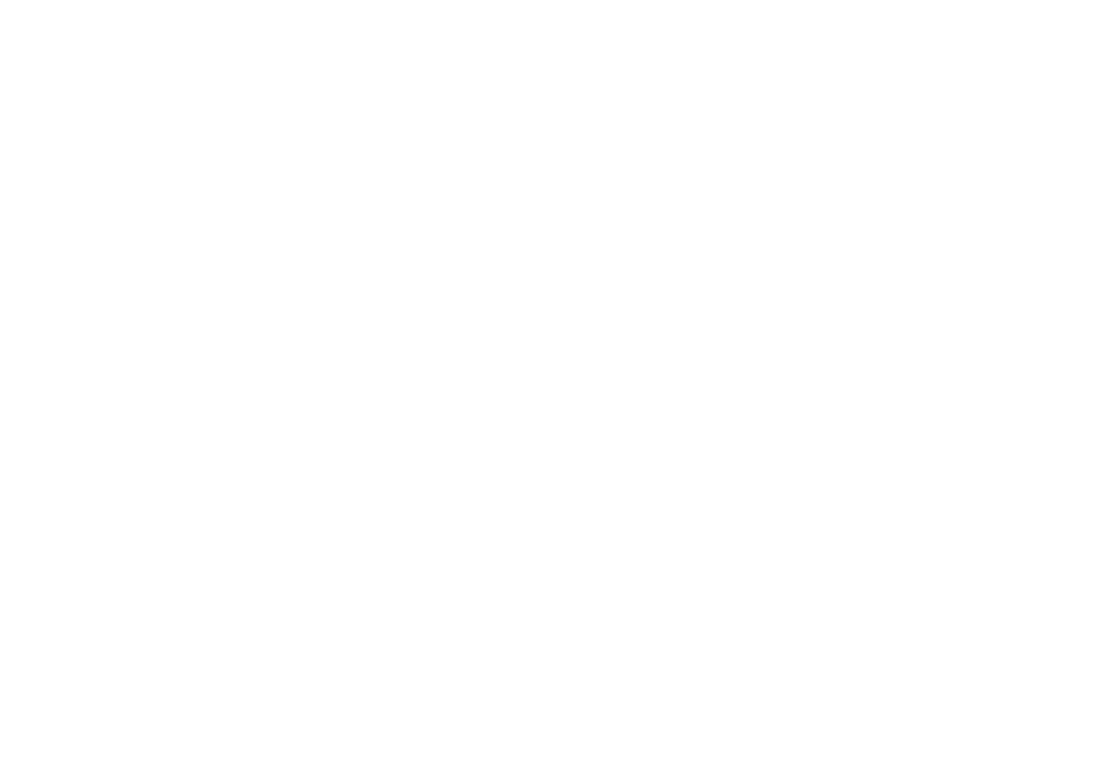

Figure 1.--Map of the United States showing basins covered by the six water-supply papers on quality of surface waters in 1967 . The shaded part represents the section of the country covered by this volume; the unshaded part represents the section of the country covered by other water-supply pafers.

A station number has been assigned as an added means of identification for each stream location where regular measurements of water quantity or quality have been made. The numbers have been assigned to conform with the standard downstream order of 
listing gaging stations. The numbering system consists of $2 \mathrm{~d}$ 'gits followed by a hyphen and a 6-digit number. The notation to the left of the hyphen identifies the Part or hydrologic region used by the Geological Survey for reporting hydrologic data. The num ber to the right of the hyphen represents the location of the station in the standard downstream order within each of the 16 parts (Fig. 1). The assigned numbers are in numerical order but: are not consecutive. They are so selected from the complete 6-c'igitnumber scale that intervening numbers will be available for future assignments to new locations. The identification number for each station in this report is printed to the left of the station name and contains only the essential digits. For example, the number is printed as 4-0100 for a station whose complete indentification number is $04-0100.00$.

Descriptive statements are given for each sampling station where chemical analyses, temperature measurements, or sediment determinations have been made. These statements in -lude location of the station, drainage area, periods of records avai]able, extremes of dissolved solids, hardness, specific conductance, temperature, sediment loads, and other pertinent data. Recorls of discharge of the streams at or near the sampling station are included in most tables of analyses.

During the water year ending September 30, 1967, the Geological Survey maintained 237 stations on 145 streams for the study of chemical and physical characteristics of surface vater. Samples were collected daily and monthly at 144 of these locations for chemical-quality studies. Samples also were collected less frequently at many other points. Water temperatures were neasured continuously at 101 and daily at 65 stations. All surface water samples collected and analyzed during the year have not been included. Single analyses made of daily samples refore compositing have not been reported. Specific conductarce is determined and reported for almost all daily samples.

At chemical-quality stations where data are continuously recorded at the stream site (monitors), the records consist of daily maximum, minimum, and mean values for each constituent measured. More detailed records (hourly values) may be ob+ained by writing the district office listed under Division of Work on pages 29 and 30 .

Quantities of suspended sediment are reported for 34 stations during the year ending September 30, 1967. Sediment samples were collected one or more times daily at most stations, depending on the rate of flow and changes in stage of the stream. Particlesize distributions of sediments were determined at 22 stations. 
Some of the stations for which data are published in this volume are included in special networks and programs. These stations are identified by their title, set in parentheses, under the station name.

Hydrologic bench-mark station is one that provides hydrologic data for a basin in which the hydrologic regimen will likely be governed solely by natural conditions. Data collected at a benchmark station may be used to separate effects of natural from manmade changes in other basins which have been dereloped and in which the physiography, climate, and geology are similar to those in the undeveloped bench-mark basin.

International Hydrological Decade (IHD) River Stations provide a general index of runoff and materials in the water balance (discharge of water, and dissolved and transported solids) of the world. In the United States, IHD Stations provide indices of runoff and the general distribution of water in the principal river basins of the conterminous United States and Alaska.

Irrigation network stations are water-quality stations located at or near certain streamflow gaging stations west of the main stem of the Mississippi River. Data collected at these statiors are used to evaluate the chemical quality of surface waters used for irrigation and the changes resulting from the drainage cf irrigated lands. Prior to water year 1966, these data were piblished in the annual water-supply paper series, "Quality of Surface Water for Irrigation, Western States."

Pesticide program is a network of regularly sampled waterquality stations where additional monthly samples are collected to determine the concentration and distribution of pesticides in streams whose waters are used for irrigation or in streams in areas where potential contamination could result from the application of the commonly used insecticides and larbicides.

Radiochemical program is a network of regularly sampled water-quality stations where additional samples are collected twice a year (at high and low flow) to be analyzed for radioisotopes. The streams that are sampled represent major drainage basins in the conterminous United States.

\section{COLLECTION AND EXAMINATION OF DATA}

Quality of water stations usually are located at or roar points on streams where streamflow is measured by the U.S. Geological Survey. The concentration of solutes and sediraents at different locations in the stream-cross section may vary widel" with dif- 
ferent rates of water discharge depending on the source of the material and the turbulence and mixing of the stream. In general, the distribution of sediment in a stream section is much more variable than the distribution of solutes. It is necessary to sample some streams at several verticals across the channel and especially for sediment, to uniformly traverse the depth of flow. These measurements require special sampling equipment to adequately integrate the vertical and lateral variability of the concentration in the section. These procedures yield a velosityweighted mean concentration for the section.

The near uniformly dispersed ions of the solute load move with the velocity of the transporting water. Accordingly, the mean section concentration of solutes determined from samples is a precise measure of the total solute load. The mean section corcentration obtained from suspended sediment samples is a less precise measure of the total sediment load, because the sediment samplers do not traverse the bottom 0.3 foot of the sampling vertical where the concentration of suspended sediment is greatest and because a significant part of the coarser particles in many streams move in essentially continuous contact with the bed and are not represented in the suspended sediment sample. Hence, the computed sediment loads presented in this report are usually less than the total sediment loads. For most streams the difference between the computed and total sediment loads will be small, in the order of a few percent.

\section{CHEMICAL QUALITY}

The methods of collecting and compositing water samples for chemical analysis are described by Rainwater and Thatcher $(1960,301$ p.). No single method of compositing samples is applicable to all problems related to the study of water quality. Although the method of 10 -day periods or the equivalent of three composite samples per month generally is practiced, modifice tions usually are made on the basis of dissolved-solids content $\varepsilon \mathrm{s}$ indicated by measurements of conductivity of daily samples, supplemented by other information such as chloride content, river stage, weather conditions and other background information of the stream.

\section{TEMPERATURE}

Daily water temperatures were measured at most of the stations at the time samples were collected for chemical quality or sediment content. So far as practicable, the water temperatures were taken at about the same time each day. Large streams have 
a small diurnal temperature change while small, shallow streams may have a daily range of several degrees and may follow closely the changes in air temperature. Some streams may be affected by waste-heat discharges. The thermometers used for determining water temperature were accurate to plus or minus $0.5^{\circ} \mathrm{F}$.

At stations where continuously recording thermorraphs are present, the records consist of maximum and minimum temperatures for each day, and the monthly averages.

\section{SEDIMENT}

In general, suspended-sediment samples were collected daily with depth-integrating cable-suspended samplers (U.S. InterAgency, 1963, and 1952.) from a fixed sampling point at one vertical in the cross section. A hand sampler was used at many stations during periods of low tlow. Depth-integrated samples were collected periodically at three or more verticals in the cross section to determine the cross-sectional distribution of the concentration of suspended sediment with respect to that at the daily sampling vertical. In streams where transverse distribution of sediment concentration ranges widely, samples were taken at two or more verticals to define more accurately the average concentration of the cross section. During periods of high or rapidly changing flow, samples generally were taken two ormcre times a day.

Sediment concentrations were determined by filtrationevaporation method. At many stations the daily mean concentration for some days was obtained by plotting the velocit:- -weighted instantaneous concentrations on the gage-height chart. The plotted concentrations, adjusted if necessary, for cross-sectional distribution were connected or averaged by continuous curves to obtain a concentration graph. This graph represented the estimated velocity-weighted concentration at any time, ant for most periods daily mean concentrations were determined from the graph. The days were divided into shorter intervals when the concentration and water discharge were changing rapidly. During some periods of minor variation in concentration, the average concentration of the samples was used as the daily mean concentration. During extended periods of relatively uniform concentration and flow, samples for a number of days were composited to obtain average concentrations and average daily loads for each period.

For some periods when no samples were collerted, daily loads of suspended sediment were estimated on the basis of water discharge, sediment concentrations observed immediately before 
and after the periods, and suspended-sediment loads for other periods of similar discharge. The estimates were further guided by weather conditions and sediment discharge for other stations.

In many instances where there were no observations for several days, the suspended-sediment loads for individual days are not estimated, because numerous factors influencing the quantities of transported sediment made it very difficult to make acc'urate estimates for individual days. However, estimated loads of suspended sediment for missing days in an otherwise continuous poriod of sampling have been included in monthly and annual totals in order to provide a complete record. For some streams, sariples were collected weekly, monthly, or less frequently, and only rates of sediment discharge at the time of sampling are slown.

In addition to the records of quantities of suspended sediment transported, records of the particle sizes of sediment are included. The particle sizes of the suspended sediment for meny of the stations, and the particle sizes of the bed material for some of the stations were determined periodically.

The size of particles in stream sediments commonly range from colloidal clay (finer than $0.001 \mathrm{~mm}$ ) to coarse sand or gravel (coarser than $1.0 \mathrm{~mm}$ ). The common methods of particle-size analyses cannot accommodate such a wide range in particle size. Hence, it was necessary to separate most samples into two parts, one coarser than $0.062 \mathrm{~mm}$ and one finer than $0.062 \mathrm{~mm}$. The separations were made by sieve or by a tube containing a settling medium of water. The coarse fractions were classified by sieve separation or by the visual accumulation tube (U.S. Inter-A 1957). The fine fractions were classified by the pipet method (Kilmer and Alexander, 1949) or the bottom withdrawal tube method (U.S. Inter-Agency, 1943).

\section{EXPRESSION OF RESULTS}

The quantities of solute concentrations analyzed in the la boratory are measured by weight-volume units (milligrams per liter) and for reporting, are converted to weight-weight units (parts per million). For most waters, this conversion is made by ass'iming that the liter of water sample weighs 1 kilogram; and thus milligrams per liter are equivalent to parts per million (ppm).

Equivalents per million are not reported, but they can be calculated easily from the parts per million data. An equivalent per million (epm) is a unit chemical combining weight of a constituent in a million unit weights of water. Chemical equivalence in 
equivalents per million can be obtained by (a) dividing the concentration in parts per million by the combining weight of that ion, or (b) multiplying the concentration (in ppm) by the reciprocals of the combining weights. The table below lists the reciprocals of the combining weights of cations and anions generally reported in water analyses. The conversion factors are computed from atomic weights based on carbon-12 (International Union of Pure and Applied Chemistry, 1961).

Results given in parts per million can be convertef to grains per United States gallon by dividing by 17.12 .

The hardness of water is conventionally expressed in all water analyses in terms of an equivalent quantity of calcium carbonate. Such a procedure is required because hardness is caused by several different cations, present in variable proportions. It should be remembered that hardness is an expression in conventional terms of a property of water. The actual presence of calcium carbonate in the concentration given is not to be assumed. The hardness caused by calcium and magnesium (and other cations if significant) equivalent to the carbonate and bicarbonate is called carbonate hardness; the hardness in excess of this quan-

Conversion factors: Parts per million to equivalents per million

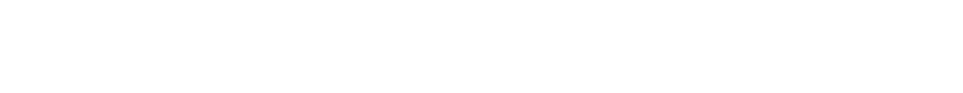

\begin{tabular}{|c|c|c|c|}
\hline Aluminum $\left(\mathrm{Al}^{+3}\right) \ldots .$. & 0.11119 & Iodide $\left(I^{-1}\right) \ldots$ & 0.00788 \\
\hline Ammonia as $\mathrm{NH}_{4}^{+1} \ldots$ & .05544 & Iron $(\mathrm{Fe}+3) \ldots$ & .05372 \\
\hline Barium $\left(\mathrm{Ba}^{+2}\right) \ldots$ & .01456 & Lead $\left(\mathrm{Pb}^{+2}\right)$. & .00965 \\
\hline Bicarbonate $\left(\mathrm{HCO}_{3}^{-}\right.$ & .01639 & Lithium $\left(\mathrm{Li}^{+1}\right)$ & .14411 \\
\hline Bromide $\left(\mathrm{Br}^{-1}\right)$.. & .01251 & Magnesium (Mg & .08226 \\
\hline Calcium $\left(\mathrm{Ca}^{+2}\right) \ldots$ & .04990 & Manganese $\left(\mathrm{Mn}^{+}\right.$ & .03640 \\
\hline Carbonate $\left(\mathrm{CO}_{3}^{-2}\right)$ & .03333 & Nickel $\left(\mathrm{Ni}^{+2}\right) \ldots$ & .03406 \\
\hline Chloride $\left(\mathrm{Cl}^{-1}\right)$. & .02821 & Nitrate $\left(\mathrm{NO}_{3}^{-1}\right)$. & .01613 \\
\hline Chromium $\left(\mathrm{Cr}^{+6}\right.$ & .11539 & Nitrite $\left(\mathrm{NO}_{2}^{-1}\right)$. & .02174 \\
\hline Cobalt $\left(\mathrm{Co}^{+2}\right) .$. & .03394 & Phosphate ( $\mathrm{PO}-{ }_{4}^{3}$ & .0315 \\
\hline Copper $\left(\mathrm{Cu}^{+2}\right) \ldots$ & .03148 & Potassium $\left(\mathrm{K}^{+1}\right)$ & .02557 \\
\hline Cyanide $\left(\mathrm{CN}^{-1}\right) .$. & .03844 & Sodium $(\mathrm{Na}+1) \ldots$ & .04350 \\
\hline Fluoride $\left(F^{-1}\right) \ldots$ & .05264 & Strontium $\left(\mathrm{Sr}^{+2}\right)$ & .0228 \\
\hline Hydrogen $\left(\mathrm{H}^{+1}\right) \ldots$ & .99209 & Sulfate $\left(\mathrm{SO}_{4}^{-2}\right) \ldots$ & \\
\hline Hydroxide $\left(\mathrm{OH}^{-1}\right)$ & .05880 & $\operatorname{Zinc}(\mathrm{Zn}+2)^{4}$ & \\
\hline
\end{tabular}

tity is called noncarbonate hardness. Hardness or alkalinity values expressed in parts per million as calcium carbonate may be converted to equivalents per million by dividing by 50 . 
The value usually reported as dissolved solids is the res:due on evaporation after drying at $180^{\circ} \mathrm{C}$ for 1 hour. For some waters, particularly those containing moderately large quantities of soluble salts, the value reported is calculated from the quantities of the various determined constituents using the carbonate equivalent of the reported bicarbonate. The calculated sum of the constituents may be given instead of or in addition to the residue. Ir the analyses of most waters used for irrigation, the quantity of dissolved solids is given in tons per acre-foot as well as in parts per million.

Specific conductance is given for most analyses and was determined by means of a conductance bridge and using a standard potassium chloride solution as reference. Specific conductance values are expressed in micromhos per centimeter at $25^{\circ} \mathrm{C}$. Specific conductance in micromhos is 1 million times the reciprocal of specific resistance at $25^{\circ} \mathrm{C}$. Specific resistance is the reristance in ohms of a column of water 1 centimeter long and 1 square centimeter in cross section.

The discharge of the streams is reported in cubic feet per second (see Streamflow, p. 25 ) and the temperature in degrees Fahrenheit. Color is expressed in units of the platinum-cobalt scale proposed by Hazen (1892). A unit of color is produced by one milligram per liter of platinum in the form of the chloroplatinate ion. Hydrogen-ion concentration is expressed in terms of $\mathrm{pH}$ units. By definition the $\mathrm{pH}$ value of a solution is the negative logarithm of the concentration of gram ions of hydrcgen.

An average of analyses for the water year is given for most daily sampling stations. Most of these averages are arithmetical, time-weighted, or discharge-weighted; when analyses during a year are all on 10-day composites of daily samples with no missing days, the arithmetical and time-weighted averages are ecuivalent. A time-weighted average represents the composition of water that would be contained in a vessel or reservoir that had received equal quantities of water from the rivereach day for the water year. A discharge-weighted average approximates the composition of water that would be found in a reservoir containirg all of the water passing a given station during the year. A dischargeweighted average is computed by multiplying the discharge for the sampling period by the concentrations of individual constituents for the corresponding period and dividing the sum of the products by the sum of the discharges. For most streams, dischergeweighted averages are lower than arithmetical averages because at times of high discharge the rivers generally have low concentrations of dissolved solids. 
A program for computing these averages by electronic digital computer was instituted in the 1962 water year. T'is program extended computations to include averages for $\mathrm{pH}$ values expressed in terms of hydrogen ion and averages for the concentration of individual constituents expressed in tons per day. Concentrations in tons per day are computed the same as daily sed:ment loads.

The concentration of sediment in parts per million is computed as 1,000,000 times the ratio of the weight of sediment to the weight of water-sediment mixture. Daily sediment loads are expressed in tons per day and except for subdivided days, are usually obtained by multiplying daily mean sediment concentrations in parts per million by the daily mean discharge in cubic feet per second, and the conversion factor, normally 0.0027 .

Particle size analyses are expressed in percentages of material finer than classified sizes (in millimeters). The size classification used in this report agrees closely with recommendations made by the American Geophysical Union Subcommittee on sediment terminology (Lane and others, 1947). The particle size distributions given in this report are not necessarily representative of the particle sizes of sediment in trarsport in the natural stream. Most of the organic matter is removed and the sample is subjected to mechanical and chemical dispersion before analysis of the silt and clay.

\section{COMPOSITION OF SURFACE WATEPS}

All natural waters contain dissolved mineral matter. The quantity of dissolved mineral matter in a natural water depends primarily on the type of rocks or soils with which the water has been in contact and the length of time of contact. Ground water is generally more highly mineralized than surface ruroff because it remains in contact with the rocks and soils for much longer periods. Some streams are fed by both surface runoff and ground water from springs or seeps. Such streams reflect the chemical character of their concentrated underground sources during dry periods and are more dilute during periots of heavy rainfall. The dissolved-solids content in a river is frequently Increased by drainage from mines or oil fields, by the addition of industrial or municipal wastes, or--in irrigated regions--by drainage from irrigated lands.

The mineral constituents and physical properties of natural waters reported in the tables of analyses include thos that have a practical bearing on water use. The results of analyse generally include silica, iron, calcium, magnesium, sodium, porassium (or 
sodium and potassium together calculated as sodium), lithium, carbonate, bicarbonate, sulfate, chloride, fluoride, nitrate, boron, $\mathrm{pH}$, dissolved solids, and specific conductance. Aluminum, manganese, color, acidity, dissolved oxygen, and other dissolved constituents and physical properties are reported for certain streams. Phenolic material and minor elements including strontium, chromium, nickel, copper, lead, zinc, cobalt, and other trace elements are determined occasionally for a few streams in connection with specific problems and the results are reported. The source and significance of the different constituents and properties of natural waters are discussed in the following paragraphs. The constituents are arranged in the order that they appear in the tables.

\section{MINERAL CONSTITUENTS IN SOLUTION}

\section{Silica $\left(\mathrm{SiO}_{2}\right)$}

Silica is dissolved from practically all rocks. Some natural surface waters contain less than 5 parts per million of silica and few contain more than 50 parts, but the more common range is from 10 to 30 parts per million. Silica affects the usefulness of a water because it contributes to the formation of boiler scale; it usually is removed from feed water for high-pressure boilers. Silica also forms troublesome deposits on the blades of steam turbines.

\section{Aluminum (Al)}

Aluminum is usually present only in negligible quantities in natural waters except in areas where the waters have been in contact with the more soluble rocks of high aluminum content such as bauxite and certain shales. Acid waters often contain large amounts of aluminum. It may be troublesome in feed waters where it tends to be deposited as a scale on boiler tubes.

Iron $(\mathrm{Fe})$

Iron is dissolved from many rocks and soils. On exposure to the air, normal basic waters that contain more than 1 part per million of iron soon become turbid with the insoluble reddish ferric oxide produced by oxidation. Surface waters, therefore, seldom contain as much as 1 part per million of dissolved iron, alth nugh some acid waters carry large quantities of iron in solution. Iron causes reddish-brown stains on porcelain or enameled wars and fixtures and on fabrics washed in the water.

Manganese (Mn)

Manganese is dissolved in appreciable quantities from rocks in some sections of the country. It resembles iron in its chemical 
behavior and in its occurrence in natural waters. Horrever, manganese in rocks is less abundant than iron. As a reault the concentration of manganese is much less than that of iron and is not regularly determined in many areas. It is especially cbjectionable in water used in laundry work and in textile processing. Concentrations as low as 0.2 part per million may cause a dark-brown or black stain on fabrics and porcelain fixtures. Appre riable quantities of manganese are often found in waters containing objectionable quantities of iron.

Calcium $(\mathrm{Ca})$

Calcium is dissolved from almost all rocks and soils, but the highest concentrations are usually found in waters that have been in contact with limestone, dolomite, and gypsum. Calcium and magnesium make water hard and are largely responsible for the formation of boiler scale. Most waters associated with granite or silicious sands contain less than 10 parts per million of calcium; waters in areas where rocks are composed of dolomite and limestone contain from 30 to 100 parts per million; and waters that have come in contact with deposits of gypsum may contain several hundred parts per million.

Magnesium (Mg)

Magnesium is dissolved from many rocks, partic'larly from dolomitic rocks. Its effect in water is similar to that of calcium. The magnesium in soft waters may amount to only 1 or 2 parts per million, but water in areas that contain large quantities of dolomite or other magnesium-bearing rocks may contain from 20 to 100 parts per million or more of magnesium.

Strontium (Sr)

Strontium is a typical alkaline-earth element and is similar chemically to calcium. Strontium may be present in natural water in amounts up to a few parts per million much more frequently than the available data indicate. In most surface water the amount of strontium is small in proportion to calcium. However, in sea water the ratio of strontium to calcium is $1: 30$.

Sodium and potassium ( $\mathrm{Na}$ and $\mathrm{K}$ )

Sodium and potassium are dissolved from practically all rocks. Sodium is the predominant cation in some of the more highly mineralized waters found in the western United States. Natural waters that contain only 3 or 4 parts per million of the two together are likely to carry almost as much potassium as sodium. As the total quantity of these constituents increases, the proportion of sodium becomes much greater. Moderate quantities of sodium and potas- 
sium have little effect on the usefulness of the water for most purposes, but waters that carry more than 50 to 100 parts per million of the two may require careful operation of steam boilers to prevent foaming. More highly mineralized waters that contain a large proportion of sodium salts may be unsatisfactory for irrigation.

In this report, sodium and potassium values that are calculated and reported as sodium are indicaled by footnote.

\section{Lithium (Li)}

Data concerning the quantity of lithium in water are scarce. It is usually found in small amounts in thermal springs and saline waters. Lithium also occurs in streams where some indus ries dump their waste water. The scarcity of lithium in rocks is responsible more than other factors for relatively small amounts present in water.

Bicarbonate, carbonate and hydroxide $\left(\mathrm{HCO}_{3}, \mathrm{CO}_{3}, \mathrm{OH}\right)$

Bicarbonate, carbonate, or hydroxide is sometimes reported as alkalinity. The alkalinity of a water is defined as its caracity to consume a strong acid to $\mathrm{pH} 4.5$. Since the major causes of alkalinity in most natural waters are carbonate and bicarl onate ions dissolved from carbonate rocks, the results are usuallir reported in terms of these constituents. Although alkalinity may suggest the presence of definite amounts of carbonate, bicarbnate or hydroxide, it may not be true due to other lons that contribute to alkalinity such as silicates phosphates, borates, possibly fluoride, and certain organic anions which may occur in cc'ored waters. The significance of alkalinity to the domestic, agricultural, and industrial user is usually dependent upon the nature of the cations $(\mathrm{Ca}, \mathrm{Mg}, \mathrm{Na}, \mathrm{K})$ associated with it. However, alkalirity in moderate amounts does not adversely affect most users.

Hydroxide may occur in water that has been softened by the lime process. Its presence in streams usually can be taken as an indication of contamination and does not represent the natural chemical character of the water.

Sulfate $\left(\mathrm{SO}_{4}\right)$

Sulfate is dissolved from many rocks and soils--in especially large quantities from gypsum and from beds of shale. It is formed also by the oxidation of sulfides of iron and is therefore present in considerable quantities in waters from mines. Sulfate in vaters that contain much calcium and magnesium causes the formation of hard scale in steam bollers and may increase the cost of sof:ening the water. 
Chloride (Cl)

Chloride is dissolved from rock materials in all parts of the country. Surface waters in the humid regions are usually low in chloride, whereas streams in arid or semiarid regions may contain several hundred parts per million of chloride leached from soils and rocks, especially where the streams receive return drainage from irrigated lands or are affected by gro ind-waterinflow carrying appreciable quantities of chloride. Large quantities of chloride in water that contains a high content of calcium and magnesium increases the water's corrosiveness.

Fluoride (F)

Fluoride has been reported as being present in some rocks to about the same extent as chloride. However, the quantity of fluoride in natural surface waters is ordinarily very small compared to that of chloride. Investigations have proved that fluoride concentrations of about 0.6 to $1.7 \mathrm{ppm}$ reduced the incidence of dental caries and that concentrations greater than $1.7 \mathrm{ppm}$ also protect the teeth from cavities but cause an undesirable black stain (Durfor and Becker, 1964, p. 20). Public Health Service, 1962 (p. 8), states, "When fluoride is naturally present in drinking water, the concentration should not average more than the appropriate upper control limit (0.6 to $1.7 \mathrm{ppm})$. Presence of fluoride in average concentration greater than two times the optimum values shall constitute grounds for rejection of the supply." Concentration higher than the stated limits may cause mottled enamel in teeth, endemic cumulative fluorosis, and skeletal effects.

Nitrate $\left(\mathrm{NO}_{3}\right)$

Nitrate in water is considered a final oxidation product of nitrogenous material and may indicate contamination by sewage or other organic matter. The quantities of nitrate present in surface waters are generally less than 5 parts per million $\left(\right.$ as $\left.\mathrm{NO}_{3}\right)$ and have no effect on the value of the water for ordinary uses.

It has been reported that as much as 2 parts per million of nitrate in boiler water tends to decrease intercrystallire cracking of boiler steel. Studies made by Faucett and Miller (1946), Waring (1949) and by the National Research Council (Maxcy, 1950) concluded that drinking water containing nitrates in excess of 44 parts per million (as $\mathrm{NO}_{3}$ ) should be regarded as unsafe for infant feeding. U.S. Public Health Service (1962) sets 45 ppm the upper limit.

Phosphate $\left(\mathrm{PO}_{4}\right)$

Phosphorus is an essential element in the growth of plants and 
animals. Some sources that contribute nitrate, such as organic wastes are also important sources of phosphate. The addition of phosphates in water treatment constitutes a possible source, although the dosage is usually small. In some areas, phosfhate fertllizers may yield some phosphate to water. A more important source is the increasing use of phosphates in detergents. Domestic and industrial sewage effluents often contain considerable amcints of phosphate.

Boron (B)

Boron in small quantities has been found essential for plant growth, but irrigation water containing more than 1 part per million boron is detrimental to citrus and other boron-sensitive crops. Boron is reported in Survey analyses of surface waters in arid and semiarid regions of the Southwest and West where irrigation is practiced or contemplated, but few of the surface waters analyzed have harmful concentrations of boron.

\section{Dissolved solids}

The reported quantity of dissolved solids--the residue on $\epsilon^{x}$ aporation--consists mainly of the dissolved mineral constituerts in the water. It may also contain some organic matter and water of crystallization. Waters with less than 500 parts per million of dissolved solids are usually satisfactory for domestic and some industrial uses. Water containing several thousand parts permillion of dissolved solids are sometimes successfully used for irrigation where practices permit the removal of soluble salts through the application of large volumes of water on well-drained lands, but generally water containing more than about $2,000 \mathrm{ppm}$ is considered to be unsuitable for long-term irrigation under average conditions.

Chromium (Cr)

Few if any waters contain chromium from natural sources. Natural waters can probably contain only traces of chromium as a cation unless the $\mathrm{pH}$ is very low. When chromium is present in water, it is usually the result of pollution by industrial westes. Fairly high concentrations of chromate anions are possible in waters having normal $\mathrm{pH}$ levels. Concentrations of more than $0.05 \mathrm{ppm}$ of chromium in the hexavalent form constitute grounds for rejection of a water for domestic use on the basis of the standards of the U.S. Public Health Service (1962).

Nickel and Cobalt (Ni, Co)

Nickel and cobalt are very similar in chemical behavic $r$ and also closely related to iron. Both are present in igneous rocks in 
small amounts and are more prevalent in silicic rocks. Any nickel in water is likely to be in small amounts and could be in a colloidal state. Cobalt may be taken into solution more readily than nickel. It may be taken into solution in small amounts through bacteriological activity similar to that causing solution of manganese. However, few data on the occurrence of either nickel or cobalt in natural water are available.

Copper $(\mathrm{Cu})$

Copper is a fairly common trace constituent of natural water. Small amounts may be introduced into water by solution of copper and brass water pipes and other copper-bearing equipment in contact with the water, or from copper salts added to control algae in open reservoirs. Copper salts such as the sulfate and chloride are highly soluble in waters with a low $\mathrm{pH}$ but in water of normal alkalinity these salts hydrolyze and the copper may be $\mathrm{p}$ recipitated. In the normal $\mathrm{pH}$ range of natural water containing carl on dioxide, the copper might be precipitated as carbonate. The oxidized portions of sulfide-copper ore bodies contain other copper compounds. The presence of copper in mine water is common.

Copper imparts a disagreeable metallic taste to water. As little as $1.5 \mathrm{ppm}$ can usually be detected, and $5 \mathrm{ppm}$ can render the water unpalatable. Copper is not considered to be a cumulative systemic poison like lead and mercury; most copp?r ingested is excreted by the body and very little is retained. The pathological effects of copper are controversial, but it is generally believed very unlikely that humans could unknowingly ingest toxic quantities from palatable drinking water. The U.S. Public Health Service (1962) recommends that copper should not exceed $1.0 \mathrm{ppm}$ in drinking and culinary water.

Lead $(\mathrm{Pb})$

Lead is only a minor element in most natural waters, but industrial or mine and smelter effluents may contain relatively large amounts of lead. Many of the commonly used lead salts are water soluble.

Traces of lead in water usually are the result of solution of lead pipe through which the water has passed. Amounts of lead of the order of $0.05 \mathrm{ppm}$ are significant, as this concentr-tion is the upper limit for drinking water in the standards adopted by the U.S. Public Health Service (1962). Higher concentrations may be added to water through industrial and mine-waste disposal. Lead in the form of sulfate is reported to be soluble in water to the extent of $31 \mathrm{ppm}$ (Seidell, 1940) at $25^{\circ} \mathrm{C}$. In natural water this concentration would not be approached, however, sin?e a $\mathrm{pH}$ of 
less than 4.5 would probably be required to prevent formetion of lead hydroxide and carbonate. It is reported (Pleissner, 1907) that at $18^{\circ} \mathrm{C}$ water free of carbon dioxide will dissolve the equivalent of $1.4 \mathrm{ppm}$ of lead and the solubility is increased nearly four fold by the presence of $2.8 \mathrm{ppm}$ of carbon dioxide in the solution. Presence of other ions may increase the solubility of lead. Zinc $(\mathrm{Zn})$

Zinc is abundant in rocks and ores but is only a minor constituent in natural water because the free metal and its oxides are only sparingly soluble. In most alkaline surface waters it is present only in trace quantities, but more may be present in acid water. Chlorides and sulfates of zinc are highly soluble. Zinc is used in many commercial products, and industrial wastes may contain large amounts.

Zinc in water does not cause serious effects on health, but produces undesirable esthetic effects. The U.S. Public Health Service $(1962$, p. 55) recommends that the zinc content not exceed $5 \mathrm{ppm}$ in drinking and culinary water.

Barium (Ba)

Barium may replace potassium in some of the igneous rock minerals, especially feldspar, and barium sulfate (barite) is a common barium mineral of secondary origin. Only traces of barium are present in surface water and sea water. Because natural water contains sulfate, barium will dissolve only in trace amounts. Barium sometimes occurs in brines from oil-well wastes.

The U.S. Public Health Service (1962) states that water containing concentrations of barium in excess of $1 \mathrm{ppm}$ is not suitable for drinking and culinary use because of the serious toxic effects of barium on heart, blood vessels, and nerves.

Bromide (Br)

Bromine is a very minor element in the earth's crust and is normally present in surface waters in only minute quantities. Measurable amounts may be found in some streams that re:eive industrial wastes, and some natural brines may contain rather high concentrations. It resembles chloride in that it tends to be concentrated in sea water.

Iodide (I)

Iodide is considerably less abundant both in rocks and water than bromine. Measurable amounts may be found in some streams that receive industrial wastes, and some natural brines may con- 
tain rather high concentrations. It occurs in sea water to the extent of less than $1 \mathrm{ppm}$. Rankama and Sahama (1950) report iodide present in rainwater to the extent of 0.001 to $0.003 \mathrm{ppm}$ and in river water in about the same amount. Few waters will contain over $2.0 \mathrm{ppm}$.

\section{PROPERTIES AND CHARACTERISTICS OF WATER}

Hardness

Hardness is the characteristic of water that receives the most attention in industrial and domestic use. It is commonly recognized by the increased quantity of soap required to produce lather. The use of hard water is also objectionable because it contributes to the formation of scale in boilers, water heaters, radiators, and pipes, with the resultant decrease in rate of heat transfer, possibility of boiler failure, and loss of flow.

Hardness is caused almost entirely by compounds of calcium and magnesium. Other constituents--such as iron, manganese, aluminum, barium, strontium, and free acid--also cause hardness, although they usually are not present in quantities large enough to have any appreciable effect.

Generally, bicarbonate and carbonate determine the proportions of "carbonate" hardness of water. Carbonate hardness is the amount of hardness chemically equivalent to the amount of bicarbonate and carbonate in solution. Carbonate hardness is approximately equal to the amount of hardness that is removed from water by boiling.

Noncarbonate hardness is the difference between the hardness calculated from the total amount of calcium and magnesium in solution and the carbonate hardness. If the carbonate hardness (expressed as calcium carbonate) equals the amount of calcium and magnesium hardness (also expressed as calcium carbonate) there is no noncarbonate hardness. Noncarbonate hardness is about equal to the amount of hardness remaining after water is boiled. The scale formed at high temperatures by the evaporation of water containing noncarbonate hardness commonly is tough, heat resistant, and difficult to remove.

Although many people talk about soft water and lard water, there has been no firm line of demarcation. Water that seems hard to an easterner may seem soft to a westerner. In this 
report hardness of water is classified as follows:

Hardness range (calcium carbonate in $\mathrm{ppm}$ )

$0-60$
$61-120$
$121-180$
more than 180

Hardness description

Soft
Moderately hard
Hard
Very hard

Durfor and Becker, 1964, p. 23-27. Acidity $\left(\mathrm{H}^{+1}\right)$

The use of the terms acidity and alkalinity is widespread in the literature of water analysis and is a cause of confusion to those who are more accustomed to seeing a $\mathrm{pH}$ of 7.0 used as a ne:utral point. Acidity of a natural water represents the content of free carbon dioxide and other uncombined gases, organic acids and salts of strong acids and weak bases that hydrolyze to give hydrogen ions. Sulfates of iron and aluminum in mine and industrial wastes are common sources of acidity. The presence of acidity is reported in those waters which have a pH below 4.5.

Sodium adsorption ratio (SAR)

The term "sodium adsorption ratio (SAR)" was introc'xced by the U.S. Salinity Laboratory Staff (1954). It is a ratio expressing the relative activity of sodium ions in exchange reaction with soil and is an index of the sodium or alkali hazard to the soil. Sodium adsorption ratio is expressed by the equation:

$$
\mathrm{SAR}=\frac{\mathrm{Na}^{+}}{\sqrt{\frac{\mathrm{Ca}^{++}+\mathrm{Mg}^{+}}{2}}}
$$

where the concentrations of the ions are expressed in millienuivalents per liter (or equivalents per million for most irrigation waters).

Waters are divided into four classes with respect to solium or alkali hazard: low, medium, high, and very high, depending upon the SAR and the specific conductance. At a conductanse of 100 micromhos per centimeter the dividing points are at SAR values of 10,18 , and 26 , but at 5,000 micromhos the corresponding 
dividing points are SAR values of approximately $2.5,6.5$, and 11 . Waters range in respect to sodium hazard from thos? which can be used for irrigation on almost all soils to those which are generally unsatisfactory for irrigation.

Specific conductance (micromhos per centimeter at $25^{\circ} \mathrm{C}$ )

Specific conductance is a convenient, rapid determination used to estimate the amount of dissolved solids in water. It is a measure of the ability of water to transmit a small electrical current (see p. 9). The more dissolved solids in water that can transmit electricity the greater the specific conductance of the water. Commonly, the amount of dissolved solids (in parts per million) is about 65 percent of the specific conductance (in micromhos). This relation is not constant from stream to stream or from well to well and it may even vary in the same source with changes in the composition of the water (Durfor and Becker, 1964 p. 27-29).

Specific conductance of most waters in the eas:ern United States is less than 1,000 micromhos, but in the arid western parts of the country, a specific conductance of more than 1,000 micromhos is common.

Hydrogen-ion concentration $(\mathrm{pH})$

Hydrogen-ion concentration is expressed in terms of $\mathrm{pH}$ units (see $\mathrm{p} .10$ ). The values of $\mathrm{pH}$ often are used as a meesure of the solvent power of water or as an indicator of the chemical behavior certain solutions may have toward rock minerals.

The degree of acidity or alkalinity of water, as indicated by the hydrogen-ion concentration, expressed as $\mathrm{pH}$, is related to the corrosive properties of water and is useful in determining the proper treatment for coagulation that may be necessary at watertreatment plants. A pH of 7.0 indicates that the water is neither acid nor alkaline. $\mathrm{pH}$ readings progressively lower than 7.0 denote increasing acidity and those progressively higrer than 7.0 denote increasing alkalinity. The $\mathrm{pH}$ of most natural surface waters ranges betweenn 6 and 8 . Some alkaline surface wat $\epsilon$ rs have $\mathrm{pH}$ values greater than 8.0 and waters containing free mineral acid or organic matter usually have $\mathrm{pH}$ values less than 4.5.

The investigator who utilizes $\mathrm{pH}$ data in his interpretations of water analyses should becareful to place pHvalues in th oir proper perspective.

Color

In water analysis the term "color" refers to the appearance of water that is free from suspended solids. Many turbid waters that appear yellow, red, or brown when viewed in the stream show 
very little color after the suspended matter has been remored. The yellow-to-brown color of some waters is usually caused by organic matter extracted from leaves, roots, and other organic substances in the ground. In some areas objectionable color in water results from industrial wastes and sewage. Clear deep water may appear blue as the result of a scattering of sunlight by the water molecules. Water for domestic use and some industrial uses should be free from any perceptible color. A color less than 15 units generally passes unnoticed (U.S. Public Health Serrice, 1962). Some swamp waters have natural color in excess of 300 units.

The extent to which a water is colored by material in solution is commonly reported as a part of a water analysis because a significant color in water may indicate the presence of organic material that may have some bearing on the dissolved solids content. Color in water is expressed in terms of units between 0 and 500 or more based on the above standard (see p.9).

Oxygen consumed

Oxygen consumed is a measure of the amount of oxygen required to oxidize unstable materials in water and may be ccrrelated with natural-water color or with some carbonaceous organic pollution from sewage or industrial wastes.

Tolerances for oxygen consumed in feed water for low- and high-pressure boilers are 15 and $3 \mathrm{ppm}$, respectively (Northeast Water Works Association, 1940). Wash water containing more than $8 \mathrm{ppm}$ has been reported to import a bad odor to textiles; concentrations for water used in beverages and brewing range from 0.5 to $5.0 \mathrm{ppm}$ (California State Water Pollution Control Board, 1952, 1954).

Dissolved oxygen (DO)

Adequate dissolved oxygen is necessary for the life of fish and other aquatic organisms and is an indicator for corrosivity of water, photosynthetic activity, and septicity. lt is one of the most important indicators of the condition of a water supply for biological, chemical and sanitary investigations (Rose, 1965).

Biochemical oxygen demand (BOD)

Biochemical oxygen demand is a measure of the oxygen required to oxidize the carbonaceous organic material usable as a source of food by aerobic organisms.

Chemical oxygen demand (COD)

Chemical oxygen demand indicates the quantity of oxidizable 
compounds present in a water and will vary with water compositions, concentration of reagent, temperature, period of contact, and other factors.

\section{Organics}

Phenols.--Phenolic material in water resources is invariably the result of pollution. Phenols are widely used as disinfectants and in the synthesis of many organic compounds. Waste products from oil refineries, coke areas, and chemical plants may contain high concentrations. Fortunately, phenols decompose in the presence of oxygen and organic material, and their persistence downstream from point of entry is relatively short lived. The rate of decomposition is dependent on the environment.

Very low concentrations impart such a disagreecble taste to water that it is highly improbable that harmful amounts could be consumed unknowingly. Reported thresholds of detection of taste and odor range from 0.001 to $0.01 \mathrm{ppm}$.

Coliform organisms.--A group of bacteria used as an indicator of the sanitary quality of the water. The number of ccliform colonies per 100 milliliters of water is determined by the immediate or delayed incubation membrane filter method. Most probable number (MPN) is also a method of determining a direct count of coliform colonies per 100 milliliters of water.

Detergents (MBAS).--Anionic surfactants (methylene blue active substance, MBAS) in detergents resist chemical oxidation and biological breakdown. Their persistence in water over long periods of time contributes to pollution of both ground water and surface water. Some of the effects produced from detergent pollution are unpleasant taste, odor, and foaming (Wayman, and others, 1962). Although the physiological implications of MBAS to human beings is unknown, prolonged ingestion of this material by rats is believed to be nontoxic (Paynter, 1960). The U.S. Public Health Service (1962) recommends that MBAS should not exceed $0.5 \mathrm{ppm}$ in drinking and culinary waters.

Temperature

Temperature is an important factor in properly c'etermining the quality of water. This is very evident for such a direct use as an industrial coolant. Temperature is also important, but perhaps not so evident, for its indirect influence upon aquatic biota, concentrations of dissolved gases, and distribution of chemical solutes in lakes and reservoirs as a consequence of thermal stratification and variation.

Surface water temperatures tend to change searnnally and 
daily with air temperatures, except for the outflow of large springs. Superimposed upon the annual temperature cycle is a daily fluctuation of temperature which is greater in warm seasons than in cold and greater in sunny periods than with a cloud cover. Natural warming is due mainly to absorption of a solar radiaticn by the water and secondarily to transfer of heat from the air. Condensation of water vapor at the water surface is reported to furnish measurable quantities of heat. Heat loss takes place largely through radiation, with further losses through evaporation and conduction to the air and to the stream-bed. Thus the temperature of a small stream generally reaches a maximum in mid- to late afternoon due to solar heating and reaches a minimum from early to mid-morning after nocturnal radiation.

Temperature variations which commonly occur during sum mer in lakes and reservoirs of temperate regions result in a separation of the water volume into a circulating upper portion and a noncirculating lower portion. Separating the two is a stratum of water of variable vertical thickness in which the temperature decreases rapidly with increasing depth. This physical division of the water mass into a circulating and a stagnant portion is the result of density differences in the water column associated with the temperature distribution. Knowledge of the stratification in a body of water may result in increased utility by locating strata of more suitable characteristics. For example, the elevation of an intake pipe may be changed to obtain water of lower temperature, higher $\mathrm{pH}$, less dissolved iron, or other desirable properties.

Temperature is a major factor in determining the effent of pollution on aquatic organisms. The resistance of fish to certain toxin substances has been shown to vary widely with temperature. The quantity of dissolved oxygen which the water can conte in is also temperature dependent. Oxygen is more soluble in cold vater than in warm water, hence the reduction of oxygen concentrations by pollution is especially serious during periods of high temperature when oxygen levels are already low. Increased temperatures also accelerate biological activity including that of the oxygenutilizing bacteria which decompose organic wastes. These pollutional effects may be especially serious when low flow conditions coincide with high temperatures. Summary temper-ture data of water are essential for planning multiple uses of water.

Turbidity

Turbidity is the optical property of a suspension with reference to the extent to which the penetration of light is inhibited by the presence of insoluble material. Turbidity is a function or both 
the concentration and particle size of the suspender material. Although it is reported in terms of parts per million of silica, it is only partly synonymous with the weight of sediment per unit volume of water.

Turbid water is abrasive in pipes, pumps, and turbine blades. In process water, turbidities much more than $1 \mathrm{ppm}$ are not tolerated by several industries, but others permit up to $50 \mathrm{ppm}$ or higher (Rainwater, Thatcher, 1960, p. 289). Although turbidity does not directly measure the safety of drinking water, it is related to the consumer's acceptance of the water. A level of 5 units of turbidity becomes objectionable to a considerable number of people (U.S. Public Health, 1962).

Sediment

Fluvial sediment is generally regarded as that sediment which is transported by, suspended in, or deposited by water. Suspended sediment is that part which remains in suspensic 7 in water owing to the upward components of turbulent currents or by colloidal suspension. Much fluvial sediment results from the natural process of erosion, which in turn is part of the geologic cycle of rock transformation. This natural procers may be accelerated by agricultural practices. Sediment is also contributed by a number of industrial and construction activities. In certain sections, waste materials from mining, logging, oil-field, and other industrial operations introduce large quantities of suspended as well as dissolved material.

The quantity of sediment, transported or available for transportation, is affected by climatic conditions, form or: nature of precipitation, character of the solid mantle, plant corer, topography, and land use. The mode and rate of sediment erosion, transport, and deposition is determined largely by the size distribution of the particles or more precisely by the fall velocities of the particles in water. Sediment particles in the sandsize (larger than $0.062 \mathrm{~mm}$ ) range do not appear to be affected by flocculation or dispersion resulting from the mineral constituents in solution. In contrast, the sedimentation diameter of clay and silt particles in suspension may vary considerably from point to point in a stream or reservoir, depending on the mineral matter in solution and in suspension and the degree of turbulence present. The size of sediment particles in transport at any point cepends on the type of erodible and soluble material in the drainag $\epsilon$ area, the degree of flocculation present, time in transport, and characteristics of the transporting flow. The flow characteristics include velocity of water, turbulence, and the depth, width, and roughness of the channel. As a result of these variable characteristics, the 
size of particles transported, as well as the total sediment load, is in constant adjustment with the characteristics and physical features of the stream and drainage area.

\section{STREAMFLOW}

Most of the records of stream discharge, used in conjunction with the chemical analyses and in the computation of sediment loads in this volume, are published in the Geological Sirvey water-supply paper series, "Surface Water Supply of the United States, 1966-70." The discharge reported for a composite sample is usually the average of daily mean discharges for the composite period. The discharges reported in the tables of single anclyses are either daily mean discharges or discharges obtained at the time samples were collected and computed from a stage-discharge relation or from a discharge measurement.

\section{PUBLICATIONS}

Reports giving records of chemical quality and temperatures of surface waters and suspended-sediment loads of streams in the area covered by this volume for the water years 1941-67, are listed below:

Numbers of water-supply papers containing records for Parts 3 and 4, 1941-67

$\begin{array}{rrrrrrrr}\text { Year } & \text { WSP } & \text { Year } & \text { WSP } & \text { Year } & \text { WSP } & \text { Year } & \text { WSP } \\ & & & & & & & \\ 1941 & 942 & 1948 & 1132 & 1955 & 1400 & 1962 & 1942 \\ 1942 & 950 & 1949 & 1162 & 1956 & 1450 & 1963 & 1948 \\ 1943 & 970 & 1950 & 1186 & 1957 & 1520 & 1964 & 1955 \\ 1944 & 1022 & 1951 & 1197 & 1958 & 1571 & 1965 & 1962 \\ 1945 & 1030 & 1952 & 1250 & 1959 & 1642 & 1966 & 1992 \\ 1946 & 1050 & 1953 & 1290 & 1960 & 1742 & 1967 & 2012 \\ 1947 & 1102 & 1954 & 1350 & 1961 & 1882 & \ldots \ldots & \ldots . .-\end{array}$

Geological Survey reports containing chemical quality, temperature, and sediment data obtained before 1941 are listed herein. Publications dealing largely with the quality of groundwater supplies and only incidentally covering the chomical composition of surface waters are not included. Publications that are out of print are preceded by an asterisk. 
PROFESSIONAL PAPER

*135. Composition of river and lake waters of the United States, 1924.

\section{BULLETINS}

*479. The geochemical interpretation of water analyses, 1911. 770. The data of geochemistry, 1924 .

\section{WATER-SUPPLY PAPERS}

*108. Quality of water in the Susquehanna River drainage basin, with an introductory chapter on physiographic features. 1904.

*161. Quality of water in the upper Ohio River basin and at Erie, Pa., 1906.

*193. The quality of surface waters in Minnesota, 1907.

*236. The quality of surface waters in the United States, Part 1, Analyses of waters east of the one hundredth meridian, 1909.

*237. The quality of the surface waters of California, 1910.

*239. The quality of surface waters of Illinois, 1910.

*273. Quality of the water supplies of Kansas, with a preliminary report on stream pollution by mine waters in southeastern Kansas, 1911.

*274. Some stream waters of the western United States, with chapters on sediment carried by the Rio Grande and the industrial application of water analys:s, 1911. *339. Quality of the surface waters of Washington, 1914. *363. Quality of the surface waters of Oregon, 1914.

*418. Mineral springs of Alaska, with a chapter on the chemical character of some surface waters of Alaska, 1917.

*596-B. Quality of water of Colorado River in 1925-26, 1928. *596-D. Quality of water of Pecos River in Texas, 1928. *596-E. Quality of the surface waters of New Jers?y, 1928. *636-A. Quality of water of the Colorado River in 1926-28, 1930. *636-B. Suspended matter in the Colorado River in 1925-28, 1930.

*638-D. Quality of water of the Colorado River in 1928-30, 1932. *839. Quality of water of the Rio Grande basin al ove Fort Quitman, Tex., 1938.

*889-E. Chemical character of surface water of Georgia, 1944. *998. Suspended sediment in the Colorado River, 1925-41, 1947. 
1048. Discharge and sediment loads in the Boise River drainage basin, Idaho, 1939-40, 1948.

1110-C. Quality of water of Conchas Reservoir, New Mexico, 1939-49, 1952.

Many of the reports listed are available for consultation in the larger public and institutional libraries. Copies of Geological Survey publications still in print may be purchased at a nominal cost from the Superintendent of Documents, Government Printing Office, Washington, D.C. 20402, who will, upon request, furnish lists giving prices.

\section{COOPERATION}

Many Municipal, State and Federal agencies assisted in collecting records for these quality-of-water investigations. Many of the investigations were supported by funds appropriated directly to the U.S. Geological Survey. The State, local, and Federal agencies that cooperated in these quality-of-water investigations are listed below:

Alabama--Geological Survey of Alabama, P. E. LaMoreauz, State geologist; Tennessee Valley Authority.

Georgia--Georgia Department of Mines, Mining and Geology, Dr. A. S. Furcron, director.

Illinois--Illinois State Department of Public Works and Buildings, F. S. Lorenz, director, through Division of W'aterways, J. C. Guillou, chief waterways engineer; Ohio River Valley Water Sanitation Commission, R. K. Horton, exe?utive director and chief engineer.

Indiana--Indiana Department of Natural Resources, J. E. Mitchell, director, through Bureau of Water and Mineral Resources, W. J. Andrews, deputy director; Indiana Board of Health, A. C. Offutt, commissioner, and B. A. Poole, director, Bureau of Environmental Sanitation; Indiana State Highway Commission, R. F. Whitehead, chairman, M. L. Hayes, executive director, F. L. Ashbaucher, chief engineer; Ohio River Valley Water Sanitation Commission, R. K. Horton, executive director and chief engineer.

Kentucky--University of Kentucky, J. W. Oswald, prerident, through State Geological Survey, W. W. Hagan, directior and State geologist; Ohio River Valley Water Sanitation Commission, R. K. Horton, executive director and chief engineer; Lexington and Fayette County Planning Commission, W. H. 
Qualls, executive director; Forest Service, U.S. Department of Agriculture; National Park Service, U.S. Department of the Interior; Corps of Engineers, U.S. Army; Tennessee Valley Authority.

Maryland--Maryland Geological Survey, K. N. Weaver, director; Maryland National Capital Park and Planning Commission, J. S. Hewins, director of planning.

Michigan--Michigan State Department of Conservation, R. A. MacMullen, director, G. A. Walker, deputy directcr, through Water Resources Commission, L. F. Oeming, executive secretary; Geological Survey Division, G. E. Eddy, chief; Fish Division, W. H. Tody, chief; Game Division, H. D. Ruhl, chief, succeeded by D. W. Douglass; Parks Division, R. O. Dodge, chief; Engineering Division, H. C. MacSwain, chief; Michigan Department of State Highways, H. E. Hill, director, Corps of Engineers, U.S. Army. Records were collected by: Branch County Board of Supervisors, Kalamaz:o County Board of Supervisors, Macomb County Board of Supervisors, Macomb County Road Commission, Oakland County D?partment of Public Works, Oakland County Drain Commission, Consumers Power Company, Cleveland-Cliffs Iron Company, and Van Buren County Board of Supervisors.

New York--New York State Department of Commerce, Bureau of Industrial Development, Henry Gallien, director; New York State Department of Conservation, Dvision of Water Resources, F. W. Montanari, assistant commissioner. Temperature records supplied by: The municipality of Watertown, Niagara-Mohawk Corporation, Rochester Gas and Electric Corporation, New York State Department of Transportation, and Mr. Douglas F. Manning.

North Carolina--North Carolina Department of Water Resources, G. E. Pickett, director.

Ohio--Ohio Department of Natural Resources, F. E. Morr, director, and C. V. Youngquist, chief, Division of Water; Ohio Department of Health, Dr. E. W. Arnold, director, and G. H. Eagle, chief engineer; Miami Conservancy District, M. L. Mitchell, chief engineer; Ohio River Valley Water Sanitation Commission, R. K. Horton, executive director and chief engineer.

Pennsylvania--Pennsylvania Department of Forest and Waters, M. K. Goddard, secretary, through Water and Power Resources Board, C. H. McConnell, chief engineer; Pennsylvania Department of Agriculture, L. H. Bull, s?cretary, 
through Soil and Water Conservation Commission, C. F. Hess, director.

Tennessee--Tennessee Department of Conservation, D. M. McSween, commissioner, succeeded by E. B. Garrett, through Division of Water Resources, R. W. Robinson, director, and Tennessee Department of Public Health, Dr. R. H. Hutcheson, commissioner, through Division of Stream Pollution Cortrol, S. L. Jones, director; Tennessee Valley Authority.

Virginia--Virginia Department of Conservation and Economic Development, M. M. Sutherland, director.

West Virginia--West Virginia Department of Natural Resources, T. R. Samsell, director, through Division of V'ater Resources, E. N. Henry, chief; Ohio River Valley V'ater Sanitation Commission, R. K. Horton, executive director and chief engineer.

Wisconsin--Wisconsin Department of Natural Resources, Division of Conservation, L. P. Voigt, administrator; University of Wisconsin, Geological and Natural History Survey, G. F. Hanson, State geologist and director.

\section{DIVISION OF WORK}

The quality-of-water work was performed by the Water Resources Division of the Geological Survey, E. L. Hendricks, chief hydrologist, and under the direction of the district chiefs listed in the preface.

Correspondence regarding the records in this report or any additional information should be directed to the district chief of the appropriate Geological Survey-Water Resources Division office indicated in the following table.
State
District Office
Address

Alabama

Tuscaloosa 35486

Box V

University

Georgia

Atlanta 30309

Room 301

900 Peachtree St. N.E.

Illinois

Champaign 61820

P. O. Box 1026

605 Neil St. 
State

Indiana

Kentucky

Maryland

Michigan

New York

North Carolina

Ohio

Pennsylvania

Tennessee

Virginia

West Virginia

Wisconsin
District Office

Indianapolis 46204

Louisville 40202

Parkville 21234

Lansing 48933

Albany 12201

Raleigh 27602

Columbus 43212

Harrisburg 17108

Nashville 37203

Richmond 23220

Charleston 25301

Madison 53706
Address

Room 516

611 North Park Ave.

Room 572,

Federal Eldg. 600 Federal Place

8809 Satyj Hill Rd.

Room 700, Capitol

Savings ant Loan

Bldg.

112 E. Alleran St.

P.O. Box 948

U.S. Post Cffice and Court Houre.

P.O. Box $2 £ 57$

Post Office Bldg. 300 Fayette-rille St.

975 West Trird Ave.

P.O. Box 1107 Federal Bldr. 228 Walnut St.

144 Federal Office Bldg.

Room 220

200 West Grace St.

Room 3303

New Federal Bldg. and Court House 500 Quarrier St. East

Room 200

1815 Univerrity Ave. 


\section{LITERATURE CITED}

American Society for Testing Materials, 1954, Manual on industrial water: Am. Soc. for Testing Mat., Philadelphia, Pa., p. 356.

Durfor, C. N. and Becker, E., 1964, Public water supplies of the 100 largest cities in the United States; 1962: U.S. Gecl. Survey Water-Supply Paper 1812, p. 20.

California State Water Pollution Control Board, 1952, Waterquality criteria: California State Water Pollution Control Board, pub. 3., p. 291-292, 377-378.

1954, Water-quality criteria: California State Water Pollution Control Board, pub. 3, Addendum no. 1., p. 291-292.

Faucett, R. L. and Miller, H. C., 1946, Methemoglobinomia occurring in infants fed milk diluted with well waters of high nitrate content: Jour. Pediatrics, v. 29, p. 593.

Hazen, Allen, 1892, A new color standard for natural waters Am. Chem. Jour., . 12, p. 427-428.

International Union of Pure and Applied Chemistry, 1961, Table of Atomic weights based on carbon-12: Chem. and Eng. News, v. 39, no. 42, Nov. 20, 1961, p. 43.

Kilmer, V. J. and Alexander, L. T., 1949, Methods of making mechanical analyses of soils: Soil Sci., v. 68, p. 15-24.

Lane, E. W., and others, 1947, Report of the Subcommittee on sediment terminology: Am. Geophys. Union Trans., v. 28, no. 6, p. 936-938.

Magistad, O. C., and Christiansen, J. E., 1944, Saline Soils, their nature and management: U. S. Dept., Agriculture Circ. 707, p. 8-9.

Maxcy, K. F., 1950, Report on the relation of nitrate concentrations in well waters to the occurrence of methemoglobinemia: Natl. Research Council, Bull. Sanitary Eng. and Environment, App. D., p. 271.

Northeastern Water Works Association, 1940, Progress report, Committee on quality Tolerances of Water for Industrial Uses: Northeast Water Works Assoc. Jour., v. 54.

Paynter, O. E., 1960, The chronic toxicity of dodecylbenzene sodium sulfonate: U.S. Public Health Conference on Physiological Aspects of Water Quality Proc., Washington, D.C., Sept. 8-9, 1960, p. 175-179.

Pleissner, M., 1907, Uber die Loblichkeit eimiger Bleiverbindungen in wasser: Arb. Kais. Gesundeitsamt. v. 26, p. $384-443$. 
Rainwater, F. H., and Thatcher, L. L., 1960, Methods for collection and analysis of water samples: U.S. Geol. Survey Water-Supply Paper 1454, $301 \mathrm{p}$.

Rankama, K., and Sahama, T. G., 1950, Geochemistry: Chicago Univ. Press, Chicago, Ill., p. 767.

Riffenburg, H. B., 1925, Chemical character of grourd waters of the northern Great Plains: U.S. Geol. Survey Water-Supply Paper 560-B, p. 31-52.

Rose, Arthur and Elizabeth, 1965, The condenset chemical dictionary: Reinhold Pub. Corp., New York, 5th ed., p. 412. Seidell, Atherton, 1940, Solubilities of inorganic and metal organic compounds, 3d ed., v. 1, D. van Nostrand, New York. p. 1409.

U.S. Inter-Agency Committee on Water Resources, Subcommittee on Sedimentation, A study of methods used in measurement and analysis of sediment loads in streams. Published by the St. Anthony Falls Hydraulic Laboratory, Minnearolis, Minn. 1943, A study of new methods of size analysis of suspended-sediment samplers, Rept. 7.

1952, The design of improved types of suspendet-sediment samplers: Rept. 6.

1957, The development and calibration of visual accumulation tube: Rept 11.

1957, Some fundamentals of particle size analysis: Rept. 12.

1959, Federal Inter-agency sedimentation instruments and reports: Rept. AA.

1963, Determinations of fluvial sediment discharge: Rept. 14.

1963, A summary of the work of the Inter-acency sedimentation project: Rept. S.

U.S. Public Health Service, 1962, Drinking water standards: U.S. Dept. Health, Education, and Welfare, Pullic Health Service: Pub. no. 956.

U.S. Salinity Laboratory Staff, 1954, Diagnosis and improvement of saline and alkali soils: U.S. Dept. Agriculture, Agriculture Handb. 60, p. 1-160.

Waring, F. H., 1949, Significance of nitrates in water supplies: Am. Water Works Assoc. Jour., v. 41, no. 2., F. 147-150. Wayman, C. H., 1962, Limitations of the methylene b? ue method for ABS determinations: U.S. Geol. Survey, Prof. Paper 450-B, art. 49, p. B117-B120.

Wayman, C. H., Robertson, J. B., and Page, H. G., 1962, Foaming characteristics of synthetic-detergent solutions: U.S. Geol. Survey, Prof. Paper 450D, art. 178, p. D198. 


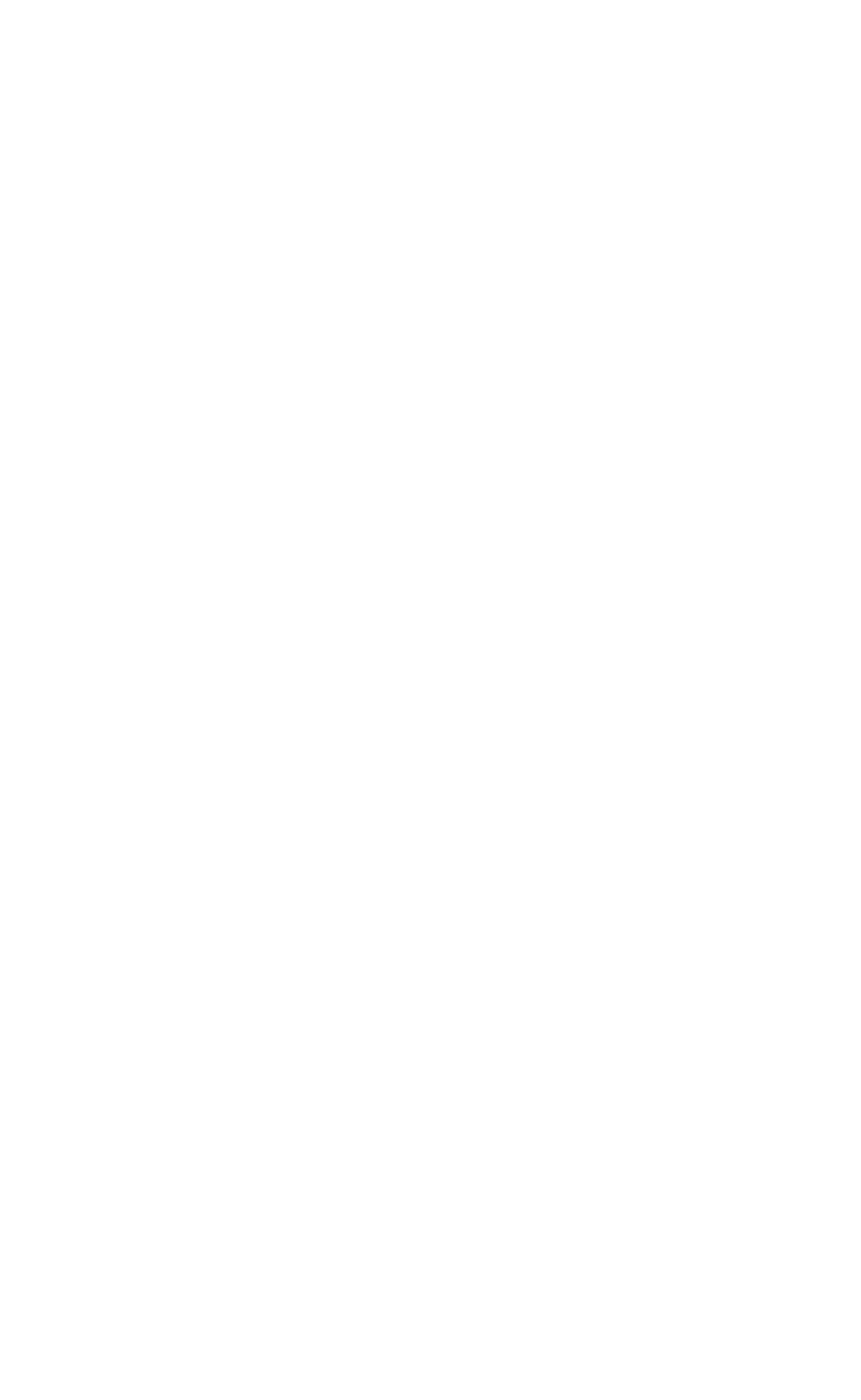




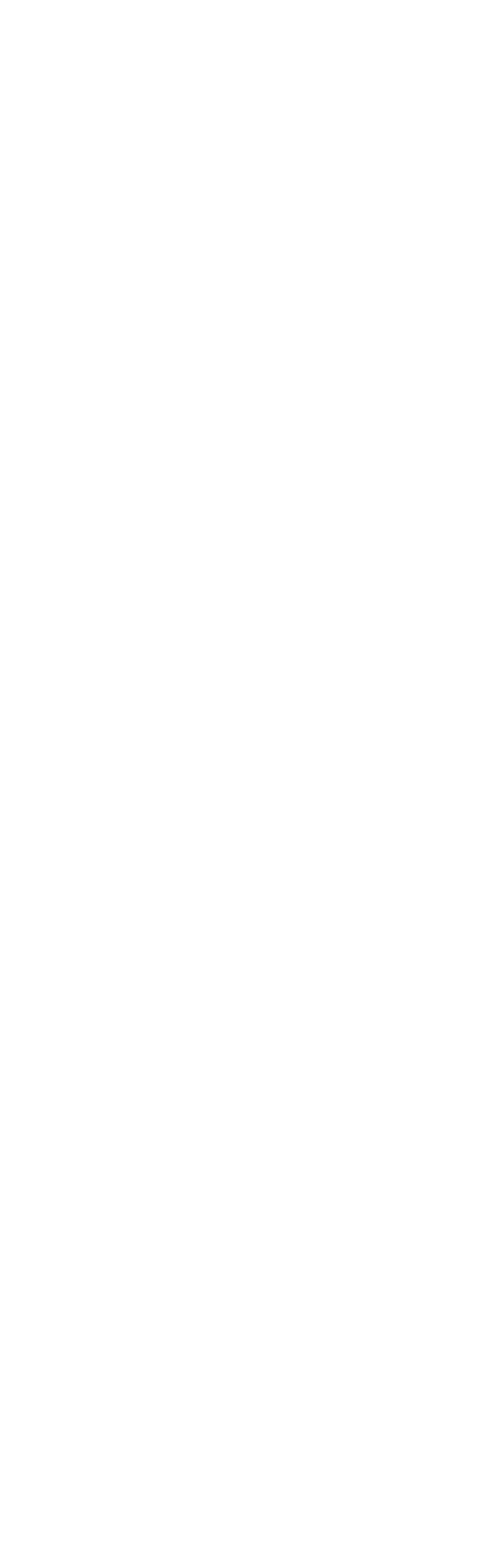

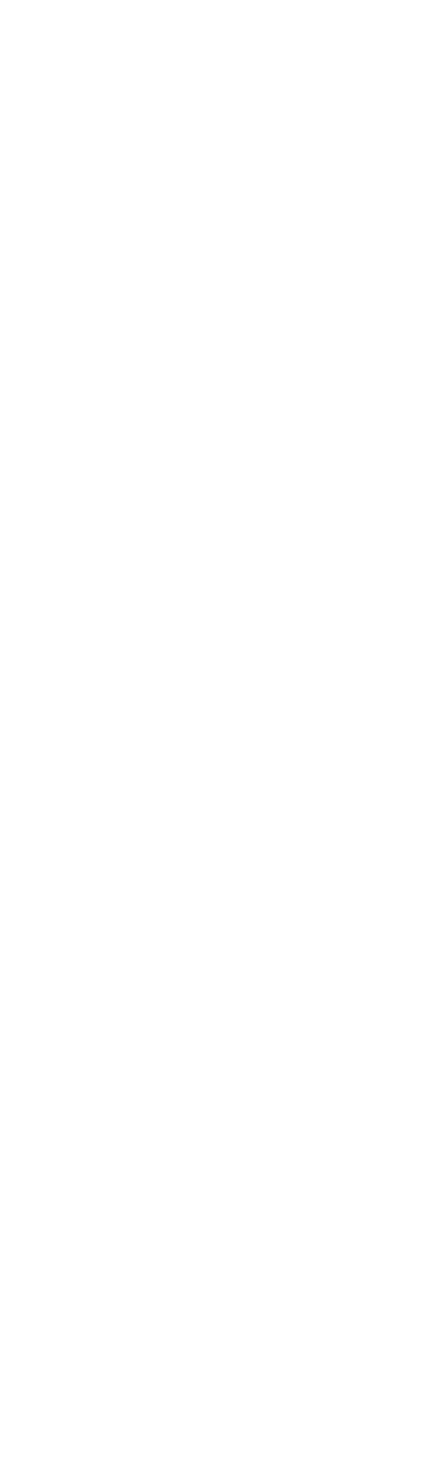




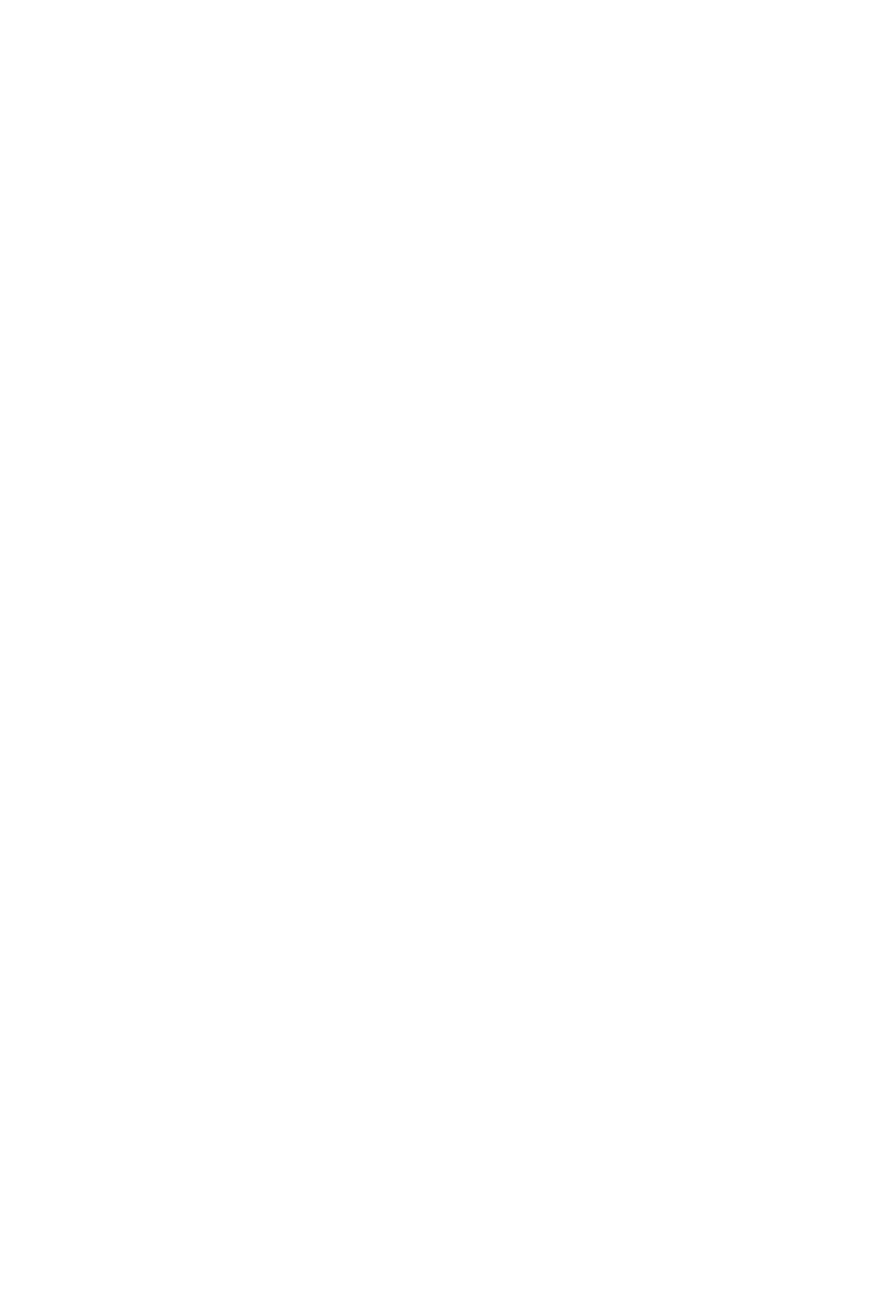




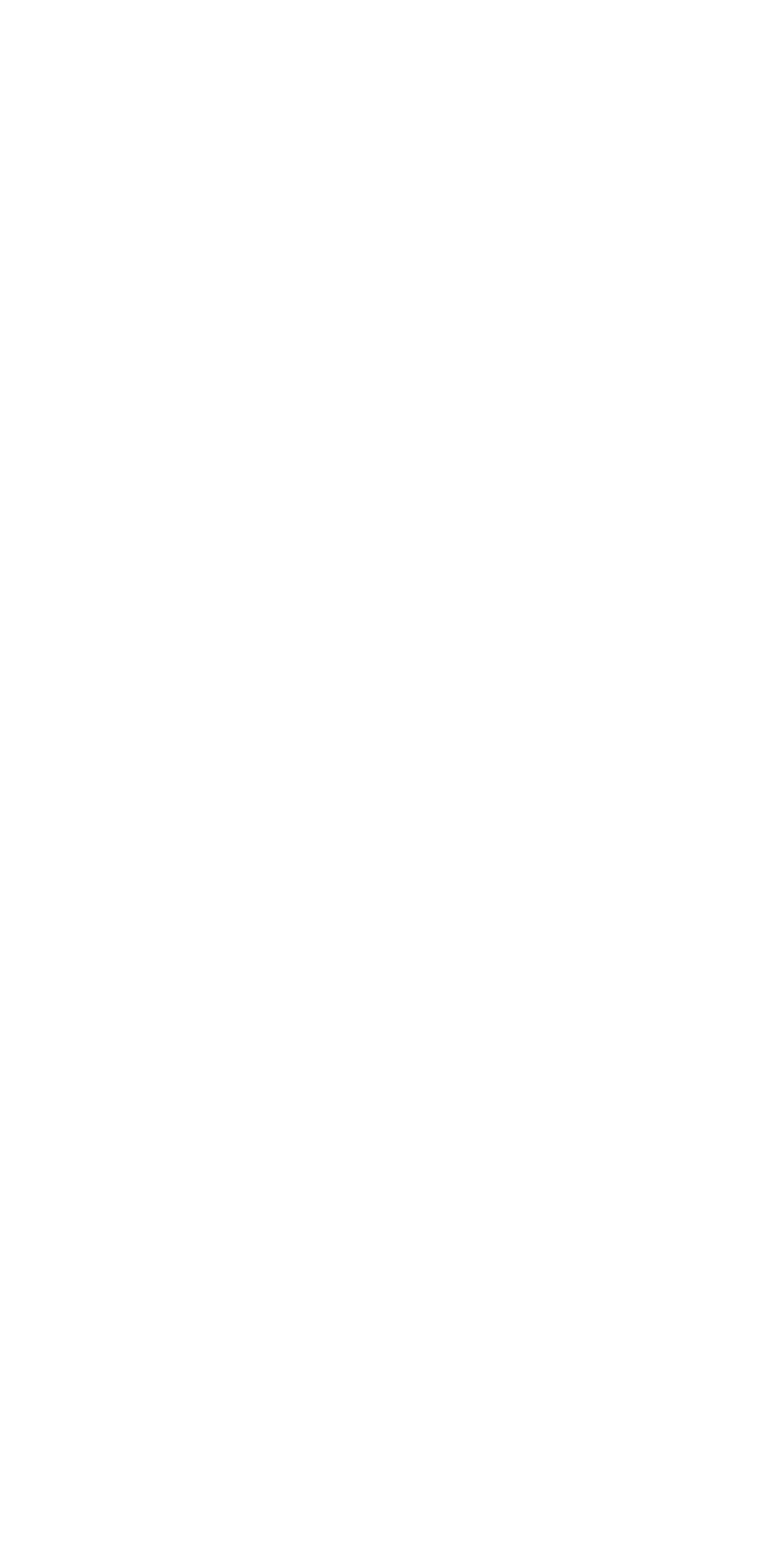




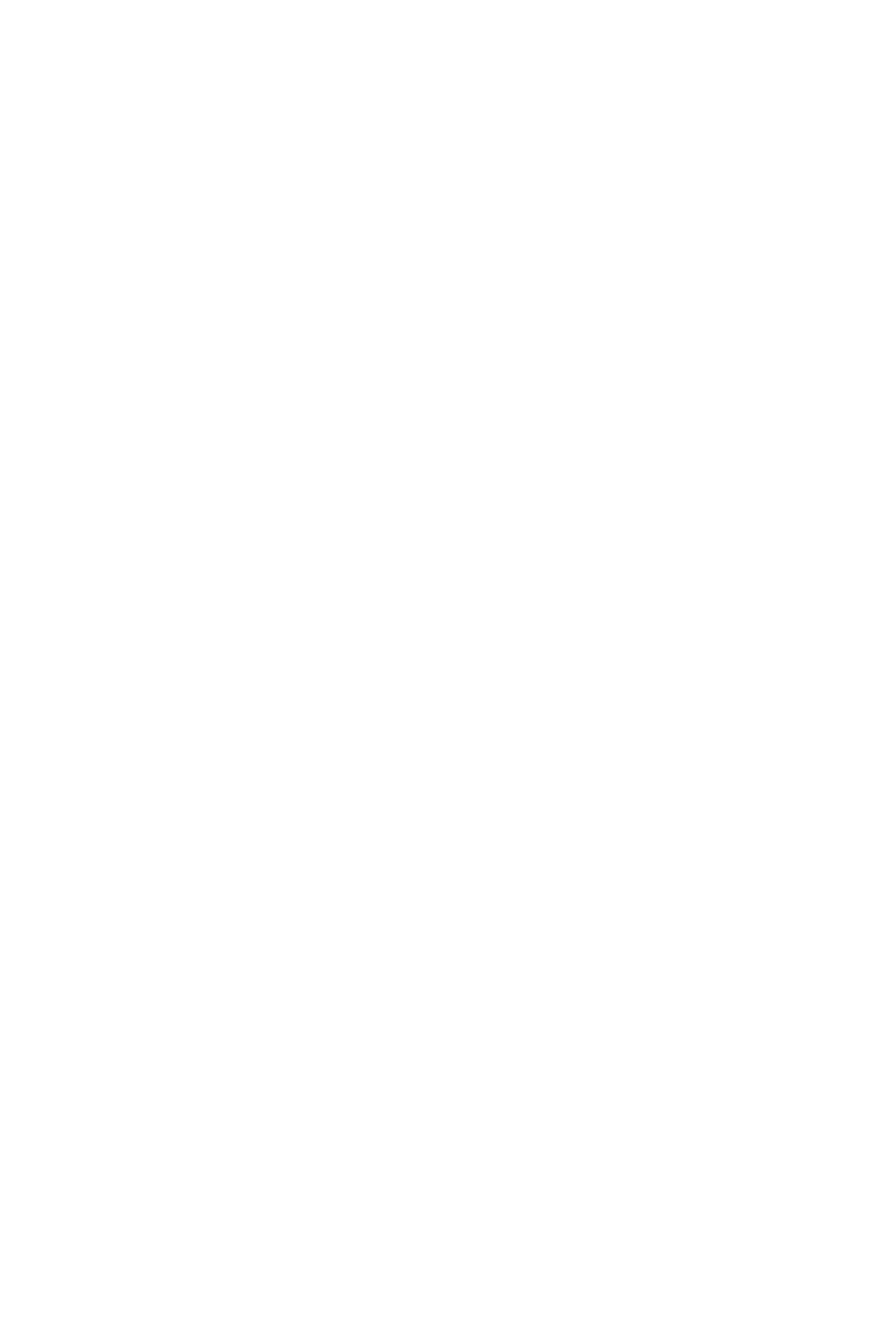




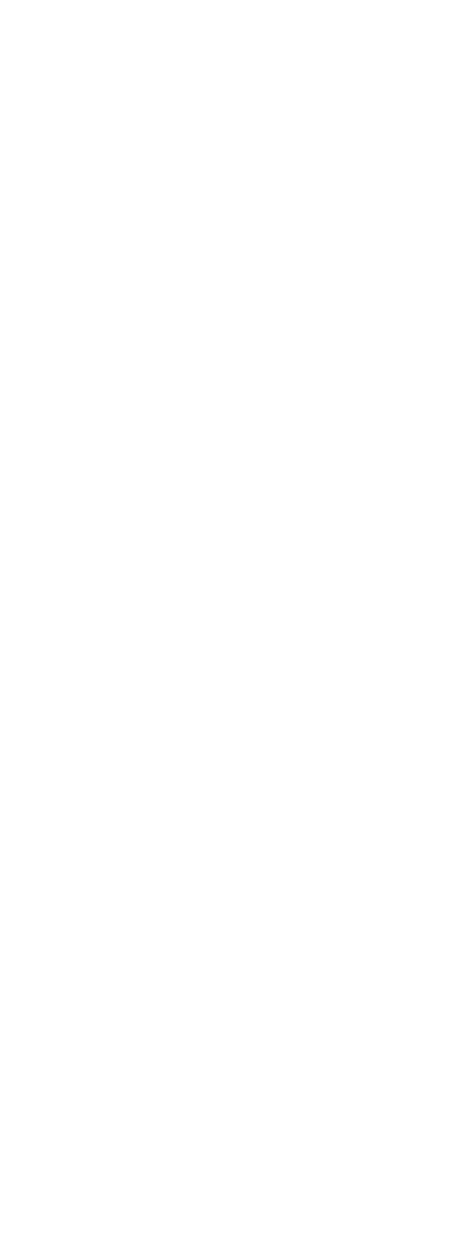

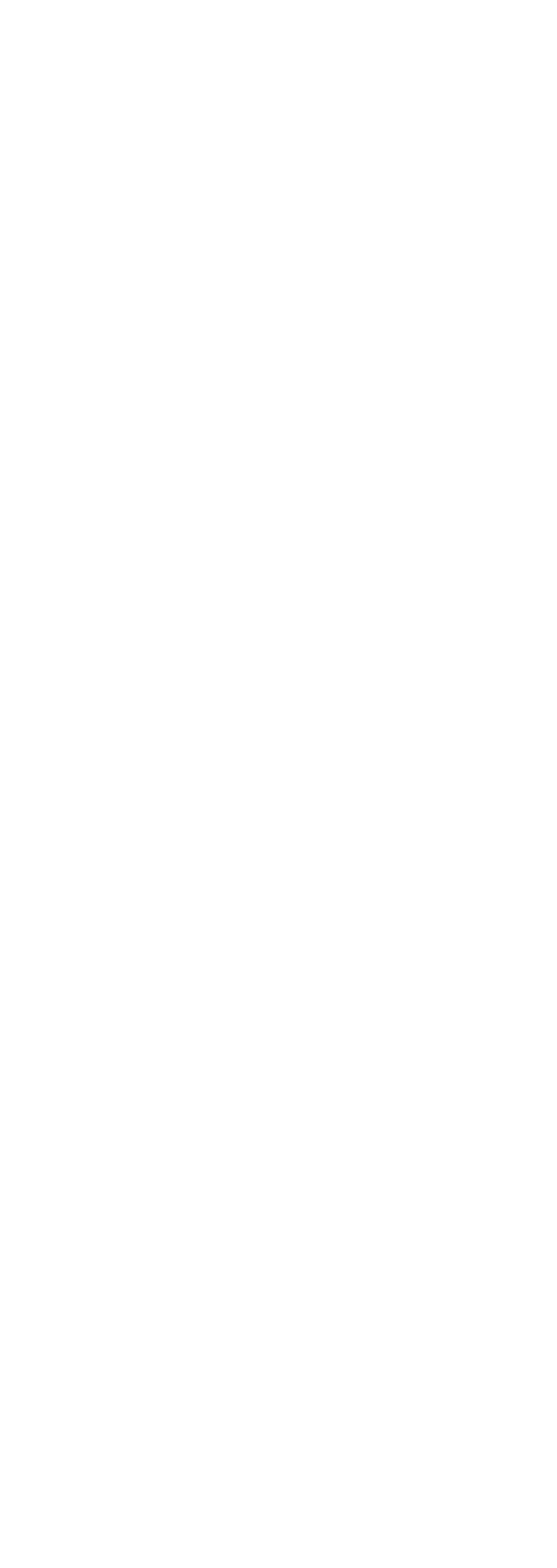




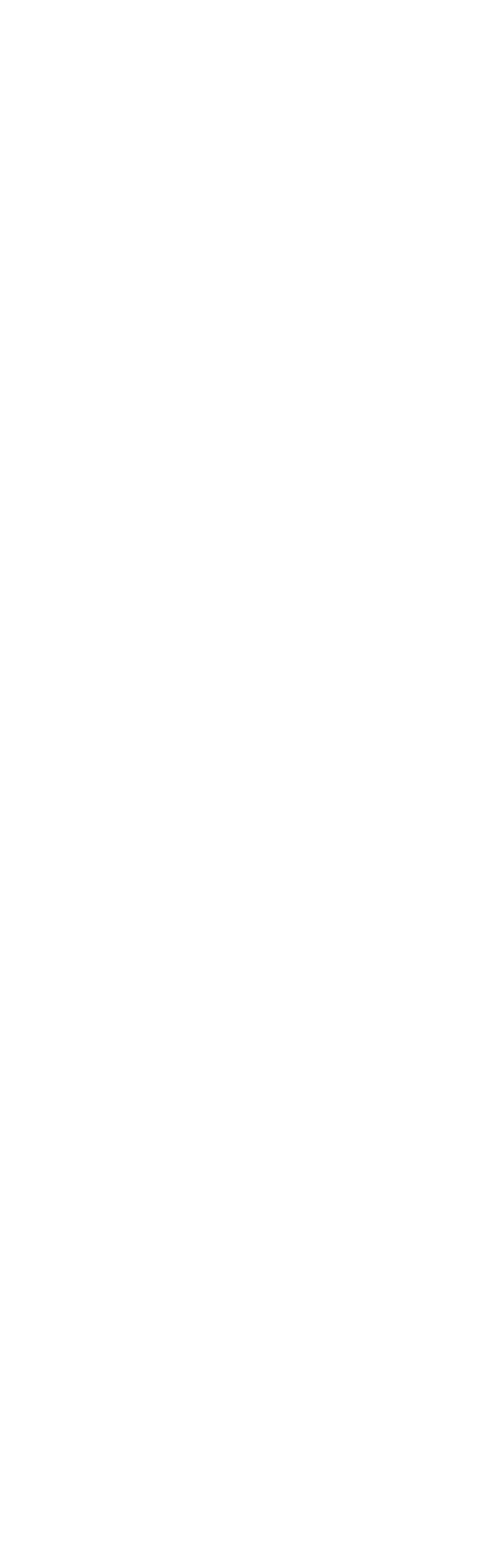




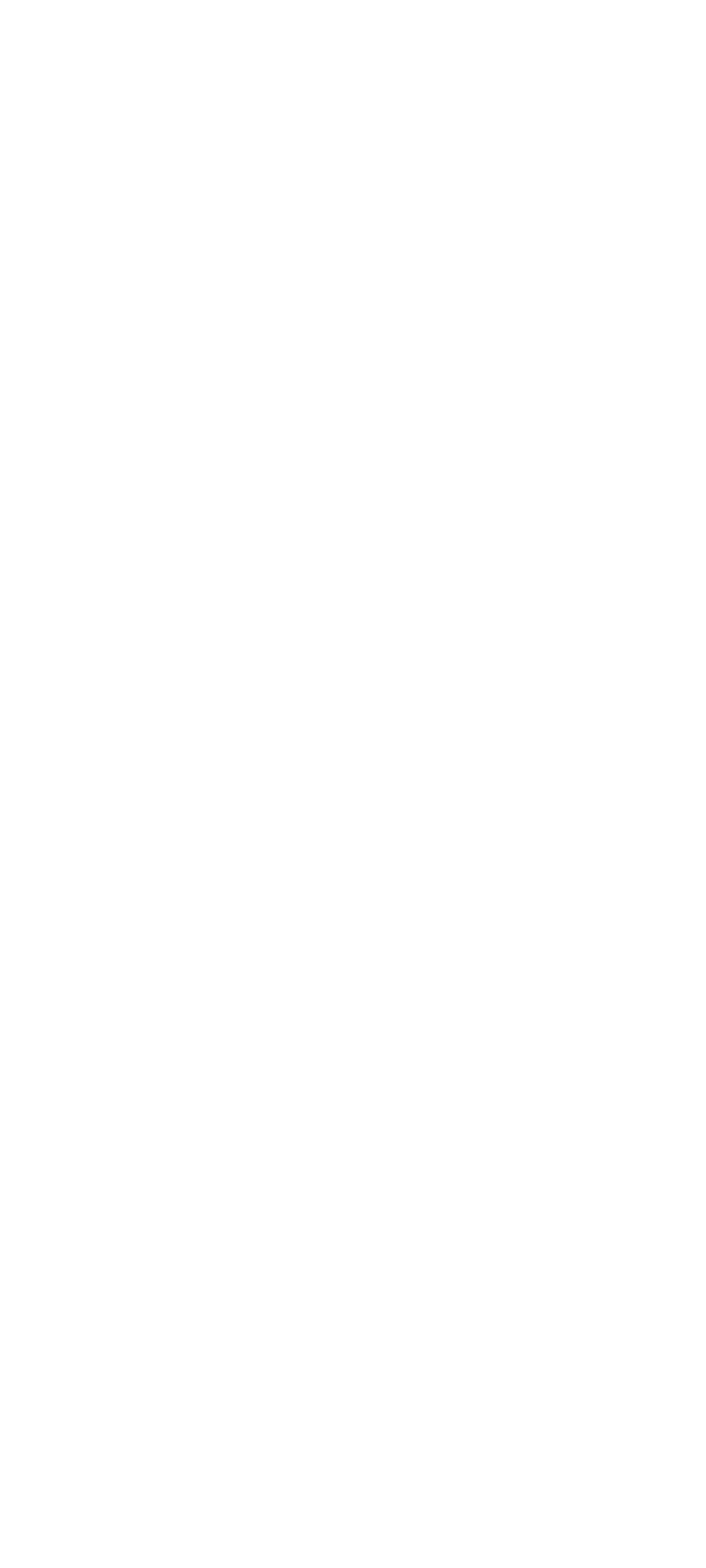




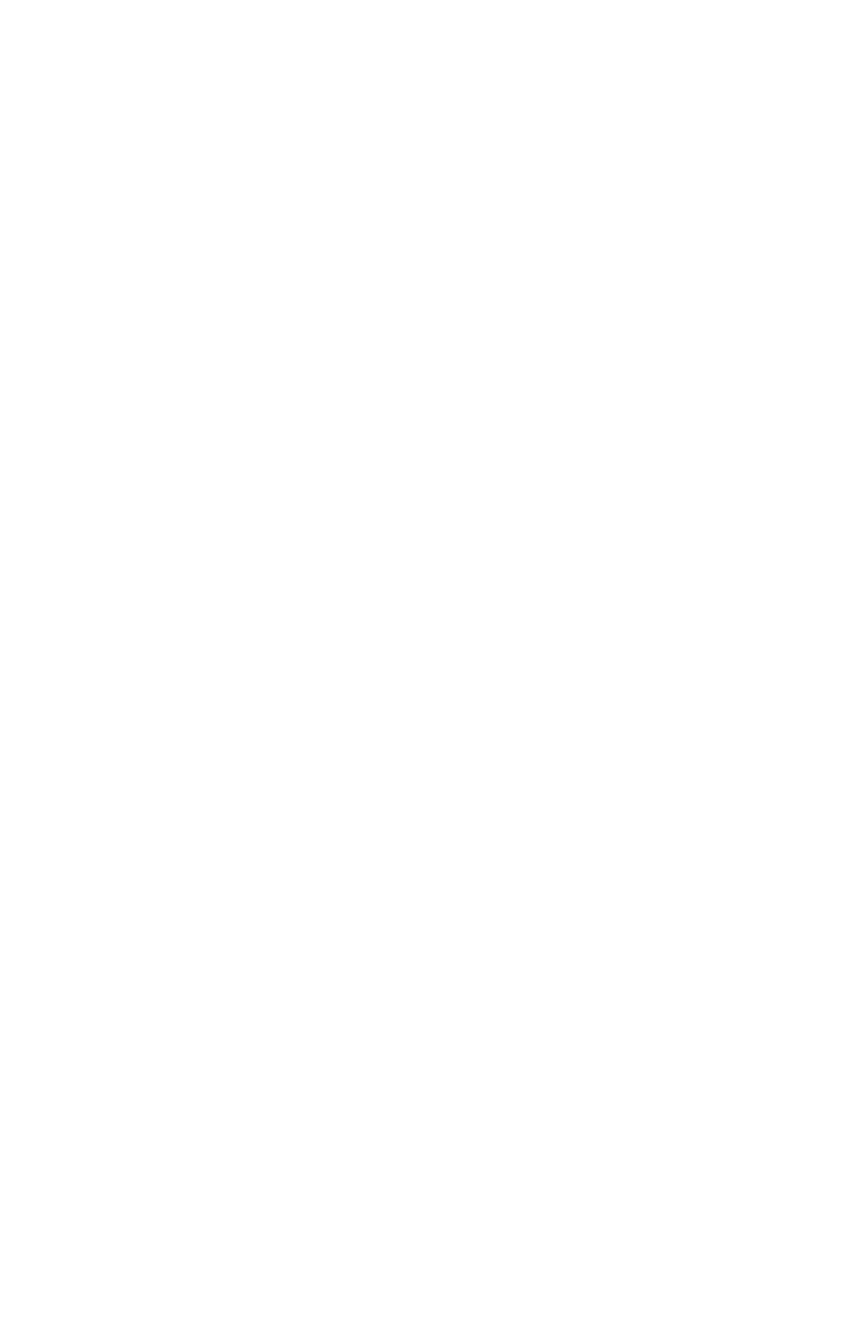



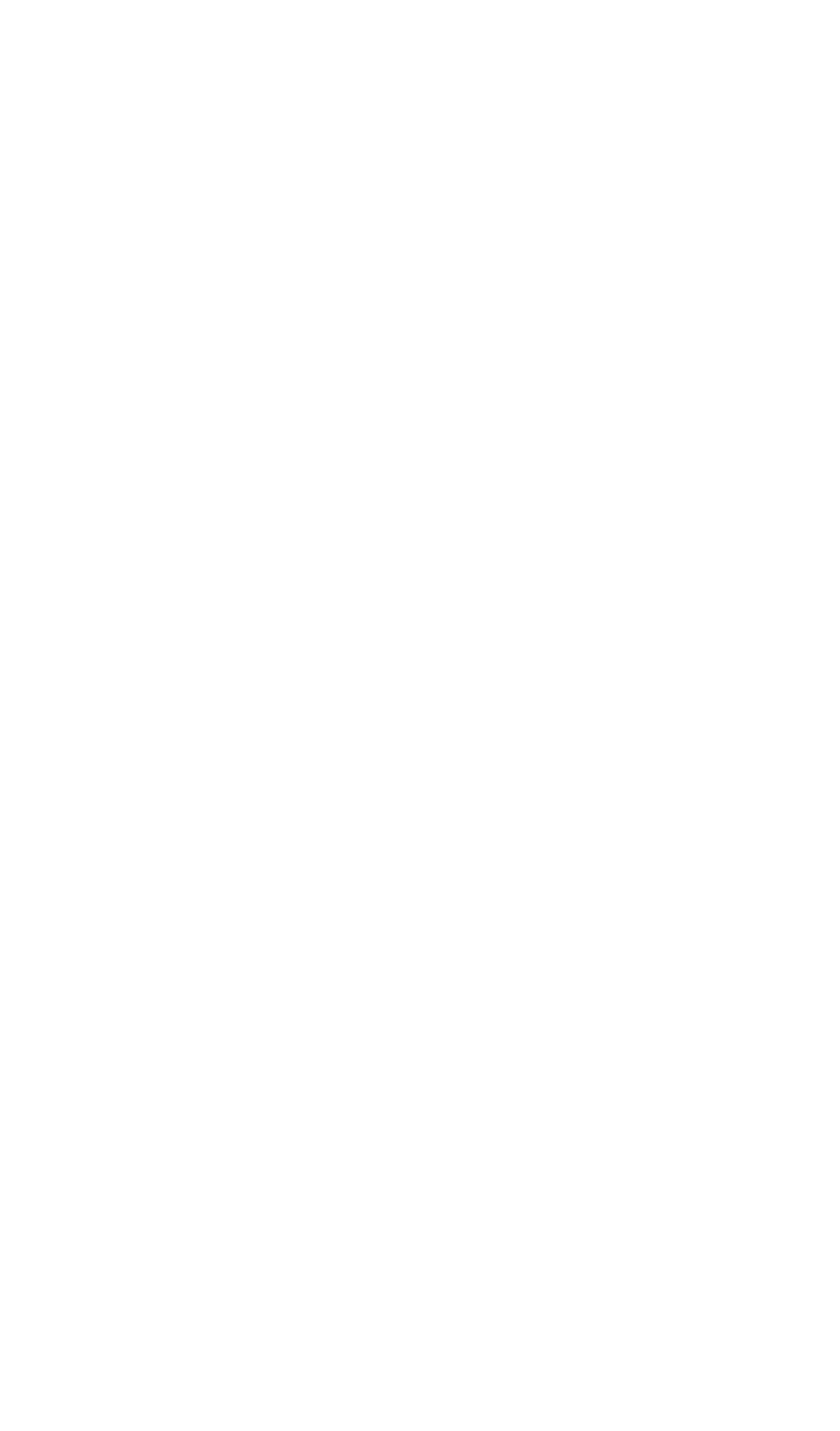


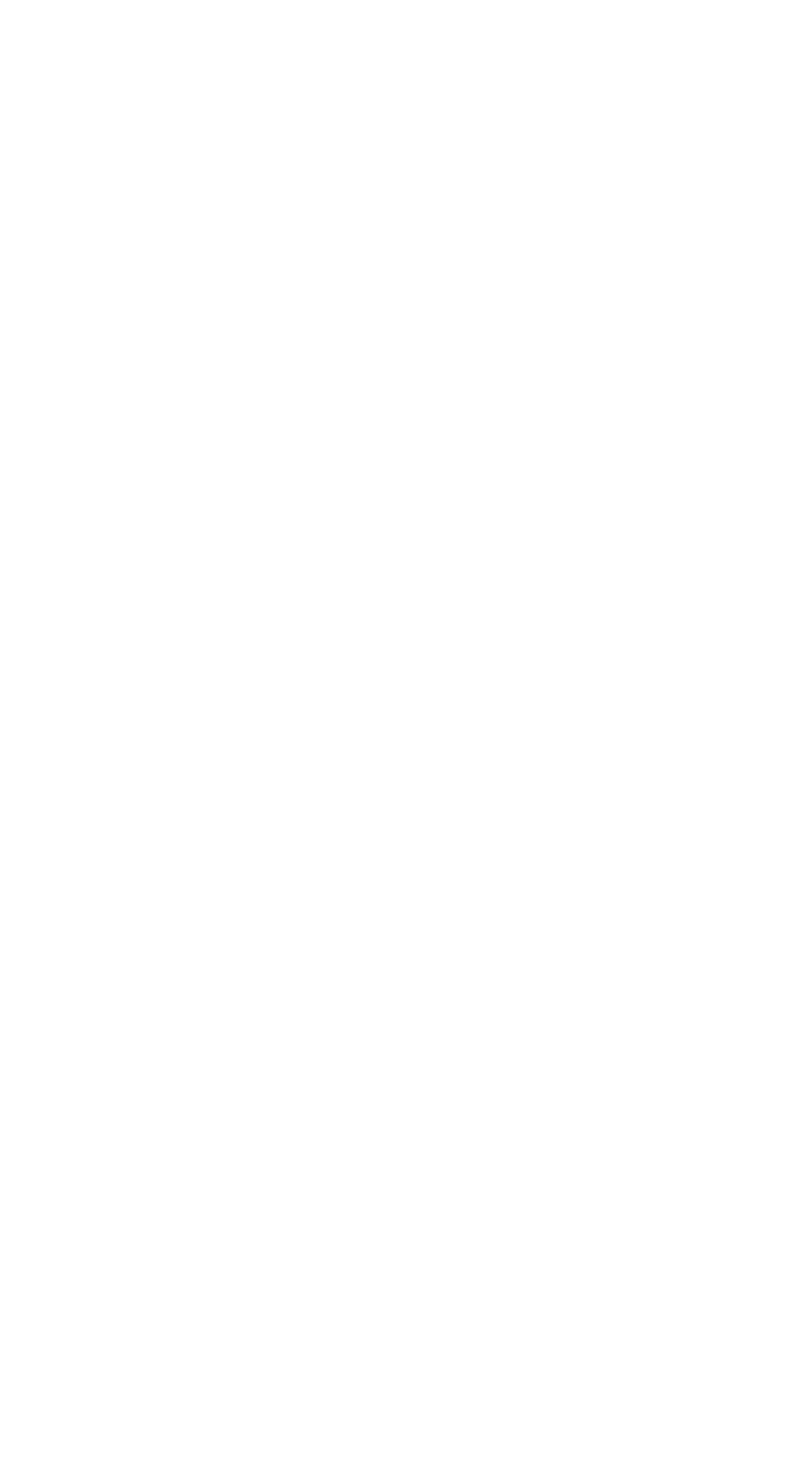




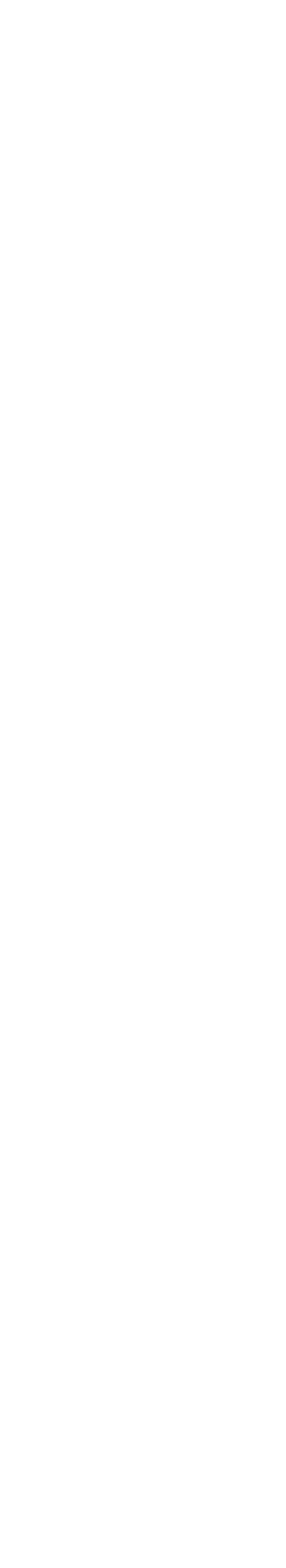

\begin{tabular}{|c|c|}
\hline$\frac{1}{8} 5$ & manome Pam \\
\hline$\frac{7}{2}$ & 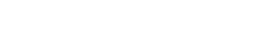 \\
\hline 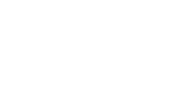 & 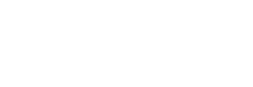 \\
\hline 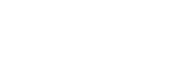 & 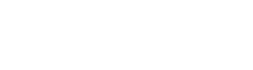 \\
\hline 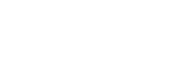 & 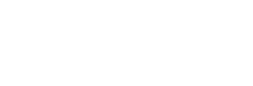 \\
\hline 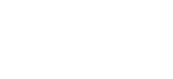 & 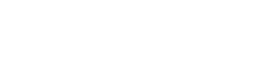 \\
\hline 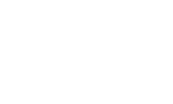 & 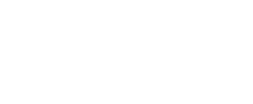 \\
\hline 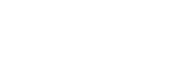 & 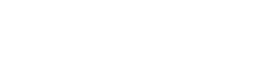 \\
\hline 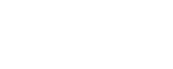 & 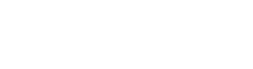 \\
\hline 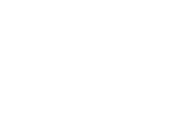 & న న \\
\hline 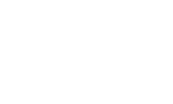 & 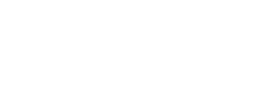 \\
\hline 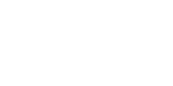 & 000000000000 \\
\hline 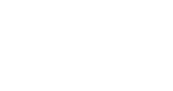 & $\approx_{\pi}^{\infty} 11: 111: 11$ \\
\hline $\begin{array}{lll} & \\
\end{array}$ & 赵承1: 111111 \\
\hline $\begin{array}{l}4 \\
\vdots \\
y\end{array}$ & 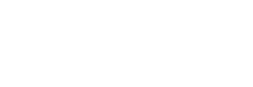 \\
\hline 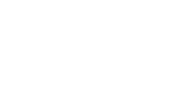 & $\infty$ \\
\hline $\begin{array}{ll} \\
\end{array}$ & श्र里:11 $111: 111$ \\
\hline 总䋗 & 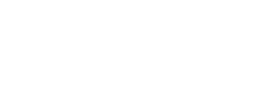 \\
\hline 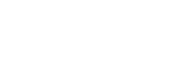 & 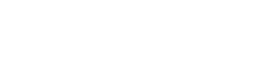 \\
\hline 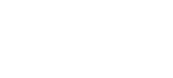 & $p=1: 11: 111:$ \\
\hline 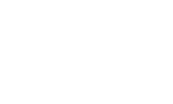 & 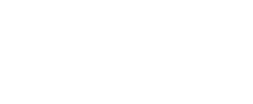 \\
\hline 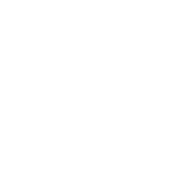 & 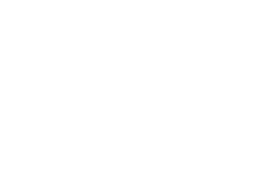 \\
\hline
\end{tabular}

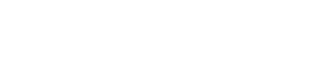

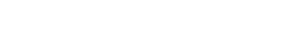

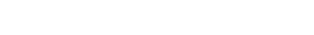

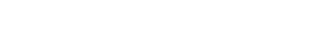

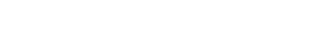

స ก กำ

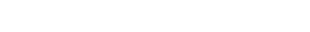

는

ㄴำ

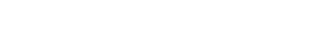

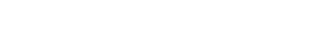

ก

인

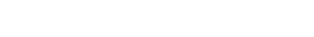

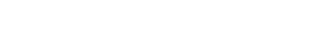

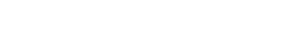

ํำำ ำ

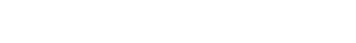

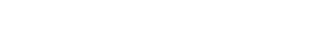

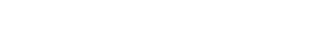

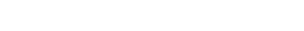

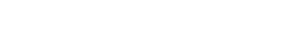

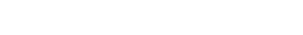

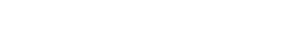

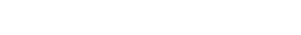

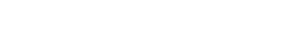

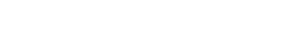

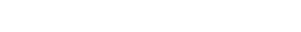

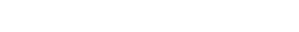

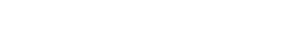

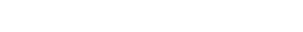

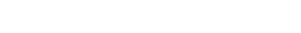

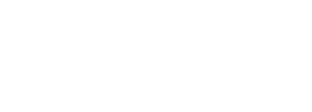




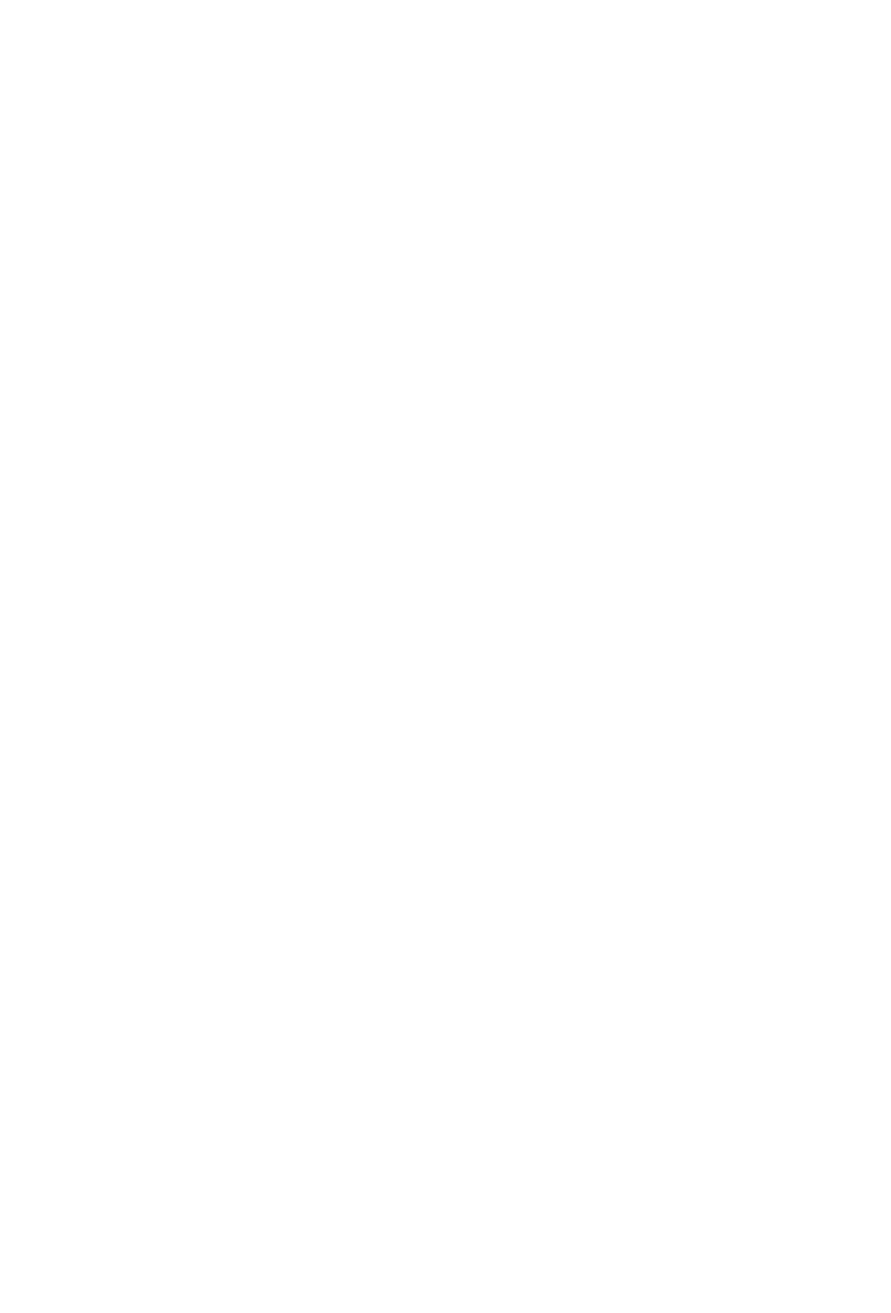




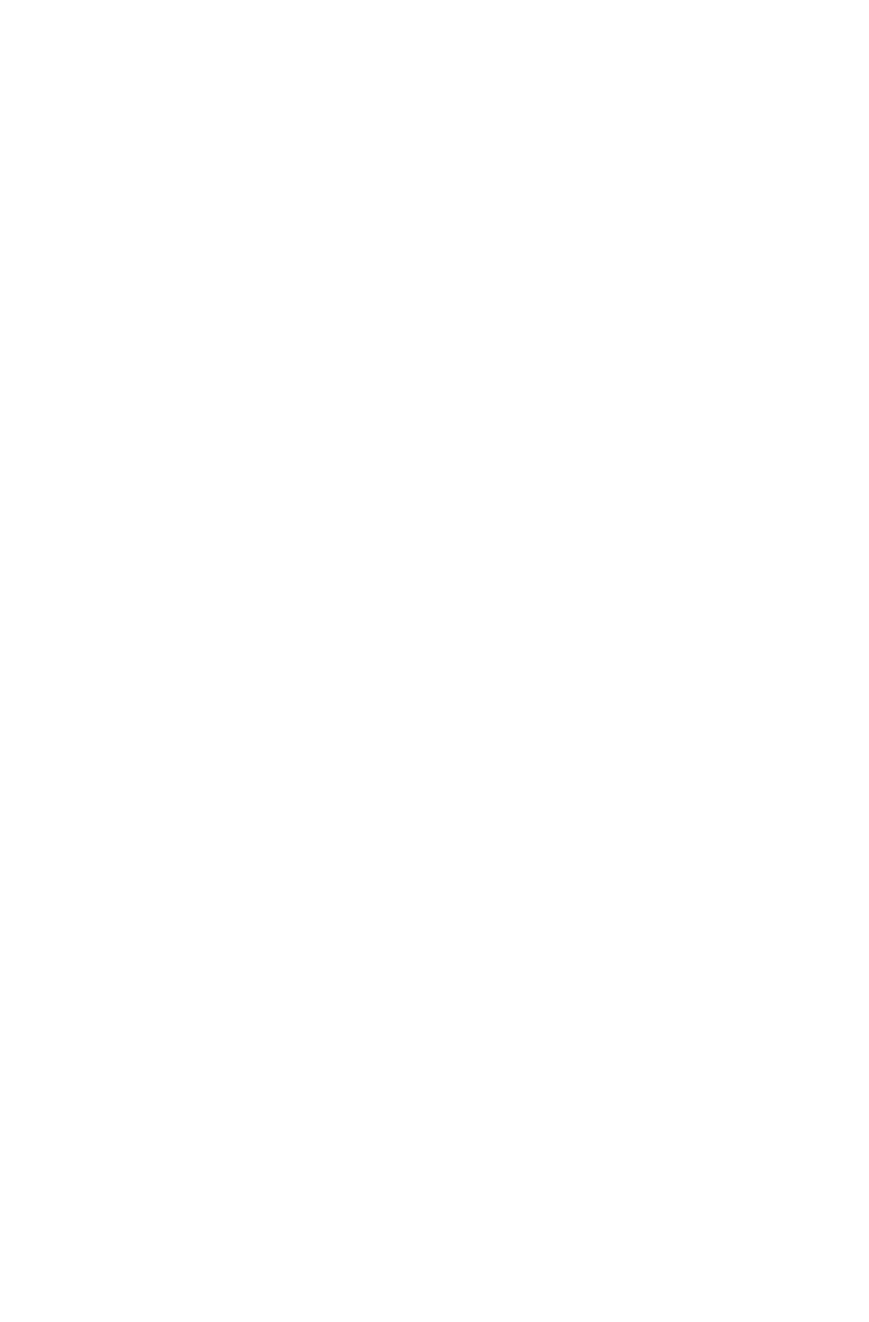




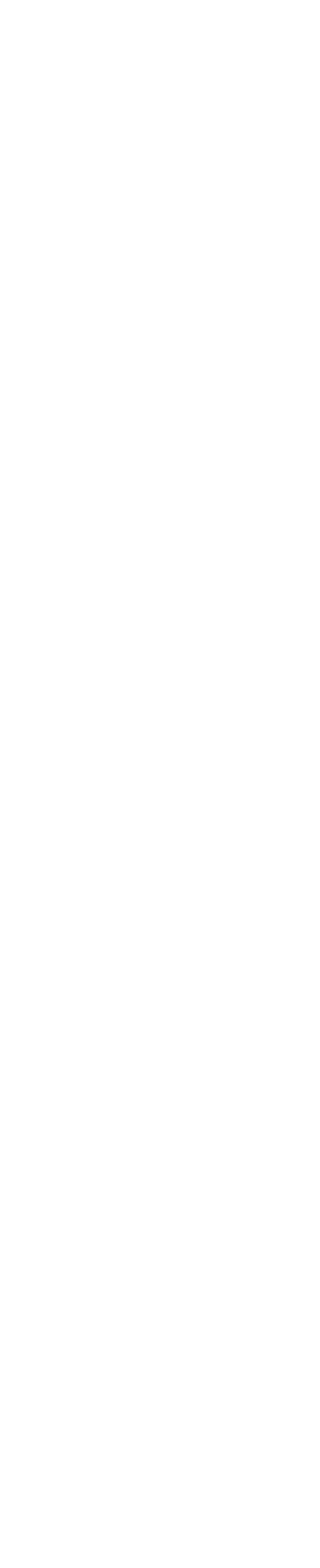

\begin{tabular}{|c|c|c|}
\hline & 8 & \\
\hline & 要 & 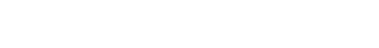 \\
\hline & 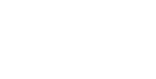 & 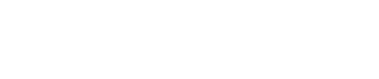 \\
\hline & 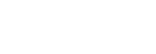 & 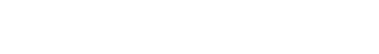 \\
\hline & 宕它客范 & 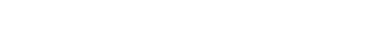 \\
\hline & 空 & 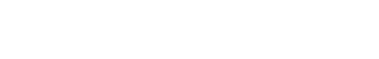 \\
\hline & 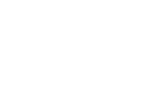 & 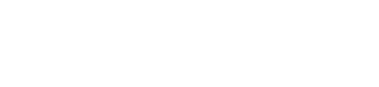 \\
\hline & 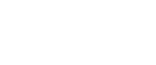 & 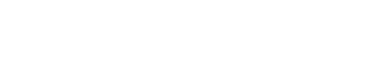 \\
\hline & 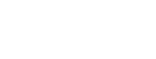 & 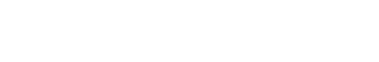 \\
\hline & 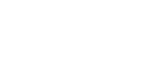 & ب̆ \\
\hline & 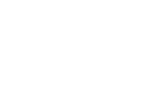 & 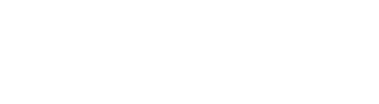 \\
\hline & 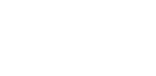 & 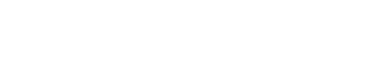 \\
\hline & 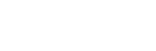 & $000000 \quad 000000000000$ \\
\hline & 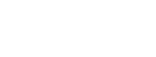 & 유 \\
\hline & 重至焉 & \\
\hline & 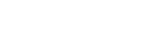 & \\
\hline & 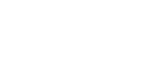 & \\
\hline & 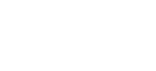 & \\
\hline & 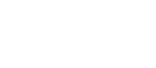 & \\
\hline & 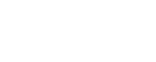 & 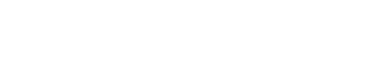 \\
\hline & 总司 & 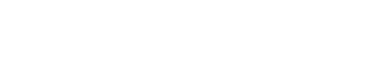 \\
\hline & 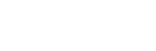 & \\
\hline & 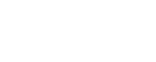 & \\
\hline & 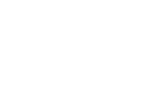 & 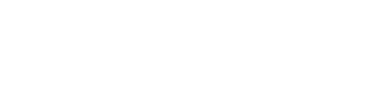 \\
\hline & 造谞 & $\begin{array}{l}\dot{0} 0: 0 \\
0 \\
0\end{array}$ \\
\hline
\end{tabular}




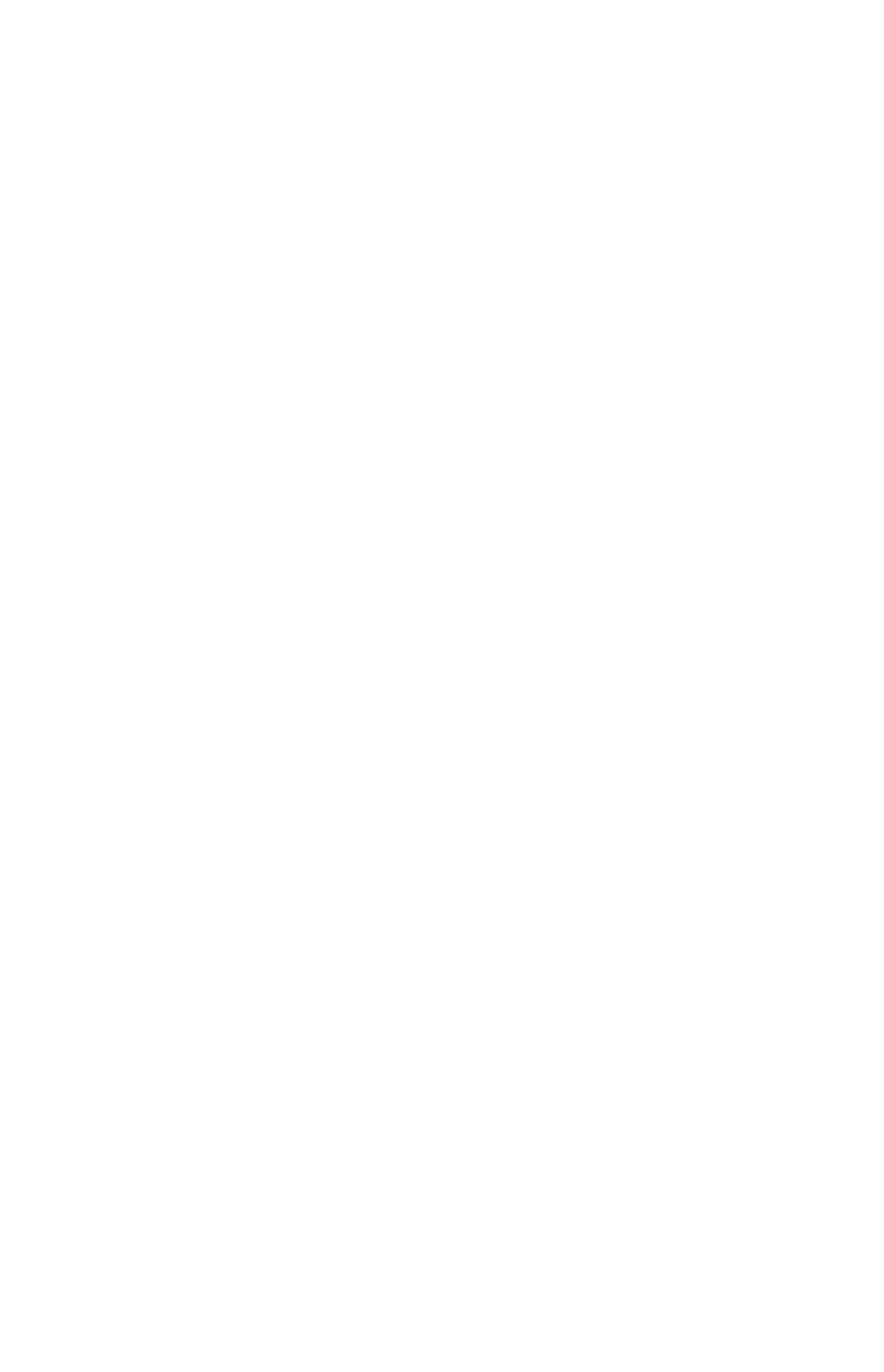




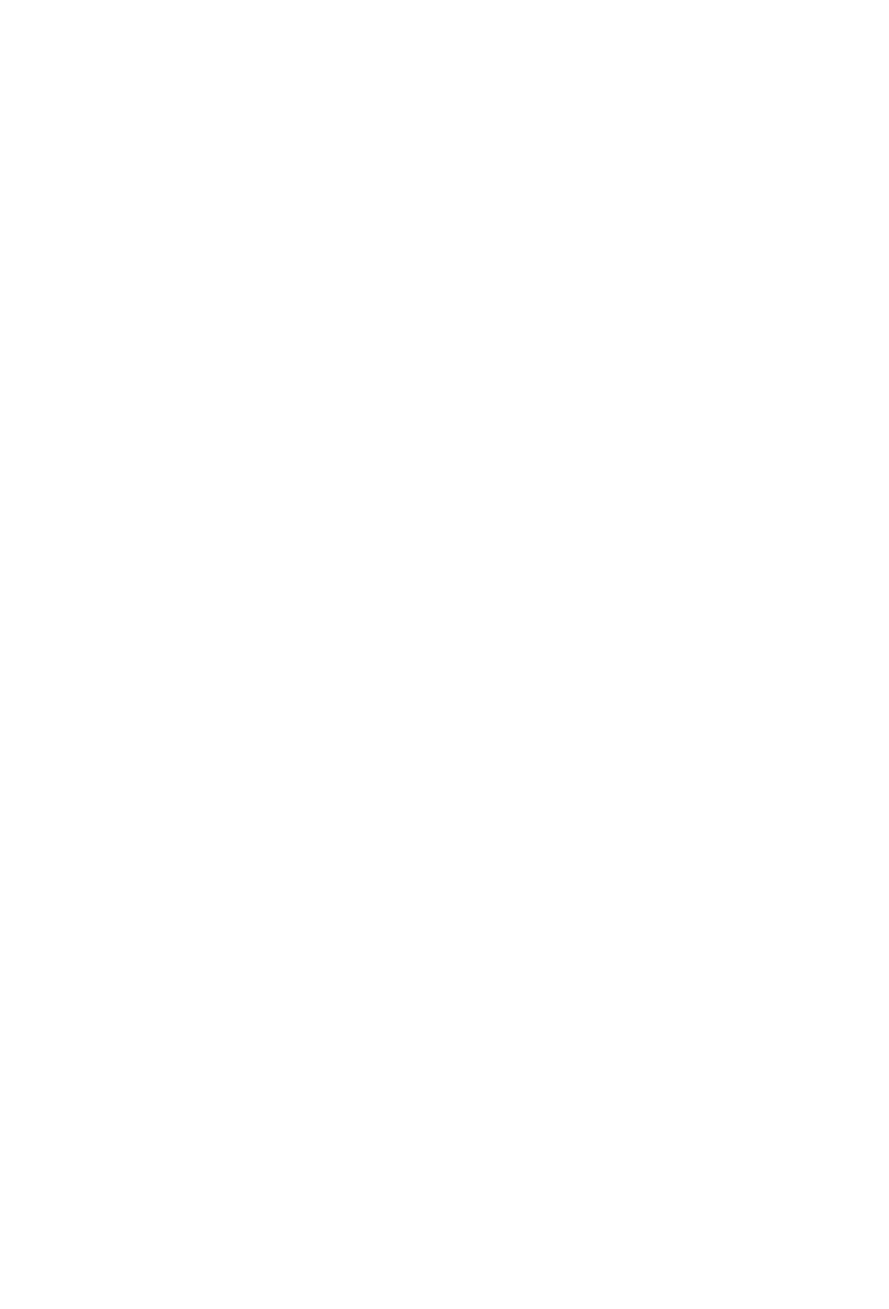




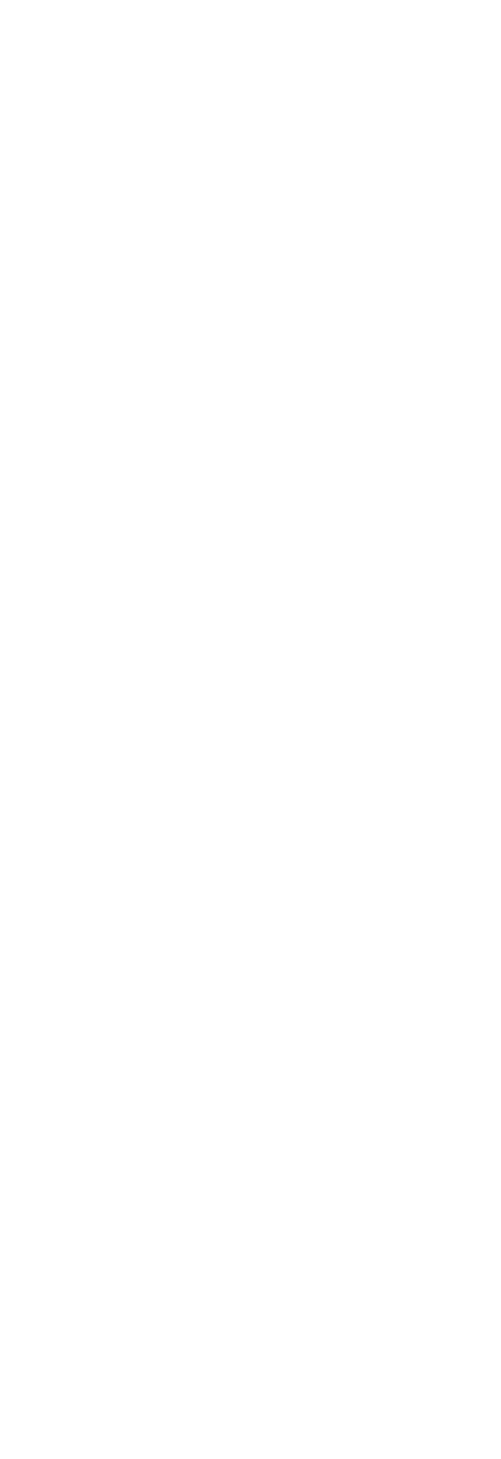




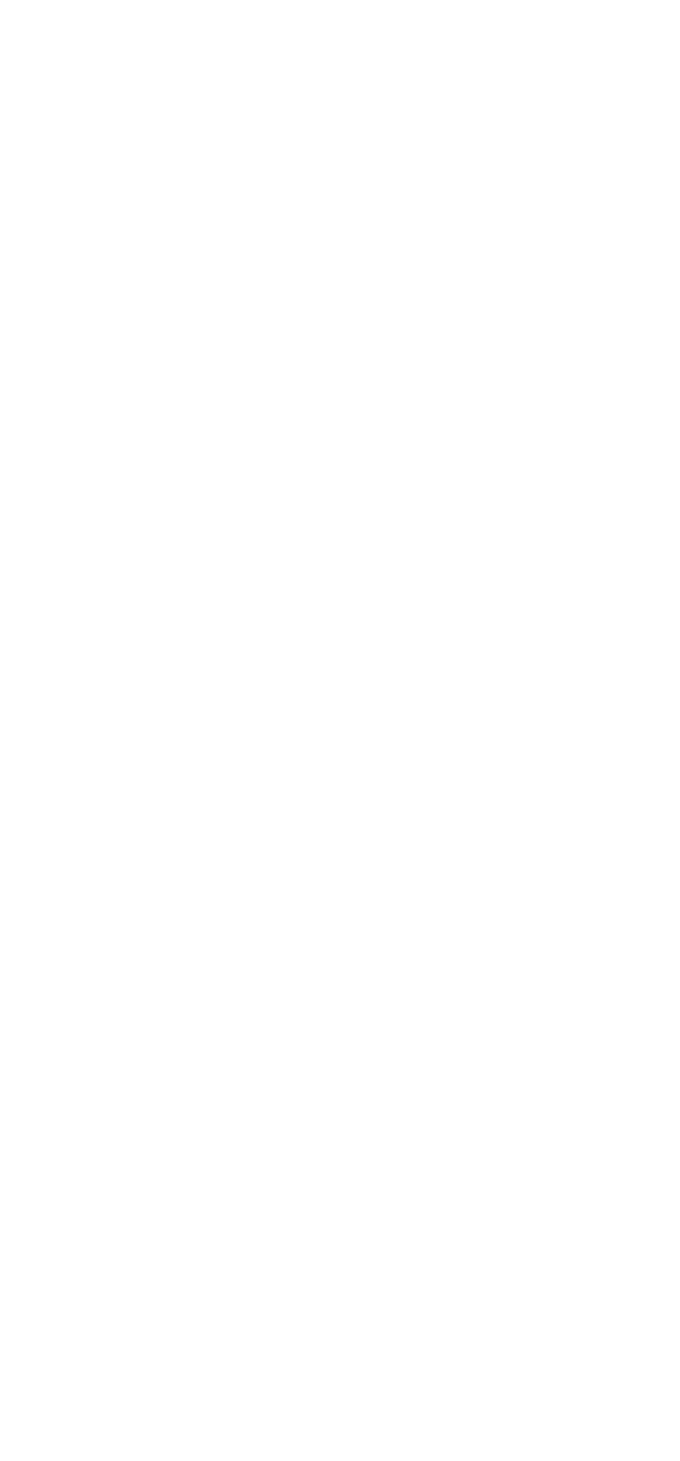



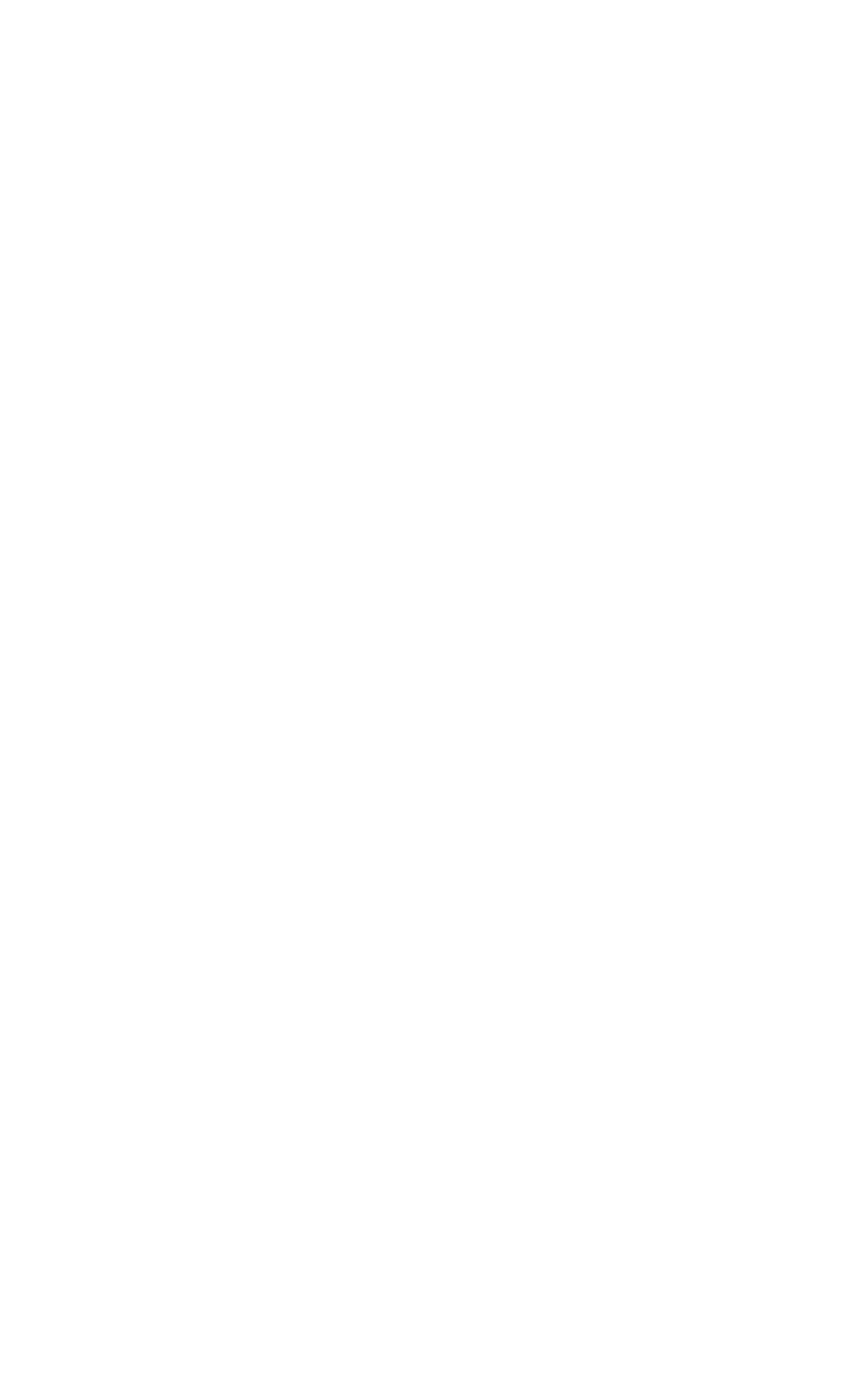
MONONGAHELA RIVER BASIN--COntInued

3-0508. ROARING CREEK AT NORTON, W. VA,--COntinued

Suspended sediment, water year October 1966 to September 1967

(Where no dafly concentrations are reported, loads are estimated. Where loads were computed fron a partly estimated-concentration graph, time-weighted concentrations are reported)

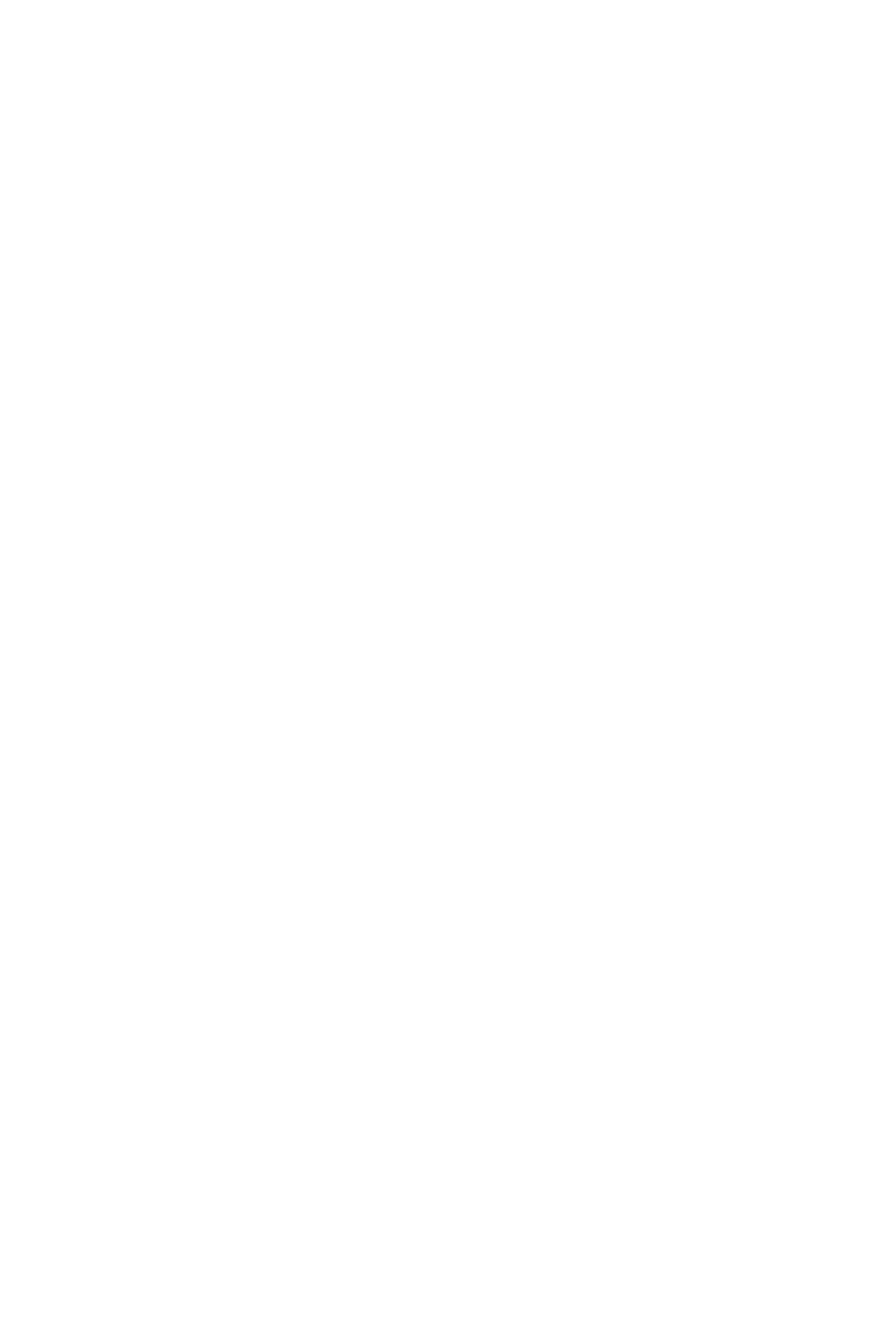

S Computed by subdividing day.

$T$ Less than 0.05 ton.

A Computed from partiy estimated-concentration graph. 
WONONGAHELA RIVER BASIN--COntInUed

3-0508. ROARING CREEK AT NORTON, W. YA.--Continued

Suspended sediment, water year October 1966 to September 1967--Continued (Where no daily concentrations are reported, loads are estimated. Where loads were computed from a partly estimated-concentration graph, time-weighted concentrations are reported)

\begin{tabular}{|c|c|c|c|c|c|c|c|c|c|}
\hline \multirow[b]{3}{*}{ Day } & \multicolumn{3}{|c|}{ APRIL } & \multicolumn{3}{|c|}{ MAY } & \multicolumn{3}{|c|}{ JUNE } \\
\hline & \multirow[b]{2}{*}{$\begin{array}{c}\text { Mean } \\
\text { dis- } \\
\text { charge } \\
(c f s)\end{array}$} & \multicolumn{2}{|c|}{ Suspended sediment } & \multirow[b]{2}{*}{$\begin{array}{c}\text { Mean } \\
\text { dis- } \\
\text { charge } \\
\text { (cfs) }\end{array}$} & \multicolumn{2}{|c|}{ Suspended sediment } & \multirow[b]{2}{*}{$\begin{array}{c}\text { Mean } \\
\text { dis- } \\
\text { charge } \\
\text { (cfs) }\end{array}$} & \multicolumn{2}{|c|}{ Suspended sediment } \\
\hline & & $\begin{array}{c}\text { Mean } \\
\text { concen- } \\
\text { tration } \\
\text { (ppm) }\end{array}$ & $\begin{array}{l}\text { Tons } \\
\text { per } \\
\text { day }\end{array}$ & & $\begin{array}{c}\text { Mean } \\
\text { concen- } \\
\text { tration } \\
\text { (ppm) }\end{array}$ & $\begin{array}{l}\text { Tons } \\
\text { per } \\
\text { day }\end{array}$ & & $\begin{array}{c}\text { Mean } \\
\text { concen- } \\
\text { tration } \\
\text { (ppm) }\end{array}$ & $\begin{array}{l}\text { Tons } \\
\text { per } \\
\text { day }\end{array}$ \\
\hline $\begin{array}{l}1 \ldots \\
2 \ldots \\
9 \ldots \\
4 \ldots \\
5 \ldots\end{array}$ & $\begin{array}{l}35 \\
32 \\
32 \\
31 \\
76\end{array}$ & $\begin{array}{r}13 \\
12 \\
9 \\
7 \\
22\end{array}$ & $\begin{array}{r}1.2 \\
1.0 \\
.8 \\
.6 \\
5.0\end{array}$ & $\begin{array}{l}48 \\
46 \\
44 \\
38 \\
36\end{array}$ & $\begin{array}{l}6 \\
7 \\
9 \\
7 \\
7\end{array}$ & $\begin{array}{r}0.8 \\
.9 \\
1.1 \\
.7 \\
.7\end{array}$ & $\begin{array}{l}81 \\
59 \\
47 \\
38 \\
30\end{array}$ & $\begin{array}{r}21 \\
11 \\
7 \\
5 \\
9\end{array}$ & $\begin{array}{r}4.6 \\
1.8 \\
.9 \\
.5 \\
.7\end{array}$ \\
\hline $\begin{array}{r}6 \ldots \\
7 \ldots \\
8 \ldots \\
9 \ldots\end{array}$ & $\begin{array}{r}117 \\
121 \\
92 \\
73 \\
69\end{array}$ & $\begin{array}{l}35 \\
75 \\
17 \\
14 \\
16\end{array}$ & $\begin{array}{l}11 \\
25 \\
4.2 \\
2.8 \\
3.0\end{array}$ & $\begin{array}{r}44 \\
358 \\
390 \\
298 \\
241\end{array}$ & $\begin{array}{r}37 \\
704 \\
88 \\
55 \\
23\end{array}$ & $\begin{array}{c}5.1 \\
763 \\
102 \\
45 \\
15\end{array}$ & $\begin{array}{l}25 \\
20 \\
17 \\
14 \\
12\end{array}$ & $\begin{array}{l}8 \\
2 \\
1 \\
1 \\
1\end{array}$ & $\begin{array}{l}.5 \\
T \\
T \\
T\end{array}$ \\
\hline $\begin{array}{l}11 \ldots \\
12 \ldots \\
13 \ldots \\
14 \ldots \\
15 \ldots\end{array}$ & $\begin{array}{l}58 \\
50 \\
55 \\
71 \\
66\end{array}$ & $\begin{array}{l}13 \\
11 \\
10 \\
10 \\
7\end{array}$ & $\begin{array}{l}2.0 \\
1.5 \\
1.5 \\
1.9 \\
1.2\end{array}$ & $\begin{array}{l}220 \\
190 \\
148 \\
194 \\
367\end{array}$ & $\begin{array}{l}60 \\
32 \\
32 \\
43 \\
65\end{array}$ & $\begin{array}{l}35 \\
16 \\
13 \\
23 \\
75\end{array}$ & $\begin{array}{l}11 \\
9.0 \\
7.6 \\
6.4 \\
5.4\end{array}$ & $\begin{array}{l}1 \\
1 \\
I \\
1 \\
1\end{array}$ & $\begin{array}{l}T \\
T \\
T \\
T \\
T\end{array}$ \\
\hline $\begin{array}{l}16 \ldots \\
17 \ldots \\
18 \ldots \\
19 \ldots \\
20 \ldots\end{array}$ & $\begin{array}{l}58 \\
60 \\
69 \\
59 \\
51\end{array}$ & $\begin{array}{r}6 \\
12 \\
13 \\
7 \\
8\end{array}$ & $\begin{array}{l}.9 \\
1.9 \\
2.4 \\
1.1 \\
1.1\end{array}$ & $\begin{array}{l}441 \\
213 \\
161 \\
125 \\
108\end{array}$ & $\begin{array}{l}55 \\
50 \\
47 \\
38 \\
22\end{array}$ & $\begin{array}{l}65 \\
29 \\
20 \\
13 \\
6.4\end{array}$ & $\begin{array}{l}4 \cdot 7 \\
4.2 \\
42 \\
47 \\
16\end{array}$ & $\begin{array}{r}1 \\
2 \\
-250 \\
34\end{array}$ & $\begin{array}{l}T \\
T \\
25 \\
30 \\
1.5\end{array}$ \\
\hline $\begin{array}{l}21 \ldots \\
22 \ldots \\
23 \ldots \\
24 \ldots \\
25 \ldots\end{array}$ & $\begin{array}{l}47 \\
66 \\
66 \\
83 \\
87\end{array}$ & $\begin{array}{r}6 \\
19 \\
8 \\
15 \\
8\end{array}$ & $\begin{array}{r}.8 \\
3.4 \\
1.4 \\
3.4 \\
1.9\end{array}$ & $\begin{array}{l}87 \\
72 \\
58 \\
48 \\
40\end{array}$ & $\begin{array}{l}12 \\
13 \\
15 \\
14 \\
11\end{array}$ & $\begin{array}{l}2.8 \\
2.5 \\
2.3 \\
1.8 \\
1.2\end{array}$ & $\begin{array}{c}9.8 \\
7.8 \\
14 \\
9.2 \\
6.4\end{array}$ & $\begin{array}{r}7 \\
6 \\
4 \\
5\end{array}$ & $\begin{array}{r}.2 \\
.1 \\
.8 \\
.1 \\
.1\end{array}$ \\
\hline $\begin{array}{l}26 \ldots \\
27 \ldots \\
28 \ldots \\
29 \ldots \\
30 \ldots \\
31 \ldots\end{array}$ & $\begin{array}{l}77 \\
73 \\
65 \\
56 \\
51 \\
--\end{array}$ & $\begin{array}{r}4 \\
5 \\
5 \\
5 \\
5 \\
- \\
\end{array}$ & $\begin{array}{r}.8 \\
1.0 \\
: 9 \\
: 8 \\
: 7 \\
--\end{array}$ & $\begin{array}{r}35 \\
29 \\
25 \\
154 \\
163 \\
108 \\
\end{array}$ & $\begin{array}{r}10 \\
13 \\
12 \\
350 \\
40 \\
32 \\
\end{array}$ & $\begin{array}{r}1.9 \\
150 \\
18 \\
9.3 \\
\end{array}$ & $\begin{array}{l}5.4 \\
4.4 \\
3.9 \\
4.0 \\
49 \\
-\end{array}$ & $\begin{array}{r}5 \\
3 \\
2 \\
-0 \\
480 \\
-\end{array}$ & $\begin{array}{c}T_{T}^{.1} \\
70^{.2} \\
-\end{array}$ \\
\hline \multirow[t]{2}{*}{ Total } & 1946 & - & 85.2 & 4529 & - & 1420.3 & 610.2 & - & 137.5 \\
\hline & \multicolumn{3}{|c|}{ JULY } & \multicolumn{3}{|c|}{ AUGUST } & \multicolumn{3}{|c|}{ SEPTEMBER } \\
\hline $\begin{array}{l}1 \ldots \\
2 \ldots \\
3 \ldots \\
4 \ldots \\
5 \ldots\end{array}$ & $\begin{array}{l}14 \\
10 \\
11 \\
6.4 \\
9.0\end{array}$ & $\begin{array}{r}39 \\
10 \\
3 \\
2 \\
1\end{array}$ & $\begin{array}{l}1.5 \\
.3 \\
.1 \\
T \\
T\end{array}$ & $\begin{array}{l}23 \\
16 \\
13 \\
12 \\
12\end{array}$ & $\begin{array}{r}12 \\
5 \\
2 \\
1 \\
1\end{array}$ & $\begin{array}{l}0.7 \\
.2 \\
.1 \\
T^{1}\end{array}$ & $\begin{array}{l}19 \\
14 \\
11 \\
9.0 \\
7.4\end{array}$ & $\begin{array}{l}8 \\
5 \\
7 \\
6 \\
4\end{array}$ & $\begin{array}{r}0.4 \\
.2 \\
.2 \\
: 1 \\
.1\end{array}$ \\
\hline $\begin{array}{r}6 \ldots \\
7 \ldots \\
9 \ldots \\
10 \ldots\end{array}$ & $\begin{array}{c}6.0 \\
5.2 \\
4.7 \\
4.7 \\
10\end{array}$ & $\begin{array}{r}1 \\
1 \\
3 \\
12 \\
12\end{array}$ & $\begin{array}{l}\mathrm{T} \\
\mathrm{T} \\
\mathrm{T} \\
.2 \\
\bullet 3\end{array}$ & $\begin{array}{l}8.4 \\
6.6 \\
5.5 \\
4.9 \\
6.6\end{array}$ & $\begin{array}{l}2 \\
3 \\
6 \\
3 \\
2\end{array}$ & $\begin{array}{l}T^{\circ I} \\
T^{\bullet I}\end{array}$ & $\begin{array}{l}6.2 \\
5.2 \\
4.7 \\
4.2 \\
4.3\end{array}$ & $\begin{array}{l}4 \\
2 \\
4 \\
3 \\
2\end{array}$ & $T_{T}^{.1}$ \\
\hline $\begin{array}{l}11 \ldots \\
12 \ldots \\
13 \ldots \\
14 \ldots \\
15 \ldots\end{array}$ & $\begin{array}{r}46 \\
207 \\
116 \\
55 \\
47\end{array}$ & $\begin{array}{l}80 \\
-38 \\
21 \\
45\end{array}$ & $\begin{array}{l}11 \\
85 \\
12 \\
3.1 \\
5.7\end{array}$ & $\begin{array}{l}5.4 \\
4.3 \\
3.8 \\
3.4 \\
3.1\end{array}$ & $\begin{array}{l}1 \\
1 \\
1 \\
1 \\
1\end{array}$ & $\begin{array}{l}T \\
T \\
T \\
T \\
T\end{array}$ & $\begin{array}{l}4.2 \\
3.8 \\
3.3 \\
3.0 \\
2.8\end{array}$ & $\begin{array}{l}1 \\
2 \\
1 \\
1 \\
1\end{array}$ & $\begin{array}{l}T \\
T \\
T \\
T \\
T\end{array}$ \\
\hline $\begin{array}{l}16 \ldots \\
17 \ldots \\
18 \ldots \\
19 \ldots \\
20 \ldots\end{array}$ & $\begin{array}{l}34 \\
22 \\
18 \\
15 \\
14\end{array}$ & $\begin{array}{r}19 \\
6 \\
4 \\
5 \\
-\end{array}$ & $\begin{array}{r}1.7 \\
.4 \\
.2 \\
.2 \\
.6\end{array}$ & $\begin{array}{l}2.9 \\
2.6 \\
2.5 \\
17 \\
39\end{array}$ & $\begin{array}{r}1 \\
2 \\
2 \\
-650\end{array}$ & $\begin{array}{r}T \\
T \\
T \\
30 \\
80\end{array}$ & $\begin{array}{l}2.6 \\
2.5 \\
2.3 \\
2.2 \\
2.4\end{array}$ & $\begin{array}{l}3 \\
2 \\
1 \\
1 \\
2\end{array}$ & $\begin{array}{l}T \\
T \\
T \\
T \\
T\end{array}$ \\
\hline $\begin{array}{l}21 \ldots \\
22 \ldots \\
23 \ldots \\
24 \ldots \\
25 \ldots\end{array}$ & $\begin{array}{l}16 \\
10 \\
8.0 \\
7.4 \\
15\end{array}$ & $\begin{array}{r}95 \\
10 \\
2 \\
2 \\
-\end{array}$ & $\begin{array}{l}4.3 \\
T^{T} \cdot 2\end{array}$ & $\begin{array}{l}15 \\
11 \\
7.2 \\
6.0 \\
18\end{array}$ & $\begin{array}{r}56 \\
14 \\
12 \\
2 \\
-\end{array}$ & $\begin{array}{r}2.3 \\
.4 \\
T^{.2} \\
18\end{array}$ & $\begin{array}{c}2.5 \\
11 \\
5.0 \\
3.3 \\
2.8\end{array}$ & $\frac{3}{4}$ & $\begin{array}{l}T \\
2 \\
T^{*} \\
T\end{array}$ \\
\hline $\begin{array}{l}26 \ldots \\
27 \ldots \\
28 \ldots \\
29 \ldots \\
30 \ldots \\
31 \ldots\end{array}$ & $\begin{array}{l}12 \\
7 \cdot 2 \\
18 \\
27 \\
66 \\
34\end{array}$ & $\begin{array}{r}2 \\
2 \\
-- \\
-- \\
150 \\
16\end{array}$ & $\begin{array}{l}T^{.1} \\
3 \\
4 \\
25 \\
1.5\end{array}$ & $\begin{array}{r}111 \\
121 \\
127 \\
65 \\
37 \\
24\end{array}$ & $\begin{array}{r}360 \\
112 \\
33 \\
35 \\
18\end{array}$ & $\begin{array}{l}130 \\
160 \\
42 \\
5.8 \\
3.5 \\
1.2\end{array}$ & $\begin{array}{r}2.5 \\
2.3 \\
169 \\
111 \\
41 \\
\end{array}$ & $\begin{array}{r}1 \\
2 \\
1240 \\
214 \\
32 \\
-- \\
\end{array}$ & $\begin{array}{r}T \\
T \\
849 \\
86 \\
3.5 \\
\end{array}$ \\
\hline Total & 877.6 & - & 160.7 & 734.2 & - & 474.9 & $464 \cdot 5$ & - & $942 \cdot 1$ \\
\hline $\begin{array}{l}\text { Total } \\
\text { Total }\end{array}$ & $\begin{array}{l}\text { discharge } \\
\text { load for }\end{array}$ & $\begin{array}{l}\text { for yea } \\
\text { fear (to }\end{array}$ & $\begin{array}{l}\text { ar (cfs-days) } \\
\text { ons) } \ldots \ldots \ldots \ldots \ldots\end{array}$ & $\cdots \cdots$ & $\ldots \ldots$ & $\cdots \cdots$ & & $\ldots \ldots$ & $\begin{array}{r}22885.3 \\
7200.8\end{array}$ \\
\hline
\end{tabular}



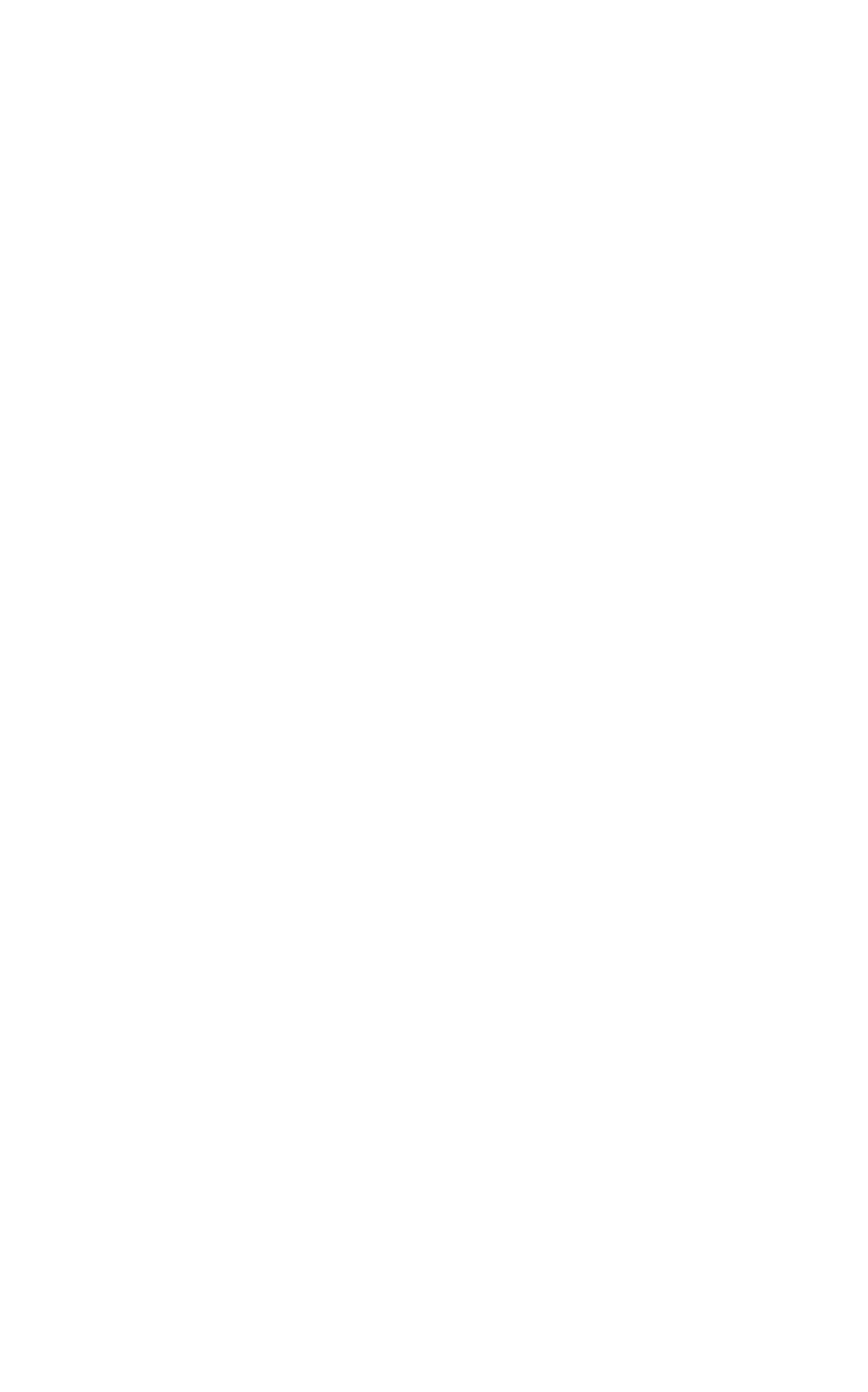
MONONGAHELA RIVER BASIN--CONTINued

3-0509. GRASSY RUN AT NORTON, W. VA.--Continued

Suspended sediment, water year October 1966 to september 1967

(Where no daily concentrations are reported, loads are estimated. Where loads wer computed from a partly estimated-concentration graph, time-weighted concentrations are reported

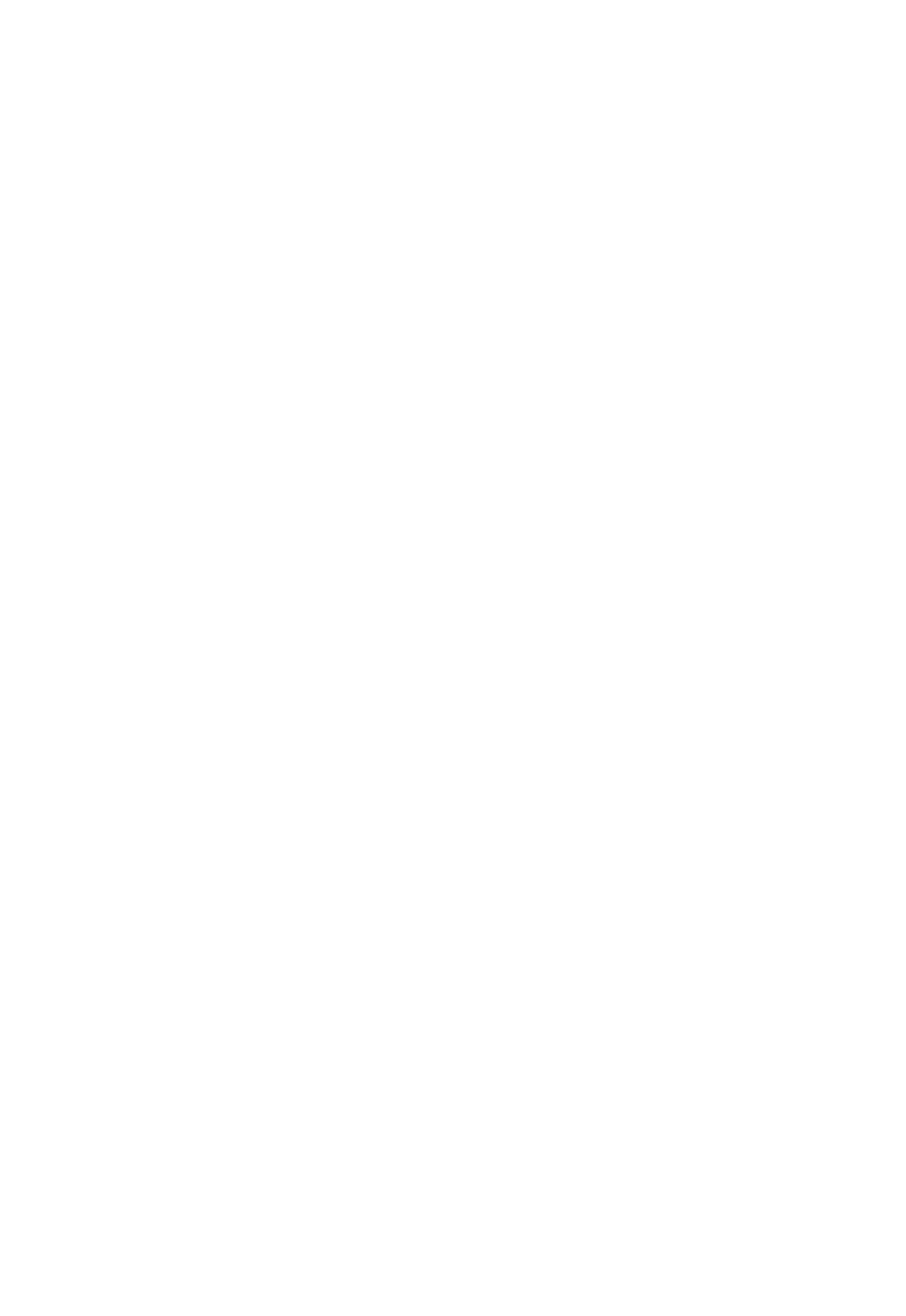

$S$ Computed by subdividing day.

A Computed from partiy estimated-concentration graph. 
MONONGAHELA RIVER BASIN- COntinued

3-0509. GRASSY RUN AT NORTON, T. VA.--Cont1nued

Suspended sediment, water year October 1966 to September 1967--Continued

(Where no daily concentrations are reported, loads are estimated. Where loads were computed from a partly estimated-concentration graph, time-weighted concentrations are reported)

\begin{tabular}{|c|c|c|c|c|c|c|c|c|c|}
\hline \multirow[b]{3}{*}{ Day } & \multicolumn{3}{|c|}{ APRIL } & \multicolumn{3}{|c|}{ MAY } & \multicolumn{3}{|c|}{ JUNE } \\
\hline & \multirow[b]{2}{*}{$\begin{array}{c}\text { Mean } \\
\text { dis- } \\
\text { charge } \\
\text { (cfB) }\end{array}$} & \multicolumn{2}{|c|}{ Suspended sediment } & \multirow[b]{2}{*}{$\begin{array}{c}\text { Mean } \\
\text { dis- } \\
\text { charge } \\
\text { (cfs) }\end{array}$} & \multicolumn{2}{|c|}{ Suspended sediment } & \multirow[b]{2}{*}{$\begin{array}{c}\text { Mean } \\
\text { dis- } \\
\text { charge } \\
\text { (cfs) }\end{array}$} & \multicolumn{2}{|c|}{ Suspended sediment } \\
\hline & & $\begin{array}{l}\text { Mean } \\
\text { concen- } \\
\text { tration } \\
\text { (ppm) }\end{array}$ & $\begin{array}{c}\text { Tons } \\
\text { per } \\
\text { day }\end{array}$ & & $\begin{array}{c}\text { Mean } \\
\text { concen- } \\
\text { tration } \\
\text { (ppm) }\end{array}$ & $\begin{array}{c}\text { Tons } \\
\text { per } \\
\text { day }\end{array}$ & & $\begin{array}{c}\text { Mean } \\
\text { concen- } \\
\text { tration } \\
\text { (ppm) }\end{array}$ & $\begin{array}{c}\text { Tons } \\
\text { per } \\
\text { day }\end{array}$ \\
\hline $\begin{array}{l}1 \ldots \\
2 \ldots \\
3 \ldots \\
4 \ldots \\
5 \ldots\end{array}$ & $\begin{array}{r}8.9 \\
8.3 \\
8.5 \\
B .1 \\
12\end{array}$ & $\begin{array}{r}8 \\
11 \\
9 \\
12 \\
90\end{array}$ & $\begin{array}{r}0.2 \\
.2 \\
.2 \\
.3\end{array}$ & $\begin{array}{l}8.1 \\
7.9 \\
7.4 \\
7.2 \\
6.8\end{array}$ & $\begin{array}{l}6 \\
8 \\
4 \\
5 \\
2\end{array}$ & $\begin{array}{r}0.1 \\
.2 \\
.1 \\
T^{.1}\end{array}$ & $\begin{array}{l}12 \\
11 \\
10 \\
9.0 \\
8.3\end{array}$ & $\begin{array}{r}7 \\
7 \\
6 \\
9 \\
11\end{array}$ & $\begin{array}{r}0.2 \\
: 2 \\
: 2 \\
: 2 \\
: 2\end{array}$ \\
\hline $\begin{array}{r}6 \ldots \\
7 \ldots \\
8 \ldots \\
9 \ldots \\
10 . .\end{array}$ & $\begin{array}{l}17 \\
18 \\
14 \\
12 \\
12\end{array}$ & $\begin{array}{l}50 \\
31 \\
20 \\
25\end{array}$ & $\begin{array}{l}4 \\
2.4 \\
1.2 \\
.6 \\
.8\end{array}$ & $\begin{array}{l}7.7 \\
48 \\
38 \\
35 \\
29\end{array}$ & $\begin{array}{l}\frac{6}{41} \\
27 \\
22\end{array}$ & $\begin{array}{l}20^{.1} \\
4.2 \\
2.6 \\
1.7\end{array}$ & $\begin{array}{l}7.7 \\
7.0 \\
6.4 \\
5.9 \\
5.3\end{array}$ & $\begin{array}{l}8 \\
7 \\
7 \\
3 \\
3\end{array}$ & $\begin{array}{l}: 2 \\
: 1 \\
T \\
T\end{array}$ \\
\hline $\begin{array}{l}11 \ldots \\
12 \ldots \\
13 \ldots \\
14 \ldots \\
15 \ldots\end{array}$ & $\begin{array}{l}10 \\
9.3 \\
10 \\
11 \\
11\end{array}$ & $\begin{array}{l}20 \\
18 \\
25 \\
17\end{array}$ & $\begin{array}{r}.5 \\
1.5 \\
.7 \\
.5\end{array}$ & $\begin{array}{l}36 \\
34 \\
25 \\
28 \\
44\end{array}$ & $\begin{array}{l}-7 \\
8 \\
25 \\
61\end{array}$ & $\begin{array}{l}11 \\
4.3 \\
.5 \\
1.9 \\
9.5\end{array}$ & $\begin{array}{l}4.8 \\
4.3 \\
4.0 \\
3.8 \\
3.6\end{array}$ & $\begin{array}{r}5 \\
8 \\
9 \\
12 \\
8\end{array}$ & $\begin{array}{l}.1 \\
: 1 \\
: 1 \\
: 1 \\
: 1\end{array}$ \\
\hline $\begin{array}{l}16 \ldots \\
17 \ldots \\
18 \ldots \\
19 \ldots \\
20 \ldots\end{array}$ & $\begin{array}{l}9.9 \\
11 \\
11 \\
9.7 \\
8.9\end{array}$ & $\begin{array}{l}8 \\
-6 \\
5 \\
5\end{array}$ & $\begin{array}{r}12 \\
: 2 \\
: 1\end{array}$ & $\begin{array}{l}43 \\
30 \\
26 \\
23 \\
19\end{array}$ & $\begin{array}{l}52 \\
33 \\
26 \\
-5\end{array}$ & $\begin{array}{r}6.4 \\
2.7 \\
1.8 \\
.8 \\
.3\end{array}$ & $\begin{array}{c}3.4 \\
3.2 \\
6.9 \\
11 \\
9.3\end{array}$ & $\begin{array}{r}11 \\
12 \\
-14 \\
14\end{array}$ & $\begin{array}{l}: 1 \\
2.1 \\
: 4\end{array}$ \\
\hline $\begin{array}{l}21 \ldots \\
22 \ldots \\
23 \ldots \\
24 \ldots \\
25 \ldots\end{array}$ & $\begin{array}{l}8.6 \\
11 \\
10 \\
12 \\
11\end{array}$ & $\begin{array}{r}7 \\
-\frac{2}{2} \\
-3\end{array}$ & $\begin{array}{l}.2 \\
: 4 \\
.1 \\
.1\end{array}$ & $\begin{array}{l}16 \\
15 \\
13 \\
12 \\
11\end{array}$ & $\begin{array}{l}5 \\
4 \\
8 \\
7 \\
5\end{array}$ & $\begin{array}{l}.2 \\
: 2 \\
: 3 \\
: 2 \\
: 1\end{array}$ & $\begin{array}{l}B .0 \\
7.0 \\
6.9 \\
6.3 \\
5.6\end{array}$ & $\begin{array}{r}6 \\
8 \\
12 \\
10 \\
8\end{array}$ & $\begin{array}{l}.1 \\
.2 \\
.2 \\
: 2 \\
.1\end{array}$ \\
\hline $\begin{array}{l}26 \ldots \\
27 \ldots \\
28 \ldots \\
29 \ldots \\
30 \ldots \\
31 \ldots\end{array}$ & $\begin{array}{l}10 \\
10 \\
9.0 \\
8.6 \\
8.3 \\
\end{array}$ & $\begin{array}{r}5 \\
6 \\
5 \\
5 \\
5 \\
-2\end{array}$ & $\begin{array}{l}.1 \\
.2 \\
.1 \\
.1 \\
: 1\end{array}$ & $\begin{array}{l}10 \\
9.4 \\
8.7 \\
17 \\
16 \\
13\end{array}$ & $\begin{array}{r}2 \\
3 \\
3 \\
50 \\
10 \\
16\end{array}$ & $\begin{array}{l}.1 \\
: 1 \\
2.4 \\
.6\end{array}$ & $\begin{array}{c}4.8 \\
4.2 \\
3.8 \\
3.6 \\
4.3 \\
--\end{array}$ & $\begin{array}{r}5 \\
2 \\
1 \\
3 \\
12 \\
- \\
\end{array}$ & $\begin{array}{l}T^{-1} \\
T \\
T \\
-1\end{array}$ \\
\hline \multirow[t]{2}{*}{ Total } & 319.1 & - & 19.3 & 644.2 & - & 72.6 & 191.4 & - & 5.8 \\
\hline & \multicolumn{3}{|c|}{ JULY } & \multicolumn{3}{|c|}{ AUGUST } & \multicolumn{3}{|c|}{ SEPTEMBER } \\
\hline $\begin{array}{l}1 \ldots \\
2 \ldots \\
3 \ldots \\
4 \ldots \\
5 \ldots\end{array}$ & $\begin{array}{l}4.0 \\
4.1 \\
4.2 \\
3.2 \\
3.0\end{array}$ & $\begin{array}{r}3 \\
9 \\
16 \\
18 \\
17\end{array}$ & $\begin{array}{l}T \\
0.1 \\
.2 \\
.2 \\
.1\end{array}$ & $\begin{array}{l}2.9 \\
2.3 \\
2.3 \\
2.4 \\
2.2\end{array}$ & $\begin{array}{r}6 \\
7 \\
-- \\
-8\end{array}$ & $\begin{array}{l}T \\
T \\
0.1 \\
\bullet^{2}\end{array}$ & $\begin{array}{l}1.8 \\
1.6 \\
1.5 \\
1.5 \\
1.5\end{array}$ & $\begin{array}{r}8 \\
5 \\
7 \\
10 \\
10\end{array}$ & $\begin{array}{l}T \\
T \\
T \\
T \\
T\end{array}$ \\
\hline $\begin{array}{r}6 \ldots \\
7 \ldots \\
9 \ldots \\
10 \ldots\end{array}$ & $\begin{array}{l}2.9 \\
2.8 \\
2.8 \\
2.8 \\
2.6\end{array}$ & $\begin{array}{l}11 \\
13 \\
12 \\
12 \\
33\end{array}$ & $\begin{array}{l}.1 \\
.1 \\
.1 \\
.1 \\
.2\end{array}$ & $\begin{array}{l}1.9 \\
1.8 \\
3.7 \\
1.8 \\
1.9\end{array}$ & $\begin{array}{r}7 \\
13 \\
12 \\
-- \\
-\end{array}$ & $\begin{array}{r}T \\
: 1 \\
: 1 \\
: 1\end{array}$ & $\begin{array}{l}1.5 \\
1.4 \\
1.4 \\
1.4 \\
1.5\end{array}$ & $\begin{array}{l}10 \\
12 \\
11 \\
11 \\
--\end{array}$ & $\begin{array}{l}T \\
T \\
T \\
T \\
0.1\end{array}$ \\
\hline $\begin{array}{l}11 \ldots \\
12 \ldots \\
13 \ldots \\
14 \ldots \\
15 \ldots\end{array}$ & $\begin{array}{l}5.4 \\
3.6 \\
2.7 \\
2.5 \\
2.9\end{array}$ & $\begin{array}{l}-- \\
17 \\
18 \\
23 \\
25\end{array}$ & $\begin{array}{l}1 \\
: 2 \\
: 1 \\
.2\end{array}$ & $\begin{array}{l}1.7 \\
1.7 \\
1.6 \\
1.6 \\
1.5\end{array}$ & $\begin{array}{l}8 \\
6 \\
8 \\
7 \\
8\end{array}$ & $\begin{array}{l}T \\
T \\
T \\
T \\
T\end{array}$ & $\begin{array}{l}1.4 \\
1.3 \\
1.3 \\
1.2 \\
1.3\end{array}$ & $\begin{array}{l}11 \\
11 \\
10 \\
10 \\
9\end{array}$ & $\begin{array}{l}T \\
T \\
T \\
T \\
T\end{array}$ \\
\hline $\begin{array}{l}16 \ldots \\
17 \ldots \\
18 \ldots \\
19 \ldots \\
20 \ldots\end{array}$ & $\begin{array}{l}2.5 \\
2.3 \\
2.2 \\
2.0 \\
2.0\end{array}$ & $\begin{array}{l}18 \\
20 \\
25 \\
18 \\
19\end{array}$ & $\begin{array}{l}.1 \\
11 \\
11 \\
01 \\
.1\end{array}$ & $\begin{array}{l}1.5 \\
1.3 \\
1.5 \\
2.8 \\
2.1\end{array}$ & $\begin{array}{r}5 \\
5 \\
6 \\
21\end{array}$ & $\begin{array}{l}T \\
T \\
T \\
\bullet 6 \\
\bullet 1\end{array}$ & $\begin{array}{l}1.3 \\
1.2 \\
1.2 \\
1.3 \\
1.3\end{array}$ & $\begin{array}{l}8 \\
9 \\
6 \\
5 \\
6\end{array}$ & $\begin{array}{l}T \\
T \\
T \\
T \\
T\end{array}$ \\
\hline $\begin{array}{l}21 \ldots \\
22 \ldots \\
23 \ldots \\
24 \ldots \\
25 \ldots\end{array}$ & $\begin{array}{l}2.0 \\
1.8 \\
1.8 \\
2.0 \\
2.3\end{array}$ & $\begin{array}{l}17 \\
16 \\
10 \\
-18\end{array}$ & $\begin{array}{l}: 1 \\
: 1 \\
: 1\end{array}$ & $\begin{array}{l}1.8 \\
1.7 \\
1.6 \\
1.6 \\
3.9\end{array}$ & $\begin{array}{r}6 \\
7 \\
8 \\
8 \\
--\end{array}$ & $\begin{array}{l}T \\
T \\
T \\
T \\
3\end{array}$ & $\begin{array}{l}2.2 \\
1.8 \\
1.4 \\
1.3 \\
1 \cdot 2\end{array}$ & $\begin{array}{l}-- \\
45 \\
14 \\
12 \\
17\end{array}$ & $\begin{array}{r}.2 \\
: 2 \\
.1 \\
.1\end{array}$ \\
\hline $\begin{array}{l}26 \ldots \\
27 \ldots \\
28 \ldots \\
29 \ldots \\
30 \ldots \\
31 \ldots\end{array}$ & $\begin{array}{l}1.9 \\
1.8 \\
4.7 \\
6.7 \\
7.4 \\
3.7\end{array}$ & $\begin{array}{l}12 \\
10 \\
-1 \\
27 \\
27 \\
10\end{array}$ & $\begin{array}{l}T^{-1} \\
2 \\
: 5 \\
: 1\end{array}$ & $\begin{array}{l}3.7 \\
7.2 \\
5.7 \\
3.1 \\
2.3 \\
2.0\end{array}$ & $\begin{array}{l}19 \\
60 \\
17 \\
13 \\
10 \\
12\end{array}$ & $\begin{array}{r}1.2 \\
: 3 \\
: 1 \\
.1\end{array}$ & $\begin{array}{l}1.2 \\
1.2 \\
19 \\
10 \\
3.8 \\
-\end{array}$ & $\begin{array}{r}42 \\
23 \\
207 \\
39 \\
27 \\
--\end{array}$ & $\begin{array}{r}13 \\
1.1 \\
: 3 \\
\because-3\end{array}$ \\
\hline Total & 96.6 & -- & 13.6 & 73.1 & -- & 6.7 & $71 \cdot 0$ & -- & 15.9 \\
\hline
\end{tabular}

S Computed by subdividing day.

Computed from partly estimated-concentrat on graph. 


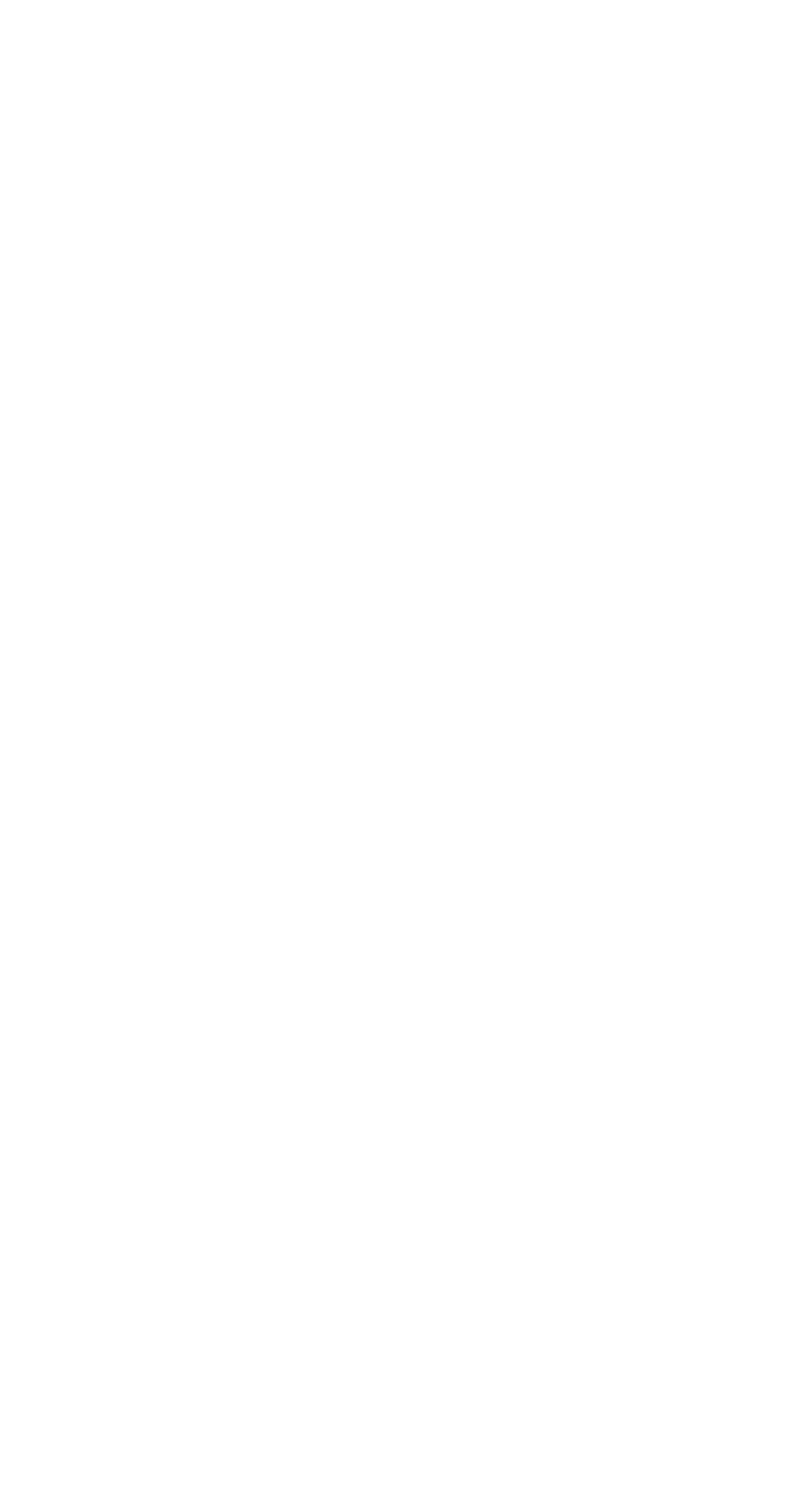




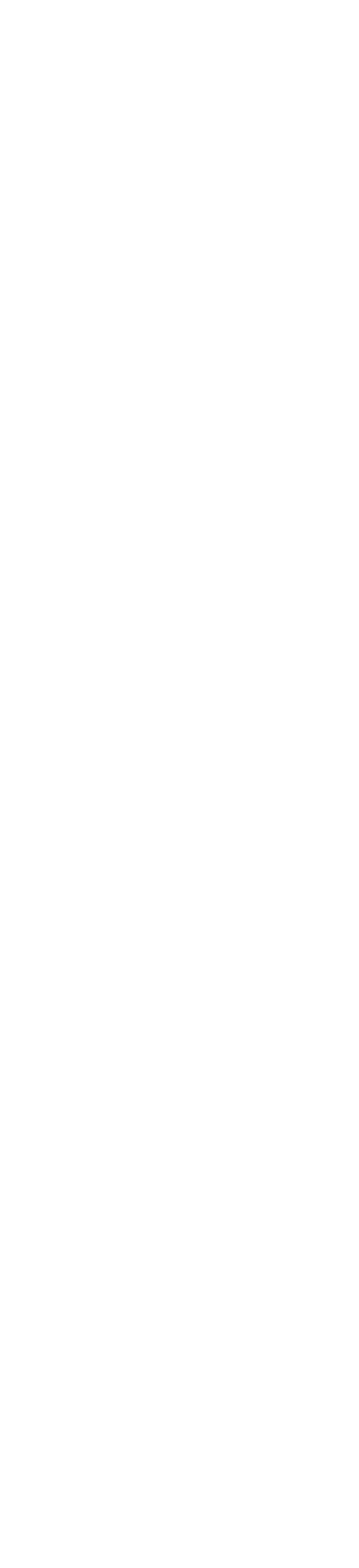

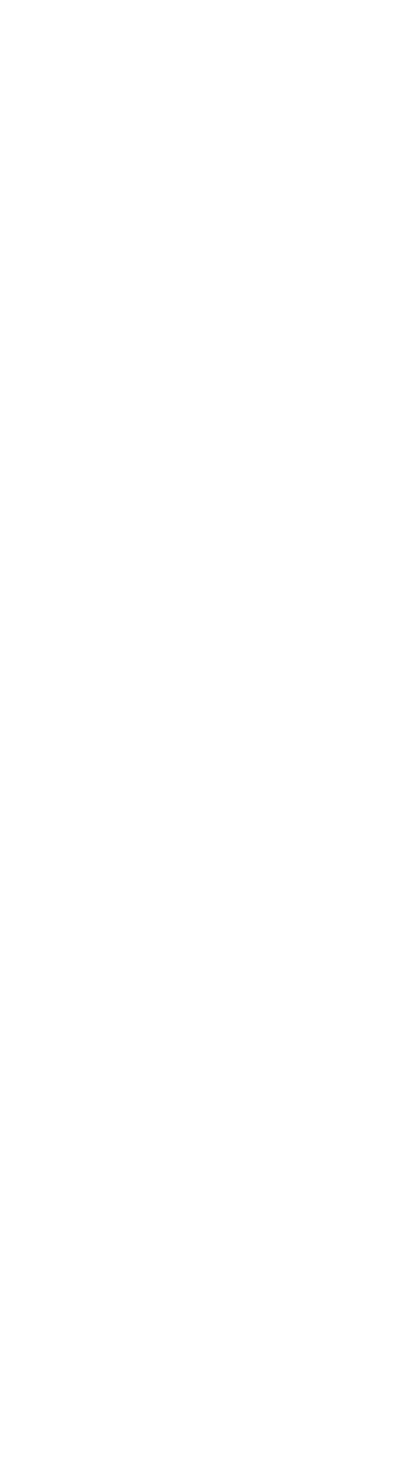




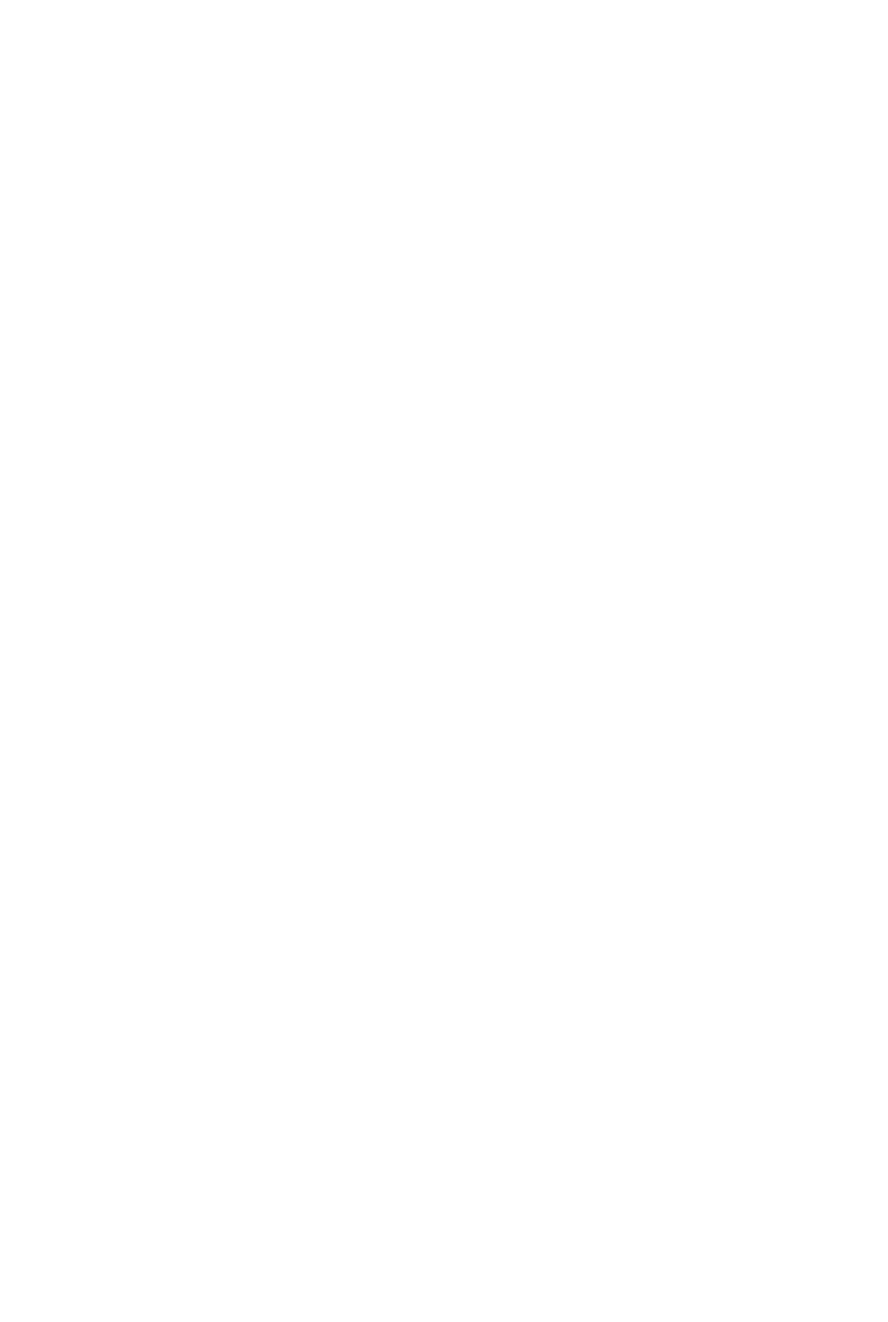




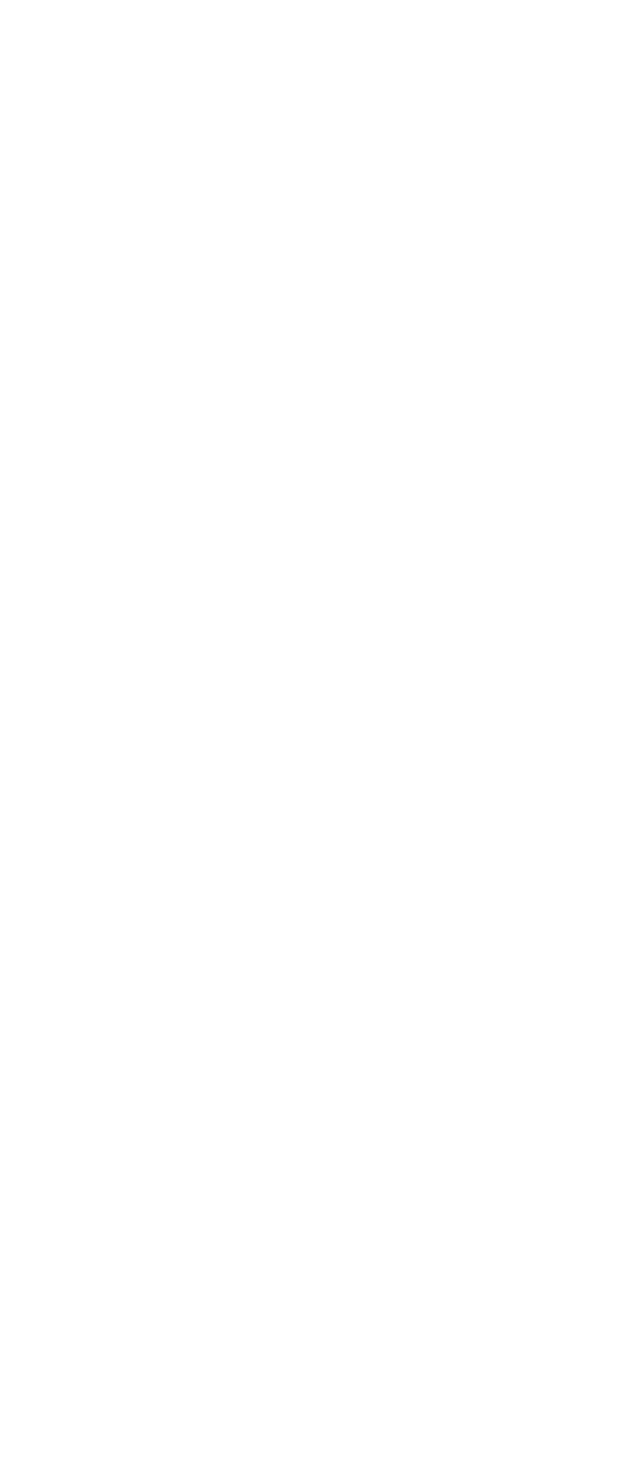




\begin{tabular}{|c|c|c|c|c|c|c|c|c|c|c|c|c|c|c|c|c|c|c|c|}
\hline & & & $\underset{\mathrm{C}}{\mathrm{b}}$ & & & & & $\stackrel{\sim}{N} \underset{\sim}{\infty}$ & If & $\stackrel{\circ i n}{m}$ & in & $\tilde{m}$ & $\approx$ g & in 0 & กี & 象 & $\approx:$ & : & $\overrightarrow{0}$ in \\
\hline & & & & & & & $\vec{n}$ & ofo & $1:$ & 品 & nnm & $1:$ & ถู & i i & 证 & 11 & 怾 & ת & 1! \\
\hline & & & 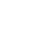 & & & & $\vec{n}$ & in $y$ & 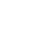 & Ny & 类角 & 11 & in $f$ & 요요 & 8 品 & 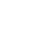 & $2:$ & $: 3$ & กิน \\
\hline & & & & & & & $\hat{v}$ & $5^{5}$ & 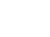 & $\therefore n$ & $\stackrel{\circ}{\circ}$ & 11 & $\vec{n}$ & $\vec{n} \hat{f}$ & 50 & : & 90 & $: 3$ & ת \\
\hline & & & $E$ & & & & $\stackrel{D}{N}$ & 30 & \$9 & min & No & $\mathrm{mm}_{\mathrm{m}}^{\mathrm{N}}$ & oin & 结 & To & 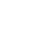 & \%5 & : జ & ת. \\
\hline & बె & & & & & & $\hat{\sim}$ & in & $\underset{y}{4}$ & $\approx N$ & $\sqrt{5}$ & $m \sim n$ & $\begin{array}{l}0 \\
5\end{array}$ & $\begin{array}{l}\infty \\
+ \\
+\end{array}$ & in & $\therefore 3$ & $\approx \pi$ & $2:$ & $\overrightarrow{6} \hat{\Omega}$ \\
\hline & & & & & & & $\stackrel{2}{N}$ & 的 & $\stackrel{n}{9}$ & $\approx N$ & 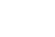 & $m_{m}^{m}$ & $\left.{ }_{f}^{\infty}\right\}$ & ${ }_{7} 0$ & $\overrightarrow{b i n}$ & 20 & $m_{0}^{0}$ & $\begin{array}{l}\infty \\
000\end{array}$ & 萬 in \\
\hline & & & & & & & $\stackrel{N}{N}$ & 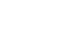 & $\overbrace{7}^{2}$ & ${ }_{n m}^{N}$ & fot & $\vec{m}$ & \$? & of & : & ती & $\div 5$ & 53 & 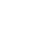 \\
\hline & & & & & & & $\underset{N}{d}$ & I & जo & ${ }_{\mathrm{m}}^{\mathrm{N}}$ & $\vec{j} \stackrel{0}{m}$ & $m m$ & $\vec{J}_{m}^{c}$ & if & in & $\approx:$ & $\sim \stackrel{\infty}{\sim 0}$ & $\approx 0$ & $\sin$ \\
\hline & & & & & $\Phi$ & & $\hat{\sim}$ & in ${ }^{\infty}$ & cim & $\mathrm{min}_{\mathrm{m}}^{4}$ & $\stackrel{\circ}{\circ}$ & $\stackrel{m}{m}$ & oro & in: is & ni: & 용 & in & $\tilde{\infty} \widetilde{N}$ & in in \\
\hline & & & 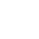 & & ฉั & & $N$ & 80 & $\dot{m} \cdot \hat{m}$ & $\stackrel{m}{m}$ & $\stackrel{m}{2} \tilde{m}$ & $m m$ & w & $\tilde{n} \tilde{N}$ & 今n & 25 & $\approx t$ & 50 & ธี \\
\hline & & & & & 8 & & $\bar{\sim}$ & $\bar{\sigma}_{t}$ & mi & i̊n & $\sim N$ & in & gim & Nig & กี & \pm 0 & :\$ & $\tilde{n} \tilde{0}$ & 80 \\
\hline 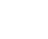 & & & & & of & & $\bar{N}$ & of & $\zeta^{\circ}$ & $\tilde{m} \stackrel{0}{m}$ & $\approx N$ & 总 & ${ }_{m}^{\infty} \tilde{m}$ & กั: & in $\sim N$ & $\approx 5$ & 点 & 90 & $\therefore \rightarrow$ \\
\hline 忩 & శ็ & & & & 4 & & 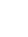 & $I^{\infty}$ & 90 & $m$ & $N N$ & $\stackrel{m}{m}$ & $\mathrm{~mm}$ & 28 & जิ & $\approx 0$ & $\therefore$ & $\stackrel{0}{0}$ & 50 \\
\hline 蛋 & & & & & $\overline{8}$ & & 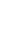 & of & 73 & $m$ & $M N$ & $n m$ & $\hat{m}$ & is & $\hat{n}^{\infty}$ & $\approx 5$ & $\begin{array}{c}9.00 \\
0.0\end{array}$ & $\begin{array}{l}\infty \\
0 \\
0\end{array}$ & $\begin{array}{lll}0 & 0 \\
0 & 0\end{array}$ \\
\hline & & & & & 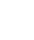 & & $\Rightarrow$ & $\tilde{n}_{0}^{\infty} \underset{5}{D}$ & ริ & m $m$ & $m \sim m$ & $\pi$ & Nin & in & 78 & m & $\approx 0$ & $\approx 5$ & s⿱ \\
\hline 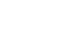 & : & & $z$ & 怨 & G & & $\stackrel{0}{-}$ & กิก & 79 & is & $\stackrel{N}{N}$ & $m$ & ơ & gin & $\vec{n} 9$ & 20 & 95 & $F M$ & 58 \\
\hline 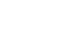 & & & & & 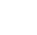 & 5 & $\approx$ & S. & I9 & $\therefore n$ & i용 & $m i$ & 合? & in & in & ח5 & 00 & $0 \overrightarrow{0}$ & mi \\
\hline & & & & & $\$$ & & \pm & $\hat{n} \tilde{n}$ & No & $m$ & $\stackrel{m}{m}$ & $\stackrel{m}{m}$ & in & ํำ & $\overrightarrow{\sigma \sigma}$ & \pm 0 & is 0 & $\infty_{0}^{\infty} \sim$ & 60 \\
\hline 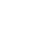 & & & & & & & $m$ & in $\bar{n}$ & in 7 & $\stackrel{\circ}{\circ}$ & $\ddot{m} N$ & $m m$ & 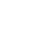 & 97 & $\vec{n} \vec{n}$ & 25 & 20 & ${ }_{0}^{\infty}-1$ & อิ \\
\hline & & & & & 4 & & $\simeq$ & in $\vec{n}$ & of & $\sim \underset{\sim}{N \infty}$ & $N \tilde{m}$ & $m m$ & of & int & min & $\sim \infty$ & $m_{0}^{0}$ & $\infty_{0}^{\infty} 5$ & $8 \pm$ \\
\hline & & & & & 藏 & & $\Rightarrow$ & ำ & 品 & in & $m \sim m$ & $\mathrm{~mm}$ & 8\% & $\vec{n}$ & 品 & $\approx D_{0}^{\infty}$ & $\approx 0$ & $5 \tilde{0}$ & oin \\
\hline & & & & & प्山 & & 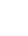 & $\overrightarrow{0}$ in & $\hat{n}^{\infty}$ & in & $M N$ & $m m$ & $3 \overrightarrow{7}$ & ถึ. & î & F屯 & $8 N$ & $\begin{array}{c}\text { mon } \\
\text { on }\end{array}$ & कू \\
\hline & & & & & & & o & N & ${ }_{f \rightarrow f}^{\infty}$ & om & $\hat{n N N}$ & $m$ & 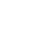 & $\approx$ 年 & $\underbrace{\infty}_{0} \underset{v}{\infty}$ & $\sim N$ & $\therefore \pi$ & $\approx 2$ & 50 \\
\hline & & & & & & & $\infty$ & in & in $y$ & $7_{m}^{\infty}$ & ${ }_{m} m$ & $m_{m}^{m}$ & $\breve{z}_{m}^{\alpha}$ & $\pi_{n}^{\infty}$ & $\underset{v}{\infty}$ & $0_{0}^{10}$ & 20 & $\approx 0$ & $\therefore 8$ \\
\hline & & & & & 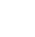 & & $\sim$ & if & $\overrightarrow{3}^{\infty}$ & 峦 & m $N$ & inm & $\overrightarrow{5}$ & $n \vec{n}$ & กิ & 50 & $\simeq 0$ & $\approx 5$ & 80 \\
\hline & & & & & & & $\infty$ & ज部 & $q^{x}$ & $\stackrel{m}{m}$ & $N N$ & 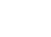 & $\overrightarrow{ \pm}$ & $\stackrel{\text { s. }}{4}$ & ज゙ & $: \overrightarrow{0}$ & 90 & त5 & sos \\
\hline & & & & & 苜 & & in & inst & $\begin{array}{c}\sim 0 \\
m\end{array}$ & $\stackrel{m}{m}$ & $\approx \sim$ & $\prod_{\infty}^{\infty}$ & gim & in & in & 50 & $\approx \stackrel{m}{0}$ & $\approx 0$ & 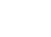 \\
\hline & & & & & & & 5 & $\tilde{n} N$ & Iin & $\vec{n}$ & $m N$ & $\stackrel{\infty}{\infty}$ & $\stackrel{m}{m}$ & ins & $\approx a$ & 89 & $\begin{array}{lll}\pi & n \\
0 & 0\end{array}$ & $\min _{0}$ & $\begin{array}{l}2 \\
0.00 \\
0\end{array}$ \\
\hline & & & & & & & $m$ & 湿 & in $\rightarrow$ & sim & $\stackrel{N}{m}$ & $\mathrm{~m}_{n}^{\infty}$ & $\stackrel{i m}{m}$ & กำ & 㶽品 & min & 200 & $\approx 5$ & Jin \\
\hline & & & & & & & N & ñ & $\tilde{I J}$ & $\hat{m}_{n}^{\circ}$ & $\min _{n \rightarrow \infty} N$ & 婇 & $\underset{m \sim n}{N}$ & $i n \vec{n}$ & $\because \tilde{N}$ & So & $\approx 0$ & $\approx: 0$ & ชี \\
\hline & & & & & & & $\rightarrow$ & in & $\stackrel{\infty}{\infty}$ & $\stackrel{\infty}{\infty} \stackrel{0}{m}$ & $\stackrel{i n}{N}$ & $\hat{m} m$ & 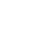 & in & in ${ }_{i n}$ & Son & 20 & $\therefore 0$ & in \\
\hline & 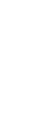 & & & 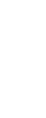 & & & $\begin{array}{l}\frac{T}{5} \\
\frac{5}{3} \\
\frac{3}{2}\end{array}$ & 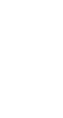 & & & & $\Sigma$ & $\frac{x}{\frac{x}{2}}$ & 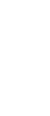 & 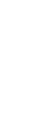 & 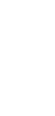 & 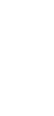 & 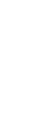 & \\
\hline
\end{tabular}




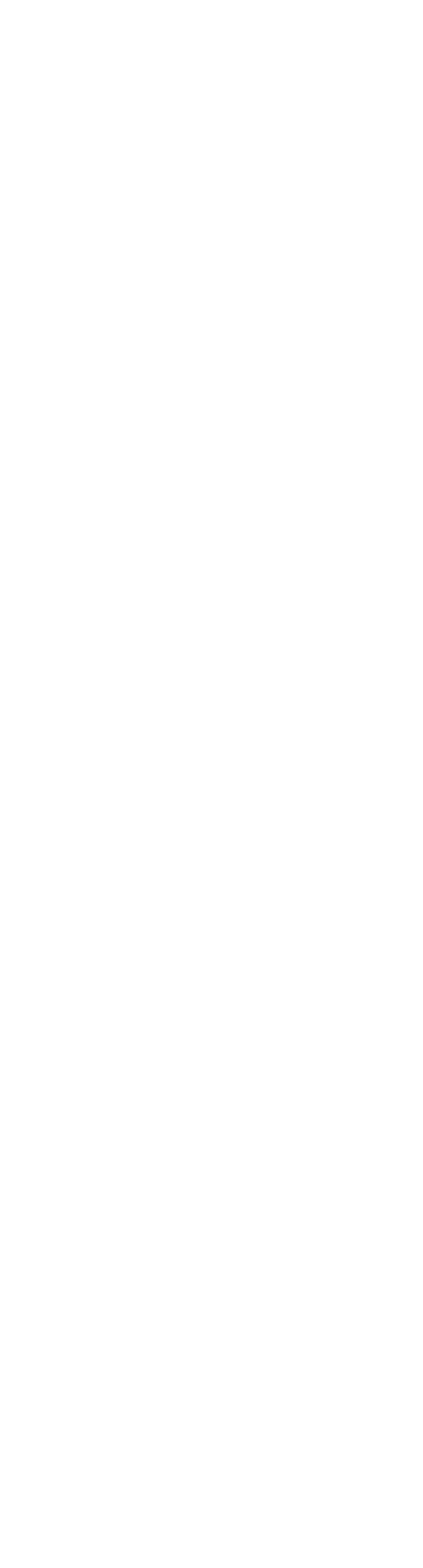




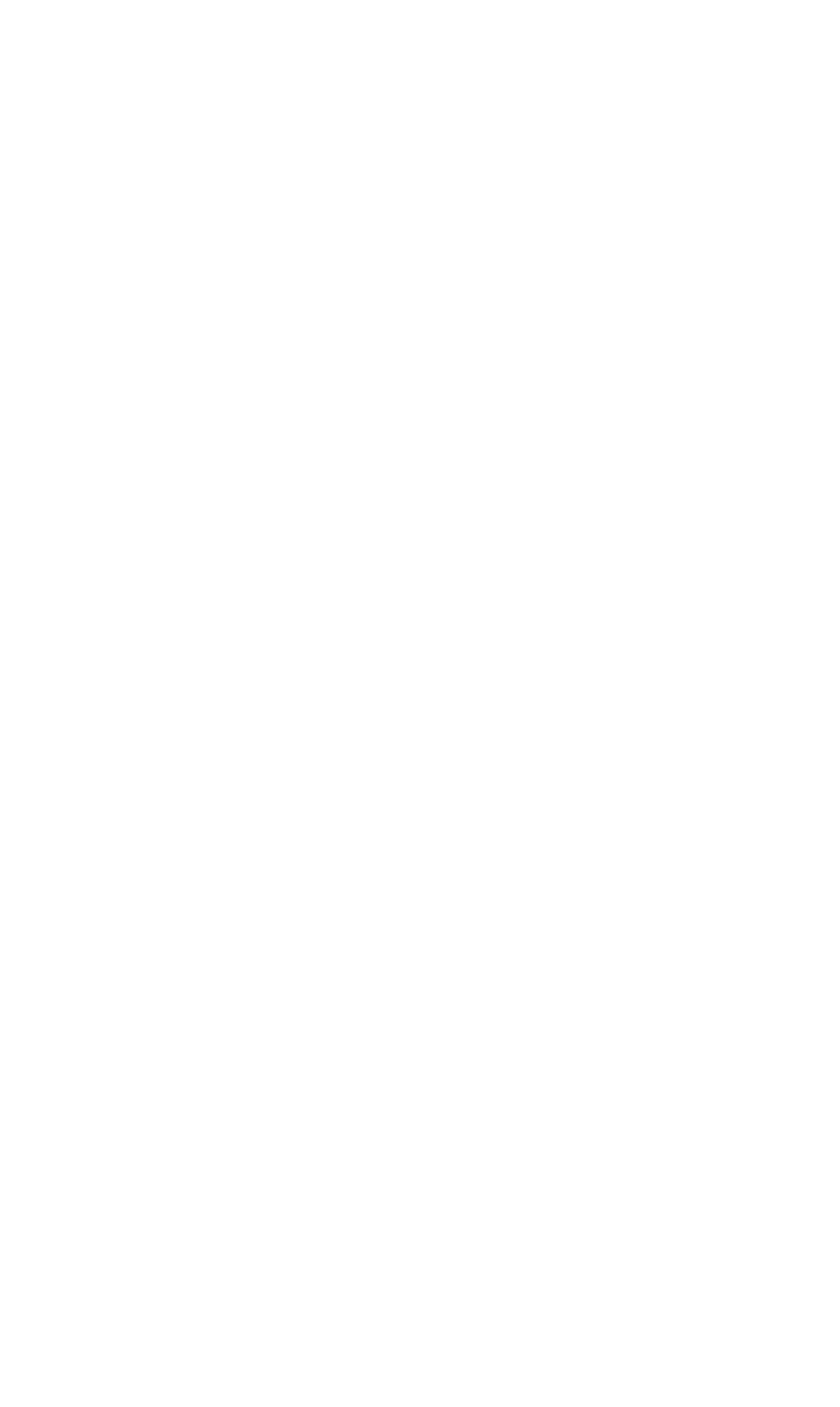




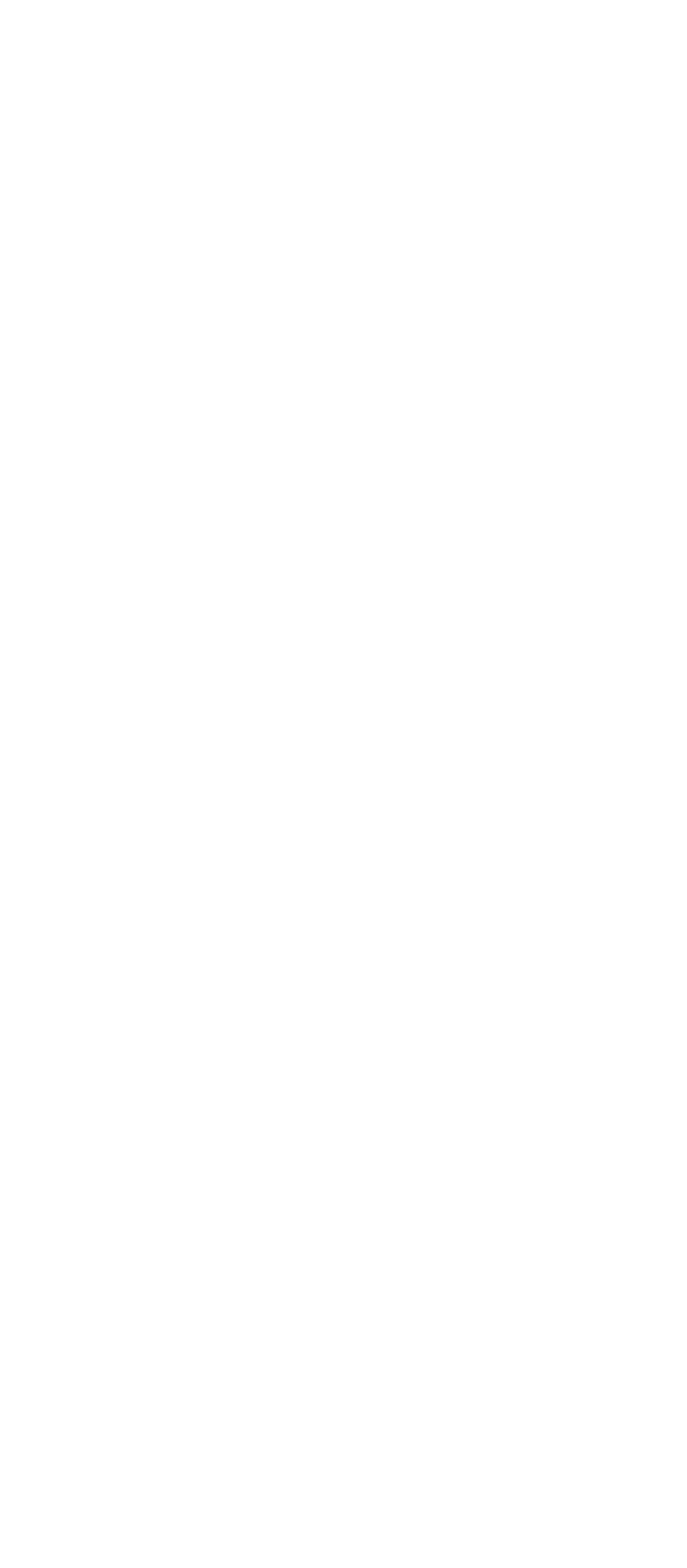




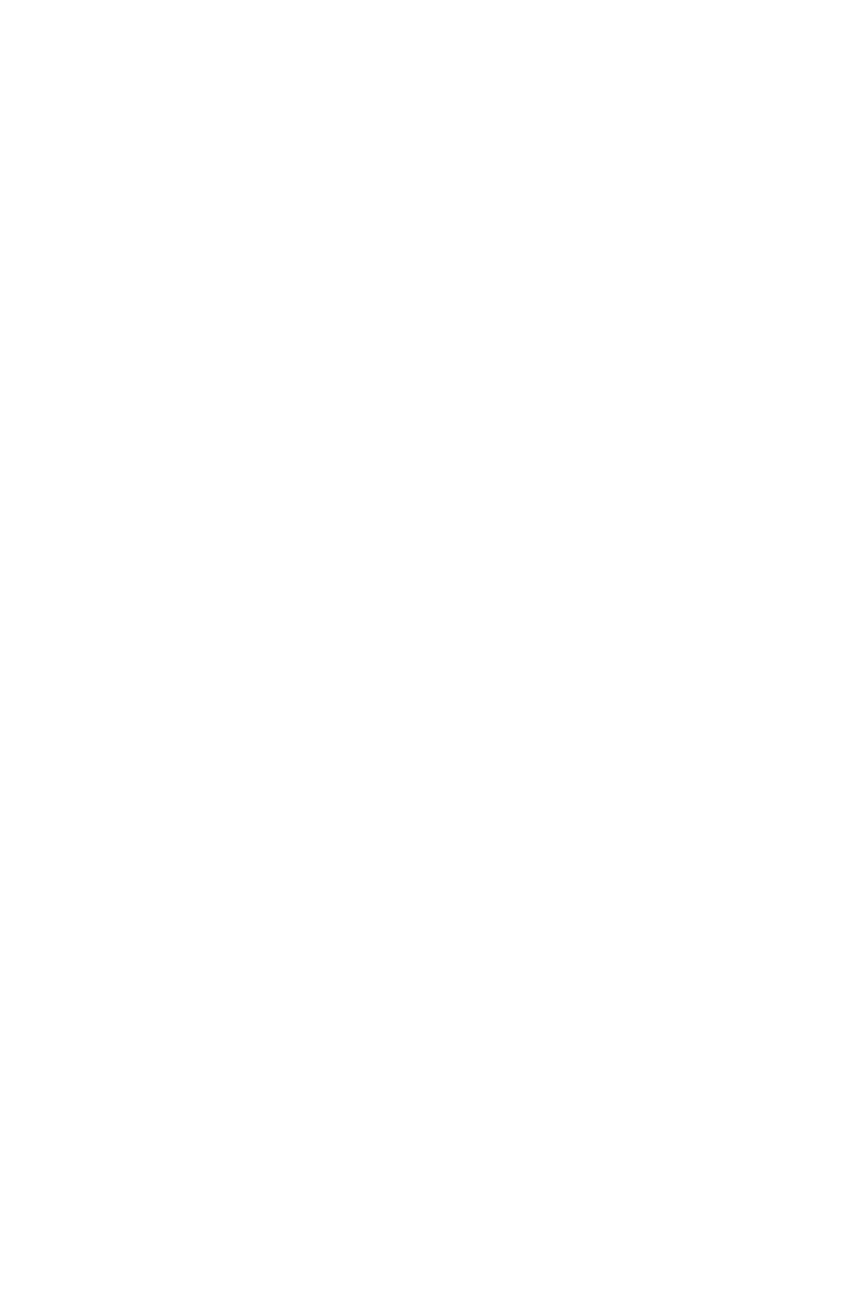




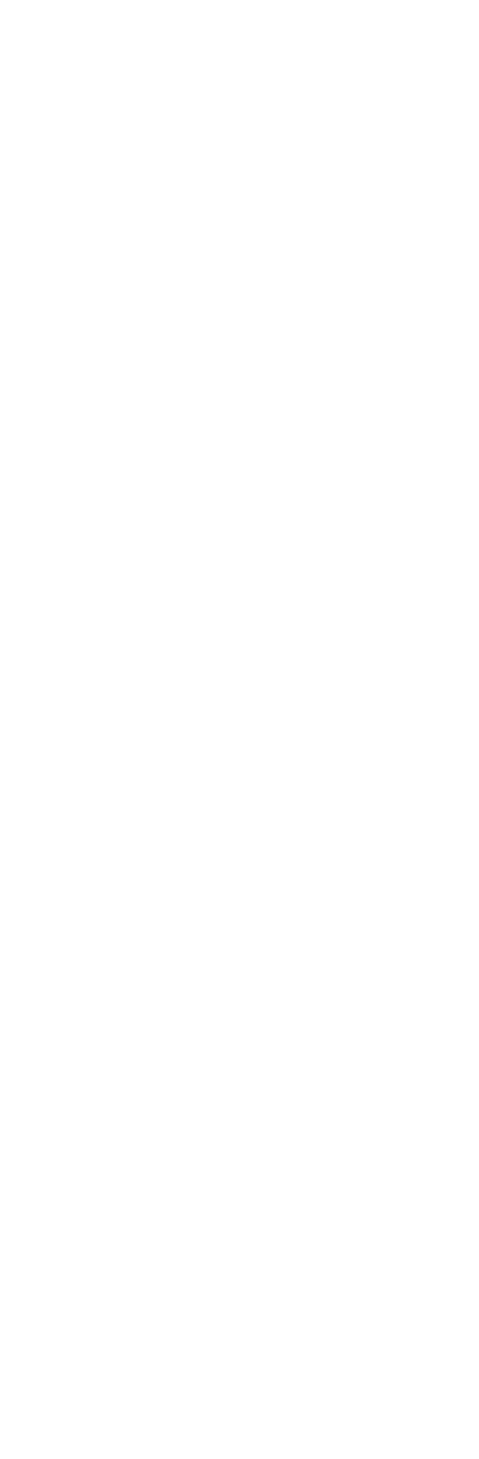




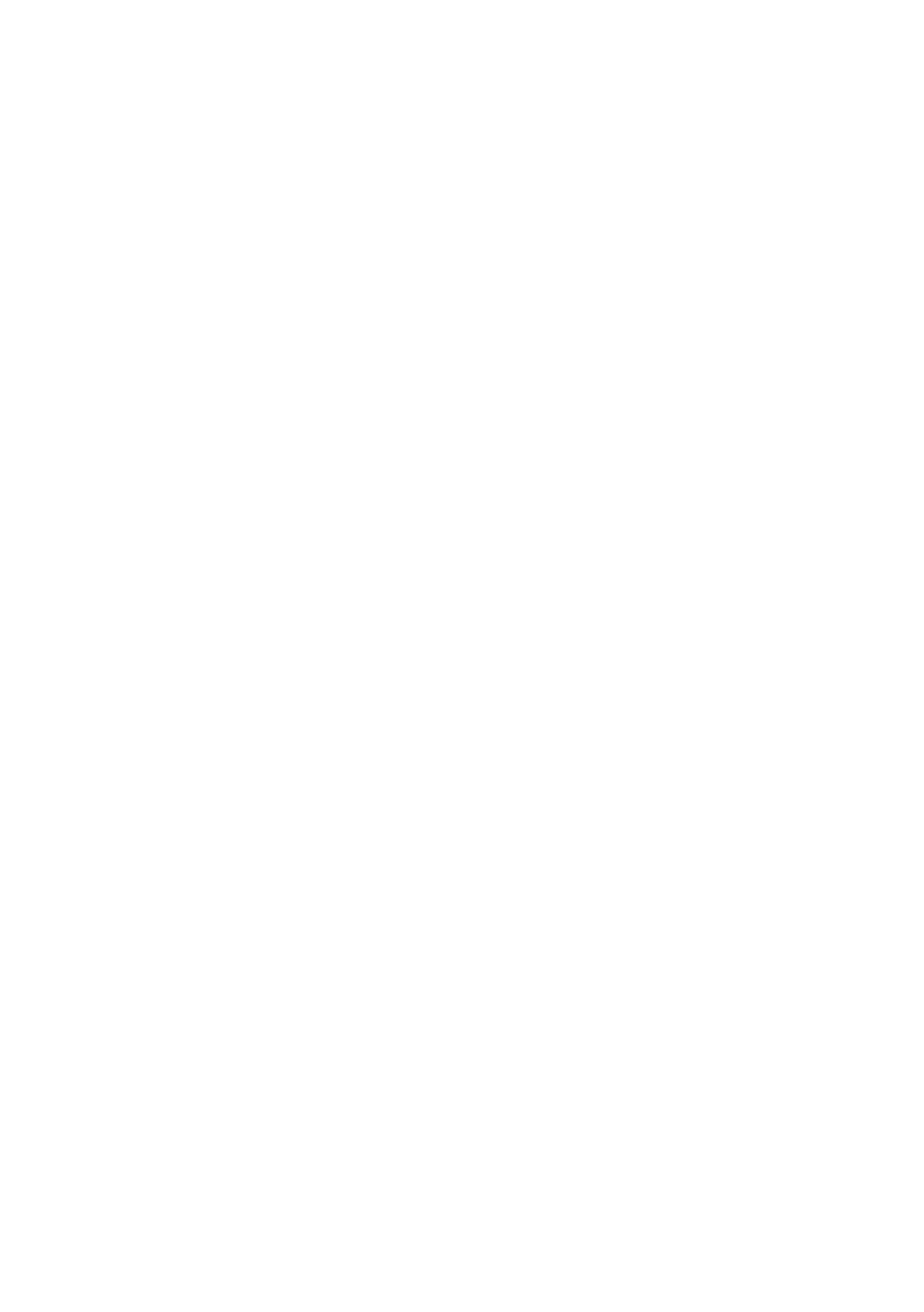




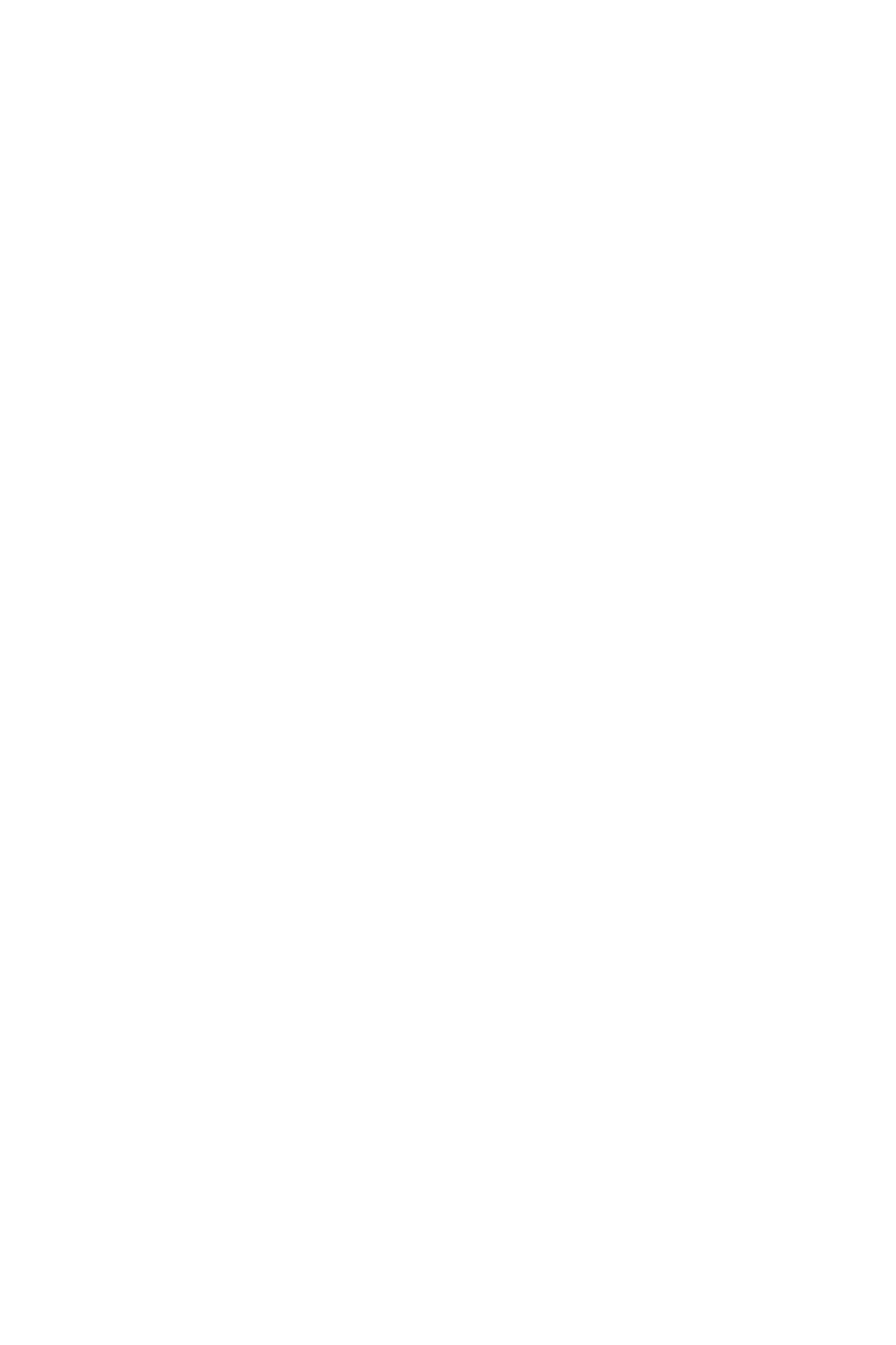


BEAVER RIVER BASIN--Continued

3-0940. YAHONING RIVER AT LEAVITTSBURG, OHIO--COnt1nued

Data from continuous recorder, July to Septemher 1967

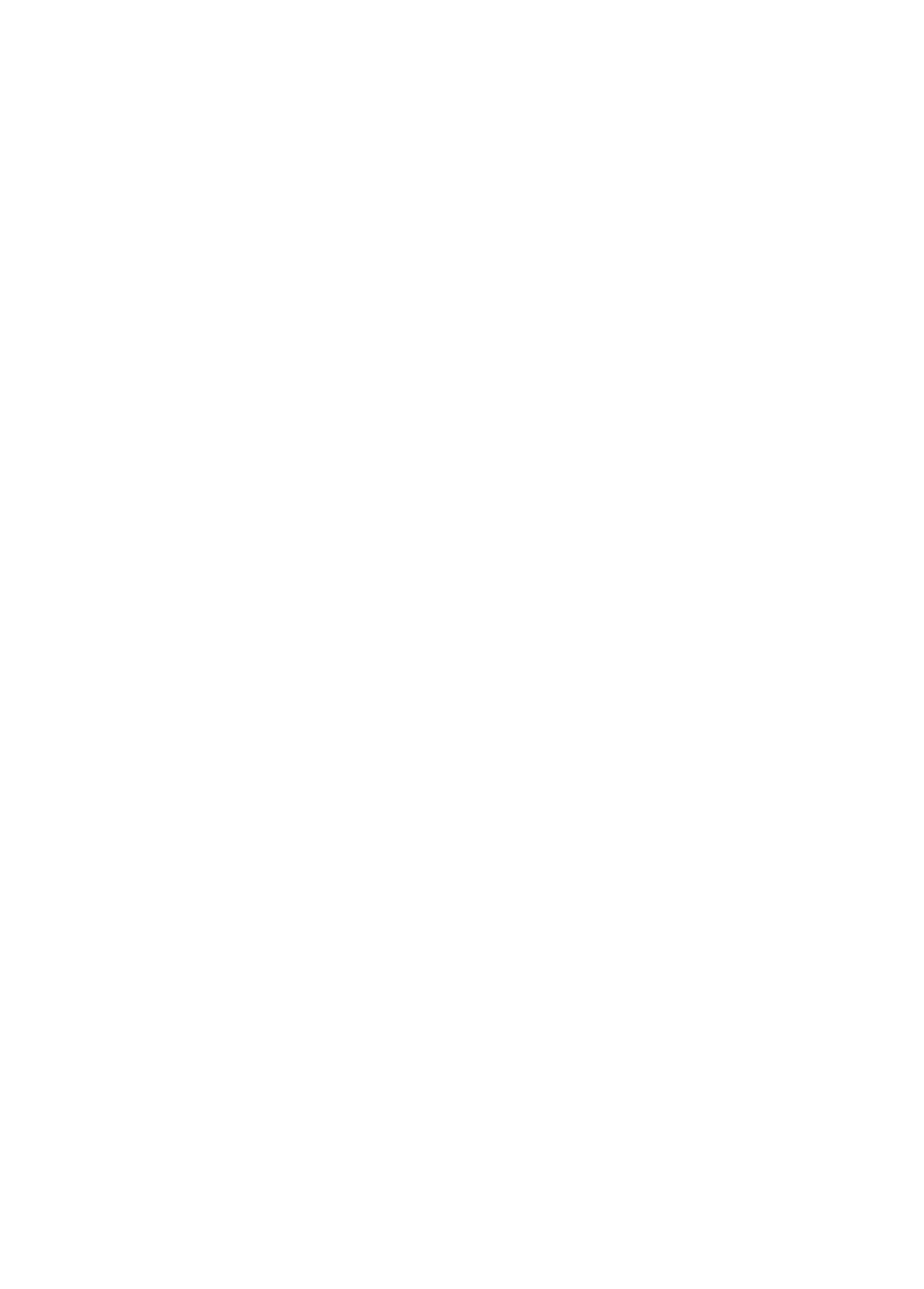




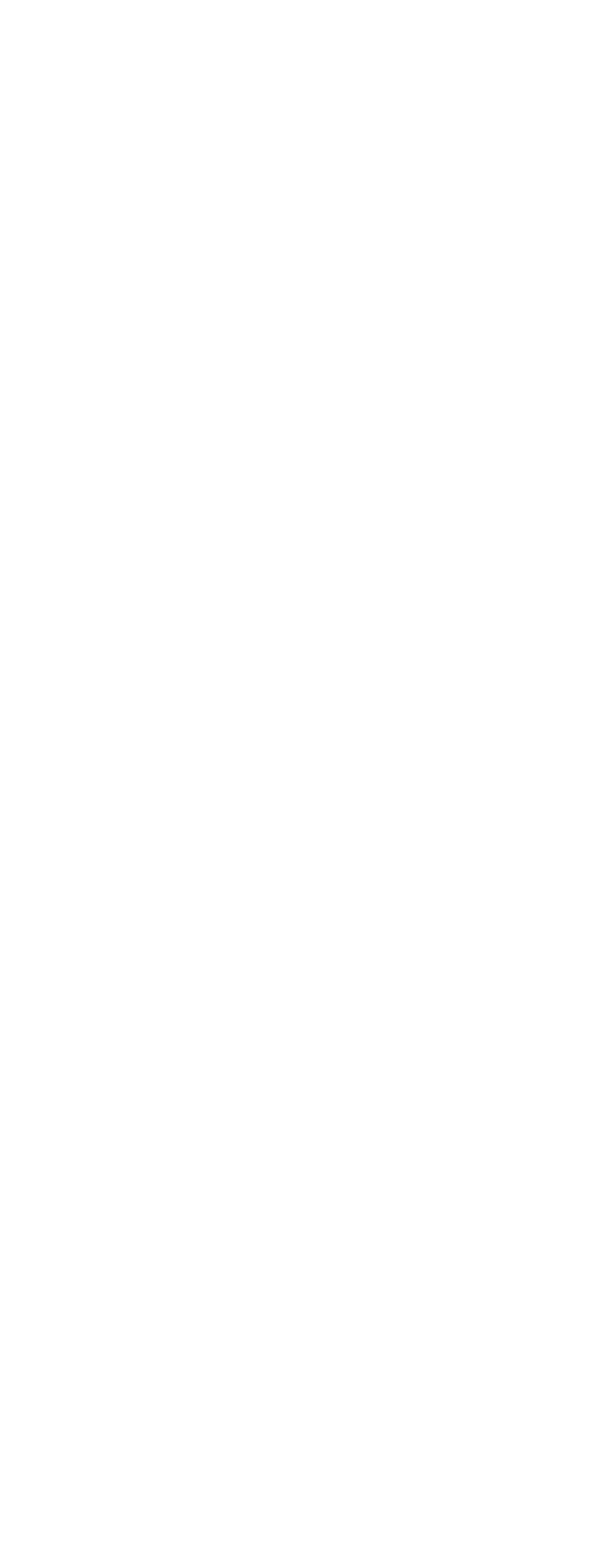


BEAVER RIVER BASIN--Continued

3-0995. WAHONING RIVER AT LOWELLVILLE, OHIO--Continued

Data from continuous recorder, October 1966 to January 1967

\begin{tabular}{|c|c|c|c|c|c|c|c|c|c|c|c|c|c|c|c|c|}
\hline \multirow{3}{*}{ Day } & \multicolumn{8}{|c|}{ OCTOBER } & \multicolumn{8}{|c|}{ NOVEMBER } \\
\hline & \multicolumn{2}{|c|}{$\begin{array}{c}\text { Specific } \\
\text { conductance } \\
\text { (micromhos } \\
\text { at } 25^{\circ} \mathrm{C} \text { ) }\end{array}$} & \multicolumn{2}{|c|}{$\mathbf{p H}$} & \multicolumn{2}{|c|}{$\begin{array}{c}\text { Dissolved } \\
\text { oxygen } \\
\text { (ppm) }\end{array}$} & \multicolumn{2}{|c|}{$\begin{array}{c}\text { Temper- } \\
\text { ature } \\
\left({ }^{\circ} \mathrm{F}\right)\end{array}$} & \multicolumn{2}{|c|}{$\begin{array}{c}\text { Specific } \\
\text { conductance } \\
\text { (micromhos } \\
\text { at } 25^{\circ} \mathrm{C} \text { ) }\end{array}$} & \multicolumn{2}{|c|}{$\mathbf{p H}$} & \multicolumn{2}{|c|}{$\begin{array}{c}\text { Dissolved } \\
\text { oxygen } \\
\text { (ppm) }\end{array}$} & \multicolumn{2}{|c|}{$\begin{array}{c}\text { Temper- } \\
\text { ature } \\
\left({ }^{\circ} \mathbf{F}\right)\end{array}$} \\
\hline & Max & Min & $\operatorname{Max}$ & Min & Max & Min & Max & Min & $\operatorname{Max}$ & Min & $\operatorname{Max}$ & Min & $\operatorname{Max}$ & Min & Max & Min \\
\hline $\begin{array}{l}1 \ldots \\
2 \ldots \\
3 \ldots \\
5 \ldots\end{array}$ & $\begin{array}{l}940 \\
880 \\
910 \\
930 \\
960\end{array}$ & $\begin{array}{l}750 \\
790 \\
860 \\
860 \\
840\end{array}$ & $=$ & $\overline{=}$ & $\begin{array}{l}3.2 \\
3.4 \\
3.3 \\
2.5 \\
2.8\end{array}$ & $\begin{array}{r}.7 \\
2.2 \\
1.4 \\
1.2 \\
.7\end{array}$ & $\begin{array}{l}90 \\
89 \\
91 \\
91 \\
91\end{array}$ & $\begin{array}{l}84 \\
83 \\
86 \\
88 \\
87\end{array}$ & $\begin{array}{r}1060 \\
1010 \\
760 \\
780 \\
720\end{array}$ & $\begin{array}{r}1010 \\
680 \\
630 \\
720 \\
660\end{array}$ & $\begin{array}{r}8.2 \\
8.0 \\
8.5 \\
-. \\
-\end{array}$ & $\begin{array}{l}6.7 \\
6.5 \\
6.5 \\
-\end{array}$ & $\begin{array}{l}1.5 \\
1.2 \\
4.6 \\
3.0 \\
2.5\end{array}$ & $\begin{array}{r}: 8 \\
: 1 \\
2.4 \\
1.7\end{array}$ & $\begin{array}{l}86 \\
84 \\
68 \\
70 \\
71\end{array}$ & $\begin{array}{l}83 \\
66 \\
64 \\
67 \\
63\end{array}$ \\
\hline $\begin{array}{l}6 \ldots \\
7 \ldots \\
0 \ldots \\
9 \ldots \\
10 \ldots\end{array}$ & $\begin{array}{r}950 \\
960 \\
1000 \\
960 \\
960\end{array}$ & $\begin{array}{l}850 \\
840 \\
930 \\
880 \\
800\end{array}$ & $\begin{array}{l}7.0 \\
7.0 \\
7.4 \\
7.7 \\
7.1\end{array}$ & $\begin{array}{l}5.4 \\
6.4 \\
6.0 \\
5.9 \\
6.0\end{array}$ & $\begin{array}{l}3.1 \\
2.0 \\
1.4 \\
1.5 \\
1.4\end{array}$ & $\begin{array}{r}1.4 \\
.8 \\
.9 \\
.7\end{array}$ & $\begin{array}{l}90 \\
94 \\
92 \\
94 \\
92\end{array}$ & $\begin{array}{l}84 \\
88 \\
87 \\
89 \\
83\end{array}$ & $\begin{array}{r}800 \\
880 \\
820 \\
-\end{array}$ & $\begin{array}{r}700 \\
720 \\
720 \\
-\end{array}$ & $\begin{array}{l}-- \\
7.7 \\
7.7 \\
8.4\end{array}$ & $\begin{array}{l}- \\
6.0 \\
6.3 \\
6.2\end{array}$ & $\begin{array}{l}1.9 \\
2.1 \\
1.5 \\
1.8 \\
1.8\end{array}$ & $\begin{array}{l}1.0 \\
1.5 \\
1.4 \\
109 \\
1.0\end{array}$ & $\begin{array}{l}70 \\
72 \\
75 \\
75 \\
72\end{array}$ & $\begin{array}{l}67 \\
68 \\
71 \\
68 \\
66\end{array}$ \\
\hline $\begin{array}{l}110 \\
12 \ldots \\
13 \ldots \\
14 \ldots \\
15 \ldots\end{array}$ & $\begin{array}{r}970 \\
1030 \\
940 \\
1000 \\
980\end{array}$ & $\begin{array}{l}850 \\
900 \\
800 \\
860 \\
890\end{array}$ & $\begin{array}{l}6.8 \\
6.9 \\
7.0 \\
7.0 \\
6.8\end{array}$ & $\begin{array}{l}5.5 \\
5.5 \\
5.9 \\
5.4 \\
5.3\end{array}$ & $\begin{array}{l}1.5 \\
1.7 \\
1.3 \\
1.3 \\
1.3\end{array}$ & $\begin{array}{r}.9 \\
1.0 \\
.7 \\
.7\end{array}$ & $\begin{array}{l}88 \\
90 \\
93 \\
97 \\
96\end{array}$ & $\begin{array}{l}85 \\
87 \\
85 \\
91 \\
88\end{array}$ & $\overline{\bar{z}}$ & $=$ & $\begin{array}{l}7.9 \\
=- \\
=-\end{array}$ & $\begin{array}{c}6.0 \\
=- \\
=-\end{array}$ & $\begin{array}{l}1.7 \\
2.1 \\
2.1 \\
2.2 \\
2.5\end{array}$ & $\begin{array}{l}.8 \\
1.7 \\
2.0 \\
1.4 \\
1.5\end{array}$ & $\begin{array}{l}71 \\
68 \\
67 \\
68 \\
74\end{array}$ & $\begin{array}{l}67 \\
67 \\
64 \\
62 \\
67\end{array}$ \\
\hline $\begin{array}{l}16 \ldots \\
17 \ldots \\
18 \ldots \\
19 \ldots \\
20 \ldots\end{array}$ & $\begin{array}{r}960 \\
1050 \\
990 \\
940 \\
910\end{array}$ & $\begin{array}{l}870 \\
900 \\
910 \\
890 \\
810\end{array}$ & $\begin{array}{l}8.2 \\
7.9 \\
6.5 \\
7.8 \\
6.0\end{array}$ & $\begin{array}{l}5.9 \\
6.1 \\
5.9 \\
6.0 \\
6.7\end{array}$ & $\begin{array}{l}1.4 \\
1.6 \\
1.4 \\
1.4 \\
1.3\end{array}$ & $\begin{array}{l}1.1 \\
1.0 \\
1.2 \\
1.2 \\
1.2\end{array}$ & $\begin{array}{l}89 \\
87 \\
87 \\
87 \\
85\end{array}$ & $\begin{array}{l}83 \\
82 \\
84 \\
84 \\
83\end{array}$ & $\begin{array}{l}780 \\
850 \\
930 \\
940 \\
890\end{array}$ & $\begin{array}{l}680 \\
770 \\
800 \\
840 \\
830\end{array}$ & $\begin{array}{l}7.4 \\
6.9 \\
7.3 \\
8.0 \\
8.0\end{array}$ & $\begin{array}{l}6.3 \\
5.5 \\
5.7 \\
5.8 \\
6.2\end{array}$ & $\begin{array}{l}1.6 \\
1.9 \\
1.8 \\
2.0 \\
2.1\end{array}$ & $\begin{array}{l}1.2 \\
1.6 \\
1.4 \\
1.5 \\
1.6\end{array}$ & $\begin{array}{l}76 \\
80 \\
81 \\
76 \\
71\end{array}$ & $\begin{array}{l}70 \\
76 \\
76 \\
71 \\
68\end{array}$ \\
\hline $\begin{array}{l}21 \ldots \\
22 \ldots \\
23 \ldots \\
24 \ldots \\
25 \ldots\end{array}$ & $\begin{array}{r}1040 \\
990 \\
1000 \\
1040 \\
1080\end{array}$ & $\begin{array}{r}870 \\
870 \\
890 \\
920 \\
1030\end{array}$ & $\begin{array}{l}8.5 \\
7.5 \\
7.9 \\
7.9 \\
6.6\end{array}$ & $\begin{array}{l}6.2 \\
6.4 \\
7.1 \\
6.3 \\
5.5\end{array}$ & $\begin{array}{l}1.5 \\
1.3 \\
1.0 \\
1.2 \\
1.4\end{array}$ & $\begin{array}{r}1.2 \\
.9 \\
\because 8 \\
1.0 \\
1.1\end{array}$ & $\begin{array}{l}89 \\
88 \\
88 \\
90 \\
90\end{array}$ & $\begin{array}{l}84 \\
84 \\
84 \\
84 \\
86\end{array}$ & $\begin{array}{r}960 \\
1010 \\
1020 \\
1040 \\
940\end{array}$ & $\begin{array}{l}850 \\
930 \\
930 \\
940 \\
910\end{array}$ & $\begin{array}{l}7.6 \\
7.0 \\
6.6 \\
8.0 \\
8.1\end{array}$ & $\begin{array}{l}6.2 \\
5.9 \\
5.6 \\
5.5 \\
6.4\end{array}$ & $\begin{array}{l}1.9 \\
1.7 \\
1.7 \\
1.7 \\
1.5\end{array}$ & $\begin{array}{l}1.5 \\
1.5 \\
1.4 \\
1.4 \\
1.3\end{array}$ & $\begin{array}{l}73 \\
77 \\
80 \\
81 \\
84\end{array}$ & $\begin{array}{l}69 \\
70 \\
76 \\
78 \\
75\end{array}$ \\
\hline $\begin{array}{l}26 \ldots \\
27 \ldots \\
28 \ldots \\
29 \ldots \\
30 \ldots \\
31 \ldots\end{array}$ & $\begin{array}{l}1070 \\
1050 \\
1080 \\
1040 \\
1070 \\
1120\end{array}$ & $\begin{array}{r}1020 \\
910 \\
940 \\
1000 \\
1010 \\
1040\end{array}$ & $\begin{array}{l}7.3 \\
7.2 \\
7.1 \\
7.2 \\
8.6 \\
7.7\end{array}$ & $\begin{array}{l}5.8 \\
5.2 \\
5.8 \\
6.3 \\
6.5 \\
6.6\end{array}$ & $\begin{array}{l}1.4 \\
2.3 \\
1.4 \\
2.0 \\
1.8 \\
1.8\end{array}$ & $\begin{array}{r}1.0 \\
1.1 \\
.8 \\
.7 \\
1.0 \\
1.0\end{array}$ & $\begin{array}{l}90 \\
89 \\
89 \\
89 \\
82 \\
85\end{array}$ & $\begin{array}{l}87 \\
85 \\
87 \\
80 \\
80 \\
80 \\
\end{array}$ & $\begin{array}{r}1000 \\
990 \\
920 \\
970 \\
1010 \\
\end{array}$ & $\begin{array}{r}880 \\
910 \\
820 \\
850 \\
910 \\
-\end{array}$ & $\begin{array}{r}8.2 \\
7.8 \\
7.5 \\
7.5 \\
7.0 \\
--\end{array}$ & $\begin{array}{l}6.8 \\
6.0 \\
6.0 \\
5.7 \\
6.0 \\
-\end{array}$ & $\begin{array}{l}1.7 \\
1.5 \\
1.5 \\
1.6 \\
1.6 \\
-\end{array}$ & $\begin{array}{l}1.5 \\
1.2 \\
1.1 \\
1.3 \\
1.3 \\
\end{array}$ & $\begin{array}{l}83 \\
79 \\
75 \\
72 \\
70 \\
-\end{array}$ & $\begin{array}{l}78 \\
75 \\
70 \\
68 \\
68 \\
\end{array}$ \\
\hline \multicolumn{9}{|c|}{ DECEMBER } & \multicolumn{8}{|c|}{ JANUARY } \\
\hline $\begin{array}{l}10 \\
2 \cdots \\
3 \bullet \\
4 \ldots \\
5 \ldots\end{array}$ & $\begin{array}{r}910 \\
990 \\
980 \\
1130 \\
1030\end{array}$ & $\begin{array}{l}820 \\
890 \\
900 \\
900 \\
950\end{array}$ & $\begin{array}{l}8.1 \\
8.0 \\
8.0 \\
8.0 \\
7.9\end{array}$ & $\begin{array}{l}6.0 \\
7.3 \\
7.6 \\
6.5 \\
6.0\end{array}$ & $\begin{array}{l}1.5 \\
1.7 \\
1.9 \\
2.0 \\
1.7\end{array}$ & $\begin{array}{l}1.2 \\
1.4 \\
1.7 \\
1.7 \\
1.2\end{array}$ & $\begin{array}{l}72 \\
69 \\
68 \\
68 \\
68\end{array}$ & $\begin{array}{l}69 \\
61 \\
65 \\
65 \\
62\end{array}$ & $\begin{array}{l}960 \\
860 \\
880 \\
920 \\
850\end{array}$ & $\begin{array}{l}790 \\
810 \\
810 \\
790 \\
780\end{array}$ & $\begin{array}{l}7.8 \\
6.5 \\
6.0 \\
6.5\end{array}$ & $\begin{array}{l}5.6 \\
5.7 \\
5.5 \\
5.6\end{array}$ & & & $\begin{array}{l}67 \\
66 \\
69 \\
69 \\
68\end{array}$ & $\begin{array}{l}65 \\
64 \\
63 \\
65 \\
62\end{array}$ \\
\hline $\begin{array}{r}6 \\
7 \ldots \\
8 \ldots \\
9 \\
10\end{array}$ & $\begin{array}{r}1120 \\
930 \\
620 \\
480 \\
\end{array}$ & $\begin{array}{l}840 \\
620 \\
460 \\
460 \\
-\end{array}$ & $\begin{array}{l}8.0 \\
7.8 \\
7.2 \\
8.0 \\
\end{array}$ & $\begin{array}{l}5.6 \\
6.2 \\
6.0 \\
6.7 \\
-.\end{array}$ & $\begin{array}{l}1.7 \\
1.5 \\
1.7 \\
2.0 \\
-.\end{array}$ & $\begin{array}{l}1.4 \\
1.2 \\
1.3 \\
1.7 \\
-.\end{array}$ & $\begin{array}{l}70 \\
73 \\
70 \\
69 \\
\end{array}$ & $\begin{array}{l}67 \\
66 \\
68 \\
65 \\
\end{array}$ & $\begin{array}{r}910 \\
960 \\
930 \\
980 \\
1000\end{array}$ & $\begin{array}{l}830 \\
840 \\
880 \\
890 \\
950\end{array}$ & $\begin{array}{l}6.4 \\
6.5 \\
6.5 \\
6.0 \\
6.2\end{array}$ & $\begin{array}{l}4.3 \\
5.1 \\
5.4 \\
5.4 \\
5.5\end{array}$ & & & $\begin{array}{l}67 \\
68 \\
66 \\
70 \\
77\end{array}$ & $\begin{array}{l}64 \\
65 \\
63 \\
62 \\
66\end{array}$ \\
\hline $\begin{array}{l}11 \ldots \\
12 \ldots \\
13 \ldots \\
14 \ldots \\
15 \ldots\end{array}$ & $\bar{I}$ & $\bar{z}$ & $\begin{array}{r}\bar{z} \\
\overline{8.5} \\
8.3\end{array}$ & $\overline{=}=$ & $\begin{array}{r}-5 \\
.6 \\
-\end{array}$ & $\begin{array}{l}.5 \\
.5 \\
. .\end{array}$ & $\begin{array}{l}-55 \\
72 \\
75 \\
71\end{array}$ & $\begin{array}{l}-5 \\
53 \\
54 \\
66 \\
61\end{array}$ & $\begin{array}{r}1100 \\
970 \\
1000 \\
990 \\
970\end{array}$ & $\begin{array}{l}930 \\
870 \\
960 \\
930 \\
910\end{array}$ & $\begin{array}{l}5.6 \\
5.9 \\
6.5 \\
6.4 \\
6.8\end{array}$ & $\begin{array}{l}4.0 \\
5.3 \\
5.7 \\
6.1 \\
6.2\end{array}$ & & & $\begin{array}{l}67 \\
66 \\
70 \\
70 \\
65\end{array}$ & $\begin{array}{l}64 \\
62 \\
65 \\
65 \\
60\end{array}$ \\
\hline $\begin{array}{l}16 \ldots \\
17 \ldots \\
18 \ldots \\
19 \ldots\end{array}$ & $\begin{array}{r}040 \\
= \\
=\end{array}$ & $\begin{array}{l}730 \\
= \\
=\end{array}$ & $\begin{array}{r}8.5 \\
8.6 \\
= \\
=\end{array}$ & $\begin{array}{r}7.4 \\
7.5 \\
=\end{array}$ & $=$ & $=$ & $\begin{array}{l}79 \\
77 \\
77 \\
76 \\
72\end{array}$ & $\begin{array}{l}71 \\
68 \\
72 \\
69 \\
66\end{array}$ & $\begin{array}{r}1090 \\
1090 \\
1070 \\
-\end{array}$ & $\begin{array}{r}950 \\
980 \\
930 \\
=\end{array}$ & $\begin{array}{r}6.9 \\
6.2 \\
6.2 \\
= \\
-\end{array}$ & $\begin{array}{r}5.8 \\
5.8 \\
5.2 \\
= \\
=\end{array}$ & & & $\begin{array}{l}63 \\
64 \\
62 \\
-\end{array}$ & $\begin{array}{r}61 \\
62 \\
58 \\
- \\
-\end{array}$ \\
\hline $\begin{array}{l}21 \ldots \\
22 \ldots \\
23 \ldots \\
24 \ldots \\
25 \ldots\end{array}$ & $\begin{array}{l}\overline{80} \\
840 \\
840 \\
840\end{array}$ & $\begin{array}{l}800 \\
810 \\
740 \\
780\end{array}$ & $\bar{z}$ & $\overline{-}$ & $\begin{array}{l}= \\
= \\
=\end{array}$ & $=$ & $\begin{array}{l}70 \\
71 \\
69 \\
63 \\
61\end{array}$ & $\begin{array}{l}67 \\
68 \\
63 \\
62 \\
56\end{array}$ & $=$ & $=$ & $=$ & $=$ & & & $=$ & $=$ \\
\hline $\begin{array}{l}26 \\
27 \ldots \\
28 \ldots \\
29 \ldots \\
30 \\
31 \ldots\end{array}$ & $\begin{array}{r}970 \\
940 \\
-0 \\
950 \\
850 \\
830\end{array}$ & $\begin{array}{r}740 \\
780 \\
-0 \\
850 \\
790 \\
770\end{array}$ & $\begin{array}{l}-\overline{0} \\
8.0 \\
8.1 \\
7.8 \\
7.8\end{array}$ & $\begin{array}{l}-- \\
6.5 \\
7.1 \\
6.2 \\
5.7 \\
6.3\end{array}$ & $=$ & $=$ & $\begin{array}{l}56 \\
64 \\
67 \\
70 \\
66 \\
66\end{array}$ & $\begin{array}{l}55 \\
55 \\
63 \\
63 \\
61 \\
62\end{array}$ & $=$ & $=$ & $\begin{array}{l}= \\
\overline{=}\end{array}$ & $=$ & & & $\begin{array}{l}= \\
=\end{array}$ & $=$ \\
\hline
\end{tabular}




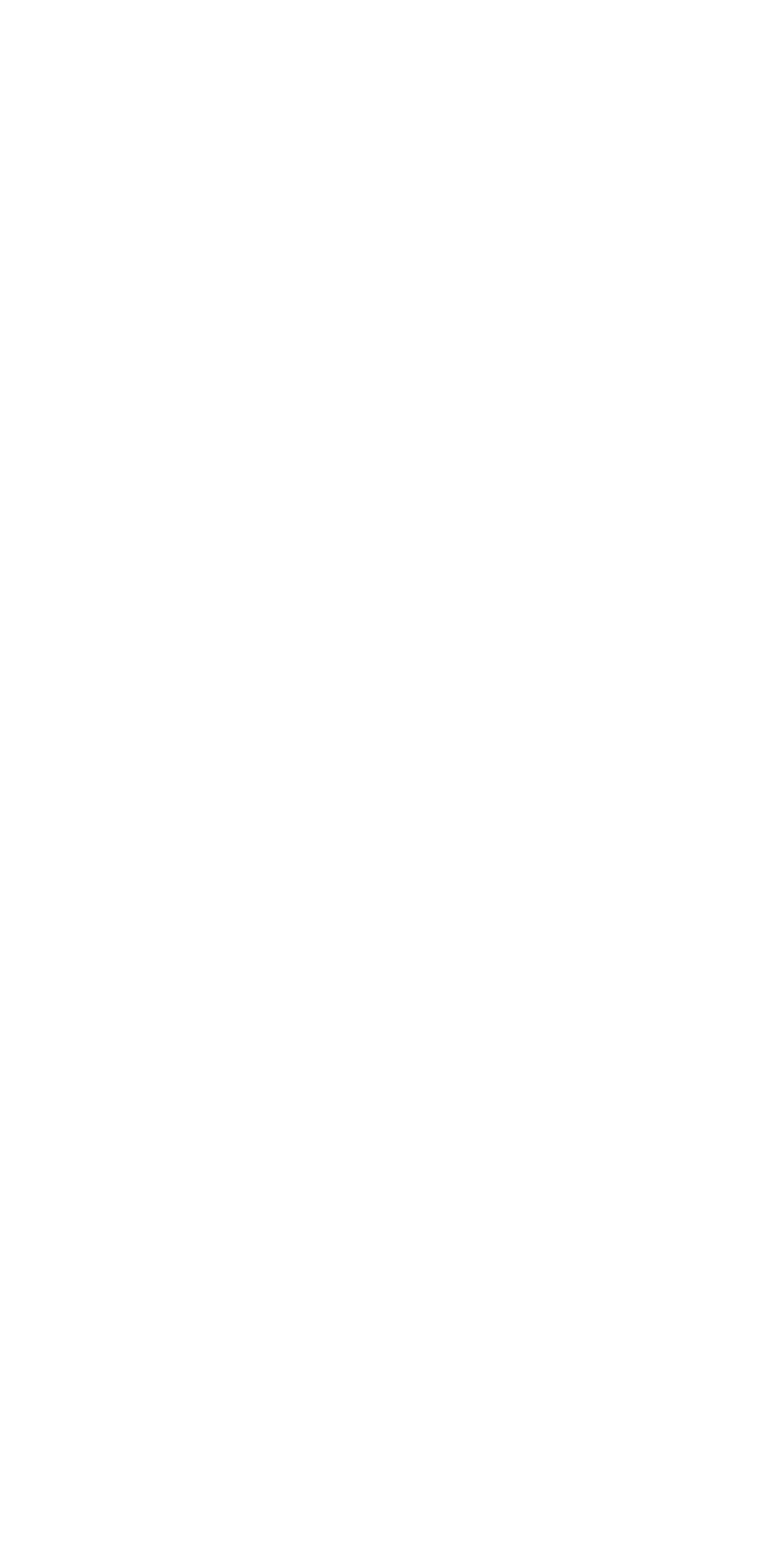


BEAVER RIVER BASIN--CONt1nued

3-0995.1. MAHONING RIVER AT OHIO-PENNSYLVANia STATE LINE, BELOW LOWELLVILLE, OHIO--CONTInued

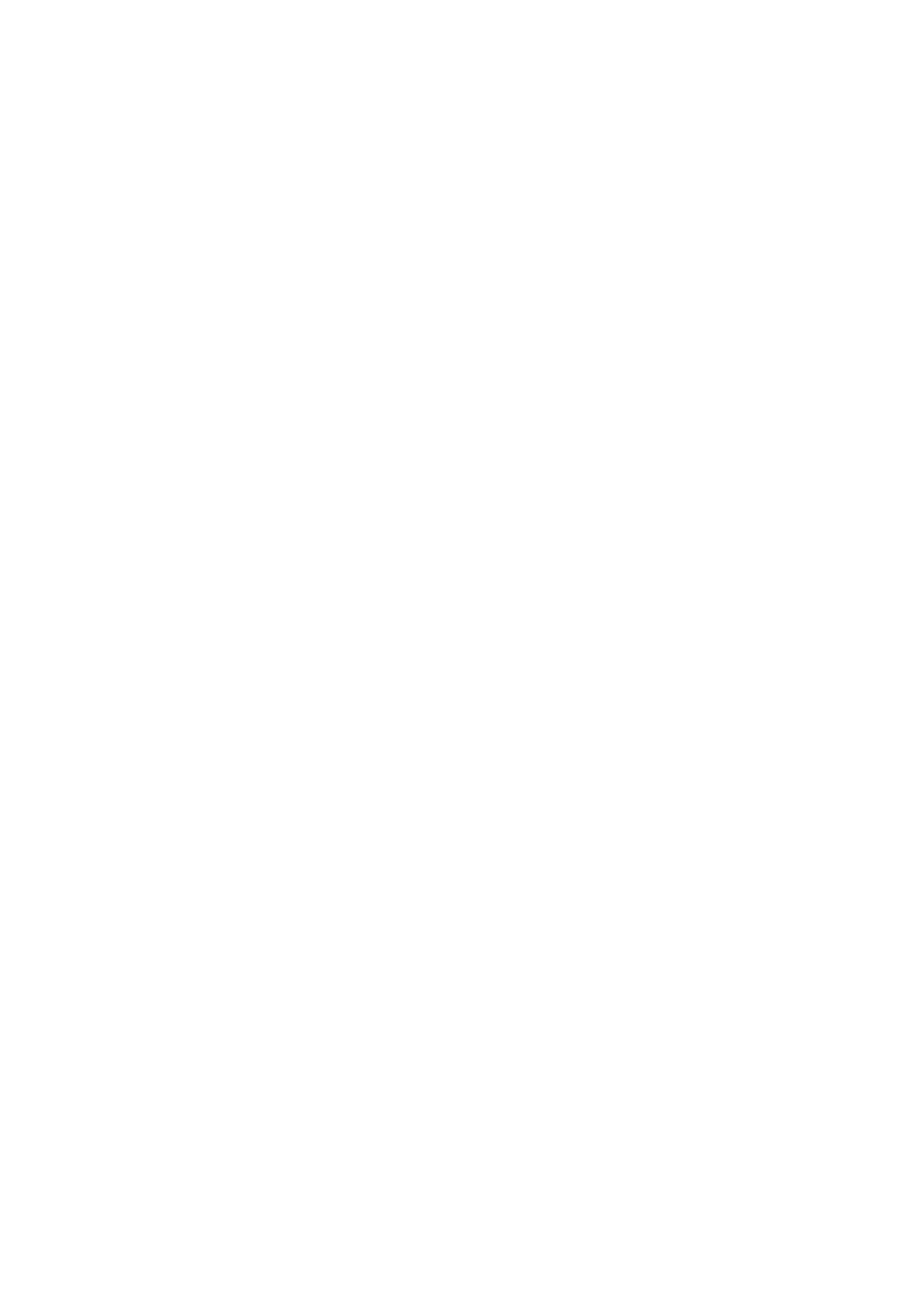


BEAVER RIVER BASIN--Continued

3-0995.1. MAHONING RIVER AT OHIO-PENNSYLVANIA STATE LINE, BELOW LOWELLVILLE, OHIO--Cont1nued

Data from continuous recorder, January to september 1967--Continued

\begin{tabular}{|c|c|c|c|c|c|c|c|c|c|c|c|c|c|c|c|c|}
\hline \multirow{3}{*}{ Day } & \multicolumn{8}{|c|}{ APR IL } & \multicolumn{8}{|c|}{ MAY } \\
\hline & \multicolumn{2}{|c|}{$\begin{array}{c}\text { Specific } \\
\text { conductance } \\
\text { (micromhos } \\
\text { at } 25^{\circ} \mathrm{C} \text { ) }\end{array}$} & \multicolumn{2}{|c|}{$\mathbf{p H}$} & \multicolumn{2}{|c|}{$\begin{array}{l}\text { Dissolved } \\
\text { oxygen } \\
\text { (ppm) }\end{array}$} & \multicolumn{2}{|c|}{$\begin{array}{c}\text { Temper- } \\
\text { ature } \\
\left({ }^{\circ} \mathrm{F}\right)\end{array}$} & \multicolumn{2}{|c|}{$\begin{array}{c}\text { Specific } \\
\text { conductance } \\
\text { (micromhos } \\
\text { at } 25^{\circ} \mathrm{C} \text { ) }\end{array}$} & \multicolumn{2}{|c|}{ pH } & \multicolumn{2}{|c|}{$\begin{array}{l}\text { Discolved } \\
\text { oxygen } \\
\text { (ppm) }\end{array}$} & \multicolumn{2}{|c|}{$\begin{array}{c}\text { Ternper- } \\
\text { ature } \\
\text { ('F) }\end{array}$} \\
\hline & Max & Min & Max & Min & $\operatorname{Max}$ & Min & Max & Min & $\operatorname{Max}$ & Min & $\operatorname{Max}$ & Min & $\operatorname{Max}$ & Min & Max & Min \\
\hline $\begin{array}{l}1 \ldots \\
2 \ldots 0 \\
3 \ldots 0 \\
4 \ldots \\
5 \ldots\end{array}$ & $=$ & $\begin{array}{l}\overline{-} \\
\overline{=} \\
=\end{array}$ & $\begin{array}{l}7.7 \\
7.8 \\
8.0 \\
7.8 \\
7.5\end{array}$ & $\begin{array}{l}6.9 \\
7.4 \\
7.3 \\
7.0 \\
6.9\end{array}$ & $\begin{array}{l}8.0 \\
7.7 \\
7.6 \\
7.3 \\
5.9\end{array}$ & $\begin{array}{l}7.3 \\
7.2 \\
6.9 \\
5.9 \\
4.7\end{array}$ & $\begin{array}{l}60 \\
62 \\
63 \\
64 \\
69\end{array}$ & $\begin{array}{l}58 \\
58 \\
59 \\
59 \\
64\end{array}$ & $\begin{array}{l}510 \\
490 \\
520 \\
570 \\
600\end{array}$ & $\begin{array}{l}440 \\
450 \\
460 \\
490 \\
560\end{array}$ & $\begin{array}{l}7.6 \\
7.5 \\
7.9 \\
8 \cdot 3 \\
8.5\end{array}$ & $\begin{array}{l}6 \cdot 9 \\
7 \cdot 2 \\
7 \cdot 3 \\
7.9 \\
8.3\end{array}$ & $\begin{array}{l}7.0 \\
7.6 \\
8.1 \\
7.5 \\
2.8\end{array}$ & $\begin{array}{l}4.7 \\
2.7 \\
2.8 \\
2.8 \\
2.7\end{array}$ & $\begin{array}{l}68 \\
72 \\
69 \\
69 \\
67\end{array}$ & $\begin{array}{l}67 \\
64 \\
58 \\
58 \\
60\end{array}$ \\
\hline $\begin{array}{l}6 \ldots \\
7 \ldots \\
8 \ldots \\
9 \ldots \\
10 \ldots\end{array}$ & $=$ & $\overline{-}$ & $\begin{array}{l}7.2 \\
7.3 \\
7.7 \\
7.5 \\
7.5\end{array}$ & $\begin{array}{l}6.5 \\
6.8 \\
6.8 \\
7.1 \\
6.7\end{array}$ & $\begin{array}{l}4.7 \\
5.7 \\
7.0 \\
6.8 \\
6.6\end{array}$ & $\begin{array}{l}3.8 \\
3.6 \\
5.6 \\
5.7 \\
5.5\end{array}$ & $\begin{array}{l}72 \\
72 \\
65 \\
63 \\
64\end{array}$ & $\begin{array}{l}69 \\
65 \\
61 \\
59 \\
61\end{array}$ & $\begin{array}{r}620 \\
=- \\
=-\end{array}$ & $\begin{array}{l}570 \\
=- \\
= \\
=-\end{array}$ & $\begin{array}{l}9.1 \\
= \\
=\end{array}$ & $\begin{array}{c}6.8 \\
=- \\
=\end{array}$ & $\overline{=}$ & $\begin{array}{l}2.8 \\
= \\
=\end{array}$ & $=$ & $\begin{array}{l}57 \\
=- \\
=\end{array}$ \\
\hline $\begin{array}{l}10 \\
200 \\
30 \\
140 \\
50\end{array}$ & $\bar{z}$ & $\begin{array}{l}-- \\
-- \\
-- \\
--\end{array}$ & $\begin{array}{l}7.4 \\
7.3 \\
7.3 \\
7.1 \\
7.2\end{array}$ & $\begin{array}{l}6.9 \\
7.0 \\
7.0 \\
6.4 \\
6.5\end{array}$ & $\begin{array}{l}6.4 \\
7.0 \\
6.9 \\
6.1 \\
5.4\end{array}$ & $\begin{array}{l}5.5 \\
5.0 \\
5.9 \\
5.4 \\
4.8\end{array}$ & $\begin{array}{l}66 \\
70 \\
73 \\
77 \\
77\end{array}$ & $\begin{array}{l}60 \\
63 \\
69 \\
72 \\
74\end{array}$ & $\begin{array}{r}430 \\
420 \\
360 \\
350 \\
--\end{array}$ & $\begin{array}{r}340 \\
350 \\
330 \\
320 \\
-\end{array}$ & $\begin{array}{l}8.1 \\
8.2 \\
7.7 \\
7.5 \\
7.7\end{array}$ & $\begin{array}{l}7.3 \\
7.6 \\
6.7 \\
7.2 \\
6.9\end{array}$ & $\begin{array}{l}8.4 \\
7.9 \\
8.9 \\
8.9 \\
8.7\end{array}$ & $\begin{array}{l}7.8 \\
6.8 \\
7.8 \\
8.5 \\
8.4\end{array}$ & $\begin{array}{l}58 \\
55 \\
56 \\
56 \\
56\end{array}$ & $\begin{array}{l}54 \\
53 \\
53 \\
55 \\
55\end{array}$ \\
\hline $\begin{array}{l}16 \ldots \\
17 \ldots \\
18 \ldots \\
19 \ldots \\
20 \ldots\end{array}$ & $\begin{array}{l}-- \\
=- \\
-\end{array}$ & $\begin{array}{l}-- \\
\overline{-} \\
\overline{-}\end{array}$ & $\begin{array}{l}7.2 \\
7.4 \\
6.9 \\
7.1 \\
7.0\end{array}$ & $\begin{array}{l}6.6 \\
6.6 \\
6.5 \\
6.4 \\
6.5\end{array}$ & $\begin{array}{l}5.2 \\
4.8 \\
4.6 \\
4.4 \\
4.6\end{array}$ & $\begin{array}{l}4.6 \\
3.5 \\
3.4 \\
2.9 \\
2.5\end{array}$ & $\begin{array}{l}79 \\
76 \\
74 \\
74 \\
76\end{array}$ & $\begin{array}{l}74 \\
72 \\
67 \\
70 \\
70\end{array}$ & $=$ & $\begin{array}{l}=- \\
\overline{-} \\
=-\end{array}$ & $\begin{array}{l}7.2 \\
7.1 \\
7.1 \\
7.1 \\
8.0\end{array}$ & $\begin{array}{l}6.8 \\
6.6 \\
6.7 \\
6.7 \\
6.9\end{array}$ & $\begin{array}{l}8.6 \\
8.1 \\
7.5 \\
6.7 \\
8.3\end{array}$ & $\begin{array}{l}8.1 \\
7.3 \\
6.7 \\
5.6 \\
5.6\end{array}$ & $\begin{array}{l}57 \\
59 \\
61 \\
63 \\
62\end{array}$ & $\begin{array}{l}54 \\
56 \\
58 \\
59 \\
59\end{array}$ \\
\hline $\begin{array}{l}21 \ldots \\
22 \ldots \\
23 \ldots \\
25 \ldots\end{array}$ & $\begin{array}{l}700 \\
690 \\
580 \\
530 \\
530\end{array}$ & $\begin{array}{l}670 \\
390 \\
510 \\
460 \\
450\end{array}$ & $\begin{array}{l}7.4 \\
8.4 \\
7.8 \\
7.7 \\
7.6\end{array}$ & $\begin{array}{l}6.6 \\
7.1 \\
7.4 \\
7.1 \\
7.2\end{array}$ & $\begin{array}{r}4.3 \\
5.4 \\
-- \\
-- \\
--\end{array}$ & $\begin{array}{r}3.9 \\
3.5 \\
=- \\
=-\end{array}$ & $\begin{array}{l}74 \\
71 \\
65 \\
63 \\
64\end{array}$ & $\begin{array}{l}70 \\
63 \\
63 \\
60 \\
58\end{array}$ & $=$ & $\begin{array}{l}= \\
=- \\
=-\end{array}$ & $\begin{array}{l}7.8 \\
7.6 \\
7.5 \\
7.5 \\
7.4\end{array}$ & $\begin{array}{l}7.4 \\
6.9 \\
6.8 \\
7.0 \\
6.6\end{array}$ & $\begin{array}{r}8.0 \\
7.1 \\
= \\
=\end{array}$ & $\begin{array}{r}7.1 \\
5.2 \\
-=- \\
--\end{array}$ & $\begin{array}{l}63 \\
64 \\
68 \\
73 \\
80\end{array}$ & $\begin{array}{l}59 \\
58 \\
60 \\
64 \\
72\end{array}$ \\
\hline $\begin{array}{l}28 \ldots \\
29 \ldots \\
30 \ldots \\
31 \ldots\end{array}$ & $\begin{array}{r}570 \\
580 \\
510 \\
520 \\
540 \\
--\end{array}$ & $\begin{array}{c}430 \\
470 \\
480 \\
480 \\
500 \\
--\end{array}$ & $\begin{array}{r}7.2 \\
7.7 \\
8.0 \\
7.9 \\
7.9 \\
-0\end{array}$ & $\begin{array}{r}6.6 \\
7.0 \\
7.4 \\
7.4 \\
7.5 \\
--\end{array}$ & $\begin{array}{r}-- \\
7.0 \\
7.0 \\
7.0 \\
--\end{array}$ & $\begin{array}{r}-- \\
6.2 \\
6.3 \\
6.0 \\
--\end{array}$ & $\begin{array}{l}66 \\
65 \\
63 \\
64 \\
67 \\
--\end{array}$ & $\begin{array}{l}62 \\
63 \\
60 \\
60 \\
62 \\
--\end{array}$ & $\begin{array}{l}-- \\
=- \\
-- \\
--\end{array}$ & $\begin{array}{l}=- \\
-- \\
-- \\
-- \\
--\end{array}$ & $\begin{array}{l}-- \\
-- \\
-- \\
--\end{array}$ & $\begin{array}{l}= \\
= \\
= \\
-\end{array}$ & $\begin{array}{l}= \\
= \\
=\end{array}$ & $\begin{array}{l}=- \\
=- \\
=- \\
--\end{array}$ & $\begin{array}{l}= \\
= \\
= \\
--\end{array}$ & $=$ \\
\hline \multicolumn{9}{|c|}{ JUNE } & \multicolumn{8}{|c|}{ JULY } \\
\hline $\begin{array}{l}1 \ldots \\
2 \ldots \\
3 \ldots \\
4 \ldots \\
5 \ldots\end{array}$ & $=$ & $\begin{array}{l}-= \\
-= \\
-\overline{-} \\
--\end{array}$ & $\begin{array}{l}=- \\
=- \\
=- \\
=-\end{array}$ & $\begin{array}{l}=- \\
=- \\
=- \\
=-\end{array}$ & $\begin{array}{l}=- \\
= \\
=- \\
=-\end{array}$ & $\begin{array}{l}-- \\
-- \\
-- \\
-\end{array}$ & & & $\begin{array}{l}= \\
= \\
=- \\
=\end{array}$ & $\begin{array}{l}=- \\
=- \\
-- \\
--\end{array}$ & $\begin{array}{l}=- \\
-z \\
=- \\
--\end{array}$ & $\begin{array}{l}=- \\
=- \\
=-\end{array}$ & $\begin{array}{l}= \\
= \\
=\end{array}$ & $\begin{array}{l}=- \\
=- \\
--\end{array}$ & $\begin{array}{l}= \\
= \\
=\end{array}$ & $\begin{array}{l}-= \\
- \\
-\end{array}$ \\
\hline $\begin{array}{l}6 \ldots \\
7 \ldots\end{array}$ & 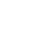 & $=$ & $=$ & -- & $=-$ & $=$ & & & -- & $=$ & $=$ & -- & $=$ & $=$ & $=$ & $=$ \\
\hline $\begin{array}{c}8 \ldots \\
9 \ldots \\
10 \ldots\end{array}$ & $=$ & $\begin{array}{l}-- \\
=-\end{array}$ & $=-$ & $\begin{array}{l}-- \\
--\end{array}$ & $=$ & $=$ & & & $\begin{array}{l}600 \\
590 \\
560\end{array}$ & $\begin{array}{l}570 \\
560 \\
520\end{array}$ & $\begin{array}{l}7.4 \\
7.5 \\
7.5\end{array}$ & $\begin{array}{l}7 \cdot 1 \\
7 \cdot 1 \\
6.8\end{array}$ & $\begin{array}{l}2.4 \\
1.8 \\
1.4\end{array}$ & $\begin{array}{r}1.7 \\
1.4 \\
.3\end{array}$ & $\begin{array}{l}86 \\
88 \\
92\end{array}$ & $\begin{array}{l}84 \\
85 \\
86\end{array}$ \\
\hline $\begin{array}{l}1 \ldots \\
2 \ldots \\
3 \ldots \\
4 \ldots \\
5 \ldots\end{array}$ & $\begin{array}{l}- \\
680 \\
660 \\
650\end{array}$ & $\begin{array}{l}-- \\
620 \\
600 \\
600\end{array}$ & $\begin{array}{r}-- \\
-- \\
7.2 \\
7.8 \\
7.3\end{array}$ & $\begin{array}{r}-- \\
6.5 \\
6.5 \\
6.0\end{array}$ & $\begin{array}{l}-1- \\
5.0 \\
5.3 \\
4.8\end{array}$ & $\begin{array}{l}-- \\
2.8 \\
2.8 \\
2.9\end{array}$ & & & $\begin{array}{l}530 \\
560 \\
570 \\
610 \\
740\end{array}$ & $\begin{array}{l}480 \\
490 \\
510 \\
570 \\
590\end{array}$ & $\begin{array}{l}7.3 \\
7.3 \\
7.3 \\
7.3 \\
7.2\end{array}$ & $\begin{array}{l}6.9 \\
6.9 \\
7.1 \\
7.2 \\
6.8\end{array}$ & $\begin{array}{l}2.6 \\
2.6 \\
1.8 \\
1.5 \\
1.5\end{array}$ & $\begin{array}{r}.3 \\
1.2 \\
1.3 \\
.9 \\
.5\end{array}$ & $\begin{array}{l}90 \\
92 \\
89 \\
87 \\
84\end{array}$ & $\begin{array}{l}84 \\
87 \\
86 \\
84 \\
81\end{array}$ \\
\hline$\because$ & $\begin{array}{l}= \\
= \\
=-\end{array}$ & $\begin{array}{l}-- \\
-- \\
--\end{array}$ & $\begin{array}{l}-- \\
=- \\
=- \\
--\end{array}$ & $\begin{array}{l}-- \\
-- \\
-- \\
--\end{array}$ & $\begin{array}{l}=- \\
=- \\
=-\end{array}$ & $\begin{array}{l}-- \\
\overline{-} \\
-- \\
--\end{array}$ & & & $\begin{array}{l}600 \\
580 \\
580 \\
570 \\
580\end{array}$ & $\begin{array}{l}480 \\
550 \\
540 \\
440 \\
560\end{array}$ & $\begin{array}{l}7.4 \\
7.4 \\
7.4 \\
7.5 \\
7.5\end{array}$ & $\begin{array}{l}7.0 \\
7.2 \\
7.1 \\
7.1 \\
7.4\end{array}$ & $\begin{array}{l}1.1 \\
2.3 \\
2.3 \\
2.0 \\
1.9\end{array}$ & $\begin{array}{r}.3 \\
1.4 \\
1.0 \\
1.0 \\
1.5\end{array}$ & $\begin{array}{l}81 \\
81 \\
84 \\
85 \\
85\end{array}$ & $\begin{array}{l}76 \\
77 \\
78 \\
75 \\
76\end{array}$ \\
\hline $4 \bullet$ & $\begin{array}{l}= \\
= \\
= \\
=\end{array}$ & $\begin{array}{l}-- \\
-- \\
-- \\
--\end{array}$ & $\begin{array}{l}=- \\
-- \\
-- \\
--\end{array}$ & $\begin{array}{l}-- \\
\overline{--} \\
\overline{--}\end{array}$ & $\begin{array}{l}=- \\
=- \\
=-\end{array}$ & $\begin{array}{l}-- \\
=- \\
--\end{array}$ & & & $\begin{array}{l}590 \\
590 \\
590 \\
570 \\
570\end{array}$ & $\begin{array}{l}570 \\
520 \\
540 \\
540 \\
490\end{array}$ & $\begin{array}{l}7.4 \\
7.4 \\
7.5 \\
7.5 \\
7.6\end{array}$ & $\begin{array}{l}7.3 \\
7 \cdot 1 \\
7.3 \\
7 \cdot 3 \\
7.0\end{array}$ & $\begin{array}{l}1.7 \\
1.6 \\
1.0 \\
.9 \\
2.1\end{array}$ & $\begin{array}{r}1.3 \\
1.0 \\
.6 \\
.6\end{array}$ & $\begin{array}{l}86 \\
85 \\
85 \\
86 \\
87\end{array}$ & $\begin{array}{l}83 \\
81 \\
82 \\
81 \\
81\end{array}$ \\
\hline $\begin{array}{l}27 \ldots \\
28 \ldots \\
29 \ldots \\
30 \ldots \\
31 \ldots\end{array}$ & $\begin{array}{l}-- \\
= \\
=-\end{array}$ & $\begin{array}{l}-- \\
-- \\
-- \\
-- \\
--\end{array}$ & $\begin{array}{l}-- \\
=- \\
=- \\
=- \\
--\end{array}$ & $\begin{array}{l}-- \\
=- \\
-- \\
--\end{array}$ & $\begin{array}{l}=- \\
=- \\
=- \\
=- \\
=-\end{array}$ & $\begin{array}{l}=- \\
=- \\
=- \\
=-\end{array}$ & & & $\begin{array}{r}580 \\
560 \\
550 \\
-- \\
--\end{array}$ & $\begin{array}{r}510 \\
520 \\
520 \\
= \\
=-\end{array}$ & $\begin{array}{r}7.0 \\
7.0 \\
7.0 \\
- \\
-\end{array}$ & $\begin{array}{r}6.7 \\
6.7 \\
6.8 \\
=- \\
=-\end{array}$ & $\begin{array}{r}2.6 \\
1.7 \\
2.3 \\
=- \\
=-\end{array}$ & $\begin{array}{r}1.7 \\
.8 \\
.6 \\
=- \\
=-\end{array}$ & $\begin{array}{l}88 \\
87 \\
87 \\
-- \\
--\end{array}$ & $\begin{array}{l}84 \\
84 \\
84 \\
-- \\
--\end{array}$ \\
\hline
\end{tabular}


BEAVER RIVER BASIN--ContInued

3-0995,1. MAHONING RIVER AT OHIO-PENNSYLVANIA STATE LINE, BELOW LOWELLVILLE, OHIO--COnt1nUed

Data from continuous recorder, January to September 1967--continued

\begin{tabular}{|c|c|c|c|c|c|c|c|c|c|c|c|c|c|c|c|c|}
\hline \multirow{3}{*}{ Day } & \multicolumn{8}{|c|}{ AUGUST } & \multicolumn{8}{|c|}{ SEPTEMBER } \\
\hline & \multicolumn{2}{|c|}{$\begin{array}{c}\text { Specific } \\
\text { conductance } \\
\text { (micromhos } \\
\text { at } 25^{\circ} \mathrm{C} \text { ) }\end{array}$} & \multicolumn{2}{|c|}{$\mathbf{p H}$} & \multicolumn{2}{|c|}{$\begin{array}{l}\text { Diswolved } \\
\text { oxygen } \\
\text { (ppm) }\end{array}$} & \multicolumn{2}{|c|}{$\begin{array}{c}\text { Temper- } \\
\text { ature } \\
\left({ }^{\circ} \mathbf{F}\right)\end{array}$} & \multicolumn{2}{|c|}{$\begin{array}{c}\text { Specific } \\
\text { conductance } \\
\text { (micromhos } \\
\text { at } 25^{\circ} \mathrm{C} \text { ) }\end{array}$} & \multicolumn{2}{|c|}{ pH } & \multicolumn{2}{|c|}{$\begin{array}{l}\text { Dissolved } \\
\text { oxygen } \\
\text { (ppm) }\end{array}$} & \multicolumn{2}{|c|}{$\begin{array}{c}\text { Temper- } \\
\text { ature } \\
\left({ }^{\circ} \mathbf{F}\right)\end{array}$} \\
\hline & Max & Min & $\operatorname{Max}$ & Min & Max & Min & Max & Min & $\operatorname{Max}$ & Min & Max & Min & Max & Min & $\operatorname{Max}$ & Min \\
\hline $\begin{array}{l}1 \ldots \\
2 \ldots \\
3 \ldots \\
4 \ldots \\
5 \ldots\end{array}$ & $\begin{array}{l}= \\
= \\
=\end{array}$ & $=$ & $\begin{array}{l}=- \\
=- \\
=- \\
=-\end{array}$ & $\begin{array}{l}=- \\
=- \\
=-\end{array}$ & $\begin{array}{l}= \\
= \\
= \\
=\end{array}$ & $\begin{array}{l}= \\
=- \\
=\end{array}$ & $\begin{array}{l}=- \\
=- \\
-\end{array}$ & $\begin{array}{l}= \\
=- \\
=\end{array}$ & $\begin{array}{l}670 \\
670 \\
640 \\
680 \\
660\end{array}$ & $\begin{array}{l}610 \\
580 \\
600 \\
640 \\
620\end{array}$ & $\begin{array}{l}7.4 \\
7.8 \\
8.0 \\
7.9 \\
7.7\end{array}$ & $\begin{array}{l}7.0 \\
7.3 \\
7.8 \\
7.4 \\
7.3\end{array}$ & $\begin{array}{l}2.6 \\
2.9 \\
3.0 \\
3.1 \\
2.7\end{array}$ & $\begin{array}{l}2.0 \\
2.3 \\
2.3 \\
2.0 \\
2.9\end{array}$ & $\begin{array}{l}90 \\
88 \\
88 \\
92 \\
88\end{array}$ & $\begin{array}{l}85 \\
85 \\
84 \\
84 \\
84\end{array}$ \\
\hline $\begin{array}{r}6 \ldots \\
7 \ldots \\
8 \ldots \\
9 \ldots \\
10 \ldots\end{array}$ & $=$ & $=$ & $\begin{array}{l}-- \\
=- \\
=- \\
--\end{array}$ & $\begin{array}{l}-- \\
=- \\
=-\end{array}$ & $\begin{array}{l}=- \\
=- \\
=- \\
--\end{array}$ & $\begin{array}{l}\ddot{-} \\
\ddot{-} \\
-\end{array}$ & $\begin{array}{l}= \\
=- \\
=\end{array}$ & $\begin{array}{l}\overline{-} \\
\overline{-} \\
=-\end{array}$ & $\begin{array}{l}690 \\
670 \\
680 \\
660 \\
660\end{array}$ & $\begin{array}{l}590 \\
630 \\
600 \\
610 \\
600\end{array}$ & $\begin{array}{l}7.8 \\
7.5 \\
7.0 \\
7.4 \\
7.7\end{array}$ & $\begin{array}{l}7.2 \\
6.4 \\
6.1 \\
6.9 \\
7.2\end{array}$ & $\begin{array}{l}2.6 \\
2.5 \\
2.0 \\
2.1 \\
2.8\end{array}$ & $\begin{array}{l}1.7 \\
1.7 \\
1.2 \\
1.2 \\
1.2\end{array}$ & $\begin{array}{l}88 \\
93 \\
94 \\
94 \\
87\end{array}$ & $\begin{array}{l}84 \\
85 \\
89 \\
87 \\
82\end{array}$ \\
\hline $\begin{array}{l}11 \ldots \\
12 \ldots \\
13 \ldots \\
14 \ldots \\
15 \ldots\end{array}$ & $=$ & $=$ & $\begin{array}{l}=- \\
=- \\
=-\end{array}$ & $\begin{array}{l}= \\
= \\
\approx \\
--\end{array}$ & $\begin{array}{l}-- \\
=- \\
=- \\
--\end{array}$ & $\begin{array}{l}\tilde{-} \\
\tilde{-} \\
-\end{array}$ & $\begin{array}{l}= \\
= \\
=\end{array}$ & $\begin{array}{l}=- \\
z- \\
=-\end{array}$ & $\begin{array}{l}740 \\
680 \\
720 \\
770 \\
800\end{array}$ & $\begin{array}{l}650 \\
640 \\
650 \\
690 \\
690\end{array}$ & $\begin{array}{l}7.3 \\
6.6 \\
7.1 \\
7.4 \\
7.9\end{array}$ & $\begin{array}{l}6.3 \\
6.0 \\
6.0 \\
6.8 \\
6.4\end{array}$ & $\begin{array}{l}2.6 \\
1.9 \\
2.0 \\
1.9 \\
2.7\end{array}$ & $\begin{array}{r}1.5 \\
1.1 \\
2.2 \\
1.1 \\
.9\end{array}$ & $\begin{array}{l}85 \\
86 \\
88 \\
89 \\
92\end{array}$ & $\begin{array}{l}80 \\
82 \\
84 \\
85 \\
88\end{array}$ \\
\hline $\begin{array}{l}16 \ldots \\
17 \ldots \\
18 \ldots \\
19 \ldots \\
20 \ldots\end{array}$ & $\begin{array}{l}= \\
- \\
-\end{array}$ & $\begin{array}{l}- \\
- \\
-\end{array}$ & $\begin{array}{l}=- \\
=- \\
=-\end{array}$ & $\begin{array}{l}= \\
\therefore \\
--\end{array}$ & $\begin{array}{l}=- \\
=- \\
=- \\
=-\end{array}$ & $\begin{array}{l}-- \\
=- \\
-\end{array}$ & $\begin{array}{l}= \\
=- \\
=\end{array}$ & $\begin{array}{l}=- \\
=- \\
=- \\
=-\end{array}$ & $\begin{array}{l}750 \\
780 \\
790 \\
760 \\
800\end{array}$ & $\begin{array}{l}690 \\
730 \\
730 \\
720 \\
700\end{array}$ & $\begin{array}{l}8.3 \\
8.0 \\
8.0 \\
7.5 \\
7.6\end{array}$ & $\begin{array}{l}7.4 \\
7.4 \\
6.9 \\
7.2 \\
6.7\end{array}$ & $\begin{array}{l}3.0 \\
3.0 \\
3.7 \\
3.1 \\
2.9\end{array}$ & $\begin{array}{l}2.1 \\
2.1 \\
2.2 \\
2.0 \\
1.9\end{array}$ & $\begin{array}{l}92 \\
91 \\
92 \\
92 \\
93\end{array}$ & $\begin{array}{l}88 \\
88 \\
88 \\
88 \\
88\end{array}$ \\
\hline $\begin{array}{l}21 \ldots \\
22 \ldots \\
23 \ldots \\
24 \ldots \\
25 \ldots\end{array}$ & $\bar{z}$ & $\bar{z}$ & $\begin{array}{l}=- \\
\overline{--} \\
\overline{7.1}\end{array}$ & $\begin{array}{l}=- \\
=- \\
6.4\end{array}$ & $\begin{array}{l}=- \\
=- \\
2.1\end{array}$ & $\begin{array}{l}=- \\
=- \\
\overline{-5}\end{array}$ & $\begin{array}{l}\overline{--} \\
\overline{--} \\
\overline{94}\end{array}$ & $\begin{array}{l}=- \\
\ddot{--} \\
89\end{array}$ & $\begin{array}{l}750 \\
720 \\
750 \\
760 \\
820\end{array}$ & $\begin{array}{l}690 \\
600 \\
700 \\
710 \\
760\end{array}$ & $\begin{array}{l}8.0 \\
7.8 \\
7.8 \\
7.8 \\
7.8\end{array}$ & $\begin{array}{l}7.6 \\
7.6 \\
7.0 \\
7.6 \\
7.4\end{array}$ & $\begin{array}{l}2.1 \\
1.8 \\
2.6 \\
3.1 \\
3.3\end{array}$ & $\begin{array}{r}.6 \\
: 6 \\
1.3 \\
2.3 \\
2.2\end{array}$ & $\begin{array}{l}93 \\
87 \\
86 \\
85 \\
85\end{array}$ & $\begin{array}{l}87 \\
83 \\
84 \\
80 \\
80\end{array}$ \\
\hline $\begin{array}{l}26 \ldots \\
27 \ldots \\
28 \ldots \\
29 \ldots \\
30 \ldots \\
31 \ldots\end{array}$ & $\begin{array}{l}710 \\
640 \\
660 \\
640 \\
630 \\
690\end{array}$ & $\begin{array}{l}620 \\
610 \\
610 \\
590 \\
580 \\
490\end{array}$ & $\begin{array}{l}7.9 \\
7.9 \\
8.0 \\
7.4 \\
7.6 \\
7.7\end{array}$ & $\begin{array}{l}6.9 \\
7.8 \\
6.8 \\
6.8 \\
7.3 \\
7.0\end{array}$ & $\begin{array}{l}2.1 \\
2.4 \\
2.4 \\
2.7 \\
2.5 \\
2.8\end{array}$ & $\begin{array}{r}1.6 \\
1.8 \\
1.9 \\
2.9 \\
.5 \\
.5\end{array}$ & $\begin{array}{l}93 \\
91 \\
90 \\
92 \\
93 \\
91\end{array}$ & $\begin{array}{l}90 \\
88 \\
87 \\
87 \\
88 \\
82\end{array}$ & $\begin{array}{l}800 \\
840 \\
820 \\
690 \\
680 \\
-\end{array}$ & $\begin{array}{l}740 \\
780 \\
600 \\
620 \\
620 \\
-\end{array}$ & $\begin{array}{r}7.8 \\
7.4 \\
7.6 \\
7.7 \\
7.9 \\
-\end{array}$ & $\begin{array}{r}7.0 \\
6.9 \\
7.0 \\
7.4 \\
7.4 \\
-\end{array}$ & $\begin{array}{r}3.8 \\
3.8 \\
3.7 \\
4.6 \\
4.9 \\
-\end{array}$ & $\begin{array}{r}2.3 \\
2.4 \\
.9 \\
3.7 \\
-.6\end{array}$ & $\begin{array}{l}87 \\
88 \\
88 \\
76 \\
75 \\
--\end{array}$ & $\begin{array}{l}83 \\
86 \\
75 \\
75 \\
73 \\
--\end{array}$ \\
\hline
\end{tabular}




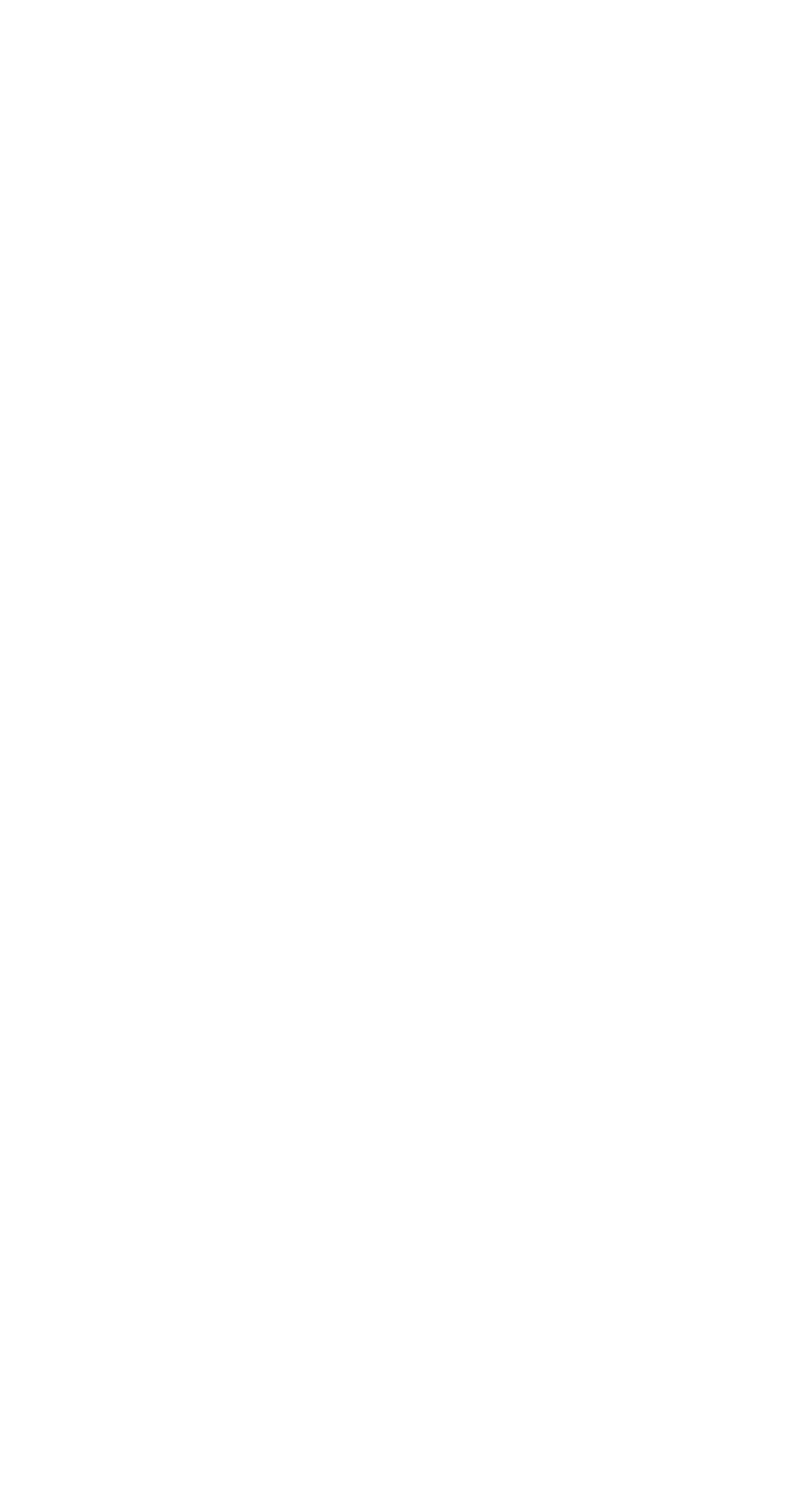




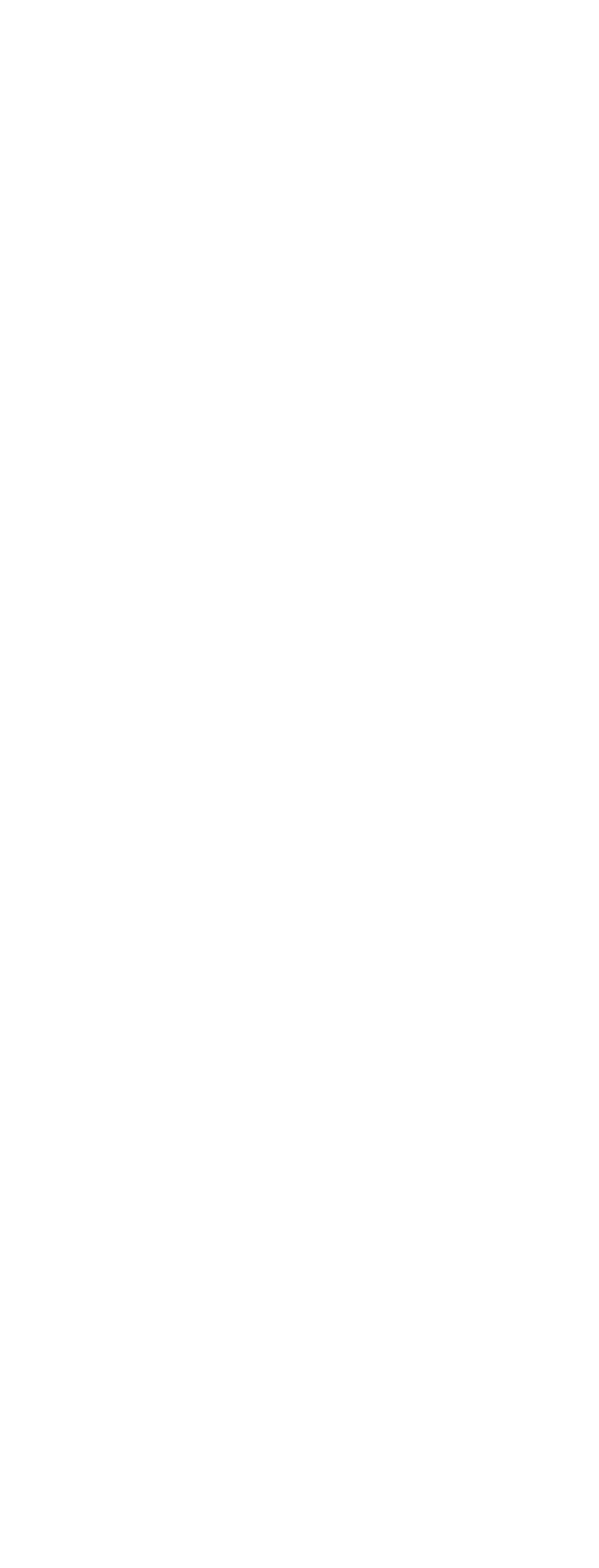

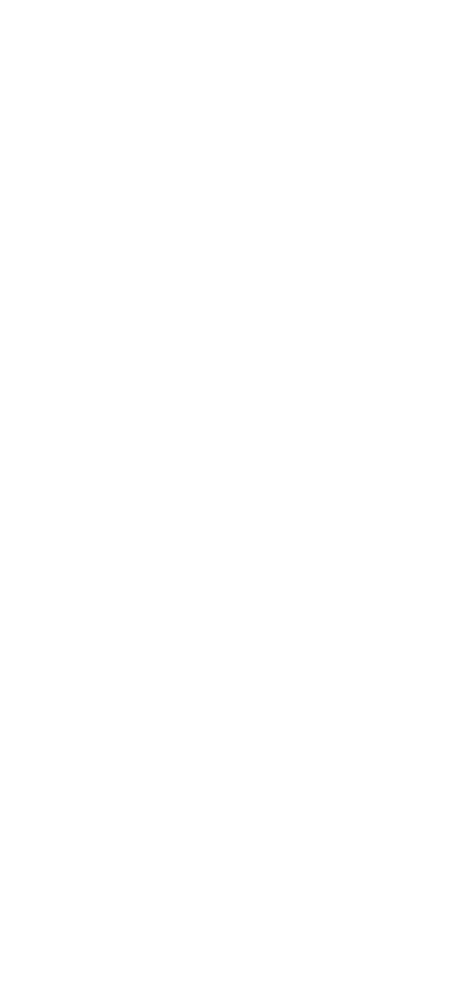




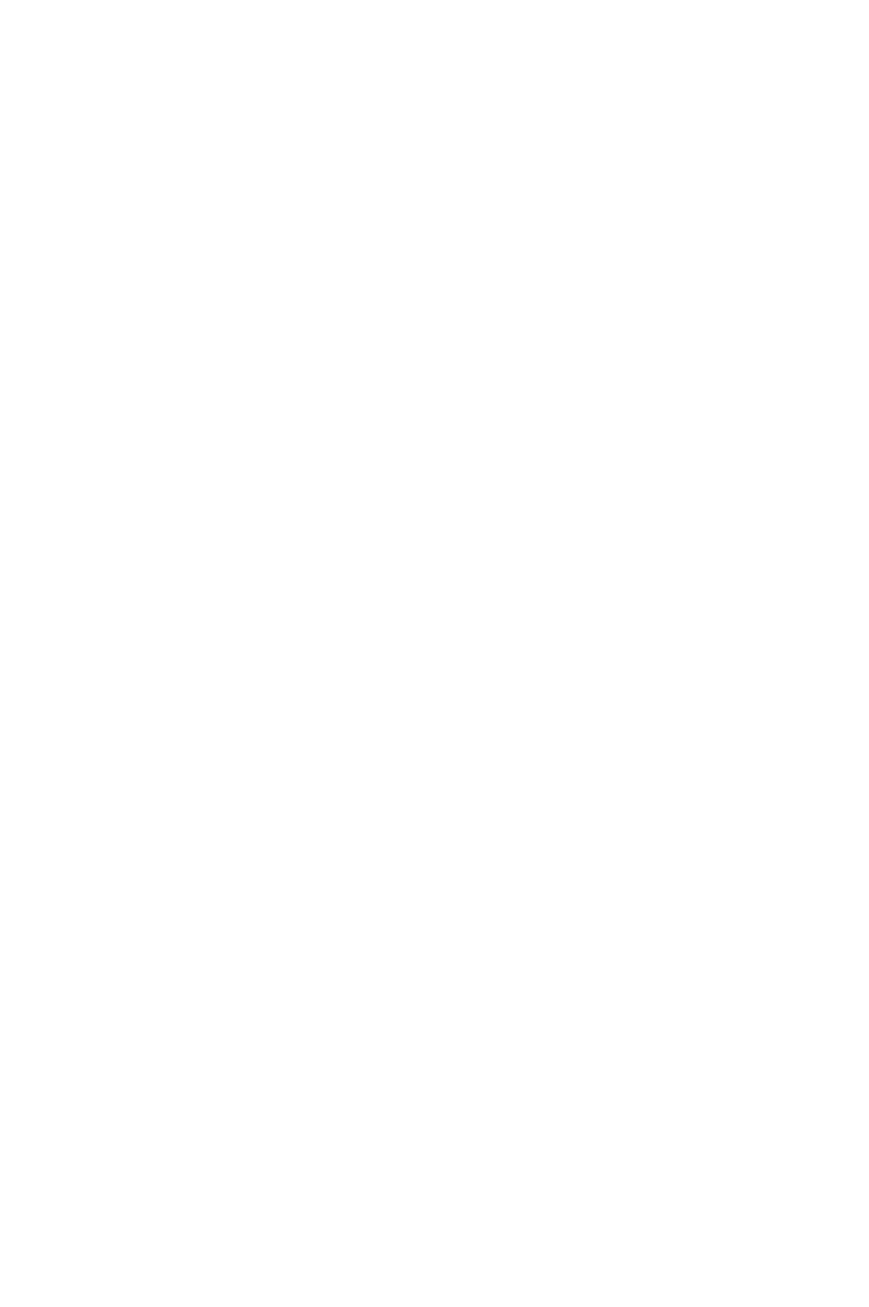




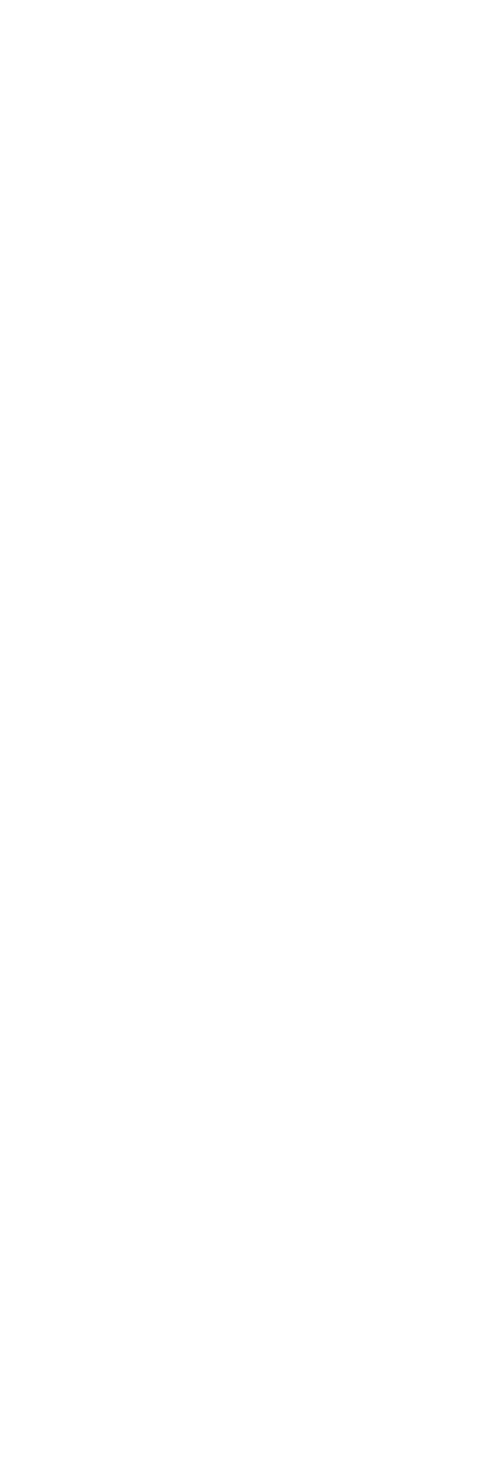



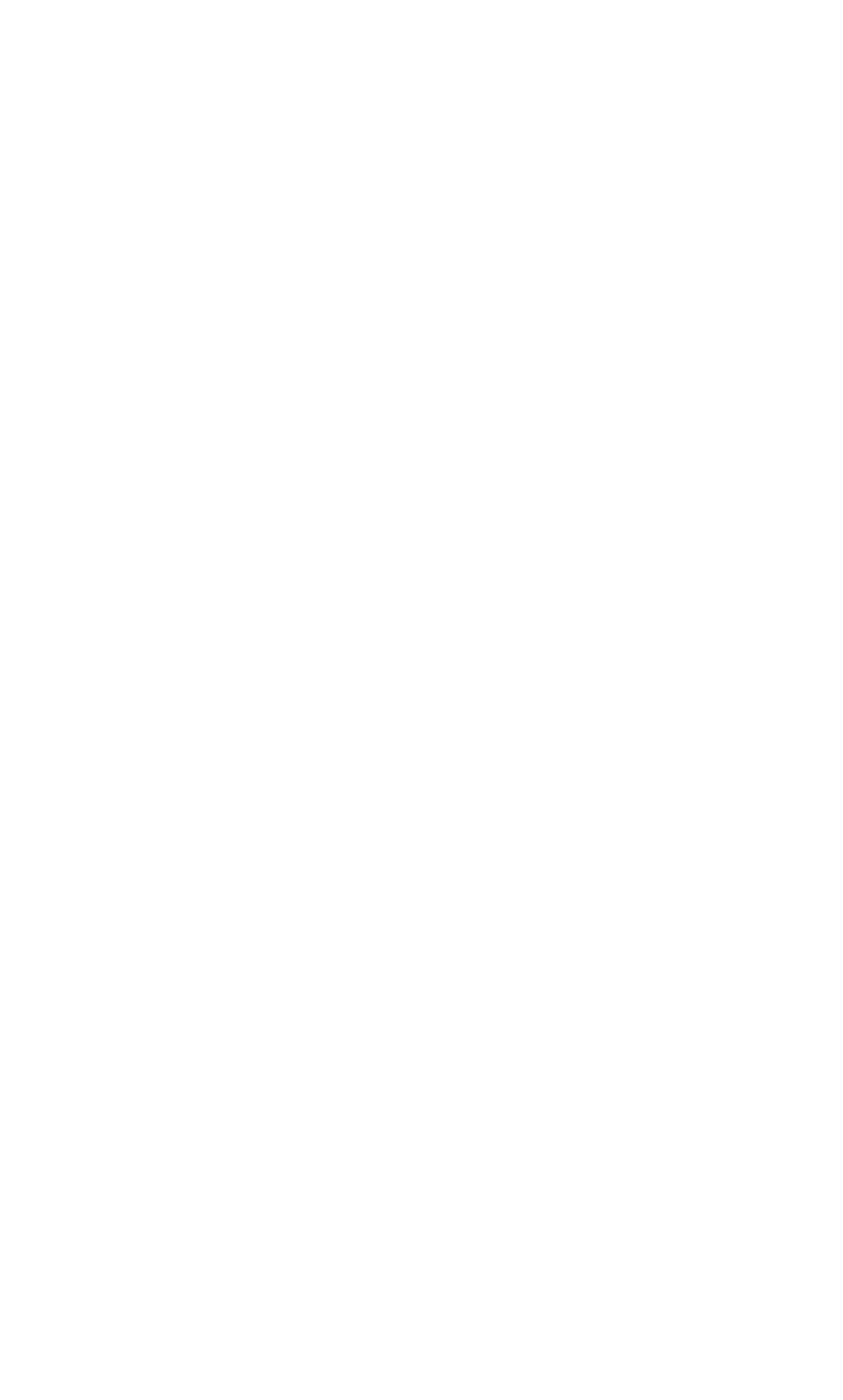
YUSKINGUM RIVER BASIN--Continued

3-1390. KILLBUCK CREEK AT KILLBUCK, OHIO--Continued

Suspended sediment, water year October 1966 to September 1967

\begin{tabular}{|c|c|c|c|c|c|c|c|c|c|}
\hline \multirow[b]{3}{*}{ Day } & \multicolumn{3}{|c|}{ OCTOBER } & \multicolumn{3}{|c|}{ NOVEMBER } & \multicolumn{3}{|c|}{ DICEMBER } \\
\hline & \multirow[b]{2}{*}{$\begin{array}{c}\text { Moan } \\
\text { dis- } \\
\text { charge } \\
\text { (cfe) }\end{array}$} & \multicolumn{2}{|c|}{ Suspended sediment } & \multirow[b]{2}{*}{$\begin{array}{c}\text { Mean } \\
\text { dig- } \\
\text { charge } \\
\text { (cfs) }\end{array}$} & \multicolumn{2}{|c|}{ Suspended sediment } & \multirow[b]{2}{*}{$\begin{array}{l}\text { Mean } \\
\text { dis- } \\
\text { charge } \\
\text { (cfs) }\end{array}$} & \multicolumn{2}{|c|}{ Suspended sediment } \\
\hline & & $\begin{array}{c}\text { Mean } \\
\text { concen- } \\
\text { tration } \\
(\mathrm{ppm})\end{array}$ & $\begin{array}{l}\text { Tons } \\
\text { per } \\
\text { day }\end{array}$ & & $\begin{array}{c}\text { Mean } \\
\text { concen- } \\
\text { tration } \\
\text { (ppm) }\end{array}$ & $\begin{array}{l}\text { Ton: } \\
\text { per } \\
\text { day }\end{array}$ & & $\begin{array}{c}\text { Mean } \\
\text { concen- } \\
\text { tration } \\
(\mathrm{ppm})\end{array}$ & $\begin{array}{l}\text { Ton: } \\
\text { per } \\
\text { day }\end{array}$ \\
\hline $\begin{array}{l}1 \ldots \\
2 \ldots \\
3 \ldots \\
4 \ldots \\
5 \ldots\end{array}$ & $\begin{array}{l}54 \\
58 \\
52 \\
45 \\
44\end{array}$ & $\begin{array}{l}55 \\
47 \\
28 \\
22 \\
26\end{array}$ & $\begin{array}{l}8.0 \\
7.4 \\
3.9 \\
2.7 \\
3.1\end{array}$ & $\begin{array}{r}44 \\
91 \\
430 \\
320 \\
189\end{array}$ & $\begin{array}{r}15 \\
21 \\
164 \\
102 \\
32\end{array}$ & $\begin{array}{l}1.8 \\
5.6 \\
190 \\
88 \\
16\end{array}$ & $\begin{array}{l}121 \\
115 \\
124 \\
121 \\
109\end{array}$ & $\begin{array}{r}9 \\
10 \\
20 \\
32 \\
31\end{array}$ & $\begin{array}{c}2.9 \\
3.1 \\
6.7 \\
10 \\
9.1\end{array}$ \\
\hline $\begin{array}{r}6 \ldots \\
7 \ldots \\
9 \ldots \\
10 \ldots\end{array}$ & $\begin{array}{l}46 \\
46 \\
46 \\
44 \\
57\end{array}$ & $\begin{array}{l}55 \\
61 \\
41 \\
30 \\
19\end{array}$ & $\begin{array}{l}6.8 \\
7.6 \\
5.1 \\
3.6 \\
2.9\end{array}$ & $\begin{array}{l}145 \\
129 \\
169 \\
210 \\
350\end{array}$ & $\begin{array}{l}18 \\
18 \\
21 \\
58 \\
80\end{array}$ & $\begin{array}{l}7.0 \\
6.3 \\
9.6 \\
33 \\
76\end{array}$ & $\begin{array}{l}129 \\
281 \\
521 \\
544 \\
916\end{array}$ & $\begin{array}{r}24 \\
17 \\
24 \\
62 \\
195\end{array}$ & $\begin{array}{l}8.4 \\
13 \\
34 \\
91 \\
526\end{array}$ \\
\hline $\begin{array}{l}11 \ldots \\
12 \ldots \\
13 \ldots \\
14 \ldots \\
15 \ldots\end{array}$ & $\begin{array}{l}52 \\
52 \\
45 \\
39 \\
37\end{array}$ & $\begin{array}{l}14 \\
18 \\
18 \\
19 \\
23\end{array}$ & $\begin{array}{l}2.0 \\
2.5 \\
2.2 \\
2.0 \\
2.3\end{array}$ & $\begin{array}{l}646 \\
539 \\
393 \\
272 \\
211\end{array}$ & $\begin{array}{r}178 \\
232 \\
108 \\
37 \\
19\end{array}$ & $\begin{array}{r}310 \\
338 \\
115 \\
27 \\
11\end{array}$ & $\begin{array}{r}1320 \\
1200 \\
1150 \\
1040 \\
832\end{array}$ & $\begin{array}{r}227 \\
207 \\
131 \\
107 \\
51\end{array}$ & $\begin{array}{l}809 \\
671 \\
407 \\
300 \\
115\end{array}$ \\
\hline $\begin{array}{l}16 \ldots \\
17 \ldots \\
18 \ldots \\
19 \ldots \\
20 \ldots\end{array}$ & $\begin{array}{l}69 \\
59 \\
46 \\
45 \\
44\end{array}$ & $\begin{array}{l}36 \\
26 \\
10 \\
11 \\
13\end{array}$ & $\begin{array}{l}6.7 \\
4.1 \\
1.2 \\
1.3 \\
1.5\end{array}$ & $\begin{array}{l}177 \\
159 \\
146 \\
133 \\
121\end{array}$ & $\begin{array}{l}12 \\
11 \\
26 \\
38 \\
37\end{array}$ & $\begin{array}{l}5.7 \\
4 \cdot 7 \\
10 \\
14 \\
12\end{array}$ & $\begin{array}{l}630 \\
497 \\
410 \\
351 \\
320\end{array}$ & $\begin{array}{l}37 \\
26 \\
26 \\
30 \\
21\end{array}$ & $\begin{array}{l}63 \\
35 \\
29 \\
28 \\
18\end{array}$ \\
\hline $\begin{array}{l}21 \ldots \\
22 \ldots \\
23 \ldots \\
24 \ldots \\
25 \ldots\end{array}$ & $\begin{array}{l}43 \\
43 \\
43 \\
40 \\
40\end{array}$ & $\begin{array}{l}23 \\
24 \\
15 \\
17 \\
16\end{array}$ & $\begin{array}{l}2.7 \\
2.8 \\
1.7 \\
1.8 \\
1.7\end{array}$ & $\begin{array}{l}117 \\
111 \\
107 \\
105 \\
102\end{array}$ & $\begin{array}{l}24 \\
12 \\
12 \\
19 \\
20\end{array}$ & $\begin{array}{l}7.6 \\
3.6 \\
3.5 \\
5.4 \\
5.5\end{array}$ & $\begin{array}{l}301 \\
277 \\
264 \\
243 \\
222\end{array}$ & $\begin{array}{r}15 \\
9 \\
8 \\
12 \\
11\end{array}$ & $\begin{array}{l}12 \\
6.7 \\
5.7 \\
7.9 \\
6.6\end{array}$ \\
\hline $\begin{array}{l}26 \ldots \\
27 \ldots \\
28 \ldots \\
29 \ldots \\
30 \ldots \\
32 \ldots\end{array}$ & $\begin{array}{l}43 \\
43 \\
41 \\
40 \\
39 \\
40\end{array}$ & $\begin{array}{l}11 \\
14 \\
20 \\
26 \\
23 \\
21\end{array}$ & $\begin{array}{l}1.3 \\
1.6 \\
2.2 \\
2.8 \\
2.4 \\
2.3\end{array}$ & $\begin{array}{r}106 \\
117 \\
129 \\
125 \\
125 \\
-\end{array}$ & $\begin{array}{l}24 \\
34 \\
45 \\
44 \\
20 \\
--\end{array}$ & $\begin{array}{c}6.9 \\
11 \\
16 \\
15 \\
6.8 \\
-\end{array}$ & $\begin{array}{l}205 \\
192 \\
182 \\
170 \\
160 \\
150\end{array}$ & $\begin{array}{r}10 \\
10 \\
11 \\
11 \\
8 \\
8\end{array}$ & $\begin{array}{l}5.5 \\
5.2 \\
5.4 \\
5.0 \\
3.5 \\
3.2\end{array}$ \\
\hline \multirow[t]{2}{*}{ Total } & 1435 & -- & 100.2 & 6018 & $\cdots$ & 1362.0 & 13097 & -- & 3245.9 \\
\hline & \multicolumn{3}{|c|}{ JANUARY } & \multicolumn{3}{|c|}{ FEBRUARY } & \multicolumn{3}{|c|}{ MARCH } \\
\hline $\begin{array}{l}1 \ldots \\
2 \ldots \\
3 \ldots \\
4 \ldots \\
5 \ldots\end{array}$ & $\begin{array}{l}140 \\
140 \\
130 \\
130 \\
120\end{array}$ & $\begin{array}{l}6 \\
5 \\
3 \\
5 \\
4\end{array}$ & $\begin{array}{l}2.3 \\
1.9 \\
1.1 \\
1.8 \\
1.3\end{array}$ & $\begin{array}{l}193 \\
384 \\
658 \\
572 \\
464\end{array}$ & $\begin{array}{r}10 \\
176 \\
239 \\
113 \\
33\end{array}$ & $\begin{array}{c}5.2 \\
256 \\
425 \\
175 \\
41\end{array}$ & $\begin{array}{l}190 \\
205 \\
311 \\
541 \\
794\end{array}$ & $\begin{array}{r}3 \\
4 \\
3 \\
21 \\
264\end{array}$ & $\begin{array}{r}1.5 \\
2.2 \\
2.5 \\
31 \\
446\end{array}$ \\
\hline $\begin{array}{r}6 \ldots . . \\
7 \ldots \\
8 \ldots \\
10 \ldots\end{array}$ & $\begin{array}{r}110 \\
110 \\
110 \\
100 \\
95\end{array}$ & $\begin{array}{l}3 \\
3 \\
4 \\
5 \\
6\end{array}$ & $\begin{array}{r}.9 \\
.9 \\
1.2 \\
1.4 \\
1.5\end{array}$ & $\begin{array}{l}339 \\
308 \\
280 \\
250 \\
240\end{array}$ & $\begin{array}{r}11 \\
10 \\
9 \\
12 \\
7\end{array}$ & $\begin{array}{l}10 \\
8.3 \\
6.8 \\
8.1 \\
4.5\end{array}$ & $\begin{array}{l}1870 \\
1830 \\
1460 \\
1260 \\
1200\end{array}$ & $\begin{array}{r}528 \\
220 \\
113 \\
47 \\
38\end{array}$ & $\begin{array}{r}2670 \\
1090 \\
445 \\
160 \\
123\end{array}$ \\
\hline $\begin{array}{l}11 \ldots \\
12 \ldots \\
13 \ldots \\
14 \ldots \\
15 \ldots\end{array}$ & $\begin{array}{l}95 \\
90 \\
90 \\
85 \\
80\end{array}$ & $\begin{array}{l}9 \\
6 \\
5 \\
5 \\
7\end{array}$ & $\begin{array}{l}2.3 \\
1.5 \\
1.2 \\
1.1 \\
1.5\end{array}$ & $\begin{array}{l}230 \\
219 \\
211 \\
215 \\
483\end{array}$ & $\begin{array}{r}6 \\
5 \\
6 \\
7 \\
35\end{array}$ & $\begin{array}{l}3.7 \\
3.0 \\
3.4 \\
4.1 \\
46\end{array}$ & $\begin{array}{l}1620 \\
1660 \\
1600 \\
1630 \\
1530\end{array}$ & $\begin{array}{r}302 \\
136 \\
108 \\
110 \\
75\end{array}$ & $\begin{array}{r}1320 \\
610 \\
467 \\
484 \\
310\end{array}$ \\
\hline $\begin{array}{l}16 \ldots \\
17 \ldots \\
18 \ldots \\
19 \ldots \\
20 \ldots\end{array}$ & $\begin{array}{l}80 \\
80 \\
80 \\
80 \\
75\end{array}$ & $\begin{array}{r}4 \\
5 \\
9 \\
10 \\
10\end{array}$ & $\begin{array}{l}.9 \\
1.1 \\
1.9 \\
2.2 \\
2.0\end{array}$ & $\begin{array}{l}705 \\
669 \\
610 \\
517 \\
434\end{array}$ & $\begin{array}{r}111 \\
121 \\
59 \\
28 \\
22\end{array}$ & $\begin{array}{r}211 \\
219 \\
97 \\
39 \\
26\end{array}$ & $\begin{array}{r}1320 \\
1180 \\
1000 \\
851 \\
799\end{array}$ & $\begin{array}{l}26 \\
44 \\
62 \\
53 \\
43\end{array}$ & $\begin{array}{r}93 \\
140 \\
167 \\
122 \\
93\end{array}$ \\
\hline $\begin{array}{l}22 \ldots \\
22 \ldots \\
23 \ldots \\
24 \ldots \\
25 \ldots\end{array}$ & $\begin{array}{l}75 \\
75 \\
75 \\
75 \\
75\end{array}$ & $\begin{array}{r}6 \\
4 \\
5 \\
8 \\
11\end{array}$ & $\begin{array}{l}1.2 \\
.8 \\
1.0 \\
1.6 \\
2.2\end{array}$ & $\begin{array}{l}393 \\
319 \\
302 \\
267 \\
230\end{array}$ & $\begin{array}{r}13 \\
6 \\
7 \\
17 \\
10\end{array}$ & $\begin{array}{c}14 \\
5.2 \\
5.7 \\
12 \\
6.2\end{array}$ & $\begin{array}{l}1290 \\
1610 \\
1510 \\
1500 \\
1440\end{array}$ & $\begin{array}{r}418 \\
133 \\
67 \\
70 \\
56\end{array}$ & $\begin{array}{r}1460 \\
578 \\
273 \\
284 \\
218\end{array}$ \\
\hline $\begin{array}{l}26 \ldots \\
27 \ldots \\
28 \ldots \\
29 \ldots \\
30 \ldots \\
31 \ldots\end{array}$ & $\begin{array}{l}100 \\
150 \\
272 \\
235 \\
178 \\
158\end{array}$ & $\begin{array}{l}13 \\
14 \\
16 \\
14 \\
12 \\
10\end{array}$ & $\begin{array}{r}3.5 \\
5.7 \\
12 \\
8.9 \\
5.8 \\
4.3\end{array}$ & $\begin{array}{r}200 \\
190 \\
200 \\
- \\
-\end{array}$ & $\begin{array}{r}3 \\
5 \\
4 \\
-- \\
-- \\
--\end{array}$ & $\begin{array}{r}1.6 \\
2.6 \\
2.2 \\
= \\
=-\end{array}$ & $\begin{array}{l}1330 \\
1160 \\
1210 \\
1580 \\
1460 \\
1390\end{array}$ & $\begin{array}{r}63 \\
73 \\
286 \\
134 \\
95 \\
95\end{array}$ & $\begin{array}{l}226 \\
229 \\
934 \\
572 \\
374 \\
357\end{array}$ \\
\hline Total & 3488 & -- & 77.0 & 10082 & -- & 1641.6 & 38331 & -- & $24282 \cdot 2$ \\
\hline
\end{tabular}


WakingU RIVER BAgIK--Continued

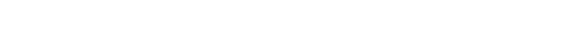

Sespended sedilont, weter year October 1966 to September 1967--Continued

\begin{tabular}{|c|c|c|c|c|c|c|c|c|c|}
\hline \multirow[b]{3}{*}{ Day } & \multicolumn{3}{|c|}{ APRIL } & \multicolumn{3}{|c|}{ MAY } & \multicolumn{3}{|c|}{ JUME } \\
\hline & \multirow[b]{2}{*}{$\begin{array}{c}\text { Mean } \\
\text { dis- } \\
\text { charge } \\
\text { (cfs) }\end{array}$} & \multicolumn{2}{|c|}{ Smepended odiment } & \multirow[b]{2}{*}{$\begin{array}{l}\text { Mean } \\
\text { dis- } \\
\text { charge } \\
\text { (cfs) }\end{array}$} & \multicolumn{2}{|c|}{ Suspended sediment } & \multirow[b]{2}{*}{$\begin{array}{l}\text { Mean } \\
\text { dis- } \\
\text { charge } \\
\text { (cfs) }\end{array}$} & \multicolumn{2}{|c|}{ Suspended secliment } \\
\hline & & $\begin{array}{c}\text { Mean } \\
\text { comeen- } \\
\text { tration } \\
(\mathrm{pmm})\end{array}$ & $\begin{array}{l}\text { Tons } \\
\text { per } \\
\text { day }\end{array}$ & & $\begin{array}{c}\text { Mean } \\
\text { concen- } \\
\text { tration } \\
\text { (ppm) }\end{array}$ & $\begin{array}{l}\text { Tons } \\
\text { per } \\
\text { day }\end{array}$ & & $\begin{array}{l}\text { Mean } \\
\text { concen- } \\
\text { tration } \\
(\text { ppm })\end{array}$ & $\begin{array}{l}\text { Tons } \\
\text { per } \\
\text { day }\end{array}$ \\
\hline $\begin{array}{l}1 \ldots \\
2 \ldots \\
3 \ldots \\
4 \ldots \\
5 \ldots\end{array}$ & $\begin{array}{r}1300 \\
1140 \\
950 \\
754 \\
679\end{array}$ & $\begin{array}{r}67 \\
72 \\
64 \\
94 \\
122\end{array}$ & $\begin{array}{l}235 \\
222 \\
164 \\
191 \\
224\end{array}$ & $\begin{array}{l}428 \\
472 \\
616 \\
595 \\
513\end{array}$ & $\begin{array}{r}90 \\
344 \\
125 \\
140 \\
125\end{array}$ & $\begin{array}{l}104 \\
184 \\
208 \\
225 \\
173\end{array}$ & $\begin{array}{l}281 \\
255 \\
216 \\
200 \\
189\end{array}$ & $\begin{array}{r}118 \\
76 \\
68 \\
69 \\
73\end{array}$ & $\begin{array}{l}90 \\
52 \\
40 \\
37 \\
37\end{array}$ \\
\hline $\begin{array}{r}6 \ldots \\
7 \ldots \\
9 \ldots \\
10 \ldots\end{array}$ & $\begin{array}{l}645 \\
631 \\
661 \\
691 \\
697\end{array}$ & $\begin{array}{l}115 \\
109 \\
178 \\
159 \\
123\end{array}$ & $\begin{array}{l}200 \\
186 \\
318 \\
297 \\
231\end{array}$ & $\begin{array}{r}510 \\
726 \\
1000 \\
1180 \\
1250\end{array}$ & $\begin{array}{l}102 \\
223 \\
229 \\
155 \\
116\end{array}$ & $\begin{array}{l}140 \\
437 \\
618 \\
494 \\
392\end{array}$ & $\begin{array}{l}181 \\
173 \\
195 \\
171 \\
171\end{array}$ & $\begin{array}{l}71 \\
60 \\
55 \\
73 \\
56\end{array}$ & $\begin{array}{l}35 \\
28 \\
29 \\
34 \\
26\end{array}$ \\
\hline $\begin{array}{l}11 \ldots \\
12 \ldots \\
13 \ldots \\
14 \ldots \\
15 \ldots\end{array}$ & $\begin{array}{l}636 \\
551 \\
542 \\
639 \\
667\end{array}$ & $\begin{array}{l}68 \\
61 \\
77 \\
62 \\
52\end{array}$ & $\begin{array}{r}151 \\
121 \\
113 \\
107 \\
94\end{array}$ & $\begin{array}{l}1390 \\
1800 \\
1680 \\
1560 \\
1540\end{array}$ & $\begin{array}{l}360 \\
126 \\
145 \\
162 \\
161\end{array}$ & $\begin{array}{l}3350 \\
612 \\
658 \\
682 \\
669\end{array}$ & $\begin{array}{l}156 \\
144 \\
132 \\
126 \\
121\end{array}$ & $\begin{array}{l}77 \\
60 \\
46 \\
50 \\
46\end{array}$ & $\begin{array}{l}32 \\
23 \\
16 \\
17 \\
16\end{array}$ \\
\hline $\begin{array}{l}16 \ldots \\
17 \ldots \ldots \\
18 \ldots \\
19 \ldots \ldots \\
20 \ldots\end{array}$ & $\begin{array}{l}630 \\
628 \\
597 \\
499 \\
434\end{array}$ & $\begin{array}{r}90 \\
153 \\
198 \\
115 \\
60\end{array}$ & $\begin{array}{r}153 \\
259 \\
319 \\
155 \\
70\end{array}$ & $\begin{array}{r}1560 \\
1350 \\
1180 \\
990 \\
778\end{array}$ & $\begin{array}{r}147 \\
151 \\
80 \\
43 \\
45\end{array}$ & $\begin{array}{r}619 \\
550 \\
255 \\
115 \\
95\end{array}$ & $\begin{array}{l}120 \\
122 \\
124 \\
115 \\
115\end{array}$ & $\begin{array}{l}44 \\
35 \\
38 \\
45 \\
42\end{array}$ & $\begin{array}{l}14 \\
12 \\
13 \\
14 \\
13\end{array}$ \\
\hline $\begin{array}{l}21 \ldots \\
22 \ldots \\
23 \ldots \\
24 \ldots \\
25 \ldots\end{array}$ & $\begin{array}{l}417 \\
869 \\
964 \\
932 \\
877\end{array}$ & $\begin{array}{r}66 \\
327 \\
311 \\
134 \\
83\end{array}$ & $\begin{array}{r}74 \\
767 \\
609 \\
337 \\
197\end{array}$ & $\begin{array}{l}607 \\
504 \\
434 \\
388 \\
352\end{array}$ & $\begin{array}{l}60 \\
71 \\
72 \\
67 \\
64\end{array}$ & $\begin{array}{l}98 \\
97 \\
84 \\
70 \\
61\end{array}$ & $\begin{array}{l}113 \\
135 \\
136 \\
117 \\
103\end{array}$ & $\begin{array}{r}58 \\
92 \\
123 \\
128 \\
114\end{array}$ & $\begin{array}{l}18 \\
34 \\
45 \\
40 \\
32\end{array}$ \\
\hline $\begin{array}{l}26 \ldots \\
27 \ldots \\
28 \ldots \\
29 \ldots \\
30 \ldots \\
31 \ldots\end{array}$ & $\begin{array}{r}778 \\
723 \\
533 \\
535 \\
472 \\
--\end{array}$ & \begin{tabular}{l|}
80 \\
87 \\
84 \\
72 \\
82 \\
--
\end{tabular} & $\begin{array}{c}168 \\
170 \\
144 \\
104 \\
105 \\
--\end{array}$ & $\begin{array}{l}319 \\
297 \\
370 \\
435 \\
440 \\
332\end{array}$ & $\begin{array}{r}68 \\
79 \\
113 \\
168 \\
224 \\
183\end{array}$ & $\begin{array}{r}59 \\
63 \\
113 \\
197 \\
266 \\
164\end{array}$ & $\begin{array}{r}96 \\
91 \\
91 \\
104 \\
182 \\
-\end{array}$ & $\begin{array}{l}88 \\
67 \\
59 \\
55 \\
67 \\
--\end{array}$ & $\begin{array}{l}23 \\
16 \\
14 \\
15 \\
33 \\
--\end{array}$ \\
\hline \multirow[t]{2}{*}{ Total } & 21171 & -- & 6685 & 25596 & -- & 9852 & 4475 & -- & 646 \\
\hline & \multicolumn{3}{|c|}{ JULY } & \multicolumn{3}{|c|}{ AUGUST } & \multicolumn{3}{|c|}{ SEPTEMBER } \\
\hline $\begin{array}{l}1 \ldots \\
2 \ldots \\
3 \ldots \\
4 \ldots \\
5 \ldots\end{array}$ & $\begin{array}{r}119 \\
95 \\
93 \\
85 \\
88\end{array}$ & $\begin{array}{l}74 \\
72 \\
77 \\
85 \\
85\end{array}$ & $\begin{array}{l}24 \\
18 \\
19 \\
20 \\
20\end{array}$ & $\begin{array}{l}65 \\
59 \\
69 \\
96 \\
73\end{array}$ & $\begin{array}{r}85 \\
82 \\
123 \\
90 \\
113\end{array}$ & $\begin{array}{l}15 \\
13 \\
23 \\
23 \\
22\end{array}$ & $\begin{array}{l}73 \\
52 \\
47 \\
43 \\
42\end{array}$ & $\begin{array}{r}132 \\
142 \\
108 \\
80 \\
76\end{array}$ & $\begin{array}{r}26 \\
20 \\
14 \\
9.3 \\
8.6\end{array}$ \\
\hline $\begin{array}{r}6 \ldots \\
7 \ldots \\
8 \ldots \\
10 . .\end{array}$ & $\begin{array}{l}81 \\
75 \\
74 \\
72 \\
70\end{array}$ & $\begin{array}{l}71 \\
65 \\
76 \\
67 \\
53\end{array}$ & $\begin{array}{l}16 \\
13 \\
15 \\
13 \\
10\end{array}$ & $\begin{array}{l}60 \\
55 \\
55 \\
54 \\
58\end{array}$ & $\begin{array}{l}85 \\
75 \\
72 \\
67 \\
66\end{array}$ & $\begin{array}{l}14 \\
11 \\
11 \\
9.8 \\
10\end{array}$ & $\begin{array}{l}41 \\
40 \\
40 \\
44 \\
66\end{array}$ & $\begin{array}{l}74 \\
66 \\
55 \\
64 \\
74\end{array}$ & $\begin{array}{l}8.2 \\
7.1 \\
5.9 \\
7.6 \\
13\end{array}$ \\
\hline $\begin{array}{l}11 \ldots \\
12 \ldots \\
13 \ldots \\
14 \ldots \\
15 \ldots\end{array}$ & $\begin{array}{l}72 \\
73 \\
68 \\
65 \\
63\end{array}$ & $\begin{array}{l}62 \\
74 \\
77 \\
92 \\
62\end{array}$ & $\begin{array}{l}12 \\
15 \\
14 \\
16 \\
11\end{array}$ & $\begin{array}{l}56 \\
50 \\
48 \\
47 \\
47\end{array}$ & $\begin{array}{r}84 \\
113 \\
101 \\
50 \\
62\end{array}$ & $\begin{array}{l}13 \\
15 \\
13 \\
6.3 \\
7.9\end{array}$ & $\begin{array}{l}52 \\
46 \\
44 \\
42 \\
40\end{array}$ & $\begin{array}{l}53 \\
70 \\
84 \\
82 \\
63\end{array}$ & $\begin{array}{c}7.4 \\
8.7 \\
10 \\
9.3 \\
6.8\end{array}$ \\
\hline $\begin{array}{l}16 \ldots \\
17 \ldots \\
18 \ldots \\
19 \ldots \\
20 \ldots\end{array}$ & $\begin{array}{l}62 \\
62 \\
63 \\
78 \\
89\end{array}$ & $\begin{array}{l}72 \\
82 \\
65 \\
68 \\
72\end{array}$ & $\begin{array}{l}12 \\
14 \\
11 \\
14 \\
17\end{array}$ & $\begin{array}{l}46 \\
45 \\
44 \\
48 \\
60\end{array}$ & $\begin{array}{l}60 \\
60 \\
87 \\
97 \\
76\end{array}$ & $\begin{array}{l}7.5 \\
7.3 \\
10 \\
13 \\
12\end{array}$ & $\begin{array}{l}40 \\
40 \\
40 \\
41 \\
43\end{array}$ & $\begin{array}{l}50 \\
67 \\
67 \\
72 \\
87\end{array}$ & $\begin{array}{l}5.4 \\
7.2 \\
7.2 \\
8.0 \\
10\end{array}$ \\
\hline $\begin{array}{l}21 \ldots \\
22 \ldots \\
23 \ldots \\
24 \ldots \\
25 \ldots\end{array}$ & $\begin{array}{l}77 \\
66 \\
59 \\
58 \\
71\end{array}$ & \begin{tabular}{l|}
82 \\
78 \\
80 \\
80 \\
92
\end{tabular} & $\begin{array}{l}17 \\
14 \\
13 \\
13 \\
18\end{array}$ & $\begin{array}{l}56 \\
48 \\
47 \\
45 \\
44\end{array}$ & $\begin{array}{l}57 \\
63 \\
74 \\
73 \\
58\end{array}$ & $\begin{array}{l}8.6 \\
8.2 \\
9.4 \\
8.9 \\
6.9\end{array}$ & $\begin{array}{l}54 \\
62 \\
57 \\
50 \\
45\end{array}$ & $\begin{array}{r}103 \\
70 \\
55 \\
55 \\
57\end{array}$ & $\begin{array}{c}15 \\
12 \\
8.5 \\
7.4 \\
6.9\end{array}$ \\
\hline $\begin{array}{l}26 \ldots \\
27 \ldots \\
28 \ldots \\
29 \ldots \\
30 \ldots \\
31 \ldots\end{array}$ & $\begin{array}{r}69 \\
60 \\
108 \\
105 \\
71 \\
65\end{array}$ & $\begin{array}{r}111 \\
108 \\
160 \\
135 \\
93 \\
88\end{array}$ & $\begin{array}{l}21 \\
17 \\
47 \\
38 \\
18 \\
15\end{array}$ & $\begin{array}{l}74 \\
54 \\
47 \\
47 \\
47 \\
86\end{array}$ & $\begin{array}{l}276 \\
312 \\
206 \\
118 \\
103 \\
168\end{array}$ & $\begin{array}{l}70 \\
45 \\
26 \\
15 \\
13 \\
39\end{array}$ & $\begin{array}{r}43 \\
49 \\
181 \\
209 \\
121 \\
--\end{array}$ & $\begin{array}{r}55 \\
74 \\
198 \\
183 \\
143 \\
--\end{array}$ & $\begin{array}{r}6.4 \\
9.8 \\
106 \\
103 \\
47\end{array}$ \\
\hline Total & 2356 & -- & 535 & 1730 & -- & 506.8 & 1787 & -- & 521.7 \\
\hline
\end{tabular}




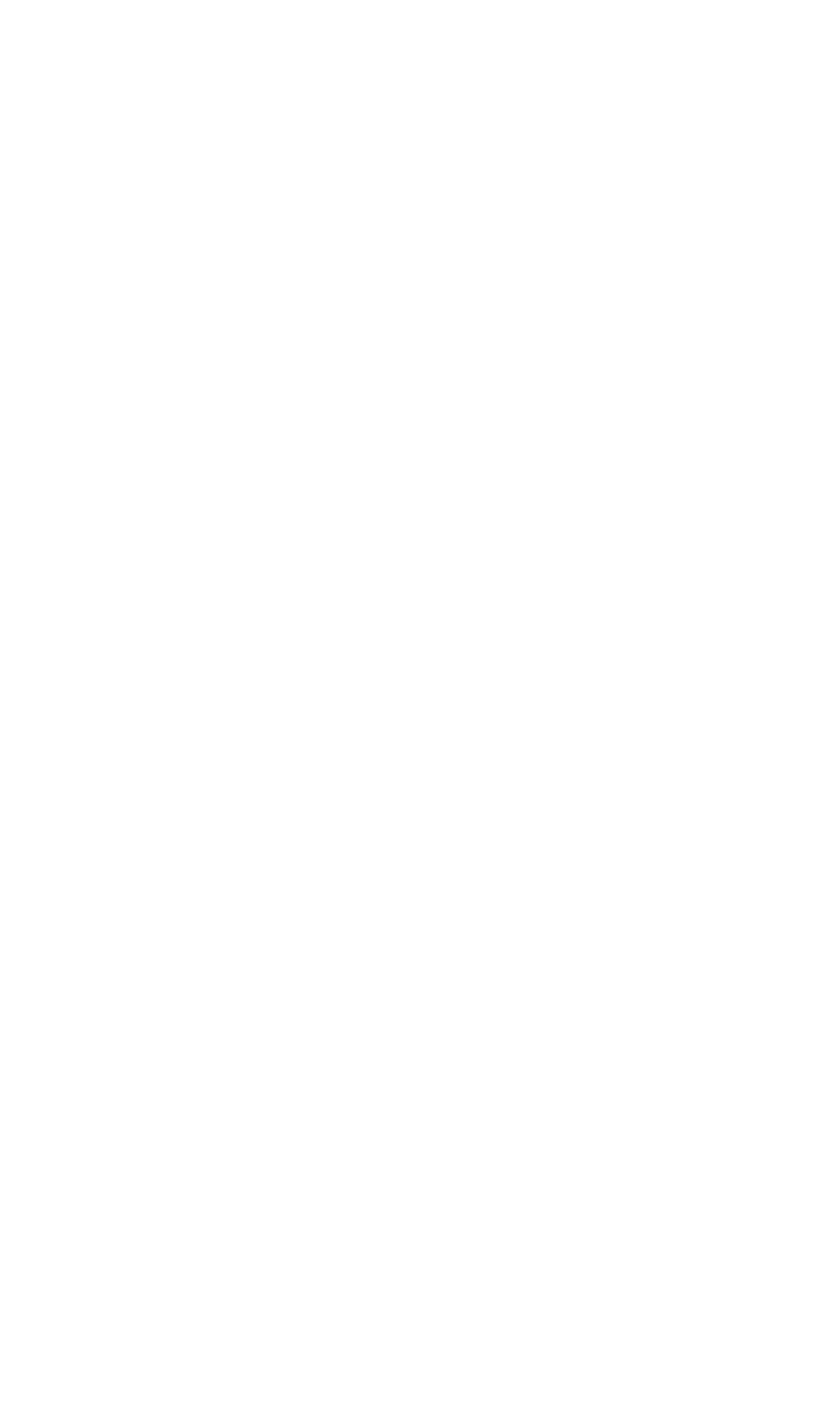



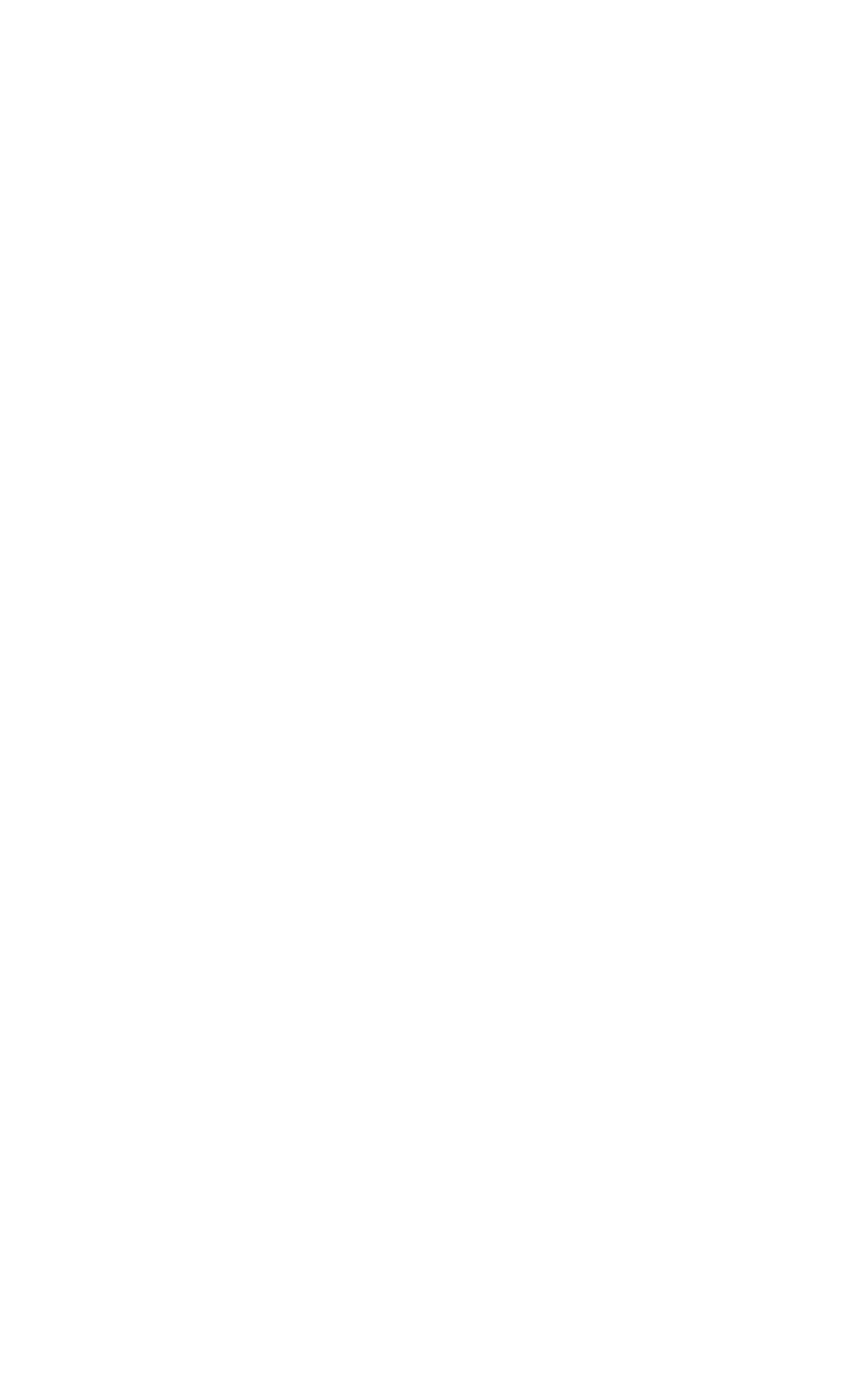
MUSKINGUY RIVER BASIN--COnt1nued

3-1445. MUSKINGUY RIVER AT DRESDEN, OHIO--COntinued

\begin{tabular}{|c|c|c|c|c|c|c|c|c|c|}
\hline \multirow[b]{3}{*}{ Day } & \multicolumn{3}{|c|}{ OCTOBER } & \multicolumn{3}{|c|}{ NOVEMBER } & \multicolumn{3}{|c|}{ DECEI \& SER } \\
\hline & \multirow[b]{2}{*}{$\begin{array}{l}\text { Mean } \\
\text { dis- } \\
\text { charge } \\
\text { (cfo) }\end{array}$} & \multicolumn{2}{|c|}{ Suspended sediment } & \multirow[b]{2}{*}{$\begin{array}{c}\text { Mean } \\
\text { dis- } \\
\text { charge } \\
\text { (cfs) }\end{array}$} & \multicolumn{2}{|c|}{ Suspended sediment } & \multirow[b]{2}{*}{$\begin{array}{l}\text { Mean } \\
\text { dis- } \\
\text { charge } \\
\text { (cfs) }\end{array}$} & \multicolumn{2}{|c|}{ Suspended sediment } \\
\hline & & $\begin{array}{c}\text { Mean } \\
\text { concen- } \\
\text { tration } \\
\text { (ppm) }\end{array}$ & $\begin{array}{l}\text { Tons } \\
\text { per } \\
\text { day }\end{array}$ & & $\begin{array}{c}\text { Mean } \\
\text { concen- } \\
\text { tration } \\
\text { (ppm) }\end{array}$ & $\begin{array}{c}\text { Tons } \\
\text { per } \\
\text { day }\end{array}$ & & $\begin{array}{c}\text { M } \cdot a n \\
\text { concen- } \\
\text { tration } \\
(\mathbf{p p m})\end{array}$ & $\begin{array}{l}\text { Tons } \\
\text { per } \\
\text { day }\end{array}$ \\
\hline $\begin{array}{l}1 \ldots \\
2 \ldots \\
3 \ldots \\
4 \ldots \\
5 \ldots\end{array}$ & $\begin{array}{l}750 \\
820 \\
955 \\
870 \\
740\end{array}$ & $\begin{array}{l}27 \\
22 \\
28 \\
23 \\
18\end{array}$ & $\begin{array}{l}55 \\
49 \\
72 \\
54 \\
36\end{array}$ & $\begin{array}{l}1050 \\
1230 \\
2310 \\
3840 \\
3540\end{array}$ & $\begin{array}{r}8 \\
15 \\
79 \\
126 \\
65\end{array}$ & $\begin{array}{r}23 \\
50 \\
493 \\
1310 \\
621\end{array}$ & $\begin{array}{l}1840 \\
1870 \\
1810 \\
1640 \\
1910\end{array}$ & $\begin{array}{r}9 \\
10 \\
13 \\
15 \\
19\end{array}$ & $\begin{array}{l}45 \\
50 \\
64 \\
66 \\
98\end{array}$ \\
\hline $\begin{array}{r}6 \ldots \\
7 \ldots \\
8 \ldots \\
9 \ldots \\
10 . .\end{array}$ & $\begin{array}{l}710 \\
691 \\
664 \\
646 \\
646\end{array}$ & $\begin{array}{l}16 \\
21 \\
14 \\
12 \\
10\end{array}$ & $\begin{array}{l}31 \\
39 \\
25 \\
21 \\
17\end{array}$ & $\begin{array}{l}2660 \\
2230 \\
2090 \\
2560 \\
3460\end{array}$ & $\begin{array}{l}37 \\
23 \\
26 \\
37 \\
61\end{array}$ & $\begin{array}{l}266 \\
138 \\
147 \\
256 \\
570\end{array}$ & $\begin{array}{r}2190 \\
2860 \\
6860 \\
10200 \\
12600\end{array}$ & $\begin{array}{r}22 \\
36 \\
117 \\
170 \\
200\end{array}$ & $\begin{array}{r}130 \\
278 \\
2170 \\
4680 \\
6800\end{array}$ \\
\hline $\begin{array}{l}11 \ldots \\
12 \ldots \\
13 \ldots \\
14 \ldots \\
15 \ldots\end{array}$ & $\begin{array}{l}655 \\
710 \\
710 \\
664 \\
655\end{array}$ & $\begin{array}{r}11 \\
9 \\
10 \\
12 \\
17\end{array}$ & $\begin{array}{l}19 \\
17 \\
19 \\
22 \\
30\end{array}$ & $\begin{array}{l}6480 \\
8330 \\
6900 \\
5100 \\
4170\end{array}$ & $\begin{array}{r}227 \\
228 \\
138 \\
72 \\
42\end{array}$ & $\begin{array}{r}4310 \\
5130 \\
2570 \\
991 \\
473\end{array}$ & $\begin{array}{l}17500 \\
18200 \\
18800 \\
16600 \\
12400\end{array}$ & $\begin{array}{r}309 \\
218 \\
145 \\
122 \\
70\end{array}$ & $\begin{array}{r}14600 \\
10700 \\
7360 \\
5470 \\
2340\end{array}$ \\
\hline $\begin{array}{l}16 \ldots \\
17 \ldots \\
18 \ldots \\
19 \ldots \\
20 \ldots\end{array}$ & $\begin{array}{l}664 \\
710 \\
810 \\
880 \\
977\end{array}$ & $\begin{array}{l}14 \\
12 \\
14 \\
18 \\
15\end{array}$ & $\begin{array}{l}25 \\
23 \\
31 \\
43 \\
40\end{array}$ & $\begin{array}{l}3780 \\
3450 \\
3100 \\
2700 \\
2550\end{array}$ & $\begin{array}{l}35 \\
30 \\
31 \\
30 \\
27\end{array}$ & $\begin{array}{l}357 \\
279 \\
259 \\
219 \\
186\end{array}$ & $\begin{array}{l}9410 \\
8010 \\
6770 \\
5540 \\
4640\end{array}$ & $\begin{array}{l}52 \\
39 \\
33 \\
32 \\
24\end{array}$ & $\begin{array}{r}1320 \\
843 \\
603 \\
479 \\
301\end{array}$ \\
\hline $\begin{array}{l}21 \ldots \\
22 \ldots \\
23 \ldots \\
24 \ldots \\
25 \ldots\end{array}$ & $\begin{array}{l}1020 \\
1090 \\
1090 \\
1080 \\
1050\end{array}$ & $\begin{array}{l}13 \\
15 \\
15 \\
13 \\
11\end{array}$ & $\begin{array}{l}36 \\
44 \\
44 \\
38 \\
31\end{array}$ & $\begin{array}{l}2410 \\
2230 \\
2120 \\
2020 \\
1920\end{array}$ & $\begin{array}{l}18 \\
15 \\
12 \\
13 \\
11\end{array}$ & $\begin{array}{r}117 \\
90 \\
69 \\
71 \\
57\end{array}$ & $\begin{array}{l}4230 \\
3850 \\
3560 \\
3310 \\
3010\end{array}$ & $\begin{array}{l}20 \\
17 \\
15 \\
11 \\
12\end{array}$ & $\begin{array}{r}228 \\
177 \\
144 \\
98 \\
98\end{array}$ \\
\hline $\begin{array}{l}26 \ldots \\
27 \ldots \\
28 \ldots \\
29 \ldots \\
30 \ldots \\
31 \ldots\end{array}$ & $\begin{array}{l}1040 \\
1040 \\
1040 \\
1030 \\
1020 \\
1020\end{array}$ & $\begin{array}{r}10 \\
12 \\
11 \\
8 \\
8 \\
6\end{array}$ & $\begin{array}{l}28 \\
34 \\
31 \\
22 \\
22 \\
17\end{array}$ & $\begin{array}{r}1760 \\
1670 \\
1720 \\
1870 \\
1850 \\
--\end{array}$ & $\begin{array}{l}17 \\
16 \\
16 \\
14 \\
11 \\
--\end{array}$ & $\begin{array}{l}81 \\
72 \\
74 \\
71 \\
55 \\
--\end{array}$ & $\begin{array}{l}2710 \\
2510 \\
2430 \\
2470 \\
2330 \\
2160\end{array}$ & $\begin{array}{l}11 \\
11 \\
10 \\
14 \\
12 \\
12\end{array}$ & $\begin{array}{l}80 \\
75 \\
66 \\
93 \\
75 \\
70\end{array}$ \\
\hline \multirow[t]{2}{*}{ Total } & 26447 & -- & 1015 & 91100 & -- & 19405 & 194220 & -1 & 59601 \\
\hline & \multicolumn{3}{|c|}{ JANUARY } & \multicolumn{3}{|c|}{ FEBRUARY } & \multicolumn{3}{|c|}{ MARCH } \\
\hline $\begin{array}{l}1 \ldots \\
2 \ldots \\
3 \ldots \\
4 \ldots \\
5 \ldots\end{array}$ & $\begin{array}{l}2310 \\
2160 \\
2050 \\
1980 \\
1890\end{array}$ & $\begin{array}{r}12 \\
9 \\
7 \\
7 \\
7\end{array}$ & $\begin{array}{l}75 \\
52 \\
39 \\
37 \\
36\end{array}$ & $\begin{array}{r}2980 \\
3780 \\
7690 \\
10900 \\
10400\end{array}$ & $\begin{array}{r}12 \\
30 \\
108 \\
160 \\
137\end{array}$ & $\begin{array}{r}97 \\
306 \\
2370 \\
4710 \\
3850\end{array}$ & $\begin{array}{r}2830 \\
2880 \\
3430 \\
5660 \\
11000\end{array}$ & $\begin{array}{r}7 \\
8 \\
15 \\
52 \\
158\end{array}$ & $\begin{array}{r}53 \\
62 \\
139 \\
866 \\
5160\end{array}$ \\
\hline $\begin{array}{r}6 \ldots \\
7 \ldots \\
8 \ldots \\
9 \ldots \\
10 . .\end{array}$ & $\begin{array}{l}1770 \\
1780 \\
1740 \\
1680 \\
1600\end{array}$ & $\begin{array}{r}11 \\
9 \\
9 \\
10 \\
8\end{array}$ & $\begin{array}{l}53 \\
43 \\
42 \\
45 \\
35\end{array}$ & $\begin{array}{l}8490 \\
6180 \\
4660 \\
4040 \\
3800\end{array}$ & $\begin{array}{l}76 \\
39 \\
27 \\
21 \\
22\end{array}$ & $\begin{array}{r}1740 \\
651 \\
340 \\
229 \\
226\end{array}$ & $\begin{array}{l}21000 \\
17600 \\
14500 \\
10800 \\
14400\end{array}$ & $\begin{array}{l}372 \\
278 \\
166 \\
133 \\
142\end{array}$ & $\begin{array}{r}21100 \\
13200 \\
6500 \\
3880 \\
5520\end{array}$ \\
\hline $\begin{array}{l}11 \ldots \\
12 \ldots \\
13 \ldots \\
14 \ldots \\
15 \ldots\end{array}$ & $\begin{array}{l}1550 \\
1490 \\
1560 \\
1550 \\
1480\end{array}$ & $\begin{array}{r}8 \\
7 \\
7 \\
10 \\
7\end{array}$ & $\begin{array}{l}33 \\
28 \\
29 \\
42 \\
28\end{array}$ & $\begin{array}{l}3960 \\
3450 \\
3160 \\
3280 \\
3510\end{array}$ & $\begin{array}{r}12 \\
8 \\
6 \\
6 \\
7\end{array}$ & $\begin{array}{r}128 \\
75 \\
51 \\
53 \\
66\end{array}$ & $\begin{array}{l}21600 \\
25100 \\
26100 \\
25900 \\
25600\end{array}$ & $\begin{array}{r}119 \\
117 \\
100 \\
90 \\
71\end{array}$ & $\begin{array}{l}6940 \\
7930 \\
7050 \\
6290 \\
4910\end{array}$ \\
\hline $\begin{array}{l}16 \ldots \\
17 \ldots \\
18 \ldots \\
19 . . \\
20 \ldots\end{array}$ & $\begin{array}{l}1470 \\
1540 \\
1290 \\
1050 \\
1090\end{array}$ & $\begin{array}{l}7 \\
9 \\
8 \\
8 \\
8\end{array}$ & $\begin{array}{l}28 \\
37 \\
28 \\
23 \\
24\end{array}$ & $\begin{array}{l}5810 \\
8850 \\
8490 \\
6980 \\
5840\end{array}$ & $\begin{array}{r}31 \\
112 \\
101 \\
56 \\
25\end{array}$ & $\begin{array}{r}522 \\
2680 \\
2320 \\
1060 \\
394\end{array}$ & $\begin{array}{l}25300 \\
24900 \\
24100 \\
23400 \\
22200\end{array}$ & $\begin{array}{l}54 \\
49 \\
43 \\
44 \\
52\end{array}$ & $\begin{array}{l}3690 \\
3290 \\
2800 \\
2780 \\
3120\end{array}$ \\
\hline $\begin{array}{l}21 \ldots \\
22 \ldots \\
23 \ldots \\
24 \ldots \\
25 \ldots\end{array}$ & $\begin{array}{l}1230 \\
1250 \\
1250 \\
1260 \\
1380\end{array}$ & $\begin{array}{l}8 \\
9 \\
7 \\
8 \\
8\end{array}$ & $\begin{array}{l}27 \\
30 \\
24 \\
27 \\
30\end{array}$ & $\begin{array}{l}5140 \\
5050 \\
4520 \\
3990 \\
3070\end{array}$ & $\begin{array}{l}16 \\
17 \\
14 \\
11 \\
11\end{array}$ & $\begin{array}{r}222 \\
232 \\
171 \\
119 \\
91\end{array}$ & $\begin{array}{l}21400 \\
24600 \\
25300 \\
24800 \\
23400\end{array}$ & $\begin{array}{r}110 \\
109 \\
67 \\
58 \\
52\end{array}$ & $\begin{array}{l}6360 \\
7240 \\
4580 \\
3880 \\
3290\end{array}$ \\
\hline $\begin{array}{l}26 \ldots \\
27 \ldots \\
28 \ldots \\
29 \ldots \\
30 \ldots \\
31 \ldots\end{array}$ & $\begin{array}{l}1470 \\
1710 \\
2550 \\
3830 \\
3880 \\
3280\end{array}$ & $\begin{array}{l}12 \\
18 \\
25 \\
42 \\
28 \\
13\end{array}$ & $\begin{array}{r}48 \\
83 \\
172 \\
434 \\
293 \\
115\end{array}$ & $\begin{array}{r}2570 \\
2830 \\
2900 \\
=- \\
=\end{array}$ & $\begin{array}{r}12 \\
9 \\
12 \\
-- \\
--\end{array}$ & $\begin{array}{l}83 \\
69 \\
94 \\
=- \\
=-\end{array}$ & $\begin{array}{l}21800 \\
17900 \\
15500 \\
20100 \\
22800 \\
21600\end{array}$ & $\begin{array}{r}46 \\
46 \\
60 \\
161 \\
113 \\
78\end{array}$ & $\begin{array}{l}2710 \\
2220 \\
2510 \\
8740 \\
6960 \\
4550\end{array}$ \\
\hline Total & 56120 & -- & 2040 & 146320 & -- & 22949 & 587500 & -- & 158320 \\
\hline
\end{tabular}


MUSKINGUM RIVER BASIN--Continued

3-1445. WUSKINGUY RIVER AT DRESDEN, OHIO--Continued

Suspended sediment, water year October 1966 to September 1967--Continued

\begin{tabular}{|c|c|c|c|c|c|c|c|c|c|}
\hline \multirow[b]{3}{*}{ Day } & \multicolumn{3}{|c|}{ APRIL } & \multicolumn{3}{|c|}{ MAY } & \multicolumn{3}{|c|}{ JUNE } \\
\hline & \multirow[b]{2}{*}{$\begin{array}{c}\text { Mean } \\
\text { dis- } \\
\text { charge } \\
\text { (cfs) }\end{array}$} & \multicolumn{2}{|c|}{ Suspended sediment } & \multirow[b]{2}{*}{$\begin{array}{c}\text { Mean } \\
\text { dis- } \\
\text { charge } \\
\text { (cfs) }\end{array}$} & \multicolumn{2}{|c|}{ Suspended sediment } & \multirow[b]{2}{*}{$\begin{array}{l}\text { Mean } \\
\text { dis- } \\
\text { charge } \\
\text { (cfs) }\end{array}$} & \multicolumn{2}{|c|}{ Suspended sedimert } \\
\hline & & $\begin{array}{l}\text { Mean } \\
\text { concen- } \\
\text { tration } \\
(\text { ppm) }\end{array}$ & $\begin{array}{l}\text { Tons } \\
\text { per } \\
\text { day }\end{array}$ & & $\begin{array}{c}\text { Mean } \\
\text { concen- } \\
\text { tration } \\
(\mathbf{p p m})\end{array}$ & $\begin{array}{l}\text { Tons } \\
\text { per } \\
\text { day }\end{array}$ & & $\begin{array}{c}\text { Mean } \\
\text { concen- } \\
\text { tration } \\
\text { (ppm) }\end{array}$ & $\begin{array}{l}\text { Tons } \\
\text { per } \\
\text { day }\end{array}$ \\
\hline $\begin{array}{l}1 \ldots \\
2 \ldots \\
3 \ldots \\
4 \ldots \\
5 \ldots\end{array}$ & $\begin{array}{l}16000 \\
13400 \\
11300 \\
14300 \\
14300\end{array}$ & $\begin{array}{l}70 \\
69 \\
63 \\
64 \\
51\end{array}$ & $\begin{array}{l}3020 \\
2500 \\
1920 \\
2470 \\
1970\end{array}$ & $\begin{array}{r}7450 \\
6820 \\
8450 \\
10500 \\
10400\end{array}$ & $\begin{array}{l}41 \\
41 \\
53 \\
88 \\
87\end{array}$ & $\begin{array}{r}825 \\
755 \\
1210 \\
2490 \\
2440\end{array}$ & $\begin{array}{l}5730 \\
4930 \\
4490 \\
4150 \\
3850\end{array}$ & $\begin{array}{l}39 \\
34 \\
27 \\
22 \\
16\end{array}$ & $\begin{array}{l}603 \\
453 \\
327 \\
247 \\
166\end{array}$ \\
\hline $\begin{array}{r}6 \ldots \\
7 \ldots \\
8 \ldots \\
10 \ldots\end{array}$ & $\begin{array}{l}12700 \\
11100 \\
11300 \\
11800 \\
10800\end{array}$ & $\begin{array}{r}49 \\
74 \\
87 \\
114 \\
81\end{array}$ & $\begin{array}{l}1680 \\
2220 \\
2650 \\
3630 \\
2360\end{array}$ & $\begin{array}{r}9450 \\
9890 \\
15100 \\
18800 \\
19700\end{array}$ & $\begin{array}{r}78 \\
74 \\
163 \\
149 \\
130\end{array}$ & $\begin{array}{l}1990 \\
1980 \\
6650 \\
7560 \\
6910\end{array}$ & $\begin{array}{l}3500 \\
3180 \\
2980 \\
2890 \\
2750\end{array}$ & $\begin{array}{l}22 \\
23 \\
25 \\
21 \\
28\end{array}$ & $\begin{array}{l}207 \\
197 \\
201 \\
164 \\
20^{\circ}\end{array}$ \\
\hline $\begin{array}{l}11 \ldots \\
12 \ldots \\
13 \ldots \\
14 \ldots \\
15 \ldots\end{array}$ & $\begin{array}{r}10200 \\
9710 \\
9350 \\
10900 \\
12400\end{array}$ & $\begin{array}{l}68 \\
59 \\
50 \\
71 \\
74\end{array}$ & $\begin{array}{l}1870 \\
1550 \\
1260 \\
2090 \\
2480\end{array}$ & $\begin{array}{l}20000 \\
20800 \\
20600 \\
20900 \\
21500\end{array}$ & $\begin{array}{r}118 \\
137 \\
86 \\
86 \\
69\end{array}$ & $\begin{array}{l}6370 \\
7690 \\
4780 \\
4850 \\
4010\end{array}$ & $\begin{array}{l}2580 \\
2400 \\
2270 \\
2130 \\
2020\end{array}$ & $\begin{array}{l}32 \\
25 \\
28 \\
28 \\
29\end{array}$ & $\begin{array}{l}223 \\
16 ? \\
172 \\
161 \\
159\end{array}$ \\
\hline $\begin{array}{l}16 \ldots \\
17 \ldots \\
18 \ldots \\
19 \ldots \\
20 \ldots\end{array}$ & $\begin{array}{r}11700 \\
10400 \\
10500 \\
10400 \\
9310\end{array}$ & $\begin{array}{l}69 \\
72 \\
98 \\
83 \\
75\end{array}$ & $\begin{array}{l}2180 \\
2020 \\
2780 \\
2330 \\
1890\end{array}$ & $\begin{array}{l}22200 \\
23000 \\
22800 \\
22100 \\
20900\end{array}$ & $\begin{array}{l}75 \\
58 \\
53 \\
52 \\
53\end{array}$ & $\begin{array}{l}4500 \\
3600 \\
3260 \\
3100 \\
2990\end{array}$ & $\begin{array}{l}1940 \\
1890 \\
1840 \\
1780 \\
1730\end{array}$ & $\begin{array}{l}27 \\
23 \\
24 \\
22 \\
26\end{array}$ & $\begin{array}{l}141 \\
117 \\
119 \\
168 \\
121\end{array}$ \\
\hline $\begin{array}{l}21 \ldots \\
22 \ldots \\
23 \ldots \\
24 \ldots \\
25 \ldots\end{array}$ & $\begin{array}{r}8310 \\
9030 \\
13800 \\
15400 \\
14900\end{array}$ & $\begin{array}{r}73 \\
98 \\
166 \\
165 \\
115\end{array}$ & $\begin{array}{l}1640 \\
2390 \\
6190 \\
6860 \\
4630\end{array}$ & $\begin{array}{r}18400 \\
14700 \\
11100 \\
9410 \\
8390\end{array}$ & $\begin{array}{l}47 \\
52 \\
48 \\
49 \\
43\end{array}$ & $\begin{array}{r}2330 \\
2060 \\
1440 \\
1240 \\
974\end{array}$ & $\begin{array}{l}1650 \\
1620 \\
1730 \\
1800 \\
1650\end{array}$ & $\begin{array}{l}23 \\
26 \\
29 \\
31 \\
30\end{array}$ & $\begin{array}{l}102 \\
114 \\
135 \\
151 \\
134\end{array}$ \\
\hline $\begin{array}{l}26 \ldots \\
27 \ldots \\
28 \ldots \\
29 \ldots \\
30 \ldots \\
31 \ldots\end{array}$ & $\begin{array}{r}13400 \\
11800 \\
10500 \\
9130 \\
8010 \\
-\end{array}$ & $\begin{array}{l}90 \\
62 \\
58 \\
52 \\
52 \\
--\end{array}$ & $\begin{array}{r}3260 \\
1980 \\
1640 \\
1280 \\
1120 \\
\end{array}$ & $\begin{array}{l}7570 \\
6620 \\
6030 \\
6060 \\
7050 \\
6770\end{array}$ & $\begin{array}{l}43 \\
36 \\
35 \\
43 \\
67 \\
52\end{array}$ & $\begin{array}{r}879 \\
643 \\
570 \\
704 \\
1280 \\
951\end{array}$ & $\begin{array}{r}1530 \\
1440 \\
1430 \\
1490 \\
1530 \\
=-\end{array}$ & $\begin{array}{l}28 \\
30 \\
32 \\
36 \\
35 \\
--\end{array}$ & $\begin{array}{l}116 \\
117 \\
124 \\
145 \\
145 \\
--\end{array}$ \\
\hline \multirow[t]{2}{*}{ Total } & 346150 & -- & 75860 & 433460 & - & 91031 & 74900 & -- & 5537 \\
\hline & \multicolumn{3}{|c|}{ JULY } & \multicolumn{3}{|c|}{ AUGUST } & \multicolumn{3}{|c|}{ SEPTEMBER } \\
\hline $\begin{array}{l}1 \ldots \\
2 \ldots \\
3 \ldots \\
4 \ldots \\
5 \ldots\end{array}$ & $\begin{array}{l}1550 \\
2200 \\
2960 \\
2400 \\
2230\end{array}$ & $\begin{array}{r}28 \\
690 \\
184 \\
60 \\
48\end{array}$ & $\begin{array}{r}117 \\
5380 \\
1470 \\
389 \\
289\end{array}$ & $\begin{array}{l}2260 \\
1810 \\
1840 \\
2800 \\
2700\end{array}$ & $\begin{array}{l}55 \\
43 \\
45 \\
84 \\
56\end{array}$ & $\begin{array}{l}336 \\
210 \\
224 \\
635 \\
408\end{array}$ & $\begin{array}{r}1070 \\
1240 \\
1080 \\
960 \\
872\end{array}$ & $\begin{array}{l}26 \\
32 \\
32 \\
34 \\
35\end{array}$ & $\begin{array}{r}75 \\
107 \\
93 \\
88 \\
82\end{array}$ \\
\hline $\begin{array}{c}6 \ldots \\
7 \ldots \\
8 \ldots \\
9 \ldots\end{array}$ & $\begin{array}{l}1920 \\
1690 \\
1530 \\
1430 \\
1350\end{array}$ & $\begin{array}{l}33 \\
27 \\
24 \\
23 \\
23\end{array}$ & $\begin{array}{r}171 \\
123 \\
99 \\
89 \\
84\end{array}$ & $\begin{array}{l}2630 \\
2260 \\
1810 \\
1540 \\
1380\end{array}$ & $\begin{array}{l}48 \\
42 \\
39 \\
31 \\
29\end{array}$ & $\begin{array}{l}341 \\
256 \\
191 \\
129 \\
108\end{array}$ & $\begin{array}{r}818 \\
776 \\
756 \\
756 \\
1000\end{array}$ & $\begin{array}{l}40 \\
26 \\
22 \\
17 \\
20\end{array}$ & $\begin{array}{l}88 \\
54 \\
45 \\
35 \\
54\end{array}$ \\
\hline $\begin{array}{l}11 \ldots \\
12 \ldots \\
13 \ldots \\
14 \ldots \\
15 \ldots\end{array}$ & $\begin{array}{l}1410 \\
1370 \\
1330 \\
1350 \\
1290\end{array}$ & $\begin{array}{l}23 \\
18 \\
22 \\
23 \\
21\end{array}$ & $\begin{array}{l}88 \\
67 \\
79 \\
84 \\
73\end{array}$ & $\begin{array}{l}1290 \\
1250 \\
1150 \\
1080 \\
1020\end{array}$ & $\begin{array}{l}19 \\
17 \\
19 \\
16 \\
15\end{array}$ & $\begin{array}{l}66 \\
57 \\
59 \\
47 \\
41\end{array}$ & $\begin{array}{r}1040 \\
1020 \\
872 \\
818 \\
766\end{array}$ & $\begin{array}{l}20 \\
20 \\
20 \\
22 \\
19\end{array}$ & $\begin{array}{l}56 \\
55 \\
47 \\
49 \\
39\end{array}$ \\
\hline $\begin{array}{l}16 \ldots \\
17 \ldots \\
18 \ldots \\
19 \ldots \\
20 \ldots\end{array}$ & $\begin{array}{l}1210 \\
1180 \\
1130 \\
1180 \\
1300\end{array}$ & $\begin{array}{l}26 \\
23 \\
22 \\
26 \\
27\end{array}$ & $\begin{array}{l}85 \\
73 \\
67 \\
83 \\
95\end{array}$ & $\begin{array}{r}960 \\
927 \\
905 \\
894 \\
1020\end{array}$ & $\begin{array}{l}18 \\
18 \\
14 \\
14 \\
18\end{array}$ & $\begin{array}{l}47 \\
45 \\
34 \\
34 \\
50\end{array}$ & $\begin{array}{l}725 \\
705 \\
695 \\
695 \\
675\end{array}$ & $\begin{array}{l}21 \\
21 \\
18 \\
17 \\
26\end{array}$ & $\begin{array}{l}41 \\
40 \\
34 \\
32 \\
29\end{array}$ \\
\hline $\begin{array}{l}21 \ldots \\
22 \ldots \\
23 \ldots \\
24 \ldots \\
25 \ldots\end{array}$ & $\begin{array}{l}1470 \\
1450 \\
1310 \\
1200 \\
1240\end{array}$ & $\begin{array}{l}35 \\
40 \\
37 \\
23 \\
26\end{array}$ & $\begin{array}{r}139 \\
157 \\
131 \\
75 \\
87\end{array}$ & $\begin{array}{r}1180 \\
1120 \\
1030 \\
960 \\
905\end{array}$ & $\begin{array}{l}17 \\
21 \\
16 \\
14 \\
12\end{array}$ & $\begin{array}{l}54 \\
64 \\
44 \\
36 \\
29\end{array}$ & $\begin{array}{l}715 \\
808 \\
949 \\
927 \\
850\end{array}$ & $\begin{array}{l}17 \\
18 \\
21 \\
19 \\
20\end{array}$ & $\begin{array}{l}33 \\
39 \\
54 \\
48 \\
46\end{array}$ \\
\hline $\begin{array}{l}26 \ldots \\
27 \ldots \\
28 \ldots \\
29 \ldots \\
30 \ldots \\
31 \ldots\end{array}$ & $\begin{array}{l}1200 \\
1260 \\
2300 \\
3340 \\
3180 \\
2740\end{array}$ & $\begin{array}{l}27 \\
27 \\
44 \\
63 \\
62 \\
55\end{array}$ & $\begin{array}{r}87 \\
92 \\
273 \\
568 \\
532 \\
407\end{array}$ & $\begin{array}{r}949 \\
1360 \\
1250 \\
1080 \\
1000 \\
1000\end{array}$ & $\begin{array}{l}11 \\
31 \\
20 \\
16 \\
17 \\
22\end{array}$ & $\begin{array}{r}28 \\
114 \\
68 \\
47 \\
46 \\
59\end{array}$ & $\begin{array}{r}787 \\
745 \\
1270 \\
2400 \\
2840 \\
--\end{array}$ & $\begin{array}{l}21 \\
20 \\
28 \\
64 \\
49 \\
--\end{array}$ & $\begin{array}{r}45 \\
40 \\
96 \\
415 \\
376 \\
--\end{array}$ \\
\hline Total & 52700 & - & 11553 & 43360 & -- & 3907 & 29630 & $-\infty$ & 2335 \\
\hline
\end{tabular}

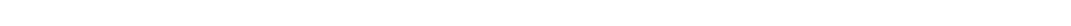

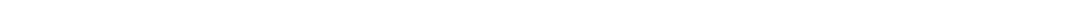




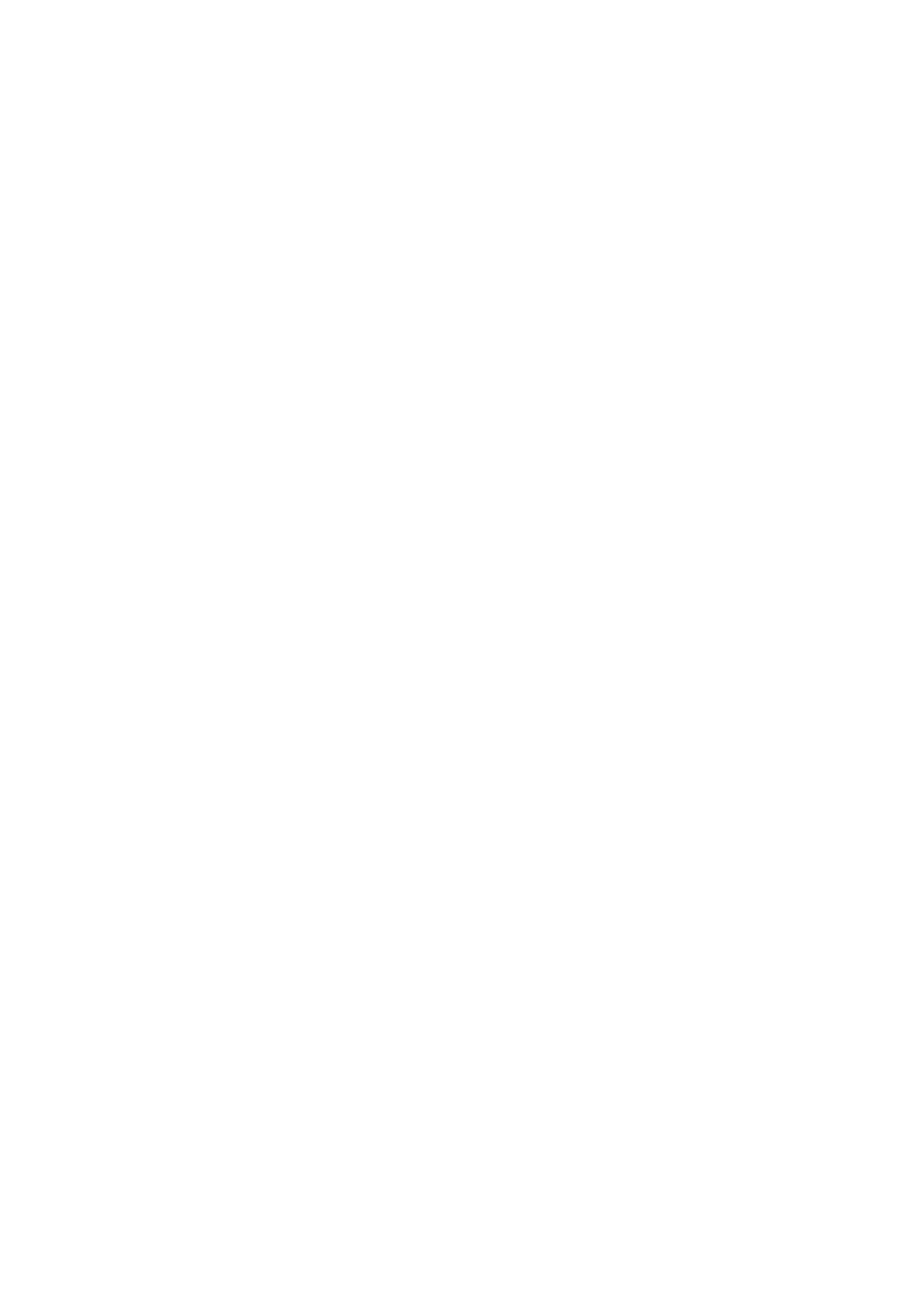




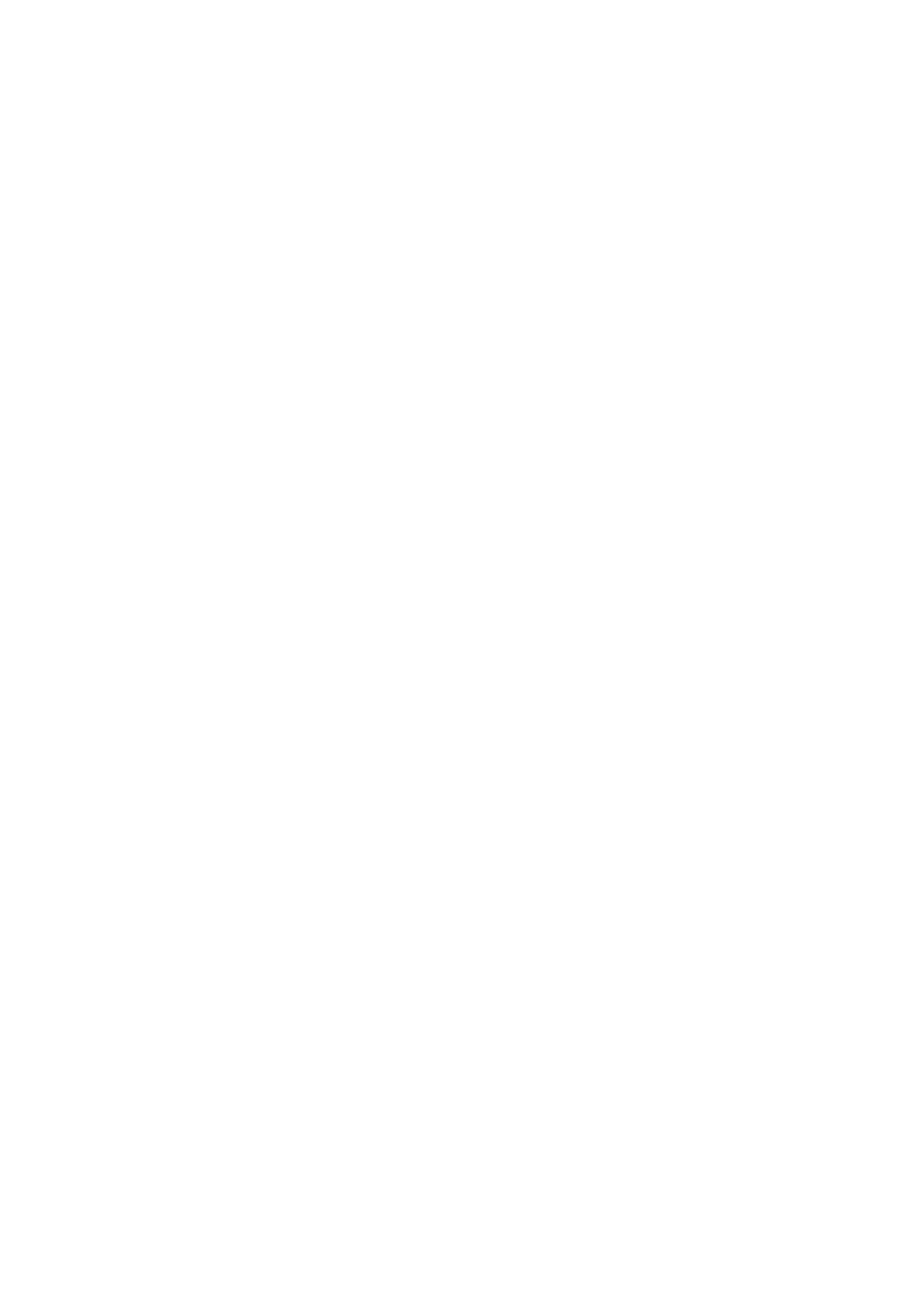




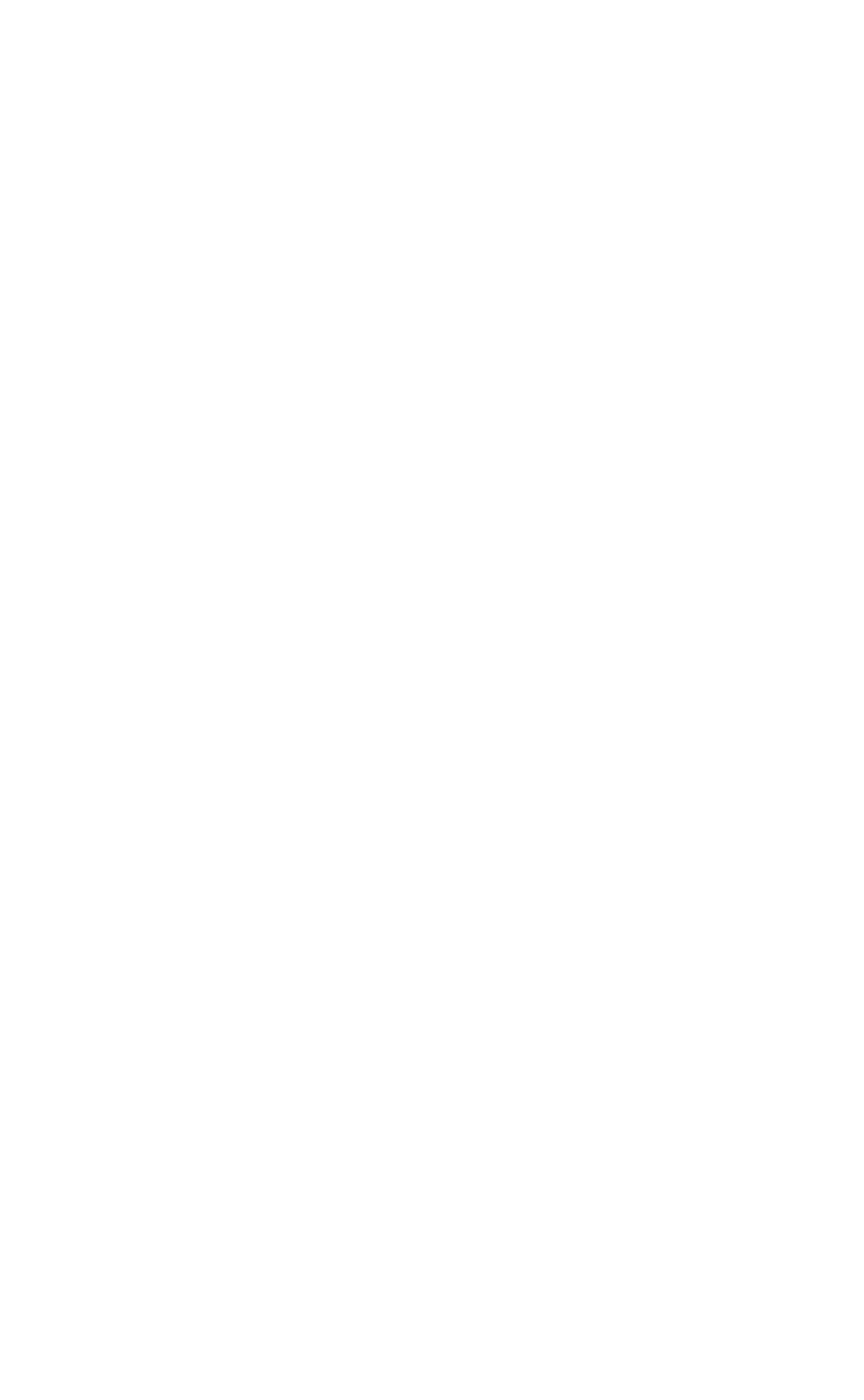


MUSKINGUH RIVER BASIN--COntinued

3-1492. MUSKINGUY RIVER AT PHILO, OHIO--Continued

Data from continuous recorder, water year October 1966 to September 1967

\begin{tabular}{|c|c|c|c|c|c|c|c|c|c|c|c|c|c|c|c|c|}
\hline \multirow{3}{*}{ Day } & \multicolumn{8}{|c|}{ OCTOBER } & \multicolumn{8}{|c|}{ MOVEMBER } \\
\hline & \multicolumn{2}{|c|}{$\begin{array}{c}\text { Specific } \\
\text { conductance } \\
\text { (micromhos } \\
\text { at } 25^{\circ} \mathrm{C} \text { ) }\end{array}$} & \multicolumn{2}{|c|}{$\mathrm{pH}$} & \multicolumn{2}{|c|}{$\begin{array}{c}\text { Dissolved } \\
\text { oxygen } \\
\text { (ppm) }\end{array}$} & \multicolumn{2}{|c|}{$\begin{array}{l}\text { Temper- } \\
\text { ature } \\
\left({ }^{\circ} \mathrm{F}\right)\end{array}$} & \multicolumn{2}{|c|}{$\begin{array}{c}\text { Specific } \\
\text { conductance } \\
\text { (micromhos } \\
\text { at } 25^{\circ} \mathrm{C} \text { ) }\end{array}$} & \multicolumn{2}{|c|}{ pH } & \multicolumn{2}{|c|}{$\begin{array}{l}\text { Dissolved } \\
\text { oxygen } \\
\text { (ppm) }\end{array}$} & \multicolumn{2}{|c|}{$\begin{array}{c}\text { Temper- } \\
\text { ature } \\
\left({ }^{\circ} \mathbf{F}\right)\end{array}$} \\
\hline & Max & Min & $\operatorname{Max}$ & Min & $\operatorname{Max}$ & Min & Max & Min & $\operatorname{Max}$ & Min & $\operatorname{Max}$ & Min & Max & Min & Max & Min \\
\hline $\begin{array}{l}1 \ldots \\
2 \ldots \\
3 \ldots \\
4 \ldots \\
5 \ldots\end{array}$ & $\begin{array}{l}1750 \\
1650 \\
1580 \\
1660 \\
1720\end{array}$ & $\begin{array}{l}1650 \\
1560 \\
1500 \\
1500 \\
1640\end{array}$ & $\begin{array}{l}7.4 \\
7.2 \\
7.2 \\
7.5 \\
7.7\end{array}$ & $\begin{array}{l}7.2 \\
6.9 \\
7.0 \\
7.1 \\
7.3\end{array}$ & $\begin{array}{r}8.0 \\
9.1 \\
9.9 \\
9.8 \\
10.1\end{array}$ & $\begin{array}{l}7.2 \\
7.5 \\
8.5 \\
8.5 \\
8.8\end{array}$ & $\begin{array}{l}61 \\
61 \\
61 \\
61 \\
60\end{array}$ & $\begin{array}{l}60 \\
59 \\
58 \\
59 \\
59\end{array}$ & $\begin{array}{l}1320 \\
1320 \\
1290 \\
1020 \\
1030\end{array}$ & $\begin{array}{r}1290 \\
1220 \\
840 \\
940 \\
960\end{array}$ & $\begin{array}{l}7.4 \\
7.3 \\
7.2 \\
7.5 \\
7.5\end{array}$ & $\begin{array}{l}7.2 \\
6.8 \\
6.4 \\
7.1 \\
7.3\end{array}$ & $\begin{array}{r}9.0 \\
8.7 \\
9.4 \\
10.1 \\
9.7\end{array}$ & $\begin{array}{l}8.4 \\
8.3 \\
8.7 \\
9.2 \\
9.5\end{array}$ & $\begin{array}{l}52 \\
51 \\
49 \\
46 \\
44\end{array}$ & $\begin{array}{l}51 \\
49 \\
46 \\
44 \\
42\end{array}$ \\
\hline $\begin{array}{r}6 \ldots \\
7 \ldots \\
8 \ldots \\
9 . \\
10 \ldots\end{array}$ & $\begin{array}{l}1760 \\
1760 \\
1640 \\
1530 \\
1650\end{array}$ & $\begin{array}{l}1660 \\
1620 \\
1520 \\
1490 \\
1490\end{array}$ & $\begin{array}{l}7.6 \\
7.6 \\
7.5 \\
7.6 \\
7.6\end{array}$ & $\begin{array}{l}7.3 \\
7.5 \\
7.3 \\
7.4 \\
7.3\end{array}$ & $\begin{array}{l}10.7 \\
10.9 \\
12.5 \\
11.2 \\
11.1\end{array}$ & $\begin{array}{l}8.9 \\
9.2 \\
8.7 \\
9.0 \\
9.0\end{array}$ & $\begin{array}{l}60 \\
60 \\
60 \\
60 \\
60\end{array}$ & $\begin{array}{l}58 \\
58 \\
58 \\
59 \\
59\end{array}$ & $\begin{array}{r}1100 \\
1130 \\
1100 \\
1030 \\
800\end{array}$ & $\begin{array}{r}980 \\
1080 \\
1000 \\
800 \\
590\end{array}$ & $\begin{array}{l}7.5 \\
7.3 \\
7.3 \\
7.3 \\
7.8\end{array}$ & $\begin{array}{l}7.2 \\
7.1 \\
7.1 \\
6.2 \\
7.0\end{array}$ & $\begin{array}{l}9.9 \\
9.8 \\
9.6 \\
9.0 \\
8.8\end{array}$ & $\begin{array}{l}9.5 \\
9.4 \\
9.0 \\
8.5 \\
7.9\end{array}$ & $\begin{array}{l}43 \\
44 \\
45 \\
49 \\
52\end{array}$ & $\begin{array}{l}42 \\
42 \\
44 \\
44 \\
49\end{array}$ \\
\hline $\begin{array}{l}11 \ldots \\
12 \ldots \\
13 \ldots \\
14 \ldots \\
15 . .\end{array}$ & $\begin{array}{l}1770 \\
1730 \\
1710 \\
1730 \\
1670\end{array}$ & $\begin{array}{l}1650 \\
1670 \\
1670 \\
1650 \\
1590\end{array}$ & $\begin{array}{l}7.6 \\
7.5 \\
7.5 \\
7.6 \\
7.6\end{array}$ & $\begin{array}{l}7.3 \\
7.2 \\
7.3 \\
7.4 \\
7.3\end{array}$ & $\begin{array}{r}11.1 \\
10.9 \\
10.0 \\
9.7 \\
9.9\end{array}$ & $\begin{array}{l}9.6 \\
9.2 \\
8.9 \\
8.6 \\
8.2\end{array}$ & $\begin{array}{l}59 \\
60 \\
60 \\
62 \\
61\end{array}$ & $\begin{array}{l}58 \\
58 \\
58 \\
59 \\
60\end{array}$ & $\begin{array}{l}710 \\
730 \\
720 \\
680 \\
690\end{array}$ & $\begin{array}{l}560 \\
680 \\
680 \\
620 \\
590\end{array}$ & $\begin{array}{l}7.3 \\
7.4 \\
7.3 \\
7.4 \\
7.4\end{array}$ & $\begin{array}{l}7.0 \\
7.1 \\
7.2 \\
7.2 \\
7.2\end{array}$ & $\begin{array}{l}8.8 \\
8.7 \\
8.8 \\
8.9 \\
9.0\end{array}$ & $\begin{array}{l}7.6 \\
8.2 \\
8.5 \\
8.6 \\
8.7\end{array}$ & $\begin{array}{l}53 \\
52 \\
51 \\
50 \\
49\end{array}$ & $\begin{array}{l}51 \\
50 \\
49 \\
47 \\
47\end{array}$ \\
\hline $\begin{array}{l}16 \ldots \\
17 \ldots \\
18 \ldots \\
19 \ldots \\
20 \ldots\end{array}$ & $\begin{array}{l}1610 \\
1630 \\
1590 \\
1570 \\
1630\end{array}$ & $\begin{array}{l}1590 \\
1590 \\
1520 \\
1510 \\
1570\end{array}$ & $\begin{array}{l}7.6 \\
7.5 \\
7.4 \\
7.5 \\
7.5\end{array}$ & $\begin{array}{l}7.4 \\
7.2 \\
7.1 \\
7.3 \\
7.4\end{array}$ & $\begin{array}{l}9.2 \\
8.3 \\
7.7 \\
7.7 \\
8.1\end{array}$ & $\begin{array}{l}7.8 \\
6.4 \\
7.0 \\
6.2 \\
7.2\end{array}$ & $\begin{array}{l}61 \\
60 \\
58 \\
57 \\
56\end{array}$ & $\begin{array}{l}59 \\
58 \\
56 \\
55 \\
54\end{array}$ & $\begin{array}{l}700 \\
780 \\
780 \\
830 \\
820\end{array}$ & $\begin{array}{l}600 \\
700 \\
720 \\
780 \\
780\end{array}$ & $\begin{array}{l}7.3 \\
7.3 \\
7.3 \\
7.4 \\
7.4\end{array}$ & $\begin{array}{l}7 \cdot 1 \\
7.1 \\
7 \cdot 1 \\
7.2 \\
7.2\end{array}$ & $\begin{array}{r}9.1 \\
9.0 \\
8.9 \\
8.8 \\
10.3\end{array}$ & $\begin{array}{l}8.8 \\
8.7 \\
8.4 \\
8.2 \\
8.5\end{array}$ & $\begin{array}{l}48 \\
47 \\
48 \\
48 \\
47\end{array}$ & $\begin{array}{l}45 \\
46 \\
46 \\
47 \\
46\end{array}$ \\
\hline $\begin{array}{l}21 \ldots \\
22 \ldots \\
23 \ldots \\
24 \ldots \\
25 \ldots\end{array}$ & $\begin{array}{l}1710 \\
1710 \\
1740 \\
1940 \\
1950\end{array}$ & $\begin{array}{l}1630 \\
1600 \\
1590 \\
1740 \\
1700\end{array}$ & $\begin{array}{l}7.6 \\
7.6 \\
7.6 \\
7.7 \\
7.7\end{array}$ & $\begin{array}{l}7.4 \\
7.4 \\
7.4 \\
7.4 \\
7.6\end{array}$ & $\begin{array}{l}8.4 \\
8.3 \\
8.8 \\
8.7 \\
8.6\end{array}$ & $\begin{array}{l}7 \cdot 3 \\
7.4 \\
7.3 \\
7 \cdot 7 \\
7.5\end{array}$ & $\begin{array}{l}55 \\
56 \\
56 \\
55 \\
55\end{array}$ & $\begin{array}{l}53 \\
54 \\
55 \\
54 \\
54\end{array}$ & $\begin{array}{l}880 \\
880 \\
900 \\
910 \\
910\end{array}$ & $\begin{array}{l}820 \\
850 \\
870 \\
890 \\
880\end{array}$ & $\begin{array}{l}7.5 \\
7.5 \\
7.4 \\
7.4 \\
7.4\end{array}$ & $\begin{array}{l}7.3 \\
7.2 \\
7.2 \\
7.2 \\
7.2\end{array}$ & $\begin{array}{r}10.4 \\
9.4 \\
9.4 \\
9.3 \\
9.1\end{array}$ & $\begin{array}{l}9.0 \\
9.0 \\
9.1 \\
8.8 \\
8.8\end{array}$ & $\begin{array}{l}47 \\
46 \\
45 \\
46 \\
46\end{array}$ & $\begin{array}{l}46 \\
44 \\
44 \\
45 \\
45\end{array}$ \\
\hline $\begin{array}{l}26 \ldots \\
27 \ldots \\
28 \ldots \\
29 \ldots \\
30 \ldots \\
31 \ldots\end{array}$ & $\begin{array}{l}1700 \\
1610 \\
1620 \\
1570 \\
1400 \\
1330\end{array}$ & $\begin{array}{l}1510 \\
1520 \\
1560 \\
1390 \\
1240 \\
1230\end{array}$ & $\begin{array}{l}7.7 \\
7.7 \\
7.7 \\
7.6 \\
7.5 \\
7.5\end{array}$ & $\begin{array}{l}7.5 \\
7.5 \\
7.3 \\
7.3 \\
7.2 \\
7.3\end{array}$ & $\begin{array}{l}8.8 \\
9.3 \\
9.1 \\
8.7 \\
8.5 \\
9.2\end{array}$ & $\begin{array}{l}7.3 \\
7.9 \\
7.9 \\
7.8 \\
7.9 \\
8.2\end{array}$ & $\begin{array}{l}55 \\
54 \\
54 \\
54 \\
53 \\
52\end{array}$ & $\begin{array}{l}53 \\
53 \\
53 \\
53 \\
52 \\
51\end{array}$ & $\begin{array}{l}980 \\
940 \\
920 \\
810 \\
820 \\
--\end{array}$ & $\begin{array}{r}900 \\
900 \\
800 \\
740 \\
760 \\
--\end{array}$ & $\begin{array}{r}7.4 \\
7.3 \\
7.4 \\
7.5 \\
7.6 \\
--\end{array}$ & $\begin{array}{l}7 \cdot 2 \\
7 \cdot 2 \\
7 \cdot 1 \\
7 \cdot 3 \\
7 \cdot 3 \\
--\end{array}$ & $\begin{array}{r}9.3 \\
9.1 \\
9.4 \\
10.3 \\
9.8 \\
--\end{array}$ & $\begin{array}{l}8.8 \\
8.5 \\
8.1 \\
8.1 \\
8.8 \\
--\end{array}$ & $\begin{array}{l}46 \\
48 \\
47 \\
45 \\
43 \\
-- \\
\end{array}$ & $\begin{array}{l}46 \\
46 \\
45 \\
43 \\
42 \\
-- \\
\end{array}$ \\
\hline \multicolumn{9}{|c|}{ DECEMBER } & \multicolumn{8}{|c|}{ JANUARY } \\
\hline $\begin{array}{l}1 \ldots \\
2 \ldots \\
3 \ldots \\
4 \ldots \\
5 \ldots\end{array}$ & $\begin{array}{r}860 \\
990 \\
1070 \\
1120 \\
1150\end{array}$ & $\begin{array}{r}790 \\
840 \\
990 \\
1060 \\
1090\end{array}$ & $\begin{array}{l}7.6 \\
7.7 \\
7.7 \\
7.8 \\
7.8\end{array}$ & $\begin{array}{l}7.5 \\
7.3 \\
7.3 \\
7.7 \\
7.2\end{array}$ & $\begin{array}{r}9.2 \\
10.5 \\
10.3 \\
14.9 \\
10.8\end{array}$ & $\begin{array}{r}8.9 \\
9.0 \\
9.8 \\
10.0 \\
10.4\end{array}$ & $\begin{array}{l}42 \\
40 \\
38 \\
35 \\
35\end{array}$ & $\begin{array}{l}40 \\
38 \\
35 \\
34 \\
34\end{array}$ & $\begin{array}{r}920 \\
960 \\
980 \\
1030 \\
1010\end{array}$ & $\begin{array}{l}890 \\
920 \\
960 \\
980 \\
980\end{array}$ & $\begin{array}{l}7.5 \\
7.3 \\
7.5 \\
7.6 \\
7.5\end{array}$ & $\begin{array}{l}7.0 \\
7.0 \\
7.1 \\
7.3 \\
7.1\end{array}$ & $\begin{array}{l}12.7 \\
10.9 \\
11 \\
11.0 \\
12.8\end{array}$ & $\begin{array}{l}10.8 \\
10.6 \\
10.7 \\
11.0 \\
10.8\end{array}$ & $\begin{array}{l}36 \\
36 \\
36 \\
36 \\
36\end{array}$ & $\begin{array}{l}34 \\
35 \\
35 \\
35 \\
34\end{array}$ \\
\hline $\begin{array}{l}6 \ldots \\
7 \ldots \\
8 \ldots \\
9 \ldots \\
10 \ldots\end{array}$ & $\begin{array}{r}1180 \\
1060 \\
650 \\
620 \\
610\end{array}$ & $\begin{array}{r}1060 \\
650 \\
590 \\
580 \\
450\end{array}$ & $\begin{array}{l}7.6 \\
7.3 \\
7.6 \\
7.5 \\
7.3\end{array}$ & $\begin{array}{l}7 \cdot 1 \\
7 \cdot 1 \\
7 \cdot 1 \\
7 \cdot 3 \\
7 \cdot 1\end{array}$ & $\begin{array}{l}10.9 \\
10.4 \\
15.0 \\
15.0 \\
15.0\end{array}$ & $\begin{array}{r}10.3 \\
9.4 \\
9.2 \\
8.6 \\
8.3\end{array}$ & $\begin{array}{l}36 \\
42 \\
43 \\
47 \\
47\end{array}$ & $\begin{array}{l}35 \\
36 \\
42 \\
43 \\
46\end{array}$ & $\begin{array}{l}1030 \\
1310 \\
1330 \\
1290 \\
1270\end{array}$ & $\begin{array}{l}1010 \\
1030 \\
1010 \\
1020 \\
1020\end{array}$ & $\begin{array}{l}7.6 \\
7.5 \\
7.5 \\
7.6 \\
7.8\end{array}$ & $\begin{array}{l}7.1 \\
6.7 \\
7.2 \\
6.8 \\
7.4\end{array}$ & $\begin{array}{l}11.2 \\
14.3 \\
13.5 \\
14.7 \\
15.0\end{array}$ & 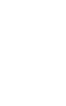 & $\begin{array}{l}37 \\
37 \\
38 \\
37 \\
36\end{array}$ & $\begin{array}{l}35 \\
36 \\
37 \\
36 \\
35\end{array}$ \\
\hline $\begin{array}{l}11 \ldots \\
12 \ldots \\
13 \ldots \\
14 \ldots \\
15 \ldots\end{array}$ & $\begin{array}{l}500 \\
530 \\
530 \\
550 \\
530\end{array}$ & $\begin{array}{l}450 \\
480 \\
410 \\
500 \\
500\end{array}$ & $\begin{array}{l}7.5 \\
7.7 \\
7.8 \\
7.8 \\
7.9\end{array}$ & $\begin{array}{l}7.1 \\
7.4 \\
7.5 \\
7.4 \\
7.5\end{array}$ & $\begin{array}{r}9.0 \\
9.8 \\
10.2 \\
12.2 \\
12.4\end{array}$ & $\begin{array}{r}8.5 \\
9.0 \\
9.7 \\
10.0 \\
10.4\end{array}$ & $\begin{array}{l}46 \\
45 \\
42 \\
41 \\
39\end{array}$ & $\begin{array}{l}44 \\
42 \\
40 \\
38 \\
38\end{array}$ & $\begin{array}{l}1340 \\
1340 \\
1340 \\
1340 \\
1130\end{array}$ & $\begin{array}{l}1040 \\
1030 \\
1040 \\
1030 \\
1040\end{array}$ & $\begin{array}{l}7.9 \\
7.9 \\
7.8 \\
7.7 \\
7.5\end{array}$ & $\begin{array}{l}7 \cdot 1 \\
7 \cdot 2 \\
7 \cdot 1 \\
7 \cdot 2 \\
7.2\end{array}$ & $\begin{array}{l}15.0 \\
11 \\
10.0 \\
10.5 \\
10.4\end{array}$ & $\begin{array}{l}10.8 \\
10.6 \\
10.4 \\
10.4 \\
10.2\end{array}$ & $\begin{array}{l}36 \\
35 \\
36 \\
37 \\
38\end{array}$ & $\begin{array}{l}35 \\
35 \\
34 \\
35 \\
37\end{array}$ \\
\hline $\begin{array}{l}16 \ldots \\
17 \ldots \\
18 \ldots \\
19 . \ldots \\
20 \ldots\end{array}$ & $\begin{array}{l}530 \\
560 \\
600 \\
610 \\
660\end{array}$ & $\begin{array}{l}470 \\
510 \\
560 \\
600 \\
610\end{array}$ & $\begin{array}{l}7.7 \\
7.7 \\
7.5 \\
7.7 \\
7.5\end{array}$ & $\begin{array}{l}7 \cdot 5 \\
7 \cdot 3 \\
7 \cdot 3 \\
7 \cdot 3 \\
7.2\end{array}$ & $\begin{array}{l}10.9 \\
110.0 \\
10.3 \\
12.0 \\
11.9\end{array}$ & $\begin{array}{r}10.3 \\
10.3 \\
10.0 \\
9.9 \\
9.9\end{array}$ & $\begin{array}{l}39 \\
38 \\
40 \\
40 \\
40\end{array}$ & $\begin{array}{l}37 \\
37 \\
38 \\
39 \\
38\end{array}$ & $\begin{array}{l}1140 \\
1140 \\
1130 \\
1110 \\
1150\end{array}$ & $\begin{array}{l}1040 \\
1050 \\
1090 \\
1100 \\
1100\end{array}$ & $\begin{array}{l}7.7 \\
7.8 \\
8.0 \\
8.0 \\
7.9\end{array}$ & $\begin{array}{l}7.2 \\
7.4 \\
7.5 \\
7.5 \\
7.4\end{array}$ & $\begin{array}{l}11.1 \\
15.0 \\
15.0 \\
13.7 \\
13.2\end{array}$ & 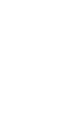 & $\begin{array}{l}37 \\
37 \\
36 \\
35 \\
35\end{array}$ & $\begin{array}{l}35 \\
36 \\
34 \\
33 \\
34\end{array}$ \\
\hline $\begin{array}{l}21 \ldots \\
22 \ldots \\
23 \ldots \\
24 \ldots \\
25 \ldots\end{array}$ & $\begin{array}{l}700 \\
720 \\
750 \\
770 \\
770\end{array}$ & $\begin{array}{l}660 \\
700 \\
680 \\
750 \\
750\end{array}$ & $\begin{array}{l}7.7 \\
7.4 \\
7.6 \\
7.6 \\
7.7\end{array}$ & $\begin{array}{l}7.1 \\
7.1 \\
7: 1 \\
7.2 \\
7.2\end{array}$ & $\begin{array}{l}10.2 \\
10.1 \\
10.8 \\
11.0 \\
11.3\end{array}$ & $\begin{array}{r}9.9 \\
9.8 \\
9.9 \\
10.2 \\
10.3\end{array}$ & $\begin{array}{l}40 \\
39 \\
39 \\
38 \\
36\end{array}$ & $\begin{array}{l}38 \\
38 \\
37 \\
36 \\
35\end{array}$ & $\begin{array}{l}1170 \\
1260 \\
1270 \\
1320 \\
1270\end{array}$ & $\begin{array}{l}1140 \\
1150 \\
1240 \\
1210 \\
1200\end{array}$ & $\begin{array}{l}7.7 \\
7.5 \\
7.2 \\
6.9 \\
6.8\end{array}$ & $\begin{array}{l}7.4 \\
7.1 \\
6.9 \\
6.7 \\
6.6\end{array}$ & $\begin{array}{l}11.7 \\
11 \\
12.1 \\
12.4 \\
12.3\end{array}$ & $\begin{array}{l}11.0 \\
10.7 \\
10.5 \\
10.9 \\
10.8\end{array}$ & $\begin{array}{l}36 \\
37 \\
40 \\
4 ? \\
44\end{array}$ & $\begin{array}{l}34 \\
35 \\
37 \\
40 \\
40\end{array}$ \\
\hline $\begin{array}{l}26 \ldots \\
27 \ldots \\
28 \ldots \\
29 \ldots \\
30 \ldots \\
31 \ldots\end{array}$ & $\begin{array}{l}860 \\
920 \\
940 \\
950 \\
870 \\
890\end{array}$ & $\begin{array}{l}770 \\
860 \\
920 \\
870 \\
850 \\
850\end{array}$ & $\begin{array}{l}7.6 \\
7.6 \\
7.6 \\
7.5 \\
7.4 \\
7.7\end{array}$ & $\begin{array}{l}7 \cdot 3 \\
7 \cdot 2 \\
7 \cdot 3 \\
7 \cdot 0 \\
7 \cdot 1 \\
7 \cdot 2\end{array}$ & $\begin{array}{l}\begin{array}{l}11 \\
11.3 \\
11.4 \\
12.9\end{array} \\
15.0 \\
15.0 \\
14.8\end{array}$ & $\begin{array}{l}10.4 \\
11.0 \\
11.2 \\
10.8 \\
10.7 \\
10.8\end{array}$ & $\begin{array}{l}35 \\
35 \\
34 \\
35 \\
35 \\
34\end{array}$ & $\begin{array}{l}34 \\
34 \\
33 \\
34 \\
34 \\
33\end{array}$ & $\begin{array}{l}1200 \\
1130 \\
1060 \\
1060 \\
1000 \\
1070\end{array}$ & $\begin{array}{r}1000 \\
1060 \\
990 \\
920 \\
890 \\
1000\end{array}$ & $\begin{array}{l}6.7 \\
6.6 \\
7.0 \\
7.4 \\
7.4 \\
7.4\end{array}$ & $\begin{array}{l}6.5 \\
6.4 \\
6.5 \\
7.0 \\
7.1 \\
7.0\end{array}$ & $\begin{array}{l}14.5 \\
15.0 \\
15.0 \\
13.2 \\
14.5 \\
13.9\end{array}$ & $\begin{array}{l}10.4 \\
10.9 \\
11.6 \\
11.9 \\
12.8 \\
12.3\end{array}$ & $\begin{array}{l}45 \\
45 \\
44 \\
39 \\
39 \\
37\end{array}$ & $\begin{array}{l}43 \\
44 \\
39 \\
37 \\
36 \\
36\end{array}$ \\
\hline
\end{tabular}


MUSKINGUM RIVER BASIN--Continued

3-1492. MUSKINGUM RIVER AT PHILO, OHIO--Continued

Data from continuous recorder, water year October 1966 to September 1967--Continued

\begin{tabular}{|c|c|c|c|c|c|c|c|c|c|c|c|c|c|c|c|c|}
\hline \multirow{3}{*}{ Day } & \multicolumn{8}{|c|}{ FEBRUARY } & \multicolumn{8}{|c|}{ MARCH } \\
\hline & \multicolumn{2}{|c|}{$\begin{array}{c}\text { Specific } \\
\text { conductance } \\
\text { (micrombos } \\
\text { at } 25^{\circ} \mathrm{C} \text { ) }\end{array}$} & \multicolumn{2}{|c|}{ pH } & \multicolumn{2}{|c|}{$\begin{array}{l}\text { Dissolved } \\
\text { oxygen } \\
\text { (ppm) }\end{array}$} & \multicolumn{2}{|c|}{$\begin{array}{c}\text { Temper- } \\
\text { ature } \\
(\mathrm{F})\end{array}$} & \multicolumn{2}{|c|}{$\begin{array}{c}\text { Specific } \\
\text { conductance } \\
\text { (micromhos } \\
\text { at } 25^{\circ} \mathrm{C} \text { ) }\end{array}$} & \multicolumn{2}{|c|}{$\mathbf{p H}$} & \multicolumn{2}{|c|}{$\begin{array}{l}\text { Dissolved } \\
\text { oxygen } \\
\text { (ppm) }\end{array}$} & \multicolumn{2}{|c|}{$\begin{array}{c}\text { Temper- } \\
\text { ature } \\
\left({ }^{\circ} \mathrm{F}\right)\end{array}$} \\
\hline & $\operatorname{Max}$ & Min & Max & Min & Max & Min & Max & Min & $\operatorname{Max}$ & Min & $\operatorname{Max}$ & Min & $M_{\text {ix }}$ & Min & Max & Min \\
\hline $\begin{array}{l}1 \ldots \\
2 \ldots \\
3 \ldots \\
4 \ldots \\
5 \ldots\end{array}$ & $\begin{array}{r}1070 \\
1070 \\
740 \\
680 \\
880\end{array}$ & $\begin{array}{l}860 \\
700 \\
660 \\
610 \\
620\end{array}$ & $\begin{array}{l}7.2 \\
7.2 \\
7.4 \\
7.5 \\
7.3\end{array}$ & $\begin{array}{l}6.8 \\
6.8 \\
6.8 \\
7.3 \\
7.1\end{array}$ & $\begin{array}{l}15.0 \\
12.1 \\
11 \\
11.4 \\
12.3\end{array}$ & $\begin{array}{l}11.6 \\
10.3 \\
10.4 \\
10.5 \\
10.5\end{array}$ & $\begin{array}{l}37 \\
39 \\
38 \\
37 \\
37\end{array}$ & $\begin{array}{l}36 \\
37 \\
37 \\
36 \\
36\end{array}$ & $\begin{array}{l}820 \\
830 \\
840 \\
730 \\
630\end{array}$ & $\begin{array}{l}780 \\
810 \\
730 \\
620 \\
470\end{array}$ & $\begin{array}{l}8.2 \\
7.9 \\
7.6 \\
7.3 \\
7.4\end{array}$ & $\begin{array}{l}7.6 \\
7 \cdot 1 \\
6.7 \\
6.8 \\
6.9\end{array}$ & $\begin{array}{l}10.3 \\
10.3 \\
90.9 \\
10.3 \\
10.5\end{array}$ & $\begin{array}{l}9.7 \\
9.5 \\
9.4 \\
9.7 \\
9.1\end{array}$ & $\begin{array}{l}34 \\
36 \\
36 \\
36 \\
38\end{array}$ & $\begin{array}{l}32 \\
33 \\
35 \\
35 \\
36\end{array}$ \\
\hline $\begin{array}{r}6 \ldots \\
7 \ldots \\
8 \ldots \\
9 \ldots \\
10 \ldots\end{array}$ & $\begin{array}{r}1040 \\
690 \\
690 \\
600 \\
690\end{array}$ & $\begin{array}{l}680 \\
640 \\
590 \\
620 \\
640\end{array}$ & $\begin{array}{l}7.5 \\
7.5 \\
7.9 \\
8.0 \\
8.0\end{array}$ & $\begin{array}{l}7.1 \\
7.2 \\
7.4 \\
7.5 \\
7.3\end{array}$ & $\begin{array}{l}12.1 \\
15.0 \\
12.4 \\
12.2 \\
12.1\end{array}$ & $\begin{array}{l}10.6 \\
10.5 \\
10.6 \\
10.5 \\
10.4\end{array}$ & $\begin{array}{l}36 \\
35 \\
33 \\
33 \\
34\end{array}$ & $\begin{array}{l}35 \\
33 \\
32 \\
32 \\
32\end{array}$ & $\begin{array}{l}470 \\
430 \\
510 \\
540 \\
440\end{array}$ & $\begin{array}{l}390 \\
390 \\
430 \\
440 \\
420\end{array}$ & $\begin{array}{l}7.2 \\
7.3 \\
7.1 \\
7.0 \\
7.4\end{array}$ & $\begin{array}{l}6.8 \\
7.0 \\
6.8 \\
6.6 \\
6.8\end{array}$ & $\begin{array}{l}10.5 \\
11.4 \\
11.2 \\
11.2 \\
10.8\end{array}$ & $\begin{array}{r}9.2 \\
9.8 \\
10.2 \\
10.4 \\
10.4\end{array}$ & $\begin{array}{l}38 \\
36 \\
38 \\
40 \\
41\end{array}$ & $\begin{array}{l}36 \\
35 \\
36 \\
38 \\
38\end{array}$ \\
\hline $\begin{array}{l}11 \ldots \\
12 \ldots \\
13 \ldots \\
14 \ldots \\
15 \ldots\end{array}$ & $\begin{array}{l}760 \\
730 \\
760 \\
810 \\
840\end{array}$ & $\begin{array}{l}670 \\
690 \\
710 \\
760 \\
800\end{array}$ & $\begin{array}{l}7.5 \\
7.6 \\
8.1 \\
7.4 \\
7.2\end{array}$ & $\begin{array}{l}7.2 \\
7.2 \\
7.1 \\
7.1 \\
6.8\end{array}$ & $\begin{array}{l}15.0 \\
15.0 \\
11.2 \\
10.6 \\
10.4\end{array}$ & $\begin{array}{r}10.4 \\
10.1 \\
10.0 \\
9.6 \\
9.0\end{array}$ & $\begin{array}{l}34 \\
34 \\
35 \\
36 \\
40\end{array}$ & $\begin{array}{l}33 \\
33 \\
33 \\
34 \\
36\end{array}$ & $\begin{array}{l}520 \\
490 \\
460 \\
470 \\
490\end{array}$ & $\begin{array}{l}440 \\
450 \\
440 \\
420 \\
460\end{array}$ & $\begin{array}{l}7.2 \\
7.3 \\
7.5 \\
7.2 \\
7.3\end{array}$ & $\begin{array}{l}7.0 \\
7.1 \\
7.2 \\
6.9 \\
7.1\end{array}$ & $\begin{array}{l}10.7 \\
10.6 \\
10.3 \\
10.2 \\
10.1\end{array}$ & $\begin{array}{l}9.9 \\
9.9 \\
9.8 \\
9.5 \\
9.7\end{array}$ & $\begin{array}{l}41 \\
42 \\
43 \\
46 \\
46\end{array}$ & $\begin{array}{l}40 \\
40 \\
41 \\
43 \\
44\end{array}$ \\
\hline $\begin{array}{l}16 \ldots \\
17 \ldots \\
18 \ldots \\
19 \ldots \\
20 \ldots\end{array}$ & $\begin{array}{l}840 \\
780 \\
750 \\
670 \\
990\end{array}$ & $\begin{array}{l}780 \\
680 \\
630 \\
590 \\
670\end{array}$ & $\begin{array}{l}7.3 \\
7.7 \\
7.9 \\
7.9 \\
7.5\end{array}$ & $\begin{array}{l}6.9 \\
7.2 \\
7.4 \\
7.4 \\
7.2\end{array}$ & $\begin{array}{l}10.7 \\
14.9 \\
11.0 \\
10.5 \\
10.5\end{array}$ & $\begin{array}{l}9.0 \\
9.4 \\
9.3 \\
9.6 \\
9.1\end{array}$ & $\begin{array}{l}40 \\
38 \\
37 \\
36 \\
37\end{array}$ & $\begin{array}{l}38 \\
36 \\
36 \\
35 \\
36\end{array}$ & $\begin{array}{l}500 \\
470 \\
520 \\
520 \\
480\end{array}$ & $\begin{array}{l}460 \\
430 \\
450 \\
460 \\
470\end{array}$ & $\begin{array}{l}7.6 \\
7.9 \\
7.9 \\
8.0 \\
8.0\end{array}$ & $\begin{array}{l}7.3 \\
7.5 \\
7.6 \\
7.8 \\
7.6\end{array}$ & $\begin{array}{l}10.0 \\
10.6 \\
10.8 \\
13.1 \\
12.6\end{array}$ & $\begin{array}{r}9.7 \\
9.8 \\
10.3 \\
10.3 \\
10.4\end{array}$ & $\begin{array}{l}44 \\
44 \\
42 \\
41 \\
41\end{array}$ & $\begin{array}{l}42 \\
42 \\
40 \\
40 \\
40\end{array}$ \\
\hline $\begin{array}{l}21 \ldots \\
22 \ldots \\
23 \ldots \\
24 \ldots \\
25 \ldots\end{array}$ & $\begin{array}{l}970 \\
950 \\
750 \\
830 \\
850\end{array}$ & $\begin{array}{l}920 \\
710 \\
690 \\
760 \\
740\end{array}$ & $\begin{array}{l}7.7 \\
7.8 \\
7.8 \\
8.1 \\
8.4\end{array}$ & $\begin{array}{l}7.1 \\
7.2 \\
7.3 \\
7.6 \\
7.8\end{array}$ & $\begin{array}{l}10.1 \\
10.7 \\
10.4 \\
10.8 \\
15.0\end{array}$ & $\begin{array}{r}9.0 \\
9.3 \\
9.0 \\
9.4 \\
10.1\end{array}$ & $\begin{array}{l}37 \\
36 \\
36 \\
35 \\
33\end{array}$ & $\begin{array}{l}36 \\
35 \\
35 \\
32 \\
32\end{array}$ & $\begin{array}{l}480 \\
460 \\
500 \\
490 \\
550\end{array}$ & $\begin{array}{l}410 \\
390 \\
460 \\
450 \\
440\end{array}$ & $\begin{array}{l}7.9 \\
8.0 \\
8.1 \\
8.0 \\
7.9\end{array}$ & $\begin{array}{l}7.4 \\
7.8 \\
7.8 \\
7.8 \\
7.6\end{array}$ & $\begin{array}{l}10.6 \\
10.6 \\
10.6 \\
13.1 \\
12.6\end{array}$ & $\begin{array}{r}10.0 \\
10.0 \\
10.2 \\
10.1 \\
9.8\end{array}$ & $\begin{array}{l}41 \\
41 \\
41 \\
41 \\
43\end{array}$ & $\begin{array}{l}40 \\
40 \\
40 \\
40 \\
40\end{array}$ \\
\hline $\begin{array}{l}26 \ldots \\
27 \ldots \\
28 \ldots \\
29 \ldots \\
30 \ldots \\
31 \ldots\end{array}$ & $\begin{array}{r}800 \\
800 \\
800 \\
-- \\
\square-\end{array}$ & $\begin{array}{r}730 \\
760 \\
770 \\
-- \\
-- \\
--\end{array}$ & $\begin{array}{r}8.3 \\
8.3 \\
8.2 \\
-- \\
-- \\
=-\end{array}$ & $\begin{array}{r}7.9 \\
8.0 \\
7.9 \\
-- \\
--\end{array}$ & $\begin{array}{r}12.7 \\
11.4 \\
10.2 \\
-- \\
--\end{array}$ & $\begin{array}{r}10.0 \\
9.8 \\
9.6 \\
-2 \\
--\end{array}$ & $\begin{array}{l}33 \\
33 \\
33 \\
-- \\
-- \\
--\end{array}$ & $\begin{array}{l}32 \\
32 \\
32 \\
-- \\
--\end{array}$ & $\begin{array}{l}560 \\
570 \\
590 \\
560 \\
490 \\
630\end{array}$ & $\begin{array}{l}500 \\
500 \\
550 \\
490 \\
460 \\
460\end{array}$ & $\begin{array}{l}7.6 \\
7.4 \\
7.2 \\
7.1 \\
7.2 \\
7.2\end{array}$ & $\begin{array}{l}7.3 \\
7.1 \\
6.7 \\
6.6 \\
7.1 \\
6.9\end{array}$ & $\begin{array}{r}10.0 \\
9.9 \\
9.2 \\
9.2 \\
9.1 \\
9.5\end{array}$ & $\begin{array}{l}9.7 \\
9.0 \\
8.6 \\
8.5 \\
8.6 \\
8.9\end{array}$ & $\begin{array}{l}45 \\
48 \\
50 \\
51 \\
51 \\
53\end{array}$ & $\begin{array}{l}42 \\
45 \\
48 \\
49 \\
49 \\
50\end{array}$ \\
\hline \multicolumn{9}{|c|}{ APR IL } & \multicolumn{8}{|c|}{ MAY } \\
\hline $\begin{array}{l}1 \bullet \\
2 \bullet \\
3 \ldots \\
4 \ldots \\
5 \ldots\end{array}$ & $\begin{array}{r}700 \\
700 \\
740 \\
-- \\
--\end{array}$ & $\begin{array}{r}630 \\
670 \\
700 \\
-- \\
--\end{array}$ & $\begin{array}{l}7.0 \\
7.0 \\
6.9 \\
7.1 \\
7.3\end{array}$ & $\begin{array}{l}6.9 \\
6.9 \\
6.8 \\
6.9 \\
7.1\end{array}$ & $\begin{array}{r}9.2 \\
9.3 \\
10.2 \\
10.3 \\
10.8\end{array}$ & $\begin{array}{r}8.9 \\
8.9 \\
8.8 \\
9.8 \\
10.0\end{array}$ & $\begin{array}{l}54 \\
57 \\
57 \\
56 \\
55\end{array}$ & $\begin{array}{l}52 \\
54 \\
55 \\
54 \\
54\end{array}$ & $\begin{array}{l}710 \\
750 \\
720 \\
730 \\
780\end{array}$ & $\begin{array}{l}670 \\
700 \\
690 \\
660 \\
630\end{array}$ & $\begin{array}{l}7.4 \\
7.4 \\
7.4 \\
7.6 \\
7.6\end{array}$ & $\begin{array}{l}7.1 \\
7.1 \\
7.2 \\
7.4 \\
7.4\end{array}$ & 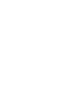 & $\begin{array}{r}8.8 \\
10.5 \\
10.9 \\
10.7 \\
10.9\end{array}$ & $\begin{array}{l}56 \\
57 \\
57 \\
57 \\
58\end{array}$ & $\begin{array}{l}55 \\
55 \\
54 \\
55 \\
55\end{array}$ \\
\hline $\begin{array}{r}6 \ldots \\
7 \ldots \\
8 \ldots \\
9 \ldots \\
10 \ldots\end{array}$ & $\begin{array}{r}7 \\
950 \\
1080 \\
1040\end{array}$ & $\begin{array}{l}-5 \\
670 \\
670 \\
740\end{array}$ & $\begin{array}{l}7.1 \\
7.1 \\
7.2 \\
7.3 \\
7.2\end{array}$ & $\begin{array}{l}7.0 \\
6.9 \\
6.9 \\
7.1 \\
7.0\end{array}$ & $\begin{array}{r}10.9 \\
11.0 \\
-2 \\
13.6\end{array}$ & $\mid \begin{array}{r}9.9 \\
10.1 \\
=- \\
11.1\end{array}$ & $\begin{array}{l}56 \\
56 \\
55 \\
54 \\
55\end{array}$ & $\begin{array}{l}54 \\
54 \\
54 \\
53 \\
54\end{array}$ & $\begin{array}{l}780 \\
670 \\
630 \\
580 \\
580\end{array}$ & $\begin{array}{l}620 \\
620 \\
570 \\
490 \\
480\end{array}$ & $\begin{array}{l}7.6 \\
7.5 \\
7.7 \\
7.7 \\
7.8\end{array}$ & $\begin{array}{l}7.4 \\
7.1 \\
7.2 \\
7.5 \\
7.5\end{array}$ & $\begin{array}{r}13.5 \\
13.6 \\
10.0 \\
9.5 \\
10.6\end{array}$ & $\begin{array}{r}10.0 \\
9.0 \\
9.5 \\
8.8 \\
8.8\end{array}$ & $\begin{array}{l}57 \\
55 \\
54 \\
53 \\
52\end{array}$ & $\begin{array}{l}54 \\
52 \\
52 \\
51 \\
50\end{array}$ \\
\hline $\begin{array}{l}11 \ldots \\
12 \ldots \\
13 \ldots \\
14 \ldots \\
15 \ldots\end{array}$ & $\begin{array}{l}800 \\
790 \\
740 \\
720 \\
640\end{array}$ & $\begin{array}{l}730 \\
710 \\
710 \\
630 \\
560\end{array}$ & $\begin{array}{l}7.4 \\
7.6 \\
7.4 \\
7.4 \\
7.5\end{array}$ & $\begin{array}{l}7.2 \\
7.4 \\
7.2 \\
7.2 \\
7.3\end{array}$ & $\begin{array}{l}12.3 \\
12.6 \\
11.8 \\
11.1 \\
11.1\end{array}$ & $\begin{array}{r}10.5 \\
10.5 \\
9.9 \\
9.5 \\
9.1\end{array}$ & $\begin{array}{l}54 \\
54 \\
53 \\
56 \\
58\end{array}$ & $\begin{array}{l}53 \\
52 \\
52 \\
53 \\
55\end{array}$ & $\begin{array}{l}560 \\
470 \\
490 \\
490 \\
450\end{array}$ & $\begin{array}{l}450 \\
450 \\
460 \\
450 \\
410\end{array}$ & $\begin{array}{l}7.7 \\
7.5 \\
7.5 \\
7.6 \\
7.5\end{array}$ & $\begin{array}{l}7.1 \\
7.3 \\
7.4 \\
7.4 \\
7.1\end{array}$ & $\begin{array}{r}10.5 \\
10.0 \\
9.8 \\
9.7 \\
9.4\end{array}$ & $\begin{array}{l}9.9 \\
8.3 \\
9.3 \\
9.2 \\
8.2\end{array}$ & $\begin{array}{l}54 \\
54 \\
54 \\
54 \\
54\end{array}$ & $\begin{array}{l}52 \\
53 \\
52 \\
53 \\
52\end{array}$ \\
\hline $\begin{array}{l}16 \ldots \\
17 \ldots \\
18 \ldots \\
19 \ldots \\
20 \ldots\end{array}$ & $\begin{array}{r}630 \\
=- \\
=-\end{array}$ & $\begin{array}{r}570 \\
-- \\
-- \\
--\end{array}$ & $\begin{array}{l}7.5 \\
7.4 \\
7.4 \\
7.5 \\
7.5\end{array}$ & $\begin{array}{l}7 \cdot 3 \\
7 \cdot 3 \\
7 \cdot 3 \\
7 \cdot 3 \\
7 \cdot 2\end{array}$ & $\begin{array}{l}10.2 \\
10.3 \\
10.9 \\
10.6 \\
10.5\end{array}$ & $\begin{array}{l}8.1 \\
8.1 \\
8.7 \\
8.8 \\
8.8\end{array}$ & $\begin{array}{l}59 \\
60 \\
60 \\
57 \\
56\end{array}$ & $\begin{array}{l}56 \\
58 \\
56 \\
55 \\
54\end{array}$ & $\begin{array}{l}480 \\
500 \\
500 \\
480 \\
480\end{array}$ & $\begin{array}{l}410 \\
460 \\
460 \\
460 \\
440\end{array}$ & $\begin{array}{l}7.5 \\
7.5 \\
7.5 \\
7.5 \\
7.6\end{array}$ & $\begin{array}{l}7 \cdot 1 \\
7 \cdot 3 \\
7 \cdot 3 \\
7.3 \\
7.2\end{array}$ & $\begin{array}{r}9.3 \\
9.2 \\
10.0 \\
10.0 \\
10.0\end{array}$ & $\begin{array}{l}8.2 \\
8.3 \\
8.3 \\
8.0 \\
7.7\end{array}$ & $\begin{array}{l}54 \\
54 \\
56 \\
57 \\
57\end{array}$ & $\begin{array}{l}51 \\
52 \\
53 \\
55 \\
55\end{array}$ \\
\hline $\begin{array}{l}21 \ldots \\
22 \ldots \\
23 \ldots \\
24 \ldots \\
25 \ldots\end{array}$ & $\begin{array}{l}-- \\
600 \\
820 \\
620\end{array}$ & $\begin{array}{r}-- \\
520 \\
580 \\
480\end{array}$ & $\begin{array}{l}7.4 \\
7.3 \\
7.4 \\
7.4 \\
7.6\end{array}$ & $\begin{array}{l}7.2 \\
6.8 \\
7.2 \\
7.2 \\
7.3\end{array}$ & $\begin{array}{r}10.4 \\
9.8 \\
10.2 \\
10.3 \\
10.7\end{array}$ & $\begin{array}{l}8.2 \\
7.3 \\
8.5 \\
8.7 \\
9.2\end{array}$ & $\begin{array}{l}56 \\
57 \\
56 \\
56 \\
53\end{array}$ & $\begin{array}{l}55 \\
55 \\
55 \\
53 \\
52\end{array}$ & $\begin{array}{l}450 \\
460 \\
480 \\
570 \\
700\end{array}$ & $\begin{array}{l}420 \\
430 \\
450 \\
460 \\
570\end{array}$ & $\begin{array}{l}7.6 \\
7.6 \\
7.7 \\
7.6 \\
7.4\end{array}$ & $\begin{array}{l}7.4 \\
7.3 \\
7.5 \\
7.2 \\
7.2\end{array}$ & $\begin{array}{l}10.0 \\
10.0 \\
10.8 \\
10.6 \\
10.0\end{array}$ & $\begin{array}{l}7.6 \\
7.5 \\
7.4 \\
7.2 \\
6.4\end{array}$ & $\begin{array}{l}58 \\
59 \\
60 \\
61 \\
62\end{array}$ & $\begin{array}{l}56 \\
56 \\
56 \\
57 \\
58\end{array}$ \\
\hline $\begin{array}{l}26 \ldots \\
27 \ldots \\
28 \ldots\end{array}$ & $\begin{array}{l}560 \\
620 \\
720\end{array}$ & $\begin{array}{l}500 \\
540 \\
610\end{array}$ & $\begin{array}{l}7.6 \\
7.5 \\
7.4\end{array}$ & $\begin{array}{l}7.3 \\
7 \cdot 3 \\
7.3\end{array}$ & $\begin{array}{l}10.8 \\
11.0 \\
11.2\end{array}$ & $\begin{array}{l}9.2 \\
9.4 \\
8.6\end{array}$ & $\begin{array}{l}53 \\
52 \\
53\end{array}$ & $\begin{array}{l}51 \\
50 \\
50\end{array}$ & $\begin{array}{l}740 \\
760 \\
740\end{array}$ & $\begin{array}{l}690 \\
680 \\
700\end{array}$ & $\begin{array}{l}7.4 \\
7.4 \\
7.4\end{array}$ & $\begin{array}{l}7.2 \\
7.2 \\
7.1\end{array}$ & $\begin{array}{r}9.2 \\
10.3 \\
10.7\end{array}$ & $\begin{array}{l}6.2 \\
6.0 \\
5.6\end{array}$ & $\begin{array}{l}63 \\
65 \\
66\end{array}$ & $\begin{array}{l}60 \\
61 \\
63\end{array}$ \\
\hline $\begin{array}{l}29 \ldots \\
30 \ldots \\
31 \ldots\end{array}$ & $\begin{array}{r}650 \\
720 \\
--\end{array}$ & $\begin{array}{r}630 \\
630 \\
--\end{array}$ & $\begin{array}{r}7.4 \\
7.3 \\
--\end{array}$ & $\begin{array}{r}7.2 \\
7.2 \\
-.2\end{array}$ & $\begin{array}{r}11.1 \\
11.0 \\
-\ldots\end{array}$ & $\begin{array}{r}9.1 \\
9.6 \\
---\end{array}$ & $\begin{array}{l}54 \\
55 \\
-\end{array}$ & $\begin{array}{l}51 \\
53 \\
--\end{array}$ & $\begin{array}{l}810 \\
810 \\
800\end{array}$ & $\begin{array}{l}740 \\
740 \\
740\end{array}$ & $\begin{array}{l}7 \cdot 3 \\
7 \cdot 3 \\
7 \cdot 3\end{array}$ & $\begin{array}{l}7.0 \\
7.1 \\
7.1\end{array}$ & $\begin{array}{l}9.8 \\
8.4 \\
7.0\end{array}$ & $\begin{array}{l}5.0 \\
5.2 \\
5.2\end{array}$ & $\begin{array}{l}67 \\
64 \\
62\end{array}$ & $\begin{array}{l}64 \\
61 \\
60\end{array}$ \\
\hline
\end{tabular}


MUSKINGUM RIVER BASIN--Continued

3-1492. NUSKINGUM RIVER AT PHILO, OHIO--Continued

Data from continuous recorder, water year October 1966 to September 1967--Continued

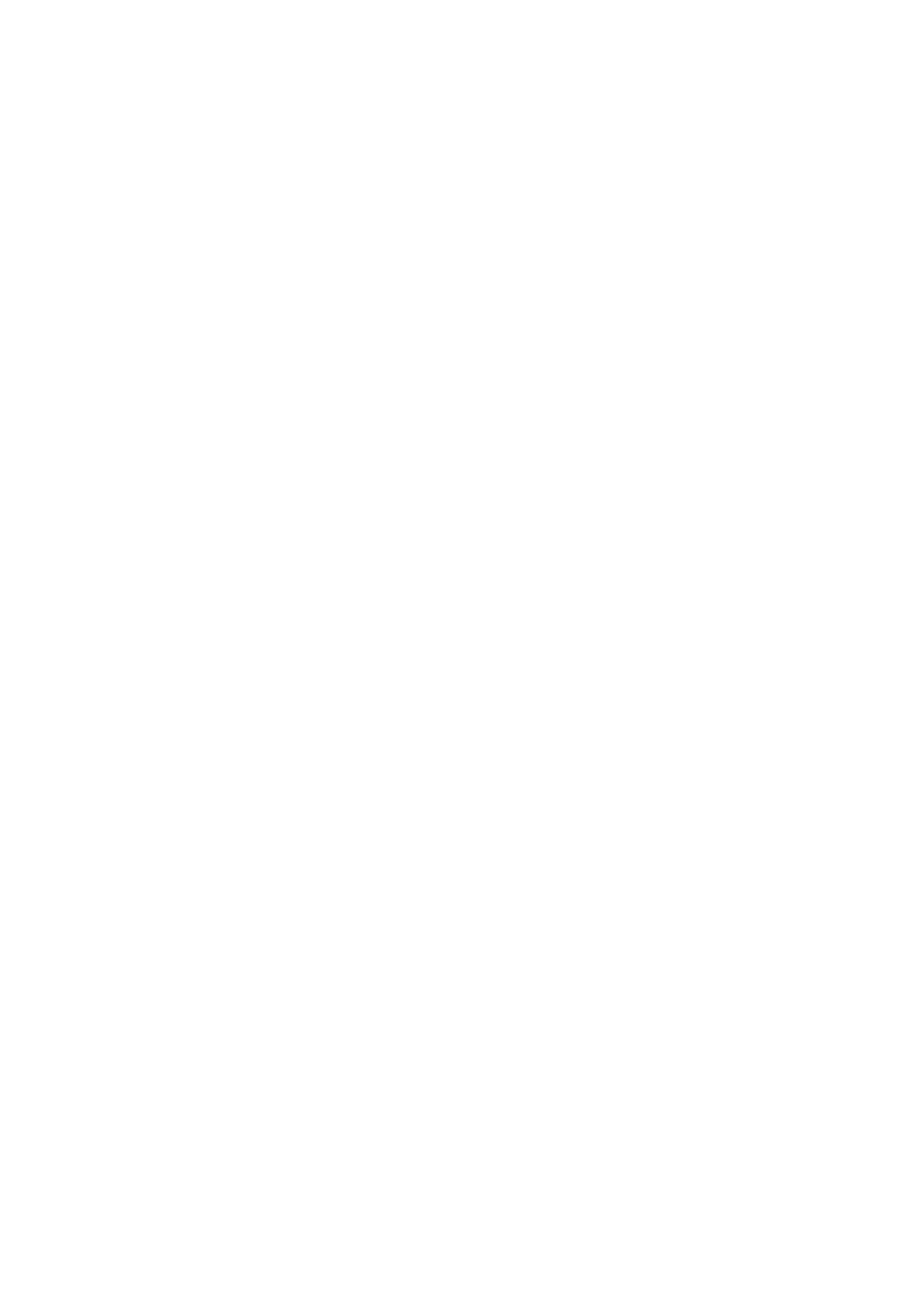




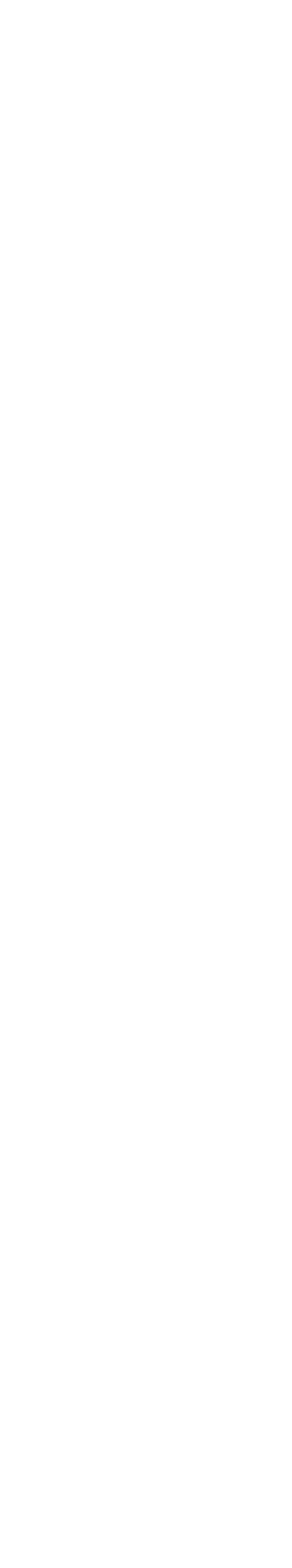

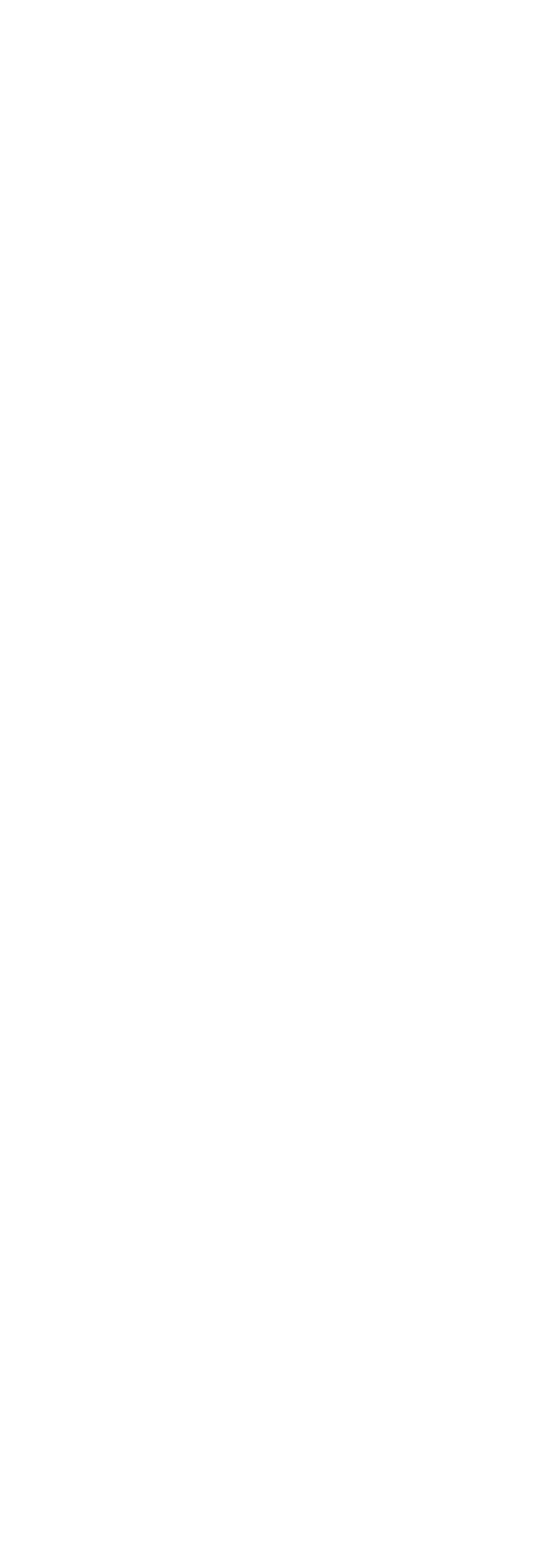



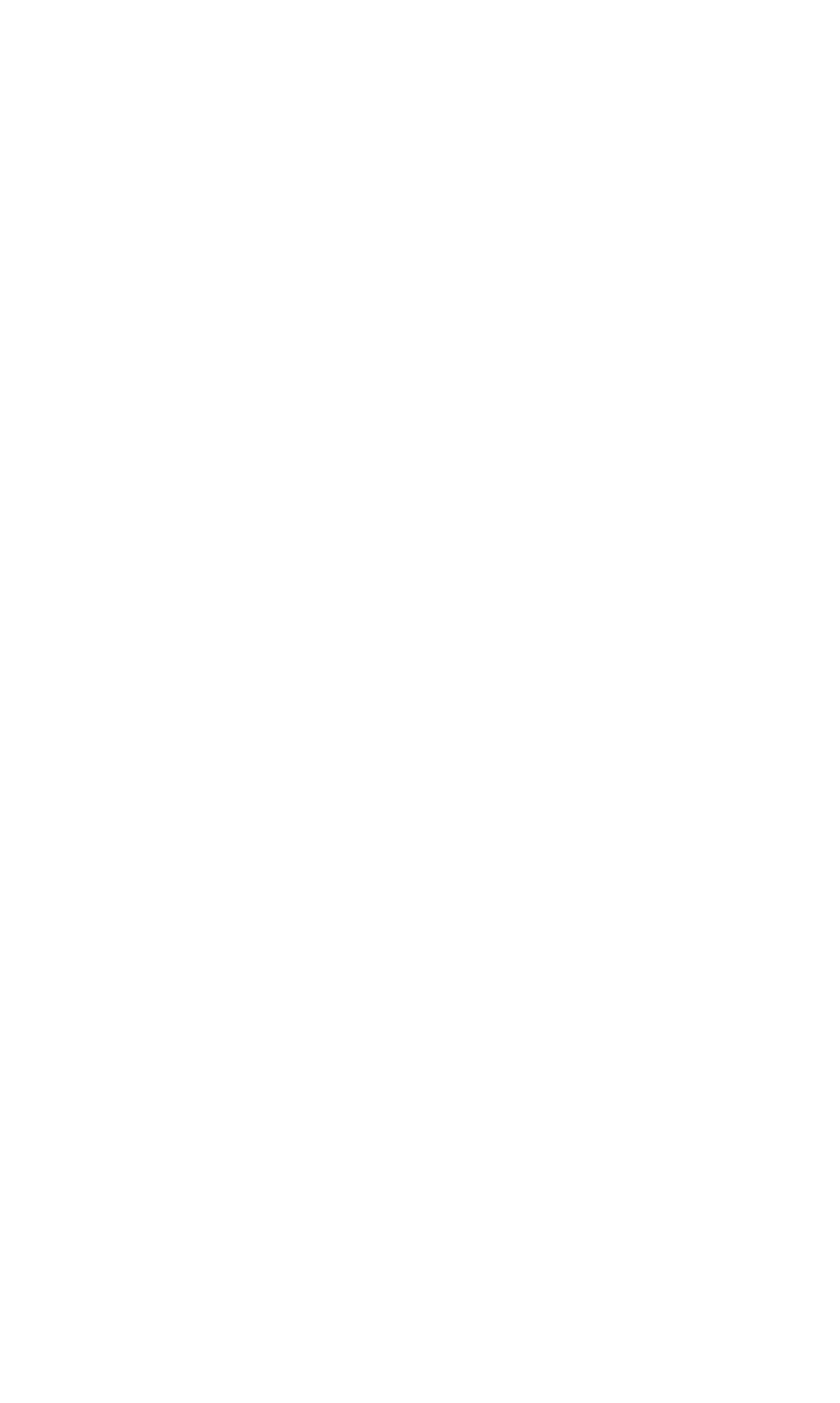


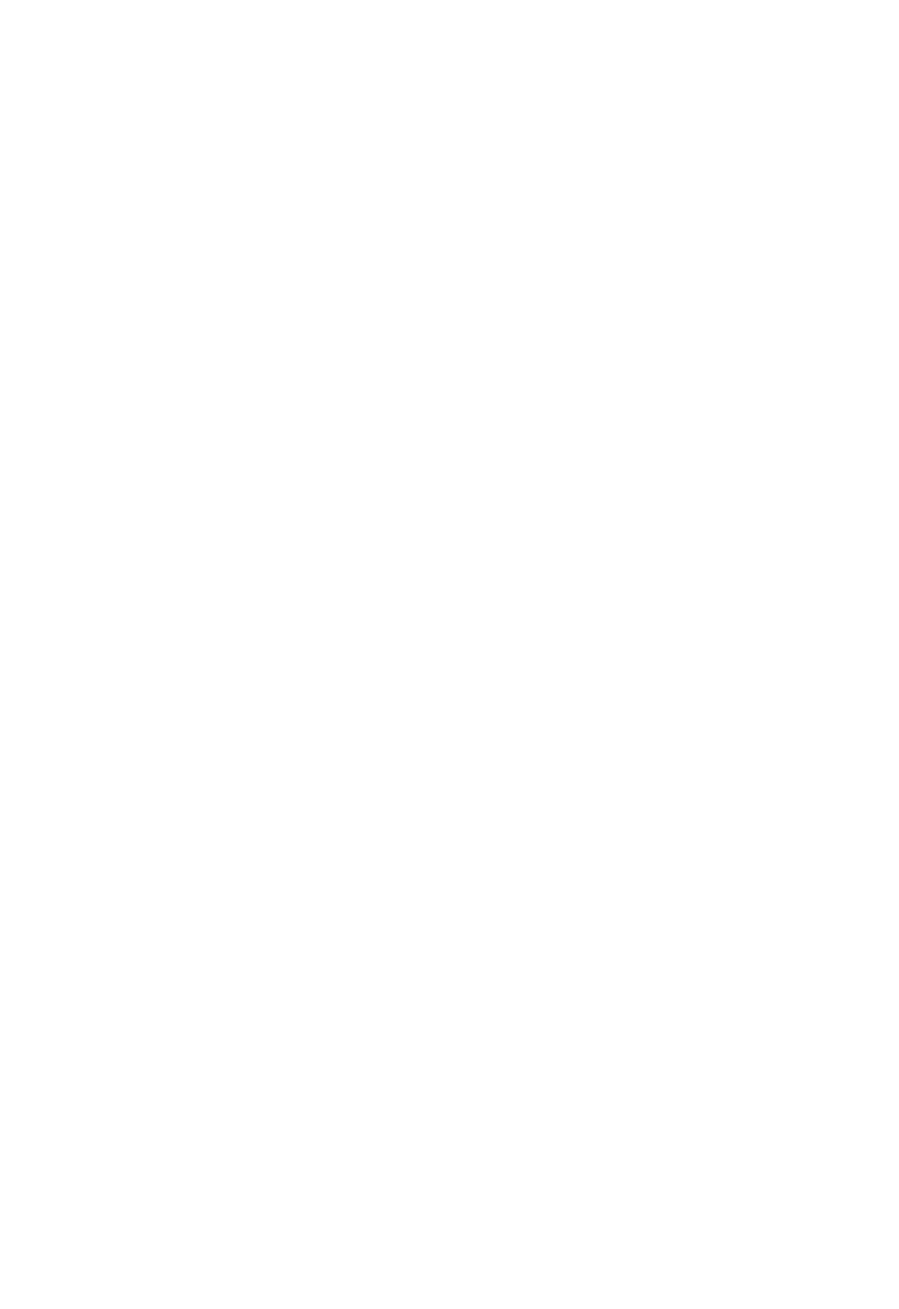




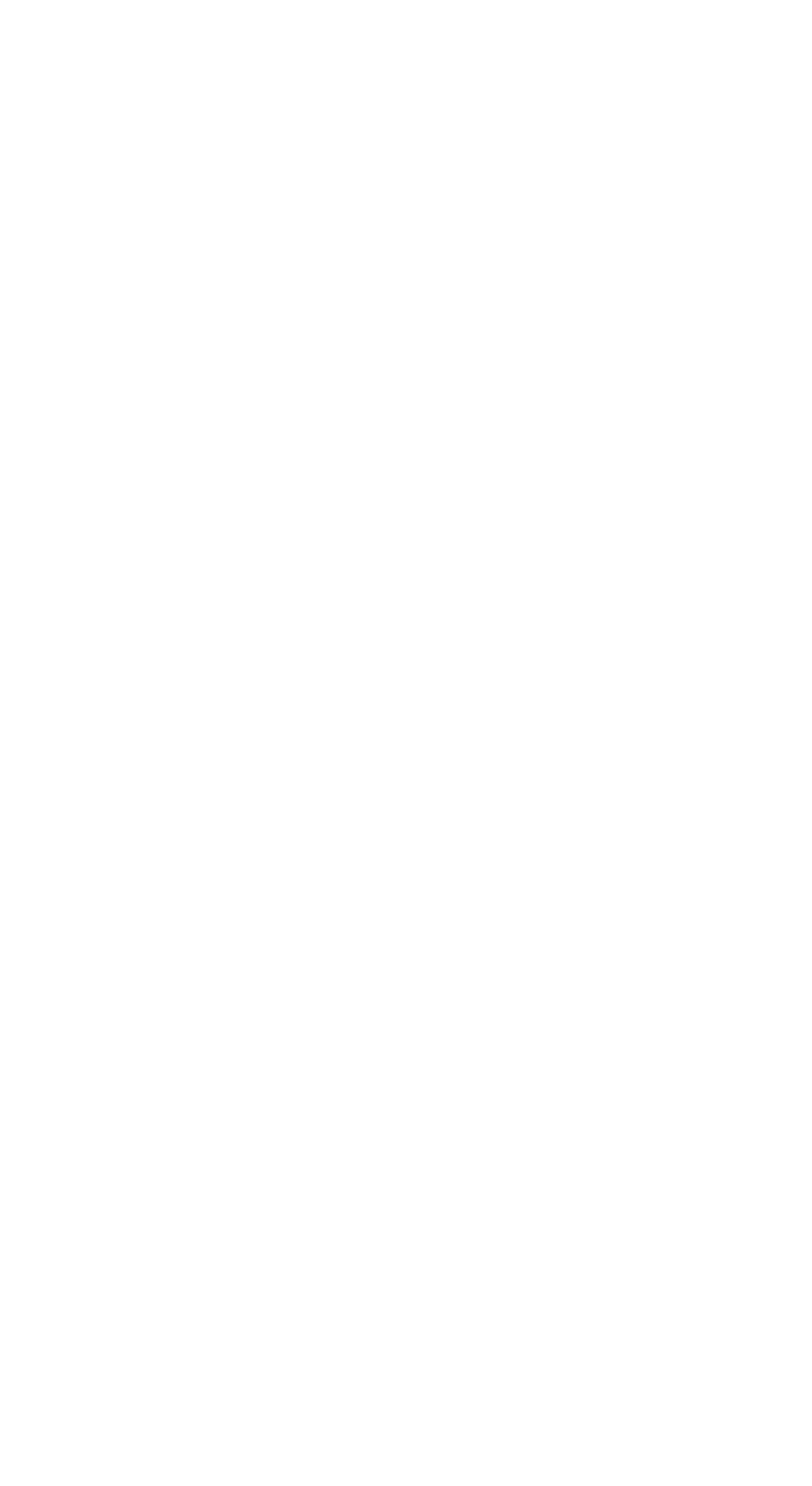


HOCKING RIVER BASIN--Continued

3-1595.1. HOCKING RIVER BELOW ATHENS, OHIO--COntinued

Data from continuous recorder, water year October 1966 to September 1967

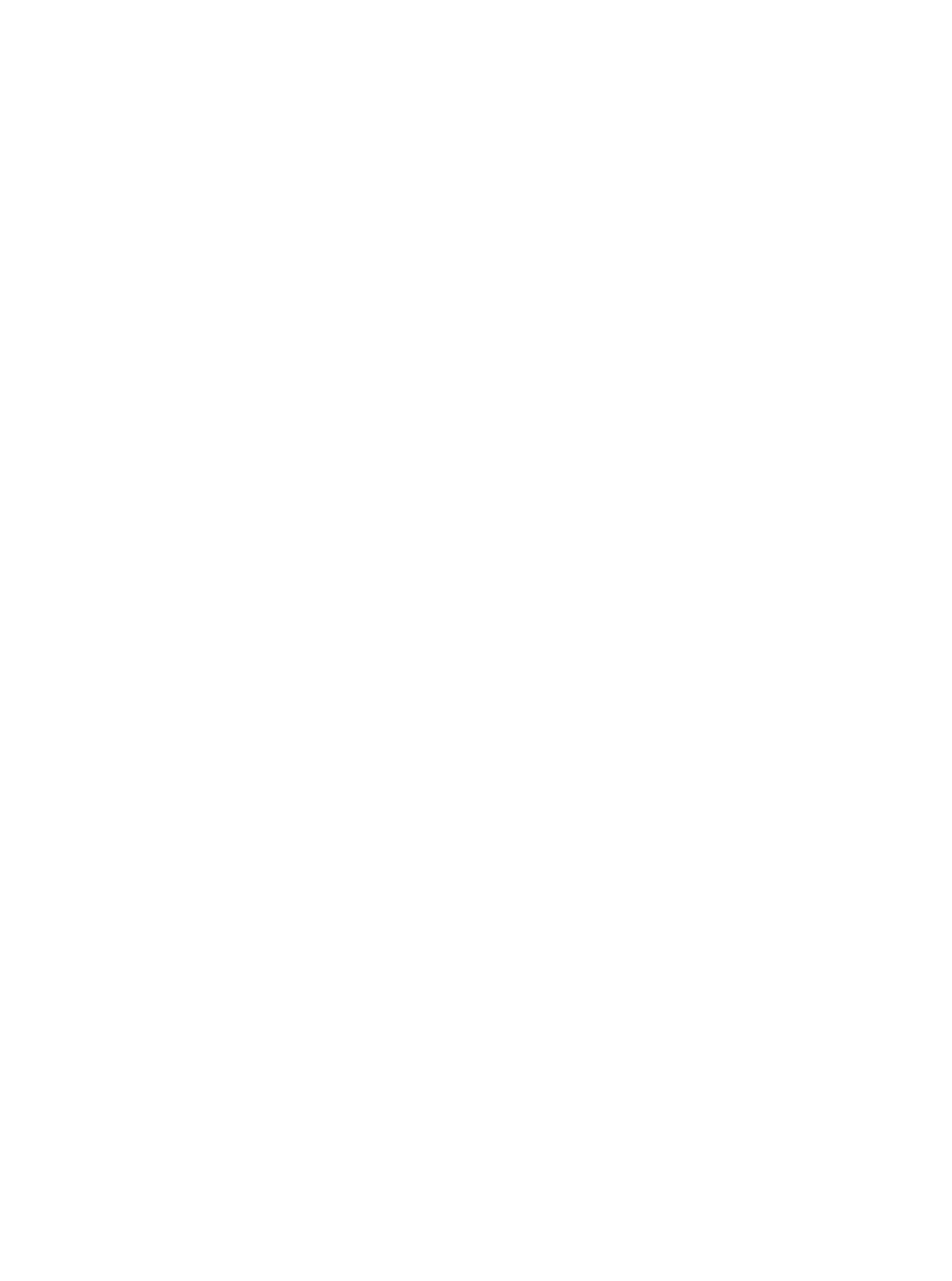


HOCKIKG RIVER BASIN--Cont1nued

3-1595,1. HOCKING RIVER BELOW ATHEN8, OHIO--Continued

Data from continuous recorder, water year October 1966 to september 1967--Continued

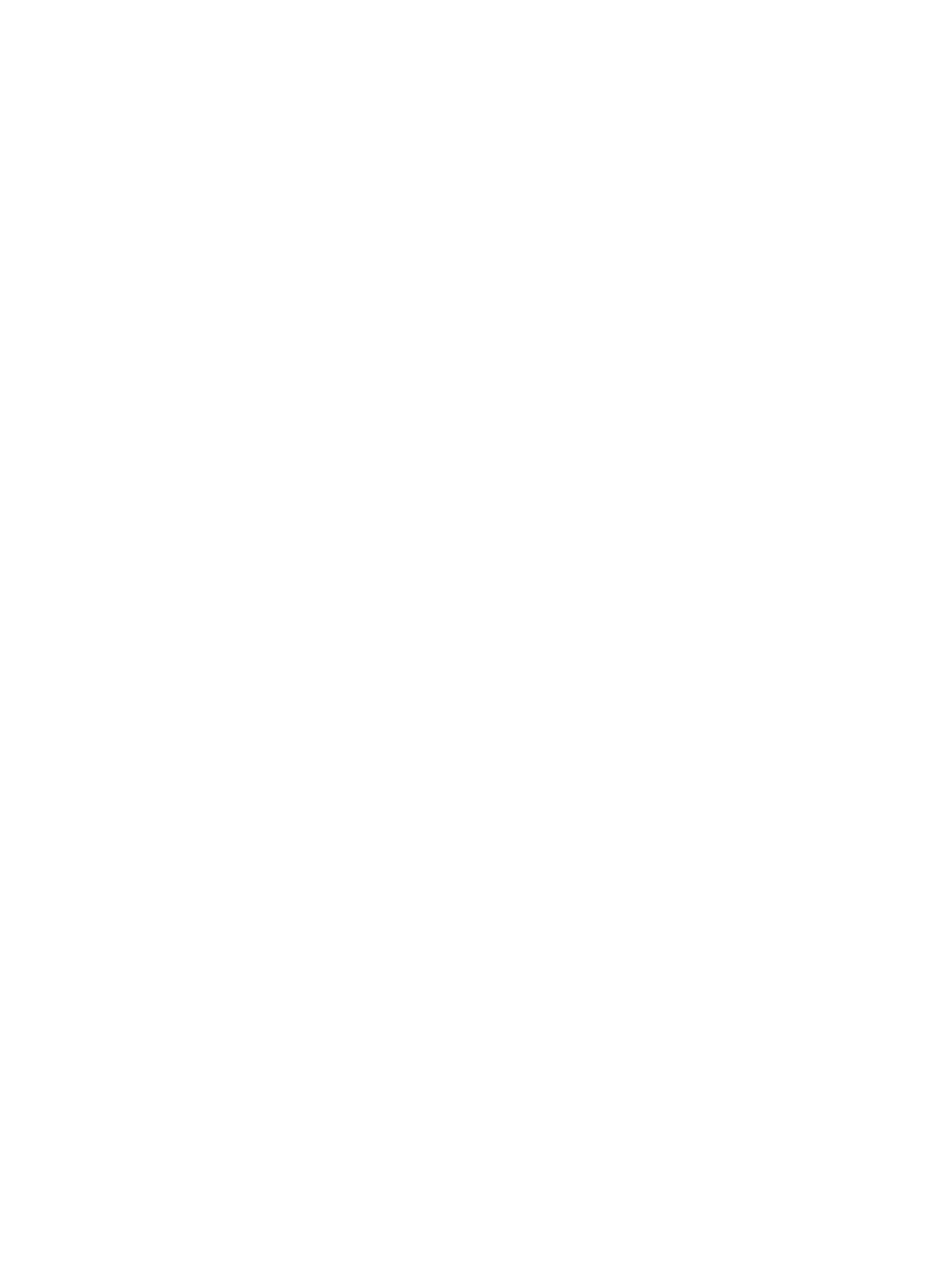



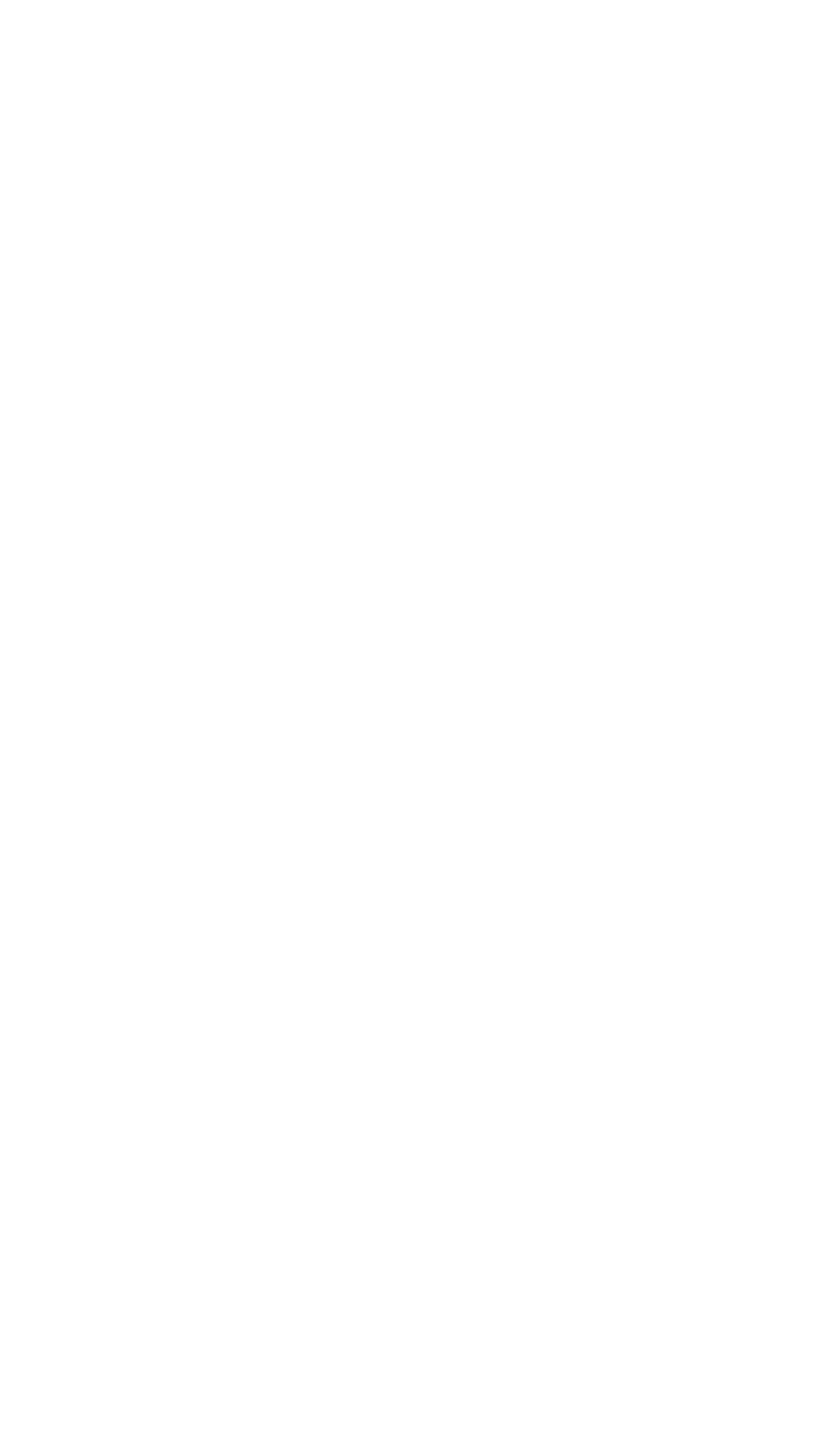


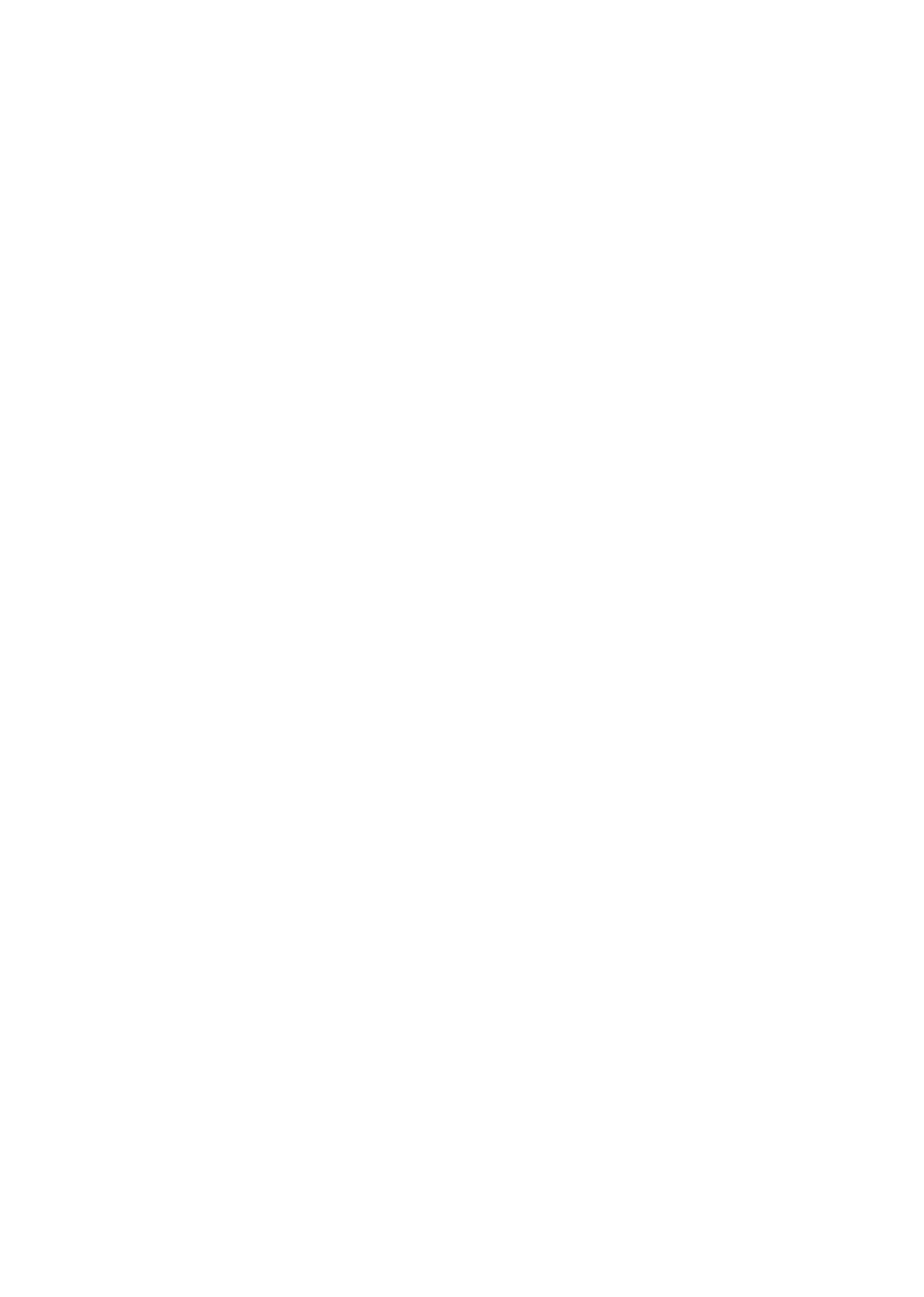




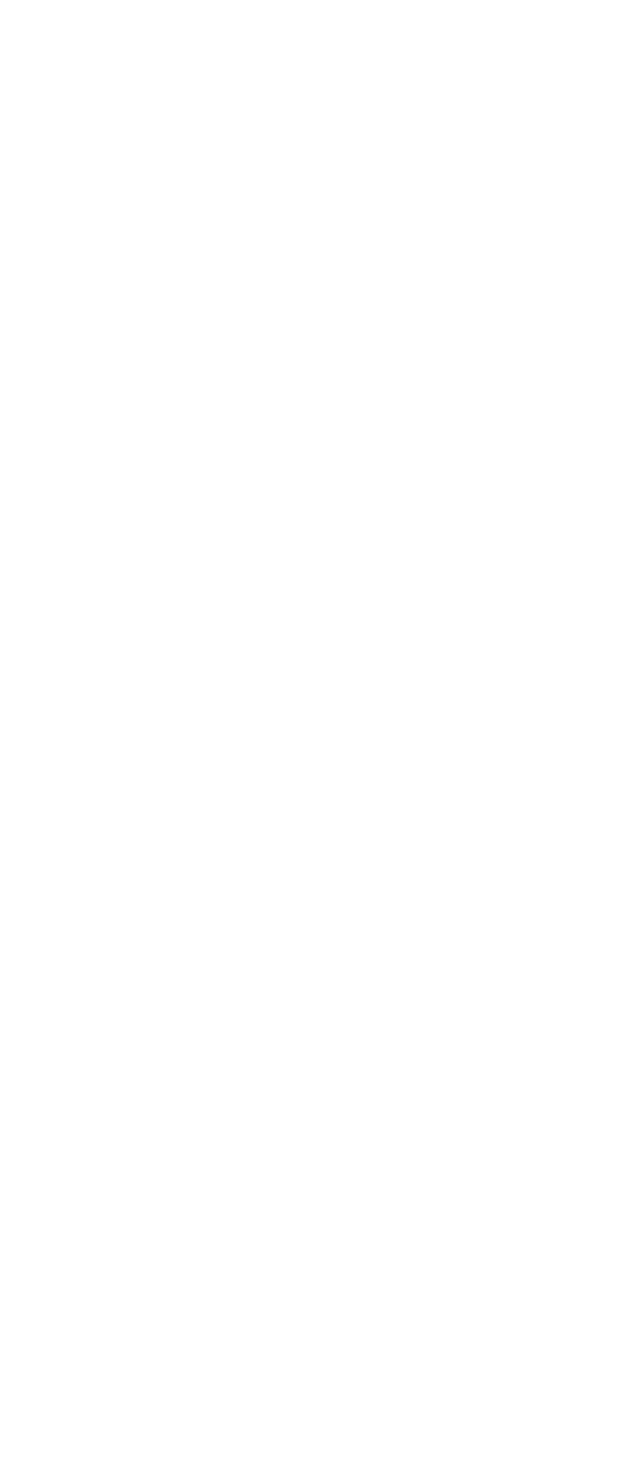




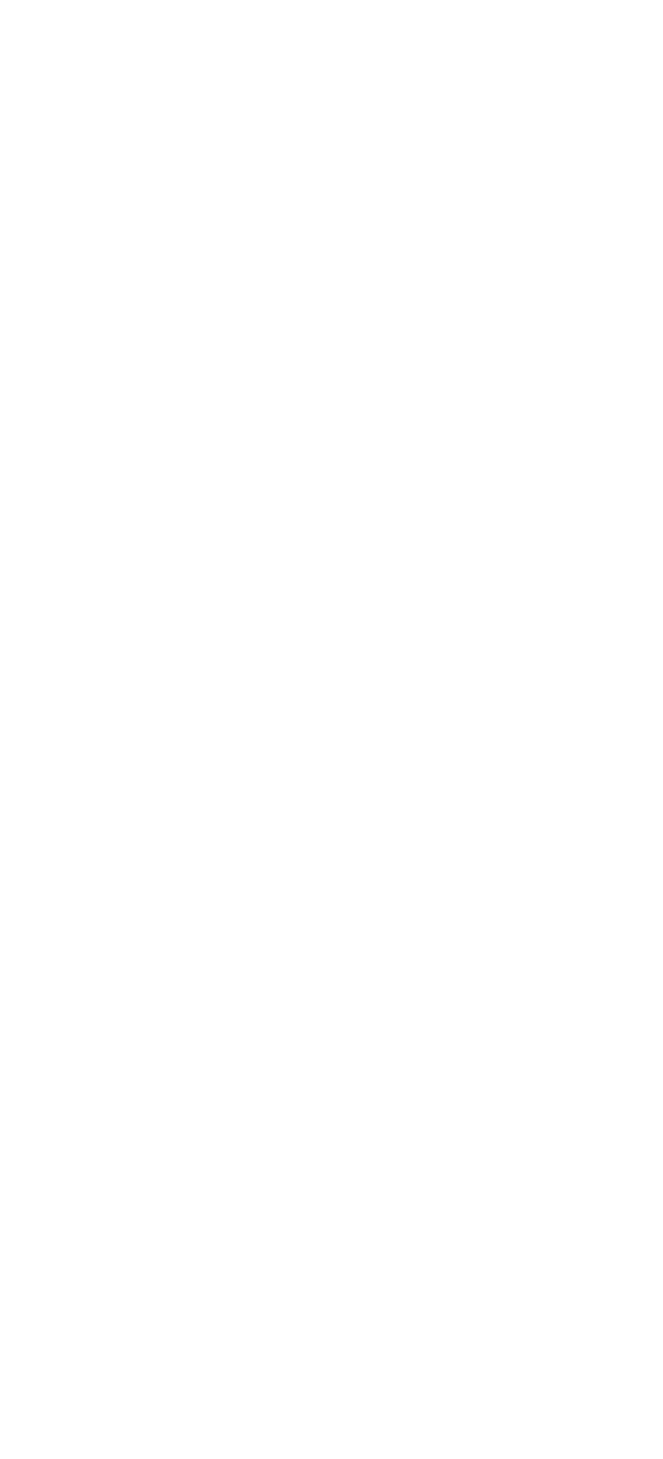




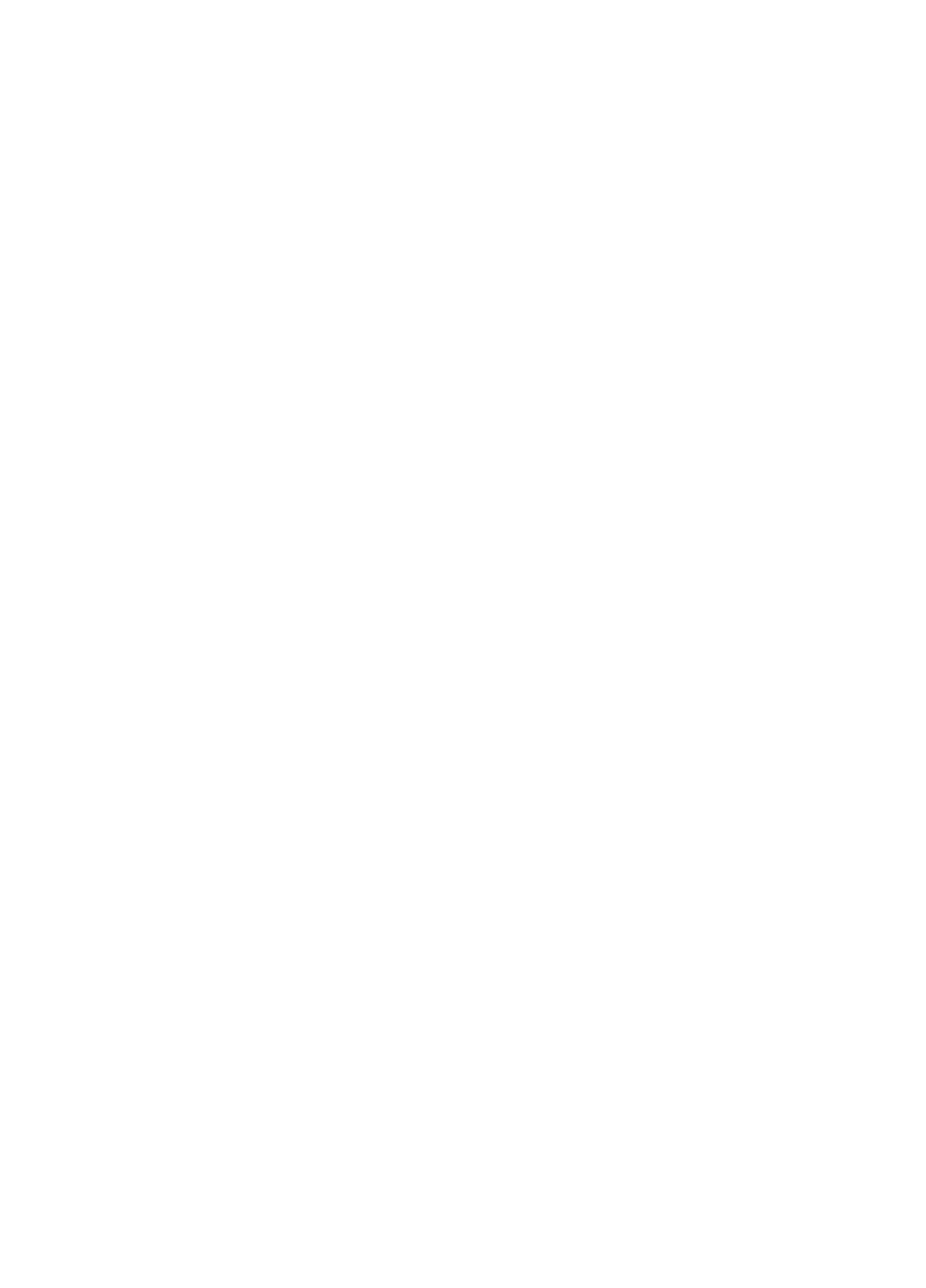




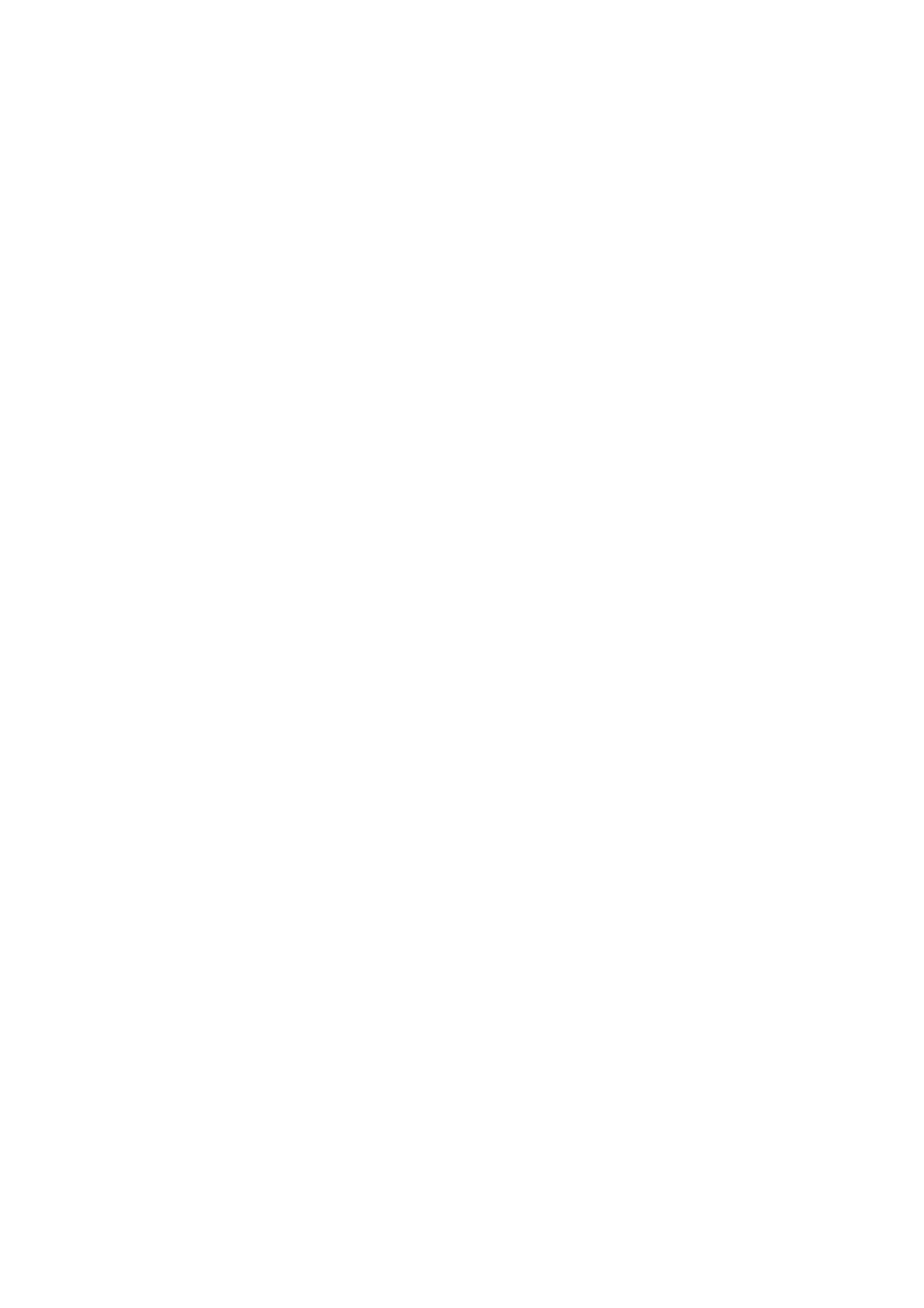




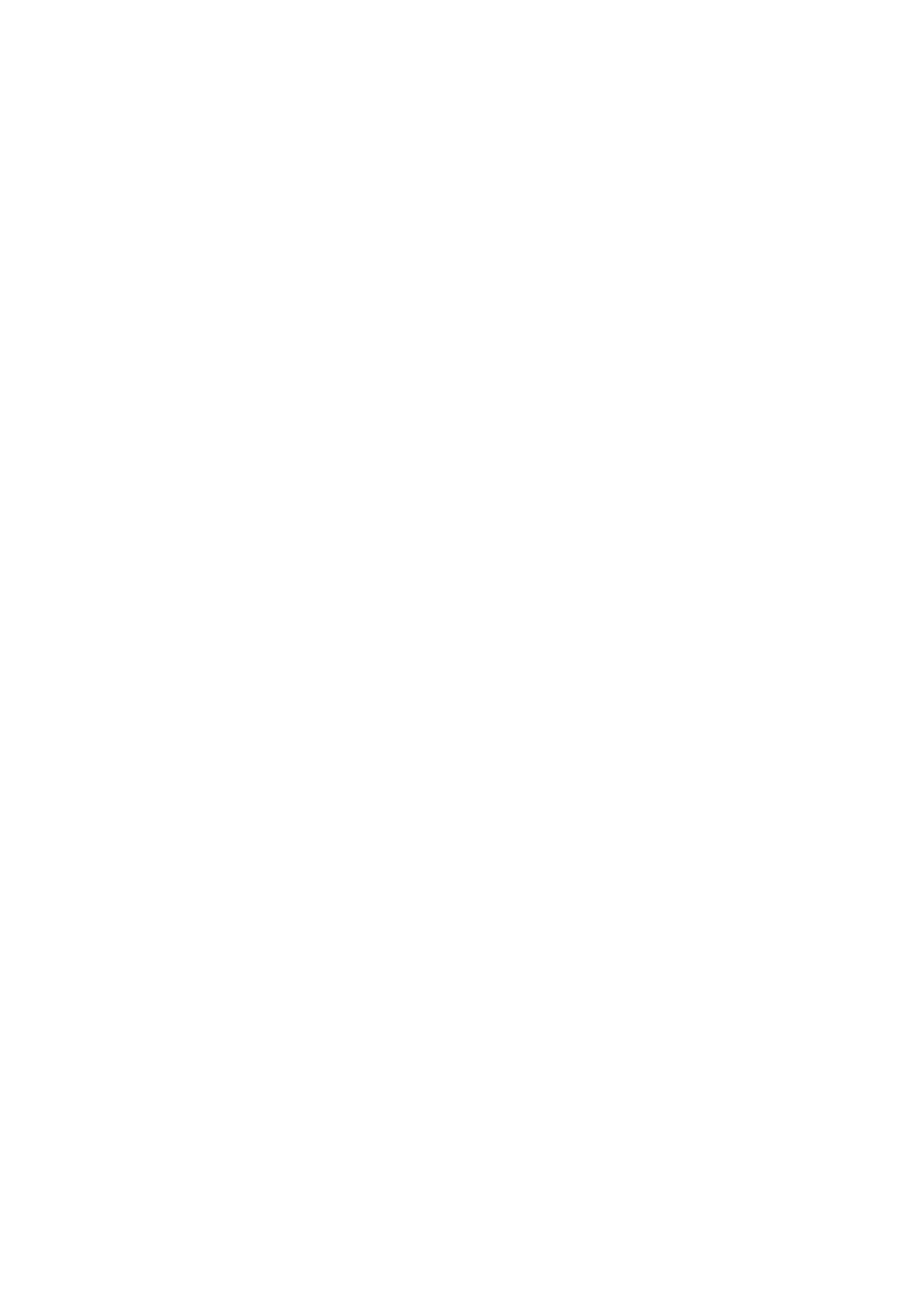




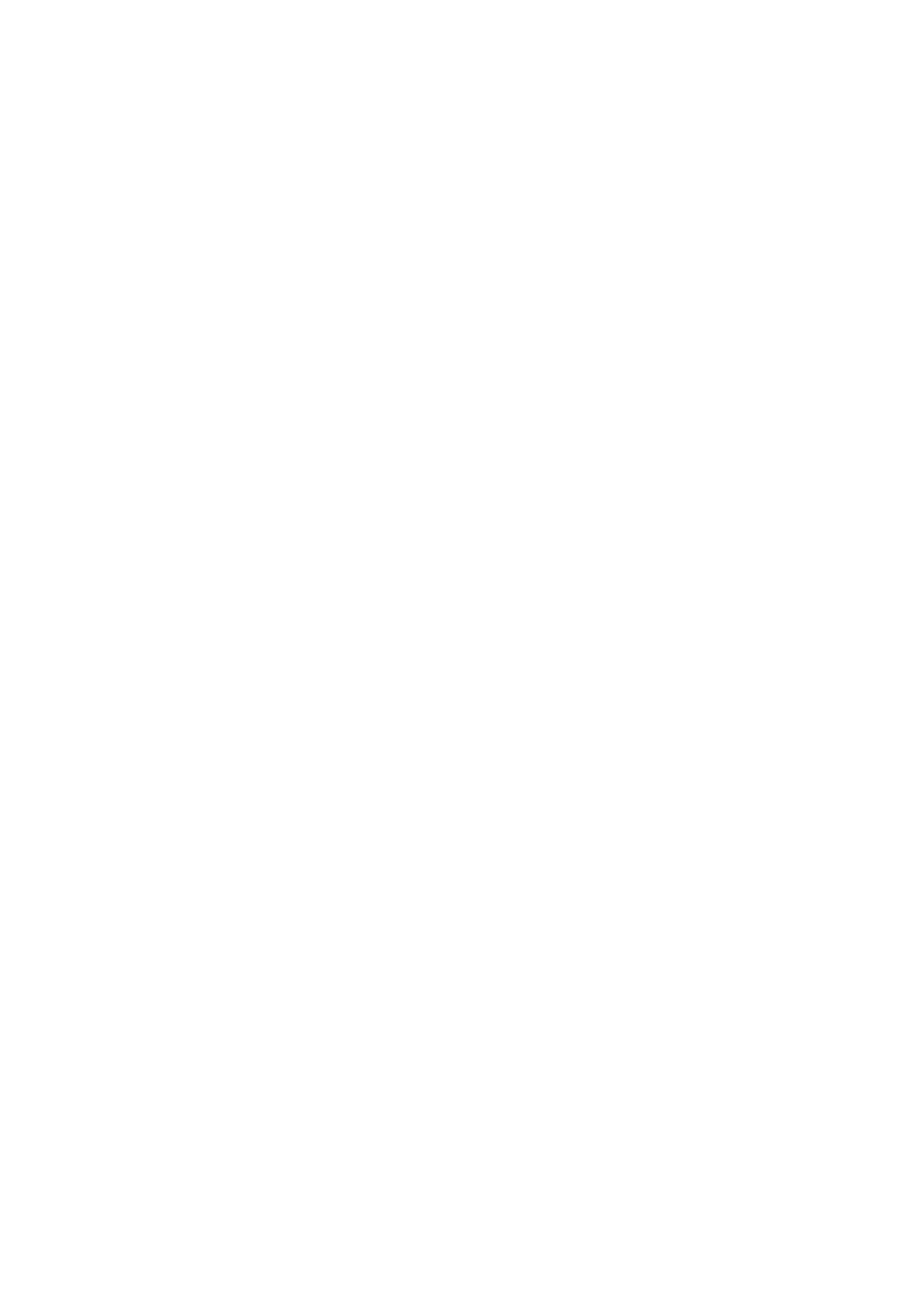




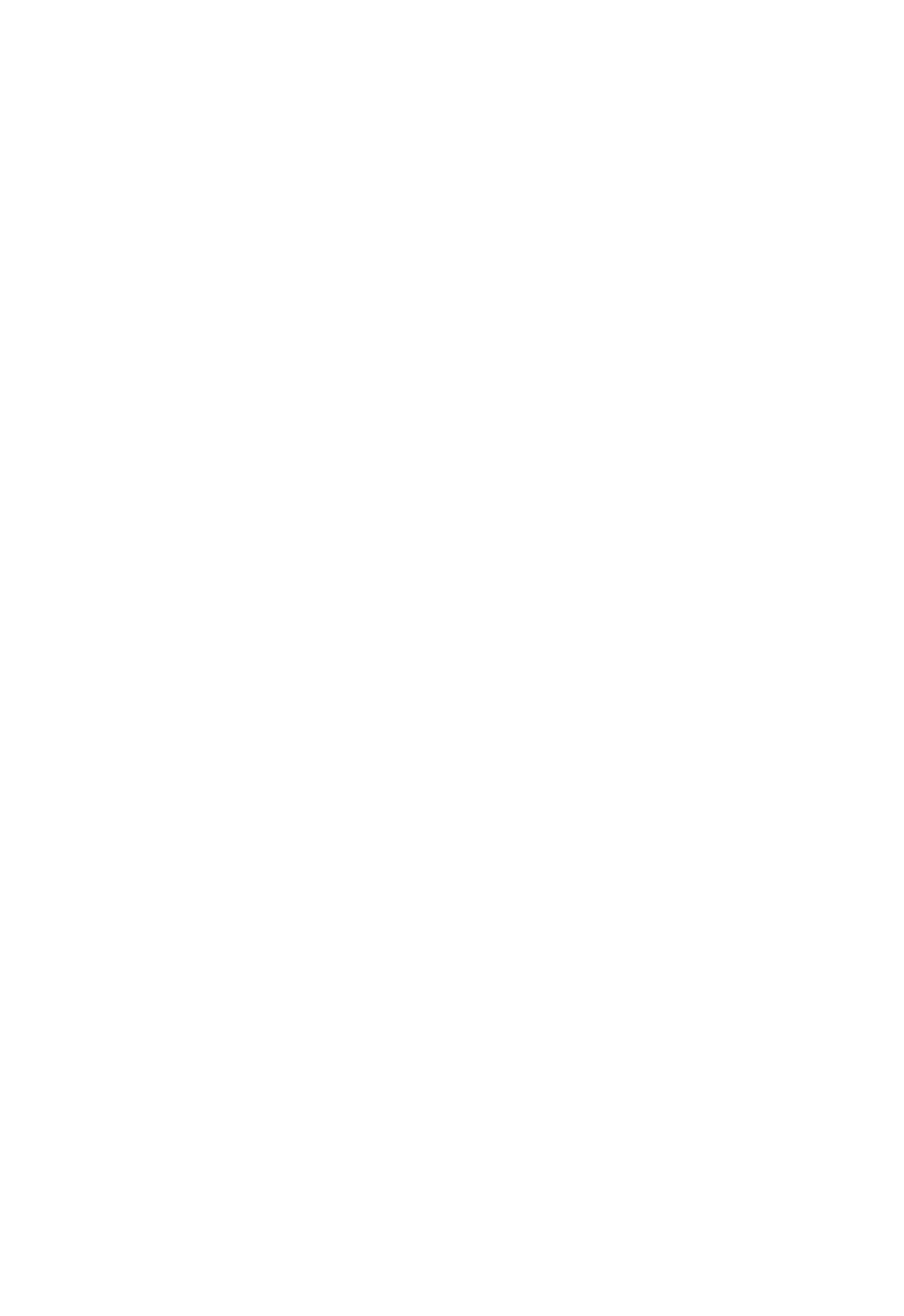




\begin{tabular}{|c|c|c|c|c|c|}
\hline \multicolumn{2}{|r|}{ 家台 } & & & & \\
\hline \multicolumn{2}{|r|}{ 垔 } & 000000 & 000000 & Dowonis & oscoson \\
\hline \multirow{2}{*}{\multicolumn{2}{|c|}{ 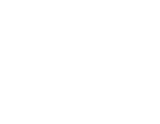 }} & 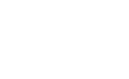 & 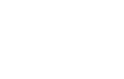 & 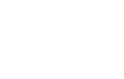 & 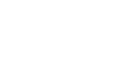 \\
\hline & & & & & \\
\hline \multirow{2}{*}{ 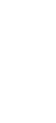 } & 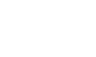 & 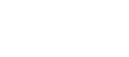 & చై & 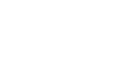 & 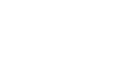 \\
\hline & 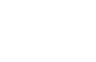 & 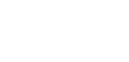 & 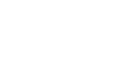 & 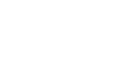 & ஊ \\
\hline \multicolumn{2}{|c|}{ चั๊ } & 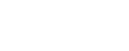 & 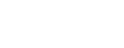 & 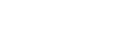 & ద్రాల్య \\
\hline
\end{tabular}

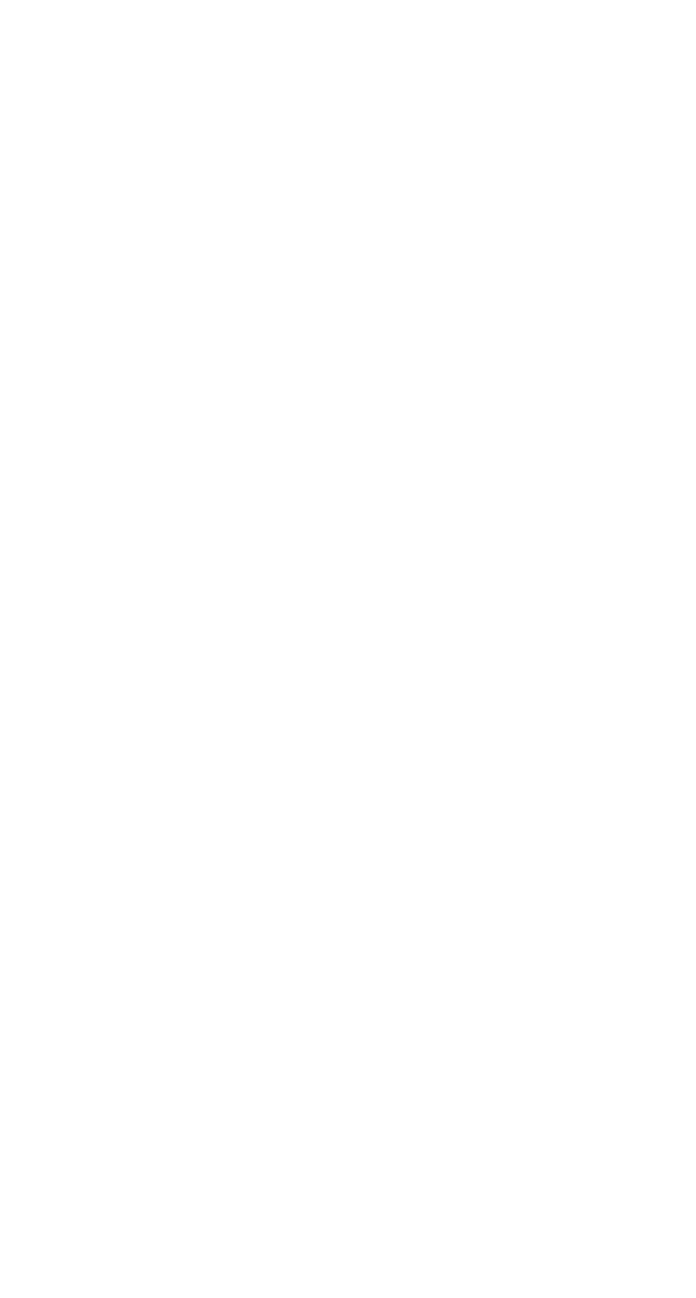




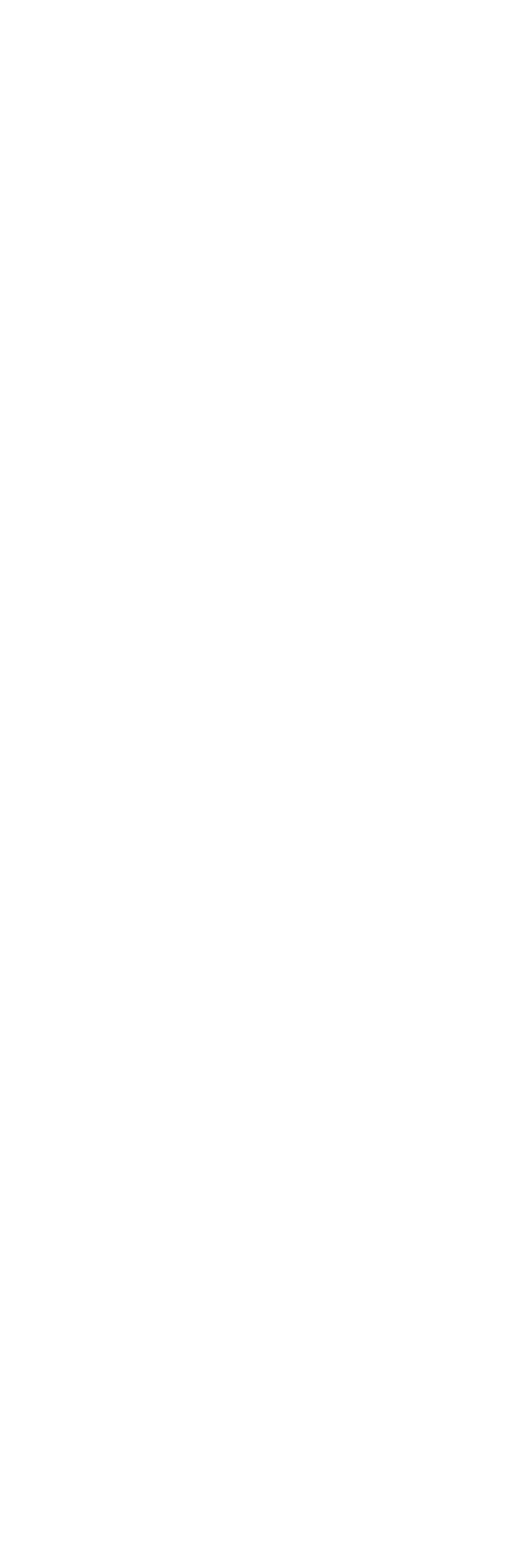

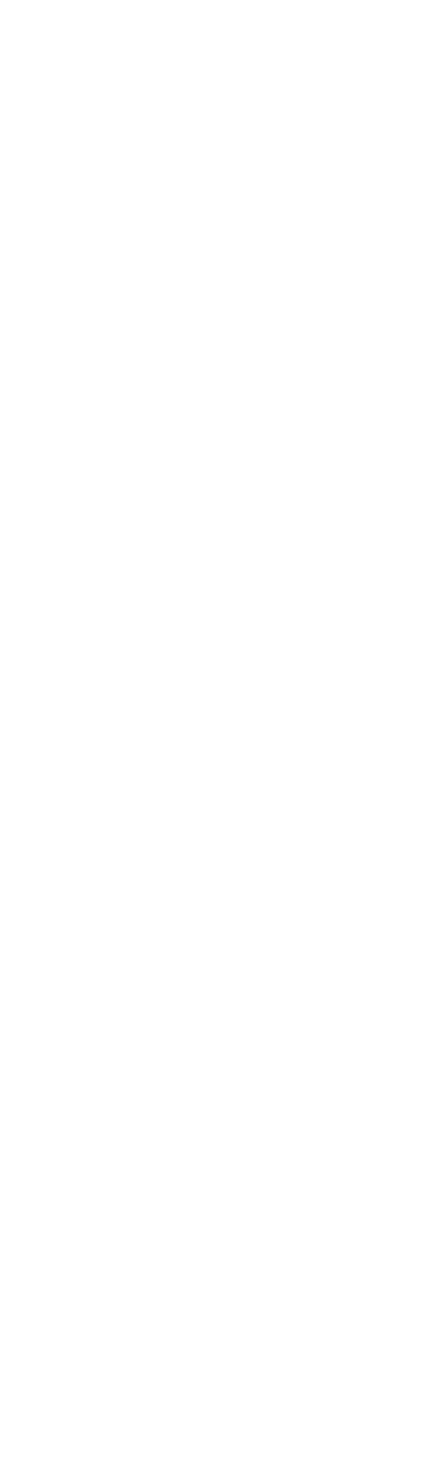




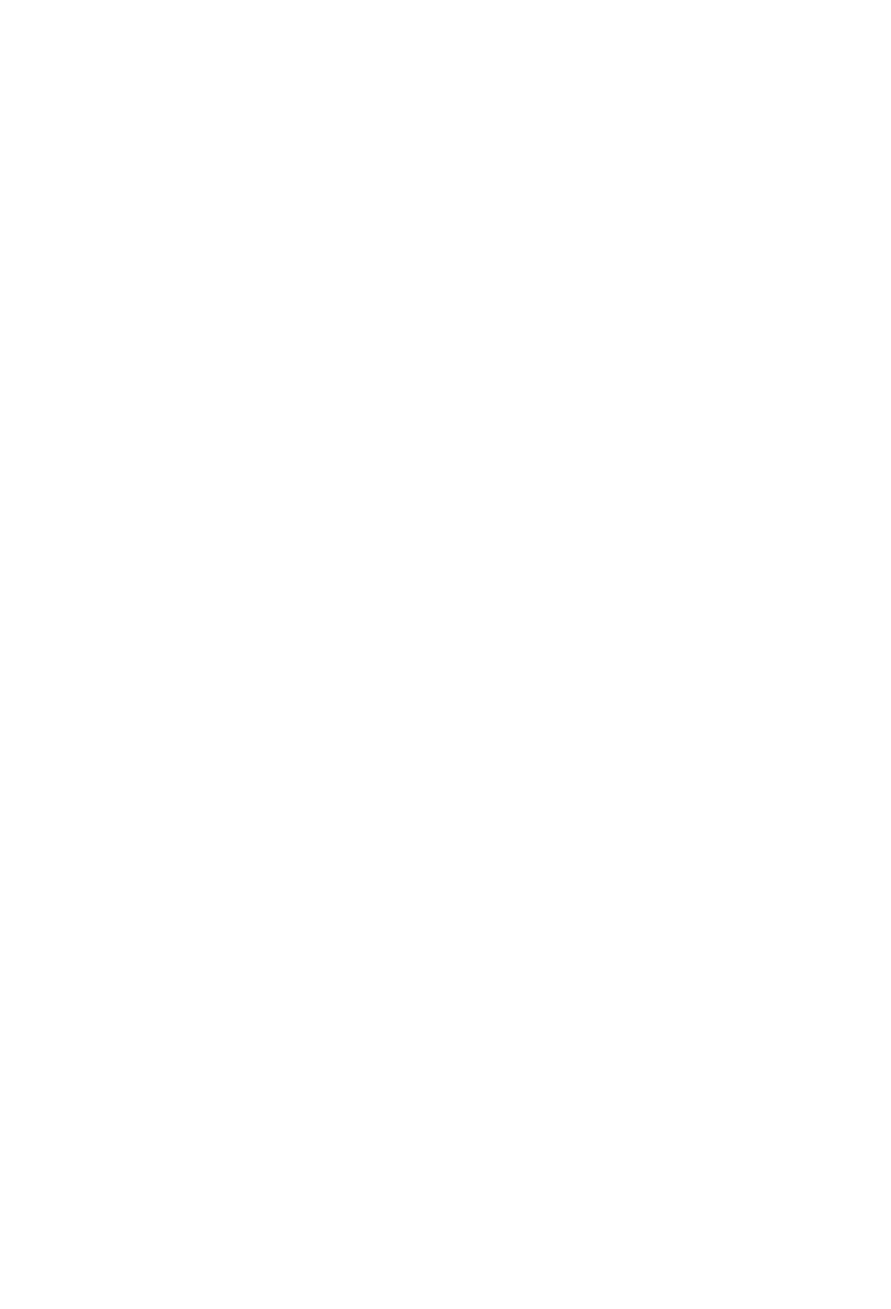




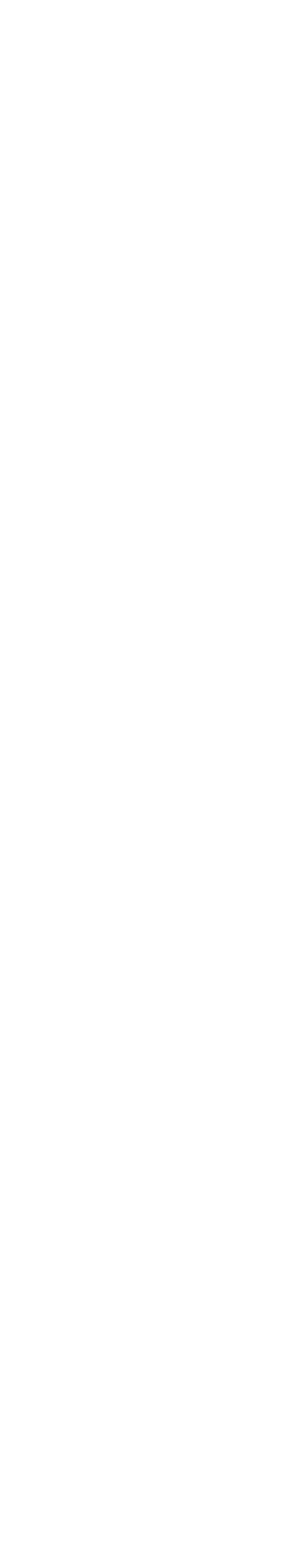

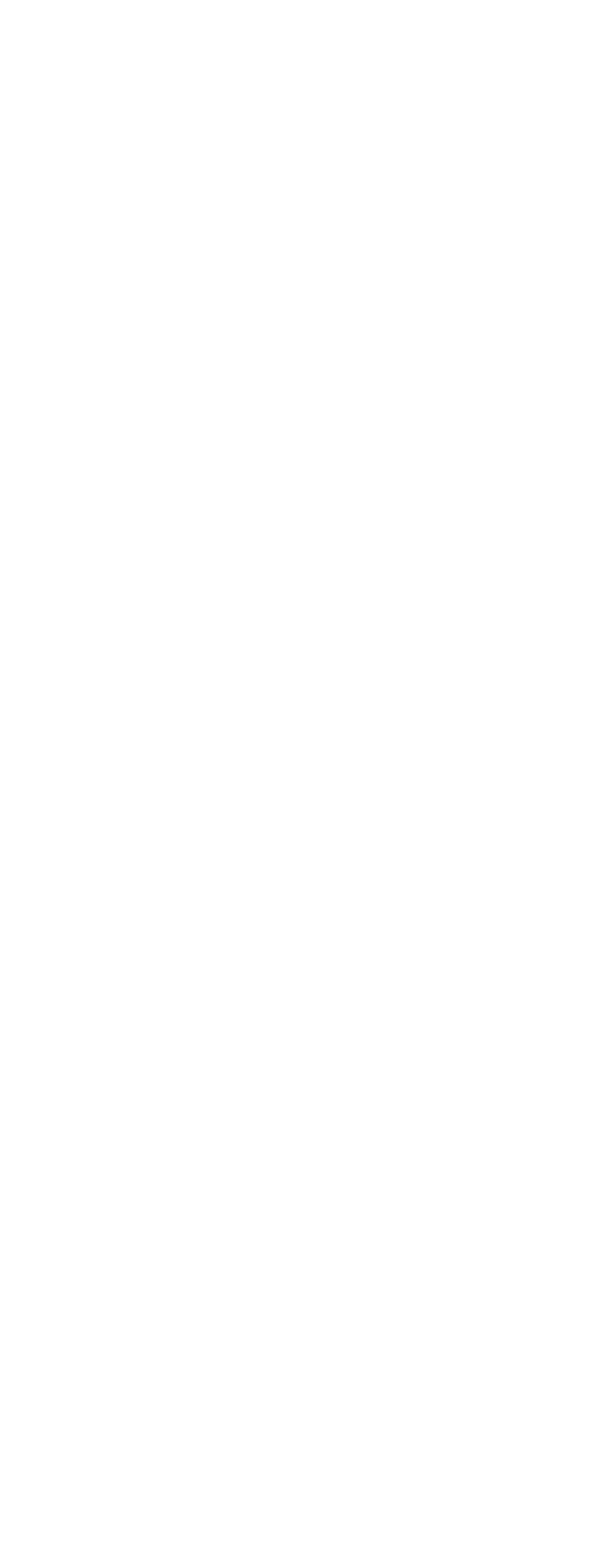




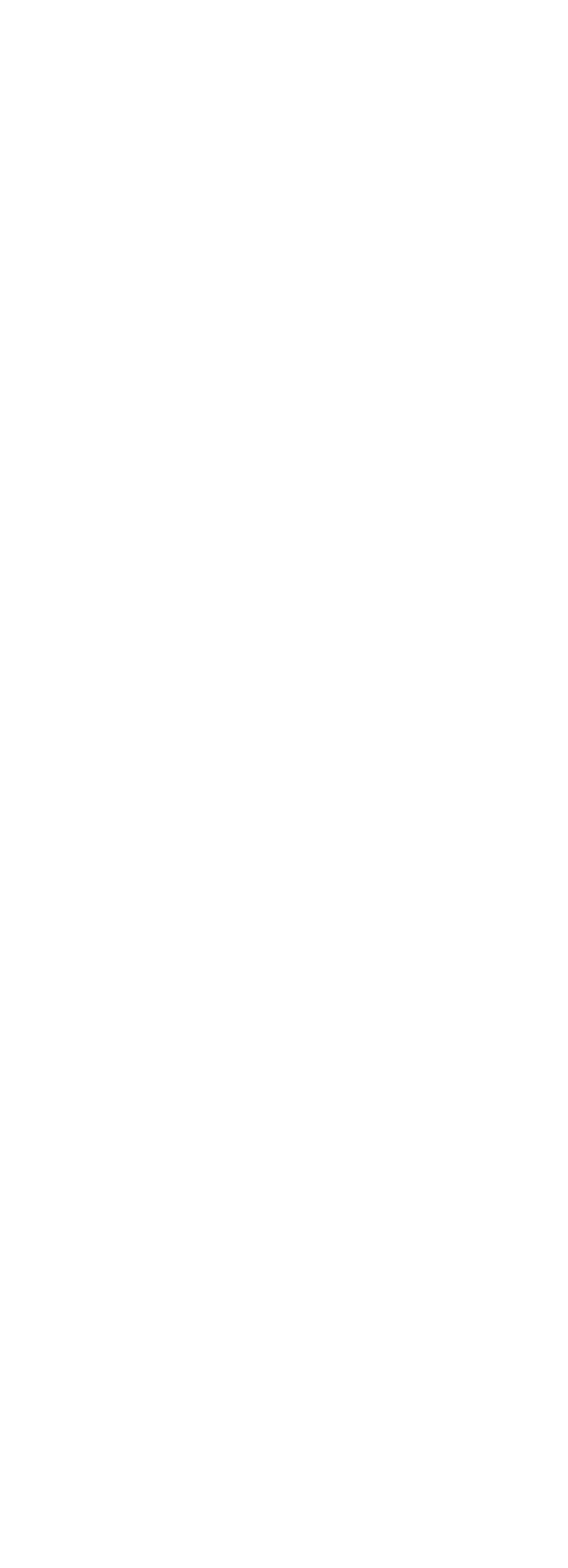


RACCOON CREEK BASIN--COntinued

3-2020. RACCOON CREEK AT ADAMSVILLE, OHIO--Continued

Data from continuous recorder, way to September 1967

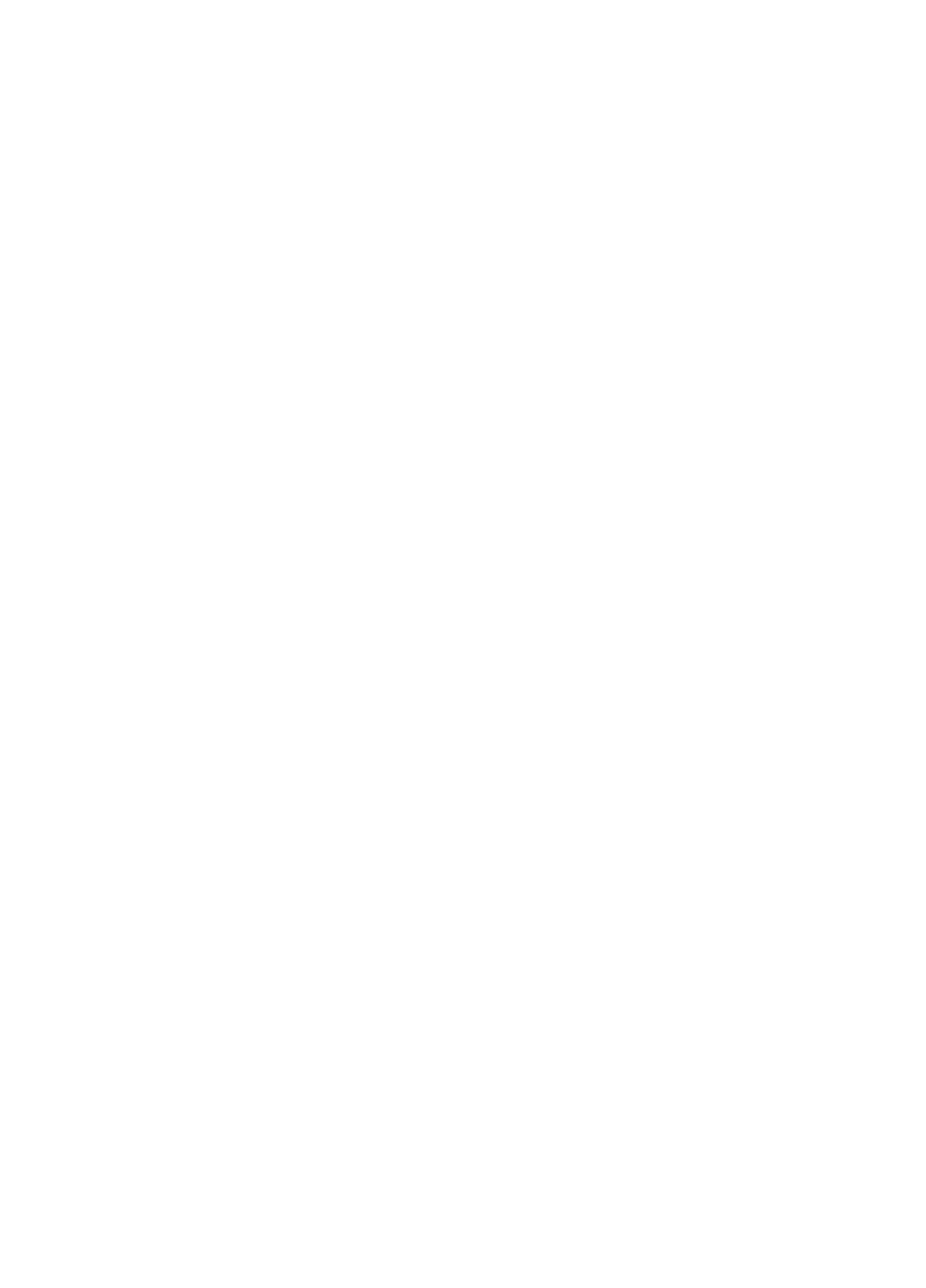


RACCOON CREEK BASIN--Continued

3-2020. RACCOON CREEK AT ADAYSVILLE, OHIO--Continued

Data from continuous recorder, way to September 1967--Continued

\begin{tabular}{|c|c|c|c|c|c|c|c|c|c|c|c|c|c|c|c|c|}
\hline \multirow{3}{*}{ Day } & \multicolumn{8}{|c|}{ AUGUST } & \multicolumn{8}{|c|}{ SEPTEMBER } \\
\hline & \multicolumn{2}{|c|}{$\begin{array}{c}\text { Specific } \\
\text { conductance } \\
\text { (micromhos } \\
\text { at } 25^{\circ} \mathrm{C} \text { ) }\end{array}$} & \multicolumn{2}{|c|}{$\mathrm{pH}$} & \multicolumn{2}{|c|}{$\begin{array}{l}\text { Diswolved } \\
\text { oxygen } \\
\text { (ppm) }\end{array}$} & \multicolumn{2}{|c|}{$\begin{array}{c}\text { Temper- } \\
\text { ature } \\
\left({ }^{\circ} \mathrm{F}\right)\end{array}$} & \multicolumn{2}{|c|}{$\begin{array}{c}\text { Specific } \\
\text { conductance } \\
\text { (micromhos } \\
\text { at } 25^{\circ} \mathrm{C} \text { ) } \\
\end{array}$} & \multicolumn{2}{|c|}{ pH } & \multicolumn{2}{|c|}{$\begin{array}{l}\text { Diseolved } \\
\text { oxygen } \\
\text { (ppm) }\end{array}$} & \multicolumn{2}{|c|}{$\begin{array}{c}\text { Temper- } \\
\text { ature } \\
(\circ \nabla)\end{array}$} \\
\hline & Max & Min & Max & Min & $\operatorname{Max}$ & Min & Max & Min & Max & Min & $\operatorname{Max}$ & Min & $\operatorname{Max}$ & Min & $\operatorname{Max}$ & Min \\
\hline $\begin{array}{l}\ldots \\
2 \ldots 0 \\
3 \ldots 0 \\
4 \ldots 0 \\
5 \ldots\end{array}$ & $\begin{array}{l}920 \\
920 \\
860 \\
700 \\
760\end{array}$ & $\begin{array}{l}860 \\
840 \\
690 \\
620 \\
660\end{array}$ & $\begin{array}{l}3.5 \\
3.4 \\
3.6 \\
3.6 \\
3.6\end{array}$ & $\begin{array}{l}3.3 \\
3.3 \\
3.3 \\
3.5 \\
3.5\end{array}$ & $\begin{array}{l}4.8 \\
5.8 \\
5.8 \\
6.0 \\
5.7\end{array}$ & $\begin{array}{l}4.4 \\
4.2 \\
5.2 \\
5.2 \\
5.3\end{array}$ & $\begin{array}{l}81 \\
80 \\
74 \\
76 \\
77\end{array}$ & $\begin{array}{l}69 \\
71 \\
71 \\
72 \\
70\end{array}$ & $\begin{array}{l}730 \\
810 \\
750 \\
740 \\
740\end{array}$ & $\begin{array}{l}650 \\
690 \\
720 \\
680 \\
710\end{array}$ & $\begin{array}{l}4 \cdot 6 \\
4 \cdot 5 \\
4 \cdot 4 \\
4 \cdot 4 \\
4 \cdot 4\end{array}$ & $\begin{array}{l}4 \cdot 4 \\
4 \cdot 3 \\
4 \cdot 2 \\
4 \cdot 2 \\
4 \cdot 2\end{array}$ & $\begin{array}{l}3.2 \\
3.2 \\
3.1 \\
3.1 \\
3.1\end{array}$ & $\begin{array}{l}2.9 \\
2.9 \\
2.8 \\
2.8 \\
2.8\end{array}$ & & \\
\hline $\begin{array}{r}6 \ldots \\
7 \ldots \\
8 \ldots \\
9 \ldots \\
10 \ldots\end{array}$ & $\begin{array}{r}770 \\
770 \\
830 \\
910 \\
1000\end{array}$ & $\begin{array}{l}660 \\
660 \\
740 \\
780 \\
870\end{array}$ & $\begin{array}{l}3.6 \\
3.6 \\
3.5 \\
3.5 \\
3.4\end{array}$ & $\begin{array}{l}3.5 \\
3.5 \\
3.4 \\
3.4 \\
3.3\end{array}$ & $\begin{array}{l}5.9 \\
6.3 \\
6.6 \\
6.7 \\
6.8\end{array}$ & $\begin{array}{l}5.5 \\
5.8 \\
6.2 \\
6.4 \\
6.4\end{array}$ & $\begin{array}{l}76 \\
73 \\
74 \\
74 \\
73\end{array}$ & $\begin{array}{l}71 \\
70 \\
69 \\
72 \\
70\end{array}$ & $\begin{array}{l}720 \\
760 \\
830 \\
830 \\
880\end{array}$ & $\begin{array}{l}660 \\
660 \\
720 \\
800 \\
820\end{array}$ & $\begin{array}{l}4 \cdot 3 \\
4 \cdot 3 \\
4 \cdot 3 \\
4 \cdot 3 \\
4 \cdot 3\end{array}$ & $\begin{array}{l}4 \cdot 1 \\
4 \cdot 1 \\
4 \cdot 1 \\
4 \cdot 1 \\
4 \cdot 2\end{array}$ & $\begin{array}{l}3.2 \\
3.5 \\
3.7 \\
3.7 \\
3.9\end{array}$ & $\begin{array}{l}3.0 \\
3.2 \\
3.4 \\
3.5 \\
2.5\end{array}$ & & \\
\hline $\begin{array}{l}11 \ldots \\
12 \ldots \\
13 \ldots \\
14 \ldots \\
15 \ldots\end{array}$ & $\begin{array}{l}910 \\
830 \\
830 \\
780 \\
770\end{array}$ & $\begin{array}{l}800 \\
780 \\
760 \\
710 \\
700\end{array}$ & $\begin{array}{l}3.5 \\
3.5 \\
3.5 \\
3.6 \\
3.6\end{array}$ & $\begin{array}{l}3.4 \\
3.4 \\
3.4 \\
3.5 \\
3.5\end{array}$ & $\begin{array}{l}7.2 \\
7.5 \\
7.7 \\
7.4 \\
7.9\end{array}$ & $\begin{array}{l}6.6 \\
7.1 \\
7.2 \\
7.2 \\
7.3\end{array}$ & $\begin{array}{l}72 \\
72 \\
71 \\
72 \\
71\end{array}$ & $\begin{array}{l}69 \\
67 \\
67 \\
66 \\
63\end{array}$ & $\begin{array}{r}900 \\
920 \\
1040 \\
960 \\
990\end{array}$ & $\begin{array}{l}820 \\
840 \\
920 \\
910 \\
930\end{array}$ & $\begin{array}{l}4.2 \\
4.2 \\
4 \cdot 1 \\
4.1 \\
4.0\end{array}$ & $\begin{array}{l}4.0 \\
3.9 \\
3.9 \\
3.8 \\
3.8\end{array}$ & $\begin{array}{l}2.8 \\
3.2 \\
3.5 \\
3.8 \\
3.9\end{array}$ & $\begin{array}{l}2.3 \\
1.7 \\
2.2 \\
3.0 \\
1.8\end{array}$ & & \\
\hline $\begin{array}{l}16 \ldots \\
17 \ldots \\
18 \ldots 0 \\
19 \ldots \\
20 \ldots\end{array}$ & $\begin{array}{l}780 \\
820 \\
820 \\
860 \\
830\end{array}$ & $\begin{array}{l}760 \\
770 \\
740 \\
750 \\
810\end{array}$ & $\begin{array}{l}3.6 \\
3.6 \\
3.7 \\
3.7 \\
3.8\end{array}$ & $\begin{array}{l}3.5 \\
3.5 \\
3.6 \\
3.6 \\
3.6\end{array}$ & $\begin{array}{l}7.8 \\
7.8 \\
7.7 \\
7.2 \\
6.5\end{array}$ & $\begin{array}{l}7.1 \\
7.0 \\
6.9 \\
6.5 \\
6.0\end{array}$ & $\begin{array}{l}70 \\
72 \\
73 \\
73 \\
76\end{array}$ & $\begin{array}{l}66 \\
69 \\
68 \\
71 \\
71\end{array}$ & $\begin{array}{r}930 \\
940 \\
960 \\
1070 \\
1190\end{array}$ & $\begin{array}{r}880 \\
870 \\
890 \\
960 \\
1070\end{array}$ & $\begin{array}{l}4.0 \\
3.9 \\
3.9 \\
3.8 \\
3.8\end{array}$ & $\begin{array}{l}3.7 \\
3.7 \\
3.7 \\
3.7 \\
3.5\end{array}$ & $\begin{array}{l}2.9 \\
3.2 \\
3.3 \\
2.9 \\
4.6\end{array}$ & $\begin{array}{l}2.4 \\
2.3 \\
2.8 \\
2.4 \\
2.5\end{array}$ & & \\
\hline $\begin{array}{l}21 \ldots \\
22 \ldots \\
23 \ldots \\
24 \ldots \\
25 \ldots\end{array}$ & $\begin{array}{l}830 \\
780 \\
790 \\
840 \\
830\end{array}$ & $\begin{array}{l}770 \\
750 \\
740 \\
790 \\
780\end{array}$ & $\begin{array}{l}3.8 \\
3.9 \\
3.9 \\
3.8 \\
3.8\end{array}$ & $\begin{array}{l}3.7 \\
3.8 \\
3.8 \\
3.7 \\
3.7\end{array}$ & $\begin{array}{l}6.1 \\
6.1 \\
6.0 \\
6.1 \\
6.0\end{array}$ & $\begin{array}{l}5.7 \\
5.6 \\
5.5 \\
5.8 \\
5.5\end{array}$ & $\begin{array}{l}73 \\
73 \\
75 \\
73 \\
74\end{array}$ & $\begin{array}{l}66 \\
64 \\
65 \\
67 \\
67\end{array}$ & $\begin{array}{l}1110 \\
1060 \\
1220 \\
1080 \\
1110\end{array}$ & $\begin{array}{r}990 \\
970 \\
980 \\
970 \\
1030\end{array}$ & $\begin{array}{l}3.6 \\
3.7 \\
3.8 \\
3.7 \\
3.6\end{array}$ & $\begin{array}{l}3.5 \\
3.5 \\
3.5 \\
3.5 \\
3.4\end{array}$ & $\begin{array}{l}5.0 \\
4.8 \\
5.5 \\
3.9 \\
4.1\end{array}$ & $\begin{array}{l}3.9 \\
2.9 \\
3.2 \\
3.8 \\
3.5\end{array}$ & 60 & 54 \\
\hline $\begin{array}{l}26 \ldots \\
27 \ldots \\
28 \ldots \\
29 \ldots \\
30 \ldots \\
31 \ldots\end{array}$ & $\begin{array}{r}870 \\
2190 \\
770 \\
660 \\
660 \\
690\end{array}$ & $\begin{array}{l}780 \\
750 \\
660 \\
600 \\
600 \\
630\end{array}$ & $\begin{array}{l}3.8 \\
4.4 \\
4.4 \\
4.4 \\
4.5 \\
4.6\end{array}$ & $\begin{array}{l}3.7 \\
3.7 \\
4.3 \\
4.3 \\
4.4 \\
4.5\end{array}$ & $\begin{array}{l}5.7 \\
5.8 \\
5.7 \\
3.7 \\
3.2 \\
3.2\end{array}$ & $\begin{array}{l}5.4 \\
4.8 \\
3.6 \\
2.9 \\
2.8 \\
2.0\end{array}$ & $\begin{array}{l}72 \\
=- \\
=-\end{array}$ & $\begin{array}{l}69 \\
=- \\
=- \\
=-\end{array}$ & $\begin{array}{l}= \\
=- \\
=- \\
=\end{array}$ & $\begin{array}{l}= \\
=- \\
=-\end{array}$ & $\begin{array}{r}3.6 \\
3.8 \\
3.9 \\
3.9 \\
3.9 \\
-.\end{array}$ & $\begin{array}{l}3.5 \\
3.6 \\
3.8 \\
3.8 \\
3.7 \\
-.\end{array}$ & $\begin{array}{l}3.6 \\
3.8 \\
5.7 \\
6.3 \\
7.0 \\
-\end{array}$ & $\begin{array}{l}3.0 \\
2.1 \\
3.8 \\
5.7 \\
4.9 \\
-.\end{array}$ & & \\
\hline
\end{tabular}




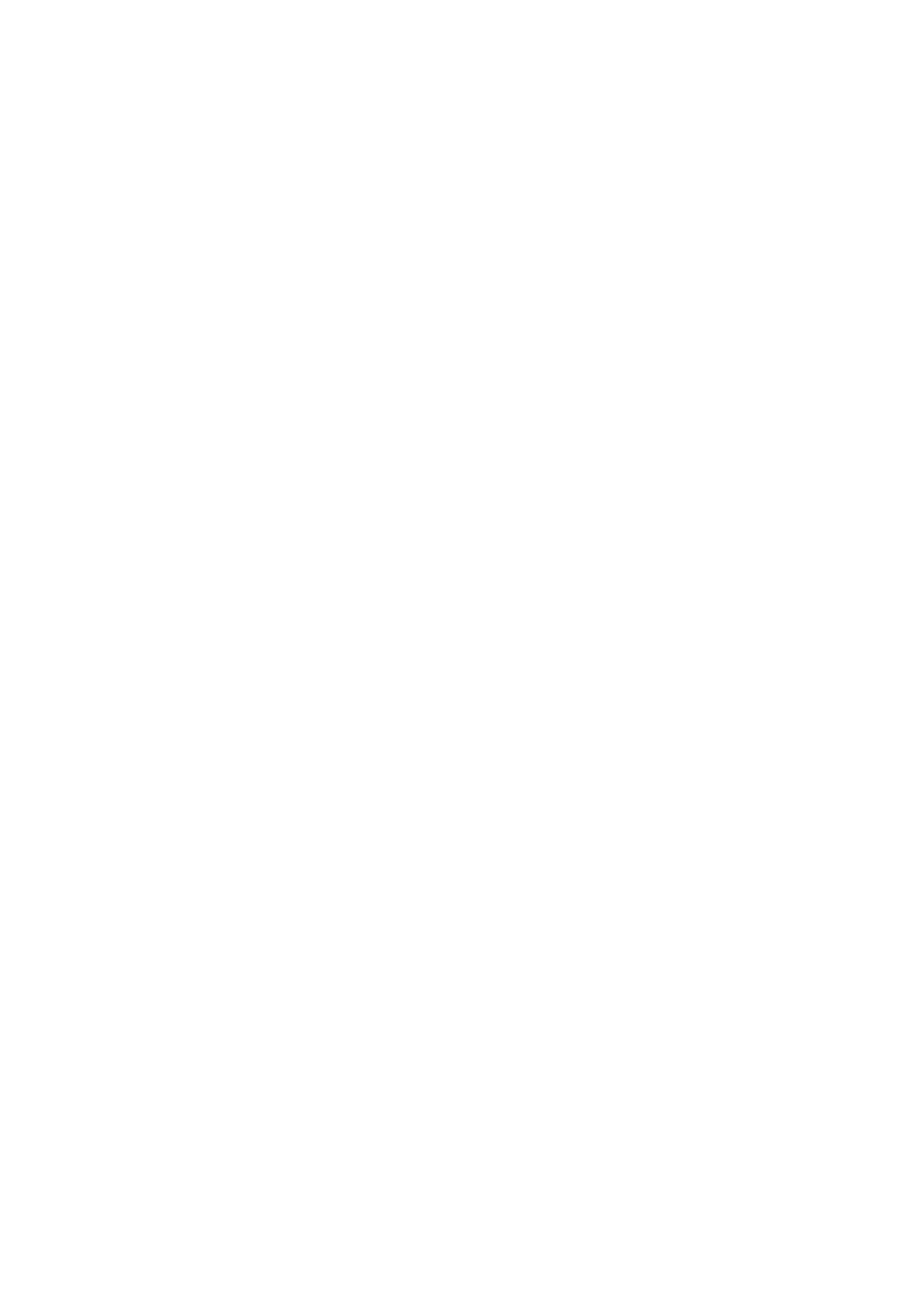




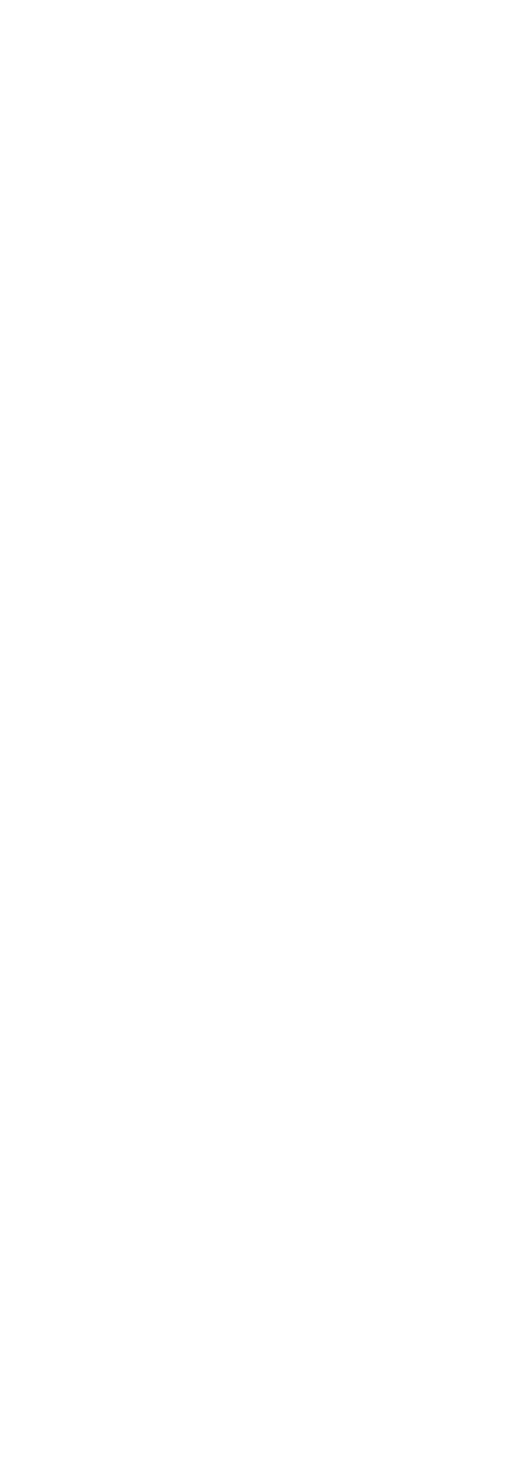




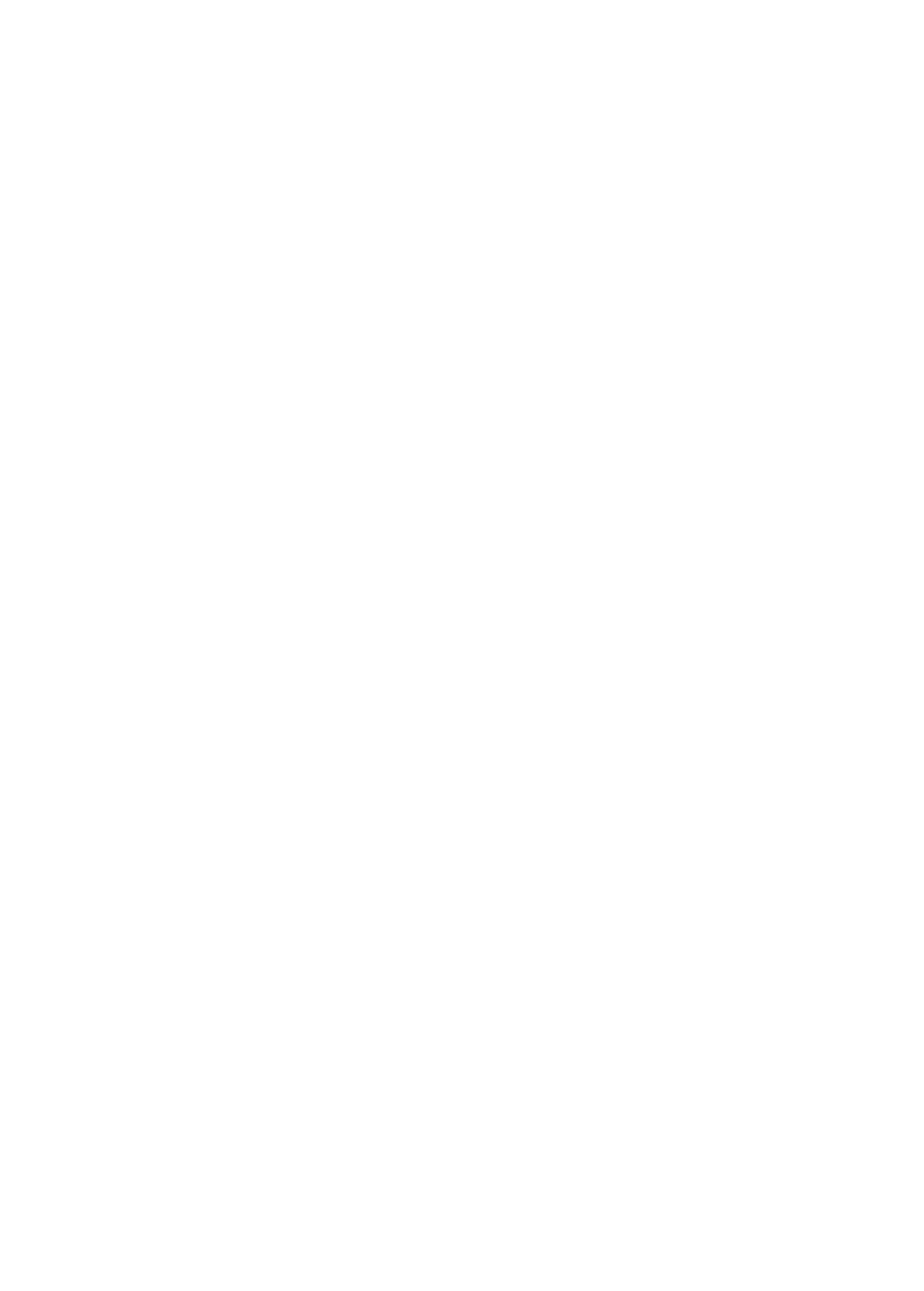




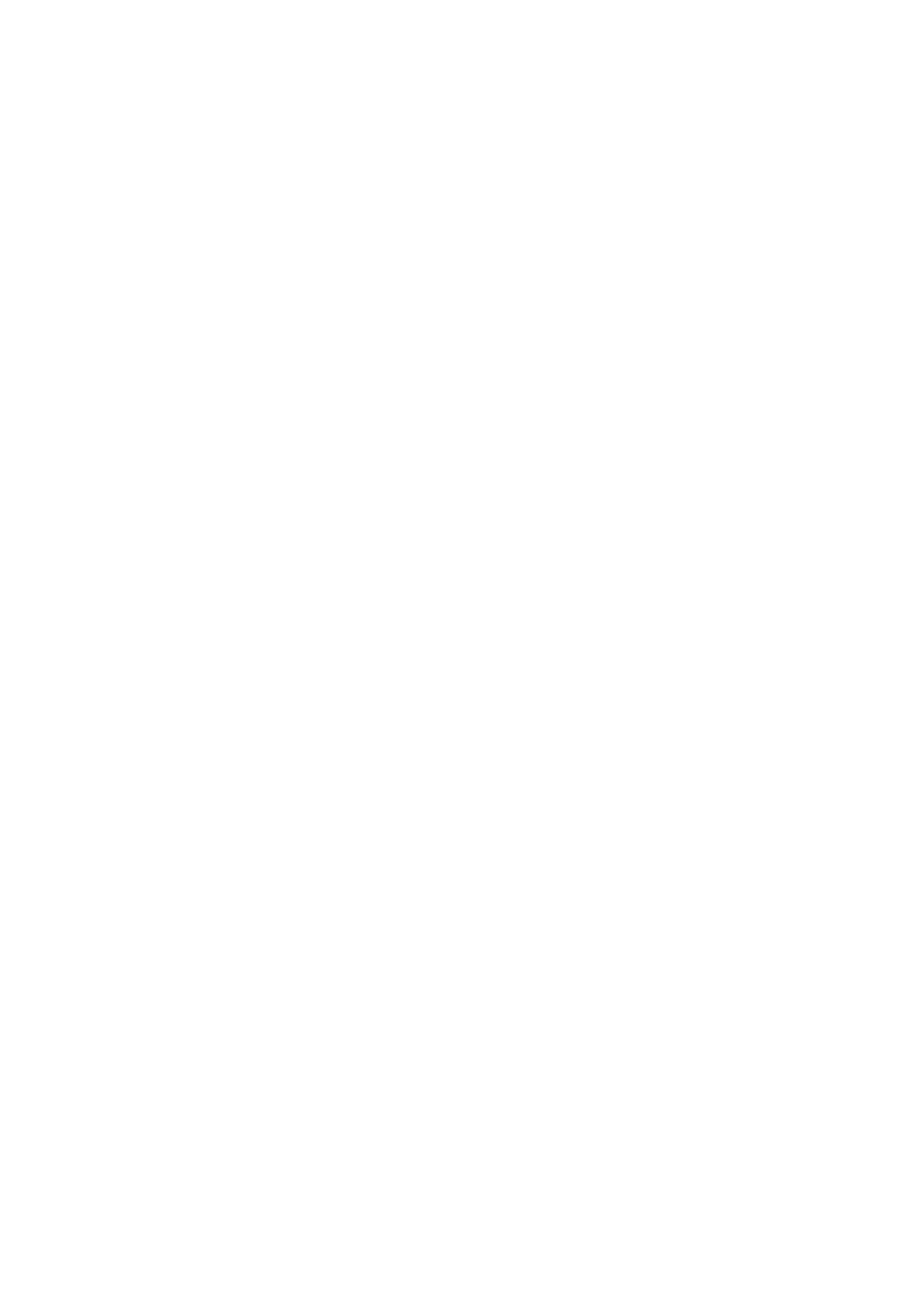




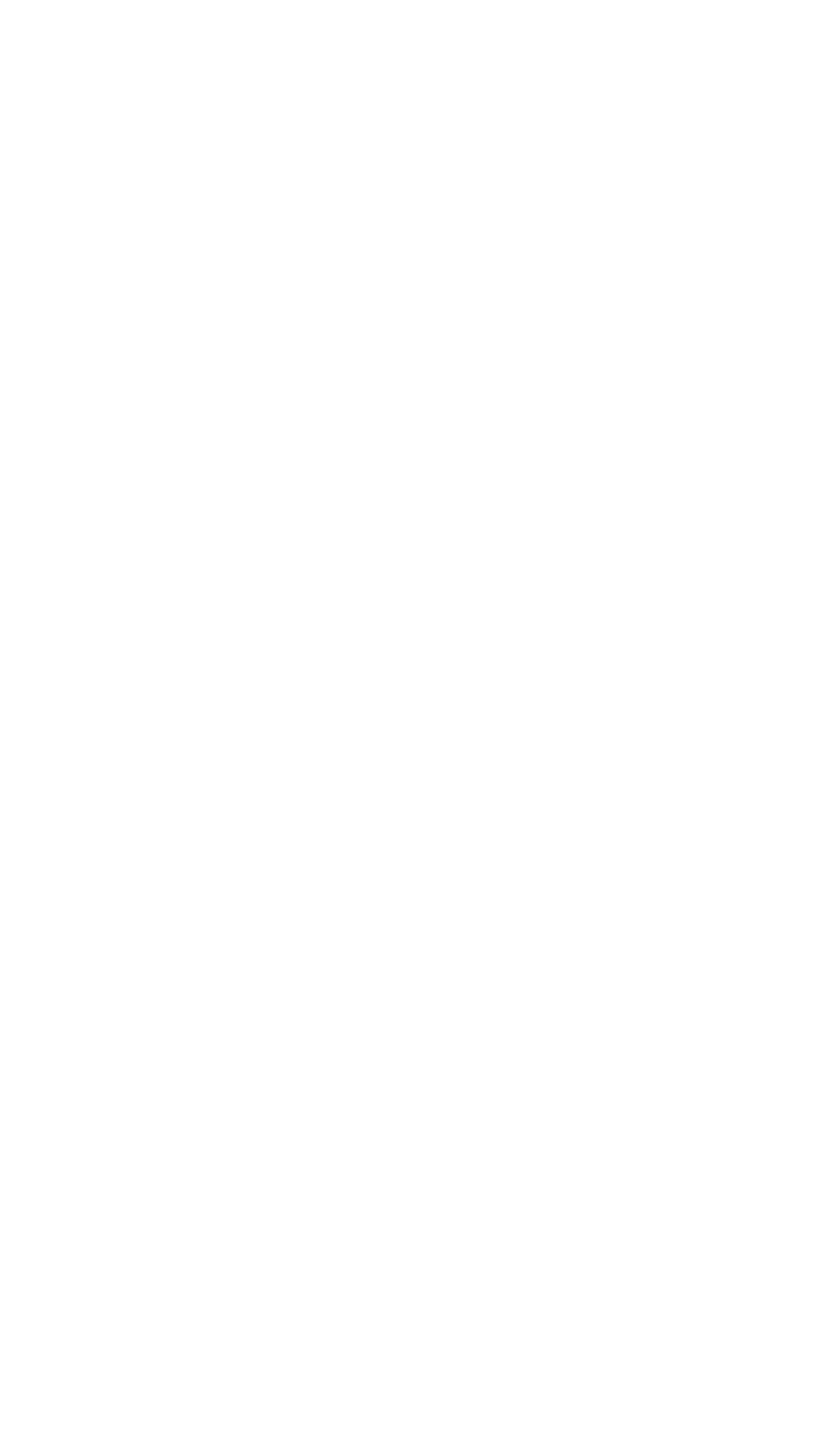


BIG SANDY RIVER BASIN--Continued

3-2125. LEVISA FORK AT PAINTSVILLE, KY.--Continued

Suspended sediment, water year October 1966 to September 1967

\begin{tabular}{|c|c|c|c|c|c|c|c|c|c|}
\hline \multirow[b]{3}{*}{ Day } & \multicolumn{3}{|c|}{ OCTOBER } & \multicolumn{3}{|c|}{ NOVEMBER } & \multicolumn{3}{|c|}{ DECEMBER } \\
\hline & \multirow[b]{2}{*}{$\begin{array}{l}\text { Mean } \\
\text { dis- } \\
\text { charge } \\
\text { (cfs) }\end{array}$} & \multicolumn{2}{|c|}{ Suspended sediment } & \multirow[b]{2}{*}{$\begin{array}{c}\text { Mean } \\
\text { dis- } \\
\text { charge } \\
\text { (cfs) }\end{array}$} & \multicolumn{2}{|c|}{ Suspended sediment } & \multirow[b]{2}{*}{$\begin{array}{l}\text { Mean } \\
\text { dis- } \\
\text { charge } \\
\text { (cfs) }\end{array}$} & \multicolumn{2}{|c|}{ Suspended sedimen } \\
\hline & & $\begin{array}{l}\text { Mean } \\
\text { concen- } \\
\text { tration } \\
\text { (ppm) }\end{array}$ & $\begin{array}{l}\text { Tons } \\
\text { per } \\
\text { day }\end{array}$ & & $\begin{array}{l}\text { Mean } \\
\text { concen- } \\
\text { tration } \\
\text { (ppm) }\end{array}$ & $\begin{array}{l}\text { Tons } \\
\text { per } \\
\text { day }\end{array}$ & & $\begin{array}{l}\text { Mean } \\
\text { concen- } \\
\text { tration } \\
\text { (ppm) }\end{array}$ & $\begin{array}{c}\text { Tons } \\
\text { per } \\
\text { day }\end{array}$ \\
\hline $\begin{array}{l}1 \ldots \\
2 \ldots \\
3 \ldots\end{array}$ & $\begin{array}{r}5410 \\
9790 \\
11400\end{array}$ & $\begin{array}{r}165 \\
1200 \\
1060\end{array}$ & $\begin{array}{r}2410 \\
31700 \\
32600\end{array}$ & $\begin{array}{r}916 \\
2260 \\
5120\end{array}$ & $\begin{array}{r}29 \\
454 \\
432\end{array}$ & $\begin{array}{r}72 \\
4200 \\
5970\end{array}$ & $\begin{array}{l}6180 \\
4710 \\
4700\end{array}$ & $\begin{array}{l}276 \\
170 \\
148\end{array}$ & $\begin{array}{r}4610 \\
2160 \\
18800\end{array}$ \\
\hline $5 \ldots$ & $\begin{array}{r}6640 \\
3680\end{array}$ & $\begin{array}{l}360 \\
170\end{array}$ & $\begin{array}{r}6450 \\
1690\end{array}$ & $\begin{array}{l}6020 \\
4510\end{array}$ & $\begin{array}{r}160 \\
87\end{array}$ & $\begin{array}{l}2600 \\
1060\end{array}$ & $\begin{array}{l}4230 \\
3420\end{array}$ & $\begin{array}{l}140 \\
132 \\
114\end{array}$ & $\begin{array}{l}1470 \\
1050\end{array}$ \\
\hline $\begin{array}{r}6 \ldots \\
7 \ldots \\
8 \ldots \\
9 \ldots \\
10 \ldots\end{array}$ & $\begin{array}{l}2650 \\
1930 \\
1460 \\
1180 \\
1060\end{array}$ & $\begin{array}{r}108 \\
90 \\
97 \\
62 \\
30\end{array}$ & $\begin{array}{r}773 \\
469 \\
382 \\
198 \\
86\end{array}$ & $\begin{array}{l}3610 \\
3150 \\
2850 \\
2750 \\
2640\end{array}$ & $\begin{array}{l}55 \\
58 \\
85 \\
48 \\
42\end{array}$ & $\begin{array}{l}536 \\
493 \\
654 \\
356 \\
299\end{array}$ & $\begin{array}{l}4100 \\
4680 \\
4500 \\
4210 \\
5220\end{array}$ & $\begin{array}{r}97 \\
104 \\
95 \\
94 \\
386\end{array}$ & $\begin{array}{l}1070 \\
1310 \\
1150 \\
1070 \\
6940\end{array}$ \\
\hline $\begin{array}{l}11 \ldots \\
12 \ldots \\
13 \ldots \\
14 \ldots \\
15 \ldots\end{array}$ & $\begin{array}{l}970 \\
886 \\
802 \\
700 \\
630\end{array}$ & $\begin{array}{l}29 \\
26 \\
30 \\
48 \\
60\end{array}$ & $\begin{array}{r}76 \\
62 \\
65 \\
91 \\
102\end{array}$ & $\begin{array}{l}2920 \\
3170 \\
3460 \\
4100 \\
3680\end{array}$ & $\begin{array}{r}45 \\
45 \\
58 \\
120 \\
102\end{array}$ & $\begin{array}{r}355 \\
385 \\
542 \\
1330 \\
1010\end{array}$ & $\begin{array}{r}11500 \\
15300 \\
11900 \\
6600 \\
4900\end{array}$ & $\begin{array}{l}985 \\
285 \\
180 \\
150 \\
121\end{array}$ & $\begin{array}{r}29700 \\
11800 \\
5780 \\
2570 \\
1600\end{array}$ \\
\hline $\begin{array}{l}16 \ldots \\
17 \ldots \\
18 \ldots \\
19 \ldots \\
20 \ldots\end{array}$ & $\begin{array}{r}665 \\
826 \\
1130 \\
1720 \\
3060\end{array}$ & $\begin{array}{r}66 \\
64 \\
120 \\
222 \\
208\end{array}$ & $\begin{array}{r}119 \\
143 \\
366 \\
1030 \\
1720\end{array}$ & $\begin{array}{l}3240 \\
2840 \\
2450 \\
2110 \\
1950\end{array}$ & $\begin{array}{l}72 \\
50 \\
41 \\
40 \\
32\end{array}$ & $\begin{array}{l}630 \\
383 \\
271 \\
228 \\
168\end{array}$ & $\begin{array}{l}3780 \\
2940 \\
2520 \\
2290 \\
2060\end{array}$ & $\begin{array}{l}89 \\
61 \\
52 \\
44 \\
37\end{array}$ & $\begin{array}{l}908 \\
484 \\
354 \\
272 \\
206\end{array}$ \\
\hline $\begin{array}{l}21 \ldots \\
22 \ldots \\
23 \ldots \\
24 \ldots \\
25 \ldots\end{array}$ & $\begin{array}{l}3200 \\
3130 \\
2090 \\
1620 \\
1580\end{array}$ & $\begin{array}{r}137 \\
83 \\
45 \\
41 \\
29\end{array}$ & $\begin{array}{r}1180 \\
701 \\
254 \\
179 \\
124\end{array}$ & $\begin{array}{l}1780 \\
1520 \\
1400 \\
1460 \\
1360\end{array}$ & $\begin{array}{l}23 \\
18 \\
14 \\
14 \\
15\end{array}$ & $\begin{array}{r}212 \\
74 \\
53 \\
55 \\
55\end{array}$ & $\begin{array}{l}1870 \\
1720 \\
1530 \\
1450 \\
1500\end{array}$ & $\begin{array}{l}29 \\
28 \\
19 \\
20 \\
22\end{array}$ & $\begin{array}{r}146 \\
130 \\
78 \\
78 \\
89\end{array}$ \\
\hline $\begin{array}{l}26 \ldots \\
27 \ldots \\
28 \ldots \\
29 \ldots \\
30 \ldots \\
31 \ldots\end{array}$ & $\begin{array}{r}1440 \\
1180 \\
1180 \\
1120 \\
1020 \\
958\end{array}$ & $\begin{array}{l}25 \\
28 \\
24 \\
12 \\
18 \\
28\end{array}$ & $\begin{array}{l}97 \\
89 \\
76 \\
36 \\
30 \\
72 \\
\end{array}$ & $\begin{array}{r}1220 \\
1230 \\
1470 \\
4140 \\
6860 \\
\end{array}$ & $\begin{array}{r}15 \\
15 \\
30 \\
312 \\
660 \\
-\end{array}$ & $\begin{array}{r}49 \\
50 \\
126 \\
4020 \\
12200 \\
\end{array}$ & $\begin{array}{r}1350 \\
1100 \\
3560 \\
17700 \\
23500 \\
19300\end{array}$ & $\begin{array}{r}26 \\
27 \\
859 \\
2300 \\
710 \\
233 \\
\end{array}$ & $\begin{array}{r}95 \\
80 \\
14400 \\
110000 \\
4500 \\
12100 \\
\end{array}$ \\
\hline \multirow[t]{2}{*}{ Total } & 75107 & -- & 83390 & 86186 & -- & 38335 & 184220 & $-\infty$ & 217380 \\
\hline & \multicolumn{3}{|c|}{ JANUARY } & \multicolumn{3}{|c|}{ FEBRUARY } & \multicolumn{3}{|c|}{ MARCH } \\
\hline $\begin{array}{l}1 \ldots \\
2 \ldots \\
3 \ldots \\
4 \ldots \\
5 \ldots\end{array}$ & $\begin{array}{l}9470 \\
5750 \\
4270 \\
3710 \\
3190\end{array}$ & $\begin{array}{r}177 \\
158 \\
128 \\
93 \\
83\end{array}$ & $\begin{array}{r}4530 \\
2450 \\
1480 \\
932 \\
715\end{array}$ & $\begin{array}{l}3630 \\
3160 \\
3350 \\
4200 \\
2380\end{array}$ & $\begin{array}{r}64 \\
50 \\
64 \\
263 \\
50\end{array}$ & $\begin{array}{r}627 \\
427 \\
579 \\
3150 \\
321\end{array}$ & $\begin{array}{l}4210 \\
4360 \\
3950 \\
3550 \\
3560\end{array}$ & $\begin{array}{r}228 \\
204 \\
100 \\
62 \\
55\end{array}$ & $\begin{array}{r}2590 \\
2400 \\
1070 \\
594 \\
529\end{array}$ \\
\hline $\begin{array}{r}6 \ldots \\
7 \ldots \\
9 \ldots \\
10 \ldots\end{array}$ & $\begin{array}{l}2850 \\
2480 \\
2210 \\
2260 \\
2610\end{array}$ & $\begin{array}{l}75 \\
63 \\
58 \\
56 \\
78\end{array}$ & $\begin{array}{l}577 \\
422 \\
346 \\
342 \\
550\end{array}$ & $\begin{array}{l}2190 \\
2090 \\
1960 \\
1830 \\
1720\end{array}$ & $\begin{array}{l}26 \\
25 \\
28 \\
30 \\
35\end{array}$ & $\begin{array}{l}154 \\
141 \\
148 \\
148 \\
163\end{array}$ & $\begin{array}{r}8020 \\
30100 \\
38200 \\
33400 \\
19500\end{array}$ & $\begin{array}{r}300 \\
2530 \\
3500 \\
2250 \\
1500\end{array}$ & $\begin{array}{r}8800 \\
206000 \\
361000 \\
203000 \\
79000\end{array}$ \\
\hline $\begin{array}{l}11 \ldots \\
12 \ldots \\
13 \ldots \\
14 \ldots \\
15 \ldots\end{array}$ & $\begin{array}{l}2760 \\
2510 \\
2230 \\
2170 \\
2500\end{array}$ & $\begin{array}{r}108 \\
70 \\
53 \\
48 \\
52\end{array}$ & $\begin{array}{l}805 \\
474 \\
319 \\
281 \\
351\end{array}$ & $\begin{array}{l}2080 \\
2870 \\
3250 \\
3110 \\
2960\end{array}$ & $\begin{array}{l}75 \\
127 \\
144 \\
134 \\
110\end{array}$ & $\begin{array}{r}421 \\
984 \\
1260 \\
1130 \\
879\end{array}$ & $\begin{array}{l}12300 \\
11500 \\
14000 \\
15800 \\
17400\end{array}$ & $\begin{array}{l}600 \\
115 \\
556 \\
480 \\
911\end{array}$ & $\begin{array}{r}19900 \\
3570 \\
21000 \\
20500 \\
42800\end{array}$ \\
\hline $\begin{array}{l}16 \ldots \\
17 \ldots \\
18 \ldots \\
19 \ldots \\
20 \ldots\end{array}$ & $\begin{array}{l}2530 \\
2310 \\
2050 \\
3890 \\
1830\end{array}$ & $\begin{array}{l}52 \\
50 \\
38 \\
27 \\
30\end{array}$ & $\begin{array}{l}355 \\
312 \\
210 \\
138 \\
148\end{array}$ & $\begin{array}{l}2930 \\
3070 \\
3210 \\
3340 \\
3700\end{array}$ & $\begin{array}{l}78 \\
60 \\
53 \\
51 \\
90\end{array}$ & $\begin{array}{l}617 \\
497 \\
459 \\
460 \\
899\end{array}$ & $\begin{array}{r}17000 \\
11400 \\
10000 \\
10900 \\
8450\end{array}$ & $\begin{array}{r}672 \\
97 \\
70 \\
168 \\
129\end{array}$ & $\begin{array}{r}30800 \\
2990 \\
1890 \\
4940 \\
2940\end{array}$ \\
\hline $\begin{array}{l}21 \ldots \\
22 \ldots \\
23 \ldots \\
24 \ldots \\
25 \ldots\end{array}$ & $\begin{array}{l}1790 \\
1810 \\
1760 \\
1720 \\
1680\end{array}$ & $\begin{array}{l}32 \\
30 \\
30 \\
35 \\
37\end{array}$ & $\begin{array}{l}155 \\
147 \\
143 \\
163 \\
168\end{array}$ & $\begin{array}{r}8360 \\
14100 \\
11700 \\
6940 \\
4530\end{array}$ & $\begin{array}{r}1140 \\
1200 \\
212 \\
125 \\
93\end{array}$ & $\begin{array}{r}28900 \\
45700 \\
6700 \\
2340 \\
1140\end{array}$ & $\begin{array}{l}5690 \\
4170 \\
3680 \\
3210 \\
3030\end{array}$ & $\begin{array}{r}132 \\
133 \\
94 \\
86 \\
84\end{array}$ & $\begin{array}{r}2030 \\
1500 \\
934 \\
745 \\
687\end{array}$ \\
\hline $\begin{array}{l}26 \ldots \\
27 \ldots \\
28 \ldots \\
29 \ldots \\
30 \ldots \\
31 \ldots\end{array}$ & $\begin{array}{l}1650 \\
4500 \\
9030 \\
9770 \\
6310 \\
4470\end{array}$ & $\begin{array}{r}33 \\
490 \\
730 \\
157 \\
98 \\
79\end{array}$ & $\begin{array}{r}147 \\
7070 \\
17800 \\
4140 \\
1670 \\
953\end{array}$ & $\begin{array}{r}3270 \\
2950 \\
3340 \\
- \\
-\end{array}$ & $\begin{array}{r}67 \\
53 \\
108 \\
-- \\
-- \\
--\end{array}$ & $\begin{array}{r}592 \\
422 \\
974 \\
-- \\
=-\end{array}$ & $\begin{array}{l}2780 \\
2540 \\
2250 \\
2470 \\
2680 \\
2500\end{array}$ & $\begin{array}{l}79 \\
90 \\
86 \\
75 \\
52 \\
25\end{array}$ & $\begin{array}{l}593 \\
617 \\
522 \\
500 \\
376 \\
169\end{array}$ \\
\hline Total & 106070 & -- & 48293 & 112220 & -- & 100232 & 312600 & - & 1024986 \\
\hline
\end{tabular}


BIG SANDY RIYER BASIN--Continued

3-2125. LEVISA FORK AT PAINTSVILLE, KY.--Continued

Suspended sediment, water year October 1966 to September 1967--Continised

\begin{tabular}{|c|c|c|c|c|c|c|c|c|c|}
\hline \multirow[b]{3}{*}{ Day } & \multirow[b]{3}{*}{$\begin{array}{c}\text { Mean } \\
\text { dis- } \\
\text { charge } \\
\text { (cfs) }\end{array}$} & \multicolumn{2}{|l|}{ APRIL } & \multicolumn{3}{|c|}{ MAY } & \multicolumn{3}{|c|}{ JUNE } \\
\hline & & \multicolumn{2}{|c|}{ Suspended sediment } & \multirow[b]{2}{*}{$\begin{array}{l}\text { Mean } \\
\text { dis- } \\
\text { charge } \\
\text { (cfs) }\end{array}$} & \multicolumn{2}{|c|}{ Suspended sediment } & \multirow{2}{*}{$\begin{array}{l}\text { Mean } \\
\text { dis- } \\
\text { charge } \\
\text { (cfa) }\end{array}$} & \multicolumn{2}{|c|}{ Suspended sediment } \\
\hline & & $\begin{array}{l}\text { Mean } \\
\text { concen- } \\
\text { tration } \\
\text { (ppm) }\end{array}$ & $\begin{array}{l}\text { Tons } \\
\text { per } \\
\text { day }\end{array}$ & & $\begin{array}{c}\text { Mean } \\
\text { concen- } \\
\text { tration } \\
(\mathrm{ppm})\end{array}$ & $\begin{array}{l}\text { Tons } \\
\text { per } \\
\text { day }\end{array}$ & & $\begin{array}{c}\text { Mean } \\
\text { ccncen- } \\
\text { tration } \\
\text { (Ipm) }\end{array}$ & $\begin{array}{l}\text { Tons } \\
\text { per } \\
\text { day }\end{array}$ \\
\hline $\begin{array}{l}1 \cdots \\
2 \cdots \\
3 \cdots \\
4 \cdots \\
5 \cdots\end{array}$ & $\begin{array}{l}2130 \\
1890 \\
1670 \\
1550 \\
1440\end{array}$ & $\begin{array}{l}13 \\
13 \\
18 \\
18 \\
17\end{array}$ & $\begin{array}{l}75 \\
66 \\
81 \\
75 \\
66\end{array}$ & $\begin{array}{l}4570 \\
3630 \\
3070 \\
2600 \\
2200\end{array}$ & $\begin{array}{r}104 \\
78 \\
62 \\
57 \\
46\end{array}$ & $\begin{array}{r}1280 \\
764 \\
514 \\
400 \\
273\end{array}$ & $\begin{array}{r}2120 \\
9440 \\
15000 \\
10800 \\
8450\end{array}$ & $\begin{array}{r}676 \\
1370 \\
625 \\
285 \\
194\end{array}$ & $\begin{array}{r}4210 \\
34900 \\
25300 \\
8310 \\
4430\end{array}$ \\
\hline $\begin{array}{r}6 \ldots \\
7 \ldots \\
9.0 \\
20 \ldots\end{array}$ & $\begin{array}{l}1340 \\
1250 \\
1170 \\
1080 \\
1020\end{array}$ & $\begin{array}{l}15 \\
14 \\
15 \\
33 \\
30\end{array}$ & $\begin{array}{l}54 \\
47 \\
47 \\
96 \\
83\end{array}$ & $\begin{array}{l}1860 \\
2960 \\
3600 \\
4060 \\
4300\end{array}$ & $\begin{array}{l}102 \\
422 \\
155 \\
160 \\
147\end{array}$ & $\begin{array}{l}512 \\
3990 \\
1510 \\
1750 \\
1710\end{array}$ & $\begin{array}{l}5750 \\
3810 \\
3230 \\
2690 \\
1590\end{array}$ & $\begin{array}{r}134 \\
112 \\
93 \\
80 \\
56\end{array}$ & $\begin{array}{r}2080 \\
1150 \\
811 \\
581 \\
240\end{array}$ \\
\hline $\begin{array}{l}11 \ldots \\
12 \ldots \\
13 \ldots\end{array}$ & $\begin{array}{l}1070 \\
1250 \\
1240\end{array}$ & $\begin{array}{l}34 \\
34 \\
27\end{array}$ & $\begin{array}{r}98 \\
115 \\
90\end{array}$ & $\begin{array}{l}4230 \\
3750 \\
4200\end{array}$ & $\begin{array}{l}115 \\
140 \\
172\end{array}$ & $\begin{array}{l}1310 \\
1420 \\
1950\end{array}$ & $\begin{array}{r}1240 \\
1000 \\
892\end{array}$ & $\begin{array}{l}37 \\
26 \\
21\end{array}$ & $\begin{array}{r}124 \\
70 \\
51\end{array}$ \\
\hline $\begin{array}{l}14 \ldots \\
15 \ldots\end{array}$ & $\begin{array}{l}1140 \\
1060\end{array}$ & $\begin{array}{l}22 \\
40\end{array}$ & $\begin{array}{r}68 \\
114\end{array}$ & $\begin{array}{r}9020 \\
14300\end{array}$ & $\begin{array}{l}2220 \\
1100\end{array}$ & $\begin{array}{l}74600 \\
42500\end{array}$ & $\begin{array}{l}790 \\
670\end{array}$ & $\begin{array}{l}18 \\
12\end{array}$ & $\begin{array}{l}38 \\
22\end{array}$ \\
\hline $\begin{array}{l}16 \ldots \\
17 \ldots \\
18 \ldots \\
19 \ldots \\
20 \ldots\end{array}$ & $\begin{array}{l}988 \\
1040 \\
1650 \\
2460 \\
2040\end{array}$ & $\begin{array}{r}20 \\
28 \\
103 \\
77 \\
53\end{array}$ & $\begin{array}{r}53 \\
79 \\
459 \\
511 \\
292\end{array}$ & $\begin{array}{r}14300 \\
13100 \\
9070 \\
5030 \\
3740\end{array}$ & $\begin{array}{l}650 \\
420 \\
195 \\
212 \\
261\end{array}$ & $\begin{array}{r}25100 \\
14900 \\
4780 \\
2880 \\
2640\end{array}$ & $\begin{array}{l}585 \\
507 \\
466 \\
500 \\
595\end{array}$ & $\begin{array}{r}5 \\
2 \\
3 \\
42 \\
16\end{array}$ & $\begin{array}{r}8 \\
3 \\
4 \\
57 \\
26\end{array}$ \\
\hline $\begin{array}{l}21 \cdots \\
22 \cdots \\
23 \cdots \\
24 \cdots \\
25 \cdots\end{array}$ & $\begin{array}{l}1690 \\
3240 \\
4230 \\
4970 \\
4330\end{array}$ & $\begin{array}{r}45 \\
467 \\
422 \\
312 \\
140\end{array}$ & $\begin{array}{r}205 \\
4740 \\
4820 \\
4190 \\
1640\end{array}$ & $\begin{array}{l}3240 \\
3050 \\
2570 \\
2380 \\
2130\end{array}$ & $\begin{array}{l}84 \\
79 \\
78 \\
62 \\
53\end{array}$ & $\begin{array}{l}735 \\
651 \\
541 \\
398 \\
305\end{array}$ & $\begin{array}{l}600 \\
507 \\
454 \\
385 \\
358\end{array}$ & $\begin{array}{l}4 \\
5 \\
9 \\
6 \\
5\end{array}$ & $\begin{array}{r}6 \\
7 \\
11 \\
6 \\
5\end{array}$ \\
\hline $\begin{array}{l}26 \ldots \\
27 \ldots \\
28 \ldots \\
29 \ldots \\
30 \ldots \\
31 \ldots\end{array}$ & $\begin{array}{r}3580 \\
6740 \\
14100 \\
11700 \\
6210 \\
-\end{array}$ & $\begin{array}{r}54 \\
583 \\
890 \\
232 \\
150 \\
- \\
\end{array}$ & $\begin{array}{r}522 \\
14400 \\
33900 \\
7330 \\
2520 \\
\end{array}$ & $\begin{array}{l}1750 \\
1580 \\
1400 \\
1130 \\
1550 \\
1670\end{array}$ & $\begin{array}{r}46 \\
42 \\
32 \\
23 \\
152 \\
159 \\
\end{array}$ & $\begin{array}{r}217 \\
179 \\
121 \\
70 \\
796 \\
717 \\
\end{array}$ & $\begin{array}{l}406 \\
655 \\
610 \\
448 \\
510 \\
-- \\
\end{array}$ & $\begin{array}{r}11 \\
12 \\
26 \\
99 \\
177 \\
-- \\
\end{array}$ & $\begin{array}{r}12 \\
21 \\
43 \\
120 \\
244 \\
\end{array}$ \\
\hline \multirow[t]{2}{*}{ Total } & 89268 & $\cdots$ & 76836 & 136040 & $\because$ & 189513 & 75058 & $\ldots$ & 82890 \\
\hline & \multicolumn{3}{|c|}{ JULY } & \multicolumn{3}{|c|}{ AUGUST } & \multicolumn{3}{|c|}{ SEPTEMBER } \\
\hline $\begin{array}{l}1 \cdots \\
2 \cdots \\
3 \cdots \\
4 \because \\
5 \cdots\end{array}$ & $\begin{array}{l}427 \\
489 \\
680 \\
690 \\
546\end{array}$ & $\begin{array}{l}196 \\
186 \\
171 \\
132 \\
210\end{array}$ & $\begin{array}{l}226 \\
246 \\
314 \\
246 \\
310\end{array}$ & $\begin{array}{r}2020 \\
1330 \\
1420 \\
1350 \\
958\end{array}$ & $\begin{array}{r}1360 \\
350 \\
178 \\
112 \\
74\end{array}$ & $\begin{array}{r}7420 \\
1260 \\
682 \\
408 \\
191\end{array}$ & $\begin{array}{l}457 \\
337 \\
310 \\
283 \\
260\end{array}$ & $\begin{array}{r}125 \\
87 \\
70 \\
64 \\
54\end{array}$ & $\begin{array}{r}154 \\
79 \\
59 \\
49 \\
38\end{array}$ \\
\hline $\begin{array}{c}6 \ldots \\
7 \ldots \\
8 \ldots \\
9 \ldots \\
10 \ldots\end{array}$ & $\begin{array}{r}886 \\
1780 \\
2520 \\
1690 \\
1520\end{array}$ & $\begin{array}{r}262 \\
532 \\
1260 \\
622 \\
607\end{array}$ & $\begin{array}{r}692 \\
2980 \\
8570 \\
2840 \\
2710\end{array}$ & $\begin{array}{l}724 \\
838 \\
560 \\
427 \\
379\end{array}$ & $\begin{array}{r}106 \\
255 \\
116 \\
78 \\
82\end{array}$ & $\begin{array}{r}207 \\
577 \\
175 \\
90 \\
84\end{array}$ & $\begin{array}{l}243 \\
214 \\
191 \\
182 \\
179\end{array}$ & $\begin{array}{l}47 \\
40 \\
35 \\
38 \\
37\end{array}$ & $\begin{array}{l}31 \\
23 \\
18 \\
19 \\
18\end{array}$ \\
\hline $\begin{array}{l}11 \ldots \\
12 \ldots \\
13 \ldots \\
14 \ldots \\
15 \ldots\end{array}$ & $\begin{array}{r}2170 \\
1140 \\
874 \\
784 \\
802\end{array}$ & $\begin{array}{r}524 \\
144 \\
121 \\
93 \\
95\end{array}$ & $\begin{array}{r}3510 \\
443 \\
286 \\
197 \\
206\end{array}$ & $\begin{array}{l}349 \\
355 \\
328 \\
263 \\
240\end{array}$ & $\begin{array}{l}69 \\
52 \\
43 \\
36 \\
34\end{array}$ & $\begin{array}{l}65 \\
50 \\
38 \\
26 \\
22\end{array}$ & $\begin{array}{l}173 \\
170 \\
165 \\
159 \\
150\end{array}$ & $\begin{array}{l}30 \\
32 \\
29 \\
23 \\
22\end{array}$ & $\begin{array}{r}14 \\
15 \\
13 \\
10 \\
9\end{array}$ \\
\hline $\begin{array}{l}16 \ldots \\
17 \ldots \\
18 \ldots \\
19 \ldots \\
20 \ldots\end{array}$ & $\begin{array}{l}874 \\
736 \\
600 \\
469 \\
463\end{array}$ & $\begin{array}{r}177 \\
140 \\
92 \\
109 \\
71\end{array}$ & $\begin{array}{r}418 \\
278 \\
149 \\
144 \\
89\end{array}$ & $\begin{array}{l}223 \\
211 \\
202 \\
205 \\
211\end{array}$ & $\begin{array}{l}25 \\
22 \\
22 \\
23 \\
22\end{array}$ & $\begin{array}{l}15 \\
13 \\
12 \\
13 \\
13\end{array}$ & $\begin{array}{l}142 \\
133 \\
130 \\
125 \\
122\end{array}$ & $\begin{array}{l}18 \\
15 \\
16 \\
14 \\
12\end{array}$ & $\begin{array}{l}7 \\
5 \\
6 \\
5 \\
4\end{array}$ \\
\hline $\begin{array}{l}21 \ldots \\
22 \ldots \\
23 \ldots \\
24 \cdots \\
25 \ldots\end{array}$ & $\begin{array}{l}451 \\
460 \\
496 \\
388 \\
364\end{array}$ & $\begin{array}{r}52 \\
54 \\
218 \\
102 \\
62\end{array}$ & $\begin{array}{r}63 \\
67 \\
292 \\
107 \\
61\end{array}$ & $\begin{array}{l}615 \\
546 \\
415 \\
439 \\
433\end{array}$ & $\begin{array}{l}240 \\
333 \\
314 \\
237 \\
196\end{array}$ & $\begin{array}{l}527 \\
491 \\
352 \\
281 \\
229\end{array}$ & $\begin{array}{l}119 \\
114 \\
106 \\
109 \\
117\end{array}$ & $\begin{array}{l}12 \\
12 \\
15 \\
13 \\
14\end{array}$ & $\begin{array}{l}4 \\
4 \\
4 \\
4\end{array}$ \\
\hline $\begin{array}{l}26 \ldots \\
27 \ldots \\
28 \ldots \\
29 \ldots \\
30 \ldots \\
31 \ldots \\
\end{array}$ & $\begin{array}{r}421 \\
1480 \\
1390 \\
862 \\
1570 \\
2640 \\
\end{array}$ & $\begin{array}{r}82 \\
975 \\
120 \\
72 \\
884 \\
1530 \\
\end{array}$ & $\begin{array}{r}101 \\
3900 \\
450 \\
168 \\
5110 \\
10900 \\
\end{array}$ & $\begin{array}{r}424 \\
424 \\
724 \\
1340 \\
1050 \\
690 \\
\end{array}$ & $\begin{array}{r}177 \\
82 \\
198 \\
1060 \\
810 \\
358 \\
\end{array}$ & $\begin{array}{r}203 \\
94 \\
535 \\
3840 \\
2300 \\
667 \\
\end{array}$ & $\begin{array}{l}114 \\
119 \\
142 \\
162 \\
234 \\
--\end{array}$ & $\begin{array}{r}10 \\
7 \\
12 \\
12 \\
8 \\
-- \\
\end{array}$ & $\begin{array}{r}3 \\
2 \\
5 \\
5 \\
5 \\
- \\
\end{array}$ \\
\hline Total & 30682 & - & 46073 & 19693 & - & 20880 & 5461 & - & 616 \\
\hline
\end{tabular}



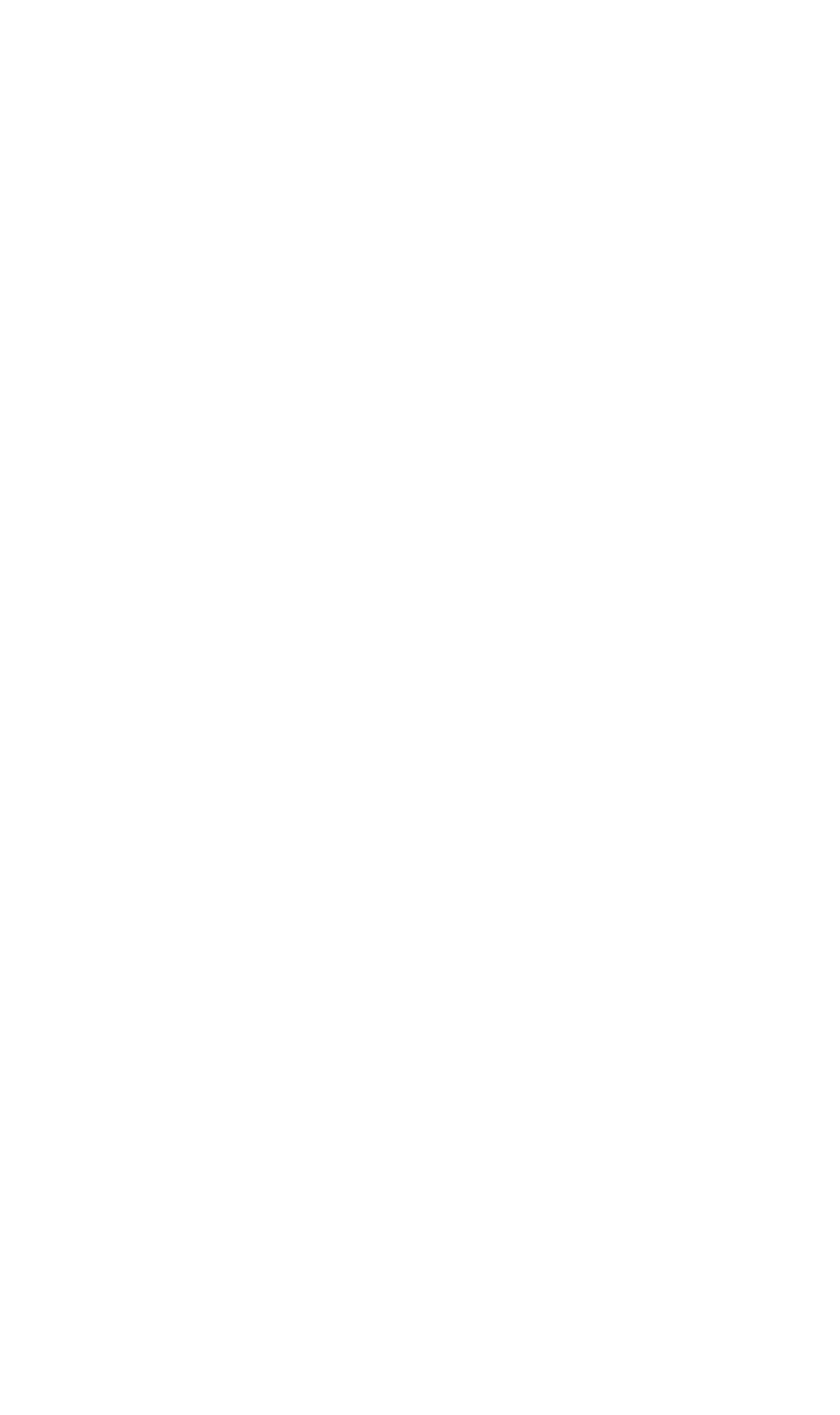

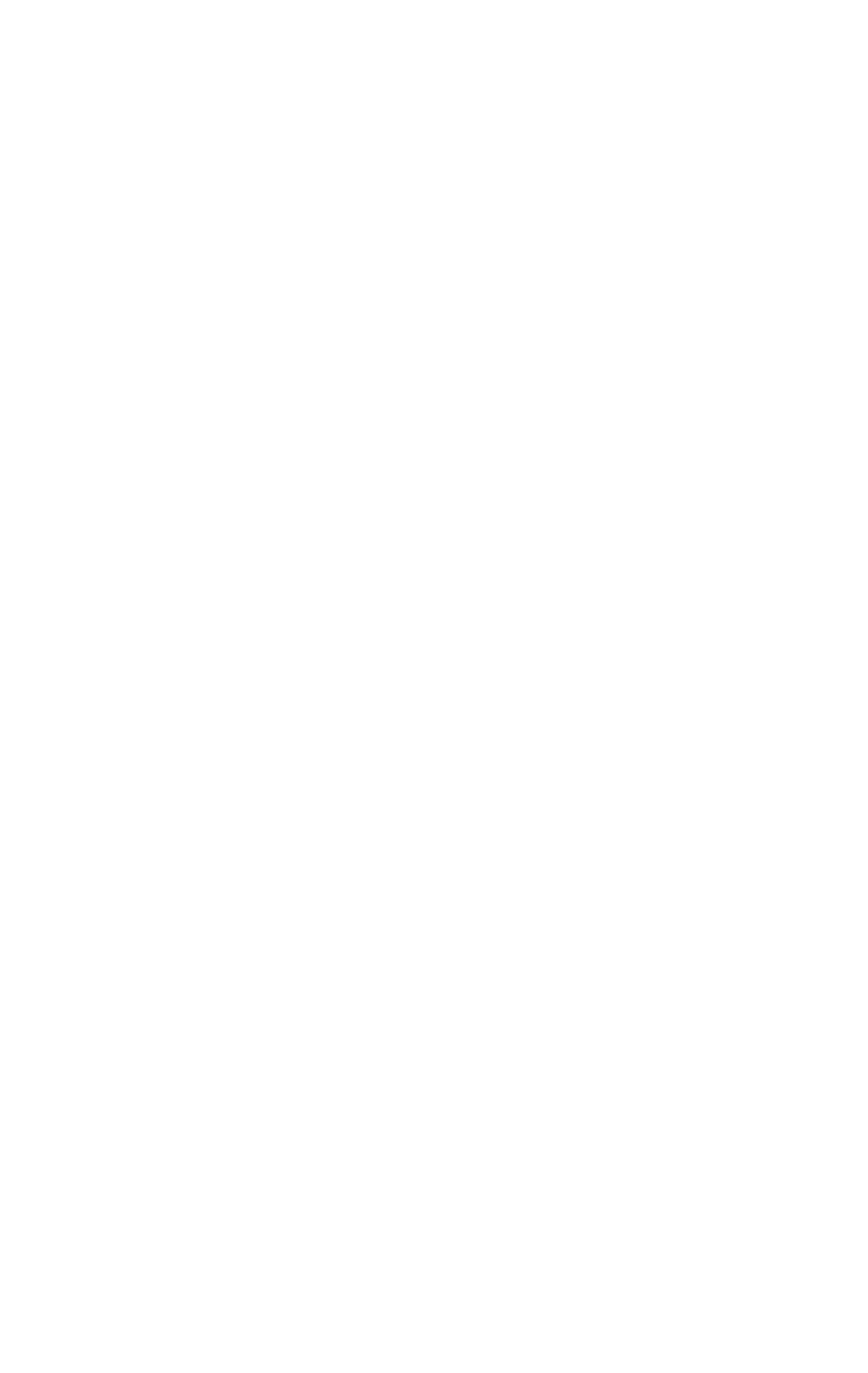
TYGARTS CREEK BASIN--Continued

3-2170. TYGARTS CREEK NEAR GREENUP, KY,--Continued

Suspended sediment, water year October 1966 to September 1967

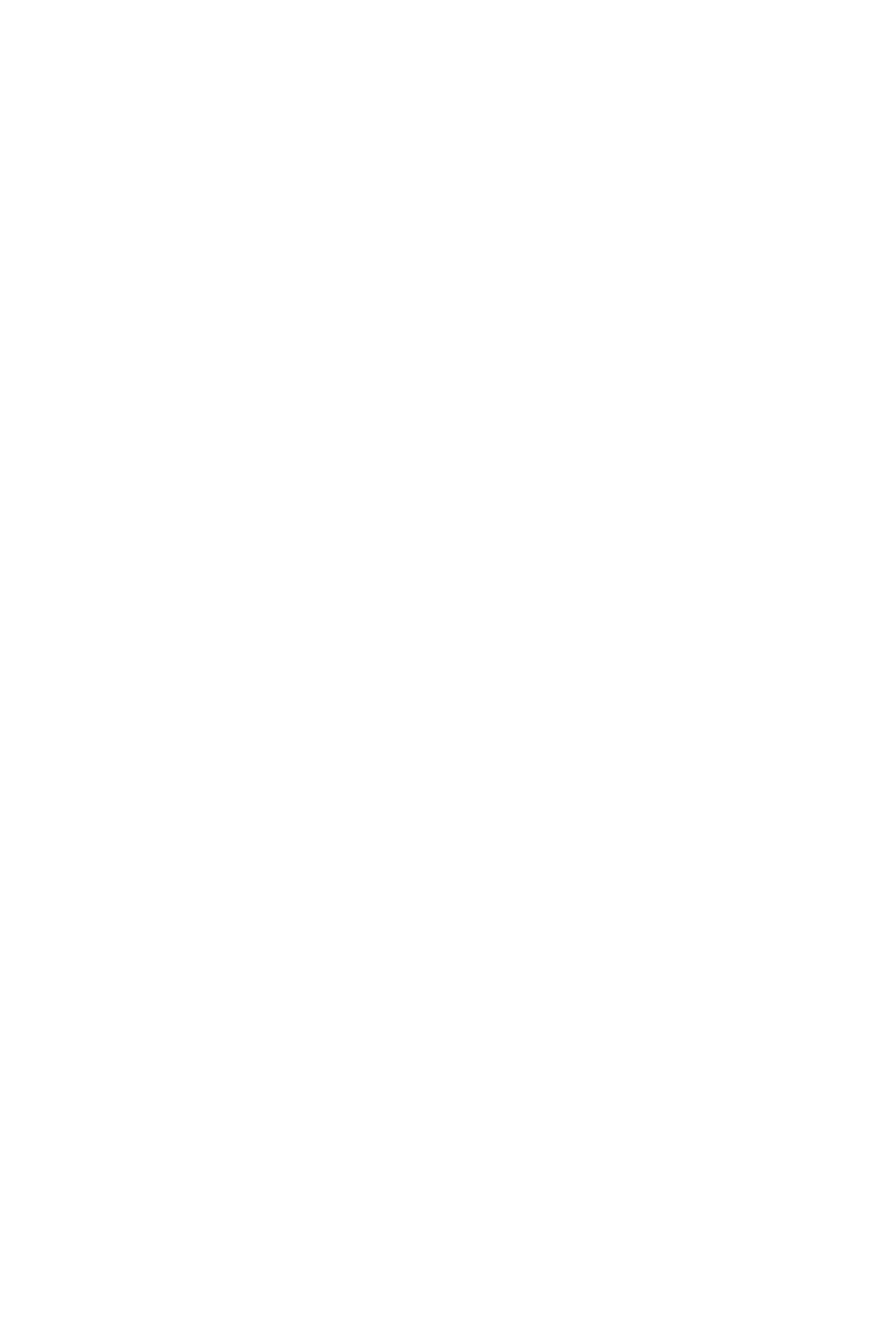


TYGARTS CREEK BASIN--Continued

3-2170. TYGARTS CREEK NEAR GREENUP, KY.--Continued

Suspended sediment, water year October 1966 to September 1967--Contirued

\begin{tabular}{|c|c|c|c|c|c|c|c|c|c|}
\hline \multirow[b]{3}{*}{ Day } & \multicolumn{3}{|c|}{ APRIL } & \multicolumn{3}{|c|}{ MAY } & \multicolumn{3}{|c|}{ JUNE } \\
\hline & \multirow[b]{2}{*}{$\begin{array}{c}\text { Mean } \\
\text { dis- } \\
\text { charge } \\
(\mathrm{cfs})\end{array}$} & \multicolumn{2}{|c|}{ Suspended sediment } & \multirow[b]{2}{*}{$\begin{array}{c}\text { Mean } \\
\text { dis- } \\
\text { charge } \\
\left(\mathrm{cf}_{\mathrm{s}}\right)\end{array}$} & \multicolumn{2}{|c|}{ Suspended sediment } & \multirow[b]{2}{*}{$\begin{array}{c}\text { Mean } \\
\text { dis- } \\
\text { charge } \\
(\text { cfs) }\end{array}$} & \multicolumn{2}{|c|}{ Suspended sediment } \\
\hline & & $\begin{array}{c}\text { Mean } \\
\text { concen- } \\
\text { tration } \\
(\mathrm{ppm})\end{array}$ & $\begin{array}{l}\text { Tons } \\
\text { per } \\
\text { day }\end{array}$ & & $\begin{array}{c}\text { Mean } \\
\text { concen- } \\
\text { tration } \\
(\text { ppm) }\end{array}$ & $\begin{array}{l}\text { Tons } \\
\text { per } \\
\text { day }\end{array}$ & & $\begin{array}{c}\text { Mean } \\
\text { concen- } \\
\text { tration } \\
\text { (ppm) }\end{array}$ & $\begin{array}{l}\text { Tons } \\
\text { per } \\
\text { day }\end{array}$ \\
\hline $\begin{array}{l}1 \ldots \\
2 \ldots \\
3 \ldots \\
4 \cdots \\
5 \cdots\end{array}$ & $\begin{array}{l}315 \\
263 \\
229 \\
210 \\
187\end{array}$ & $\begin{array}{r}12 \\
6 \\
2 \\
3 \\
3\end{array}$ & $\begin{array}{l}10 \\
4.3 \\
1.2 \\
1.7 \\
1.5\end{array}$ & $\begin{array}{l}287 \\
318 \\
414 \\
346 \\
270\end{array}$ & $\begin{array}{r}8 \\
8 \\
8 \\
12 \\
8\end{array}$ & $\begin{array}{c}6.2 \\
6.9 \\
8.9 \\
11 \\
5.8\end{array}$ & $\begin{array}{l}64 \\
68 \\
72 \\
72 \\
83\end{array}$ & $\begin{array}{l}7 \\
5 \\
7 \\
3 \\
4\end{array}$ & $\begin{array}{r}1.2 \\
.9 \\
1.4 \\
.6 \\
.9\end{array}$ \\
\hline $\begin{array}{r}6 \ldots \\
7 \ldots \\
8 \ldots \\
9 \ldots \\
10 . .\end{array}$ & $\begin{array}{r}170 \\
152 \\
130 \\
115 \\
1050\end{array}$ & $\begin{array}{r}2 \\
2 \\
2 \\
2 \\
322\end{array}$ & $\begin{array}{r}.9 \\
.8 \\
1220^{.6}\end{array}$ & $\begin{array}{r}281 \\
5850 \\
6830 \\
1550 \\
528\end{array}$ & $\begin{array}{r}20 \\
672 \\
302 \\
76 \\
40\end{array}$ & $\begin{array}{r}20 \\
11300 \\
6380 \\
318 \\
57\end{array}$ & $\begin{array}{l}60 \\
47 \\
37 \\
32 \\
27\end{array}$ & $\begin{array}{l}2 \\
5 \\
3 \\
3 \\
5\end{array}$ & $\begin{array}{l}.3 \\
.6 \\
.3 \\
.3 \\
.4\end{array}$ \\
\hline $\begin{array}{l}11 \ldots \\
12 \ldots \\
13 \ldots \\
14 \ldots \\
15 \ldots\end{array}$ & $\begin{array}{r}1120 \\
565 \\
556 \\
638 \\
474\end{array}$ & $\begin{array}{r}103 \\
58 \\
30 \\
18 \\
16\end{array}$ & $\begin{array}{r}330 \\
88 \\
45 \\
31 \\
20\end{array}$ & $\begin{array}{r}682 \\
770 \\
544 \\
880 \\
2720\end{array}$ & $\begin{array}{r}23 \\
28 \\
30 \\
64 \\
255\end{array}$ & $\begin{array}{r}42 \\
58 \\
44 \\
200 \\
1870\end{array}$ & $\begin{array}{l}25 \\
22 \\
20 \\
18 \\
17\end{array}$ & $\begin{array}{r}4 \\
8 \\
11 \\
8 \\
7\end{array}$ & $\begin{array}{l}.3 \\
.5 \\
.6 \\
.4 \\
.3\end{array}$ \\
\hline $\begin{array}{l}16 \ldots \\
17 \ldots \\
18 \ldots \\
19 \ldots \\
20 \ldots\end{array}$ & $\begin{array}{r}376 \\
685 \\
1770 \\
784 \\
519\end{array}$ & $\begin{array}{r}10 \\
62 \\
175 \\
80 \\
48\end{array}$ & $\begin{array}{r}10 \\
239 \\
836 \\
169 \\
67\end{array}$ & $\begin{array}{r}2310 \\
1040 \\
703 \\
494 \\
590\end{array}$ & $\begin{array}{r}114 \\
42 \\
22 \\
15 \\
20\end{array}$ & $\begin{array}{r}756 \\
118 \\
42 \\
20 \\
32\end{array}$ & $\begin{array}{l}17 \\
15 \\
14 \\
13 \\
26\end{array}$ & $\begin{array}{l}7 \\
7 \\
8 \\
5 \\
7\end{array}$ & $\begin{array}{l}.3 \\
.3 \\
.3 \\
.2 \\
.5\end{array}$ \\
\hline $\begin{array}{l}21 \ldots \\
22 \ldots \\
23 \ldots \\
24 \ldots \\
25 \ldots\end{array}$ & $\begin{array}{r}406 \\
864 \\
1090 \\
655 \\
519\end{array}$ & $\begin{array}{l}17 \\
60 \\
92 \\
37 \\
23\end{array}$ & $\begin{array}{r}19 \\
186 \\
271 \\
65 \\
32\end{array}$ & $\begin{array}{l}383 \\
305 \\
246 \\
176 \\
145\end{array}$ & $\begin{array}{l}62 \\
64 \\
34 \\
16 \\
12\end{array}$ & $\begin{array}{l}64 \\
53 \\
23 \\
7.6 \\
4.7\end{array}$ & $\begin{array}{l}20 \\
15 \\
14 \\
14 \\
14\end{array}$ & $\begin{array}{l}3 \\
4 \\
4 \\
3 \\
5\end{array}$ & $\begin{array}{l}.2 \\
.2 \\
.2 \\
: 1 \\
.2\end{array}$ \\
\hline $\begin{array}{l}26 \ldots \\
27 \ldots \\
28 \ldots \\
29 \ldots \\
30 \ldots \\
31 \ldots\end{array}$ & $\begin{array}{l}519 \\
638 \\
474 \\
372 \\
315 \\
--\end{array}$ & $\begin{array}{r}14 \\
16 \\
12 \\
11 \\
8 \\
--\end{array}$ & $\begin{array}{l}20 \\
28 \\
15 \\
11 \\
6.8 \\
---\end{array}$ & $\begin{array}{r}113 \\
98 \\
86 \\
69 \\
77 \\
74\end{array}$ & $\begin{array}{l}8 \\
8 \\
5 \\
4 \\
7 \\
6\end{array}$ & $\begin{array}{r}2.4 \\
2.1 \\
1.2 \\
.7 \\
1.5 \\
1.2\end{array}$ & $\begin{array}{l}13 \\
12 \\
11 \\
12 \\
12 \\
--\end{array}$ & \begin{tabular}{r|}
7 \\
5 \\
3 \\
2 \\
2 \\
--
\end{tabular} & $\begin{array}{l}.2 \\
: 2 \\
: 1 \\
: 1 \\
: 1 \\
-:\end{array}$ \\
\hline \multirow[t]{2}{*}{ Total } & 16260 & -- & 3730.5 & 29179 & -- & 21457.2 & 886 & -- & $12 \cdot 2$ \\
\hline & \multicolumn{3}{|c|}{ JULY } & \multicolumn{3}{|c|}{ AUGUST } & \multicolumn{3}{|c|}{ SE ?TEMBER } \\
\hline $\begin{array}{l}1 \ldots \\
2 \ldots \\
3 \ldots \\
4 \ldots \\
5 \ldots\end{array}$ & $\begin{array}{l}20 \\
50 \\
26 \\
17 \\
14\end{array}$ & \begin{tabular}{r|}
13 \\
15 \\
2 \\
2 \\
2
\end{tabular} & $\begin{array}{r}0.7 \\
2.4 \\
.1 \\
.1 \\
.1\end{array}$ & $\begin{array}{r}34 \\
43 \\
205 \\
140 \\
48\end{array}$ & $\begin{array}{r}5 \\
8 \\
18 \\
94 \\
57\end{array}$ & $\begin{array}{l}0.5 \\
12.9 \\
32 \\
7.9\end{array}$ & $\begin{array}{l}7.0 \\
7.2 \\
6.5 \\
5.8 \\
5.0\end{array}$ & \begin{tabular}{r|}
5 \\
7 \\
12 \\
12 \\
12
\end{tabular} & $\begin{array}{r}0.1 \\
.1 \\
.2 \\
.2 \\
.2\end{array}$ \\
\hline $\begin{array}{c}6 \ldots \\
7 \ldots \\
8 \ldots \\
10 \ldots\end{array}$ & $\begin{array}{l}13 \\
13 \\
12 \\
11 \\
11\end{array}$ & $\begin{array}{l}3 \\
3 \\
2 \\
2 \\
2\end{array}$ & $\begin{array}{l}.1 \\
.1 \\
: 1 \\
: 1 \\
11\end{array}$ & $\begin{array}{l}24 \\
18 \\
13 \\
10 \\
8.0\end{array}$ & $\begin{array}{l}94 \\
70 \\
47 \\
41 \\
34\end{array}$ & $\begin{array}{r}6.1 \\
3.4 \\
1.6 \\
1.1 \\
.7\end{array}$ & $\begin{array}{l}4.2 \\
4.0 \\
3.5 \\
3.2 \\
3.8\end{array}$ & $\begin{array}{r}10 \\
8 \\
8 \\
5 \\
5\end{array}$ & $\begin{array}{r}: 1 \\
: 1 \\
\cdot 1 \\
\cdot 1\end{array}$ \\
\hline $\begin{array}{l}11 \ldots \\
12 \ldots \\
13 \ldots \\
14 \ldots \\
15 \ldots\end{array}$ & $\begin{array}{l}11 \\
11 \\
12 \\
17 \\
13\end{array}$ & $\begin{array}{l}2 \\
2 \\
3 \\
7 \\
3\end{array}$ & $\begin{array}{l}.1 \\
: 1 \\
: 1 \\
.3 \\
.1\end{array}$ & $\begin{array}{l}6.0 \\
5.2 \\
4.2 \\
3.5 \\
3.5\end{array}$ & $\begin{array}{l}32 \\
31 \\
25 \\
22 \\
18\end{array}$ & $\begin{array}{l}.5 \\
.4 \\
.3 \\
.2 \\
.2\end{array}$ & $\begin{array}{l}3.8 \\
3.2 \\
3.0 \\
2.5 \\
1.6\end{array}$ & $\begin{array}{l}7 \\
8 \\
8 \\
8 \\
8\end{array}$ & $\begin{array}{l}: 1 \\
: 1 \\
T^{1}\end{array}$ \\
\hline $\begin{array}{l}16 \ldots \\
17 \ldots \\
18 \ldots \\
19 \ldots \\
20 \ldots\end{array}$ & $\begin{array}{c}13 \\
12 \\
10 \\
8.2 \\
7.5\end{array}$ & $\begin{array}{l}2 \\
1 \\
1 \\
2 \\
2\end{array}$ & $\begin{array}{l}T^{\bullet 1} \\
T \\
T\end{array}$ & $\begin{array}{l}2.8 \\
2.0 \\
1.8 \\
2.0 \\
1.6\end{array}$ & $\begin{array}{l}15 \\
13 \\
12 \\
10 \\
10\end{array}$ & $\begin{array}{l}: 1 \\
: 1 \\
: 1\end{array}$ & $\begin{array}{r}1.4 \\
1.4 \\
1.2 \\
1.0 \\
.8\end{array}$ & $\begin{array}{l}8 \\
7 \\
5 \\
4 \\
3\end{array}$ & $\begin{array}{l}\mathbf{T} \\
\mathbf{T} \\
\mathbf{T} \\
\mathbf{T} \\
\mathbf{T}\end{array}$ \\
\hline $\begin{array}{l}21 \ldots \\
22 \ldots \\
23 \ldots \\
24 \ldots \\
25 \ldots\end{array}$ & $\begin{array}{l}6.2 \\
6.2 \\
5.8 \\
5.2 \\
6.0\end{array}$ & $\begin{array}{l}2 \\
1 \\
1 \\
1 \\
2\end{array}$ & $\begin{array}{l}T \\
T \\
T \\
T \\
T\end{array}$ & $\begin{array}{l}1.4 \\
1.0 \\
1.6 \\
18 \\
20\end{array}$ & $\begin{array}{r}9 \\
8 \\
8 \\
43 \\
187\end{array}$ & $\begin{array}{r}T \\
T \\
T \\
11 \\
11\end{array}$ & $\begin{array}{l}.6 \\
.4 \\
.2 \\
.2\end{array}$ & $\begin{array}{l}5 \\
4 \\
3 \\
4 \\
0\end{array}$ & $\begin{array}{l}T \\
T \\
T \\
T \\
0\end{array}$ \\
\hline $\begin{array}{l}26 \ldots \\
27 \ldots \\
28 \ldots \\
29 \ldots \\
30 \ldots \\
31 \ldots\end{array}$ & $\begin{array}{r}8.0 \\
7.0 \\
4.5 \\
9.2 \\
20 \\
28\end{array}$ & $\begin{array}{l}5 \\
3 \\
7 \\
6 \\
7 \\
6\end{array}$ & $\begin{array}{l}.1 \\
.1 \\
.1 \\
.1 \\
.4 \\
.5\end{array}$ & $\begin{array}{l}6.2 \\
5.8 \\
6.2 \\
7.8 \\
7.2 \\
6.5\end{array}$ & $\begin{array}{r}50 \\
14 \\
7 \\
4 \\
2 \\
2\end{array}$ & $\begin{array}{l}.8 \\
.2 \\
.1 \\
T \\
T\end{array}$ & $\begin{array}{l}0 \\
0 \\
1.0 \\
1.6 \\
1.4 \\
-\end{array}$ & $\begin{array}{r}0 \\
0 \\
5 \\
7 \\
6 \\
--\end{array}$ & $\begin{array}{l}0 \\
0 \\
T \\
T \\
T \\
-\end{array}$ \\
\hline Total & 407.8 & -- & 0.2 & 657.3 & -- & 91.6 & 75.5 & -- & $1 \cdot 8$ \\
\hline
\end{tabular}

$T$ Less than 0.05 ton. 


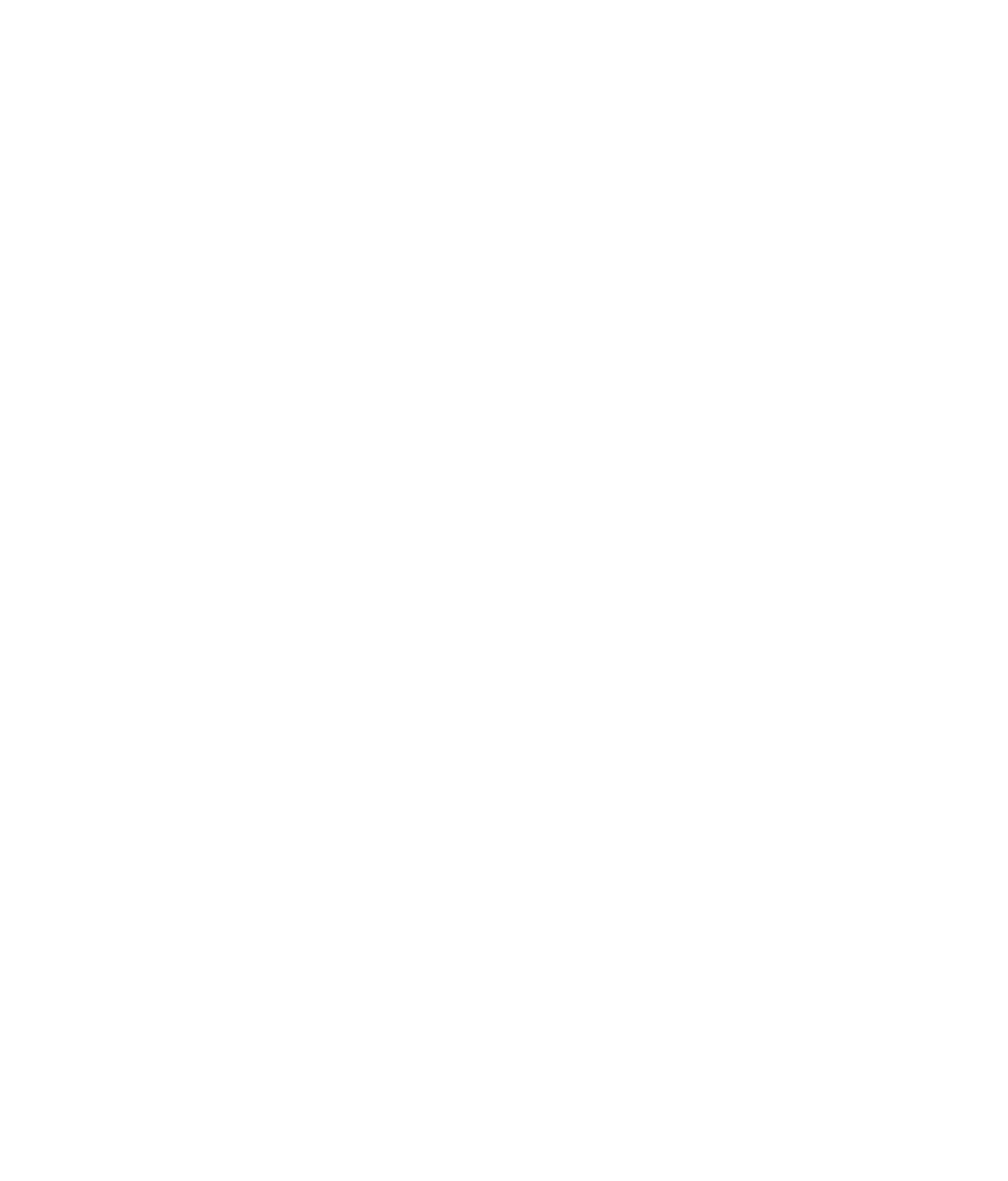




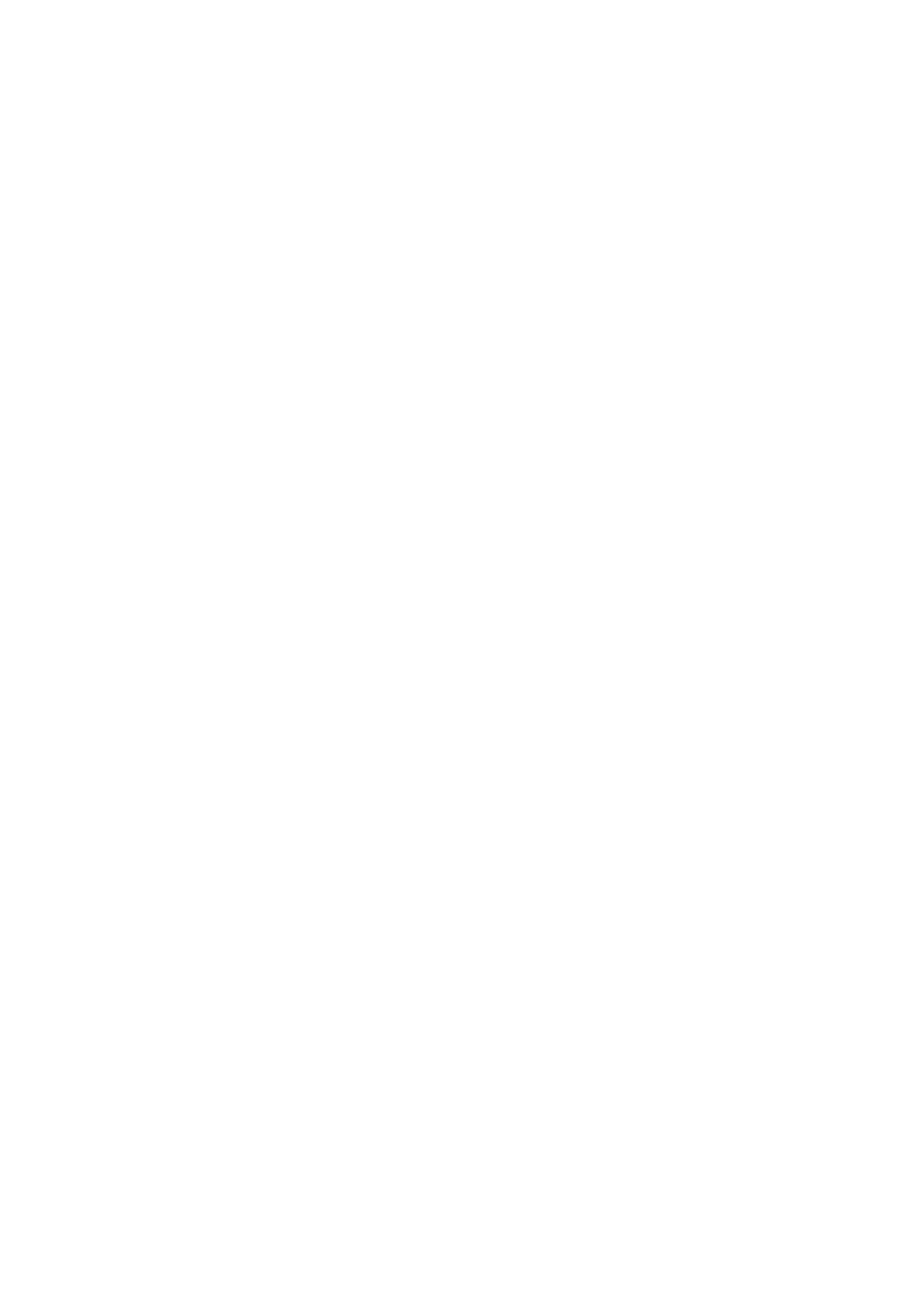




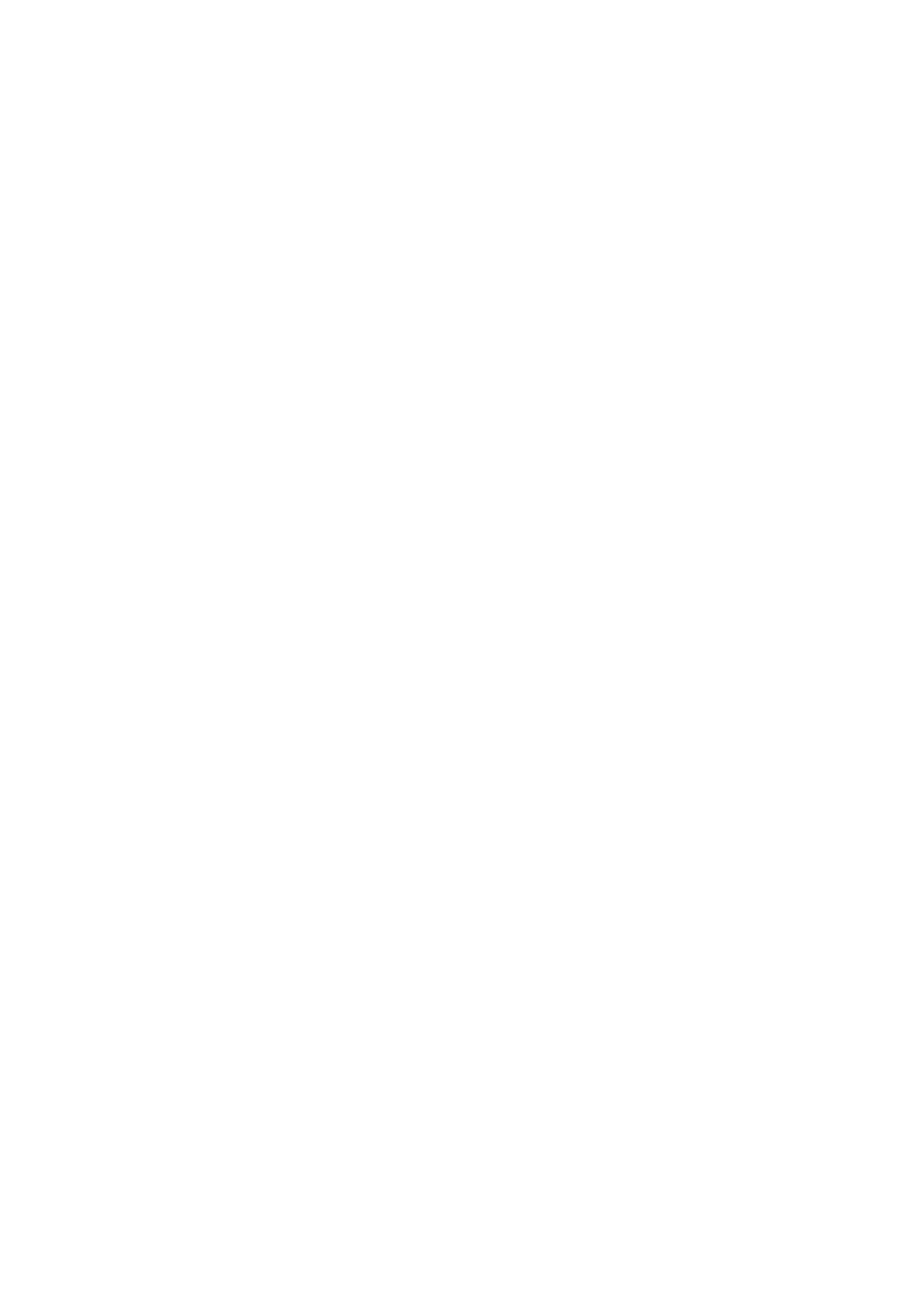




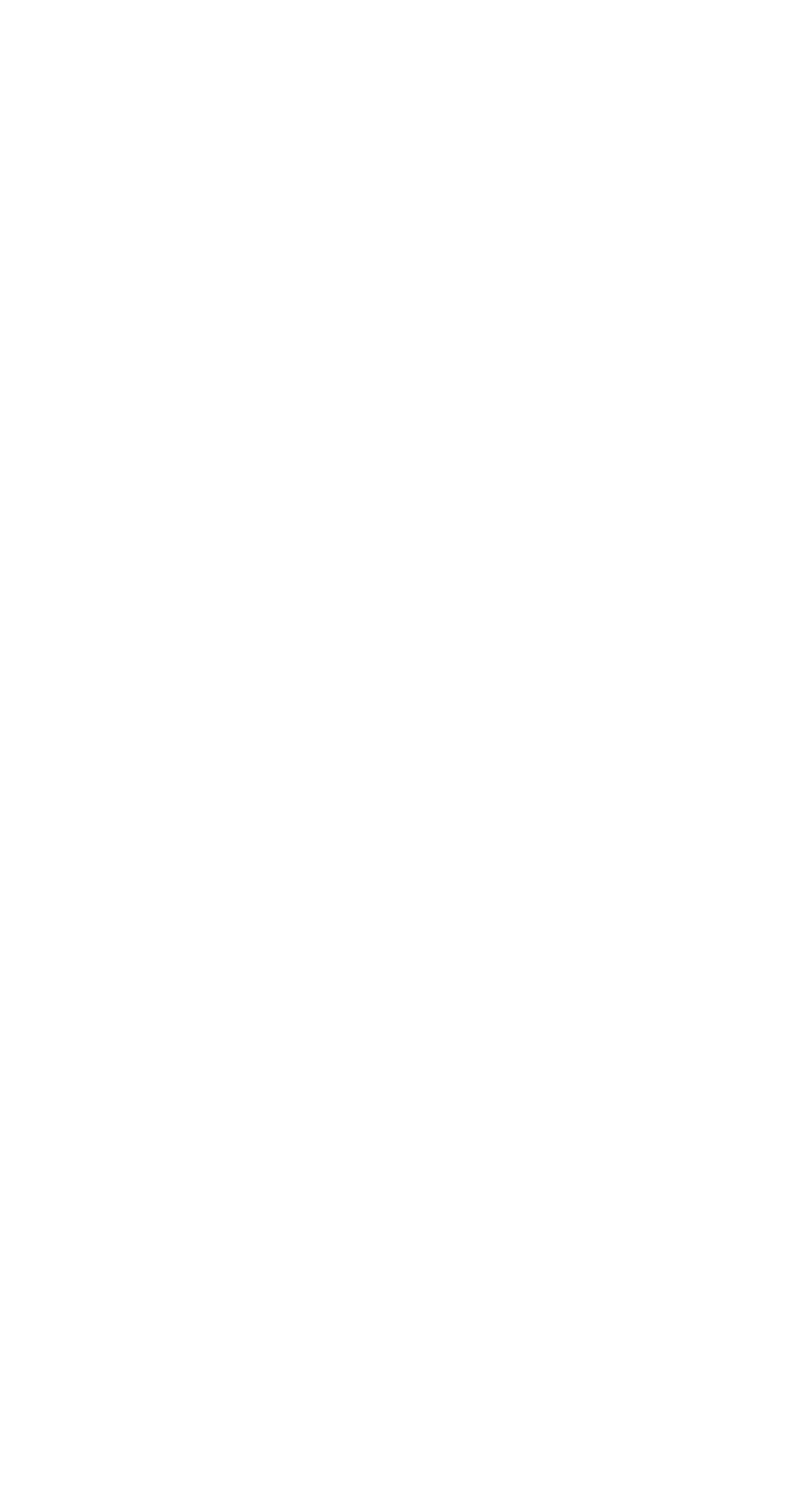


1118 1118 1118 1118 1118 1119 1118

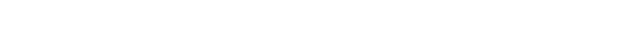

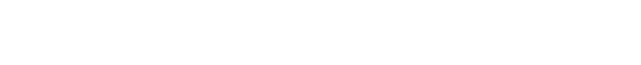

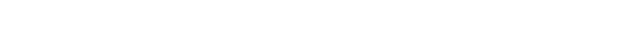

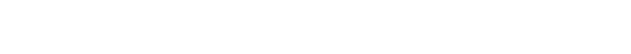

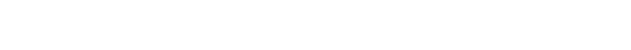

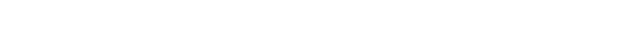

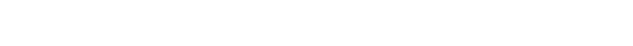

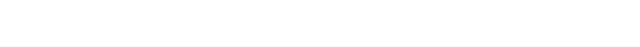

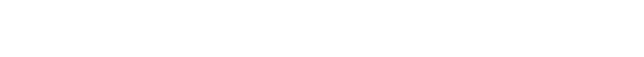

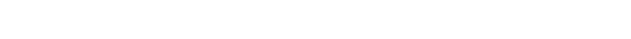

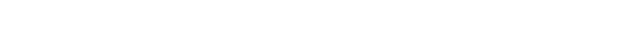

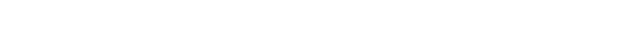
0010010001000010010000100100

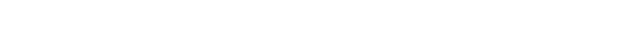

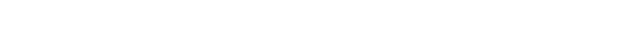

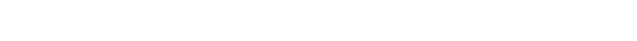

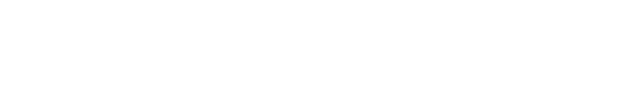

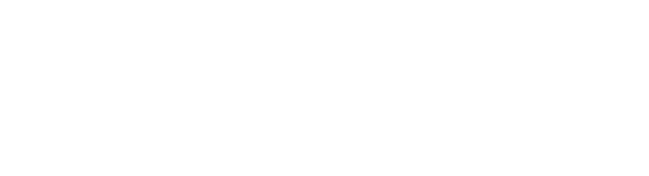

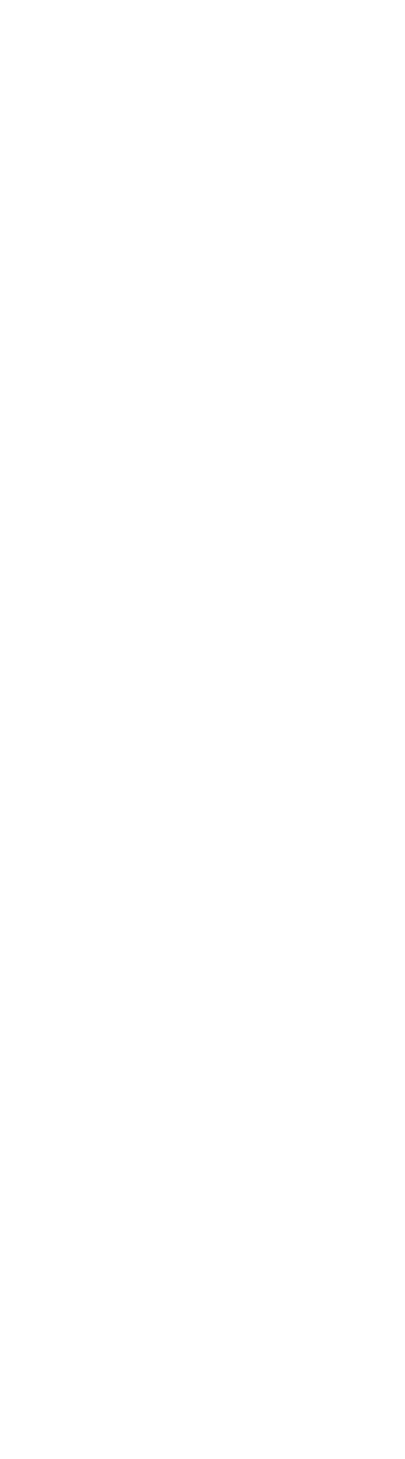




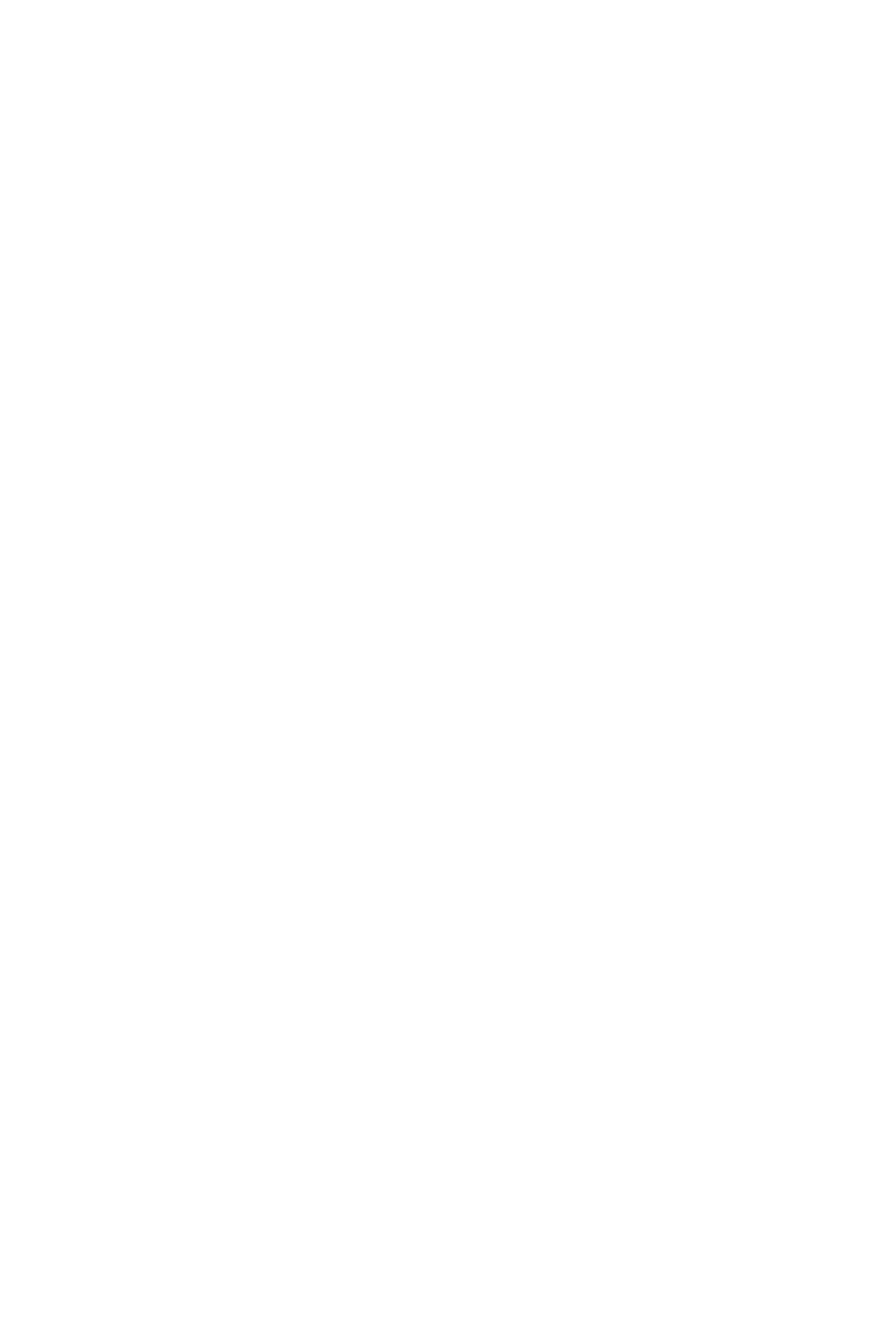




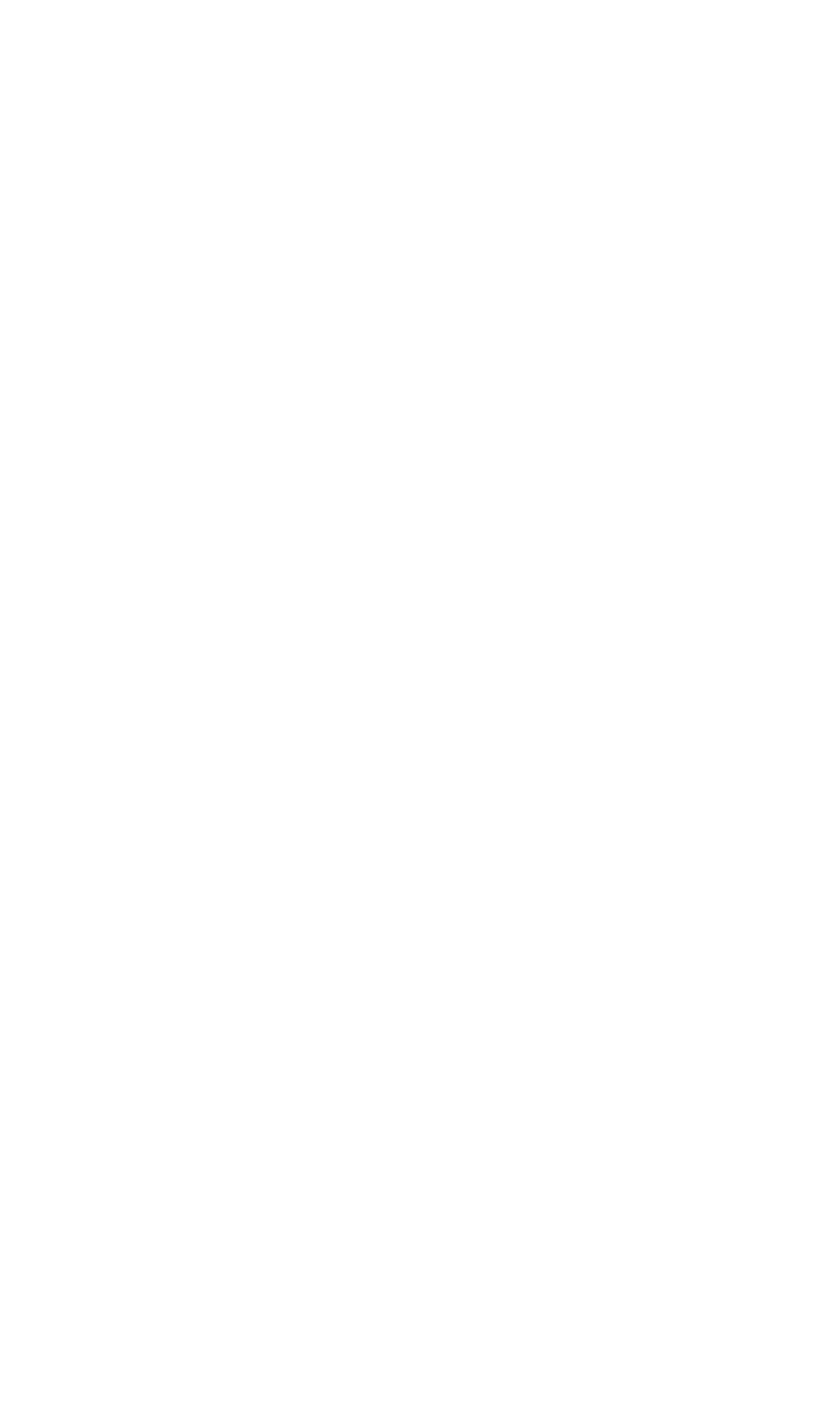


SCIOTO RIVER BASIN--Continued

3-2296. SCIOTO RIVER BELOW SHADEVILLE, OHIO--CON tInUEd

Data from continuous recorder, water year October 1966 to September 1967

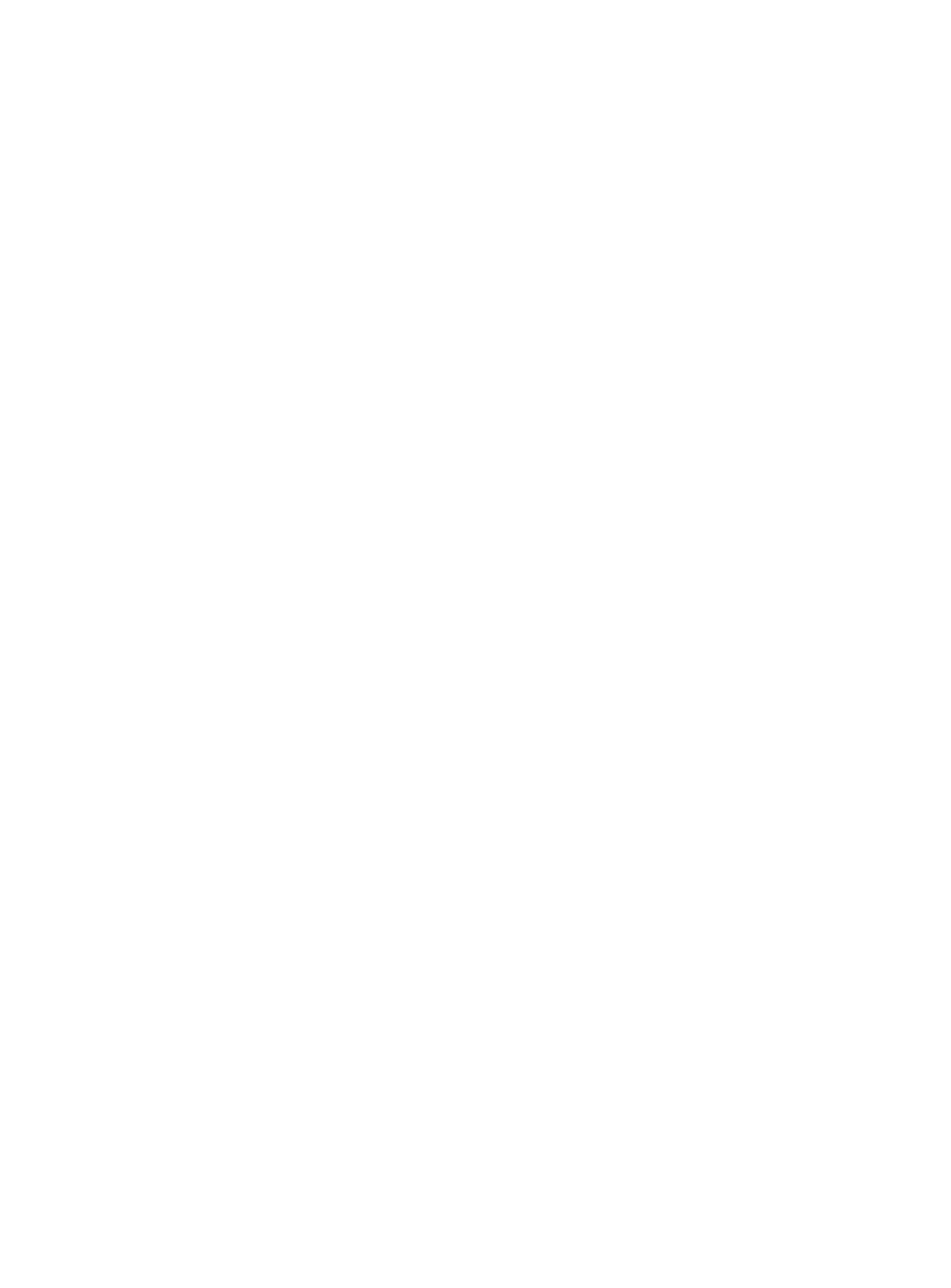


OHIO RIVER BASIN

SCIOTO RIVER BASIN--Continued

3-2296. SCIOTO RIVER BELOW SHADEVILLE, OHIO--COntInUed

Data from continuous recorder, water year October 1966 to September 1967--Continued

\begin{tabular}{|c|c|c|c|c|c|c|c|c|c|c|c|c|c|c|c|c|c|c|}
\hline \multirow{2}{*}{ Day } & \multicolumn{6}{|c|}{ APRIL } & \multicolumn{6}{|c|}{ MAY } & \multicolumn{6}{|c|}{ JUNE } \\
\hline & Max & Min & Max & Min & Max & $\operatorname{Min}$ & Max & Min & Max & $\operatorname{Min}$ & Max & $\mathbf{M i n}$ & $\operatorname{Max}$ & Min & $\operatorname{Max}$ & Min & $\mathbf{M} \times \mathbf{v}$ & Min \\
\hline $\begin{array}{l}1 \\
2 \\
3 \\
4 \\
5\end{array}$ & $\begin{array}{l}480 \\
510 \\
540 \\
590 \\
500\end{array}$ & $\begin{array}{l}430 \\
460 \\
510 \\
480 \\
520\end{array}$ & $\begin{array}{l}9.8 \\
9.1 \\
8.7 \\
8.7 \\
8.1\end{array}$ & $\begin{array}{l}8.9 \\
8.5 \\
8.3 \\
8.1 \\
7.2\end{array}$ & $\begin{array}{l}55 \\
57 \\
57 \\
55 \\
53\end{array}$ & $\begin{array}{l}51 \\
53 \\
54 \\
51 \\
52\end{array}$ & $\begin{array}{l}680 \\
670 \\
670 \\
510 \\
570\end{array}$ & $\begin{array}{l}630 \\
620 \\
510 \\
470 \\
480\end{array}$ & $\begin{array}{l}- \\
-- \\
- \\
-\end{array}$ & $\begin{array}{l}-- \\
-- \\
-- \\
--\end{array}$ & $\begin{array}{l}61 \\
61 \\
59 \\
58 \\
60\end{array}$ & $\begin{array}{l}59 \\
59 \\
57 \\
56 \\
57\end{array}$ & $\begin{array}{l}-- \\
-- \\
-- \\
-- \\
--\end{array}$ & $\begin{array}{l}-- \\
-- \\
--\end{array}$ & $\begin{array}{l}3.1 \\
3.9 \\
4.6 \\
3.9 \\
2.9\end{array}$ & $\begin{array}{r}0.6 \\
.5 \\
.8 \\
.6 \\
.5\end{array}$ & $\begin{array}{l}67 \\
68 \\
71 \\
72 \\
74\end{array}$ & $\begin{array}{l}63 \\
63 \\
65 \\
68 \\
68\end{array}$ \\
\hline $\begin{array}{r}0 \\
7 \\
8 \\
9 \\
10\end{array}$ & $\begin{array}{l}680 \\
560 \\
480 \\
480 \\
580\end{array}$ & $\begin{array}{l}420 \\
370 \\
440 \\
470 \\
480\end{array}$ & $\begin{array}{l}7.7 \\
7.7 \\
8.1 \\
8.2 \\
7.9\end{array}$ & $\begin{array}{l}7.1 \\
7.1 \\
7.5 \\
7.5 \\
7.2\end{array}$ & $\begin{array}{l}55 \\
55 \\
54 \\
55 \\
56\end{array}$ & $\begin{array}{l}52 \\
53 \\
52 \\
52 \\
54\end{array}$ & $\begin{array}{l}-- \\
-- \\
-- \\
--\end{array}$ & $\overline{-}$ & $\begin{array}{l}-- \\
-- \\
--\end{array}$ & $\begin{array}{l}-- \\
-- \\
-- \\
--\end{array}$ & $\begin{array}{l}60 \\
57 \\
54 \\
55 \\
55\end{array}$ & $\begin{array}{l}57 \\
53 \\
51 \\
53 \\
52\end{array}$ & $\begin{array}{l}- \\
- \\
-- \\
-- \\
--\end{array}$ & $\begin{array}{l}-- \\
-- \\
--\end{array}$ & $\begin{array}{r}1.4 \\
.7 \\
.2 \\
.3 \\
.2\end{array}$ & $\begin{array}{l}.3 \\
.2 \\
.1 \\
.1 \\
.1\end{array}$ & $\begin{array}{l}75 \\
75 \\
76 \\
77 \\
78\end{array}$ & $\begin{array}{l}70 \\
72 \\
72 \\
73 \\
73\end{array}$ \\
\hline $\begin{array}{l}16 \\
17 \\
18 \\
19 \\
20\end{array}$ & $\begin{array}{l}500 \\
560 \\
600 \\
030 \\
600\end{array}$ & $\begin{array}{l}440 \\
500 \\
550 \\
600 \\
630\end{array}$ & $\begin{array}{l}6.4 \\
5.9 \\
6.1 \\
5.9 \\
5.6\end{array}$ & $\begin{array}{l}5.5 \\
5.4 \\
5.6 \\
5.2 \\
3.3\end{array}$ & $\begin{array}{l}62 \\
64 \\
62 \\
01 \\
61\end{array}$ & $\begin{array}{l}59 \\
60 \\
58 \\
57 \\
56\end{array}$ & $\begin{array}{l}470 \\
460 \\
520 \\
490 \\
540\end{array}$ & $\begin{array}{l}380 \\
420 \\
430 \\
440 \\
470\end{array}$ & $\begin{array}{l}6.6 \\
6.5 \\
6.0 \\
5.3 \\
4.9\end{array}$ & $\begin{array}{l}5.7 \\
5.7 \\
5.0 \\
4.7 \\
4.3\end{array}$ & $\begin{array}{l}55 \\
57 \\
59 \\
59 \\
62\end{array}$ & $\begin{array}{l}53 \\
55 \\
56 \\
58 \\
58\end{array}$ & $\begin{array}{c}900 \\
760 \\
730 \\
720 \\
-\end{array}$ & $\begin{array}{r}760 \\
600 \\
630 \\
640 \\
-\end{array}$ & $\begin{array}{l}.1 \\
.1 \\
.5 \\
.2 \\
.1\end{array}$ & $\begin{array}{l}.0 \\
.0 \\
.1 \\
.1 \\
.0\end{array}$ & $\begin{array}{l}80 \\
80 \\
80 \\
78 \\
79\end{array}$ & $\begin{array}{l}76 \\
75 \\
77 \\
74 \\
73\end{array}$ \\
\hline $\begin{array}{l}21 \\
22 \\
23 \\
24 \\
25\end{array}$ & $\begin{array}{l}720 \\
680 \\
600 \\
520 \\
530\end{array}$ & $\begin{array}{l}650 \\
510 \\
480 \\
490 \\
500\end{array}$ & $\begin{array}{r}5.4 \\
7.9 \\
10.4 \\
11.9 \\
12.3\end{array}$ & $\begin{array}{r}4.4 \\
3.5 \\
7.3 \\
10.5 \\
11.5\end{array}$ & $\begin{array}{l}61 \\
62 \\
59 \\
58 \\
56\end{array}$ & $\begin{array}{l}59 \\
59 \\
57 \\
54 \\
53\end{array}$ & $\begin{array}{c}600 \\
620 \\
710 \\
-- \\
--\end{array}$ & $\begin{array}{r}530 \\
550 \\
580 \\
--\end{array}$ & $\begin{array}{l}4.9 \\
4.4 \\
5.2 \\
3.2 \\
2.0\end{array}$ & $\begin{array}{l}4.1 \\
3.7 \\
3.1 \\
2.0 \\
1.2\end{array}$ & $\begin{array}{l}63 \\
64 \\
64 \\
66 \\
68\end{array}$ & $\begin{array}{l}59 \\
60 \\
59 \\
61 \\
63\end{array}$ & $\begin{array}{l}z \\
z \\
z \\
z\end{array}$ & $\begin{array}{l}- \\
- \\
-\end{array}$ & $\begin{array}{l}.1 \\
.1 \\
.1 \\
.1 \\
.1\end{array}$ & $\begin{array}{l}.0 \\
.0 \\
.0 \\
.0 \\
.0\end{array}$ & $\begin{array}{l}77 \\
76 \\
77 \\
78 \\
77\end{array}$ & $\begin{array}{l}75 \\
74 \\
72 \\
74 \\
75\end{array}$ \\
\hline $\begin{array}{l}26 \\
27 \\
28 \\
29 \\
30 \\
31\end{array}$ & $\begin{array}{l}580 \\
610 \\
630 \\
640 \\
690 \\
-\end{array}$ & $\begin{array}{l}530 \\
530 \\
590 \\
630 \\
640 \\
-\end{array}$ & $\begin{array}{l}- \\
-- \\
z- \\
z\end{array}$ & $\begin{array}{l}-- \\
-- \\
-- \\
-- \\
--\end{array}$ & $\begin{array}{l}56 \\
57 \\
59 \\
60 \\
60 \\
--\end{array}$ & $\begin{array}{l}53 \\
52 \\
53 \\
55 \\
57 \\
--\end{array}$ & $\begin{array}{l}-- \\
-- \\
\overline{--} \\
-- \\
--\end{array}$ & $\begin{array}{l}- \\
-- \\
-- \\
-- \\
-\end{array}$ & $\begin{array}{r}1.7 \\
.8 \\
.9 \\
1.3 \\
1.0 \\
2.1\end{array}$ & $\begin{array}{l}.6 \\
.3 \\
.2 \\
.3 \\
.6 \\
.7\end{array}$ & $\begin{array}{l}67 \\
70 \\
71 \\
70 \\
67 \\
67\end{array}$ & $\begin{array}{l}64 \\
64 \\
67 \\
67 \\
64 \\
63\end{array}$ & $\begin{array}{l}-- \\
z- \\
z- \\
z- \\
--\end{array}$ & $\begin{array}{l}- \\
\overline{-} \\
\overline{-} \\
-\end{array}$ & $\begin{array}{l}-1 \\
.1 \\
-1 \\
.1 \\
-1 \\
-1\end{array}$ & $\begin{array}{l}.0 \\
.0 \\
.0 \\
.0 \\
.0 \\
-0\end{array}$ & $\begin{array}{l}77 \\
80 \\
78 \\
74 \\
76 \\
-\end{array}$ & $\begin{array}{l}71 \\
73 \\
72 \\
70 \\
71 \\
--1\end{array}$ \\
\hline $\begin{array}{r}6 \\
7 \\
8 \\
9 \\
10\end{array}$ & $\begin{array}{r}820 \\
880 \\
-- \\
--\end{array}$ & $\begin{array}{c}600 \\
7>0 \\
-- \\
--\end{array}$ & $\begin{array}{r}4.1 \\
1.5 \\
.3 \\
.2 \\
.2\end{array}$ & $\begin{array}{r}1.5 \\
.2 \\
.2 \\
.1 \\
.1\end{array}$ & $\begin{array}{l}74 \\
74 \\
77 \\
78 \\
82\end{array}$ & $\begin{array}{l}71 \\
71 \\
71 \\
73 \\
73\end{array}$ & $\begin{array}{l}780 \\
780 \\
840 \\
850 \\
870\end{array}$ & $\begin{array}{l}710 \\
080 \\
730 \\
730 \\
810\end{array}$ & $\begin{array}{l}.1 \\
.1 \\
.1 \\
.1 \\
.1\end{array}$ & $\begin{array}{l}.0 \\
.0 \\
.0 \\
.0 \\
.0\end{array}$ & $\begin{array}{l}77 \\
75 \\
77 \\
77 \\
76\end{array}$ & $\begin{array}{l}72 \\
72 \\
71 \\
74 \\
72\end{array}$ & $\begin{array}{l}910 \\
930 \\
940 \\
950 \\
940\end{array}$ & $\begin{array}{l}850 \\
870 \\
920 \\
920 \\
890\end{array}$ & $\begin{array}{r}5.5 \\
3.8 \\
1.7 \\
.7 \\
1.0\end{array}$ & $\begin{array}{l}.3 \\
.6 \\
.3 \\
.2 \\
.3\end{array}$ & $\begin{array}{l}77 \\
77 \\
75 \\
75 \\
76\end{array}$ & $\begin{array}{l}72 \\
72 \\
72 \\
73 \\
71\end{array}$ \\
\hline $\begin{array}{l}11 \\
12 \\
13 \\
14 \\
15\end{array}$ & $\begin{array}{r}880 \\
890 \\
910 \\
950 \\
-\end{array}$ & $\begin{array}{r}700 \\
830 \\
830 \\
840 \\
-\end{array}$ & $\begin{array}{l}.6 \\
.3 \\
.4 \\
.2 \\
.2\end{array}$ & $\begin{array}{l}.2 \\
.1 \\
.1 \\
.1 \\
.1\end{array}$ & $\begin{array}{l}82 \\
85 \\
78 \\
75 \\
74\end{array}$ & $\begin{array}{l}72 \\
74 \\
73 \\
71 \\
70\end{array}$ & $\begin{array}{l}900 \\
920 \\
910 \\
890 \\
890\end{array}$ & $\begin{array}{l}770 \\
880 \\
820 \\
700 \\
760\end{array}$ & $\begin{array}{l}.1 \\
.1 \\
.1 \\
.1 \\
.1\end{array}$ & $\begin{array}{l}.0 \\
.0 \\
.0 \\
.0 \\
.0\end{array}$ & $\begin{array}{l}74 \\
74 \\
73 \\
74 \\
75\end{array}$ & $\begin{array}{l}69 \\
68 \\
68 \\
68 \\
69\end{array}$ & $\begin{array}{c}930 \\
910 \\
-- \\
--\end{array}$ & $\begin{array}{r}820 \\
830 \\
-- \\
--\end{array}$ & $\begin{array}{r}1.8 \\
1.9 \\
= \\
=\end{array}$ & $\begin{array}{r}.3 \\
.4 \\
- \\
--\end{array}$ & $\begin{array}{l}74 \\
77 \\
74 \\
75 \\
82\end{array}$ & $\begin{array}{l}68 \\
67 \\
69 \\
68 \\
69\end{array}$ \\
\hline $\begin{array}{l}16 \\
17 \\
18 \\
19 \\
20\end{array}$ & $\overline{-}$ & $=$ & $\begin{array}{l}.2 \\
.2 \\
.2 \\
.2 \\
.2\end{array}$ & $\begin{array}{l}.1 \\
.1 \\
.1 \\
.1 \\
.1\end{array}$ & $\begin{array}{l}74 \\
75 \\
81 \\
80 \\
78\end{array}$ & $\begin{array}{l}69 \\
69 \\
73 \\
72 \\
72\end{array}$ & $\begin{array}{l}970 \\
990 \\
970 \\
980 \\
970\end{array}$ & $\begin{array}{l}880 \\
900 \\
870 \\
900 \\
750\end{array}$ & $\begin{array}{l}.1 \\
.1 \\
.1 \\
.1 \\
.1\end{array}$ & $\begin{array}{l}.0 \\
.0 \\
.0 \\
.0 \\
.0\end{array}$ & $\begin{array}{l}76 \\
76 \\
75 \\
77 \\
75\end{array}$ & $\begin{array}{l}70 \\
72 \\
73 \\
72 \\
72\end{array}$ & $\begin{array}{l}-- \\
-- \\
-- \\
-- \\
--\end{array}$ & $\begin{array}{l}-- \\
\overline{-} \\
--\end{array}$ & $\begin{array}{l}-- \\
-- \\
--\end{array}$ & $\overline{-}$ & $\begin{array}{l}76 \\
75 \\
82 \\
79 \\
77\end{array}$ & $\begin{array}{l}70 \\
71 \\
73 \\
73 \\
72\end{array}$ \\
\hline $\begin{array}{l}21 \\
22 \\
23 \\
24 \\
25\end{array}$ & $\begin{array}{r}690 \\
- \\
-\end{array}$ & $\begin{array}{c}500 \\
-- \\
-- \\
-\end{array}$ & $\begin{array}{l}.4 \\
-- \\
-- \\
--\end{array}$ & $\begin{array}{l}-2 \\
-- \\
--\end{array}$ & $\begin{array}{l}73 \\
-- \\
-- \\
--\end{array}$ & $\begin{array}{c}70 \\
-- \\
-- \\
--\end{array}$ & $\begin{array}{r}820 \\
\text { UbD } \\
-- \\
-- \\
--\end{array}$ & $\begin{array}{r}720 \\
730 \\
-- \\
--\end{array}$ & $\begin{array}{l}.2 \\
.1 \\
: 1 \\
: 1 \\
.1\end{array}$ & $\begin{array}{l}.0 \\
.0 \\
.0 \\
.0 \\
.0\end{array}$ & $\begin{array}{l}75 \\
73 \\
75 \\
74 \\
73\end{array}$ & $\begin{array}{l}70 \\
69 \\
69 \\
70 \\
71\end{array}$ & $\begin{array}{l}930 \\
890 \\
840 \\
920 \\
960\end{array}$ & $\begin{array}{l}870 \\
800 \\
780 \\
830 \\
890\end{array}$ & $\begin{array}{l}3.3 \\
3.5 \\
3.2 \\
2.8 \\
3.1\end{array}$ & $\begin{array}{r}1.5 \\
.7 \\
1.6 \\
1.2 \\
1.4\end{array}$ & $\begin{array}{l}77 \\
70 \\
66 \\
66 \\
66\end{array}$ & $\begin{array}{l}70 \\
65 \\
62 \\
63 \\
60\end{array}$ \\
\hline $\begin{array}{l}20 \\
27 \\
28 \\
29 \\
30 \\
31\end{array}$ & $\begin{array}{r}-- \\
-- \\
830 \\
830 \\
-- \\
--\end{array}$ & $\begin{array}{l}-- \\
-- \\
220 \\
5=0 \\
-- \\
-\end{array}$ & $\begin{array}{r}-.2 \\
.4 \\
.8 \\
.4 \\
.2\end{array}$ & $\begin{array}{l}-. \\
.4 \\
.3 \\
.4 \\
.2 \\
.1\end{array}$ & $\begin{array}{l}-- \\
84 \\
83 \\
77 \\
78 \\
76\end{array}$ & $\begin{array}{l}-- \\
80 \\
74 \\
73 \\
73 \\
73\end{array}$ & $\begin{array}{l}-- \\
-- \\
-- \\
-- \\
940\end{array}$ & $\begin{array}{c}-- \\
-- \\
-- \\
-- \\
-- \\
760\end{array}$ & $\begin{array}{l}.1 \\
.1 \\
.1 \\
.1 \\
.1 \\
.1\end{array}$ & $\begin{array}{l}.0 \\
.0 \\
.0 \\
.0 \\
.0 \\
.0\end{array}$ & $\begin{array}{l}74 \\
74 \\
71 \\
75 \\
75 \\
73\end{array}$ & $\begin{array}{l}72 \\
70 \\
68 \\
67 \\
69 \\
68\end{array}$ & $\begin{array}{l}950 \\
970 \\
890 \\
580 \\
040 \\
--\end{array}$ & $\begin{array}{l}880 \\
870 \\
530 \\
500 \\
550 \\
-\end{array}$ & $\begin{array}{r}2.9 \\
3.3 \\
3.6 \\
3.8 \\
4.2 \\
-\end{array}$ & $\begin{array}{r}1.4 \\
.8 \\
.3 \\
3.3 \\
3.3 \\
.0\end{array}$ & $\begin{array}{l}76 \\
77 \\
65 \\
58 \\
57 \\
--\end{array}$ & $\begin{array}{l}61 \\
64 \\
58 \\
56 \\
55 \\
--\end{array}$ \\
\hline
\end{tabular}




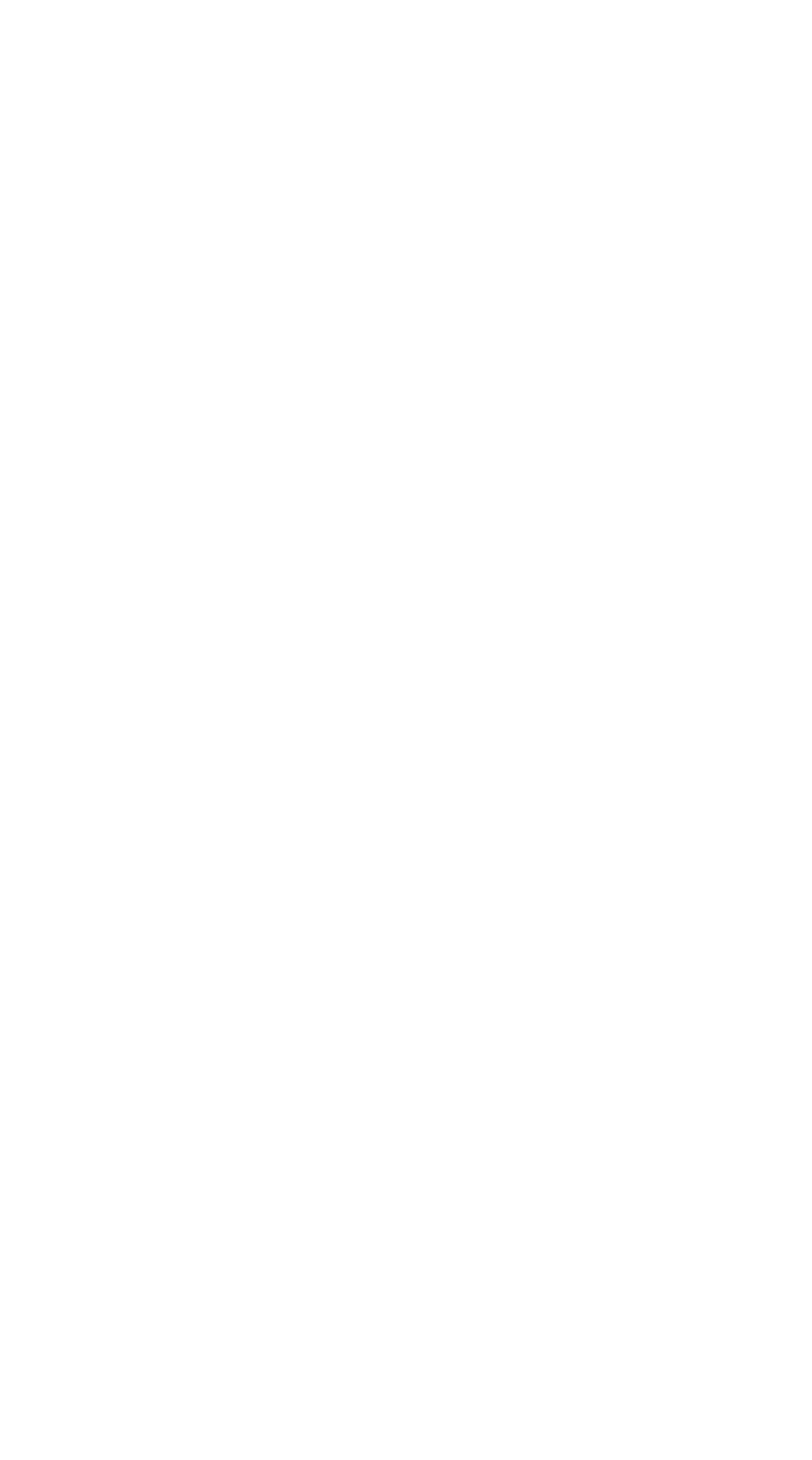


1191118 1191118 118 1118 1119

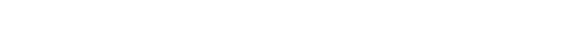

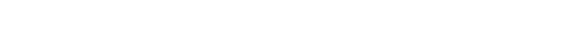

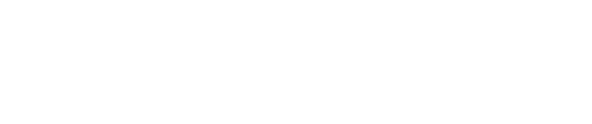

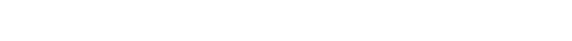

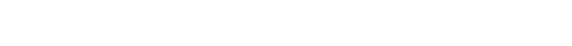

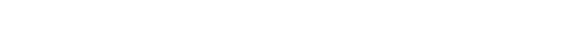

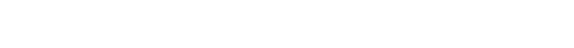

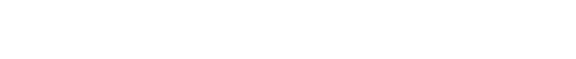

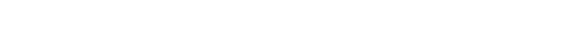

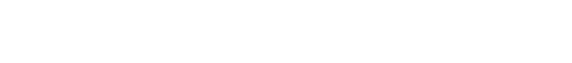

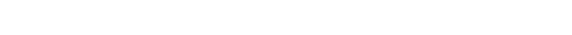
0000010 0NO 000000000000

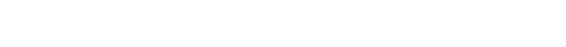

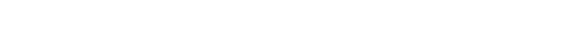

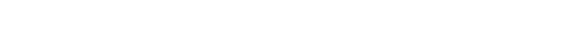
19.



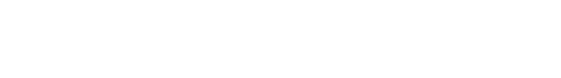
$\overline{\vdots \vdots \vdots} \vdots \vdots \vdots \vdots \vdots \vdots \vdots \overline{\mathrm{o}}$

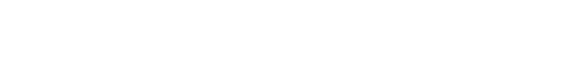

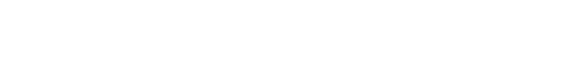

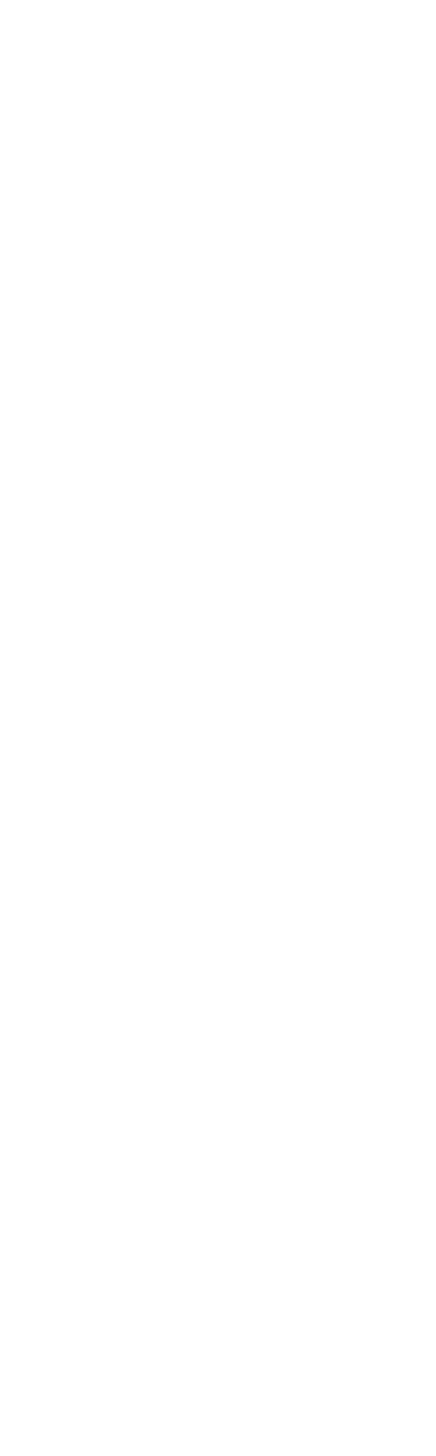




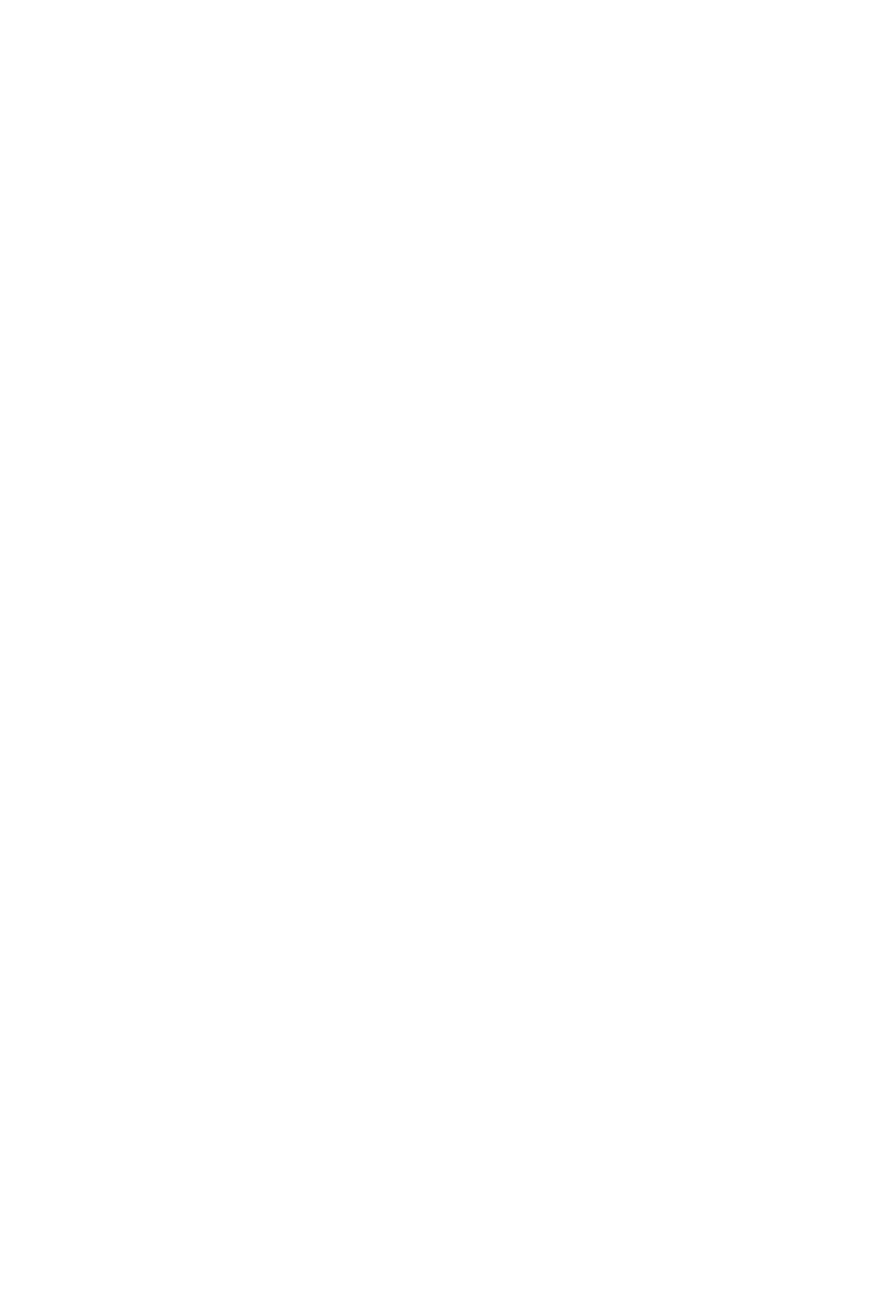




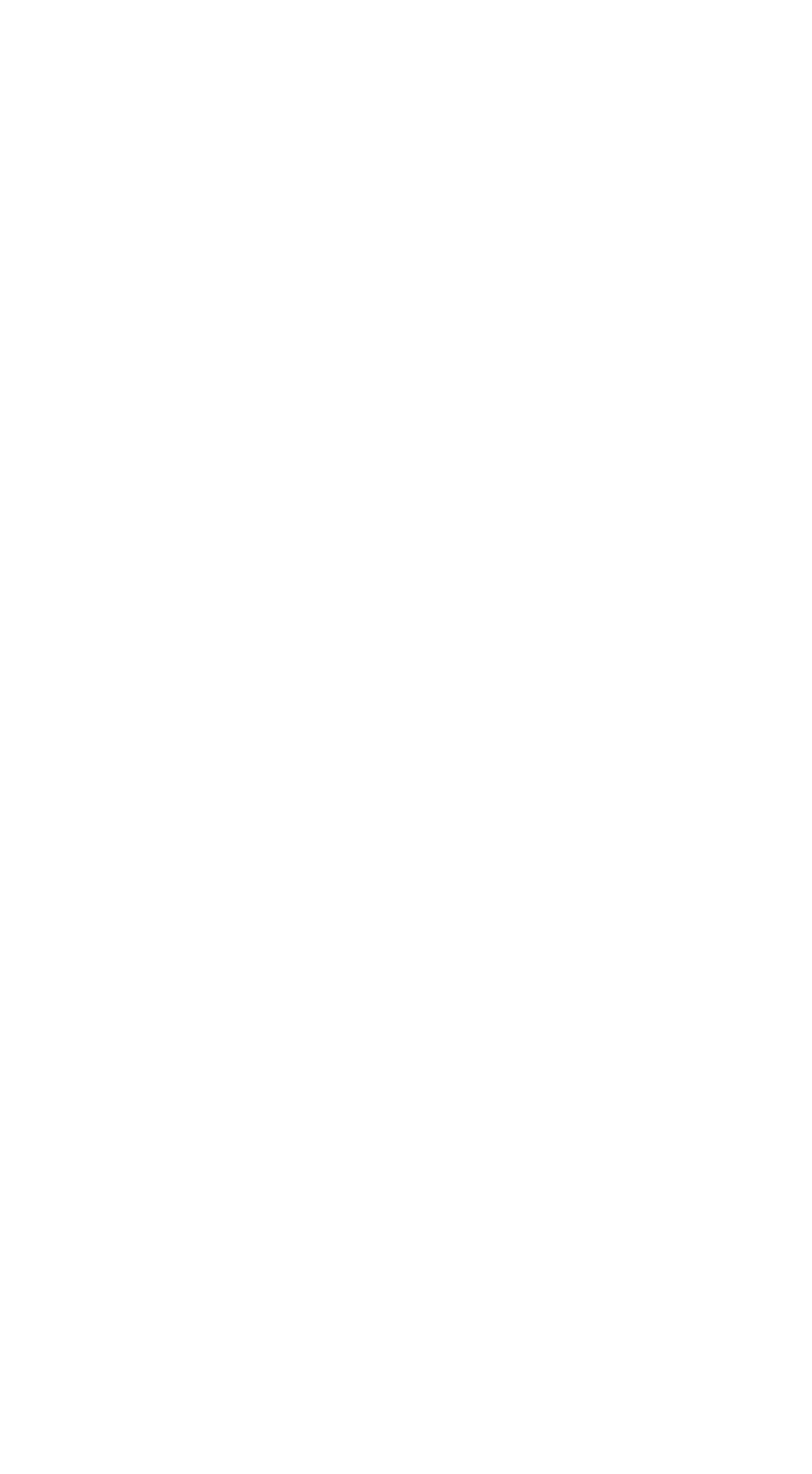


SCIOTO RIVER BASIN--COntinued

3-2315. SCIOTO RIVER AT CHILLICOTHE, OHIO--CONtinued

Data from continuous recorder, water year October 1966 to September 1967

\begin{tabular}{|c|c|c|c|c|c|c|c|c|c|c|c|c|c|c|c|c|c|c|}
\hline \multirow{2}{*}{ Day } & \multicolumn{6}{|c|}{ ULTODER } & \multicolumn{6}{|c|}{ NÜVEMUER } & \multicolumn{6}{|c|}{ DECEMDER } \\
\hline & $\operatorname{Max}$ & Min & $\operatorname{Max}$ & Min & Max & Min & Max & Min & Max & Min & Max & Min & Max & Nin & Max & Min & $\mathbf{M a x}$ & Min \\
\hline $\begin{array}{l}1 \\
2 \\
3 \\
4 \\
5\end{array}$ & $\begin{array}{l}-- \\
-- \\
=- \\
--\end{array}$ & $\begin{array}{l}-- \\
-- \\
-- \\
--\end{array}$ & $\begin{array}{l}5.3 \\
5.1 \\
6.6 \\
5.8 \\
6.6\end{array}$ & $\begin{array}{l}3.7 \\
3.7 \\
3.8 \\
4.1 \\
4.0\end{array}$ & $\begin{array}{l}63 \\
61 \\
62 \\
63 \\
62\end{array}$ & $\begin{array}{l}59 \\
58 \\
57 \\
60 \\
58\end{array}$ & $\begin{array}{l}720 \\
700 \\
730 \\
820 \\
550\end{array}$ & $\begin{array}{l}680 \\
680 \\
060 \\
640 \\
600\end{array}$ & $\begin{array}{l}5.9 \\
6.1 \\
6.3 \\
4.8 \\
7.2\end{array}$ & $\begin{array}{l}4.8 \\
5.1 \\
4.7 \\
2.9 \\
4.2\end{array}$ & $\begin{array}{l}53 \\
51 \\
47 \\
48 \\
45\end{array}$ & $\begin{array}{l}51 \\
46 \\
44 \\
44 \\
43\end{array}$ & $\begin{array}{l}770 \\
770 \\
750 \\
830 \\
820\end{array}$ & $\begin{array}{l}710 \\
720 \\
720 \\
750 \\
780\end{array}$ & $\begin{array}{r}8.0 \\
8.9 \\
9.7 \\
10.1 \\
10.4\end{array}$ & $\begin{array}{l}7.0 \\
7.7 \\
8.9 \\
9.7 \\
9.8\end{array}$ & $\begin{array}{l}44 \\
43 \\
39 \\
37 \\
38\end{array}$ & $\begin{array}{l}43 \\
39 \\
37 \\
35 \\
30\end{array}$ \\
\hline $\begin{array}{r}6 \\
7 \\
8 \\
8 \\
10\end{array}$ & $\begin{array}{l}=- \\
=- \\
=- \\
--\end{array}$ & $\begin{array}{l}-- \\
-- \\
-- \\
--\end{array}$ & $\begin{array}{l}6.1 \\
6.4 \\
7.0 \\
0.0 \\
7.2\end{array}$ & $\begin{array}{l}4.2 \\
4.3 \\
4.6 \\
3.7 \\
4.5\end{array}$ & $\begin{array}{l}61 \\
61 \\
61 \\
61 \\
63\end{array}$ & $\begin{array}{l}56 \\
55 \\
56 \\
59 \\
59\end{array}$ & $\begin{array}{l}690 \\
740 \\
740 \\
710 \\
730\end{array}$ & $\begin{array}{l}630 \\
690 \\
680 \\
610 \\
590\end{array}$ & $\begin{array}{l}7.0 \\
6.6 \\
6.4 \\
6.1 \\
6.0\end{array}$ & $\begin{array}{l}6.4 \\
5.5 \\
6.0 \\
4.3 \\
3.1\end{array}$ & $\begin{array}{l}45 \\
48 \\
49 \\
53 \\
55\end{array}$ & $\begin{array}{l}43 \\
44 \\
47 \\
49 \\
53\end{array}$ & $\begin{array}{l}910 \\
720 \\
680 \\
620 \\
640\end{array}$ & $\begin{array}{l}690 \\
660 \\
590 \\
600 \\
370\end{array}$ & $\begin{array}{r}10.5 \\
10.1 \\
9.1 \\
9.0 \\
9.0\end{array}$ & $\begin{array}{l}9.5 \\
8.5 \\
8.1 \\
8.5 \\
8.2\end{array}$ & $\begin{array}{l}41 \\
40 \\
48 \\
50 \\
50\end{array}$ & $\begin{array}{l}38 \\
41 \\
45 \\
48 \\
47\end{array}$ \\
\hline $\begin{array}{l}10 \\
17 \\
18 \\
19 \\
26\end{array}$ & $\begin{array}{l}880 \\
860 \\
850 \\
880 \\
900\end{array}$ & $\begin{array}{l}860 \\
790 \\
800 \\
850 \\
870\end{array}$ & $\begin{array}{l}5.4 \\
5.4 \\
5.1 \\
5.3 \\
4.8\end{array}$ & $\begin{array}{l}2.9 \\
3.2 \\
4.3 \\
4.2 \\
2.4\end{array}$ & $\begin{array}{l}61 \\
59 \\
56 \\
55 \\
57\end{array}$ & $\begin{array}{l}58 \\
56 \\
55 \\
54 \\
53\end{array}$ & $\begin{array}{l}600 \\
650 \\
670 \\
680 \\
680\end{array}$ & $\begin{array}{l}590 \\
600 \\
640 \\
660 \\
670\end{array}$ & $\begin{array}{l}8.7 \\
8.7 \\
7.9 \\
7.4 \\
7.5\end{array}$ & $\begin{array}{l}7.2 \\
6.5 \\
7.2 \\
7.1 \\
7.0\end{array}$ & $\begin{array}{l}48 \\
49 \\
52 \\
51 \\
49\end{array}$ & $\begin{array}{l}46 \\
47 \\
49 \\
49 \\
47\end{array}$ & $\begin{array}{l}510 \\
550 \\
570 \\
610 \\
610\end{array}$ & $\begin{array}{l}460 \\
490 \\
530 \\
550 \\
580\end{array}$ & $\begin{array}{l}10.4 \\
10.7 \\
10.4 \\
10.4 \\
10.3\end{array}$ & $\begin{array}{r}10.3 \\
10.1 \\
9.7 \\
9.6 \\
9.9\end{array}$ & $\begin{array}{l}40 \\
40 \\
42 \\
42 \\
42\end{array}$ & $\begin{array}{l}39 \\
39 \\
40 \\
41 \\
41\end{array}$ \\
\hline $\begin{array}{l}21 \\
22 \\
23 \\
24 \\
25\end{array}$ & $\begin{array}{l}900 \\
870 \\
830 \\
850 \\
870\end{array}$ & $\begin{array}{l}870 \\
820 \\
620 \\
830 \\
840\end{array}$ & $\begin{array}{l}5.1 \\
5.7 \\
5.9 \\
5.6 \\
6.1\end{array}$ & $\begin{array}{l}3.0 \\
4.0 \\
4.2 \\
4.3 \\
4.6\end{array}$ & $\begin{array}{l}57 \\
56 \\
59 \\
58 \\
57\end{array}$ & $\begin{array}{l}52 \\
52 \\
55 \\
54 \\
53\end{array}$ & $\begin{array}{l}700 \\
710 \\
720 \\
710 \\
750\end{array}$ & $\begin{array}{l}680 \\
690 \\
700 \\
700 \\
710\end{array}$ & $\begin{array}{l}7.8 \\
8.0 \\
8.1 \\
7.2 \\
7.0\end{array}$ & $\begin{array}{l}7.5 \\
7.5 \\
7.2 \\
6.6 \\
6.0\end{array}$ & $\begin{array}{l}48 \\
47 \\
48 \\
49 \\
51\end{array}$ & $\begin{array}{l}46 \\
45 \\
45 \\
48 \\
49\end{array}$ & $\begin{array}{l}650 \\
670 \\
690 \\
710 \\
710\end{array}$ & $\begin{array}{l}600 \\
630 \\
650 \\
680 \\
690\end{array}$ & $\begin{array}{r}10.3 \\
9.7 \\
9.5 \\
9.8 \\
9.9\end{array}$ & $\begin{array}{l}9.4 \\
9.0 \\
9.0 \\
9.3 \\
9.3\end{array}$ & $\begin{array}{l}42 \\
42 \\
41 \\
39 \\
38\end{array}$ & $\begin{array}{l}41 \\
41 \\
39 \\
38 \\
36\end{array}$ \\
\hline $\begin{array}{l}26 \\
27 \\
28 \\
29 \\
30 \\
31\end{array}$ & $\begin{array}{l}890 \\
920 \\
950 \\
910 \\
870 \\
790\end{array}$ & $\begin{array}{l}860 \\
890 \\
900 \\
840 \\
780 \\
720\end{array}$ & $\begin{array}{l}5.9 \\
4.3 \\
3.1 \\
5.2 \\
7.0 \\
6.7\end{array}$ & $\begin{array}{l}4.3 \\
3.0 \\
1.6 \\
2.0 \\
4.1 \\
5.1\end{array}$ & $\begin{array}{l}57 \\
55 \\
58 \\
56 \\
55 \\
54\end{array}$ & $\begin{array}{l}52 \\
52 \\
54 \\
54 \\
52 \\
50\end{array}$ & $\begin{array}{c}770 \\
760 \\
770 \\
760 \\
750 \\
--\end{array}$ & $\begin{array}{l}730 \\
750 \\
740 \\
740 \\
720 \\
-\end{array}$ & $\begin{array}{l}6.1 \\
6.5 \\
6.7 \\
7.1 \\
7.5 \\
--.\end{array}$ & $\begin{array}{l}5.6 \\
5.6 \\
5.7 \\
6.6 \\
6.8 \\
-.\end{array}$ & $\begin{array}{l}51 \\
53 \\
52 \\
48 \\
45 \\
--\end{array}$ & $\begin{array}{l}50 \\
51 \\
48 \\
44 \\
44 \\
-\end{array}$ & $\begin{array}{l}700 \\
710 \\
720 \\
740 \\
740 \\
840\end{array}$ & $\begin{array}{l}690 \\
690 \\
690 \\
690 \\
710 \\
730\end{array}$ & $\begin{array}{r}10.1 \\
10.1 \\
10.2 \\
10.5 \\
10.6 \\
9.6\end{array}$ & $\begin{array}{l}9.2 \\
9.4 \\
9.5 \\
9.6 \\
9.0 \\
8.2\end{array}$ & $\begin{array}{l}36 \\
35 \\
36 \\
36 \\
36 \\
37\end{array}$ & $\begin{array}{l}35 \\
34 \\
34 \\
35 \\
34 \\
35\end{array}$ \\
\hline $\begin{array}{r}6 \\
7 \\
8 \\
9 \\
10\end{array}$ & $\begin{array}{l}750 \\
760 \\
700 \\
770 \\
790\end{array}$ & $\begin{array}{l}730 \\
740 \\
740 \\
750 \\
730\end{array}$ & $\begin{array}{l}8.9 \\
8.2 \\
8.0 \\
8.0 \\
8.7\end{array}$ & $\begin{array}{l}8.0 \\
7.7 \\
7.7 \\
6.9 \\
7.9\end{array}$ & $\begin{array}{l}39 \\
41 \\
42 \\
41 \\
39\end{array}$ & $\begin{array}{l}38 \\
38 \\
39 \\
39 \\
37\end{array}$ & $\begin{array}{r}-- \\
\overline{--} \\
700 \\
700\end{array}$ & $\begin{array}{r}-- \\
-- \\
670 \\
680\end{array}$ & $\begin{array}{l}12.2 \\
12.0 \\
11.9 \\
11.4 \\
11.0\end{array}$ & $\begin{array}{l}11.2 \\
11.8 \\
11.3 \\
11.0 \\
10.7\end{array}$ & $\begin{array}{l}36 \\
35 \\
34 \\
36 \\
37\end{array}$ & $\begin{array}{l}35 \\
34 \\
32 \\
34 \\
34\end{array}$ & $\begin{array}{l}510 \\
410 \\
430 \\
470 \\
480\end{array}$ & $\begin{array}{l}390 \\
390 \\
410 \\
430 \\
460\end{array}$ & $\begin{array}{l}10.3 \\
11.0 \\
11.0 \\
11.4 \\
10.9\end{array}$ & $\begin{array}{r}9.6 \\
10.3 \\
10.4 \\
10.9 \\
10.6\end{array}$ & $\begin{array}{l}37 \\
35 \\
36 \\
38 \\
40\end{array}$ & $\begin{array}{l}34 \\
33 \\
34 \\
36 \\
37\end{array}$ \\
\hline $\begin{array}{l}11 \\
12 \\
13 \\
14 \\
15\end{array}$ & $\begin{array}{l}750 \\
810 \\
760 \\
760 \\
780\end{array}$ & $\begin{array}{l}730 \\
740 \\
730 \\
740 \\
750\end{array}$ & $\begin{array}{l}9.4 \\
8.8 \\
9.1 \\
8.5 \\
8.1\end{array}$ & $\begin{array}{l}8.3 \\
6.4 \\
7.7 \\
7.7 \\
6.8\end{array}$ & $\begin{array}{l}38 \\
39 \\
39 \\
42 \\
41\end{array}$ & $\begin{array}{l}36 \\
36 \\
37 \\
39 \\
40\end{array}$ & $\begin{array}{l}700 \\
700 \\
710 \\
710 \\
710\end{array}$ & $\begin{array}{l}690 \\
680 \\
690 \\
690 \\
690\end{array}$ & $\begin{array}{l}10.7 \\
10.5 \\
10.4 \\
10.4 \\
10.2\end{array}$ & $\begin{array}{r}10.0 \\
9.9 \\
9.9 \\
10.0 \\
9.4\end{array}$ & $\begin{array}{l}39 \\
38 \\
38 \\
40 \\
44\end{array}$ & $\begin{array}{l}36 \\
36 \\
35 \\
36 \\
39\end{array}$ & $\begin{array}{l}490 \\
480 \\
450 \\
450 \\
400\end{array}$ & $\begin{array}{l}480 \\
440 \\
440 \\
310 \\
320\end{array}$ & $\begin{array}{r}10.6 \\
10.2 \\
10.4 \\
10.2 \\
9.3\end{array}$ & $\begin{array}{r}10.0 \\
10.0 \\
10.2 \\
9.1 \\
3.2\end{array}$ & $\begin{array}{l}44 \\
44 \\
44 \\
48 \\
48\end{array}$ & $\begin{array}{l}40 \\
43 \\
42 \\
44 \\
45\end{array}$ \\
\hline $\begin{array}{l}16 \\
17 \\
18 \\
19 \\
20\end{array}$ & $\begin{array}{l}770 \\
760 \\
760 \\
780 \\
780\end{array}$ & $\begin{array}{l}740 \\
740 \\
740 \\
750 \\
740\end{array}$ & $\begin{array}{l}8.7 \\
8.7 \\
9.5 \\
9.6 \\
9.8\end{array}$ & $\begin{array}{l}7.1 \\
8.2 \\
8.5 \\
8.8 \\
8.0\end{array}$ & $\begin{array}{l}40 \\
39 \\
37 \\
36 \\
37\end{array}$ & $\begin{array}{l}38 \\
37 \\
34 \\
33 \\
35\end{array}$ & $\begin{array}{l}710 \\
700 \\
630 \\
610 \\
630\end{array}$ & $\begin{array}{l}690 \\
630 \\
560 \\
570 \\
610\end{array}$ & $\begin{array}{r}9.4 \\
10.8 \\
11.9 \\
12.0 \\
11.8\end{array}$ & $\begin{array}{r}8.2 \\
8.2 \\
10.8 \\
11.8 \\
11.1\end{array}$ & $\begin{array}{l}44 \\
42 \\
37 \\
37 \\
37\end{array}$ & $\begin{array}{l}41 \\
37 \\
36 \\
35 \\
36\end{array}$ & $\begin{array}{l}430 \\
500 \\
540 \\
560 \\
570\end{array}$ & $\begin{array}{l}400 \\
430 \\
500 \\
540 \\
560\end{array}$ & $\begin{array}{r}5.9 \\
9.2 \\
10.2 \\
10.5 \\
10.3\end{array}$ & $\begin{array}{r}3.1 \\
5.9 \\
9.2 \\
10.2 \\
10.1\end{array}$ & $\begin{array}{l}45 \\
43 \\
41 \\
42 \\
43\end{array}$ & $\begin{array}{l}42 \\
41 \\
40 \\
41 \\
42\end{array}$ \\
\hline $\begin{array}{l}21 \\
22 \\
23 \\
24 \\
25\end{array}$ & $\begin{array}{r}820 \\
820 \\
800 \\
-- \\
--\end{array}$ & $\begin{array}{r}780 \\
790 \\
790 \\
-- \\
--\end{array}$ & $\begin{array}{l}8.0 \\
7.2 \\
8.1 \\
7.6 \\
6.9\end{array}$ & $\begin{array}{l}7.2 \\
6.5 \\
7.0 \\
6.4 \\
5.6\end{array}$ & $\begin{array}{l}39 \\
43 \\
47 \\
50 \\
52\end{array}$ & $\begin{array}{l}36 \\
39 \\
43 \\
47 \\
49\end{array}$ & $\begin{array}{l}650 \\
670 \\
700 \\
720 \\
730\end{array}$ & $\begin{array}{l}620 \\
640 \\
670 \\
690 \\
550\end{array}$ & $\begin{array}{l}11.1 \\
10.7 \\
10.6 \\
10.6 \\
10.7\end{array}$ & $\begin{array}{l}10.6 \\
10.2 \\
10.3 \\
10.2 \\
10.3\end{array}$ & $\begin{array}{l}38 \\
37 \\
38 \\
36 \\
33\end{array}$ & $\begin{array}{l}36 \\
36 \\
36 \\
33 \\
32\end{array}$ & $\begin{array}{l}570 \\
510 \\
500 \\
520 \\
500\end{array}$ & $\begin{array}{l}510 \\
430 \\
430 \\
500 \\
480\end{array}$ & $\begin{array}{l}10.3 \\
11.0 \\
11.1 \\
10.8 \\
10.7\end{array}$ & $\begin{array}{l}10.0 \\
10.1 \\
10.8 \\
10.6 \\
10.2\end{array}$ & $\begin{array}{l}43 \\
42 \\
42 \\
41 \\
42\end{array}$ & $\begin{array}{l}42 \\
41 \\
40 \\
40 \\
40\end{array}$ \\
\hline $\begin{array}{l}26 \\
27 \\
28 \\
29 \\
30 \\
31\end{array}$ & $\begin{array}{l}-- \\
-- \\
-- \\
=- \\
--\end{array}$ & $\begin{array}{l}-- \\
-- \\
-- \\
-- \\
--\end{array}$ & $\begin{array}{r}6.9 \\
6.8 \\
6.4 \\
8.0 \\
10.8 \\
10.9\end{array}$ & $\begin{array}{l}5.4 \\
5.3 \\
5.4 \\
5.2 \\
8.0 \\
9.9\end{array}$ & $\begin{array}{l}52 \\
53 \\
48 \\
44 \\
41 \\
39\end{array}$ & $\begin{array}{l}51 \\
48 \\
44 \\
40 \\
38 \\
38\end{array}$ & $\begin{array}{r}750 \\
760 \\
760 \\
-- \\
-- \\
--\end{array}$ & $\begin{array}{r}550 \\
730 \\
740 \\
-- \\
-- \\
--\end{array}$ & $\begin{array}{r}10.6 \\
9.6 \\
9.6 \\
-- \\
-- \\
--\end{array}$ & $\begin{array}{r}9.2 \\
8.9 \\
9.0 \\
-- \\
-- \\
--\end{array}$ & $\begin{array}{l}34 \\
34 \\
36 \\
-- \\
-- \\
--\end{array}$ & $\begin{array}{l}32 \\
32 \\
34 \\
-- \\
-- \\
--\end{array}$ & $\begin{array}{l}530 \\
560 \\
570 \\
500 \\
510 \\
550\end{array}$ & $\begin{array}{l}500 \\
530 \\
500 \\
410 \\
450 \\
500\end{array}$ & $\begin{array}{r}10.2 \\
9.3 \\
8.5 \\
7.8 \\
8.8 \\
8.9\end{array}$ & $\begin{array}{l}9.3 \\
8.5 \\
7.2 \\
7.5 \\
7.8 \\
8.3\end{array}$ & $\begin{array}{l}46 \\
51 \\
53 \\
53 \\
52 \\
53\end{array}$ & $\begin{array}{l}42 \\
46 \\
51 \\
52 \\
50 \\
50\end{array}$ \\
\hline
\end{tabular}


SCIOTO RIVER BASIN---Continued

3-2315. SCIOTO RIVER AT CHILLICOTHE, OHIO--Continued

Data from continuous recorder, water year october 1966 to september 1967--Continued

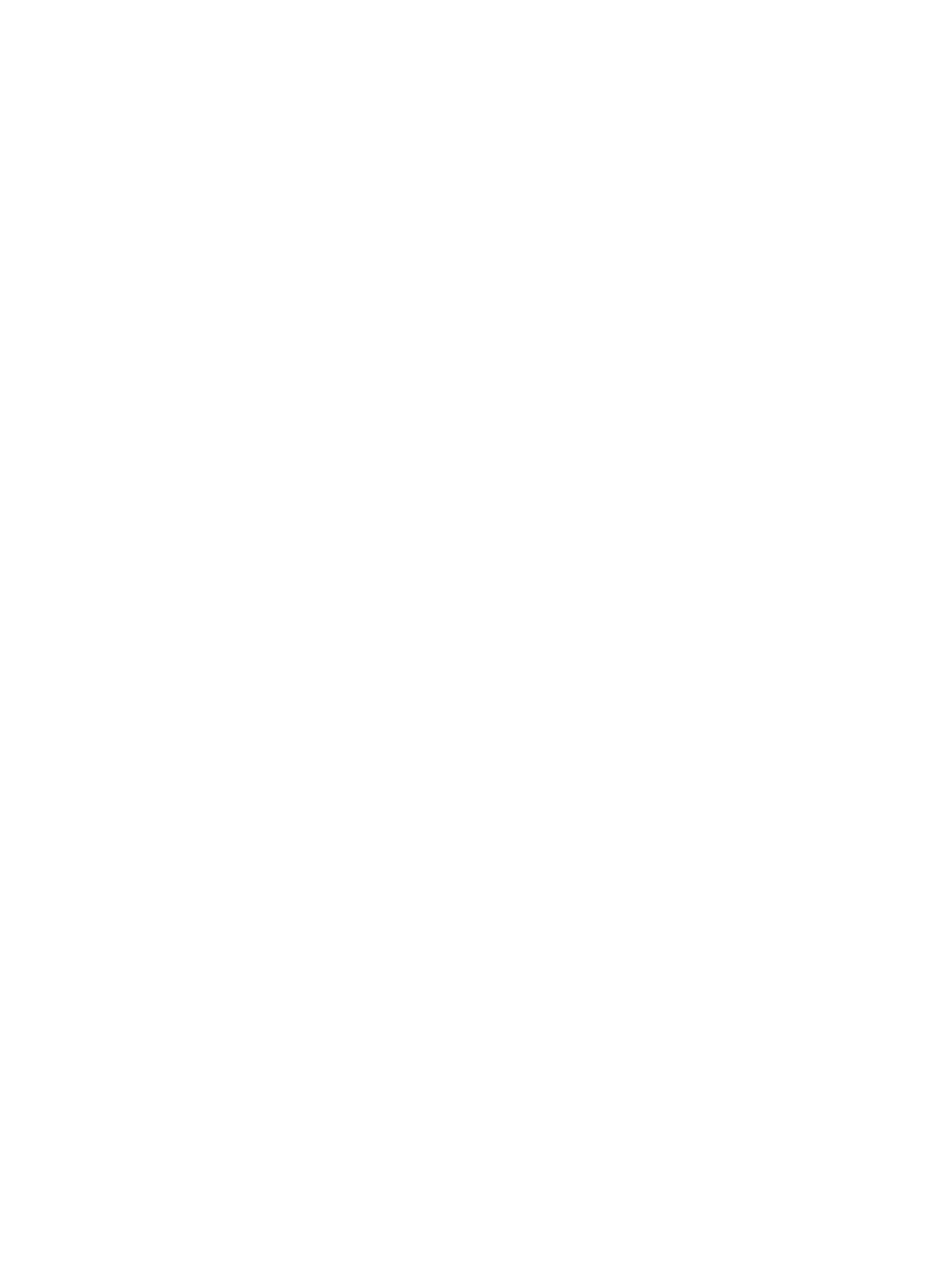




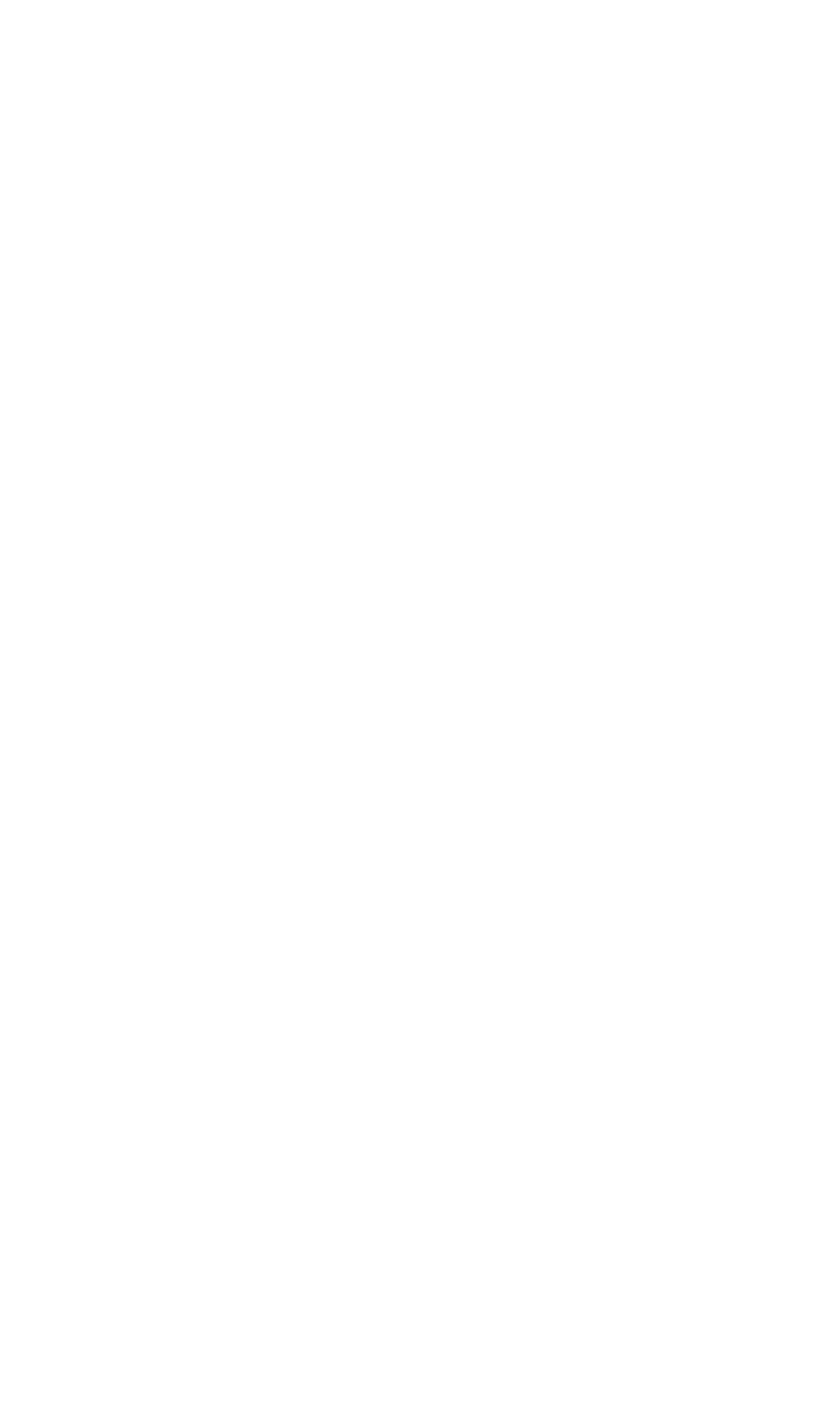




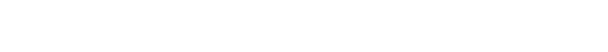

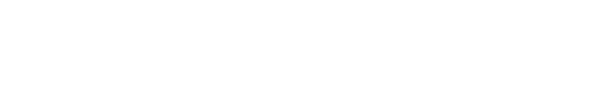
क人

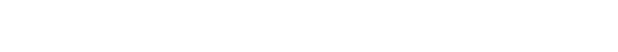

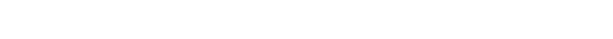

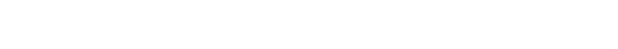

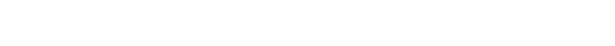
1 1 1 梁 1 1

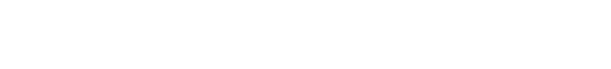

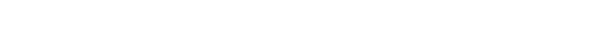

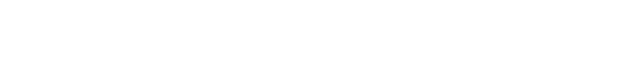

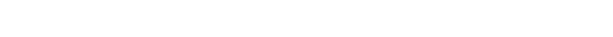
$0,00 * 100,00,10000,000,00-100$

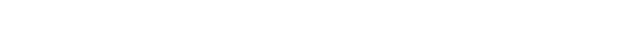

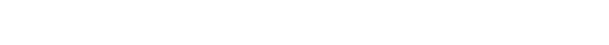

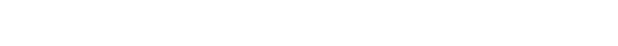

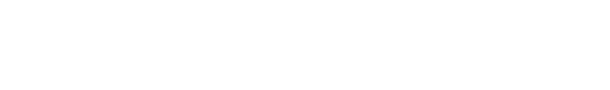

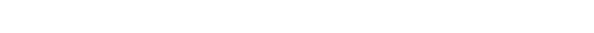

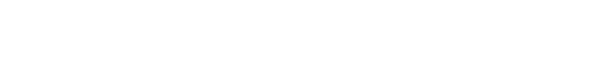

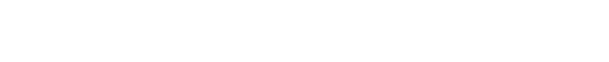




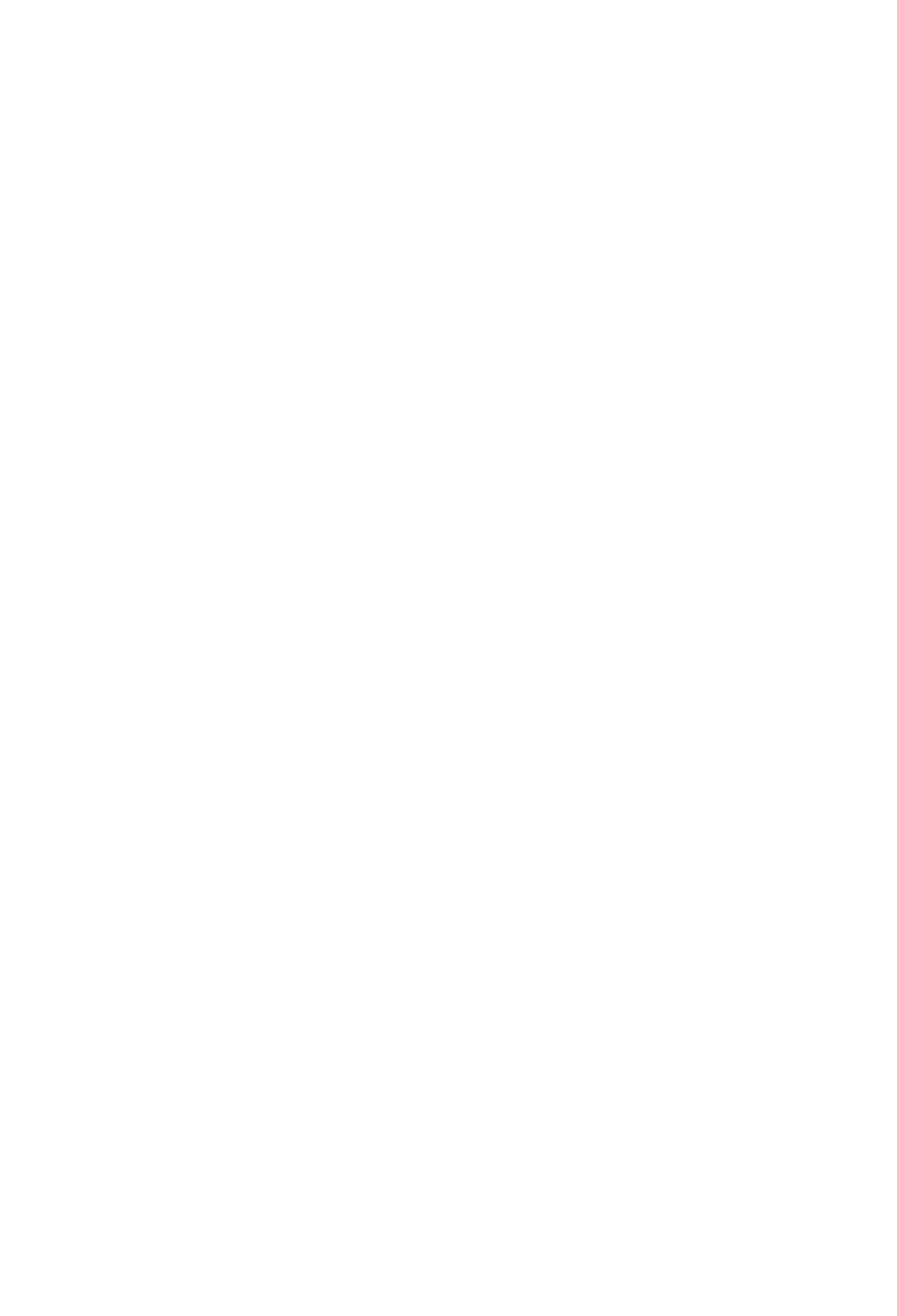




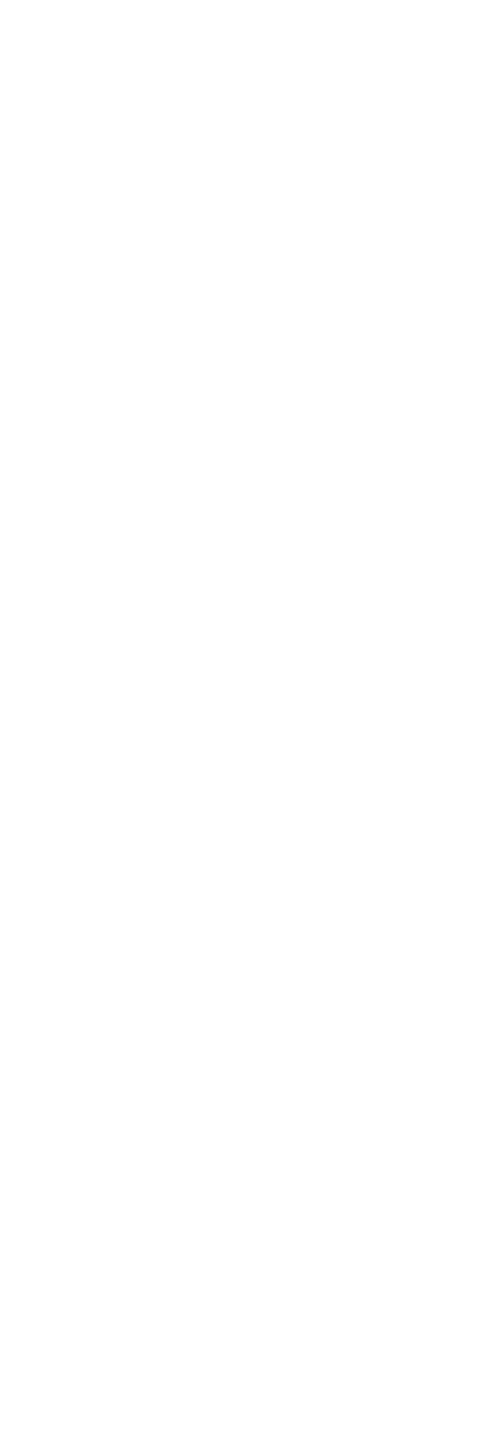




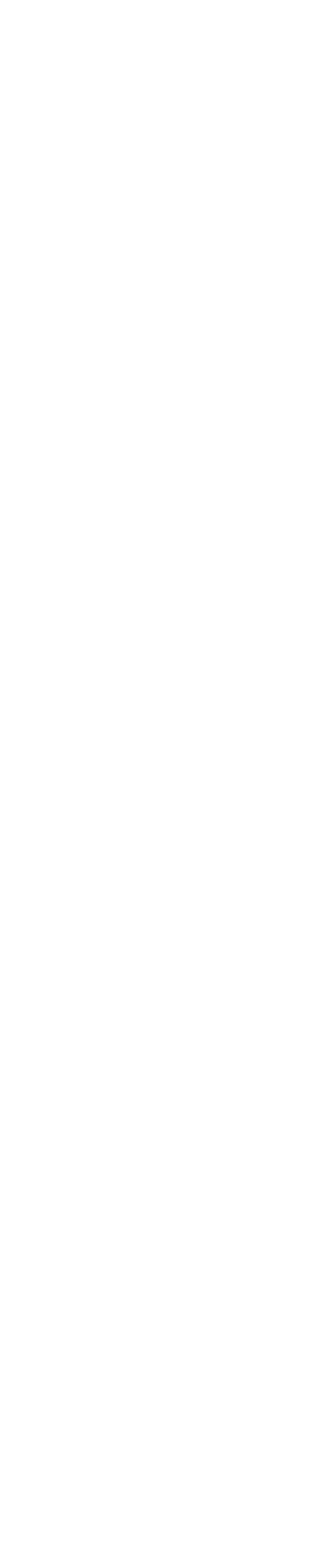

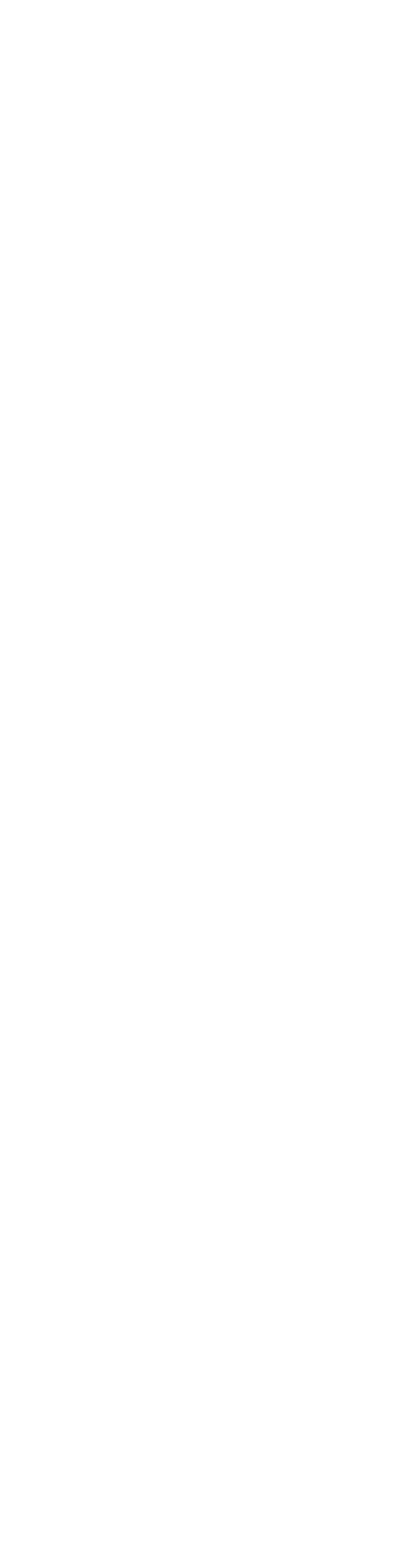


SCIOTO RIVER BASIN--Continued

3-2345. SCIOTO RIVER AT HIGBY, OHIO--Continued

Data from continuous recorder, March to September 1967

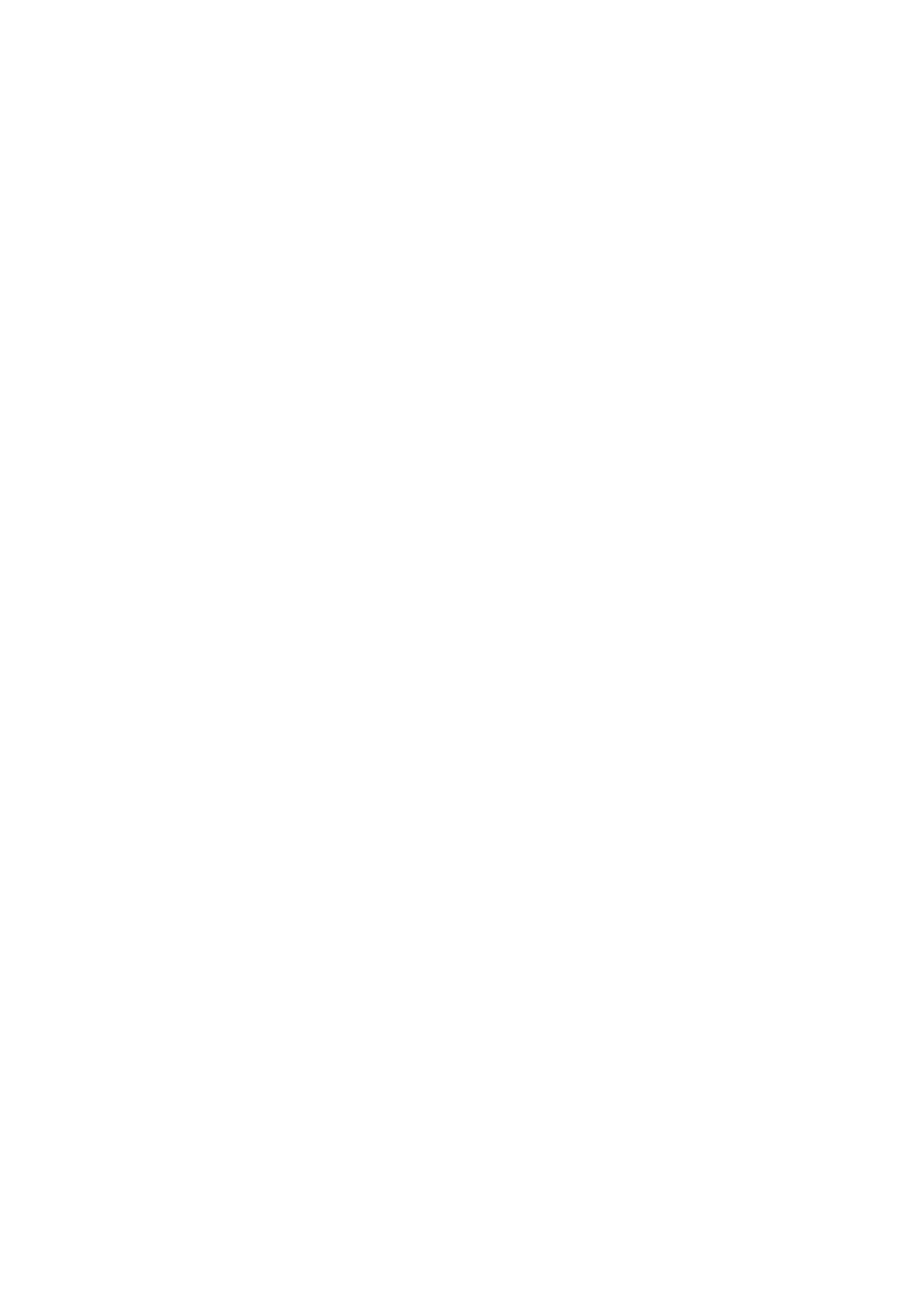


SCIOTO RIVER BASIN--Continued

3-2345. SCIOTO RIVER AT HIGBY, OHIO--continued

Data from continuous recorder, March to september $1967--$ Continued

\begin{tabular}{|c|c|c|c|c|c|c|c|c|c|c|c|c|c|c|c|c|}
\hline \multirow{3}{*}{ Day } & \multicolumn{8}{|c|}{ JUNE } & \multicolumn{8}{|c|}{ JULY } \\
\hline & \multicolumn{2}{|c|}{$\begin{array}{c}\text { Specific } \\
\text { conductance } \\
\text { (micromho } \\
\text { at } 25^{\circ} \mathrm{C} \text { ) }\end{array}$} & \multicolumn{2}{|c|}{$\mathrm{pH}$} & \multicolumn{2}{|c|}{$\begin{array}{l}\text { Dissolved } \\
\text { oxygen } \\
\text { (ppm) }\end{array}$} & \multicolumn{2}{|c|}{$\begin{array}{c}\text { Temper- } \\
\text { ature } \\
\left({ }^{\circ} \mathrm{F}\right)\end{array}$} & \multicolumn{2}{|c|}{$\begin{array}{c}\text { Specific } \\
\text { conductance } \\
\text { (micromhos } \\
\text { at } 25^{\circ} \mathrm{C} \text { ) }\end{array}$} & \multicolumn{2}{|c|}{ pH } & \multicolumn{2}{|c|}{$\begin{array}{c}\text { Dissolved } \\
\text { oxygen } \\
\text { (ppm) }\end{array}$} & \multicolumn{2}{|c|}{$\begin{array}{c}\text { Temper- } \\
\text { ature } \\
\left({ }^{\circ} \mathrm{F}\right)\end{array}$} \\
\hline & Max & Min & $\operatorname{Max}$ & Min & Max & Min & $\operatorname{Max}$ & Min & $\operatorname{Max}$ & Min & $\operatorname{Max}$ & Min & Max & Min & Max & Min \\
\hline $\begin{array}{l}1 \cdots \\
2 \cdots \\
3 \bullet 0 \\
4 \cdots \\
5 \cdots\end{array}$ & $=$ & $\begin{array}{l}= \\
= \\
=\end{array}$ & $\begin{array}{l}= \\
= \\
=\end{array}$ & $=$ & $\begin{array}{l}= \\
= \\
=\end{array}$ & $\begin{array}{l}\overline{-} \\
\overline{-}\end{array}$ & $\begin{array}{l}= \\
= \\
= \\
=\end{array}$ & $=$ & & & & & & & & \\
\hline 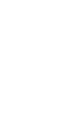 & $\begin{array}{l}= \\
720 \\
710 \\
740\end{array}$ & $\begin{array}{l}=- \\
670 \\
670 \\
690\end{array}$ & $\begin{array}{l}-. \\
7.7 \\
7.6 \\
7.6\end{array}$ & $\begin{array}{l}-- \\
7.5 \\
7.5 \\
7.5\end{array}$ & $\begin{array}{l}= \\
\overline{9.5} \\
0.4\end{array}$ & $\overline{--}$ & $\begin{array}{l}- \\
\overline{76} \\
77 \\
79\end{array}$ & $\begin{array}{l}-- \\
72 \\
74 \\
74\end{array}$ & & & & & & & & \\
\hline $\begin{array}{l}11 \ldots \\
12 \ldots \\
13 \ldots \\
14 \ldots \\
15 \ldots\end{array}$ & $\frac{710}{770}$ & $\begin{array}{r}690 \\
-0 \\
730 \\
740\end{array}$ & $\begin{array}{l}7.7 \\
= \\
7.7 \\
7.7\end{array}$ & $\begin{array}{l}7.4 \\
7.2 \\
7.6 \\
7.6\end{array}$ & $\begin{array}{r}11.9 \\
7.9 \\
4.1\end{array}$ & $\begin{array}{l}3.8 \\
-0 \\
4.0 \\
1.8\end{array}$ & $\begin{array}{l}79 \\
\overline{-1} \\
83\end{array}$ & $\frac{75}{79}$ & & & & & & & & \\
\hline $\begin{array}{l}16 \ldots 0 \\
17 \ldots 0 \\
18 \ldots 0 \\
19 \ldots 0 \\
20 \ldots\end{array}$ & $\begin{array}{l}750 \\
740 \\
740 \\
820 \\
\end{array}$ & $\begin{array}{l}670 \\
710 \\
660 \\
720 \\
\end{array}$ & $\begin{array}{l}7.7 \\
7.7 \\
7.7 \\
7.6 \\
-1\end{array}$ & $\begin{array}{l}7.6 \\
7.4 \\
7.5 \\
7.5 \\
-\end{array}$ & $\begin{array}{l}3.0 \\
4.7 \\
5.8 \\
4.6 \\
-\end{array}$ & $\begin{array}{r}1.19 \\
\because 99 \\
1.3\end{array}$ & $\begin{array}{l}83 \\
83 \\
82 \\
80 \\
-\end{array}$ & $\begin{array}{l}80 \\
78 \\
78 \\
77 \\
-\end{array}$ & & & & & & & & \\
\hline $\begin{array}{l}21 \ldots \\
22 \ldots \\
23 \ldots \\
24 \ldots \\
25 \ldots\end{array}$ & $=$ & 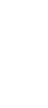 & 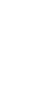 & $\begin{array}{l}= \\
= \\
=\end{array}$ & $\bar{z}$ & $=$ & 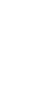 & $=$ & & & & & & & & \\
\hline $\begin{array}{l}26 \ldots \\
27 \ldots 0 \\
28 \cdots \\
29 \ldots \\
30 \ldots \\
31 \ldots\end{array}$ & $=$ & $\overline{ }=$ & $\bar{E}=$ & $\begin{array}{l}= \\
=\end{array}$ & $=$ & $\overline{-}$ & $\begin{array}{l}\overline{ } \\
\bar{z}\end{array}$ & $=$ & & & & & & & & \\
\hline \multicolumn{9}{|c|}{ AUGUST } & \multicolumn{8}{|c|}{ SEPTEMBER } \\
\hline $\begin{array}{l}100 \\
200 \\
300 \\
500\end{array}$ & $=$ & $\overline{=}$ & & & $=$ & $\begin{array}{l}= \\
\overline{-}\end{array}$ & $=$ & $\overline{=}$ & $\begin{array}{l}880 \\
860 \\
630 \\
770 \\
750\end{array}$ & $\begin{array}{l}840 \\
820 \\
760 \\
710 \\
720\end{array}$ & & & $\begin{array}{r}.5 \\
3.9 \\
4.9 \\
6.5\end{array}$ & $\begin{array}{r}.4 \\
.4 \\
.4 \\
2.0\end{array}$ & $\begin{array}{l}74 \\
73 \\
73 \\
72 \\
73\end{array}$ & $\begin{array}{l}70 \\
69 \\
69 \\
69 \\
69\end{array}$ \\
\hline $\begin{array}{r}6 \ldots \\
7 \ldots \\
8 \ldots \\
900 \\
10 \ldots\end{array}$ & $\overline{=}=$ & $\bar{z}=$ & & & $\bar{z}$ & $=$ & $\bar{z}$ & $\begin{array}{l}= \\
=\end{array}$ & $\begin{array}{l}770 \\
770 \\
700 \\
660 \\
670\end{array}$ & $\begin{array}{l}750 \\
690 \\
650 \\
650 \\
320\end{array}$ & & & $\begin{array}{l}6.0 \\
8.5 \\
7.1 \\
4.9 \\
4.6\end{array}$ & $\begin{array}{l}2.4 \\
2.9 \\
4.0 \\
2.9 \\
2.1\end{array}$ & $\begin{array}{l}74 \\
74 \\
73 \\
72 \\
72\end{array}$ & $\begin{array}{l}70 \\
70 \\
71 \\
71 \\
70\end{array}$ \\
\hline $\begin{array}{l}11 \ldots \\
12 \ldots \\
13 \ldots \\
14 \ldots \\
15 \ldots\end{array}$ & $\begin{array}{r}10 \overline{10} \\
1010 \\
880 \\
920\end{array}$ & $\begin{array}{l}860 \\
880 \\
710 \\
710\end{array}$ & & & $\begin{array}{r}- \\
3.6 \\
2.0 \\
13.3 \\
0.5\end{array}$ & $\begin{array}{r}-.6 \\
.6 \\
.9 \\
1.7\end{array}$ & $\begin{array}{l}-76 \\
76 \\
76 \\
77\end{array}$ & $\begin{array}{l}\overline{72} \\
72 \\
72 \\
72\end{array}$ & $\begin{array}{l}720 \\
730 \\
110 \\
840 \\
840\end{array}$ & $\begin{array}{l}650 \\
710 \\
710 \\
800 \\
000\end{array}$ & & & $\begin{array}{l}5.0 \\
4.3 \\
2.7 \\
4.0 \\
2.1\end{array}$ & $\begin{array}{r}2.7 \\
2.8 \\
.4 \\
.4\end{array}$ & $\begin{array}{l}71 \\
70 \\
71 \\
71 \\
71\end{array}$ & $\begin{array}{l}68 \\
67 \\
68 \\
68 \\
67\end{array}$ \\
\hline $\begin{array}{l}16 \ldots \\
27 \ldots \\
18 \ldots \\
19 \ldots 0 \\
20 \ldots\end{array}$ & $\begin{array}{r}900 \\
970 \\
1910 \\
970 \\
960\end{array}$ & $\begin{array}{l}900 \\
940 \\
960 \\
960 \\
940\end{array}$ & & & $\begin{array}{r}1.7 \\
.7 \\
1.7 \\
2.3\end{array}$ & $\begin{array}{l}.6 \\
.6 \\
.5 \\
.5 \\
.5\end{array}$ & $\begin{array}{l}78 \\
78 \\
78 \\
77 \\
78\end{array}$ & $\begin{array}{l}74 \\
75 \\
76 \\
75 \\
75\end{array}$ & $\begin{array}{r}900 \\
930 \\
970 \\
980 \\
1020\end{array}$ & $\begin{array}{l}820 \\
890 \\
910 \\
920 \\
960\end{array}$ & & & $\begin{array}{l}.8 \\
.8 \\
.7 \\
.4\end{array}$ & $\begin{array}{l}.3 \\
: 3 \\
: 3 \\
: 3 \\
: 3\end{array}$ & $\begin{array}{l}71 \\
72 \\
74 \\
74 \\
73\end{array}$ & $\begin{array}{l}60 \\
69 \\
71 \\
72 \\
72\end{array}$ \\
\hline $\begin{array}{l}21 \ldots \\
22 \ldots \\
23 \ldots \\
24 \ldots \\
25 \ldots\end{array}$ & $\begin{array}{l}950 \\
890 \\
920 \\
990 \\
910\end{array}$ & $\begin{array}{l}880 \\
810 \\
880 \\
880 \\
850\end{array}$ & & & $\begin{array}{l}5.7 \\
3.8 \\
1.9 \\
.5 \\
1.3\end{array}$ & $\begin{array}{l}.5 \\
.4 \\
.4 \\
.4\end{array}$ & $\begin{array}{l}78 \\
78 \\
79 \\
78 \\
77\end{array}$ & $\begin{array}{l}75 \\
74 \\
76 \\
76 \\
75\end{array}$ & $\begin{array}{r}960 \\
1000 \\
1010 \\
1050 \\
1010\end{array}$ & $\begin{array}{l}920 \\
920 \\
950 \\
990 \\
950\end{array}$ & & & $\begin{array}{r}1.0 \\
.5 \\
.5 \\
.4\end{array}$ & $\begin{array}{l}\cdot 3 \\
: 3 \\
: 3 \\
: 3 \\
.3\end{array}$ & $\begin{array}{l}73 \\
72 \\
69 \\
67 \\
66\end{array}$ & $\begin{array}{l}72 \\
68 \\
65 \\
65 \\
63\end{array}$ \\
\hline $\begin{array}{l}26 \ldots \\
27 \ldots \\
28 \ldots \\
29 \ldots \\
30 \ldots \\
31 \ldots\end{array}$ & $\begin{array}{l}920 \\
890 \\
770 \\
740 \\
810 \\
870\end{array}$ & $\begin{array}{l}990 \\
770 \\
700 \\
700 \\
720 \\
750\end{array}$ & & & $\begin{array}{r}.5 \\
1.4 \\
.5 \\
.6 \\
.5\end{array}$ & $\begin{array}{l}.4 \\
.4 \\
.4 \\
.4 \\
.4\end{array}$ & $\begin{array}{l}77 \\
77 \\
76 \\
76 \\
77 \\
77\end{array}$ & $\begin{array}{l}76 \\
75 \\
72 \\
72 \\
74 \\
74\end{array}$ & $\begin{array}{l}950 \\
850 \\
980 \\
790 \\
850 \\
\end{array}$ & $\begin{array}{l}760 \\
780 \\
770 \\
710 \\
710\end{array}$ & & & $\begin{array}{r}3.1 \\
.7 \\
.4 \\
2.2 \\
-0\end{array}$ & $\begin{array}{l}.3 \\
.3 \\
.3 \\
.4 \\
.0 \\
\end{array}$ & $\begin{array}{l}66 \\
68 \\
67 \\
62 \\
62 \\
\end{array}$ & $\begin{array}{l}62 \\
65 \\
62 \\
60 \\
59 \\
--\end{array}$ \\
\hline
\end{tabular}



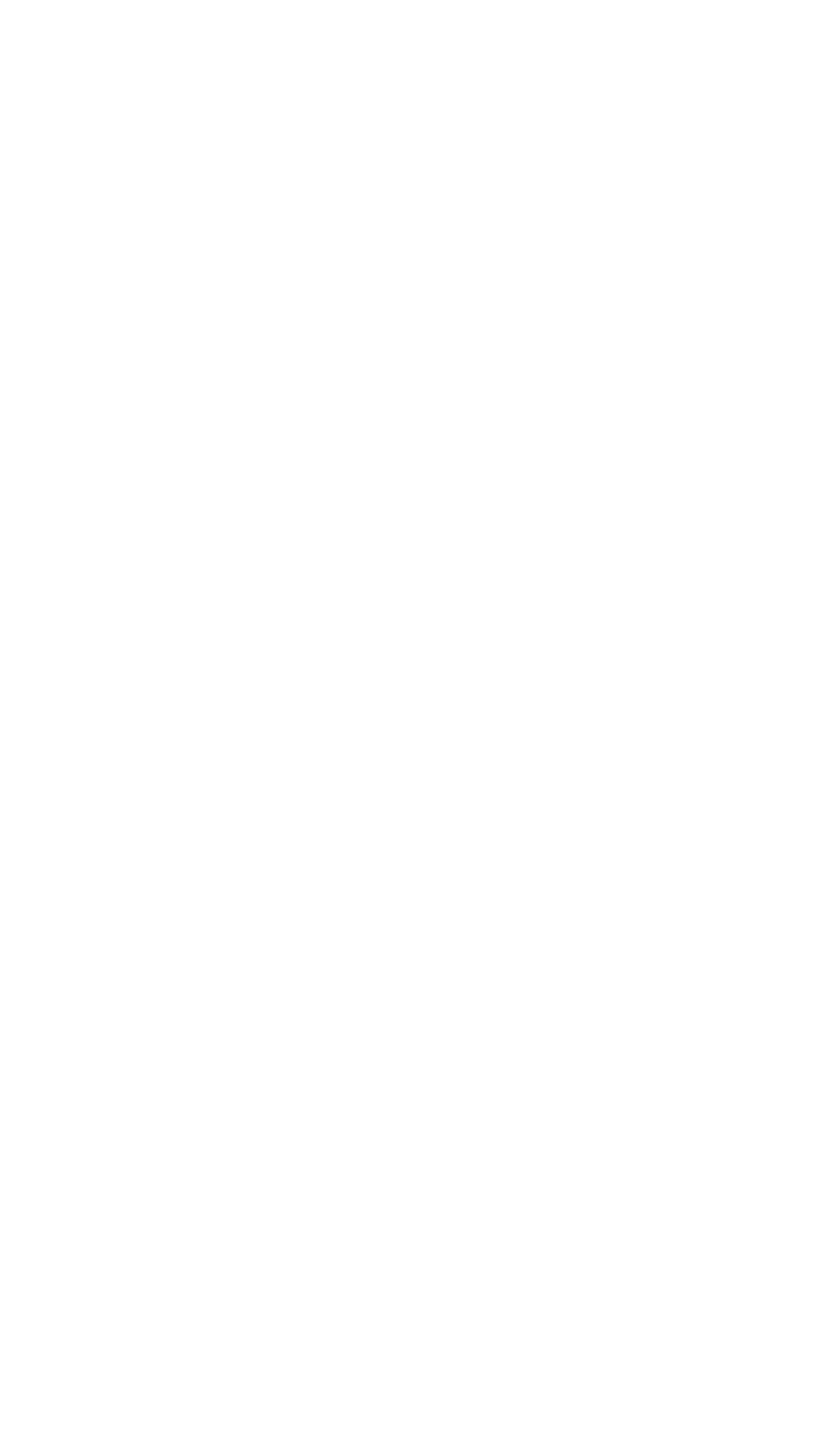
SCIOTO RIVER BASIN--Continued

3-2345. SCIOTO RIVER AT HIGBY, OHIO--Continued

Suspended sediment, water year October 1966 to September 1967

\begin{tabular}{|c|c|c|c|c|c|c|c|c|c|}
\hline \multirow[b]{3}{*}{ Day } & \multicolumn{3}{|c|}{ OCTOBER } & \multicolumn{3}{|c|}{ MOVEMBER } & \multicolumn{3}{|c|}{ DECEYGER } \\
\hline & \multirow[b]{2}{*}{$\begin{array}{c}\text { Mean } \\
\text { dis- } \\
\text { charge } \\
\text { (cfs) }\end{array}$} & \multicolumn{2}{|c|}{ Suspended sediment } & \multirow[b]{2}{*}{$\begin{array}{l}\text { Mean } \\
\text { dis- } \\
\text { charge } \\
\text { (cfs) }\end{array}$} & \multicolumn{2}{|c|}{ Suspended sediment } & \multirow[b]{2}{*}{$\begin{array}{c}\text { Mean } \\
\text { dis- } \\
\text { charge } \\
\text { (cfs) }\end{array}$} & \multicolumn{2}{|c|}{ Srrspended sediment } \\
\hline & & $\begin{array}{c}\text { Mean } \\
\text { concen- } \\
\text { tration } \\
\text { (ppm) }\end{array}$ & $\begin{array}{l}\text { Tons } \\
\text { per } \\
\text { day }\end{array}$ & & $\begin{array}{l}\text { Mean } \\
\text { concen- } \\
\text { tration } \\
\text { (ppm) }\end{array}$ & $\begin{array}{l}\text { Tons } \\
\text { per } \\
\text { day }\end{array}$ & & $\begin{array}{c}\text { Mean } \\
\text { corcen- } \\
\text { tration } \\
\text { (ppm) }\end{array}$ & $\begin{array}{l}\text { Tons } \\
\text { per } \\
\text { day }\end{array}$ \\
\hline $\begin{array}{l}1 \ldots \\
2 \ldots \\
3 \ldots \\
4 \ldots \\
5 \ldots\end{array}$ & $\begin{array}{l}814 \\
950 \\
989 \\
877 \\
800\end{array}$ & $\begin{array}{r}25 \\
24 \\
19 \\
9 \\
12\end{array}$ & $\begin{array}{l}55 \\
62 \\
51 \\
21 \\
26\end{array}$ & $\begin{array}{r}636 \\
712 \\
1210 \\
2310 \\
2040\end{array}$ & $\begin{array}{l}19 \\
17 \\
43 \\
52 \\
37\end{array}$ & $\begin{array}{r}33 \\
33 \\
140 \\
324 \\
204\end{array}$ & $\begin{array}{l}3490 \\
3480 \\
3210 \\
2870 \\
2800\end{array}$ & $\begin{array}{l}53 \\
41 \\
28 \\
21 \\
25\end{array}$ & $\begin{array}{l}499 \\
385 \\
243 \\
163 \\
189\end{array}$ \\
\hline $\begin{array}{r}6 \ldots \\
7 \ldots \\
0 \ldots \\
10 \ldots\end{array}$ & $\begin{array}{l}735 \\
674 \\
640 \\
619 \\
628\end{array}$ & $\begin{array}{l}18 \\
13 \\
11 \\
13 \\
14\end{array}$ & $\begin{array}{l}36 \\
24 \\
19 \\
22 \\
24\end{array}$ & $\begin{array}{l}1690 \\
1910 \\
2000 \\
4030 \\
7790\end{array}$ & $\begin{array}{r}36 \\
45 \\
51 \\
250 \\
721\end{array}$ & $\begin{array}{r}164 \\
232 \\
275 \\
2720 \\
17600\end{array}$ & $\begin{array}{r}2920 \\
5400 \\
10200 \\
13100 \\
26300\end{array}$ & $\begin{array}{r}26 \\
62 \\
216 \\
233 \\
348\end{array}$ & $\begin{array}{r}205 \\
1200 \\
5950 \\
8240 \\
26200\end{array}$ \\
\hline $\begin{array}{l}11 \ldots \\
12 \ldots \\
13 \ldots \\
14 \ldots 0 \\
15 \ldots 0\end{array}$ & $\begin{array}{l}618 \\
665 \\
612 \\
605 \\
592\end{array}$ & $\begin{array}{l}17 \\
19 \\
20 \\
22 \\
23\end{array}$ & $\begin{array}{l}28 \\
34 \\
33 \\
36 \\
37\end{array}$ & $\begin{array}{r}13700 \\
14500 \\
11700 \\
9080 \\
7810\end{array}$ & $\begin{array}{r}676 \\
119 \\
104 \\
96 \\
81\end{array}$ & $\begin{array}{r}25000 \\
4660 \\
3290 \\
2350 \\
1710\end{array}$ & $\begin{array}{l}35300 \\
33300 \\
33700 \\
26100 \\
18400\end{array}$ & $\begin{array}{l}355 \\
265 \\
121 \\
115 \\
131\end{array}$ & $\begin{array}{r}33800 \\
23800 \\
11000 \\
8100 \\
6510\end{array}$ \\
\hline $\begin{array}{l}1600 \\
1700 \\
1800 \\
1900 \\
20.0\end{array}$ & $\begin{array}{l}591 \\
659 \\
663 \\
620 \\
612\end{array}$ & $\begin{array}{l}25 \\
26 \\
24 \\
16 \\
14\end{array}$ & $\begin{array}{l}40 \\
46 \\
43 \\
27 \\
23\end{array}$ & $\begin{array}{l}5550 \\
4100 \\
3470 \\
3060 \\
2760\end{array}$ & $\begin{array}{l}52 \\
43 \\
35 \\
28 \\
43\end{array}$ & $\begin{array}{l}779 \\
476 \\
328 \\
231 \\
320\end{array}$ & $\begin{array}{r}13500 \\
9640 \\
7440 \\
6000 \\
5600\end{array}$ & $\begin{array}{r}115 \\
68 \\
39 \\
48 \\
67\end{array}$ & $\begin{array}{r}4190 \\
1770 \\
783 \\
778 \\
1010\end{array}$ \\
\hline $\begin{array}{l}21 \ldots \\
22 \ldots 0 \\
230 \\
21400 \\
25 \ldots 0\end{array}$ & $\begin{array}{l}603 \\
605 \\
595 \\
580 \\
559\end{array}$ & $\begin{array}{l}15 \\
13 \\
15 \\
14 \\
13\end{array}$ & $\begin{array}{l}24 \\
21 \\
24 \\
22 \\
20\end{array}$ & $\begin{array}{l}2520 \\
2290 \\
2180 \\
2090 \\
1810\end{array}$ & $\begin{array}{r}29 \\
21 \\
28 \\
23\end{array}$ & $\begin{array}{r}197 \\
56 \\
124 \\
158 \\
112\end{array}$ & $\begin{array}{l}4900 \\
4540 \\
3950 \\
3520 \\
3310\end{array}$ & $\begin{array}{l}80 \\
40 \\
33 \\
31 \\
24\end{array}$ & $\begin{array}{r}1060 \\
490 \\
352 \\
295 \\
214\end{array}$ \\
\hline $\begin{array}{l}26 \ldots \\
27 \ldots \\
28 \ldots \\
29 \ldots \\
30 \ldots \\
31 \ldots\end{array}$ & $\begin{array}{r}553 \\
1080 \\
1200 \\
1210 \\
1130 \\
764\end{array}$ & $\begin{array}{l}14 \\
26 \\
24 \\
20 \\
20 \\
21\end{array}$ & $\begin{array}{l}21 \\
76 \\
78 \\
65 \\
61 \\
43\end{array}$ & $\begin{array}{r}1880 \\
2130 \\
2280 \\
2430 \\
3020 \\
-\end{array}$ & $\begin{array}{l}27 \\
39 \\
38 \\
37 \\
46 \\
-\end{array}$ & $\begin{array}{l}137 \\
224 \\
234 \\
243 \\
391 \\
\end{array}$ & $\begin{array}{l}3020 \\
2680 \\
2580 \\
2600 \\
2680 \\
2600 \\
\end{array}$ & $\begin{array}{l}22 \\
21 \\
26 \\
31 \\
26 \\
19 \\
\end{array}$ & $\begin{array}{l}179 \\
152 \\
181 \\
218 \\
188 \\
133 \\
\end{array}$ \\
\hline \multirow[t]{2}{*}{ Total } & 22842 & - & 1142 & 122688 & - & 62745 & 299130 & - & 138477 \\
\hline & \multicolumn{3}{|c|}{ JAMUARY } & \multicolumn{3}{|c|}{ FEBRUARY } & \multicolumn{3}{|c|}{ MAPCH } \\
\hline $\begin{array}{l}1 \ldots \\
2 \ldots \\
30 \\
4 \ldots \\
50\end{array}$ & $\begin{array}{l}2430 \\
2420 \\
2390 \\
2300 \\
2190\end{array}$ & $\begin{array}{l}20 \\
13 \\
14 \\
11 \\
22\end{array}$ & $\begin{array}{r}131 \\
85 \\
90 \\
68 \\
130\end{array}$ & $\begin{array}{r}3810 \\
4920 \\
12500 \\
14600 \\
12900\end{array}$ & $\begin{array}{r}95 \\
108 \\
510 \\
238 \\
104\end{array}$ & $\begin{array}{r}977 \\
1700 \\
17200 \\
10200 \\
3620\end{array}$ & $\begin{array}{r}2270 \\
2280 \\
3210 \\
5570 \\
10300\end{array}$ & $\begin{array}{r}14 \\
16 \\
43 \\
124 \\
232\end{array}$ & $\begin{array}{r}86 \\
96 \\
373 \\
1860 \\
6450\end{array}$ \\
\hline $\begin{array}{l}6 \ldots \\
7 \ldots \\
8 \ldots \\
10 \\
100\end{array}$ & $\begin{array}{l}2030 \\
1980 \\
1980 \\
1970 \\
1920\end{array}$ & $\begin{array}{l}24 \\
19 \\
17 \\
18 \\
18\end{array}$ & $\begin{array}{r}132 \\
102 \\
91 \\
96 \\
93\end{array}$ & $\begin{array}{l}9440 \\
6600 \\
4400 \\
3680 \\
3520\end{array}$ & $\begin{array}{l}82 \\
66 \\
45 \\
44 \\
40\end{array}$ & $\begin{array}{r}2090 \\
1180 \\
535 \\
437 \\
380\end{array}$ & $\begin{array}{l}25200 \\
32500 \\
35600 \\
33600 \\
24200\end{array}$ & $\begin{array}{r}408 \\
317 \\
247 \\
158 \\
98\end{array}$ & $\begin{array}{r}27000 \\
27000 \\
23700 \\
14300 \\
6400\end{array}$ \\
\hline $\begin{array}{l}11 \ldots \\
12 \ldots \\
13 \ldots 0 \\
14 \ldots 0 \\
15 \ldots\end{array}$ & $\begin{array}{l}1860 \\
1750 \\
1720 \\
1740 \\
1740\end{array}$ & $\begin{array}{l}17 \\
14 \\
14 \\
11 \\
11\end{array}$ & $\begin{array}{l}85 \\
66 \\
65 \\
52 \\
52\end{array}$ & $\begin{array}{l}3520 \\
3510 \\
3280 \\
3200 \\
3320\end{array}$ & $\begin{array}{l}33 \\
28 \\
28 \\
44 \\
52\end{array}$ & $\begin{array}{l}314 \\
265 \\
248 \\
380 \\
466\end{array}$ & $\begin{array}{l}21800 \\
21000 \\
21900 \\
28400 \\
33700\end{array}$ & $\begin{array}{l}150 \\
159 \\
125 \\
896 \\
485\end{array}$ & $\begin{array}{r}8830 \\
9020 \\
7390 \\
68900 \\
44100\end{array}$ \\
\hline $\begin{array}{l}16 \ldots 0 \\
17 \ldots \\
1800 \\
190 . \\
20 \ldots\end{array}$ & $\begin{array}{l}1710 \\
1640 \\
1550 \\
1440 \\
1390\end{array}$ & $\begin{array}{l}16 \\
12 \\
11 \\
10 \\
10\end{array}$ & $\begin{array}{l}74 \\
53 \\
46 \\
39 \\
38\end{array}$ & $\begin{array}{l}3550 \\
6000 \\
7580 \\
5680 \\
4130\end{array}$ & $\begin{array}{l}42 \\
95 \\
91 \\
52 \\
32\end{array}$ & $\begin{array}{r}403 \\
1540 \\
1860 \\
795 \\
357\end{array}$ & $\begin{array}{r}31100 \\
22700 \\
13800 \\
10500 \\
8560\end{array}$ & $\begin{array}{r}324 \\
195 \\
129 \\
95 \\
79\end{array}$ & $\begin{array}{r}27200 \\
12000 \\
4810 \\
2690 \\
1830\end{array}$ \\
\hline $\begin{array}{l}21 \ldots \\
22 \ldots \\
23 \ldots \\
24 \ldots \\
25 \ldots\end{array}$ & $\begin{array}{l}1400 \\
1400 \\
1430 \\
1450 \\
1490\end{array}$ & $\begin{array}{l}8 \\
11 \\
11 \\
15 \\
16\end{array}$ & $\begin{array}{l}30 \\
42 \\
42 \\
59 \\
64\end{array}$ & $\begin{array}{l}3690 \\
3540 \\
3200 \\
2890 \\
2390\end{array}$ & $\begin{array}{l}30 \\
28 \\
23 \\
24 \\
19\end{array}$ & $\begin{array}{l}299 \\
268 \\
199 \\
187 \\
123\end{array}$ & $\begin{array}{l}11900 \\
18800 \\
21600 \\
20100 \\
14900\end{array}$ & $\begin{array}{r}122 \\
157 \\
130 \\
110 \\
77\end{array}$ & $\begin{array}{l}3920 \\
7970 \\
7580 \\
5970 \\
3100\end{array}$ \\
\hline $\begin{array}{l}26 \ldots \\
27 \ldots \\
28 \ldots \\
29 \ldots \\
30 \ldots \\
31 \ldots\end{array}$ & $\begin{array}{l}1520 \\
1690 \\
2440 \\
4270 \\
4400 \\
3810\end{array}$ & $\begin{array}{r}16 \\
27 \\
86 \\
112 \\
75 \\
68\end{array}$ & $\begin{array}{r}66 \\
123 \\
567 \\
1290 \\
991 \\
700\end{array}$ & $\begin{array}{r}2090 \\
2210 \\
2300 \\
= \\
=\end{array}$ & $\begin{array}{l}15 \\
16 \\
15 \\
= \\
=\end{array}$ & $\begin{array}{l}85 \\
95 \\
93 \\
= \\
=\end{array}$ & $\begin{array}{r}10700 \\
8080 \\
7500 \\
13800 \\
15700 \\
15300 \\
\end{array}$ & $\begin{array}{r}68 \\
70 \\
89 \\
361 \\
165 \\
115 \\
\end{array}$ & $\begin{array}{r}2960 \\
1330 \\
1800 \\
13500 \\
6990 \\
4750\end{array}$ \\
\hline Total & 63450 & -- & 3462 & 142430 & - & 46296 & 546570 & - & 354707 \\
\hline
\end{tabular}


SCIOTO RIVER BASIN--Continued

3-2345. SCIOTO RIVER AT HIGBY, OHIO--Continued

Suspended sediment, water year October 1966 to September 1967--Continued

\begin{tabular}{|c|c|c|c|c|c|c|c|c|c|}
\hline \multirow[b]{3}{*}{ Day } & \multicolumn{3}{|c|}{ APRIL } & \multicolumn{3}{|c|}{ MaY } & \multicolumn{3}{|c|}{ JUNE } \\
\hline & \multirow[b]{2}{*}{$\begin{array}{c}\text { Mean } \\
\text { dio- } \\
\text { charge } \\
\text { (cfs) }\end{array}$} & \multicolumn{2}{|c|}{ Suspended sediment } & \multirow[b]{2}{*}{$\begin{array}{c}\text { Mean } \\
\text { dis- } \\
\text { charge } \\
\text { (cfs) }\end{array}$} & \multicolumn{2}{|c|}{ Suspended sediment } & \multirow[b]{2}{*}{$\begin{array}{l}\text { Mean } \\
\text { dis- } \\
\text { charge } \\
\text { (cfs) }\end{array}$} & \multicolumn{2}{|c|}{ Suspended sedimen } \\
\hline & & $\begin{array}{c}\text { Mean } \\
\text { concen- } \\
\text { tration } \\
(\mathrm{ppm})\end{array}$ & $\begin{array}{l}\text { Tons } \\
\text { per } \\
\text { day }\end{array}$ & & $\begin{array}{l}\text { Mean } \\
\text { concen- } \\
\text { tration } \\
\text { (ppm) }\end{array}$ & $\begin{array}{l}\text { Tons } \\
\text { per } \\
\text { day }\end{array}$ & & $\begin{array}{l}\text { Mean } \\
\text { concen- } \\
\text { tration } \\
\text { (ppm) }\end{array}$ & $\begin{array}{l}\text { Ton: } \\
\text { per } \\
\text { day }\end{array}$ \\
\hline $\begin{array}{l}1 \ldots \\
200 \\
30 \\
4 \ldots \\
50\end{array}$ & $\begin{array}{r}13500 \\
10100 \\
6780 \\
5170 \\
0260\end{array}$ & $\begin{array}{r}79 \\
141 \\
207 \\
80 \\
415\end{array}$ & $\begin{array}{r}2880 \\
3850 \\
1960 \\
2120 \\
13500\end{array}$ & $\begin{array}{l}3400 \\
3370 \\
4420 \\
7720 \\
7620\end{array}$ & $\begin{array}{r}55 \\
37 \\
86 \\
192 \\
74\end{array}$ & $\begin{array}{r}505 \\
337 \\
1030 \\
4000 \\
1520\end{array}$ & $\begin{array}{l}3240 \\
2980 \\
2700 \\
2600 \\
2430\end{array}$ & $\begin{array}{r}100 \\
84 \\
78 \\
73 \\
74\end{array}$ & $\begin{array}{l}875 \\
676 \\
585 \\
512 \\
486\end{array}$ \\
\hline $\begin{array}{r}6.0 \\
7 \ldots \\
8.0 \\
9.0 \\
10 \ldots\end{array}$ & $\begin{array}{r}16000 \\
12100 \\
8940 \\
7720 \\
6660\end{array}$ & $\begin{array}{r}620 \\
275 \\
149 \\
82 \\
69\end{array}$ & $\begin{array}{r}26800 \\
8980 \\
3600 \\
1700 \\
1240\end{array}$ & $\begin{array}{r}7240 \\
15300 \\
16700 \\
21700 \\
19900\end{array}$ & $\begin{array}{l}72 \\
376 \\
324 \\
254 \\
194\end{array}$ & $\begin{array}{r}1410 \\
15500 \\
16400 \\
14900 \\
10400\end{array}$ & $\begin{array}{l}2310 \\
2180 \\
2120 \\
2020 \\
1940\end{array}$ & $\begin{array}{l}72 \\
62 \\
42 \\
26 \\
29\end{array}$ & $\begin{array}{l}449 \\
365 \\
240 \\
142 \\
152\end{array}$ \\
\hline $\begin{array}{l}11 \ldots \\
12 \ldots \\
13 \ldots \\
14 \ldots \\
15 \ldots\end{array}$ & $\begin{array}{l}5760 \\
4920 \\
\$ 420 \\
3130 \\
7620\end{array}$ & $\begin{array}{l}68 \\
67 \\
64 \\
70 \\
90\end{array}$ & $\begin{array}{r}1060 \\
890 \\
764 \\
970 \\
1850\end{array}$ & $\begin{array}{l}17600 \\
20400 \\
21800 \\
18000 \\
16700\end{array}$ & $\begin{array}{l}269 \\
327 \\
408 \\
196 \\
214\end{array}$ & $\begin{array}{r}12800 \\
10000 \\
24000 \\
9530 \\
9650\end{array}$ & $\begin{array}{l}1860 \\
1760 \\
1680 \\
1640 \\
1560\end{array}$ & $\begin{array}{l}38 \\
35 \\
35 \\
34 \\
22\end{array}$ & $\begin{array}{r}191 \\
166 \\
159 \\
151 \\
93\end{array}$ \\
\hline $\begin{array}{l}16 \ldots 0 \\
1700 \\
1800 \\
19 \ldots 0 \\
20 \ldots\end{array}$ & $\begin{array}{l}1000 \\
6120 \\
5190 \\
4260 \\
3650\end{array}$ & $\begin{array}{l}44 \\
34 \\
32 \\
38 \\
42\end{array}$ & $\begin{array}{r}1300 \\
562 \\
448 \\
437 \\
424\end{array}$ & $\begin{array}{l}24300 \\
23600 \\
18600 \\
15000 \\
12300\end{array}$ & $\begin{array}{l}305 \\
273 \\
223 \\
187 \\
170\end{array}$ & $\begin{array}{r}20000 \\
17400 \\
11200 \\
7570 \\
5650\end{array}$ & $\begin{array}{l}1600 \\
1680 \\
2090 \\
2160 \\
2080\end{array}$ & $\begin{array}{l}17 \\
26 \\
35 \\
38 \\
41\end{array}$ & $\begin{array}{r}73 \\
118 \\
198 \\
222 \\
230\end{array}$ \\
\hline $\begin{array}{l}21 \ldots \\
22 \ldots \\
23 \ldots \\
24 \ldots \\
25 \ldots\end{array}$ & $\begin{array}{l}3340 \\
5030 \\
7140 \\
8300 \\
8020\end{array}$ & $\begin{array}{r}55 \\
221 \\
273 \\
168 \\
120\end{array}$ & $\begin{array}{l}496 \\
3400 \\
3340 \\
3760 \\
2600\end{array}$ & $\begin{array}{l}6520 \\
6040 \\
4830 \\
4140 \\
3720\end{array}$ & $\begin{array}{l}137 \\
119 \\
116 \\
112 \\
100\end{array}$ & $\begin{array}{l}3150 \\
1940 \\
1510 \\
1250 \\
1000\end{array}$ & $\begin{array}{l}1930 \\
1800 \\
1910 \\
1790 \\
1600\end{array}$ & $\begin{array}{l}35 \\
28 \\
36 \\
43 \\
43\end{array}$ & $\begin{array}{l}182 \\
136 \\
186 \\
200 \\
186\end{array}$ \\
\hline $\begin{array}{l}26 \ldots \\
27 \ldots \\
28 \ldots \\
29 \ldots \\
30 \ldots \\
32 \ldots\end{array}$ & $\begin{array}{r}6360 \\
5220 \\
4760 \\
4160 \\
3690 \\
-\end{array}$ & $\begin{array}{l}93 \\
90 \\
80 \\
62 \\
49 \\
-\end{array}$ & $\begin{array}{r}1600 \\
1270 \\
1030 \\
696 \\
488 \\
\end{array}$ & $\begin{array}{l}3420 \\
3240 \\
3050 \\
3450 \\
4260 \\
3610\end{array}$ & $\begin{array}{r}93 \\
75 \\
79 \\
108 \\
228 \\
141\end{array}$ & $\begin{array}{r}766 \\
656 \\
651 \\
1010 \\
2560 \\
1370\end{array}$ & $\begin{array}{l}1480 \\
1400 \\
1290 \\
1320 \\
1800 \\
\end{array}$ & $\begin{array}{l}45 \\
50 \\
48 \\
53 \\
58 \\
-\end{array}$ & $\begin{array}{l}180 \\
169 \\
167 \\
189 \\
282 \\
-\end{array}$ \\
\hline \multirow[t]{2}{*}{ Total } & 206320 & - & 93085 & 345850 & - & 217665 & 59030 & - & 7988 \\
\hline & \multicolumn{3}{|c|}{ JULY } & \multicolumn{3}{|c|}{ AUGUST } & \multicolumn{3}{|c|}{ SEPTEMBER } \\
\hline $\begin{array}{l}2 \ldots \\
200 \\
300 \\
4 \ldots \\
50\end{array}$ & $\begin{array}{l}1470 \\
1320 \\
1330 \\
1520 \\
1250\end{array}$ & $\begin{array}{l}56 \\
58 \\
65 \\
66 \\
60\end{array}$ & $\begin{array}{l}222 \\
207 \\
233 \\
271 \\
202\end{array}$ & $\begin{array}{l}1170 \\
1290 \\
1240 \\
1420 \\
1470\end{array}$ & $\begin{array}{l}19 \\
19 \\
13 \\
13 \\
17\end{array}$ & $\begin{array}{l}60 \\
66 \\
44 \\
50 \\
67\end{array}$ & $\begin{array}{l}769 \\
805 \\
643 \\
526 \\
466\end{array}$ & $\begin{array}{l}18 \\
17 \\
14 \\
29 \\
24\end{array}$ & $\begin{array}{l}37 \\
37 \\
24 \\
27 \\
30\end{array}$ \\
\hline $\begin{array}{r}6 \ldots \\
7 \ldots \\
6 \ldots \\
90 \\
10 \ldots\end{array}$ & $\begin{array}{r}1190 \\
1150 \\
1090 \\
1030 \\
990\end{array}$ & $\begin{array}{l}50 \\
32 \\
47 \\
52 \\
24\end{array}$ & $\begin{array}{r}161 \\
99 \\
138 \\
145 \\
64\end{array}$ & $\begin{array}{r}1310 \\
1080 \\
970 \\
930 \\
910\end{array}$ & $\begin{array}{r}14 \\
12 \\
13 \\
12 \\
8\end{array}$ & $\begin{array}{l}50 \\
35 \\
34 \\
30 \\
20\end{array}$ & $\begin{array}{l}434 \\
434 \\
434 \\
442 \\
458\end{array}$ & $\begin{array}{l}30 \\
43 \\
52 \\
49 \\
41\end{array}$ & $\begin{array}{l}35 \\
50 \\
61 \\
50 \\
51\end{array}$ \\
\hline $\begin{array}{l}11 \ldots \\
12 \ldots \\
13 \ldots \\
14 \ldots \\
15 \ldots\end{array}$ & $\begin{array}{l}990 \\
980 \\
970 \\
920 \\
900\end{array}$ & $\begin{array}{l}15 \\
24 \\
21 \\
43 \\
52\end{array}$ & $\begin{array}{r}40 \\
64 \\
55 \\
107 \\
126\end{array}$ & $\begin{array}{l}841 \\
796 \\
751 \\
697 \\
679\end{array}$ & $\begin{array}{l}10 \\
15 \\
18 \\
21 \\
21\end{array}$ & $\begin{array}{l}23 \\
32 \\
36 \\
40 \\
38\end{array}$ & $\begin{array}{l}490 \\
466 \\
458 \\
466 \\
458\end{array}$ & $\begin{array}{l}25 \\
17 \\
12 \\
12 \\
19\end{array}$ & $\begin{array}{l}33 \\
21 \\
15 \\
15 \\
23\end{array}$ \\
\hline $\begin{array}{l}16 \ldots \\
17 \ldots \\
18 \ldots \\
19 \ldots \\
20 \ldots\end{array}$ & $\begin{array}{r}670 \\
970 \\
970 \\
1180 \\
1180\end{array}$ & $\begin{array}{l}35 \\
35 \\
27 \\
27 \\
30\end{array}$ & $\begin{array}{l}82 \\
92 \\
71 \\
86 \\
96\end{array}$ & $\begin{array}{l}670 \\
670 \\
652 \\
652 \\
679\end{array}$ & $\begin{array}{l}23 \\
21 \\
24 \\
23 \\
23\end{array}$ & $\begin{array}{l}42 \\
38 \\
42 \\
40 \\
42\end{array}$ & $\begin{array}{l}450 \\
434 \\
434 \\
418 \\
418\end{array}$ & $\begin{array}{l}17 \\
19 \\
19 \\
22 \\
20\end{array}$ & $\begin{array}{l}21 \\
22 \\
22 \\
25 \\
23\end{array}$ \\
\hline $\begin{array}{l}21 \ldots \\
22 \ldots \\
23 \ldots \\
24 \ldots \\
25 \ldots\end{array}$ & $\begin{array}{l}1280 \\
1140 \\
1110 \\
1110 \\
1050\end{array}$ & $\begin{array}{l}25 \\
17 \\
15 \\
16 \\
12\end{array}$ & $\begin{array}{l}86 \\
52 \\
45 \\
48 \\
34\end{array}$ & $\begin{array}{l}778 \\
823 \\
688 \\
652 \\
625\end{array}$ & $\begin{array}{l}37 \\
40 \\
27 \\
19 \\
18\end{array}$ & $\begin{array}{r}70 \\
107 \\
50 \\
33 \\
30\end{array}$ & $\begin{array}{l}450 \\
517 \\
580 \\
535 \\
434\end{array}$ & $\begin{array}{l}22 \\
20 \\
16 \\
21 \\
13\end{array}$ & $\begin{array}{l}27 \\
28 \\
28 \\
36 \\
28\end{array}$ \\
\hline $\begin{array}{l}26 \ldots \\
27 \ldots \\
20 \ldots \\
29 \ldots \\
30 \ldots \\
31 \ldots\end{array}$ & $\begin{array}{l}1030 \\
1000 \\
1270 \\
1940 \\
1370 \\
1300\end{array}$ & $\begin{array}{l}10 \\
11 \\
38 \\
37 \\
22 \\
17\end{array}$ & $\begin{array}{r}26 \\
30 \\
120 \\
194 \\
81 \\
60\end{array}$ & $\begin{array}{l}634 \\
634 \\
760 \\
661 \\
616 \\
580\end{array}$ & $\begin{array}{l}15 \\
13 \\
12 \\
13 \\
16 \\
14\end{array}$ & $\begin{array}{l}26 \\
22 \\
25 \\
23 \\
27 \\
22\end{array}$ & $\begin{array}{r}410 \\
442 \\
724 \\
1560 \\
1510 \\
\end{array}$ & $\begin{array}{r}8 \\
19 \\
24 \\
46 \\
24 \\
\end{array}$ & $\begin{array}{r}9 \\
29 \\
47 \\
194 \\
98 \\
-\end{array}$ \\
\hline Total & 35770 & - & 3339 & 26320 & - & 1272 & 17065 & - & 1225 \\
\hline
\end{tabular}

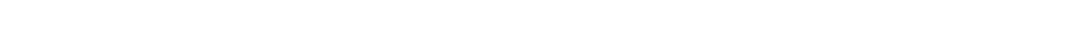

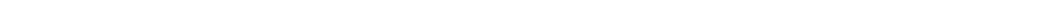




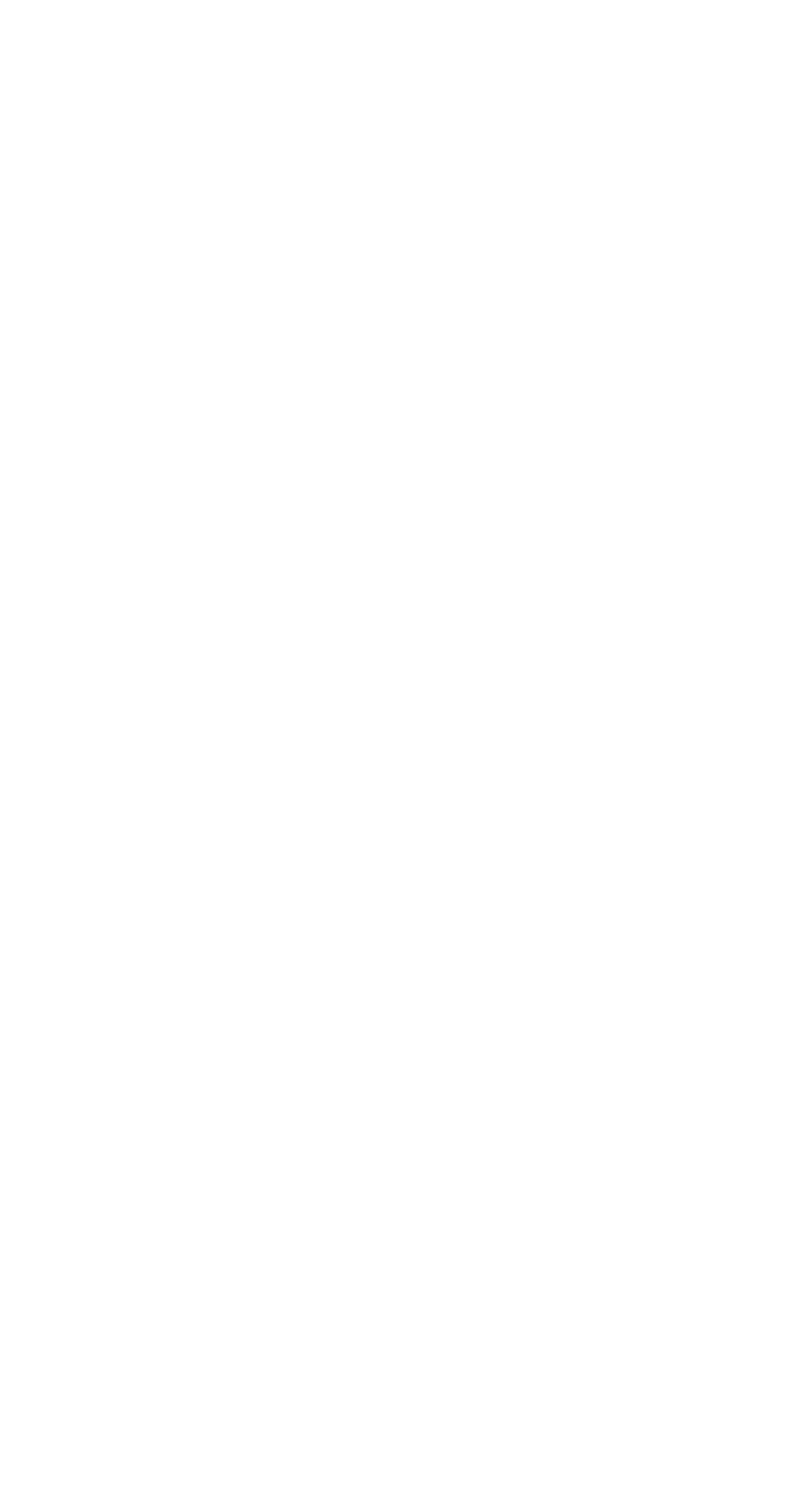




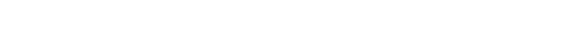

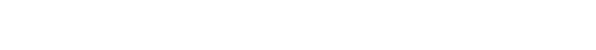

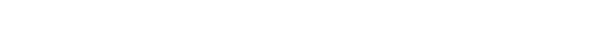

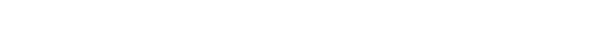

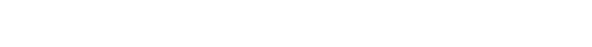

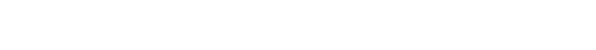

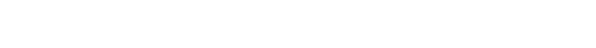

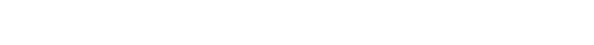

$111811181118111119111 \%$ 1 $111 \%$ mºg

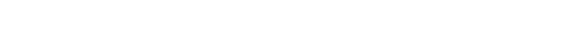

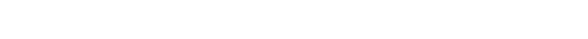

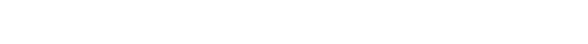
001001000100000000000000

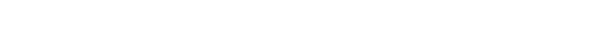

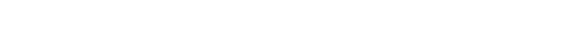

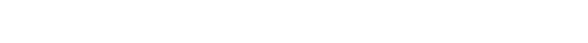

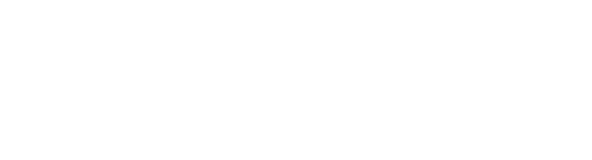

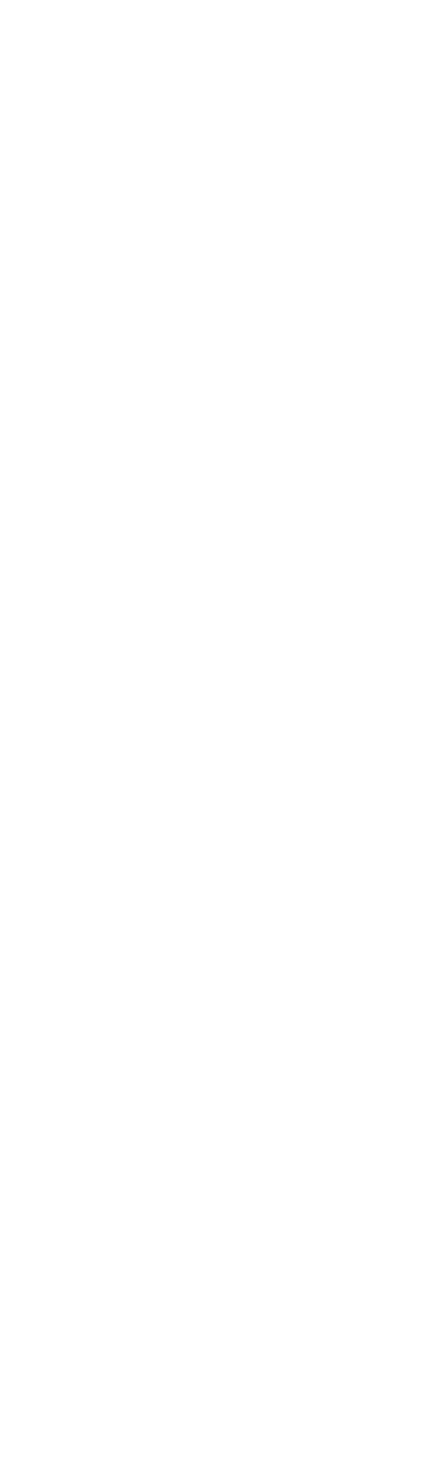




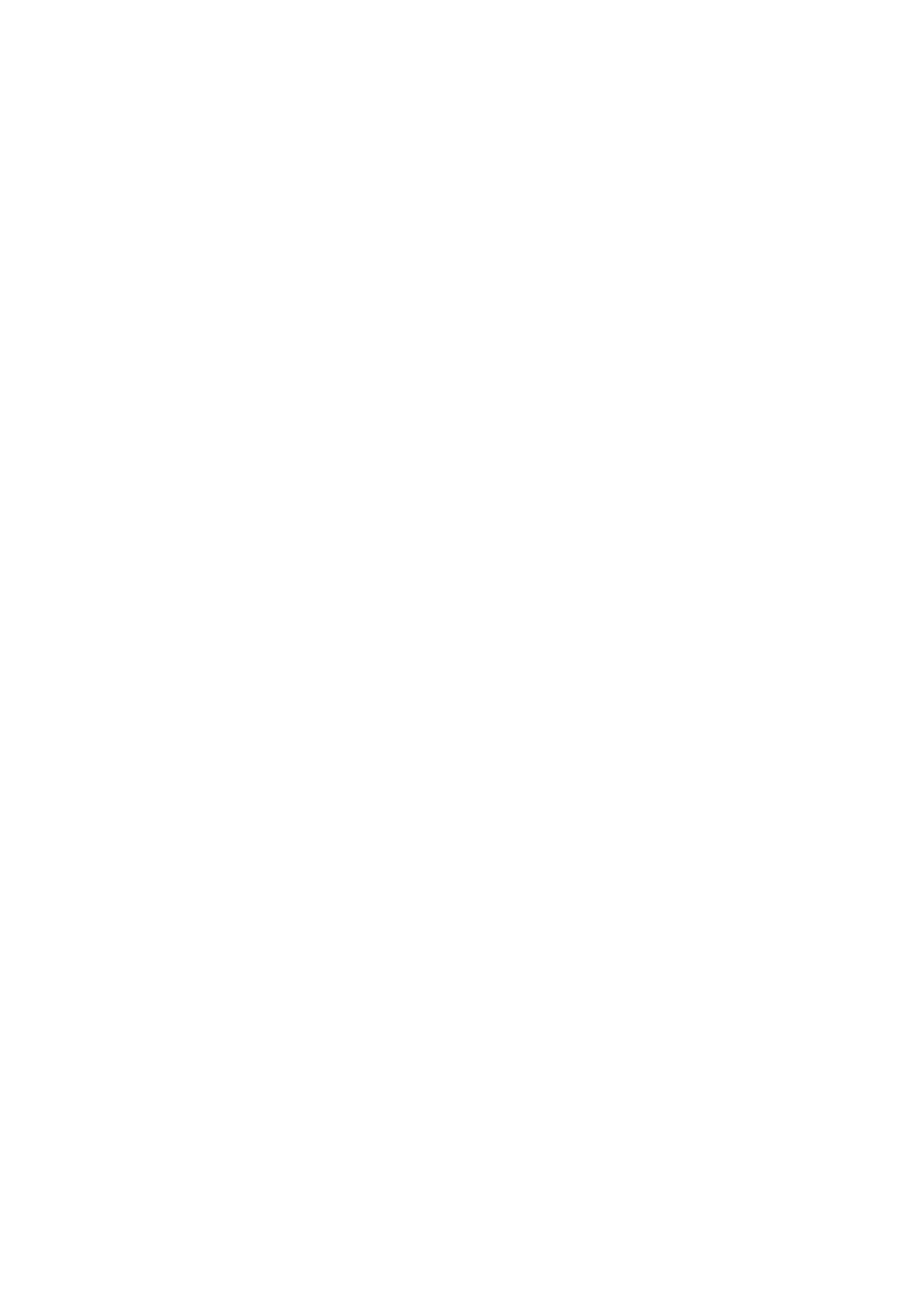



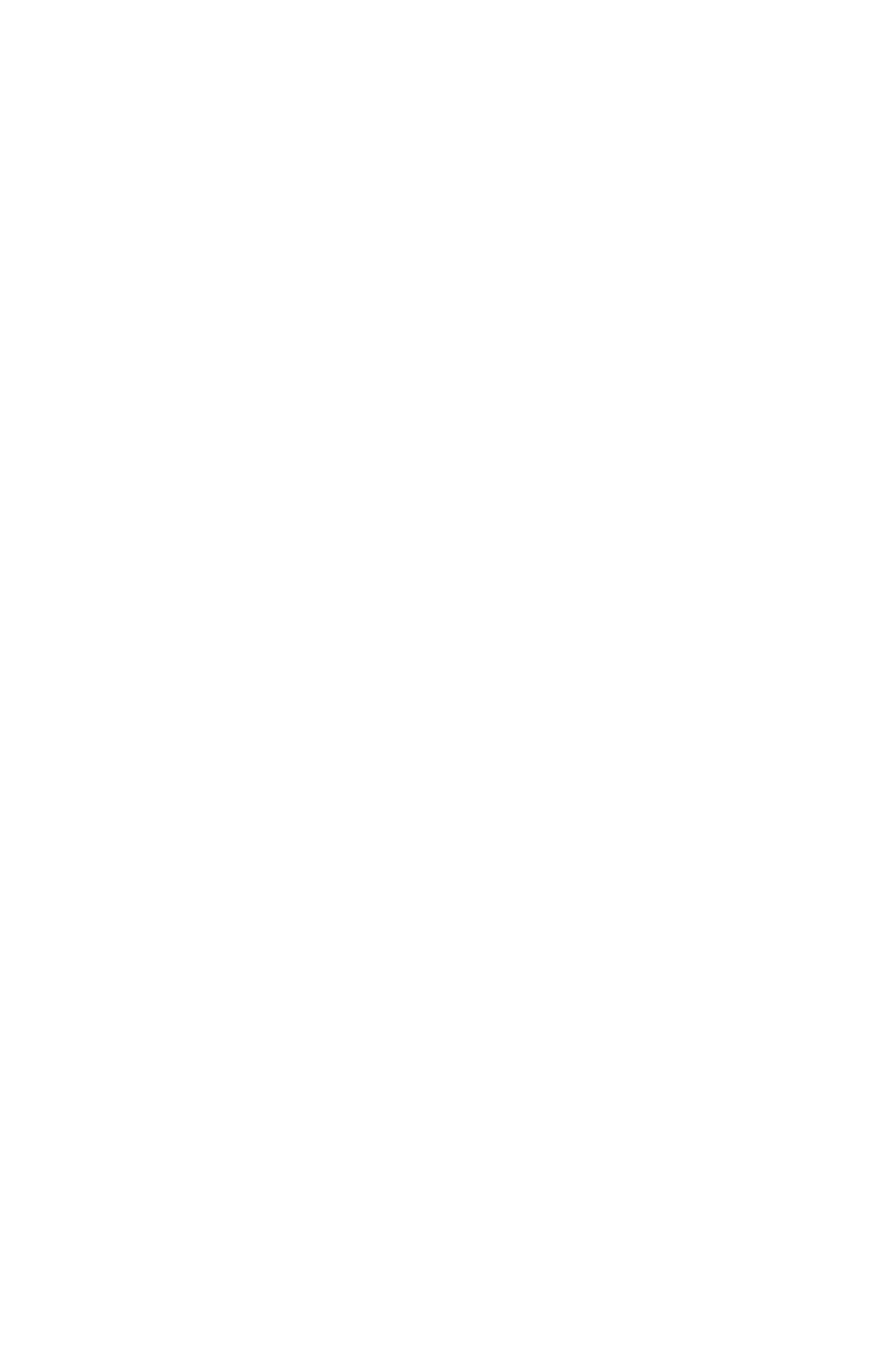


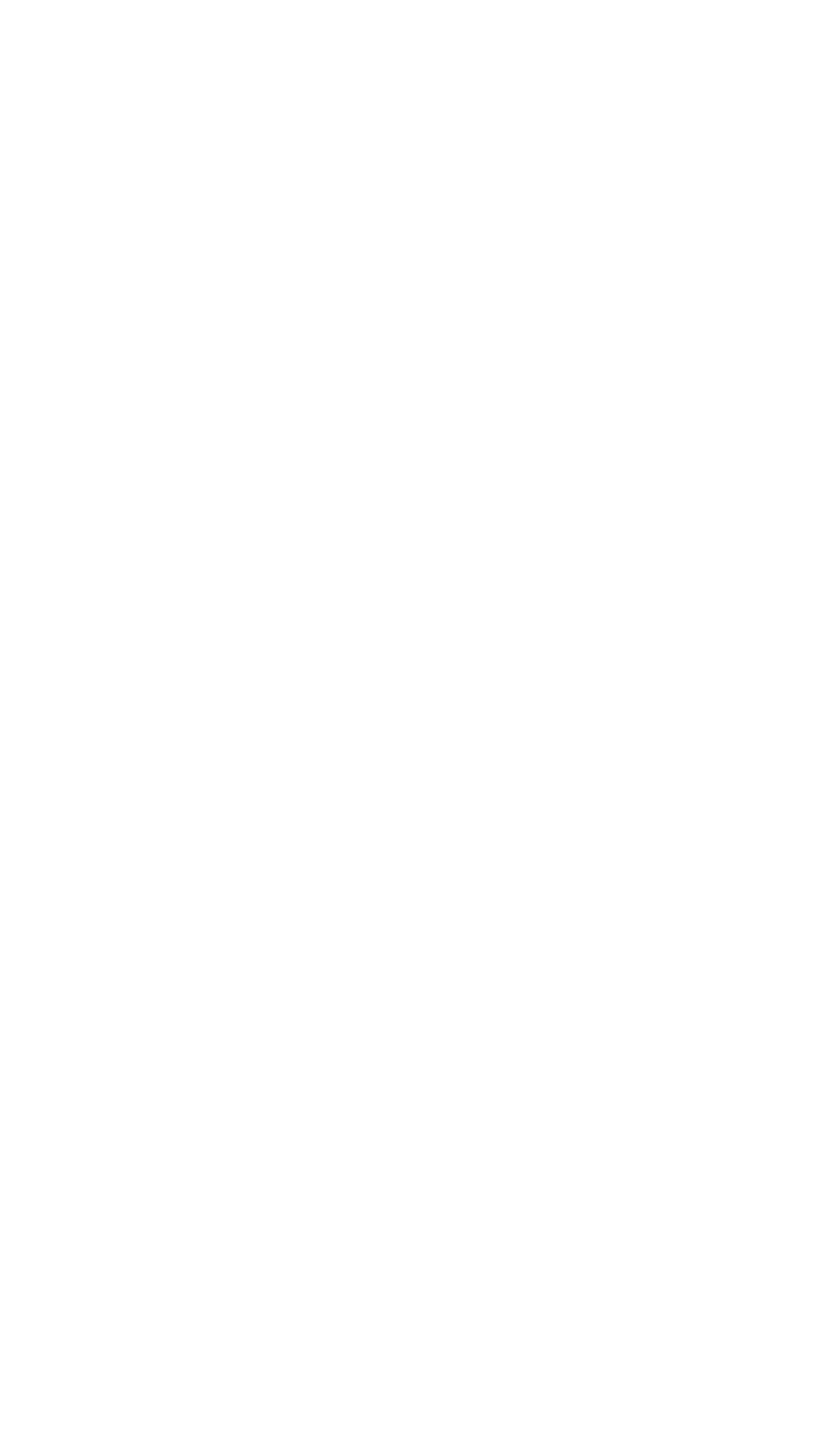




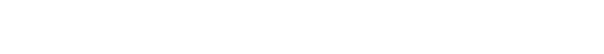

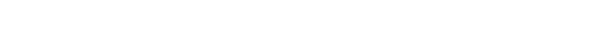

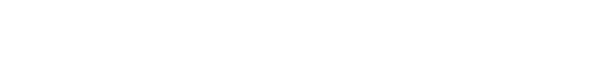

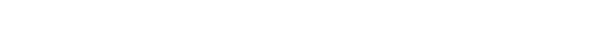

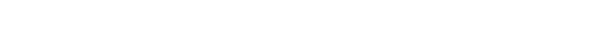

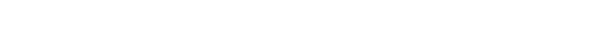

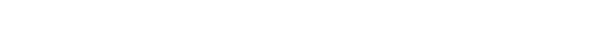

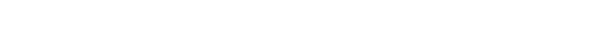

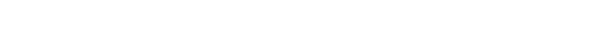
में।

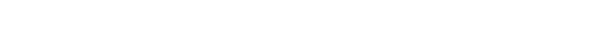

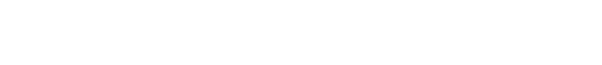

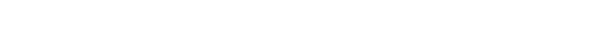
$001^{m} 11^{0} 1000100000100,00000$

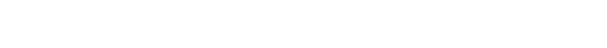

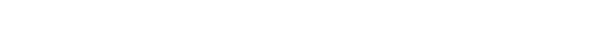

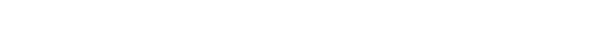

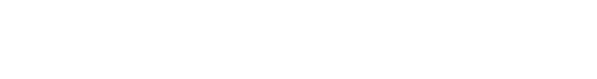
$\because \cdots \cdots: \cdots:$

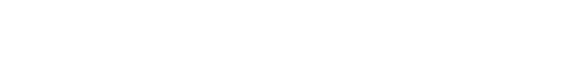

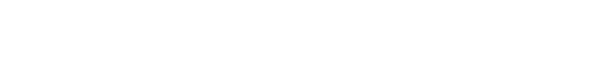

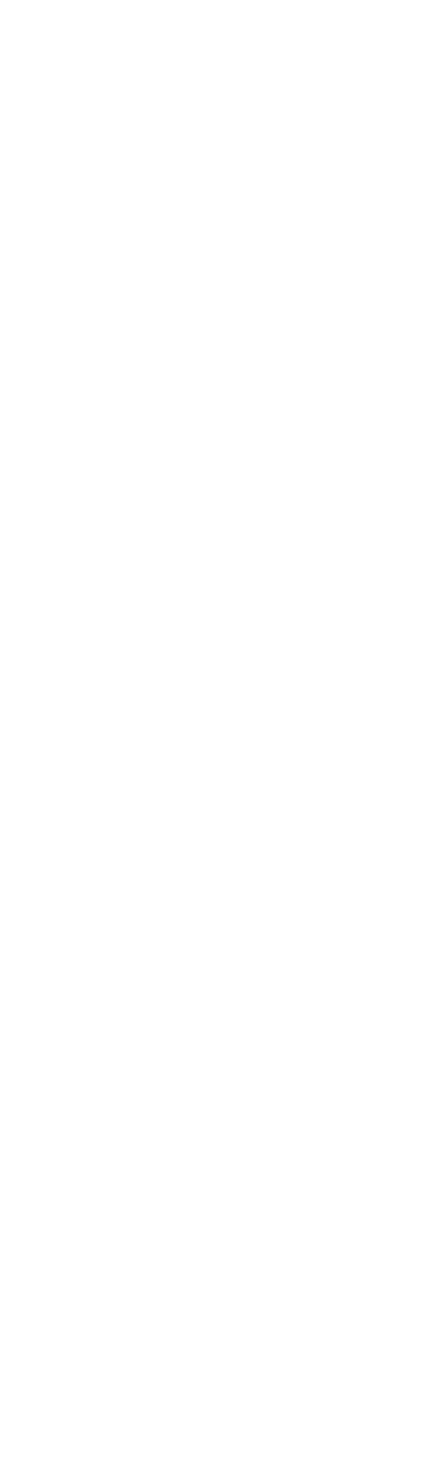




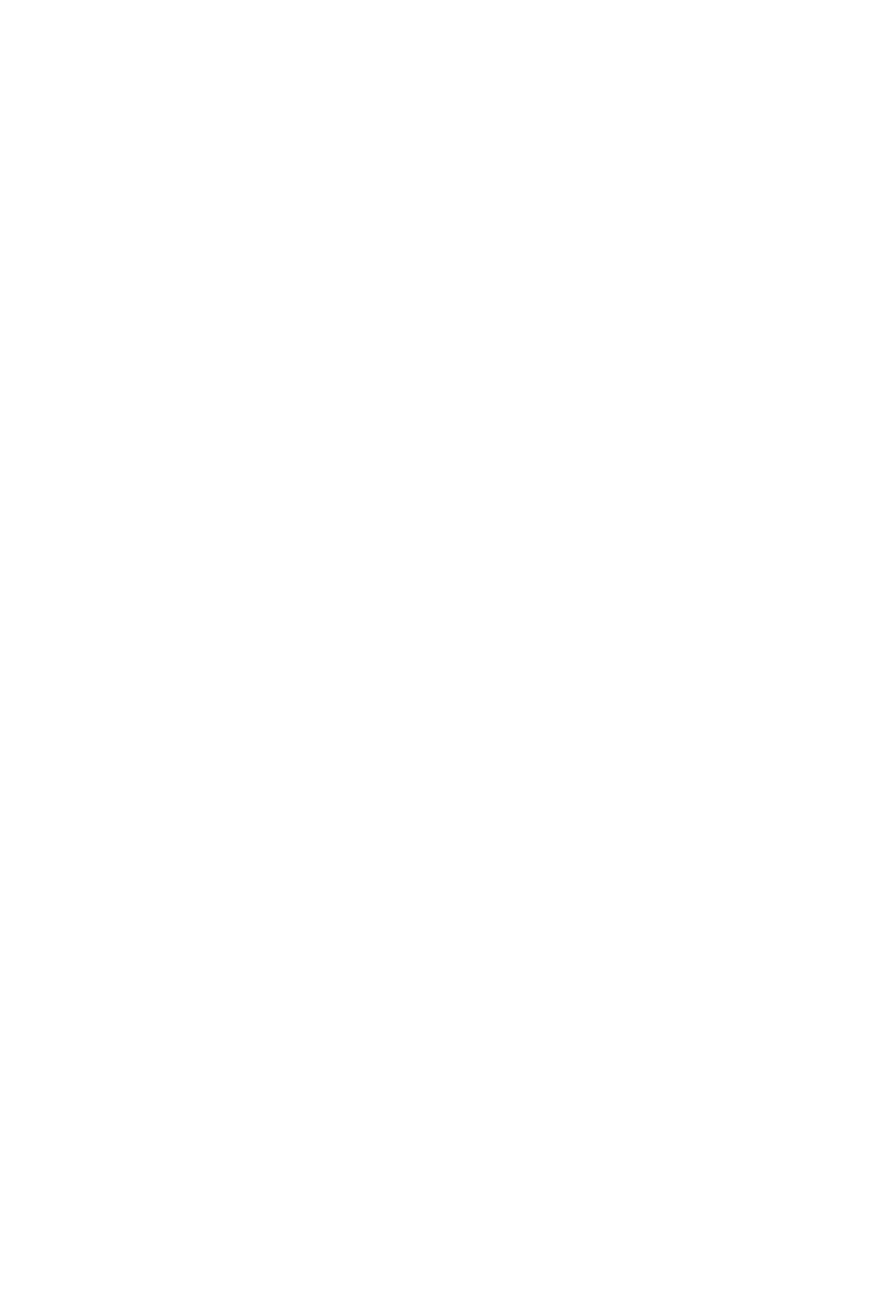



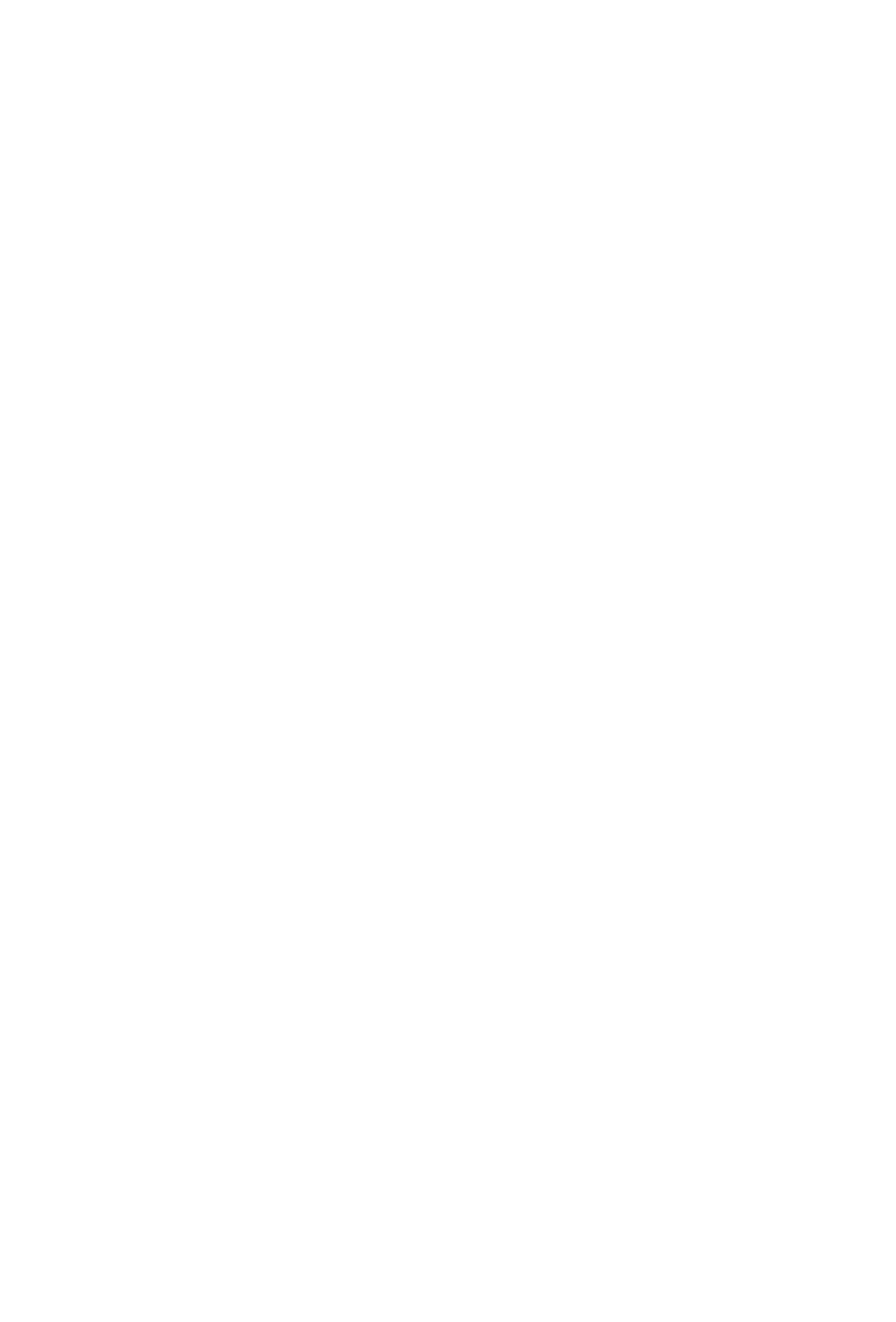

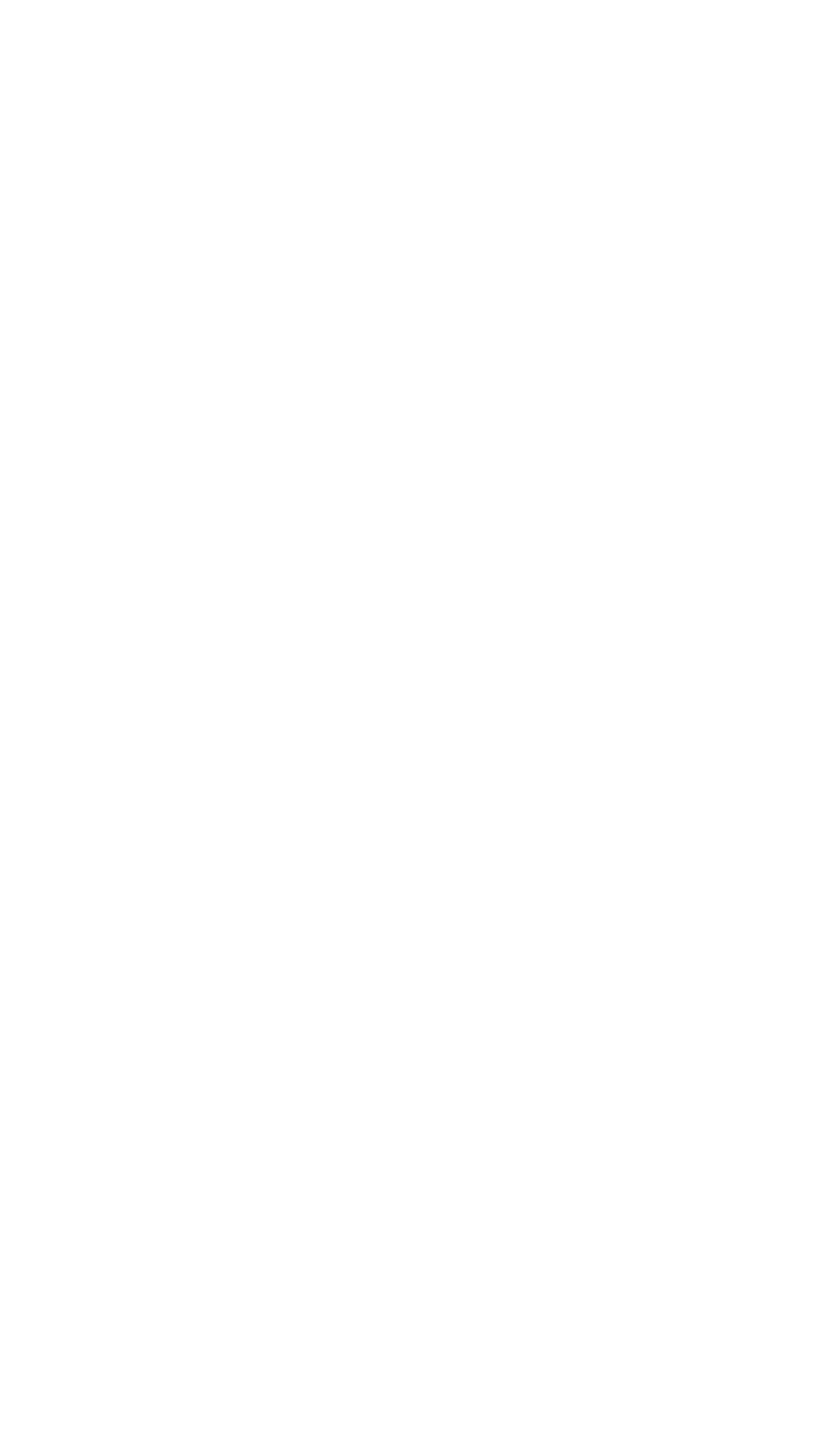
LICKING RIVER BASIN--COntinued

3-2495. LICKING RIVER AT FARMERS, KY.--Continued

Suspended sediment, water year October 1966 to September 1967

\begin{tabular}{|c|c|c|c|c|c|c|c|c|c|}
\hline \multirow[b]{3}{*}{ Day } & \multicolumn{3}{|c|}{ OCTOBER } & \multicolumn{3}{|c|}{ MOVEMBER } & \multicolumn{3}{|c|}{ DECEMEER } \\
\hline & \multirow[b]{2}{*}{$\begin{array}{c}\text { Mean } \\
\text { dis- } \\
\text { charge } \\
\text { (cfs) }\end{array}$} & \multicolumn{2}{|c|}{ Suspended sediment } & \multirow[b]{2}{*}{$\begin{array}{c}\text { Mean } \\
\text { dis- } \\
\text { charge } \\
(\text { cfs) }\end{array}$} & \multicolumn{2}{|c|}{ Suspended sediment } & \multirow[b]{2}{*}{$\begin{array}{c}\text { Mean } \\
\text { dis- } \\
\text { charge } \\
\text { (cfs) }\end{array}$} & \multicolumn{2}{|c|}{ Suspended sediment } \\
\hline & & $\begin{array}{l}\text { Mean } \\
\text { concen- } \\
\text { tration } \\
\text { (ppm) }\end{array}$ & $\begin{array}{l}\text { Tons } \\
\text { per } \\
\text { day }\end{array}$ & & $\begin{array}{c}\text { Mean } \\
\text { concen- } \\
\text { tration } \\
\text { (ppm) }\end{array}$ & $\begin{array}{l}\text { Tons } \\
\text { per } \\
\text { day }\end{array}$ & & $\begin{array}{c}\text { Mean } \\
\text { concen- } \\
\text { tration } \\
(\mathrm{ppm})\end{array}$ & $\begin{array}{l}\text { Tons } \\
\text { per } \\
\text { day }\end{array}$ \\
\hline $\begin{array}{l}1 \ldots \\
2 \ldots \\
3 \ldots \\
3 \ldots \\
3 \ldots\end{array}$ & $\begin{array}{r}700 \\
1910 \\
1500 \\
1090 \\
715\end{array}$ & $\begin{array}{r}67 \\
206 \\
123 \\
54 \\
33\end{array}$ & $\begin{array}{r}127 \\
1060 \\
525 \\
159 \\
64\end{array}$ & $\begin{array}{r}85 \\
182 \\
1920 \\
2620 \\
2040\end{array}$ & $\begin{array}{r}3 \\
7 \\
126 \\
152 \\
106\end{array}$ & $\begin{array}{r}1 \\
3 \\
727 \\
1080 \\
584\end{array}$ & $\begin{array}{r}112 \\
1030 \\
1170 \\
1030 \\
092\end{array}$ & $\begin{array}{l}10 \\
10 \\
15 \\
10 \\
5\end{array}$ & $\begin{array}{l}13 \\
28 \\
47 \\
28 \\
12\end{array}$ \\
\hline $\begin{array}{r}6 \ldots \\
7 \ldots \\
8 \ldots \\
9 \ldots \\
10 \ldots\end{array}$ & $\begin{array}{l}514 \\
389 \\
323 \\
275 \\
242\end{array}$ & $\begin{array}{r}23 \\
15 \\
12 \\
10 \\
8\end{array}$ & $\begin{array}{r}32 \\
16 \\
10 \\
7 \\
5\end{array}$ & $\begin{array}{r}1350 \\
1140 \\
1000 \\
670 \\
780\end{array}$ & $\begin{array}{l}45 \\
24 \\
18 \\
17 \\
14\end{array}$ & $\begin{array}{r}164 \\
74 \\
49 \\
40 \\
29\end{array}$ & $\begin{array}{l}1430 \\
2280 \\
2290 \\
3170 \\
7050\end{array}$ & $\begin{array}{r}24 \\
58 \\
57 \\
139 \\
203\end{array}$ & $\begin{array}{r}107 \\
357 \\
346 \\
1390 \\
3860\end{array}$ \\
\hline $\begin{array}{l}11 \ldots \\
12 \ldots \\
13 \ldots \\
14 \ldots \\
15 \ldots\end{array}$ & $\begin{array}{l}233 \\
194 \\
167 \\
149 \\
137\end{array}$ & $\begin{array}{l}7 \\
7 \\
7 \\
7 \\
8\end{array}$ & $\begin{array}{l}4 \\
4 \\
3 \\
3 \\
3\end{array}$ & $\begin{array}{r}1640 \\
1710 \\
1260 \\
944 \\
733\end{array}$ & $\begin{array}{r}123 \\
138 \\
96 \\
20 \\
11\end{array}$ & $\begin{array}{r}600 \\
637 \\
191 \\
51 \\
22\end{array}$ & $\begin{array}{l}8790 \\
6140 \\
4740 \\
2470 \\
1690\end{array}$ & $\begin{array}{r}152 \\
115 \\
92 \\
73 \\
46\end{array}$ & $\begin{array}{r}3 \times 10 \\
2 \times 30 \\
1180 \\
487 \\
210\end{array}$ \\
\hline $\begin{array}{l}16 \ldots \\
17 \ldots \\
18 \ldots \\
19 \ldots \\
20 \ldots\end{array}$ & $\begin{array}{l}125 \\
118 \\
134 \\
144 \\
167\end{array}$ & $\begin{array}{l}6 \\
5 \\
5 \\
5 \\
5\end{array}$ & $\begin{array}{l}2 \\
2 \\
2 \\
2 \\
2\end{array}$ & $\begin{array}{l}586 \\
490 \\
423 \\
375 \\
333\end{array}$ & $\begin{array}{l}7 \\
7 \\
5 \\
4 \\
3\end{array}$ & $\begin{array}{l}11 \\
9 \\
6 \\
4 \\
3\end{array}$ & $\begin{array}{r}1290 \\
1040 \\
872 \\
733 \\
659\end{array}$ & $\begin{array}{r}27 \\
17 \\
11 \\
8 \\
7\end{array}$ & $\begin{array}{l}94 \\
48 \\
26 \\
16 \\
12\end{array}$ \\
\hline $\begin{array}{l}21 \ldots \\
22 \cdots \\
23 \ldots \\
24 \ldots \\
25 \cdots\end{array}$ & $\begin{array}{l}182 \\
176 \\
188 \\
176 \\
144\end{array}$ & $\begin{array}{l}5 \\
5 \\
5 \\
4 \\
3\end{array}$ & $\begin{array}{l}2 \\
2 \\
3 \\
2 \\
1\end{array}$ & $\begin{array}{l}297 \\
269 \\
245 \\
228 \\
217\end{array}$ & $\begin{array}{l}3 \\
2 \\
2 \\
2 \\
2\end{array}$ & $\begin{array}{l}2 \\
1 \\
1 \\
1 \\
1\end{array}$ & $\begin{array}{l}581 \\
512 \\
451 \\
410 \\
384\end{array}$ & $\begin{array}{l}5 \\
4 \\
4 \\
4\end{array}$ & $\begin{array}{l}8 \\
6 \\
5 \\
4 \\
3\end{array}$ \\
\hline $\begin{array}{l}26 \ldots \\
27 \ldots \\
28 \ldots \\
29 \ldots \\
30 \ldots \\
31 \ldots\end{array}$ & $\begin{array}{r}133 \\
119 \\
107 \\
99 \\
91 \\
83\end{array}$ & $\begin{array}{l}3 \\
3 \\
3 \\
2 \\
2 \\
3\end{array}$ & $\begin{array}{l}1 \\
1 \\
1 \\
1 \\
1 \\
1\end{array}$ & $\begin{array}{r}228 \\
285 \\
340 \\
485 \\
651 \\
-\end{array}$ & $\begin{array}{r}2 \\
5 \\
4 \\
6 \\
-\end{array}$ & $\begin{array}{r}1 \\
4 \\
5 \\
11 \\
\end{array}$ & $\begin{array}{r}345 \\
281 \\
1070 \\
5500 \\
5890 \\
4600\end{array}$ & $\begin{array}{r}3 \\
3 \\
81 \\
234 \\
189 \\
142\end{array}$ & $\begin{array}{r}3 \\
2 \\
328 \\
3470 \\
3710 \\
1760\end{array}$ \\
\hline \multirow[t]{2}{*}{ Total } & 10804 & - & 2048 & 23726 & - & 4316 & 71982 & - & 23700 \\
\hline & \multicolumn{3}{|c|}{ JANUARY } & \multicolumn{3}{|c|}{ FEBRUARY } & \multicolumn{3}{|c|}{ MARCH } \\
\hline $\begin{array}{l}2 \ldots \\
2 \ldots \\
30 . \\
4 \ldots \\
50 .\end{array}$ & $\begin{array}{r}3430 \\
1870 \\
1380 \\
1120 \\
922\end{array}$ & $\begin{array}{l}92 \\
44 \\
29 \\
19 \\
12\end{array}$ & $\begin{array}{r}852 \\
222 \\
108 \\
57 \\
30\end{array}$ & $\begin{array}{l}1190 \\
1250 \\
1900 \\
1820 \\
1540\end{array}$ & $\begin{array}{l}30 \\
24 \\
36 \\
48 \\
28\end{array}$ & $\begin{array}{r}96 \\
75 \\
287 \\
236 \\
116\end{array}$ & $\begin{array}{l}1460 \\
1470 \\
1400 \\
1400 \\
1380\end{array}$ & $\begin{array}{l}18 \\
18 \\
22 \\
18 \\
26\end{array}$ & $\begin{array}{r}71 \\
71 \\
83 \\
68 \\
106\end{array}$ \\
\hline $\begin{array}{r}6 \ldots \\
7 \ldots \\
8 \ldots \\
9 \ldots \\
10 \ldots\end{array}$ & $\begin{array}{l}773 \\
665 \\
595 \\
525 \\
462\end{array}$ & $\begin{array}{l}8 \\
6 \\
5 \\
4 \\
2\end{array}$ & $\begin{array}{r}17 \\
11 \\
8 \\
6 \\
2\end{array}$ & $\begin{array}{r}1300 \\
1120 \\
915 \\
764 \\
680\end{array}$ & $\begin{array}{r}19 \\
13 \\
11 \\
8 \\
7\end{array}$ & $\begin{array}{l}67 \\
39 \\
27 \\
17 \\
13\end{array}$ & $\begin{array}{r}7370 \\
13400 \\
16800 \\
13400 \\
10700\end{array}$ & $\begin{array}{l}576 \\
364 \\
184 \\
152 \\
145\end{array}$ & $\begin{array}{r}11500 \\
13200 \\
8350 \\
5300 \\
4190\end{array}$ \\
\hline $\begin{array}{l}11 \ldots \\
12 \ldots \\
13 \ldots \\
14 \ldots \\
15 \ldots\end{array}$ & $\begin{array}{l}409 \\
368 \\
342 \\
372 \\
485\end{array}$ & $\begin{array}{l}2 \\
2 \\
2 \\
5 \\
7\end{array}$ & $\begin{array}{l}2 \\
2 \\
2 \\
5 \\
9\end{array}$ & $\begin{array}{l}773 \\
832 \\
880 \\
880 \\
870\end{array}$ & $\begin{array}{l}8 \\
6 \\
7 \\
8 \\
8\end{array}$ & $\begin{array}{l}17 \\
18 \\
17 \\
19 \\
19\end{array}$ & $\begin{array}{l}8870 \\
3650 \\
1960 \\
1980 \\
4320\end{array}$ & $\begin{array}{r}62 \\
82 \\
86 \\
62 \\
199\end{array}$ & $\begin{array}{r}1960 \\
808 \\
455 \\
331 \\
2760\end{array}$ \\
\hline $\begin{array}{l}16 \ldots \\
17 \ldots \\
18 \ldots \\
19 \ldots \\
20 \ldots\end{array}$ & $\begin{array}{l}501 \\
465 \\
427 \\
380 \\
368\end{array}$ & $\begin{array}{l}5 \\
5 \\
5 \\
5 \\
5\end{array}$ & $\begin{array}{l}7 \\
6 \\
6 \\
5 \\
5\end{array}$ & $\begin{array}{l}840 \\
817 \\
763 \\
725 \\
802\end{array}$ & $\begin{array}{l}9 \\
8 \\
7 \\
8 \\
7\end{array}$ & $\begin{array}{l}20 \\
18 \\
14 \\
16 \\
15\end{array}$ & $\begin{array}{l}7230 \\
6160 \\
4040 \\
2460 \\
1740\end{array}$ & $\begin{array}{r}356 \\
178 \\
151 \\
78 \\
49\end{array}$ & $\begin{array}{r}6950 \\
2960 \\
1650 \\
518 \\
230\end{array}$ \\
\hline $\begin{array}{l}21 \ldots \\
22 \ldots \\
23 \ldots \\
24 \ldots \\
25 \ldots\end{array}$ & $\begin{array}{l}378 \\
398 \\
424 \\
424 \\
409\end{array}$ & $\begin{array}{l}4 \\
3 \\
4 \\
5 \\
5\end{array}$ & $\begin{array}{l}4 \\
3 \\
5 \\
6 \\
6\end{array}$ & $\begin{array}{l}1360 \\
1740 \\
1910 \\
1610 \\
1210\end{array}$ & $\begin{array}{l}22 \\
41 \\
62 \\
45 \\
12\end{array}$ & $\begin{array}{r}81 \\
193 \\
320 \\
196 \\
39\end{array}$ & $\begin{array}{l}1610 \\
1730 \\
1600 \\
1410 \\
1240\end{array}$ & $\begin{array}{l}35 \\
32 \\
29 \\
25 \\
21\end{array}$ & $\begin{array}{r}152 \\
149 \\
125 \\
95 \\
70\end{array}$ \\
\hline $\begin{array}{l}26 \ldots \\
27 \ldots \\
28 \ldots \\
30 \ldots \\
31 \ldots\end{array}$ & $\begin{array}{r}400 \\
615 \\
1420 \\
2240 \\
2110 \\
1500\end{array}$ & $\begin{array}{r}5 \\
26 \\
48 \\
108 \\
97 \\
63\end{array}$ & $\begin{array}{r}5 \\
43 \\
184 \\
653 \\
553 \\
255\end{array}$ & $\begin{array}{r}1030 \\
869 \\
1160 \\
= \\
=\end{array}$ & $\begin{array}{l}12 \\
12 \\
12 \\
= \\
-\end{array}$ & $\begin{array}{l}33 \\
28 \\
38 \\
= \\
=-\end{array}$ & $\begin{array}{r}1110 \\
977 \\
1020 \\
1290 \\
1220 \\
1180\end{array}$ & $\begin{array}{l}18 \\
14 \\
25 \\
32 \\
24 \\
23\end{array}$ & $\begin{array}{r}54 \\
37 \\
69 \\
111 \\
79 \\
73\end{array}$ \\
\hline Total & 26177 & - & 3079 & 31450 & - & 2074 & 125577 & - & 62773 \\
\hline
\end{tabular}

$T$ Less than 0.50 ton. 
LICKING RIVER BASIN--Continued

3-2495. LICKING RIVER AT FARMERS, KY.--Continued

Suspended sediment, water year October 1966 to September 1967--Continued

\begin{tabular}{|c|c|c|c|c|c|c|c|c|c|}
\hline \multirow[b]{3}{*}{ Day } & \multicolumn{3}{|c|}{ APRIL } & \multicolumn{3}{|c|}{ MAY } & \multicolumn{3}{|c|}{ JUNE } \\
\hline & \multirow[b]{2}{*}{$\begin{array}{l}\text { Mean } \\
\text { dis- } \\
\text { charge } \\
\text { (cfs) }\end{array}$} & \multicolumn{2}{|c|}{ Suspended sediment } & \multirow[b]{2}{*}{$\begin{array}{c}\text { Mean } \\
\text { dis- } \\
\text { charge } \\
\text { (cfo) }\end{array}$} & \multicolumn{2}{|c|}{ Suspended sediment } & \multirow[b]{2}{*}{$\begin{array}{c}\text { Mean } \\
\text { dis- } \\
\text { charge } \\
(c f s)\end{array}$} & \multicolumn{2}{|c|}{ Suspended sediment } \\
\hline & & $\begin{array}{c}\text { Mean } \\
\text { concen- } \\
\text { tration } \\
(\mathrm{ppm})\end{array}$ & $\begin{array}{l}\text { Tons } \\
\text { per } \\
\text { day }\end{array}$ & & $\begin{array}{c}\text { Mean } \\
\text { concen- } \\
\text { tration } \\
(\text { ppm })\end{array}$ & $\begin{array}{l}\text { Tons } \\
\text { per } \\
\text { day }\end{array}$ & & $\begin{array}{c}\text { Mean } \\
\text { cuncen- } \\
\text { tration } \\
\text { (ppm) }\end{array}$ & $\begin{array}{l}\text { Tons } \\
\text { per } \\
\text { day }\end{array}$ \\
\hline $\begin{array}{l}100 \\
200 \\
300 \\
400 \\
50\end{array}$ & $\begin{array}{r}1060 \\
941 \\
845 \\
756 \\
671\end{array}$ & $\begin{array}{l}23 \\
20 \\
17 \\
12 \\
11\end{array}$ & $\begin{array}{l}66 \\
51 \\
39 \\
24 \\
20\end{array}$ & $\begin{array}{l}1080 \\
1180 \\
1480 \\
1480 \\
1220\end{array}$ & $\begin{array}{l}15 \\
18 \\
27 \\
28 \\
18\end{array}$ & $\begin{array}{r}44 \\
51 \\
108 \\
112 \\
59\end{array}$ & $\begin{array}{r}368 \\
404 \\
518 \\
1080 \\
850\end{array}$ & $\begin{array}{r}9 \\
8 \\
35 \\
49 \\
38\end{array}$ & $\begin{array}{r}9 \\
9 \\
56 \\
143 \\
87\end{array}$ \\
\hline $\begin{array}{r}6 \ldots \\
7 \ldots \\
90 \\
90\end{array}$ & $\begin{array}{l}609 \\
558 \\
499 \\
443 \\
640\end{array}$ & $\begin{array}{r}9 \\
6 \\
4 \\
24\end{array}$ & $\begin{array}{r}15 \\
9 \\
5 \\
4 \\
48\end{array}$ & $\begin{array}{l}1080 \\
5350 \\
9650 \\
7000 \\
3600\end{array}$ & $\begin{array}{r}9 \\
427 \\
324 \\
91 \\
96\end{array}$ & $\begin{array}{r}26 \\
8490 \\
8440 \\
1720 \\
933\end{array}$ & $\begin{array}{l}642 \\
518 \\
410 \\
347 \\
302\end{array}$ & $\begin{array}{l}20 \\
15 \\
12 \\
10 \\
9\end{array}$ & $\begin{array}{r}35 \\
21 \\
19 \\
9 \\
7\end{array}$ \\
\hline $\begin{array}{l}11 \ldots \\
12 \ldots \\
13 \ldots \\
14 \ldots \\
15 \ldots\end{array}$ & $\begin{array}{l}964 \\
673 \\
598 \\
562 \\
505\end{array}$ & $\begin{array}{r}25 \\
15 \\
7 \\
7 \\
7\end{array}$ & $\begin{array}{l}58 \\
27 \\
11 \\
11 \\
10\end{array}$ & $\begin{array}{l}2200 \\
1730 \\
1420 \\
3240 \\
7800\end{array}$ & $\begin{array}{r}60 \\
43 \\
29 \\
255 \\
746\end{array}$ & $\begin{array}{r}356 \\
201 \\
111 \\
4100 \\
15700\end{array}$ & $\begin{array}{l}272 \\
239 \\
221 \\
191 \\
154\end{array}$ & $\begin{array}{r}7 \\
7 \\
6 \\
9 \\
10\end{array}$ & $\begin{array}{l}5 \\
5 \\
5 \\
5 \\
4\end{array}$ \\
\hline $\begin{array}{l}16 \ldots \\
17.0 \\
18.0 \\
190 . \\
20 .\end{array}$ & $\begin{array}{l}458 \\
1230 \\
2620 \\
1550 \\
1300\end{array}$ & $\begin{array}{r}6 \\
214 \\
240 \\
76 \\
30\end{array}$ & $\begin{array}{r}7 \\
652 \\
1700 \\
318 \\
133\end{array}$ & $\begin{array}{r}10600 \\
11200 \\
10000 \\
8400 \\
4600\end{array}$ & $\begin{array}{r}396 \\
196 \\
92 \\
63 \\
47\end{array}$ & $\begin{array}{r}11300 \\
5930 \\
2480 \\
1430 \\
584\end{array}$ & $\begin{array}{l}157 \\
139 \\
127 \\
125 \\
122\end{array}$ & $\begin{array}{l}11 \\
10 \\
10 \\
10 \\
10\end{array}$ & $\begin{array}{l}5 \\
4 \\
3 \\
3 \\
3\end{array}$ \\
\hline $\begin{array}{l}21 \ldots \\
22 \ldots \\
23 \ldots \\
24 \cdots \\
25 \cdots\end{array}$ & $\begin{array}{l}1160 \\
3260 \\
5020 \\
3760 \\
2530\end{array}$ & $\begin{array}{r}30 \\
164 \\
239 \\
139 \\
94\end{array}$ & $\begin{array}{r}94 \\
1700 \\
3160 \\
1950 \\
642\end{array}$ & $\begin{array}{r}2120 \\
1430 \\
1200 \\
950 \\
765\end{array}$ & $\begin{array}{l}81 \\
72 \\
57 \\
40 \\
27\end{array}$ & $\begin{array}{r}464 \\
278 \\
185 \\
109 \\
56\end{array}$ & $\begin{array}{r}115 \\
111 \\
108 \\
102 \\
99\end{array}$ & $\begin{array}{l}10 \\
10 \\
10 \\
10 \\
10\end{array}$ & $\begin{array}{l}3 \\
3 \\
3 \\
3 \\
3\end{array}$ \\
\hline $\begin{array}{l}26 \ldots \\
27 \ldots \\
28 \ldots \\
29 \cdots \\
30 \ldots \\
31 \ldots\end{array}$ & $\begin{array}{l}1580 \\
1320 \\
1320 \\
1170 \\
1010 \\
\end{array}$ & $\begin{array}{l}44 \\
23 \\
19 \\
18 \\
16 \\
\end{array}$ & $\begin{array}{r}188 \\
94 \\
68 \\
57 \\
44 \\
\end{array}$ & $\begin{array}{l}618 \\
526 \\
442 \\
383 \\
365 \\
353 \\
\end{array}$ & $\begin{array}{l}22 \\
18 \\
13 \\
12 \\
10 \\
10 \\
\end{array}$ & $\begin{array}{l}37 \\
26 \\
16 \\
12 \\
10 \\
10 \\
\end{array}$ & $\begin{array}{l}104 \\
108 \\
137 \\
134 \\
120 \\
-\end{array}$ & $\begin{array}{r}10 \\
10 \\
10 \\
10 \\
-8 \\
-\end{array}$ & $\begin{array}{r}3 \\
3 \\
4 \\
3 \\
-\end{array}$ \\
\hline \multirow[t]{2}{*}{ Total } & 39712 & - & 10605 & 103462 & - & 63378 & 8324 & - & 463 \\
\hline & \multicolumn{3}{|c|}{ JULY } & \multicolumn{3}{|c|}{ AUEUST } & \multicolumn{3}{|c|}{ SEP-FABER } \\
\hline $\begin{array}{l}100 \\
200 \\
300 \\
50 \\
50\end{array}$ & $\begin{array}{l}319 \\
239 \\
178 \\
178 \\
195\end{array}$ & $\begin{array}{l}17 \\
16 \\
16 \\
22 \\
31\end{array}$ & $\begin{array}{r}15 \\
10 \\
11 \\
16\end{array}$ & $\begin{array}{l}204 \\
198 \\
189 \\
179 \\
240\end{array}$ & $\begin{array}{l}26 \\
23 \\
22 \\
20 \\
30\end{array}$ & $\begin{array}{l}14 \\
12 \\
11 \\
10 \\
22\end{array}$ & $\begin{array}{l}40 \\
30 \\
36 \\
35 \\
35\end{array}$ & $\begin{array}{r}10 \\
10 \\
9 \\
8 \\
8\end{array}$ & $\begin{array}{l}2 \\
1 \\
1 \\
3 \\
1\end{array}$ \\
\hline $\begin{array}{l}6 \ldots \\
7 \ldots \\
60 \\
90 \\
90\end{array}$ & $\begin{array}{l}188 \\
146 \\
448 \\
314 \\
364\end{array}$ & $\begin{array}{l}37 \\
33 \\
46 \\
59 \\
51\end{array}$ & $\begin{array}{l}19 \\
13 \\
63 \\
82 \\
30\end{array}$ & $\begin{array}{r}187 \\
113 \\
88 \\
70 \\
61\end{array}$ & $\begin{array}{l}18 \\
18 \\
19 \\
22 \\
18\end{array}$ & $\begin{array}{l}9 \\
5 \\
5 \\
4 \\
3\end{array}$ & $\begin{array}{l}34 \\
33 \\
32 \\
31 \\
31\end{array}$ & $:$ & $\begin{array}{l}1 \\
2 \\
2 \\
2 \\
1\end{array}$ \\
\hline $\begin{array}{l}11 \ldots \\
12 \ldots \\
13 \ldots \\
14 \ldots \\
15 \ldots\end{array}$ & $\begin{array}{l}385 \\
898 \\
977 \\
445 \\
301\end{array}$ & $\begin{array}{r}43 \\
78 \\
260 \\
114 \\
61\end{array}$ & $\begin{array}{r}45 \\
176 \\
422 \\
137 \\
50\end{array}$ & $\begin{array}{l}55 \\
51 \\
47 \\
44 \\
42\end{array}$ & $\begin{array}{l}18 \\
18 \\
16 \\
14 \\
12\end{array}$ & $\begin{array}{l}3 \\
2 \\
2 \\
2 \\
1\end{array}$ & $\begin{array}{l}32 \\
46 \\
38 \\
33 \\
31\end{array}$ & $\begin{array}{l}8 \\
8 \\
8 \\
8\end{array}$ & $\begin{array}{l}1 \\
1 \\
1 \\
1 \\
1\end{array}$ \\
\hline $\begin{array}{l}16 \ldots \\
17 \ldots \\
18 \ldots \\
19 \ldots \\
20 \ldots\end{array}$ & $\begin{array}{l}233 \\
188 \\
153 \\
127 \\
108\end{array}$ & $\begin{array}{l}30 \\
28 \\
22 \\
19 \\
17\end{array}$ & $\begin{array}{r}24 \\
14 \\
9 \\
7 \\
5\end{array}$ & $\begin{array}{l}40 \\
39 \\
39 \\
37 \\
37\end{array}$ & $\begin{array}{l}12 \\
10 \\
10 \\
10 \\
11\end{array}$ & $\begin{array}{l}1 \\
1 \\
1 \\
1 \\
1\end{array}$ & $\begin{array}{l}30 \\
29 \\
29 \\
29 \\
29\end{array}$ & $\begin{array}{l}8 \\
8 \\
8 \\
8\end{array}$ & $\begin{array}{l}2 \\
1 \\
2 \\
1 \\
2\end{array}$ \\
\hline $\begin{array}{l}22 \ldots \\
22 \ldots \\
23 \ldots \\
24 \ldots \\
25 \ldots\end{array}$ & $\begin{array}{l}93 \\
84 \\
78 \\
67 \\
74\end{array}$ & $\begin{array}{l}14 \\
31 \\
70 \\
18 \\
12\end{array}$ & $\begin{array}{r}4 \\
7 \\
15 \\
3 \\
2\end{array}$ & $\begin{array}{l}36 \\
35 \\
35 \\
34 \\
39\end{array}$ & $\begin{array}{r}12 \\
10 \\
8 \\
7 \\
10\end{array}$ & $\begin{array}{l}1 \\
1 \\
1 \\
1 \\
1\end{array}$ & $\begin{array}{l}29 \\
29 \\
28 \\
28 \\
28\end{array}$ & $\begin{array}{l}8 \\
8 \\
8 \\
7\end{array}$ & $\begin{array}{l}1 \\
1 \\
1 \\
1 \\
1\end{array}$ \\
\hline $\begin{array}{l}26 \ldots \\
27 \ldots \\
28 \ldots \\
29 \ldots \\
30 \ldots \\
31 \ldots\end{array}$ & $\begin{array}{l}73 \\
124 \\
134 \\
133 \\
198 \\
235 .\end{array}$ & $\begin{array}{l}10 \\
19 \\
38 \\
44 \\
90 \\
58\end{array}$ & $\begin{array}{r}2 \\
6 \\
14 \\
18 \\
48 \\
37\end{array}$ & $\begin{array}{l}38 \\
36 \\
37 \\
39 \\
38 \\
39\end{array}$ & $\begin{array}{l}8 \\
9 \\
8 \\
8 \\
8\end{array}$ & $\begin{array}{l}1 \\
1 \\
1 \\
1 \\
1 \\
1\end{array}$ & $\begin{array}{l}27 \\
27 \\
32 \\
33 \\
41 \\
-\end{array}$ & $\begin{array}{r}3 \\
6 \\
12 \\
13 \\
7 \\
-\end{array}$ & $\begin{array}{l}1 \\
1 \\
2 \\
1 \\
1 \\
-\end{array}$ \\
\hline Total & 7837 & - & 1332 & 2368 & - & 221 & 973 & - & 29 \\
\hline T & d fo & $(t o$ & & & & & & $\cdots$ & $\begin{array}{l}451989 \\
173220\end{array}$ \\
\hline
\end{tabular}




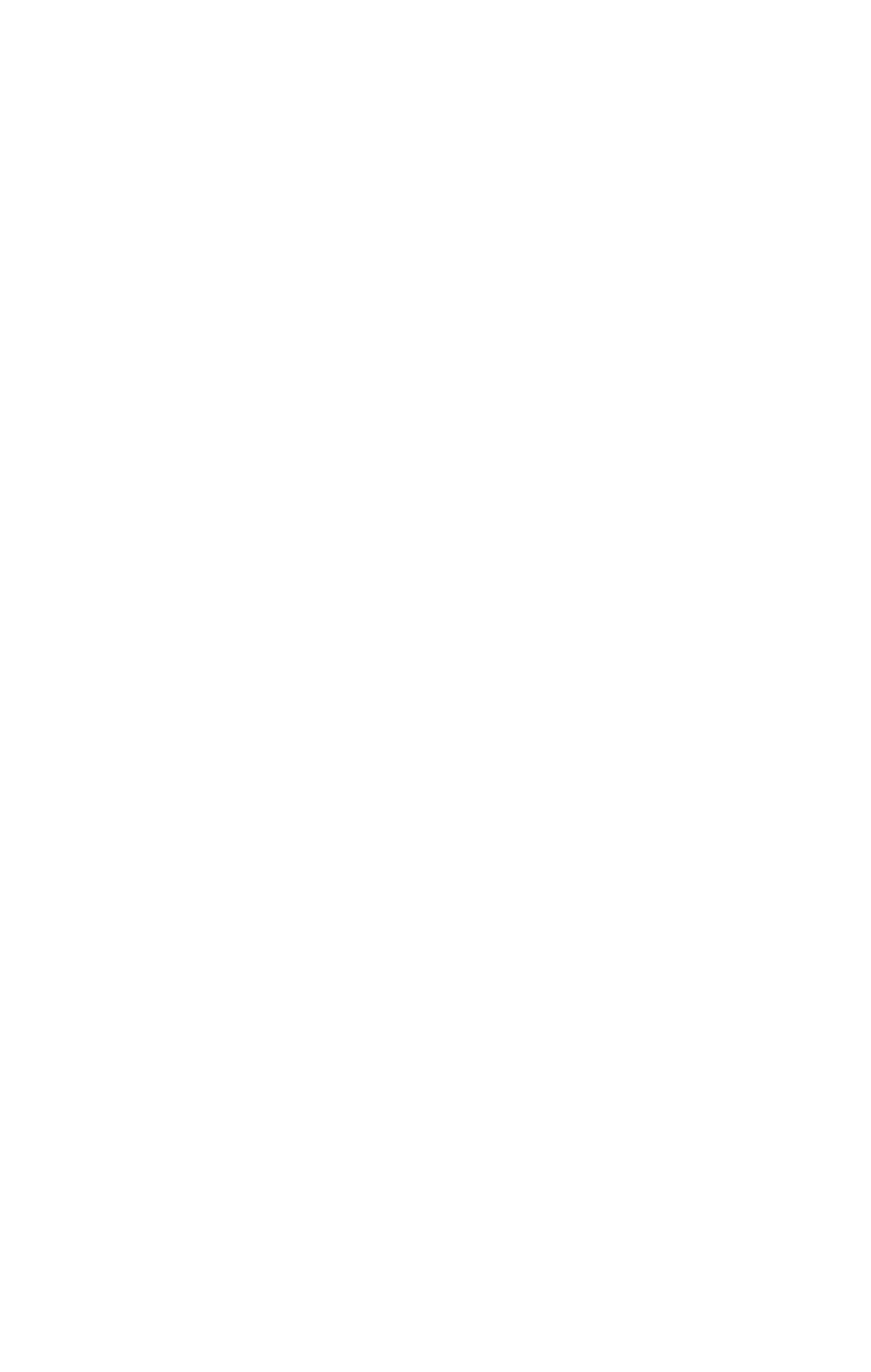



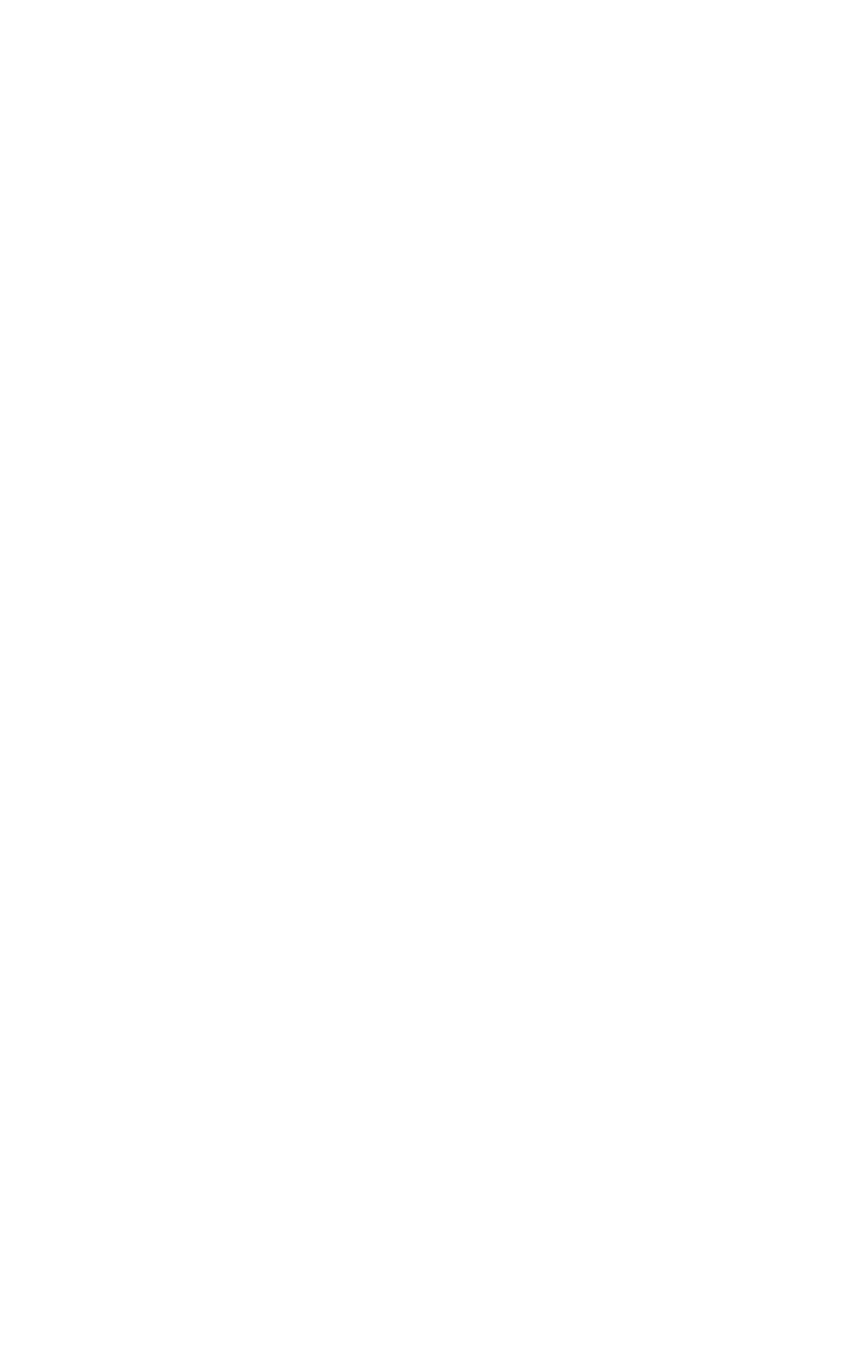


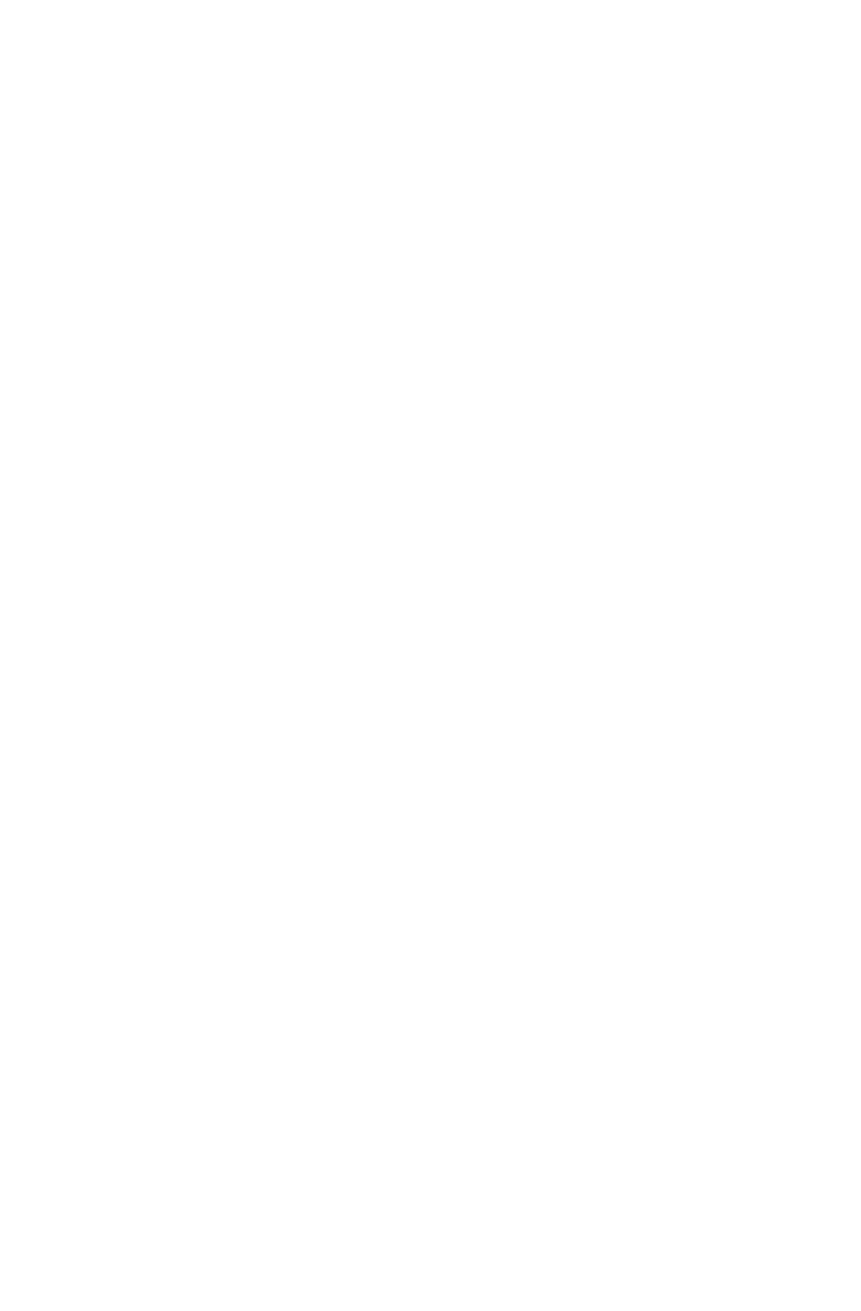


LICKING RIVER BASIN--COntinued

3-2515. LICKING RIVER AT MCKINNEYSBURG, KY.--Continued Suspended sediment, water year October 1966 to September 1967

\begin{tabular}{|c|c|c|c|c|c|c|c|c|c|}
\hline \multirow[b]{3}{*}{ Day } & \multicolumn{3}{|c|}{ OCTOBER } & \multicolumn{3}{|c|}{ NOVEMBER } & \multicolumn{3}{|c|}{ DECEMBER } \\
\hline & \multirow[b]{2}{*}{$\begin{array}{l}\text { Mean } \\
\text { dis- } \\
\text { charge } \\
\text { (cfs) }\end{array}$} & \multicolumn{2}{|c|}{ Suspended vediment } & \multirow[b]{2}{*}{$\begin{array}{c}\text { Mean } \\
\text { dis- } \\
\text { charge } \\
\text { (cfs) }\end{array}$} & \multicolumn{2}{|c|}{ Suspended sediment } & \multirow[b]{2}{*}{$\begin{array}{c}\text { Mean } \\
\text { dis- } \\
\text { charge } \\
\text { (cfs) }\end{array}$} & \multicolumn{2}{|c|}{ Suspended sediment } \\
\hline & & $\begin{array}{c}\text { Mean } \\
\text { concen- } \\
\text { tration } \\
(\mathrm{ppm})\end{array}$ & $\begin{array}{l}\text { Tons } \\
\text { per } \\
\text { day }\end{array}$ & & $\begin{array}{c}\text { Mean } \\
\text { concen- } \\
\text { tration } \\
(\text { ppm) }\end{array}$ & $\begin{array}{c}\text { Tons } \\
\text { per } \\
\text { day }\end{array}$ & & $\begin{array}{c}\text { Mean } \\
\text { concen- } \\
\text { tration } \\
(\mathrm{ppm})\end{array}$ & $\begin{array}{l}\text { Tons } \\
\text { per } \\
\text { day }\end{array}$ \\
\hline $\begin{array}{l}1 \ldots \\
2 \ldots \\
3 \ldots \\
4 \cdots \\
5 \ldots\end{array}$ & $\begin{array}{l}2470 \\
2260 \\
2390 \\
2580 \\
1900\end{array}$ & $\begin{array}{l}342 \\
192 \\
149 \\
225 \\
153\end{array}$ & $\begin{array}{r}2280 \\
1170 \\
961 \\
1570 \\
785\end{array}$ & $\begin{array}{r}231 \\
384 \\
3300 \\
4500 \\
5380\end{array}$ & $\begin{array}{r}7 \\
50 \\
382 \\
254 \\
243\end{array}$ & $\begin{array}{r}4 \\
94 \\
3400 \\
3090 \\
3530\end{array}$ & $\begin{array}{l}2380 \\
2580 \\
2610 \\
2530 \\
3480\end{array}$ & $\begin{array}{l}45 \\
38 \\
33 \\
33 \\
50\end{array}$ & $\begin{array}{l}289 \\
265 \\
233 \\
225 \\
556\end{array}$ \\
\hline $\begin{array}{c}6 \ldots \\
7 \ldots \\
8 \ldots \\
9 \ldots\end{array}$ & $\begin{array}{r}1350 \\
992 \\
760 \\
638 \\
558\end{array}$ & $\begin{array}{r}100 \\
63 \\
45 \\
39 \\
29\end{array}$ & $\begin{array}{r}364 \\
169 \\
92 \\
67 \\
44\end{array}$ & $\begin{array}{l}6760 \\
5710 \\
3940 \\
2650 \\
7770\end{array}$ & $\begin{array}{r}218 \\
150 \\
100 \\
77 \\
652\end{array}$ & $\begin{array}{r}3980 \\
2310 \\
1060 \\
551 \\
22500\end{array}$ & $\begin{array}{r}6490 \\
5920 \\
6350 \\
11600 \\
25900\end{array}$ & $\begin{array}{l}184 \\
164 \\
153 \\
379 \\
462\end{array}$ & $\begin{array}{r}3220 \\
2620 \\
2620 \\
14900 \\
32300\end{array}$ \\
\hline $\begin{array}{l}11 \ldots \\
12 \ldots \\
13 \ldots \\
14 \ldots \\
15 \ldots\end{array}$ & $\begin{array}{l}498 \\
446 \\
398 \\
382 \\
366\end{array}$ & $\begin{array}{l}22 \\
18 \\
17 \\
14 \\
13\end{array}$ & $\begin{array}{l}30 \\
22 \\
18 \\
14 \\
13\end{array}$ & $\begin{array}{l}9640 \\
6880 \\
5200 \\
3250 \\
2310\end{array}$ & $\begin{array}{r}618 \\
291 \\
187 \\
103 \\
78\end{array}$ & $\begin{array}{r}17000 \\
5410 \\
2630 \\
904 \\
486\end{array}$ & $\begin{array}{l}29000 \\
25100 \\
20100 \\
16200 \\
10700\end{array}$ & $\begin{array}{r}293 \\
195 \\
120 \\
72 \\
67\end{array}$ & $\begin{array}{r}22900 \\
13200 \\
6510 \\
3150 \\
1940\end{array}$ \\
\hline $\begin{array}{l}16 \ldots \\
17 \ldots \\
18 \ldots \\
19 \ldots \\
20 \ldots\end{array}$ & $\begin{array}{l}347 \\
340 \\
288 \\
269 \\
255\end{array}$ & $\begin{array}{r}12 \\
10 \\
8 \\
8 \\
7\end{array}$ & $\begin{array}{r}11 \\
9 \\
6 \\
6 \\
5\end{array}$ & $\begin{array}{r}1800 \\
1470 \\
1240 \\
1090 \\
956\end{array}$ & $\begin{array}{l}48 \\
36 \\
23 \\
20 \\
16\end{array}$ & $\begin{array}{r}233 \\
143 \\
77 \\
59 \\
41\end{array}$ & $\begin{array}{l}4870 \\
3020 \\
2430 \\
2050 \\
1780\end{array}$ & $\begin{array}{l}68 \\
52 \\
33 \\
27 \\
20\end{array}$ & $\begin{array}{r}894 \\
424 \\
217 \\
149 \\
96\end{array}$ \\
\hline $\begin{array}{l}21 \ldots \\
22 \ldots \\
23 \ldots \\
24 \ldots \\
25 \ldots\end{array}$ & $\begin{array}{l}262 \\
265 \\
321 \\
359 \\
347\end{array}$ & \begin{tabular}{r|}
8 \\
9 \\
12 \\
12 \\
8
\end{tabular} & $\begin{array}{r}6 \\
6 \\
10 \\
12 \\
7\end{array}$ & $\begin{array}{l}842 \\
760 \\
685 \\
626 \\
906\end{array}$ & $\begin{array}{r}12 \\
10 \\
12 \\
8 \\
70\end{array}$ & $\begin{array}{r}27 \\
21 \\
22 \\
14 \\
304\end{array}$ & $\begin{array}{l}1590 \\
1430 \\
1290 \\
1030 \\
1040\end{array}$ & \begin{tabular}{r|}
16 \\
11 \\
8 \\
7 \\
7
\end{tabular} & $\begin{array}{l}69 \\
42 \\
28 \\
19 \\
20\end{array}$ \\
\hline $\begin{array}{l}26 \ldots \\
27 \ldots \\
28 \ldots \\
29 \ldots \\
30 \ldots \\
31 \ldots\end{array}$ & $\begin{array}{l}343 \\
332 \\
314 \\
288 \\
262 \\
238\end{array}$ & \begin{tabular}{r|}
8 \\
9 \\
12 \\
10 \\
9 \\
8
\end{tabular} & $\begin{array}{r}7 \\
8 \\
10 \\
8 \\
6 \\
5\end{array}$ & $\begin{array}{r}2320 \\
1410 \\
1510 \\
1940 \\
2180 \\
--\end{array}$ & $\begin{array}{r}216 \\
99 \\
57 \\
49 \\
46 \\
-\end{array}$ & $\begin{array}{r}1350 \\
377 \\
232 \\
257 \\
271 \\
-- \\
\end{array}$ & $\begin{array}{r}956 \\
878 \\
2300 \\
6190 \\
8490 \\
8360 \\
\end{array}$ & $\begin{array}{r}5 \\
8 \\
172 \\
273 \\
315 \\
202 \\
\end{array}$ & $\begin{array}{r}13 \\
19 \\
1940 \\
4560 \\
7220 \\
4560 \\
\end{array}$ \\
\hline \multirow[t]{2}{*}{ Total } & 22818 & -- & 7721 & 87640 & -- & 70377 & 218644 & -- & 125198 \\
\hline & \multicolumn{3}{|c|}{ JANUARY } & \multicolumn{3}{|c|}{ FEBRUARY } & \multicolumn{3}{|c|}{ MARCH } \\
\hline $\begin{array}{l}1 \ldots \\
2 \ldots \\
3 \ldots \\
4 \ldots \\
5 \ldots\end{array}$ & $\begin{array}{l}7180 \\
5860 \\
4310 \\
2810 \\
2210\end{array}$ & $\begin{array}{r}122 \\
176 \\
108 \\
61 \\
40\end{array}$ & $\begin{array}{r}2370 \\
2780 \\
1260 \\
463 \\
239\end{array}$ & $\begin{array}{l}3180 \\
3530 \\
5520 \\
6080 \\
5410\end{array}$ & $\begin{array}{r}98 \\
144 \\
186 \\
178 \\
148\end{array}$ & $\begin{array}{r}841 \\
1370 \\
2770 \\
2920 \\
2160\end{array}$ & $\begin{array}{l}3530 \\
4260 \\
4640 \\
4220 \\
4540\end{array}$ & $\begin{array}{r}52 \\
57 \\
76 \\
191 \\
530\end{array}$ & $\begin{array}{r}496 \\
656 \\
952 \\
2180 \\
6500\end{array}$ \\
\hline $\begin{array}{c}6 \ldots \\
7 \ldots \\
8 \ldots \\
9 \ldots \\
10 \ldots\end{array}$ & $\begin{array}{l}1870 \\
1640 \\
1490 \\
1360 \\
1240\end{array}$ & $\begin{array}{l}27 \\
21 \\
16 \\
12 \\
12\end{array}$ & $\begin{array}{r}136 \\
93 \\
64 \\
44 \\
40\end{array}$ & $\begin{array}{l}4000 \\
3050 \\
2480 \\
2100 \\
1820\end{array}$ & $\begin{array}{l}76 \\
42 \\
28 \\
18 \\
15\end{array}$ & $\begin{array}{r}821 \\
346 \\
187 \\
102 \\
74\end{array}$ & $\begin{array}{l}16500 \\
25300 \\
27500 \\
26900 \\
27600\end{array}$ & $\begin{array}{r}1470 \\
988 \\
534 \\
384 \\
240\end{array}$ & $\begin{array}{l}68800 \\
67500 \\
39600 \\
27900 \\
17900\end{array}$ \\
\hline $\begin{array}{l}11 \ldots \\
12 \ldots \\
13 \ldots \\
14 \ldots \\
15 \ldots\end{array}$ & $\begin{array}{r}1130 \\
1020 \\
920 \\
840 \\
880\end{array}$ & $\begin{array}{r}10 \\
9 \\
8 \\
8 \\
10\end{array}$ & $\begin{array}{l}31 \\
25 \\
20 \\
18 \\
24\end{array}$ & $\begin{array}{l}1720 \\
1630 \\
1660 \\
1630 \\
1600\end{array}$ & $\begin{array}{r}10 \\
7 \\
5 \\
5 \\
6\end{array}$ & $\begin{array}{l}46 \\
31 \\
22 \\
22 \\
26\end{array}$ & $\begin{array}{l}26100 \\
22200 \\
18200 \\
10900 \\
21800\end{array}$ & $\begin{array}{r}167 \\
138 \\
106 \\
88 \\
1690\end{array}$ & $\begin{array}{r}11800 \\
8270 \\
5210 \\
2590 \\
105000\end{array}$ \\
\hline $\begin{array}{l}16 \ldots \\
17 \ldots \\
18 \ldots \\
19 \ldots \\
20 \ldots\end{array}$ & $\begin{array}{r}1180 \\
1230 \\
1200 \\
1090 \\
960\end{array}$ & $\begin{array}{l}10 \\
12 \\
14 \\
12 \\
10\end{array}$ & $\begin{array}{l}32 \\
40 \\
45 \\
35 \\
26\end{array}$ & $\begin{array}{l}1610 \\
1580 \\
1530 \\
1490 \\
1810\end{array}$ & \begin{tabular}{r|}
8 \\
7 \\
5 \\
5 \\
29
\end{tabular} & $\begin{array}{r}35 \\
30 \\
21 \\
20 \\
208\end{array}$ & $\begin{array}{r}24400 \\
19800 \\
14100 \\
9530 \\
6260\end{array}$ & $\begin{array}{r}1190 \\
580 \\
254 \\
168 \\
145\end{array}$ & $\begin{array}{r}78400 \\
31000 \\
9670 \\
4320 \\
2450\end{array}$ \\
\hline $\begin{array}{l}21 \ldots \\
22 \ldots \\
23 \ldots \\
24 \ldots \\
25 \ldots\end{array}$ & $\begin{array}{r}930 \\
920 \\
930 \\
970 \\
1010\end{array}$ & $\begin{array}{l}8 \\
4 \\
5 \\
8 \\
9\end{array}$ & $\begin{array}{l}20 \\
10 \\
13 \\
21 \\
25\end{array}$ & $\begin{array}{l}4050 \\
4980 \\
4500 \\
3640 \\
3310\end{array}$ & $\begin{array}{r}121 \\
123 \\
81 \\
30 \\
18\end{array}$ & $\begin{array}{r}1320 \\
1650 \\
984 \\
295 \\
161\end{array}$ & $\begin{array}{l}5500 \\
4560 \\
4430 \\
3750 \\
3170\end{array}$ & $\begin{array}{r}230 \\
112 \\
77 \\
72 \\
61\end{array}$ & $\begin{array}{r}3420 \\
1380 \\
921 \\
729 \\
522\end{array}$ \\
\hline $\begin{array}{l}26 \ldots \\
27 \ldots \\
28 \ldots \\
29 \ldots \\
30 \ldots \\
31 \ldots\end{array}$ & $\begin{array}{l}1030 \\
1290 \\
2820 \\
3790 \\
3600 \\
3670\end{array}$ & $\begin{array}{r}8 \\
29 \\
136 \\
177 \\
114 \\
70\end{array}$ & $\begin{array}{r}22 \\
131 \\
1040 \\
1810 \\
1110 \\
694\end{array}$ & $\begin{array}{r}3090 \\
3070 \\
3290 \\
-- \\
=- \\
--\end{array}$ & $\begin{array}{l}18 \\
18 \\
22 \\
-- \\
-- \\
--\end{array}$ & $\begin{array}{r}150 \\
149 \\
195 \\
-- \\
-- \\
--\end{array}$ & $\begin{array}{l}2770 \\
2450 \\
2650 \\
4980 \\
6620 \\
4770\end{array}$ & $\begin{array}{r}57 \\
50 \\
52 \\
186 \\
315 \\
180\end{array}$ & $\begin{array}{r}426 \\
331 \\
372 \\
2500 \\
5630 \\
2320\end{array}$ \\
\hline Total & 61380 & -- & 12681 & 83360 & -- & 16956 & 363930 & -- & 509745 \\
\hline
\end{tabular}


LICKING RIVER BASIN--Contınued

3-2515. LICKING RIVER AT MCKINNEYSBURG, KY.--Continued

Suspended sediment, water year October 1966 to September 1967--Continued

\begin{tabular}{|c|c|c|c|c|c|c|c|c|c|}
\hline \multirow[b]{3}{*}{ Day } & \multicolumn{3}{|c|}{ APRIL } & \multicolumn{3}{|c|}{ MAY } & \multicolumn{3}{|c|}{ JUNE } \\
\hline & \multirow[b]{2}{*}{$\begin{array}{c}\text { Mean } \\
\text { die- } \\
\text { charge } \\
\text { (cfo) }\end{array}$} & \multicolumn{2}{|c|}{ Suspended sediment } & \multirow[b]{2}{*}{$\begin{array}{l}\text { Mean } \\
\text { dis- } \\
\text { charge } \\
\text { (cfe) }\end{array}$} & \multicolumn{2}{|c|}{ Suspended sediment } & \multirow[b]{2}{*}{$\begin{array}{l}\text { Mean } \\
\text { die- } \\
\text { charge } \\
\text { (cfs) }\end{array}$} & \multicolumn{2}{|c|}{ Suspended sediment } \\
\hline & & $\begin{array}{c}\text { Mean } \\
\text { concen- } \\
\text { tration } \\
(\mathrm{ppm})\end{array}$ & $\begin{array}{l}\text { Tons } \\
\text { per } \\
\text { day }\end{array}$ & & $\begin{array}{c}\text { Mean } \\
\text { concen- } \\
\text { tration } \\
(\mathrm{ppm})\end{array}$ & $\begin{array}{l}\text { Tons } \\
\text { per } \\
\text { day }\end{array}$ & & $\begin{array}{c}\text { Mean } \\
\text { concen- } \\
\text { tration } \\
\text { (ppm) }\end{array}$ & $\begin{array}{l}\text { Tons } \\
\text { per } \\
\text { day }\end{array}$ \\
\hline $\begin{array}{l}1 \ldots \\
2 \ldots \\
3 \ldots \\
4 \ldots \\
5 \ldots\end{array}$ & $\begin{array}{l}3210 \\
2660 \\
2320 \\
2080 \\
1900\end{array}$ & $\begin{array}{l}98 \\
68 \\
53 \\
43 \\
36\end{array}$ & $\begin{array}{l}849 \\
468 \\
332 \\
241 \\
185\end{array}$ & $\begin{array}{l}2500 \\
5330 \\
5490 \\
5030 \\
3860\end{array}$ & $\begin{array}{r}62 \\
208 \\
188 \\
127 \\
92\end{array}$ & $\begin{array}{r}418 \\
3440 \\
2790 \\
1720 \\
959\end{array}$ & $\begin{array}{r}860 \\
836 \\
956 \\
1630 \\
2090\end{array}$ & $\begin{array}{l}13 \\
16 \\
20 \\
47 \\
65\end{array}$ & $\begin{array}{r}30 \\
36 \\
52 \\
207 \\
367\end{array}$ \\
\hline $\begin{array}{r}6 \ldots \\
7 \ldots \\
8 \ldots \\
10 \ldots\end{array}$ & $\begin{array}{l}1730 \\
1580 \\
1430 \\
1300 \\
2040\end{array}$ & $\begin{array}{r}28 \\
23 \\
23 \\
21 \\
104\end{array}$ & $\begin{array}{r}131 \\
98 \\
89 \\
74 \\
761\end{array}$ & $\begin{array}{r}3170 \\
16200 \\
18200 \\
18000 \\
15700\end{array}$ & $\begin{array}{r}84 \\
737 \\
700 \\
475 \\
232\end{array}$ & $\begin{array}{r}775 \\
32200 \\
34400 \\
23100 \\
9830\end{array}$ & $\begin{array}{r}1960 \\
1490 \\
1160 \\
950 \\
790\end{array}$ & $\begin{array}{l}76 \\
58 \\
32 \\
25 \\
17\end{array}$ & $\begin{array}{r}402 \\
233 \\
100 \\
64 \\
36\end{array}$ \\
\hline $\begin{array}{l}11 \ldots \\
12 \ldots \\
13 \ldots \\
14 \ldots \\
15 \ldots\end{array}$ & $\begin{array}{l}2970 \\
4190 \\
2840 \\
2160 \\
1980\end{array}$ & $\begin{array}{r}216 \\
264 \\
186 \\
94 \\
72\end{array}$ & $\begin{array}{r}1730 \\
2990 \\
1430 \\
548 \\
385\end{array}$ & $\begin{array}{r}11800 \\
6270 \\
3740 \\
7520 \\
13400\end{array}$ & $\begin{array}{l}124 \\
108 \\
107 \\
526 \\
596\end{array}$ & $\begin{array}{r}3950 \\
1830 \\
1080 \\
14100 \\
21600\end{array}$ & $\begin{array}{l}670 \\
582 \\
502 \\
438 \\
390\end{array}$ & $\begin{array}{l}18 \\
16 \\
12 \\
15 \\
15\end{array}$ & $\begin{array}{l}33 \\
25 \\
16 \\
18 \\
16\end{array}$ \\
\hline $\begin{array}{l}16 \ldots: \\
17 \ldots \\
18 \ldots \\
19 \ldots \\
20.0\end{array}$ & $\begin{array}{l}1760 \\
5380 \\
7200 \\
8090 \\
5520\end{array}$ & $\begin{array}{r}54 \\
730 \\
1010 \\
800 \\
284\end{array}$ & $\begin{array}{r}257 \\
19100 \\
19600 \\
17500 \\
4230\end{array}$ & $\begin{array}{l}16100 \\
16100 \\
15000 \\
14100 \\
13200\end{array}$ & $\begin{array}{l}460 \\
297 \\
258 \\
175 \\
113\end{array}$ & $\begin{array}{r}20000 \\
12900 \\
10400 \\
6660 \\
4030\end{array}$ & $\begin{array}{l}336 \\
295 \\
262 \\
504 \\
622\end{array}$ & $\begin{array}{l}14 \\
15 \\
12 \\
41 \\
27\end{array}$ & $\begin{array}{r}13 \\
12 \\
8 \\
66 \\
45\end{array}$ \\
\hline $\begin{array}{l}21 \ldots \\
22 \ldots \\
23 \ldots \\
24 \ldots \\
25 \ldots\end{array}$ & $\begin{array}{l}2560 \\
6910 \\
6420 \\
9020 \\
7460\end{array}$ & $\begin{array}{l}170 \\
365 \\
350 \\
243 \\
208\end{array}$ & $\begin{array}{l}1180 \\
6810 \\
7960 \\
5920 \\
4190\end{array}$ & $\begin{array}{r}11500 \\
6780 \\
3400 \\
2490 \\
2030\end{array}$ & $\begin{array}{l}83 \\
69 \\
73 \\
63 \\
52\end{array}$ & $\begin{array}{r}2580 \\
1260 \\
670 \\
424 \\
285\end{array}$ & $\begin{array}{l}340 \\
291 \\
244 \\
221 \\
204\end{array}$ & $\begin{array}{l}30 \\
35 \\
37 \\
32 \\
34\end{array}$ & $\begin{array}{l}28 \\
27 \\
24 \\
19 \\
19\end{array}$ \\
\hline $\begin{array}{l}26 \ldots \\
27 \ldots \\
28 \ldots \\
29 \ldots \\
30 \ldots \\
31 \ldots\end{array}$ & $\begin{array}{r}6230 \\
4760 \\
3760 \\
3040 \\
2660 \\
-\end{array}$ & $\begin{array}{r}170 \\
102 \\
88 \\
74 \\
110 \\
--\end{array}$ & $\begin{array}{r}2860 \\
1310 \\
893 \\
607 \\
790 \\
-\end{array}$ & $\begin{array}{r}1720 \\
1480 \\
1280 \\
1120 \\
998 \\
902\end{array}$ & $\begin{array}{l}55 \\
43 \\
33 \\
23 \\
16 \\
13\end{array}$ & $\begin{array}{r}255 \\
172 \\
114 \\
70 \\
43 \\
32\end{array}$ & $\begin{array}{r}184 \\
162 \\
150 \\
181 \\
218 \\
-\end{array}$ & $\begin{array}{l}39 \\
30 \\
35 \\
36 \\
28 \\
--\end{array}$ & $\begin{array}{l}19 \\
13 \\
14 \\
18 \\
16 \\
--\end{array}$ \\
\hline \multirow[t]{2}{*}{ Total } & 117160 & -- & 103538 & 244410 & -- & 212087 & 19518 & -- & 1976 \\
\hline & \multicolumn{3}{|c|}{ JULY } & \multicolumn{3}{|c|}{ AUGUST } & \multicolumn{3}{|c|}{ SEPTEMBER } \\
\hline $\begin{array}{l}1 \ldots \\
2 \ldots \\
3 \ldots \\
4 \ldots \\
5 \ldots\end{array}$ & $\begin{array}{l}227 \\
416 \\
546 \\
486 \\
366\end{array}$ & $\begin{array}{l}33 \\
60 \\
58 \\
36 \\
32\end{array}$ & $\begin{array}{l}20 \\
67 \\
86 \\
47 \\
32\end{array}$ & $\begin{array}{r}1090 \\
1360 \\
1060 \\
685 \\
490\end{array}$ & $\begin{array}{r}126 \\
143 \\
146 \\
96 \\
122\end{array}$ & $\begin{array}{l}371 \\
525 \\
418 \\
178 \\
161\end{array}$ & $\begin{array}{l}65 \\
61 \\
57 \\
56 \\
55\end{array}$ & $\begin{array}{l}50 \\
46 \\
39 \\
36 \\
37\end{array}$ & $\begin{array}{l}9 \\
8 \\
6 \\
6 \\
5\end{array}$ \\
\hline $\begin{array}{r}6 \ldots \\
7 \ldots \\
8 \ldots \\
90 \\
10\end{array}$ & $\begin{array}{l}291 \\
325 \\
306 \\
280 \\
346\end{array}$ & $\begin{array}{l}30 \\
34 \\
33 \\
36 \\
56\end{array}$ & $\begin{array}{l}24 \\
30 \\
27 \\
27 \\
65\end{array}$ & $\begin{array}{l}402 \\
317 \\
321 \\
284 \\
195\end{array}$ & $\begin{array}{l}78 \\
66 \\
59 \\
52 \\
46\end{array}$ & $\begin{array}{l}85 \\
56 \\
51 \\
40 \\
24\end{array}$ & $\begin{array}{l}55 \\
55 \\
53 \\
53 \\
51\end{array}$ & $\begin{array}{l}39 \\
40 \\
39 \\
33 \\
30\end{array}$ & $\begin{array}{l}6 \\
6 \\
6 \\
5 \\
4\end{array}$ \\
\hline $\begin{array}{l}11 \ldots \\
12 \ldots \\
13 \ldots \\
14 \ldots \\
15 \ldots\end{array}$ & $\begin{array}{r}760 \\
582 \\
494 \\
860 \\
1050\end{array}$ & $\begin{array}{l}91 \\
52 \\
40 \\
73 \\
88\end{array}$ & $\begin{array}{r}187 \\
82 \\
53 \\
170 \\
249\end{array}$ & $\begin{array}{r}147 \\
121 \\
102 \\
90 \\
81\end{array}$ & $\begin{array}{l}40 \\
35 \\
30 \\
29 \\
28\end{array}$ & $\begin{array}{r}16 \\
11 \\
8 \\
7 \\
6\end{array}$ & $\begin{array}{l}50 \\
48 \\
47 \\
53 \\
54\end{array}$ & $\begin{array}{l}33 \\
35 \\
30 \\
33 \\
32\end{array}$ & $\begin{array}{l}4 \\
5 \\
4 \\
5 \\
5\end{array}$ \\
\hline $\begin{array}{l}16 \ldots \\
17 \ldots \\
18 \ldots \\
19 \ldots \\
20 \ldots\end{array}$ & $\begin{array}{l}700 \\
502 \\
390 \\
299 \\
241\end{array}$ & $\begin{array}{l}66 \\
51 \\
42 \\
43 \\
38\end{array}$ & $\begin{array}{r}125 \\
69 \\
44 \\
35 \\
25\end{array}$ & $\begin{array}{l}74 \\
71 \\
68 \\
65 \\
69\end{array}$ & $\begin{array}{l}30 \\
29 \\
30 \\
32 \\
32\end{array}$ & $\begin{array}{l}6 \\
6 \\
6 \\
6 \\
6\end{array}$ & $\begin{array}{l}47 \\
46 \\
46 \\
51 \\
54\end{array}$ & $\begin{array}{l}42 \\
36 \\
34 \\
35 \\
35\end{array}$ & $\begin{array}{l}5 \\
4 \\
4 \\
5 \\
5\end{array}$ \\
\hline $\begin{array}{l}21 \ldots \\
22 \ldots \\
23 \ldots \\
24 \ldots \\
25 \ldots\end{array}$ & $\begin{array}{l}210 \\
187 \\
152 \\
132 \\
189\end{array}$ & $\begin{array}{l}33 \\
30 \\
27 \\
26 \\
33\end{array}$ & $\begin{array}{r}19 \\
15 \\
11 \\
9 \\
17\end{array}$ & $\begin{array}{l}65 \\
61 \\
61 \\
58 \\
57\end{array}$ & $\begin{array}{l}32 \\
32 \\
30 \\
32 \\
33\end{array}$ & $\begin{array}{l}6 \\
5 \\
5 \\
5 \\
5\end{array}$ & $\begin{array}{l}50 \\
47 \\
43 \\
41 \\
38\end{array}$ & $\begin{array}{l}34 \\
32 \\
29 \\
31 \\
28\end{array}$ & $\begin{array}{l}5 \\
4 \\
3 \\
3 \\
3\end{array}$ \\
\hline $\begin{array}{l}26 \ldots \\
27 \ldots \\
28 \ldots \\
29 \ldots \\
30 \ldots \\
31 \ldots\end{array}$ & $\begin{array}{l}212 \\
152 \\
132 \\
144 \\
152 \\
511\end{array}$ & $\begin{array}{r}32 \\
30 \\
30 \\
26 \\
22 \\
100\end{array}$ & $\begin{array}{r}18 \\
12 \\
11 \\
10 \\
9 \\
148\end{array}$ & $\begin{array}{r}467 \\
737 \\
256 \\
108 \\
74 \\
69\end{array}$ & $\begin{array}{r}48 \\
119 \\
77 \\
53 \\
53 \\
53\end{array}$ & $\begin{array}{r}69 \\
237 \\
53 \\
15 \\
11 \\
10\end{array}$ & $\begin{array}{r}38 \\
36 \\
1550 \\
1280 \\
469 \\
--0\end{array}$ & $\begin{array}{r}23 \\
28 \\
413 \\
207 \\
84 \\
--\end{array}$ & $\begin{array}{r}2 \\
3 \\
1910 \\
715 \\
106 \\
--\end{array}$ \\
\hline Total & 11640 & -- & 1743 & 9105 & -- & 2408 & 4649 & -- & 2861 \\
\hline
\end{tabular}

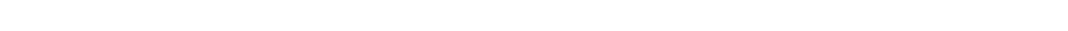




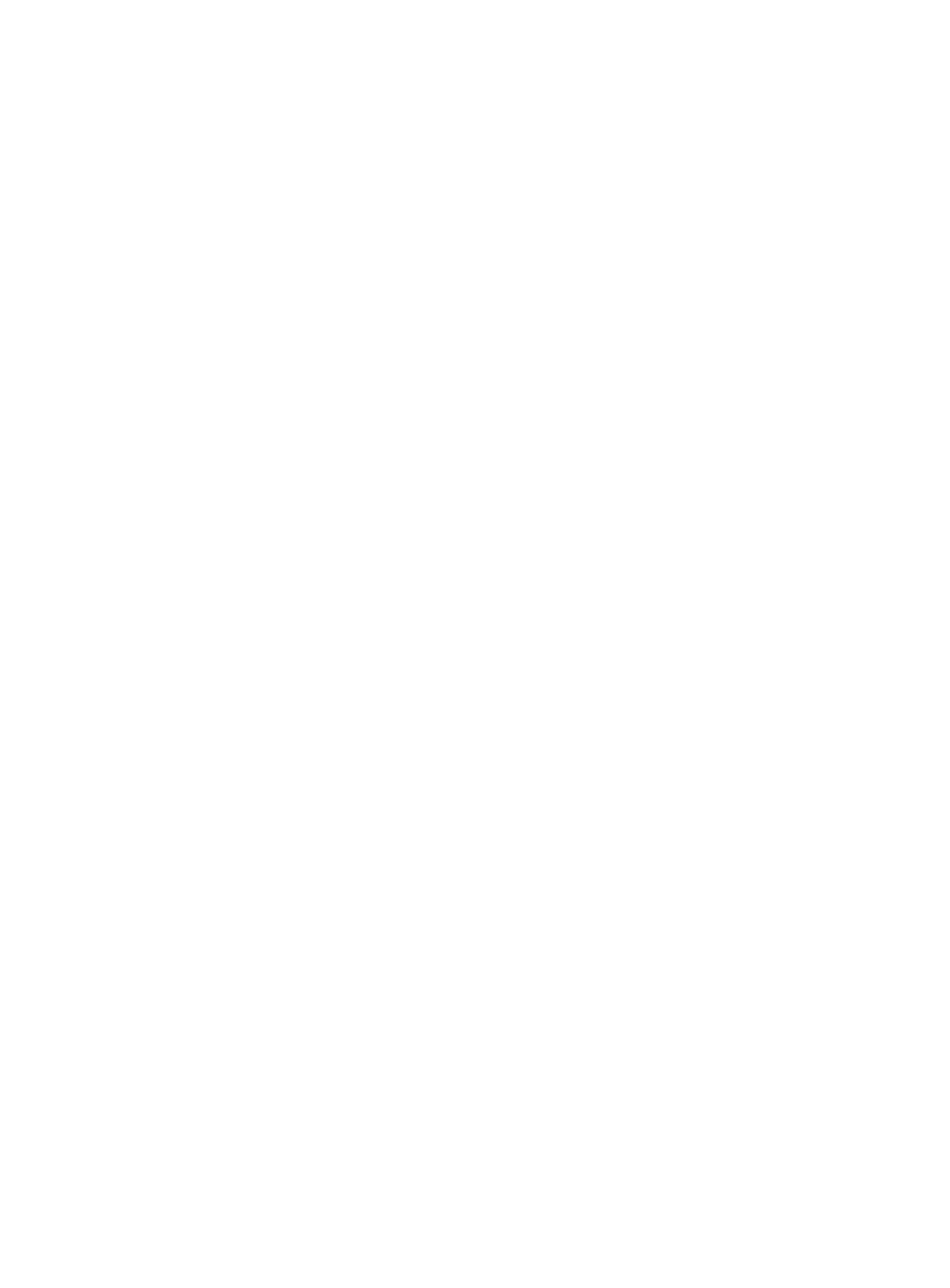




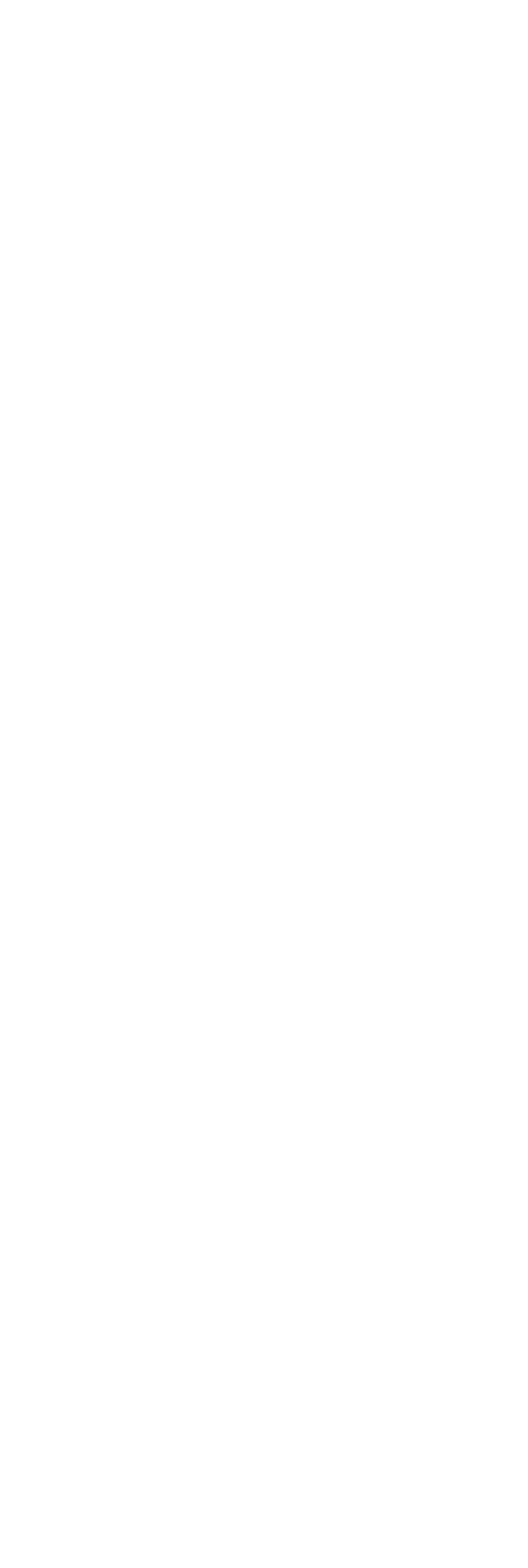

\begin{tabular}{|c|c|c|}
\hline \multicolumn{2}{|c|}{ 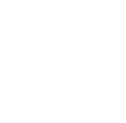 } & 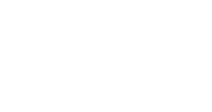 \\
\hline & 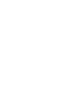 & 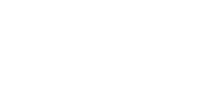 \\
\hline & 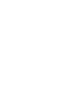 & \\
\hline & 章行 & بَ \\
\hline & 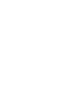 & $\dddot{0}$ \\
\hline$y$ & 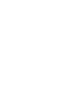 & 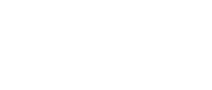 \\
\hline . & 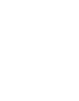 & 1111: \\
\hline $\begin{array}{l}0 \\
\text { g. } \\
0 \\
0 \\
0\end{array}$ & 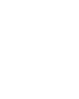 & 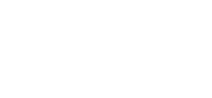 \\
\hline 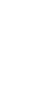 & 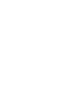 & 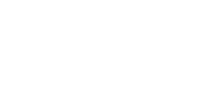 \\
\hline & 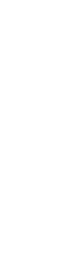 & 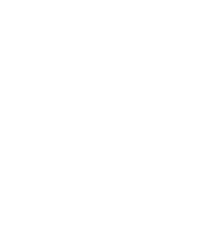 \\
\hline
\end{tabular}




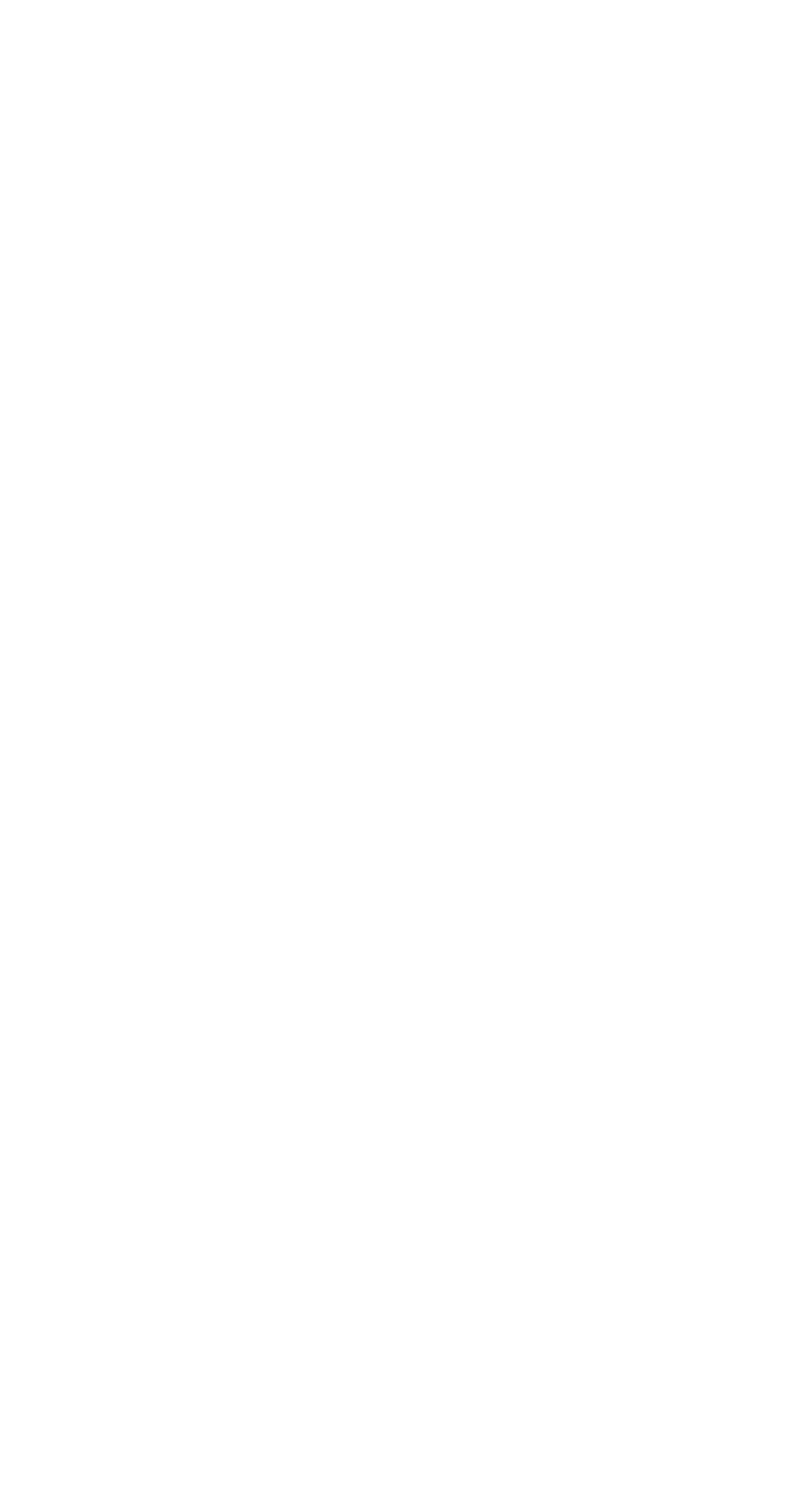




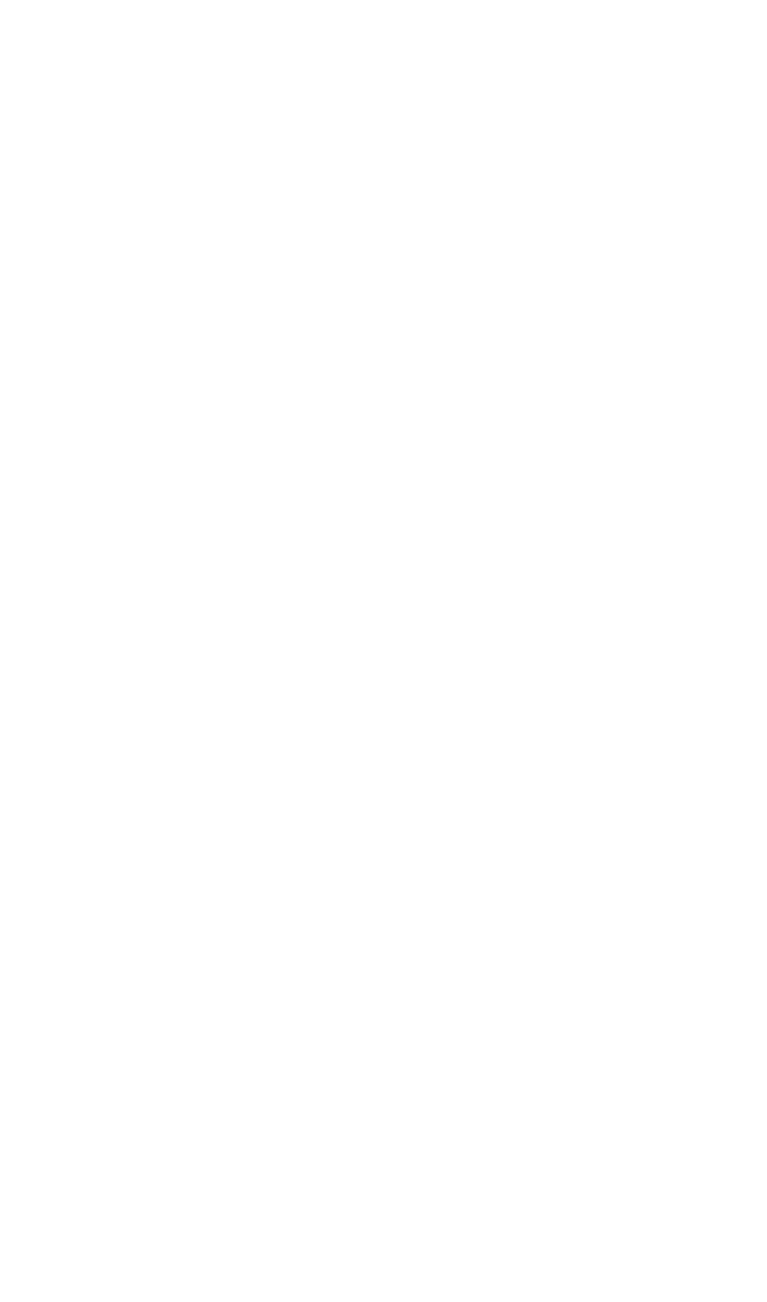


GREAT MIAMI RIVER BASIN--Continued

3-2650. STILLWATER RIVER AT PLEASANT HILL, OHIO

LOCATION.--Lat $40^{\circ} \mathrm{O} 3^{\prime} 28^{\prime \prime}$, long $84^{\circ} 21^{\prime} 22^{\prime \prime}$, at gaging station at highway bridge, 0.8 mile northwest of Pleasant Hill, Miami County, and 2 miles downstream from Painter Creek.

DRAINAGE AREA, -503 square miles.

RECORDS AVAILABLE. --Water temperatures: October 1964 to September 1966

Sediment records: October 1963 to September 1967.

EXTREMES, 1966-67.--Sediment concentrations: Maximum daily, 424 ppm Mar. 14; minimum daily, 2 ppm on several days during January.

Sediment loads: Maximum daily, 6,220 tons May 7 ; minimum daily, 0,4 ton Nov, 4

EXTREMES, 1963-67.--Sediment concentrations: Maximum daily, 1,300 ppm Apr. 9, 1965; minimum daily,

$1 \mathrm{ppm}$ on several days during January 1966.

Sediment loads: Maximum daily, 21,400 tons Apr. 21, 1964; minimum daily, 0.1 ton on many days during 1963-65.

REMARKS. --Flow affected by ice Feb. 8-12.

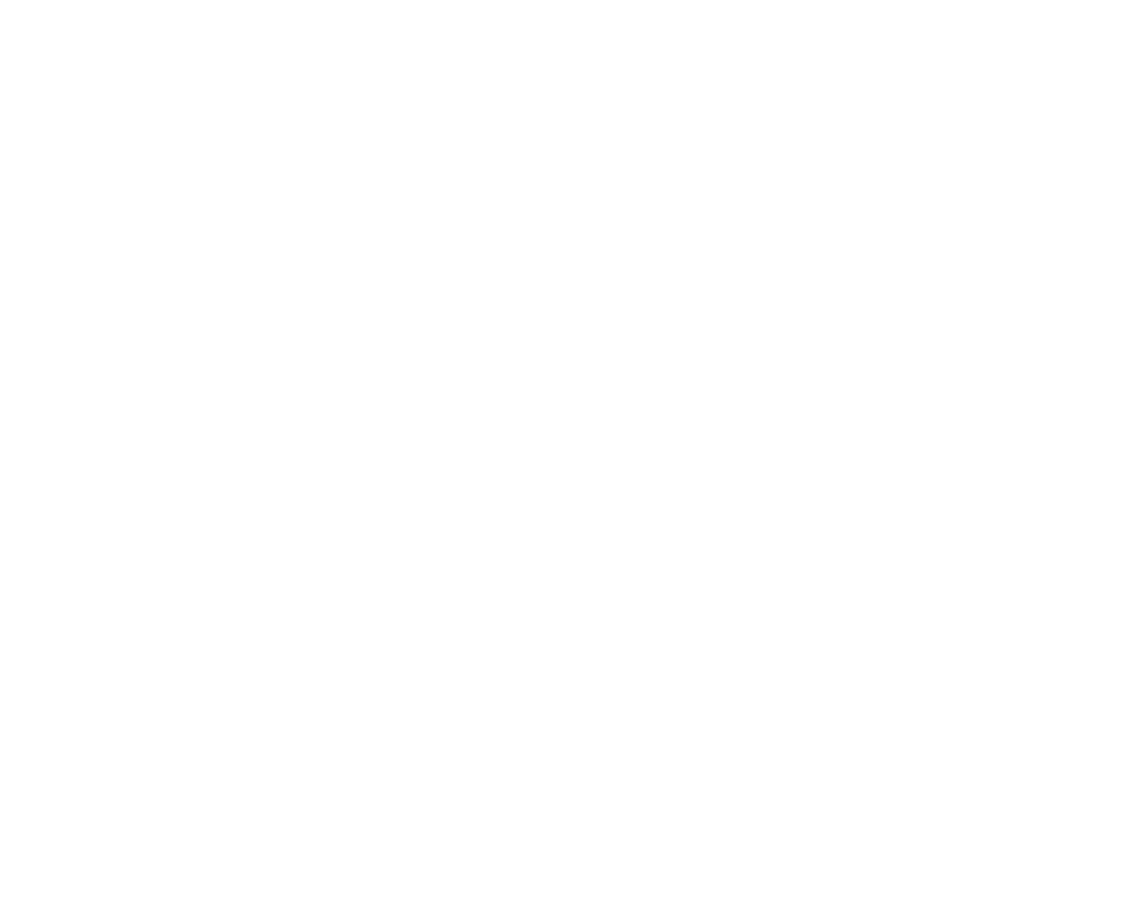

$S$ Computed by subdividing day.

B Computed from estimated-concentration graph. 
GREAT MIAMI RIVER BASIN--Continued

3-2650. STILLWATER RIVER AT PLEASANT HILL, OHIO--Continued

Suspended sediment, water year October 1966 to September 1967--Continued

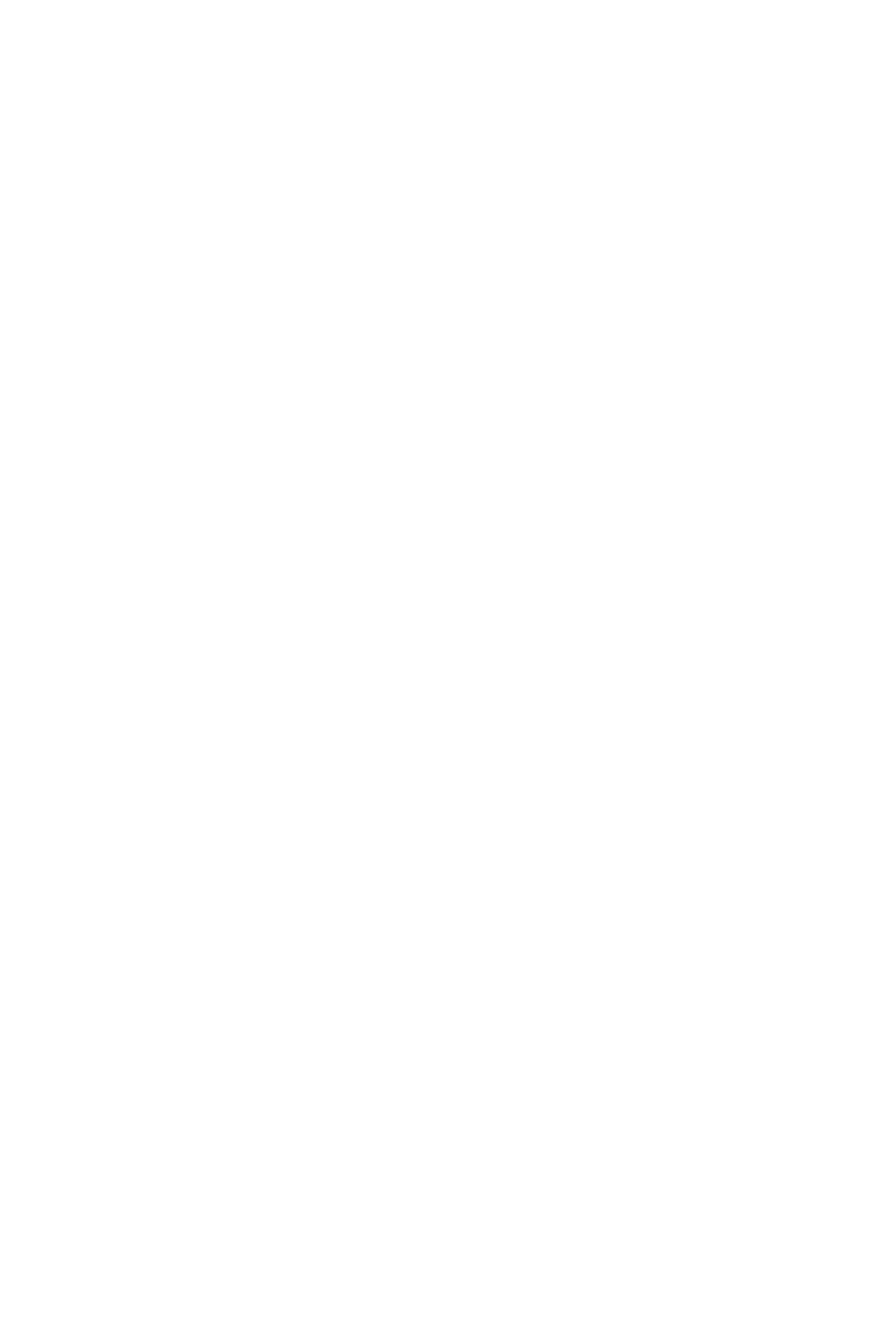

E Estimated.

$S$ Computed by subdividing day

A Computed from partly estimated-concentration graph.

B Computed from estimated-concentration graph. 
GREAT MIAMI RIVER BASIN--Continued

3-2650. STILLWATER RIVER AT PLEASANT HILL, OHIO--Continued

Suspended sediment, water year October 1966 to September 1967--Continved

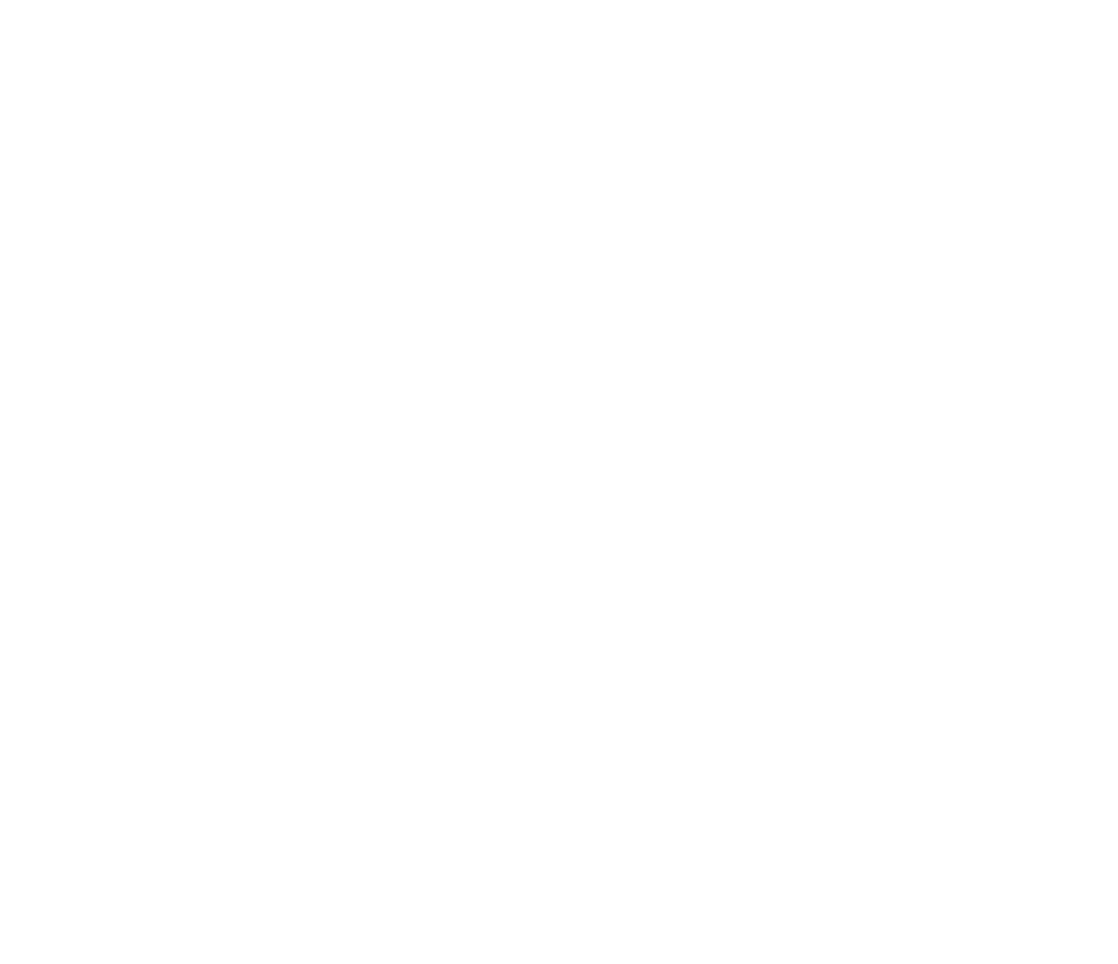

B Computed from estimated-concentration graph. 


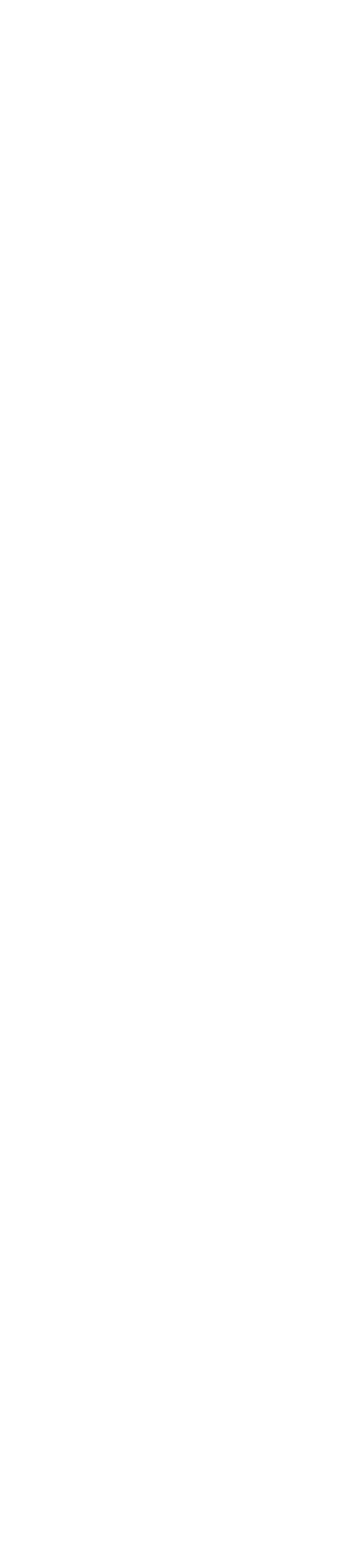




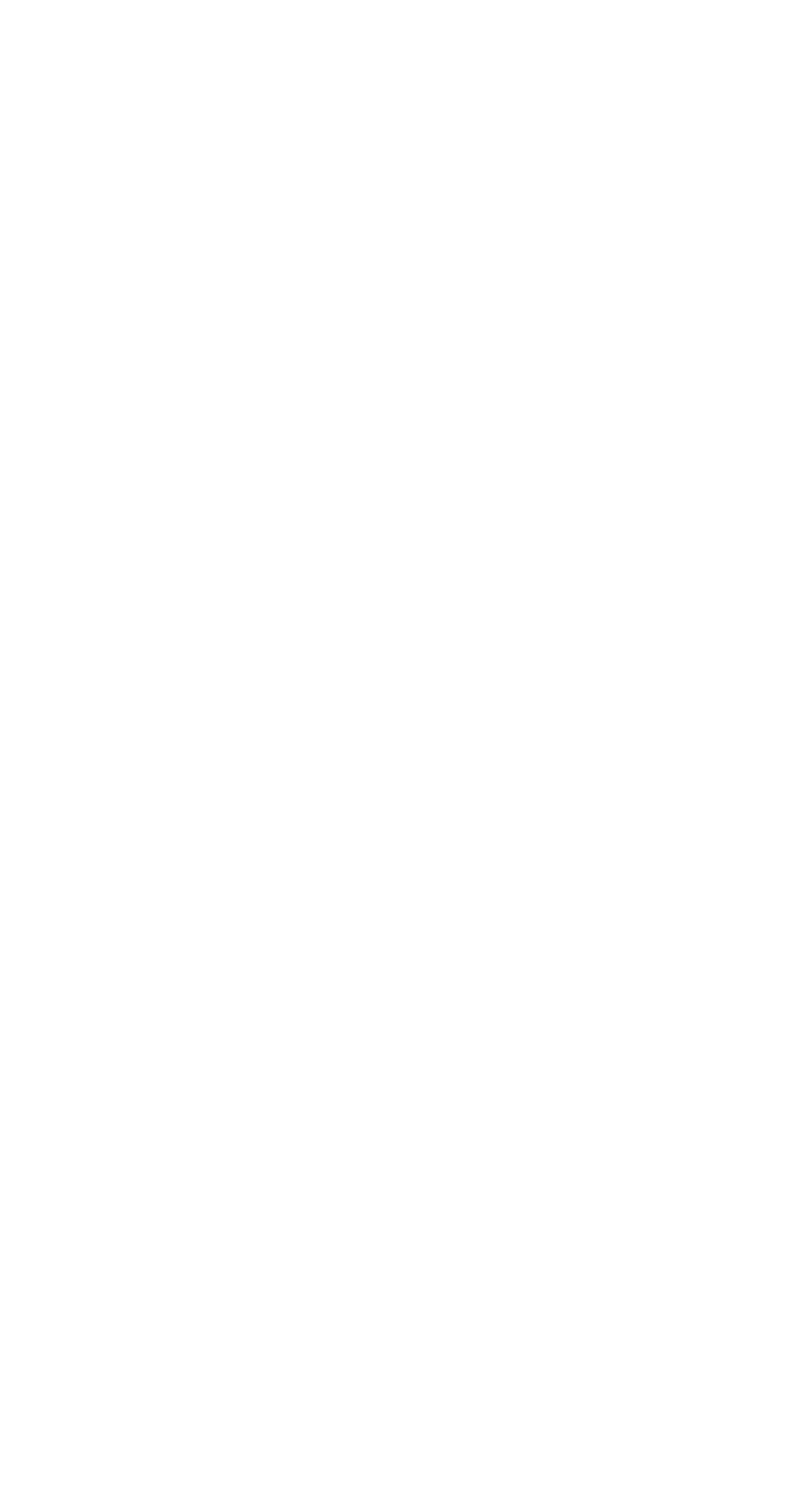




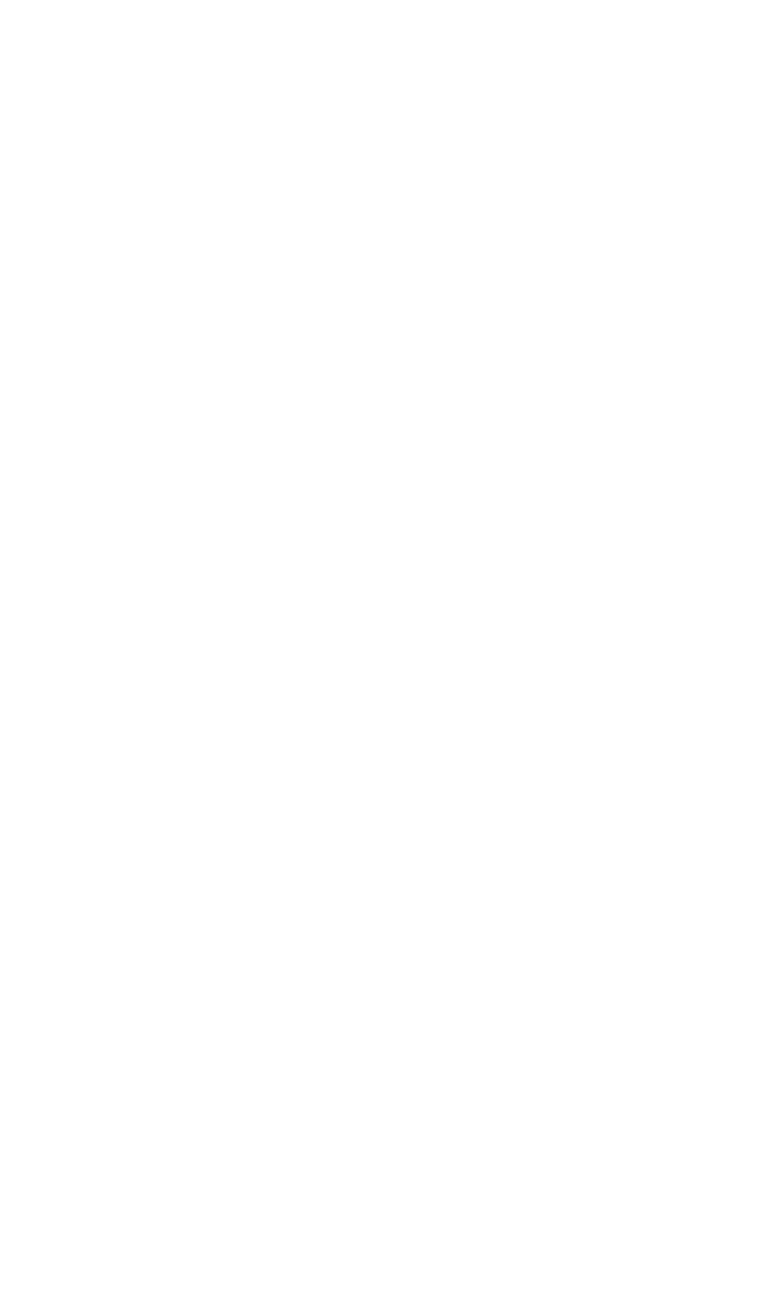



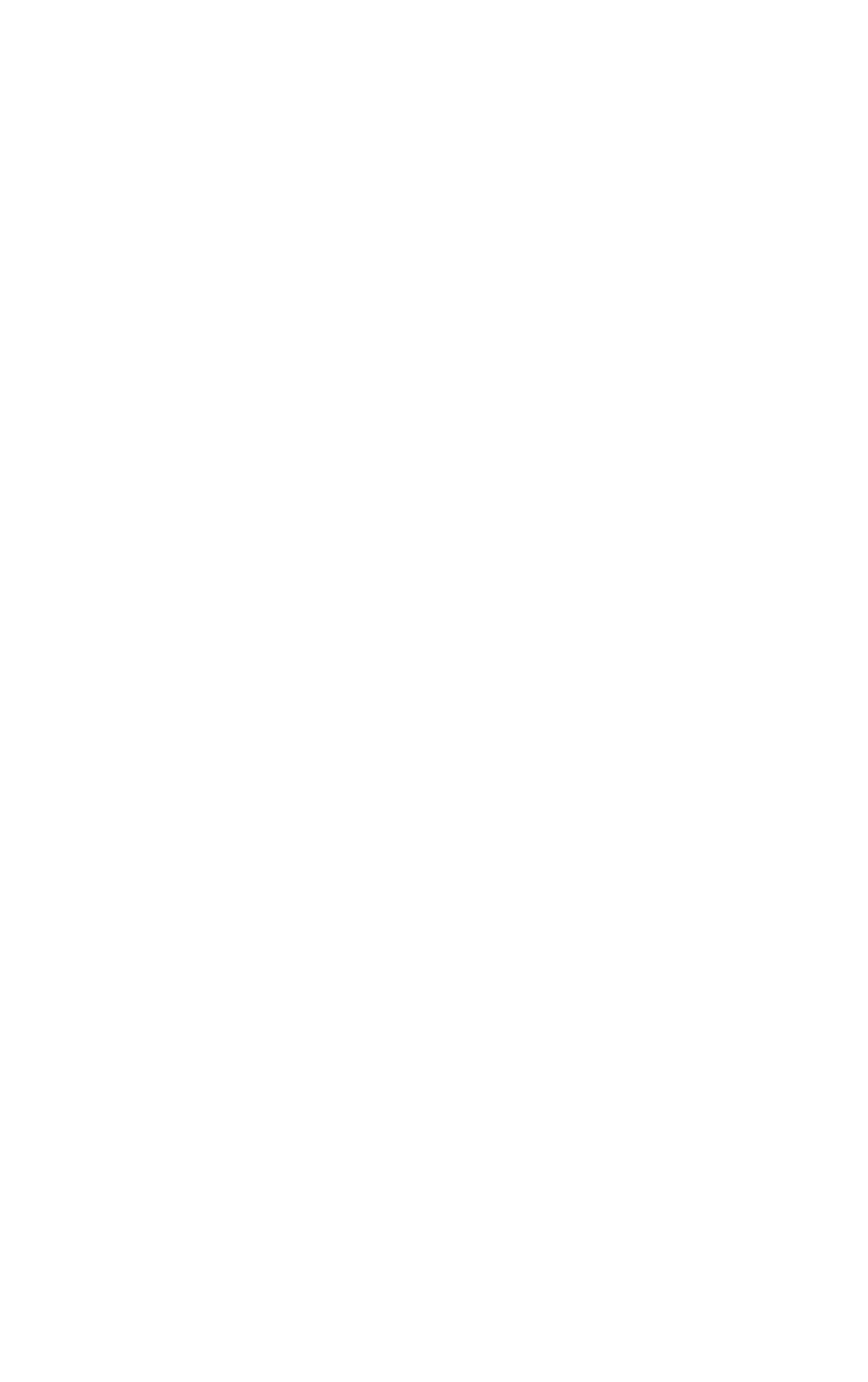
GREAT MIAMI RIVER BASIN--Continued

3-2678. MAD RIVER AT EAGLE CITY, OHIO--Cont1nued

Suspended sediment, water year October 1966 to September 1967

(where no daily concentrations are reported, loads are estimated. Where loads were computed from a

\begin{tabular}{|c|c|c|c|c|c|c|c|c|c|c|}
\hline \multirow[b]{3}{*}{ Day } & \multicolumn{3}{|c|}{ OCTO8ER } & \multicolumn{3}{|c|}{ NOVEMBER } & \multicolumn{4}{|c|}{ DECEMBER } \\
\hline & \multirow[b]{2}{*}{$\begin{array}{l}\text { Mean } \\
\text { dis- } \\
\text { charge } \\
\text { (cfa) }\end{array}$} & \multicolumn{2}{|c|}{ Suspended sediment } & \multirow[b]{2}{*}{$\begin{array}{c}\text { Mean } \\
\text { dis- } \\
\text { charge } \\
\text { (cfs) }\end{array}$} & \multicolumn{2}{|c|}{ Suspended sediment } & \multirow[b]{2}{*}{$\begin{array}{c}\text { Mean } \\
\text { dis- } \\
\text { charge } \\
\text { (cfs) }\end{array}$} & \multicolumn{3}{|c|}{ Suspended sediment } \\
\hline & & $\begin{array}{c}\text { Mean } \\
\text { concen- } \\
\text { tration } \\
\text { (ppm) }\end{array}$ & $\begin{array}{l}\text { Tons } \\
\text { per } \\
\text { day }\end{array}$ & & $\begin{array}{l}\text { Mean } \\
\text { concen- } \\
\text { tration } \\
\text { (ppm) }\end{array}$ & $\begin{array}{l}\text { Tons } \\
\text { per } \\
\text { day }\end{array}$ & & $\begin{array}{c}\text { Mean } \\
\text { concen- } \\
\text { tration } \\
\text { (ppm) }\end{array}$ & & $\begin{array}{l}\text { Tons } \\
\text { pivr } \\
\text { day }\end{array}$ \\
\hline $\begin{array}{l}1 \ldots \\
2 \ldots \\
3 \ldots \\
5 \ldots\end{array}$ & $\begin{array}{r}105 \\
97 \\
92 \\
97 \\
95\end{array}$ & $\begin{array}{r}8 \\
6 \\
2 \\
3 \\
13\end{array}$ & $\begin{array}{r}2.3 \\
1.6 \\
.5 \\
.8 \\
3.3\end{array}$ & $\begin{array}{r}92 \\
101 \\
101 \\
99 \\
99\end{array}$ & $\begin{array}{l}4 \\
4 \\
8 \\
8 \\
6\end{array}$ & $\begin{array}{l}1.0 \\
1.1 \\
2.2 \\
2.1 \\
1.6\end{array}$ & $\begin{array}{l}163 \\
157 \\
149 \\
146 \\
202\end{array}$ & $\begin{array}{r}7 \\
7 \\
11 \\
11 \\
17\end{array}$ & & $\begin{array}{l}3.1 \\
3.0 \\
4.4 \\
4.3 \\
9.3\end{array}$ \\
\hline $\begin{array}{r}6 \ldots \\
7 \ldots \\
8 \ldots \\
10 \ldots\end{array}$ & $\begin{array}{l}95 \\
92 \\
92 \\
95 \\
97\end{array}$ & $\begin{array}{l}48 \\
35 \\
45 \\
38 \\
30\end{array}$ & $\begin{array}{c}12 \\
8.7 \\
11 \\
9.7 \\
7.9\end{array}$ & $\begin{array}{r}97 \\
118 \\
315 \\
230 \\
788\end{array}$ & $\begin{array}{r}2 \\
-220 \\
50 \\
700\end{array}$ & $\begin{array}{c}17^{.5} \\
200 \\
31 \\
2500\end{array}$ & $\begin{array}{r}517 \\
675 \\
558 \\
690 \\
1990\end{array}$ & $\begin{array}{r}58 \\
98 \\
58 \\
-- \\
572\end{array}$ & 5 & $\begin{array}{r}81 \\
194 \\
87 \\
140 \\
3460\end{array}$ \\
\hline $\begin{array}{l}11 \ldots \\
12 \ldots \\
13 \ldots \\
14 \ldots \\
15 \ldots\end{array}$ & $\begin{array}{r}97 \\
92 \\
92 \\
90 \\
103\end{array}$ & $\begin{array}{l}30 \\
33 \\
47 \\
53 \\
18\end{array}$ & $\begin{array}{l}7.9 \\
8.2 \\
12 \\
13 \\
5.0\end{array}$ & $\begin{array}{l}620 \\
335 \\
241 \\
204 \\
189\end{array}$ & $\begin{array}{r}212 \\
42 \\
53 \\
66 \\
102\end{array}$ & $\begin{array}{r}444 \\
38 \\
34 \\
36 \\
52\end{array}$ & $\begin{array}{l}840 \\
558 \\
436 \\
360 \\
315\end{array}$ & $\begin{array}{l}94 \\
49 \\
37 \\
41 \\
56\end{array}$ & 5 & $\begin{array}{r}233 \\
74 \\
44 \\
40 \\
48\end{array}$ \\
\hline $\begin{array}{l}16 \ldots \\
17 \ldots \\
18 \ldots \\
19 \ldots \\
20 \ldots\end{array}$ & $\begin{array}{r}103 \\
99 \\
99 \\
97 \\
97\end{array}$ & $\begin{array}{l}46 \\
45 \\
14 \\
21 \\
38\end{array}$ & $\begin{array}{l}13 \\
12 \\
3.7 \\
5.5 \\
10\end{array}$ & $\begin{array}{l}177 \\
166 \\
160 \\
154 \\
149\end{array}$ & $\begin{array}{r}76 \\
110 \\
125 \\
95 \\
48\end{array}$ & $\begin{array}{l}36 \\
49 \\
54 \\
40 \\
19\end{array}$ & $\begin{array}{l}291 \\
264 \\
252 \\
230 \\
227\end{array}$ & $\begin{array}{l}67 \\
81 \\
50 \\
44 \\
47\end{array}$ & & $\begin{array}{l}53 \\
58 \\
34 \\
27 \\
29\end{array}$ \\
\hline $\begin{array}{l}21 \ldots \\
22 \ldots \\
23 \ldots \\
24 \ldots \\
25 \ldots\end{array}$ & $\begin{array}{l}97 \\
95 \\
92 \\
90 \\
90\end{array}$ & $\begin{array}{l}31 \\
29 \\
50 \\
34 \\
10\end{array}$ & $\begin{array}{r}8.1 \\
7.4 \\
12 \\
8.3 \\
2.4\end{array}$ & $\begin{array}{l}146 \\
143 \\
141 \\
136 \\
133\end{array}$ & $\begin{array}{r}83 \\
102 \\
57 \\
63 \\
64\end{array}$ & $\begin{array}{l}33 \\
39 \\
22 \\
23 \\
23\end{array}$ & $\begin{array}{l}211 \\
204 \\
192 \\
186 \\
180\end{array}$ & $\begin{array}{l}44 \\
44 \\
56 \\
43 \\
33\end{array}$ & & $\begin{array}{l}25 \\
24 \\
29 \\
22 \\
16\end{array}$ \\
\hline $\begin{array}{l}26 \ldots \\
27 \ldots \\
28 \ldots \\
29 \ldots \\
30 \ldots \\
31 \ldots\end{array}$ & $\begin{array}{l}92 \\
90 \\
92 \\
90 \\
90 \\
90\end{array}$ & $\begin{array}{r}10 \\
16 \\
15 \\
11 \\
10 \\
6\end{array}$ & $\begin{array}{l}2.5 \\
3.9 \\
3.7 \\
2.7 \\
2.4 \\
1.5\end{array}$ & $\begin{array}{r}133 \\
202 \\
195 \\
177 \\
166 \\
-\cdots \\
\end{array}$ & $\begin{array}{l}38 \\
33 \\
14 \\
11 \\
10 \\
- \\
\end{array}$ & $\begin{array}{r}14 \\
18 \\
7.4 \\
5.3 \\
4.5 \\
-.\end{array}$ & $\begin{array}{l}168 \\
166 \\
174 \\
177 \\
163 \\
160\end{array}$ & $\begin{array}{l}44 \\
28 \\
30 \\
21 \\
19 \\
27 \\
\end{array}$ & & $\begin{array}{l}20 \\
13 \\
14 \\
10 \\
8.4 \\
12 \\
\end{array}$ \\
\hline \multirow[t]{2}{*}{ Total } & 2934 & -- & 203.0 & 6007 & -- & 3747.7 & 11001 & -- & & 4819.5 \\
\hline & \multicolumn{3}{|c|}{ JANUARY } & \multicolumn{3}{|c|}{ FEBRUARY } & \multicolumn{4}{|c|}{ MARCH } \\
\hline $\begin{array}{l}1 \ldots \\
2 \ldots \\
3 \ldots \\
4 \ldots \\
5 \ldots\end{array}$ & $\begin{array}{l}160 \\
154 \\
154 \\
152 \\
152\end{array}$ & $\begin{array}{r}20 \\
13 \\
12 \\
9 \\
8\end{array}$ & $\begin{array}{l}8.6 \\
5.4 \\
5.0 \\
3.7 \\
3.3\end{array}$ & $\begin{array}{l}166 \\
361 \\
378 \\
248 \\
211\end{array}$ & $\begin{array}{r}13 \\
90 \\
9 \\
6\end{array}$ & $\begin{array}{l}5.8 \\
390 \\
100 \\
6.0 \\
3.4\end{array}$ & $\begin{array}{r}133 \\
146 \\
327 \\
391 \\
1660\end{array}$ & $\begin{array}{r}10 \\
13 \\
76 \\
48 \\
727\end{array}$ & s & $\begin{array}{r}3.6 \\
5.1 \\
86 \\
51 \\
4530\end{array}$ \\
\hline $\begin{array}{r}6 \ldots \\
7 \ldots \\
8 \ldots \\
10 \ldots\end{array}$ & $\begin{array}{l}146 \\
149 \\
146 \\
141 \\
141\end{array}$ & $\begin{array}{r}8 \\
11 \\
7 \\
9 \\
45\end{array}$ & $\begin{array}{r}3.2 \\
4.4 \\
2.8 \\
3.4 \\
17\end{array}$ & $\begin{array}{l}183 \\
171 \\
163 \\
166 \\
166\end{array}$ & $\begin{array}{r}3 \\
5 \\
8 \\
39 \\
51\end{array}$ & $\begin{array}{r}2.5 \\
2.3 \\
3.5 \\
17 \\
23\end{array}$ & $\begin{array}{r}2040 \\
800 \\
600 \\
550 \\
1030\end{array}$ & $\begin{array}{r}546 \\
60 \\
40 \\
58 \\
--\end{array}$ & 5 & $\begin{array}{r}3620 \\
130 \\
65 \\
86 \\
2300\end{array}$ \\
\hline $\begin{array}{l}11 \ldots \\
12 \ldots \\
13 \ldots \\
14 \ldots \\
15 \ldots\end{array}$ & $\begin{array}{l}141 \\
138 \\
138 \\
141 \\
138\end{array}$ & $\begin{array}{l}11 \\
40 \\
45 \\
52 \\
63\end{array}$ & $\begin{array}{l}4.2 \\
15 \\
17 \\
20 \\
23\end{array}$ & $\begin{array}{l}168 \\
152 \\
154 \\
160 \\
189\end{array}$ & $\begin{array}{l}55 \\
78 \\
14 \\
35 \\
21\end{array}$ & $\begin{array}{l}25 \\
32 \\
5.8 \\
15 \\
11\end{array}$ & $\begin{array}{r}1220 \\
775 \\
651 \\
960 \\
650\end{array}$ & $\begin{array}{r}300 \\
47 \\
56 \\
611 \\
58\end{array}$ & $B$ & $\begin{array}{r}1200 \\
98 \\
98 \\
1960 \\
102\end{array}$ \\
\hline $\begin{array}{l}16 \ldots \\
17 \ldots \\
18 \ldots \\
19 \ldots \\
20 \ldots\end{array}$ & $\begin{array}{l}133 \\
136 \\
128 \\
130 \\
130\end{array}$ & $\begin{array}{l}43 \\
52 \\
38 \\
44 \\
51\end{array}$ & $\begin{array}{l}15 \\
19 \\
13 \\
15 \\
18\end{array}$ & $\begin{array}{l}224 \\
183 \\
160 \\
152 \\
152\end{array}$ & $\begin{array}{l}47 \\
39 \\
23 \\
52 \\
45\end{array}$ & $\begin{array}{l}28 \\
19 \\
9.9 \\
21 \\
18\end{array}$ & $\begin{array}{l}470 \\
490 \\
400 \\
370 \\
450\end{array}$ & $\begin{array}{l}55 \\
56 \\
55 \\
71 \\
52\end{array}$ & & $\begin{array}{l}70 \\
65 \\
59 \\
71 \\
63\end{array}$ \\
\hline $\begin{array}{l}21 \ldots \\
22 \ldots \\
23 \ldots \\
24 \ldots \\
25 \ldots\end{array}$ & $\begin{array}{l}130 \\
130 \\
128 \\
130 \\
133\end{array}$ & $\begin{array}{l}74 \\
58 \\
34 \\
36 \\
37\end{array}$ & $\begin{array}{l}26 \\
20 \\
12 \\
13 \\
13\end{array}$ & $\begin{array}{l}152 \\
146 \\
146 \\
128 \\
138\end{array}$ & $\begin{array}{l}36 \\
32 \\
17 \\
18 \\
18\end{array}$ & $\begin{array}{l}15 \\
13 \\
6.7 \\
6.2 \\
6.7\end{array}$ & $\begin{array}{r}1320 \\
650 \\
520 \\
450 \\
420\end{array}$ & $\begin{array}{r}281 \\
48 \\
44 \\
47 \\
64\end{array}$ & is & $\begin{array}{r}1090 \\
84 \\
62 \\
57 \\
73\end{array}$ \\
\hline $\begin{array}{l}26 \ldots \\
27 \ldots \\
28 \ldots \\
29 \ldots \\
30 \ldots \\
31 \ldots\end{array}$ & $\begin{array}{l}138 \\
163 \\
176 \\
154 \\
146 \\
149\end{array}$ & $\begin{array}{l}35 \\
26 \\
14 \\
27 \\
26 \\
17\end{array}$ & $\begin{array}{l}13 \\
11 \\
6.7 \\
11 \\
10 \\
6.8\end{array}$ & $\begin{array}{r}136 \\
136 \\
141 \\
=- \\
=- \\
\end{array}$ & $\begin{array}{r}20 \\
8 \\
9 \\
-- \\
-- \\
-- \\
\end{array}$ & $\begin{array}{r}7.3 \\
2.9 \\
3.4 \\
-- \\
-- \\
\end{array}$ & $\begin{array}{l}390 \\
360 \\
888 \\
615 \\
540 \\
440\end{array}$ & $\begin{array}{l}70 \\
64 \\
-5 \\
95 \\
52 \\
60\end{array}$ & A & $\begin{array}{r}74 \\
62 \\
650 \\
230 \\
76 \\
71\end{array}$ \\
\hline Total & 4425 & -- & 358.5 & 5030 & - & 798.4 & 20846 & -- & & 17191.7 \\
\hline
\end{tabular}

S Computed by subdividing day.

A Computed from partly estimated-concentration graph.

B Computed from estimated-concentration graph. 
GREAT MIAMI RIVER BASIN--Continued

3-2678. MAD RIVER AT EAGLE CITY, OHIO--Continued

Suspended sediment, water year October 1966 to September 1967--Continued

(Where no dally concentrations are reported, loads are estimated. Where loads were computed from a partly estimated or estimated-concentration graph, time-weighted concentrations are reported)

\begin{tabular}{|c|c|c|c|c|c|c|c|c|c|}
\hline \multirow[b]{3}{*}{ Day } & \multicolumn{3}{|c|}{ APRIL } & \multicolumn{3}{|c|}{ MAY } & \multicolumn{3}{|c|}{ JIJNE } \\
\hline & \multirow[b]{2}{*}{$\begin{array}{c}\text { Mean } \\
\text { dis- } \\
\text { charge } \\
\text { (cfs) }\end{array}$} & \multicolumn{2}{|c|}{ Suspended sediment } & \multirow[b]{2}{*}{$\begin{array}{c}\text { Mean } \\
\text { dis- } \\
\text { charge } \\
\text { (cfs) }\end{array}$} & \multicolumn{2}{|c|}{ Suspended sediment } & \multirow[b]{2}{*}{$\begin{array}{c}\text { Mean } \\
\text { dis- } \\
\text { charge } \\
\text { (cfs) }\end{array}$} & \multicolumn{2}{|c|}{ Suspended sediment } \\
\hline & & $\begin{array}{l}\text { Mean } \\
\text { concen- } \\
\text { tration } \\
\text { (ppm) }\end{array}$ & $\begin{array}{l}\text { Tons } \\
\text { per } \\
\text { day }\end{array}$ & & $\begin{array}{c}\text { Mean } \\
\text { concen- } \\
\text { tration } \\
(\text { ppm) }\end{array}$ & $\begin{array}{c}\text { Tons } \\
\text { per } \\
\text { day }\end{array}$ & & $\begin{array}{c}\text { Noan } \\
\text { concen- } \\
\text { tration } \\
(\text { ppm) }\end{array}$ & $\begin{array}{l}\text { Tons } \\
\text { per } \\
\text { day }\end{array}$ \\
\hline $\begin{array}{l}1 \ldots \\
2 \ldots \\
3 \ldots \\
4 \ldots \\
5 \ldots\end{array}$ & $\begin{array}{l}400 \\
360 \\
340 \\
320 \\
651\end{array}$ & $\begin{array}{l}45 \\
38 \\
32 \\
37 \\
--\end{array}$ & $\begin{array}{r}49 \\
37 \\
29 \\
32 \\
270\end{array}$ & $\begin{array}{l}240 \\
409 \\
398 \\
310 \\
286\end{array}$ & $\begin{array}{r}9 \\
22 \\
95 \\
133\end{array}$ & $\begin{array}{l}5.8 \\
40 \\
24 \\
80 \\
103\end{array}$ & $\begin{array}{l}276 \\
265 \\
265 \\
254 \\
248\end{array}$ & $\begin{array}{r}42 \\
15 \\
21 \\
7 \\
7\end{array}$ & $\begin{array}{l}31 \\
11 \\
15 \\
4.8 \\
4.7\end{array}$ \\
\hline $\begin{array}{r}6 \ldots \\
7 \ldots \\
8 \ldots \\
9 \ldots\end{array}$ & $\begin{array}{l}710 \\
489 \\
394 \\
366 \\
346\end{array}$ & $\begin{array}{l}60 \\
26 \\
25 \\
66 \\
83\end{array}$ & $\begin{array}{r}110 \\
34 \\
27 \\
65 \\
78\end{array}$ & $\begin{array}{r}324 \\
2160 \\
1130 \\
736 \\
552\end{array}$ & $\begin{array}{r}75 \\
1080 \\
215 \\
105 \\
76\end{array}$ & $\begin{array}{r}66 \\
8400 \\
656 \\
209 \\
113\end{array}$ & $\begin{array}{l}240 \\
237 \\
230 \\
223 \\
220\end{array}$ & $\begin{array}{l}14 \\
18 \\
90 \\
71 \\
60\end{array}$ & $\begin{array}{l}9.1 \\
12 \\
56 \\
43 \\
36\end{array}$ \\
\hline $\begin{array}{l}11 \ldots \\
12 \ldots \\
13 \ldots \\
14 \ldots \\
15 \ldots\end{array}$ & $\begin{array}{l}324 \\
307 \\
328 \\
342 \\
318\end{array}$ & $\begin{array}{l}97 \\
66 \\
70 \\
67 \\
81\end{array}$ & $\begin{array}{l}85 \\
55 \\
62 \\
62 \\
70\end{array}$ & $\begin{array}{r}1350 \\
780 \\
566 \\
497 \\
830\end{array}$ & $\begin{array}{r}328 \\
112 \\
82 \\
90 \\
157\end{array}$ & $\begin{array}{r}1490 \\
236 \\
125 \\
121 \\
352\end{array}$ & $\begin{array}{l}212 \\
206 \\
206 \\
206 \\
206\end{array}$ & $\begin{array}{r}71 \\
129 \\
119 \\
118 \\
108\end{array}$ & $\begin{array}{l}41 \\
72 \\
66 \\
66 \\
60\end{array}$ \\
\hline $\begin{array}{l}16 \ldots \\
17 \ldots \\
18 \ldots \\
19 \ldots \\
20 \ldots\end{array}$ & $\begin{array}{l}293 \\
293 \\
286 \\
272 \\
262\end{array}$ & $\begin{array}{l}45 \\
58 \\
45 \\
50 \\
75\end{array}$ & $\begin{array}{l}36 \\
46 \\
35 \\
37 \\
53\end{array}$ & $\begin{array}{l}646 \\
525 \\
501 \\
441 \\
394\end{array}$ & $\begin{array}{r}100 \\
78 \\
80 \\
107 \\
130\end{array}$ & $\begin{array}{l}174 \\
111 \\
108 \\
127 \\
138\end{array}$ & $\begin{array}{l}206 \\
209 \\
206 \\
206 \\
206\end{array}$ & $\begin{array}{r}63 \\
85 \\
90 \\
127 \\
115\end{array}$ & $\begin{array}{l}35 \\
48 \\
50 \\
71 \\
64\end{array}$ \\
\hline $\begin{array}{l}21 \ldots \\
22 \ldots \\
23 \ldots \\
24 \ldots \\
25 \ldots\end{array}$ & $\begin{array}{l}276 \\
513 \\
370 \\
374 \\
328\end{array}$ & $\begin{array}{l}56 \\
80 \\
21 \\
23 \\
22\end{array}$ & $\begin{array}{r}42 \\
123 \\
21 \\
23 \\
19\end{array}$ & $\begin{array}{l}366 \\
352 \\
338 \\
328 \\
318\end{array}$ & $\begin{array}{r}108 \\
77 \\
97 \\
100 \\
77\end{array}$ & $\begin{array}{r}107 \\
73 \\
89 \\
89 \\
66\end{array}$ & $\begin{array}{l}206 \\
209 \\
209 \\
190 \\
189\end{array}$ & \begin{tabular}{l|}
92 \\
92 \\
97 \\
64 \\
90
\end{tabular} & $\begin{array}{l}51 \\
52 \\
55 \\
33 \\
46\end{array}$ \\
\hline $\begin{array}{l}26 \ldots \\
27 \ldots \\
28 \ldots \\
29 \ldots \\
30 \ldots \\
31 \ldots\end{array}$ & $\begin{array}{r}321 \\
290 \\
265 \\
251 \\
244 \\
--\end{array}$ & $\begin{array}{l}37 \\
22 \\
18 \\
20 \\
16 \\
-- \\
\end{array}$ & $\begin{array}{l}32 \\
17 \\
13 \\
14 \\
11 \\
-- \\
\end{array}$ & $\begin{array}{l}321 \\
300 \\
293 \\
349 \\
314 \\
286 \\
\end{array}$ & $\begin{array}{l}75 \\
80 \\
95 \\
43 \\
24 \\
33 \\
\end{array}$ & $\begin{array}{l}65 \\
65 \\
75 \\
41 \\
20 \\
25\end{array}$ & $\begin{array}{l}189 \\
186 \\
195 \\
202 \\
198 \\
-\end{array}$ & $\begin{array}{r}123 \\
82 \\
44 \\
59 \\
41 \\
-- \\
\end{array}$ & $\begin{array}{l}63 \\
41 \\
23 \\
32 \\
22 \\
-\end{array}$ \\
\hline \multirow[t]{2}{*}{ Total } & 10633 & - & 1587 & 16640 & 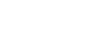 & 13393.8 & 6500 & -- & 1213.6 \\
\hline & \multicolumn{3}{|c|}{ JULY } & \multicolumn{3}{|c|}{ AUGUST } & \multicolumn{3}{|c|}{ SEP EMBER } \\
\hline $\begin{array}{l}1 \ldots \\
2 \ldots \\
3 \ldots \\
4 \ldots \\
5 \ldots\end{array}$ & $\begin{array}{l}192 \\
171 \\
157 \\
160 \\
160\end{array}$ & $\begin{array}{l}29 \\
37 \\
47 \\
25 \\
36\end{array}$ & $\begin{array}{l}15 \\
17 \\
20 \\
11 \\
16\end{array}$ & $\begin{array}{l}212 \\
154 \\
140 \\
140 \\
130\end{array}$ & $\begin{array}{l}85 \\
84 \\
70 \\
68 \\
71\end{array}$ & $\begin{array}{l}49 \\
35 \\
26 \\
26 \\
25\end{array}$ & $\begin{array}{l}114 \\
109 \\
112 \\
112 \\
109\end{array}$ & $\begin{array}{l}48 \\
35 \\
36 \\
28 \\
17\end{array}$ & $\begin{array}{l}15 \\
10 \\
11 \\
8.5 \\
5.0\end{array}$ \\
\hline $\begin{array}{r}6 \ldots \\
7 \ldots \\
8 \ldots \\
9 \ldots \\
10 \ldots\end{array}$ & $\begin{array}{l}157 \\
149 \\
149 \\
143 \\
143\end{array}$ & $\begin{array}{l}42 \\
27 \\
23 \\
29 \\
41\end{array}$ & $\begin{array}{l}18 \\
11 \\
9 \cdot 3 \\
11 \\
16\end{array}$ & $\begin{array}{l}130 \\
120 \\
124 \\
116 \\
116\end{array}$ & $\begin{array}{l}51 \\
31 \\
32 \\
34 \\
36\end{array}$ & $\begin{array}{l}18 \\
10 \\
11 \\
11 \\
11\end{array}$ & $\begin{array}{l}116 \\
112 \\
116 \\
121 \\
119\end{array}$ & $\begin{array}{r}16 \\
13 \\
18 \\
50 \\
103\end{array}$ & $\begin{array}{l}5.0 \\
3.9 \\
5.6 \\
16 \\
33\end{array}$ \\
\hline $\begin{array}{l}11 \ldots \\
12 \ldots \\
13 \ldots \\
14 \ldots \\
15 \ldots\end{array}$ & $\begin{array}{l}143 \\
141 \\
136 \\
138 \\
133\end{array}$ & $\begin{array}{r}39 \\
37 \\
32 \\
100 \\
58\end{array}$ & $\begin{array}{l}15 \\
14 \\
12 \\
37 \\
21\end{array}$ & $\begin{array}{l}114 \\
110 \\
110 \\
110 \\
110\end{array}$ & $\begin{array}{l}68 \\
97 \\
89 \\
88 \\
86\end{array}$ & $\begin{array}{l}21 \\
29 \\
26 \\
26 \\
26\end{array}$ & $\begin{array}{l}112 \\
112 \\
112 \\
109 \\
109\end{array}$ & $\begin{array}{r}111 \\
105 \\
86 \\
102 \\
90\end{array}$ & $\begin{array}{l}34 \\
32 \\
26 \\
30 \\
26\end{array}$ \\
\hline $\begin{array}{l}16 \ldots \\
17 \ldots \\
18 \ldots \\
19 \ldots \\
20 \ldots\end{array}$ & $\begin{array}{l}133 \\
131 \\
131 \\
154 \\
141\end{array}$ & $\begin{array}{r}62 \\
134 \\
119 \\
112 \\
148\end{array}$ & $\begin{array}{l}22 \\
47 \\
42 \\
47 \\
56\end{array}$ & $\begin{array}{l}110 \\
110 \\
110 \\
120 \\
120\end{array}$ & $\begin{array}{r}67 \\
117 \\
112 \\
85 \\
84\end{array}$ & $\begin{array}{l}20 \\
35 \\
33 \\
28 \\
27\end{array}$ & $\begin{array}{l}114 \\
109 \\
112 \\
107 \\
110\end{array}$ & $\begin{array}{l}44 \\
49 \\
51 \\
53 \\
65\end{array}$ & $\begin{array}{l}14 \\
14 \\
15 \\
15 \\
19\end{array}$ \\
\hline $\begin{array}{l}21 \ldots \\
22 \ldots \\
23 \ldots \\
24 \ldots \\
25 \ldots\end{array}$ & $\begin{array}{l}143 \\
133 \\
124 \\
128 \\
126\end{array}$ & $\begin{array}{r}130 \\
42 \\
63 \\
63 \\
22\end{array}$ & $\begin{array}{l}50 \\
15 \\
21 \\
22 \\
7.5\end{array}$ & $\begin{array}{l}119 \\
121 \\
114 \\
112 \\
119\end{array}$ & $\begin{array}{l}80 \\
88 \\
74 \\
71 \\
76\end{array}$ & $\begin{array}{l}26 \\
29 \\
23 \\
21 \\
24\end{array}$ & $\begin{array}{l}110 \\
109 \\
112 \\
102 \\
109\end{array}$ & $\begin{array}{l}25 \\
45 \\
35 \\
18 \\
19\end{array}$ & $\begin{array}{l}7.4 \\
13 \\
11 \\
5.0 \\
5.6\end{array}$ \\
\hline $\begin{array}{l}26 \ldots \\
27 \ldots \\
28 \ldots \\
29 \ldots \\
30 \ldots \\
31 \ldots\end{array}$ & $\begin{array}{l}126 \\
124 \\
138 \\
131 \\
131 \\
322\end{array}$ & $\begin{array}{r}69 \\
67 \\
84 \\
64 \\
67 \\
300\end{array}$ & $\begin{array}{r}23 \\
22 \\
31 \\
23 \\
24 \\
300\end{array}$ & $\begin{array}{l}119 \\
121 \\
116 \\
114 \\
114 \\
116 \\
\end{array}$ & $\begin{array}{l}95 \\
63 \\
73 \\
68 \\
49 \\
60 \\
\end{array}$ & $\begin{array}{l}31 \\
21 \\
23 \\
21 \\
15 \\
19\end{array}$ & $\begin{array}{r}100 \\
100 \\
126 \\
124 \\
114 \\
--\end{array}$ & $\begin{array}{l}13 \\
22 \\
24 \\
31 \\
17 \\
--\end{array}$ & $\begin{array}{r}3.5 \\
5.9 \\
8.2 \\
10 \\
5.2 \\
-. .\end{array}$ \\
\hline Total & 4588 & - & 995.8 & 3791 & - & 746 & 3352 & -- ! & 412.8 \\
\hline $\begin{array}{l}\text { Tota] } \\
\text { Tota }\end{array}$ & $\begin{array}{l}\text { dischare } \\
\text { load for }\end{array}$ & $\begin{array}{l}\text { for yea } \\
\text { ear (to }\end{array}$ & $\begin{array}{l}\text { ar (cfs-days) } \\
\text { ons) } \ldots \ldots \ldots \ldots\end{array}$ & $\ldots \ldots$ & $\cdots \cdots$ & $\cdots \cdots \cdots \cdots$ & $\cdots \cdots$ & $\cdots \cdots \cdots$ & $\begin{array}{l}95747 \\
45467.8\end{array}$ \\
\hline
\end{tabular}

A Computed from partly estimated-concentration graph. 


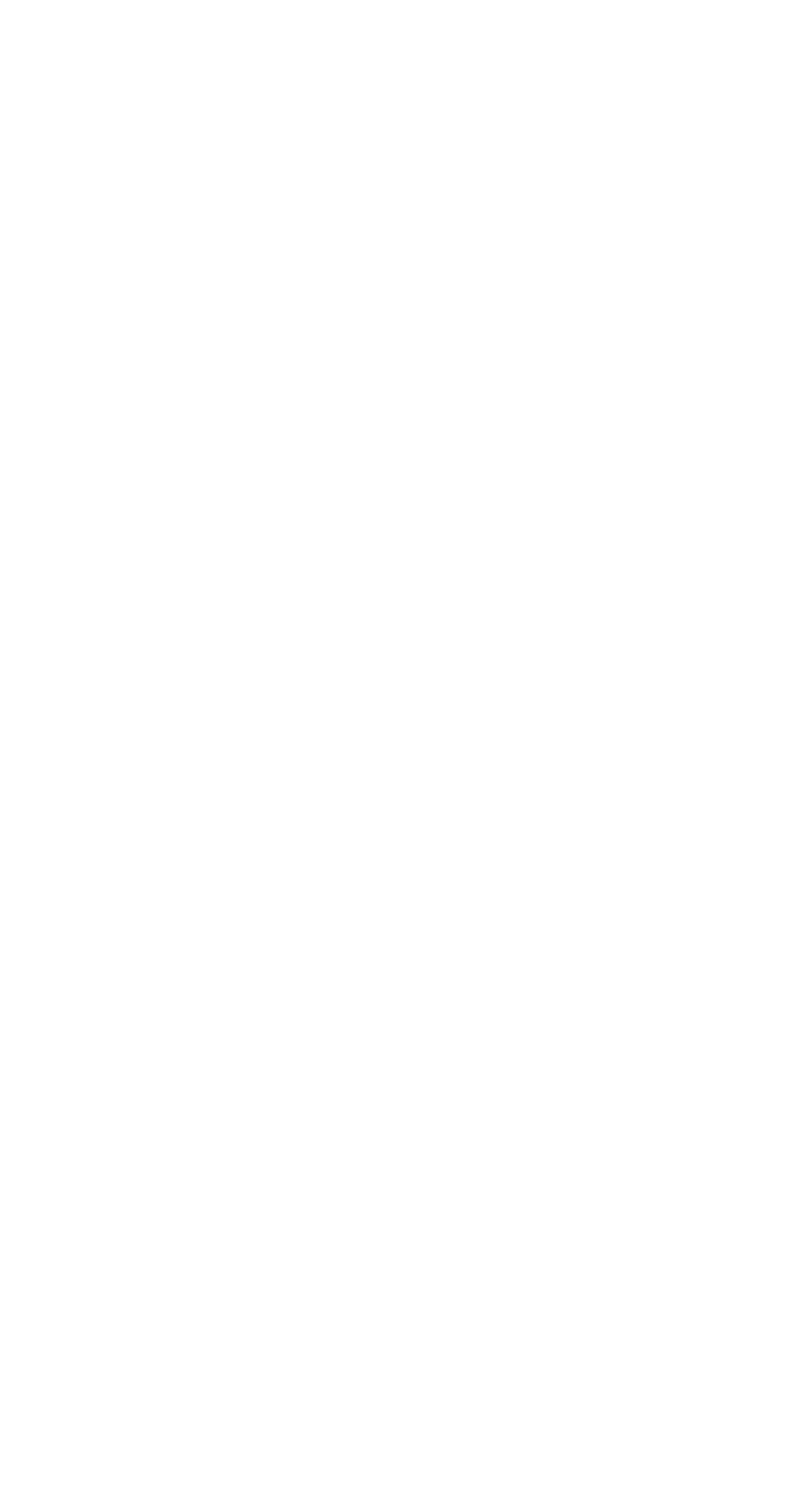




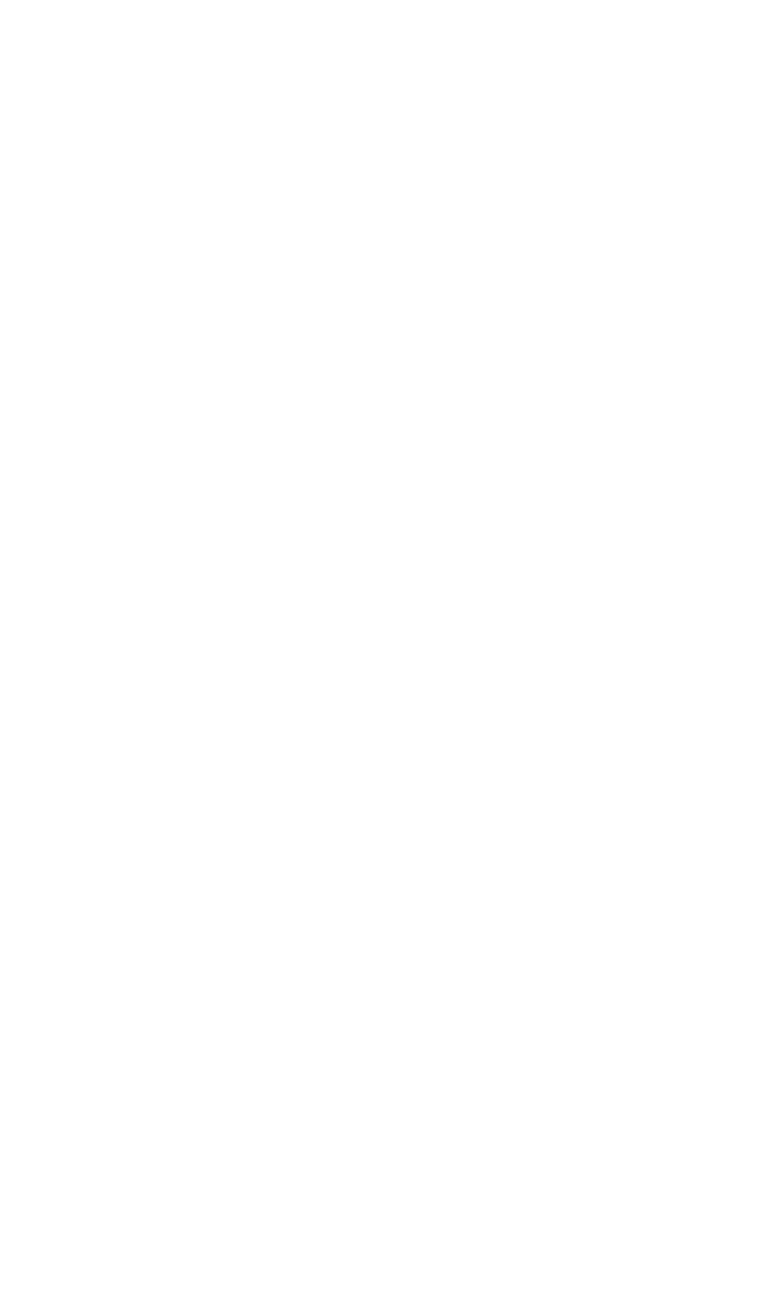




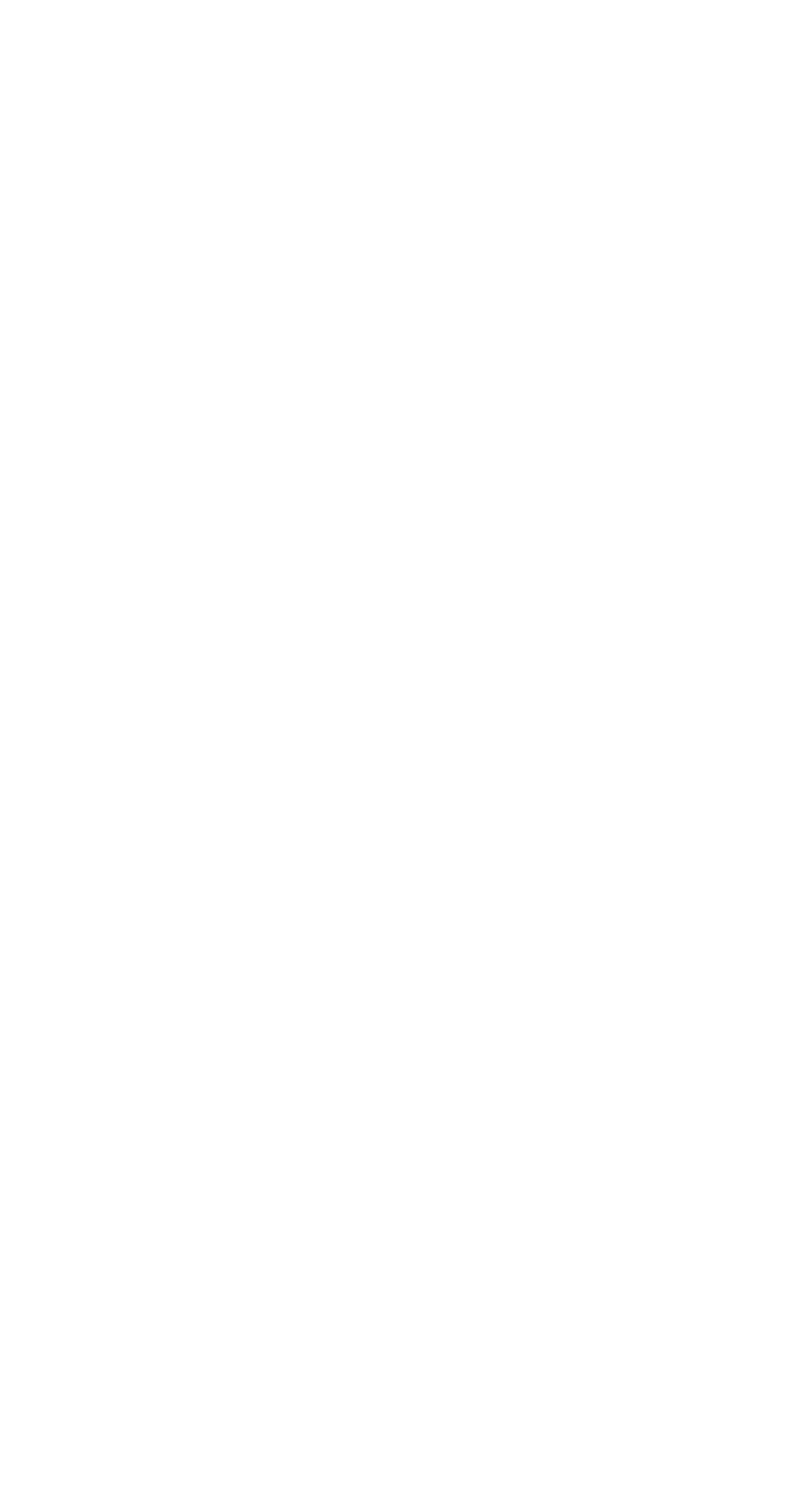




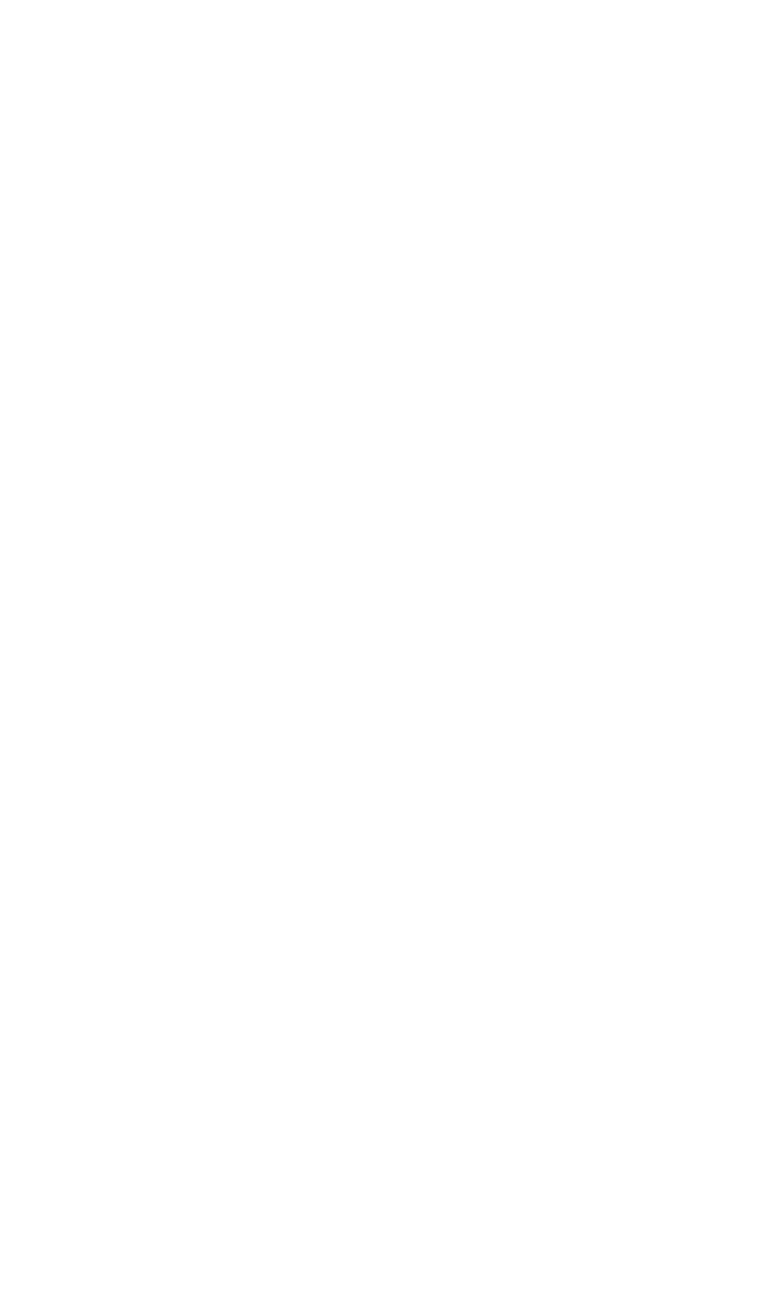




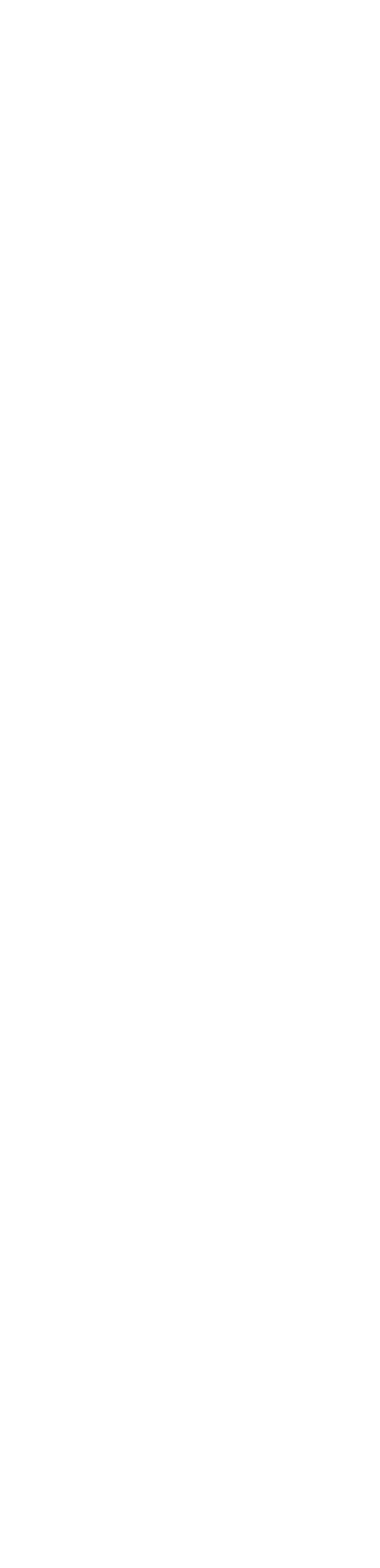

\begin{tabular}{|c|c|}
\hline $\mid \dot{s}=\underline{\underline{g}}$ & \\
\hline 容密 & \\
\hline$\left.\frac{1}{d}\right)^{2}$ & \\
\hline$\frac{\pi}{2}$ & 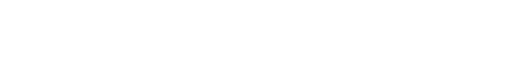 \\
\hline 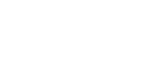 & 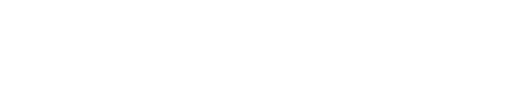 \\
\hline 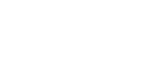 & \\
\hline 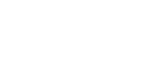 & 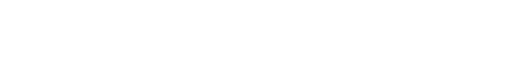 \\
\hline 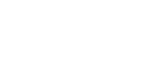 & 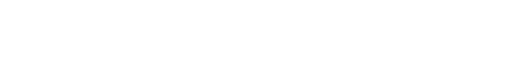 \\
\hline 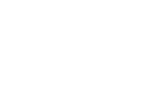 & 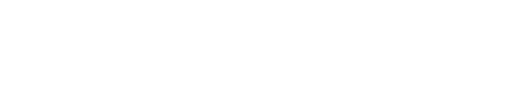 \\
\hline 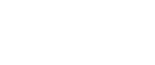 & 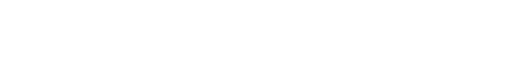 \\
\hline$\frac{1}{2} \frac{0}{2}$ & $=$ \\
\hline 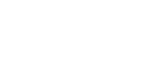 & 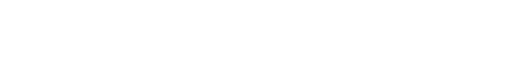 \\
\hline 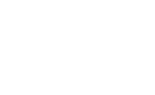 & 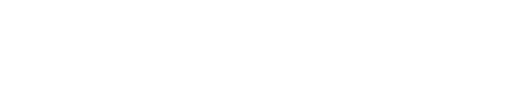 \\
\hline 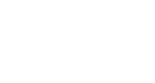 & 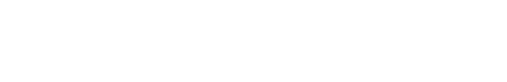 \\
\hline 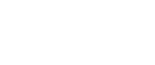 & $000000 \quad 0000000000000 \quad 000+\infty 0^{0} 0$ \\
\hline 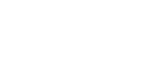 & 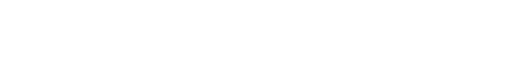 \\
\hline 害息垔 & \\
\hline 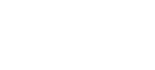 & \\
\hline 害要 & \\
\hline 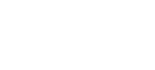 & \\
\hline 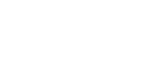 & \\
\hline 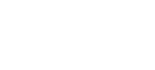 & \\
\hline 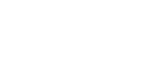 & \\
\hline 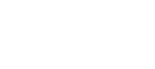 & \\
\hline 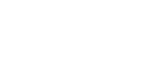 & \\
\hline 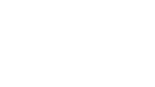 & 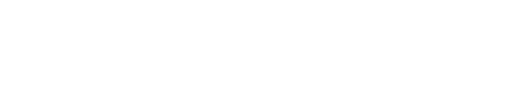 \\
\hline 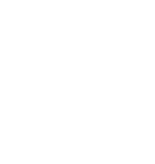 & 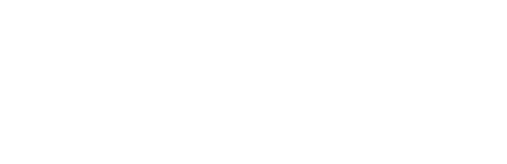 \\
\hline
\end{tabular}



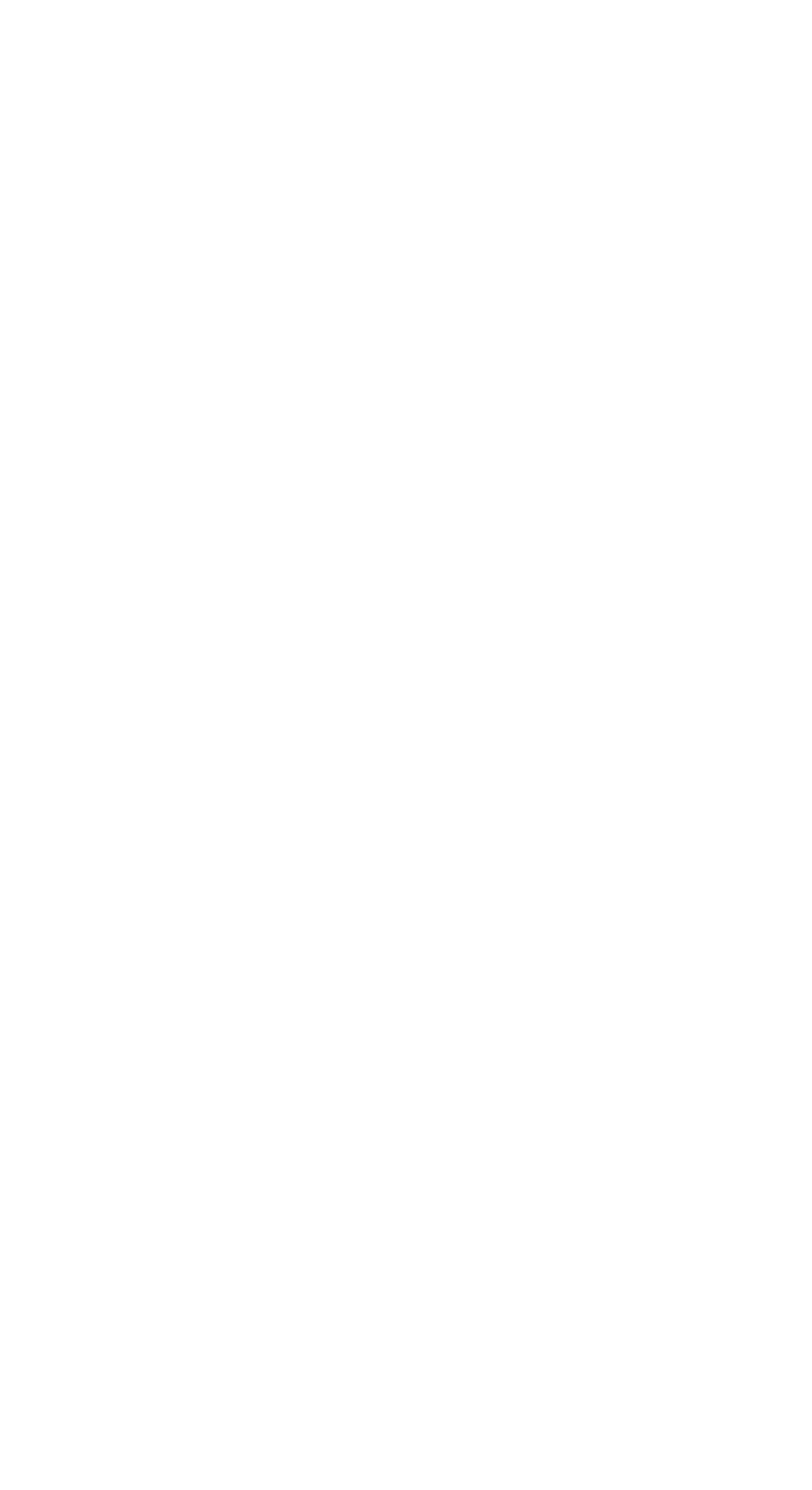
GREAT MIAMI RIVER BASIN--Continued

3-2716. GREAT MIAMI RIVER NEAR MIAMISBURG, OHIO--COnt1nued

Data from continuous recorder, water year October 1966 to September 1967

\begin{tabular}{|c|c|c|c|c|c|c|c|c|c|c|c|c|c|c|c|c|}
\hline \multirow{3}{*}{ Day } & \multicolumn{8}{|c|}{ OCTOBER } & \multicolumn{8}{|c|}{ NOVEMBER } \\
\hline & \multicolumn{2}{|c|}{$\begin{array}{c}\text { Specific } \\
\text { conductance } \\
\text { (micromhos } \\
\left.\text { at } 25^{\circ} \mathrm{C}\right) \\
\end{array}$} & \multicolumn{2}{|c|}{$\mathbf{p H}$} & \multicolumn{2}{|c|}{$\begin{array}{l}\text { Dissolved } \\
\text { oxygen } \\
\text { (ppm) }\end{array}$} & \multicolumn{2}{|c|}{$\begin{array}{l}\text { Temper- } \\
\text { ature } \\
\left({ }^{\circ} \mathrm{F}\right)\end{array}$} & \multicolumn{2}{|c|}{$\begin{array}{c}\text { Specific } \\
\text { conductance } \\
\text { (micromhos } \\
\text { at } 25^{\circ} \mathrm{C} \text { ) } \\
\end{array}$} & \multicolumn{2}{|c|}{$\mathbf{p H}$} & \multicolumn{2}{|c|}{$\begin{array}{c}\text { Dissolved } \\
\text { oxygen } \\
\text { (ppm) }\end{array}$} & \multicolumn{2}{|c|}{$\begin{array}{c}\text { Temper- } \\
\text { ature } \\
\left({ }^{\circ} \mathrm{F}\right)\end{array}$} \\
\hline & Max & Min & Max & Min & Max & Min & Max & Min & Max & Min & $\operatorname{Max}$ & Min & Max & Min & $N^{4} \times x$ & Min \\
\hline $\begin{array}{l}\ldots \\
2 \ldots \\
3 \ldots \\
4 \ldots \\
5 \cdots\end{array}$ & $\begin{array}{r}830 \\
730 \\
730 \\
-\overline{810}\end{array}$ & $\begin{array}{r}730 \\
690 \\
720 \\
-- \\
780\end{array}$ & $\begin{array}{r}7.8 \\
7.7 \\
7.7 \\
-- \\
7.8\end{array}$ & $\begin{array}{l}7.6 \\
7.6 \\
7.6 \\
-.7 \\
7.7\end{array}$ & $\begin{array}{l}2.0 \\
1.6 \\
1.6 \\
-1.6\end{array}$ & $\begin{array}{l}1.1 \\
1.0 \\
1.1 \\
-1.0\end{array}$ & $\begin{array}{l}68 \\
68 \\
71 \\
73\end{array}$ & $\begin{array}{l}67 \\
64 \\
64 \\
-2 \\
70\end{array}$ & $\begin{array}{r}880 \\
890 \\
870 \\
1000 \\
1000\end{array}$ & $\begin{array}{l}860 \\
860 \\
850 \\
830 \\
940\end{array}$ & $\begin{array}{l}7.9 \\
7.9 \\
7.9 \\
7.9 \\
7.9\end{array}$ & $\begin{array}{l}7.8 \\
7.8 \\
7.7 \\
7.8 \\
7.8\end{array}$ & $\begin{array}{l}2.4 \\
3.0 \\
5.3 \\
5.4 \\
5.8\end{array}$ & $\begin{array}{l}1.8 \\
1.7 \\
2.9 \\
4.1 \\
4.4\end{array}$ & $\begin{array}{l}66 \\
62 \\
56 \\
52 \\
52\end{array}$ & $\begin{array}{l}62 \\
56 \\
52 \\
48 \\
50\end{array}$ \\
\hline $\begin{array}{r}6 \ldots \\
7 \ldots \\
8 \ldots \\
9 \ldots \\
10 \ldots\end{array}$ & $\begin{array}{l}860 \\
850 \\
900 \\
870 \\
850\end{array}$ & $\begin{array}{l}770 \\
800 \\
820 \\
840 \\
750\end{array}$ & $\begin{array}{l}7.8 \\
7.8 \\
7.8 \\
7.9 \\
7.9\end{array}$ & $\begin{array}{l}7.7 \\
7.6 \\
7.6 \\
7.7 \\
7.7\end{array}$ & $\begin{array}{l}1.3 \\
1.7 \\
1.5 \\
1.3 \\
1.9\end{array}$ & $\begin{array}{r}.6 \\
1.0 \\
.7 \\
.7 \\
.4\end{array}$ & $\begin{array}{l}74 \\
75 \\
72 \\
71 \\
71\end{array}$ & $\begin{array}{l}68 \\
70 \\
67 \\
68 \\
70\end{array}$ & $\begin{array}{l}940 \\
890 \\
850 \\
700 \\
710\end{array}$ & $\begin{array}{l}880 \\
810 \\
700 \\
640 \\
530\end{array}$ & $\begin{array}{l}7.9 \\
7.9 \\
8.0 \\
8.1 \\
8.2\end{array}$ & $\begin{array}{l}7.8 \\
7.8 \\
7.9 \\
8.0 \\
7.6\end{array}$ & $\begin{array}{l}5.5 \\
6.3 \\
6.3 \\
7.8 \\
7.0\end{array}$ & $\begin{array}{l}4.4 \\
5.2 \\
5.5 \\
6.2 \\
5.5\end{array}$ & $\begin{array}{l}52 \\
52 \\
55 \\
54 \\
57\end{array}$ & $\begin{array}{l}51 \\
50 \\
53 \\
52 \\
53\end{array}$ \\
\hline $\begin{array}{l}11 \ldots \\
12 \ldots \\
13 \ldots \\
14 \ldots \\
15 \ldots\end{array}$ & $\begin{array}{l}760 \\
740 \\
790 \\
820 \\
820\end{array}$ & $\begin{array}{l}720 \\
660 \\
730 \\
770 \\
780\end{array}$ & $\begin{array}{l}8.0 \\
7.6 \\
7.7 \\
7.8 \\
7.9\end{array}$ & $\begin{array}{l}7.6 \\
7.5 \\
7.6 \\
7.6 \\
7.8\end{array}$ & $\begin{array}{l}2.9 \\
1.7 \\
1.3 \\
2.0 \\
1.9\end{array}$ & $\begin{array}{r}1.0 \\
.8 \\
.5 \\
.5 \\
.4\end{array}$ & $\begin{array}{l}70 \\
71 \\
74 \\
74 \\
67\end{array}$ & $\begin{array}{l}68 \\
66 \\
68 \\
66 \\
66\end{array}$ & $\begin{array}{l}590 \\
630 \\
660 \\
680 \\
740\end{array}$ & $\begin{array}{l}470 \\
590 \\
610 \\
640 \\
680\end{array}$ & $\begin{array}{l}8.2 \\
8.3 \\
8.3 \\
8.2 \\
8.2\end{array}$ & $\begin{array}{l}7.8 \\
8.0 \\
8.1 \\
8.0 \\
7.9\end{array}$ & $\begin{array}{l}7.7 \\
8.6 \\
9.6 \\
9.5 \\
9.2\end{array}$ & $\begin{array}{l}7.0 \\
7.7 \\
8.6 \\
9.2 \\
8.9\end{array}$ & $\begin{array}{l}53 \\
52 \\
50 \\
49 \\
50\end{array}$ & $\begin{array}{l}51 \\
50 \\
49 \\
48 \\
49\end{array}$ \\
\hline $\begin{array}{l}16 \ldots \\
17 \ldots \\
18 \ldots \\
19 \ldots \\
20 \ldots\end{array}$ & $\begin{array}{l}810 \\
760 \\
790 \\
810 \\
800\end{array}$ & $\begin{array}{l}760 \\
660 \\
740 \\
780 \\
780\end{array}$ & $\begin{array}{l}7.9 \\
7.9 \\
7.8 \\
7.8 \\
7.7\end{array}$ & $\begin{array}{l}7.8 \\
7.8 \\
7.7 \\
7.7 \\
7.6\end{array}$ & $\begin{array}{l}2.4 \\
3.3 \\
3.1 \\
1.6 \\
1.8\end{array}$ & $\begin{array}{r}.5 \\
.8 \\
1.3 \\
.7 \\
.8\end{array}$ & $\begin{array}{l}66 \\
64 \\
64 \\
63 \\
62\end{array}$ & $\begin{array}{l}64 \\
63 \\
63 \\
62 \\
61\end{array}$ & $\begin{array}{l}760 \\
790 \\
790 \\
810 \\
830\end{array}$ & $\begin{array}{l}710 \\
740 \\
740 \\
760 \\
780\end{array}$ & $\begin{array}{l}8.2 \\
8.2 \\
8.1 \\
8.1 \\
8.2\end{array}$ & $\begin{array}{l}7.8 \\
7.9 \\
7.7 \\
7.7 \\
8.0\end{array}$ & $\begin{array}{l}9.2 \\
7.9 \\
7.8 \\
7.6 \\
8.0\end{array}$ & $\begin{array}{l}7.9 \\
7.5 \\
6.8 \\
6.7 \\
7.4\end{array}$ & $\begin{array}{l}52 \\
53 \\
56 \\
56 \\
55\end{array}$ & $\begin{array}{l}50 \\
52 \\
52 \\
55 \\
54\end{array}$ \\
\hline $\begin{array}{l}21 \ldots \\
22 \ldots \\
23 \ldots \\
24 \ldots \\
25 \ldots\end{array}$ & $\begin{array}{l}820 \\
830 \\
830 \\
840 \\
850\end{array}$ & $\begin{array}{l}770 \\
770 \\
800 \\
800 \\
800\end{array}$ & $\begin{array}{l}7.7 \\
7.8 \\
7.9 \\
7.9 \\
7.8\end{array}$ & $\begin{array}{l}7.6 \\
7.7 \\
7.8 \\
7.8 \\
7.7\end{array}$ & $\begin{array}{l}2.7 \\
1.4 \\
1.1 \\
1.1 \\
1.6\end{array}$ & $\begin{array}{l}.7 \\
.6 \\
.4 \\
.5 \\
.6\end{array}$ & $\begin{array}{l}63 \\
64 \\
65 \\
65 \\
67\end{array}$ & $\begin{array}{l}62 \\
63 \\
64 \\
63 \\
65\end{array}$ & $\begin{array}{l}810 \\
830 \\
840 \\
860 \\
840\end{array}$ & $\begin{array}{l}750 \\
780 \\
800 \\
830 \\
800\end{array}$ & $\begin{array}{l}8.2 \\
8.2 \\
8.2 \\
8.2 \\
8.2\end{array}$ & $\begin{array}{l}8.0 \\
7.9 \\
7.9 \\
8.1 \\
8.1\end{array}$ & $\begin{array}{l}7.9 \\
7.9 \\
7.1 \\
6.6 \\
8.9\end{array}$ & $\begin{array}{l}7.2 \\
6.7 \\
6.3 \\
5.8 \\
5.9\end{array}$ & $\begin{array}{l}54 \\
54 \\
55 \\
57 \\
59\end{array}$ & $\begin{array}{l}52 \\
53 \\
54 \\
55 \\
57\end{array}$ \\
\hline $\begin{array}{l}26 \ldots \\
27 \ldots \\
28 \ldots \\
29 \ldots \\
30 \ldots \\
31 \ldots\end{array}$ & $\begin{array}{l}860 \\
870 \\
870 \\
900 \\
910 \\
900\end{array}$ & $\begin{array}{l}830 \\
830 \\
810 \\
870 \\
870 \\
850\end{array}$ & $\begin{array}{l}7.8 \\
7.8 \\
7.7 \\
7.9 \\
7.8 \\
7.9\end{array}$ & $\begin{array}{l}7.7 \\
7.7 \\
7.6 \\
7.7 \\
7.7 \\
7.8\end{array}$ & $\begin{array}{l}1.0 \\
1.2 \\
1.1 \\
1.6 \\
1.7 \\
3.4\end{array}$ & $\begin{array}{r}.3 \\
.7 \\
.6 \\
1.1 \\
1.4 \\
1.7\end{array}$ & $\begin{array}{l}68 \\
68 \\
68 \\
67 \\
67 \\
67\end{array}$ & $\begin{array}{l}65 \\
65 \\
66 \\
65 \\
65 \\
65\end{array}$ & $\begin{array}{l}810 \\
820 \\
790 \\
670 \\
680 \\
--\end{array}$ & $\begin{array}{r}790 \\
740 \\
570 \\
470 \\
620 \\
--\end{array}$ & $\begin{array}{l}8.1 \\
8.1 \\
8.4 \\
8.2 \\
8.2 \\
--\end{array}$ & $\begin{array}{l}7.9 \\
8.0 \\
8.0 \\
8.0 \\
8.1 \\
--\end{array}$ & $\begin{array}{r}>15.0 \\
7.0 \\
8.8 \\
10.3 \\
>15.0 \\
--\end{array}$ & $\begin{array}{l}6.4 \\
5.9 \\
6.6 \\
8.7 \\
9.2 \\
-.\end{array}$ & $\begin{array}{l}57 \\
56 \\
54 \\
52 \\
48 \\
--\end{array}$ & $\begin{array}{l}56 \\
54 \\
52 \\
48 \\
44 \\
--\end{array}$ \\
\hline \multicolumn{9}{|c|}{ DECEMBER } & \multicolumn{8}{|c|}{ JANUARY } \\
\hline $\begin{array}{l}1 \ldots \\
2 \cdots \\
3 \ldots \\
4 \ldots \\
5 \cdots\end{array}$ & $\begin{array}{l}720 \\
780 \\
800 \\
800 \\
810\end{array}$ & $\begin{array}{l}660 \\
710 \\
730 \\
720 \\
750\end{array}$ & $\begin{array}{r}8.3 \\
8.5 \\
8.5 \\
-.- \\
8.3\end{array}$ & $\begin{array}{r}8.0 \\
8.1 \\
7.8 \\
-\overline{8.1}\end{array}$ & $\begin{array}{l}12.2 \\
12.0 \\
12.1 \\
11 \\
11.8 \\
11.6\end{array}$ & $\begin{array}{r}9.6 \\
9.4 \\
9.8 \\
9.6 \\
10.4\end{array}$ & $\begin{array}{l}47 \\
=- \\
=-\end{array}$ & $\begin{array}{l}45 \\
=- \\
=- \\
=-\end{array}$ & $\begin{array}{l}810 \\
840 \\
810 \\
840 \\
820\end{array}$ & $\begin{array}{l}780 \\
800 \\
790 \\
780 \\
810\end{array}$ & $\begin{array}{l}8.1 \\
8.1 \\
8.1 \\
8.1 \\
8.1\end{array}$ & $\begin{array}{l}8.0 \\
8.0 \\
8.0 \\
8.0 \\
8.0\end{array}$ & $\begin{array}{l}10.2 \\
10.6 \\
10.6 \\
10.3 \\
10.0\end{array}$ & $\begin{array}{l}9.5 \\
8.9 \\
9.2 \\
8.9 \\
8.0\end{array}$ & $\begin{array}{l}44 \\
45 \\
-- \\
-- \\
--\end{array}$ & $\begin{array}{l}44 \\
44 \\
-- \\
-- \\
--\end{array}$ \\
\hline $\begin{array}{r}6 \ldots \\
7 \ldots \\
8 \ldots \\
9 \ldots \\
10 \ldots\end{array}$ & $\begin{array}{l}850 \\
740 \\
560 \\
540 \\
500\end{array}$ & $\begin{array}{l}700 \\
560 \\
540 \\
500 \\
400\end{array}$ & $\begin{array}{r}8.4 \\
8.4 \\
-- \\
--\end{array}$ & $\begin{array}{r}8.2 \\
8.1 \\
-- \\
-- \\
--\end{array}$ & $\begin{array}{r}10.7 \\
11.0 \\
8.0 \\
7.5 \\
7.8\end{array}$ & $\begin{array}{l}9.3 \\
8.0 \\
7.2 \\
6.6 \\
7.0\end{array}$ & $\begin{array}{l}=- \\
50 \\
=-\end{array}$ & $\begin{array}{l}-- \\
-- \\
-- \\
--\end{array}$ & $\begin{array}{l}870 \\
860 \\
850 \\
830 \\
830\end{array}$ & $\begin{array}{l}830 \\
820 \\
820 \\
780 \\
780\end{array}$ & $\begin{array}{l}8.1 \\
8.1 \\
8.1 \\
8.1 \\
8.1\end{array}$ & $\begin{array}{r}8.0 \\
8.0 \\
7.9 \\
8.0 \\
--\end{array}$ & $\begin{array}{l}=- \\
=- \\
=- \\
--\end{array}$ & $\begin{array}{l}-- \\
-- \\
=- \\
--\end{array}$ & $\begin{array}{l}=- \\
z- \\
z-\end{array}$ & $\begin{array}{l}=- \\
=- \\
=- \\
=\end{array}$ \\
\hline $\begin{array}{l}11 \ldots \\
12 \ldots \\
13 \ldots \\
14 \ldots \\
15 \ldots\end{array}$ & $\begin{array}{l}420 \\
410 \\
480 \\
580 \\
610\end{array}$ & $\begin{array}{l}370 \\
390 \\
400 \\
480 \\
580\end{array}$ & $\begin{array}{l}-\approx \\
\therefore \\
-\therefore\end{array}$ & $\begin{array}{l}=- \\
=- \\
--\end{array}$ & $\begin{array}{l}9.0 \\
9.2 \\
9.9 \\
9.7 \\
9.4\end{array}$ & $\begin{array}{l}7.8 \\
8.7 \\
8.9 \\
9.3 \\
8.1\end{array}$ & $\begin{array}{l}=- \\
=- \\
=-\end{array}$ & $\begin{array}{l}=- \\
=- \\
=- \\
=-\end{array}$ & $\begin{array}{l}830 \\
830 \\
830 \\
850 \\
840\end{array}$ & $\begin{array}{l}810 \\
810 \\
810 \\
810 \\
830\end{array}$ & $\begin{array}{l}-.- \\
8.1 \\
8.1 \\
8.1 \\
8.1\end{array}$ & $\begin{array}{l}-- \\
8.0 \\
8.0 \\
8.0 \\
8.0\end{array}$ & $\begin{array}{l}= \\
= \\
=\end{array}$ & $\begin{array}{l}-- \\
-- \\
-- \\
--\end{array}$ & $\begin{array}{l}=- \\
\ddot{--} \\
--\end{array}$ & $\begin{array}{l}= \\
=- \\
=\end{array}$ \\
\hline $\begin{array}{l}16 \ldots \\
17 \ldots \\
18 \ldots \\
19 \ldots \\
20 \ldots\end{array}$ & $\begin{array}{l}640 \\
670 \\
680 \\
710 \\
720\end{array}$ & $\begin{array}{l}610 \\
640 \\
670 \\
680 \\
690\end{array}$ & $\begin{array}{l}-- \\
-- \\
-- \\
--\end{array}$ & $\begin{array}{l}-\approx \\
-- \\
--\end{array}$ & $\begin{array}{l}9.8 \\
9.6 \\
9.6 \\
9.5 \\
9.3\end{array}$ & $\begin{array}{l}7.1 \\
8.8 \\
7.8 \\
8.6 \\
8.4\end{array}$ & $\begin{array}{l}= \\
=- \\
-- \\
-\end{array}$ & $\begin{array}{l}=- \\
=- \\
=- \\
=-\end{array}$ & $\begin{array}{l}850 \\
860 \\
840 \\
860 \\
860\end{array}$ & $\begin{array}{l}800 \\
800 \\
820 \\
830 \\
840\end{array}$ & $\begin{array}{l}8.1 \\
8.1 \\
8.1 \\
8.1 \\
8.1\end{array}$ & $\begin{array}{l}8.0 \\
8.0 \\
8.0 \\
8.0 \\
8.0\end{array}$ & 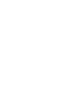 & $\begin{array}{l}=- \\
=- \\
=- \\
=-\end{array}$ & $\begin{array}{l}=- \\
\overline{--} \\
=-\end{array}$ & 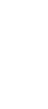 \\
\hline $\begin{array}{l}21 \ldots \\
22 \ldots \\
23 \ldots \\
24 \ldots \\
25 \ldots\end{array}$ & $\begin{array}{l}730 \\
740 \\
730 \\
740 \\
750\end{array}$ & $\begin{array}{l}710 \\
720 \\
710 \\
710 \\
710\end{array}$ & $\begin{array}{l}=- \\
=- \\
=- \\
--\end{array}$ & $\begin{array}{l}=- \\
=- \\
=- \\
--\end{array}$ & $\begin{array}{r}9.3 \\
9.2 \\
9.8 \\
9.8 \\
10.0\end{array}$ & $\begin{array}{l}8.5 \\
8.5 \\
9.0 \\
9.4 \\
9.2\end{array}$ & $\begin{array}{l}=- \\
=- \\
=- \\
--\end{array}$ & $\begin{array}{l}\because- \\
\because- \\
--\end{array}$ & $\begin{array}{l}870 \\
870 \\
870 \\
860 \\
860\end{array}$ & $\begin{array}{r}840 \\
860 \\
830 \\
830 \\
--\end{array}$ & $\begin{array}{l}8.1 \\
8.1 \\
8.2 \\
8.2 \\
8.1\end{array}$ & $\begin{array}{l}8.0 \\
8.1 \\
8.0 \\
8.0 \\
8.0\end{array}$ & $=$ & $\begin{array}{l}=- \\
-- \\
-- \\
--\end{array}$ & $\begin{array}{l}=- \\
\ddot{-} \\
=\end{array}$ & 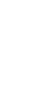 \\
\hline $\begin{array}{l}26 \ldots \\
27 \ldots \\
28 \ldots \\
29 \ldots \\
30 \ldots \\
31 \ldots\end{array}$ & $\begin{array}{r}770 \\
750 \\
780 \\
1110 \\
860 \\
860\end{array}$ & $\begin{array}{l}720 \\
700 \\
720 \\
750 \\
780 \\
780\end{array}$ & $\begin{array}{l}-- \\
\overline{--} \\
=- \\
\overline{--}\end{array}$ & $\begin{array}{l}=- \\
=- \\
=- \\
-- \\
8.0\end{array}$ & $\begin{array}{r}10.0 \\
10.2 \\
9.9 \\
9.7 \\
11.3 \\
11.1\end{array}$ & $\begin{array}{r}9.4 \\
9.6 \\
9.1 \\
9.1 \\
8.9 \\
10.1\end{array}$ & $\begin{array}{l}=- \\
=- \\
=- \\
--\end{array}$ & $\begin{array}{l}=- \\
z- \\
=- \\
=-\end{array}$ & $\begin{array}{l}860 \\
840 \\
820 \\
690 \\
690 \\
730\end{array}$ & $\begin{array}{l}830 \\
800 \\
690 \\
570 \\
640 \\
680\end{array}$ & $\begin{array}{l}8.1 \\
8.2 \\
8.1 \\
8.1 \\
8.1 \\
8.1\end{array}$ & $\begin{array}{l}8.0 \\
8.1 \\
8.0 \\
8.0 \\
8.0 \\
8.0\end{array}$ & $=$ & $\begin{array}{l}=- \\
=- \\
=- \\
=-\end{array}$ & $\begin{array}{l}=- \\
=- \\
=- \\
=\end{array}$ & $\begin{array}{l}= \\
\because- \\
=- \\
--\end{array}$ \\
\hline
\end{tabular}


GREAT MIAMI RIVER BASIN--Continued

3-2716. GREAT MIAMI RIVER NEAR MIAMISBURG, OHIO--Continued

Data from continuous recorder, water year October 1966 to September 1967--Continued

\begin{tabular}{|c|c|c|c|c|c|c|c|c|c|c|c|c|c|c|c|c|}
\hline \multirow{3}{*}{ Day } & \multicolumn{8}{|c|}{ FEBRUARY } & \multicolumn{8}{|c|}{ MARCH } \\
\hline & \multicolumn{2}{|c|}{$\begin{array}{l}\text { Specific } \\
\text { conductance } \\
\text { (micromhos } \\
\text { at } 25^{\circ} \mathrm{C} \text { ) }\end{array}$} & \multicolumn{2}{|c|}{$\mathbf{p H}$} & \multicolumn{2}{|c|}{$\begin{array}{c}\text { Dissolved } \\
\text { oxygen } \\
\text { (ppm) }\end{array}$} & \multicolumn{2}{|c|}{$\begin{array}{l}\text { Temper- } \\
\text { ature } \\
(\mathrm{F})\end{array}$} & \multicolumn{2}{|c|}{$\begin{array}{l}\text { Specific } \\
\text { conductance } \\
\text { (micromhos } \\
\text { at } 25^{\circ} \mathrm{C} \text { ) }\end{array}$} & \multicolumn{2}{|c|}{$\mathbf{p H}$} & \multicolumn{2}{|c|}{$\begin{array}{c}\text { D'ssolved } \\
\text { oxygen } \\
\text { (ppm) }\end{array}$} & \multicolumn{2}{|c|}{$\begin{array}{c}\text { Temper- } \\
\text { ature } \\
\left({ }^{\circ} \mathrm{F}\right)\end{array}$} \\
\hline & $\operatorname{Max}$ & Min & $\operatorname{Max}$ & Min & $\operatorname{Max}$ & Min & Max & Min & Max & Min & Max & Min & Max & Min & $\operatorname{Max}$ & Min \\
\hline $\begin{array}{l}1 \ldots \\
2 \ldots \\
3 \ldots \\
5 \ldots\end{array}$ & $\begin{array}{l}760 \\
740 \\
670 \\
550 \\
640\end{array}$ & $\begin{array}{l}700 \\
610 \\
510 \\
500 \\
550\end{array}$ & $\begin{array}{l}8.1 \\
8.1 \\
8.1 \\
8.1 \\
8.1\end{array}$ & $\begin{array}{l}8.0 \\
8.0 \\
8.0 \\
8.0 \\
8.0\end{array}$ & $\begin{array}{l}-- \\
-- \\
--\end{array}$ & $\begin{array}{l}-- \\
=- \\
-- \\
--\end{array}$ & & & $\begin{array}{r}-- \\
\overline{--} \\
790 \\
--\end{array}$ & $\begin{array}{c}-- \\
-- \\
-- \\
--\end{array}$ & $\begin{array}{l}-- \\
-- \\
-- \\
8.6 \\
--\end{array}$ & $\begin{array}{l}-- \\
\overline{--} \\
8.4\end{array}$ & $=$ & $=-$ & & \\
\hline $\begin{array}{c}6 \ldots \\
7 \ldots \\
8 \ldots \\
9 \ldots\end{array}$ & $\begin{array}{l}710 \\
870 \\
780 \\
800 \\
790\end{array}$ & $\begin{array}{l}630 \\
690 \\
720 \\
780 \\
770\end{array}$ & $\begin{array}{l}8.1 \\
8.1 \\
8.1 \\
8.3 \\
8.5\end{array}$ & $\begin{array}{l}8.0 \\
8.0 \\
8.0 \\
8.1 \\
8.2\end{array}$ & $\begin{array}{l}= \\
= \\
= \\
10.8\end{array}$ & $\mid \begin{array}{c}-- \\
-- \\
-- \\
-- \\
10.2\end{array}$ & & & $\begin{array}{l}560 \\
570 \\
560 \\
590 \\
610\end{array}$ & $\begin{array}{l}400 \\
420 \\
480 \\
550 \\
590\end{array}$ & $\begin{array}{l}8.5 \\
8.5 \\
8.4 \\
8.4 \\
8.4\end{array}$ & $\begin{array}{l}8.0 \\
8.1 \\
8.2 \\
8.1 \\
8.2\end{array}$ & $\begin{array}{l}- \\
- \\
-\end{array}$ & $\begin{array}{l}=- \\
=- \\
--\end{array}$ & & \\
\hline $\begin{array}{l}11 \cdots \\
12 \ldots \\
13 \ldots \\
14 \cdots \\
15 \cdots\end{array}$ & $\begin{array}{l}850 \\
810 \\
830 \\
820\end{array}$ & $\begin{array}{l}-- \\
760 \\
780 \\
790 \\
790\end{array}$ & $\begin{array}{l}-- \\
8.9 \\
8.8 \\
8.8 \\
8.7\end{array}$ & $\begin{array}{l}-- \\
8.3 \\
8.4 \\
8.4 \\
8.5\end{array}$ & $\begin{array}{l}10.9 \\
11.8 \\
11.5 \\
11.1 \\
10.4\end{array}$ & $\begin{array}{r}-- \\
10.5 \\
10.6 \\
9.7 \\
9.3\end{array}$ & & & $\begin{array}{r}630 \\
-- \\
630 \\
600\end{array}$ & $\begin{array}{r}530 \\
-2 \\
-- \\
570 \\
470\end{array}$ & $\begin{array}{r}8.5 \\
-.- \\
8.3 \\
8.2\end{array}$ & $\begin{array}{r}8.2 \\
\overline{--} \\
8.1 \\
8.0\end{array}$ & $\begin{array}{l}-- \\
= \\
--\end{array}$ & $\begin{array}{l}-- \\
-- \\
-- \\
--\end{array}$ & & \\
\hline $\begin{array}{l}16 \ldots \\
17 \ldots \\
18 \ldots \\
19 \ldots \\
20 \ldots\end{array}$ & $\begin{array}{r}820 \\
720 \\
690 \\
720\end{array}$ & $\begin{array}{l}770 \\
-- \\
690 \\
560 \\
670\end{array}$ & $\begin{array}{r}8.7 \\
-.- \\
8.8 \\
8.6 \\
8.6\end{array}$ & $\begin{array}{r}8.5 \\
-.4 \\
8.4 \\
8.3 \\
8.3\end{array}$ & $\begin{array}{r}10.8 \\
-. \\
12.0 \\
12.3 \\
12.2\end{array}$ & $\begin{array}{r}9.1 \\
-2 \\
11.6 \\
11.6 \\
11.0\end{array}$ & & & $\begin{array}{l}520 \\
570 \\
620 \\
640 \\
650\end{array}$ & $\begin{array}{l}460 \\
520 \\
570 \\
620 \\
540\end{array}$ & $\begin{array}{l}8.4 \\
8.4 \\
8.4 \\
8.4 \\
8.3\end{array}$ & $\begin{array}{l}8.2 \\
8.2 \\
8.0 \\
8.0 \\
8.1\end{array}$ & $\begin{array}{l}9.1 \\
9.5 \\
9.9 \\
9.8 \\
9.8\end{array}$ & $\begin{array}{l}8.7 \\
8.9 \\
9.1 \\
9.5 \\
8.9\end{array}$ & & \\
\hline $\begin{array}{l}21 \ldots \\
22 \ldots \\
23 \ldots \\
24 \ldots \\
25 \ldots\end{array}$ & $\begin{array}{l}730 \\
730 \\
770 \\
790 \\
840\end{array}$ & $\begin{array}{l}700 \\
700 \\
720 \\
750 \\
780\end{array}$ & $\begin{array}{l}8.5 \\
8.7 \\
8.8 \\
8.9 \\
9.0\end{array}$ & $\begin{array}{l}8.2 \\
8.5 \\
8.5 \\
8.5 \\
8.6\end{array}$ & $\begin{array}{r}12.6 \\
13.4 \\
13.9 \\
-- \\
--\end{array}$ & $\begin{array}{r}10.6 \\
11.7 \\
11.9 \\
-- \\
--\end{array}$ & & & $\begin{array}{l}660 \\
610 \\
570 \\
620 \\
660\end{array}$ & $\begin{array}{l}610 \\
490 \\
490 \\
570 \\
620\end{array}$ & $\begin{array}{l}8.4 \\
8.4 \\
8.4 \\
8.5 \\
8.5\end{array}$ & $\begin{array}{l}8.2 \\
8.2 \\
8.1 \\
8.1 \\
8.2\end{array}$ & $\begin{array}{l}9.3 \\
9.6 \\
9.4 \\
9.1 \\
9.0\end{array}$ & $\begin{array}{l}8.6 \\
9.1 \\
8.8 \\
8.7 \\
8.7\end{array}$ & & \\
\hline $\begin{array}{l}26 \ldots \\
27 \ldots \\
28 \ldots \\
29 \ldots \\
30 \ldots \\
31 \ldots\end{array}$ & $\begin{array}{r}880 \\
=- \\
=- \\
=-\end{array}$ & $\begin{array}{r}820 \\
=- \\
=- \\
=\end{array}$ & $\begin{array}{c}8.7 \\
-- \\
-- \\
-- \\
-- \\
\end{array}$ & $\begin{array}{c}8.4 \\
-\square \\
-\square \\
-- \\
--\end{array}$ & $\begin{array}{l}=- \\
=- \\
=- \\
=- \\
--\end{array}$ & $\begin{array}{l}-- \\
-- \\
-- \\
-- \\
--\end{array}$ & & & $\begin{array}{r}690 \\
700 \\
700 \\
=- \\
- \\
560\end{array}$ & $\begin{array}{r}660 \\
670 \\
600 \\
-2 \\
=- \\
480\end{array}$ & $\begin{array}{r}8.4 \\
8.4 \\
8.2 \\
-.- \\
8.1\end{array}$ & $\begin{array}{r}8.1 \\
8.1 \\
8.1 \\
=- \\
7.9\end{array}$ & $\begin{array}{r}8.7 \\
8.4 \\
8.1 \\
=- \\
-\overline{8.5}\end{array}$ & $\begin{array}{r}8.4 \\
7.5 \\
7.2 \\
-.2 \\
8.2\end{array}$ & & \\
\hline \multicolumn{9}{|c|}{ APRIL } & \multicolumn{6}{|c|}{ MAY } & & \\
\hline $\begin{array}{l}1 \ldots \\
2 \ldots \\
3 \ldots \\
4 \bullet \\
5 \ldots\end{array}$ & $\begin{array}{l}600 \\
630 \\
660 \\
690 \\
690\end{array}$ & $\begin{array}{l}560 \\
600 \\
630 \\
660 \\
510\end{array}$ & $\begin{array}{l}8.2 \\
8.2 \\
8.2 \\
8.3 \\
8.3\end{array}$ & $\begin{array}{l}8.0 \\
8 \cdot 0 \\
8.1 \\
8.2 \\
8.1\end{array}$ & $\begin{array}{l}8.6 \\
8.3 \\
8.9 \\
9.8 \\
9.5\end{array}$ & $\begin{array}{l}8.0 \\
8.0 \\
7.8 \\
8.5 \\
8.7\end{array}$ & & & $\begin{array}{l}720 \\
710 \\
650 \\
600 \\
630\end{array}$ & $\begin{array}{l}680 \\
610 \\
540 \\
550 \\
600\end{array}$ & $\begin{array}{l}7.8 \\
8.2 \\
8.2 \\
8.2 \\
8.2\end{array}$ & $\begin{array}{l}7.6 \\
7.5 \\
8.1 \\
8.0 \\
8.0\end{array}$ & $\begin{array}{r}-- \\
8.1 \\
9.4 \\
=- \\
--\end{array}$ & $\begin{array}{r}-- \\
6.5 \\
7.9 \\
--\end{array}$ & & \\
\hline $\begin{array}{c}6 \ldots \\
7 \ldots \\
8 \ldots \\
10 \ldots\end{array}$ & $\begin{array}{l}570 \\
540 \\
590 \\
620 \\
520\end{array}$ & $\begin{array}{l}490 \\
510 \\
540 \\
580 \\
600\end{array}$ & $\begin{array}{l}8.1 \\
7.9 \\
7.8 \\
7.8 \\
7.8\end{array}$ & $\begin{array}{l}7.8 \\
7.8 \\
7.6 \\
7.6 \\
7.6\end{array}$ & $\begin{array}{r}9.8 \\
10.4 \\
10.8 \\
10.9 \\
10.2\end{array}$ & $\begin{array}{r}9.1 \\
9.7 \\
10.6 \\
10.1 \\
10.0\end{array}$ & ! & & $\begin{array}{l}650 \\
570 \\
450 \\
390 \\
460\end{array}$ & $\begin{array}{l}570 \\
350 \\
330 \\
340 \\
390\end{array}$ & $\begin{array}{l}8.2 \\
8.1 \\
8.0 \\
8.0 \\
8.1\end{array}$ & $\begin{array}{l}8.0 \\
8.0 \\
7.8 \\
7.8 \\
7.8\end{array}$ & $\begin{array}{l}-- \\
-- \\
--\end{array}$ & $\begin{array}{l}-- \\
z- \\
=-\end{array}$ & & \\
\hline $\begin{array}{l}11 \ldots \\
12 \ldots \\
13 \ldots \\
14 \ldots \\
15 \ldots\end{array}$ & $\begin{array}{l}640 \\
650 \\
690 \\
690 \\
690\end{array}$ & $\begin{array}{l}620 \\
640 \\
650 \\
590 \\
530\end{array}$ & $\begin{array}{l}7.9 \\
7.9 \\
7.9 \\
7.9 \\
8.1\end{array}$ & $\begin{array}{l}7.7 \\
7.7 \\
7.8 \\
7.6 \\
7.8\end{array}$ & $\begin{array}{l}10.6 \\
10.9 \\
10.0 \\
11.0 \\
11.1\end{array}$ & $\begin{array}{r}10.1 \\
10.0 \\
9.4 \\
8.9 \\
9.1\end{array}$ & & & $\begin{array}{l}500 \\
500 \\
490 \\
530 \\
540\end{array}$ & $\begin{array}{l}370 \\
410 \\
440 \\
450 \\
420\end{array}$ & $\begin{array}{l}8.0 \\
8.0 \\
8.0 \\
8.1 \\
8.0\end{array}$ & $\begin{array}{l}7.9 \\
7.9 \\
7.9 \\
8.0 \\
7.9\end{array}$ & $\begin{array}{l}-- \\
z- \\
--\end{array}$ & $\begin{array}{l}-- \\
-- \\
-- \\
--\end{array}$ & & \\
\hline $\begin{array}{l}16 \ldots \\
17 \ldots \\
18 \ldots \\
19 \ldots \\
20 \ldots\end{array}$ & $\begin{array}{l}700 \\
710 \\
700 \\
730 \\
740\end{array}$ & $\begin{array}{l}690 \\
650 \\
660 \\
700 \\
720\end{array}$ & $\begin{array}{l}8.0 \\
8.0 \\
7.9 \\
7.9 \\
8.1\end{array}$ & $\begin{array}{l}7.8 \\
7.8 \\
7.7 \\
7.7 \\
7.8\end{array}$ & $\begin{array}{r}10.9 \\
9.7 \\
9.6 \\
11.0 \\
11.1\end{array}$ & $\begin{array}{r}9.0 \\
8.0 \\
7.4 \\
8.6 \\
8.9\end{array}$ & & & $\begin{array}{l}580 \\
610 \\
610 \\
650 \\
690\end{array}$ & $\begin{array}{l}520 \\
570 \\
540 \\
610 \\
640\end{array}$ & $\begin{array}{l}8.0 \\
8.1 \\
8.0 \\
7.9 \\
7.9\end{array}$ & $\begin{array}{l}7.9 \\
7.9 \\
7.7 \\
7.7 \\
7.7\end{array}$ & $\begin{array}{l}-- \\
--\end{array}$ & $\begin{array}{l}-- \\
-- \\
--\end{array}$ & 1 & \\
\hline $\begin{array}{l}21 \ldots \\
22 \ldots \\
23 \ldots \\
24 \ldots \\
25 \ldots\end{array}$ & $\begin{array}{l}750 \\
700 \\
670 \\
640 \\
630\end{array}$ & $\begin{array}{l}670 \\
550 \\
620 \\
580 \\
610\end{array}$ & $\begin{array}{l}7.9 \\
7.8 \\
7.9 \\
7.8 \\
7.8\end{array}$ & $\begin{array}{l}7.7 \\
7.5 \\
7.8 \\
7.7 \\
7.5\end{array}$ & $\begin{array}{c}9.0 \\
=- \\
=- \\
=-\end{array}$ & $\begin{array}{r}7.7 \\
=- \\
-- \\
=- \\
--\end{array}$ & & & $\begin{array}{l}700 \\
700 \\
720 \\
720 \\
720\end{array}$ & $\begin{array}{l}670 \\
660 \\
670 \\
690 \\
690\end{array}$ & $\begin{array}{l}8.1 \\
8.1 \\
8.1 \\
8.2 \\
8.4\end{array}$ & $\begin{array}{l}7.7 \\
7.8 \\
7.9 \\
8.0 \\
8.2\end{array}$ & $\begin{array}{l}-- \\
-- \\
--\end{array}$ & 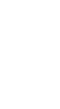 & & \\
\hline $\begin{array}{l}26 \ldots \\
27 \ldots \\
28 \ldots \\
29 \ldots \\
30 \ldots \\
31 \ldots\end{array}$ & $\begin{array}{r}650 \\
680 \\
700 \\
720 \\
730 \\
--\end{array}$ & $\begin{array}{l}630 \\
640 \\
670 \\
700 \\
710 \\
--\end{array}$ & $\begin{array}{l}7.9 \\
7.8 \\
7.9 \\
7.9 \\
7.8 \\
-.\end{array}$ & $\begin{array}{l}7.7 \\
7.7 \\
7.7 \\
7.7 \\
7.6 \\
-.\end{array}$ & $\begin{array}{l}-= \\
-- \\
- \\
-=\end{array}$ & $\begin{array}{l}-- \\
-- \\
-- \\
-- \\
--\end{array}$ & & & $\begin{array}{l}730 \\
700 \\
700 \\
570 \\
670 \\
710\end{array}$ & $\begin{array}{l}620 \\
580 \\
530 \\
540 \\
580 \\
660\end{array}$ & $\begin{array}{l}8.4 \\
8.6 \\
8.8 \\
8.5 \\
8.2 \\
8.2\end{array}$ & $\begin{array}{l}8.1 \\
8.0 \\
8.2 \\
7.9 \\
7.8 \\
8.0\end{array}$ & $\begin{array}{l}= \\
=- \\
=- \\
=-\end{array}$ & $\begin{array}{l}=- \\
=- \\
z- \\
z-\end{array}$ & ' & 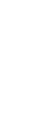 \\
\hline
\end{tabular}


GREAT MIAMI RIVER BASIN--Continued

3-2716. GREAT MIAMI RIVER NEAR MIAMISBURG, OHIO--Continued

Data from continuous recorder, water year October 1966 to September 1967--Continued

\begin{tabular}{|c|c|c|c|c|c|c|c|c|c|c|c|c|c|c|c|c|}
\hline \multirow{3}{*}{ Day } & \multicolumn{8}{|c|}{ JUNE } & \multicolumn{8}{|c|}{ JULY } \\
\hline & \multicolumn{2}{|c|}{$\begin{array}{c}\text { Specific } \\
\text { conductance } \\
\text { (micromhos } \\
\text { at } 25^{\circ} \mathrm{C} \text { ) } \\
\end{array}$} & \multicolumn{2}{|c|}{ pH } & \multicolumn{2}{|c|}{$\begin{array}{l}\text { Dissolved } \\
\text { oxygen } \\
\text { (ppm) }\end{array}$} & \multicolumn{2}{|c|}{$\begin{array}{c}\text { Temper- } \\
\text { ature } \\
\left({ }^{\circ} \mathbf{F}\right)\end{array}$} & \multicolumn{2}{|c|}{$\begin{array}{c}\text { Specific } \\
\text { conductance } \\
\text { (micromhos } \\
\text { at } 25: \mathrm{C} \text { ) }\end{array}$} & \multicolumn{2}{|c|}{ pH } & \multicolumn{2}{|c|}{$\begin{array}{l}\text { Dissolved } \\
\text { oxygen } \\
\text { (ppm) }\end{array}$} & \multicolumn{2}{|c|}{$\begin{array}{c}\text { Temper- } \\
\text { ature } \\
\left({ }^{\circ} \mathrm{F}\right)\end{array}$} \\
\hline & $\operatorname{Max}$ & Min & $\operatorname{Max}$ & Min & $\operatorname{Max}$ & Min & $\operatorname{Max}$ & Min & $\operatorname{Max}$ & Min & $\operatorname{Max}$ & Min & $\operatorname{Max}$ & Min & Max & Min \\
\hline $\begin{array}{l}1 \bullet \\
2 \bullet \\
3 \bullet \\
4 \bullet \\
5 \bullet\end{array}$ & $\begin{array}{l}730 \\
740 \\
750 \\
740 \\
730\end{array}$ & $\begin{array}{l}690 \\
720 \\
700 \\
690 \\
680\end{array}$ & $\begin{array}{l}8.4 \\
8.5 \\
8.5 \\
8.8 \\
8.9\end{array}$ & $\begin{array}{l}8.0 \\
8.2 \\
8.2 \\
8.2 \\
8.2\end{array}$ & & & & 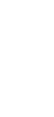 & $\begin{array}{l}680 \\
690 \\
680 \\
720 \\
720\end{array}$ & $\begin{array}{l}540 \\
640 \\
640 \\
670 \\
680\end{array}$ & $\begin{array}{l}8.2 \\
8.4 \\
8.7 \\
8.6 \\
8.6\end{array}$ & $\begin{array}{l}7.7 \\
7.8 \\
7.9 \\
7.9 \\
8.1\end{array}$ & $\begin{array}{l}= \\
\overline{-} \\
\overline{-} \\
-\end{array}$ & $\begin{array}{l}-- \\
-- \\
-- \\
-- \\
--\end{array}$ & $\begin{array}{l}z- \\
z- \\
z- \\
--\end{array}$ & $\begin{array}{l}-- \\
-- \\
-- \\
--\end{array}$ \\
\hline $\begin{array}{c}6 \ldots \\
7 \ldots \\
8 \ldots \\
9 \ldots \\
10 \ldots\end{array}$ & $\begin{array}{l}740 \\
730 \\
740 \\
740 \\
750\end{array}$ & $\begin{array}{l}700 \\
700 \\
710 \\
700 \\
710\end{array}$ & $\begin{array}{l}8.5 \\
8.3 \\
8.4 \\
8.1 \\
8.3\end{array}$ & $\begin{array}{l}8.0 \\
7.8 \\
7.9 \\
7.8 \\
7.7\end{array}$ & & & & & $\begin{array}{l}740 \\
760 \\
760 \\
750 \\
740\end{array}$ & $\begin{array}{l}720 \\
720 \\
730 \\
740 \\
720\end{array}$ & $\begin{array}{l}8.6 \\
8.3 \\
8.3 \\
8.4 \\
8.5\end{array}$ & $\begin{array}{l}7.8 \\
7.8 \\
7.9 \\
8.0 \\
8.1\end{array}$ & $\begin{array}{l}=- \\
=- \\
=-\end{array}$ & $\begin{array}{l}= \\
=- \\
=\end{array}$ & $\begin{array}{l}-- \\
=- \\
=- \\
--\end{array}$ & $\begin{array}{l}-- \\
-- \\
-- \\
--\end{array}$ \\
\hline $\begin{array}{l}11 \ldots \\
12 \ldots \\
13 \ldots \\
14 \ldots \\
15 \ldots\end{array}$ & $\begin{array}{l}750 \\
760 \\
770 \\
770 \\
770\end{array}$ & $\begin{array}{l}710 \\
690 \\
730 \\
730 \\
740\end{array}$ & $\begin{array}{l}8.8 \\
9.0 \\
8.8 \\
8.1 \\
8.0\end{array}$ & $\begin{array}{l}7.9 \\
8.2 \\
8.0 \\
7.8 \\
7.7\end{array}$ & & | & | & & $\begin{array}{l}780 \\
770 \\
790 \\
780\end{array}$ & $\begin{array}{l}-- \\
730 \\
740 \\
750 \\
770\end{array}$ & $\begin{array}{r}-- \\
8.0 \\
8.0 \\
7.9 \\
8.1\end{array}$ & $\begin{array}{l}-.- \\
7.6 \\
7.8 \\
7.8 \\
7.7\end{array}$ & $\begin{array}{c}-- \\
\overline{--} \\
3.2 \\
3.3\end{array}$ & $\begin{array}{r}-- \\
=- \\
1.7 \\
1.2\end{array}$ & $\begin{array}{l}-- \\
-- \\
-- \\
80 \\
79\end{array}$ & $\begin{array}{l}-- \\
-- \\
-- \\
78 \\
77\end{array}$ \\
\hline $\begin{array}{l}16 \ldots \\
17 \ldots \\
18 \ldots \\
19 \ldots \\
20 \ldots\end{array}$ & $\begin{array}{l}790 \\
780 \\
770 \\
720 \\
760\end{array}$ & $\begin{array}{l}750 \\
740 \\
650 \\
640 \\
710\end{array}$ & $\begin{array}{l}8.0 \\
8.0 \\
8.2 \\
8.5 \\
8.2\end{array}$ & $\begin{array}{l}7.7 \\
7.7 \\
7.8 \\
7.6 \\
7.8\end{array}$ & & & & & $\begin{array}{l}790 \\
770 \\
760 \\
780 \\
780\end{array}$ & $\begin{array}{l}770 \\
730 \\
730 \\
740 \\
750\end{array}$ & $\begin{array}{l}8.0 \\
8.2 \\
8.1 \\
7.9 \\
7.9\end{array}$ & $\begin{array}{l}7.5 \\
7.6 \\
7.7 \\
7.5 \\
7.6\end{array}$ & $\begin{array}{l}3.7 \\
5.5 \\
5.2 \\
4.2 \\
--\end{array}$ & $\begin{array}{l}1.1 \\
1.8 \\
1.8 \\
1.1 \\
1.3\end{array}$ & $\begin{array}{l}77 \\
77 \\
77 \\
78 \\
78\end{array}$ & $\begin{array}{l}76 \\
76 \\
76 \\
76 \\
78\end{array}$ \\
\hline $\begin{array}{l}21 \ldots \\
22 \ldots \\
23 \ldots \\
24 \ldots \\
25 \ldots\end{array}$ & $\begin{array}{l}750 \\
750 \\
710 \\
690 \\
690\end{array}$ & $\begin{array}{l}710 \\
690 \\
680 \\
680 \\
660\end{array}$ & $\begin{array}{l}8.1 \\
8.1 \\
8.3 \\
8.3 \\
8.3\end{array}$ & $\begin{array}{l}7.6 \\
7.9 \\
7.8 \\
7.8 \\
7.8\end{array}$ & & & & & $\begin{array}{l}760 \\
740 \\
760 \\
750 \\
750\end{array}$ & $\begin{array}{l}700 \\
680 \\
740 \\
720 \\
720\end{array}$ & $\begin{array}{l}8.1 \\
8.1 \\
8.1 \\
8.0 \\
8.0\end{array}$ & $\begin{array}{l}7.6 \\
7.5 \\
7.7 \\
7.7 \\
7.6\end{array}$ & $\begin{array}{l}-- \\
-- \\
-- \\
--\end{array}$ & $\begin{array}{l}=- \\
=- \\
--\end{array}$ & $\begin{array}{l}78 \\
-- \\
-- \\
--\end{array}$ & $\begin{array}{l}77 \\
-- \\
-- \\
--\end{array}$ \\
\hline $\begin{array}{l}26 \ldots \\
27 \ldots \\
28 \ldots \\
29 \ldots \\
30 \ldots \\
31 \ldots\end{array}$ & $\begin{array}{r}710 \\
-0 \\
700 \\
700 \\
600 \\
-+\end{array}$ & $\begin{array}{r}660 \\
-- \\
670 \\
490 \\
520 \\
--\end{array}$ & $\begin{array}{r}8.2 \\
-- \\
8.3 \\
8.2 \\
7.9 \\
--\end{array}$ & $\begin{array}{r}7.8 \\
-.8 \\
7.8 \\
7.8 \\
7.7 \\
-.-\end{array}$ & & & & & $\begin{array}{l}770 \\
780 \\
780 \\
760 \\
600 \\
610\end{array}$ & $\begin{array}{l}740 \\
750 \\
720 \\
450 \\
430 \\
460\end{array}$ & $\begin{array}{l}7.9 \\
7.7 \\
7.7 \\
7.7 \\
7.5 \\
8.0\end{array}$ & $\begin{array}{l}7.5 \\
7.5 \\
7.5 \\
7.3 \\
7.2 \\
7.5\end{array}$ & $\begin{array}{r}-- \\
1.5 \\
-- \\
--\end{array}$ & $\begin{array}{l}-- \\
-1 \\
=- \\
--\end{array}$ & $\begin{array}{l}= \\
= \\
= \\
=\end{array}$ & $\begin{array}{l}= \\
= \\
= \\
=\end{array}$ \\
\hline \multicolumn{9}{|c|}{ AUGUST } & \multicolumn{8}{|c|}{ SEPTEMBER } \\
\hline $\begin{array}{l}1 \ldots \\
2 \ldots \\
3 \ldots \\
4 \ldots \\
5 \bullet\end{array}$ & $\begin{array}{l}620 \\
640 \\
670 \\
690 \\
700\end{array}$ & $\begin{array}{l}500 \\
610 \\
620 \\
660 \\
680\end{array}$ & $\begin{array}{l}7.7 \\
7.9 \\
8.7 \\
8.5 \\
7.9\end{array}$ & $\begin{array}{l}7.4 \\
7.5 \\
7.8 \\
7.8 \\
7.5\end{array}$ & $\begin{array}{l}3.4 \\
4.0 \\
5.9 \\
5.0 \\
3.1\end{array}$ & $\begin{array}{l}2.2 \\
2.1 \\
2.3 \\
1.8 \\
1.6\end{array}$ & 1 & & $\begin{array}{l}800 \\
800 \\
800 \\
790 \\
800\end{array}$ & $\begin{array}{l}740 \\
770 \\
750 \\
750 \\
750\end{array}$ & $\begin{array}{l}8.2 \\
8.2 \\
8.3 \\
8.3 \\
8.3\end{array}$ & $\begin{array}{l}7.9 \\
8.0 \\
8.1 \\
8.2 \\
8.0\end{array}$ & $\begin{array}{l}5.3 \\
5.5 \\
6.9 \\
7.0 \\
8.0\end{array}$ & $\begin{array}{l}4.0 \\
4.7 \\
4.9 \\
5.9 \\
3.4\end{array}$ & & \\
\hline $\begin{array}{r}6 \ldots \\
7 \ldots \\
8 \ldots \\
9 \ldots \\
10 \ldots\end{array}$ & $\begin{array}{l}720 \\
720 \\
730 \\
760 \\
770\end{array}$ & $\begin{array}{l}690 \\
700 \\
710 \\
730 \\
740\end{array}$ & $\begin{array}{l}7.5 \\
7.7 \\
7.8 \\
7.9 \\
7.9\end{array}$ & $\begin{array}{l}7.4 \\
7.5 \\
7.5 \\
7.7 \\
7.7\end{array}$ & $\begin{array}{l}3.2 \\
3.8 \\
3.8 \\
3.0 \\
4.5\end{array}$ & $\begin{array}{l}1.7 \\
2.1 \\
1.7 \\
1.0 \\
1.1\end{array}$ & & & $\begin{array}{l}840 \\
800 \\
800 \\
810 \\
810\end{array}$ & $\begin{array}{l}730 \\
780 \\
720 \\
730 \\
770\end{array}$ & $\begin{array}{l}8.2 \\
8.3 \\
8.0 \\
8.0 \\
7.9\end{array}$ & $\begin{array}{l}8.0 \\
7.8 \\
7.7 \\
7.6 \\
7.7\end{array}$ & $\begin{array}{l}5.6 \\
6.3 \\
4.8 \\
5.0 \\
6.3\end{array}$ & $\begin{array}{r}1.2 \\
1.0 \\
3.0 \\
.8 \\
4.9\end{array}$ & & \\
\hline $\begin{array}{l}11 \ldots \\
12 \ldots \\
13 \ldots \\
14 \ldots \\
15 \ldots\end{array}$ & $\begin{array}{l}780 \\
810 \\
820 \\
820 \\
810\end{array}$ & $\begin{array}{l}760 \\
790 \\
800 \\
780 \\
770\end{array}$ & $\begin{array}{l}8.1 \\
7.9 \\
8.0 \\
8.3 \\
8.3\end{array}$ & $\begin{array}{l}7.7 \\
7.7 \\
7.8 \\
7.9 \\
7.9\end{array}$ & $\begin{array}{l}-- \\
=- \\
4.2 \\
3.7\end{array}$ & $\begin{array}{r}-- \\
=- \\
2.6 \\
2.4\end{array}$ & & & $\begin{array}{l}830 \\
830 \\
810 \\
840 \\
830\end{array}$ & $\begin{array}{l}780 \\
760 \\
770 \\
750 \\
780\end{array}$ & $\begin{array}{l}8.0 \\
8.0 \\
8.1 \\
8.0 \\
8.0\end{array}$ & $\begin{array}{l}7.7 \\
7.6 \\
7.8 \\
7.6 \\
7.8\end{array}$ & $\begin{array}{l}6.2 \\
6.4 \\
7.5 \\
7.6 \\
7.7\end{array}$ & $\begin{array}{l}4 \cdot 2 \\
4 \cdot 2 \\
4.4 \\
4.3 \\
2.9\end{array}$ & & \\
\hline $\begin{array}{l}16 \ldots \\
17 \ldots \\
18 \ldots \\
19 \ldots \\
20 \ldots\end{array}$ & $\begin{array}{l}820 \\
830 \\
840 \\
830 \\
830\end{array}$ & $\begin{array}{l}790 \\
800 \\
800 \\
800 \\
810\end{array}$ & $\begin{array}{l}8.0 \\
7.8 \\
7.8 \\
7.8 \\
7.7\end{array}$ & $\begin{array}{l}7.7 \\
7.7 \\
7.7 \\
7.7 \\
7.6\end{array}$ & $\begin{array}{l}2.8 \\
1.8 \\
1.7 \\
1.5 \\
1.4\end{array}$ & $\begin{array}{r}1.0 \\
1.9 \\
.0 \\
.9\end{array}$ & & & $\begin{array}{l}840 \\
800 \\
830 \\
800 \\
810\end{array}$ & $\begin{array}{l}770 \\
770 \\
740 \\
710 \\
750\end{array}$ & $\begin{array}{l}8.0 \\
8.0 \\
7.9 \\
8.0 \\
8.1\end{array}$ & $\begin{array}{l}7.8 \\
7.7 \\
7.7 \\
7.7 \\
7.8\end{array}$ & $\begin{array}{l}4.9 \\
4.0 \\
4.7 \\
5.2 \\
5.2\end{array}$ & $\begin{array}{l}1.2 \\
3.3 \\
3.5 \\
2.8 \\
2.3\end{array}$ & & \\
\hline $\begin{array}{l}21 \ldots \\
22 \ldots \\
23 \ldots \\
24 \ldots \\
25 \ldots\end{array}$ & $\begin{array}{l}820 \\
810 \\
810 \\
810 \\
810\end{array}$ & $\begin{array}{l}780 \\
770 \\
750 \\
760 \\
750\end{array}$ & $\begin{array}{l}7.7 \\
7.8 \\
8.1 \\
8.2 \\
8.0\end{array}$ & $\begin{array}{l}7.6 \\
7.7 \\
7.7 \\
7.7 \\
7.7\end{array}$ & $\begin{array}{l}2.7 \\
1.6 \\
5.0 \\
5.4 \\
--\end{array}$ & $\begin{array}{l}.9 \\
.9 \\
.9 \\
: 9 \\
-9\end{array}$ & & & $\begin{array}{r}810 \\
790 \\
=- \\
=-\end{array}$ & $\begin{array}{c}770 \\
-- \\
-- \\
--\end{array}$ & $\begin{array}{l}8.3 \\
8.0 \\
8.0 \\
8.1 \\
8.1\end{array}$ & $\begin{array}{l}7.8 \\
7.7 \\
7.7 \\
7.9 \\
7.8\end{array}$ & $\mid \begin{array}{r}10.1 \\
3.7 \\
6.2 \\
6.0 \\
5.8\end{array}$ & $\begin{array}{l}2.2 \\
1.7 \\
2.0 \\
3.4 \\
3.0\end{array}$ & & \\
\hline $\begin{array}{l}26 \ldots \\
27 \ldots \\
28 \ldots \\
29 \ldots \\
30 \ldots \\
31 \ldots\end{array}$ & $\begin{array}{l}800 \\
820 \\
820 \\
790 \\
780 \\
790\end{array}$ & $\begin{array}{l}770 \\
780 \\
760 \\
730 \\
710 \\
710\end{array}$ & $\begin{array}{l}8.1 \\
8.1 \\
8.0 \\
8.1 \\
8.2 \\
8.1\end{array}$ & $\begin{array}{l}7.8 \\
8.0 \\
7.8 \\
8.0 \\
7.8 \\
7.9\end{array}$ & $\begin{array}{r}-- \\
-- \\
-- \\
4.9 \\
5.3 \\
4.8\end{array}$ & $\begin{array}{c}-- \\
-- \\
-- \\
4.2 \\
3.7 \\
3.6\end{array}$ & & & $\begin{array}{l}=- \\
=- \\
=- \\
=-\end{array}$ & $\begin{array}{l}-- \\
-- \\
-- \\
-- \\
--\end{array}$ & $\begin{array}{l}8.2 \\
8.6 \\
8.5 \\
8.4 \\
8.1 \\
-. .\end{array}$ & $\begin{array}{l}8.0 \\
8.0 \\
8.0 \\
8.0 \\
8.0 \\
--\end{array}$ & $\begin{array}{r}4.6 \\
10.5 \\
9.6 \\
7.9 \\
5.7 \\
-0\end{array}$ & $\begin{array}{r}3.2 \\
3.2 \\
3.9 \\
3.7 \\
4.2 \\
--\end{array}$ & & \\
\hline
\end{tabular}




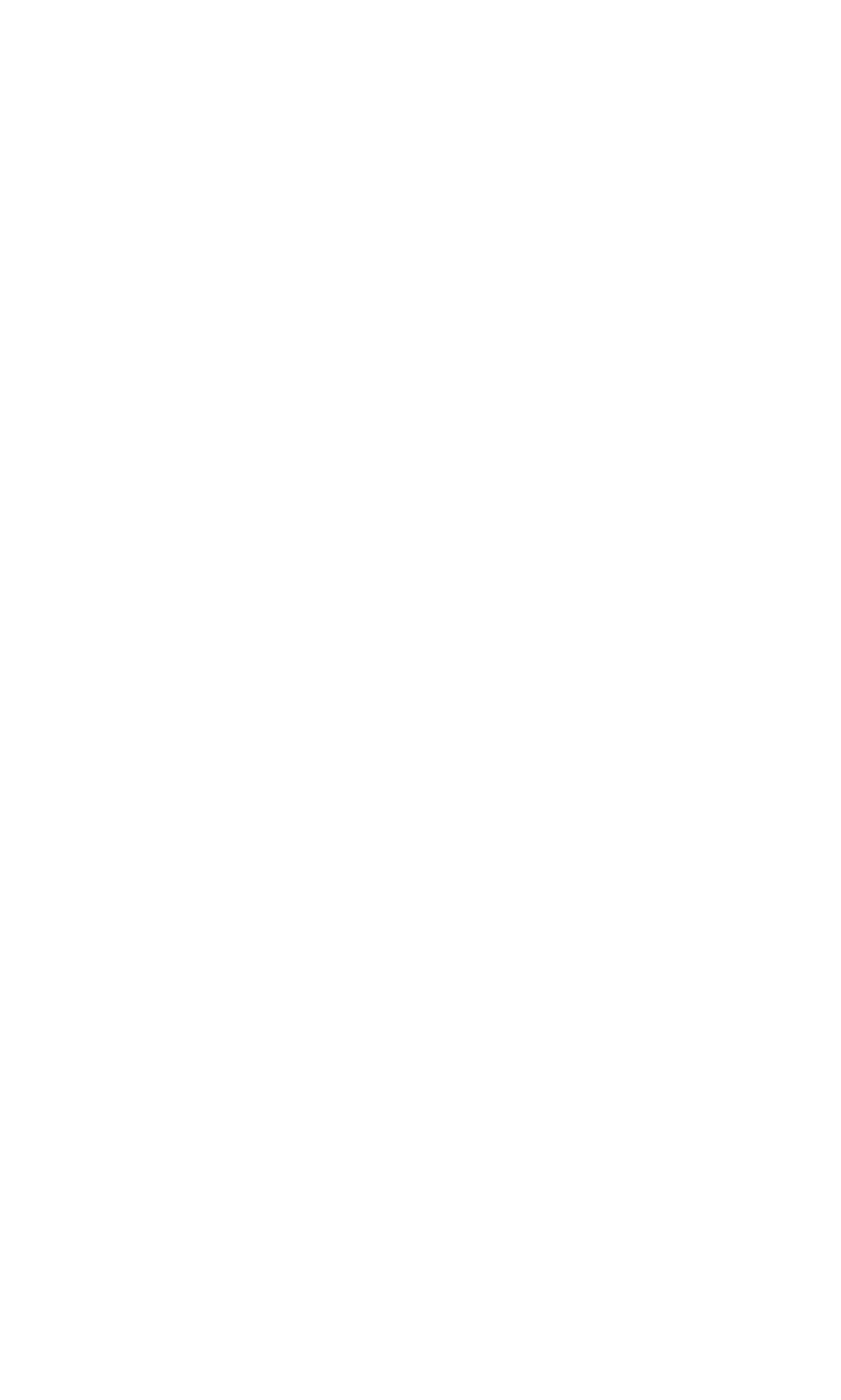




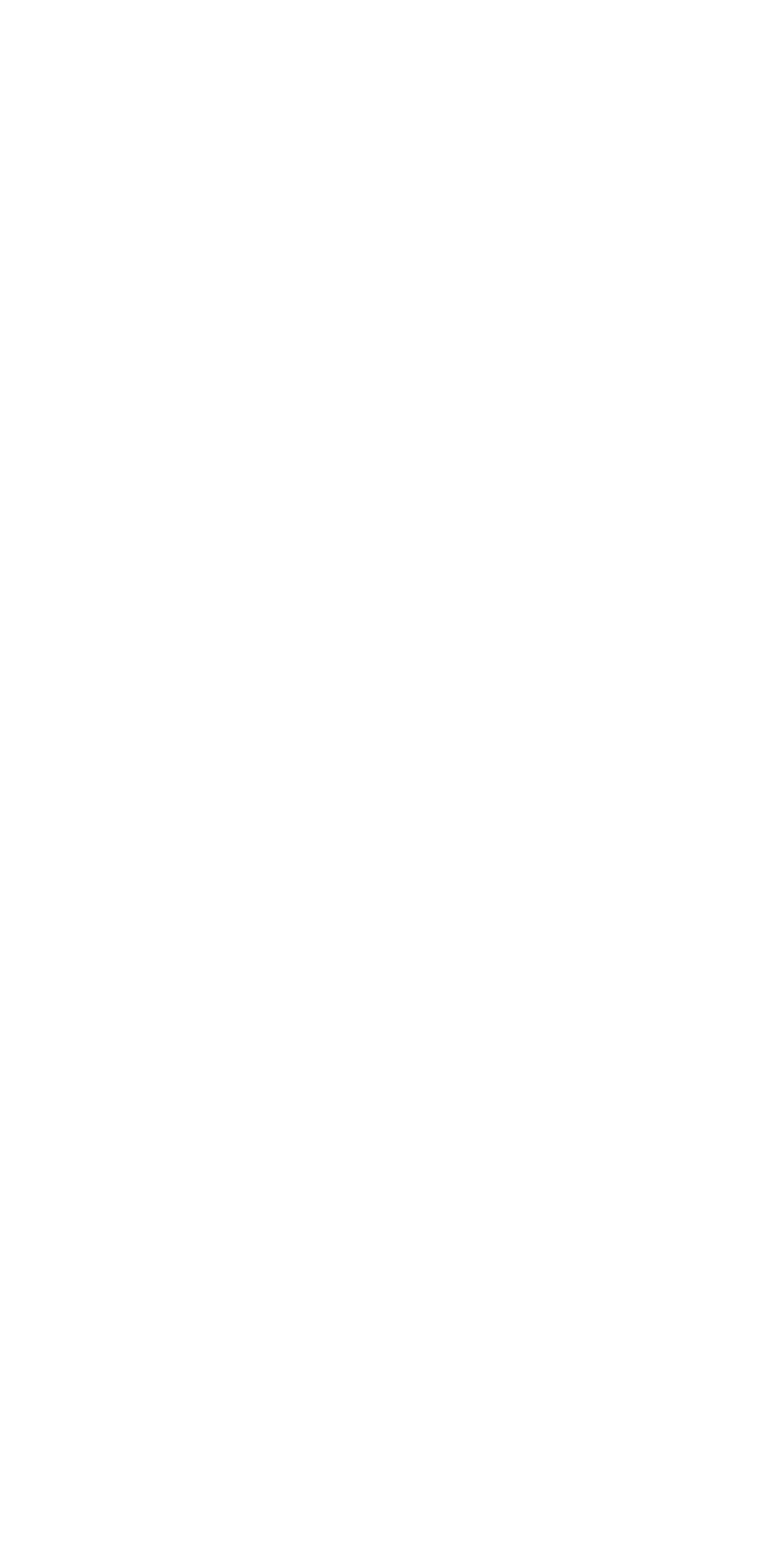




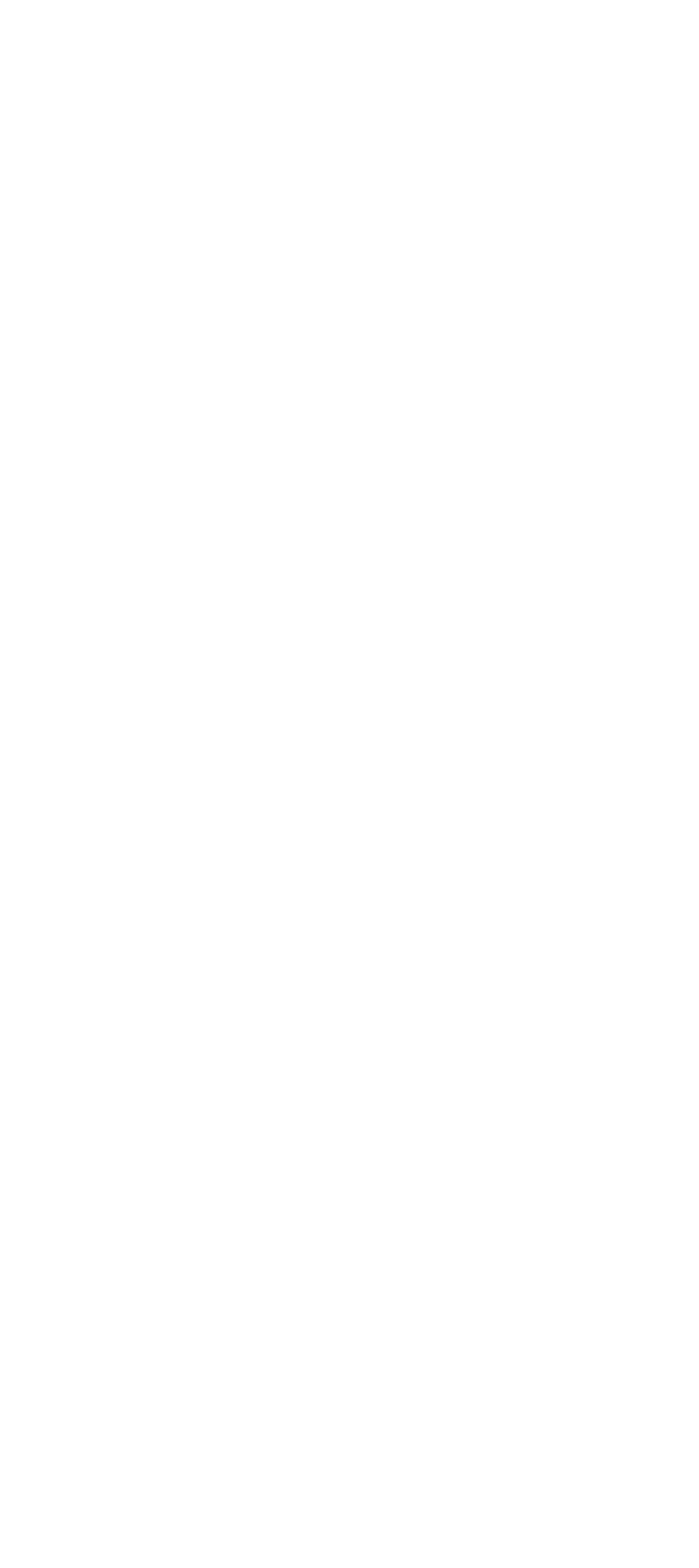




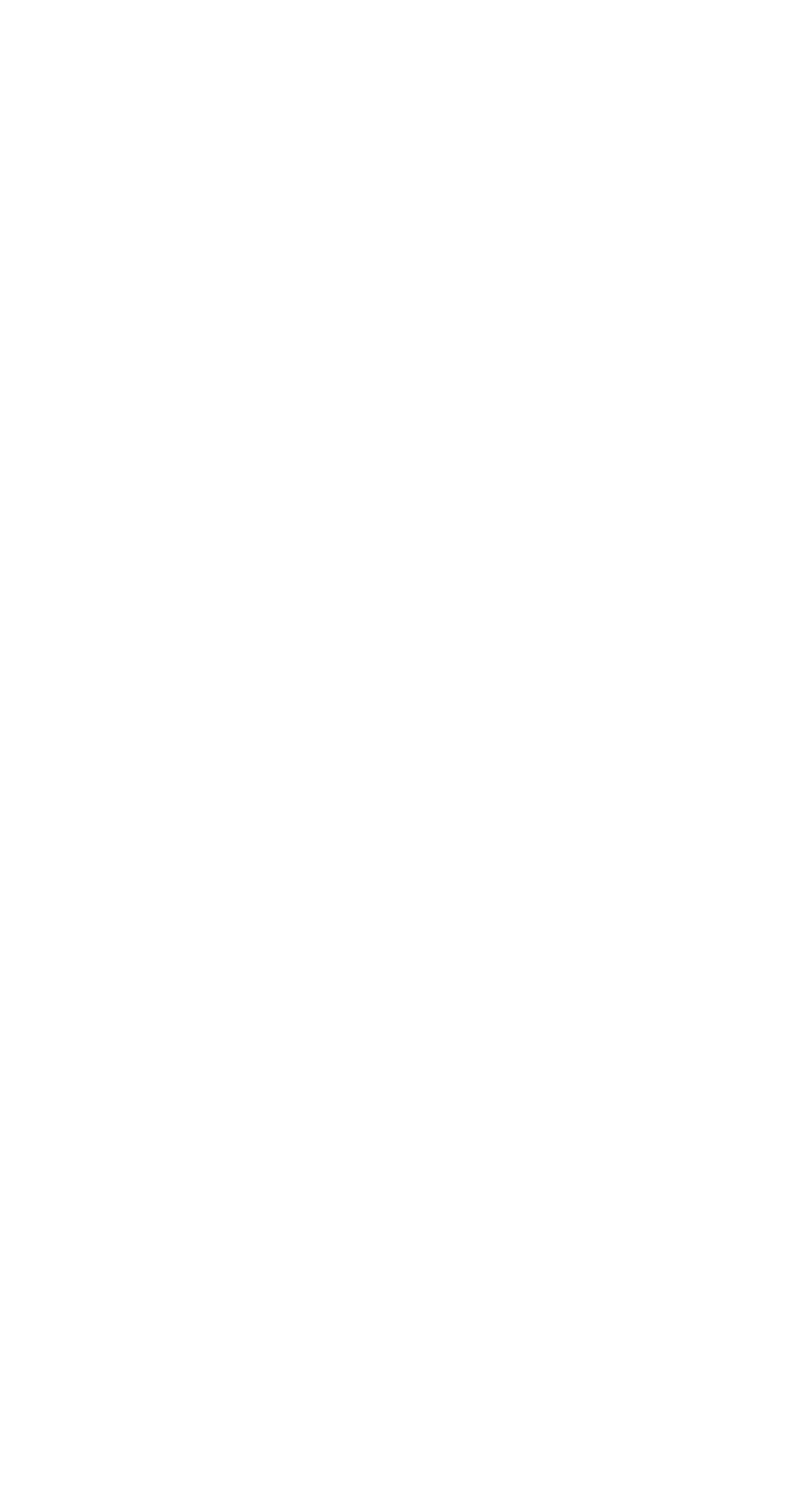




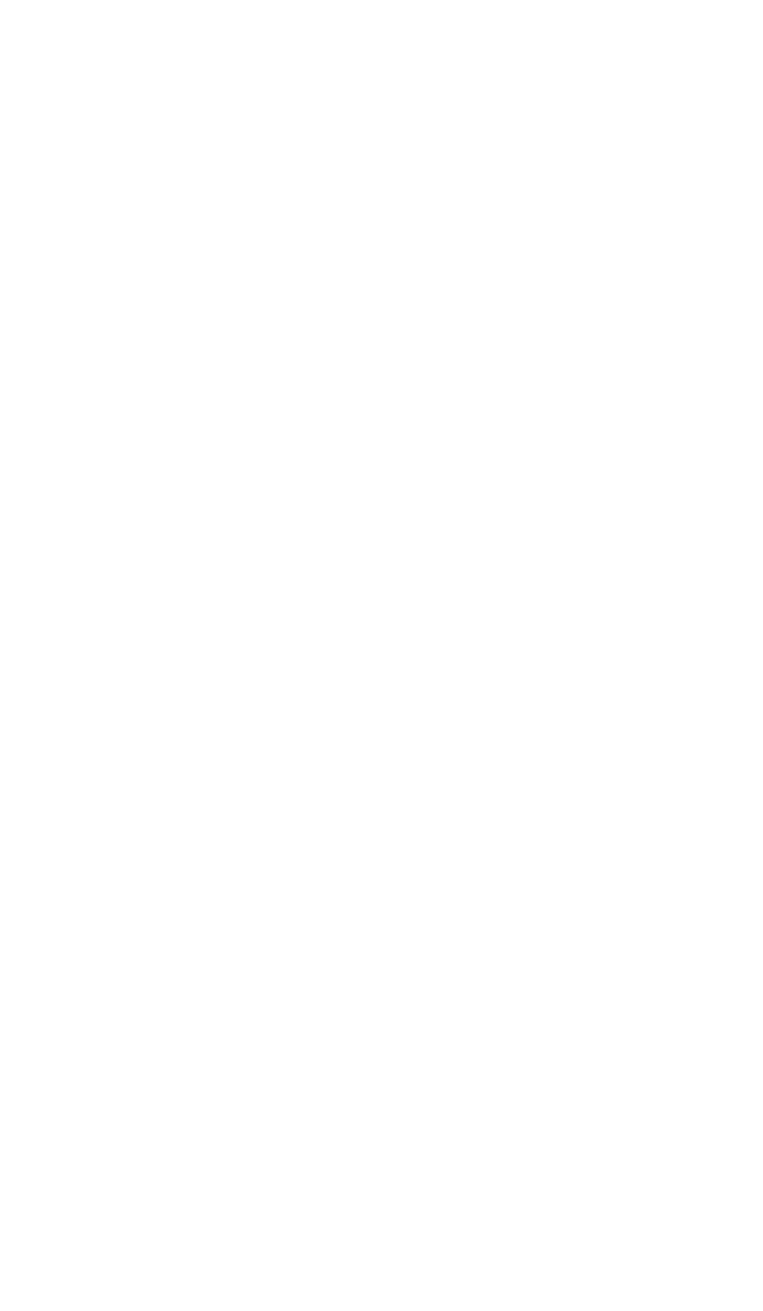




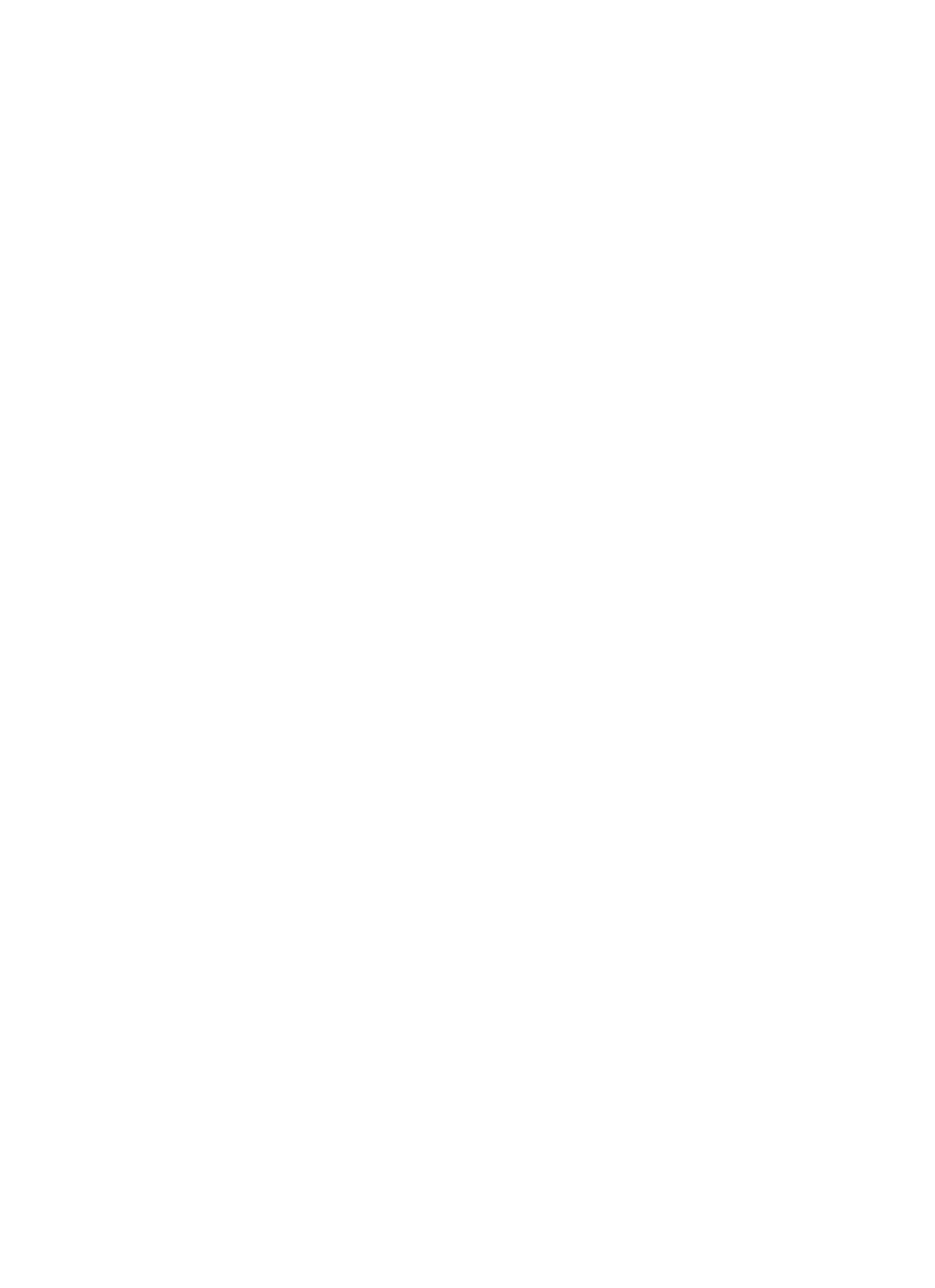




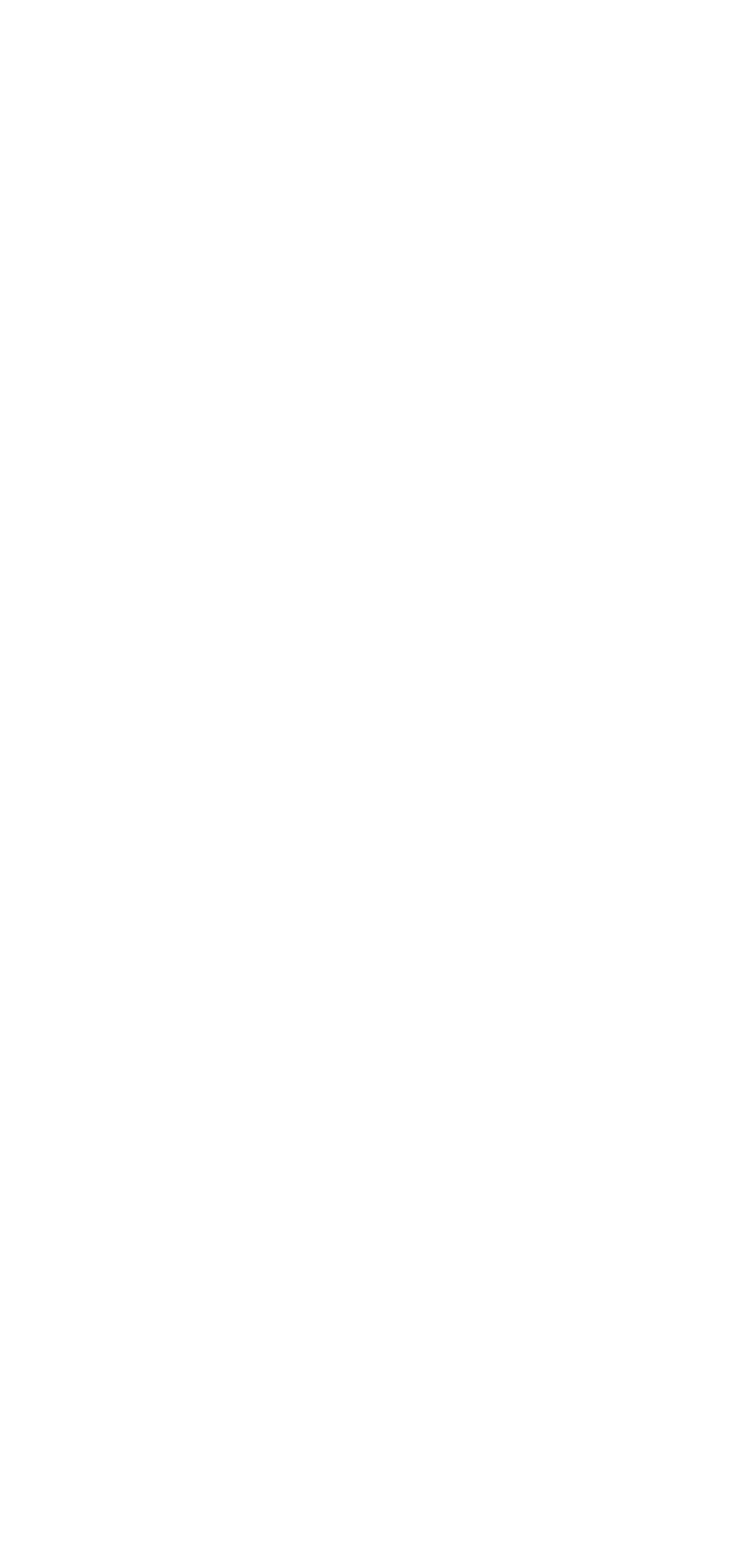




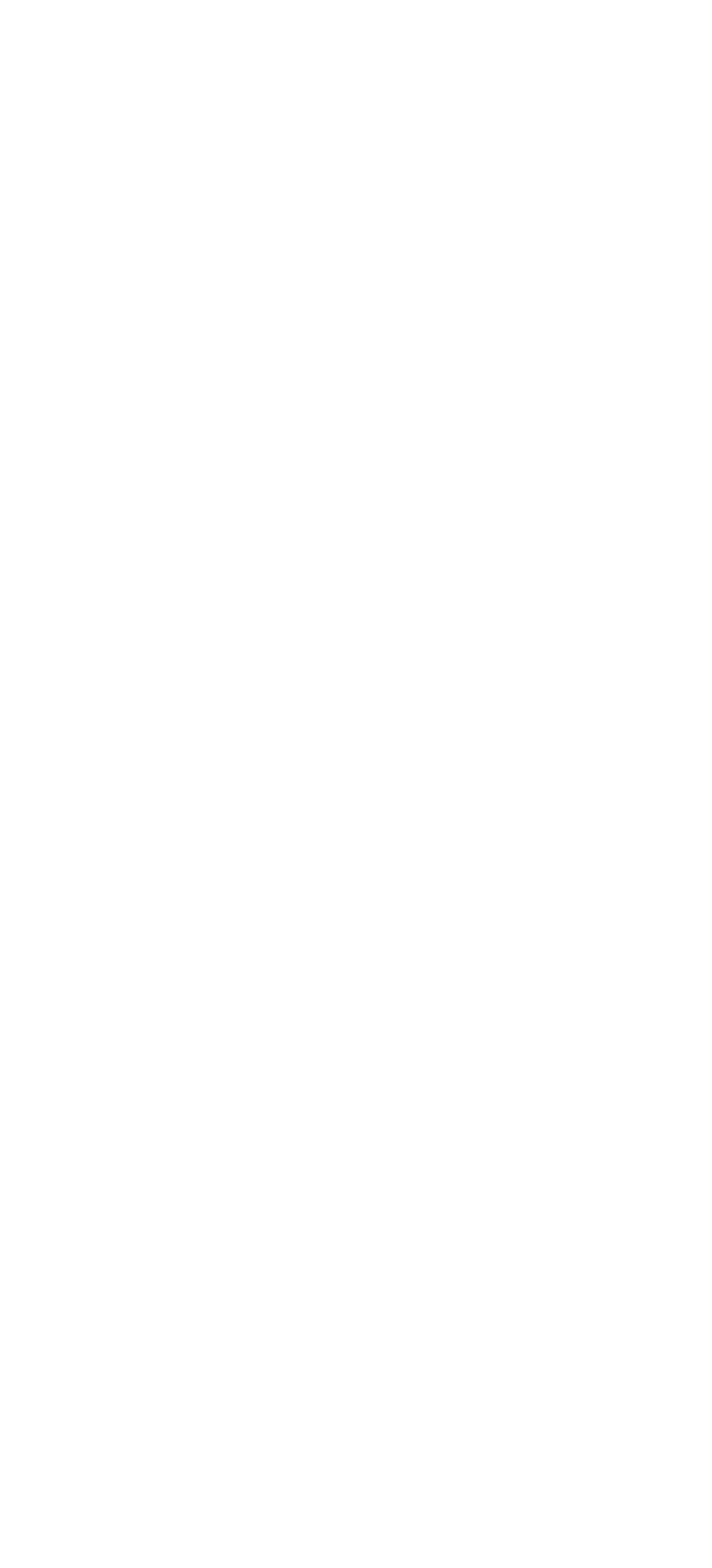




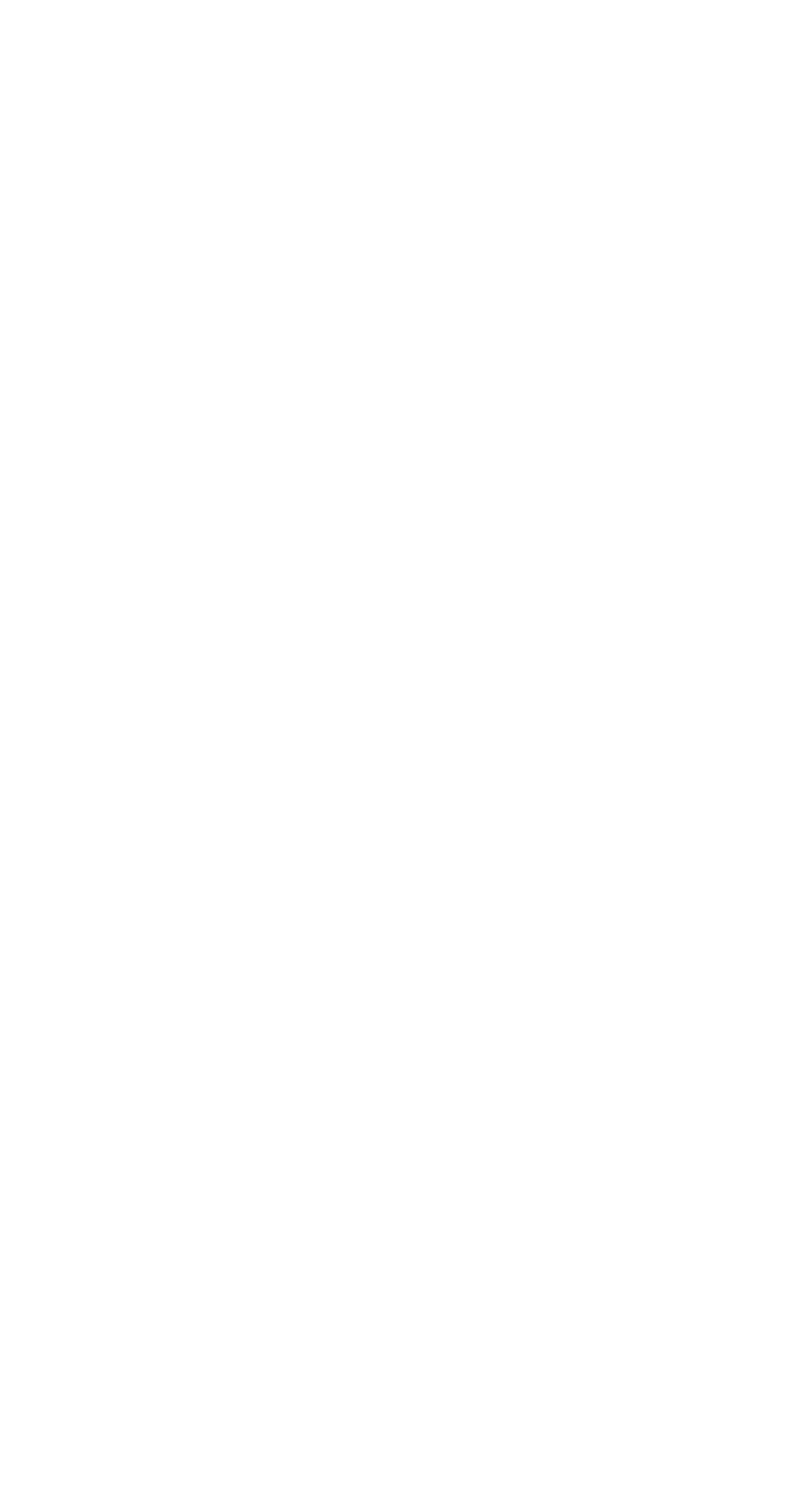


GREAT MIAMI RIVER BASIN--Continued

3-2746. GREAT MIAMI RIVER AT NEW BALTIMORE, OHIO--Continued

Data from continuous recorder, water year October 1966 to September 1967

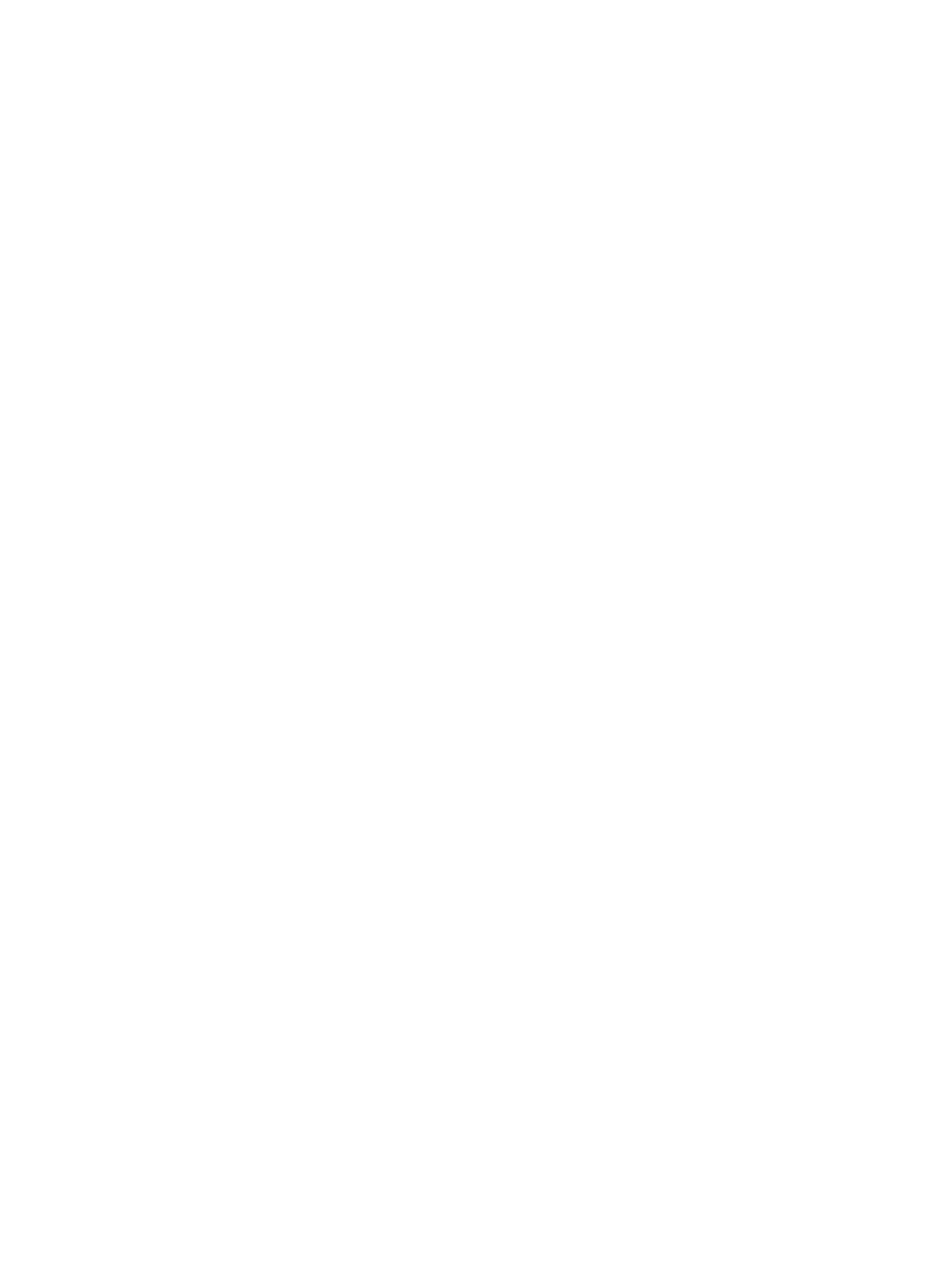


GREAT MIAMI RIVER BASIN--COntInued

3-2746. GREAT MIAMI RIVER AT NEW BALTIMORE, OHIO--Continued

Data from continuous recorder, water year 0ctober 1966 to September 1967--Continued

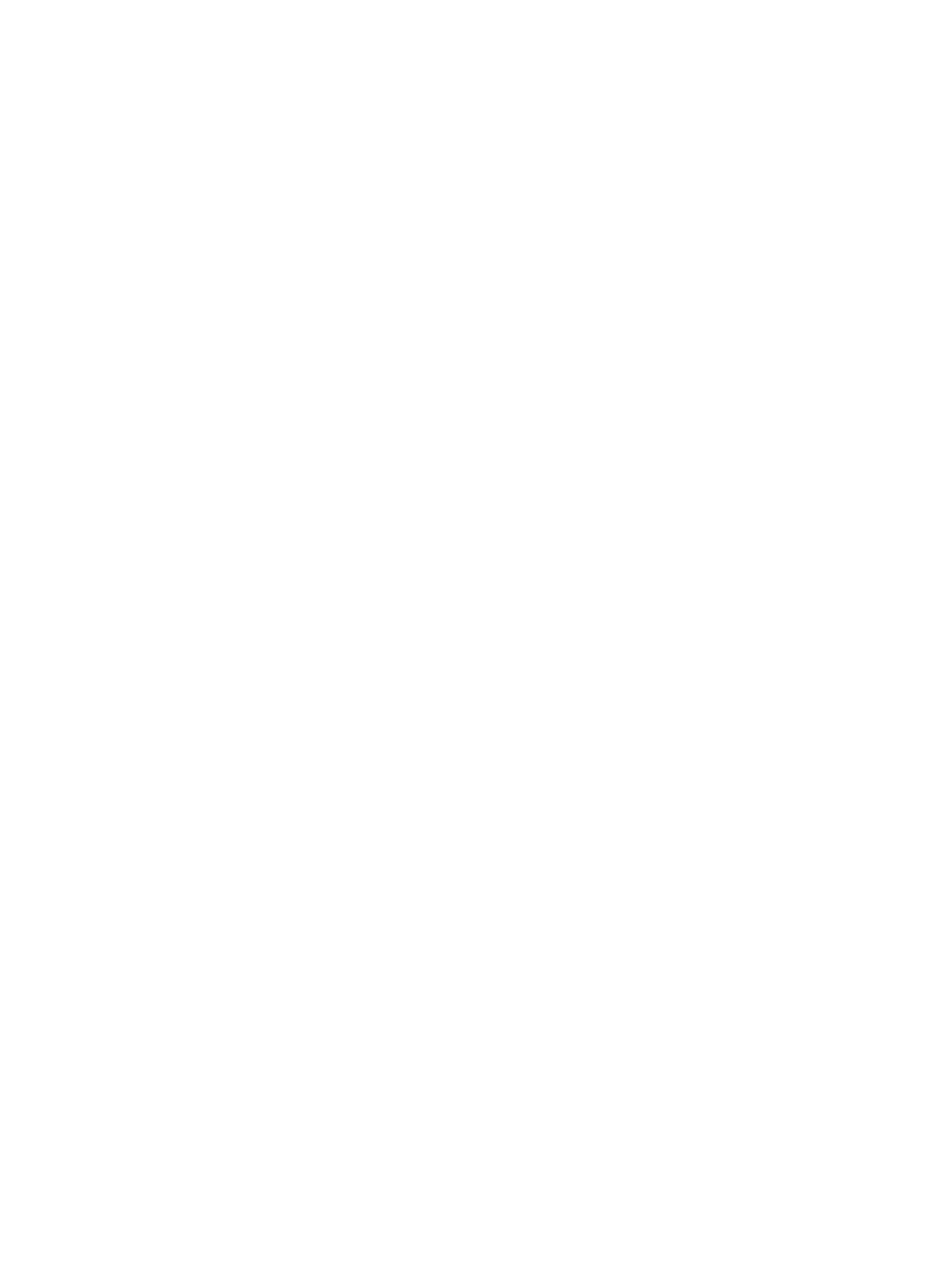




\begin{tabular}{|c|c|}
\hline 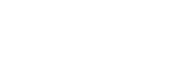 & 110 1110 11189 111\% 11 \\
\hline $\begin{array}{ll}0 \\
0\end{array}$ & 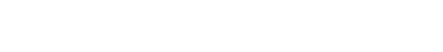 \\
\hline 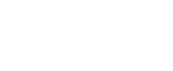 & 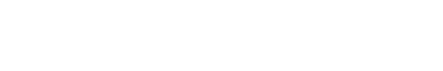 \\
\hline$\frac{1}{0}$ & \\
\hline 咅 & 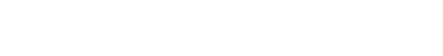 \\
\hline 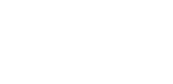 & 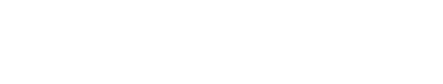 \\
\hline 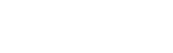 & \\
\hline 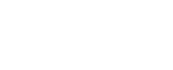 & 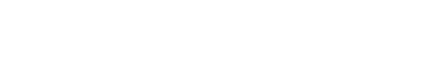 \\
\hline 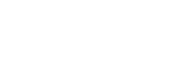 & 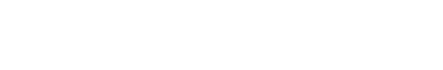 \\
\hline 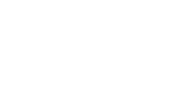 & 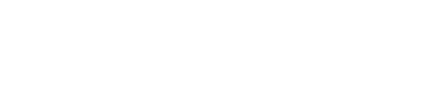 \\
\hline 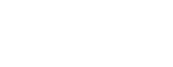 & 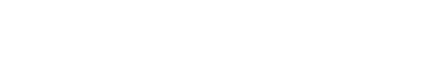 \\
\hline 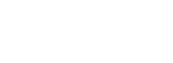 & 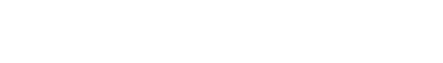 \\
\hline 毵害馬 & 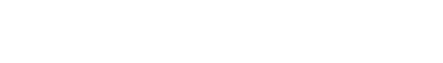 \\
\hline 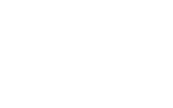 & 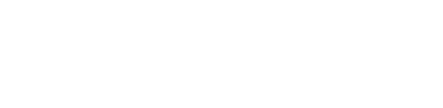 \\
\hline 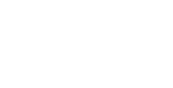 & 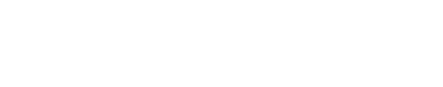 \\
\hline 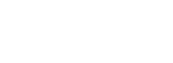 & $0,1000,1000,000,000,00$ \\
\hline 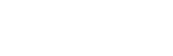 & 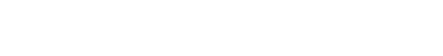 \\
\hline 竎是是 & \\
\hline 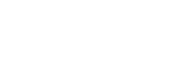 & \\
\hline 善要 & - \\
\hline 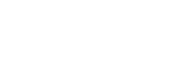 & 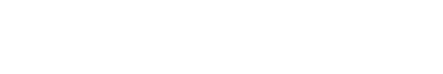 \\
\hline 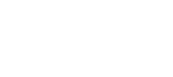 & 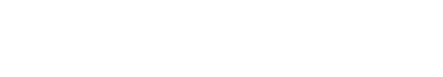 \\
\hline 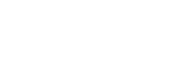 & \\
\hline 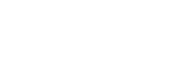 & \\
\hline 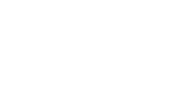 & \\
\hline 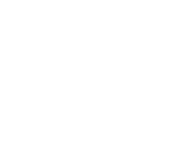 & 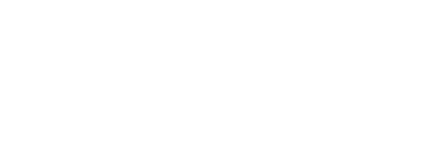 \\
\hline
\end{tabular}




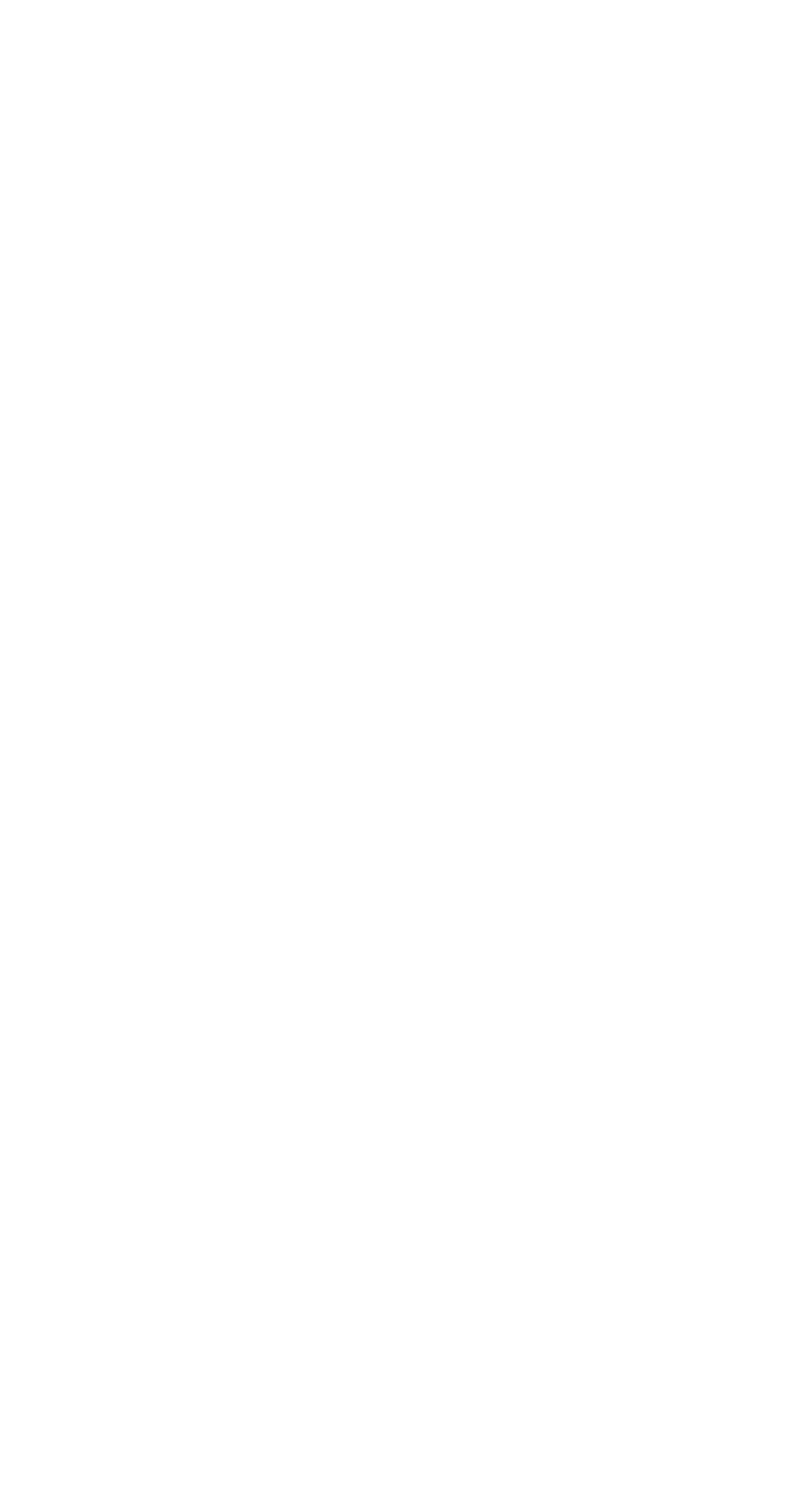




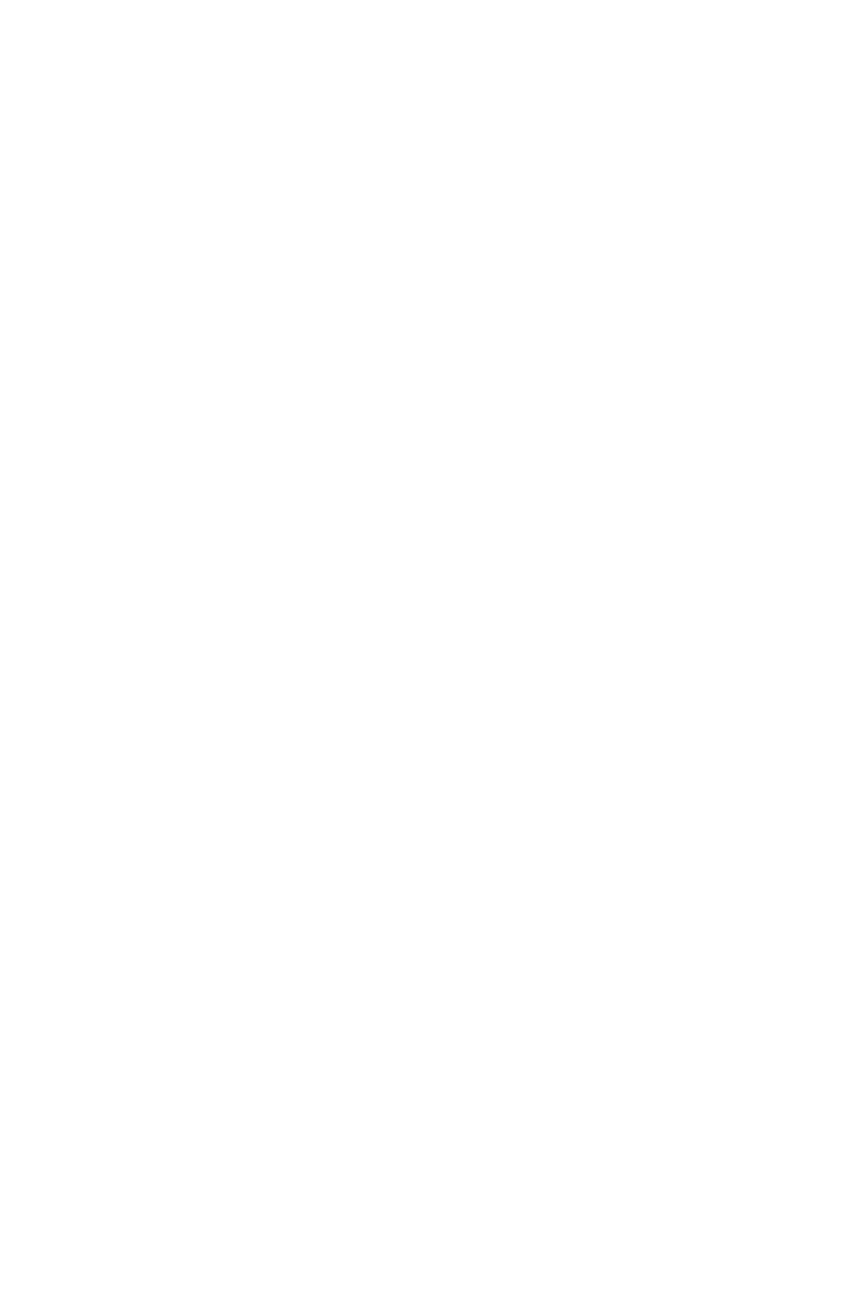




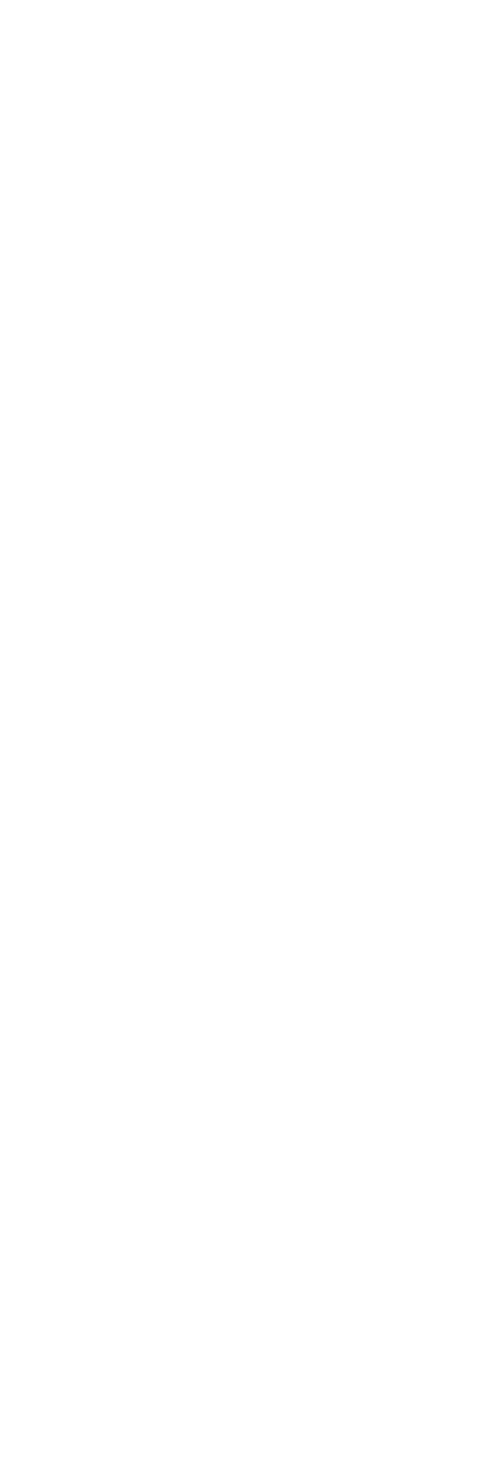




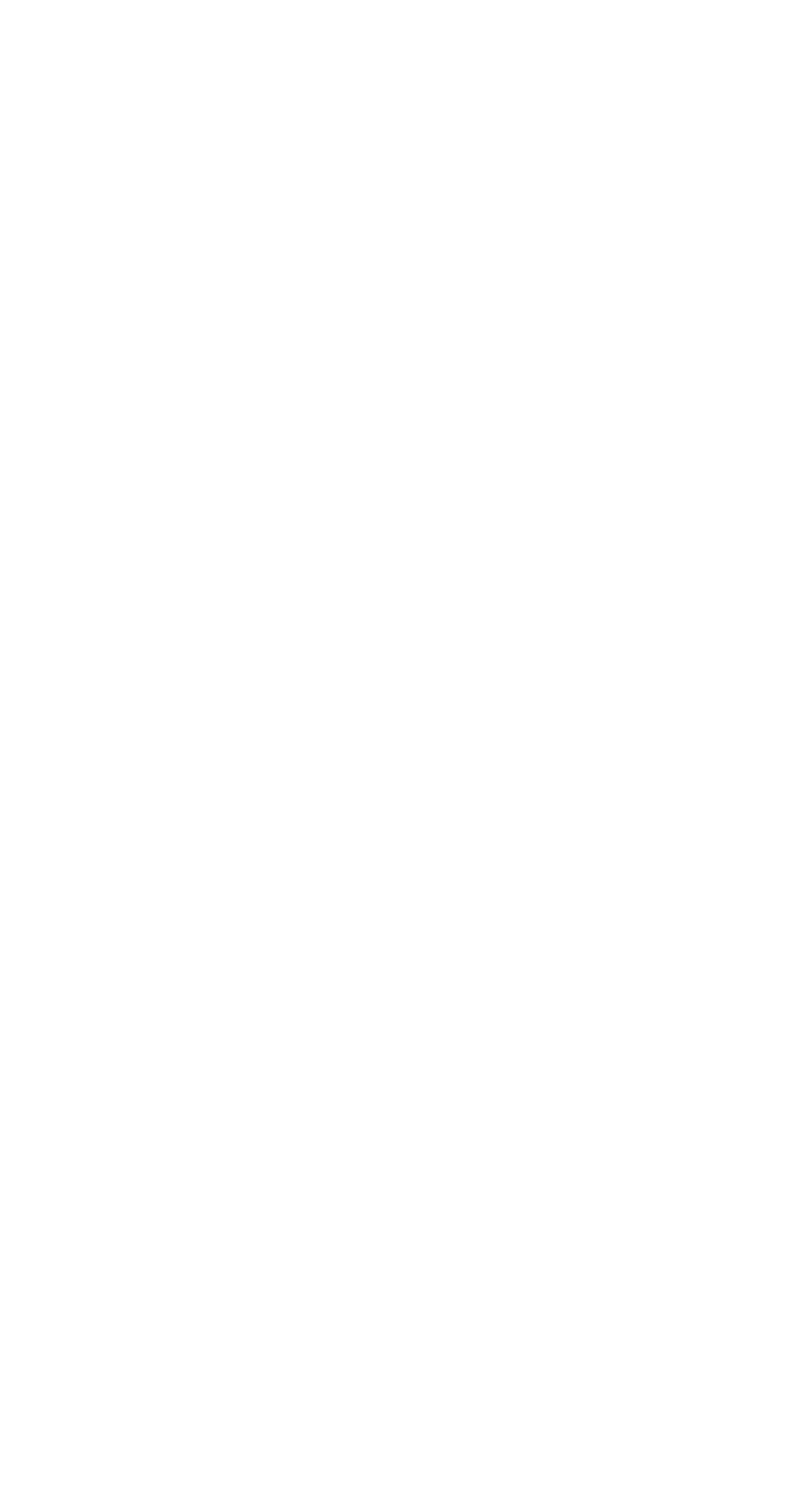




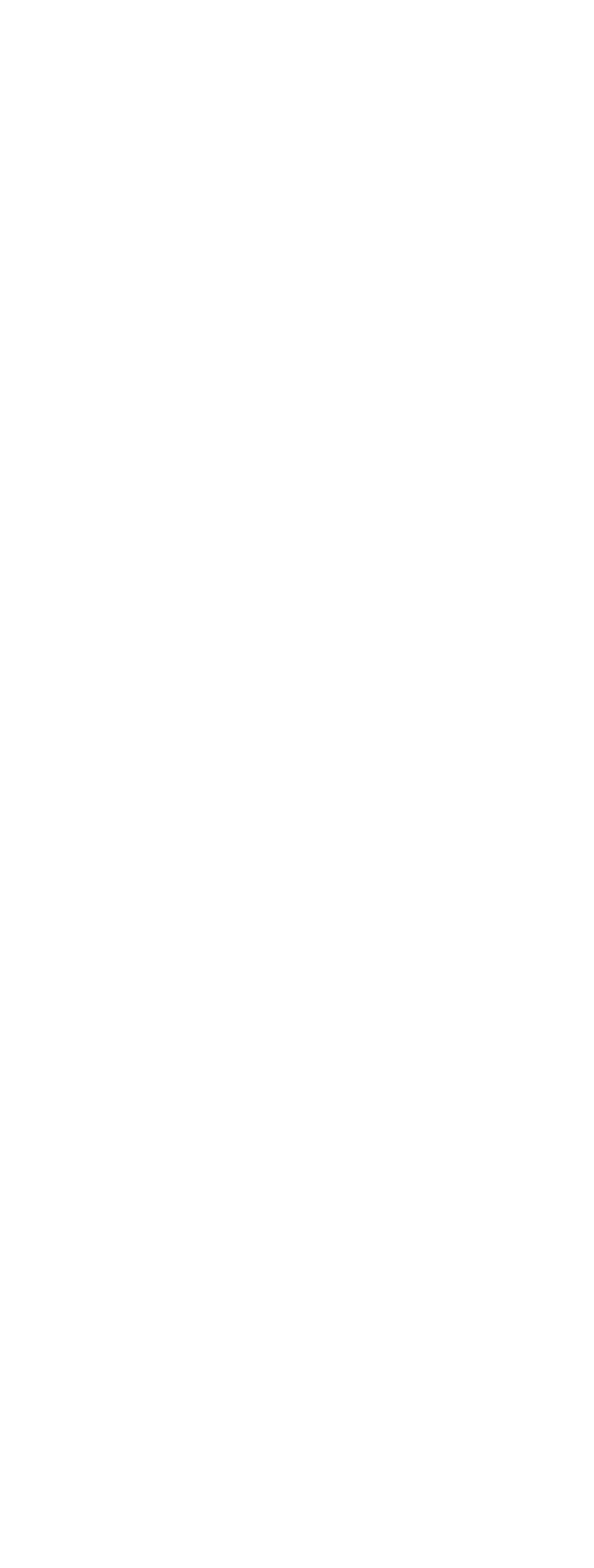




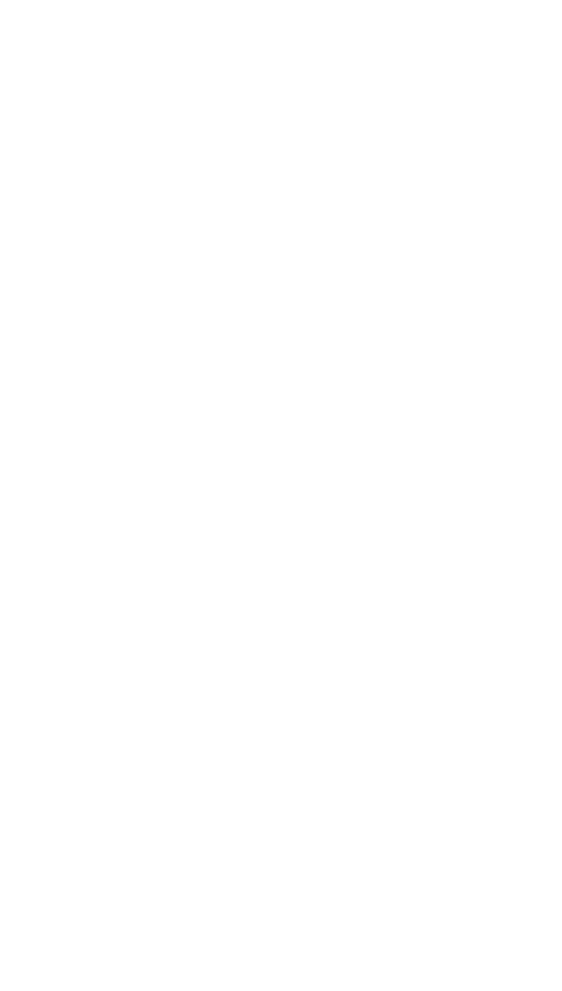

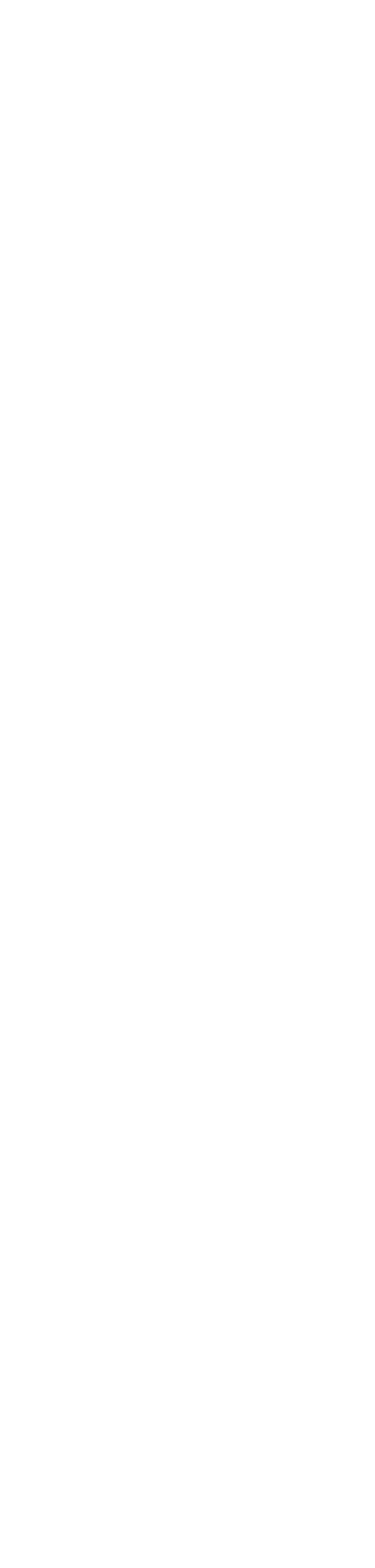




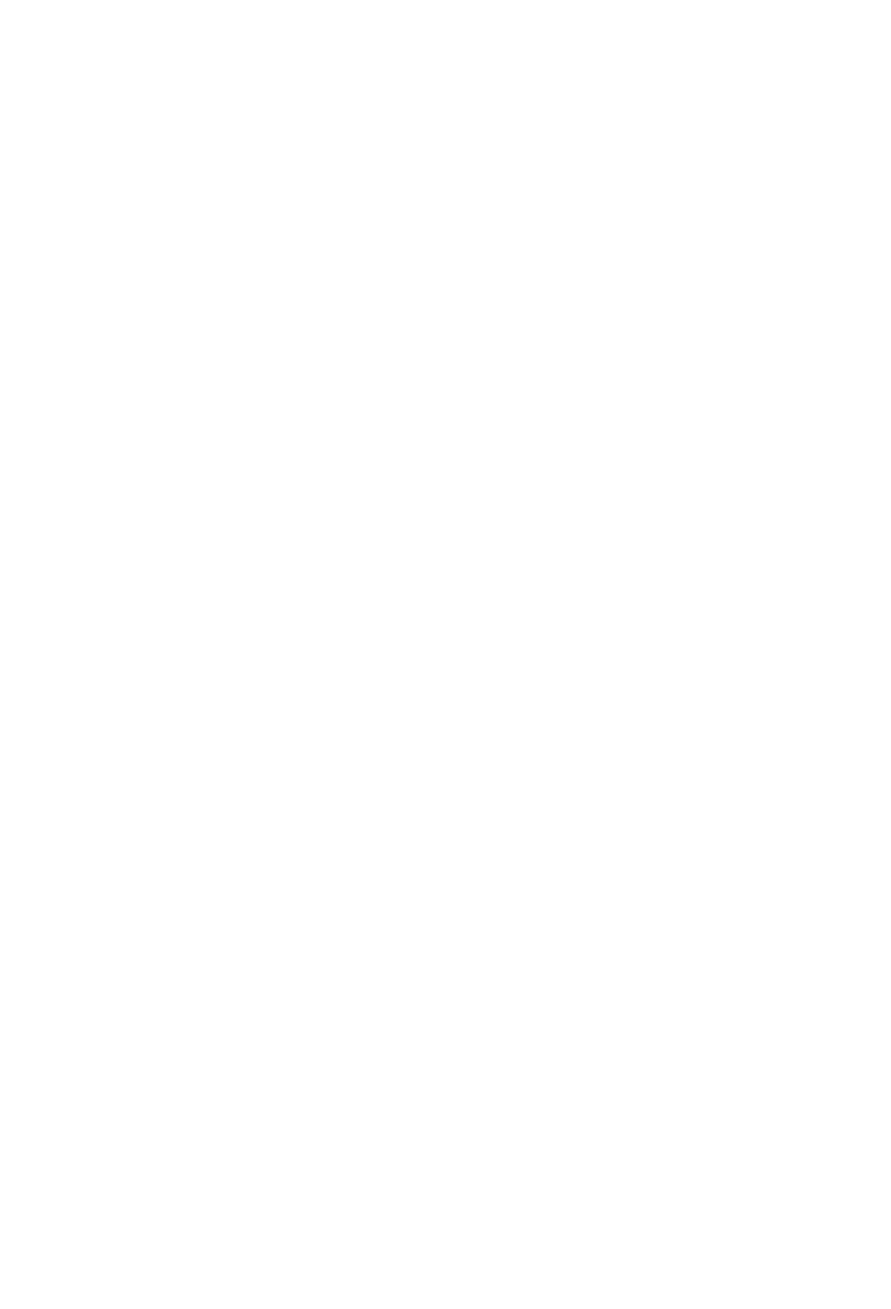


OHIO RIVER HAIN STEM-CONTIInUed

3-2772. OHIO RIVER AT MARKLAND DAM, NEAR WARSAI, KY.--Continued

Radioisotopes in water, October 1964 to September 1967

Units of measurement: Uranium, micrograms per liter of water; radium, as radium-226, in picocurles per liter of water; gross beta radiation as strontium-90-yttrium-90, in picocuries per liter of water; gross alpha radiation, as micrograms of uranium equivalent per liter of water;

extractable alpha, as uranium, in micrograms of uranium per liter of

water; tritium as tritium units (approximately equal to 3.2 picocuries

per liter). A picocurie is one milionth of the amount of radioactivity

represented by a microcurie, which is the quantity of radiation represented by one millionth of a gram of radium-226. A picocurie of radium results in 2.22 disiategrations per minute. A tritium unit is equal to one tritium atom in $10^{+} 18$ protium (ordinary hydrogen) atoms.

Symbols used: ND, sought but not detected by method used; NS, no sample

\begin{tabular}{|c|c|c|c|c|c|c|}
\hline \multirow[b]{2}{*}{$\begin{array}{l}\text { Date of } \\
\text { collection }\end{array}$} & \multicolumn{6}{|c|}{ Determination } \\
\hline & $\begin{array}{c}\text { Uranium } \\
\mu \mathrm{g} / 1\end{array}$ & $\begin{array}{l}\text { Radium } \\
\mathrm{pc} / 1\end{array}$ & $\begin{array}{c}\text { Gross } \\
\mathrm{pc} / 1\end{array}$ & $\underset{\mu g / 1}{\operatorname{Gross} \alpha}$ & $\begin{array}{l}\text { Extract- } \\
\text { able } \alpha \\
\mu \mathrm{g} / 1\end{array}$ & $\begin{array}{c}\text { Tritium } \\
\text { T.U. }\end{array}$ \\
\hline $\begin{array}{l}\text { Oct. } 27,1964 \ldots \ldots \\
\text { Nov. } 17, \ldots \ldots \ldots \ldots \\
\text { Dec. } 15, \ldots, \ldots \ldots \\
\text { Jan. } 12,1965 \ldots \ldots \\
\text { Feb. } 16, \ldots \ldots \ldots \ldots \\
\text { Mar. } 16, \ldots \ldots \ldots \ldots \\
\text { Apr. } 13, \ldots \ldots \ldots\end{array}$ & $\begin{array}{l}<0.4 \\
<.4 \\
<.4 \\
<.4 \\
<.4 \\
<.4 \\
<.4\end{array}$ & $\begin{array}{l}0.1 \\
<.1 \\
<.1 \\
.1 \\
<.1 \\
<.1 \\
<1\end{array}$ & $\begin{array}{l}10 \\
6.6 \\
6.3 \\
8.5 \\
7.3 \\
5.1 \\
9.8\end{array}$ & $\begin{array}{l}2,1 \\
\text { ND } \\
\text { ND } \\
\text { ND } \\
1,5 \\
\text { ND } \\
\text { ND }\end{array}$ & $\begin{array}{r}<0.6 \\
<.6 \\
<.6 \\
<.8 \\
<.6 \\
<.5 \\
<.5 \\
<.6\end{array}$ & $\begin{array}{r}6 \overline{-} \\
630 \\
745 \\
625 \\
555 \\
--\end{array}$ \\
\hline 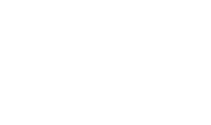 & $\begin{array}{l}<.4 \\
\text { NS } \\
<.4 \\
<.4 \\
<.4 \\
<.4\end{array}$ & $\begin{array}{r}.1 \\
\text { NS } \\
<.1 \\
.1 \\
.1 \\
<.1\end{array}$ & $\begin{array}{l}4.5 \\
\text { NS } \\
6.3 \\
8.1 \\
7.2 \\
8.3\end{array}$ & $\begin{array}{l}2.1 \\
\mathrm{NS} \\
1.5 \\
\mathrm{ND} \\
\mathrm{ND} \\
1.3\end{array}$ & $\begin{array}{l}<.6 \\
\text { NS } \\
<.6 \\
<.6 \\
\text { ND } \\
<.6\end{array}$ & $\begin{array}{l}660 \\
560 \\
450 \\
625 \\
620 \\
445\end{array}$ \\
\hline $\begin{array}{ll}\text { Oct. } & 22 \ldots \ldots \ldots \ldots \\
\text { Nov. } 8 \ldots \ldots \ldots \ldots \\
\text { Dec. } 19 \ldots \ldots \ldots \ldots \\
\text { Jan. } 21,1966 \ldots \ldots \\
\text { Feb. } 18 \ldots \ldots \ldots \ldots \\
\text { Mar. } 18 \ldots \ldots \ldots \ldots\end{array}$ & $\begin{array}{l}<.4 \\
<.4 \\
<.4 \\
<.4 \\
<.4 \\
<.4\end{array}$ & $\begin{array}{r}.1 \\
<.1 \\
<.1 \\
.1 \\
.1 \\
.1\end{array}$ & $\begin{array}{l}8.3 \\
6.1 \\
7.7 \\
6.7 \\
9.8 \\
2.8\end{array}$ & $\begin{array}{l}\mathrm{ND} \\
1.5 \\
8.5 \\
.4 \\
2.6 \\
.4\end{array}$ & $\begin{array}{l}\text { ND } \\
<.6 \\
<.6 \\
<.6 \\
<.6 \\
<.6\end{array}$ & $\begin{array}{l}435 \\
375 \\
415 \\
355 \\
325 \\
330\end{array}$ \\
\hline 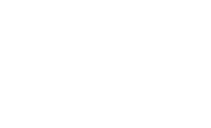 & $\begin{array}{r}<.4 \\
<.4 \\
.4 \\
<.4 \\
.6 \\
.4\end{array}$ & $\begin{array}{l}<.1 \\
<.1 \\
<.1 \\
<.1 \\
<.1 \\
<.1\end{array}$ & $\begin{array}{l}4.4 \\
4.3 \\
4.0 \\
5.0 \\
6.9 \\
6.7\end{array}$ & $\begin{array}{l}<.4 \\
1.4 \\
<.4 \\
2.0 \\
.6 \\
.7\end{array}$ & $\begin{array}{l}<.6 \\
<.6 \\
<.6 \\
<.6 \\
<.6 \\
<.6\end{array}$ & $\begin{array}{l}429 \\
371 \\
365 \\
388 \\
413 \\
366\end{array}$ \\
\hline $\begin{array}{ll}\text { Oct. } & 20 \ldots \ldots \ldots \ldots \\
\text { Nov. } & 30 \ldots \ldots \ldots \ldots \\
\text { Dec. } & 21 \ldots \ldots \ldots \ldots \\
\text { Jan. } & 20,1967 \ldots \ldots \\
\text { Feb. } 20 \ldots \ldots \ldots \ldots \\
\text { Mar. } 23 \ldots \ldots \ldots \ldots\end{array}$ & $\begin{array}{l}<.4 \\
<.4 \\
<.4 \\
<.4 \\
<.4 \\
<.4\end{array}$ & $\begin{array}{l}<.1 \\
.1 \\
<.1 \\
<.1 \\
<.1 \\
<.1\end{array}$ & $\begin{array}{r}7.9 \\
10 \\
5.0 \\
4.0 \\
3.4 \\
3.8\end{array}$ & $\begin{array}{l}1.9 \\
.5 \\
3.1 \\
1.2 \\
3.7 \\
3.8\end{array}$ & $\begin{array}{l}<.6 \\
<.6 \\
<.6 \\
<.6 \\
<.6 \\
<.6\end{array}$ & $\begin{array}{l}371 \\
346 \\
367 \\
380 \\
322 \\
255\end{array}$ \\
\hline 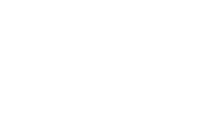 & $\begin{array}{l}<.4 \\
<.4 \\
<.4 \\
<.4 \\
<.4 \\
<.4\end{array}$ & $\begin{array}{l}<.1 \\
<.1 \\
<.1 \\
<.1 \\
<.1 \\
.1\end{array}$ & $\begin{array}{l}3.7 \\
3.5 \\
4.0 \\
5.4 \\
6.9 \\
4.6\end{array}$ & $\begin{array}{l}<.4 \\
2.1 \\
.8 \\
5.0 \\
2.2 \\
2.8\end{array}$ & $\begin{array}{l}<.6 \\
<.6 \\
<.6 \\
<.6 \\
<.6 \\
<.6\end{array}$ & $\begin{array}{r}270 \\
215 \\
-\overline{2} \\
280 \\
243 \\
225\end{array}$ \\
\hline
\end{tabular}




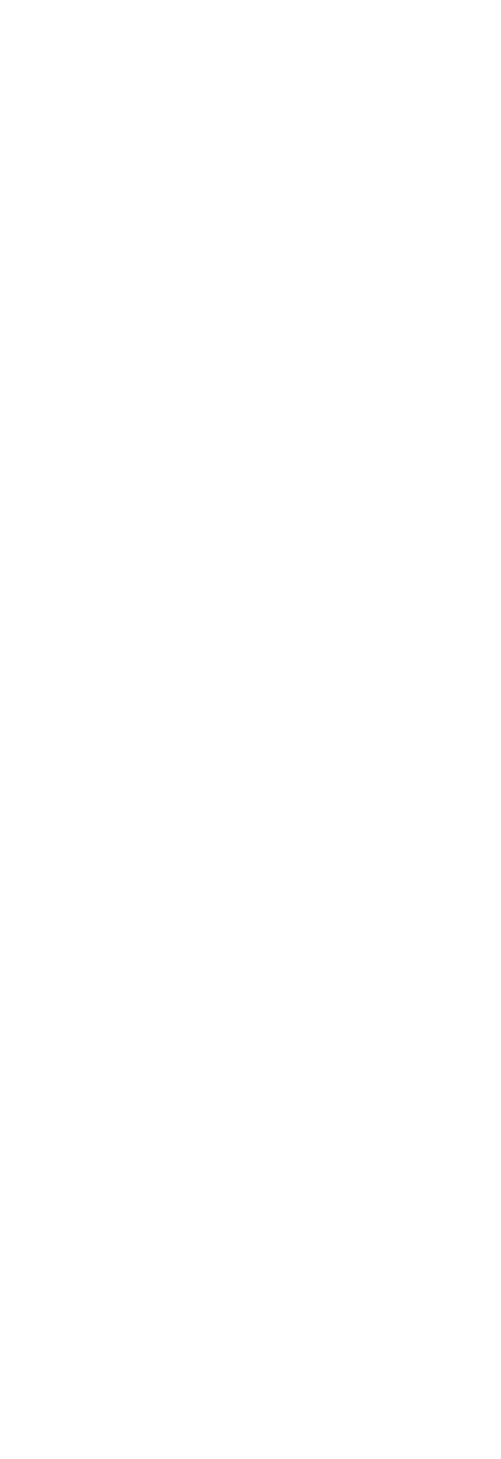




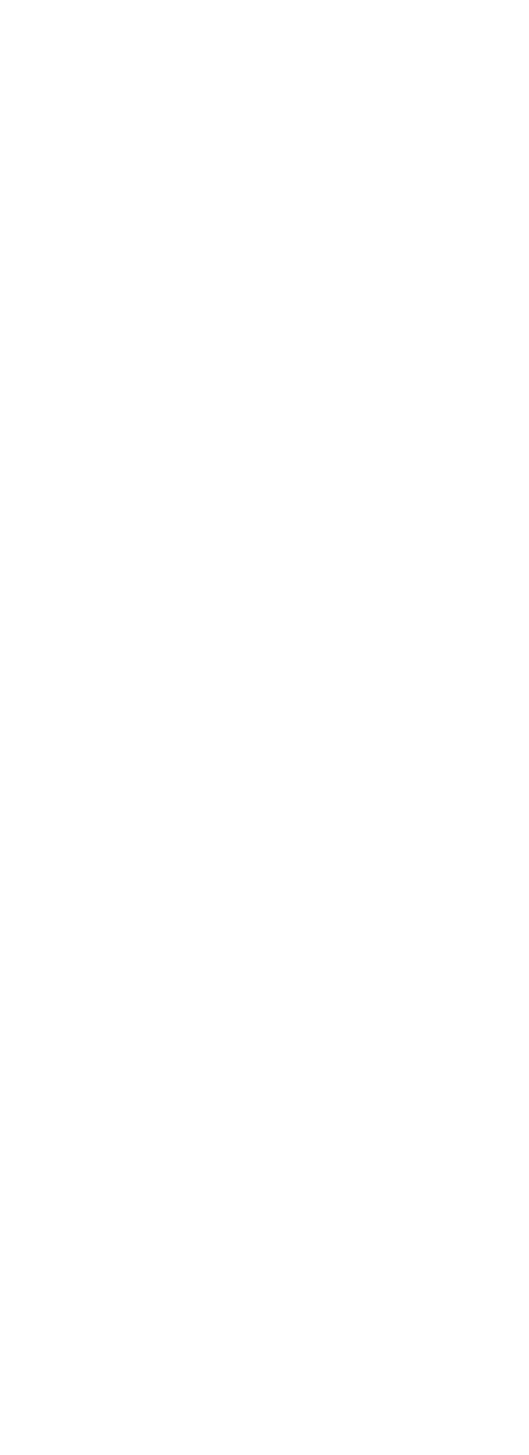




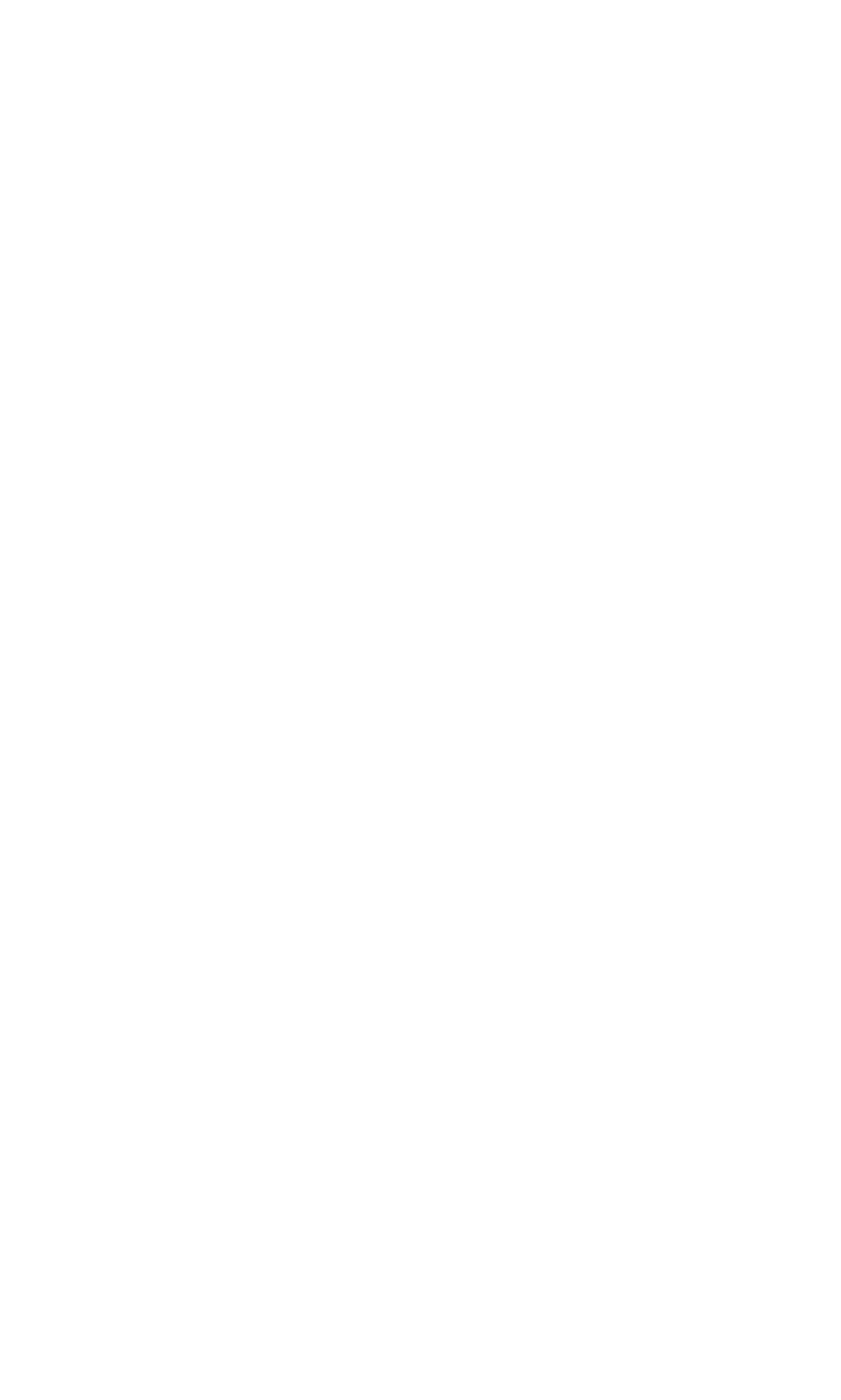




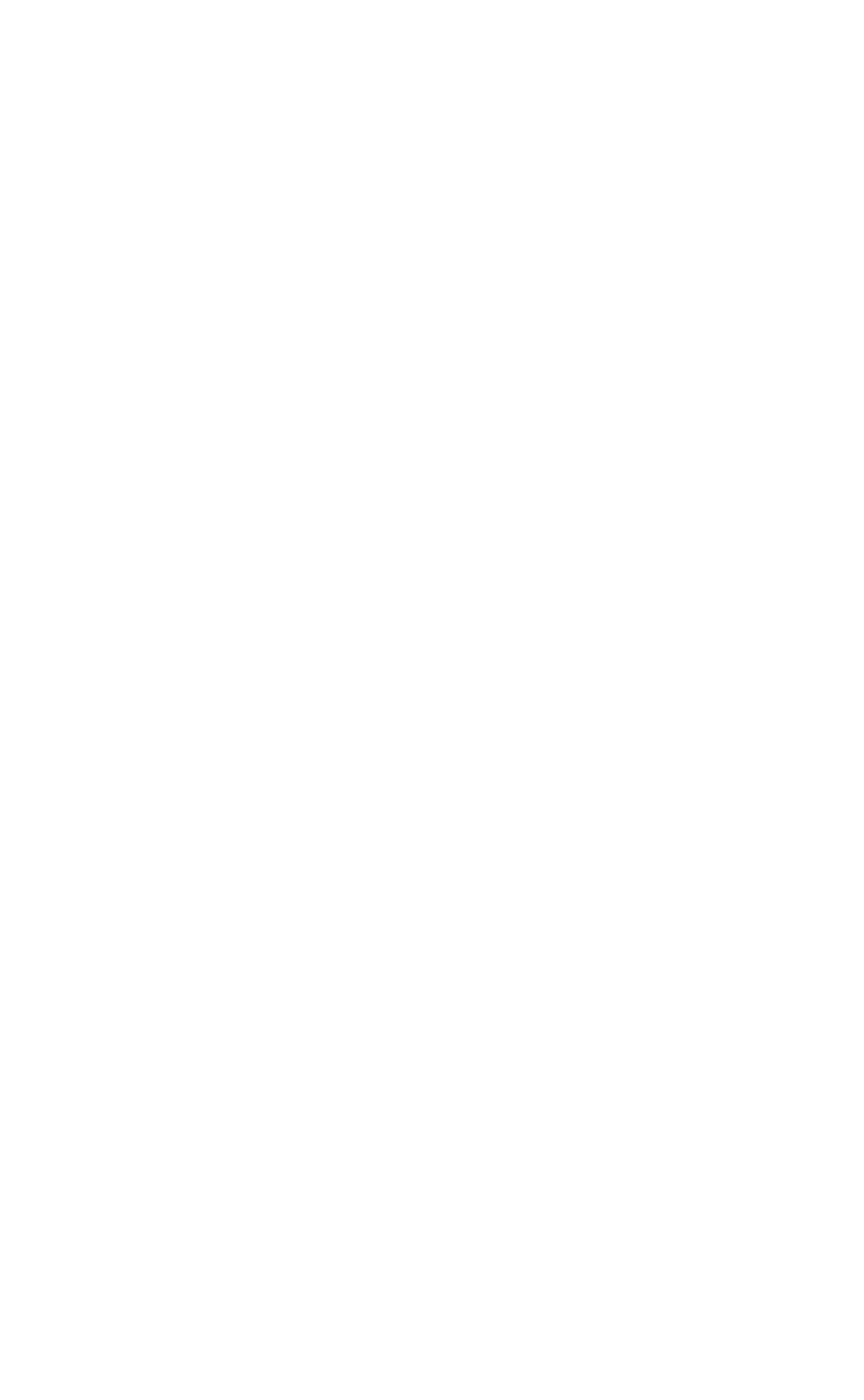




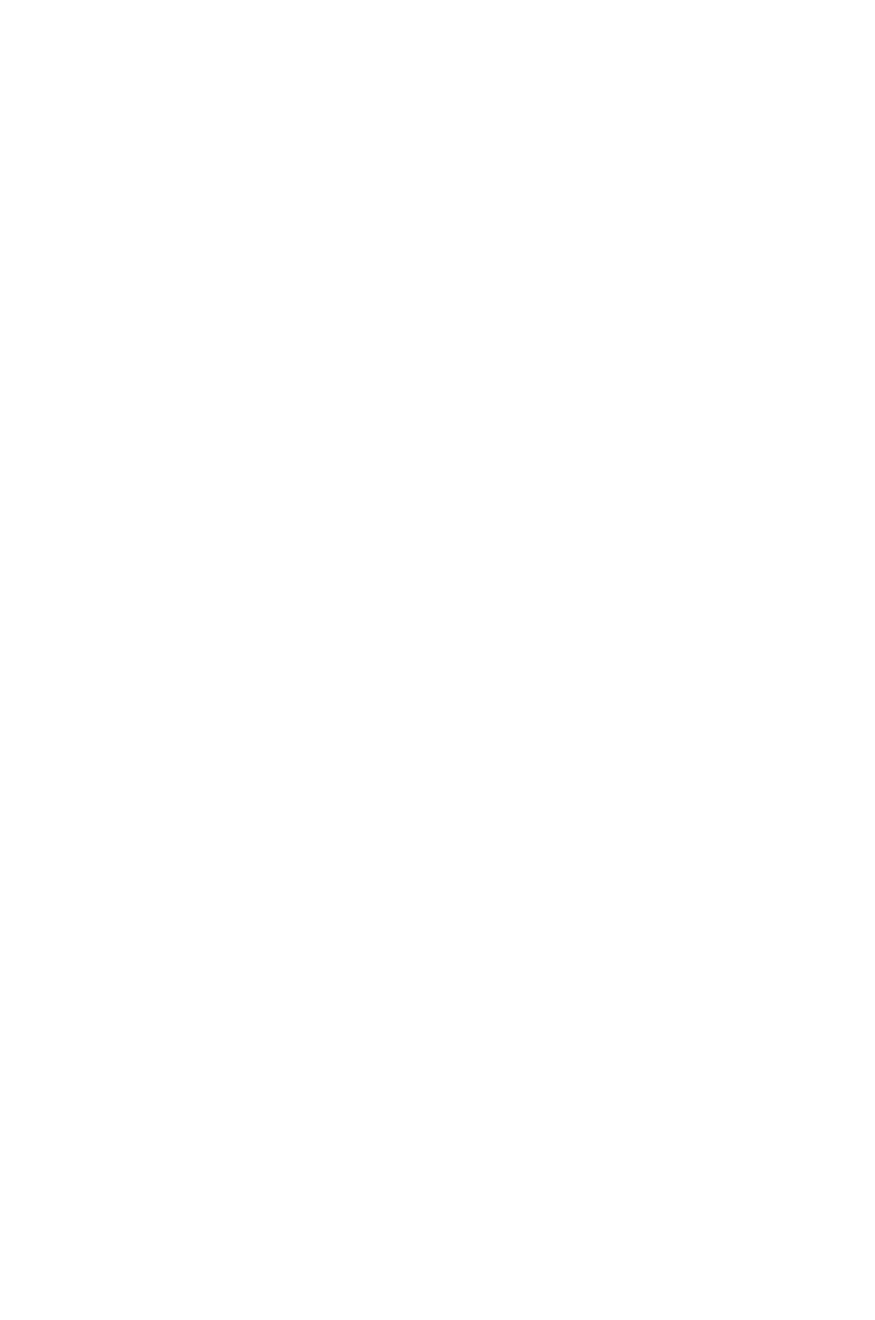




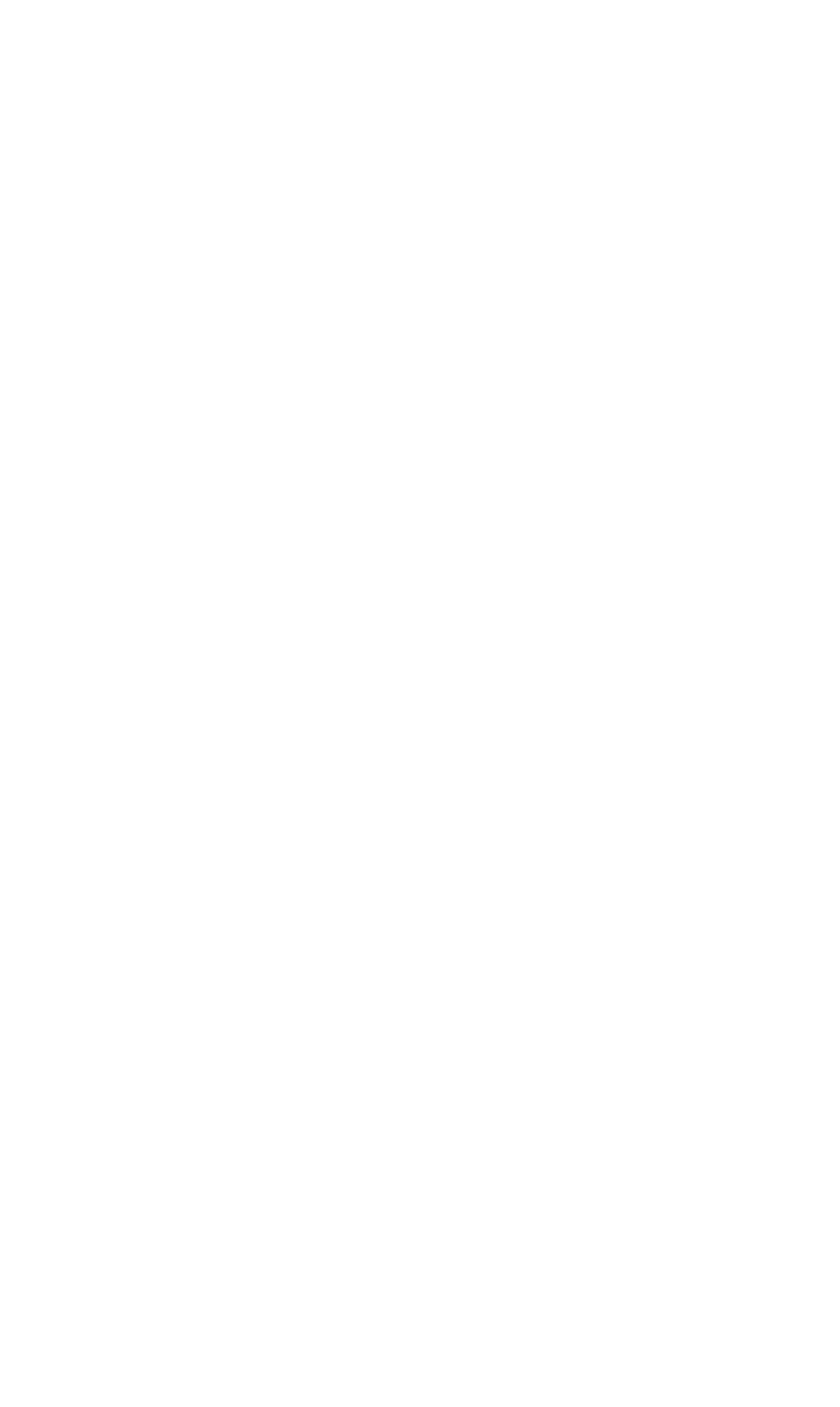




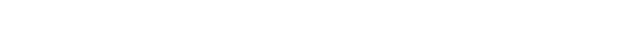

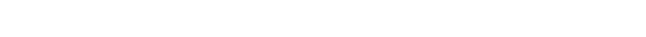

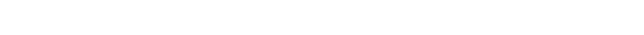




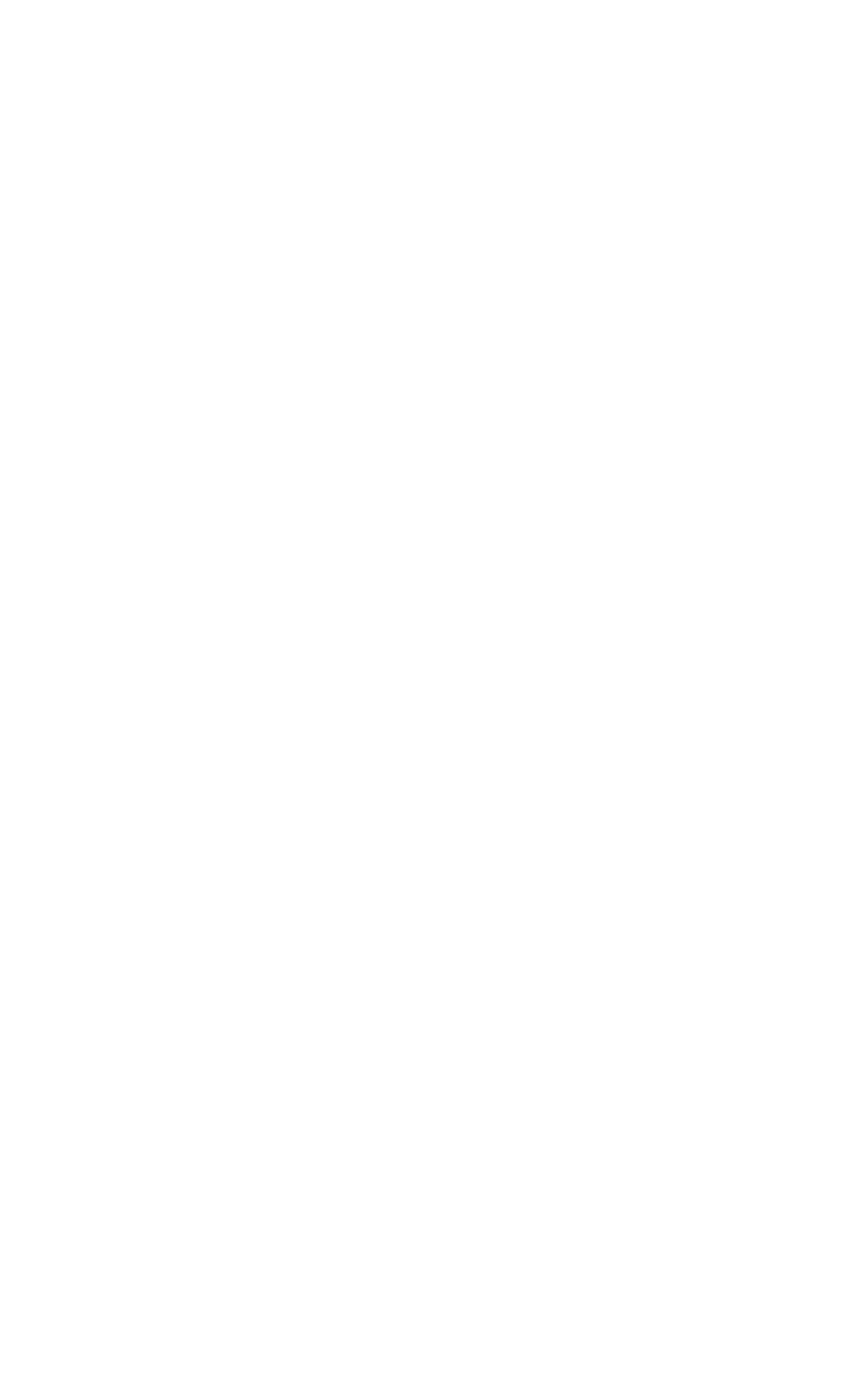



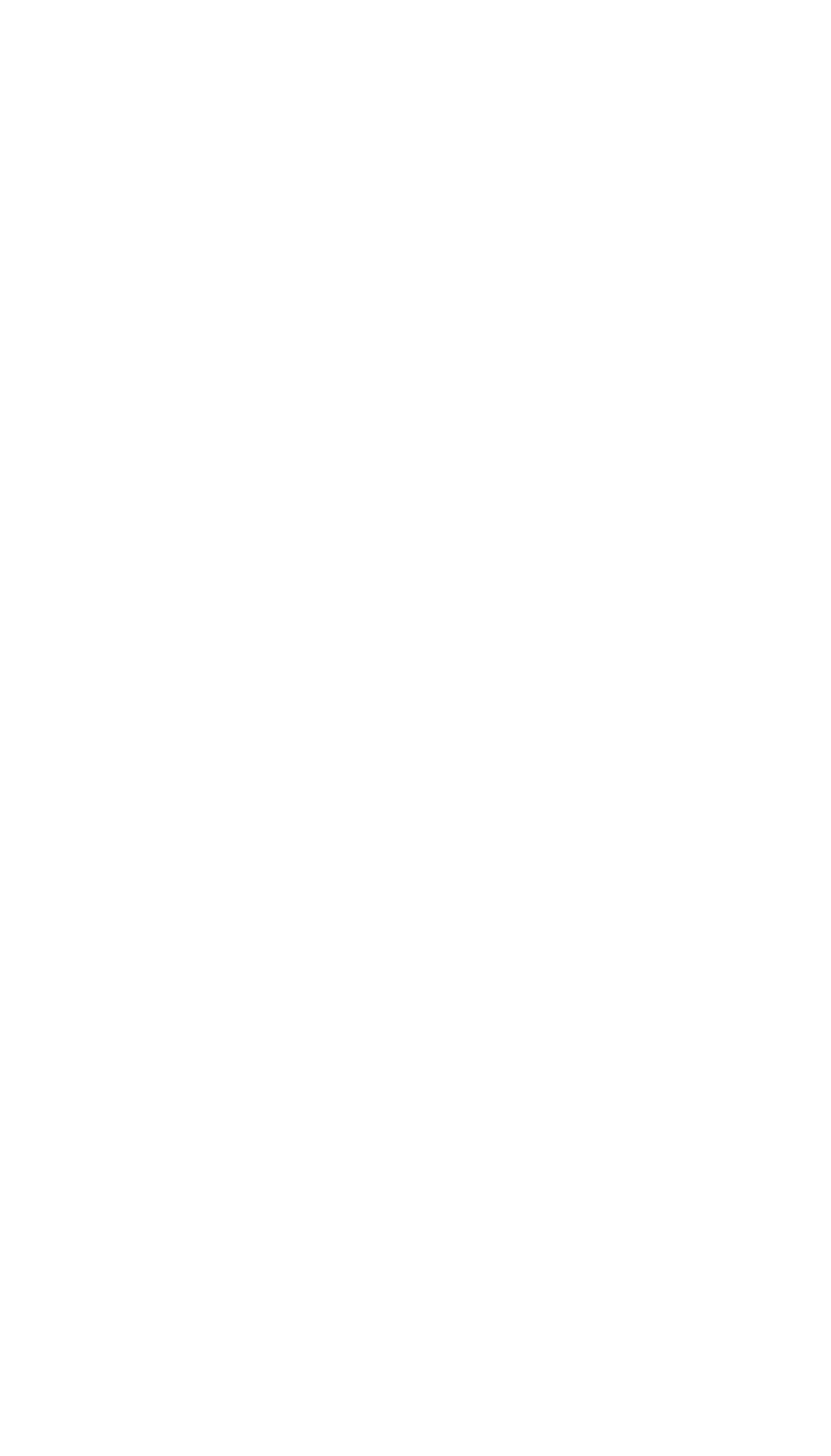

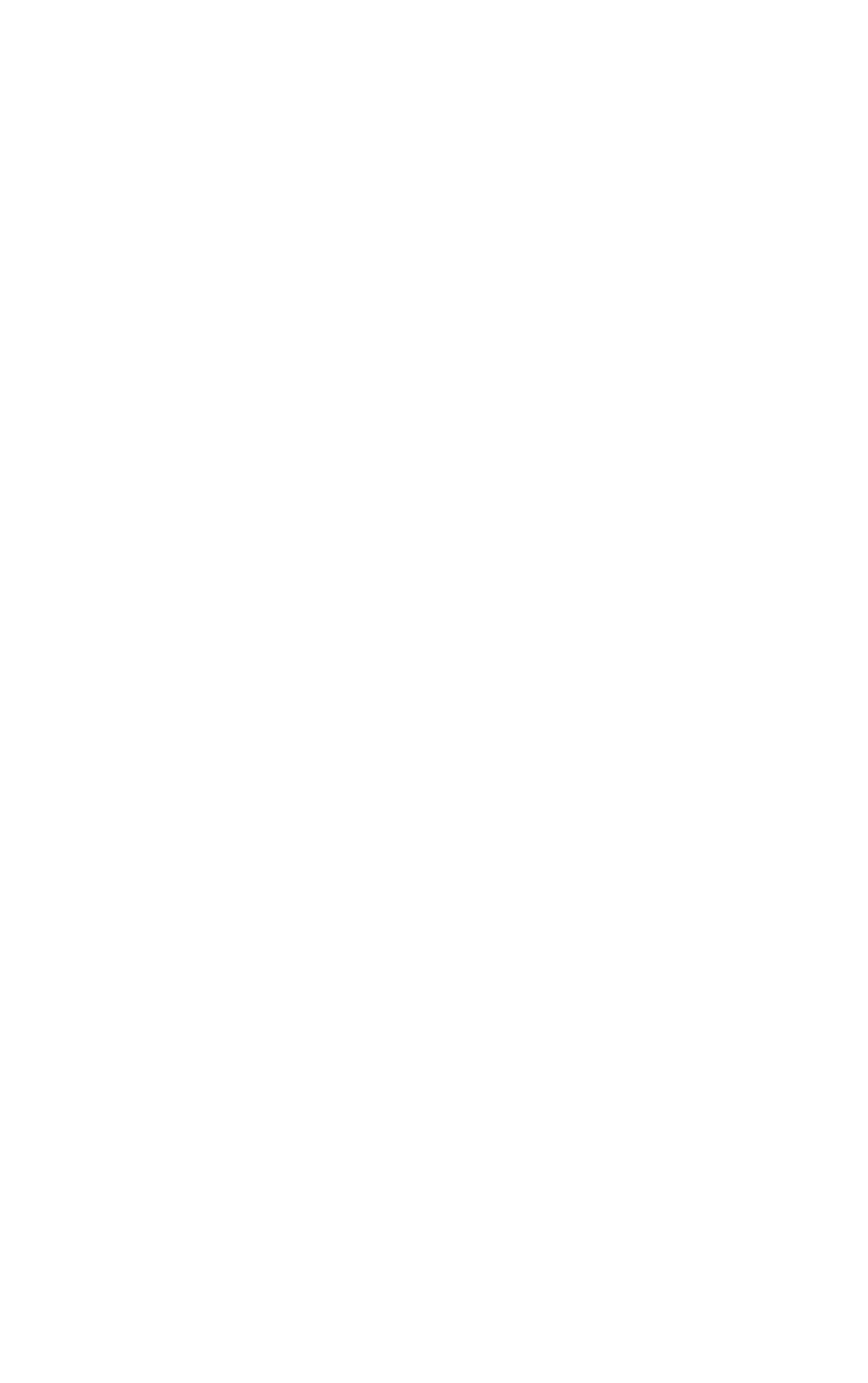
KENTUCKY RIVER BASIN--COntinued

3-2875. KENTUCKY RIVER AT LOCK 4, AT FRANKFORT, KY.--Continued

Suspended sediment, water year October 1966 to September 1967

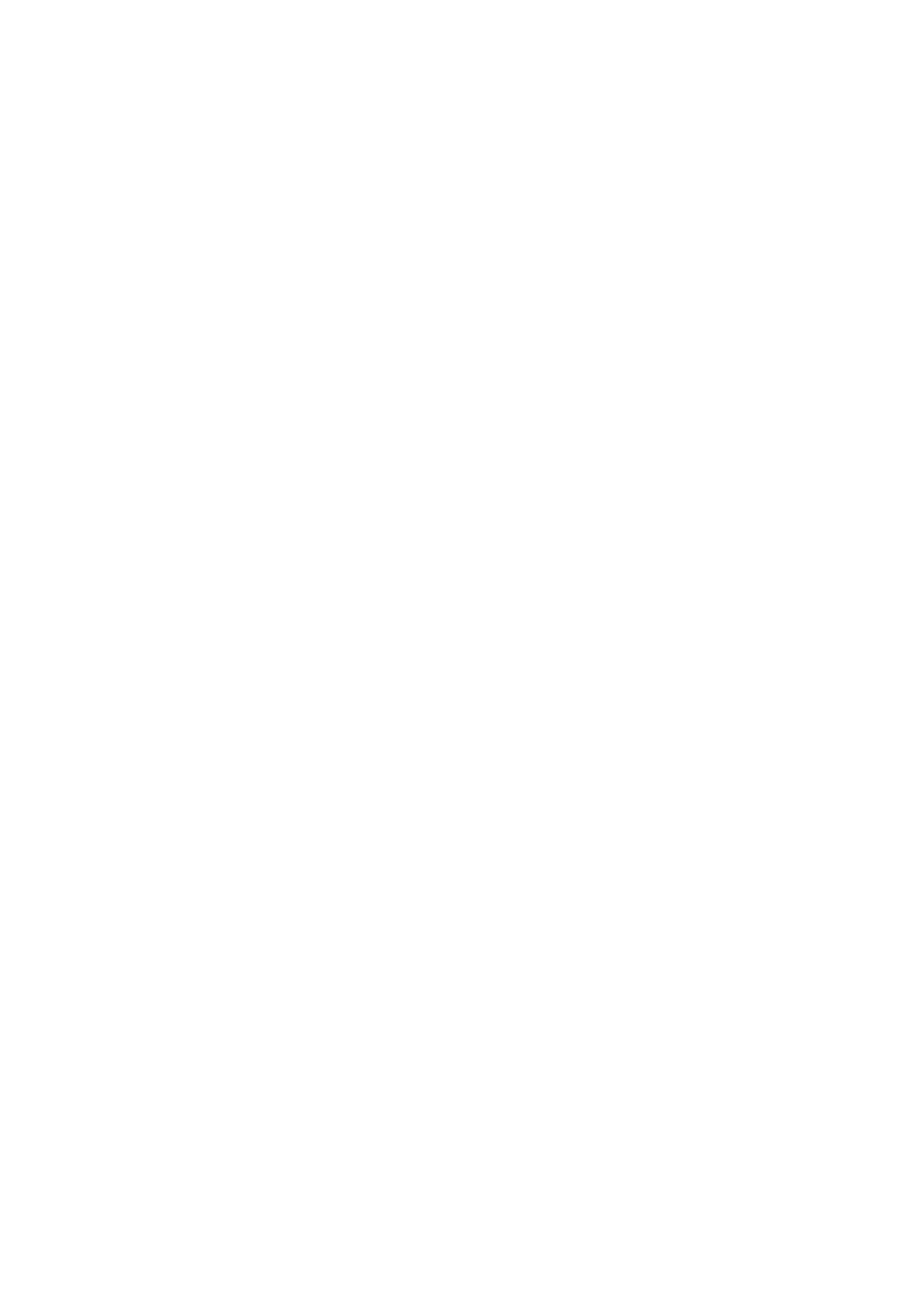


KENTUCKY RIVER BASIN--Continued

3-2875. KENTUCKY RIVER AT LOCK 4, AT FRANKFORT, KY.--Continued

Suspended sediment, water year october 1966 to September 1967--Continued

\begin{tabular}{|c|c|c|c|c|c|c|c|c|c|}
\hline \multirow[b]{3}{*}{ Day } & \multirow[b]{3}{*}{$\begin{array}{c}\text { Mean } \\
\text { dis- } \\
\text { charge } \\
\text { (cfs) }\end{array}$} & \multicolumn{2}{|l|}{ APRIL } & \multicolumn{3}{|c|}{ MAY } & \multicolumn{3}{|c|}{ JUNE } \\
\hline & & \multicolumn{2}{|c|}{ Suspended sediment } & \multirow[b]{2}{*}{$\begin{array}{c}\text { Mean } \\
\text { dis- } \\
\text { charge } \\
\text { (cfs) }\end{array}$} & \multicolumn{2}{|c|}{ Suspended sediment } & \multirow[b]{2}{*}{$\begin{array}{c}\text { Mean } \\
\text { dis- } \\
\text { charge } \\
\text { (cfs) }\end{array}$} & \multicolumn{2}{|c|}{ Suspended sedimen } \\
\hline & & $\begin{array}{c}\text { Mean } \\
\text { concen- } \\
\text { tration } \\
(\text { ppm) }\end{array}$ & $\begin{array}{c}\text { Tons } \\
\text { per } \\
\text { day }\end{array}$ & & $\begin{array}{c}\text { Mean } \\
\text { concen- } \\
\text { tration } \\
\text { (ppm) }\end{array}$ & $\begin{array}{c}\text { Tons } \\
\text { per } \\
\text { day }\end{array}$ & & \begin{tabular}{|c} 
Mean \\
concen- \\
tration \\
(ppm)
\end{tabular} & $\begin{array}{c}\text { Tons } \\
\text { per } \\
\text { day }\end{array}$ \\
\hline $\begin{array}{l}1 \ldots \\
2 \ldots \\
3 \ldots \\
4 \ldots \\
5 \ldots\end{array}$ & $\begin{array}{r}13600 \\
11000 \\
9120 \\
6840 \\
5450\end{array}$ & $\begin{array}{l}84 \\
83 \\
62 \\
41 \\
41\end{array}$ & $\begin{array}{r}3080 \\
2470 \\
1530 \\
757 \\
603\end{array}$ & $\begin{array}{l}14200 \\
17000 \\
19400 \\
17600 \\
13600\end{array}$ & $\begin{array}{l}129 \\
162 \\
202 \\
186 \\
109\end{array}$ & $\begin{array}{r}4950 \\
7440 \\
10600 \\
8840 \\
4000\end{array}$ & $\begin{array}{r}1540 \\
2550 \\
13000 \\
24800 \\
25200\end{array}$ & $\begin{array}{r}25 \\
35 \\
146 \\
264 \\
380\end{array}$ & $\begin{array}{r}104 \\
284 \\
5650 \\
17700 \\
25900\end{array}$ \\
\hline $\begin{array}{r}6 \ldots \\
7 \ldots \\
9 \ldots \\
10 \ldots\end{array}$ & $\begin{array}{l}5060 \\
4290 \\
3640 \\
3160 \\
4360\end{array}$ & $\begin{array}{l}37 \\
28 \\
25 \\
22 \\
33\end{array}$ & $\begin{array}{l}505 \\
324 \\
246 \\
188 \\
388\end{array}$ & $\begin{array}{l}11200 \\
19700 \\
23500 \\
20100 \\
15200\end{array}$ & $\begin{array}{r}62 \\
496 \\
172 \\
179 \\
203\end{array}$ & $\begin{array}{r}1870 \\
26400 \\
10900 \\
9710 \\
8330\end{array}$ & $\begin{array}{r}16800 \\
13100 \\
9550 \\
6840 \\
5450\end{array}$ & $\begin{array}{r}405 \\
315 \\
245 \\
148 \\
97\end{array}$ & $\begin{array}{r}18400 \\
11100 \\
6320 \\
2730 \\
1430\end{array}$ \\
\hline $\begin{array}{l}11 \ldots \\
12 \ldots \\
13 \ldots \\
14 \ldots \\
15 \ldots\end{array}$ & $\begin{array}{l}3920 \\
3440 \\
3520 \\
3280 \\
3120\end{array}$ & $\begin{array}{l}20 \\
18 \\
16 \\
14 \\
14\end{array}$ & $\begin{array}{l}212 \\
167 \\
152 \\
124 \\
118\end{array}$ & $\begin{array}{r}10900 \\
9360 \\
9550 \\
23100 \\
43300\end{array}$ & $\begin{array}{r}210 \\
90 \\
42 \\
514 \\
1280\end{array}$ & $\begin{array}{r}6180 \\
2270 \\
1080 \\
37900 \\
150000\end{array}$ & $\begin{array}{l}3600 \\
2480 \\
1910 \\
1460 \\
1660\end{array}$ & $\begin{array}{l}76 \\
58 \\
45 \\
38 \\
35\end{array}$ & $\begin{array}{l}739 \\
388 \\
232 \\
150 \\
157\end{array}$ \\
\hline $\begin{array}{l}16 \ldots \\
17 \ldots \\
18 \ldots \\
19 \ldots \\
20 \ldots\end{array}$ & $\begin{array}{l}2850 \\
2580 \\
2620 \\
2770 \\
2730\end{array}$ & $\begin{array}{r}13 \\
11 \\
10 \\
10 \\
8\end{array}$ & $\begin{array}{r}100 \\
77 \\
71 \\
75 \\
59\end{array}$ & $\begin{array}{l}48700 \\
49500 \\
49100 \\
31100 \\
14800\end{array}$ & $\begin{array}{l}688 \\
475 \\
560 \\
465 \\
265\end{array}$ & $\begin{array}{l}90500 \\
63500 \\
74200 \\
39000 \\
10600\end{array}$ & $\begin{array}{r}1570 \\
1260 \\
1000 \\
960 \\
766\end{array}$ & $\begin{array}{l}33 \\
33 \\
33 \\
30 \\
25\end{array}$ & $\begin{array}{r}140 \\
112 \\
89 \\
78 \\
52\end{array}$ \\
\hline $\begin{array}{l}21 \ldots \\
22 \ldots \\
23 \ldots \\
24 \ldots \\
25 \ldots\end{array}$ & $\begin{array}{r}3360 \\
6180 \\
10200 \\
11400 \\
9980\end{array}$ & $\begin{array}{r}9 \\
18 \\
30 \\
27 \\
23\end{array}$ & $\begin{array}{r}82 \\
300 \\
826 \\
831 \\
620\end{array}$ & $\begin{array}{r}11700 \\
10100 \\
9500 \\
7700 \\
6320\end{array}$ & $\begin{array}{r}168 \\
135 \\
106 \\
78 \\
59\end{array}$ & $\begin{array}{l}5310 \\
3680 \\
2720 \\
1620 \\
1010\end{array}$ & $\begin{array}{l}804 \\
618 \\
672 \\
709 \\
728\end{array}$ & $\begin{array}{l}25 \\
23 \\
22 \\
20 \\
21\end{array}$ & $\begin{array}{l}54 \\
38 \\
40 \\
38 \\
41\end{array}$ \\
\hline $\begin{array}{l}26 \ldots \\
27 \ldots \\
28 \ldots \\
29 \ldots \\
30 \ldots \\
31 \ldots\end{array}$ & $\begin{array}{r}8500 \\
9220 \\
14800 \\
21500 \\
18400 \\
--\end{array}$ & $\begin{array}{r}19 \\
25 \\
70 \\
169 \\
188 \\
-- \\
\end{array}$ & $\begin{array}{r}436 \\
622 \\
3110 \\
9810 \\
9340 \\
-- \\
\end{array}$ & $\begin{array}{l}5960 \\
5060 \\
3560 \\
2620 \\
1940 \\
1540 \\
\end{array}$ & $\begin{array}{l}50 \\
42 \\
42 \\
39 \\
32 \\
29 \\
\end{array}$ & $\begin{array}{l}805 \\
574 \\
404 \\
276 \\
168 \\
121 \\
\end{array}$ & $\begin{array}{l}728 \\
960 \\
823 \\
880 \\
960 \\
-- \\
\end{array}$ & $\begin{array}{l}20 \\
17 \\
15 \\
15 \\
14 \\
--\end{array}$ & $\begin{array}{l}39 \\
44 \\
33 \\
36 \\
36 \\
--\end{array}$ \\
\hline \multirow[t]{2}{*}{ Total } & 210890 & $-\infty$ & 37223 & 526910 & -- & 584958 & 143378 & - & 92154 \\
\hline & \multicolumn{3}{|c|}{ JULY } & \multicolumn{3}{|c|}{ AUGUST } & \multicolumn{3}{|c|}{ SEPTEMBER } \\
\hline $\begin{array}{l}1 \ldots \\
2 \ldots \\
3 \ldots \\
4 \ldots\end{array}$ & $\begin{array}{l}1000 \\
1690 \\
1690 \\
1460 \\
1080\end{array}$ & $\begin{array}{r}13 \\
320 \\
54 \\
26 \\
24\end{array}$ & $\begin{array}{r}35 \\
1670 \\
246 \\
102 \\
70\end{array}$ & $\begin{array}{l}6670 \\
7250 \\
5150 \\
3480 \\
2700\end{array}$ & $\begin{array}{l}37 \\
41 \\
37 \\
29 \\
31\end{array}$ & $\begin{array}{l}606 \\
803 \\
514 \\
272 \\
226\end{array}$ & $\begin{array}{l}843 \\
690 \\
600 \\
510 \\
600\end{array}$ & $\begin{array}{l}15 \\
16 \\
11 \\
12 \\
13\end{array}$ & $\begin{array}{l}34 \\
30 \\
18 \\
17 \\
21\end{array}$ \\
\hline $\begin{array}{c}6 \ldots \\
7 \ldots \\
9 \ldots \\
10 \ldots\end{array}$ & $\begin{array}{r}960 \\
2520 \\
5450 \\
7200 \\
6140\end{array}$ & $\begin{array}{l}23 \\
27 \\
33 \\
43 \\
38\end{array}$ & $\begin{array}{r}60 \\
184 \\
486 \\
836 \\
630\end{array}$ & $\begin{array}{l}2200 \\
1690 \\
1630 \\
1460 \\
1130\end{array}$ & $\begin{array}{l}34 \\
31 \\
28 \\
27 \\
27\end{array}$ & $\begin{array}{r}202 \\
141 \\
123 \\
106 \\
82\end{array}$ & $\begin{array}{l}600 \\
880 \\
510 \\
510 \\
406\end{array}$ & $\begin{array}{l}12 \\
11 \\
11 \\
11 \\
10\end{array}$ & $\begin{array}{l}19 \\
26 \\
15 \\
15 \\
11\end{array}$ \\
\hline $\begin{array}{l}11 \ldots \\
12 \ldots \\
13 \ldots \\
14 \ldots \\
15 \ldots\end{array}$ & $\begin{array}{l}6400 \\
5960 \\
6140 \\
5360 \\
5530\end{array}$ & $\begin{array}{l}42 \\
40 \\
44 \\
43 \\
39\end{array}$ & $\begin{array}{l}726 \\
644 \\
729 \\
622 \\
582\end{array}$ & $\begin{array}{l}980 \\
880 \\
766 \\
636 \\
564\end{array}$ & $\begin{array}{l}23 \\
22 \\
22 \\
23 \\
22\end{array}$ & $\begin{array}{l}61 \\
52 \\
46 \\
39 \\
34\end{array}$ & $\begin{array}{l}350 \\
330 \\
360 \\
960 \\
880\end{array}$ & $\begin{array}{r}11 \\
10 \\
9 \\
10 \\
11\end{array}$ & $\begin{array}{r}10 \\
9 \\
9 \\
26 \\
26\end{array}$ \\
\hline $\begin{array}{l}16 \ldots \\
17 \ldots \\
18 \ldots \\
19 \ldots \\
20 \ldots\end{array}$ & $\begin{array}{l}4420 \\
3000 \\
2580 \\
1660 \\
1460\end{array}$ & $\begin{array}{l}34 \\
29 \\
29 \\
30 \\
27\end{array}$ & $\begin{array}{l}406 \\
235 \\
202 \\
134 \\
106\end{array}$ & $\begin{array}{l}618 \\
672 \\
600 \\
564 \\
528\end{array}$ & $\begin{array}{l}20 \\
19 \\
19 \\
17 \\
16\end{array}$ & $\begin{array}{l}33 \\
34 \\
31 \\
26 \\
23\end{array}$ & $\begin{array}{l}960 \\
636 \\
350 \\
445 \\
471\end{array}$ & $\begin{array}{r}10 \\
10 \\
9 \\
7 \\
6\end{array}$ & $\begin{array}{r}26 \\
17 \\
9 \\
8 \\
8\end{array}$ \\
\hline $\begin{array}{l}21 \ldots \\
22 \ldots \\
23 \ldots \\
24 \ldots \\
25 \ldots\end{array}$ & $\begin{array}{l}2070 \\
1510 \\
1340 \\
1060 \\
1020\end{array}$ & $\begin{array}{l}24 \\
18 \\
18 \\
18 \\
14\end{array}$ & $\begin{array}{r}134 \\
73 \\
65 \\
52 \\
39\end{array}$ & $\begin{array}{l}528 \\
510 \\
510 \\
510 \\
510\end{array}$ & $\begin{array}{l}17 \\
16 \\
12 \\
11 \\
10\end{array}$ & $\begin{array}{l}24 \\
22 \\
17 \\
15 \\
14\end{array}$ & $\begin{array}{l}880 \\
742 \\
880 \\
600 \\
419\end{array}$ & $\begin{array}{r}8 \\
9 \\
14 \\
12 \\
14\end{array}$ & $\begin{array}{l}19 \\
18 \\
33 \\
19 \\
16\end{array}$ \\
\hline $\begin{array}{l}26 \ldots \\
27 \ldots \\
28 \ldots \\
29 \ldots \\
30 \ldots \\
31 \ldots\end{array}$ & $\begin{array}{r}980 \\
1370 \\
1510 \\
1480 \\
1820 \\
2770\end{array}$ & $\begin{array}{l}13 \\
13 \\
15 \\
18 \\
47 \\
27 \\
\end{array}$ & $\begin{array}{r}34 \\
48 \\
61 \\
72 \\
231 \\
202 \\
\end{array}$ & $\begin{array}{r}1160 \\
880 \\
785 \\
747 \\
785 \\
804 \\
\end{array}$ & $\begin{array}{l}54 \\
45 \\
34 \\
24 \\
22 \\
18 \\
\end{array}$ & $\begin{array}{r}169 \\
107 \\
72 \\
48 \\
47 \\
39\end{array}$ & $\begin{array}{r}823 \\
600 \\
1130 \\
1240 \\
1020 \\
--\end{array}$ & $\begin{array}{l}11 \\
11 \\
11 \\
12 \\
11 \\
-2\end{array}$ & $\begin{array}{l}24 \\
18 \\
34 \\
40 \\
30 \\
--\end{array}$ \\
\hline Total & 88630 & -- & 9716 & 47897 & -- & 4088 & 20225 & -- & 605 \\
\hline
\end{tabular}




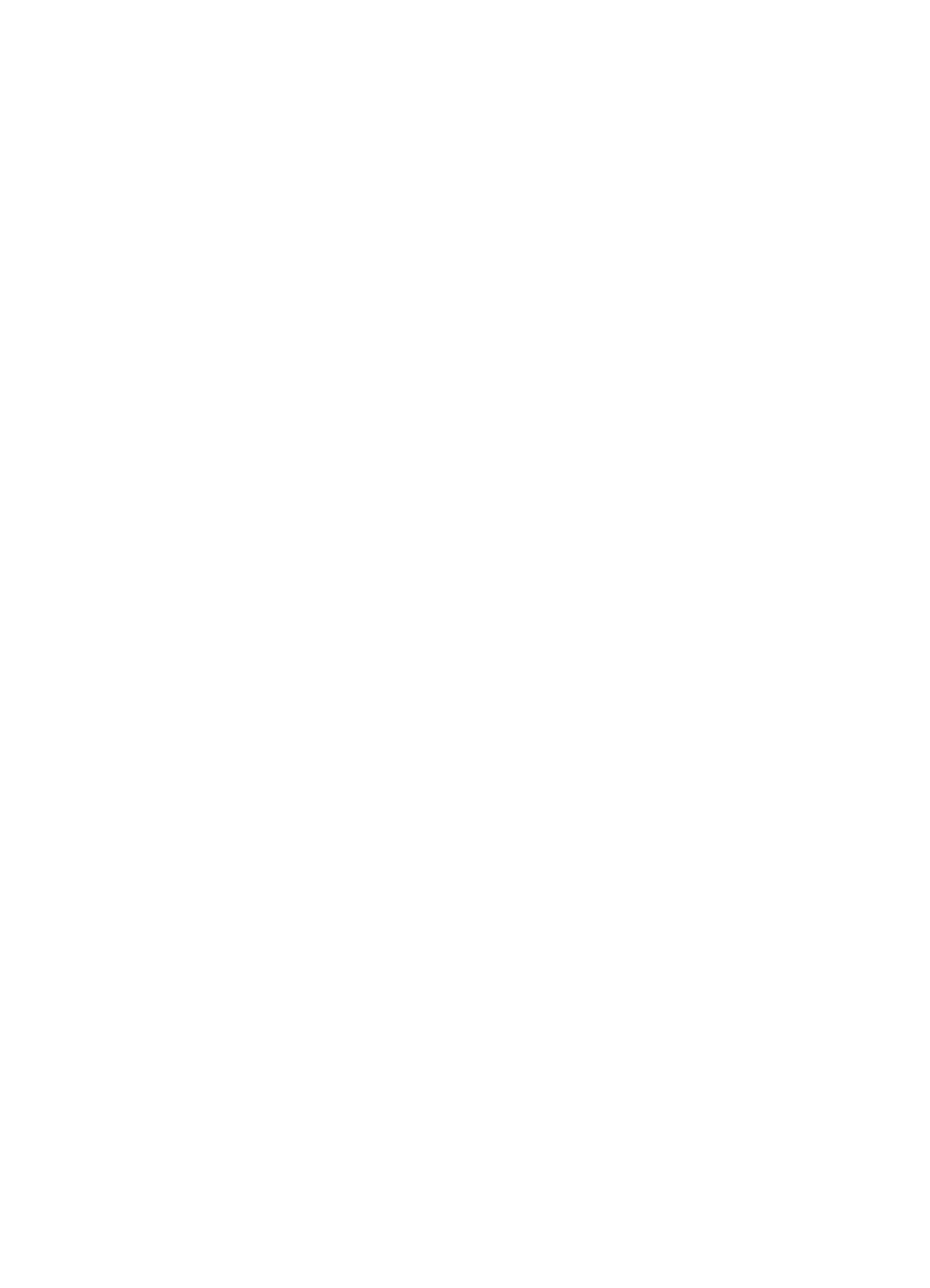



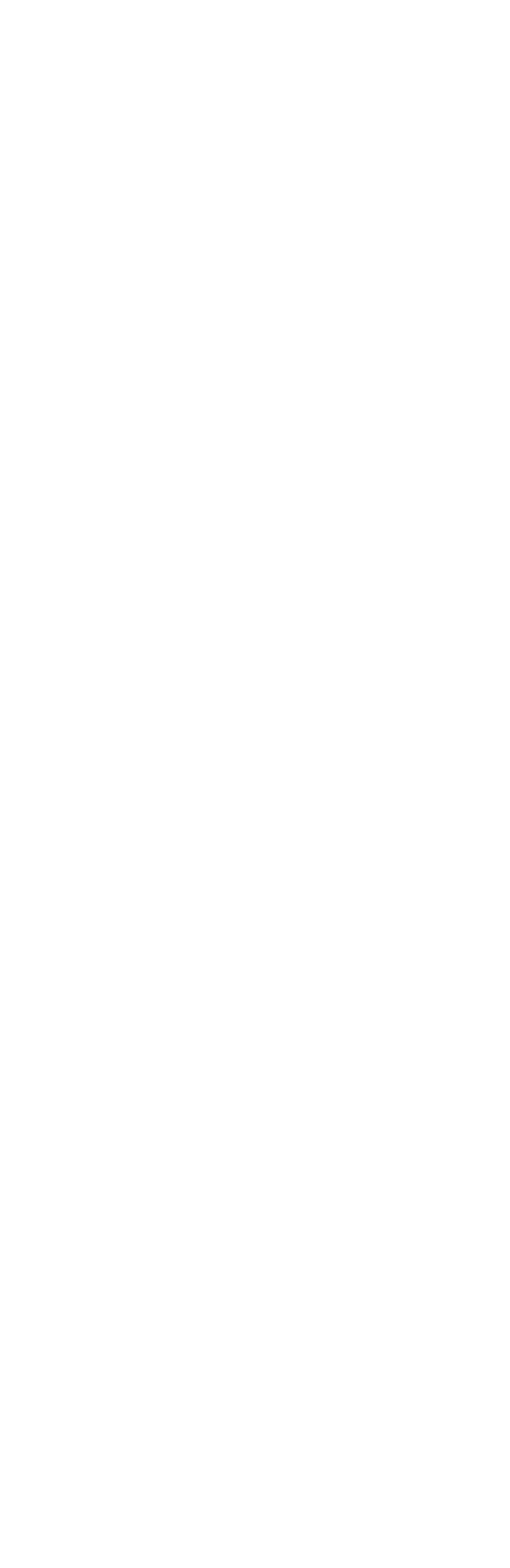
KENTUCKY RIVER BASIN--Continued

3-2915. EAGLE CREEK AT GLENCOE, KY,--Continued

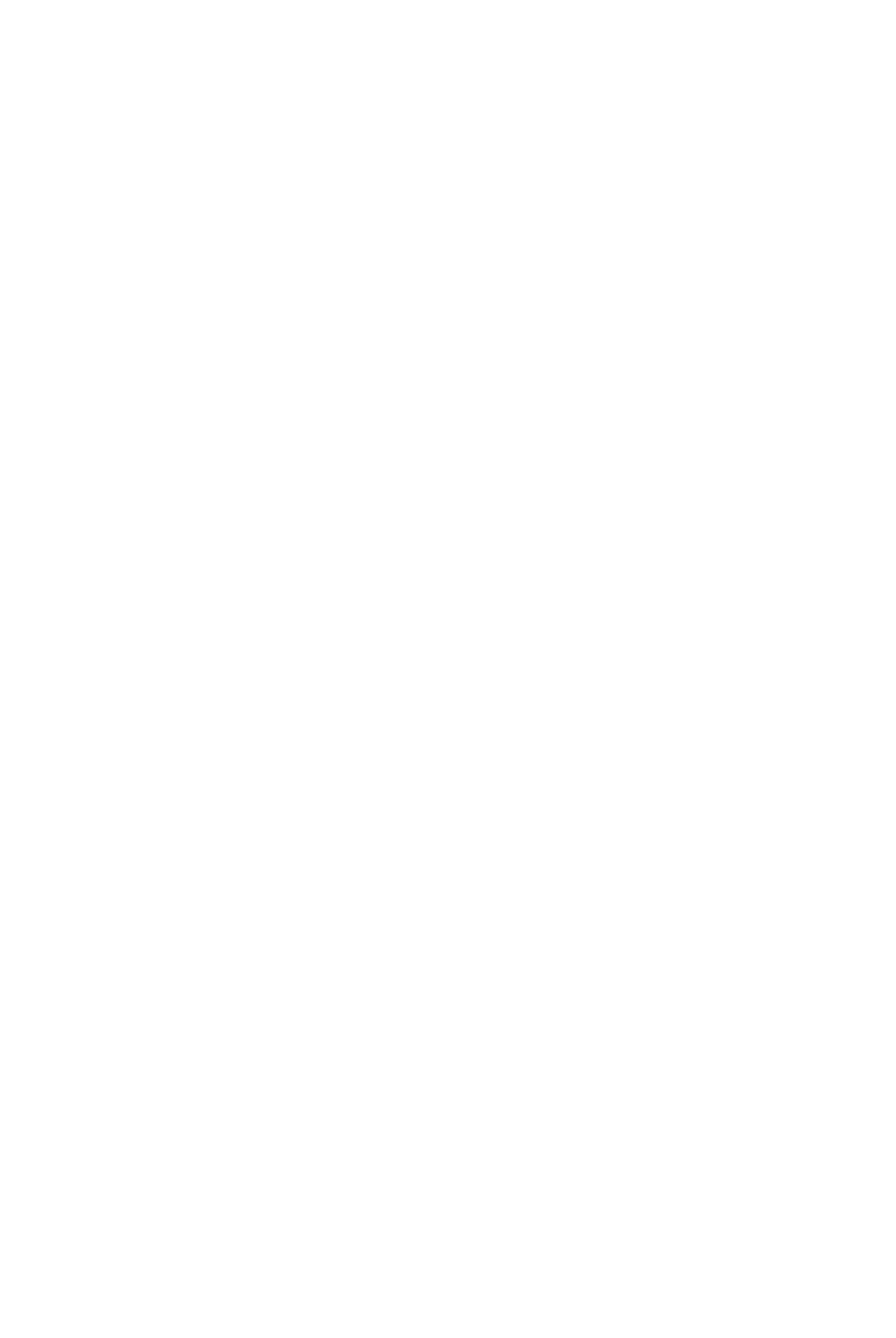

$T$ Less than 0.50 ton. 
KENTUCKY RIVER BASIN--COntinued

3-2915. EAGLE CREEK AT GLENCOE, KY.--Continued

Suspended sediment, water year October 1966 to September 1967--Continued

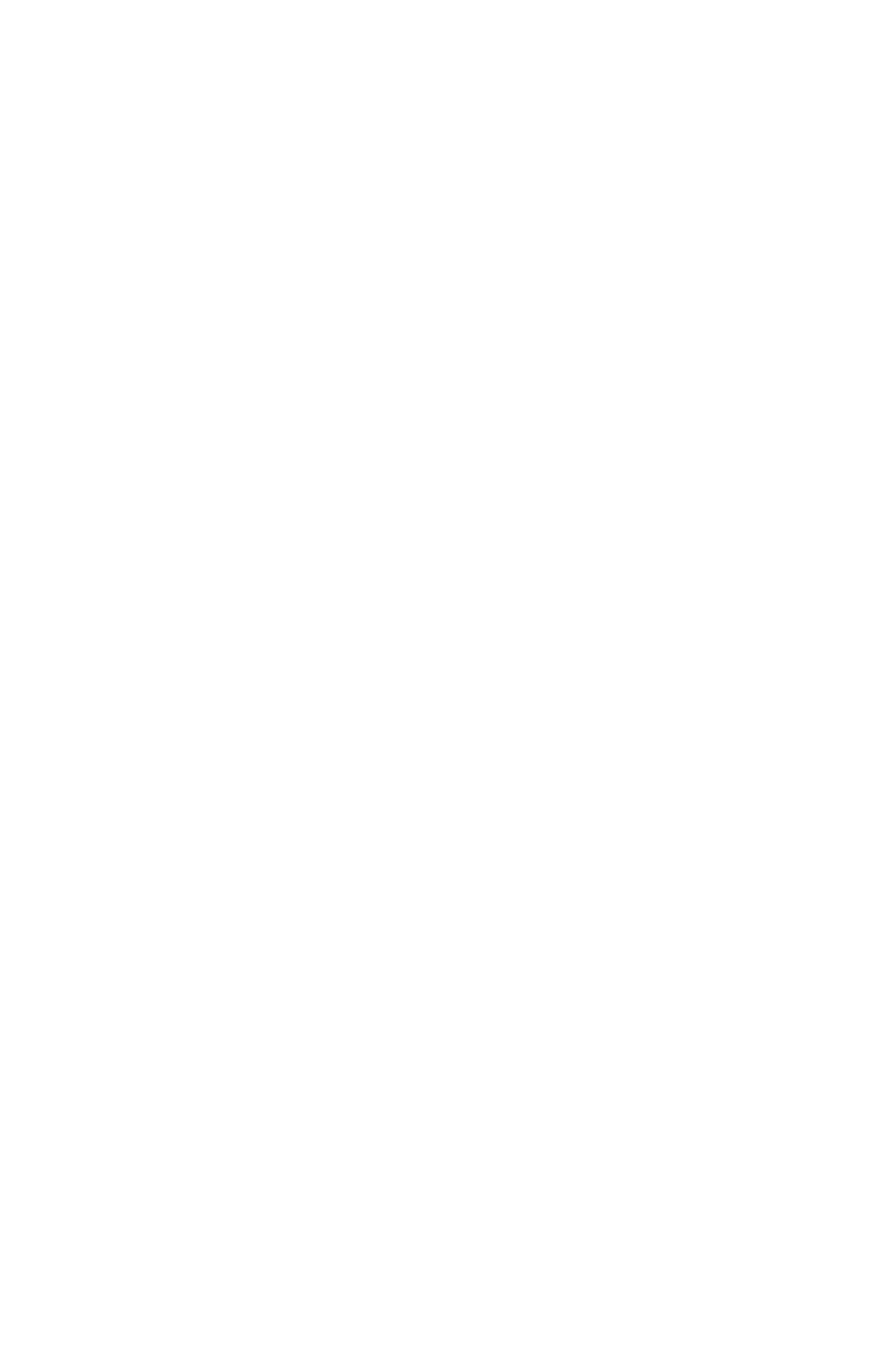




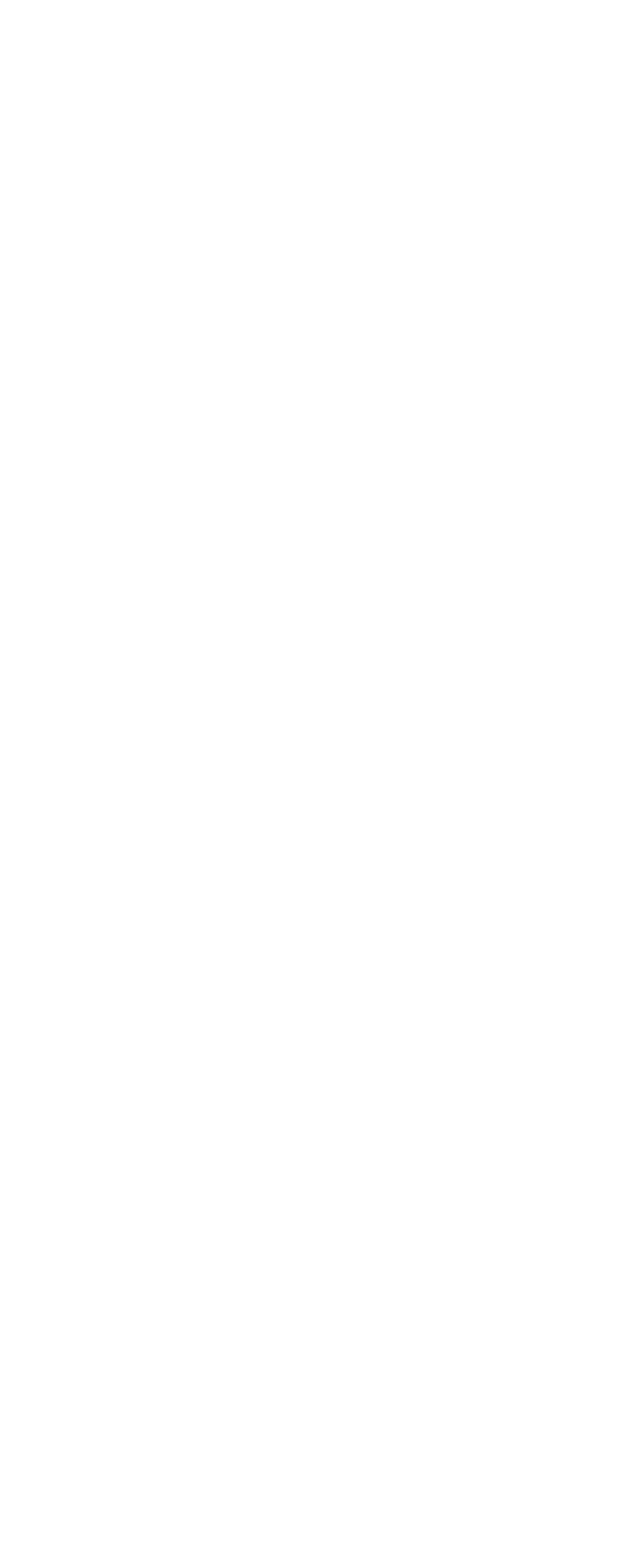




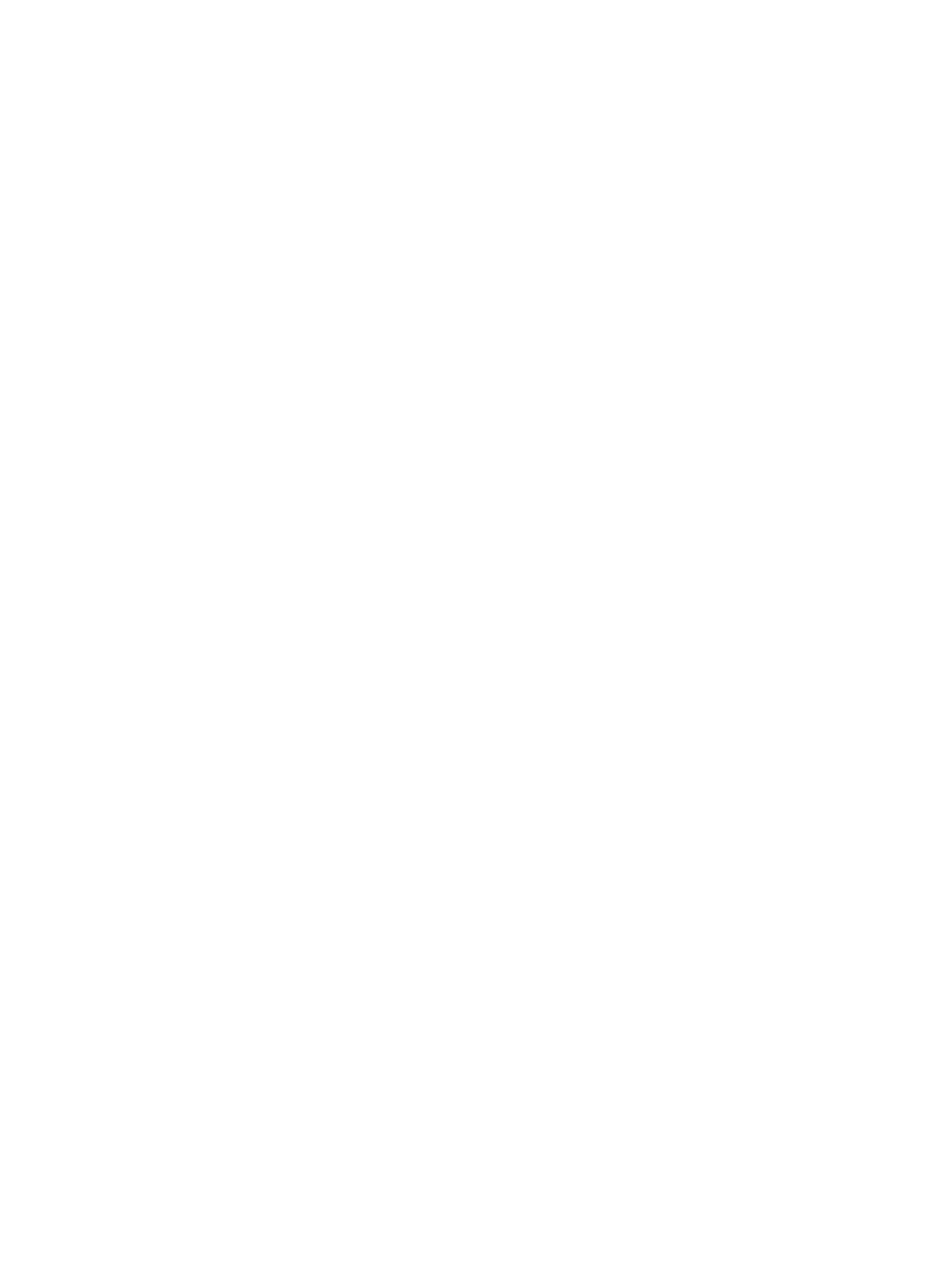




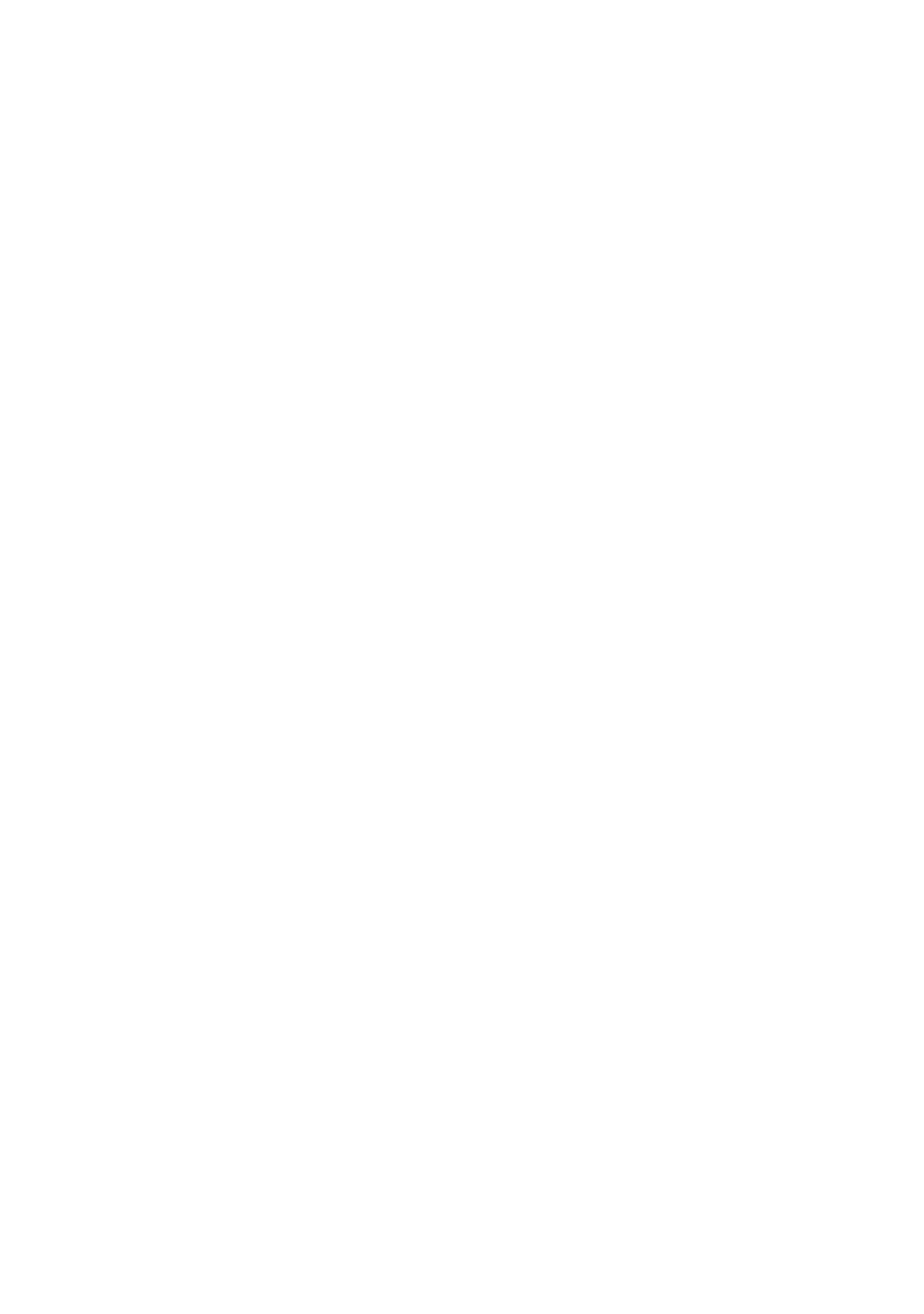




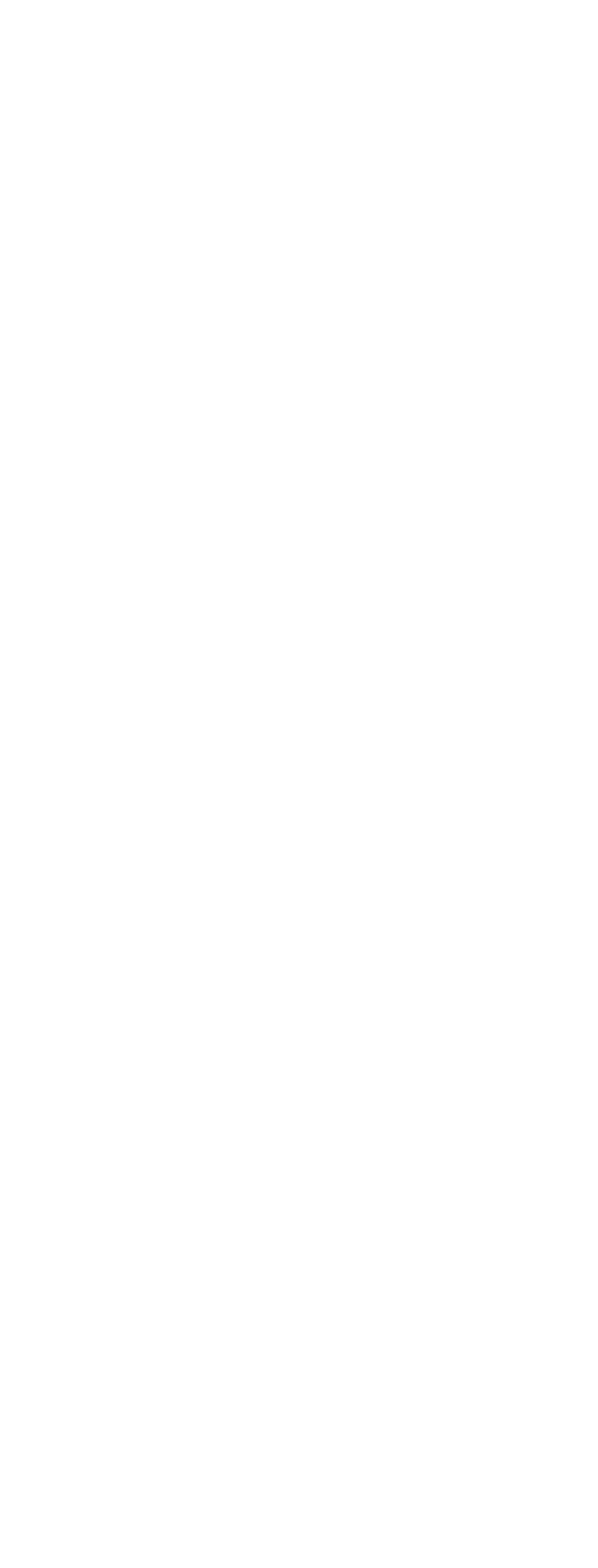




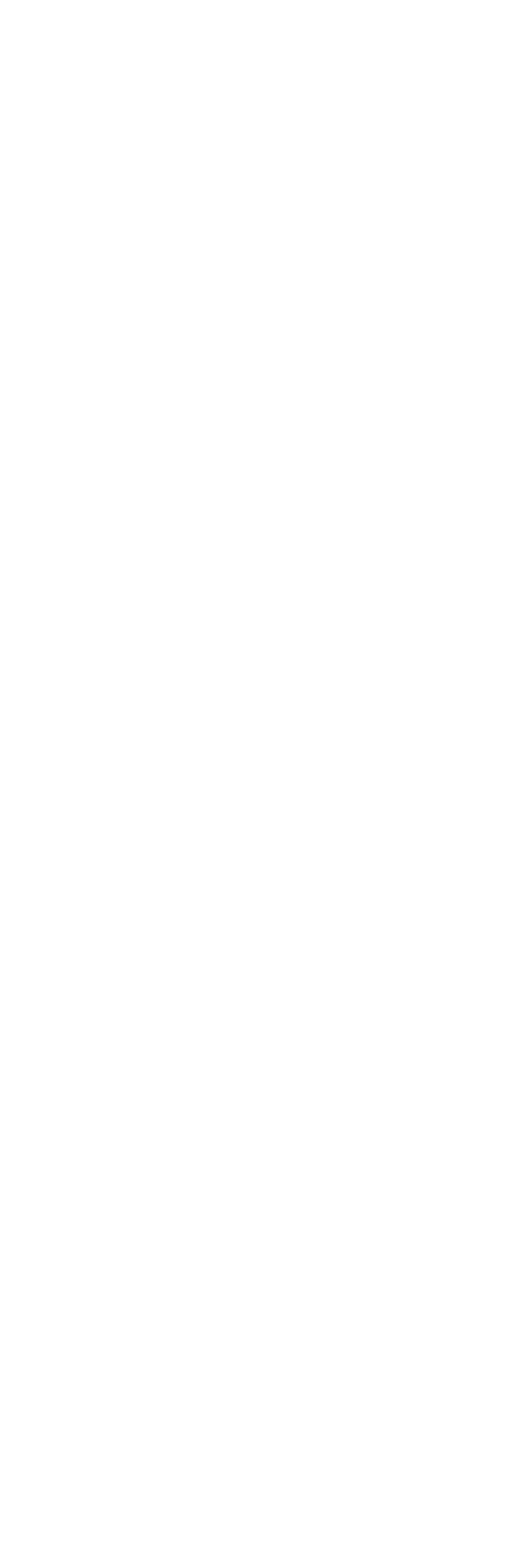




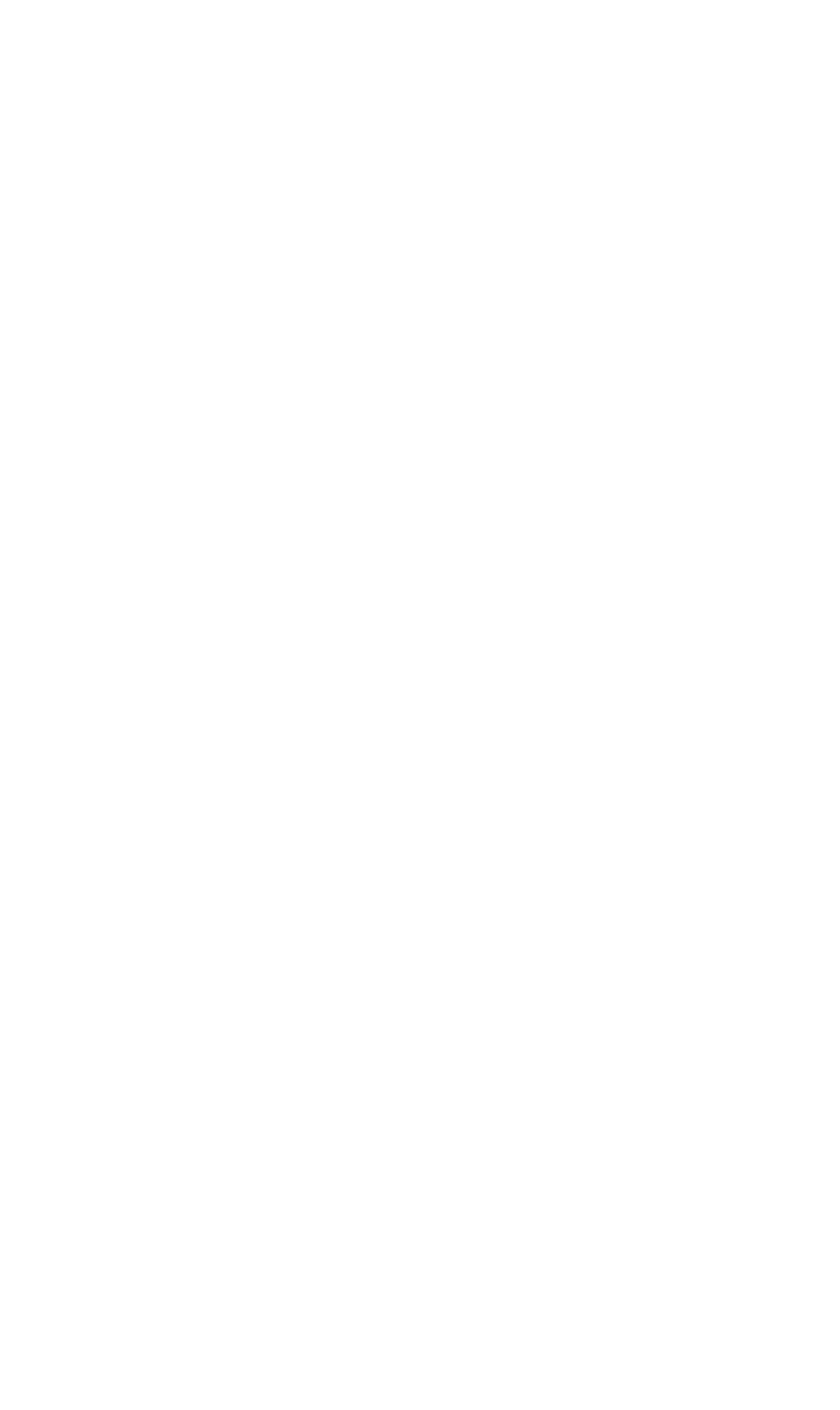




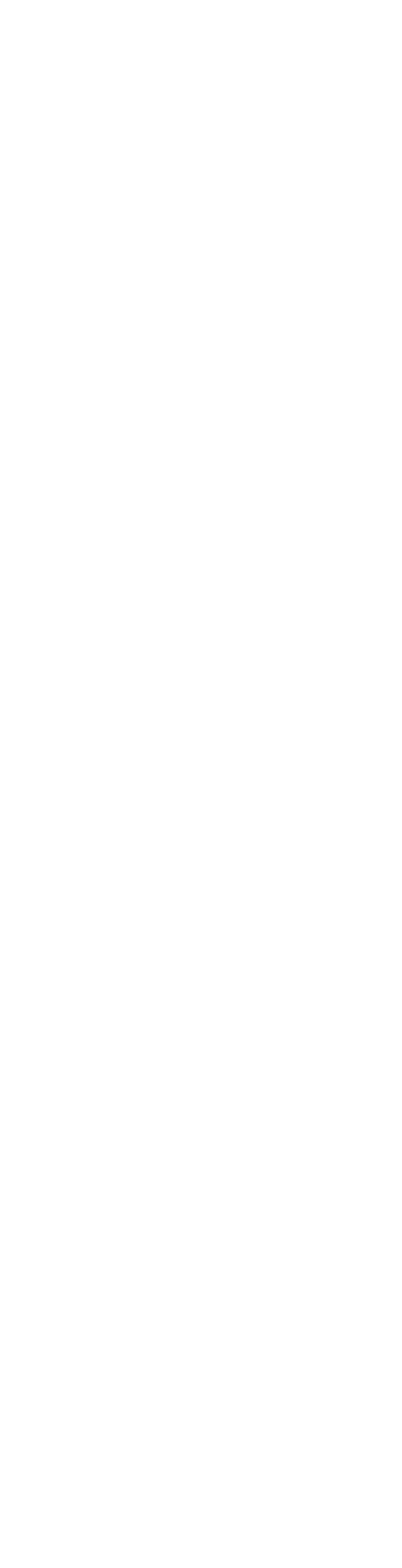

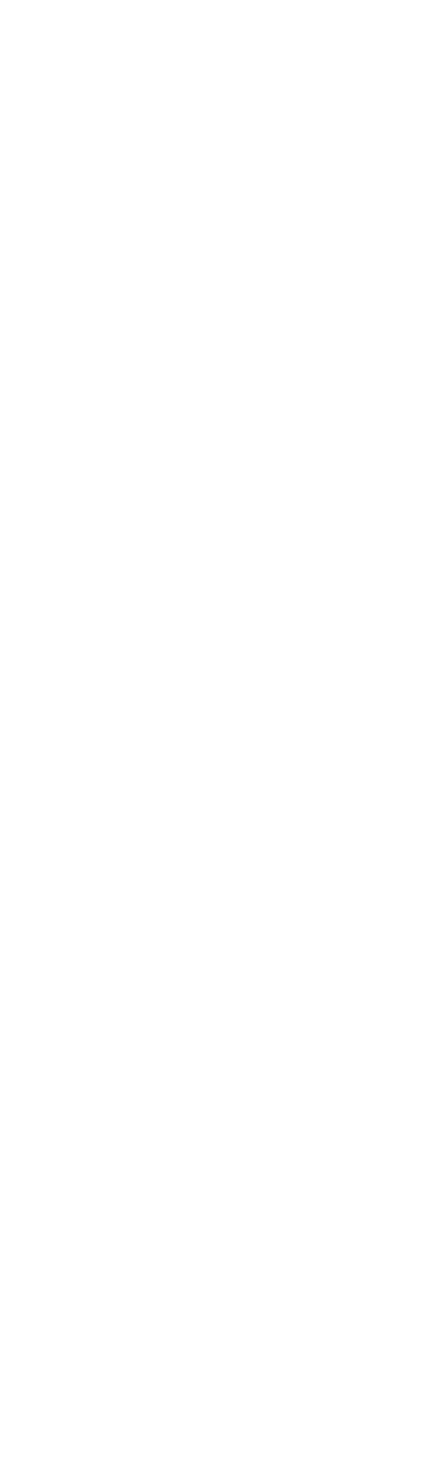




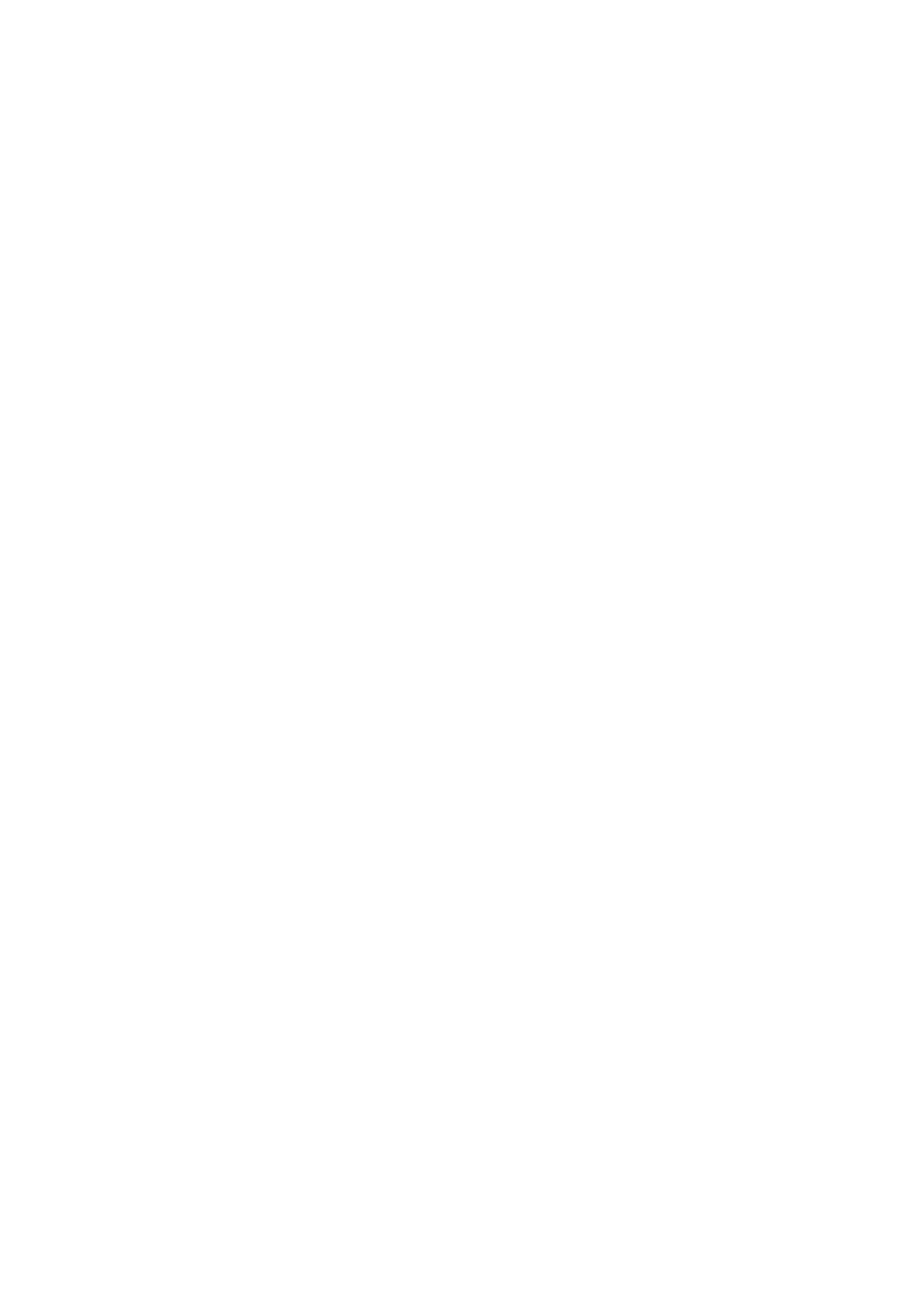


GREEN RIVER BASIN--Continued

3-3085. GREEN RIVER AT MUNFORDVILLE, KY.--Continued

Suspended sediment, water year October 1966 to September 1967

\begin{tabular}{|c|c|c|c|c|c|c|c|c|c|}
\hline \multirow[b]{3}{*}{ Day } & \multicolumn{3}{|c|}{ OCTOBER } & \multicolumn{3}{|c|}{ NOVEMBER } & \multicolumn{3}{|c|}{ DECEMBER } \\
\hline & \multirow[b]{2}{*}{$\begin{array}{c}\text { Mean } \\
\text { dis- } \\
\text { charge } \\
(\mathrm{cfs})\end{array}$} & \multicolumn{2}{|c|}{ Suspended sediment } & \multirow[b]{2}{*}{$\begin{array}{c}\text { Mean } \\
\text { dis- } \\
\text { charge } \\
\text { (cfs) }\end{array}$} & \multicolumn{2}{|c|}{ Suspended sediment } & \multirow[b]{2}{*}{$\begin{array}{c}\text { Mean } \\
\text { dis- } \\
\text { charge } \\
\text { (cfs) }\end{array}$} & \multicolumn{2}{|c|}{ Suspended sediment } \\
\hline & & $\begin{array}{c}\text { Mean } \\
\text { concen- } \\
\text { tration } \\
(\mathrm{ppm})\end{array}$ & $\begin{array}{l}\text { Tons } \\
\text { per } \\
\text { day }\end{array}$ & & $\begin{array}{c}\text { Mean } \\
\text { concen- } \\
\text { tration } \\
(\mathrm{ppm})\end{array}$ & $\begin{array}{l}\text { Tons } \\
\text { per } \\
\text { day }\end{array}$ & & $\begin{array}{c}\text { Mean } \\
\text { concen- } \\
\text { tration } \\
\text { (ppm) }\end{array}$ & $\begin{array}{l}\text { Tons } \\
\text { per } \\
\text { day }\end{array}$ \\
\hline $\begin{array}{l}1 \ldots \\
2 \ldots \\
3 \ldots \\
4 \ldots \\
5 \ldots\end{array}$ & $\begin{array}{r}933 \\
1790 \\
1510 \\
1650 \\
1320\end{array}$ & $\begin{array}{r}62 \\
170 \\
101 \\
88 \\
70\end{array}$ & $\begin{array}{l}156 \\
822 \\
412 \\
392 \\
249\end{array}$ & $\begin{array}{r}477 \\
560 \\
724 \\
1160 \\
1780\end{array}$ & $\begin{array}{l}11 \\
10 \\
12 \\
17 \\
33\end{array}$ & $\begin{array}{r}14 \\
15 \\
23 \\
53 \\
159\end{array}$ & $\begin{array}{l}1770 \\
1620 \\
1470 \\
1320 \\
1200\end{array}$ & $\begin{array}{r}12 \\
12 \\
11 \\
9 \\
8\end{array}$ & $\begin{array}{l}57 \\
52 \\
44 \\
32 \\
26\end{array}$ \\
\hline $\begin{array}{c}6 \ldots \\
7 \ldots \\
8 \ldots \\
10 \ldots\end{array}$ & $\begin{array}{r}1030 \\
894 \\
699 \\
616 \\
1730\end{array}$ & $\begin{array}{r}53 \\
46 \\
37 \\
29 \\
145\end{array}$ & $\begin{array}{r}147 \\
111 \\
70 \\
48 \\
834\end{array}$ & $\begin{array}{l}4740 \\
6500 \\
6540 \\
5720 \\
6280\end{array}$ & $\begin{array}{l}261 \\
178 \\
142 \\
103 \\
154\end{array}$ & $\begin{array}{l}3690 \\
3120 \\
2510 \\
1590 \\
2610\end{array}$ & $\begin{array}{r}1240 \\
1440 \\
1540 \\
3250 \\
13800\end{array}$ & $\begin{array}{r}8 \\
10 \\
15 \\
145 \\
394\end{array}$ & $\begin{array}{r}27 \\
39 \\
62 \\
2190 \\
13700\end{array}$ \\
\hline $\begin{array}{l}11 \ldots \\
12 \ldots \\
13 \ldots \\
14 \ldots \\
15 \ldots\end{array}$ & $\begin{array}{l}2180 \\
1660 \\
1510 \\
1320 \\
1120\end{array}$ & $\begin{array}{r}152 \\
76 \\
57 \\
54 \\
47\end{array}$ & $\begin{array}{l}895 \\
341 \\
232 \\
192 \\
142\end{array}$ & $\begin{array}{r}10700 \\
8560 \\
6180 \\
5010 \\
4020\end{array}$ & $\begin{array}{r}312 \\
111 \\
93 \\
77 \\
62\end{array}$ & $\begin{array}{r}9010 \\
2570 \\
1550 \\
1040 \\
673\end{array}$ & $\begin{array}{r}17200 \\
16000 \\
12400 \\
9720 \\
8010\end{array}$ & $\begin{array}{r}170 \\
125 \\
109 \\
99 \\
89\end{array}$ & $\begin{array}{l}7890 \\
5400 \\
3650 \\
2600 \\
1920\end{array}$ \\
\hline $\begin{array}{l}16 \ldots \\
17 \ldots \\
18 \ldots \\
19 \ldots \\
20 \ldots\end{array}$ & $\begin{array}{l}1420 \\
1460 \\
1200 \\
1110 \\
1100\end{array}$ & $\begin{array}{l}59 \\
58 \\
43 \\
37 \\
48\end{array}$ & $\begin{array}{l}226 \\
229 \\
139 \\
111 \\
143\end{array}$ & $\begin{array}{l}3140 \\
2490 \\
2010 \\
1690 \\
1460\end{array}$ & $\begin{array}{l}46 \\
37 \\
33 \\
29 \\
26\end{array}$ & $\begin{array}{l}390 \\
249 \\
179 \\
132 \\
102\end{array}$ & $\begin{array}{l}6770 \\
5690 \\
5090 \\
4270 \\
3330\end{array}$ & $\begin{array}{l}66 \\
53 \\
42 \\
31 \\
24\end{array}$ & $\begin{array}{r}1210 \\
814 \\
577 \\
357 \\
216\end{array}$ \\
\hline $\begin{array}{l}21 \ldots \\
22 \ldots \\
23 \ldots \\
24 \ldots \\
25 \ldots\end{array}$ & $\begin{array}{r}1030 \\
954 \\
881 \\
808 \\
743\end{array}$ & $\begin{array}{l}42 \\
40 \\
35 \\
31 \\
21\end{array}$ & $\begin{array}{r}117 \\
103 \\
83 \\
68 \\
42\end{array}$ & $\begin{array}{r}1290 \\
1140 \\
1030 \\
938 \\
872\end{array}$ & $\begin{array}{r}19 \\
16 \\
11 \\
9 \\
11\end{array}$ & $\begin{array}{l}66 \\
49 \\
31 \\
23 \\
26\end{array}$ & $\begin{array}{l}2510 \\
1960 \\
1630 \\
1480 \\
1310\end{array}$ & $\begin{array}{l}22 \\
19 \\
14 \\
13 \\
13\end{array}$ & $\begin{array}{r}149 \\
101 \\
62 \\
52 \\
46\end{array}$ \\
\hline $\begin{array}{l}26 \ldots \\
27 \ldots \\
28 \ldots \\
29 \ldots \\
30 \ldots \\
31 \ldots\end{array}$ & $\begin{array}{l}681 \\
631 \\
585 \\
543 \\
507 \\
474\end{array}$ & $\begin{array}{r}20 \\
11 \\
9 \\
9 \\
8 \\
9\end{array}$ & $\begin{array}{l}37 \\
19 \\
14 \\
13 \\
11 \\
12 \\
\end{array}$ & $\begin{array}{r}920 \\
1550 \\
1700 \\
1860 \\
1920 \\
-- \\
\end{array}$ & $\begin{array}{l}13 \\
34 \\
34 \\
23 \\
17 \\
\end{array}$ & $\begin{array}{r}32 \\
142 \\
156 \\
117 \\
88 \\
-\end{array}$ & $\begin{array}{r}1170 \\
1080 \\
4380 \\
13500 \\
12300 \\
8980 \\
\end{array}$ & $\begin{array}{r}13 \\
13 \\
419 \\
359 \\
125 \\
77 \\
\end{array}$ & $\begin{array}{r}41 \\
38 \\
7290 \\
13100 \\
4150 \\
1870 \\
\end{array}$ \\
\hline \multirow[t]{2}{*}{ Total } & 34089 & - & 6410 & 92981 & -- & 30409 & 167430 & -- & 67762 \\
\hline & \multicolumn{3}{|c|}{ JANUARY } & \multicolumn{3}{|c|}{ FEBRUARY } & \multicolumn{3}{|c|}{ MARCH } \\
\hline $\begin{array}{l}1 \ldots \\
2 \ldots \\
3 \ldots \\
4 \ldots \\
5 \ldots\end{array}$ & $\begin{array}{l}7500 \\
6580 \\
5580 \\
4710 \\
3800\end{array}$ & $\begin{array}{l}57 \\
81 \\
49 \\
37 \\
24\end{array}$ & $\begin{array}{r}1150 \\
1440 \\
738 \\
471 \\
246\end{array}$ & $\begin{array}{l}3430 \\
2930 \\
2910 \\
2940 \\
2890\end{array}$ & $\begin{array}{l}51 \\
34 \\
28 \\
35 \\
29\end{array}$ & $\begin{array}{l}472 \\
269 \\
220 \\
278 \\
226\end{array}$ & $\begin{array}{l}3710 \\
3590 \\
3720 \\
3470 \\
3410\end{array}$ & $\begin{array}{r}103 \\
35 \\
38 \\
39 \\
59\end{array}$ & $\begin{array}{r}1030 \\
339 \\
382 \\
365 \\
543\end{array}$ \\
\hline $\begin{array}{c}6 \ldots \\
7 \ldots \\
9 \ldots \\
10 \ldots\end{array}$ & $\begin{array}{l}2970 \\
2400 \\
2030 \\
1780 \\
1590\end{array}$ & $\begin{array}{l}22 \\
19 \\
15 \\
13 \\
11\end{array}$ & $\begin{array}{r}176 \\
123 \\
82 \\
62 \\
47\end{array}$ & $\begin{array}{l}2770 \\
2510 \\
2200 \\
1930 \\
1740\end{array}$ & $\begin{array}{l}23 \\
19 \\
16 \\
12 \\
11\end{array}$ & $\begin{array}{r}172 \\
129 \\
95 \\
63 \\
52\end{array}$ & $\begin{array}{l}11400 \\
25400 \\
33100 \\
29200 \\
21800\end{array}$ & $\begin{array}{l}737 \\
570 \\
185 \\
173 \\
217\end{array}$ & $\begin{array}{l}26000 \\
39100 \\
16500 \\
13600 \\
12800\end{array}$ \\
\hline $\begin{array}{l}11 \ldots \\
12 \ldots \\
13 \ldots \\
14 \ldots \\
15 \ldots\end{array}$ & $\begin{array}{l}1460 \\
1340 \\
1230 \\
1230 \\
1560\end{array}$ & $\begin{array}{r}8 \\
8 \\
10 \\
9 \\
12\end{array}$ & $\begin{array}{l}32 \\
29 \\
33 \\
30 \\
51\end{array}$ & $\begin{array}{l}1620 \\
1490 \\
1360 \\
1270 \\
1190\end{array}$ & $\begin{array}{r}8 \\
8 \\
8 \\
7 \\
10\end{array}$ & $\begin{array}{l}35 \\
32 \\
29 \\
24 \\
32\end{array}$ & $\begin{array}{l}14800 \\
13300 \\
18700 \\
19100 \\
15000\end{array}$ & $\begin{array}{r}213 \\
1040 \\
835 \\
210 \\
117\end{array}$ & $\begin{array}{r}8510 \\
37300 \\
42200 \\
10800 \\
4740\end{array}$ \\
\hline $\begin{array}{l}16 \ldots \\
17 \ldots \\
18 \ldots \\
19 \ldots \\
20 \ldots\end{array}$ & $\begin{array}{l}1670 \\
1550 \\
1480 \\
1360 \\
1290\end{array}$ & $\begin{array}{l}14 \\
12 \\
12 \\
12 \\
12\end{array}$ & $\begin{array}{l}63 \\
50 \\
48 \\
44 \\
42\end{array}$ & $\begin{array}{r}1110 \\
1070 \\
1030 \\
992 \\
1010\end{array}$ & $\begin{array}{r}9 \\
3 \\
4 \\
10 \\
6\end{array}$ & $\begin{array}{r}27 \\
9 \\
11 \\
27 \\
22\end{array}$ & $\begin{array}{r}11300 \\
9720 \\
8780 \\
7660 \\
6720\end{array}$ & $\begin{array}{l}164 \\
153 \\
140 \\
127 \\
112\end{array}$ & $\begin{array}{l}5000 \\
4020 \\
3320 \\
2630 \\
2030\end{array}$ \\
\hline $\begin{array}{l}21 \ldots \\
22 \ldots \\
23 \ldots \\
24 \ldots \\
25 \ldots\end{array}$ & $\begin{array}{l}1260 \\
1220 \\
1220 \\
1210 \\
1210\end{array}$ & $\begin{array}{r}9 \\
8 \\
12 \\
12 \\
12\end{array}$ & $\begin{array}{l}31 \\
26 \\
40 \\
39 \\
39\end{array}$ & $\begin{array}{l}2070 \\
2780 \\
2730 \\
2790 \\
2420\end{array}$ & $\begin{array}{l}32 \\
40 \\
23 \\
19 \\
15\end{array}$ & $\begin{array}{r}214 \\
300 \\
170 \\
143 \\
98\end{array}$ & $\begin{array}{l}6310 \\
6000 \\
5110 \\
4280 \\
3460\end{array}$ & $\begin{array}{l}93 \\
79 \\
66 \\
55 \\
51\end{array}$ & $\begin{array}{r}1580 \\
1280 \\
911 \\
636 \\
476\end{array}$ \\
\hline $\begin{array}{l}26 \ldots \\
27 \ldots \\
28 \ldots \\
29 \ldots \\
30 \ldots \\
31 \ldots\end{array}$ & $\begin{array}{l}1290 \\
1610 \\
4380 \\
4550 \\
4510 \\
4020\end{array}$ & $\begin{array}{r}20 \\
63 \\
151 \\
94 \\
77 \\
68\end{array}$ & $\begin{array}{r}70 \\
337 \\
1790 \\
1150 \\
938 \\
738\end{array}$ & $\begin{array}{r}1980 \\
1680 \\
2410 \\
=- \\
=\end{array}$ & $\begin{array}{r}12 \\
8 \\
71 \\
-- \\
-- \\
-- \\
\end{array}$ & $\begin{array}{r}64 \\
41 \\
539 \\
-- \\
-- \\
-- \\
\end{array}$ & $\begin{array}{l}2790 \\
2290 \\
2020 \\
3330 \\
3940 \\
4310\end{array}$ & $\begin{array}{r}47 \\
38 \\
37 \\
91 \\
117 \\
105\end{array}$ & $\begin{array}{r}354 \\
235 \\
202 \\
836 \\
1240 \\
1220 \\
\end{array}$ \\
\hline Total & 79790 & -- & 10155 & 57452 & -- & 3793 & 307720 & -- & 240179 \\
\hline
\end{tabular}


GREEN RIVER BASIN--Continued

3-3085. GREEN RIVER AT MUNFORDVILLE, KY.--Continued

Suspended sediment, water year october 1966 to September 1967--Continued

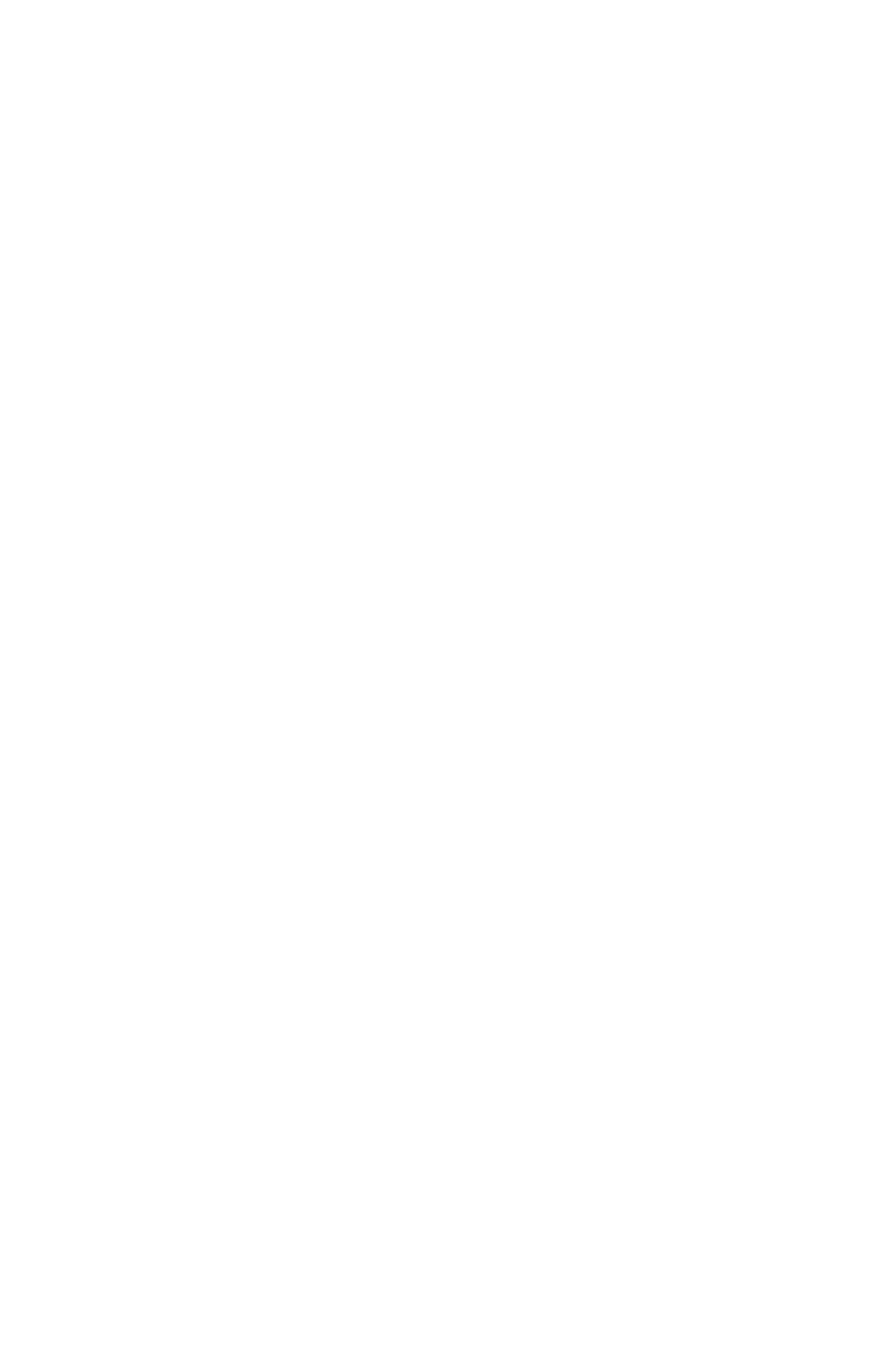




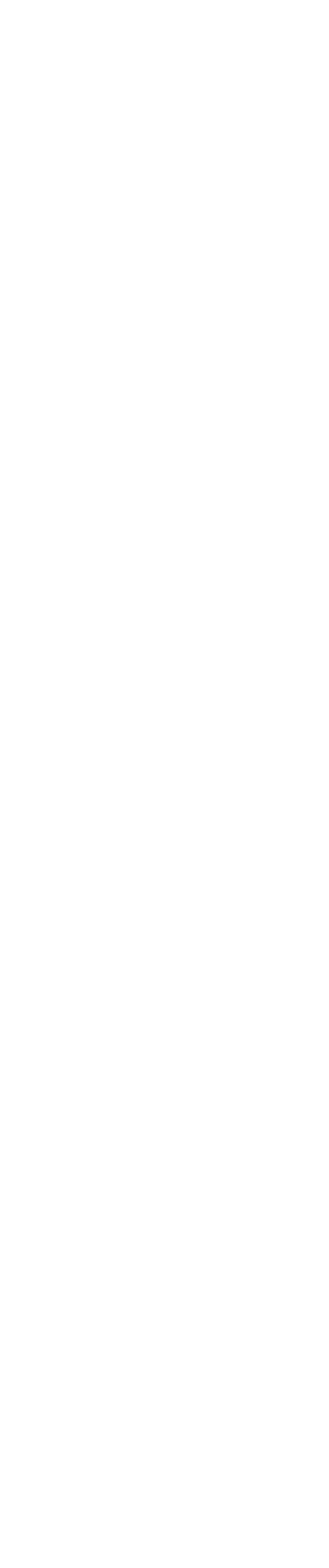




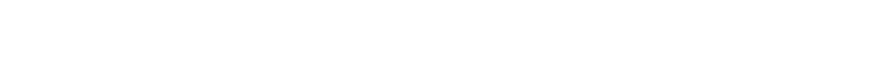

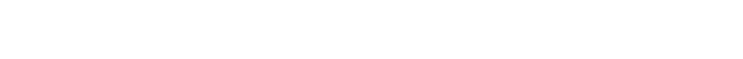

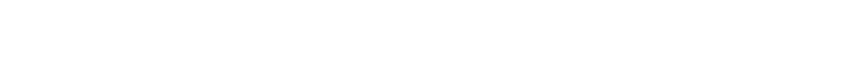

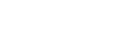

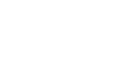

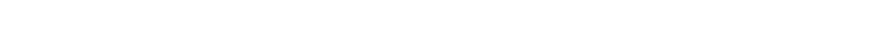

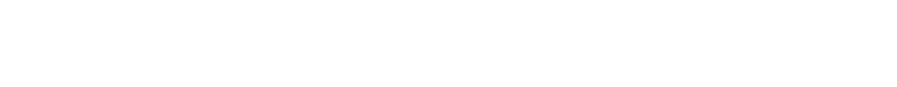

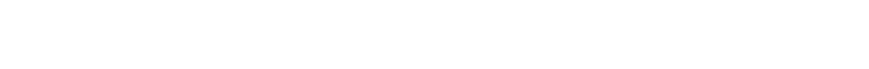

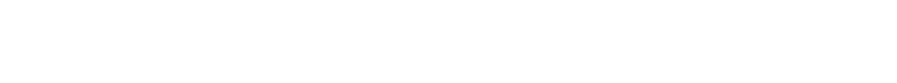

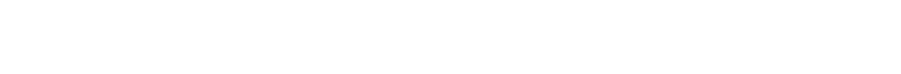

ब 造

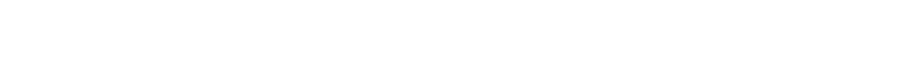

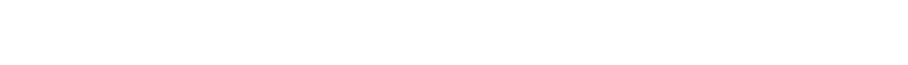

\begin{tabular}{|c|c|}
\hline 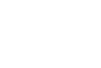 & 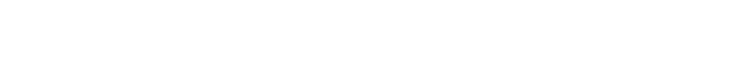 \\
\hline 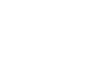 & 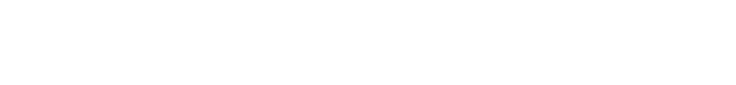 \\
\hline 需当无 & 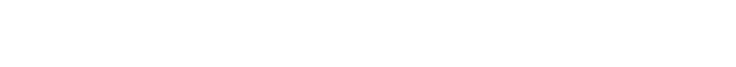 \\
\hline 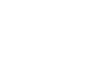 & 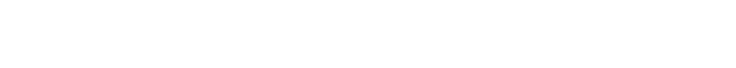 \\
\hline 苾矛 & 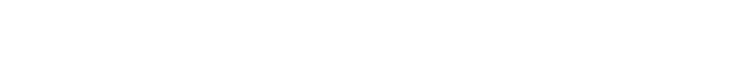 \\
\hline 焉是全 & $\ddot{0}$ \\
\hline 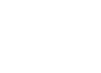 & 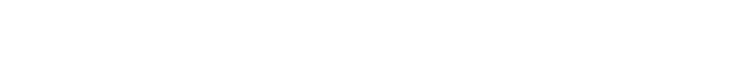 \\
\hline 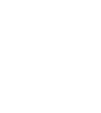 & \\
\hline 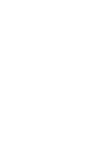 & $\begin{array}{l}0 \\
0 \\
0\end{array}$ \\
\hline
\end{tabular}



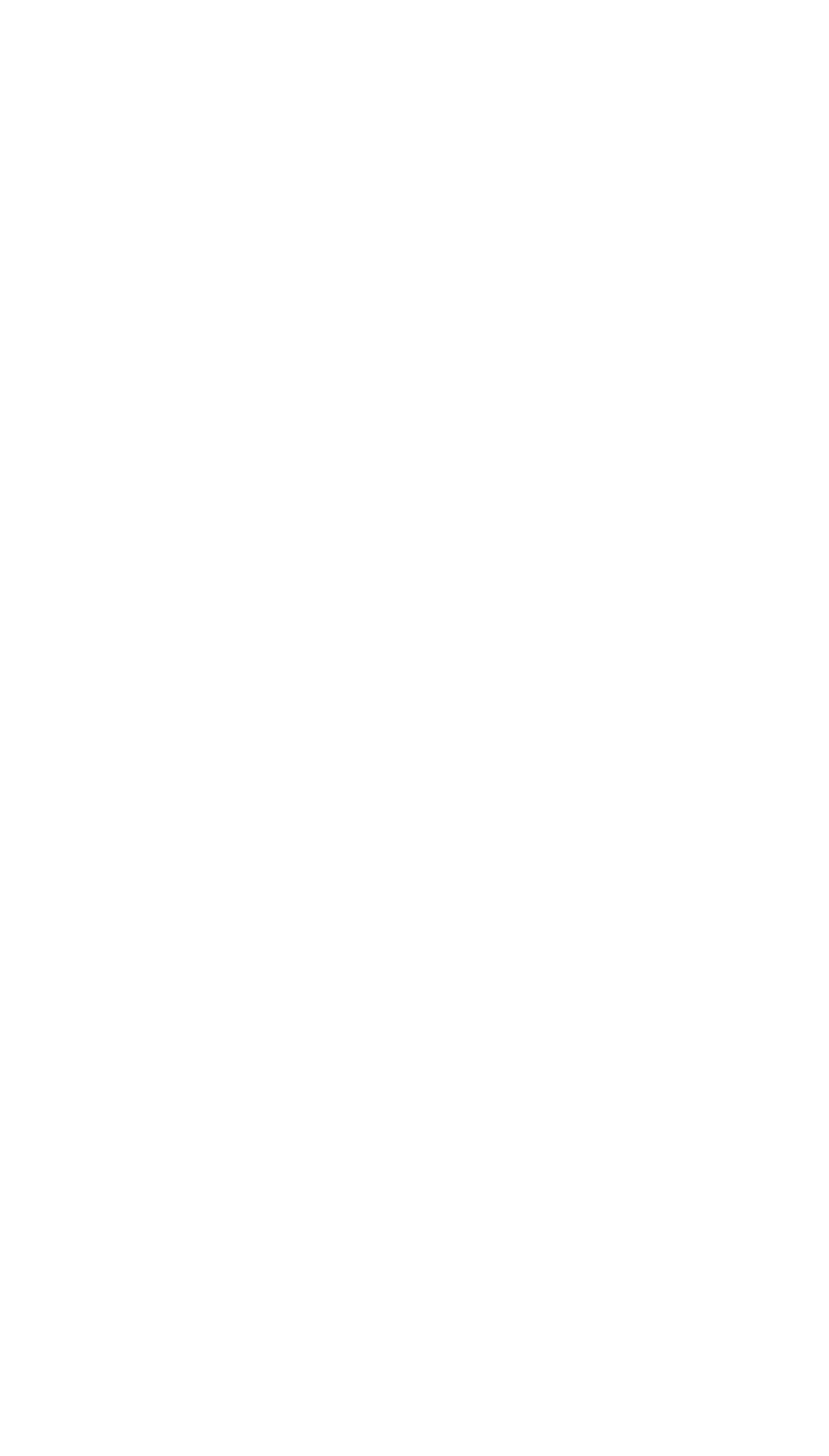


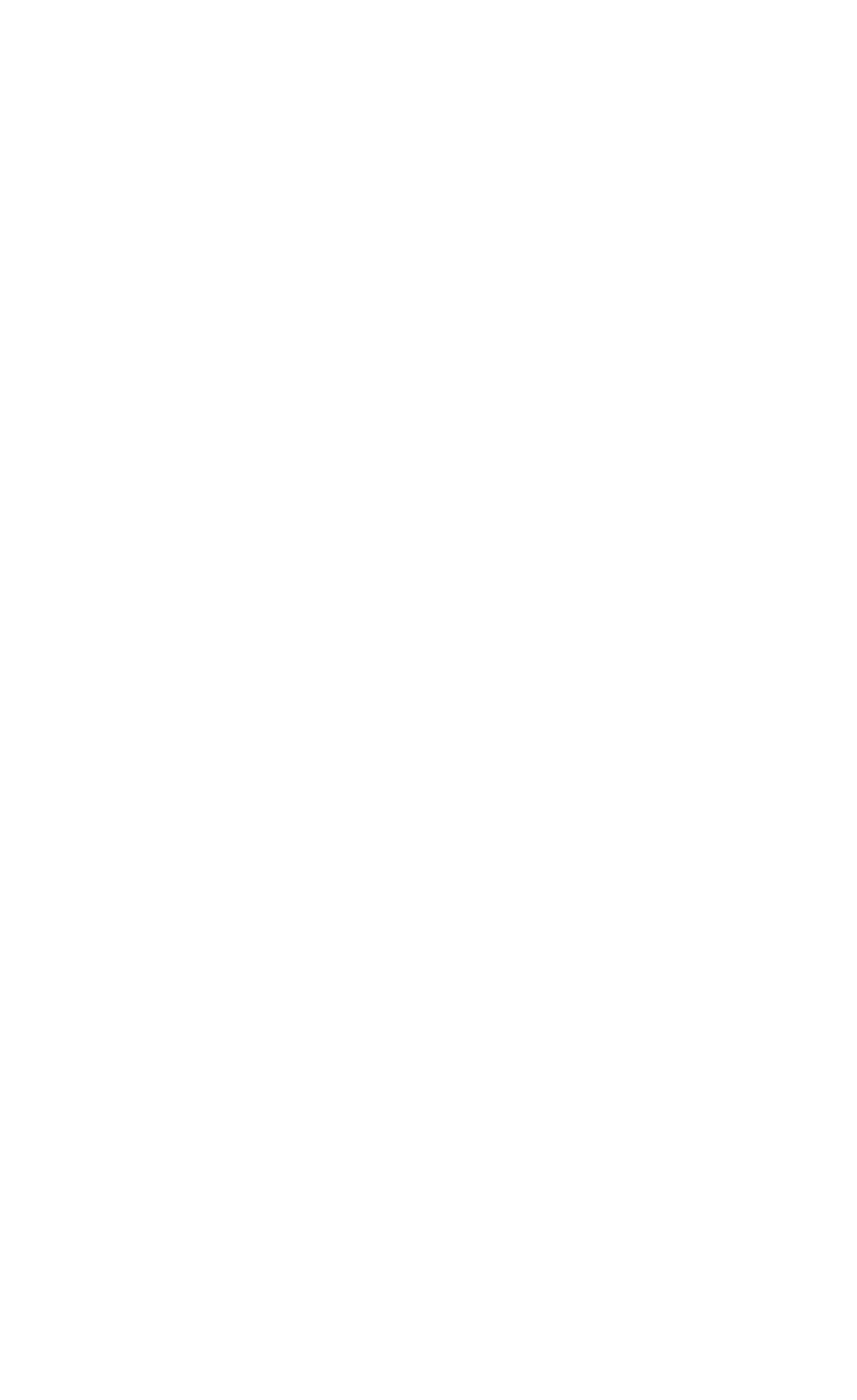




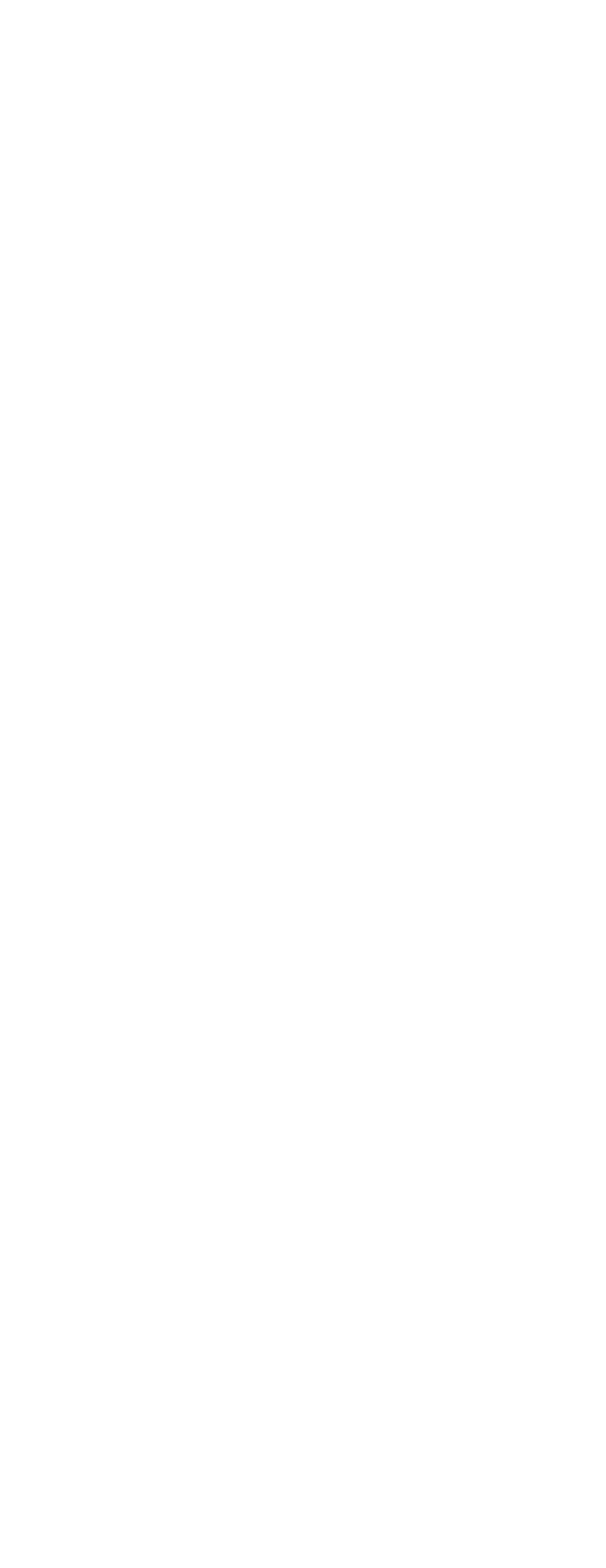




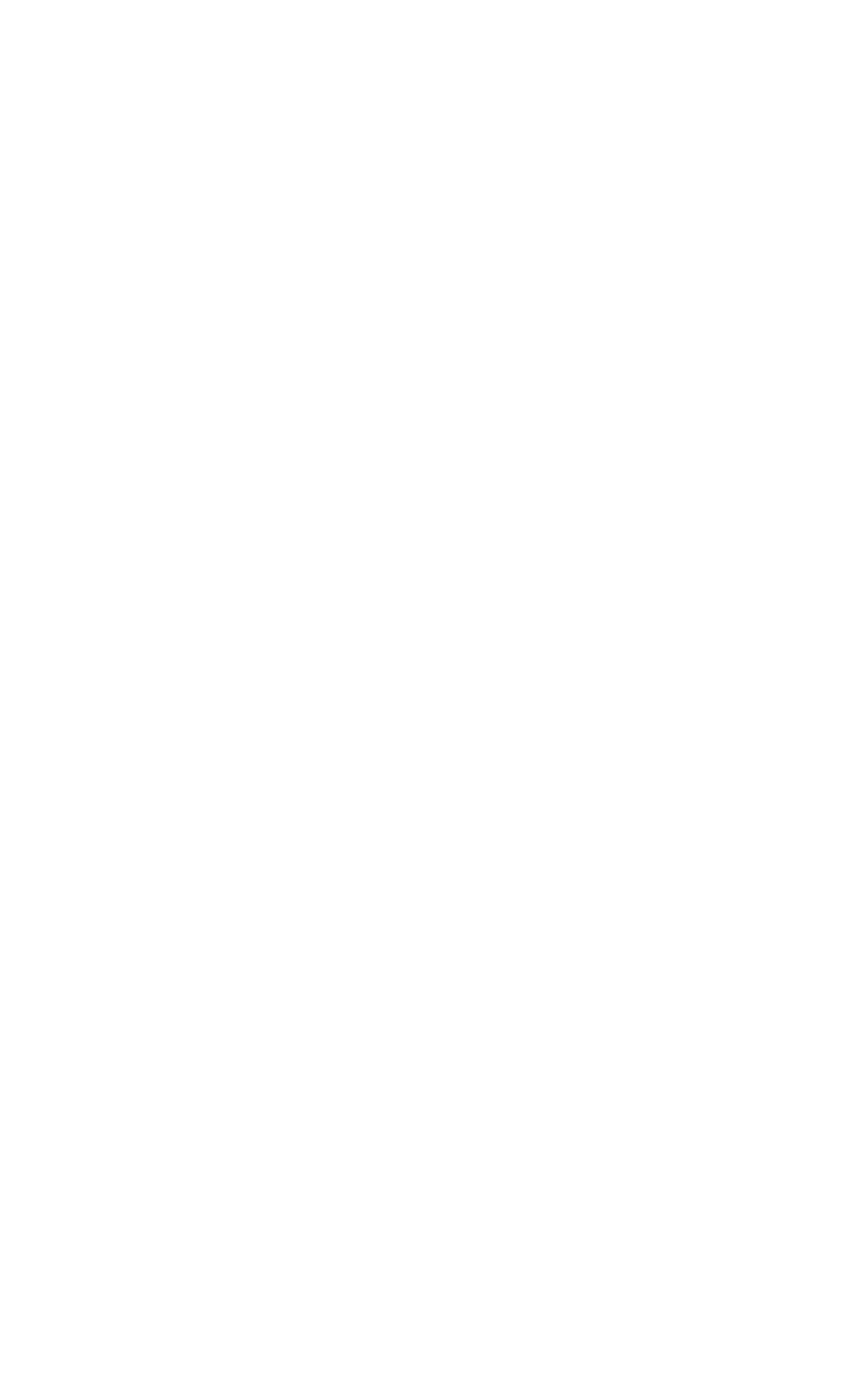




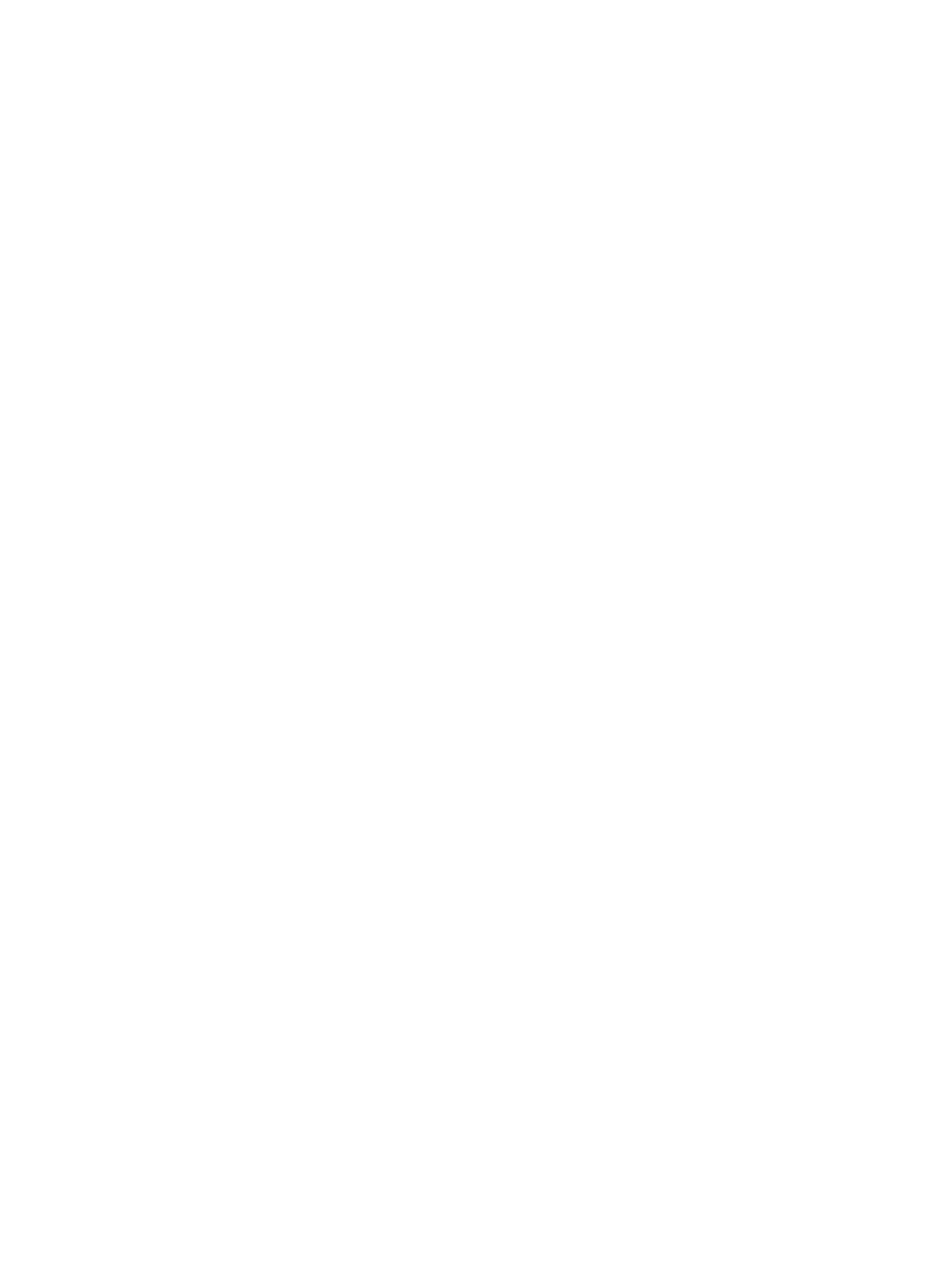




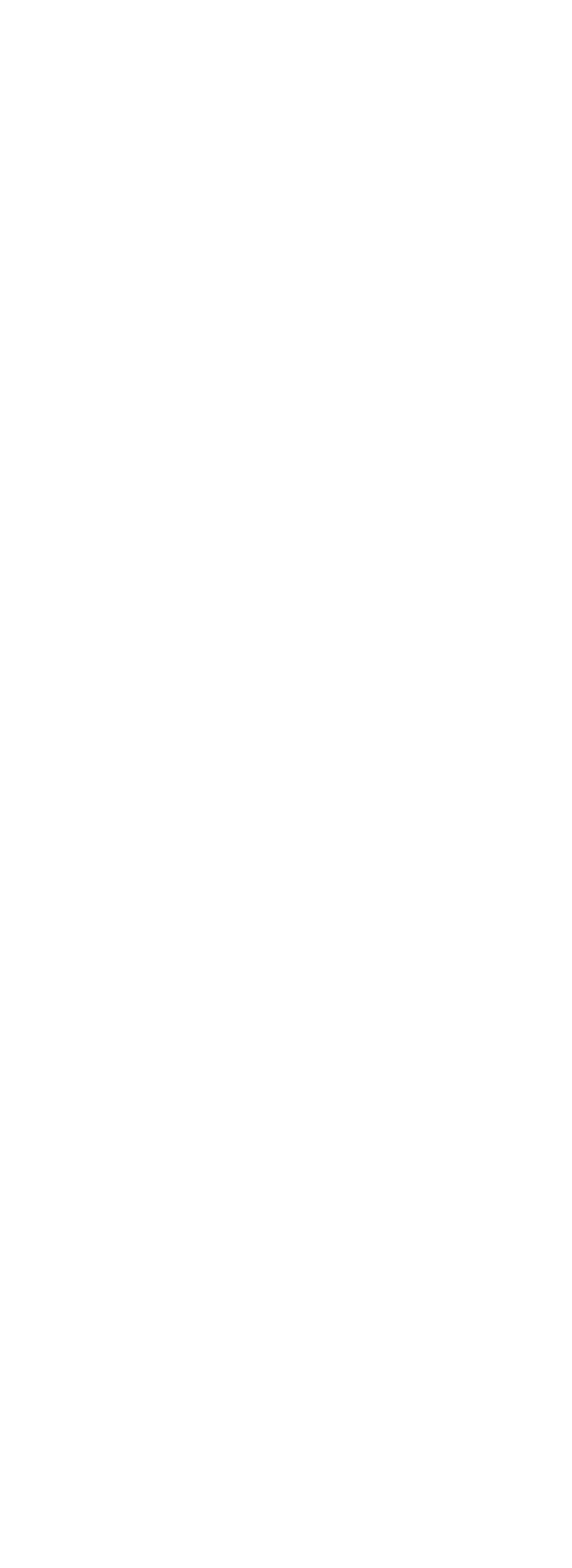




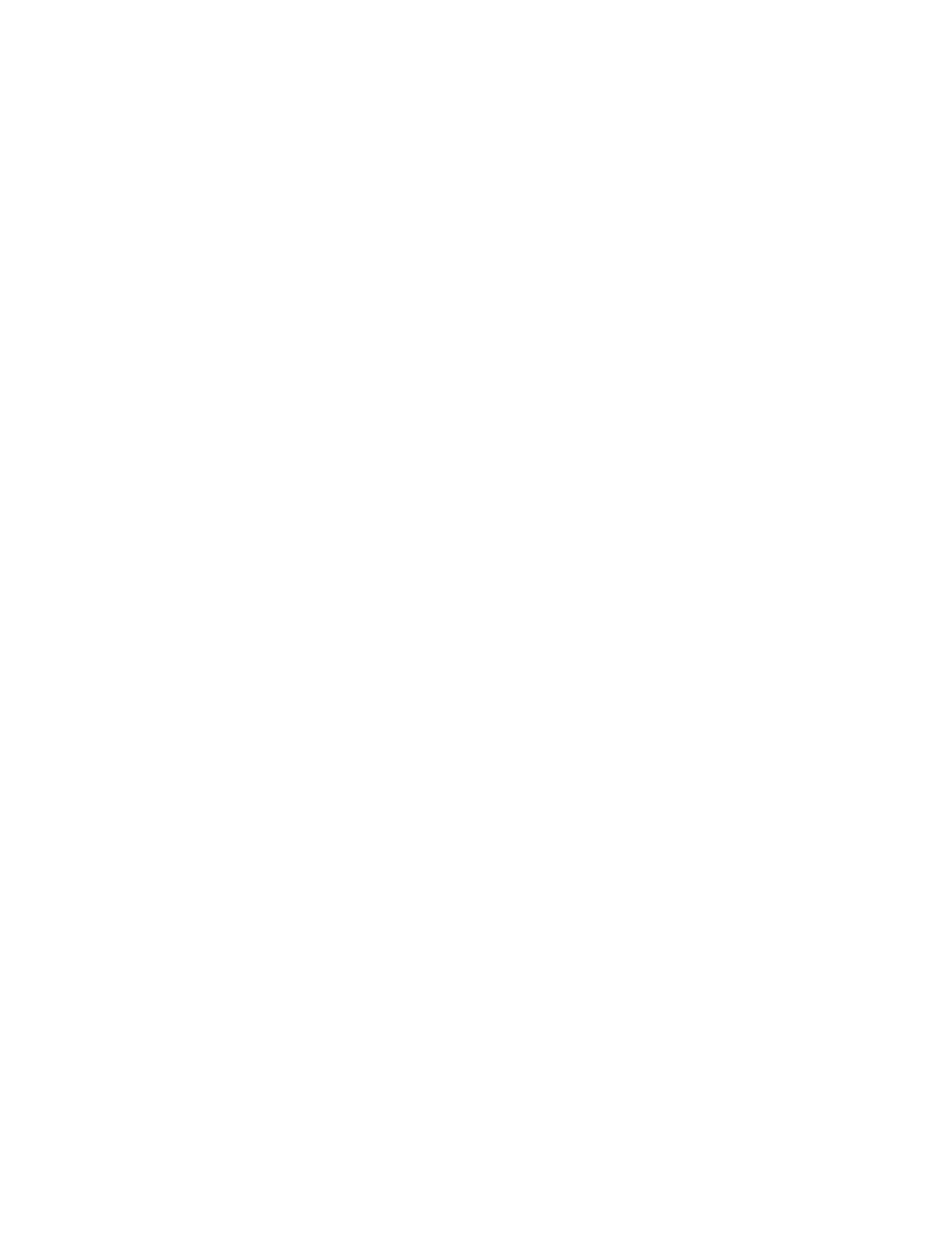




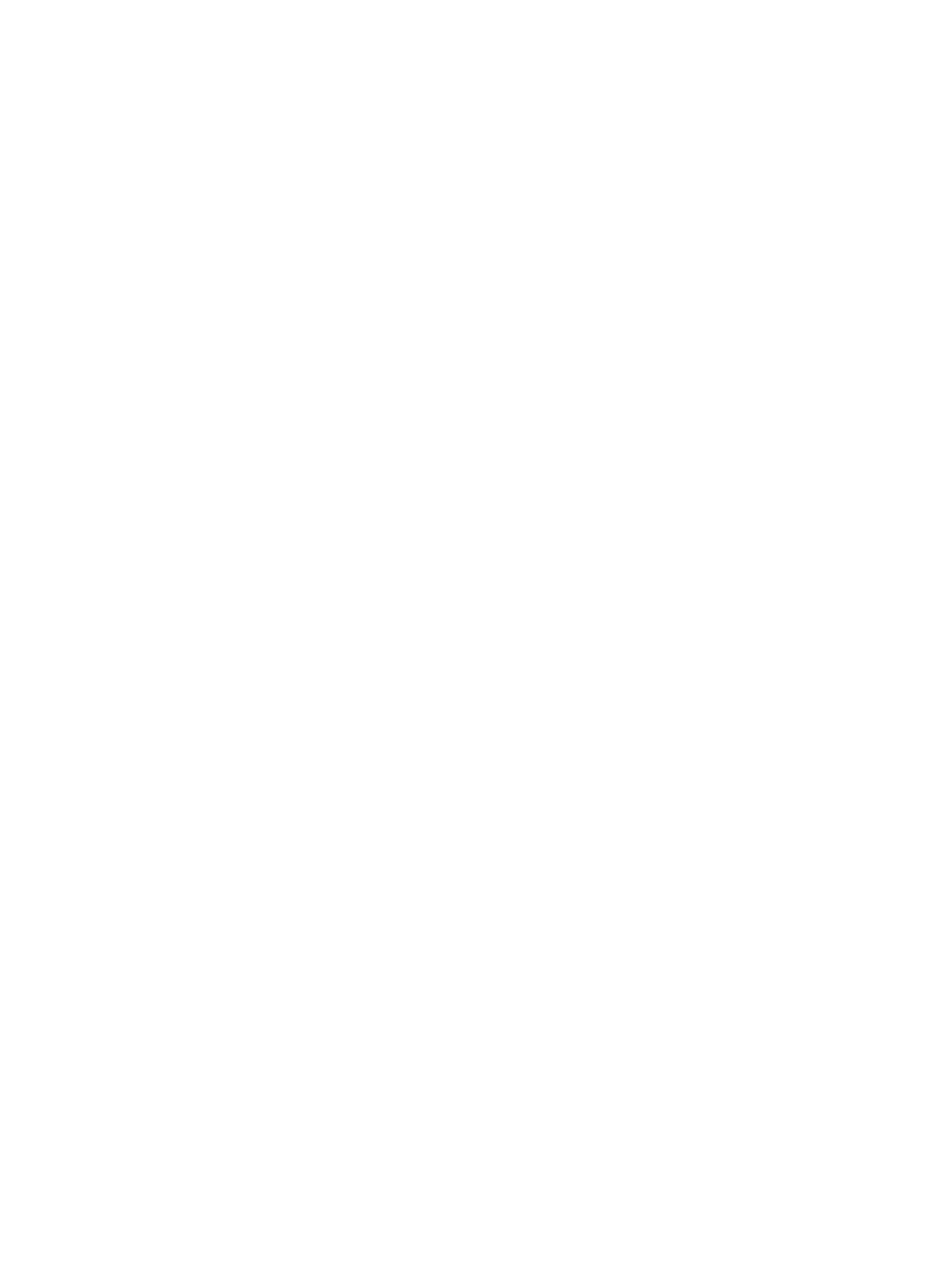




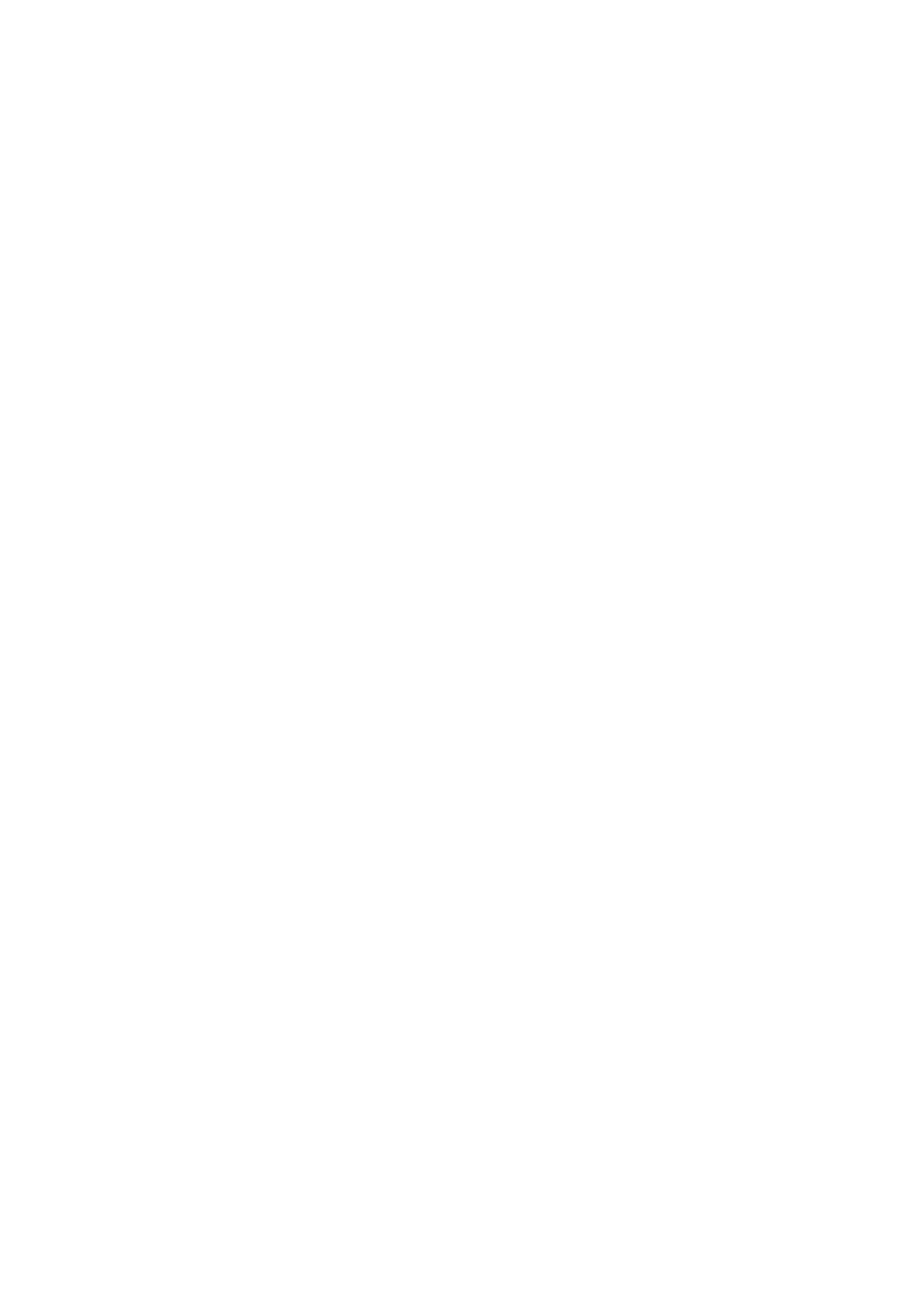




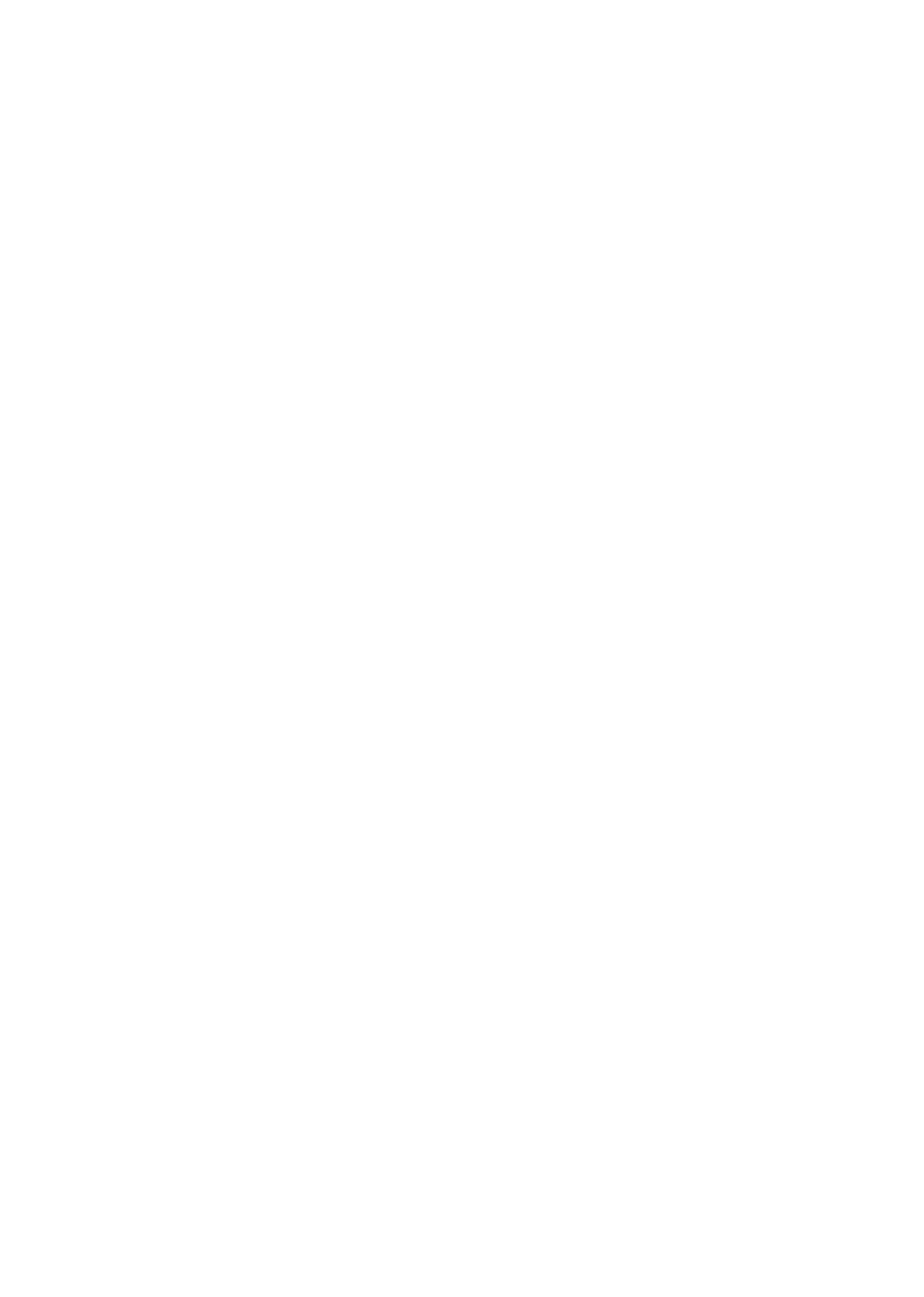



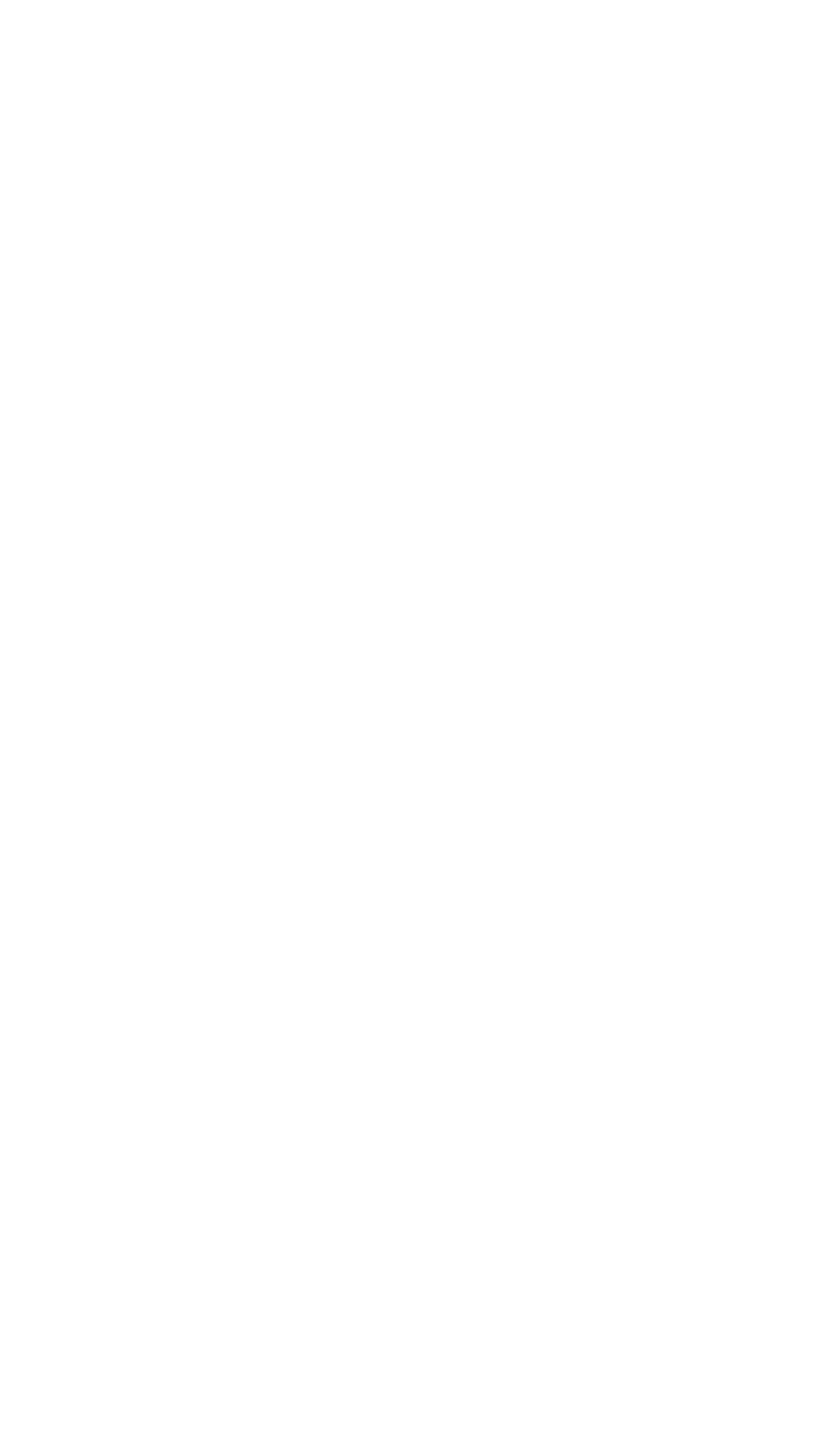

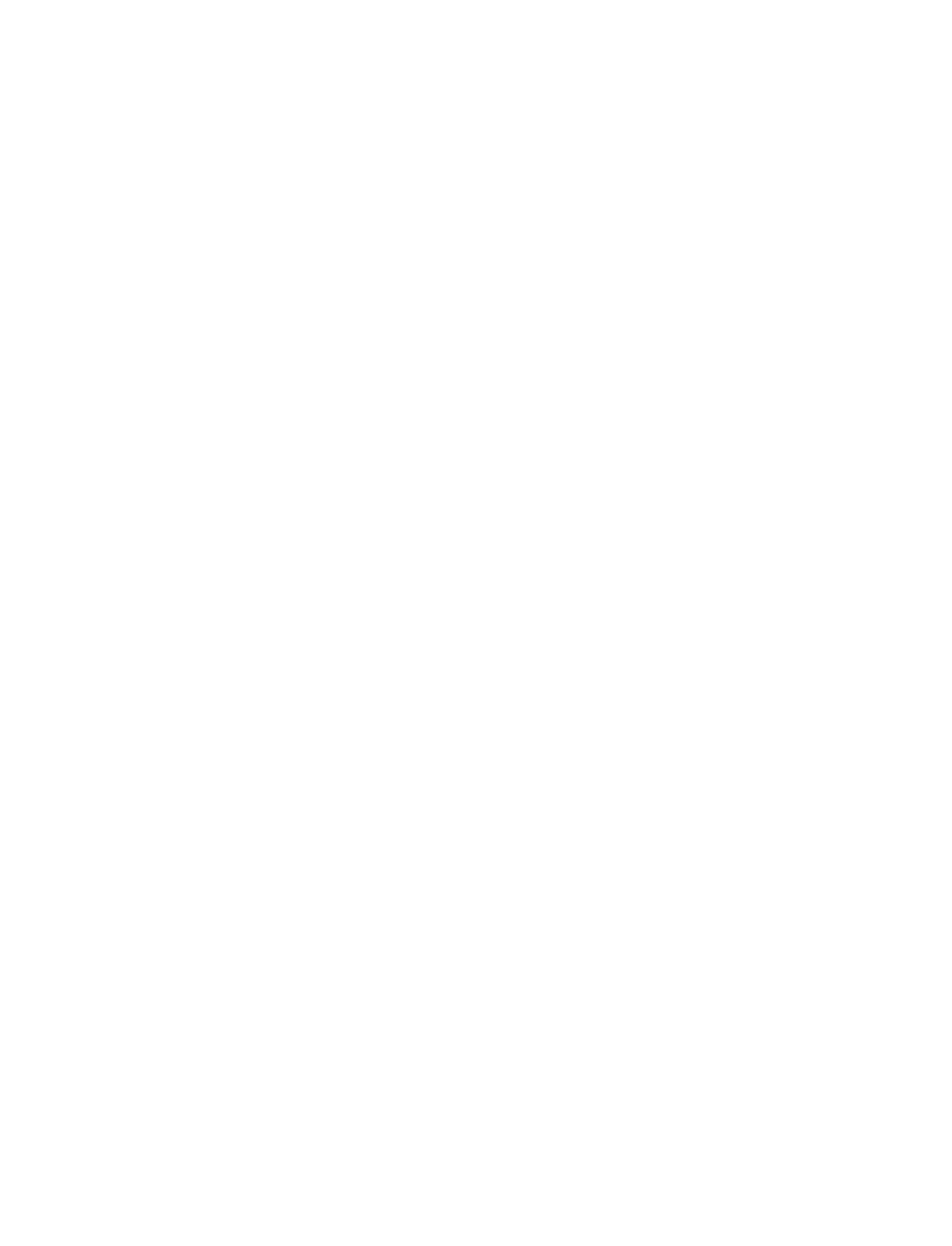
TABASH RIVER BASIN--Continued

3-3408. BIG RACCOON CREEK NEAR FINCASTLE, IND.--Continued

Suspended sediment, water year October 1966 to September 1967 (Where no daily concentrations are reported, loads are estimated)

\begin{tabular}{|c|c|c|c|c|c|c|c|c|c|c|}
\hline \multirow[b]{3}{*}{ Day } & \multicolumn{3}{|c|}{ OCTOBER } & \multicolumn{3}{|c|}{ NOVEMBER } & \multicolumn{4}{|c|}{ DECEMBER } \\
\hline & \multirow[b]{2}{*}{$\begin{array}{c}\text { Mean } \\
\text { dis- } \\
\text { charge } \\
\text { (cfs) }\end{array}$} & \multicolumn{2}{|c|}{ Suspended sediment } & \multirow[b]{2}{*}{$\begin{array}{c}\text { Mean } \\
\text { dis- } \\
\text { charge } \\
\text { (cfs) }\end{array}$} & \multicolumn{2}{|c|}{ Suspended sediment } & \multirow[b]{2}{*}{$\begin{array}{c}\text { Mean } \\
\text { dis- } \\
\text { charge } \\
\text { (cfs) }\end{array}$} & \multicolumn{3}{|c|}{ Suspended sedimen } \\
\hline & & $\begin{array}{l}\text { Mean } \\
\text { concen- } \\
\text { tration } \\
\text { (ppm) }\end{array}$ & $\begin{array}{l}\text { Tons } \\
\text { per } \\
\text { day }\end{array}$ & & $\begin{array}{l}\text { Mean } \\
\text { concen- } \\
\text { tration } \\
\text { (ppm) }\end{array}$ & $\begin{array}{c}\text { Tons } \\
\text { per } \\
\text { day }\end{array}$ & & $\begin{array}{c}\text { Mean } \\
\text { concen- } \\
\text { tration } \\
\text { (ppm) }\end{array}$ & & $\begin{array}{c}\text { Tons } \\
\text { per } \\
\text { day }\end{array}$ \\
\hline $\begin{array}{l}1 \ldots \\
2 \ldots \\
3 \ldots \\
4 \ldots\end{array}$ & $\begin{array}{l}4.9 \\
3.8 \\
3.7 \\
3.1 \\
3.1\end{array}$ & $\begin{array}{r}37 \\
12 \\
13 \\
6 \\
7\end{array}$ & $\begin{array}{l}T \\
T \\
T \\
T \\
T\end{array}$ & $\begin{array}{l}3.7 \\
4.2 \\
4.7 \\
4.9 \\
5.6\end{array}$ & $\begin{array}{r}181 \\
101 \\
61 \\
19 \\
9\end{array}$ & $\begin{array}{l}2 \\
1 \\
1 \\
T \\
T\end{array}$ & $\begin{array}{l}41 \\
28 \\
21 \\
21 \\
56\end{array}$ & $\begin{array}{r}107 \\
52 \\
41 \\
27 \\
60\end{array}$ & B & $\begin{array}{r}12 \\
4 \\
2 \\
2 \\
11\end{array}$ \\
\hline $\begin{array}{r}6 \ldots \\
7 \ldots \\
9 \ldots \\
10 . .\end{array}$ & $\begin{array}{l}2.7 \\
2.6 \\
2.3 \\
2.6 \\
2.8\end{array}$ & $\begin{array}{l}7 \\
7 \\
8 \\
8 \\
6\end{array}$ & $\begin{array}{l}T \\
T \\
T \\
T \\
T\end{array}$ & $\begin{array}{c}5.6 \\
7.8 \\
10 \\
9.1 \\
15\end{array}$ & $\begin{array}{r}33 \\
24 \\
17 \\
12 \\
100\end{array}$ & $\begin{array}{l}T \\
1 \\
T \\
T \\
4\end{array}$ & $\begin{array}{r}113 \\
612 \\
1680 \\
2160 \\
1440\end{array}$ & $\begin{array}{l}2200 \\
2210 \\
3380 \\
1820\end{array}$ & $\begin{array}{l}A \\
S\end{array}$ & $\begin{array}{r}85 \\
4600 \\
11500 \\
19700 \\
7080\end{array}$ \\
\hline $\begin{array}{l}11 \ldots \\
12 \ldots \\
13 \ldots \\
14 \ldots \\
15 \ldots\end{array}$ & $\begin{array}{l}2.7 \\
2.6 \\
2.6 \\
2.8 \\
3.2\end{array}$ & $\begin{array}{l}7 \\
7 \\
7 \\
6 \\
7\end{array}$ & $\begin{array}{l}\mathrm{T} \\
\mathrm{T} \\
\mathrm{T} \\
\mathrm{T} \\
\mathrm{T}\end{array}$ & $\begin{array}{l}15 \\
11 \\
7.2 \\
6.2 \\
5.3\end{array}$ & $\begin{array}{r}144 \\
69 \\
25 \\
15 \\
11\end{array}$ & $\begin{array}{l}6 \\
2 \\
T \\
T \\
T\end{array}$ & $\begin{array}{l}743 \\
440 \\
320 \\
250 \\
204\end{array}$ & $\begin{array}{r}1430 \\
1170 \\
780 \\
410 \\
265\end{array}$ & & $\begin{array}{r}2870 \\
1390 \\
674 \\
277 \\
146\end{array}$ \\
\hline $\begin{array}{l}16 \ldots \\
17 \ldots \\
18 \ldots \\
19 . . \\
20 .\end{array}$ & $\begin{array}{l}3.6 \\
3.4 \\
3.1 \\
3.1 \\
3.0\end{array}$ & $\begin{array}{r}6 \\
15 \\
11 \\
6 \\
5\end{array}$ & $\begin{array}{l}T \\
T \\
T \\
T \\
T\end{array}$ & $\begin{array}{l}5.4 \\
4.9 \\
4.5 \\
4.0 \\
3.8\end{array}$ & $\begin{array}{r}11 \\
12 \\
12 \\
6 \\
4\end{array}$ & $\begin{array}{l}T \\
T \\
T \\
T \\
T\end{array}$ & $\begin{array}{l}183 \\
168 \\
155 \\
137 \\
129\end{array}$ & $\begin{array}{r}208 \\
91 \\
8 \\
1.3 \\
36\end{array}$ & & $\begin{array}{r}103 \\
41 \\
3 \\
5 \\
13\end{array}$ \\
\hline $\begin{array}{l}21 \ldots \\
22 \ldots \\
23 \ldots \\
24 \ldots \\
25 \ldots\end{array}$ & $\begin{array}{l}3.0 \\
2.7 \\
2.6 \\
2.8 \\
2.8\end{array}$ & $\begin{array}{r}8 \\
25 \\
33 \\
13 \\
35\end{array}$ & $\begin{array}{l}T \\
T \\
T \\
T \\
T\end{array}$ & $\begin{array}{l}3.7 \\
3.6 \\
3.6 \\
3.4 \\
6.0\end{array}$ & $\begin{array}{r}3 \\
13 \\
25 \\
18 \\
6\end{array}$ & $\begin{array}{l}T \\
T \\
T \\
T \\
T\end{array}$ & $\begin{array}{r}110 \\
97 \\
84 \\
76 \\
68\end{array}$ & $\begin{array}{r}33 \\
22 \\
11 \\
5 \\
4\end{array}$ & & $\begin{array}{r}10 \\
6 \\
2 \\
1 \\
1\end{array}$ \\
\hline $\begin{array}{l}26 \ldots \\
27 \ldots \\
28 \ldots \\
29 \ldots \\
30 \ldots \\
31 \ldots\end{array}$ & $\begin{array}{l}3.1 \\
3.4 \\
3.7 \\
3.7 \\
3.7 \\
3.7 \\
\end{array}$ & $\begin{array}{r}96 \\
117 \\
126 \\
141 \\
130 \\
110 \\
\end{array}$ & $\begin{array}{l}1 \\
1 \\
1 \\
1 \\
1 \\
1 \\
\end{array}$ & $\begin{array}{l}8.3 \\
34 \\
68 \\
85 \\
58 \\
--\end{array}$ & $\begin{array}{r}8 \\
236 \\
205 \\
208 \\
158 \\
- \\
\end{array}$ & $\begin{array}{l}T \\
25 \\
38 \\
48 \\
25 \\
-- \\
\end{array}$ & $\begin{array}{l}62 \\
57 \\
53 \\
50 \\
47 \\
45 \\
\end{array}$ & $\begin{array}{r}18 \\
32 \\
50 \\
90 \\
18 \\
9 \\
\end{array}$ & A & $\begin{array}{r}3 \\
5 \\
7 \\
12 \\
2 \\
1 \\
\end{array}$ \\
\hline \multirow[t]{2}{*}{ Total } & 96.9 & -- & 9 & 411.5 & - & 157 & 9650 & - & & 48568 \\
\hline & \multicolumn{3}{|c|}{ JANUARY } & \multicolumn{3}{|c|}{ FEBRUARY } & \multicolumn{4}{|c|}{ MARCH } \\
\hline $\begin{array}{l}1 \ldots \\
2 \ldots \\
3 \ldots \\
4 \ldots \\
5 . .\end{array}$ & $\begin{array}{l}43 \\
42 \\
41 \\
40 \\
40\end{array}$ & $\begin{array}{r}6 \\
3 \\
5 \\
89 \\
102\end{array}$ & $\begin{array}{r}1 \\
T \\
1 \\
10 \\
11\end{array}$ & $\begin{array}{l}211 \\
922 \\
551 \\
300 \\
218\end{array}$ & $\begin{array}{r}107 \\
1900 \\
1100 \\
335 \\
36\end{array}$ & \begin{tabular}{|rr} 
& 61 \\
$A$ & 5500 \\
$A$ & 1600 \\
& 271 \\
& 21
\end{tabular} & $\begin{array}{r}43 \\
47 \\
75 \\
69 \\
106\end{array}$ & $\begin{array}{r}5 \\
20 \\
102 \\
67 \\
55\end{array}$ & $A$ & $\begin{array}{r}1 \\
3 \\
21 \\
12 \\
20\end{array}$ \\
\hline $\begin{array}{r}6 \ldots \\
7 \ldots \\
8 . \\
9 . \\
10 .\end{array}$ & $\begin{array}{r}40 \\
160 \\
144 \\
80 \\
42\end{array}$ & $\begin{array}{r}103 \\
650 \\
347 \\
187 \\
--\end{array}$ & $\begin{array}{r}11 \\
330 \\
135 \\
40 \\
19\end{array}$ & $\begin{array}{r}155 \\
127 \\
110 \\
95 \\
80\end{array}$ & $\begin{array}{r}18 \\
18 \\
12 \\
10 \\
7\end{array}$ & $\begin{array}{l}8 \\
6 \\
4 \\
3 \\
2\end{array}$ & $\begin{array}{l}333 \\
224 \\
190 \\
166 \\
323\end{array}$ & $\begin{array}{r}-5 \\
51 \\
38 \\
30 \\
150\end{array}$ & A & $\begin{array}{r}100 \\
31 \\
19 \\
13 \\
130\end{array}$ \\
\hline $\begin{array}{l}11 \ldots \\
12 \ldots \\
13 \ldots \\
14 \ldots \\
15 \ldots\end{array}$ & $\begin{array}{l}34 \\
32 \\
30 \\
29 \\
27\end{array}$ & $\begin{array}{r}-- \\
134 \\
85 \\
47 \\
10\end{array}$ & $\begin{array}{r}14 \\
12 \\
7 \\
4 \\
1\end{array}$ & $\begin{array}{l}72 \\
70 \\
71 \\
70 \\
71\end{array}$ & $\begin{array}{r}7 \\
42 \\
17 \\
2 \\
3\end{array}$ & $\begin{array}{l}1 \\
8 \\
3 \\
T \\
1\end{array}$ & $\begin{array}{l}443 \\
300 \\
229 \\
186 \\
158\end{array}$ & $\begin{array}{l}1 \overline{89} \\
168 \\
125 \\
103\end{array}$ & & $\begin{array}{r}300 \\
153 \\
104 \\
63 \\
44\end{array}$ \\
\hline $\begin{array}{l}16 \ldots \\
17 \ldots \\
18 \ldots \\
19 \ldots \\
20 \ldots\end{array}$ & $\begin{array}{l}26 \\
26 \\
26 \\
26 \\
26\end{array}$ & $\begin{array}{r}89 \\
265 \\
22 \\
12 \\
12\end{array}$ & $\begin{array}{r}6 \\
19 \\
2 \\
1 \\
1\end{array}$ & $\begin{array}{l}72 \\
64 \\
62 \\
62 \\
59\end{array}$ & $\begin{array}{l}5 \\
5 \\
6 \\
6 \\
6\end{array}$ & $\begin{array}{l}1 \\
1 \\
1 \\
1 \\
1\end{array}$ & $\begin{array}{r}131 \\
124 \\
103 \\
97 \\
158\end{array}$ & $\begin{array}{r}103 \\
90 \\
76 \\
41 \\
1000\end{array}$ & $A$ & $\begin{array}{r}36 \\
30 \\
21 \\
11 \\
600\end{array}$ \\
\hline $\begin{array}{l}21 \ldots \\
22 \ldots \\
23 \ldots \\
24 \ldots \\
25 \ldots\end{array}$ & $\begin{array}{l}26 \\
30 \\
35 \\
45 \\
64\end{array}$ & $\begin{array}{r}12 \\
12 \\
16 \\
100 \\
189\end{array}$ & $\begin{array}{r}1 \\
1 \\
2 \\
12 \\
33\end{array}$ & $\begin{array}{l}53 \\
47 \\
46 \\
45 \\
37\end{array}$ & $\begin{array}{l}6 \\
6 \\
7 \\
7 \\
7\end{array}$ & $\begin{array}{l}1 \\
1 \\
1 \\
1 \\
1\end{array}$ & $\begin{array}{l}555 \\
338 \\
235 \\
185 \\
168\end{array}$ & $\begin{array}{r}4300 \\
2500 \\
1040 \\
620 \\
520\end{array}$ & A & $\begin{array}{r}6400 \\
2280 \\
660 \\
310 \\
236\end{array}$ \\
\hline $\begin{array}{l}26 \ldots \\
27 \ldots \\
28 \ldots \\
29 \ldots \\
30 \ldots \\
31 \ldots\end{array}$ & $\begin{array}{l}178 \\
952 \\
418 \\
242 \\
180 \\
169 \\
\end{array}$ & $\begin{array}{r}-- \\
-- \\
422 \\
126 \\
12 \\
16 \\
\end{array}$ & $\begin{array}{r}700 \\
7700 \\
476 \\
88 \\
6 \\
7 \\
\end{array}$ & $\begin{array}{l}35 \\
40 \\
44 \\
-- \\
-- \\
-- \\
\end{array}$ & $\begin{array}{r}7 \\
8 \\
8 \\
--- \\
-- \\
\end{array}$ & $\begin{array}{r}1 \\
1 \\
1 \\
-- \\
-+ \\
- \\
\end{array}$ & $\begin{array}{l}148 \\
137 \\
561 \\
543 \\
310 \\
215 \\
\end{array}$ & $\begin{array}{r}350 \\
150 \\
1760 \\
2140 \\
1900 \\
528 \\
\end{array}$ & 5 & $\begin{array}{r}140 \\
55 \\
3720 \\
3140 \\
1590 \\
307 \\
\end{array}$ \\
\hline Total & 3293 & -- & 9651 & 3789 & -- & 7502 & 6900 & -- & & 20550 \\
\hline
\end{tabular}


WABASH RIVER BASIN--Continued

3-3408. BIG RACCOON CREEK NEAR FINCASTLE, IND.--Continued

Suspended sediment, water year October 1966 to September 1967--Continued

\begin{tabular}{|c|c|c|c|c|c|c|c|c|c|}
\hline \multirow[b]{3}{*}{ Day } & \multicolumn{3}{|c|}{ APRIL } & \multicolumn{3}{|c|}{ MAY } & \multicolumn{3}{|c|}{ JUNE } \\
\hline & \multirow[b]{2}{*}{$\begin{array}{l}\text { Mean } \\
\text { dis- } \\
\text { charge } \\
\text { (cfs) }\end{array}$} & \multicolumn{2}{|c|}{ Suspended sediment } & \multirow[b]{2}{*}{$\begin{array}{c}\text { Mean } \\
\text { dis- } \\
\text { charge } \\
(\mathrm{cfs})\end{array}$} & \multicolumn{2}{|c|}{ Suspended sediment } & \multirow[b]{2}{*}{$\begin{array}{l}\text { Mean } \\
\text { dis- } \\
\text { charge } \\
\text { (cfs) }\end{array}$} & \multicolumn{2}{|c|}{ Suspended sedi nent } \\
\hline & & $\begin{array}{c}\text { Mean } \\
\text { concen- } \\
\text { tration } \\
\text { (ppm) }\end{array}$ & $\begin{array}{l}\text { Tons } \\
\text { per } \\
\text { day }\end{array}$ & & $\begin{array}{l}\text { Mean } \\
\text { concen- } \\
\text { tration } \\
(\text { ppm) }\end{array}$ & $\begin{array}{l}\text { Tons } \\
\text { per } \\
\text { day }\end{array}$ & & $\begin{array}{c}\text { Mean } \\
\text { concen- } \\
\text { tration } \\
(\text { ppm) }\end{array}$ & $\begin{array}{l}\text { Tons } \\
\text { per } \\
\text { dzy }\end{array}$ \\
\hline $\begin{array}{l}1 \ldots \\
2 \ldots \\
3 \ldots \\
4 \ldots \\
5 .\end{array}$ & $\begin{array}{l}162 \\
137 \\
127 \\
110 \\
264\end{array}$ & $\begin{array}{r}273 \\
162 \\
57 \\
28 \\
850\end{array}$ & $\begin{array}{r}119 \\
60 \\
20 \\
8 \\
900\end{array}$ & $\begin{array}{l}62 \\
58 \\
46 \\
41 \\
40\end{array}$ & $\begin{array}{l}6 \\
4 \\
6 \\
7 \\
6\end{array}$ & $\begin{array}{l}1 \\
1 \\
1 \\
1 \\
1\end{array}$ & $\begin{array}{l}52 \\
43 \\
39 \\
38 \\
35\end{array}$ & $\begin{array}{l}25 \\
13 \\
15 \\
14 \\
13\end{array}$ & $\begin{array}{l}4 \\
2 \\
2 \\
1 \\
1\end{array}$ \\
\hline $\begin{array}{r}6 \ldots \\
7 \ldots \\
8 \ldots \\
9 \ldots \\
10 \ldots\end{array}$ & $\begin{array}{l}496 \\
287 \\
214 \\
178 \\
150\end{array}$ & $\begin{array}{r}1200 \\
272 \\
167 \\
154 \\
140\end{array}$ & A $\begin{array}{r}1600 \\
211 \\
96 \\
74 \\
57\end{array}$ & $\begin{array}{r}74 \\
1560 \\
946 \\
465 \\
296\end{array}$ & $\begin{array}{r}160 \\
1300 \\
484 \\
154 \\
170\end{array}$ & $\begin{array}{r}45 \\
5500 \\
1380 \\
193 \\
136\end{array}$ & $\begin{array}{l}33 \\
32 \\
30 \\
29 \\
28\end{array}$ & $\begin{array}{l}12 \\
12 \\
12 \\
11 \\
10\end{array}$ & $\begin{array}{l}1 \\
1 \\
1 \\
1 \\
1\end{array}$ \\
\hline $\begin{array}{l}11 \ldots \\
12 \ldots \\
13 \ldots \\
14 \ldots \\
15 \ldots\end{array}$ & $\begin{array}{l}125 \\
105 \\
109 \\
112 \\
153\end{array}$ & $\begin{array}{r}125 \\
109 \\
38 \\
19 \\
--\end{array}$ & $\begin{array}{r}42 \\
31 \\
11 \\
6 \\
20\end{array}$ & $\begin{array}{l}658 \\
504 \\
298 \\
264 \\
262\end{array}$ & $\begin{array}{r}341 \\
342 \\
90 \\
81 \\
67\end{array}$ & $\begin{array}{r}686 \\
465 \\
72 \\
58 \\
47\end{array}$ & $\begin{array}{l}27 \\
24 \\
21 \\
18 \\
17\end{array}$ & $\begin{array}{r}15 \\
17 \\
12 \\
7 \\
20\end{array}$ & $\begin{array}{l}1 \\
1 \\
1 \\
T \\
1\end{array}$ \\
\hline $\begin{array}{l}16 \ldots \\
17 \ldots \\
18 \ldots \\
19 \ldots \\
20 \ldots\end{array}$ & $\begin{array}{r}133 \\
139 \\
109 \\
84 \\
74\end{array}$ & $\begin{array}{l}14 \\
-- \\
21 \\
13 \\
16\end{array}$ & $\begin{array}{r}5 \\
30 \\
6 \\
3 \\
3\end{array}$ & $\begin{array}{l}222 \\
200 \\
167 \\
136 \\
105\end{array}$ & $\begin{array}{l}30 \\
23 \\
18 \\
20 \\
23\end{array}$ & $\begin{array}{r}18 \\
12 \\
8 \\
7 \\
7\end{array}$ & $\begin{array}{l}15 \\
14 \\
13 \\
13 \\
12\end{array}$ & $\begin{array}{r}34 \\
17 \\
8 \\
8 \\
8\end{array}$ & $\begin{array}{l}1 \\
1 \\
T \\
T \\
T\end{array}$ \\
\hline $\begin{array}{l}21 \ldots \\
22 \ldots \\
23 \ldots \\
24 \ldots \\
25 \ldots\end{array}$ & $\begin{array}{r}76 \\
104 \\
86 \\
83 \\
73\end{array}$ & $\begin{array}{r}17 \\
134 \\
42 \\
16 \\
10\end{array}$ & $\begin{array}{r}3 \\
38 \\
10 \\
4 \\
2\end{array}$ & $\begin{array}{l}88 \\
79 \\
71 \\
68 \\
62\end{array}$ & $\begin{array}{l}27 \\
26 \\
24 \\
22 \\
20\end{array}$ & $\begin{array}{l}6 \\
6 \\
5 \\
4 \\
3\end{array}$ & $\begin{array}{l}13 \\
13 \\
13 \\
13 \\
14\end{array}$ & $\begin{array}{l}8 \\
8 \\
8 \\
8 \\
8\end{array}$ & $\begin{array}{l}T \\
T \\
T \\
T \\
T\end{array}$ \\
\hline $\begin{array}{l}26 \ldots \\
27 \ldots \\
28 \ldots \\
29 \ldots \\
30 \ldots \\
31 \ldots\end{array}$ & $\begin{array}{l}74 \\
73 \\
63 \\
59 \\
61 \\
--\end{array}$ & $\begin{array}{r}11 \\
12 \\
10 \\
8 \\
7 \\
-- \\
\end{array}$ & $\begin{array}{r}2 \\
2 \\
2 \\
1 \\
1 \\
-- \\
\end{array}$ & $\begin{array}{l}56 \\
52 \\
49 \\
77 \\
67 \\
65 \\
\end{array}$ & $\begin{array}{r}14 \\
8 \\
13 \\
168 \\
100 \\
74\end{array}$ & $\begin{array}{r}2 \\
1 \\
2 \\
35 \\
18 \\
13 \\
\end{array}$ & $\begin{array}{l}12 \\
11 \\
11 \\
11 \\
10 \\
-\end{array}$ & $\begin{array}{l}12 \\
27 \\
23 \\
15 \\
14 \\
-\end{array}$ & $\begin{array}{r}T \\
1 \\
1 \\
T \\
T \\
--\end{array}$ \\
\hline \multirow[t]{2}{*}{ Total } & 4020 & -- & 3367 & 7138 & -- & 8734 & 654 & -- & 27 \\
\hline & \multicolumn{3}{|c|}{ IULX } & \multicolumn{3}{|c|}{ AUGUST } & \multicolumn{3}{|c|}{ SEPTEMBER } \\
\hline $\begin{array}{l}1 \ldots \\
2 \ldots \\
3 \ldots \\
4 \ldots \\
5 \ldots\end{array}$ & $\begin{array}{l}9.8 \\
9.6 \\
8.8 \\
8.4 \\
8.0\end{array}$ & $\begin{array}{l}15 \\
15 \\
15 \\
15 \\
16\end{array}$ & $\begin{array}{l}T \\
T \\
T \\
T \\
T\end{array}$ & $\begin{array}{r}19 \\
29 \\
190 \\
75 \\
33\end{array}$ & $\begin{array}{r}69 \\
58 \\
1400 \\
227 \\
35\end{array}$ & $\begin{array}{r}4 \\
5 \\
865 \\
51 \\
3\end{array}$ & $\begin{array}{l}5.1 \\
4.9 \\
4.7 \\
4.5 \\
4.5\end{array}$ & $\begin{array}{l}11 \\
10 \\
25 \\
24 \\
12\end{array}$ & $\begin{array}{l}T \\
T \\
T \\
T \\
T\end{array}$ \\
\hline $\begin{array}{r}6 \ldots \\
7 \ldots \\
8 \ldots \\
9 \ldots \\
10 \ldots\end{array}$ & $\begin{array}{l}8.0 \\
7.8 \\
7.4 \\
7.4 \\
7.6\end{array}$ & $\begin{array}{l}18 \\
18 \\
19 \\
20 \\
21\end{array}$ & $\begin{array}{l}T \\
T \\
T \\
T \\
T\end{array}$ & $\begin{array}{l}21 \\
16 \\
13 \\
15 \\
12\end{array}$ & $\begin{array}{l}20 \\
24 \\
25 \\
25 \\
25\end{array}$ & $\begin{array}{l}1 \\
1 \\
1 \\
1 \\
1\end{array}$ & $\begin{array}{l}4.3 \\
4.2 \\
4.0 \\
4.9 \\
5.8\end{array}$ & $\begin{array}{r}12 \\
12 \\
13 \\
13 \\
5\end{array}$ & $\begin{array}{l}T \\
T \\
T \\
T \\
T\end{array}$ \\
\hline $\begin{array}{l}11 \ldots \\
12 \ldots \\
13 . \\
14 \ldots \\
15 .\end{array}$ & $\begin{array}{l}7.4 \\
8.2 \\
6.8 \\
6.1 \\
6.2\end{array}$ & $\begin{array}{r}22 \\
22 \\
24 \\
20 \\
7\end{array}$ & $\begin{array}{l}T \\
T \\
T \\
T \\
T\end{array}$ & $\begin{array}{l}9.1 \\
8.0 \\
7.4 \\
6.9 \\
6.6\end{array}$ & $\begin{array}{l}26 \\
25 \\
26 \\
31 \\
49\end{array}$ & $\begin{array}{l}1 \\
1 \\
1 \\
1 \\
1\end{array}$ & $\begin{array}{l}5.1 \\
4.5 \\
4.1 \\
3.9 \\
3.8\end{array}$ & $\begin{array}{l}12 \\
22 \\
25 \\
23 \\
22\end{array}$ & $\begin{array}{l}T \\
T \\
T \\
T \\
T\end{array}$ \\
\hline $\begin{array}{l}16 \ldots \\
17 \ldots \\
18 \ldots \\
19 \ldots \\
20 \ldots\end{array}$ & $\begin{array}{l}5.8 \\
5.7 \\
5.9 \\
5.6 \\
5.8\end{array}$ & $\begin{array}{l}10 \\
14 \\
13 \\
16 \\
22\end{array}$ & $\begin{array}{l}\mathrm{T} \\
\mathrm{T} \\
\mathrm{T} \\
\mathrm{T} \\
\mathrm{T}\end{array}$ & $\begin{array}{l}6.3 \\
6.1 \\
6.3 \\
8.8 \\
8.1\end{array}$ & $\begin{array}{l}63 \\
64 \\
41 \\
25 \\
22\end{array}$ & $\begin{array}{l}1 \\
1 \\
1 \\
1 \\
T\end{array}$ & $\begin{array}{l}3.6 \\
3.6 \\
4.4 \\
4.1 \\
4.1\end{array}$ & $\begin{array}{r}24 \\
41 \\
25 \\
6 \\
6\end{array}$ & $\begin{array}{l}\mathrm{T} \\
\mathrm{T} \\
\mathrm{T} \\
\mathrm{T} \\
\mathrm{T}\end{array}$ \\
\hline $\begin{array}{l}21 \ldots \\
22 \ldots \\
23 \ldots \\
24 \ldots \\
25 \ldots\end{array}$ & $\begin{array}{l}6.0 \\
5.4 \\
5.8 \\
8.4 \\
7.1\end{array}$ & $\begin{array}{l}28 \\
18 \\
14 \\
18 \\
25\end{array}$ & $\begin{array}{l}\mathrm{T} \\
\mathrm{T} \\
\mathrm{T} \\
\mathrm{T} \\
\mathrm{T}\end{array}$ & $\begin{array}{l}6.9 \\
6.2 \\
5.9 \\
5.7 \\
6.1\end{array}$ & $\begin{array}{r}33 \\
21 \\
28 \\
52 \\
240\end{array}$ & $\begin{array}{l}1 \\
T \\
T \\
1 \\
4\end{array}$ & $\begin{array}{l}4.2 \\
4.1 \\
3.9 \\
3.5 \\
3.4\end{array}$ & $\begin{array}{l}7 \\
7 \\
8 \\
7 \\
7\end{array}$ & $\begin{array}{l}T \\
T \\
T \\
T \\
T\end{array}$ \\
\hline $\begin{array}{l}26 \ldots \\
27 \ldots \\
28 \ldots \\
29 \ldots \\
30 \ldots \\
31 \ldots\end{array}$ & $\begin{array}{r}5.7 \\
184 \\
187 \\
51 \\
27 \\
22 \\
\end{array}$ & $\begin{array}{r}8 \\
750 \\
1470 \\
278 \\
132 \\
90 \\
\end{array}$ & $\begin{array}{r}T \\
985 \\
825 \\
44 \\
10 \\
5 \\
\end{array}$ & $\begin{array}{l}5.9 \\
5.4 \\
5.4 \\
5.2 \\
5.0 \\
4.9\end{array}$ & $\begin{array}{r}340 \\
163 \\
113 \\
32 \\
12 \\
14\end{array}$ & $\begin{array}{l}5 \\
2 \\
2 \\
T \\
T \\
T\end{array}$ & $\begin{array}{l}3.2 \\
3.5 \\
3.8 \\
3.5 \\
3.5 \\
-- \\
\end{array}$ & $\begin{array}{r}18 \\
21 \\
15 \\
9 \\
9 \\
-- \\
\end{array}$ & $\begin{array}{r}T \\
T \\
T \\
T \\
T \\
-\square \\
\end{array}$ \\
\hline Total & $655 . \overrightarrow{7}$ & -- & 1878 & 559.2 & - & 959 & 124.7 & -- & 5 \\
\hline
\end{tabular}

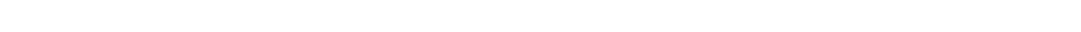

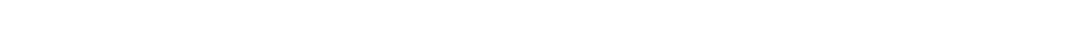
$T$ Less than 0.50 ton. 


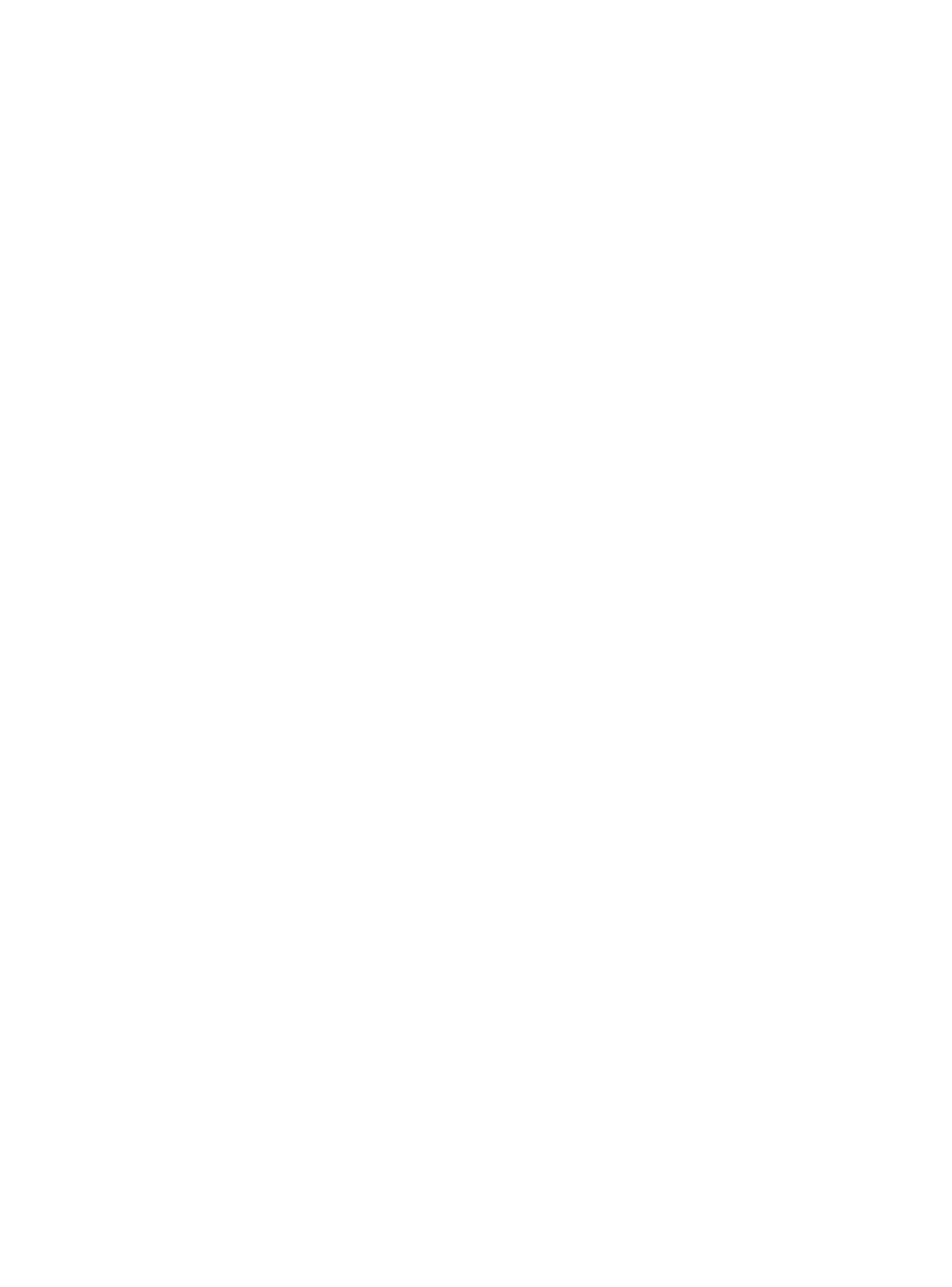




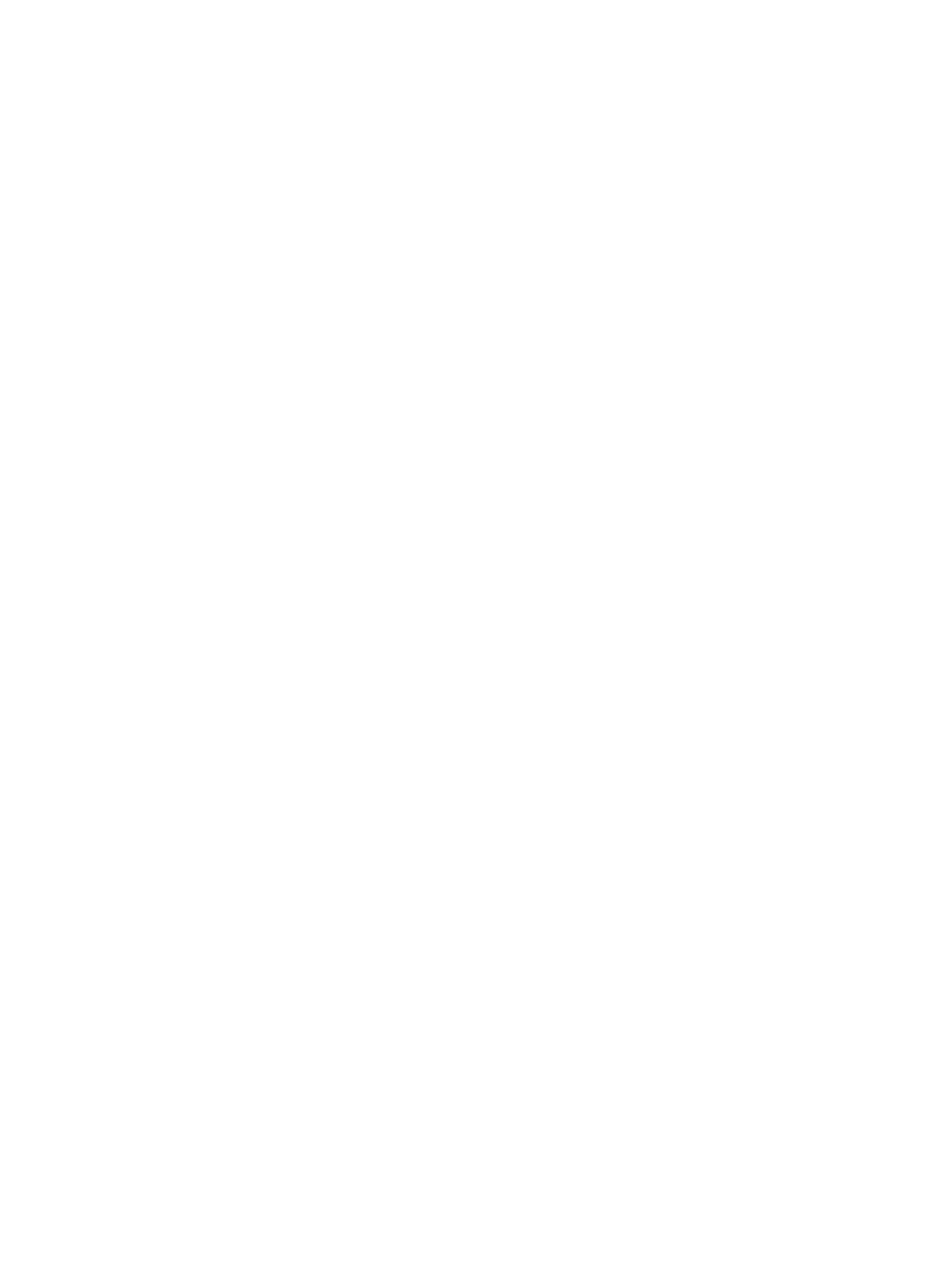




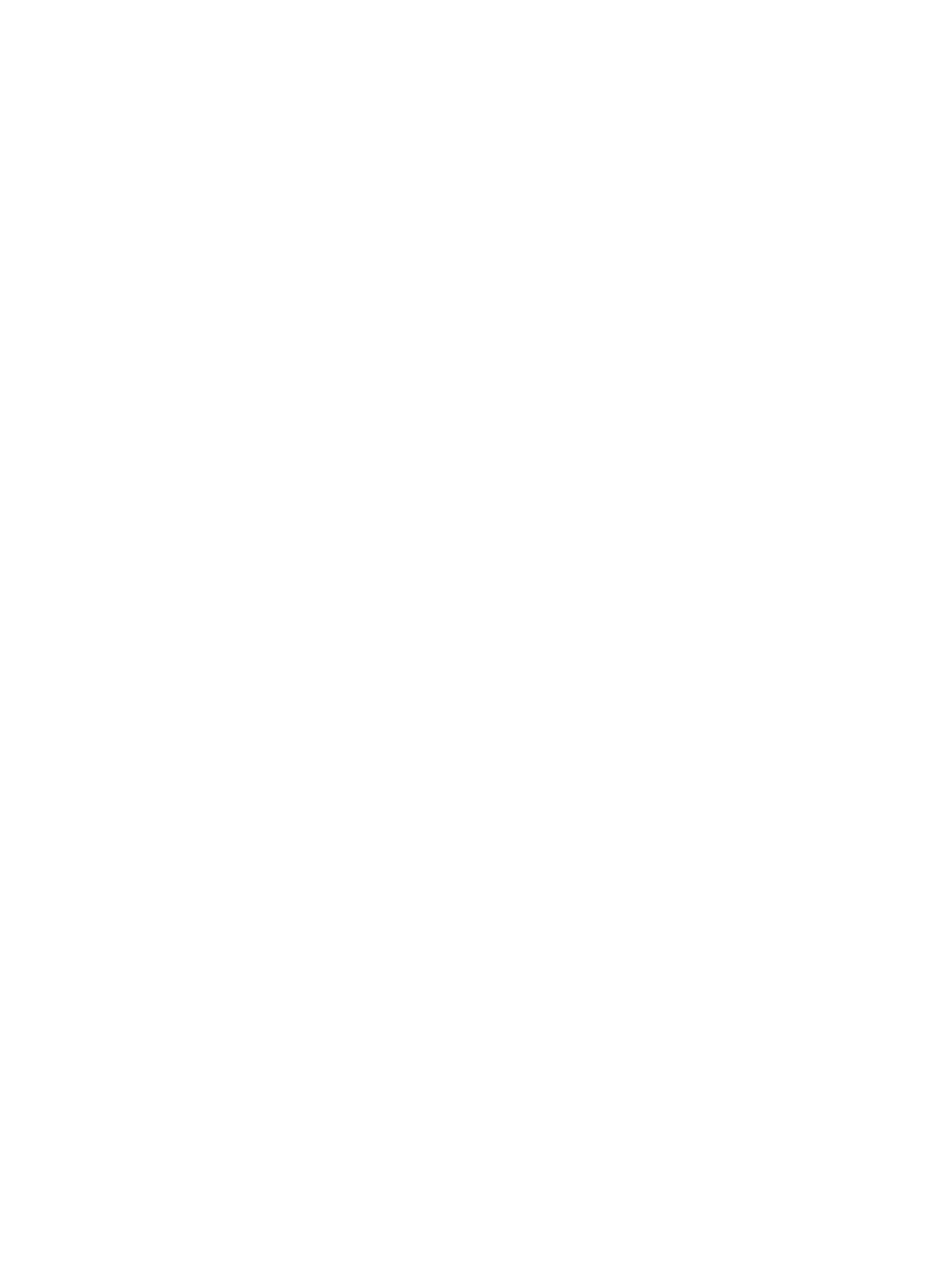




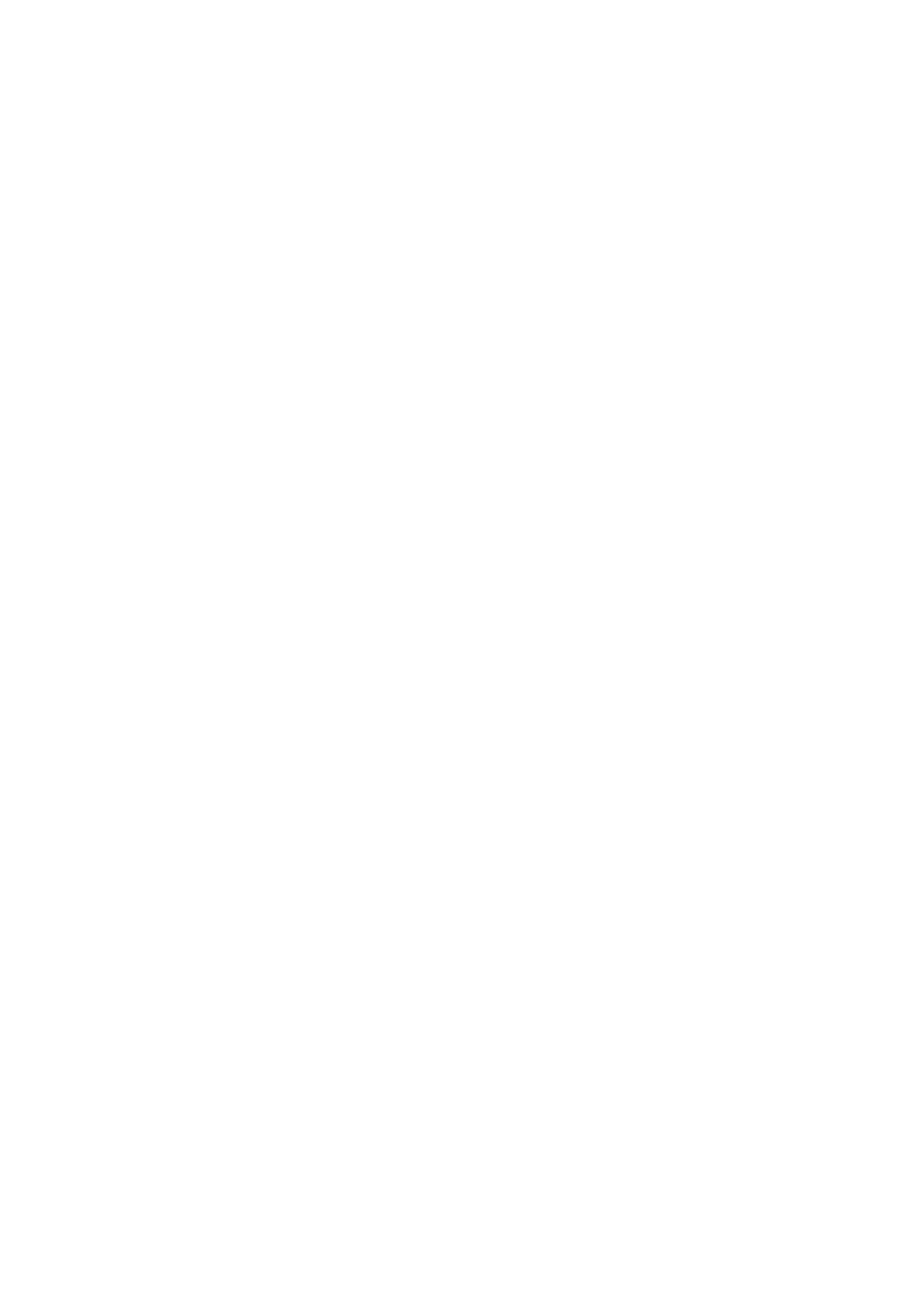




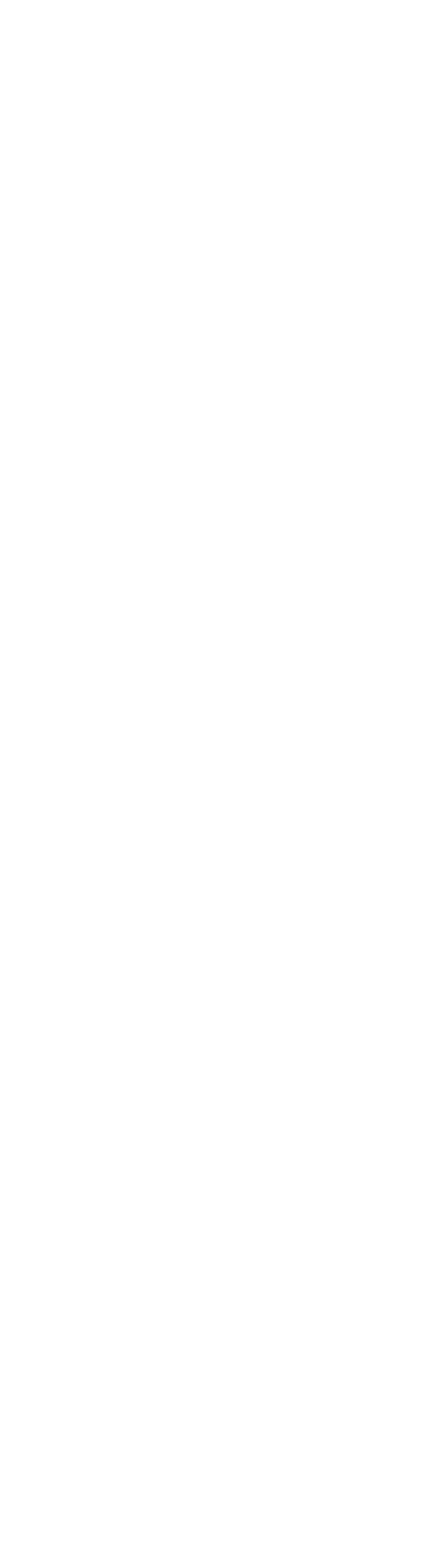




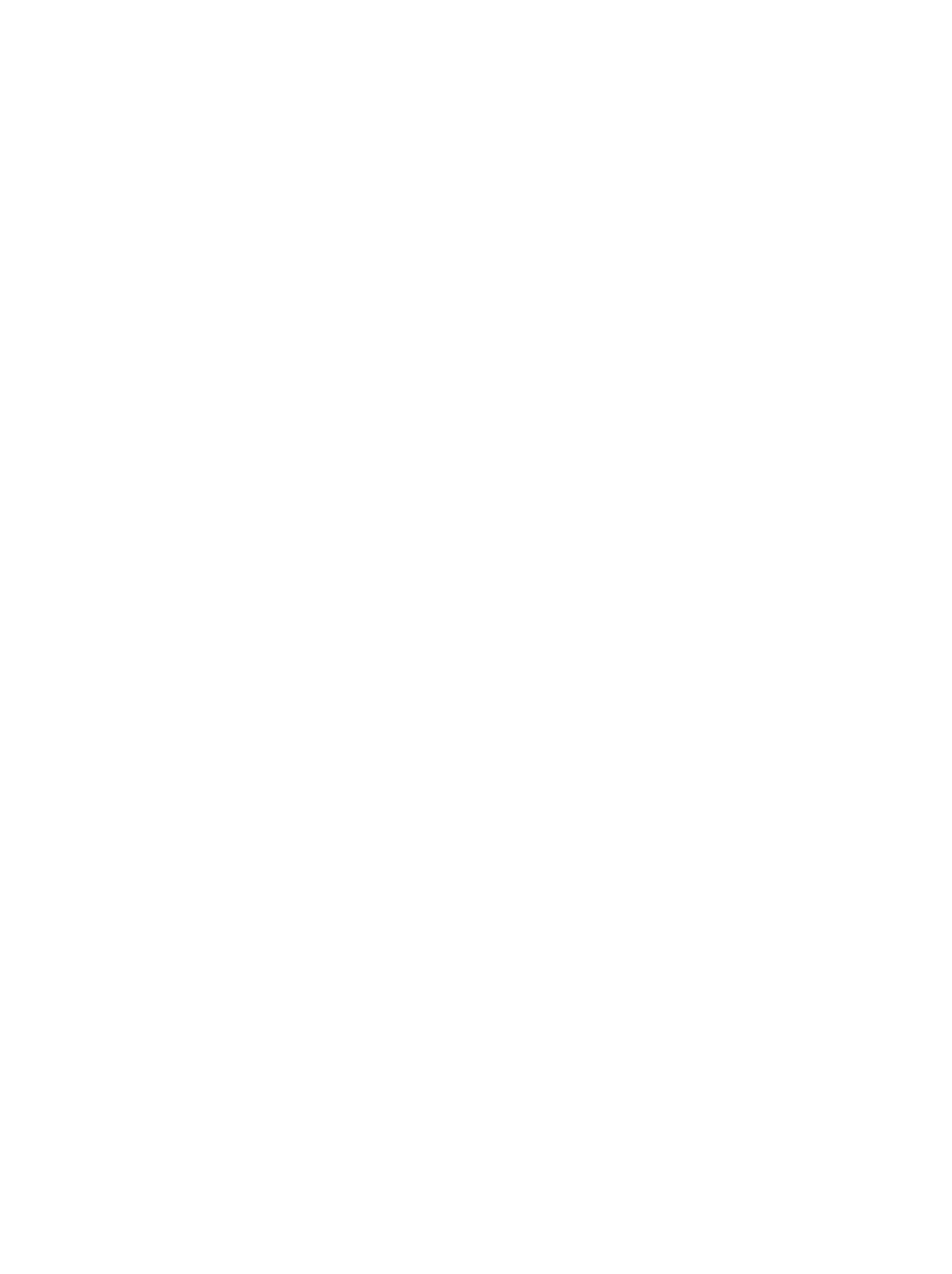


WABASH RIVER BASIN--Continued

3-3655. EAST FORK WHITE RIVER AT SEYMOUR, IND.--Continued

Suspended sediment, water year October 1966 to September 1967

\begin{tabular}{|c|c|c|c|c|c|c|c|c|c|}
\hline \multirow[b]{3}{*}{ Day } & \multicolumn{3}{|c|}{ OCTOBER } & \multicolumn{3}{|c|}{ NOVEMBER } & \multicolumn{3}{|c|}{ DECEMBER } \\
\hline & \multirow[b]{2}{*}{$\begin{array}{l}\text { Mean } \\
\text { dis- } \\
\text { charge } \\
\text { (cfs) }\end{array}$} & \multicolumn{2}{|c|}{ Suspended sediment } & \multirow[b]{2}{*}{$\begin{array}{l}\text { Mean } \\
\text { dis- } \\
\text { charge } \\
\text { (cfs) }\end{array}$} & \multicolumn{2}{|c|}{ Suspended sediment } & \multirow[b]{2}{*}{$\begin{array}{c}\text { Mean } \\
\text { dis- } \\
\text { charge } \\
\text { (cfs) }\end{array}$} & \multicolumn{2}{|c|}{ Suspended sedimen } \\
\hline & & $\begin{array}{c}\text { Mean } \\
\text { concen- } \\
\text { tration } \\
(\text { ppm) }\end{array}$ & $\begin{array}{l}\text { Tons } \\
\text { per } \\
\text { day }\end{array}$ & & $\begin{array}{c}\text { Mean } \\
\text { concen- } \\
\text { tration } \\
(\text { ppm) }\end{array}$ & $\begin{array}{l}\text { Tons } \\
\text { per } \\
\text { day }\end{array}$ & & $\begin{array}{c}\text { Mean } \\
\text { concen- } \\
\text { tration } \\
(\mathrm{ppm})\end{array}$ & $\begin{array}{l}\text { Tons } \\
\text { per } \\
\text { day }\end{array}$ \\
\hline $\begin{array}{l}1 \ldots \\
2 \ldots \\
3 \ldots \\
4 \ldots \\
5 . .\end{array}$ & $\begin{array}{l}354 \\
356 \\
356 \\
389 \\
369\end{array}$ & $\begin{array}{l}28 \\
28 \\
27 \\
27 \\
27\end{array}$ & $\begin{array}{l}27 \\
27 \\
24 \\
28 \\
27\end{array}$ & $\begin{array}{l}291 \\
302 \\
316 \\
310 \\
318\end{array}$ & $\begin{array}{r}20 \\
16 \\
8 \\
5 \\
4\end{array}$ & $\begin{array}{r}16 \\
13 \\
7 \\
4 \\
3\end{array}$ & $\begin{array}{l}6750 \\
4290 \\
3320 \\
2670 \\
2350\end{array}$ & $\begin{array}{l}87 \\
51 \\
39 \\
33 \\
31\end{array}$ & $\begin{array}{r}1590 \\
591 \\
350 \\
238 \\
197\end{array}$ \\
\hline $\begin{array}{r}6 \ldots \\
7 \ldots \\
8 \ldots \\
9 \ldots \\
10 \ldots\end{array}$ & $\begin{array}{l}340 \\
325 \\
315 \\
305 \\
311\end{array}$ & $\begin{array}{l}27 \\
27 \\
27 \\
25 \\
25\end{array}$ & $\begin{array}{l}25 \\
24 \\
23 \\
20 \\
20\end{array}$ & $\begin{array}{r}329 \\
364 \\
576 \\
1540 \\
2790\end{array}$ & $\begin{array}{r}5 \\
6 \\
14 \\
82 \\
210\end{array}$ & $\begin{array}{r}4 \\
6 \\
22 \\
391 \\
1600\end{array}$ & $\begin{array}{r}2780 \\
4810 \\
8940 \\
13400 \\
24600\end{array}$ & $\begin{array}{r}47 \\
196 \\
282 \\
230 \\
327\end{array}$ & $\begin{array}{r}353 \\
2690 \\
6810 \\
8320 \\
21700\end{array}$ \\
\hline $\begin{array}{l}11 \ldots \\
12 \ldots \\
13 \ldots \\
14 \ldots \\
15 \ldots\end{array}$ & $\begin{array}{l}345 \\
325 \\
320 \\
312 \\
324\end{array}$ & $\begin{array}{l}23 \\
24 \\
25 \\
25 \\
25\end{array}$ & $\begin{array}{l}21 \\
21 \\
22 \\
21 \\
22\end{array}$ & $\begin{array}{l}4180 \\
4300 \\
3420 \\
2600 \\
2070\end{array}$ & $\begin{array}{r}-\overline{2} \\
98 \\
55 \\
37\end{array}$ & $\begin{array}{r}400 \\
3300 \\
905 \\
386 \\
207\end{array}$ & $\begin{array}{r}32900 \\
30400 \\
25000 \\
15700 \\
8690\end{array}$ & $\begin{array}{r}289 \\
201 \\
132 \\
81 \\
67\end{array}$ & $\begin{array}{r}25700 \\
16500 \\
8910 \\
3430 \\
1570\end{array}$ \\
\hline $\begin{array}{l}16 \ldots \\
17 \ldots \\
18 \ldots \\
19 \ldots \\
20 \ldots\end{array}$ & $\begin{array}{l}334 \\
359 \\
361 \\
376 \\
371\end{array}$ & $\begin{array}{r}25 \\
25 \\
26 \\
16 \\
9\end{array}$ & $\begin{array}{r}23 \\
24 \\
25 \\
16 \\
9\end{array}$ & $\begin{array}{l}1740 \\
1520 \\
1360 \\
1240 \\
1130\end{array}$ & $\begin{array}{l}30 \\
29 \\
27 \\
25 \\
23\end{array}$ & $\begin{array}{r}141 \\
119 \\
99 \\
84 \\
70\end{array}$ & $\begin{array}{l}6240 \\
5120 \\
4420 \\
3910 \\
3490\end{array}$ & $\begin{array}{l}50 \\
41 \\
39 \\
38 \\
27\end{array}$ & $\begin{array}{l}842 \\
567 \\
465 \\
401 \\
254\end{array}$ \\
\hline $\begin{array}{l}21 \ldots \\
22 \ldots \\
23 \ldots \\
24 \ldots \\
25 \ldots\end{array}$ & $\begin{array}{l}361 \\
350 \\
334 \\
323 \\
317\end{array}$ & $\begin{array}{l}13 \\
18 \\
18 \\
18 \\
18\end{array}$ & $\begin{array}{l}13 \\
17 \\
16 \\
16 \\
15\end{array}$ & $\begin{array}{r}1040 \\
972 \\
917 \\
869 \\
845\end{array}$ & $\begin{array}{l}21 \\
19 \\
18 \\
16 \\
16\end{array}$ & $\begin{array}{l}59 \\
50 \\
45 \\
38 \\
37\end{array}$ & $\begin{array}{l}3170 \\
2870 \\
2600 \\
2370 \\
2200\end{array}$ & $\begin{array}{l}25 \\
22 \\
21 \\
17 \\
18\end{array}$ & $\begin{array}{l}214 \\
170 \\
147 \\
109 \\
107\end{array}$ \\
\hline $\begin{array}{l}26 \ldots \\
27 \ldots \\
28 \ldots \\
29 \ldots \\
30 \ldots \\
31 \ldots\end{array}$ & $\begin{array}{l}312 \\
307 \\
303 \\
298 \\
294 \\
291 \\
\end{array}$ & $\begin{array}{l}18 \\
17 \\
16 \\
16 \\
17 \\
18 \\
\end{array}$ & $\begin{array}{l}15 \\
14 \\
13 \\
13 \\
13 \\
14 \\
\end{array}$ & $\begin{array}{r}831 \\
1150 \\
4560 \\
7610 \\
8960 \\
\end{array}$ & $\begin{array}{r}16 \\
61 \\
439 \\
341 \\
169 \\
-- \\
\end{array}$ & $\begin{array}{r}36 \\
248 \\
5400 \\
7010 \\
4090 \\
-- \\
\end{array}$ & $\begin{array}{l}2020 \\
1840 \\
1870 \\
3030 \\
3300 \\
2670 \\
\end{array}$ & $\begin{array}{r}12 \\
9 \\
13 \\
40 \\
36 \\
22 \\
\end{array}$ & $\begin{array}{r}65 \\
45 \\
66 \\
330 \\
321 \\
159 \\
\end{array}$ \\
\hline \multirow[t]{2}{*}{ Total } & 10337 & - & 608 & 58450 & -- & 28790 & 237720 & - & 103211 \\
\hline & \multicolumn{3}{|c|}{ JANUARY } & \multicolumn{3}{|c|}{ FEBRUARY } & \multicolumn{3}{|c|}{ MARCH } \\
\hline $\begin{array}{l}1 \ldots \\
2 \ldots \\
3 \ldots \\
5 \ldots\end{array}$ & $\begin{array}{l}2270 \\
2050 \\
1880 \\
1750 \\
1650\end{array}$ & $\begin{array}{r}12 \\
11 \\
10 \\
9 \\
8\end{array}$ & $\begin{array}{l}74 \\
61 \\
51 \\
43 \\
36\end{array}$ & $\begin{array}{l}2740 \\
3360 \\
8180 \\
9780 \\
8440\end{array}$ & $\begin{array}{r}27 \\
67 \\
360 \\
177 \\
97\end{array}$ & $\begin{array}{r}200 \\
717 \\
7950 \\
4670 \\
2210\end{array}$ & $\begin{array}{l}1090 \\
1100 \\
1300 \\
2040 \\
2700\end{array}$ & $\begin{array}{r}6 \\
8 \\
14 \\
25 \\
65\end{array}$ & $\begin{array}{r}18 \\
24 \\
49 \\
138 \\
511\end{array}$ \\
\hline $\begin{array}{r}6 \ldots \\
7 \ldots \\
8 \ldots \\
90\end{array}$ & $\begin{array}{l}1560 \\
1560 \\
1980 \\
2490 \\
2270\end{array}$ & $\begin{array}{r}9 \\
8 \\
11 \\
31 \\
28\end{array}$ & $\begin{array}{r}38 \\
34 \\
59 \\
208 \\
172\end{array}$ & $\begin{array}{l}6050 \\
4580 \\
3460 \\
2930 \\
2710\end{array}$ & $\begin{array}{l}60 \\
64 \\
29 \\
27 \\
38\end{array}$ & $\begin{array}{l}980 \\
791 \\
271 \\
214 \\
278\end{array}$ & $\begin{array}{r}7310 \\
12200 \\
12500 \\
10400 \\
8100\end{array}$ & $\begin{array}{r}386 \\
276 \\
151 \\
93 \\
71\end{array}$ & $\begin{array}{l}7620 \\
9090 \\
5100 \\
2610 \\
1550\end{array}$ \\
\hline $\begin{array}{l}11 \ldots \\
12 \ldots \\
13 \ldots \\
14 \ldots \\
15 \ldots\end{array}$ & $\begin{array}{l}1890 \\
1660 \\
1570 \\
1520 \\
1450\end{array}$ & $\begin{array}{r}23 \\
10 \\
9 \\
8 \\
9\end{array}$ & $\begin{array}{r}117 \\
45 \\
38 \\
33 \\
35\end{array}$ & $\begin{array}{l}2470 \\
2230 \\
1960 \\
1800 \\
1730\end{array}$ & $\begin{array}{l}37 \\
38 \\
47 \\
46 \\
34\end{array}$ & $\begin{array}{l}247 \\
229 \\
249 \\
224 \\
159\end{array}$ & $\begin{array}{l}6880 \\
5930 \\
5170 \\
4540 \\
4890\end{array}$ & $\begin{array}{l}63 \\
63 \\
57 \\
65 \\
80\end{array}$ & $\begin{array}{r}1170 \\
1010 \\
796 \\
797 \\
1100\end{array}$ \\
\hline $\begin{array}{l}16 \ldots \\
17 \ldots \\
18 \ldots \\
19 \ldots \\
20 \ldots\end{array}$ & $\begin{array}{l}1370 \\
1280 \\
1170 \\
1070 \\
1070\end{array}$ & $\begin{array}{r}6 \\
6 \\
6 \\
7 \\
12\end{array}$ & $\begin{array}{l}22 \\
21 \\
19 \\
20 \\
35 \\
38\end{array}$ & $\begin{array}{l}1680 \\
1640 \\
1600 \\
1530 \\
1470\end{array}$ & $\begin{array}{l}48 \\
40 \\
43 \\
32 \\
36\end{array}$ & $\begin{array}{l}218 \\
177 \\
186 \\
132 \\
143\end{array}$ & $\begin{array}{l}5460 \\
4400 \\
3690 \\
3150 \\
2930\end{array}$ & $\begin{array}{r}102 \\
65 \\
42 \\
23 \\
21\end{array}$ & $\begin{array}{r}1500 \\
772 \\
418 \\
196 \\
166\end{array}$ \\
\hline $\begin{array}{l}21 \ldots \\
22 \ldots \\
23 \ldots \\
24 \ldots \\
25 \ldots\end{array}$ & $\begin{array}{l}1080 \\
1070 \\
1090 \\
1110 \\
1140\end{array}$ & $\begin{array}{l}13 \\
20 \\
31 \\
21 \\
28\end{array}$ & $\begin{array}{l}38 \\
58 \\
91 \\
63 \\
86\end{array}$ & $\begin{array}{l}1420 \\
1370 \\
1310 \\
1220 \\
1050\end{array}$ & $\begin{array}{r}24 \\
7 \\
9 \\
11 \\
14\end{array}$ & $\begin{array}{l}92 \\
26 \\
32 \\
36 \\
40\end{array}$ & $\begin{array}{r}6350 \\
10200 \\
9520 \\
7550 \\
5630\end{array}$ & $\begin{array}{r}196 \\
181 \\
118 \\
87 \\
63\end{array}$ & $\begin{array}{r}3560 \\
4980 \\
3030 \\
1770 \\
958\end{array}$ \\
\hline $\begin{array}{l}26 \ldots \\
27 \ldots \\
28 \ldots \\
29 \ldots \\
30 \ldots \\
31 \ldots\end{array}$ & $\begin{array}{l}1190 \\
2000 \\
4260 \\
4550 \\
3770 \\
3040\end{array}$ & $\begin{array}{l}41 \\
80 \\
70 \\
77 \\
40 \\
26 \\
\end{array}$ & $\begin{array}{r}132 \\
510 \\
2000 \\
946 \\
407 \\
213\end{array}$ & $\begin{array}{r}1010 \\
1050 \\
1080 \\
-- \\
--\end{array}$ & $\begin{array}{l}12 \\
23 \\
16 \\
-- \\
-- \\
--\end{array}$ & $\begin{array}{l}33 \\
65 \\
47 \\
-- \\
-- \\
--\end{array}$ & $\begin{array}{l}4570 \\
3940 \\
3900 \\
5630 \\
5950 \\
5390 \\
\end{array}$ & $\begin{array}{r}59 \\
58 \\
66 \\
133 \\
92 \\
-71 \\
\end{array}$ & $\begin{array}{r}728 \\
617 \\
695 \\
2020 \\
1480 \\
1030\end{array}$ \\
\hline Total & 57810 & -- & 5705 & 79850 & -- & 20816 & 174410 & $\cdots$ & 55503 \\
\hline
\end{tabular}


WABASH RIVER BASIN--Continued

3-3655. EAST FORK WHITE RIVER AT SEYMOUR, IND..-COnt1nued

Suspended sediment, water year October 1966 to September 1967--Continued

\begin{tabular}{|c|c|c|c|c|c|c|c|c|c|}
\hline \multirow[b]{3}{*}{ Day } & \multirow[b]{3}{*}{$\begin{array}{l}\text { Mean } \\
\text { die- } \\
\text { charge } \\
\text { (cfs) }\end{array}$} & \multicolumn{2}{|c|}{ APBIL } & \multirow[b]{3}{*}{$\begin{array}{c}\text { Mean } \\
\text { dis- } \\
\text { charge } \\
(c f B)\end{array}$} & \multicolumn{2}{|c|}{ MAI } & \multirow[b]{3}{*}{$\begin{array}{l}\text { Mean } \\
\text { dis- } \\
\text { charge } \\
\text { (cfs) }\end{array}$} & \multirow{2}{*}{\multicolumn{2}{|c|}{ SUNE }} \\
\hline & & \multicolumn{2}{|c|}{ Suspended rediment } & & \multicolumn{2}{|c|}{ Suspended sediment } & & & \\
\hline & & $\begin{array}{c}\text { Mean } \\
\text { concen- } \\
\text { tration } \\
\text { (ppm) }\end{array}$ & $\begin{array}{l}\text { Tons } \\
\text { per } \\
\text { day }\end{array}$ & & $\begin{array}{c}\text { Mean } \\
\text { concen- } \\
\text { tration } \\
\text { (ppm) }\end{array}$ & $\begin{array}{l}\text { Tons } \\
\text { per } \\
\text { day }\end{array}$ & & $\begin{array}{c}\text { Mean } \\
\text { concen- } \\
\text { tration } \\
(\text { ppm) }\end{array}$ & $\begin{array}{l}\text { Tons } \\
\text { per } \\
\text { day }\end{array}$ \\
\hline $\begin{array}{l}1 \ldots \\
2 \ldots \\
3 \ldots \\
4 \ldots \\
5 \ldots\end{array}$ & $\begin{array}{l}4270 \\
3490 \\
3050 \\
2760 \\
2500\end{array}$ & $\begin{array}{l}46 \\
43 \\
75 \\
53 \\
43\end{array}$ & $\begin{array}{l}530 \\
405 \\
618 \\
395 \\
290\end{array}$ & $\begin{array}{l}2170 \\
6950 \\
9460 \\
6030 \\
4300\end{array}$ & $\begin{array}{r}65 \\
408 \\
204 \\
86 \\
64\end{array}$ & $\begin{array}{rr}381 \\
\mathrm{~s} & 7660 \\
5490 \\
& 1400 \\
743\end{array}$ & $\begin{array}{l}2450 \\
2160 \\
1960 \\
1910 \\
1830\end{array}$ & $\begin{array}{l}52 \\
57 \\
46 \\
59 \\
56\end{array}$ & $\begin{array}{l}344 \\
332 \\
243 \\
304 \\
277\end{array}$ \\
\hline $\begin{array}{r}6 \ldots \\
7 \ldots \\
8 \ldots \\
9 \ldots \\
10 \ldots\end{array}$ & $\begin{array}{l}2560 \\
4020 \\
4230 \\
3650 \\
3100\end{array}$ & $\begin{array}{l}47 \\
75 \\
70 \\
58 \\
66\end{array}$ & $\begin{array}{l}325 \\
814 \\
799 \\
572 \\
552\end{array}$ & $\begin{array}{r}3420 \\
6610 \\
14600 \\
13000 \\
11000\end{array}$ & $\begin{array}{r}58 \\
310 \\
279 \\
118 \\
69\end{array}$ & \begin{tabular}{|r} 
A \\
536 \\
6800 \\
11000 \\
4140 \\
2050
\end{tabular} & $\begin{array}{l}1720 \\
1610 \\
1580 \\
1500 \\
1420\end{array}$ & $\begin{array}{l}48 \\
58 \\
56 \\
41 \\
38\end{array}$ & $\begin{array}{l}223 \\
252 \\
239 \\
166 \\
146\end{array}$ \\
\hline $\begin{array}{l}11 \ldots \\
12 \ldots \\
13 \ldots \\
14 \ldots \\
15 .\end{array}$ & $\begin{array}{l}2730 \\
2390 \\
2180 \\
2080 \\
2010\end{array}$ & $\begin{array}{l}53 \\
51 \\
47 \\
54 \\
39\end{array}$ & $\begin{array}{l}391 \\
329 \\
277 \\
303 \\
212\end{array}$ & $\begin{array}{r}8220 \\
6480 \\
7180 \\
7600 \\
11300\end{array}$ & $\begin{array}{r}54 \\
66 \\
78 \\
87 \\
180\end{array}$ & $\begin{array}{l}1200 \\
1150 \\
1510 \\
1790 \\
5500\end{array}$ & $\begin{array}{l}1350 \\
1260 \\
1190 \\
1140 \\
1090\end{array}$ & $\begin{array}{l}38 \\
37 \\
33 \\
30 \\
30\end{array}$ & $\begin{array}{r}139 \\
126 \\
106 \\
92 \\
88\end{array}$ \\
\hline $\begin{array}{l}16 \ldots \\
17 \ldots \\
18 \ldots \\
19 \ldots \\
20 .\end{array}$ & $\begin{array}{l}1900 \\
2150 \\
2750 \\
2040 \\
1750\end{array}$ & $\begin{array}{r}46 \\
110 \\
38 \\
45\end{array}$ & $\begin{array}{l}236 \\
410 \\
800 \\
209 \\
213\end{array}$ & $\begin{array}{r}15400 \\
11600 \\
10300 \\
8440 \\
6920\end{array}$ & $\begin{array}{r}140 \\
74 \\
76 \\
54 \\
70\end{array}$ & $\begin{array}{l}5800 \\
2320 \\
2110 \\
1230 \\
1310\end{array}$ & $\begin{array}{r}1040 \\
1000 \\
963 \\
922 \\
889\end{array}$ & $\begin{array}{l}30 \\
28 \\
30 \\
31 \\
30\end{array}$ & $\begin{array}{l}84 \\
76 \\
78 \\
77 \\
72\end{array}$ \\
\hline $\begin{array}{l}21 \ldots \\
22 \ldots \\
23 \ldots \\
24 \ldots \\
25 \ldots\end{array}$ & $\begin{array}{l}1720 \\
5130 \\
5280 \\
4390 \\
4020\end{array}$ & $\begin{array}{r}50 \\
451 \\
193 \\
95 \\
76\end{array}$ & $\begin{array}{r}232 \\
6250 \\
3040 \\
1130 \\
825\end{array}$ & $\begin{array}{l}5320 \\
4280 \\
3630 \\
3200 \\
2870\end{array}$ & $\begin{array}{l}79 \\
83 \\
86 \\
83 \\
96\end{array}$ & $\begin{array}{r}1130 \\
959 \\
843 \\
717 \\
744\end{array}$ & $\begin{array}{r}886 \\
962 \\
1100 \\
1120 \\
1050\end{array}$ & $\begin{array}{l}32 \\
30 \\
35 \\
40 \\
48\end{array}$ & $\begin{array}{r}77 \\
78 \\
104 \\
121 \\
136\end{array}$ \\
\hline $\begin{array}{l}26 \ldots \\
27 \ldots \\
28 \ldots \\
29 \ldots \\
30 \ldots \\
31 \ldots\end{array}$ & $\begin{array}{r}3300 \\
3030 \\
2650 \\
2320 \\
2120 \\
-- \\
\end{array}$ & $\begin{array}{l}51 \\
40 \\
50 \\
56 \\
54 \\
-- \\
\end{array}$ & $\begin{array}{r}454 \\
327 \\
358 \\
351 \\
309 \\
- \\
\end{array}$ & $\begin{array}{l}2580 \\
2350 \\
2160 \\
2160 \\
2470 \\
2640 \\
\end{array}$ & $\begin{array}{l}73 \\
75 \\
75 \\
72 \\
59 \\
66 \\
\end{array}$ & $\begin{array}{l}509 \\
476 \\
437 \\
420 \\
393 \\
470 \\
\end{array}$ & $\begin{array}{l}968 \\
915 \\
873 \\
829 \\
796 \\
- \\
\end{array}$ & $\begin{array}{l}44 \\
45 \\
46 \\
55 \\
88 \\
-- \\
\end{array}$ & $\begin{array}{c}115 \\
111 \\
108 \\
123 \\
189 \\
--\end{array}$ \\
\hline \multirow[t]{2}{*}{ Total } & 89570 & -- & 21956 & 204640 & -- & 71218 & 38483 & - & 4626 \\
\hline & \multicolumn{3}{|c|}{ JULY } & \multicolumn{3}{|c|}{ AUGUST } & \multicolumn{3}{|c|}{ SEPTEMBER } \\
\hline $\begin{array}{l}1 \ldots \\
2 \ldots \\
3 \ldots \\
4 \ldots \\
5 \ldots\end{array}$ & $\begin{array}{l}861 \\
968 \\
830 \\
762 \\
727\end{array}$ & $\begin{array}{l}-- \\
-- \\
63 \\
67 \\
59\end{array}$ & $\begin{array}{l}130 \\
190 \\
141 \\
138 \\
116\end{array}$ & $\begin{array}{l}450 \\
436 \\
424 \\
411 \\
394\end{array}$ & $\begin{array}{l}40 \\
35 \\
32 \\
30 \\
30\end{array}$ & $\begin{array}{l}49 \\
41 \\
37 \\
33 \\
32\end{array}$ & $\begin{array}{l}275 \\
269 \\
262 \\
257 \\
253\end{array}$ & $\begin{array}{l}41 \\
39 \\
36 \\
34 \\
34\end{array}$ & $\begin{array}{l}30 \\
28 \\
25 \\
24 \\
23\end{array}$ \\
\hline $\begin{array}{r}6 \ldots \\
7 \ldots \\
8 \ldots \\
9 . \\
10 .\end{array}$ & $\begin{array}{l}701 \\
677 \\
657 \\
636 \\
628\end{array}$ & $\begin{array}{l}56 \\
52 \\
52 \\
51 \\
51\end{array}$ & $\begin{array}{r}106 \\
95 \\
92 \\
88 \\
86\end{array}$ & $\begin{array}{l}379 \\
370 \\
371 \\
374 \\
356\end{array}$ & $\begin{array}{l}33 \\
34 \\
35 \\
38 \\
38\end{array}$ & $\begin{array}{l}34 \\
34 \\
35 \\
38 \\
37\end{array}$ & $\begin{array}{l}251 \\
246 \\
243 \\
244 \\
242\end{array}$ & $\begin{array}{l}34 \\
35 \\
35 \\
32 \\
29\end{array}$ & $\begin{array}{l}23 \\
23 \\
23 \\
21 \\
19\end{array}$ \\
\hline $\begin{array}{l}11 \ldots \\
12 \ldots \\
13 \ldots \\
14 \ldots \\
15 \ldots\end{array}$ & $\begin{array}{l}609 \\
596 \\
578 \\
561 \\
545\end{array}$ & $\begin{array}{l}49 \\
42 \\
36 \\
34 \\
44\end{array}$ & $\begin{array}{l}81 \\
68 \\
56 \\
51 \\
65\end{array}$ & $\begin{array}{l}344 \\
334 \\
322 \\
319 \\
312\end{array}$ & $\begin{array}{l}34 \\
33 \\
36 \\
36 \\
32\end{array}$ & $\begin{array}{l}32 \\
30 \\
31 \\
31 \\
27\end{array}$ & $\begin{array}{l}239 \\
238 \\
238 \\
235 \\
232\end{array}$ & $\begin{array}{l}28 \\
30 \\
32 \\
34 \\
35\end{array}$ & $\begin{array}{l}18 \\
19 \\
21 \\
22 \\
22\end{array}$ \\
\hline $\begin{array}{l}16 \ldots \\
17 \ldots \\
18 \ldots \\
19 \ldots \\
20 \ldots\end{array}$ & $\begin{array}{l}528 \\
512 \\
508 \\
503 \\
501\end{array}$ & $\begin{array}{l}43 \\
38 \\
37 \\
36 \\
39\end{array}$ & $\begin{array}{l}61 \\
53 \\
51 \\
49 \\
53\end{array}$ & $\begin{array}{l}307 \\
301 \\
306 \\
308 \\
302\end{array}$ & $\begin{array}{l}31 \\
30 \\
28 \\
27 \\
25\end{array}$ & $\begin{array}{l}26 \\
24 \\
23 \\
22 \\
20\end{array}$ & $\begin{array}{l}228 \\
228 \\
224 \\
223 \\
223\end{array}$ & $\begin{array}{l}30 \\
26 \\
22 \\
22 \\
22\end{array}$ & $\begin{array}{l}18 \\
16 \\
13 \\
13 \\
13\end{array}$ \\
\hline $\begin{array}{l}21 \ldots \\
22 \ldots \\
23 \ldots \\
24 \ldots \\
25 \ldots\end{array}$ & $\begin{array}{l}504 \\
489 \\
485 \\
474 \\
519\end{array}$ & $\begin{array}{l}41 \\
35 \\
34 \\
33 \\
45\end{array}$ & $\begin{array}{l}56 \\
46 \\
45 \\
42 \\
63\end{array}$ & $\begin{array}{l}306 \\
309 \\
301 \\
293 \\
310\end{array}$ & $\begin{array}{l}24 \\
29 \\
30 \\
30 \\
35\end{array}$ & $\begin{array}{l}20 \\
24 \\
24 \\
24 \\
30\end{array}$ & $\begin{array}{l}227 \\
223 \\
218 \\
214 \\
212\end{array}$ & $\begin{array}{l}21 \\
21 \\
21 \\
21 \\
20\end{array}$ & $\begin{array}{l}13 \\
13 \\
12 \\
12 \\
11\end{array}$ \\
\hline $\begin{array}{l}26 \ldots \\
27 \ldots \\
28 \ldots \\
29 \ldots \\
30 \ldots \\
31 \ldots\end{array}$ & $\begin{array}{l}455 \\
445 \\
573 \\
528 \\
481 \\
462 \\
\end{array}$ & $\begin{array}{l}37 \\
37 \\
-- \\
44 \\
29 \\
30 \\
\end{array}$ & $\begin{array}{l}45 \\
44 \\
85 \\
63 \\
38 \\
35 \\
\end{array}$ & $\begin{array}{l}633 \\
372 \\
312 \\
298 \\
297 \\
284 \\
\end{array}$ & $\begin{array}{l}71 \\
60 \\
45 \\
44 \\
43 \\
42 \\
\end{array}$ & $\begin{array}{r}121 \\
60 \\
38 \\
35 \\
34 \\
32 \\
\end{array}$ & $\begin{array}{r}211 \\
213 \\
217 \\
213 \\
213 \\
-- \\
\end{array}$ & $\begin{array}{l}17 \\
15 \\
10 \\
10 \\
10 \\
- \\
\end{array}$ & $\begin{array}{r}10 \\
9 \\
6 \\
6 \\
6 \\
\end{array}$ \\
\hline Total & 18303 & -- & 2332 & 10835 & -- & 1078 & 7011 & -- & 512 \\
\hline
\end{tabular}

Total discharge for year (cfs-days) . . . . . . . . . . . . . . . . . . . . . . . .

Total load for year (tons)

E Estimated

$S$ Computed by subdividing day.

A Computed from partly estimated-concentration graph B Computed from estimated-concentration graph. 


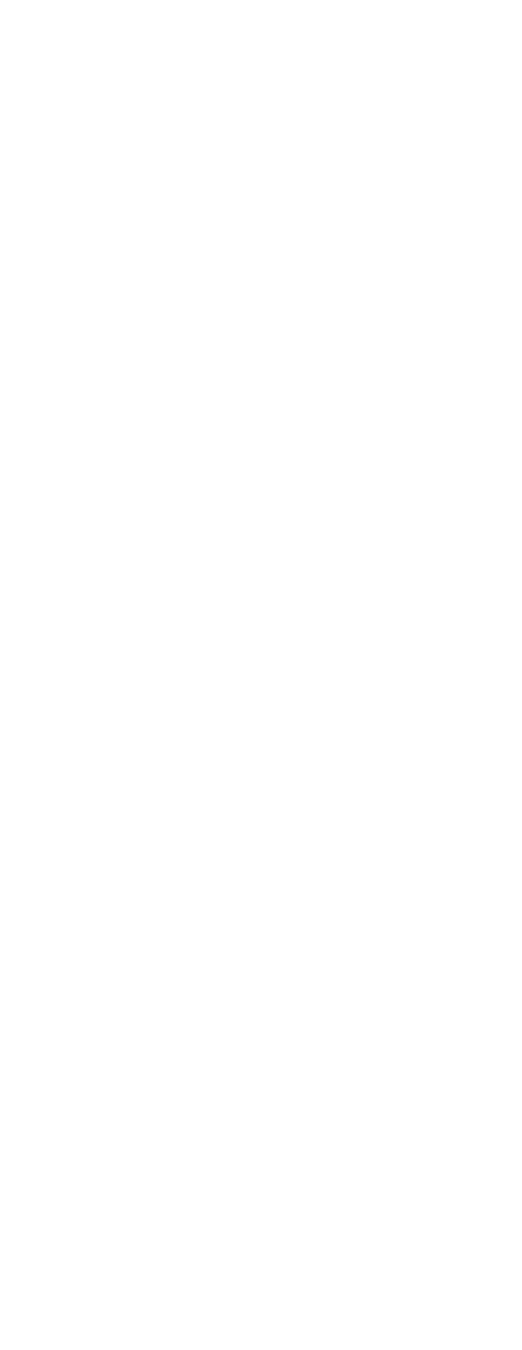




\section{:}

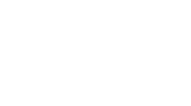

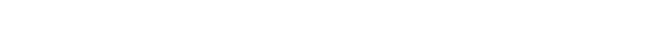

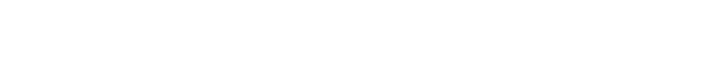




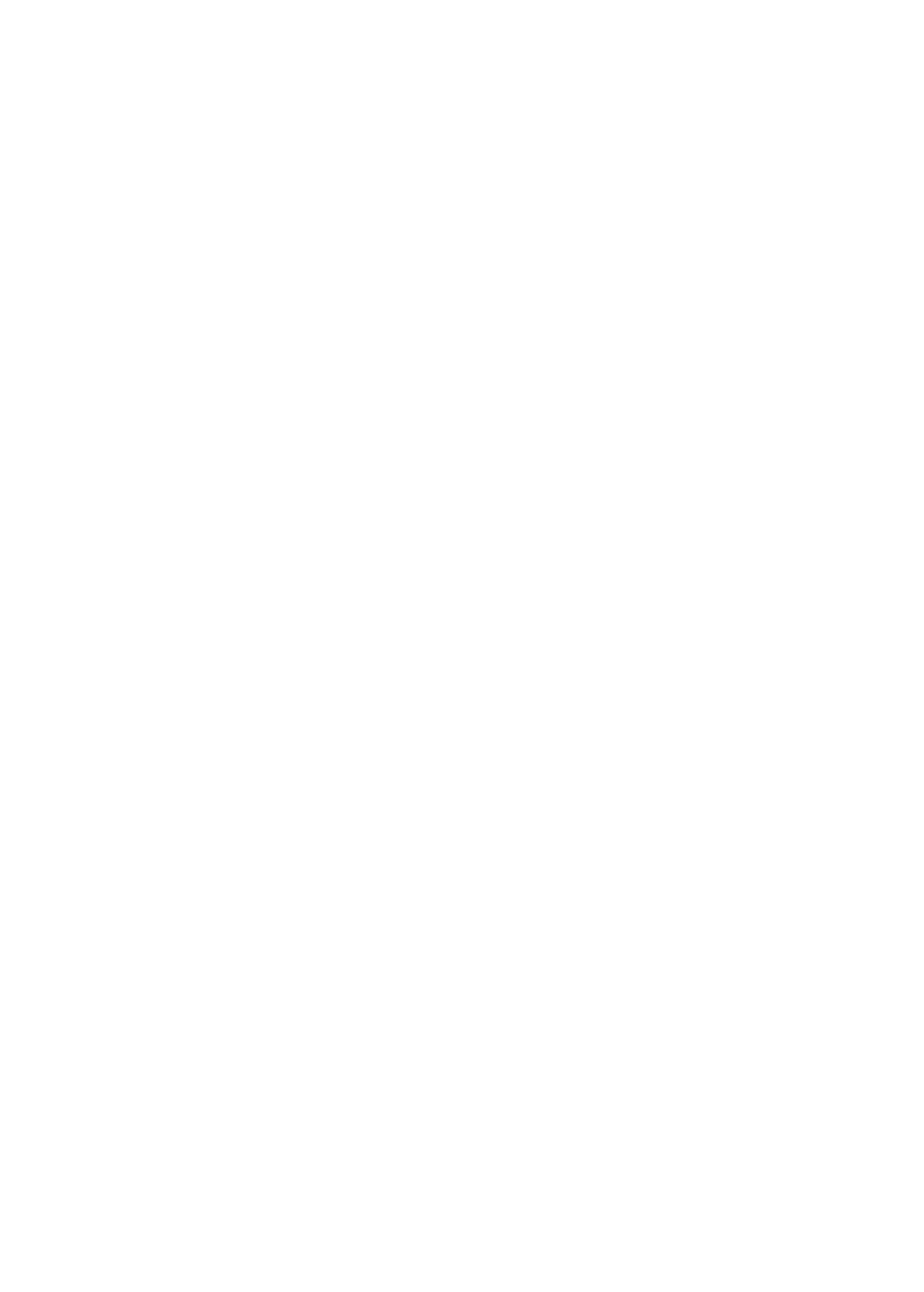




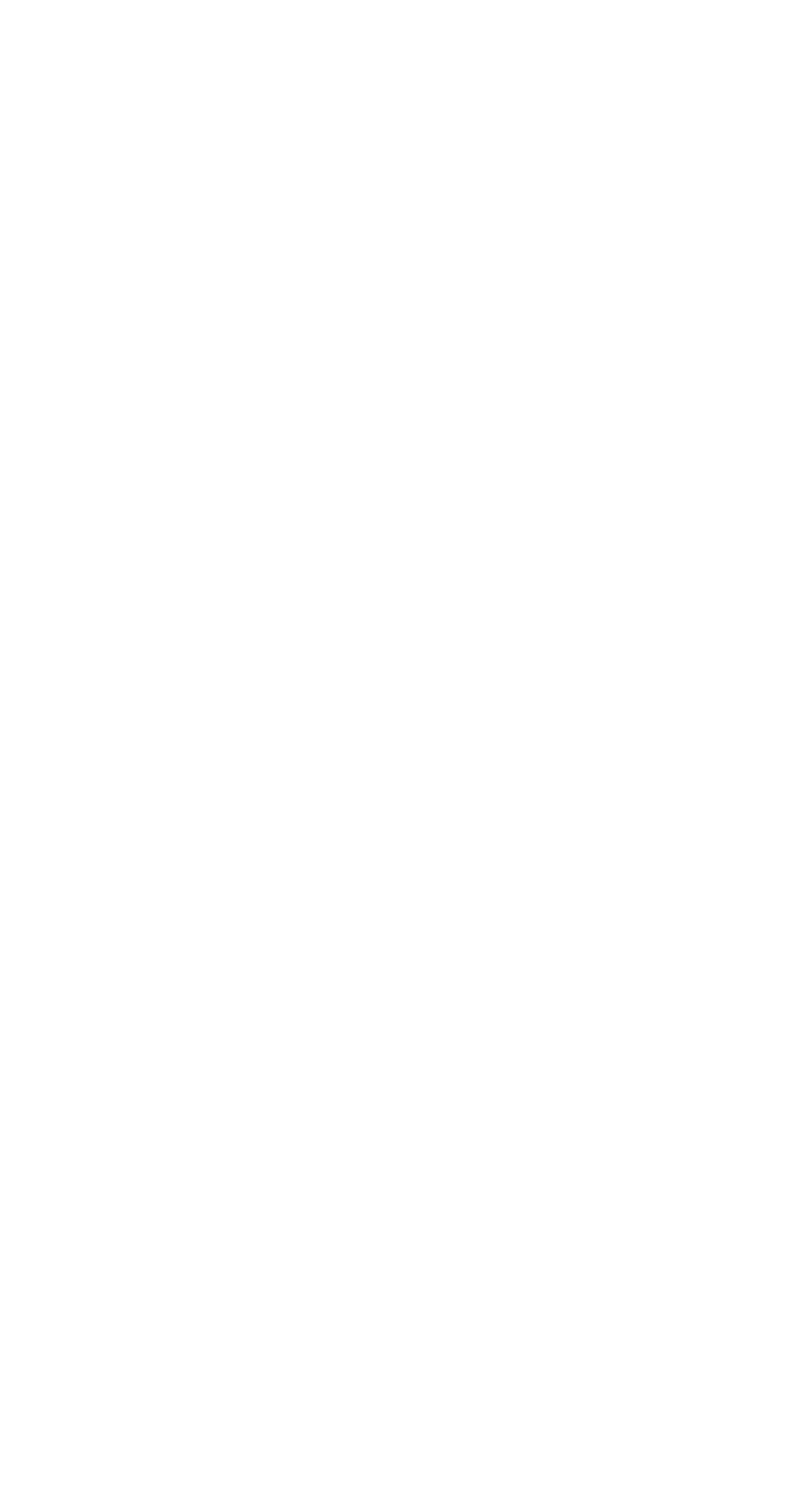




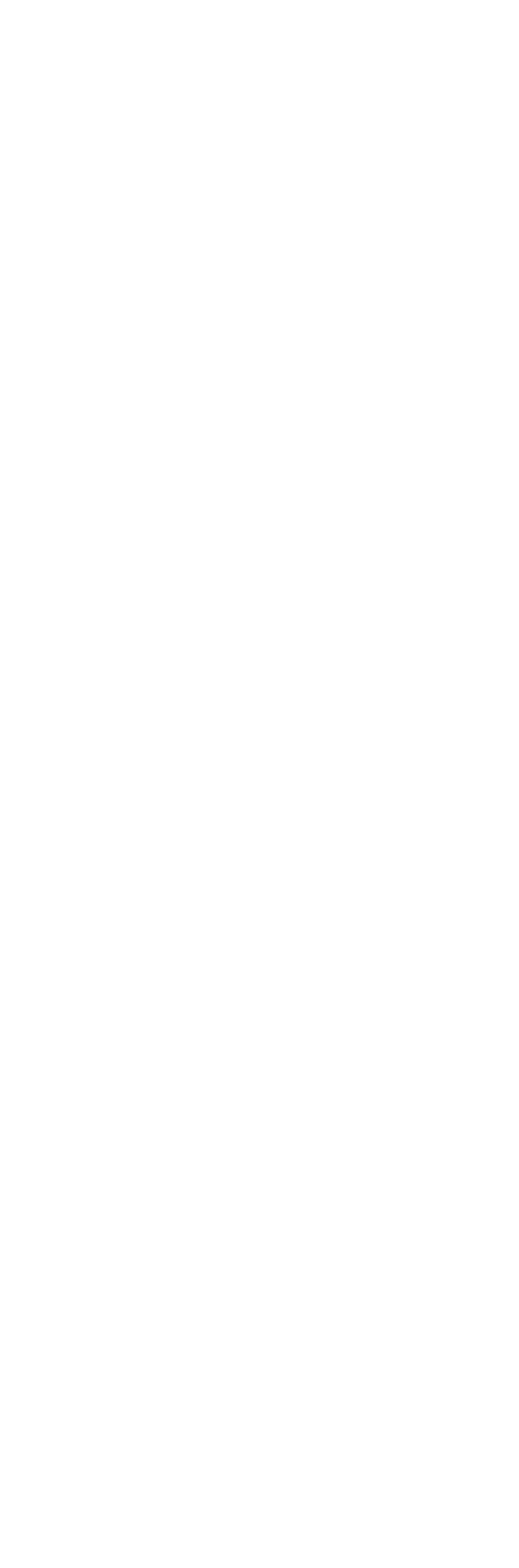




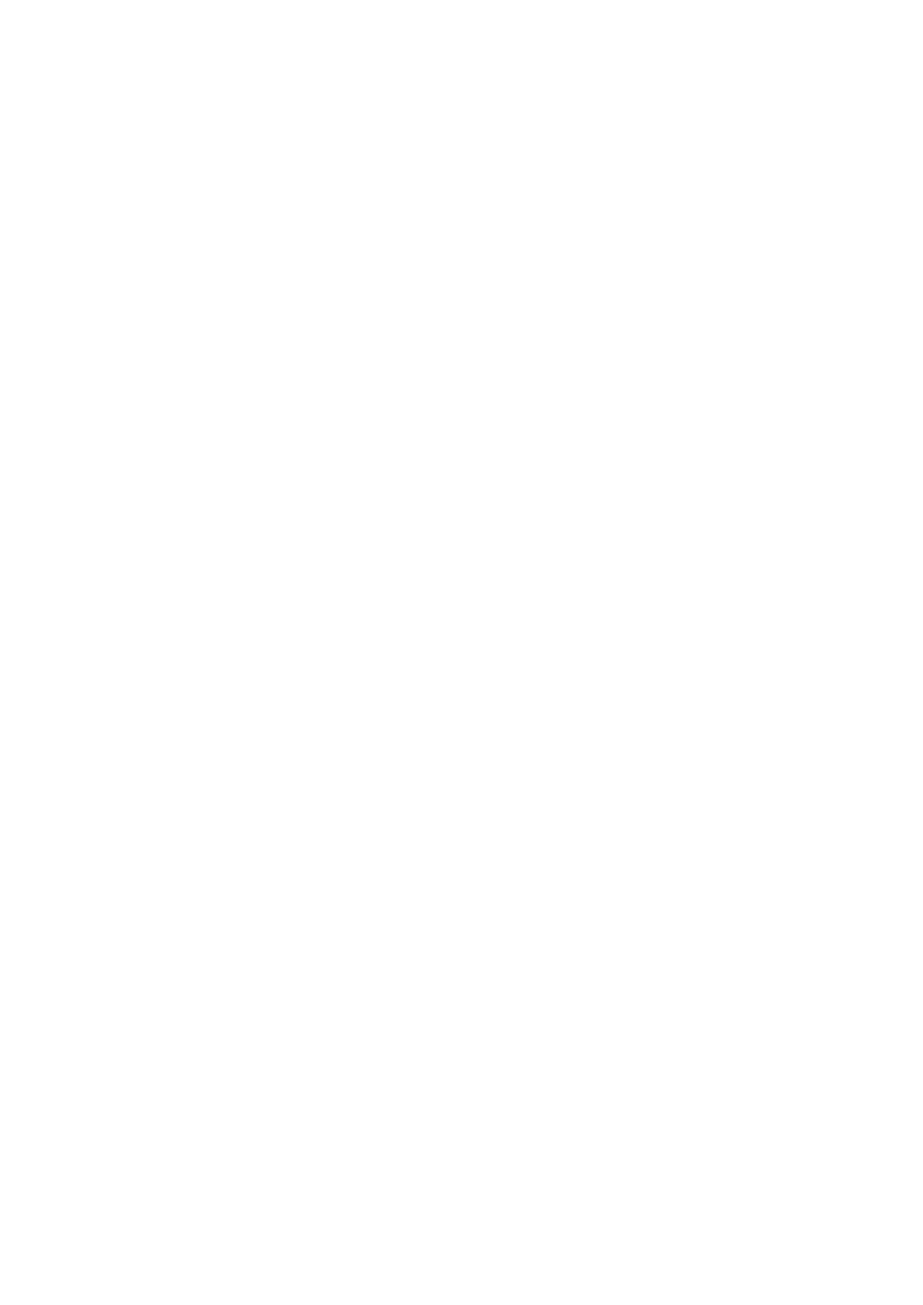




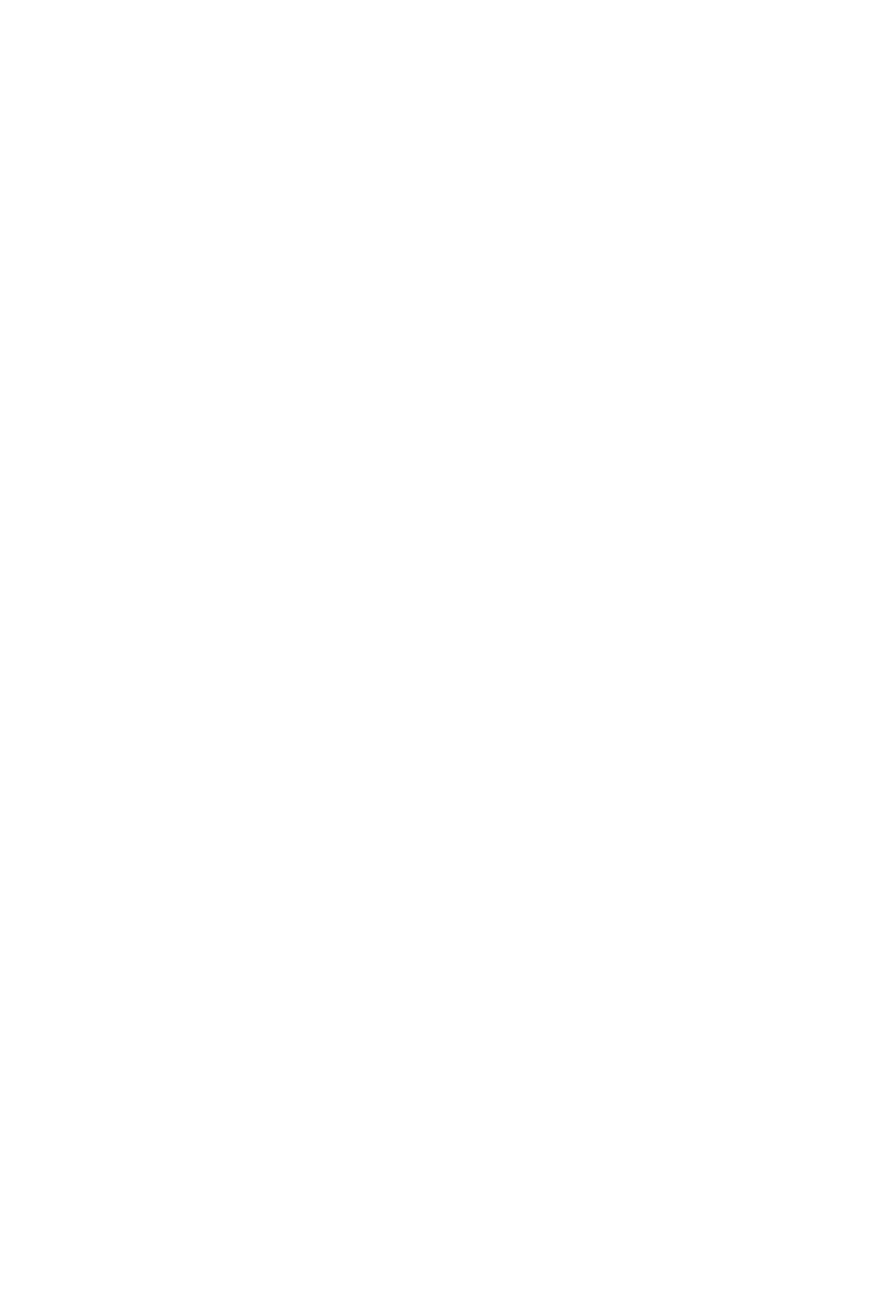




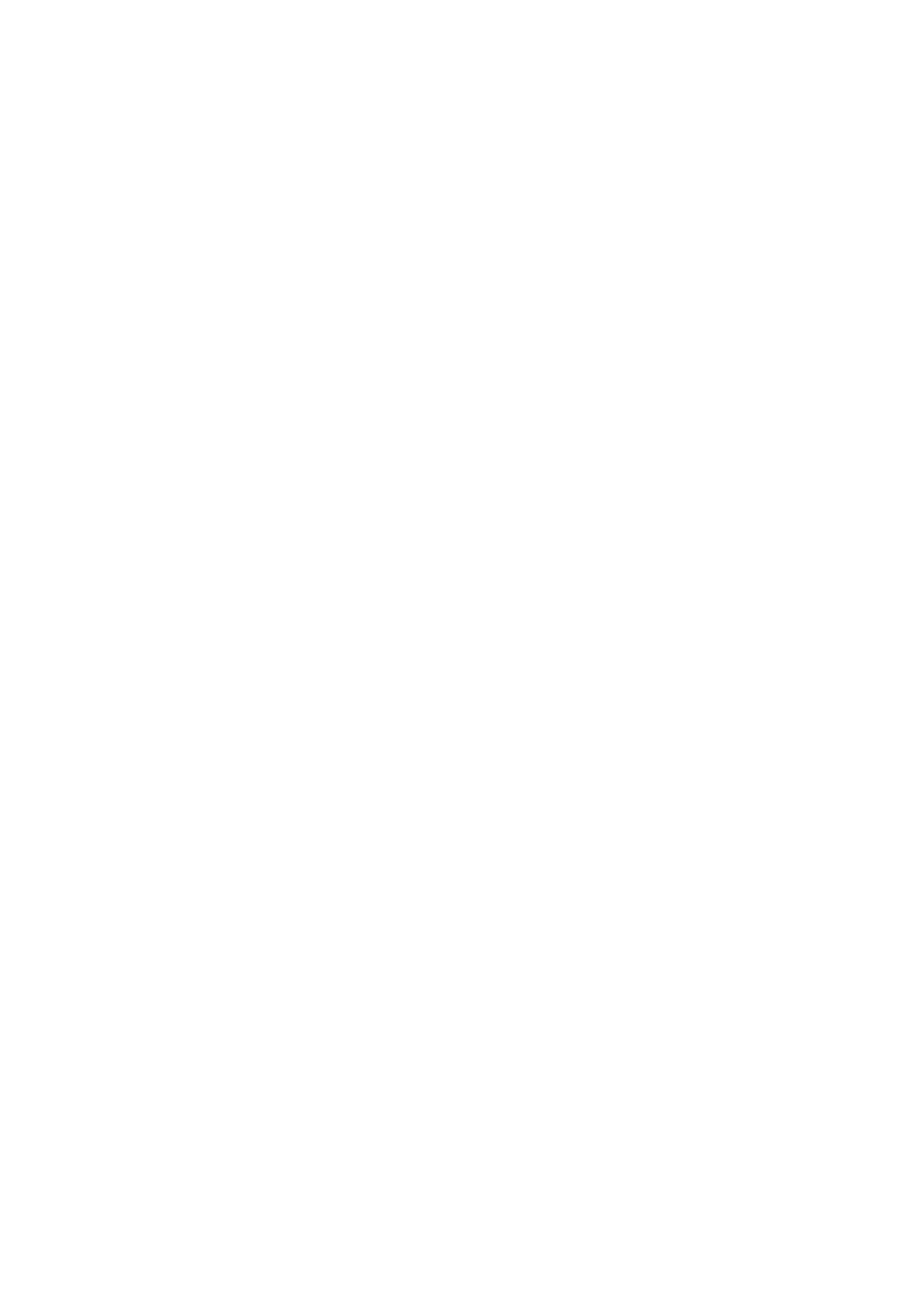




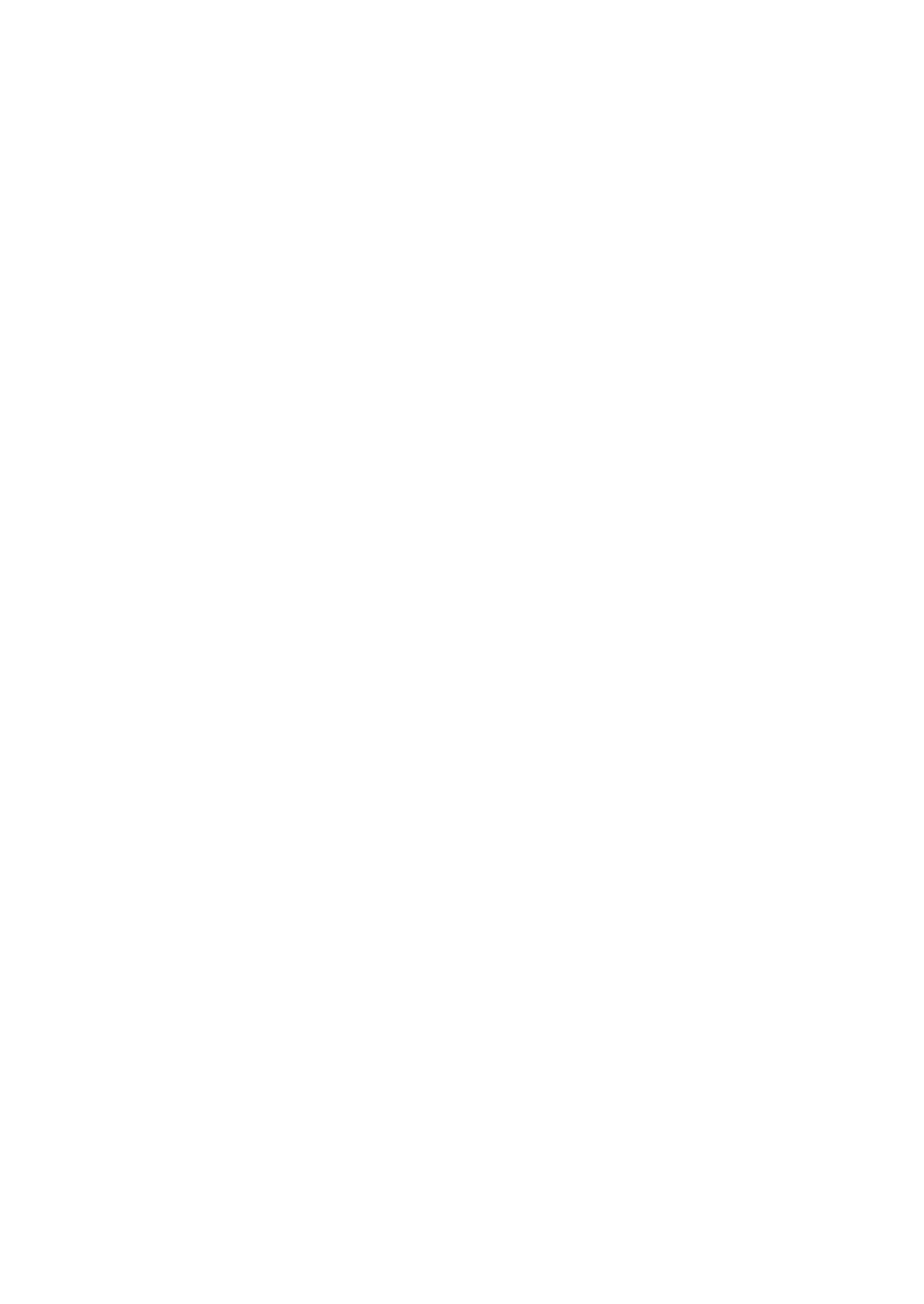




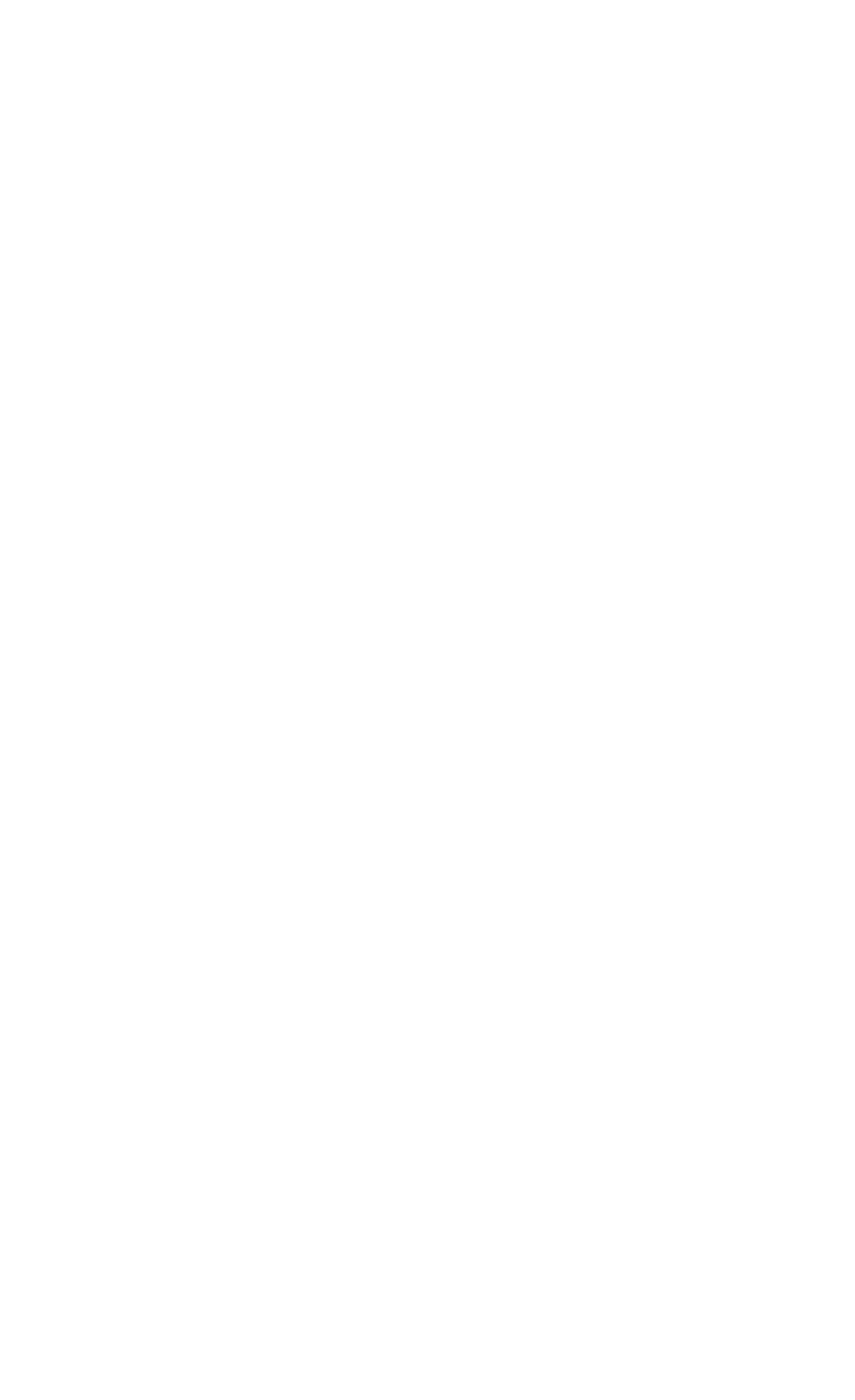


TRADEWATER RIVER BASIN--Continued

3-3830. TRADEWATER RIVER AT OLNEY, KY.--Continued Suspended sediment, water year October 1966 to September 1967

\begin{tabular}{|c|c|c|c|c|c|c|c|c|c|}
\hline \multirow[b]{3}{*}{ Day } & \multicolumn{3}{|c|}{ OCTOBER } & \multicolumn{3}{|c|}{ NOVEMBER } & \multicolumn{3}{|c|}{ DECEMBER } \\
\hline & \multirow[b]{2}{*}{$\begin{array}{c}\text { Mean } \\
\text { dis- } \\
\text { charge } \\
\text { (cfs) }\end{array}$} & \multicolumn{2}{|c|}{ Suspended sediment } & \multirow[b]{2}{*}{$\begin{array}{c}\text { Mean } \\
\text { dis- } \\
\text { charge } \\
\text { (cfs) }\end{array}$} & \multicolumn{2}{|c|}{ Suspended sediment } & \multirow[b]{2}{*}{$\begin{array}{c}\text { Mean } \\
\text { dis- } \\
\text { charge } \\
\text { (cfs) }\end{array}$} & \multicolumn{2}{|c|}{ Suspended sediment } \\
\hline & & $\begin{array}{c}\text { Mean } \\
\text { concen- } \\
\text { tration } \\
(\mathrm{ppm})\end{array}$ & $\begin{array}{l}\text { Tons } \\
\text { per } \\
\text { day }\end{array}$ & & $\begin{array}{c}\text { Mean } \\
\text { concen- } \\
\text { tration } \\
\text { (ppm) }\end{array}$ & $\begin{array}{l}\text { Tons } \\
\text { per } \\
\text { day }\end{array}$ & & $\begin{array}{c}\text { Mean } \\
\text { concen- } \\
\text { tration } \\
(\mathrm{ppm})\end{array}$ & $\begin{array}{l}\text { Tons } \\
\text { per } \\
\text { day }\end{array}$ \\
\hline $\begin{array}{l}1 \ldots \\
2 \ldots \\
3 \ldots \\
4 \ldots \\
5 \ldots\end{array}$ & $\begin{array}{r}0.60 \\
.50 \\
.50 \\
.90 \\
.90\end{array}$ & $\begin{array}{l}5 \\
5 \\
5 \\
4 \\
4\end{array}$ & $\begin{array}{l}T \\
T \\
T \\
T \\
T \\
T\end{array}$ & $\begin{array}{l}1.1 \\
1.1 \\
1.3 \\
1.1 \\
1.1\end{array}$ & $\begin{array}{l}1 \\
1 \\
1 \\
2 \\
2\end{array}$ & $\begin{array}{l}\text { T } \\
\text { T. } \\
\text { T } \\
\text { I } \\
\text { T }\end{array}$ & $\begin{array}{l}17 \\
15 \\
14 \\
14 \\
14\end{array}$ & $\begin{array}{l}2 \\
2 \\
2 \\
2 \\
2\end{array}$ & $\begin{array}{r}0.1 \\
: 1 \\
: 1 \\
: 1 \\
.1\end{array}$ \\
\hline $\begin{array}{r}6 \ldots \\
7 \ldots \\
8 \ldots \\
10 \ldots\end{array}$ & $\begin{array}{l}.70 \\
.70 \\
2.1 \\
2.2 \\
2.9\end{array}$ & $\begin{array}{l}4 \\
3 \\
3 \\
3 \\
3\end{array}$ & $\begin{array}{l}T \\
T \\
T \\
T \\
T \\
T\end{array}$ & $\begin{array}{l}.90 \\
1.1 \\
1.1 \\
1.3 \\
5.9\end{array}$ & $\begin{array}{l}2 \\
2 \\
2 \\
2 \\
3\end{array}$ & $\begin{array}{l}T \\
T \\
T \\
T \\
T\end{array}$ & $\begin{array}{r}21 \\
138 \\
261 \\
293 \\
675\end{array}$ & $\begin{array}{r}2 \\
2 \\
5 \\
12 \\
30\end{array}$ & $\begin{array}{r}.1 \\
.7 \\
3.5 \\
9.5 \\
60\end{array}$ \\
\hline $\begin{array}{l}11 \ldots \\
12 \ldots \\
13 \ldots \\
14 \ldots \\
15 \ldots\end{array}$ & $\begin{array}{l}1.7 \\
.90 \\
.70 \\
.70 \\
1.8\end{array}$ & $\begin{array}{l}3 \\
4 \\
4 \\
4 \\
4\end{array}$ & $\begin{array}{l}T \\
T \\
T \\
T \\
T\end{array}$ & $\begin{array}{l}6.8 \\
86 \\
95 \\
44 \\
23\end{array}$ & $\begin{array}{l}3 \\
3 \\
3 \\
3 \\
3\end{array}$ & $\begin{array}{r}0.1 \\
.7 \\
.8 \\
.4 \\
.2\end{array}$ & $\begin{array}{l}856 \\
892 \\
893 \\
611 \\
378\end{array}$ & $\begin{array}{r}72 \\
42 \\
21 \\
12 \\
9\end{array}$ & $\begin{array}{c}166 \\
101 \\
51 \\
20 \\
9.2\end{array}$ \\
\hline $\begin{array}{l}16 \ldots \\
17 \ldots \\
18 \ldots \\
19 \ldots \\
20 \ldots\end{array}$ & $\begin{array}{l}4.7 \\
1.8 \\
1.0 \\
.70 \\
1.7\end{array}$ & $\begin{array}{l}5 \\
5 \\
5 \\
5 \\
4\end{array}$ & $\begin{array}{l}0.1 \\
T \\
T \\
T \\
T\end{array}$ & $\begin{array}{l}16 \\
8.7 \\
3.9 \\
4.3 \\
5.4\end{array}$ & $\begin{array}{l}3 \\
3 \\
4 \\
4 \\
4\end{array}$ & $\begin{array}{l}.1 \\
T^{\circ} \\
.1\end{array}$ & $\begin{array}{r}201 \\
125 \\
97 \\
81 \\
71\end{array}$ & $\begin{array}{l}4 \\
2 \\
3 \\
3 \\
2\end{array}$ & $\begin{array}{r}2.2 \\
.7 \\
.8 \\
.7 \\
.4\end{array}$ \\
\hline $\begin{array}{l}21 \ldots \\
22 \ldots \\
23 \ldots \\
24 \ldots \\
25 \ldots\end{array}$ & $\begin{array}{l}3.8 \\
3.0 \\
2.7 \\
2.2 \\
2.0\end{array}$ & $\begin{array}{l}3 \\
2 \\
2 \\
2 \\
2\end{array}$ & $\begin{array}{l}T \\
T \\
\vdots \\
\vdots \\
1\end{array}$ & $\begin{array}{l}5.5 \\
6.5 \\
5.6 \\
4.8 \\
7.2\end{array}$ & $\begin{array}{l}4 \\
4 \\
4 \\
3 \\
3\end{array}$ & $\begin{array}{r}.1 \\
.1 \\
.1 \\
.1\end{array}$ & $\begin{array}{l}62 \\
54 \\
48 \\
43 \\
40\end{array}$ & $\begin{array}{l}2 \\
2 \\
2 \\
2 \\
2\end{array}$ & $\begin{array}{l}\cdot 3 \\
: 3 \\
: 3 \\
: 2 \\
: 2\end{array}$ \\
\hline $\begin{array}{l}26 \ldots \\
27 \ldots \\
28 \ldots \\
29 \ldots \\
30 \ldots \\
31 \ldots\end{array}$ & $\begin{array}{r}1.8 \\
1.8 \\
1.4 \\
1.1 \\
1.2 \\
.90 \\
\end{array}$ & $\begin{array}{l}2 \\
1 \\
1 \\
1 \\
1 \\
1 \\
\end{array}$ & $\begin{array}{l}T \\
T \\
T \\
T \\
T \\
T\end{array}$ & $\begin{array}{l}13 \\
13 \\
24 \\
24 \\
20\end{array}$ & $\begin{array}{r}2 \\
2 \\
2 \\
2 \\
2 \\
-- \\
\end{array}$ & $\begin{array}{l}.1 \\
.1 \\
.1 \\
: 1 \\
: 1 \\
-:-\end{array}$ & $\begin{array}{r}37 \\
34 \\
349 \\
892 \\
918 \\
947 \\
\end{array}$ & $\begin{array}{r}2 \\
2 \\
30 \\
104 \\
130 \\
38\end{array}$ & $\begin{array}{r}.2 \\
43^{.2} \\
250 \\
322 \\
97\end{array}$ \\
\hline \multirow[t]{2}{*}{ Total } & 49.60 & - & 0.4 & 432.70 & -- & 3.6 & 9091 & -- & 1140.0 \\
\hline & \multicolumn{3}{|c|}{ JANUARY } & \multicolumn{3}{|c|}{ FEBRUARY } & \multicolumn{3}{|c|}{ MARCH } \\
\hline $\begin{array}{l}1 \ldots \\
2 \ldots \\
3 \ldots \\
4 \ldots \\
5 \ldots\end{array}$ & $\begin{array}{l}779 \\
485 \\
305 \\
177 \\
128\end{array}$ & $\begin{array}{r}21 \\
15 \\
9 \\
8 \\
8\end{array}$ & $\begin{array}{l}44 \\
20 \\
7.4 \\
3.8 \\
2.8\end{array}$ & $\begin{array}{l}411 \\
377 \\
643 \\
652 \\
494\end{array}$ & $\begin{array}{l}7 \\
17 \\
65 \\
40 \\
20\end{array}$ & $\begin{array}{r}7.8 \\
18 \\
113 \\
70 \\
27\end{array}$ & $\begin{array}{l}890 \\
882 \\
678 \\
486 \\
373\end{array}$ & $\begin{array}{r}66 \\
35 \\
20 \\
12 \\
6\end{array}$ & $\begin{array}{c}159 \\
83 \\
37 \\
16 \\
6.0\end{array}$ \\
\hline $\begin{array}{r}6 \ldots \\
7 \ldots \\
8 \ldots \\
9 \ldots \\
10\end{array}$ & $\begin{array}{r}105 \\
97 \\
97 \\
99 \\
100\end{array}$ & $\begin{array}{l}7 \\
7 \\
7 \\
7 \\
6\end{array}$ & $\begin{array}{l}2.0 \\
1.8 \\
1.8 \\
1.9 \\
1.6\end{array}$ & $\begin{array}{l}375 \\
262 \\
187 \\
143 \\
123\end{array}$ & $\begin{array}{r}11 \\
5 \\
2 \\
4 \\
4\end{array}$ & $\begin{array}{l}11 \\
3.5 \\
1.0 \\
1.5 \\
1.3\end{array}$ & $\begin{array}{r}888 \\
1520 \\
1760 \\
2510 \\
3050\end{array}$ & $\begin{array}{r}120 \\
140 \\
93 \\
84 \\
41\end{array}$ & $\begin{array}{l}310 \\
575 \\
442 \\
569 \\
338\end{array}$ \\
\hline $\begin{array}{l}11 \ldots \\
12 \ldots \\
13 \ldots \\
14 \ldots \\
15 \ldots\end{array}$ & $\begin{array}{l}87 \\
74 \\
67 \\
66 \\
65\end{array}$ & $\begin{array}{l}6 \\
5 \\
4 \\
3 \\
3\end{array}$ & $\begin{array}{r}1.4 \\
1.0 \\
.7 \\
.5 \\
.5\end{array}$ & $\begin{array}{r}114 \\
103 \\
91 \\
81 \\
74\end{array}$ & $\begin{array}{l}4 \\
4 \\
3 \\
3 \\
3\end{array}$ & $\begin{array}{r}1.2 \\
1.1 \\
.7 \\
.7 \\
.6\end{array}$ & $\begin{array}{r}2790 \\
2310 \\
1920 \\
1400 \\
961\end{array}$ & $\begin{array}{r}18 \\
12 \\
11 \\
13 \\
8\end{array}$ & $\begin{array}{r}136 \\
75 \\
57 \\
49 \\
21\end{array}$ \\
\hline $\begin{array}{l}16 \ldots \\
17 \ldots \\
18 \ldots \\
19 \ldots \\
20 \ldots\end{array}$ & $\begin{array}{l}61 \\
59 \\
52 \\
45 \\
39\end{array}$ & $\begin{array}{l}3 \\
3 \\
3 \\
3 \\
2\end{array}$ & $\begin{array}{l}.5 \\
.5 \\
.4 \\
.4 \\
.2\end{array}$ & $\begin{array}{l}69 \\
66 \\
67 \\
68 \\
88\end{array}$ & $\begin{array}{l}3 \\
2 \\
2 \\
2 \\
2\end{array}$ & $\begin{array}{l}.6 \\
.4 \\
.4 \\
.4 \\
.5\end{array}$ & $\begin{array}{l}605 \\
398 \\
252 \\
183 \\
160\end{array}$ & $\begin{array}{l}2 \\
2 \\
4 \\
3 \\
2\end{array}$ & $\begin{array}{r}3.3 \\
2.1 \\
2.7 \\
1.5 \\
.9\end{array}$ \\
\hline $\begin{array}{l}21 \ldots \\
22 \ldots \\
23 \ldots \\
24 \ldots \\
25 \ldots\end{array}$ & $\begin{array}{l}39 \\
40 \\
44 \\
49 \\
51\end{array}$ & $\begin{array}{l}2 \\
2 \\
2 \\
2 \\
2\end{array}$ & $\begin{array}{l}.2 \\
.2 \\
.2 \\
.3 \\
.3\end{array}$ & $\begin{array}{l}237 \\
444 \\
381 \\
291 \\
215\end{array}$ & $\begin{array}{l}19 \\
40 \\
28 \\
21 \\
14\end{array}$ & $\begin{array}{l}15 \\
48 \\
29 \\
16 \\
8.1\end{array}$ & $\begin{array}{l}176 \\
217 \\
242 \\
211 \\
176\end{array}$ & $\begin{array}{r}5 \\
12 \\
11 \\
9 \\
5\end{array}$ & $\begin{array}{l}2.4 \\
7.0 \\
7.2 \\
5.1 \\
2.4\end{array}$ \\
\hline $\begin{array}{l}26 \ldots \\
27 \ldots \\
28 \ldots \\
29 \ldots \\
30 \ldots \\
31 \ldots\end{array}$ & $\begin{array}{r}167 \\
800 \\
1000 \\
985 \\
930 \\
623\end{array}$ & $\begin{array}{r}8 \\
97 \\
78 \\
68 \\
28 \\
17 \\
\end{array}$ & $\begin{array}{l}4.1 \\
231 \\
211 \\
181 \\
70 \\
29 \\
\end{array}$ & $\begin{array}{r}151 \\
192 \\
734 \\
-- \\
=- \\
--\end{array}$ & $\begin{array}{r}7 \\
27 \\
124 \\
-- \\
-- \\
--\end{array}$ & $\begin{array}{r}2.9 \\
18 \\
246 \\
-- \\
=-\end{array}$ & $\begin{array}{l}151 \\
133 \\
120 \\
111 \\
102 \\
92\end{array}$ & $\begin{array}{l}5 \\
2 \\
2 \\
2 \\
2 \\
1 \\
\end{array}$ & $\begin{array}{r}2.0 \\
.7 \\
.6 \\
.6 \\
.6 \\
.2 \\
\end{array}$ \\
\hline Total & 7715 & -- & 820.5 & 7133 & - & 643.7 & 25747 & -- & 2912.3 \\
\hline
\end{tabular}

$\mathrm{T}$ Less than 0.05 ton. 
TRADEWATER RIVER BASIN--Continued

3-3830. TRADEWATER RIVER AT OLNEY, KY.--COntinued

Suspended sediment, water year October 1966 to September 1967--Continued

\begin{tabular}{|c|c|c|c|c|c|c|c|c|c|}
\hline \multirow[b]{3}{*}{ Day } & \multicolumn{3}{|c|}{ APR IL } & \multicolumn{3}{|c|}{ MAY } & \multicolumn{3}{|c|}{ JUNE } \\
\hline & \multirow[b]{2}{*}{$\begin{array}{c}\text { Mean } \\
\text { dis- } \\
\text { charge } \\
\text { (cfB) }\end{array}$} & \multicolumn{2}{|c|}{ Suspended sediment } & \multirow[b]{2}{*}{$\begin{array}{c}\text { Mean } \\
\text { dis- } \\
\text { charge } \\
(\text { cfs) }\end{array}$} & \multicolumn{2}{|c|}{ Suspended sediment } & \multirow[b]{2}{*}{$\begin{array}{c}\text { Mean } \\
\text { dis- } \\
\text { charge } \\
\text { (cfs) }\end{array}$} & \multicolumn{2}{|c|}{ Suspended sedimert } \\
\hline & & $\begin{array}{c}\text { Mean } \\
\text { concen- } \\
\text { tration } \\
(\mathrm{ppm})\end{array}$ & $\begin{array}{l}\text { Tons } \\
\text { per } \\
\text { day }\end{array}$ & & $\begin{array}{c}\text { Mean } \\
\text { concen- } \\
\text { tration } \\
(\mathbf{p p m})\end{array}$ & $\begin{array}{c}\text { Tons } \\
\text { per } \\
\text { day }\end{array}$ & & $\begin{array}{c}\text { Mean } \\
\text { concen- } \\
\text { tration } \\
(\text { ppm })\end{array}$ & $\begin{array}{l}\text { Tons } \\
\text { per } \\
\text { day }\end{array}$ \\
\hline $\begin{array}{l}1 \ldots \\
2 \ldots \\
3 \ldots \\
4 \ldots \\
5 \ldots\end{array}$ & $\begin{array}{l}82 \\
74 \\
67 \\
59 \\
55\end{array}$ & $\begin{array}{l}1 \\
1 \\
1 \\
1 \\
1\end{array}$ & $\begin{array}{l}0.2 \\
.2 \\
.2 \\
.2 \\
.1\end{array}$ & $\begin{array}{r}200 \\
904 \\
1030 \\
968 \\
684\end{array}$ & $\begin{array}{r}61 \\
170 \\
55 \\
32 \\
16\end{array}$ & $\begin{array}{r}50 \\
410 \\
153 \\
84 \\
30\end{array}$ & $\begin{array}{l}38 \\
54 \\
51 \\
45 \\
40\end{array}$ & $\begin{array}{l}7 \\
6 \\
6 \\
5 \\
5\end{array}$ & $\begin{array}{l}0.7 \\
.8 \\
.8 \\
.6 \\
.5\end{array}$ \\
\hline $\begin{array}{r}6 \ldots \\
7 \ldots \\
8 \ldots \\
9 \ldots\end{array}$ & $\begin{array}{l}52 \\
48 \\
43 \\
39 \\
41\end{array}$ & $\begin{array}{l}1 \\
2 \\
2 \\
2 \\
2\end{array}$ & $\begin{array}{l}.1 \\
.3 \\
.2 \\
.2 \\
.2\end{array}$ & $\begin{array}{l}441 \\
314 \\
325 \\
341 \\
241\end{array}$ & $\begin{array}{r}6 \\
2 \\
12 \\
13 \\
2\end{array}$ & $\begin{array}{l}7.1 \\
1.7 \\
11 \\
12 \\
1.3\end{array}$ & $\begin{array}{l}36 \\
31 \\
27 \\
23 \\
19\end{array}$ & $\begin{array}{l}5 \\
5 \\
5 \\
5 \\
5\end{array}$ & $\begin{array}{l}.5 \\
: 4 \\
: 4 \\
: 3 \\
: 3\end{array}$ \\
\hline $\begin{array}{l}11 \ldots \\
12 \ldots \\
13 \ldots \\
14 \ldots \\
15 \ldots\end{array}$ & $\begin{array}{l}50 \\
57 \\
52 \\
49 \\
47\end{array}$ & $\begin{array}{l}2 \\
2 \\
2 \\
2 \\
2\end{array}$ & $\begin{array}{l}.3 \\
.3 \\
.3 \\
.3 \\
.3\end{array}$ & $\begin{array}{r}162 \\
126 \\
116 \\
761 \\
1970\end{array}$ & $\begin{array}{r}2 \\
2 \\
2 \\
74 \\
120\end{array}$ & $\begin{array}{r}: 9 \\
196^{.6} \\
638\end{array}$ & $\begin{array}{l}15 \\
12 \\
10 \\
8.2 \\
6.4\end{array}$ & $\begin{array}{l}5 \\
5 \\
5 \\
6 \\
7\end{array}$ & $\begin{array}{l}: 2 \\
: 2 \\
: 1 \\
: 1 \\
.1\end{array}$ \\
\hline $\begin{array}{l}16 \ldots \\
17 \ldots \\
18 \ldots \\
19 \ldots \\
20 \ldots\end{array}$ & $\begin{array}{l}44 \\
40 \\
34 \\
30 \\
26\end{array}$ & $\begin{array}{l}2 \\
2 \\
2 \\
3 \\
3\end{array}$ & $\begin{array}{l}.2 \\
.2 \\
.2 \\
.2 \\
.2\end{array}$ & $\begin{array}{l}2350 \\
2830 \\
2890 \\
2440 \\
1820\end{array}$ & $\begin{array}{l}54 \\
44 \\
32 \\
21 \\
14\end{array}$ & $\begin{array}{r}343 \\
336 \\
250 \\
138 \\
69\end{array}$ & $\begin{array}{l}4.7 \\
3.2 \\
3.8 \\
2.9 \\
1.7\end{array}$ & $\begin{array}{l}7 \\
5 \\
4 \\
4 \\
4\end{array}$ & 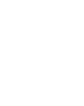 \\
\hline $\begin{array}{l}21 \ldots \\
22 \ldots \\
23 \ldots \\
24 \ldots \\
25 \ldots\end{array}$ & $\begin{array}{l}25 \\
30 \\
39 \\
52 \\
73\end{array}$ & $\begin{array}{l}3 \\
4 \\
5 \\
5 \\
6\end{array}$ & $\begin{array}{r}.2 \\
.3 \\
.5 \\
.7 \\
1.2\end{array}$ & $\begin{array}{r}1200 \\
686 \\
392 \\
181 \\
102\end{array}$ & $\begin{array}{r}13 \\
9 \\
7 \\
7 \\
7\end{array}$ & $\begin{array}{l}42 \\
17 \\
7.4 \\
3.4 \\
1.9\end{array}$ & $\begin{array}{r}15 \\
207 \\
155 \\
115 \\
68\end{array}$ & $\begin{array}{r}14 \\
159 \\
130 \\
9 \\
4\end{array}$ & $\begin{array}{l}95^{.6} \\
54 \\
2.8 \\
.7\end{array}$ \\
\hline $\begin{array}{l}26 \ldots \\
27 \ldots \\
28 \ldots \\
29 \ldots \\
30 \ldots \\
31 \ldots\end{array}$ & $\begin{array}{l}113 \\
227 \\
345 \\
266 \\
171 \\
-- \\
\end{array}$ & $\begin{array}{r}8 \\
21 \\
22 \\
5 \\
4 \\
- \\
\end{array}$ & $\begin{array}{l}2.4 \\
13 \\
20 \\
3.6 \\
1.8 \\
--\end{array}$ & $\begin{array}{l}78 \\
61 \\
49 \\
40 \\
34 \\
31\end{array}$ & $\begin{array}{l}6 \\
5 \\
5 \\
6 \\
7 \\
7\end{array}$ & $\begin{array}{l}1.3 \\
.8 \\
.7 \\
.6 \\
.6 \\
.6\end{array}$ & $\begin{array}{r}42 \\
32 \\
36 \\
57 \\
251 \\
-\end{array}$ & $\begin{array}{r}3 \\
4 \\
10 \\
7 \\
13 \\
--\end{array}$ & $\begin{array}{r}: 3 \\
1 \cdot 3 \\
1.1 \\
12 \\
--\end{array}$ \\
\hline \multirow[t]{2}{*}{ Total } & 2330 & -- & 48.1 & 23767 & -- & 2808.6 & 1409.9 & - & 174.0 \\
\hline & \multicolumn{3}{|c|}{ JULY } & \multicolumn{3}{|c|}{ AUGUST } & \multicolumn{3}{|c|}{ SEPTEMBER } \\
\hline $\begin{array}{l}1 \ldots \\
2 \ldots \\
3 \ldots \\
4 \ldots \\
5 \ldots\end{array}$ & $\begin{array}{r}225 \\
105 \\
58 \\
36 \\
26\end{array}$ & $\begin{array}{l}9 \\
7 \\
8 \\
7 \\
6\end{array}$ & $\begin{array}{r}5.5 \\
2.0 \\
1.3 \\
.7 \\
.4\end{array}$ & $\begin{array}{r}78 \\
58 \\
78 \\
125 \\
82\end{array}$ & $\begin{array}{l}6 \\
5 \\
8 \\
7 \\
5\end{array}$ & $\begin{array}{r}1.3 \\
.8 \\
1.7 \\
2.4 \\
1.1\end{array}$ & $\begin{array}{l}8.8 \\
7.9 \\
7.2 \\
7.2 \\
6.3\end{array}$ & $\begin{array}{l}1 \\
1 \\
1 \\
1 \\
1\end{array}$ & $\begin{array}{l}T \\
T \\
T \\
T \\
T\end{array}$ \\
\hline $\begin{array}{r}6 \ldots \\
7 \ldots \\
9 \ldots \\
10 \ldots\end{array}$ & $\begin{array}{l}138 \\
525 \\
612 \\
340 \\
133\end{array}$ & $\begin{array}{r}18 \\
45 \\
25 \\
6 \\
4\end{array}$ & $\begin{array}{l}6.7 \\
64 \\
41 \\
5.5 \\
1.4\end{array}$ & $\begin{array}{r}57 \\
34 \\
24 \\
37 \\
157\end{array}$ & $\begin{array}{r}3 \\
2 \\
2 \\
4 \\
18\end{array}$ & $\begin{array}{r}.5 \\
.2 \\
.1 \\
.4 \\
8.8\end{array}$ & $\begin{array}{c}5.9 \\
4.9 \\
6.6 \\
10 \\
8.9\end{array}$ & $\begin{array}{l}1 \\
2 \\
2 \\
2 \\
2\end{array}$ & $\begin{array}{l}T \\
T \\
T \\
0.1 \\
T\end{array}$ \\
\hline $\begin{array}{l}11 \ldots \\
12 \ldots \\
13 \ldots \\
14 \ldots \\
15 \ldots\end{array}$ & $\begin{array}{l}144 \\
299 \\
370 \\
545 \\
370\end{array}$ & $\begin{array}{r}7 \\
13 \\
13 \\
27 \\
8\end{array}$ & $\begin{array}{l}2.7 \\
10 \\
13 \\
40 \\
8.0\end{array}$ & $\begin{array}{r}252 \\
132 \\
61 \\
35 \\
24\end{array}$ & $\begin{array}{r}12 \\
8 \\
5 \\
3 \\
2\end{array}$ & $\begin{array}{r}8.2 \\
2.9 \\
.8 \\
.3 \\
.1\end{array}$ & $\begin{array}{l}7 \cdot 2 \\
11 \\
17 \\
19 \\
15\end{array}$ & $\begin{array}{l}2 \\
2 \\
2 \\
2 \\
1\end{array}$ & $\begin{array}{l}r \\
: 1 \\
: 1 \\
r^{\prime}\end{array}$ \\
\hline $\begin{array}{l}16 \ldots \\
17 \ldots \\
18 \ldots \\
19 \ldots \\
20 \ldots\end{array}$ & $\begin{array}{r}136 \\
72 \\
49 \\
36 \\
29\end{array}$ & $\begin{array}{l}4 \\
4 \\
4 \\
4 \\
4\end{array}$ & $\begin{array}{r}1.5 \\
.8 \\
.5 \\
.4 \\
.3\end{array}$ & $\begin{array}{l}19 \\
16 \\
13 \\
11 \\
9.5\end{array}$ & $\begin{array}{l}2 \\
2 \\
2 \\
1 \\
1\end{array}$ & $\begin{array}{l}: 1 \\
: 1 \\
T_{T}^{-1}\end{array}$ & $\begin{array}{l}11 \\
7.2 \\
5.9 \\
5.8 \\
7.2\end{array}$ & $\begin{array}{l}1 \\
1 \\
1 \\
1 \\
1\end{array}$ & $\begin{array}{l}\mathrm{T} \\
\mathrm{T} \\
\mathrm{T} \\
\mathrm{T} \\
\mathrm{T}\end{array}$ \\
\hline $\begin{array}{l}21 \ldots \\
22 \ldots \\
23 \ldots \\
24 \ldots \\
25 \ldots\end{array}$ & $\begin{array}{l}29 \\
27 \\
23 \\
35 \\
31\end{array}$ & $\begin{array}{l}3 \\
3 \\
3 \\
3 \\
2\end{array}$ & $\begin{array}{l}.2 \\
.2 \\
.2 \\
.3 \\
.2\end{array}$ & $\begin{array}{l}8.4 \\
7.8 \\
8.1 \\
7.8 \\
7.0\end{array}$ & $\begin{array}{l}1 \\
1 \\
1 \\
1 \\
1\end{array}$ & $\begin{array}{l}T \\
T \\
T \\
T \\
T\end{array}$ & $\begin{array}{l}14 \\
25 \\
50 \\
28 \\
16\end{array}$ & $\begin{array}{r}1 \\
15 \\
39 \\
16 \\
2\end{array}$ & $\begin{array}{l}T \\
1.7 \\
5.3 \\
1.3 \\
.1\end{array}$ \\
\hline $\begin{array}{l}26 \ldots \\
27 \ldots \\
28 \ldots \\
29 \ldots \\
30 \ldots \\
31 \ldots\end{array}$ & $\begin{array}{r}25 \\
28 \\
90 \\
150 \\
151 \\
110\end{array}$ & $\begin{array}{r}1 \\
2 \\
20 \\
40 \\
19 \\
7\end{array}$ & $\begin{array}{r}.1 \\
.2 \\
5.4 \\
16 \\
7.7 \\
2.1\end{array}$ & $\begin{array}{l}6.4 \\
6.4 \\
6.0 \\
8.0 \\
5.4 \\
7.1\end{array}$ & $\begin{array}{l}1 \\
1 \\
1 \\
1 \\
1 \\
1\end{array}$ & $\begin{array}{l}T \\
T \\
T \\
T \\
T \\
T\end{array}$ & $\begin{array}{r}11 \\
6.5 \\
5.1 \\
3.0 \\
3.2 \\
-\end{array}$ & $\begin{array}{r}2 \\
2 \\
2 \\
2 \\
2 \\
- \\
\end{array}$ & $\begin{array}{l}.1 \\
T \\
T \\
T \\
T \\
--\end{array}$ \\
\hline Total & 4947 & -- & 238.3 & 1378.9 & -- & 30.2 & 341.8 & -- & 9.5 \\
\hline $\begin{array}{l}\text { Total } \\
\text { Total }\end{array}$ & $\begin{array}{l}\text { discharg } \\
\text { load for }\end{array}$ & $\begin{array}{l}\text { for year } \\
\text { ear (ton }\end{array}$ & $\begin{array}{l}\text { s-days }) \\
\ldots \ldots \ldots\end{array}$ & $\ldots \ldots$ & $\ldots \ldots$ & $\ldots \ldots$ & $\ldots \ldots \ldots$ & $\cdots \cdots \cdots$ & $\begin{array}{r}84342.9 \\
88.29 .2\end{array}$ \\
\hline
\end{tabular}




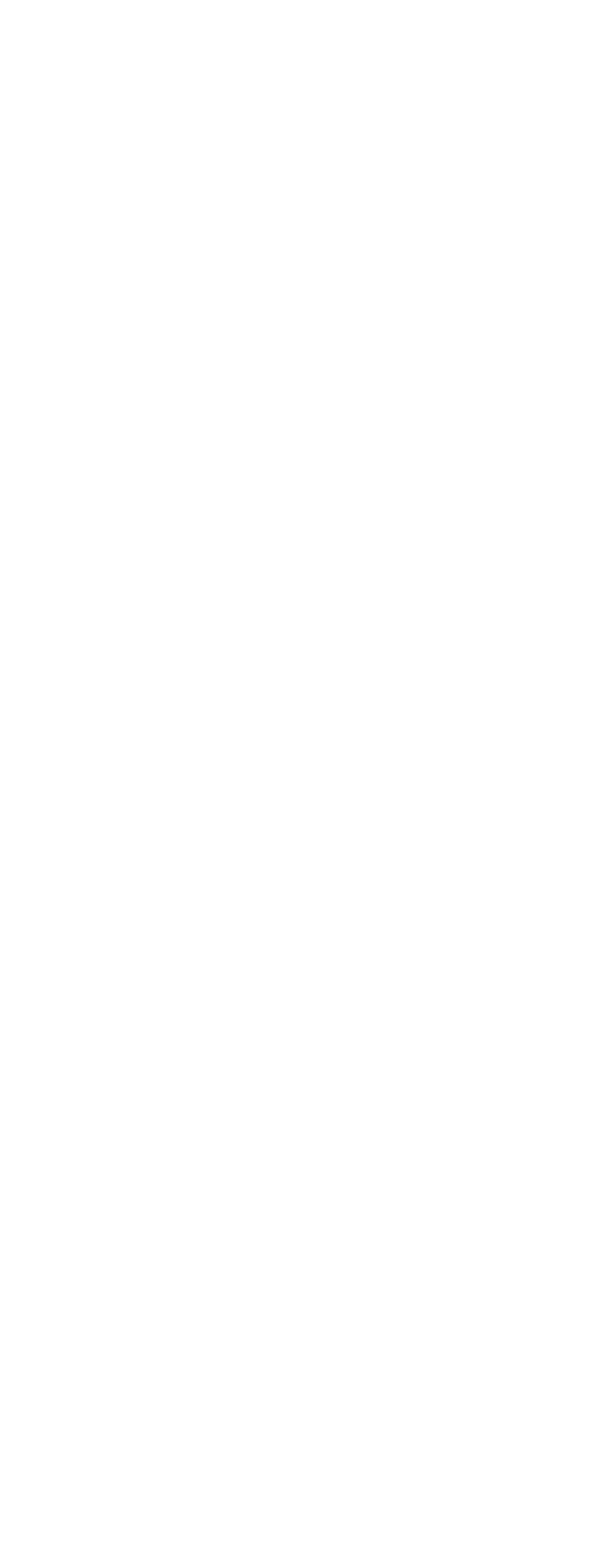




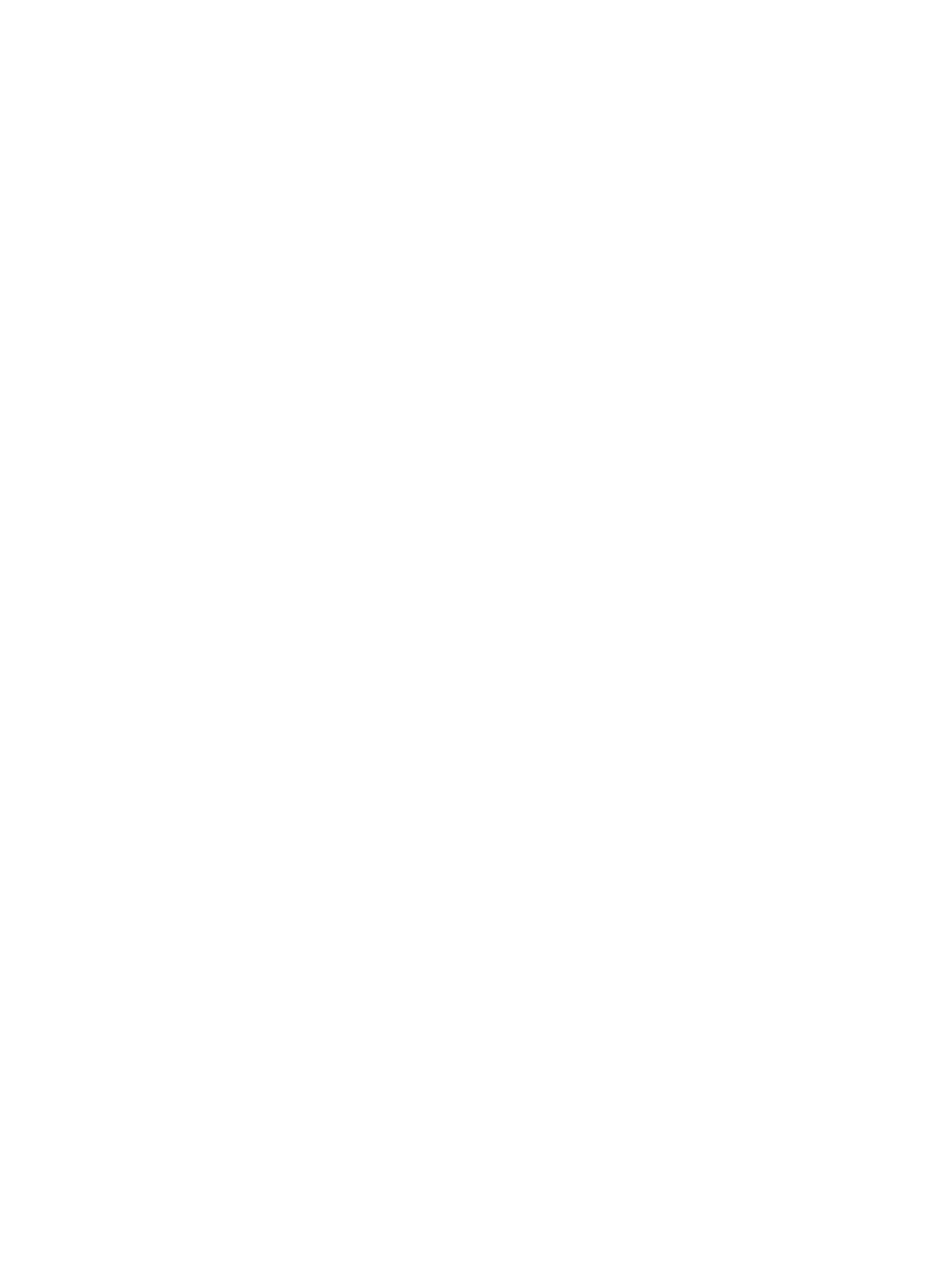




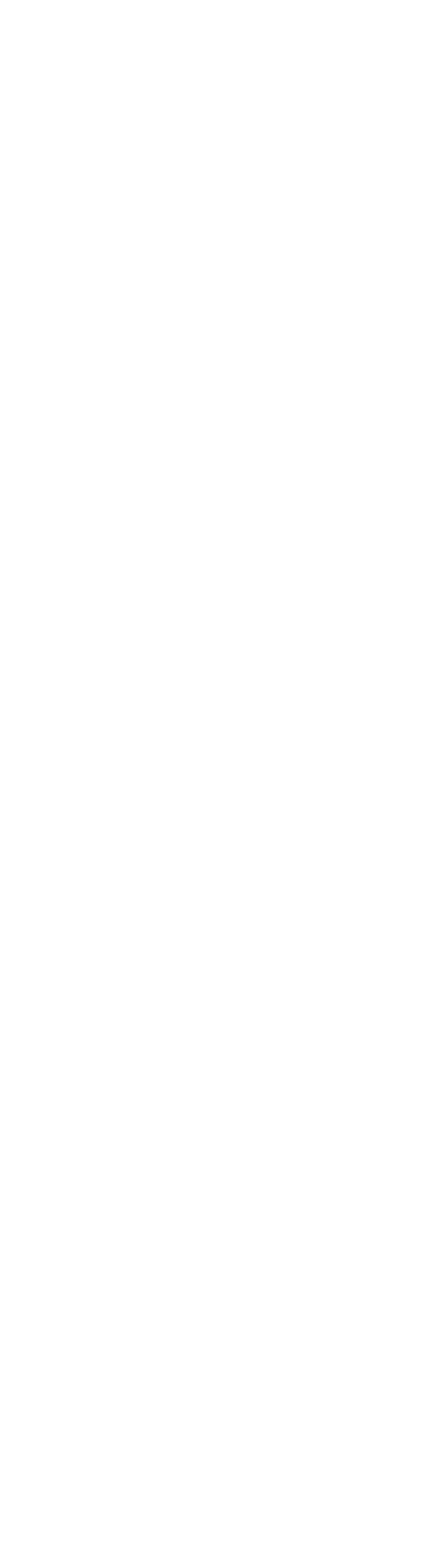




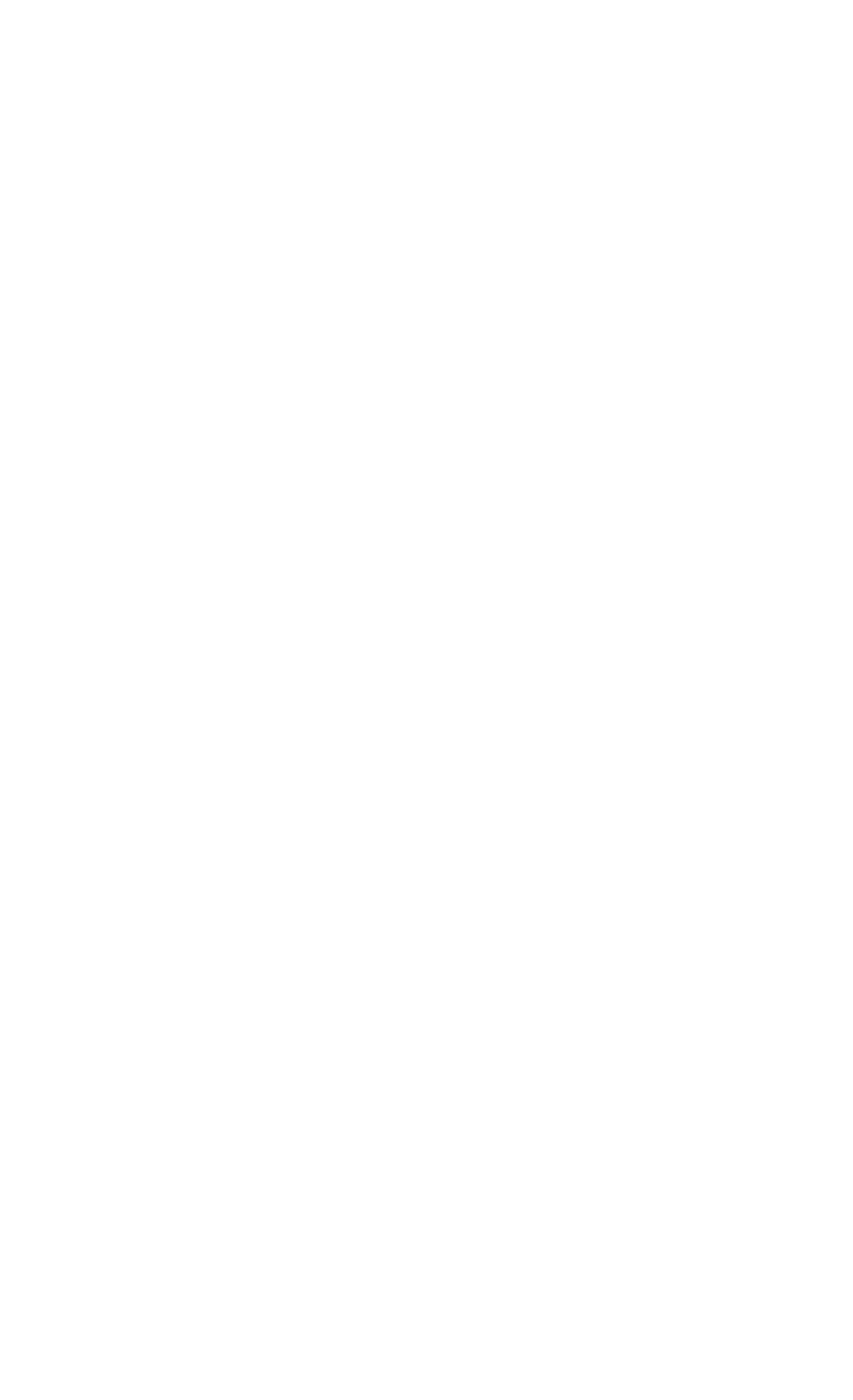




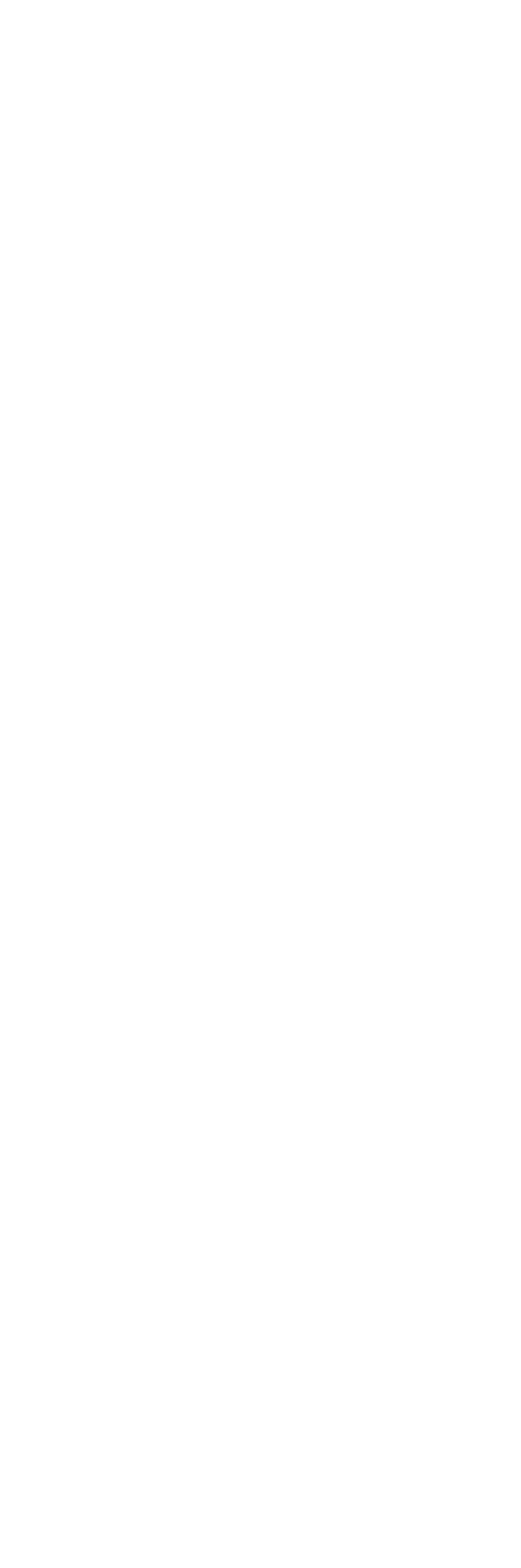




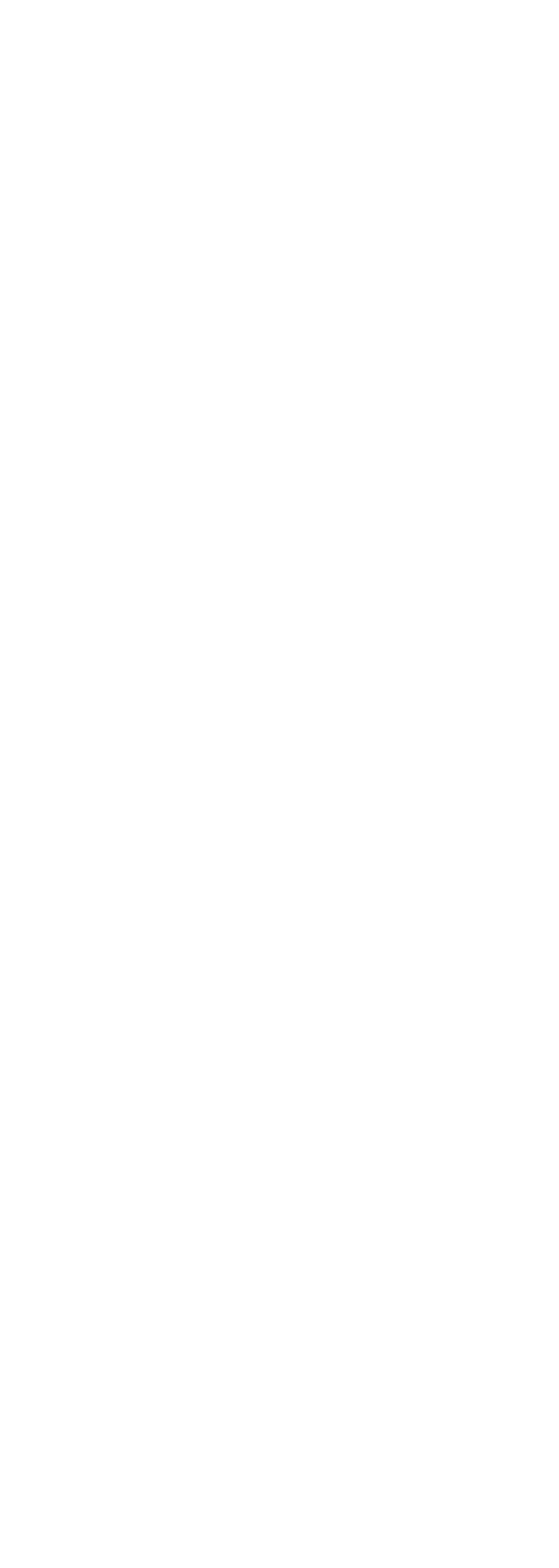




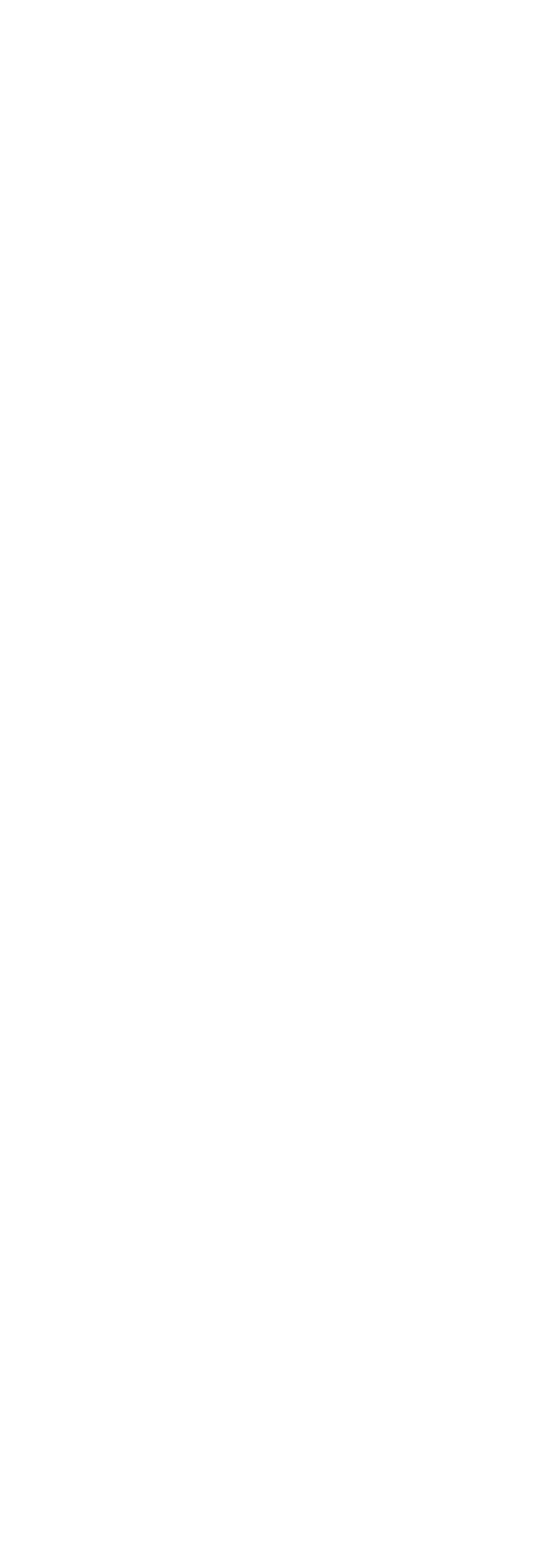




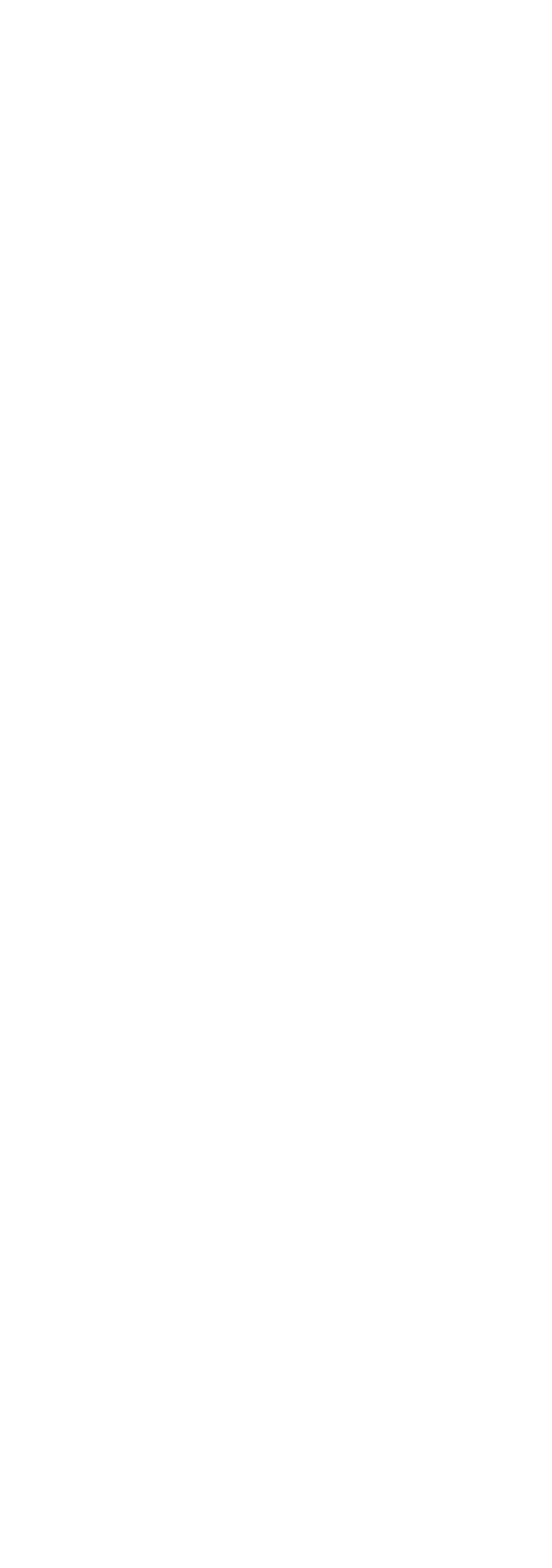




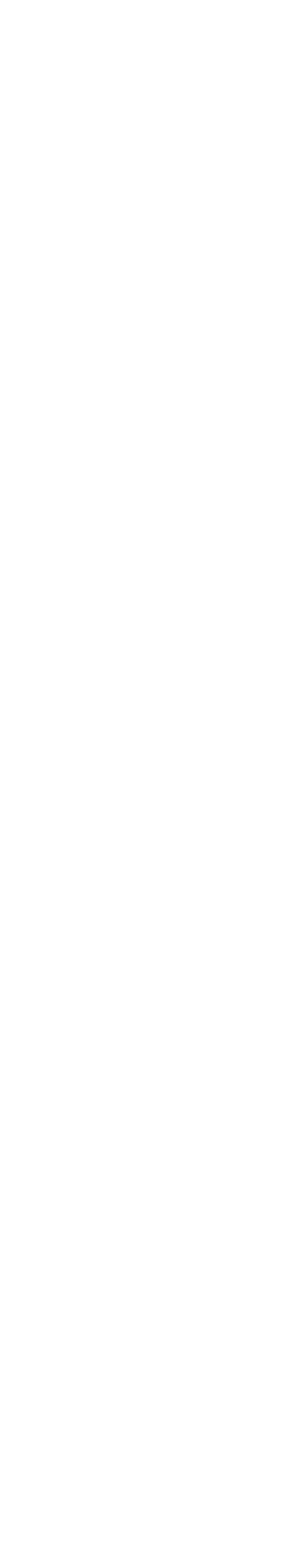

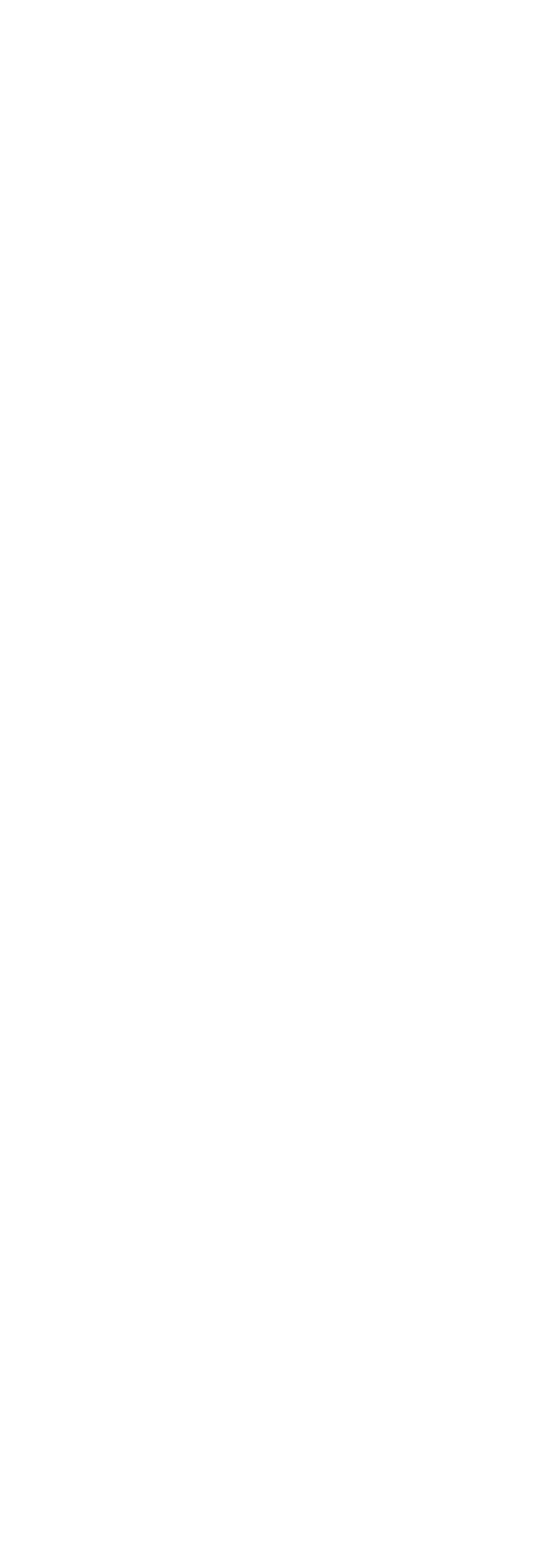




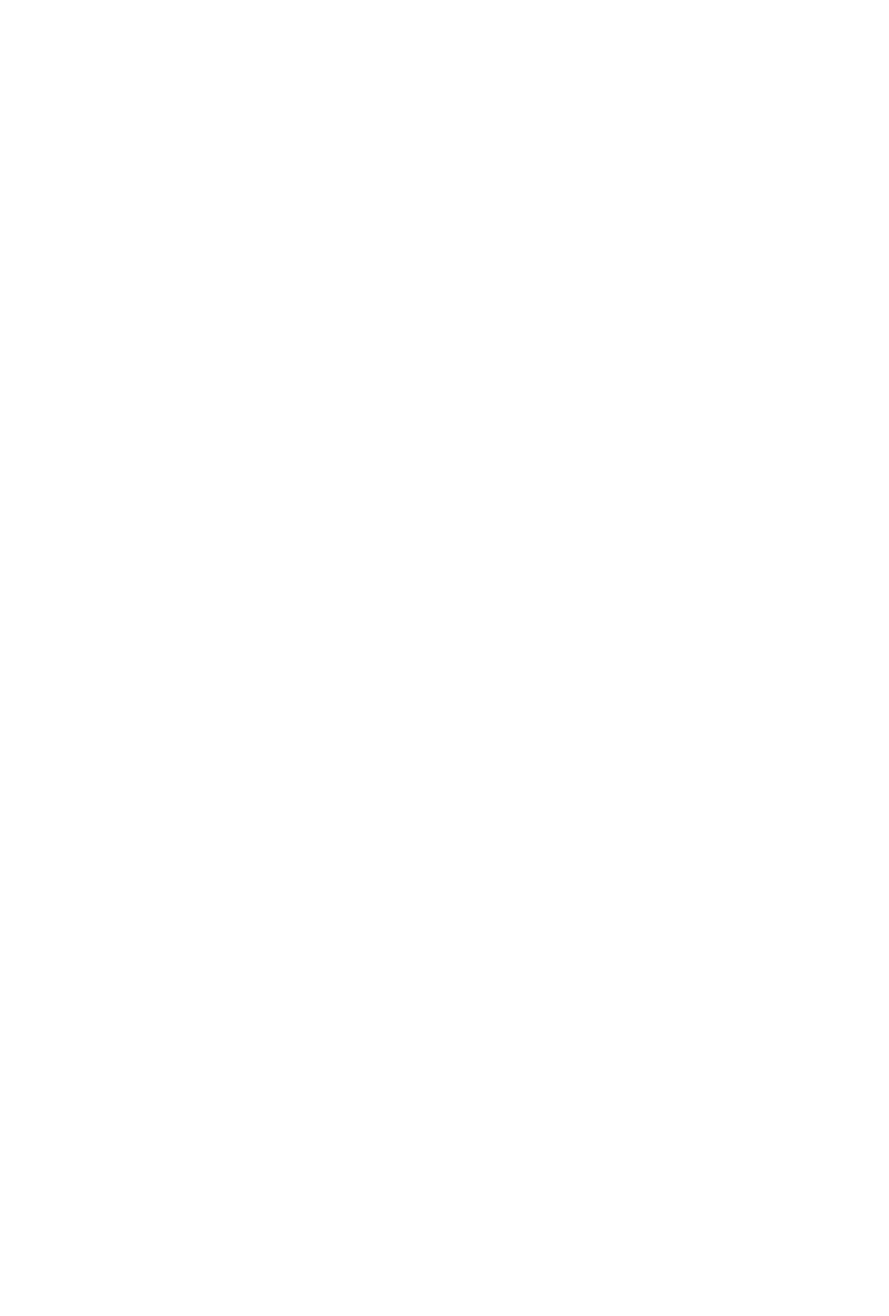




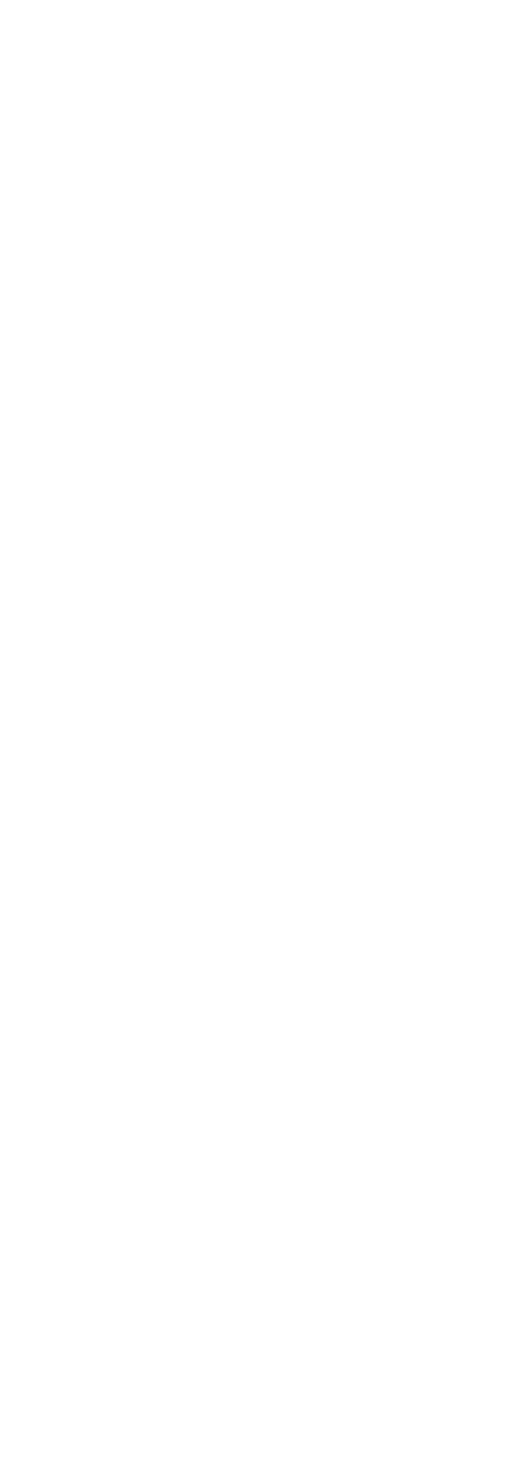

\begin{tabular}{|c|c|c|}
\hline 递 & 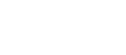 & מำ \\
\hline 胥 & 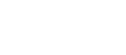 & 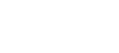 \\
\hline 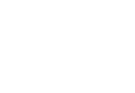 & 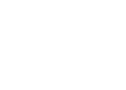 & 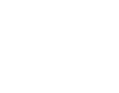 \\
\hline 点 & 000000 & ONOHOO \\
\hline 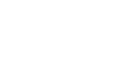 & 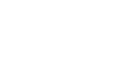 & $\stackrel{\sim}{\infty} \underset{\sim}{\infty} \stackrel{\sim}{\infty} \underset{\sim}{\infty} \underset{\sim}{\infty} \stackrel{\sim}{0}$ \\
\hline 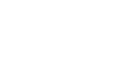 & ర్ન & 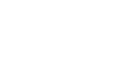 \\
\hline 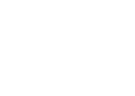 & 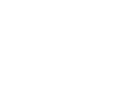 & పై \\
\hline 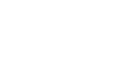 & 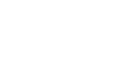 & †:৪ะ: \\
\hline 至焉完 & $\mathfrak{0}^{\circ}$ & 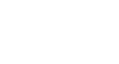 \\
\hline 官氙可 & 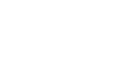 & $\because 0 \because 0 \because \because$ \\
\hline 总 & 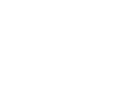 & 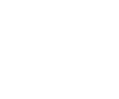 \\
\hline 劳 & 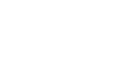 & : \\
\hline 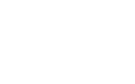 & 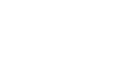 & 유 \\
\hline 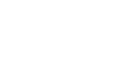 & 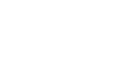 & 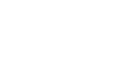 \\
\hline 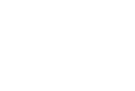 & 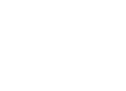 & 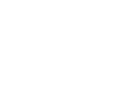 \\
\hline 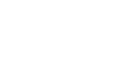 & 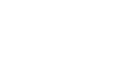 & 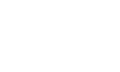 \\
\hline 离总氖 & 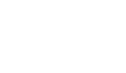 & نُ \\
\hline 总 & ะே: & คํํ유 \\
\hline 矛葛 & 규억ㄱㄱㄱㅍ & $\dot{\sigma}^{\circ}=00=0$ \\
\hline 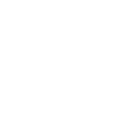 & & \\
\hline 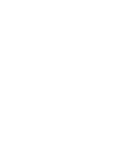 & 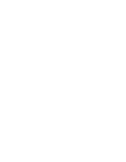 & $\begin{array}{r}\vdots \\
\vdots \vdots \\
\vdots \\
\vdots \\
\vdots\end{array}$ \\
\hline
\end{tabular}




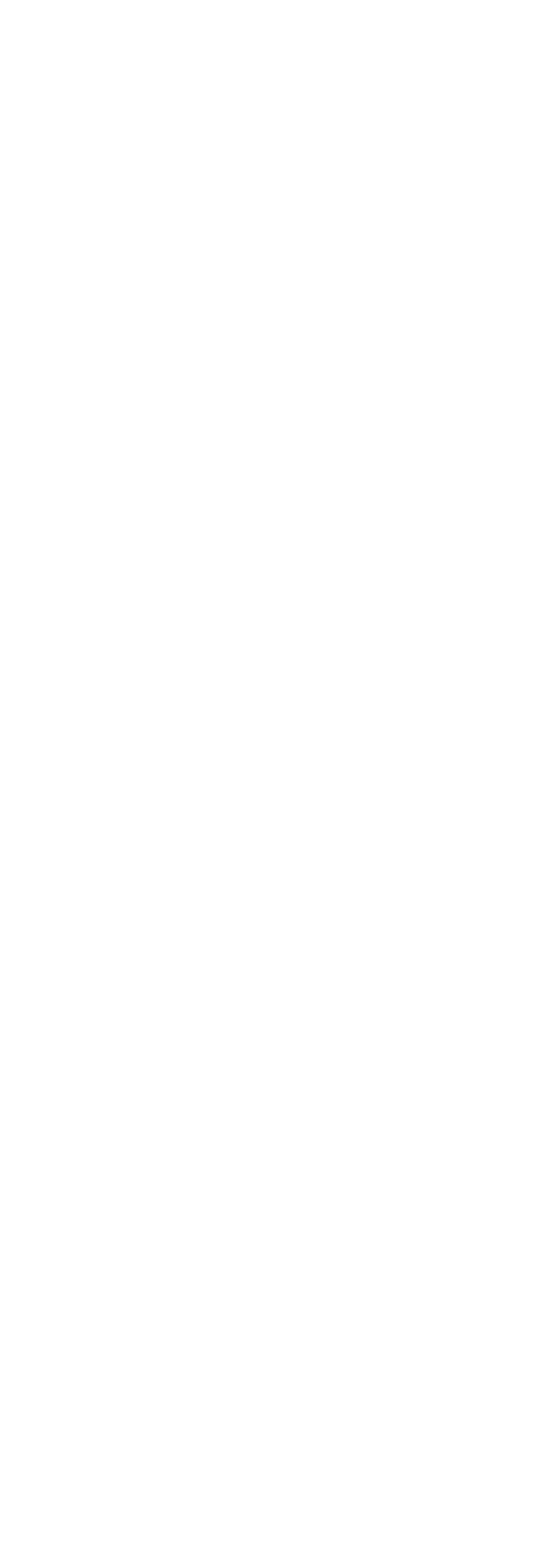




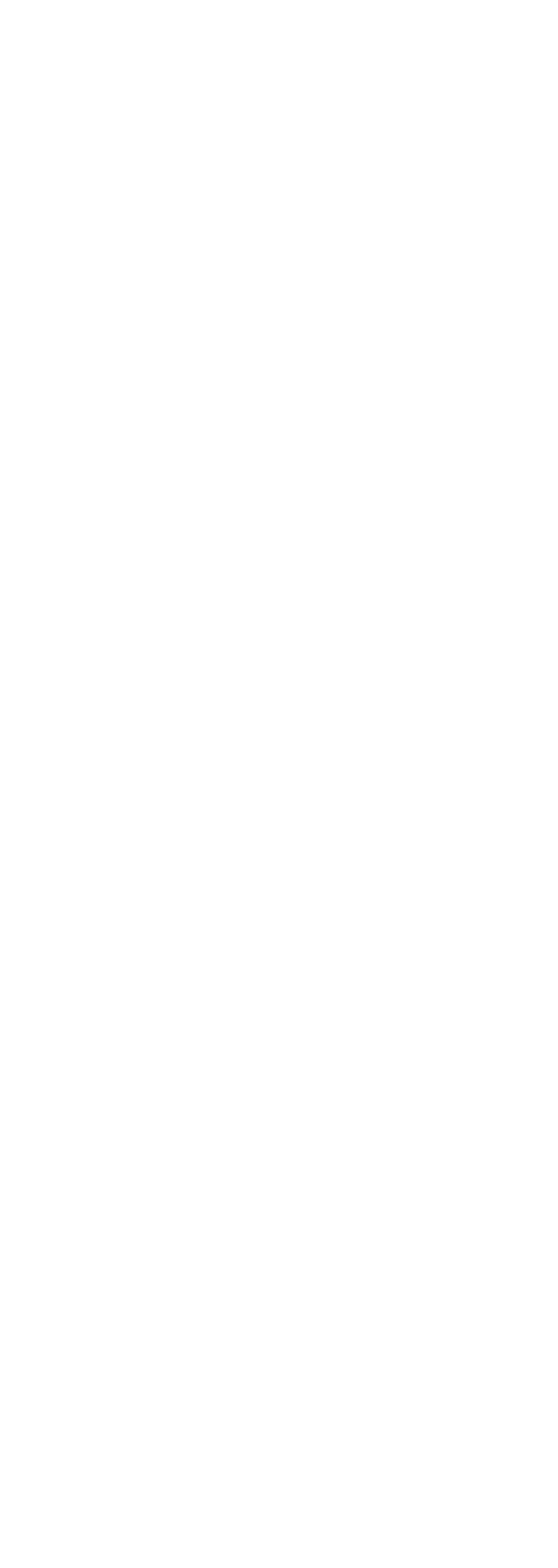




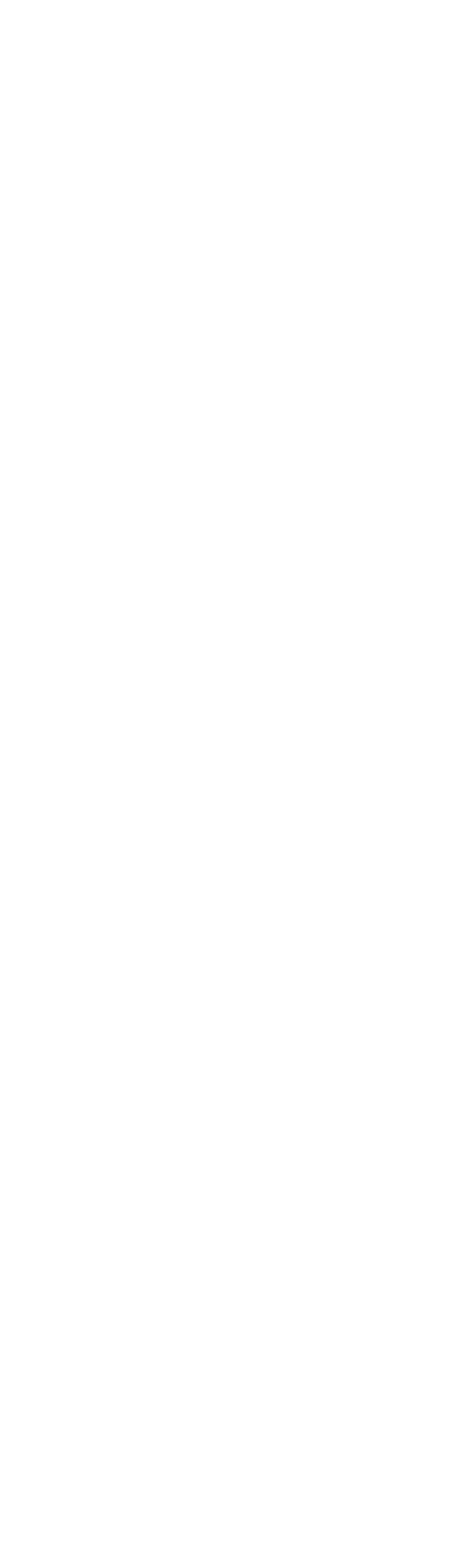




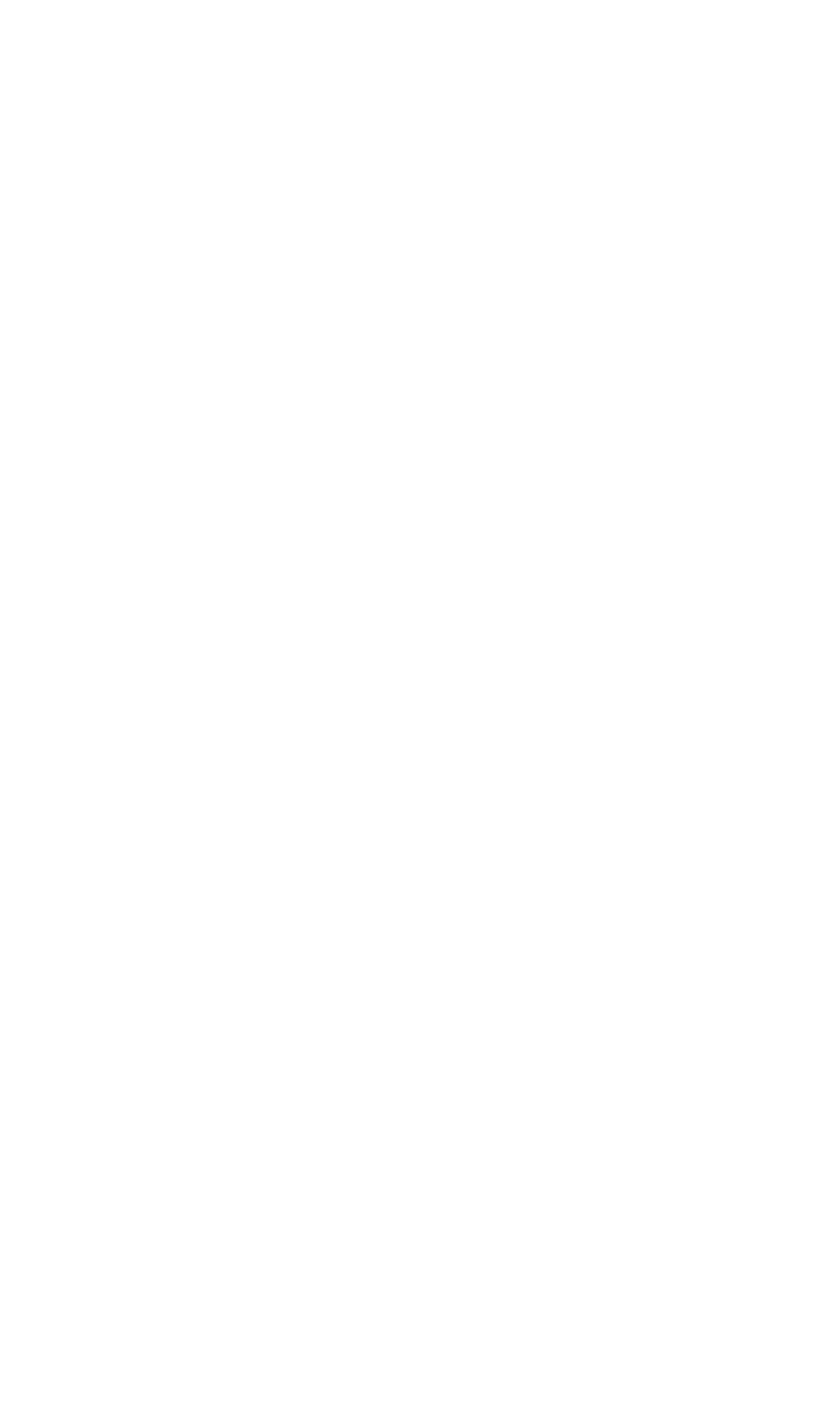



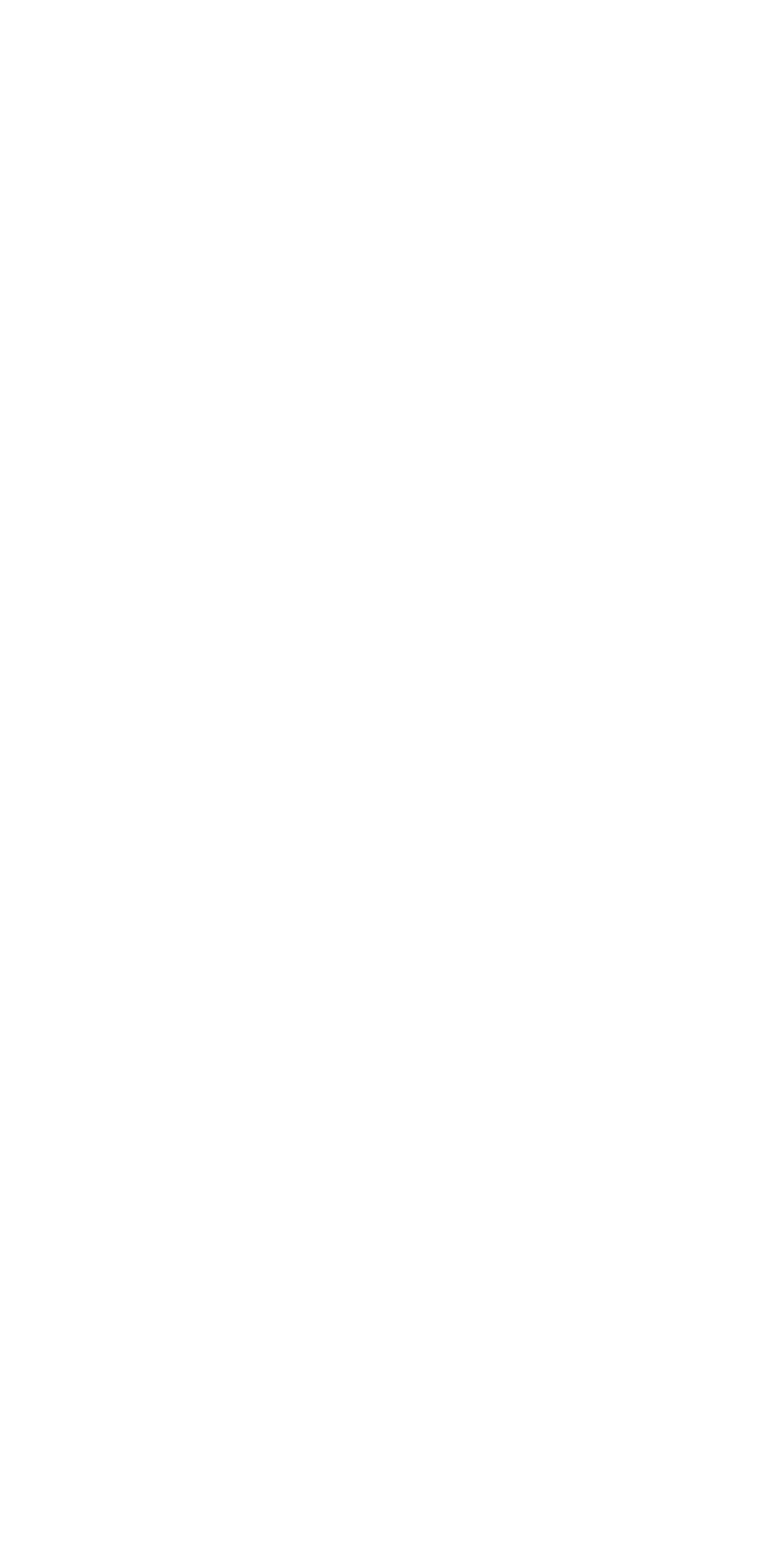

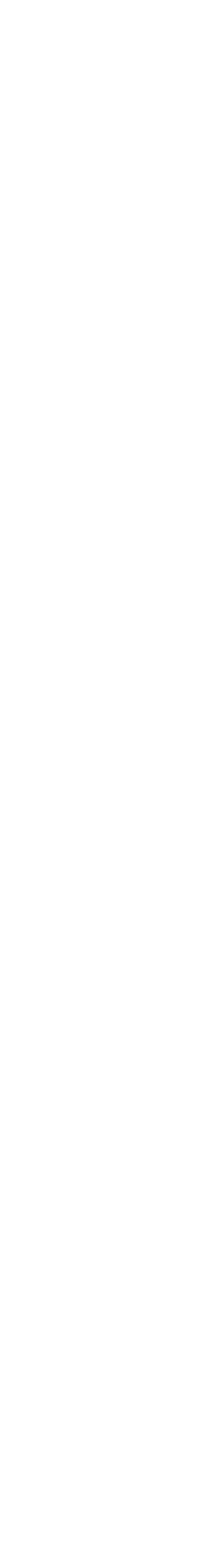




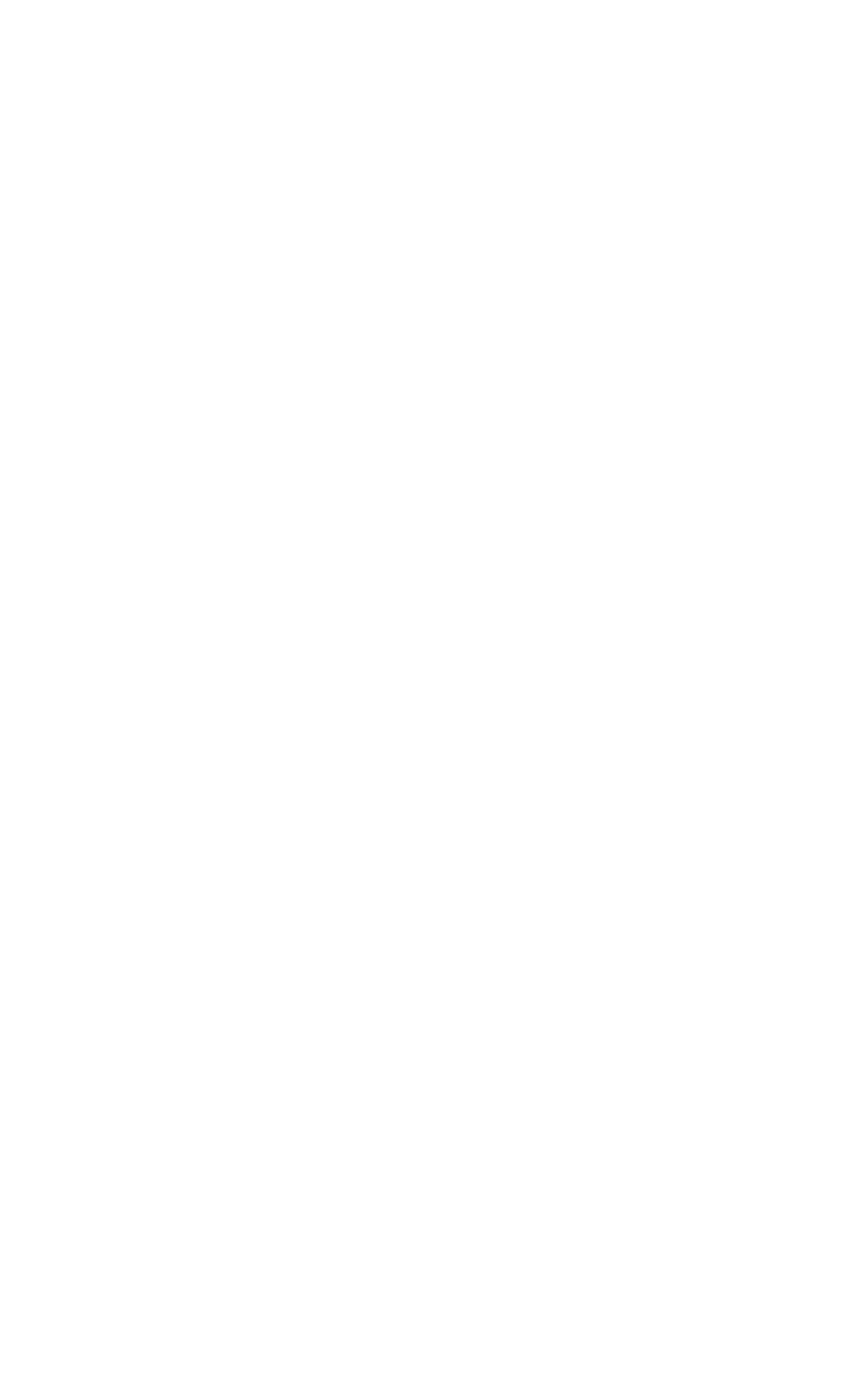




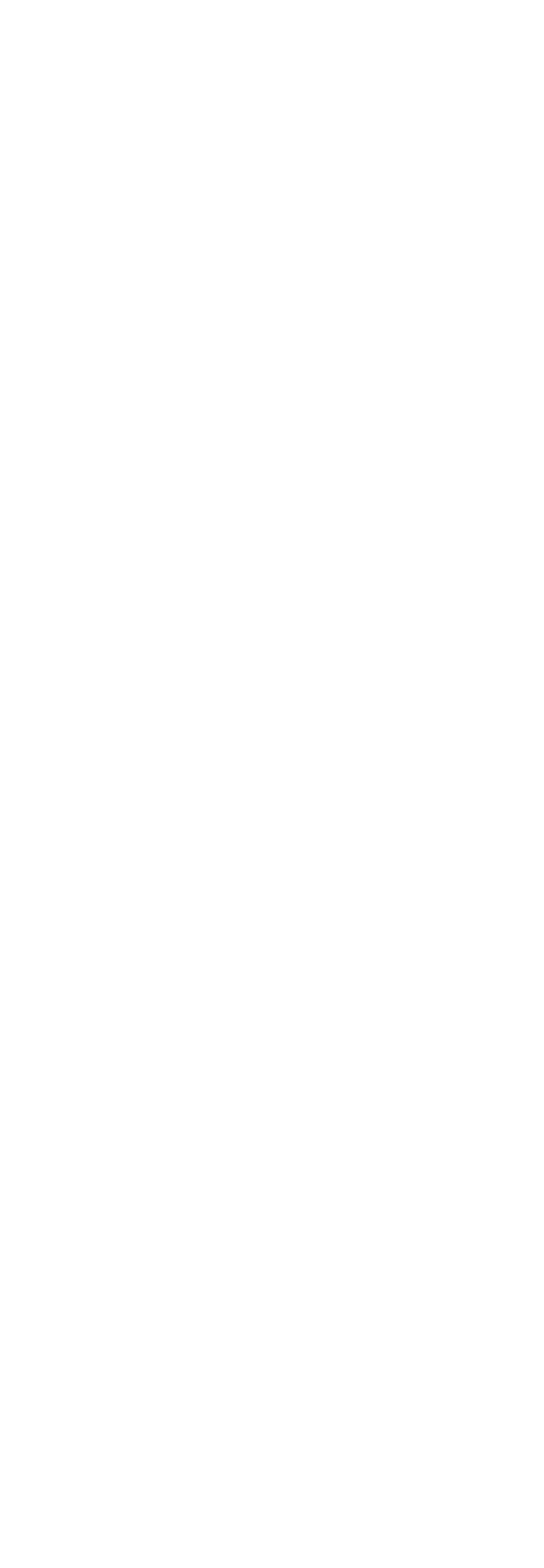




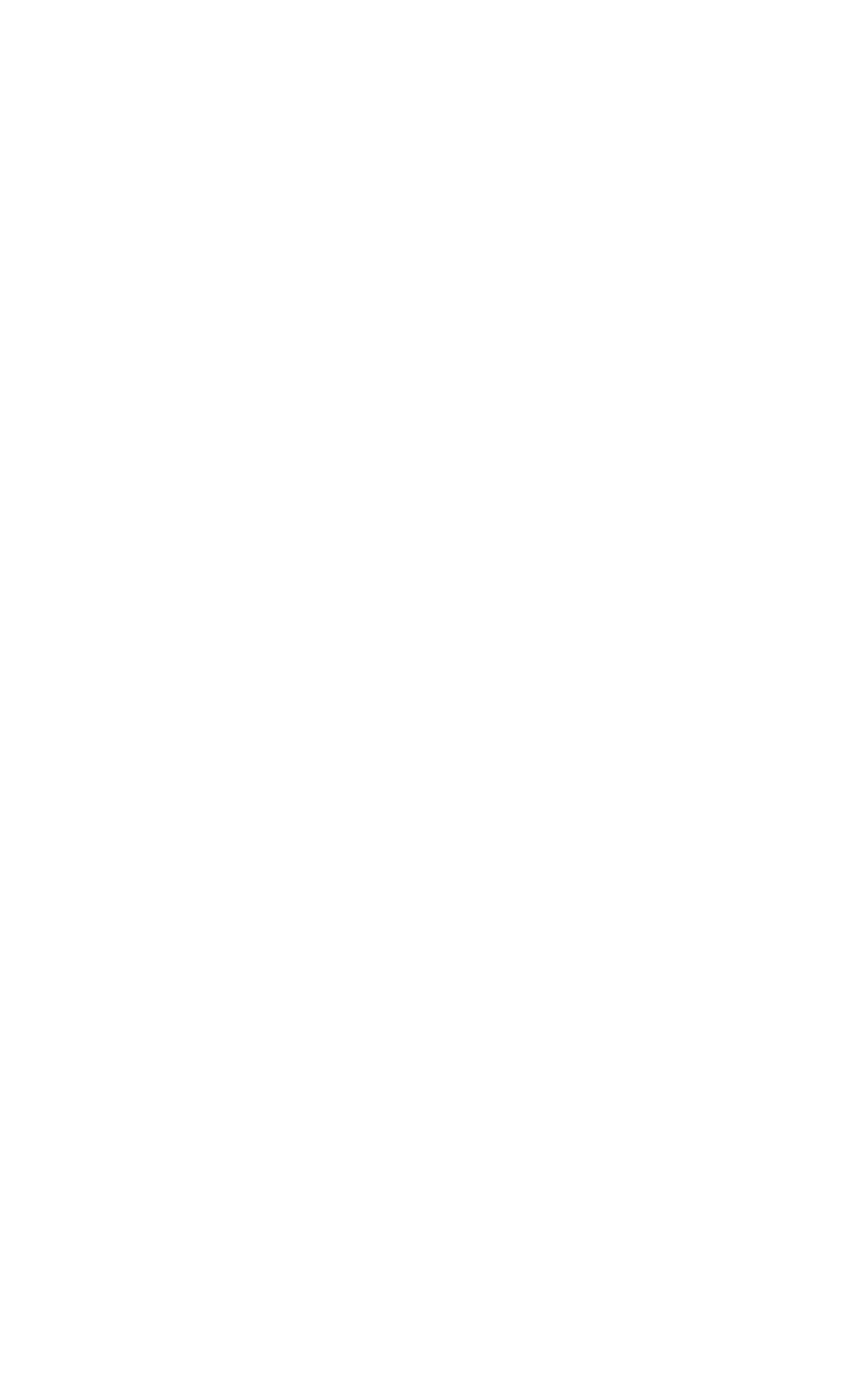




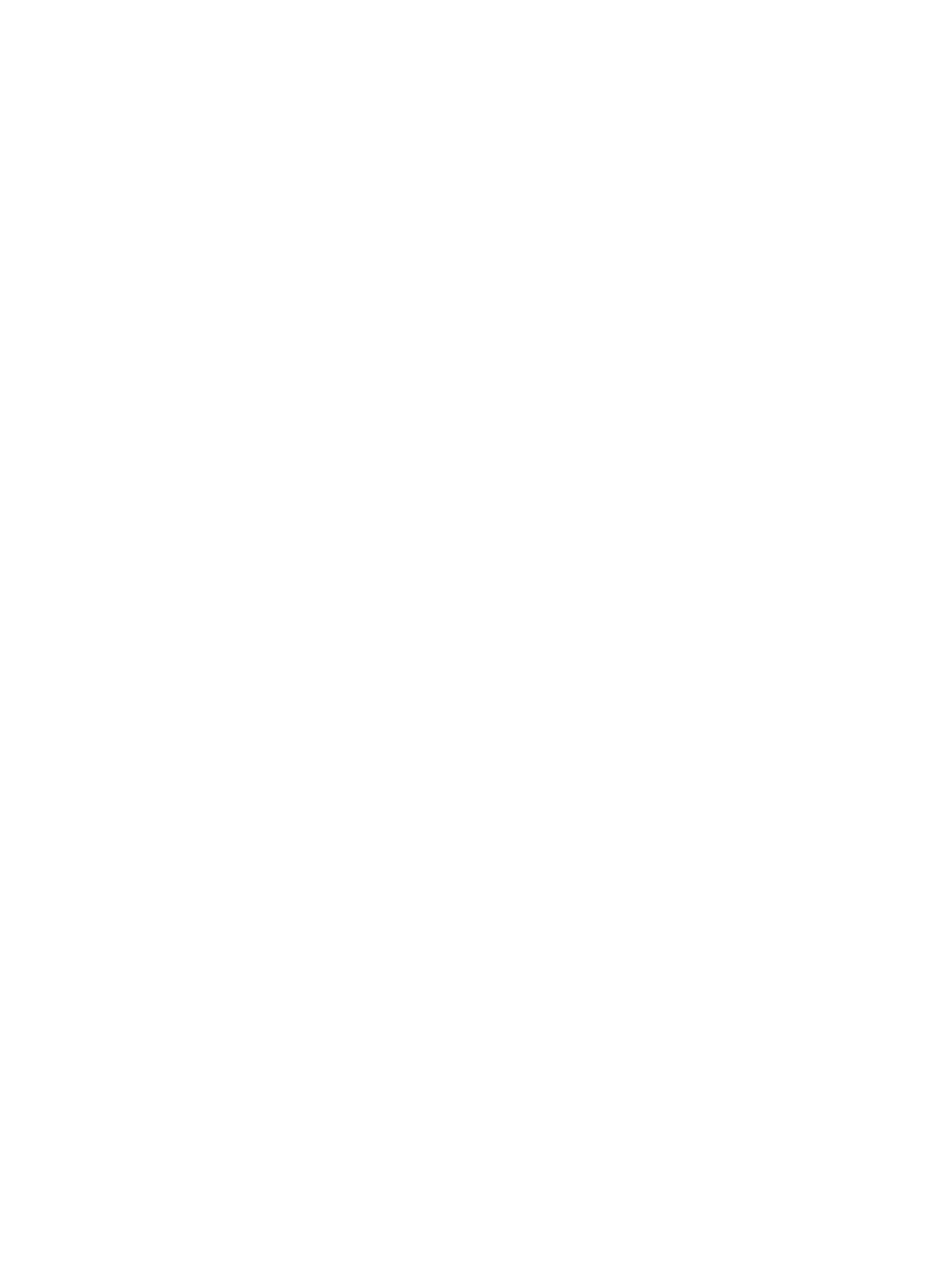



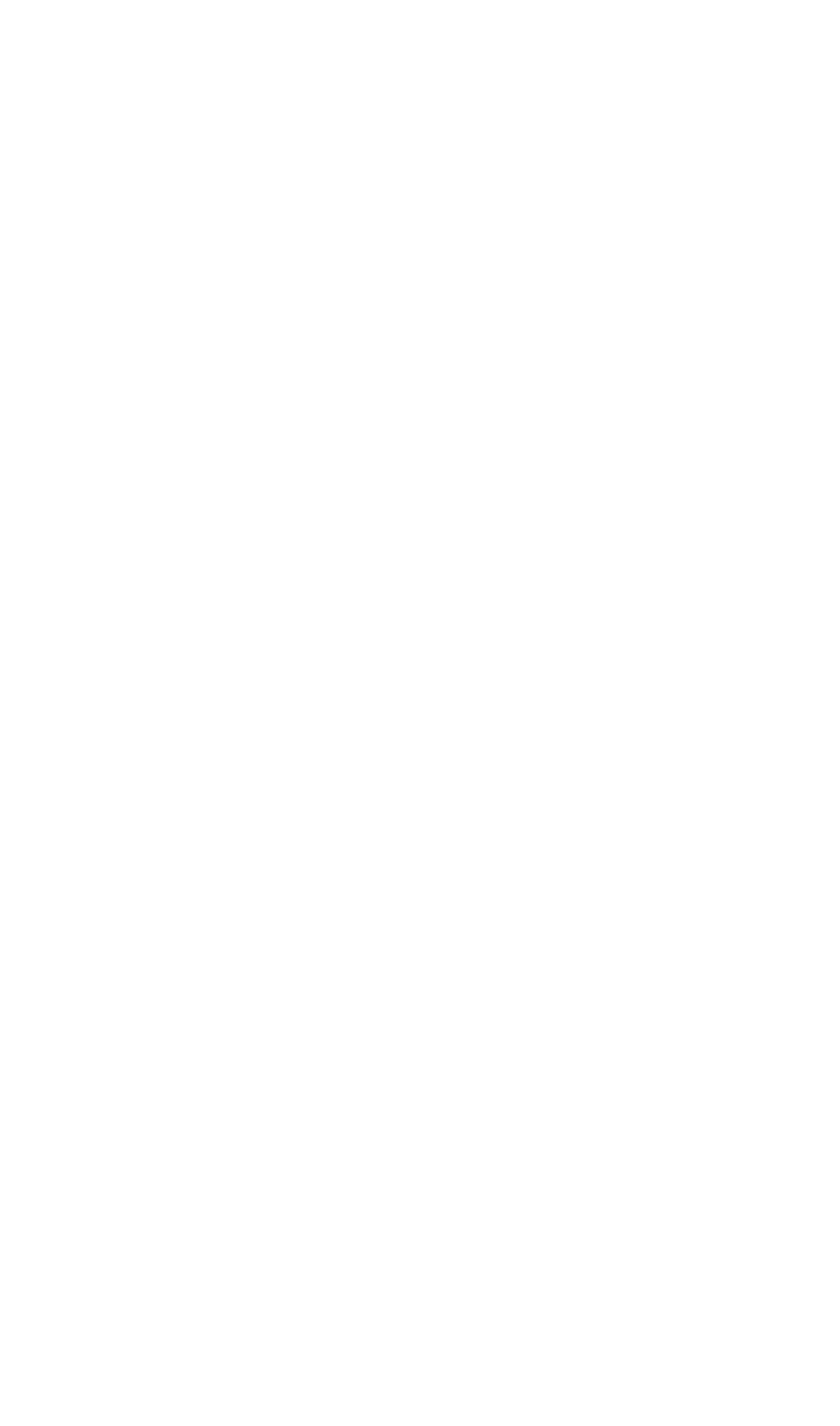


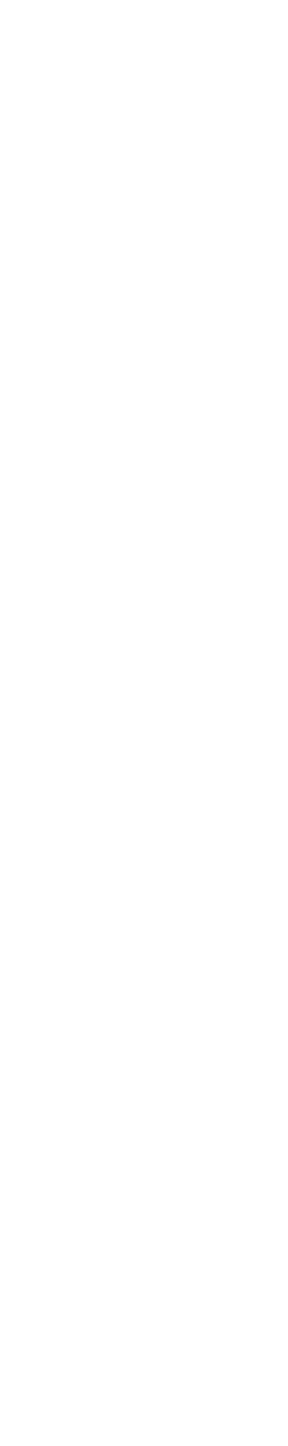

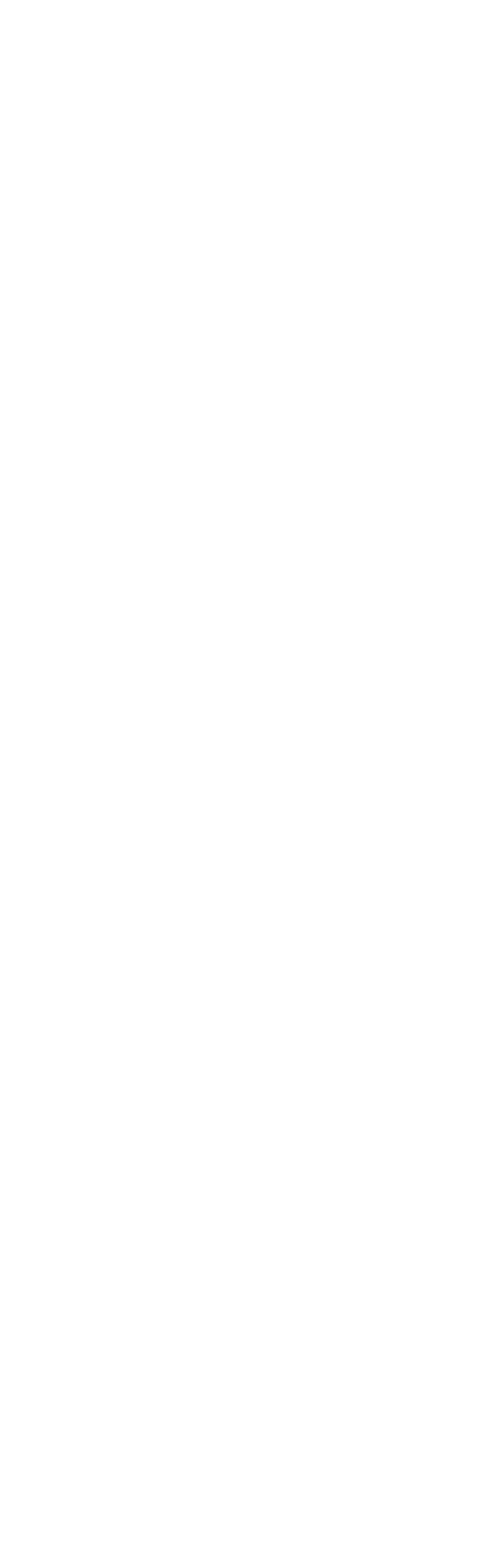




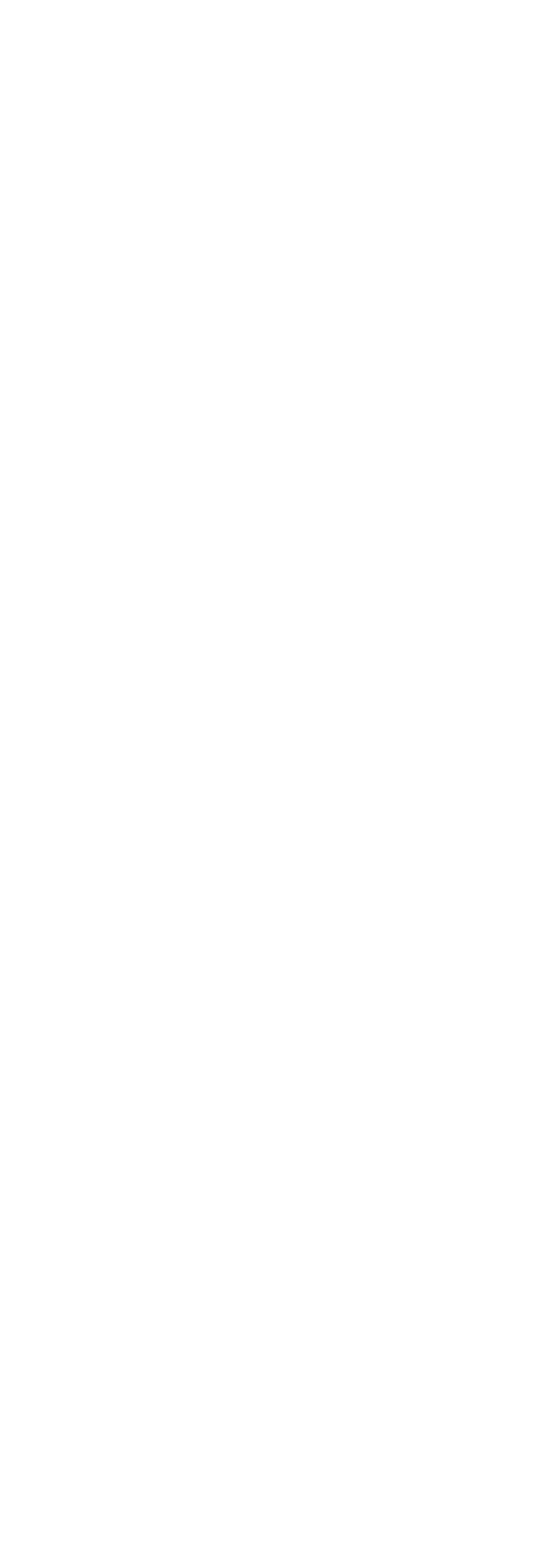




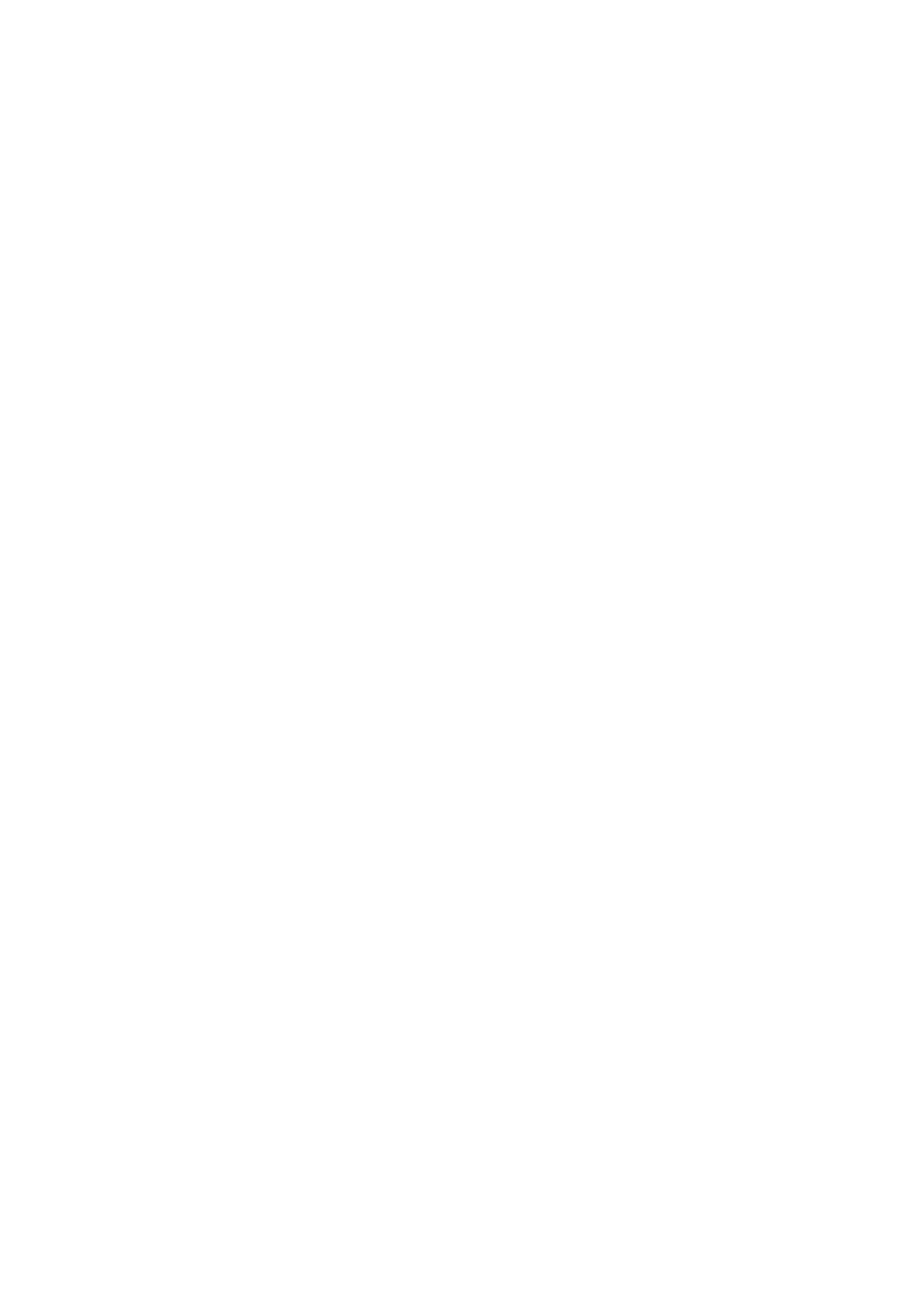




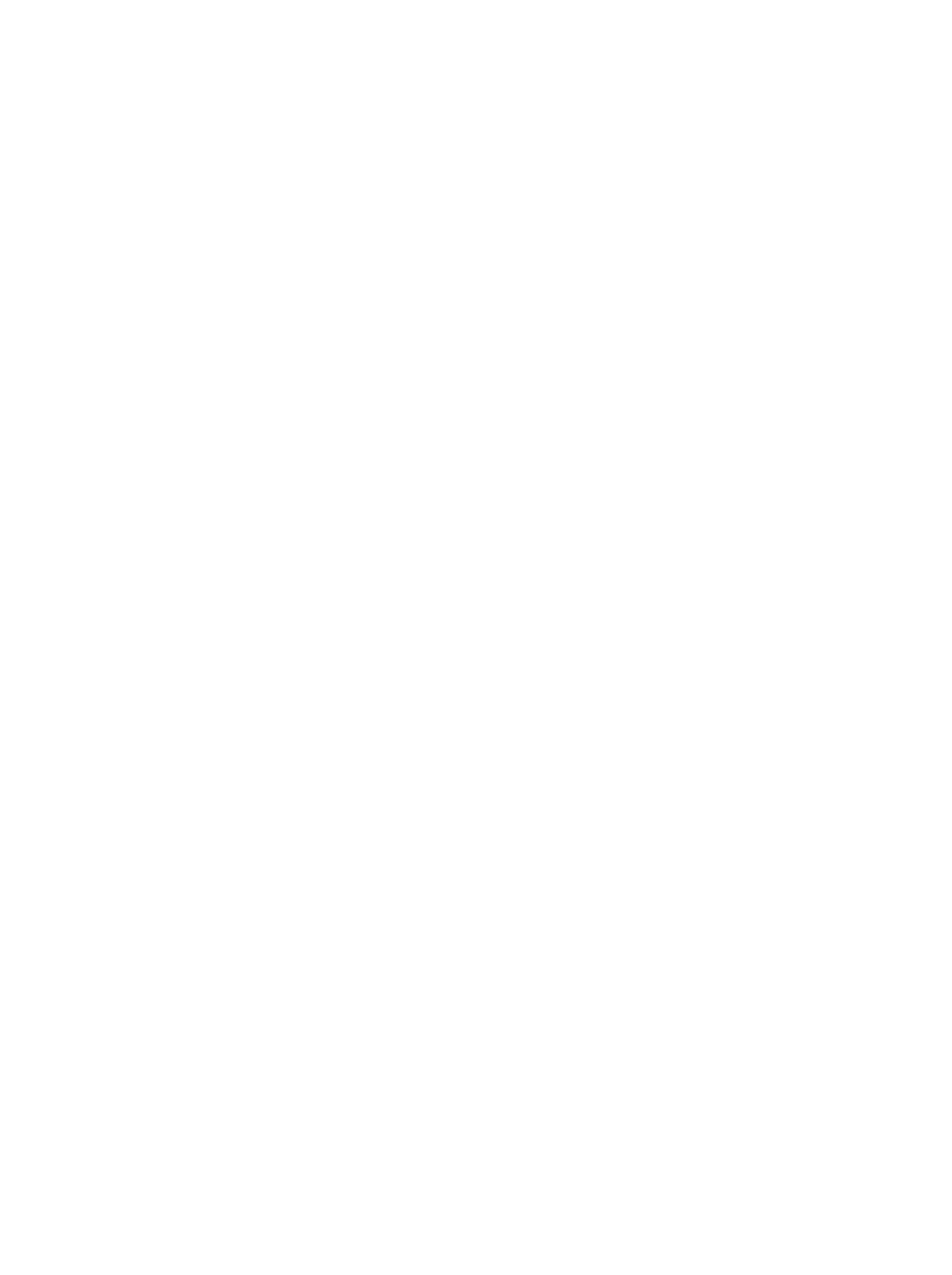




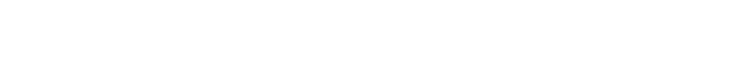

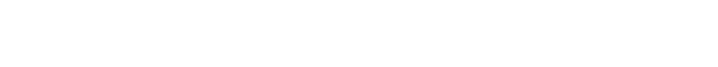

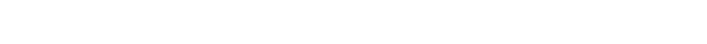

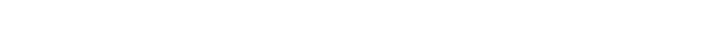

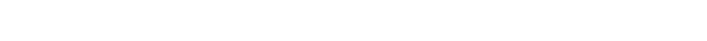

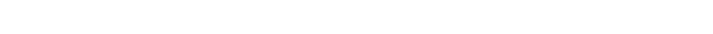

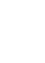

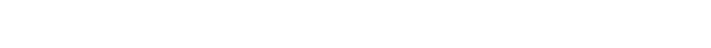

$\stackrel{-\infty}{\circ}$

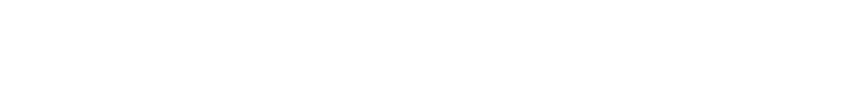

c.

ก 药

ता in

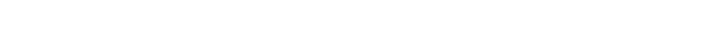

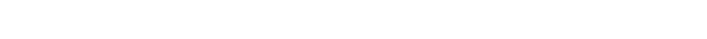

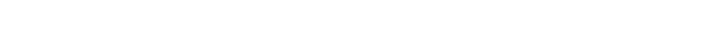

$\therefore-{ }^{-1}$

I

이 jo⿱⺈

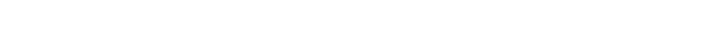

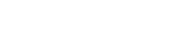

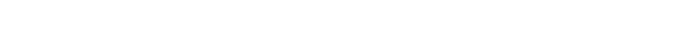
고ำ

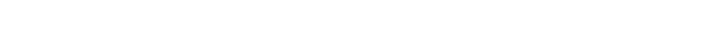

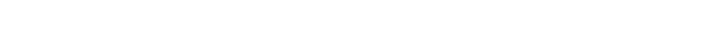

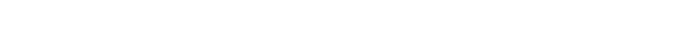
$\infty$ | 是最-

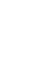
co

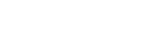

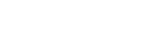

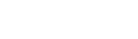

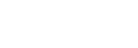

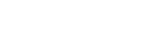

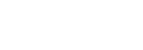
in

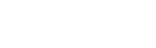

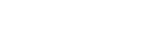

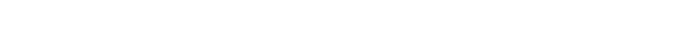
n 8⿻

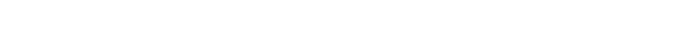

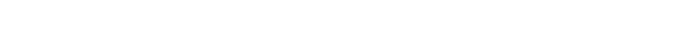

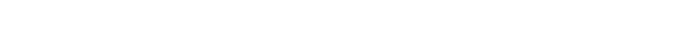

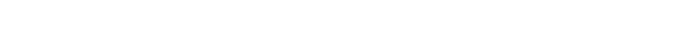

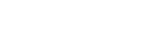

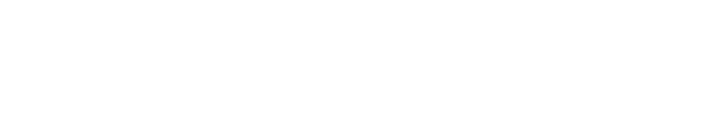




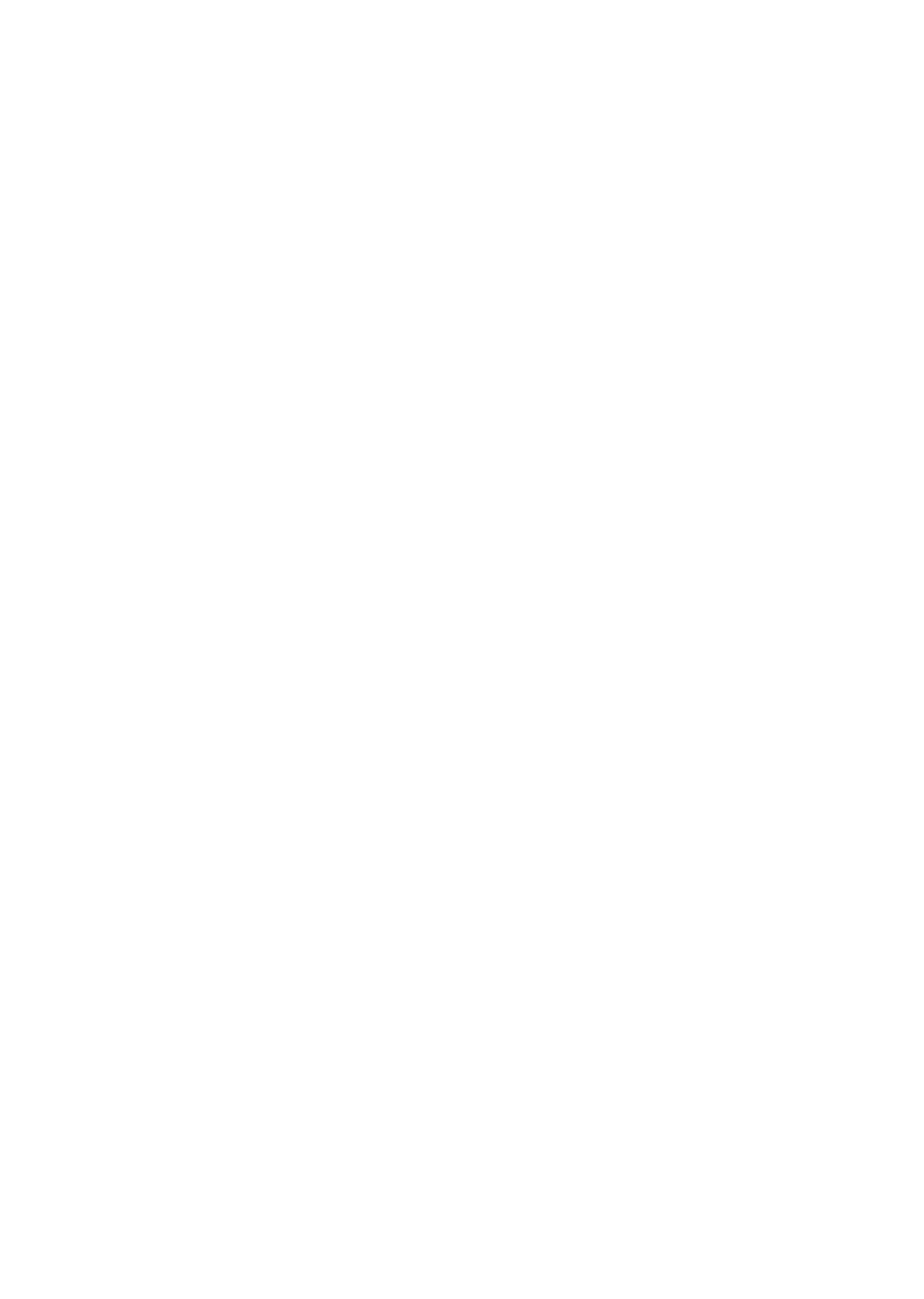




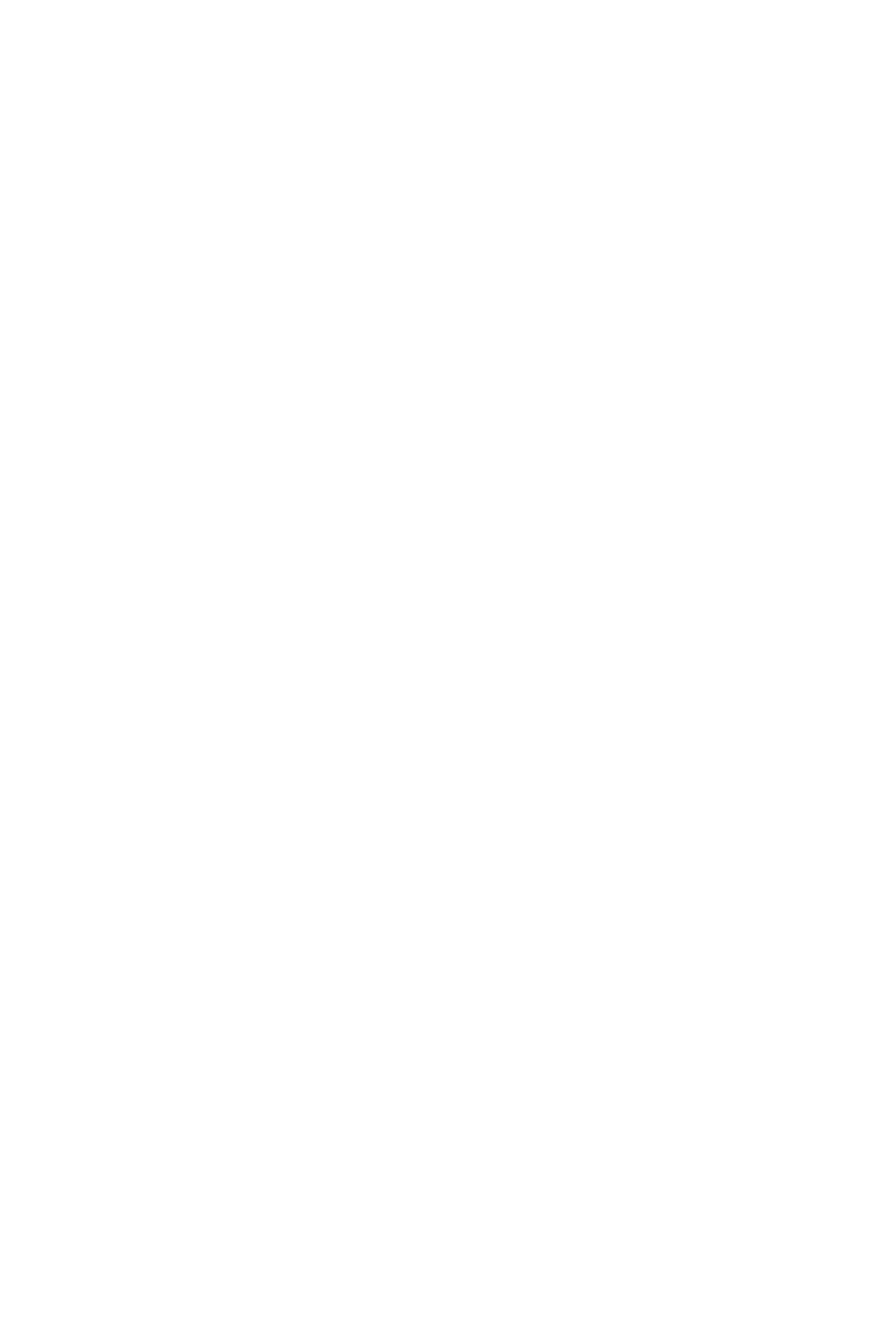



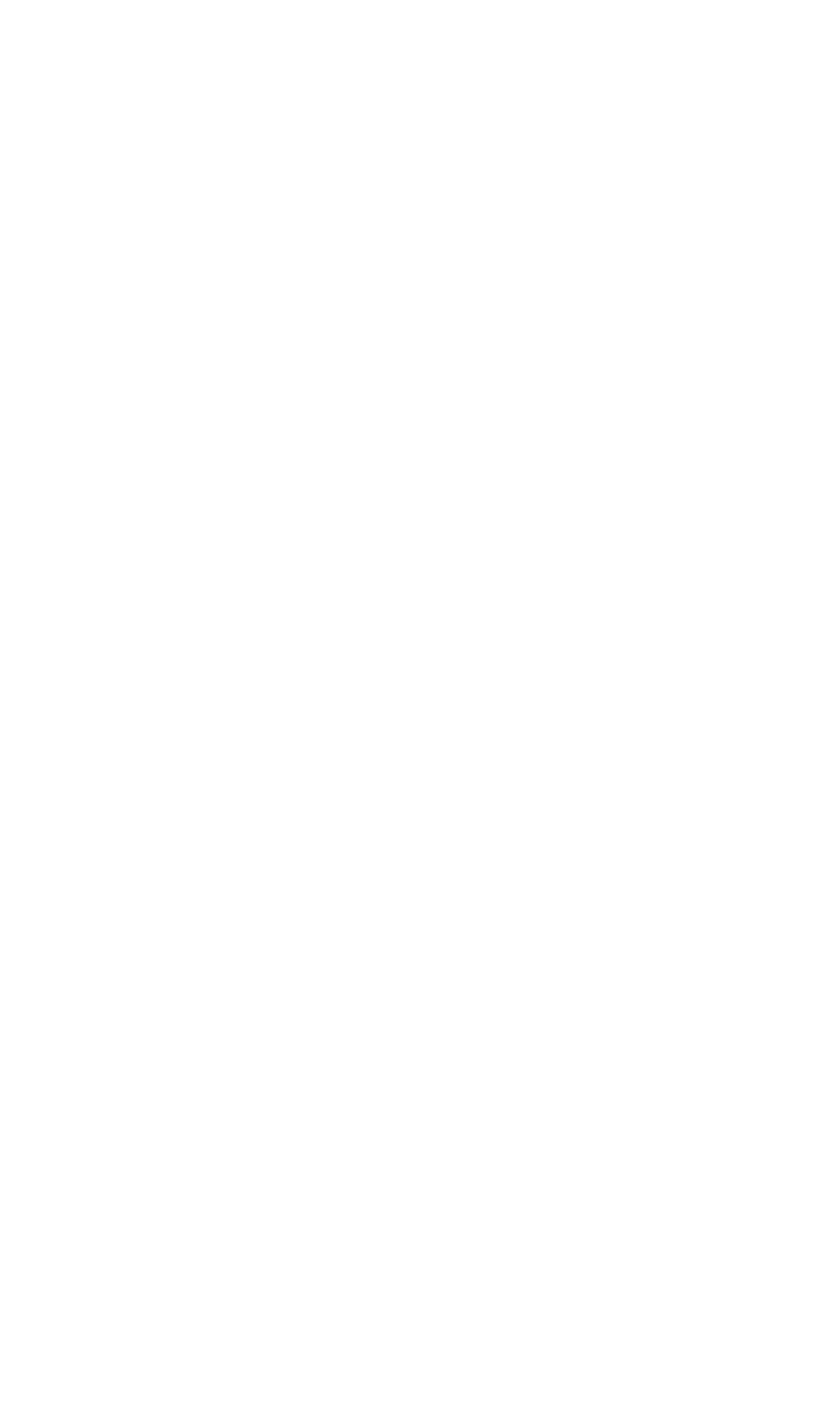

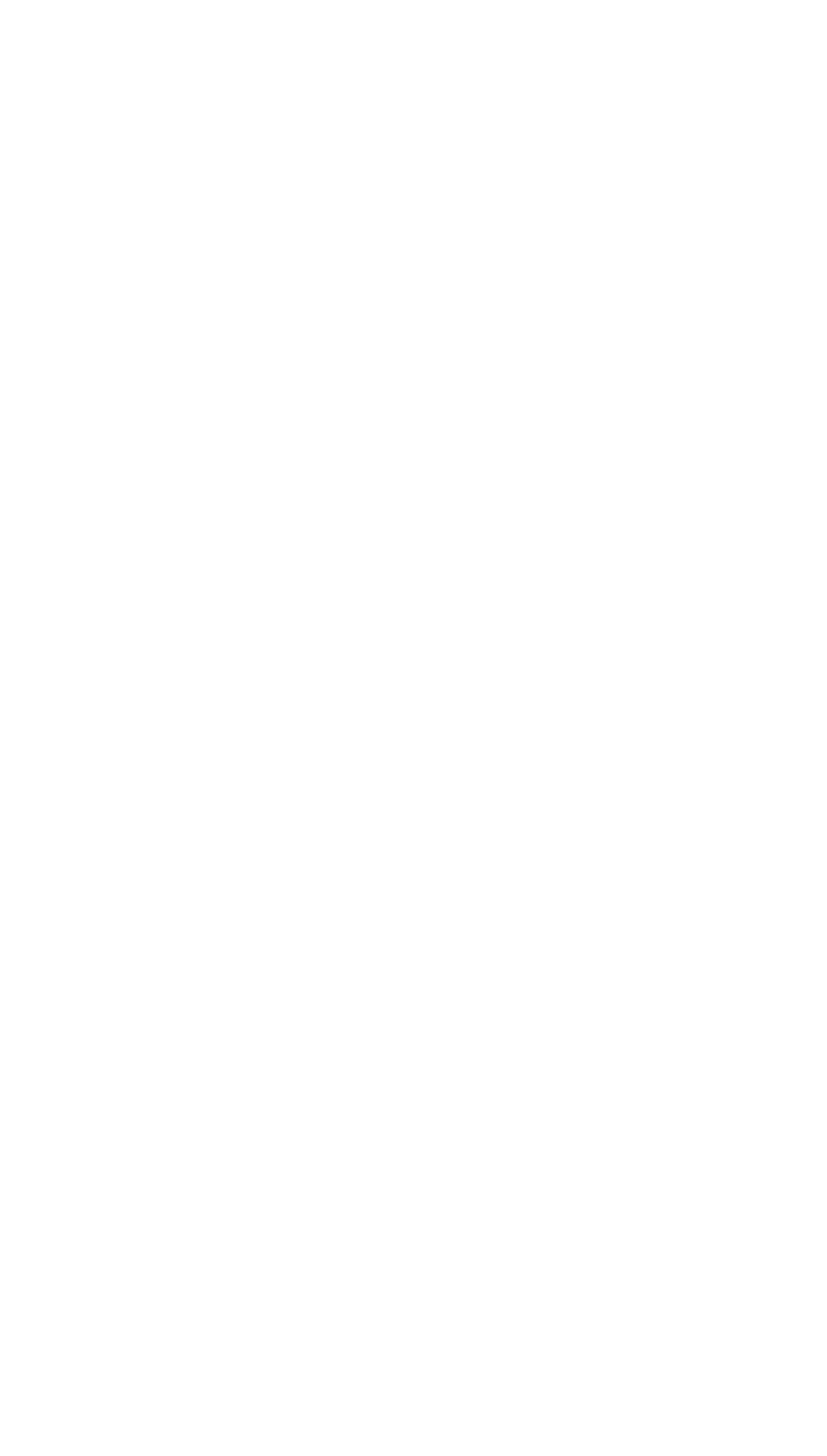


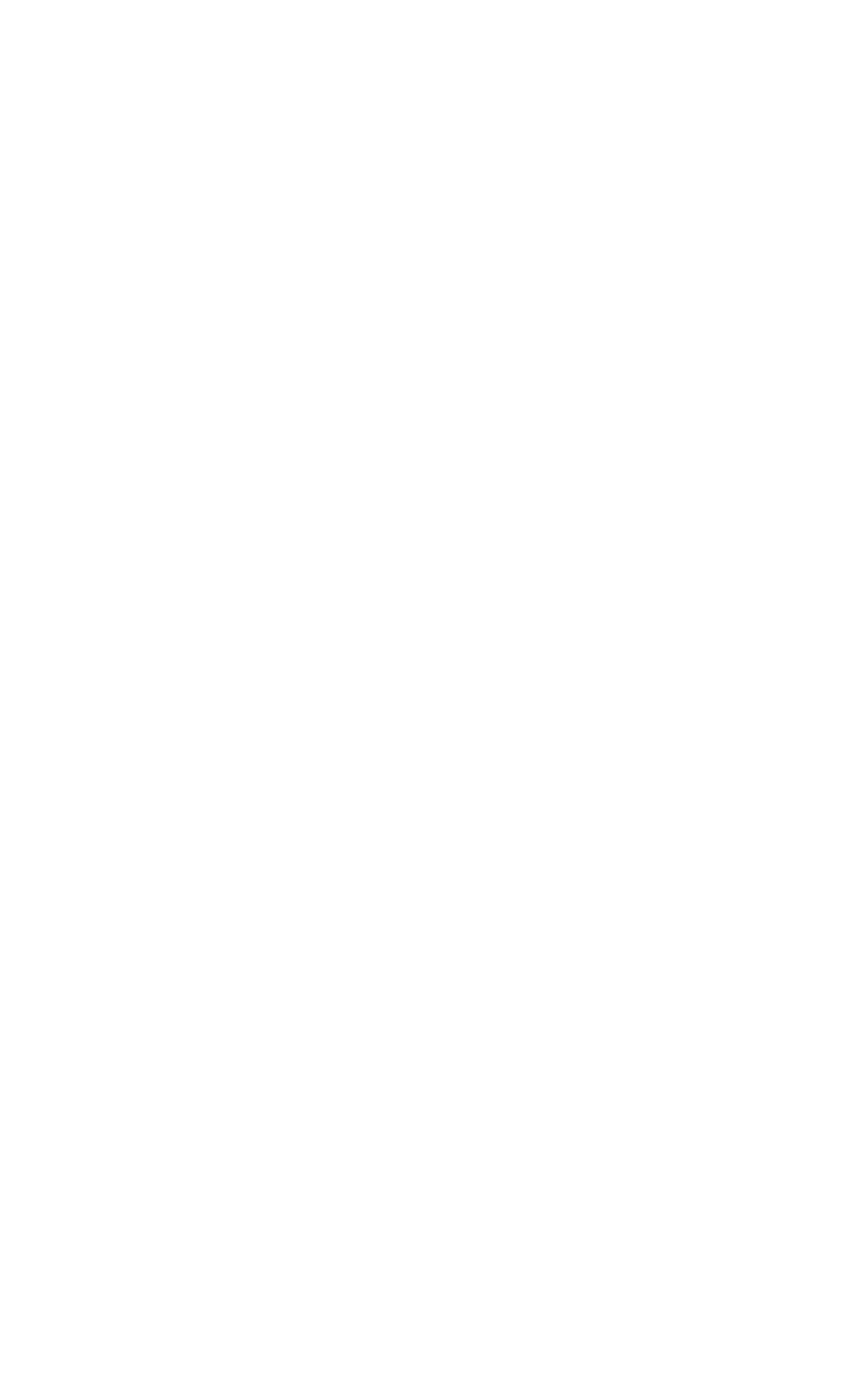




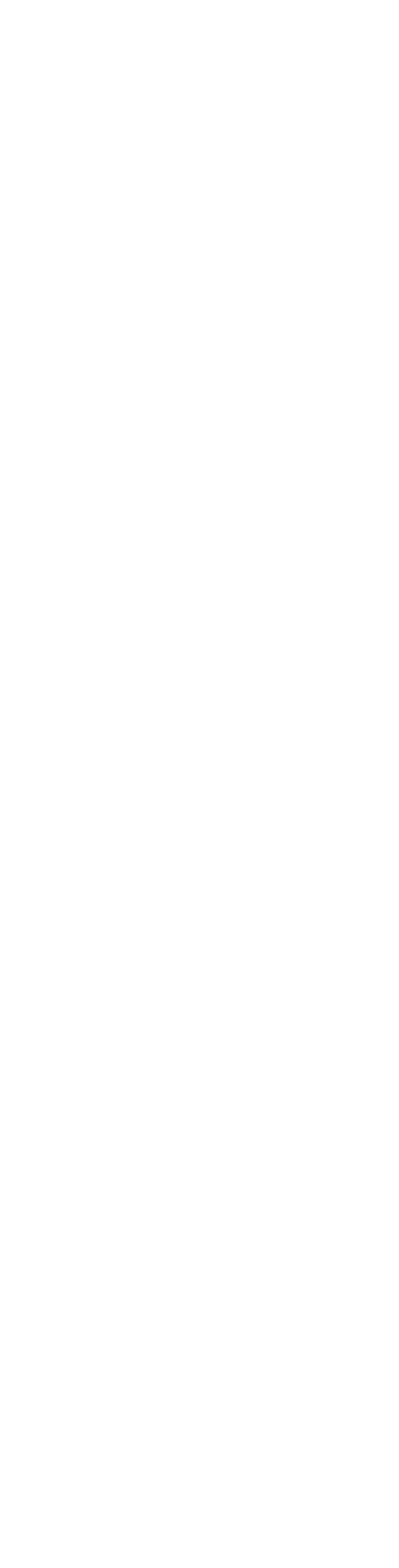




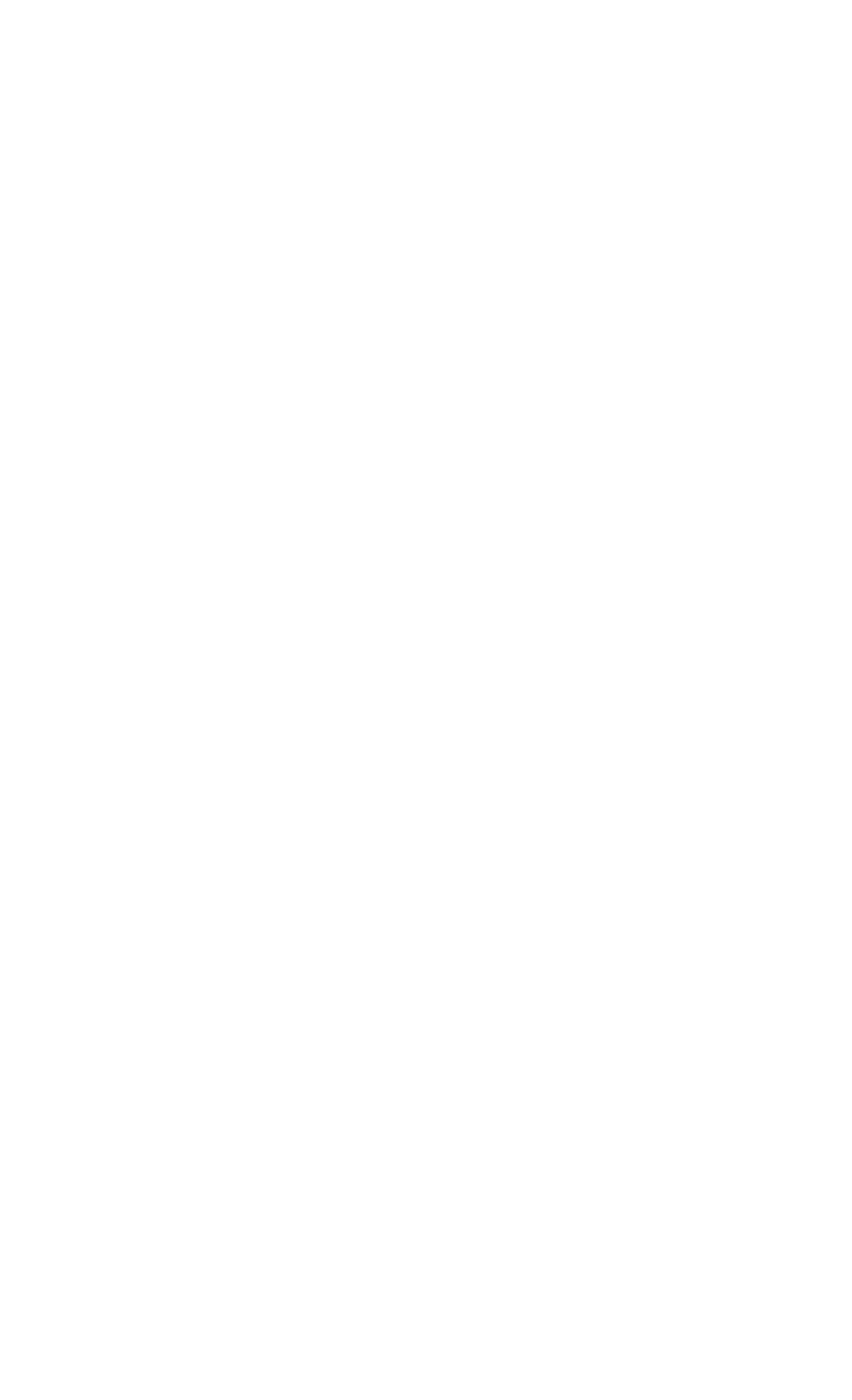




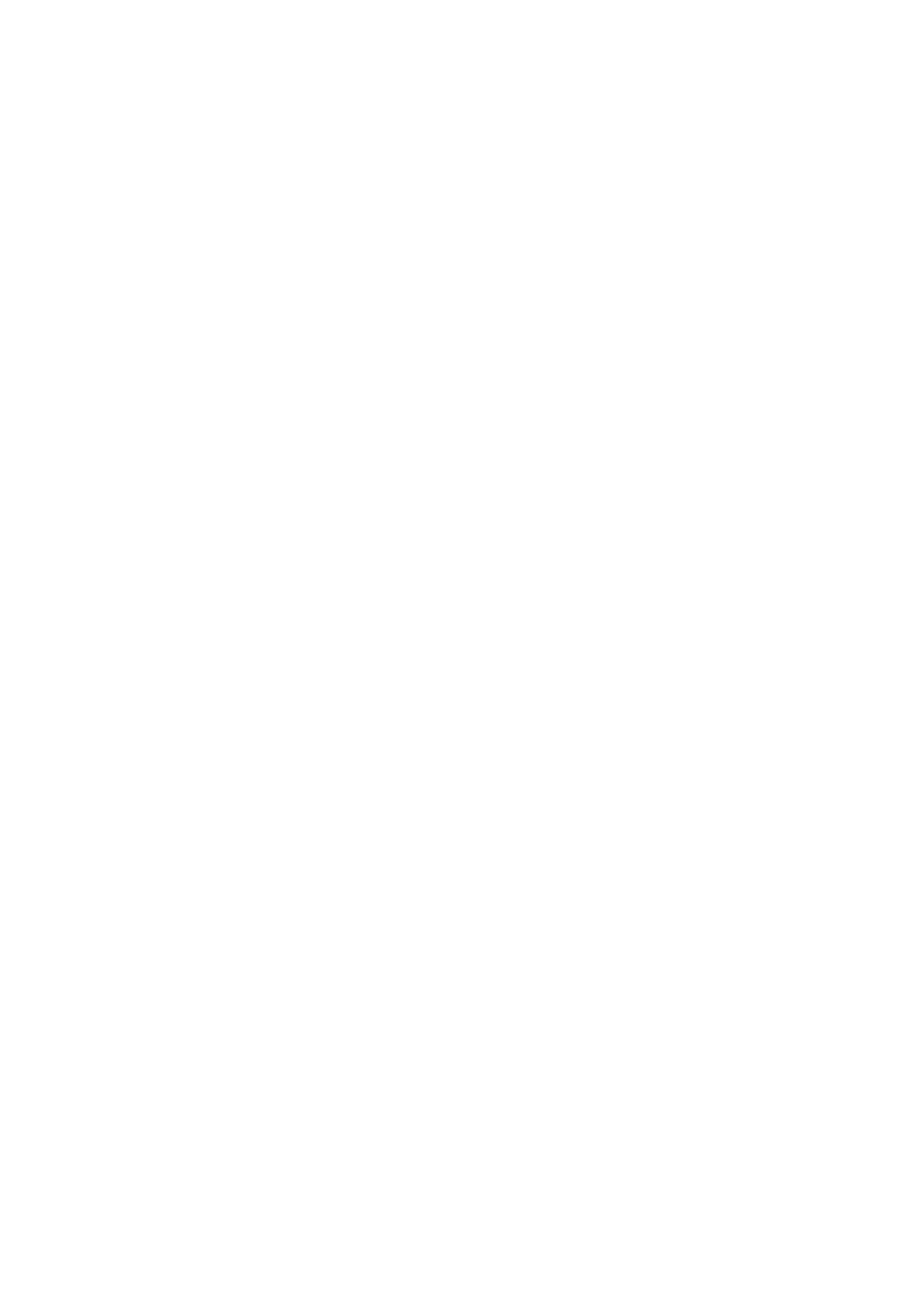




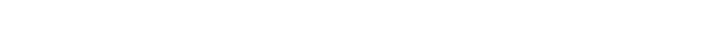

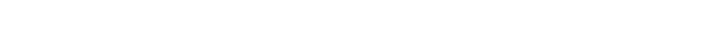

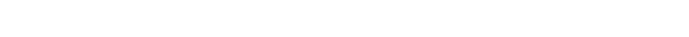

1) 0 -

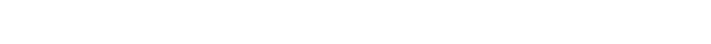

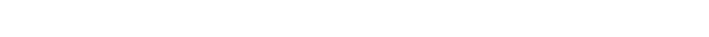

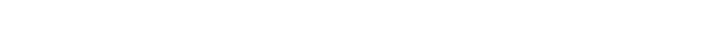

ㄱ. चु

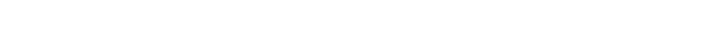

运

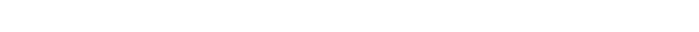

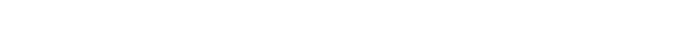
F केन (5)

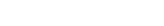

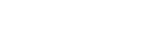

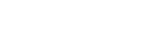

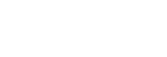

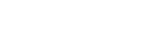

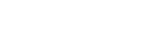




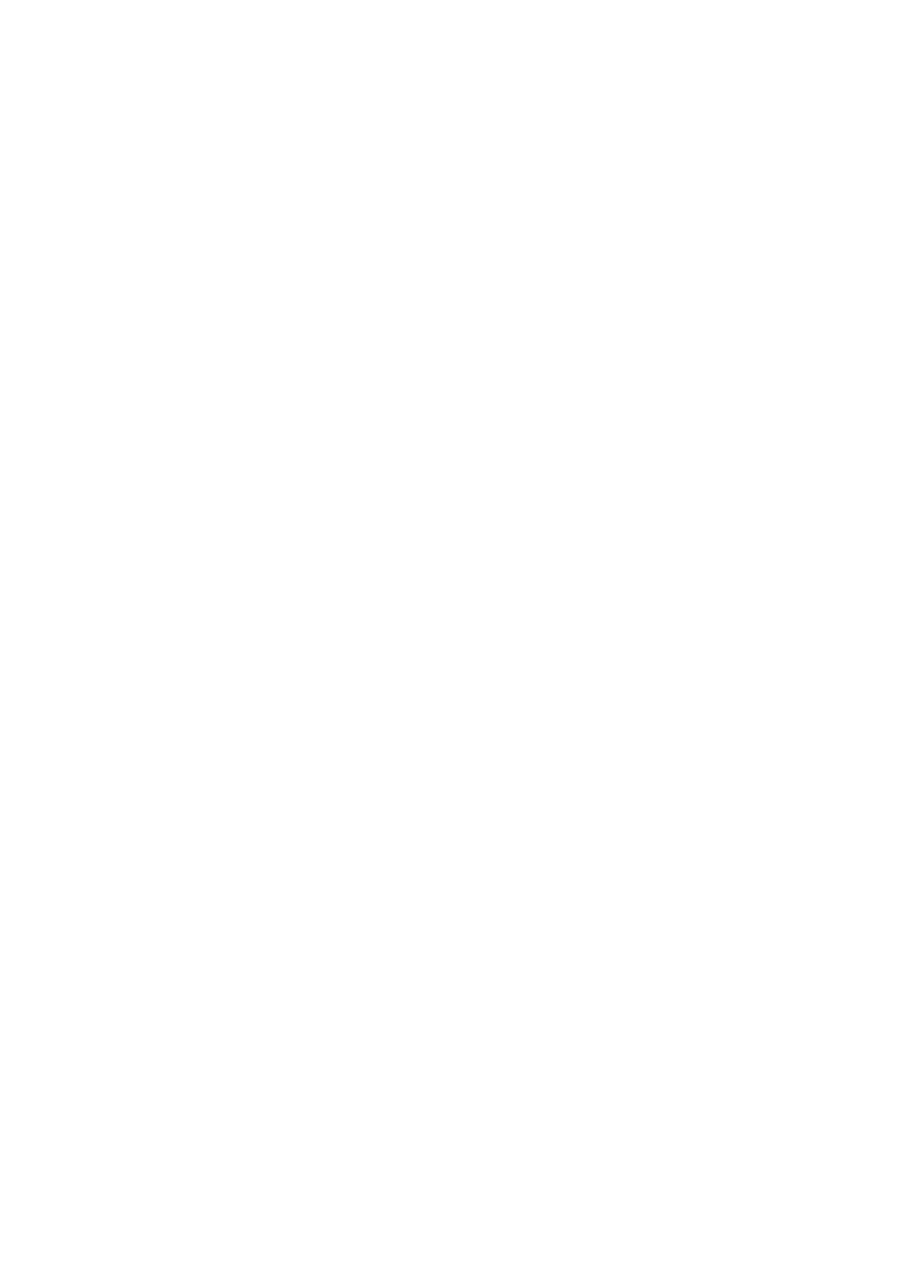




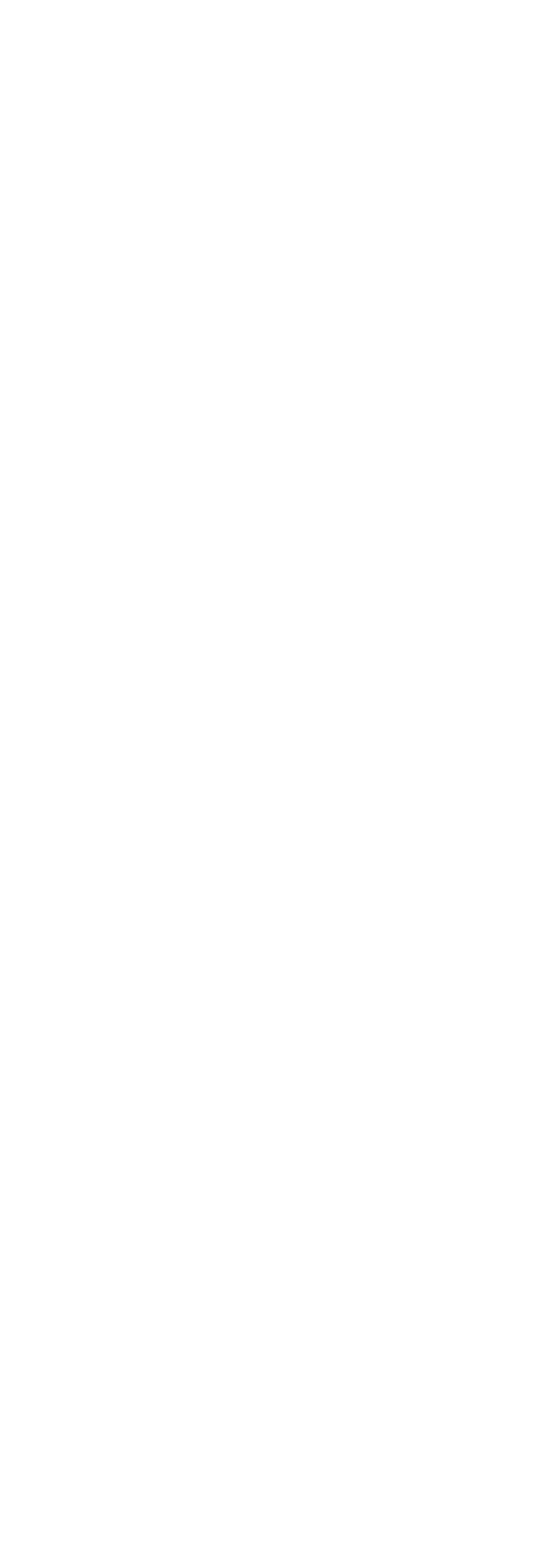




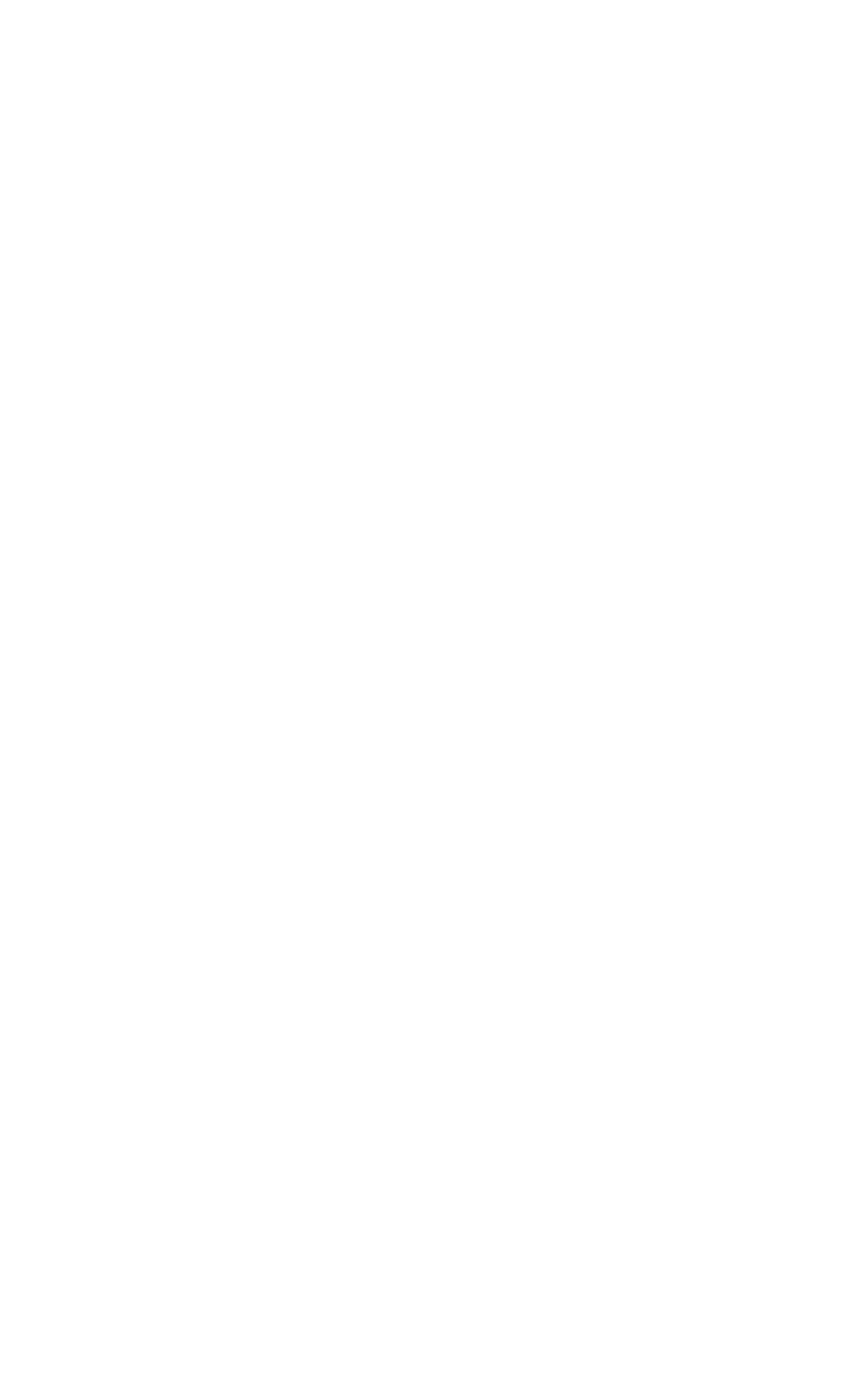


考

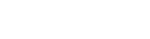

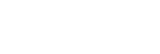

产

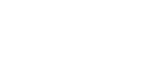

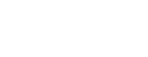

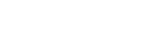
-5

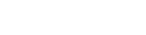

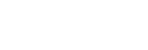
Tom

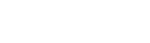

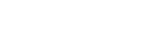
1.

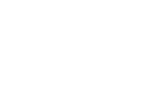

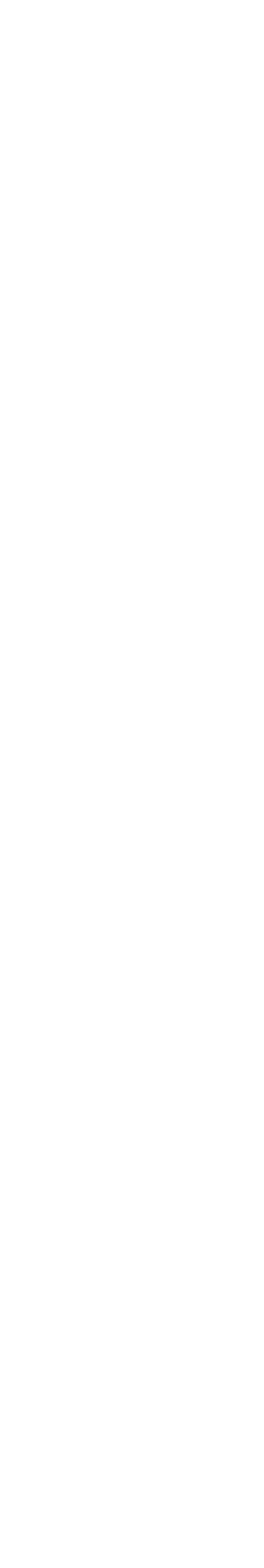




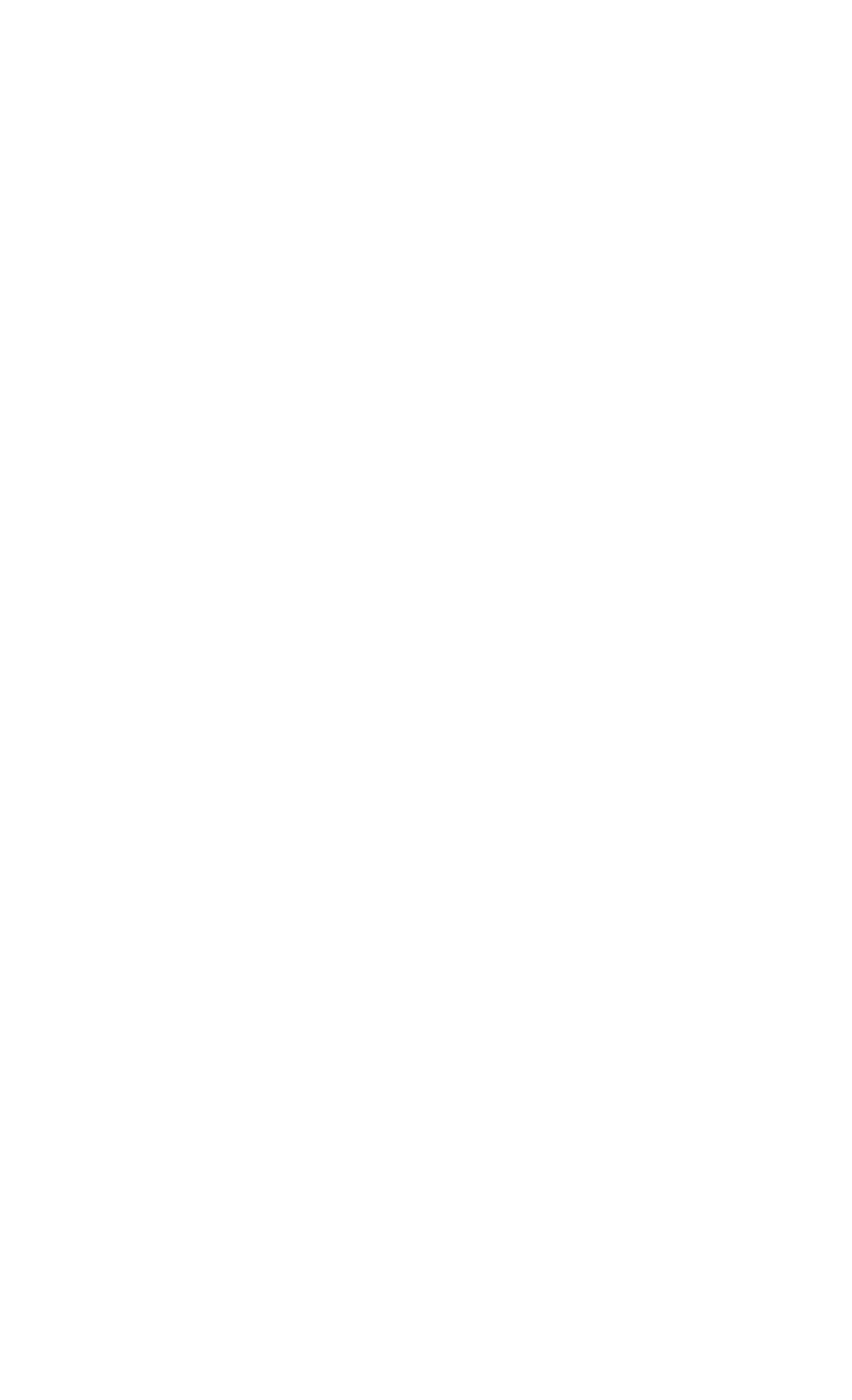




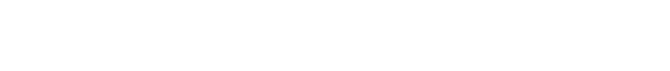

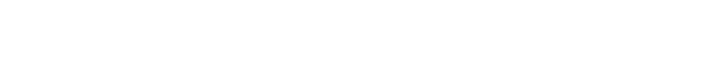

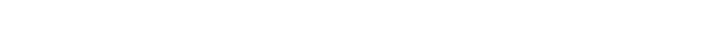

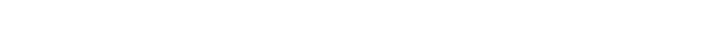
a

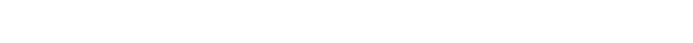

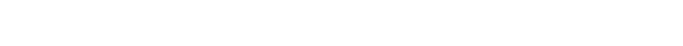

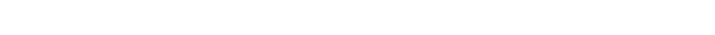

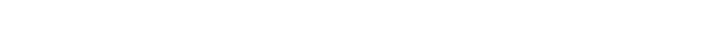

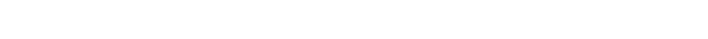

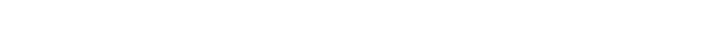
a

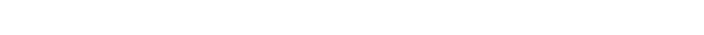
$\therefore$ 㫷

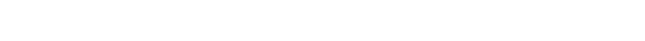

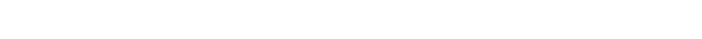

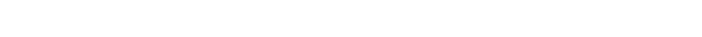

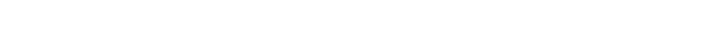

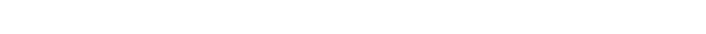

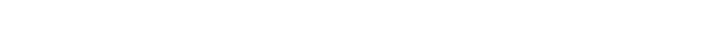
$=0$ ले 


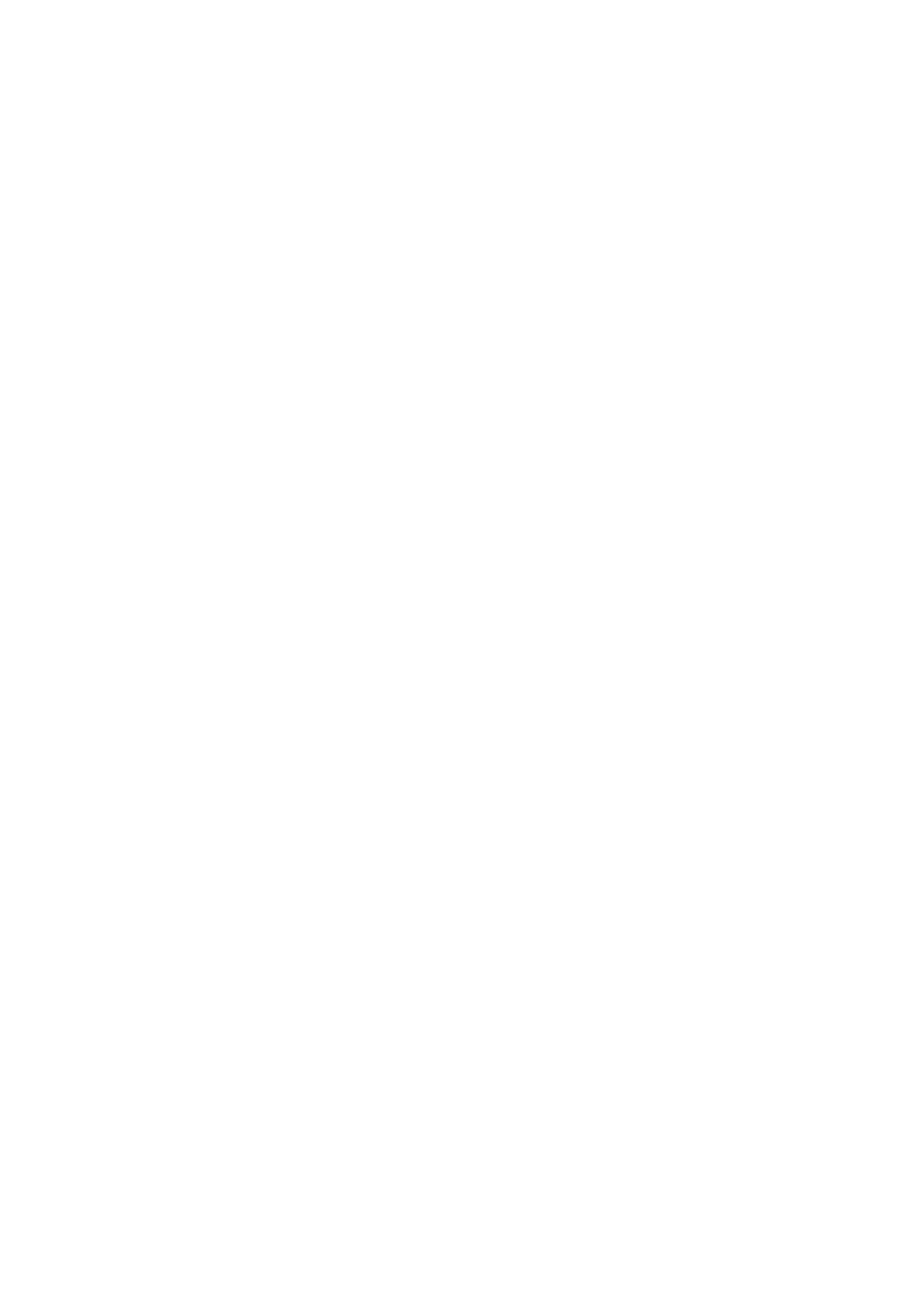




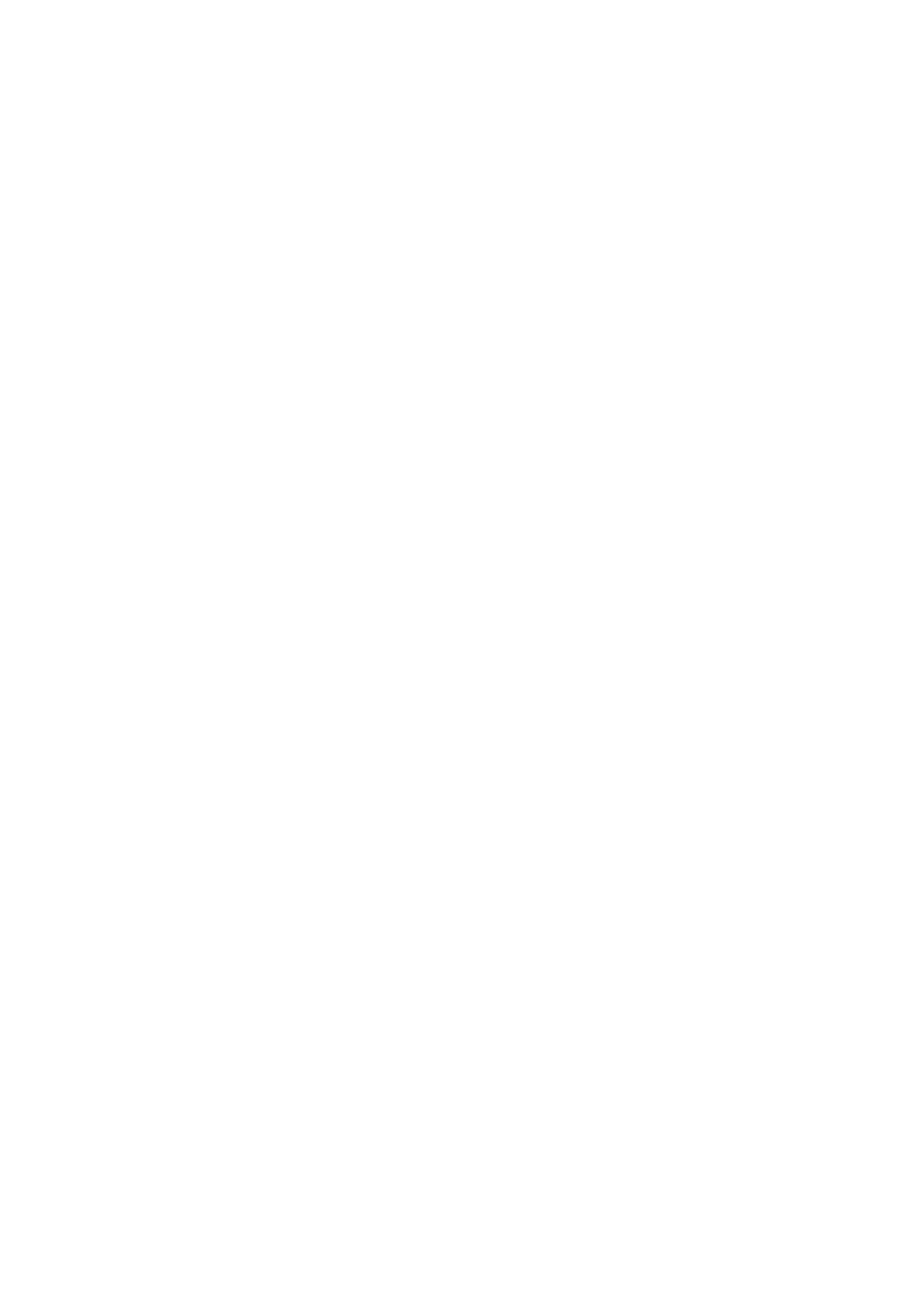




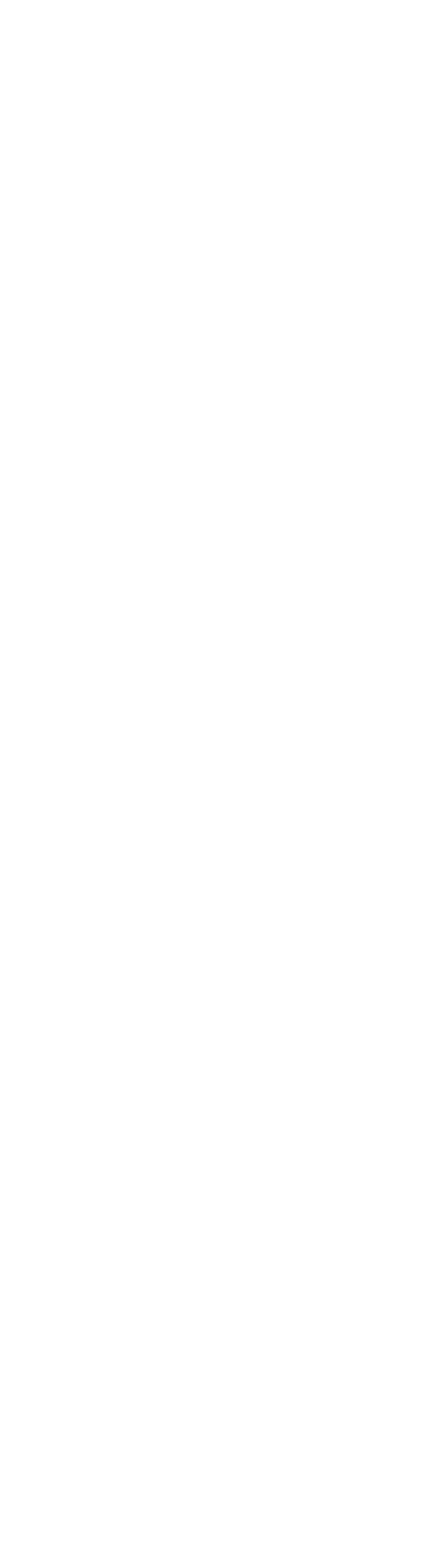




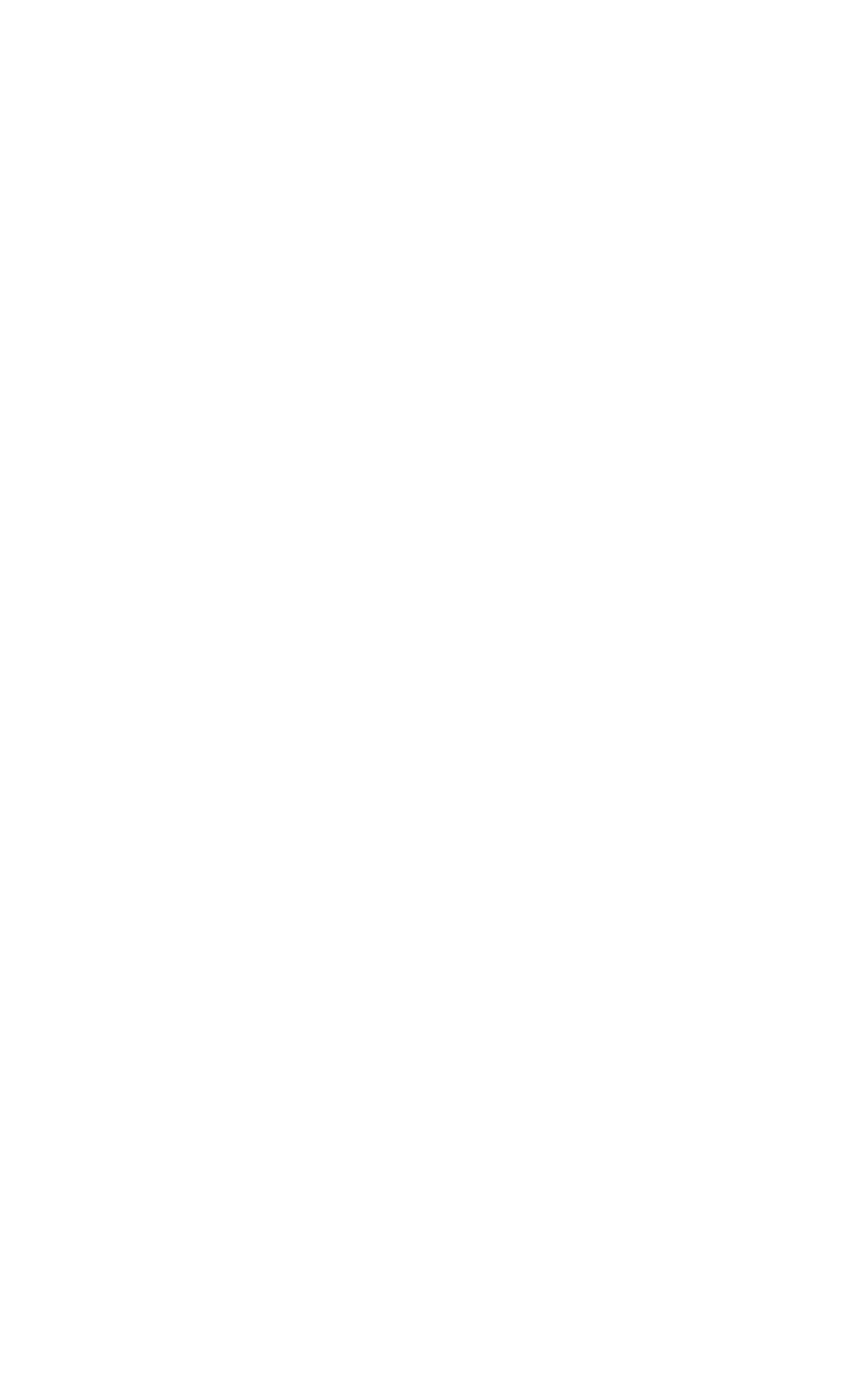




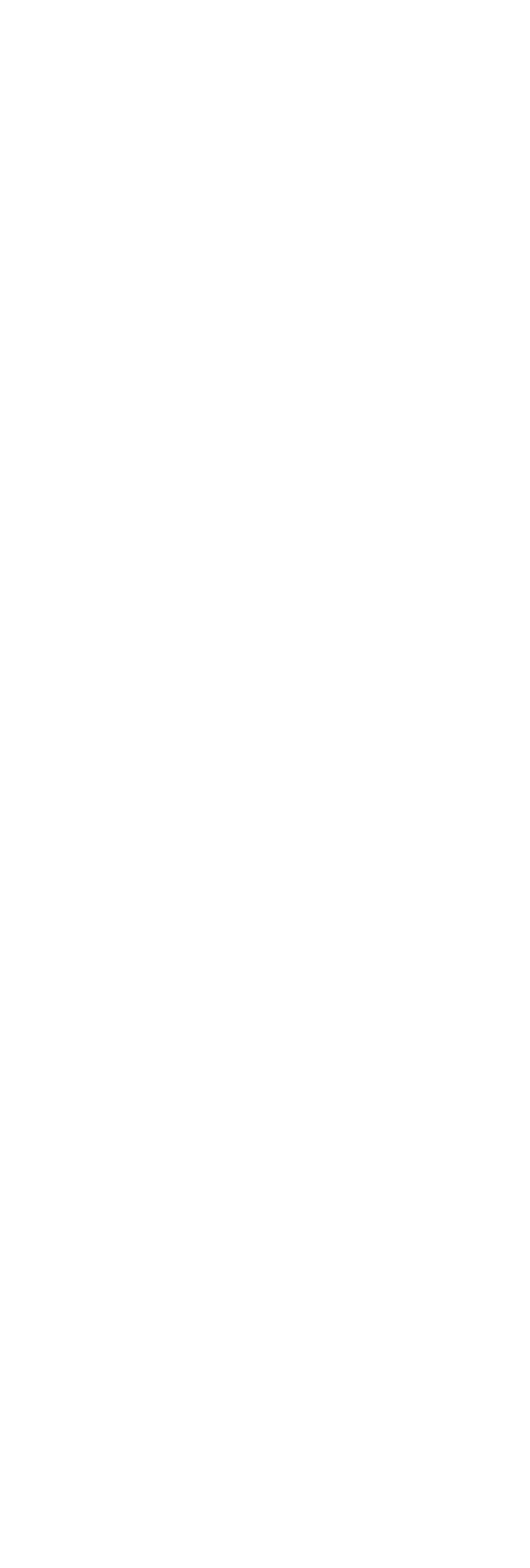




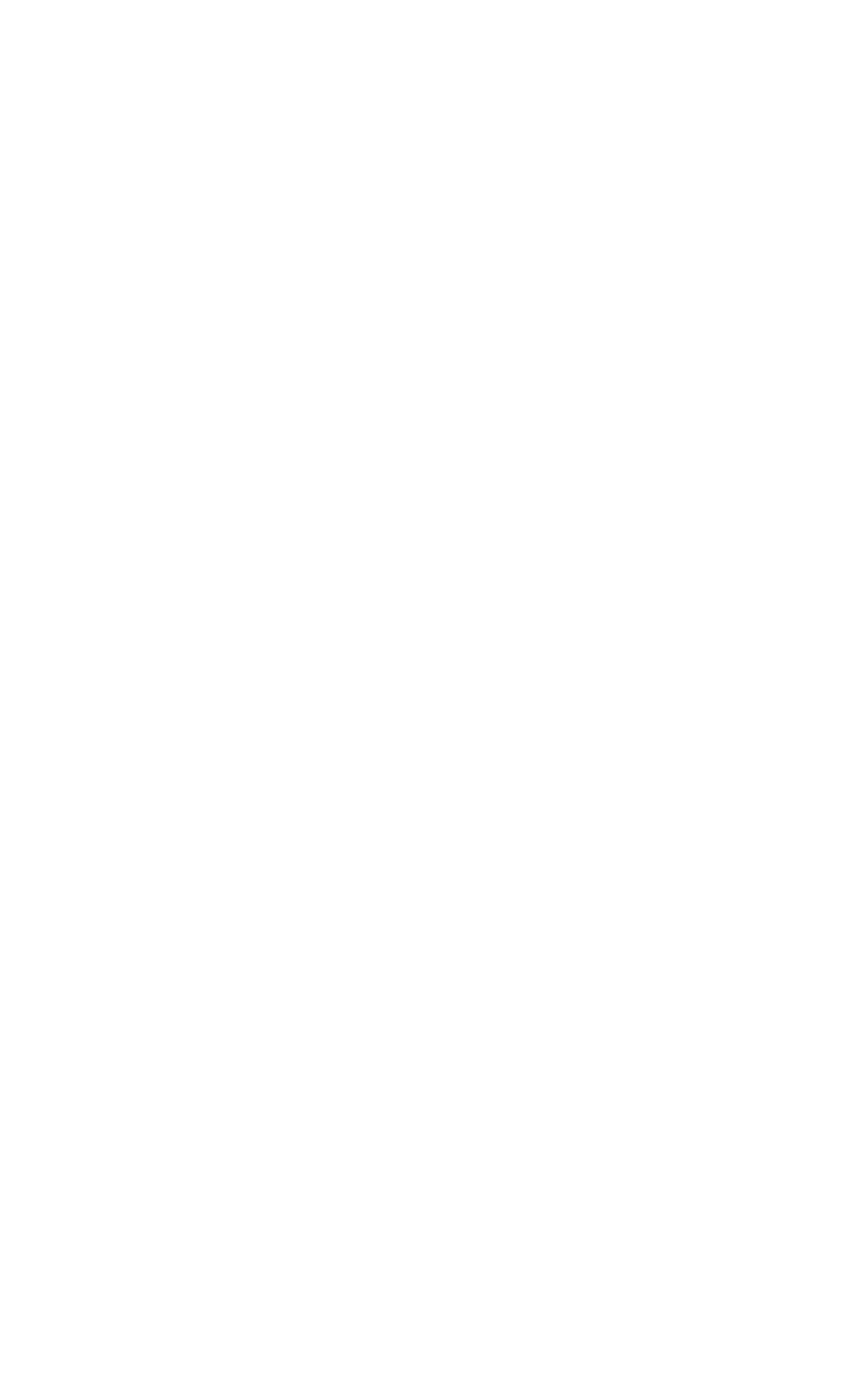




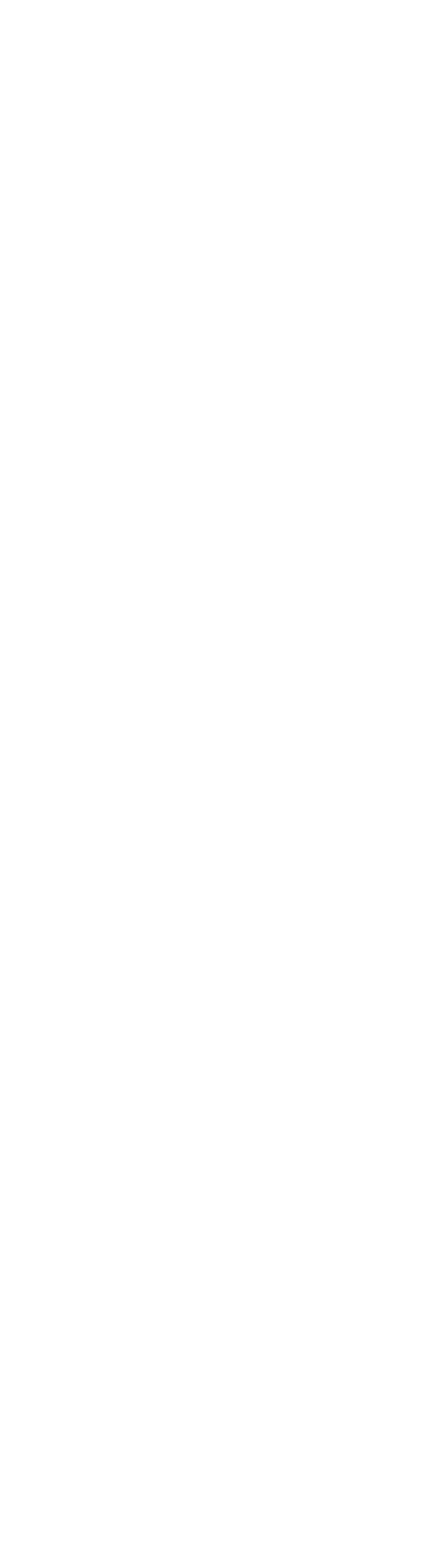




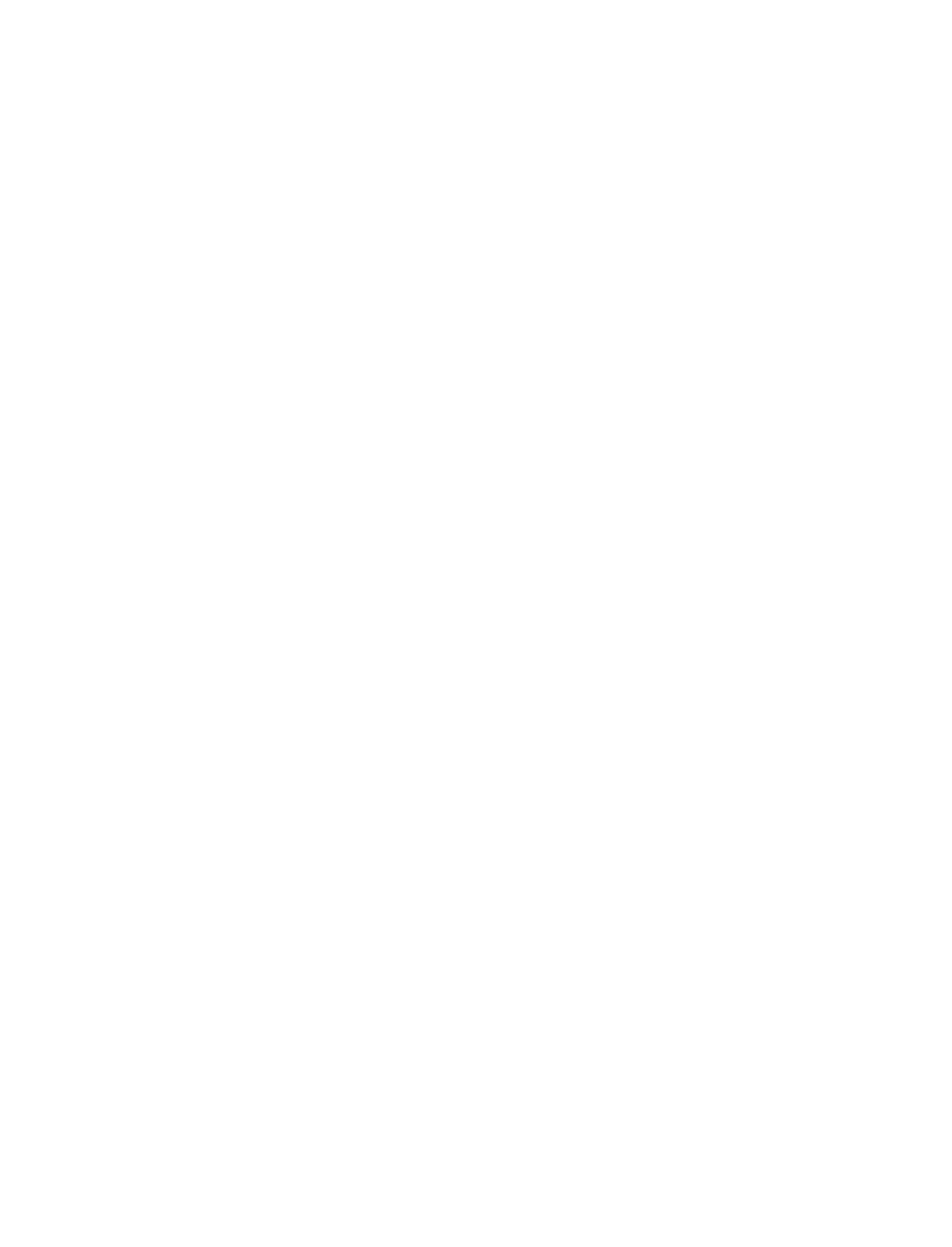




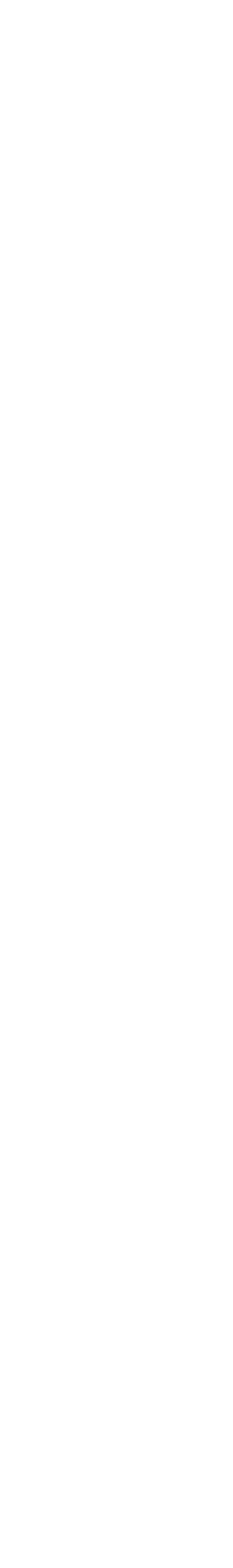

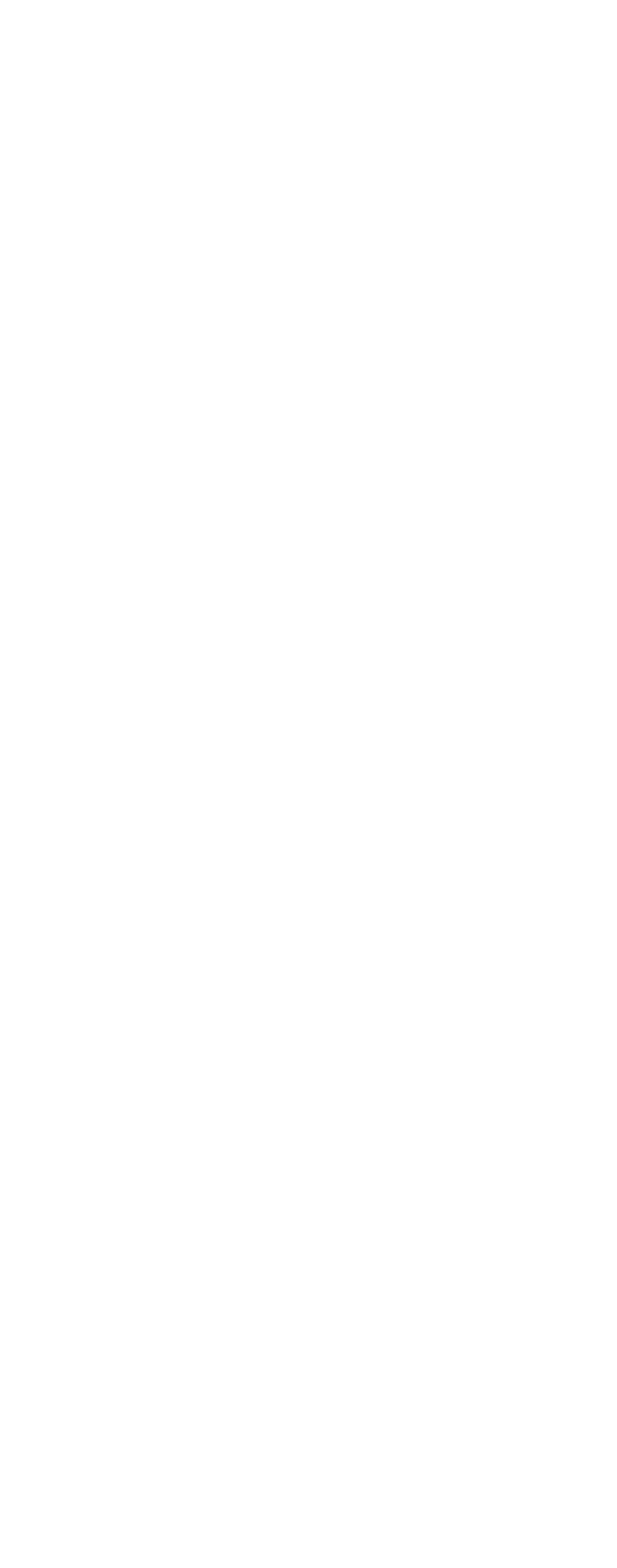




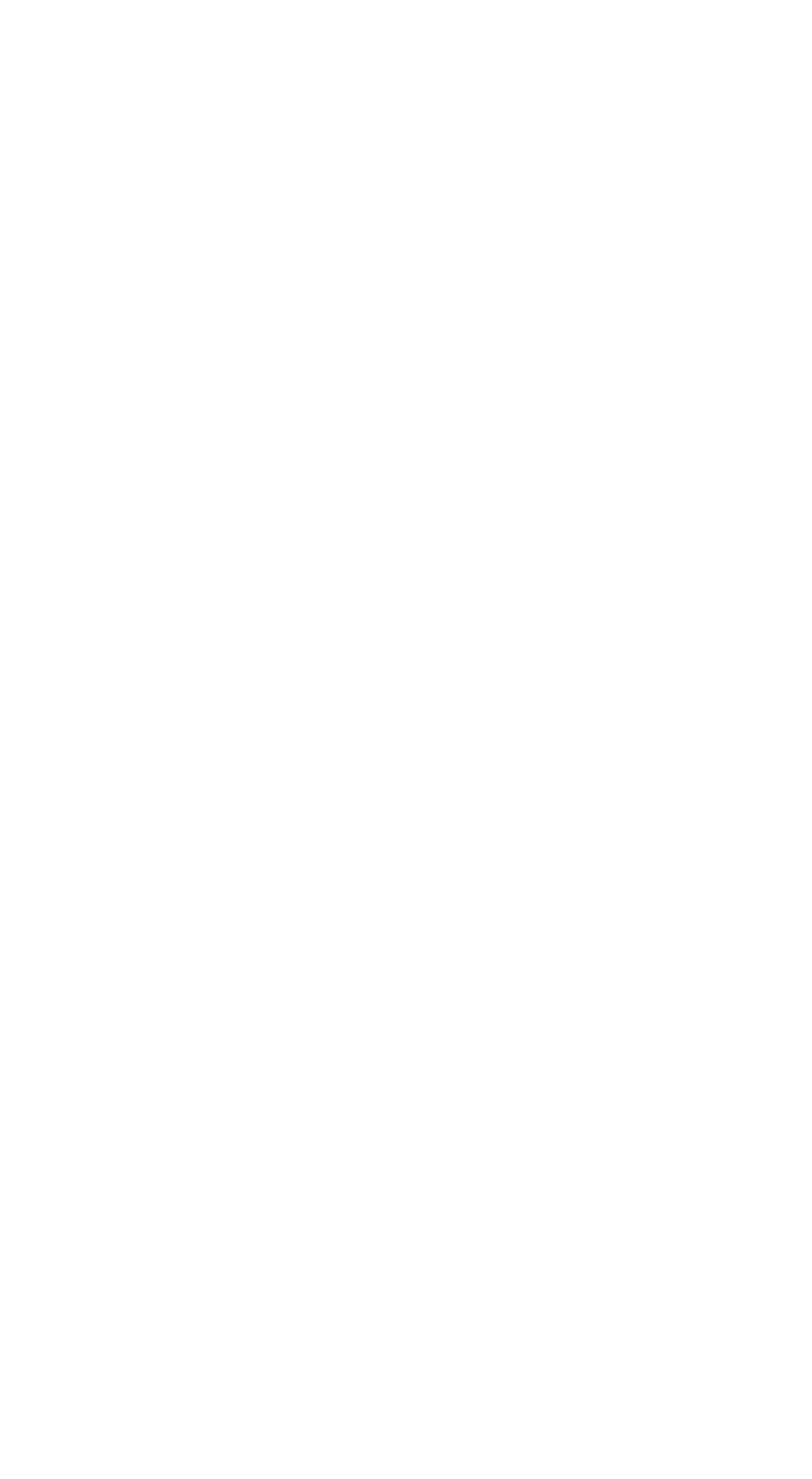




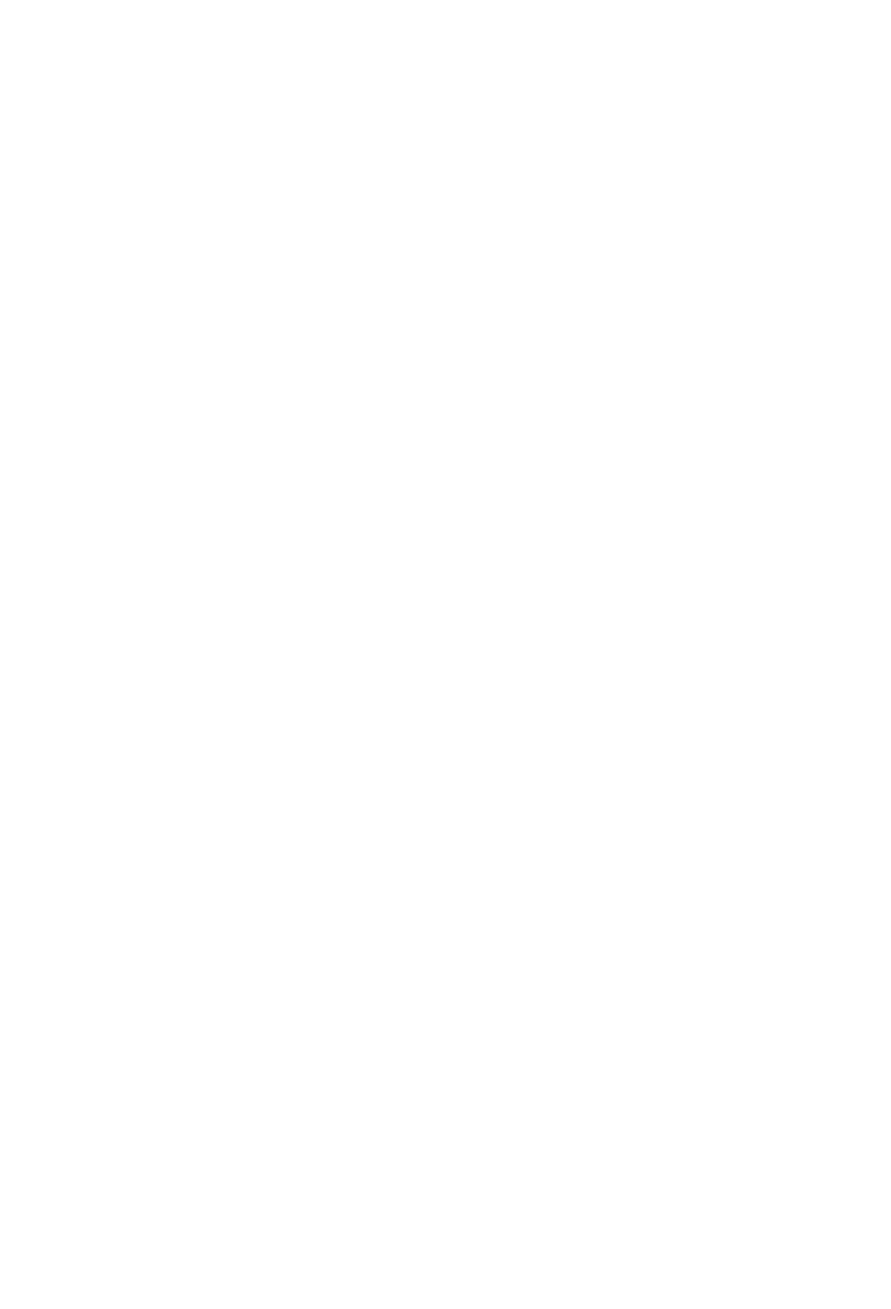




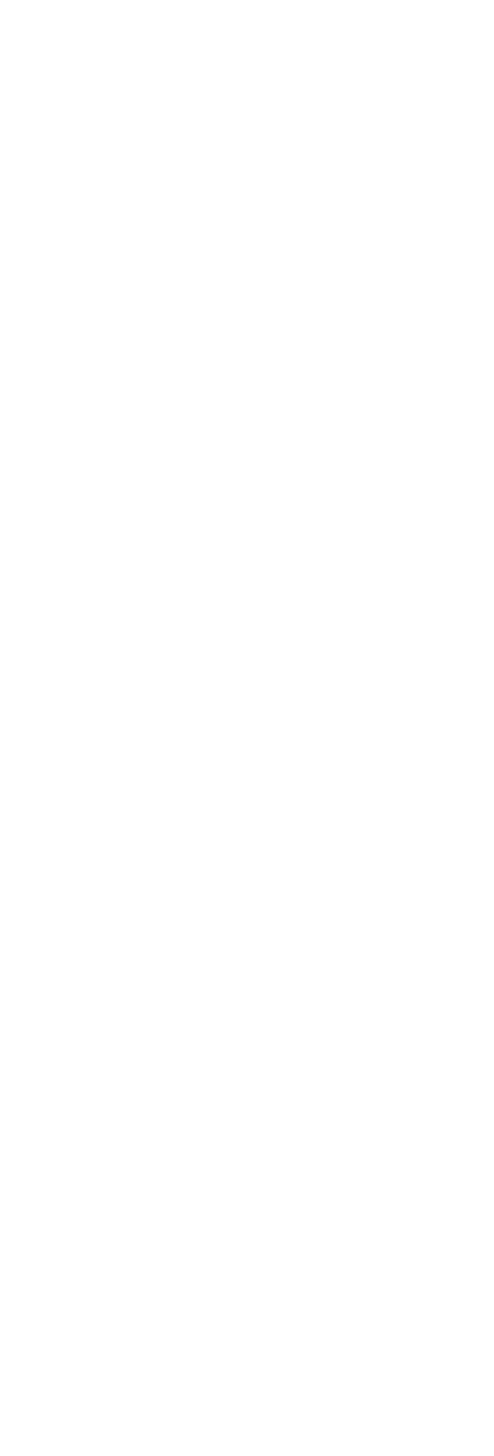




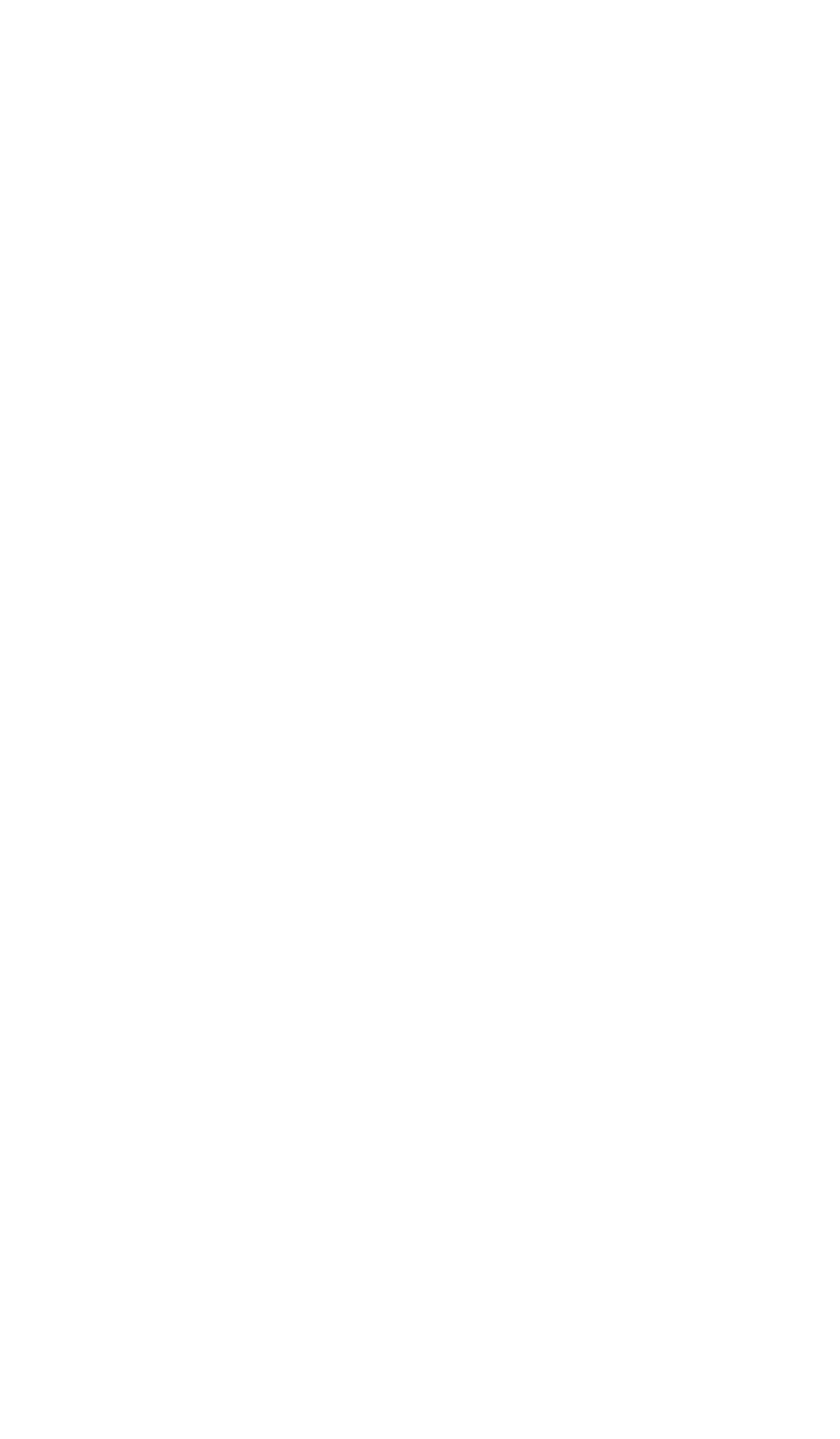




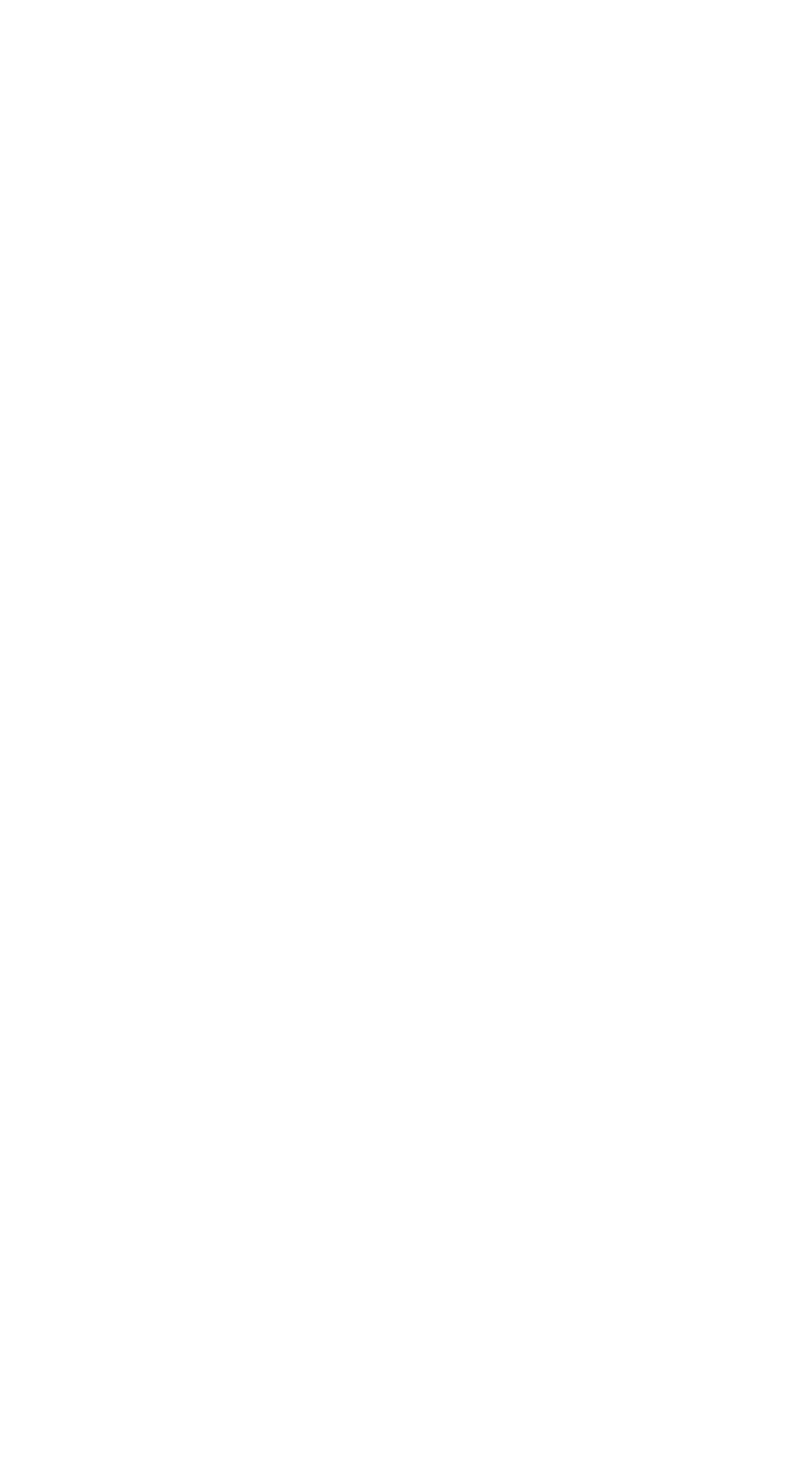




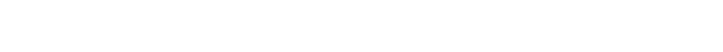

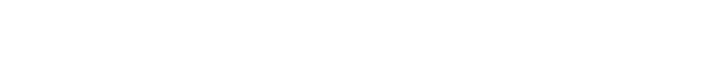

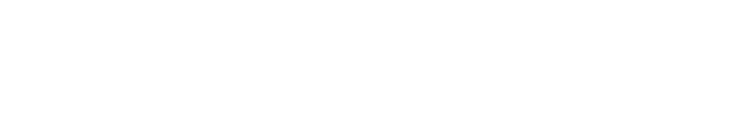

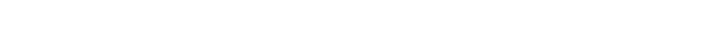

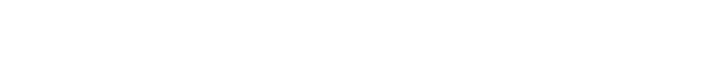

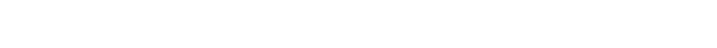

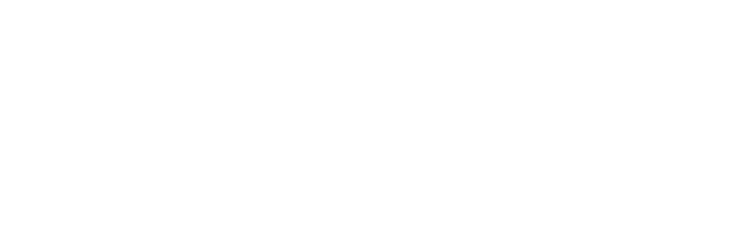

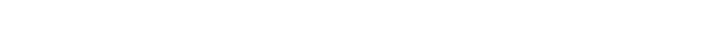
की.

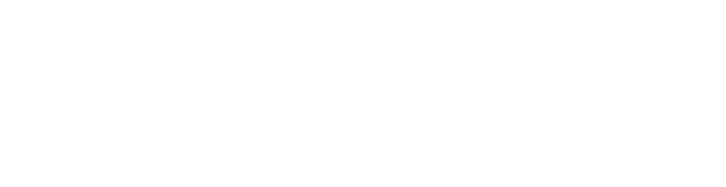

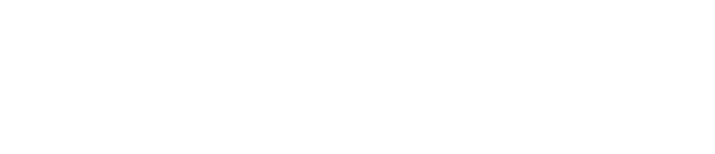

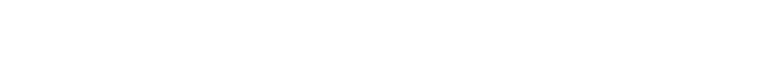

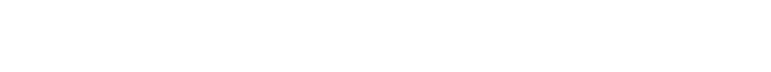
Oo

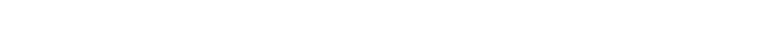

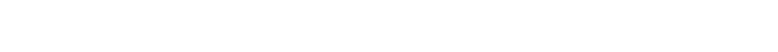

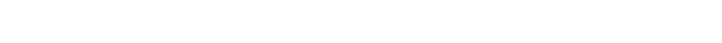

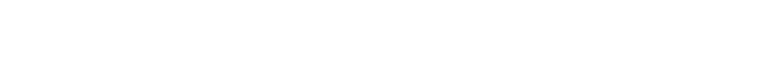
F⿻ำ 


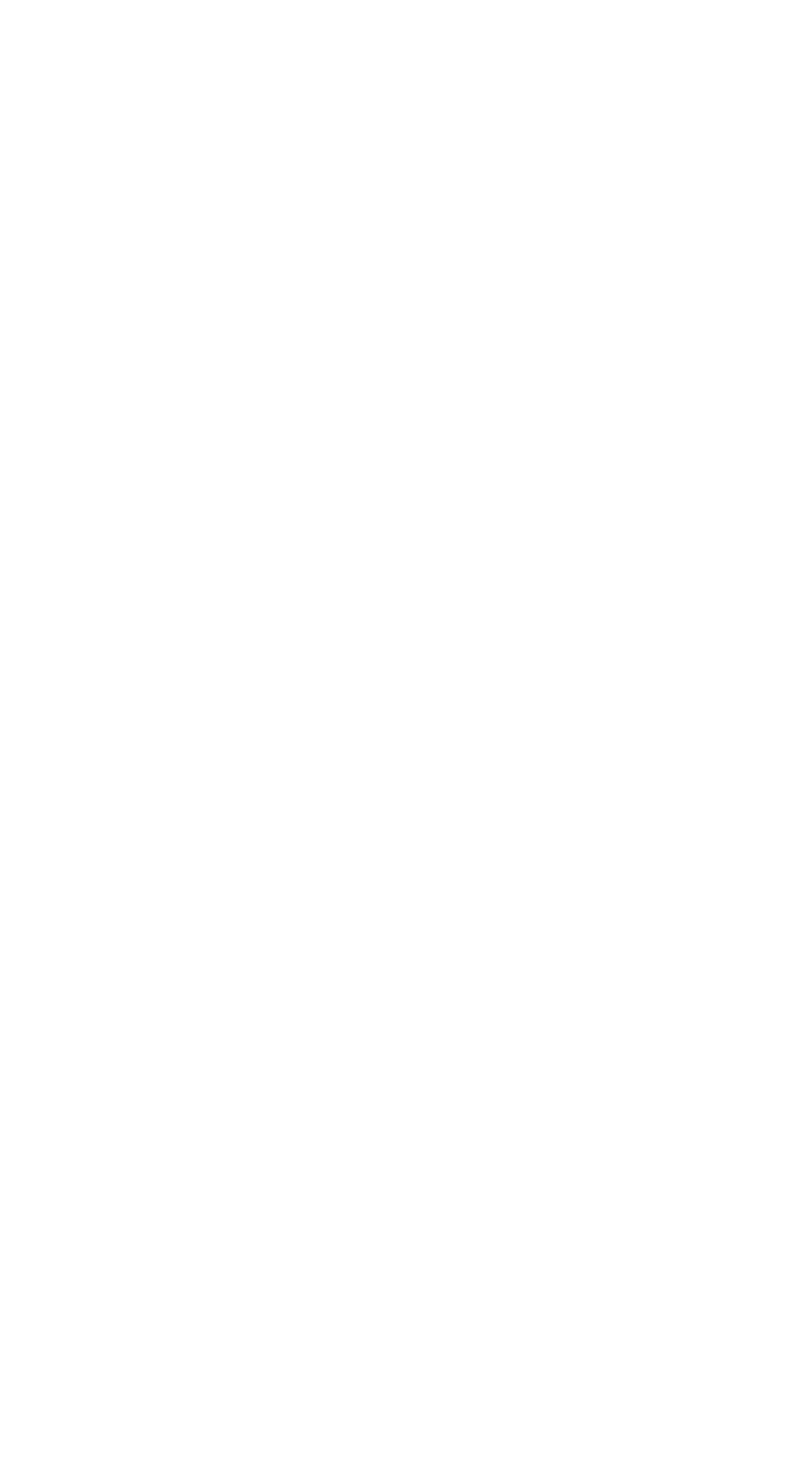




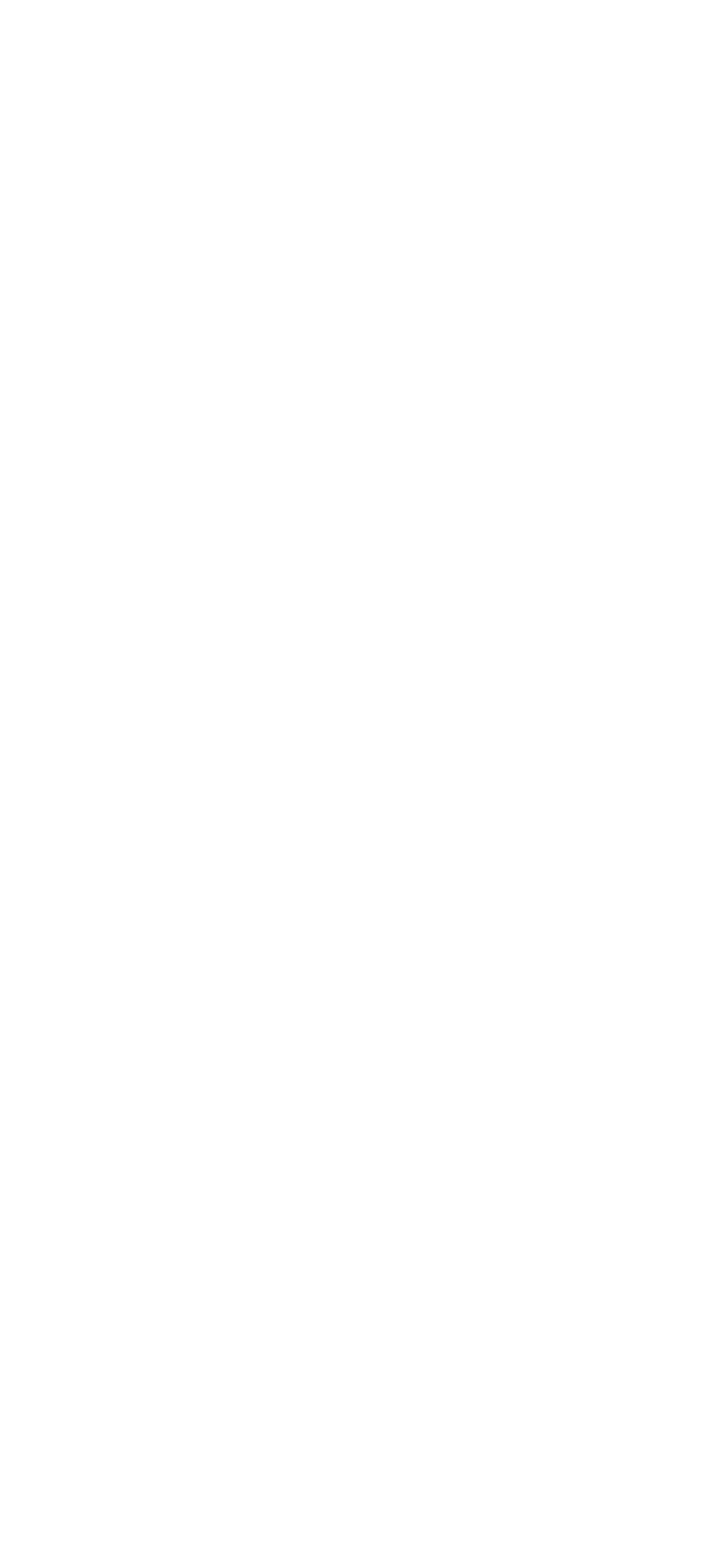




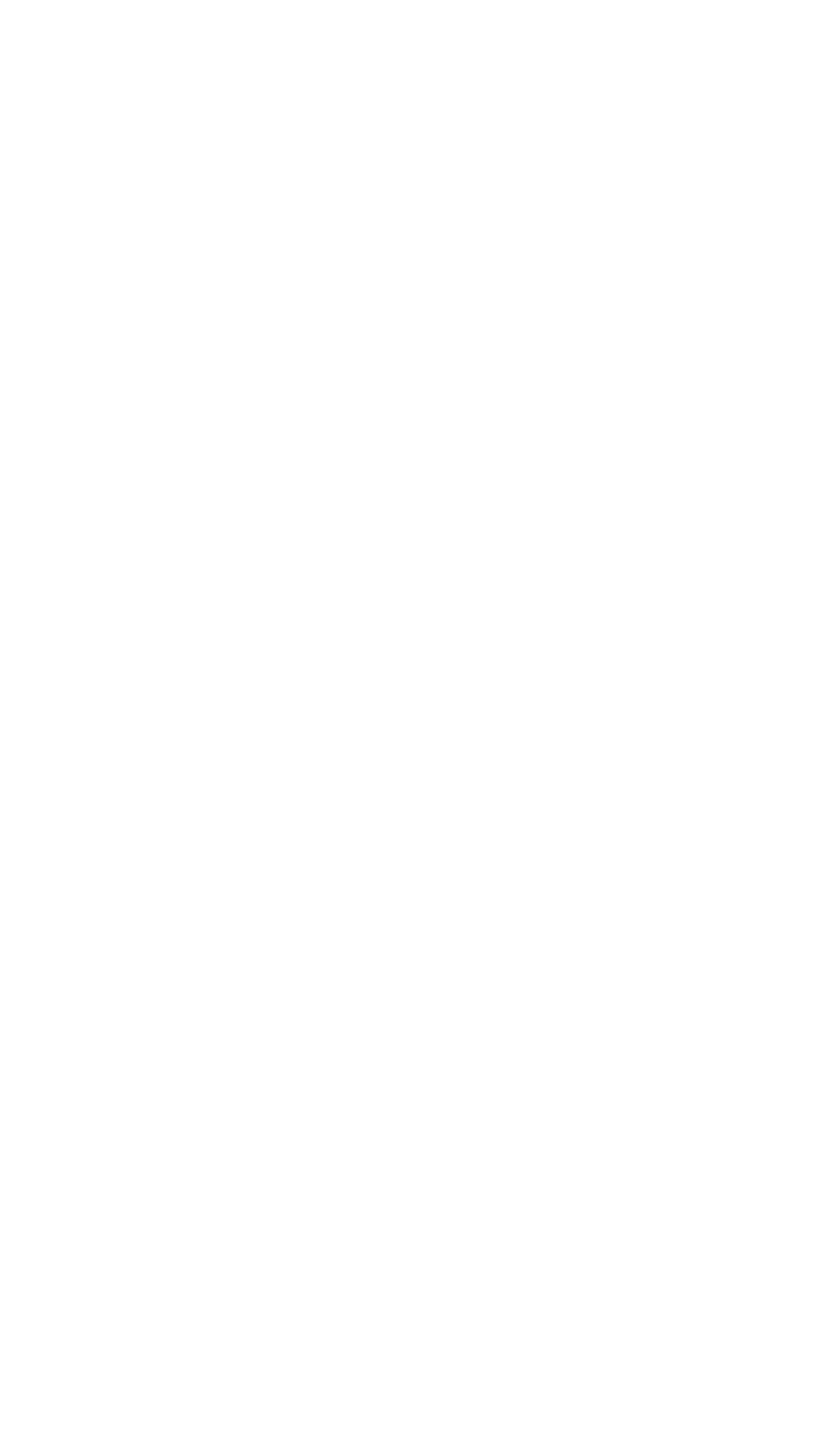




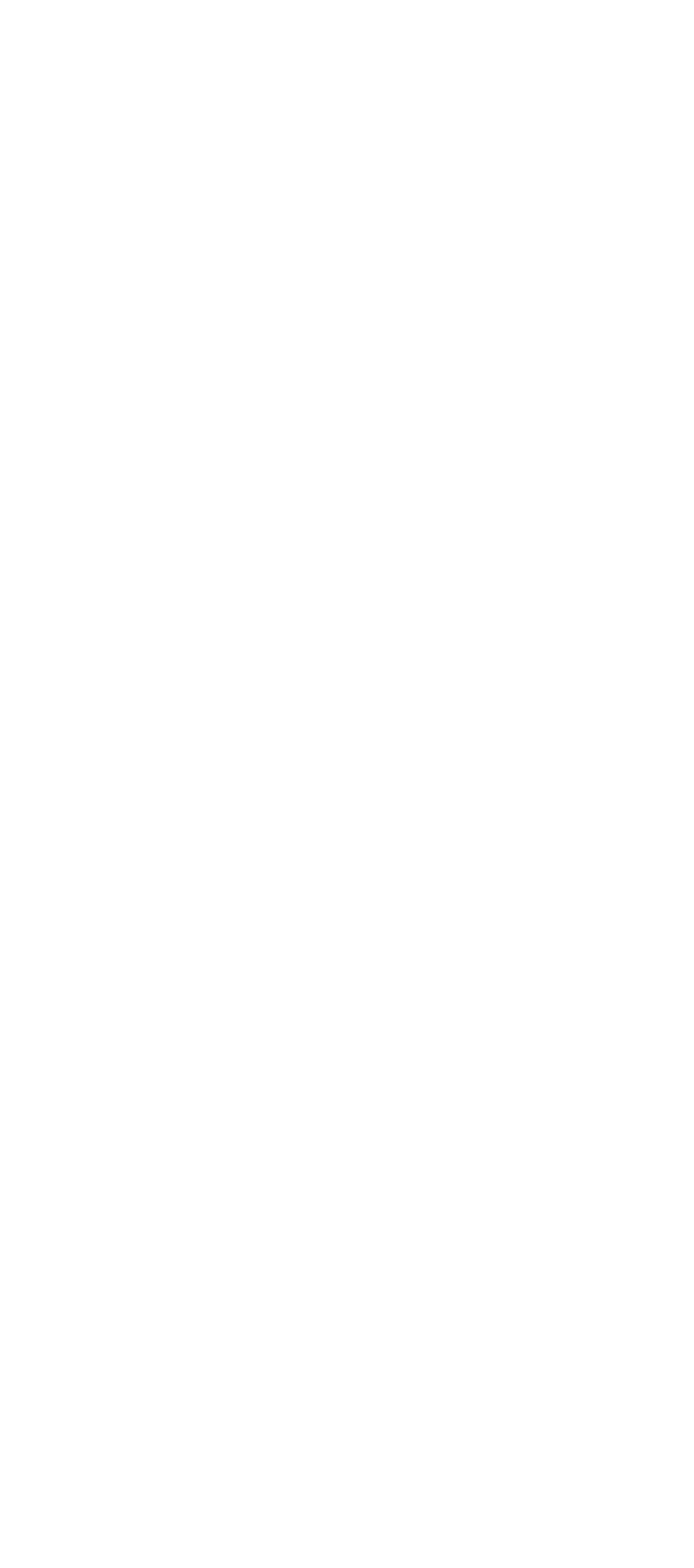




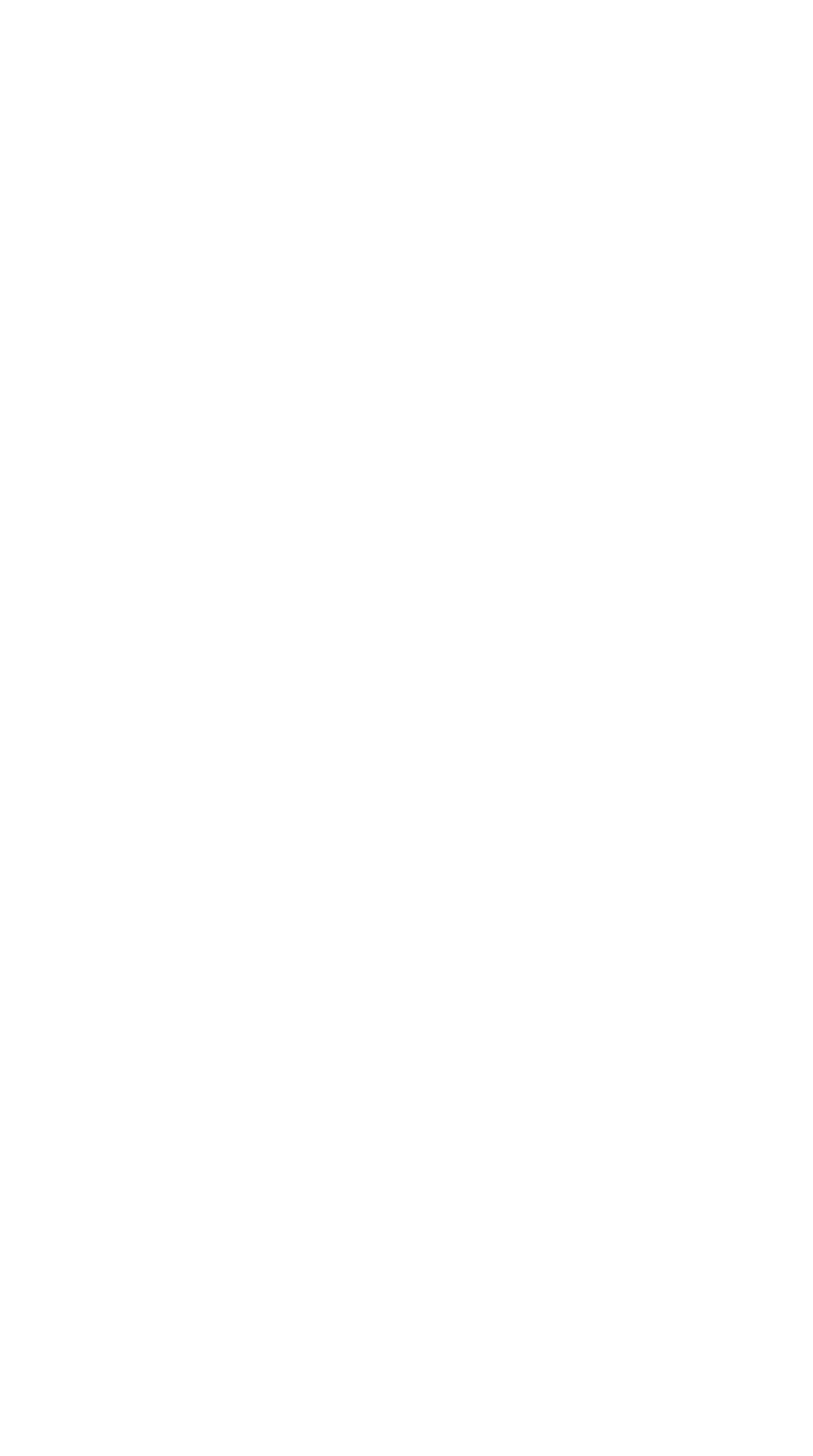




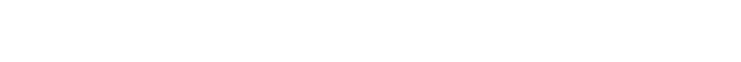

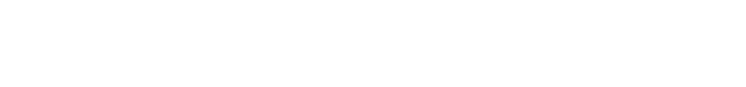

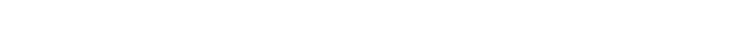

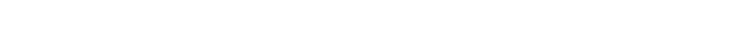

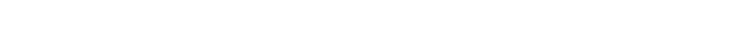

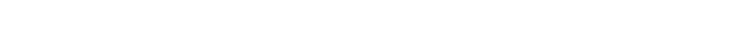

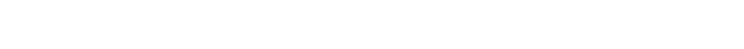

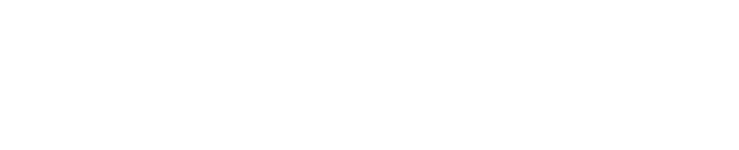

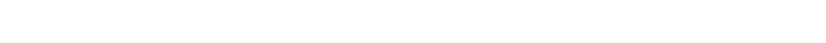

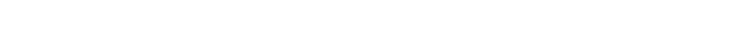
\הำ

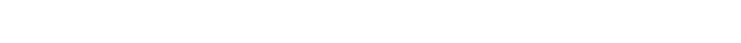
Gg

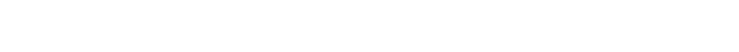

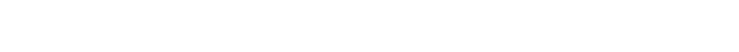

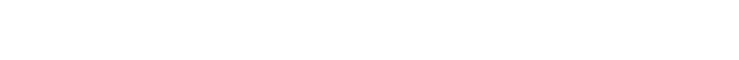

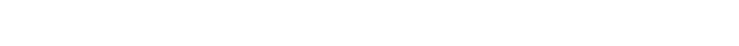
\%.

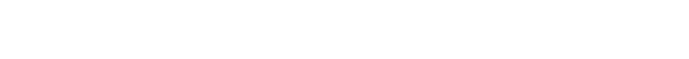

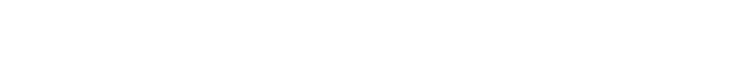
ลู่สม ล

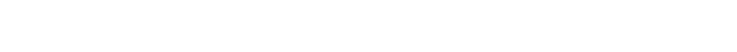

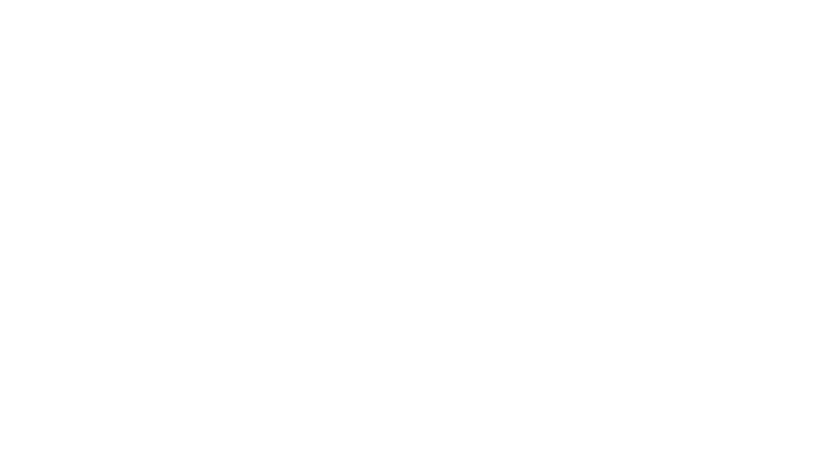




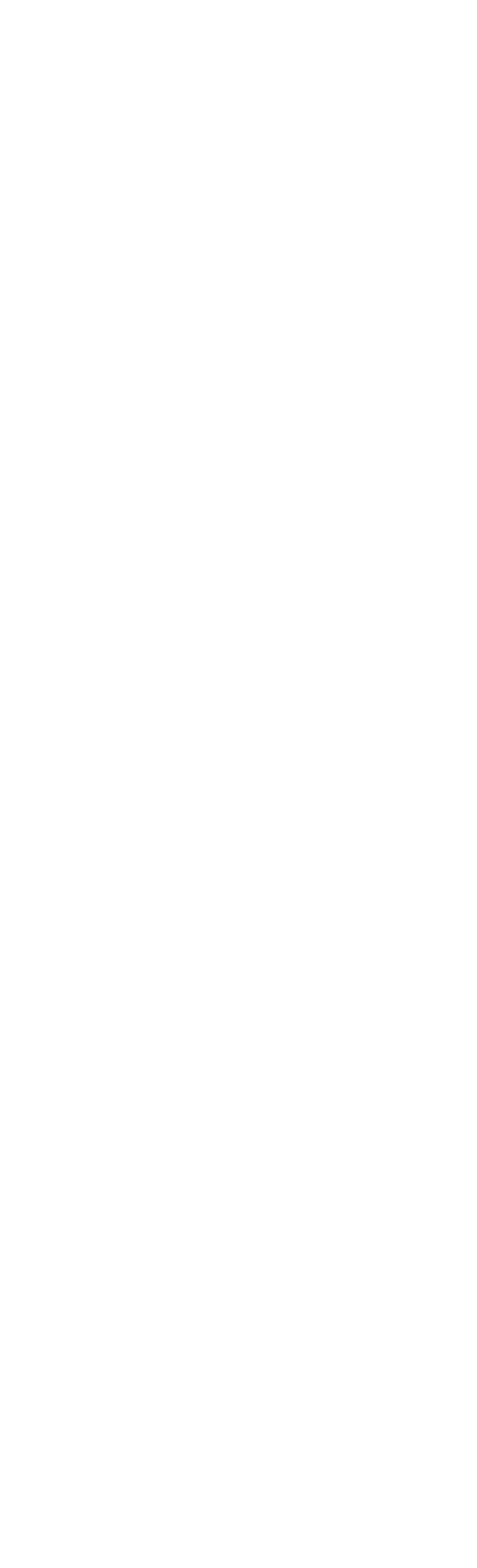




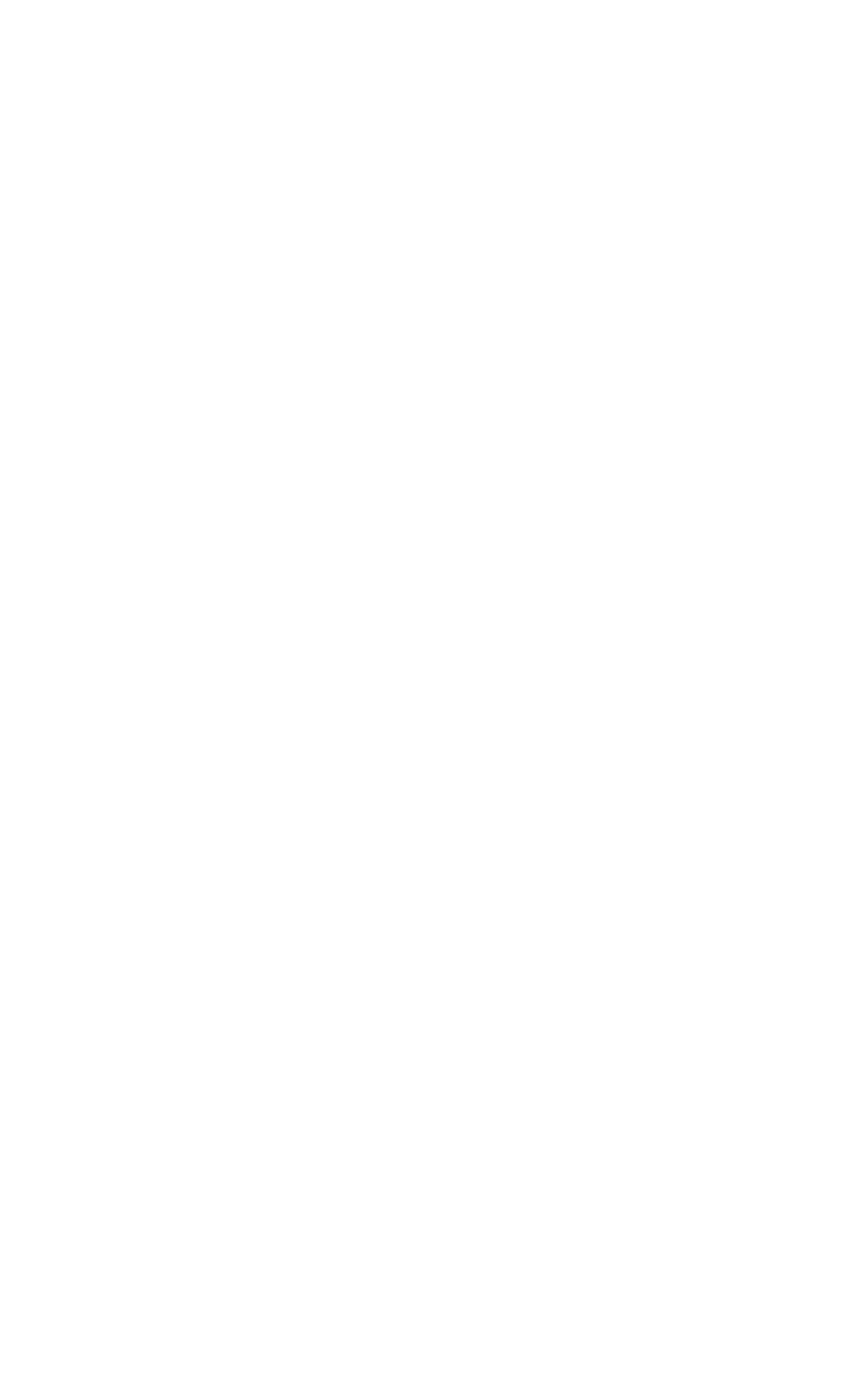




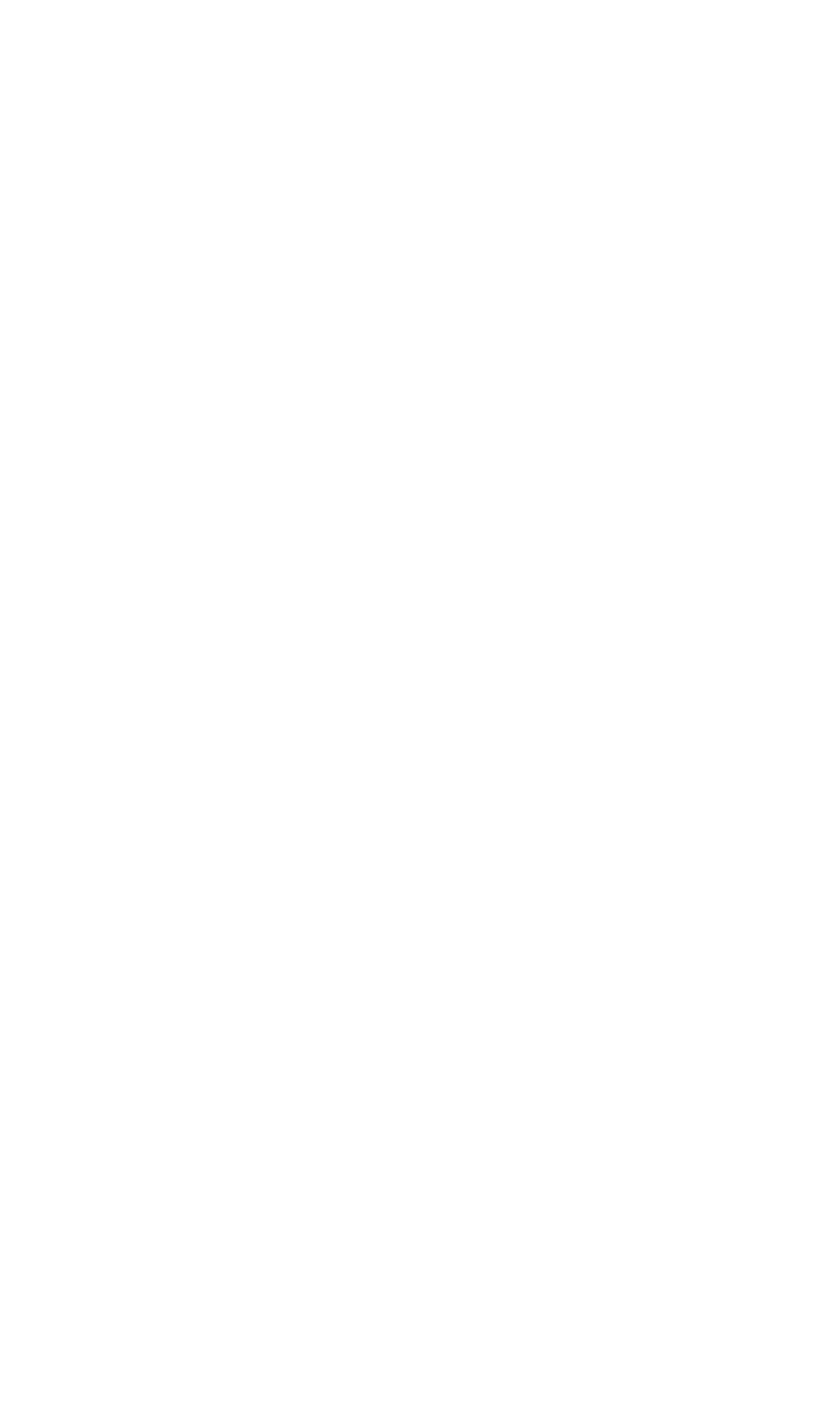




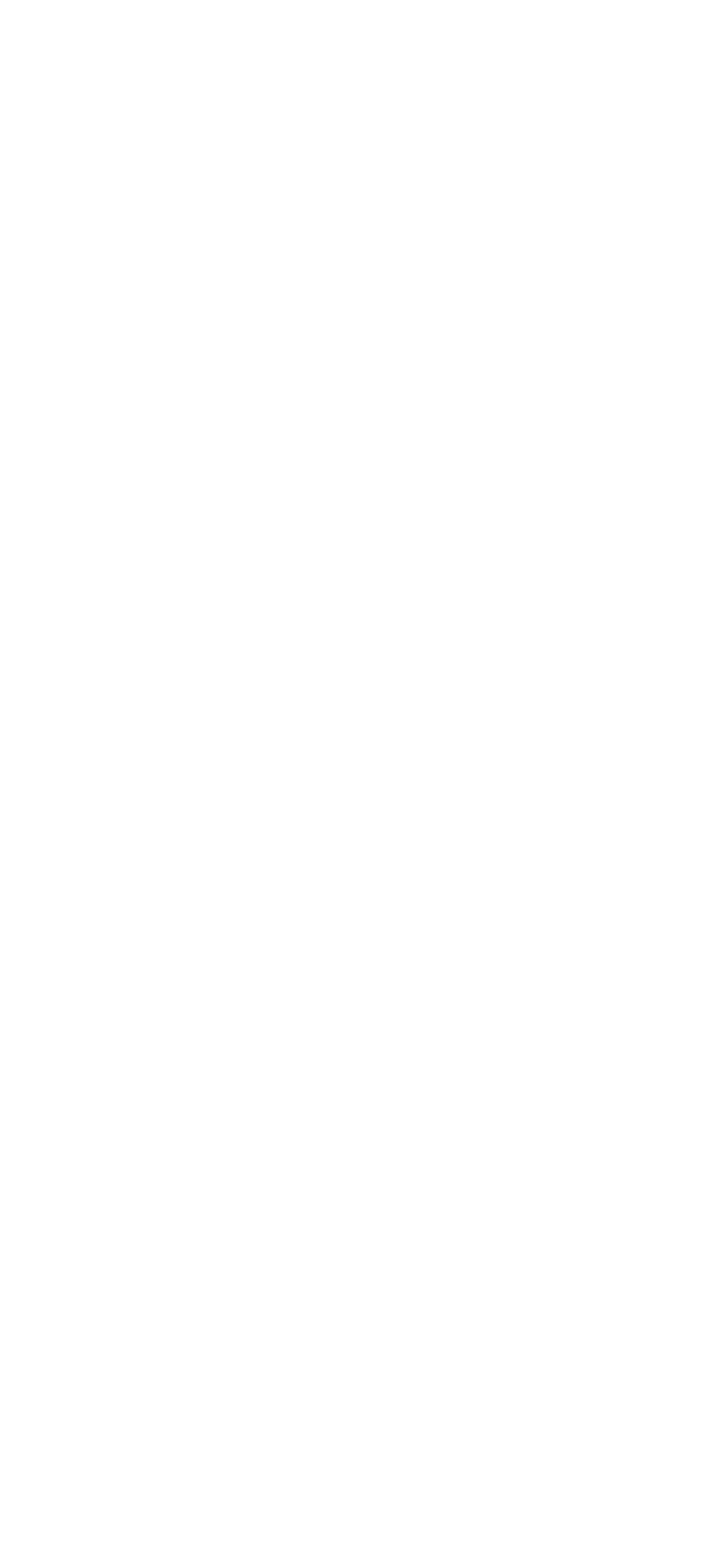




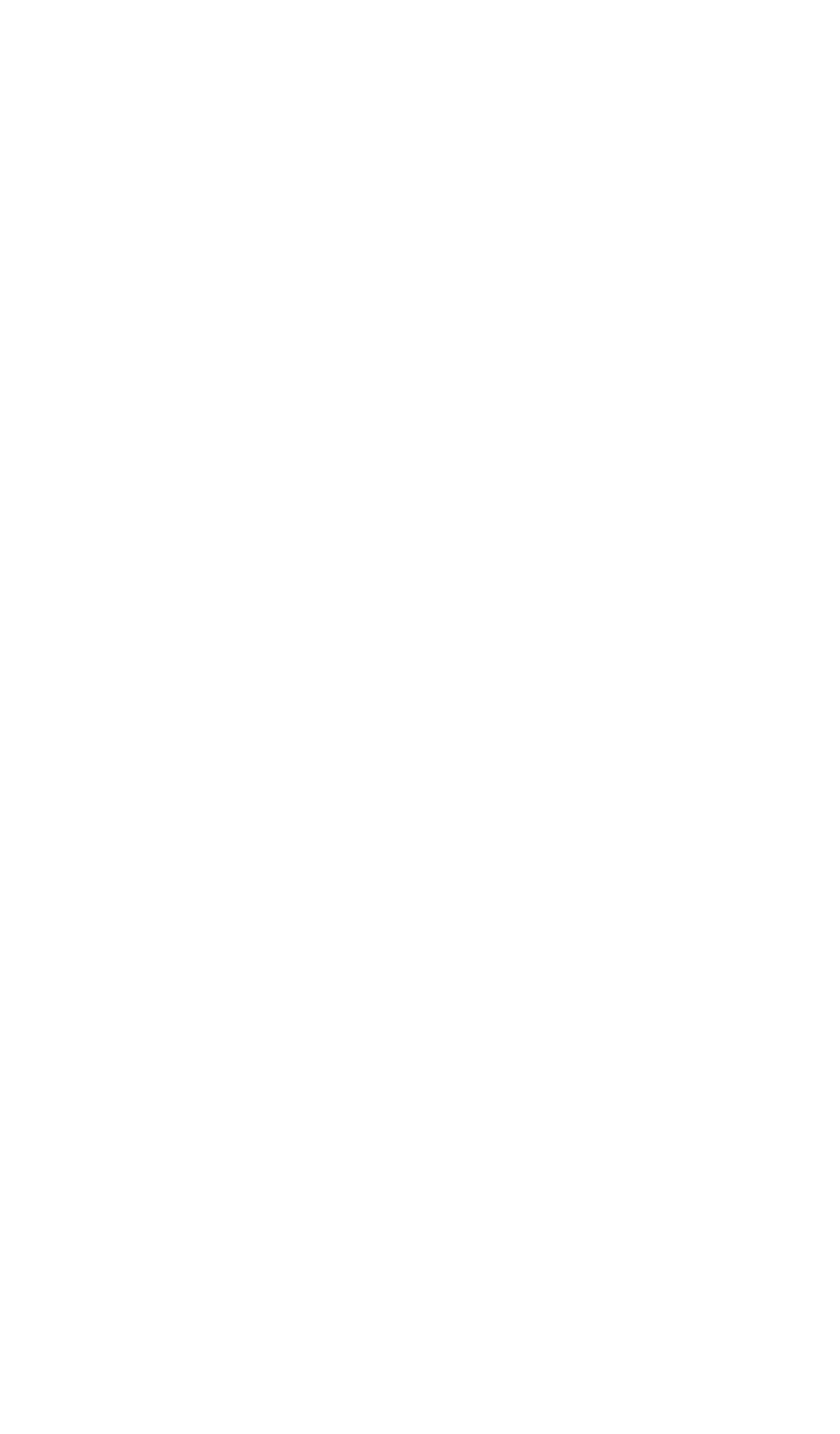




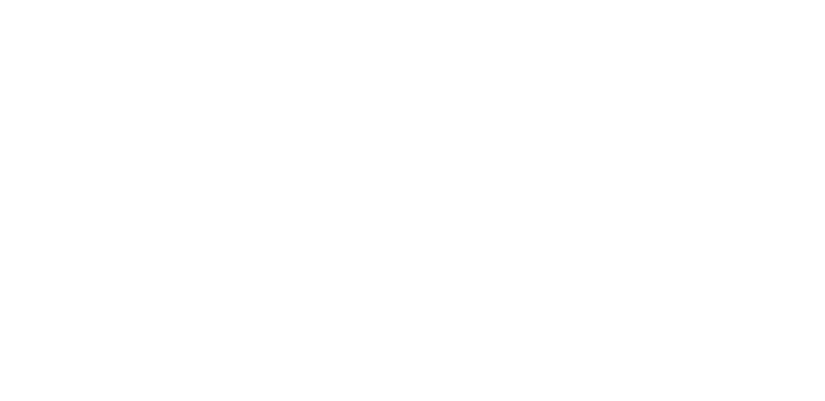

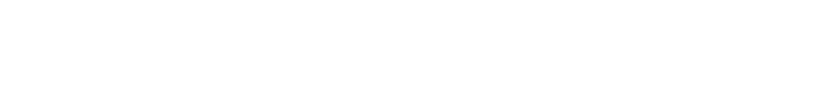

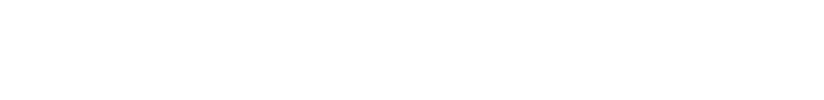

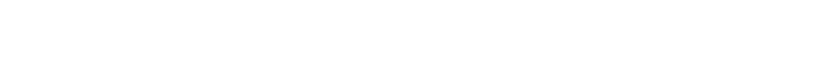

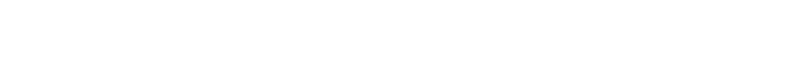

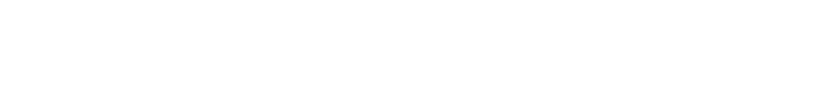
a

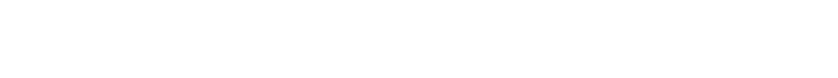
D

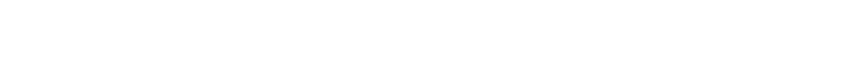

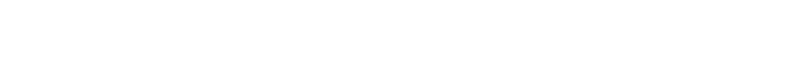
递圈

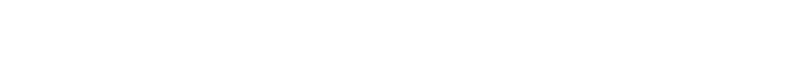

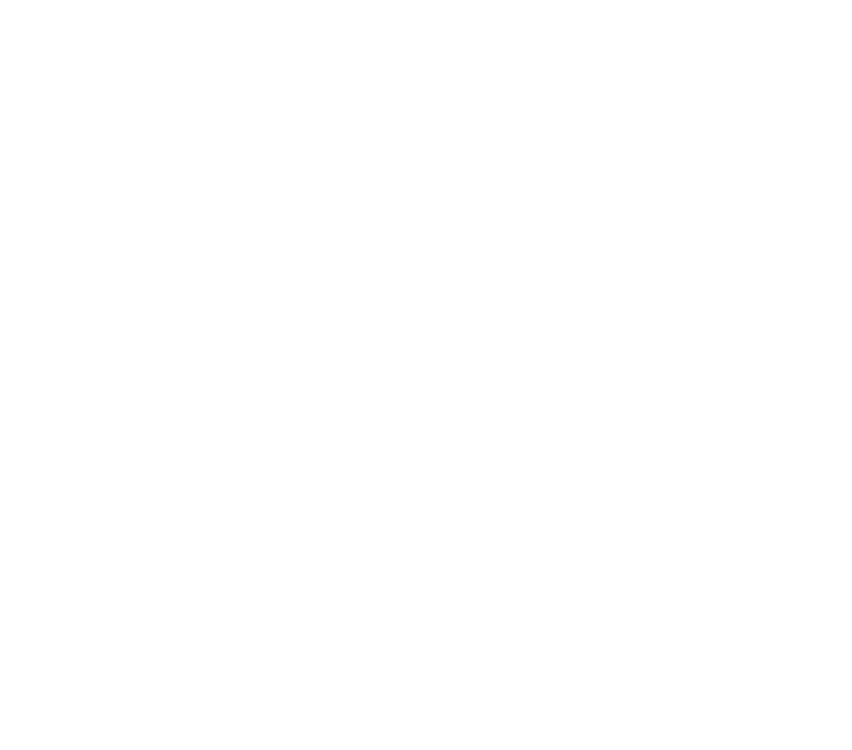




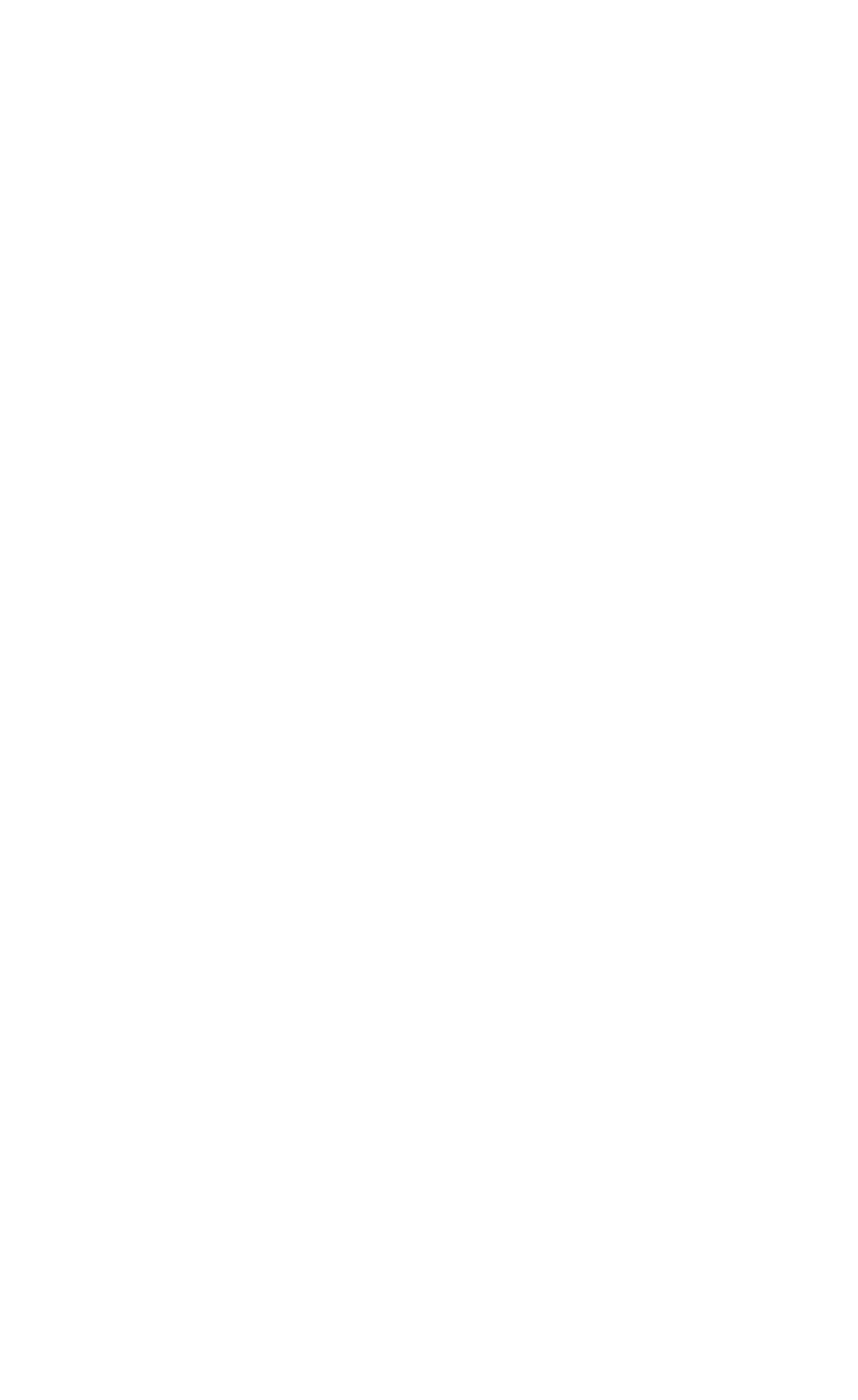




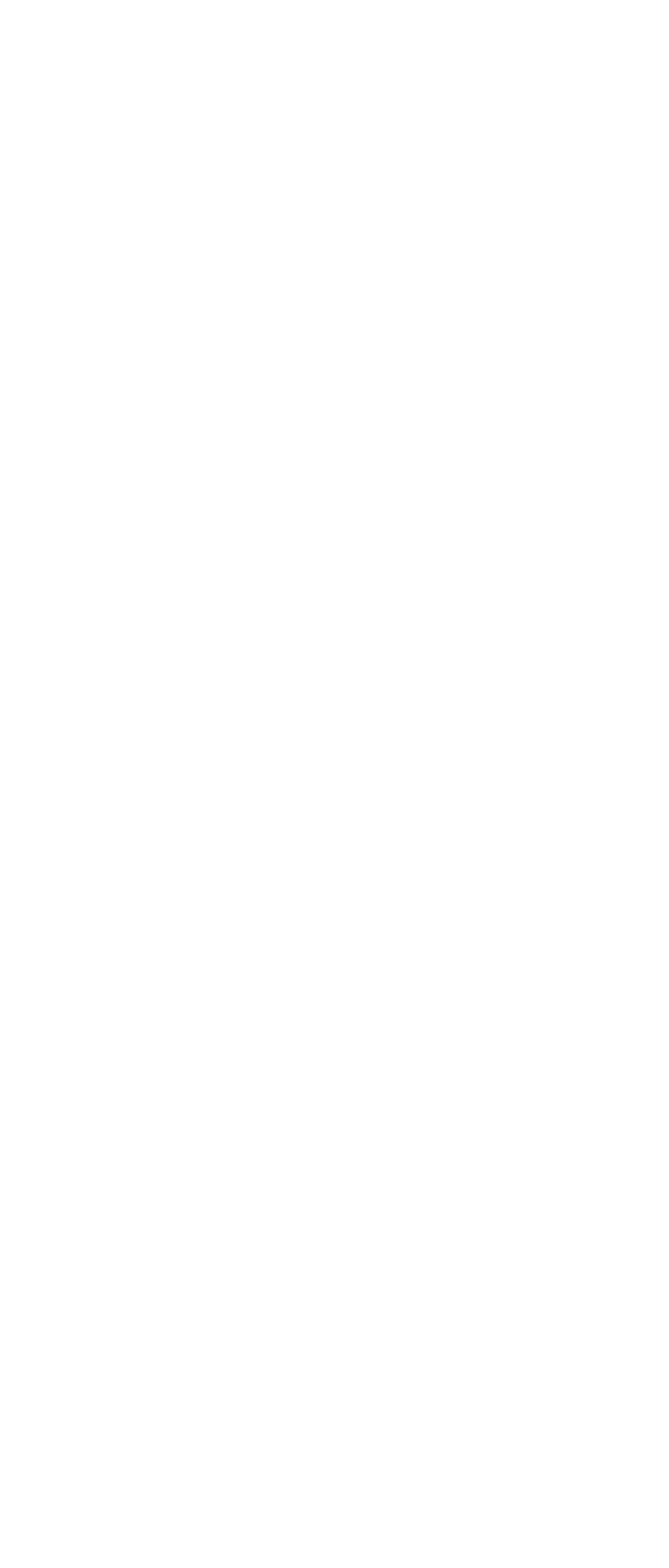




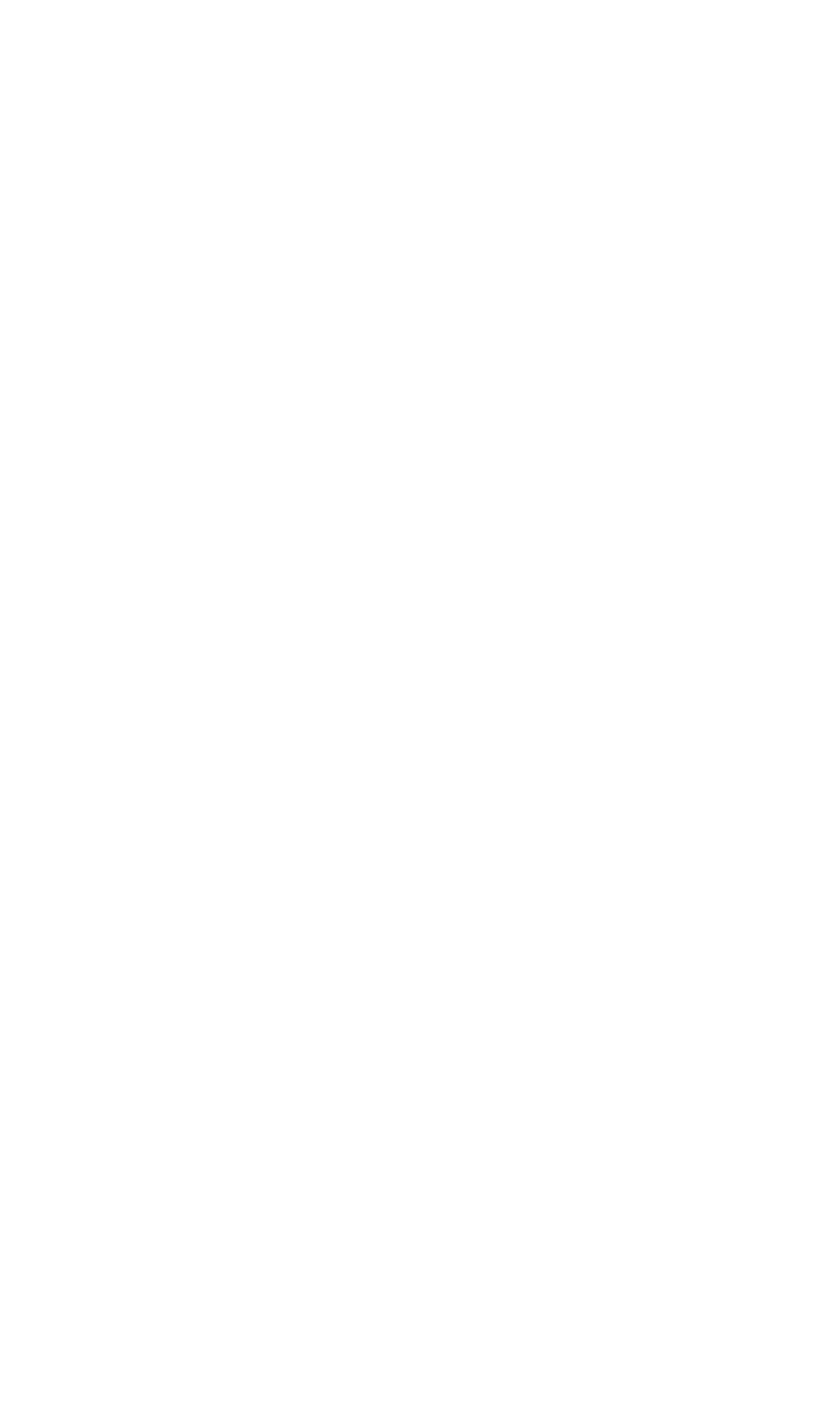




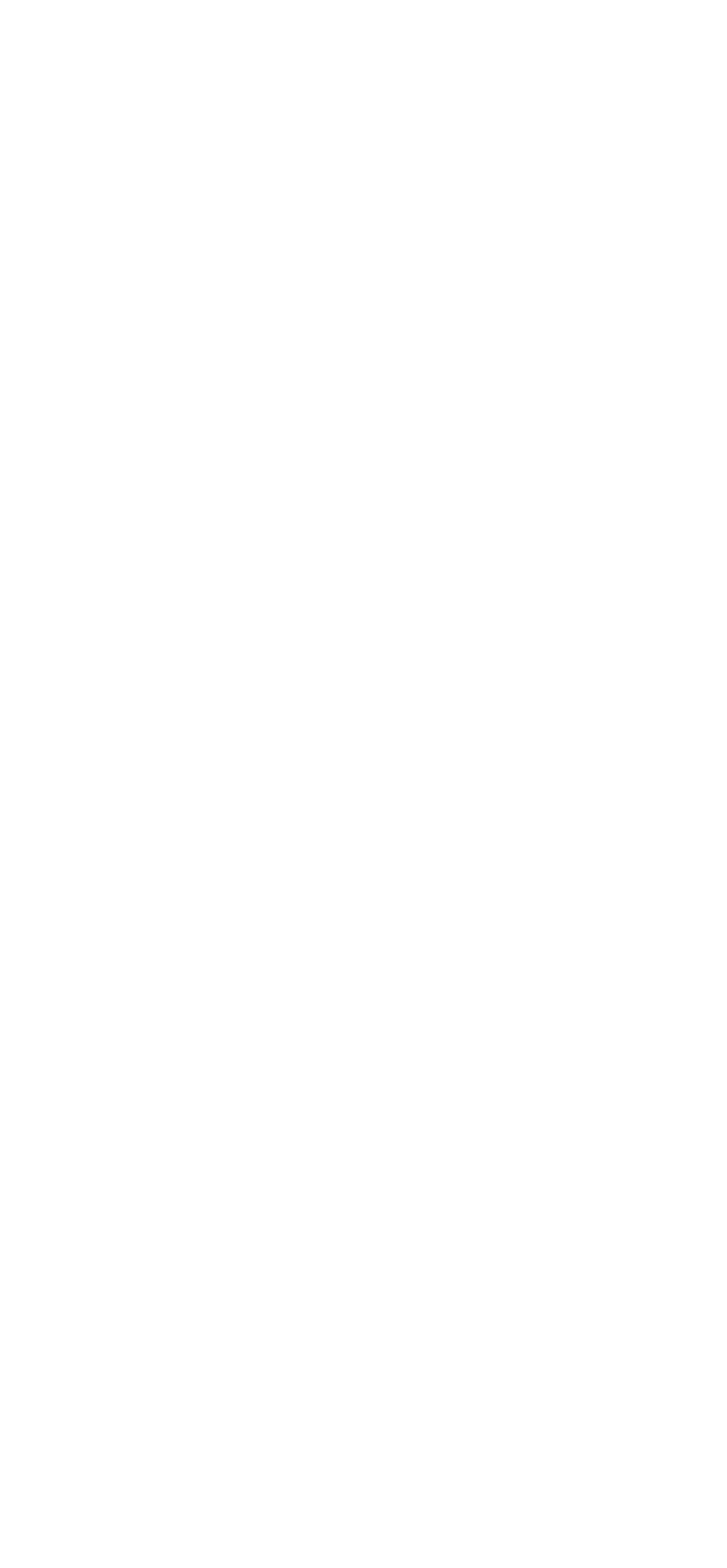




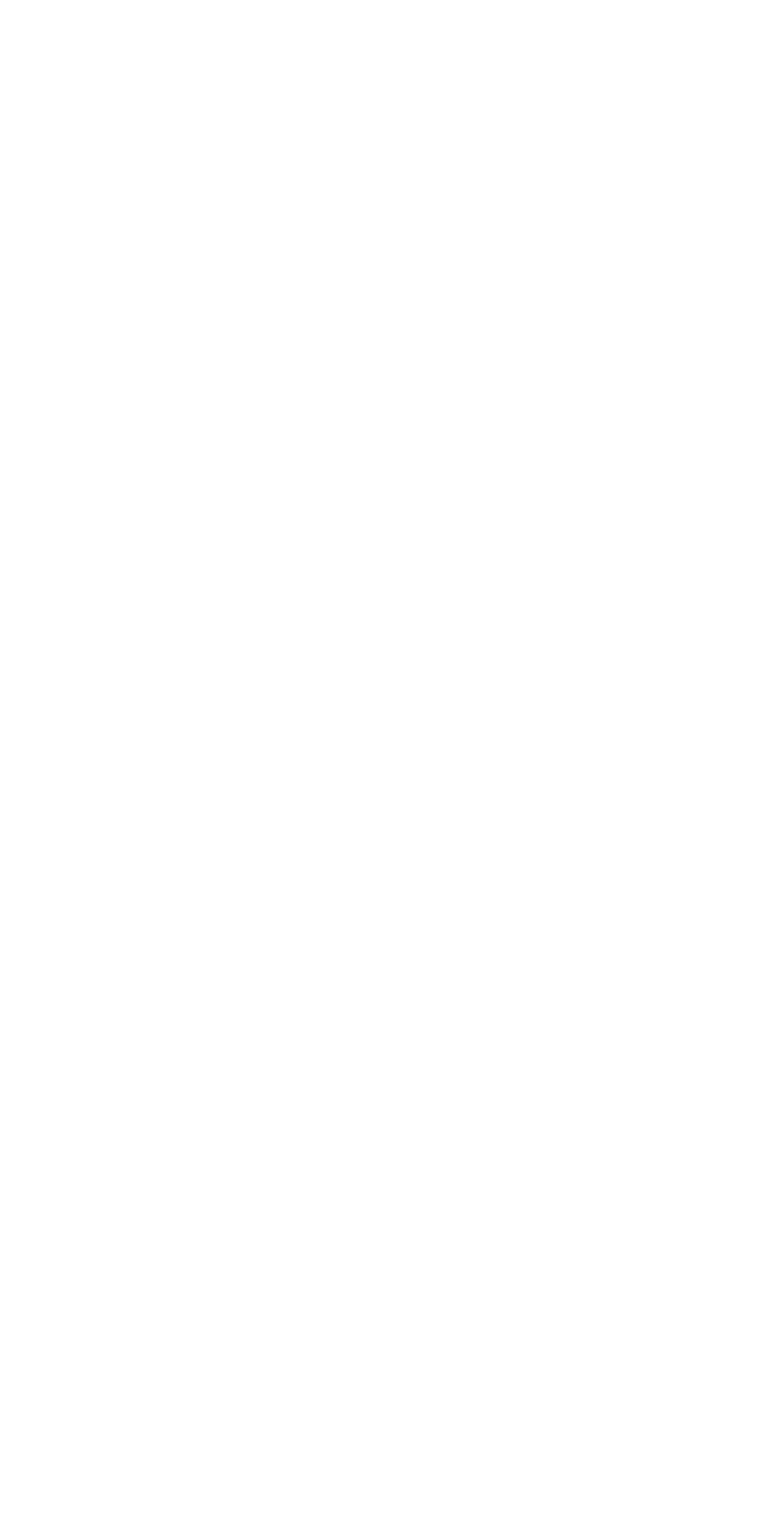




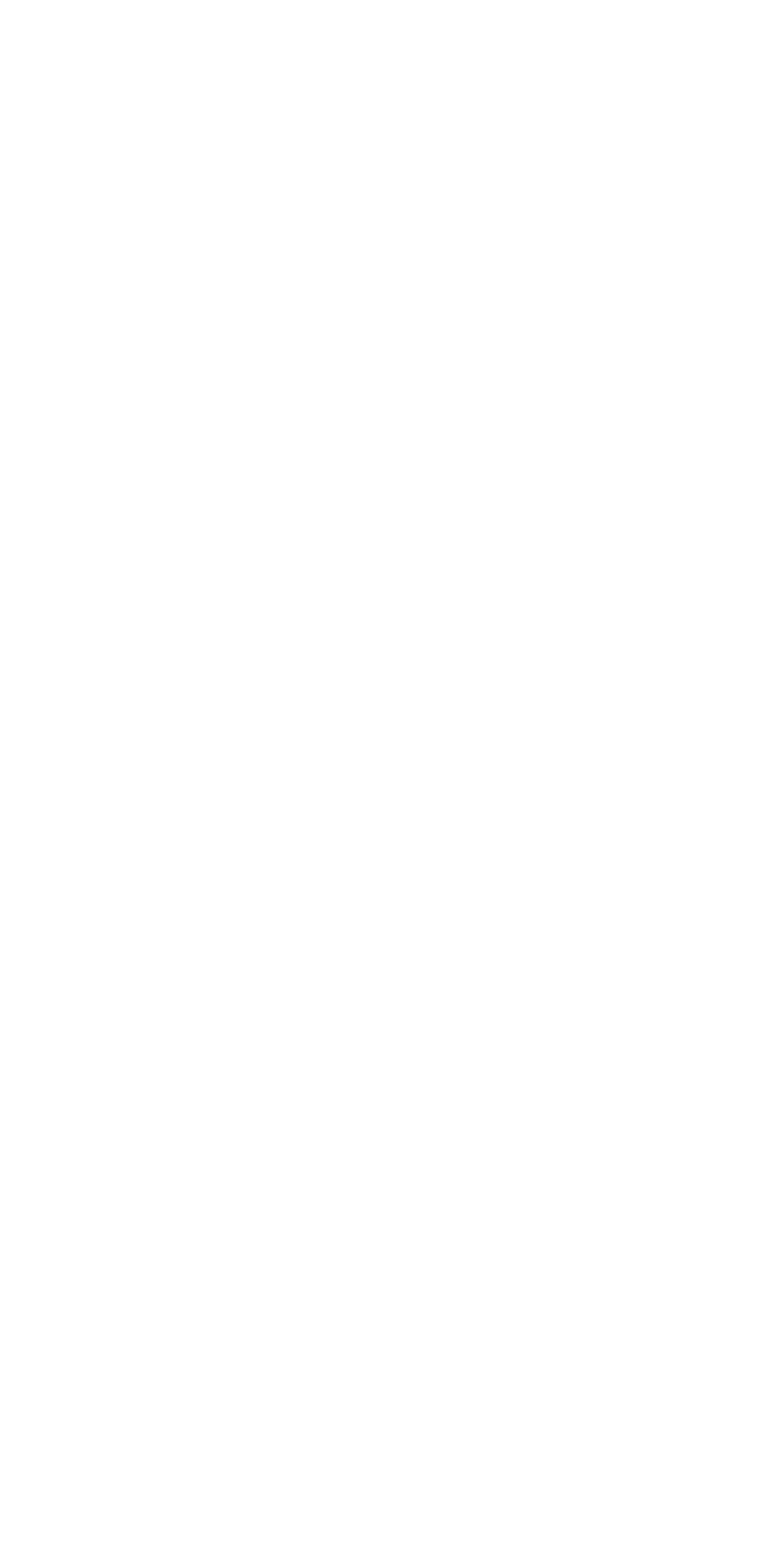




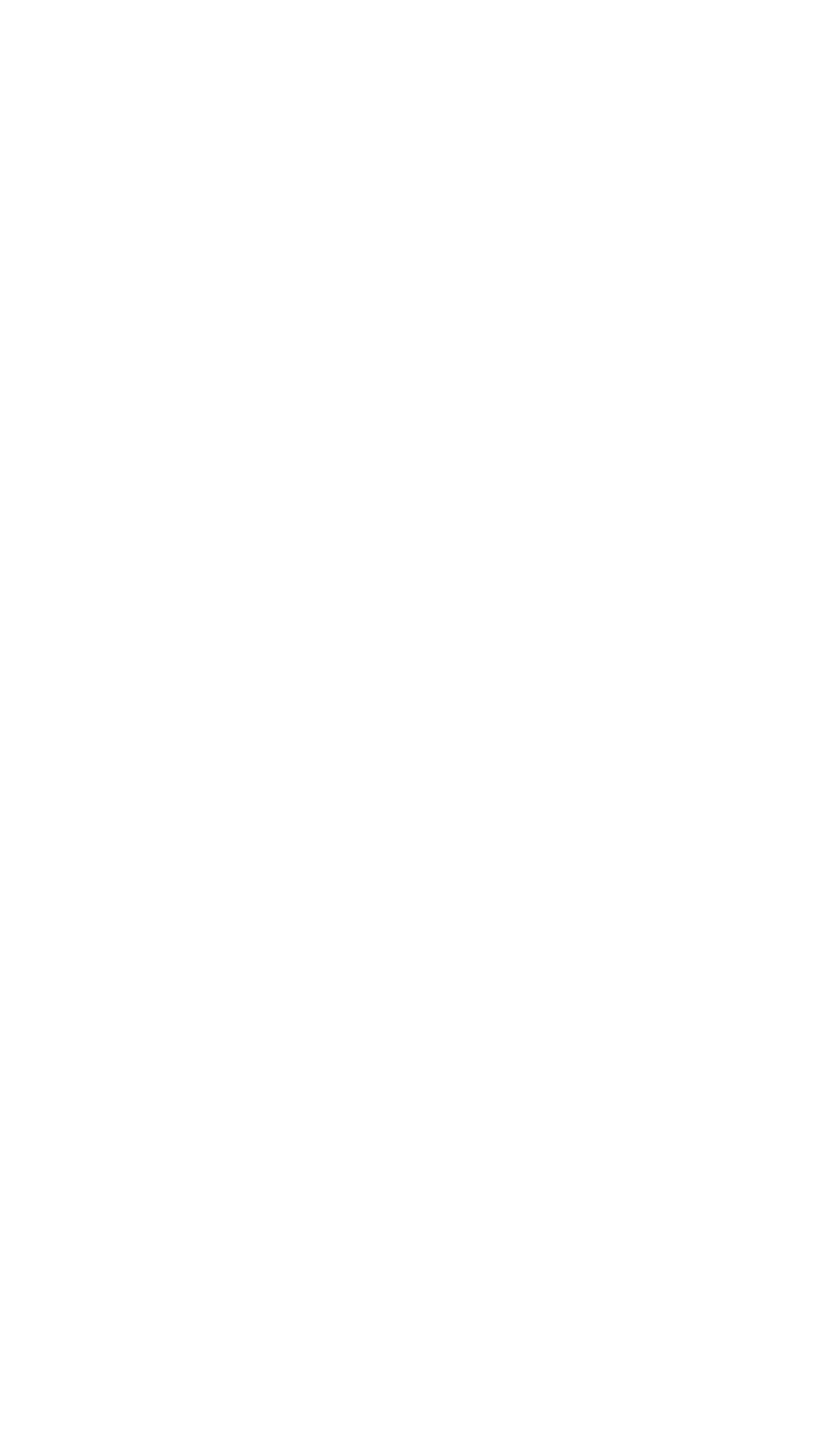




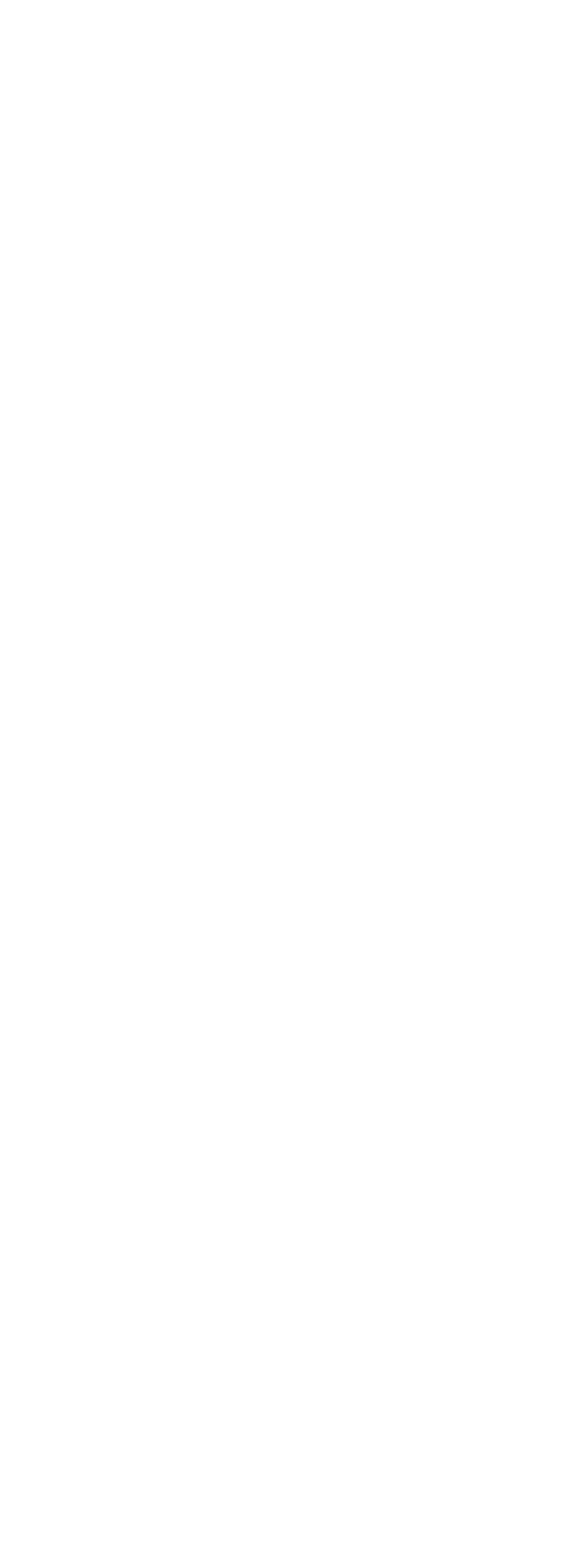



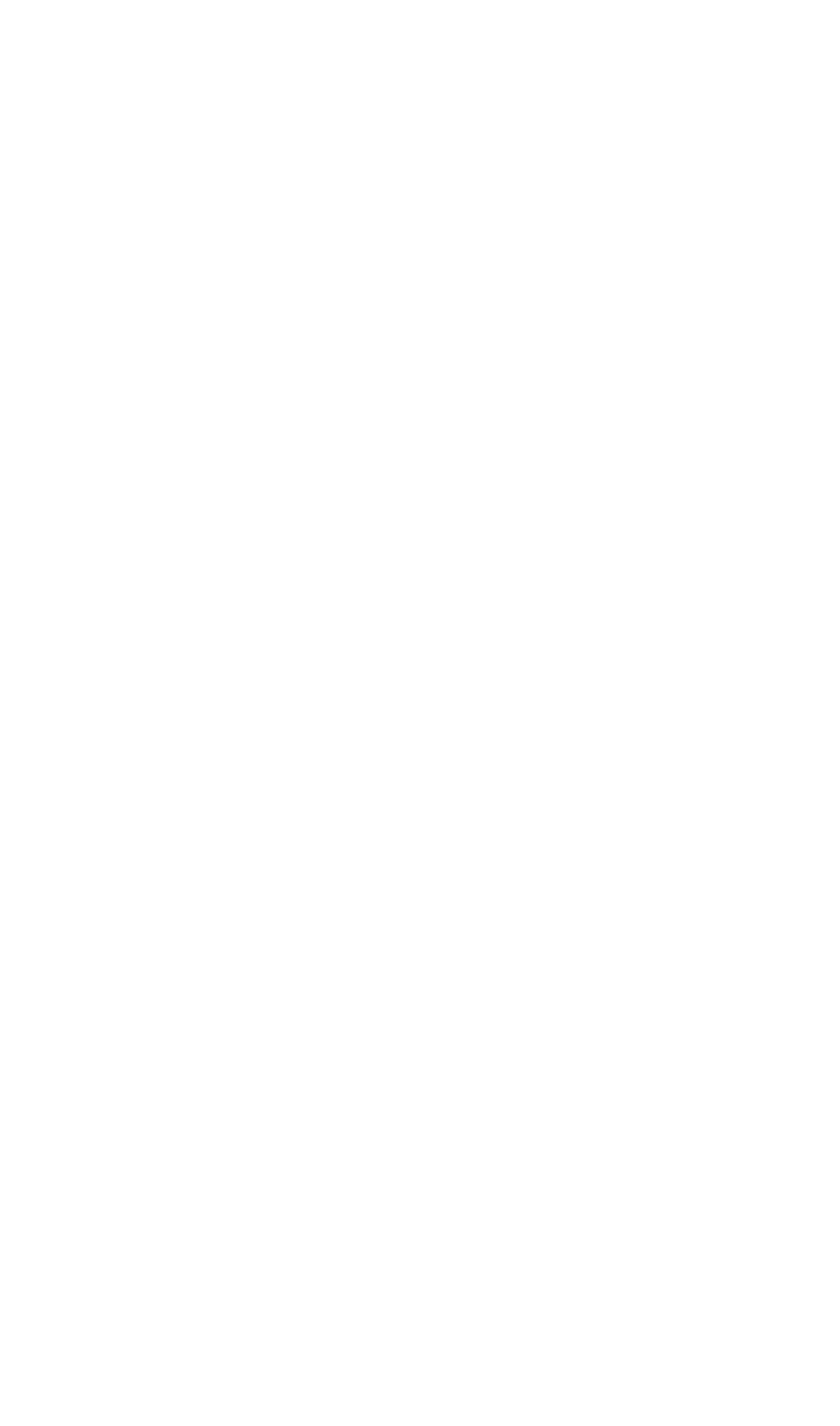


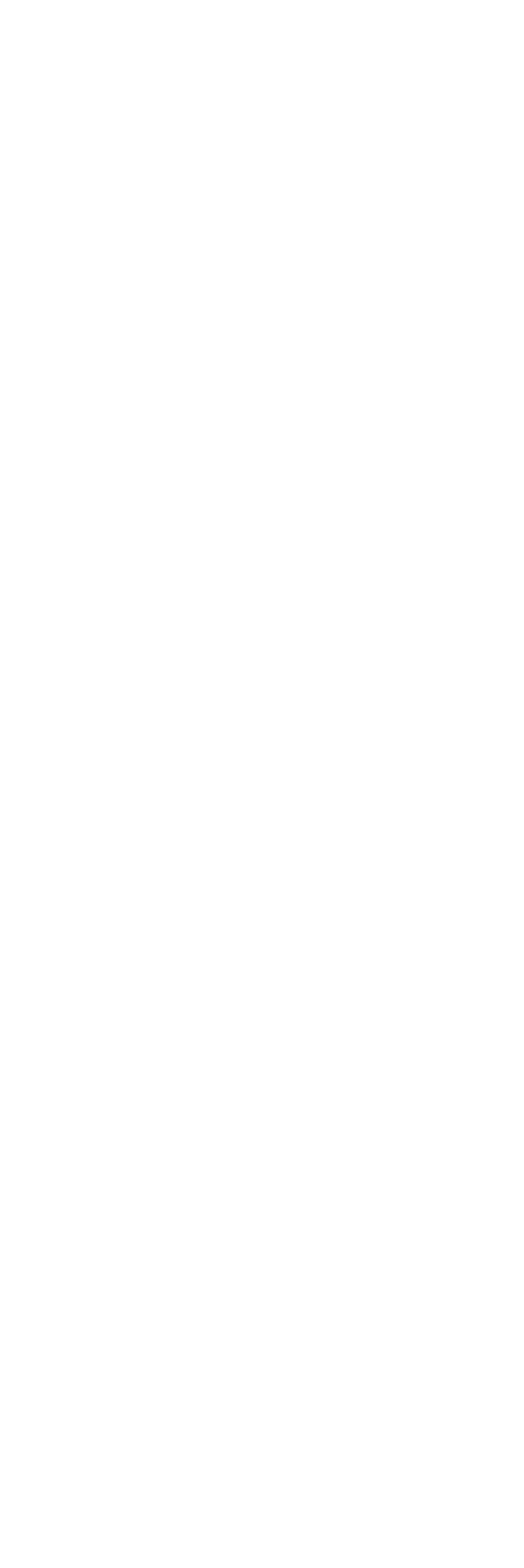




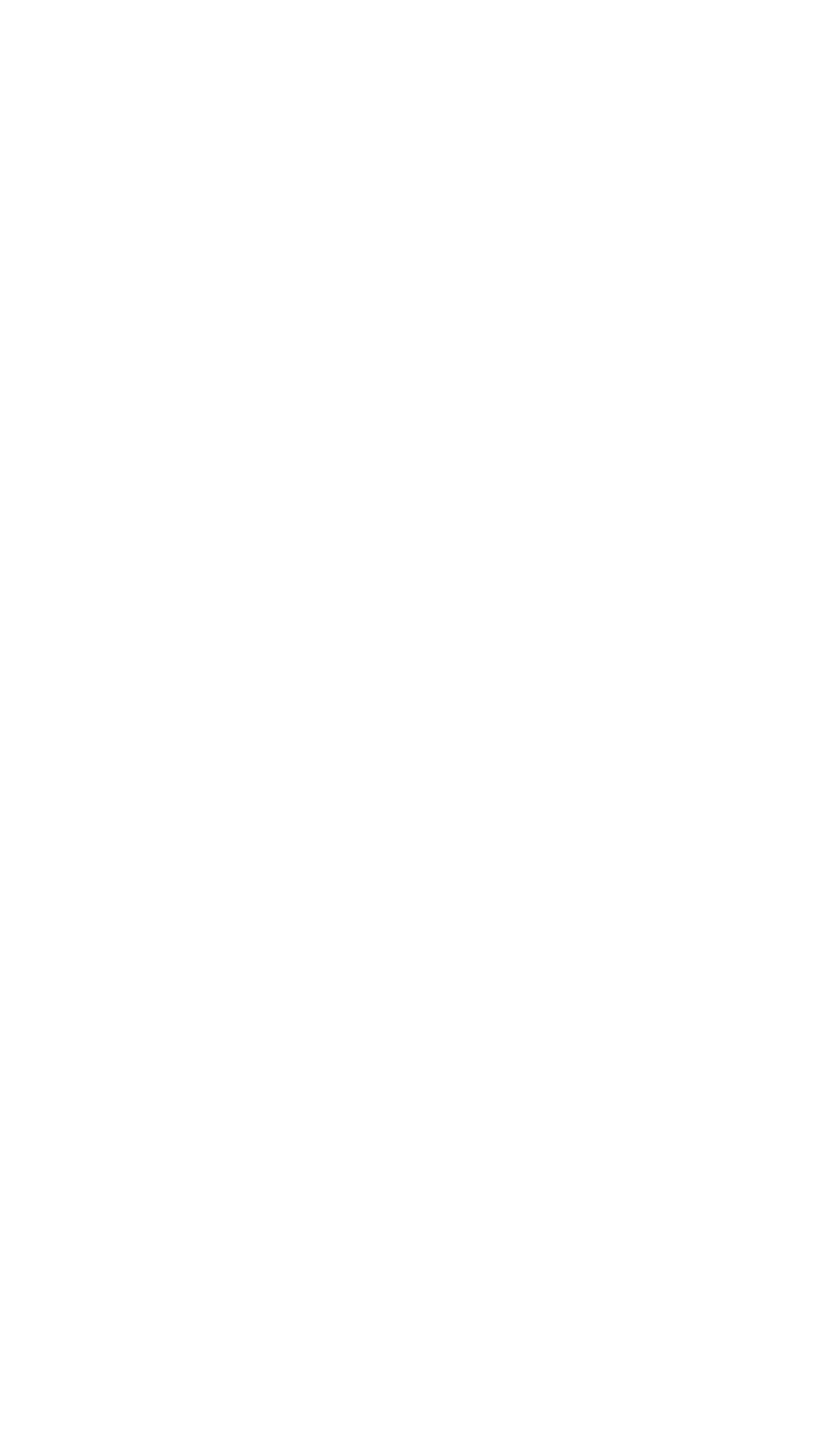




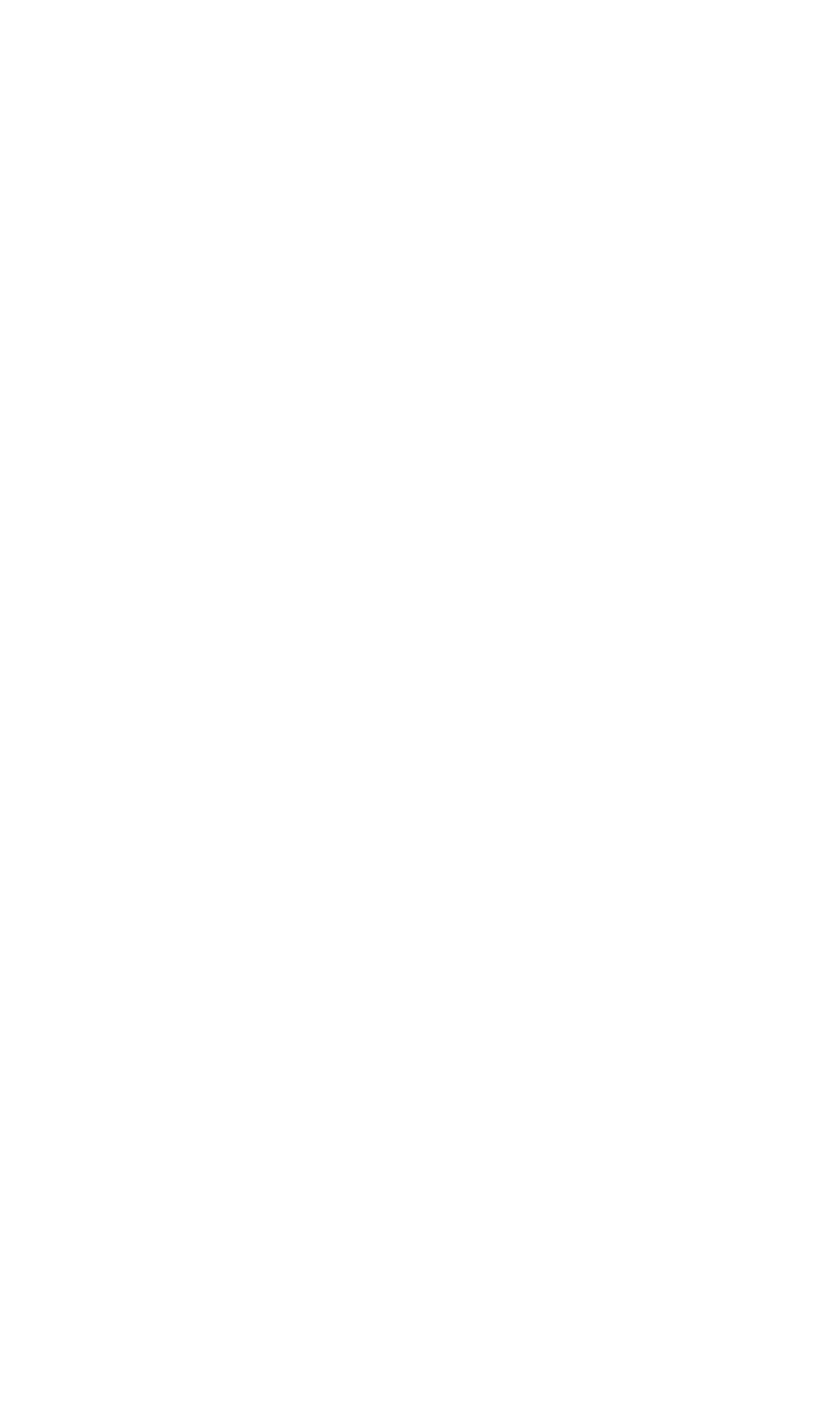




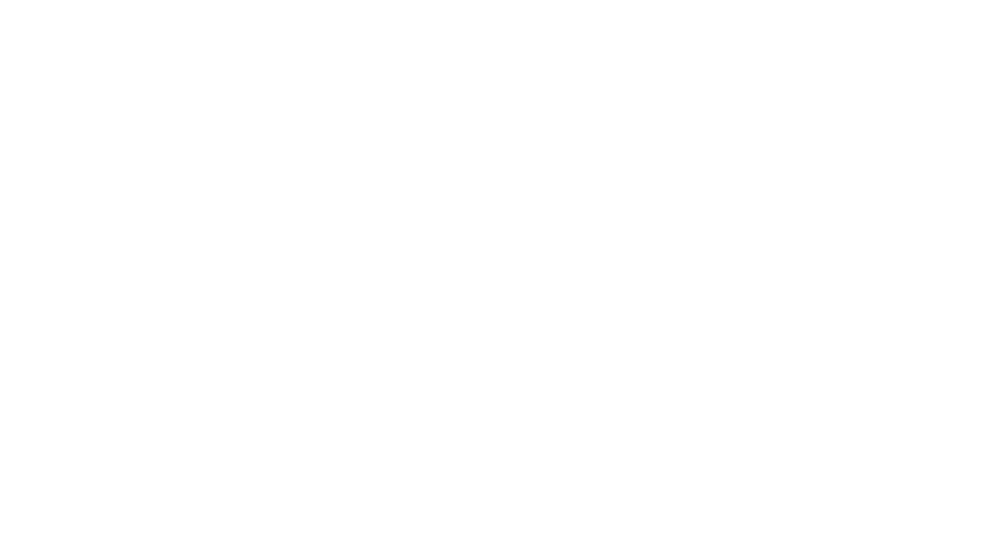

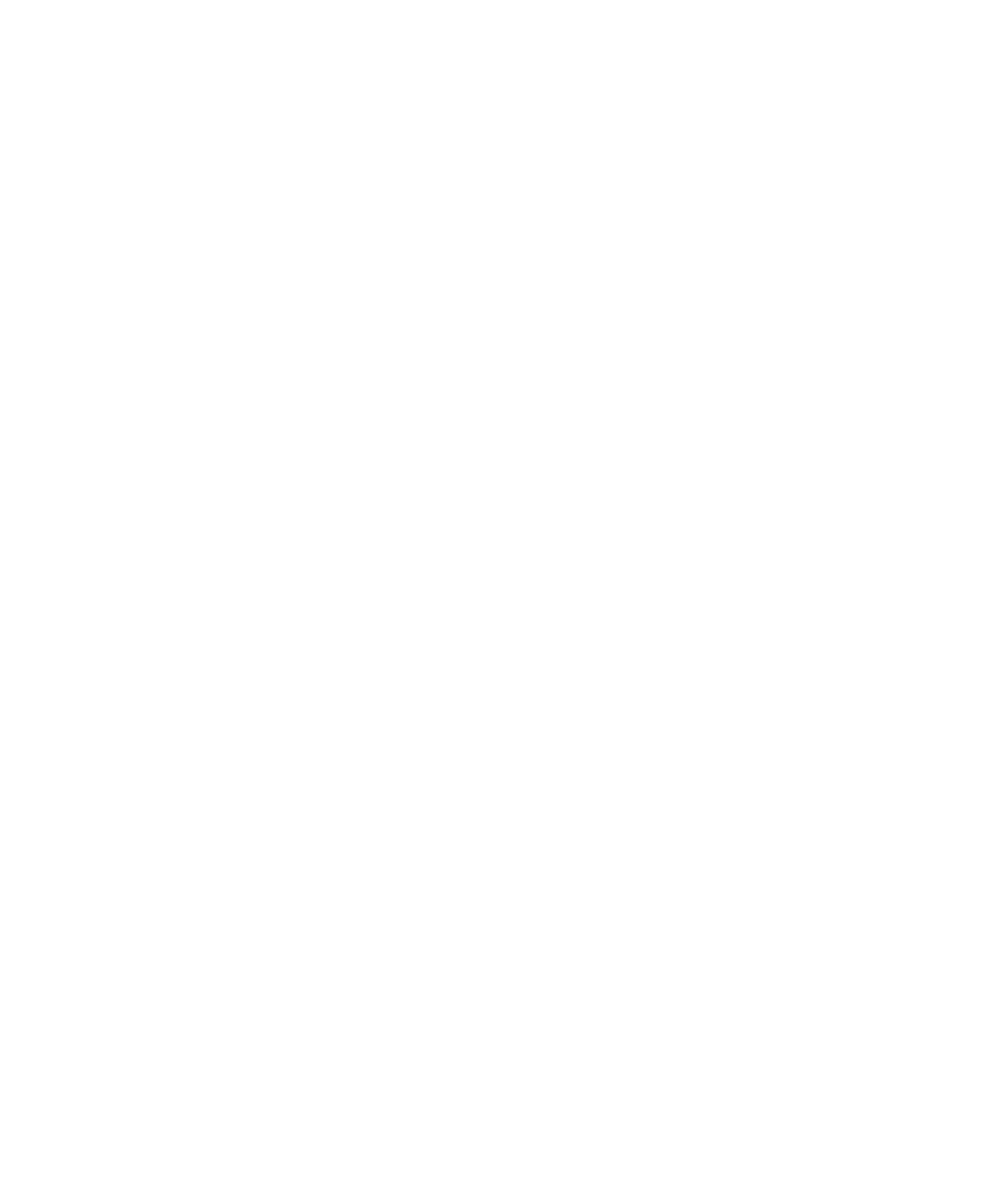




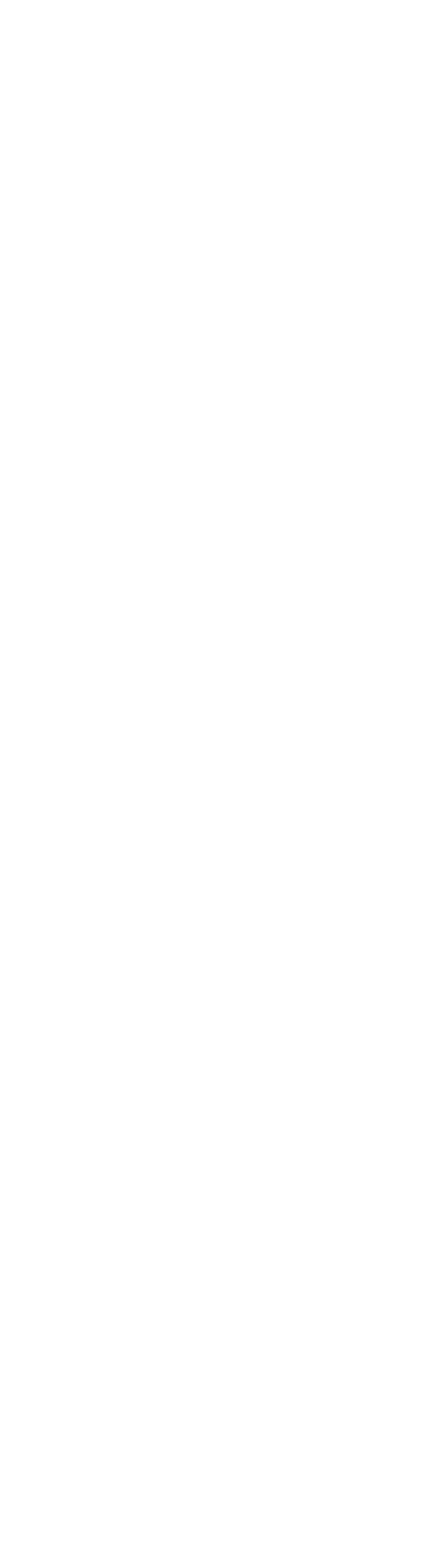




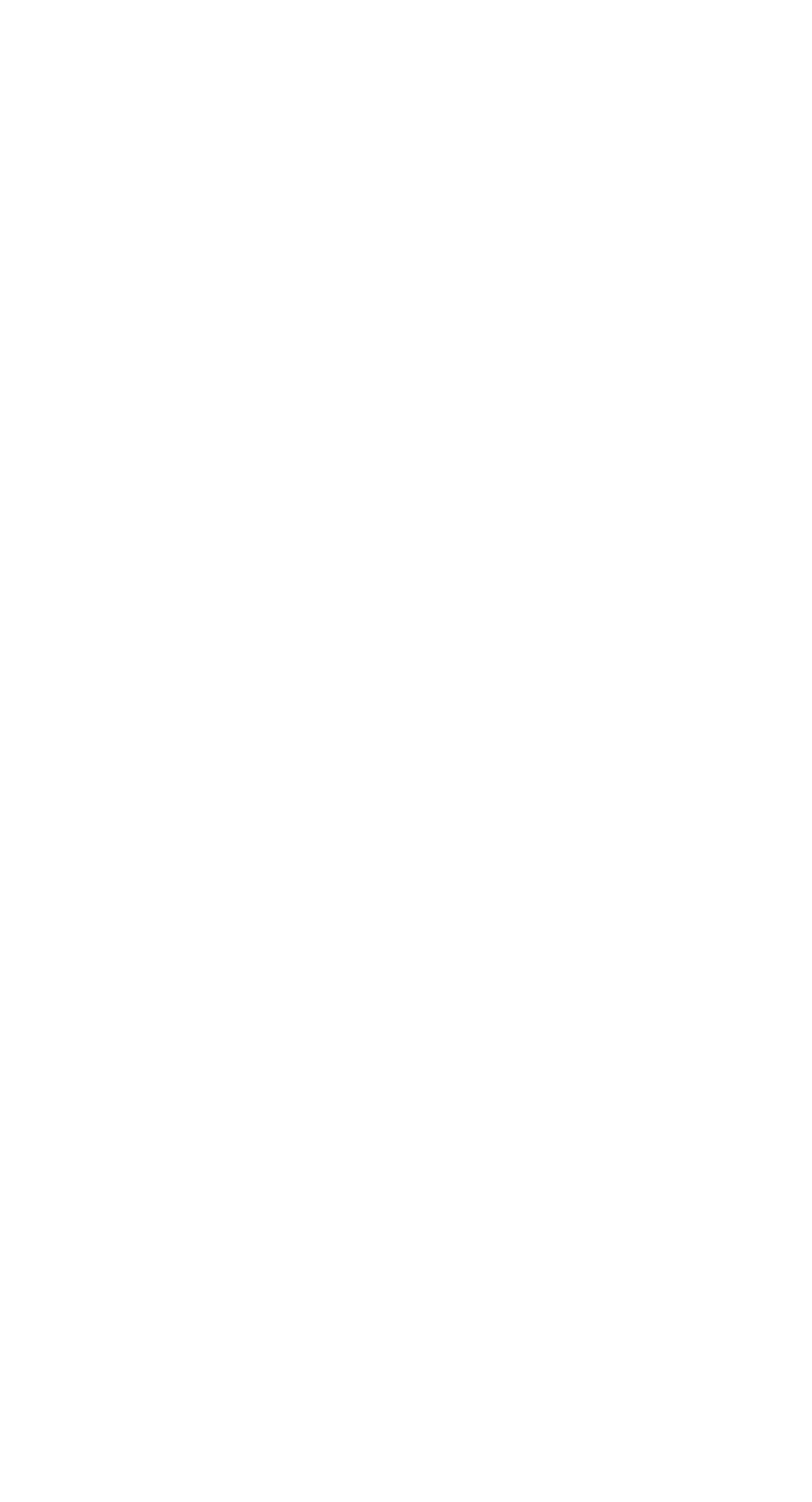




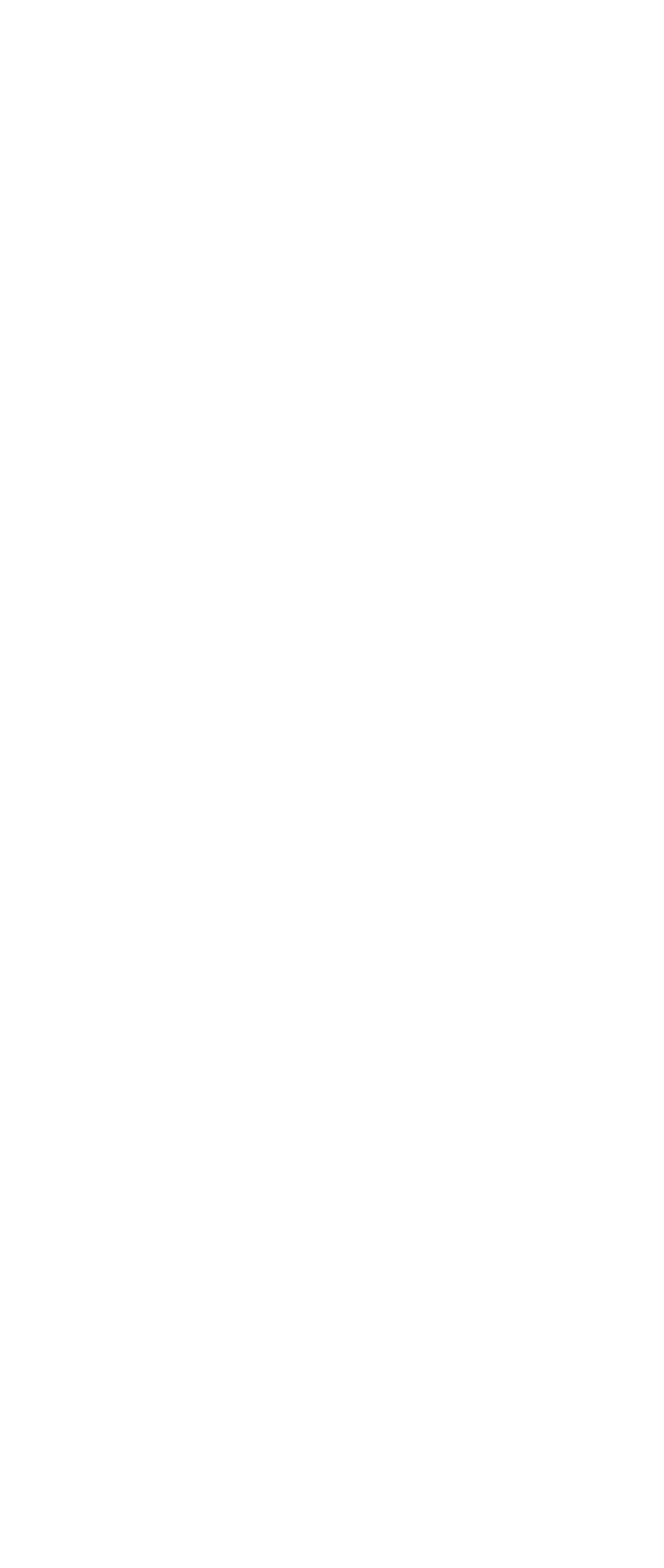




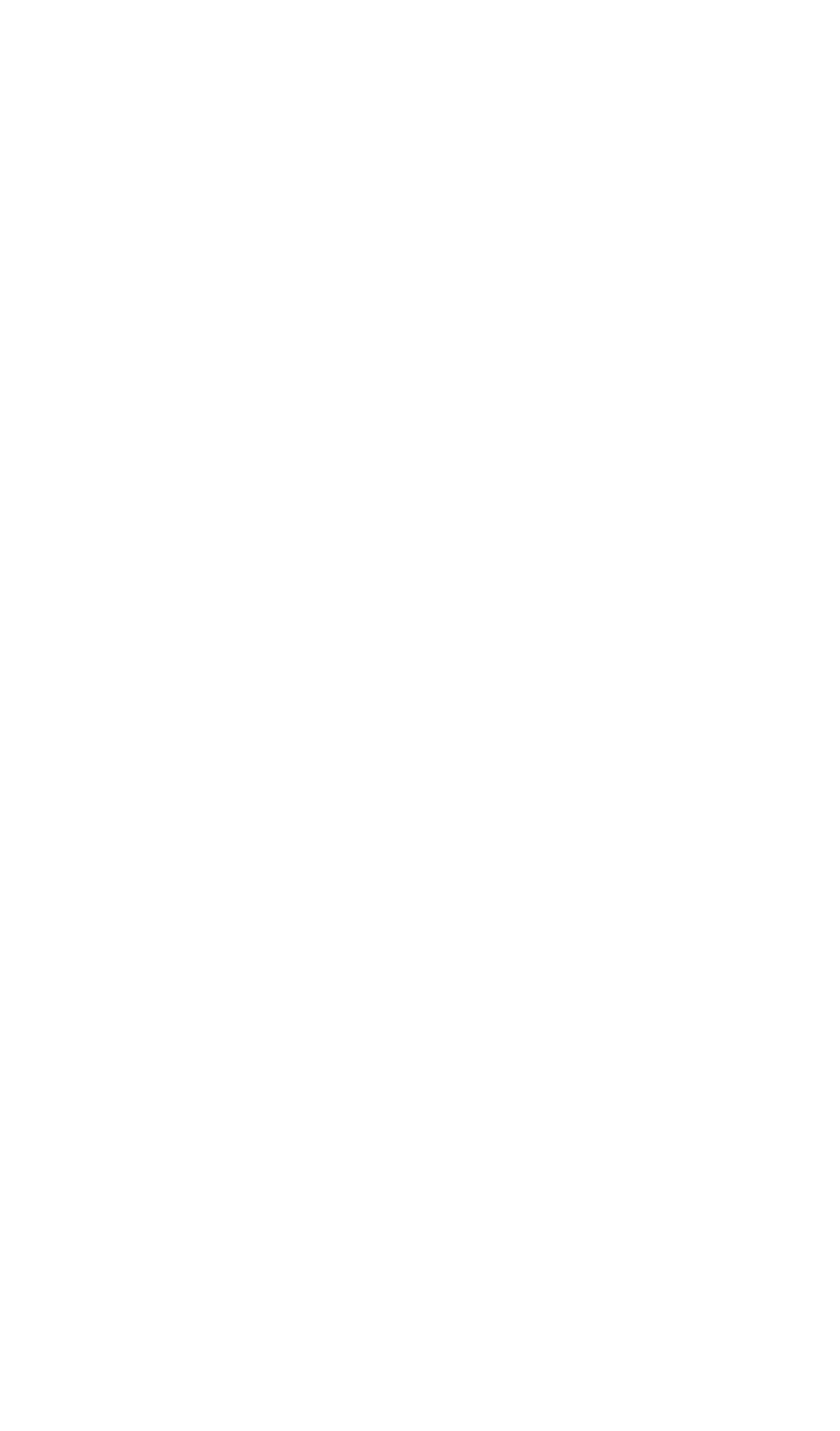




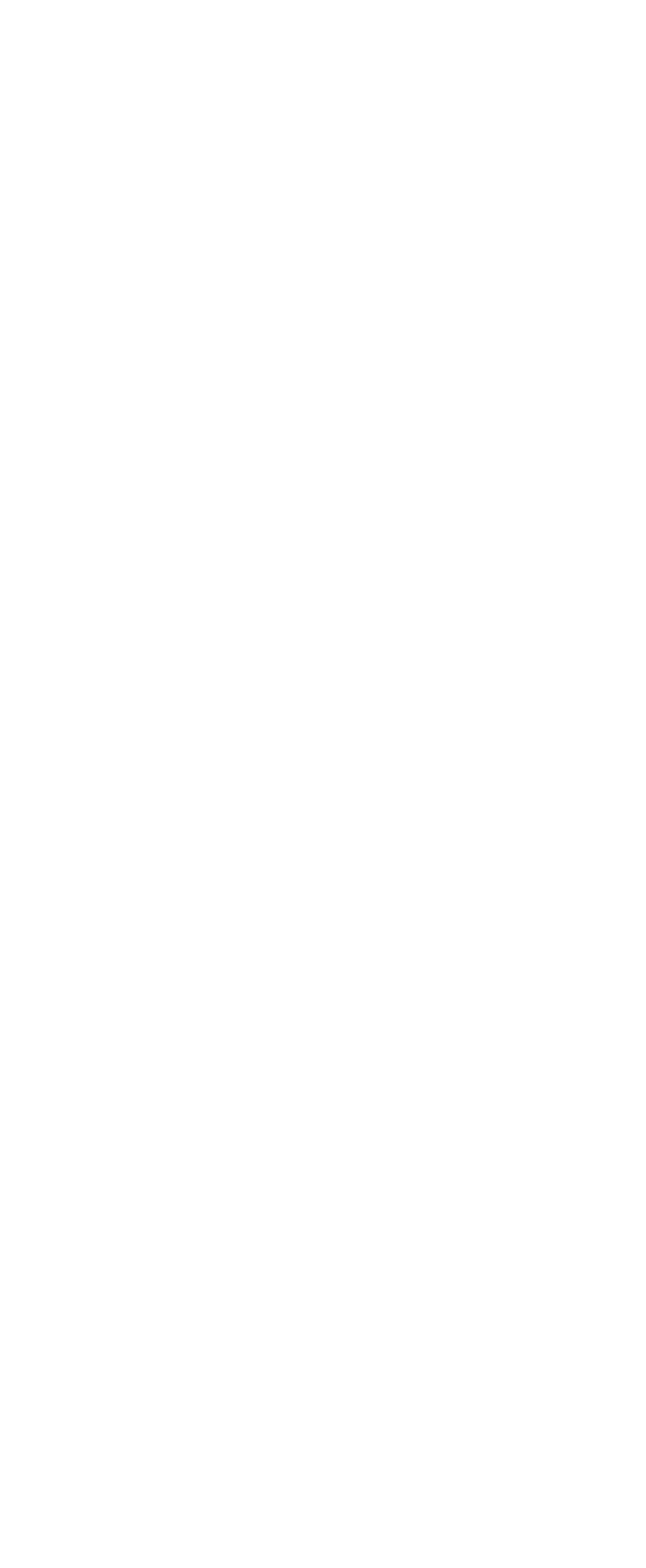



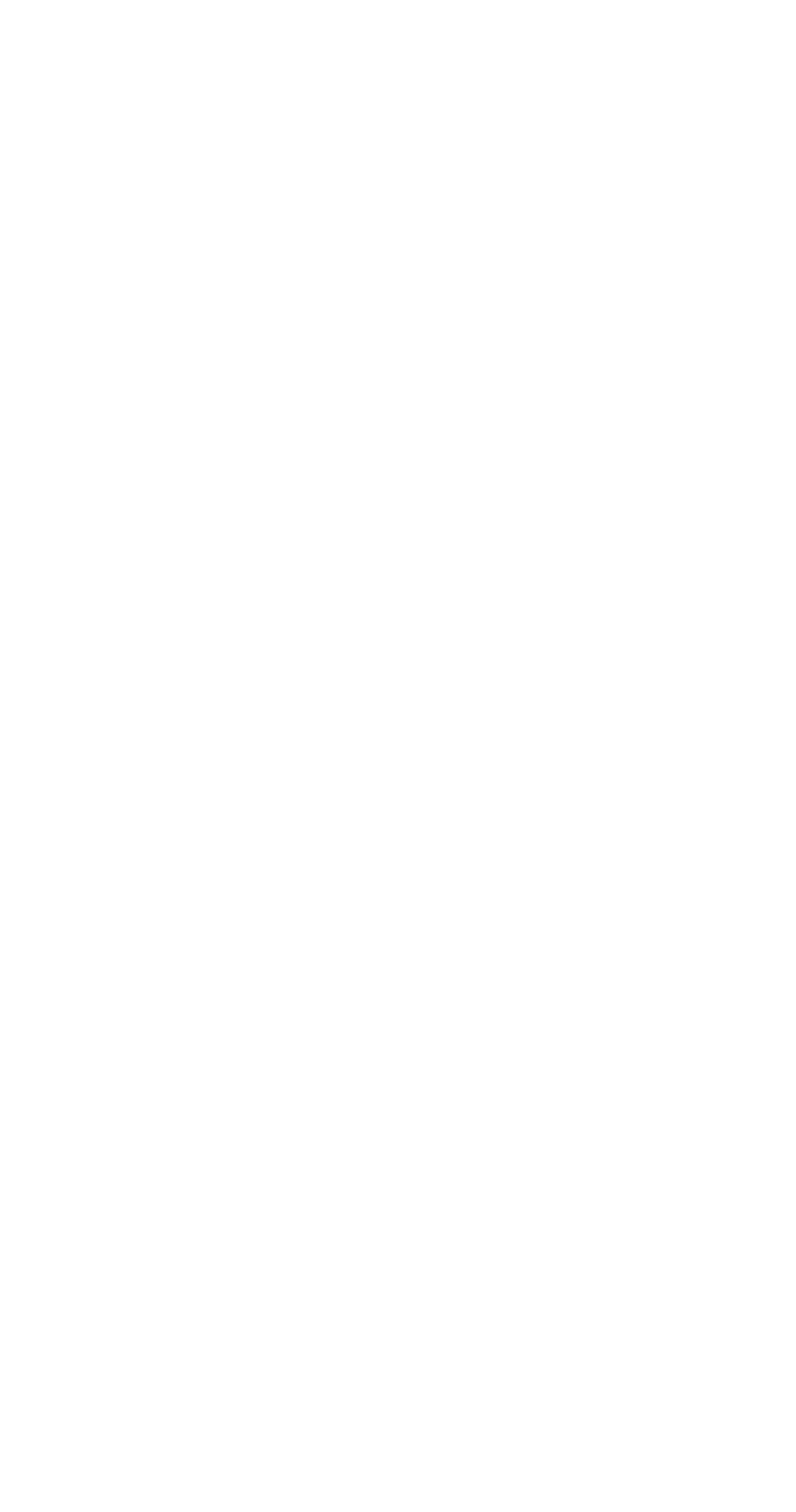

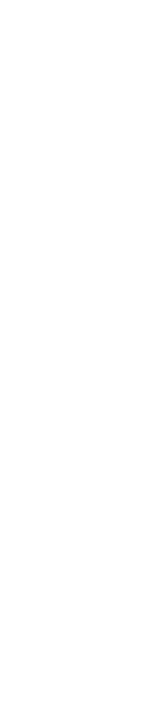

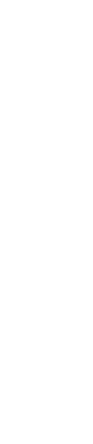




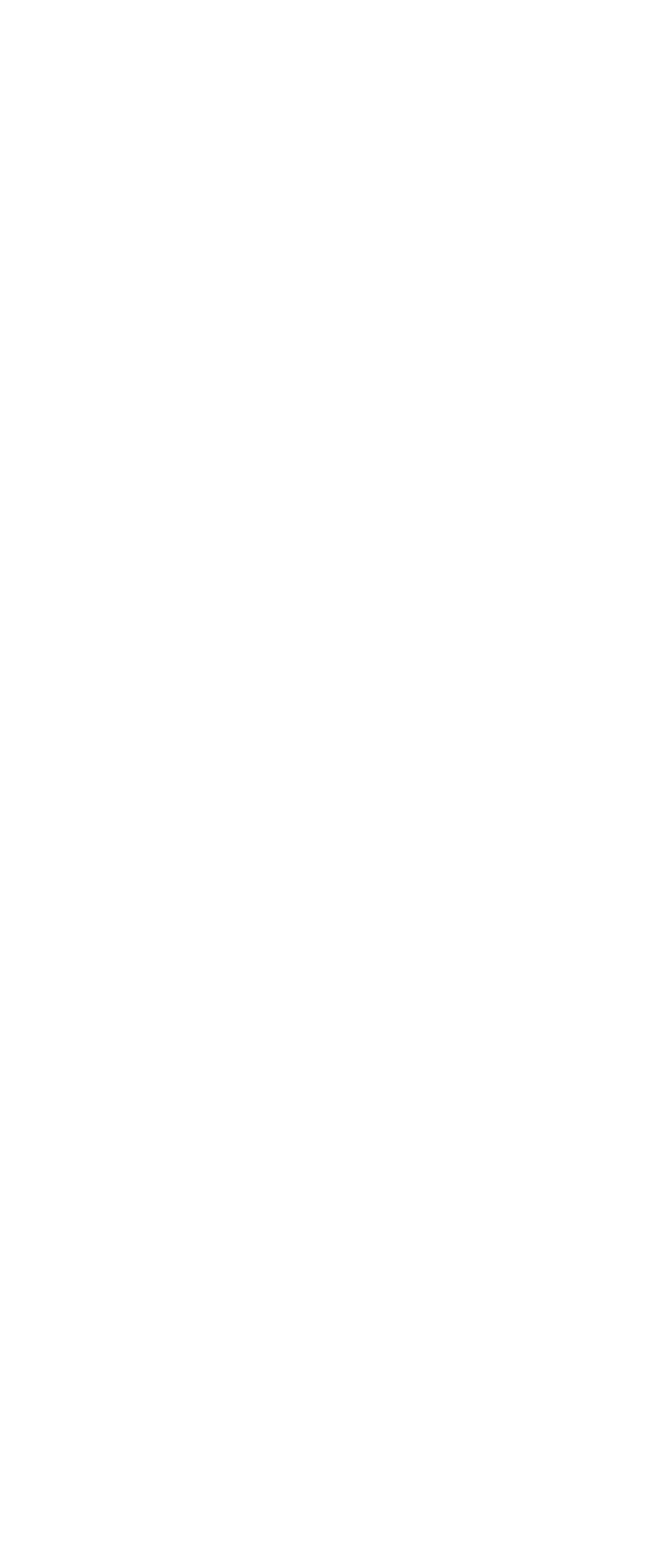




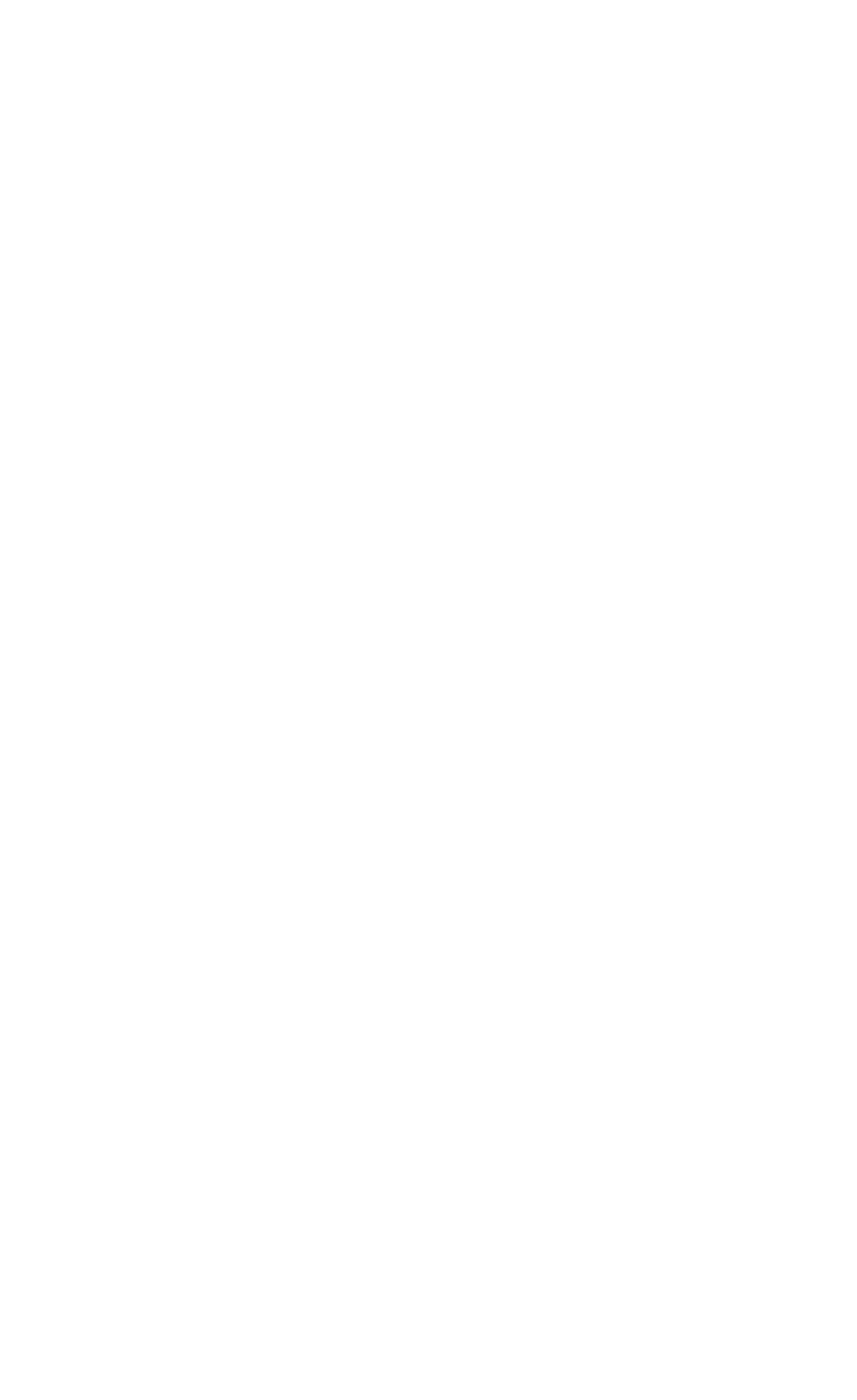




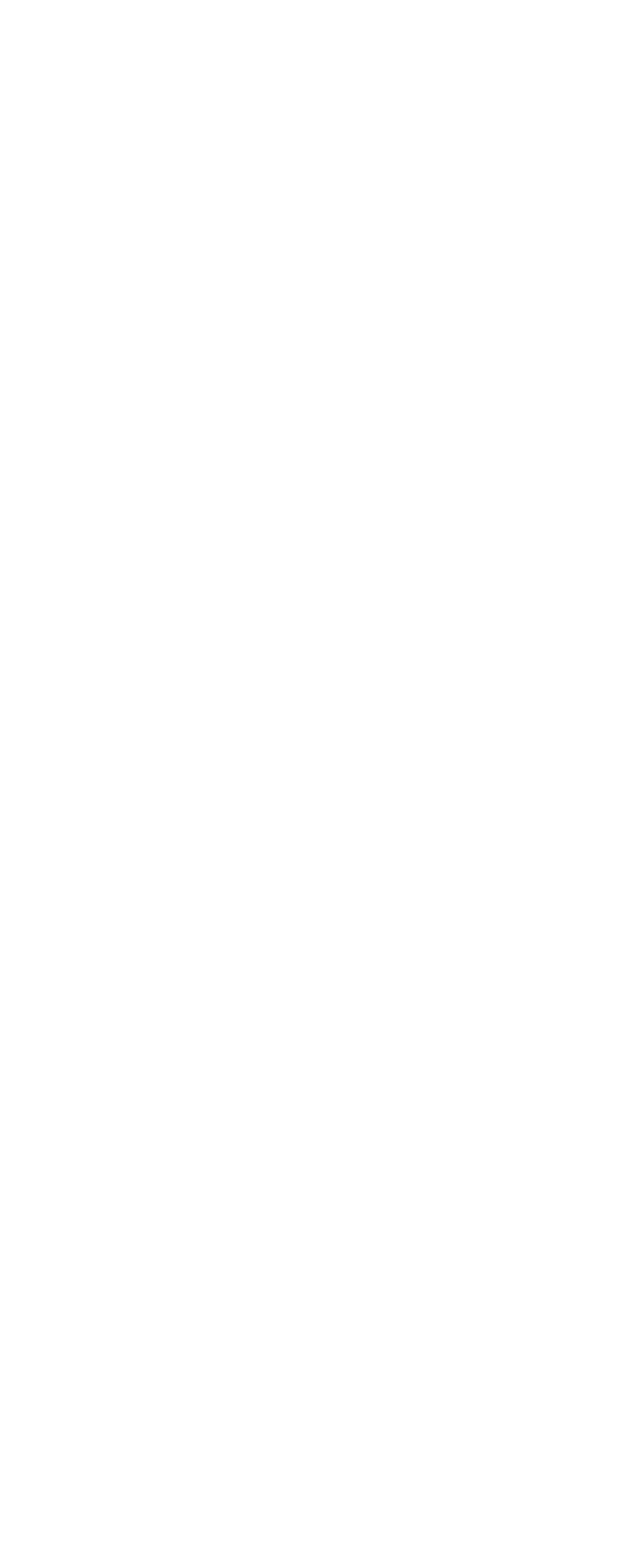




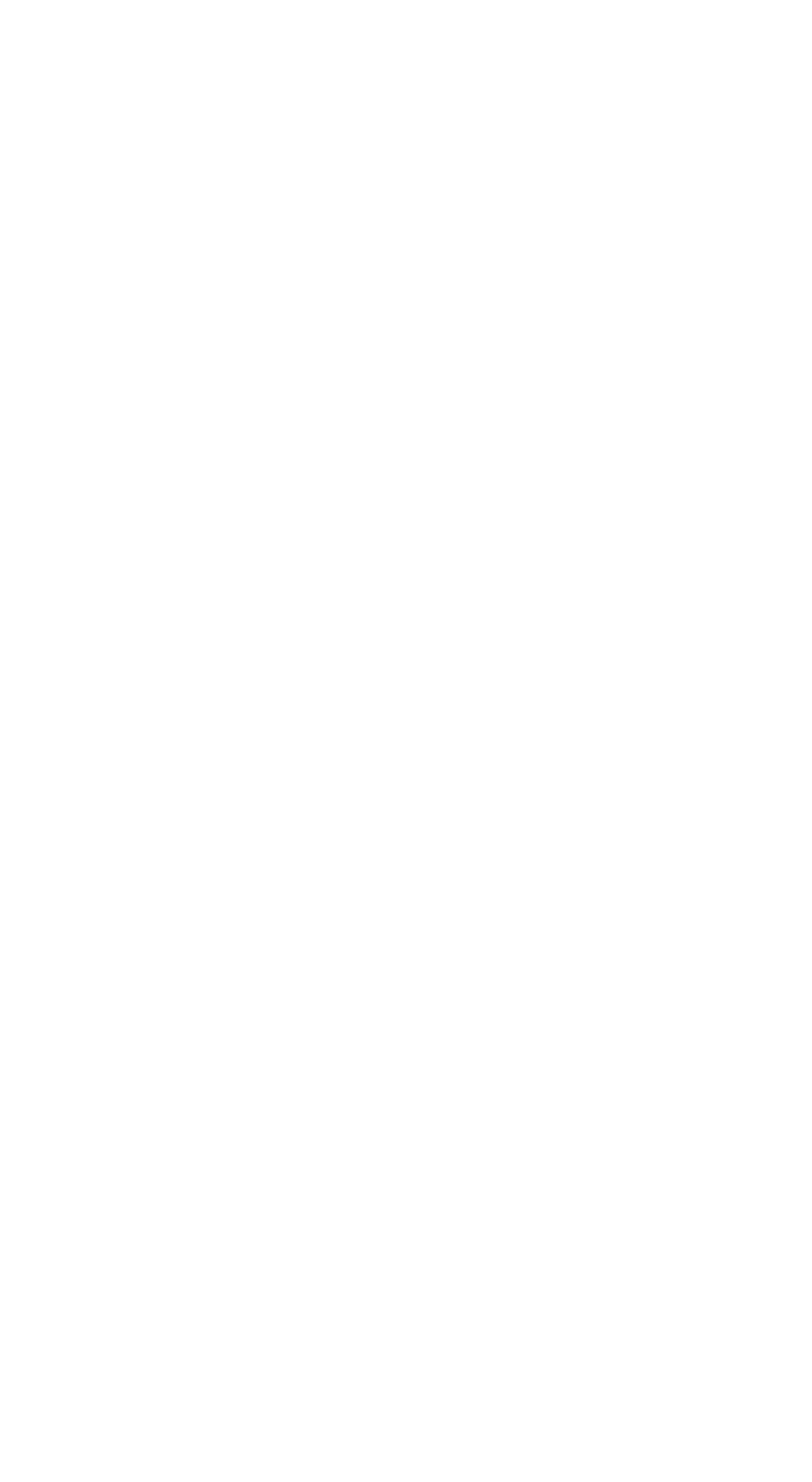




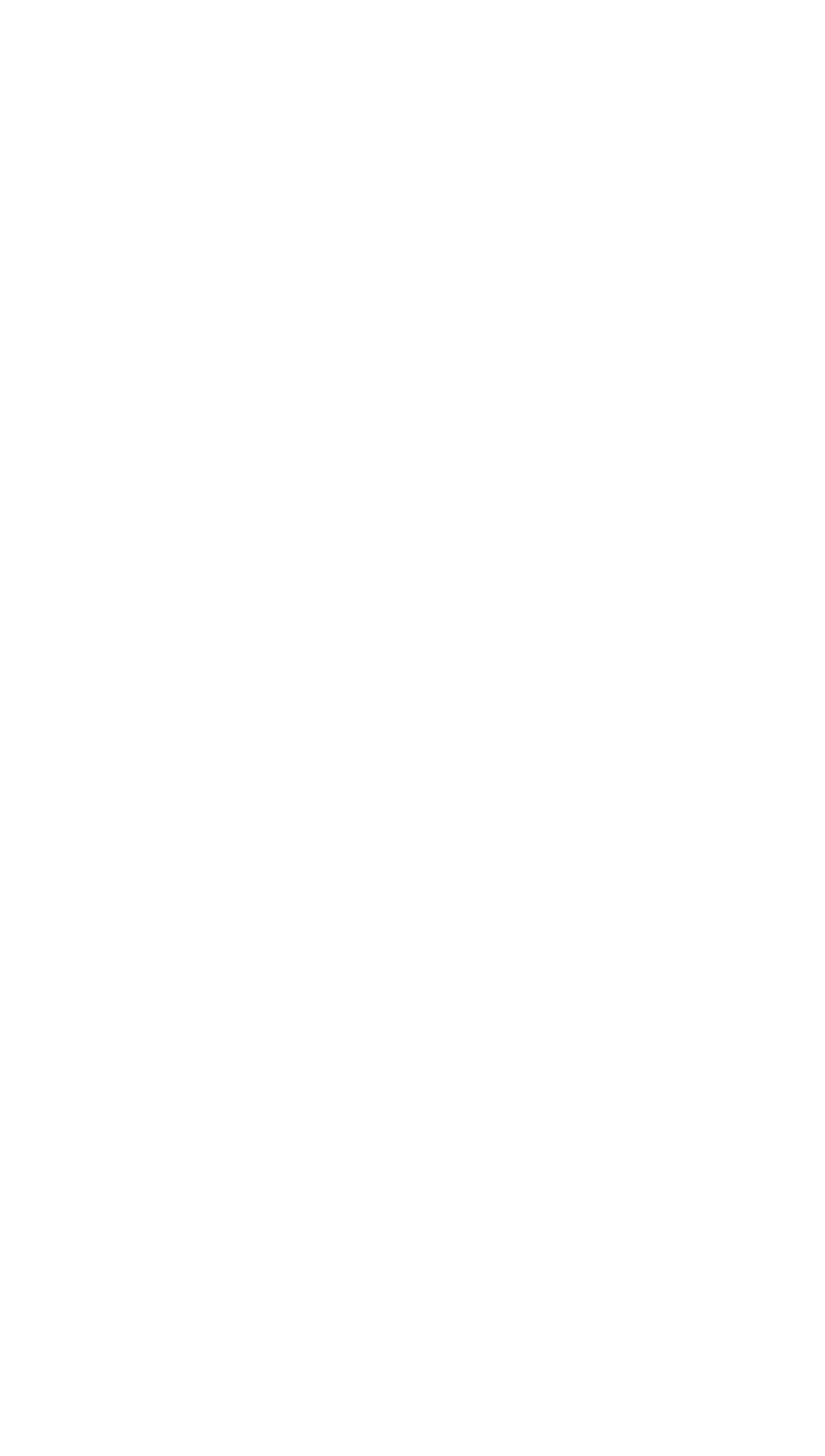




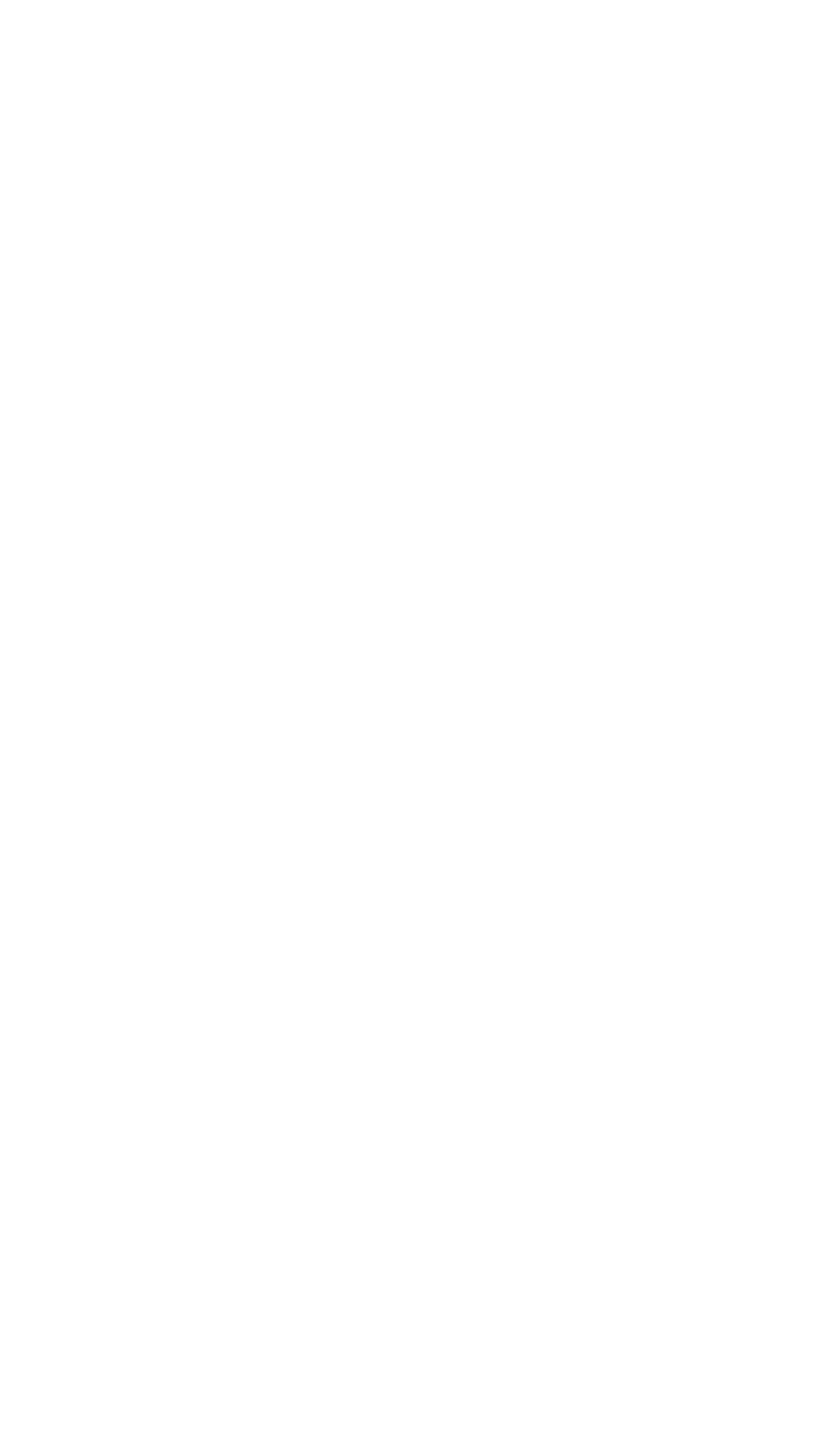




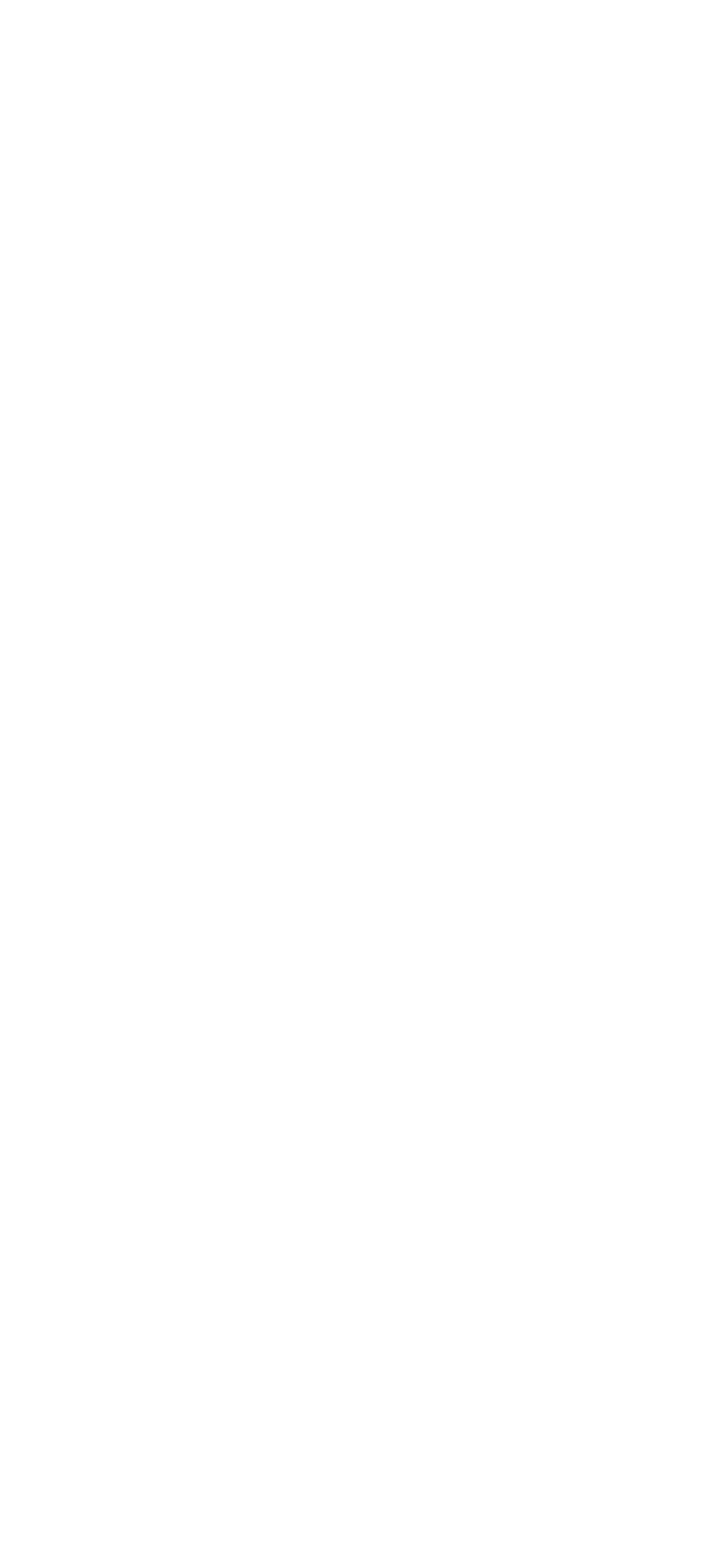




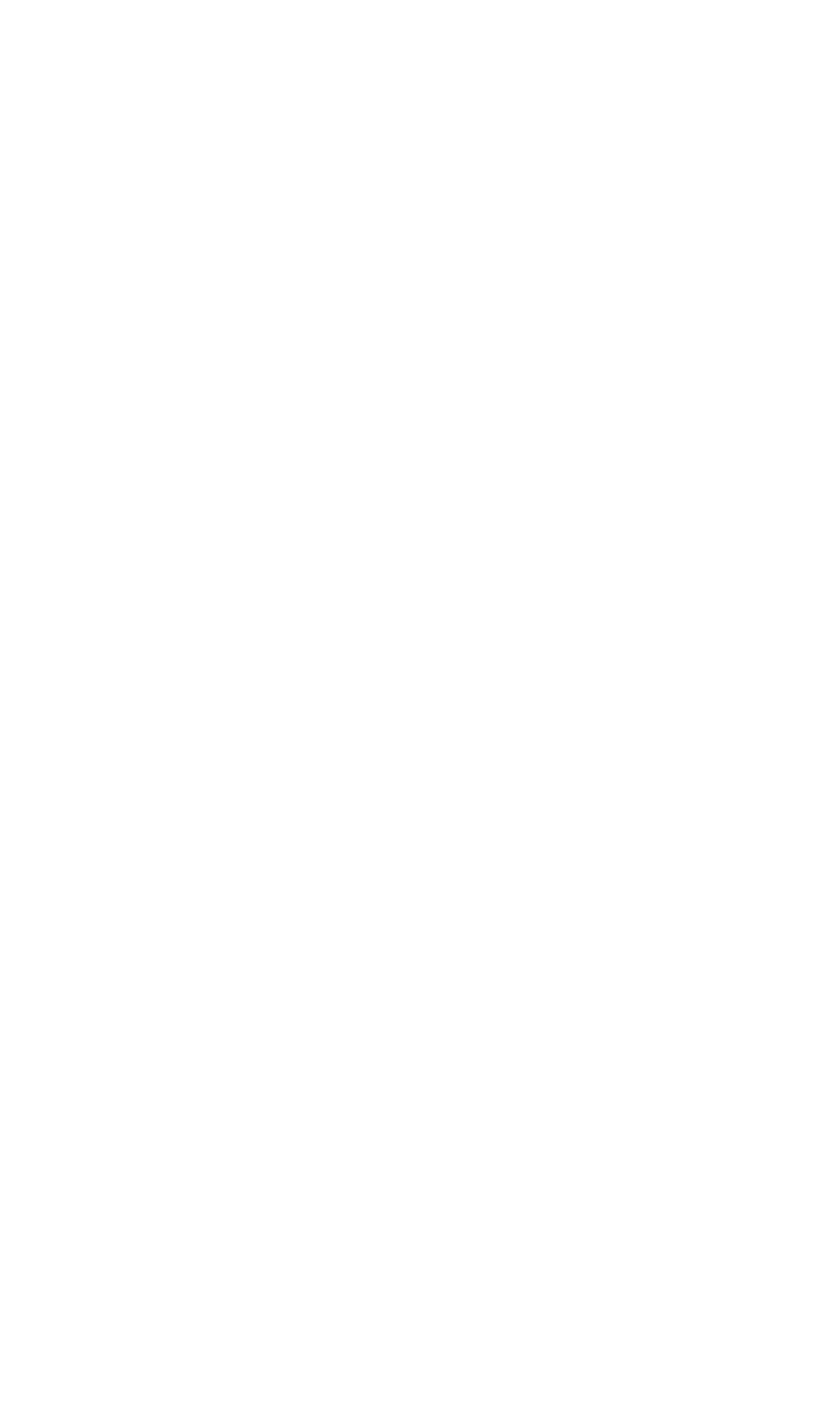




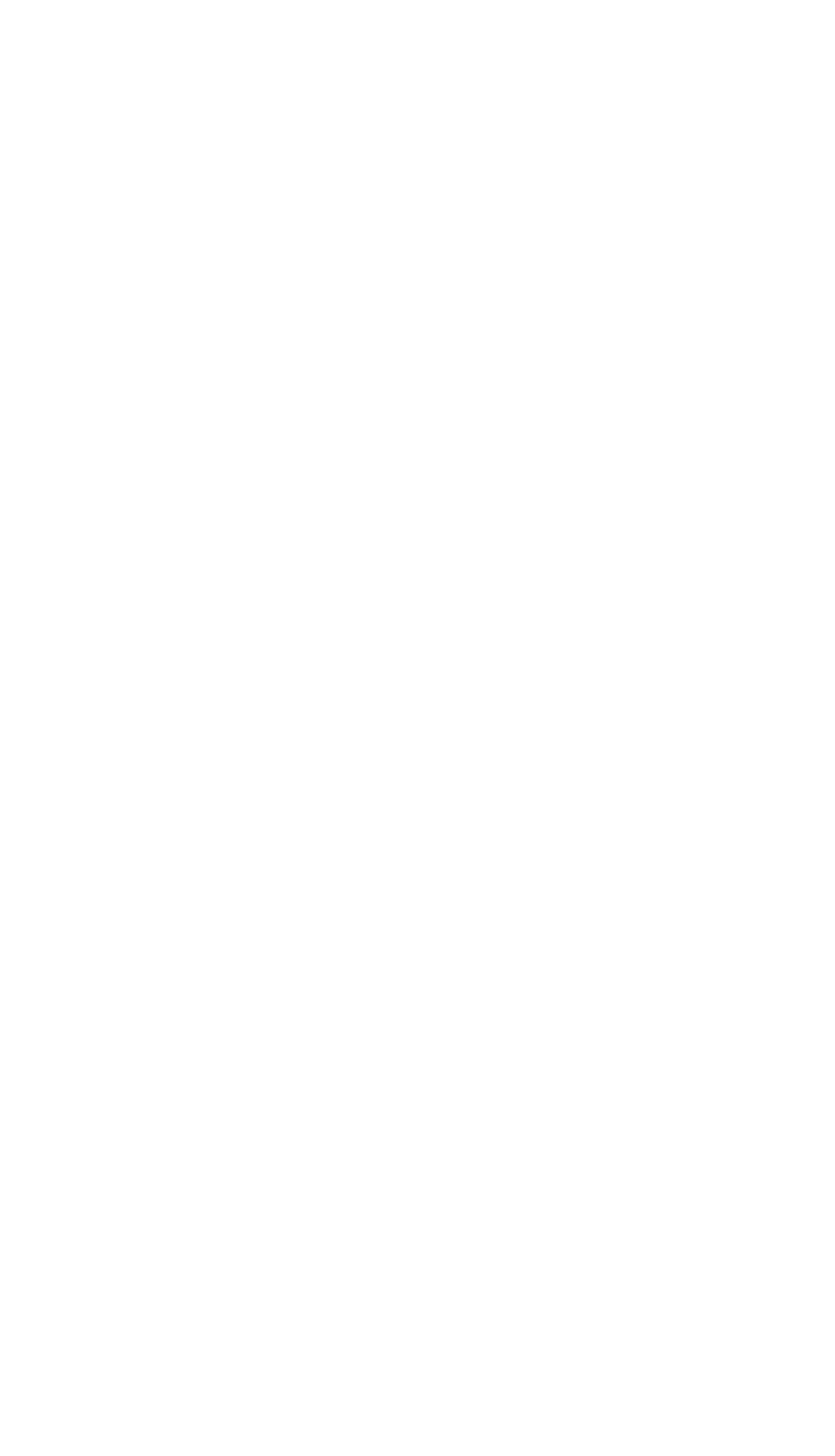




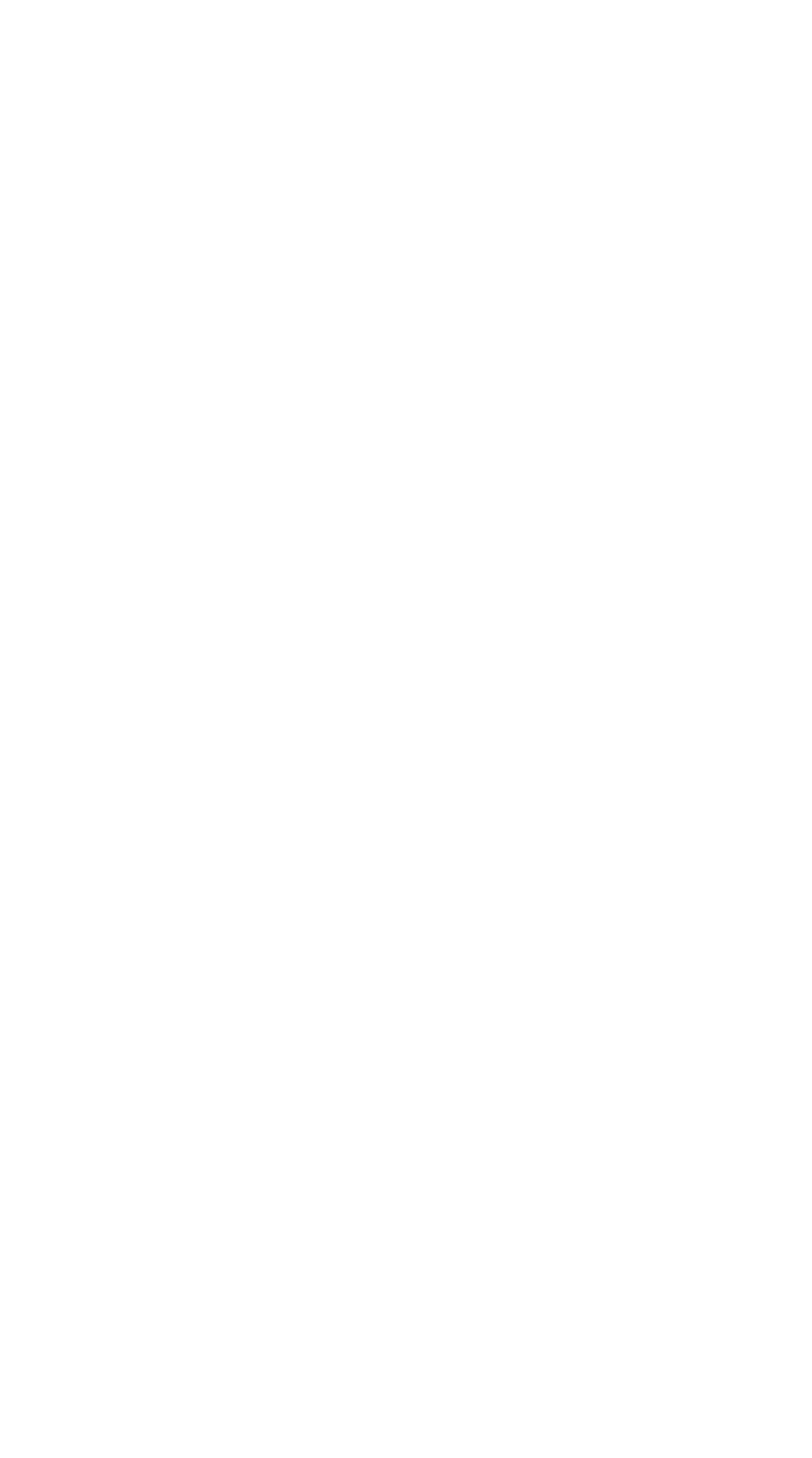




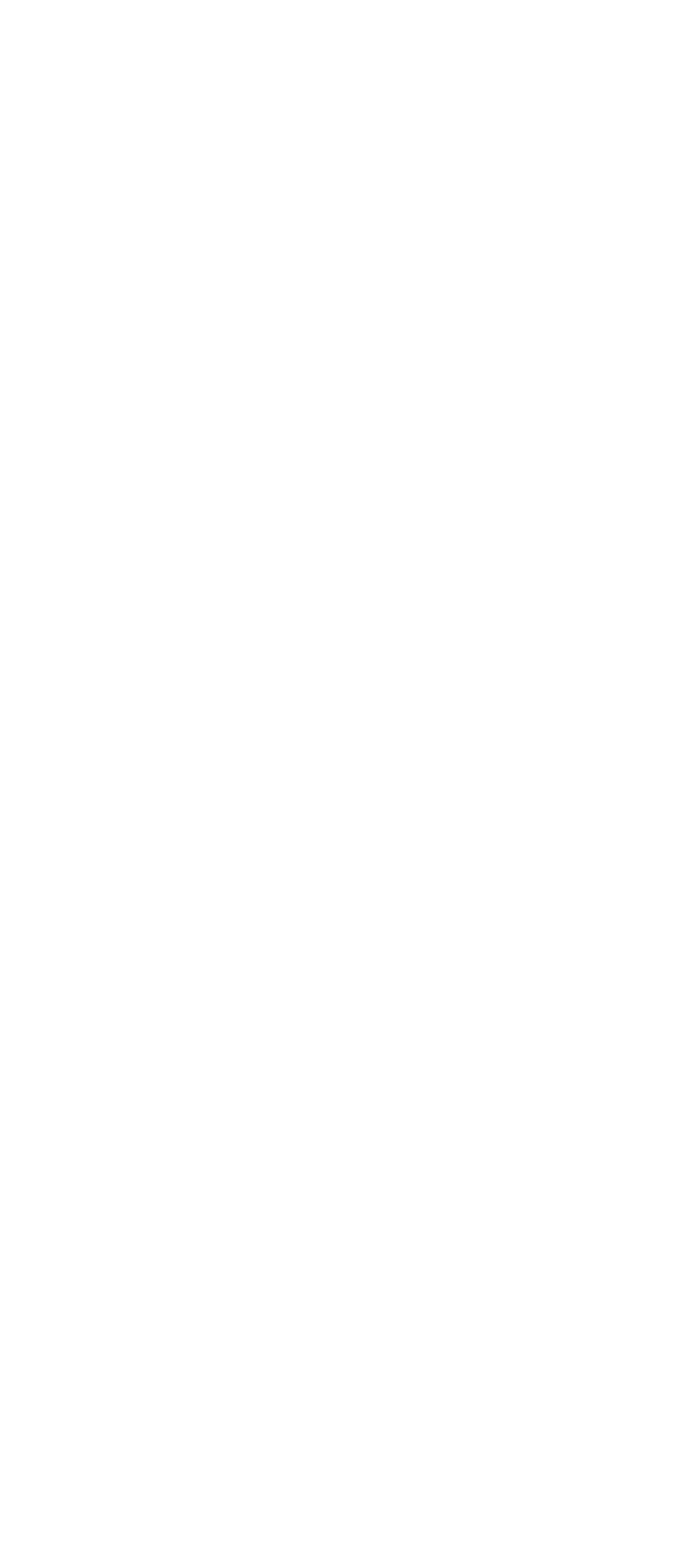




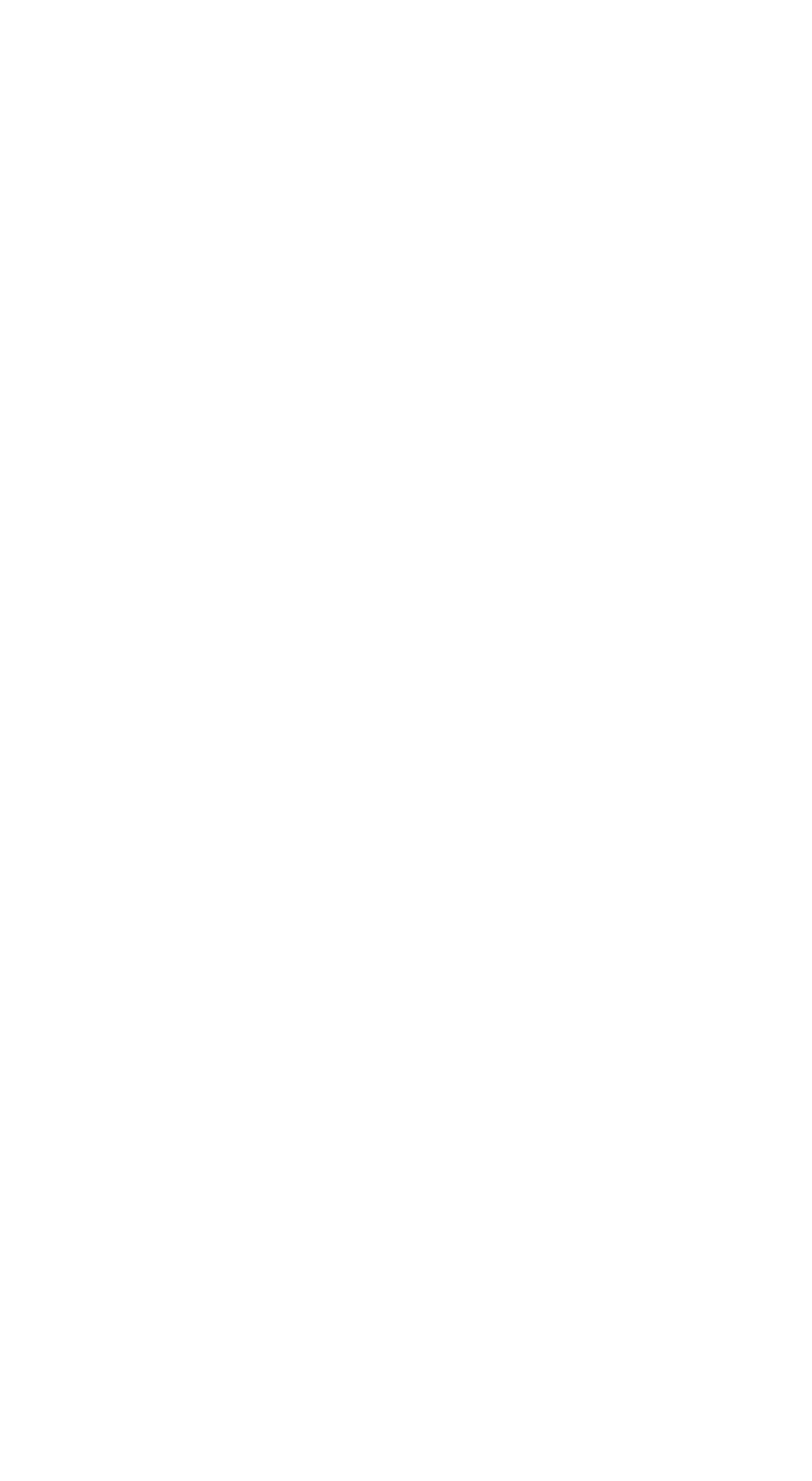




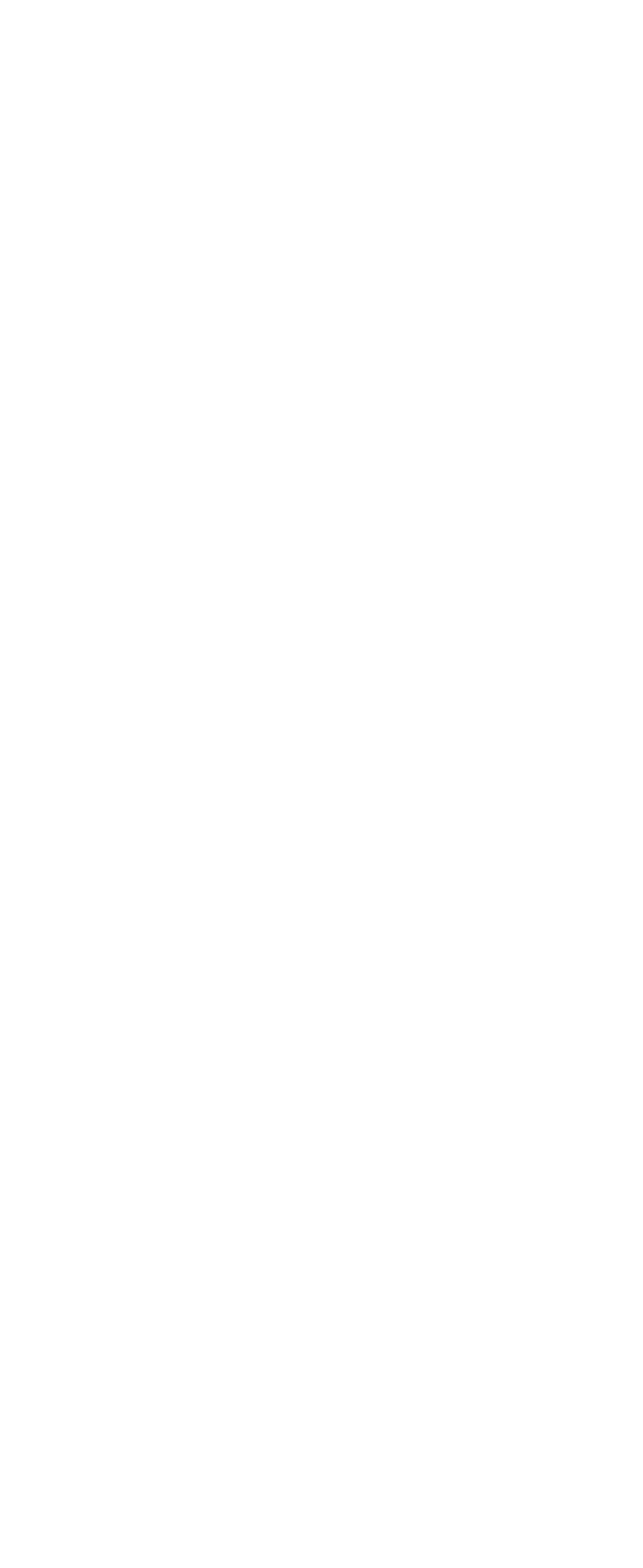




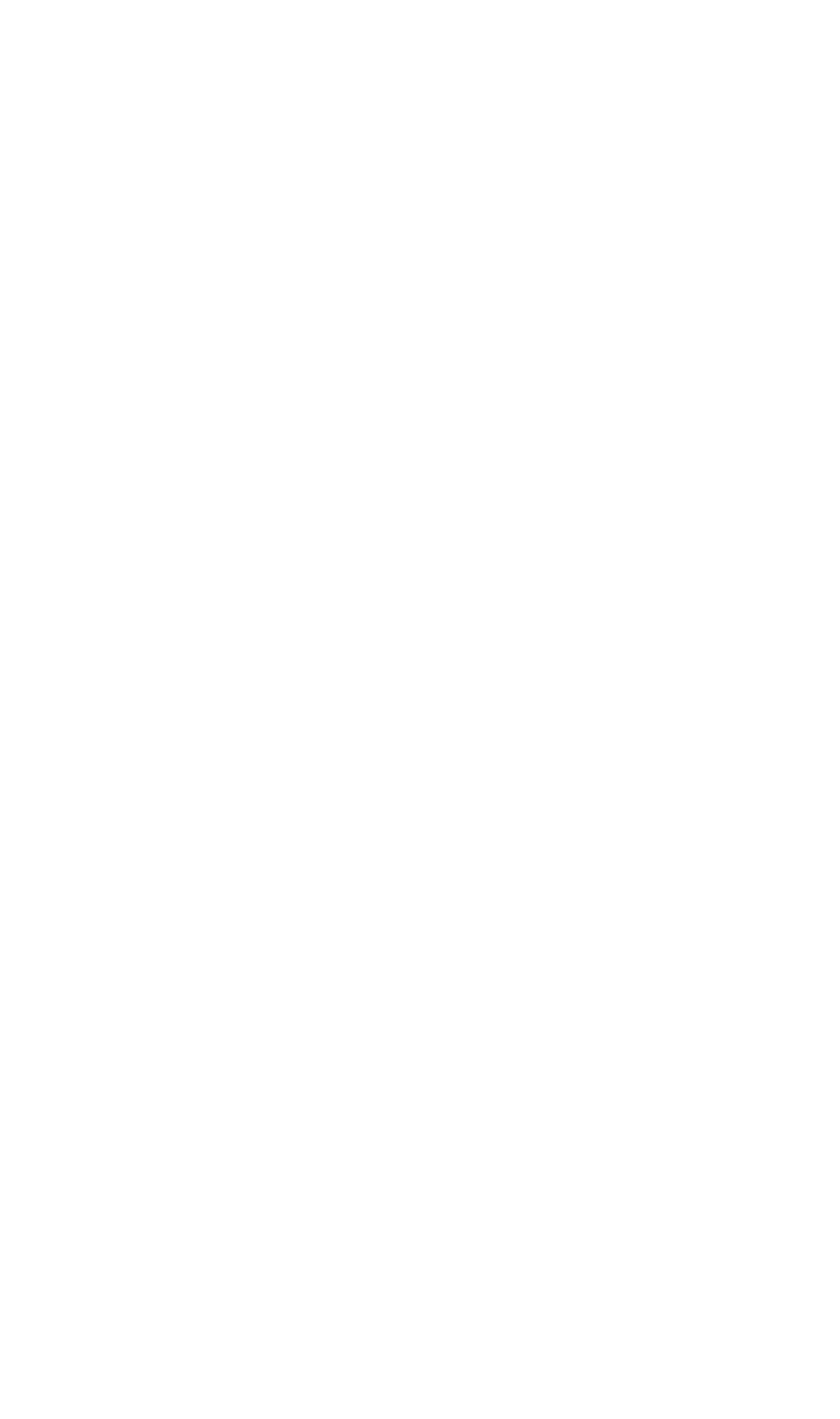



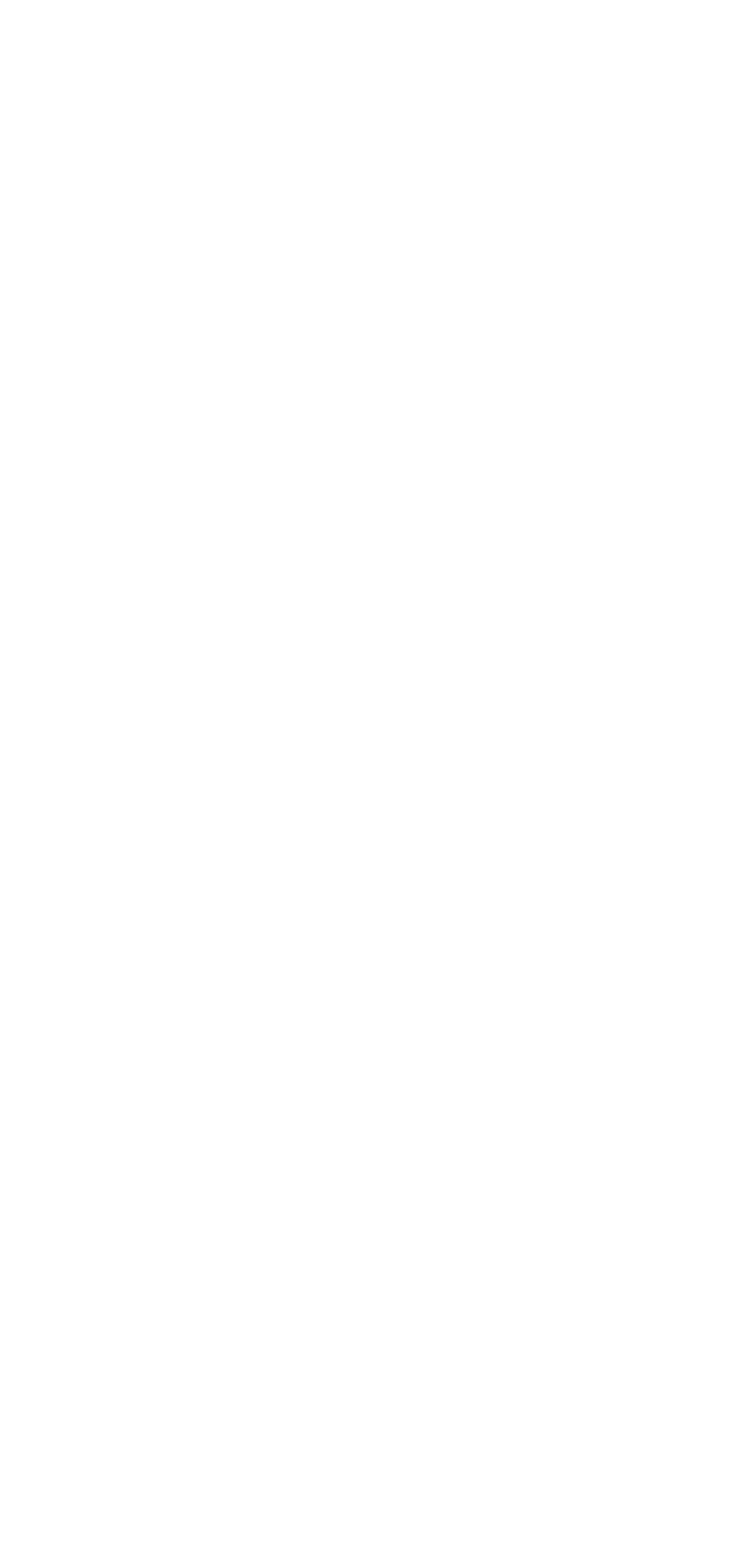


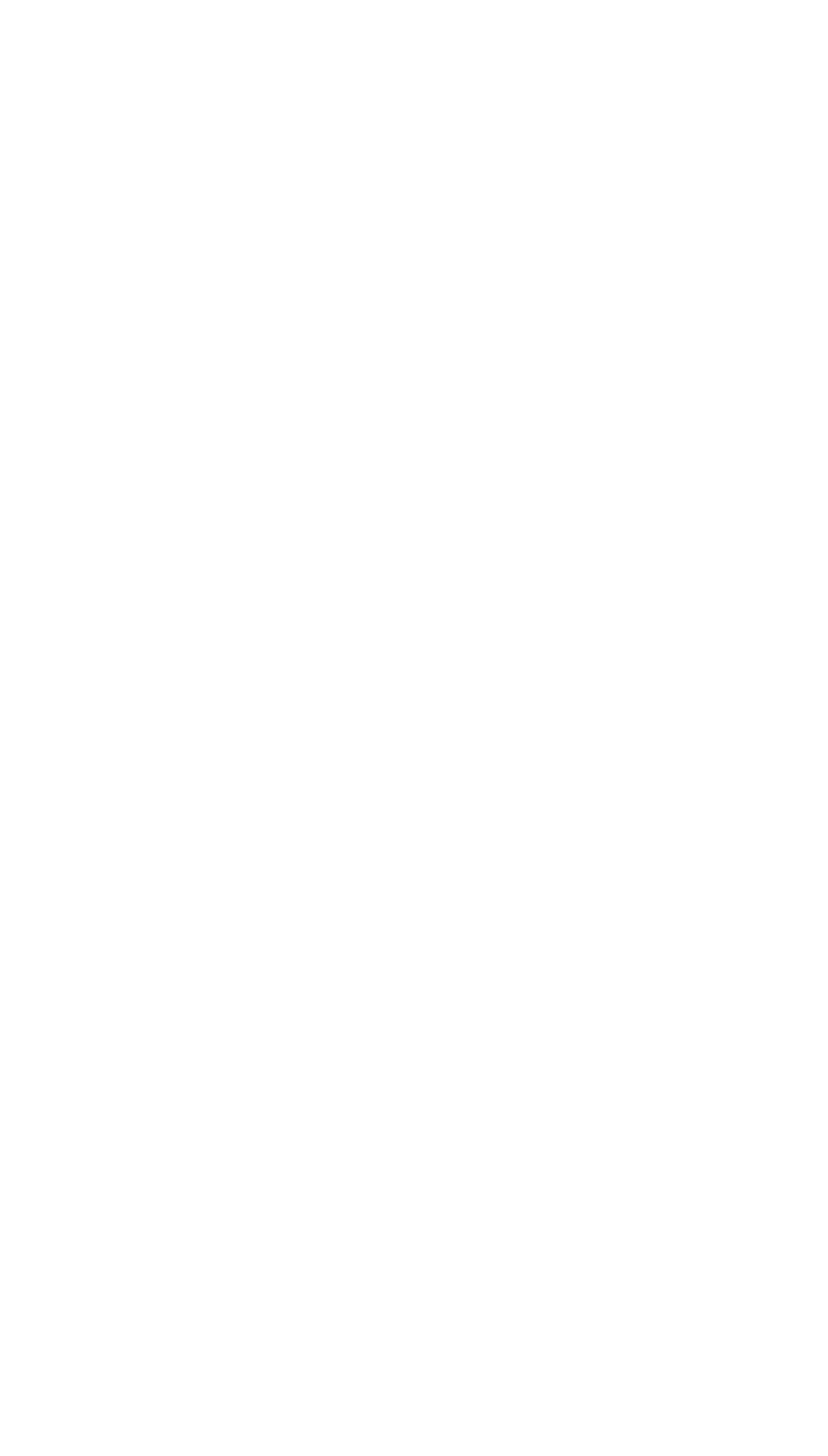



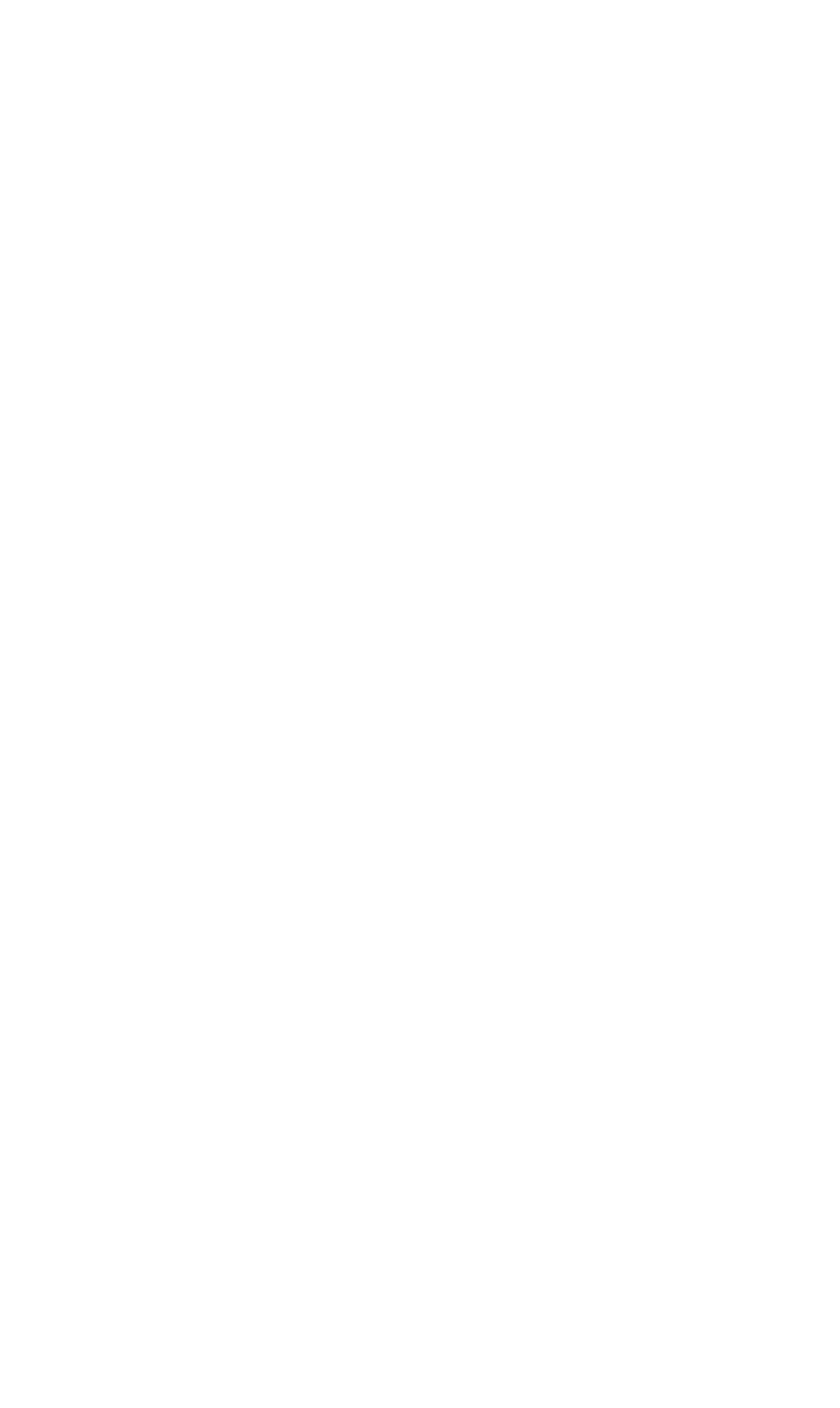

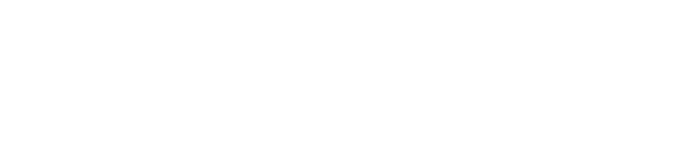
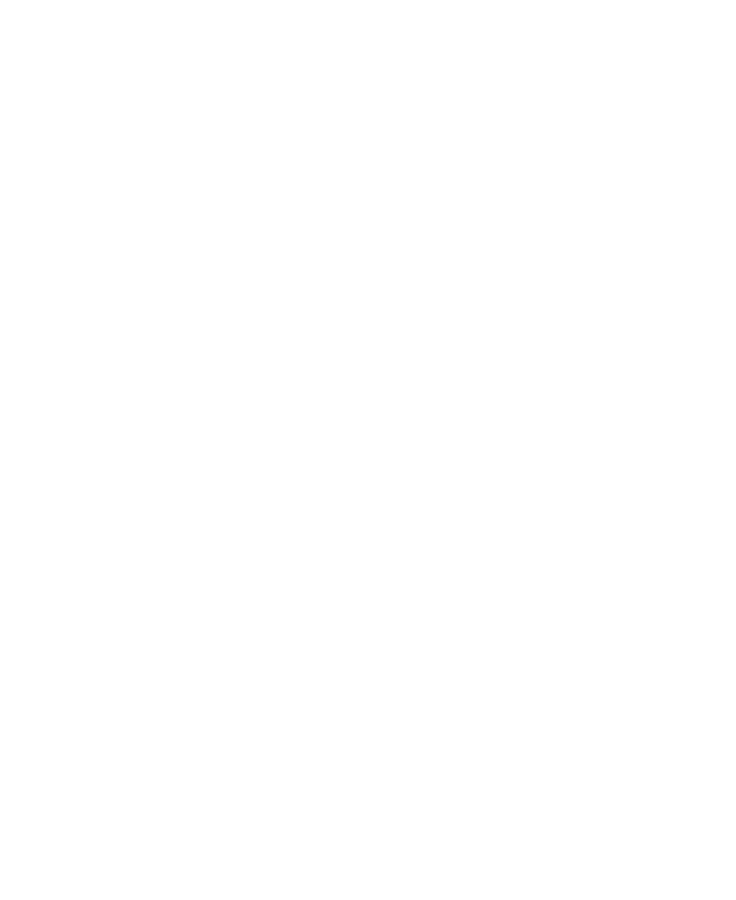


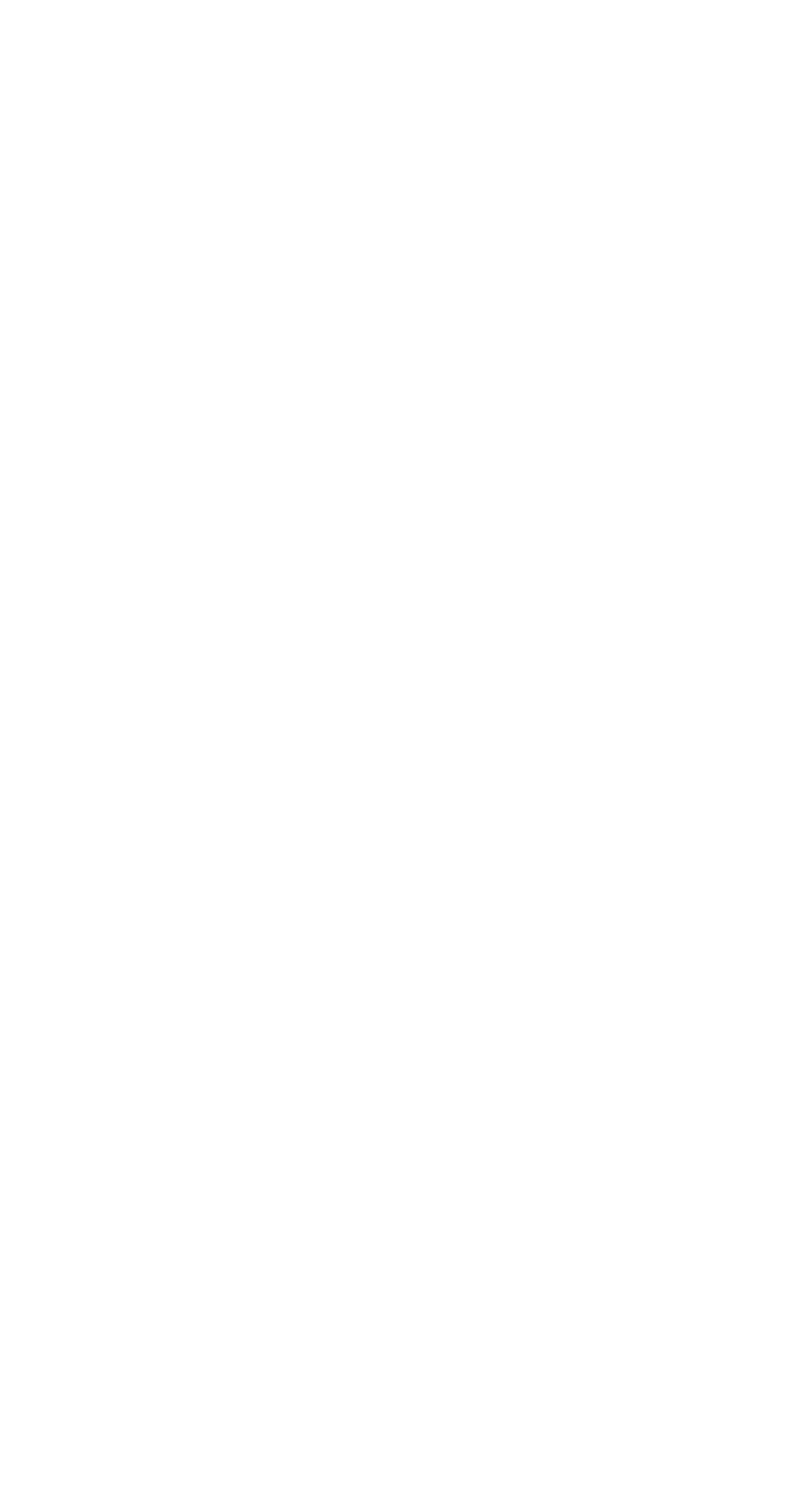




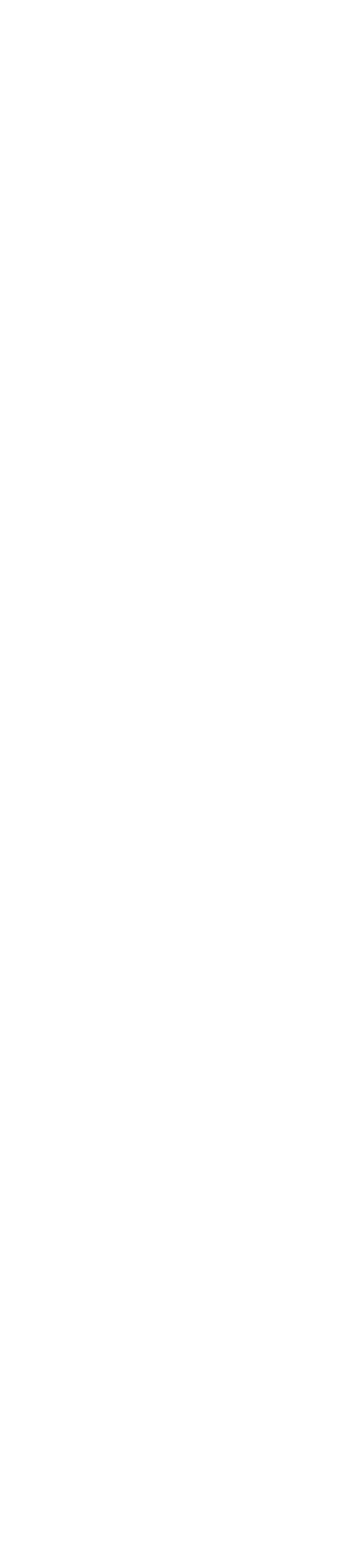


题

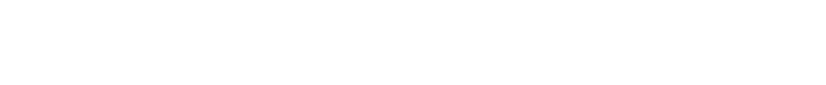

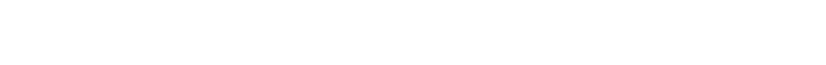

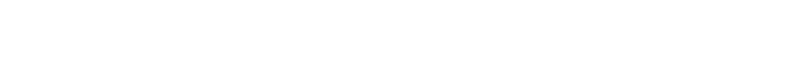

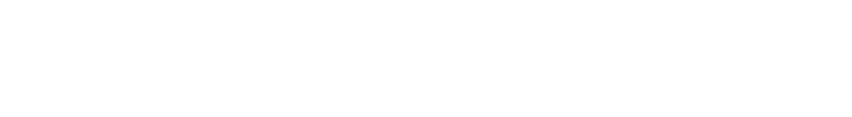

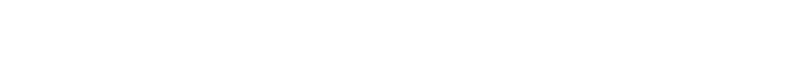

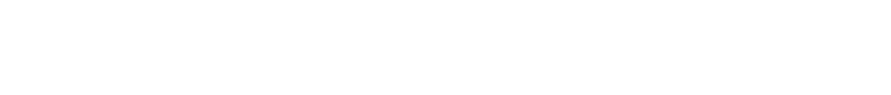

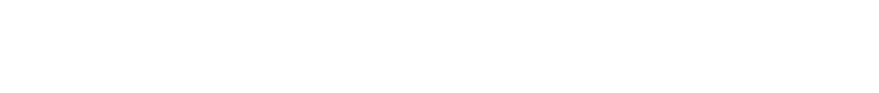

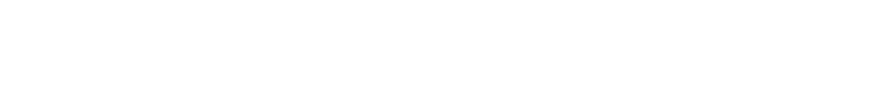

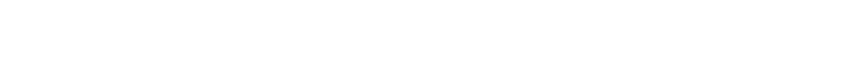

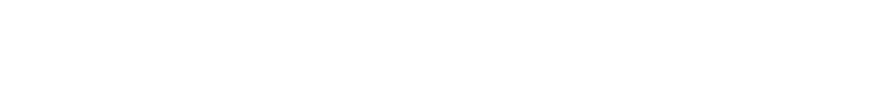

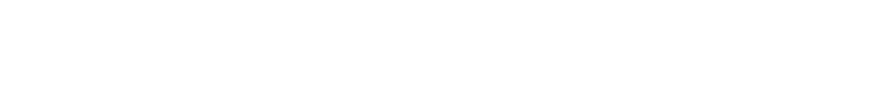

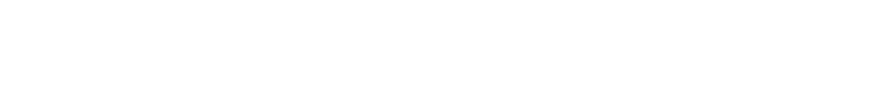

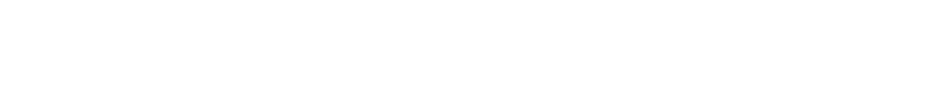

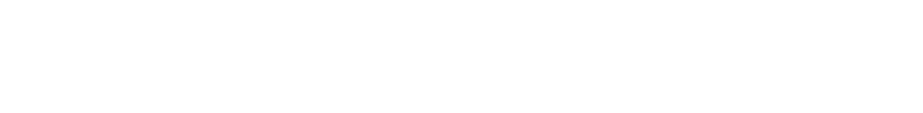

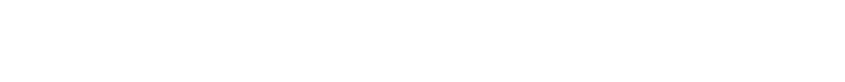

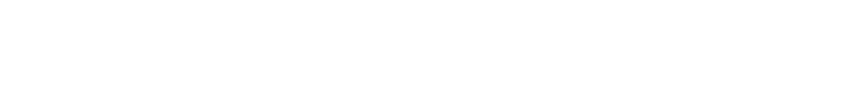

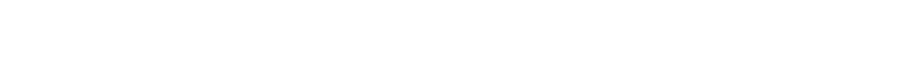

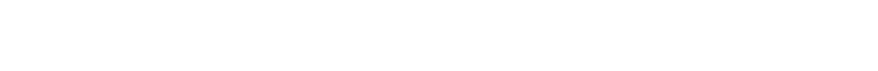
势盽

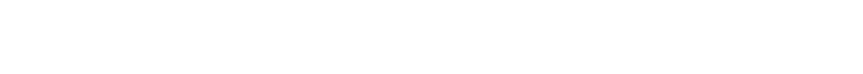

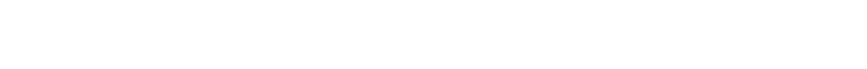

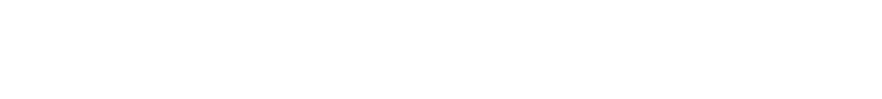

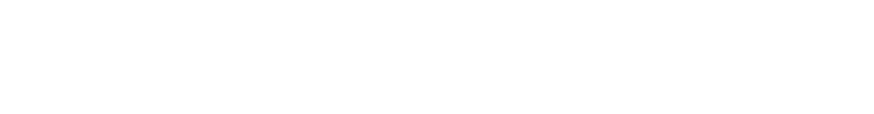




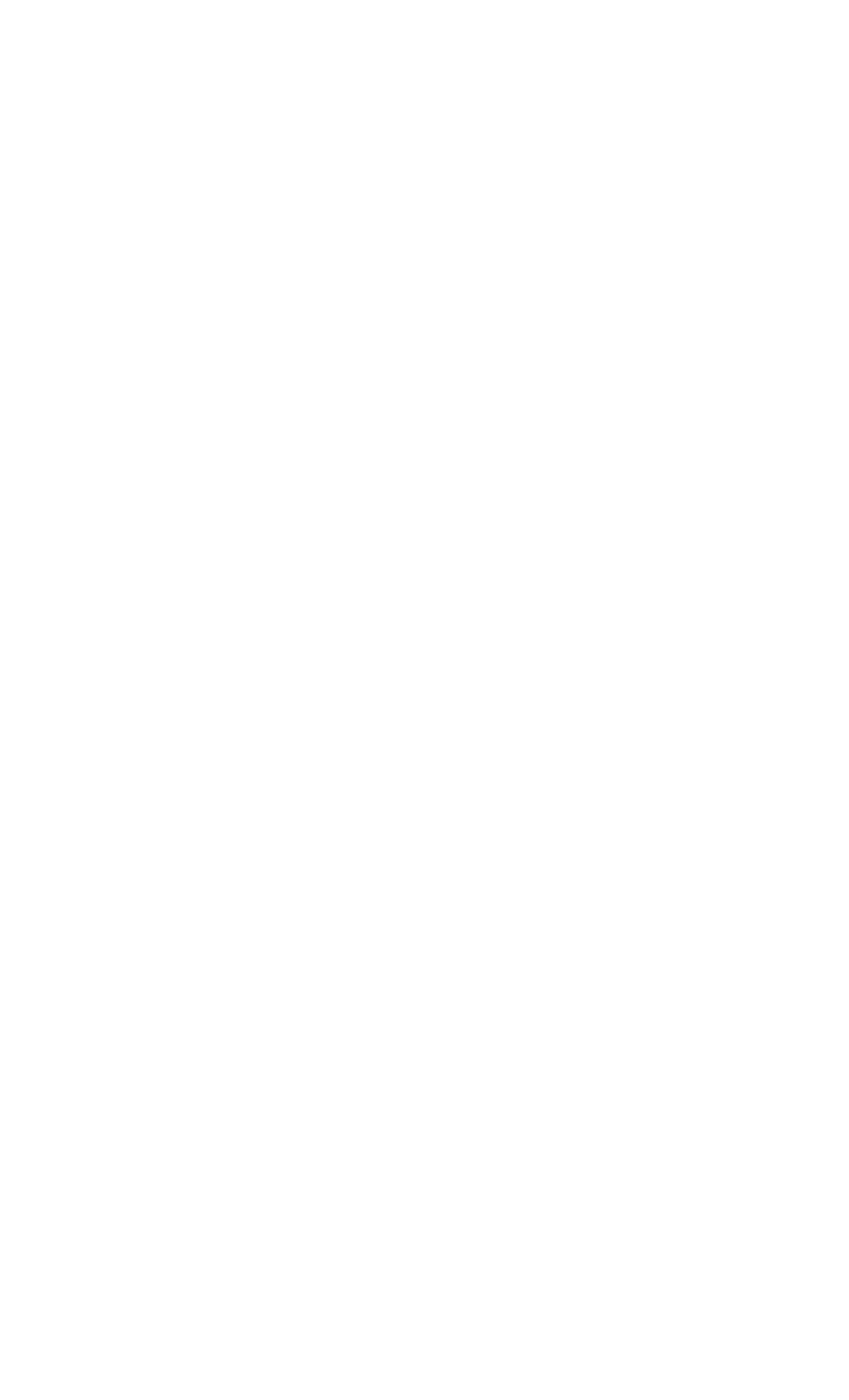




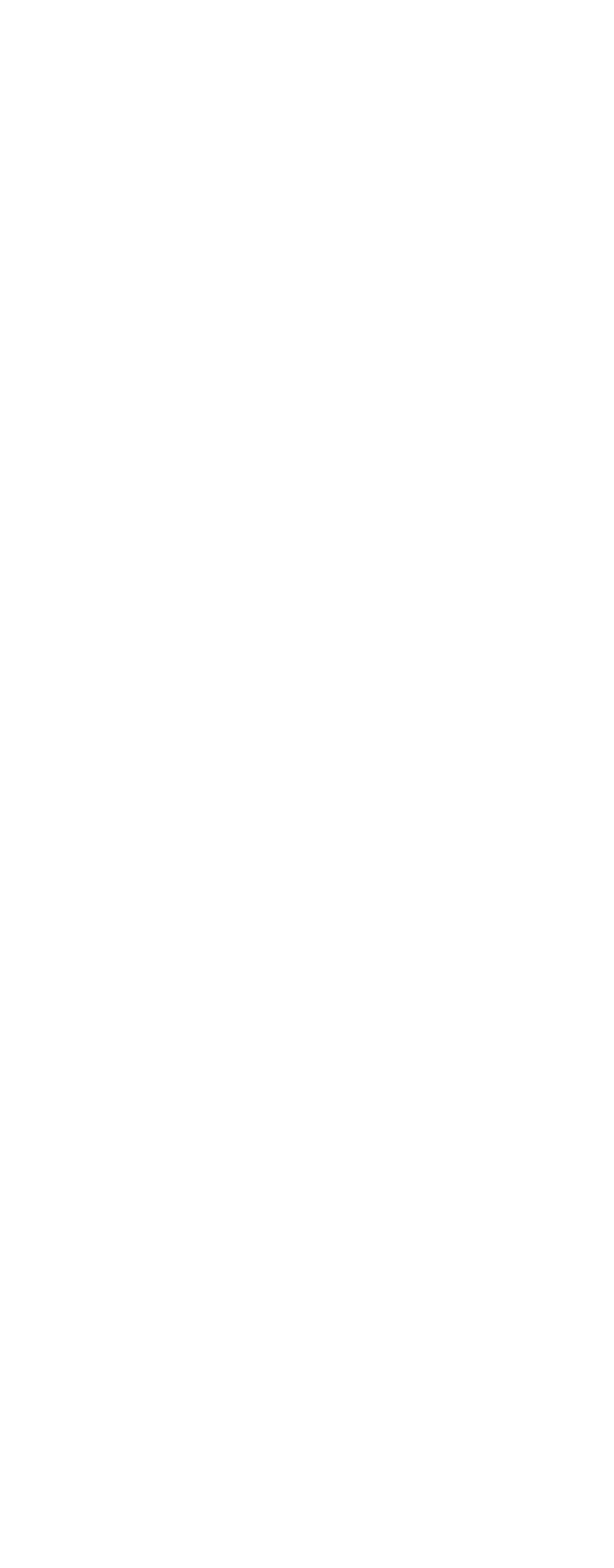




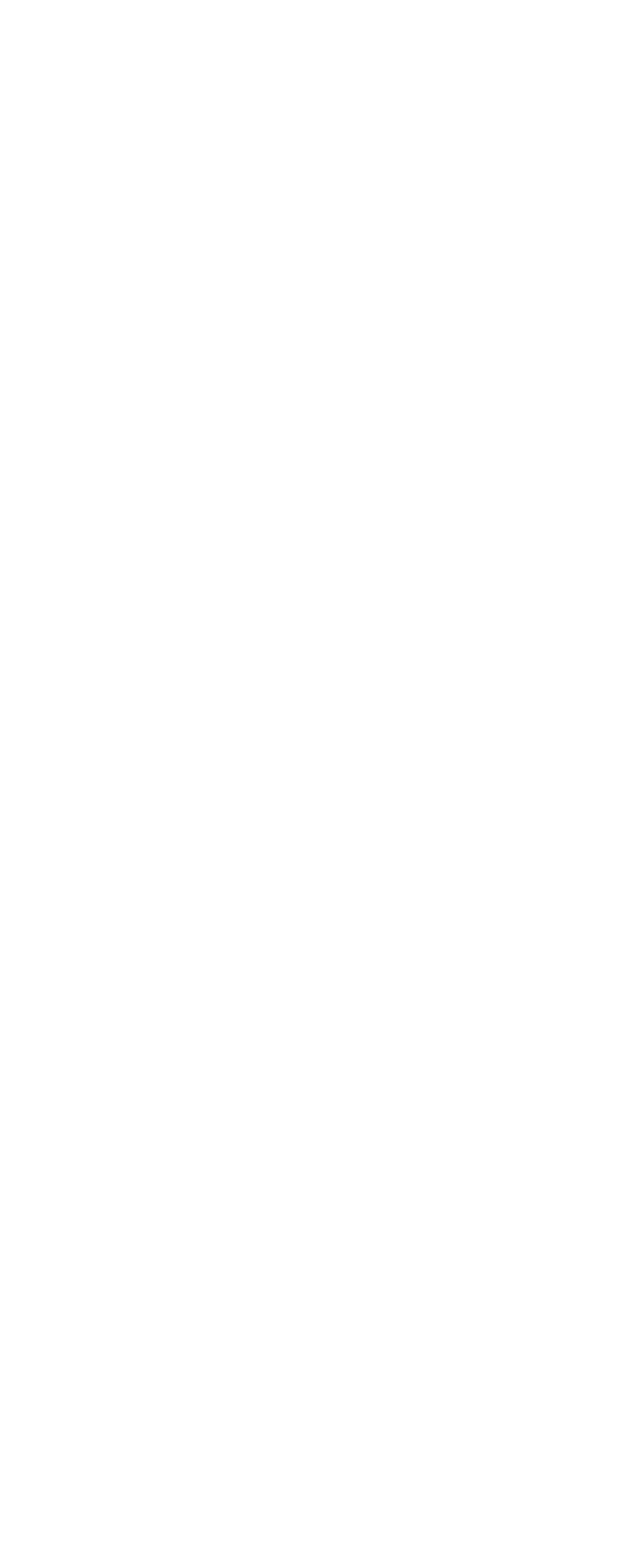




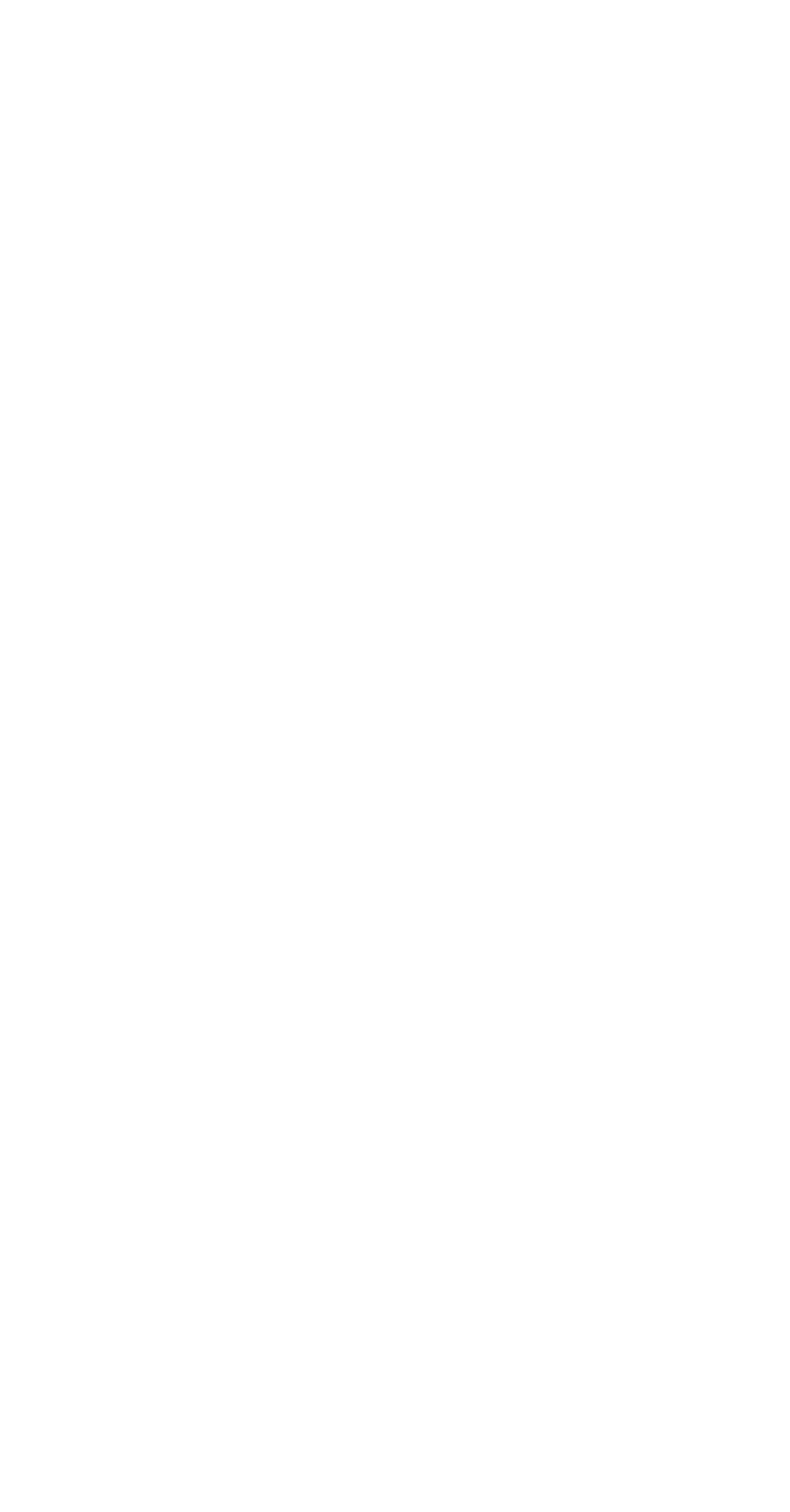


RECORDS AVAILABLE FOR WATER TBMPERATURES

Unpublished records of water temperature have been collected for several years on 13 streams in the Ohio River basin in Kentucky. Water temperatures were measured one day each week, once or twice a day. These records are available in files of the District Office of the U.S. Geological Survey, Water Resources Division, Louisville, Ky.

Stations in the Ohio River basin for which water-temperature records are available

Station
number

Station name

LITTLE SANDY RIVER BASIN

$3-2165$

Little Sandy River at Grayson, Ky

KENTUCKY RIVER BASIN

3-2800. North Fork Kentucky River at Jackson, Ky..........

3-2810. Middle Fork Kentucky River at Tallega, Ky ..........

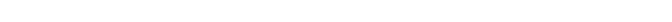

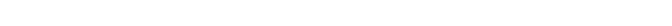

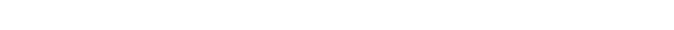

\section{SALT RIVER BASIN}

3-2985. Salt River at Shepherdsville, Ky

CUMBERLAND RIVER BASIN

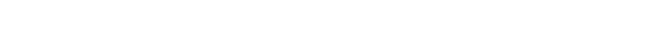

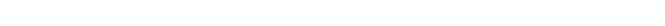

3-4045. Cumberland River at Cumberland Falls, Ky.

3-4050. Laurel River at Corbin, Ky.

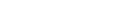

y........

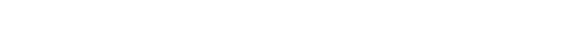

$3-4385$.

Cumber land River at Smithland, Ky....

\section{TENNESSEE RIVER BASIN}

3-6095. Tennessee River at Kentucky Dam, near Paducah, Ky...

A Approximately (at Gilbertsville).

\begin{tabular}{|c|c|}
\hline $\begin{array}{l}\text { Drainage } \\
\text { area } \\
\text { (sq mi) }\end{array}$ & $\begin{array}{c}\text { Records } \\
\text { available } \\
\text { (water years) }\end{array}$ \\
\hline
\end{tabular}

400

$1950-67$

$\begin{array}{rc}1,101 & 1949-67 \\ 537 & 1949-67 \\ 722 & 1949-67 \\ 4,528 & 1949-62 ; 1965-67 \\ 318 & 1949-67\end{array}$

1,197

$1949-52 ; 1933-67$

$\begin{array}{rr}374 & 1950-67 \\ 58.2 & 1949-67 \\ 1,977 & 1949-67 \\ 201 & 1950-67 \\ 604 & 1949-67 \\ 1,083 & 1949-67 \\ 244 & 1959-67 \\ 17,913 & 1949-67\end{array}$

1949-61; $1962-67$ 


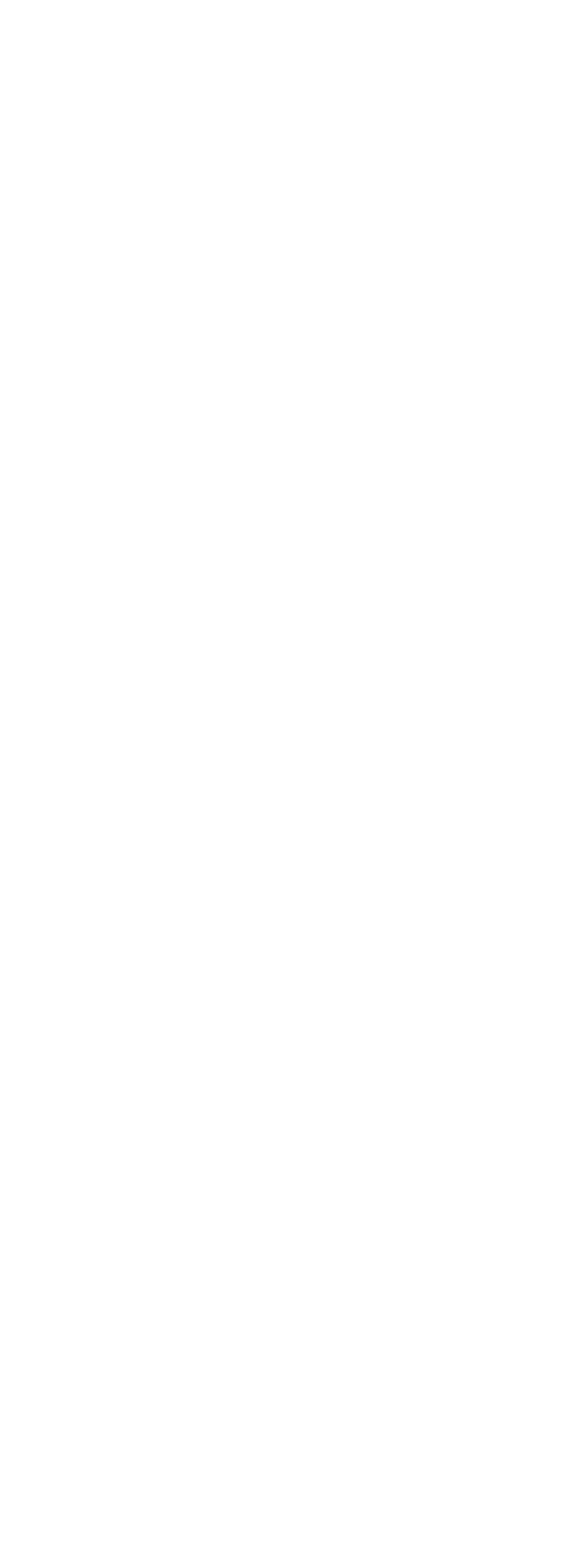




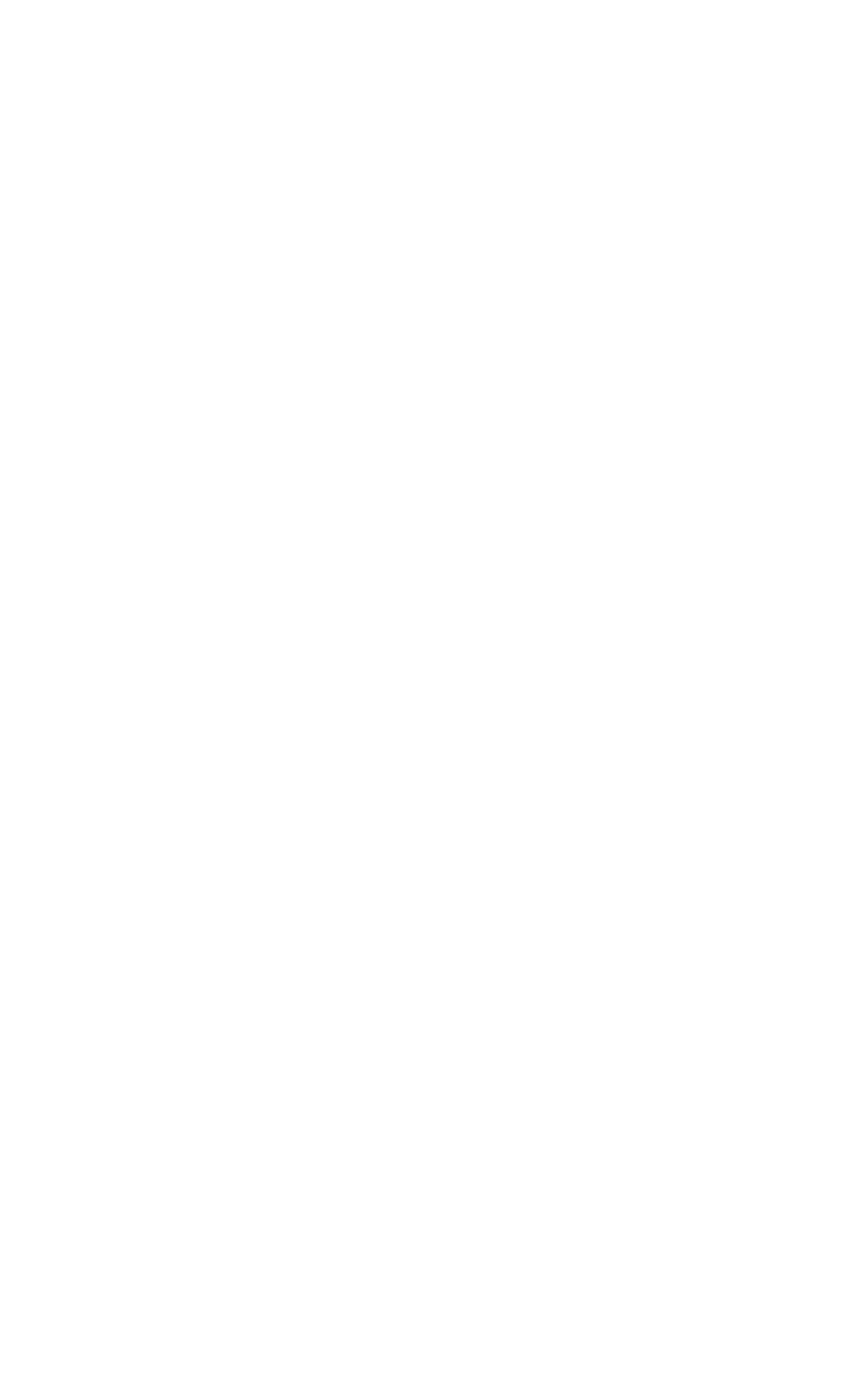




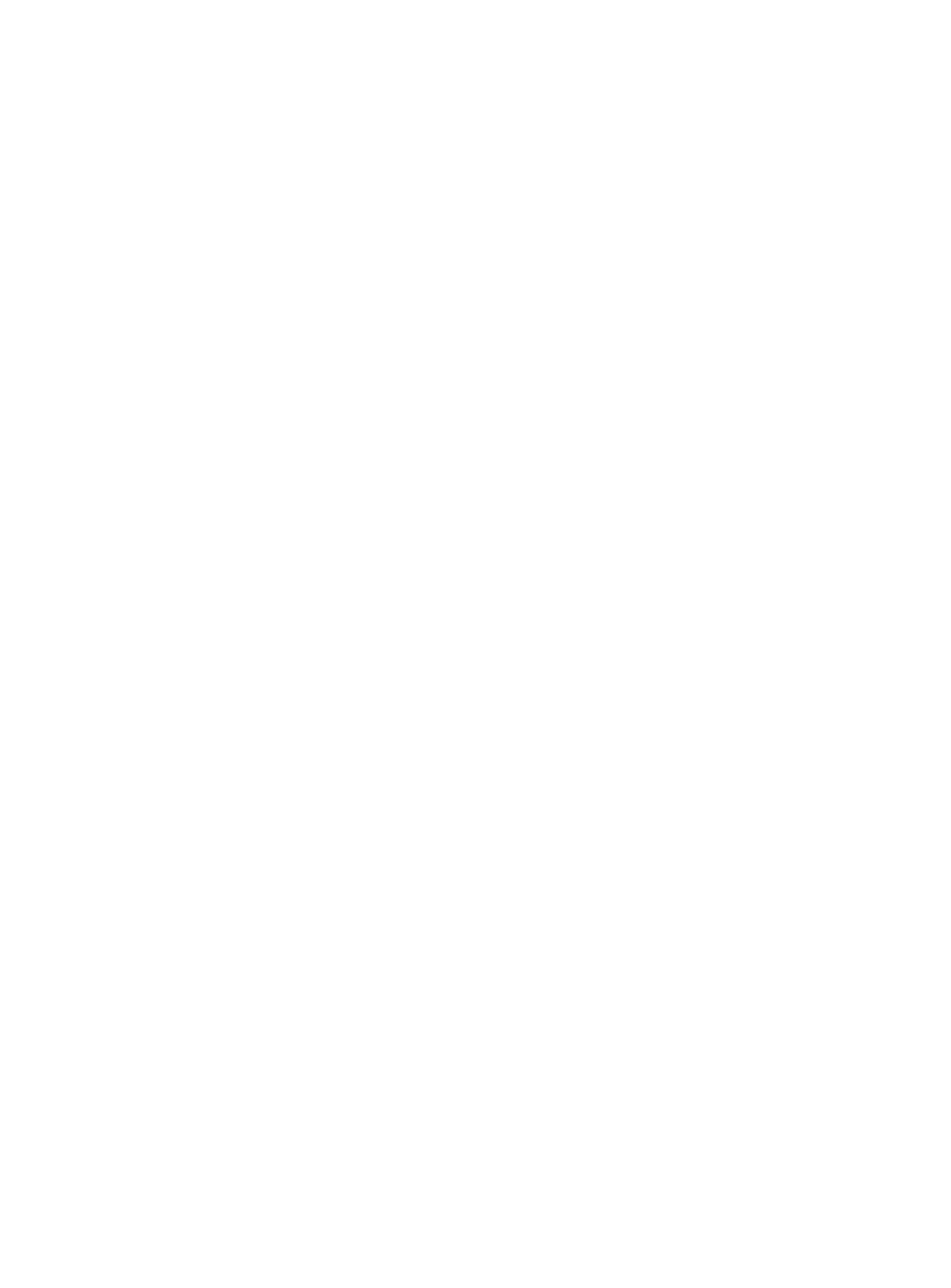




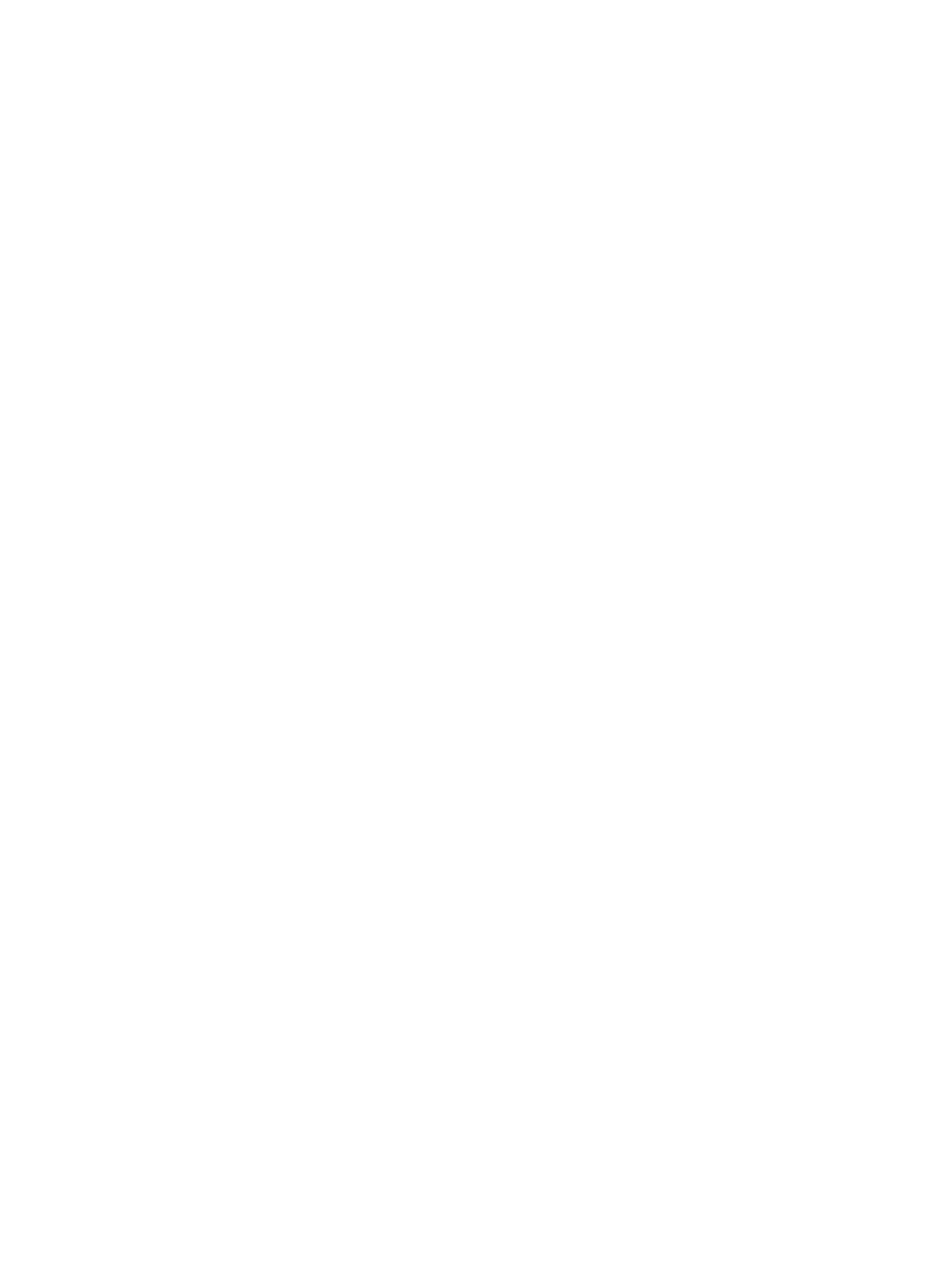




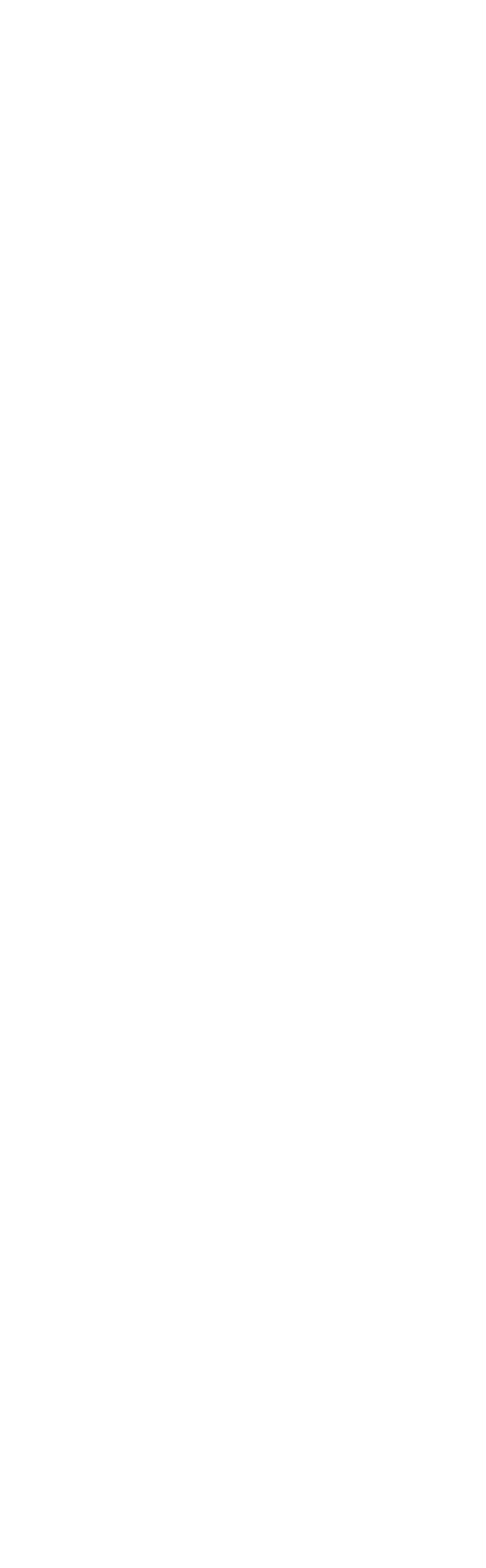




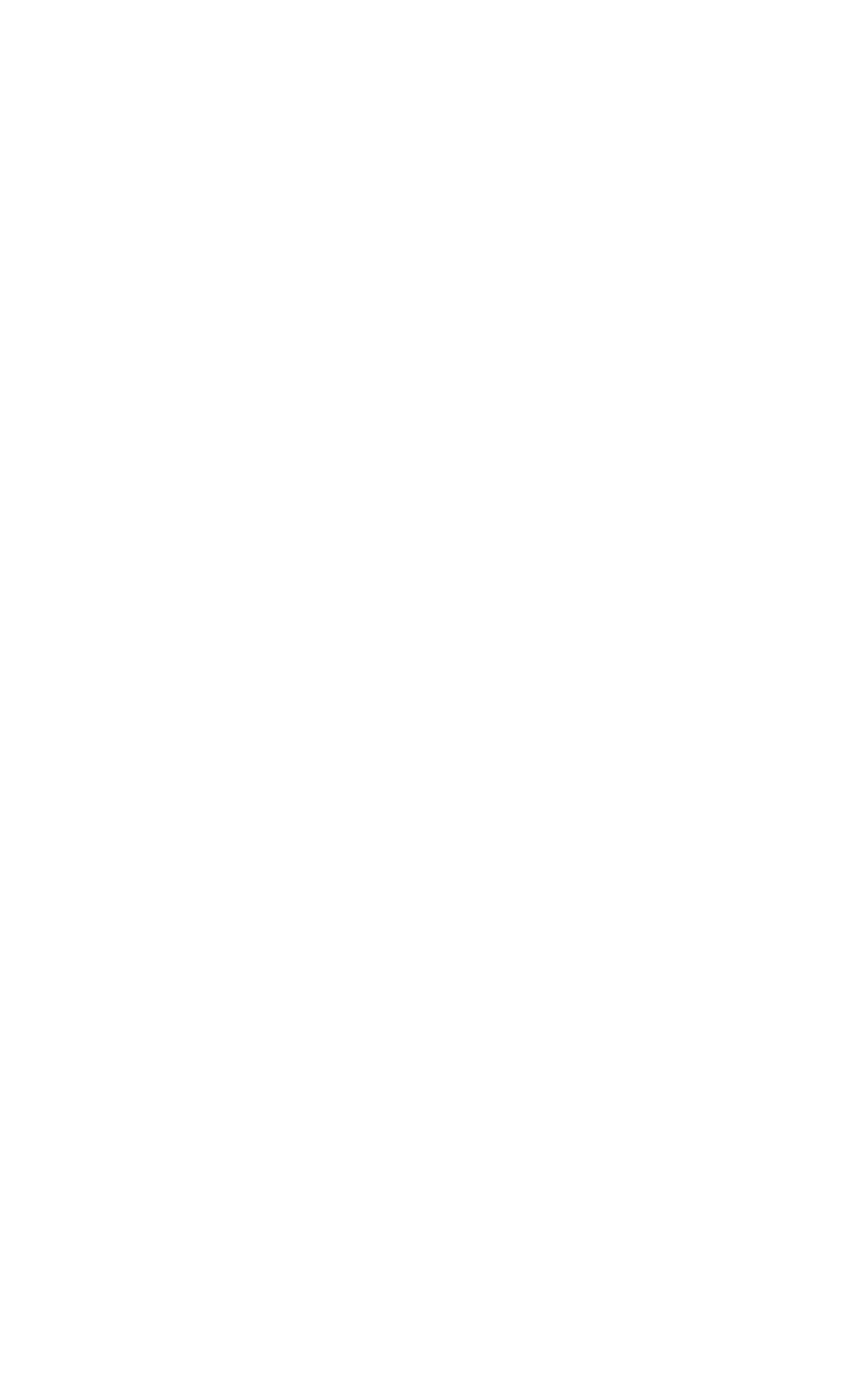




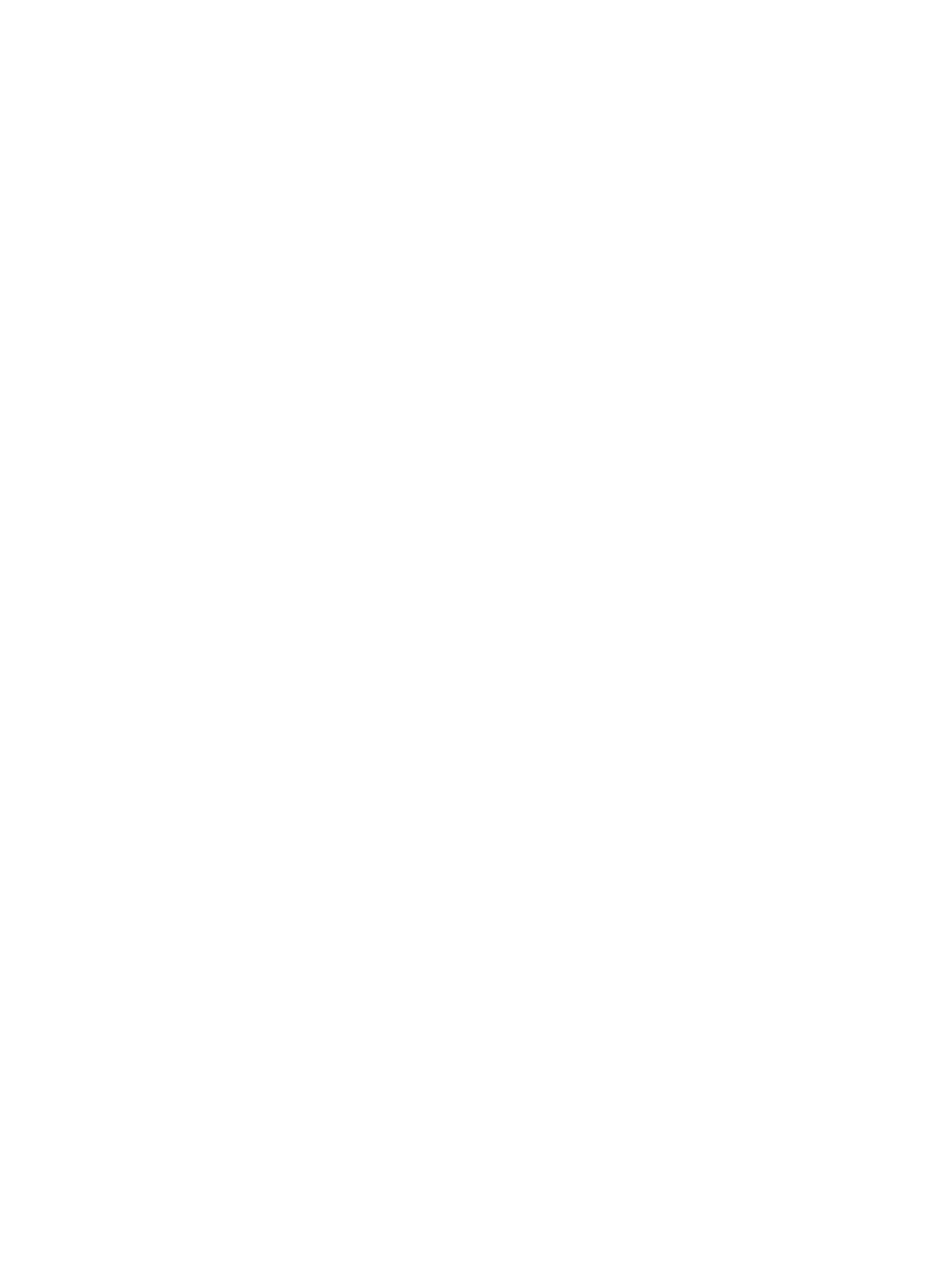




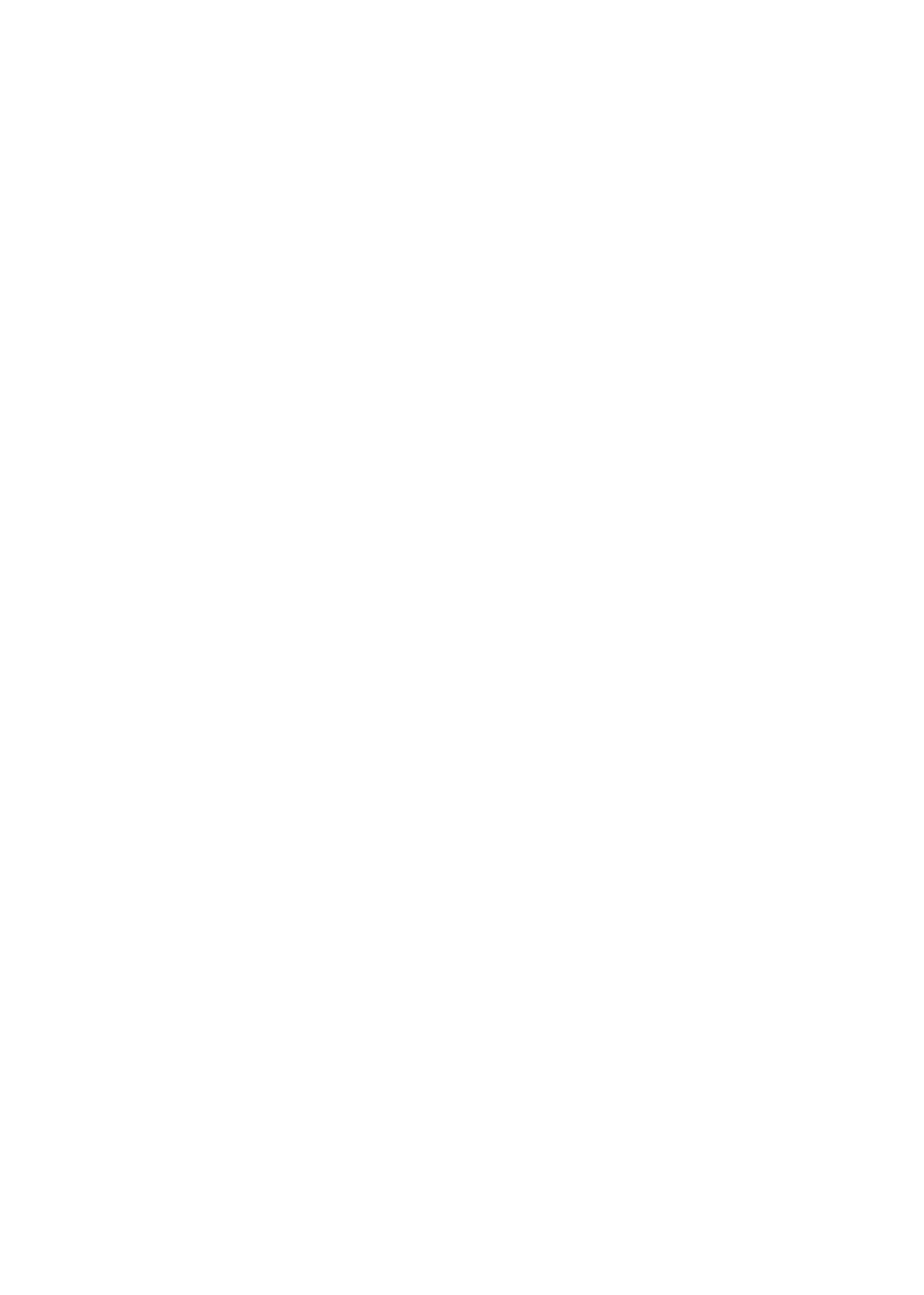




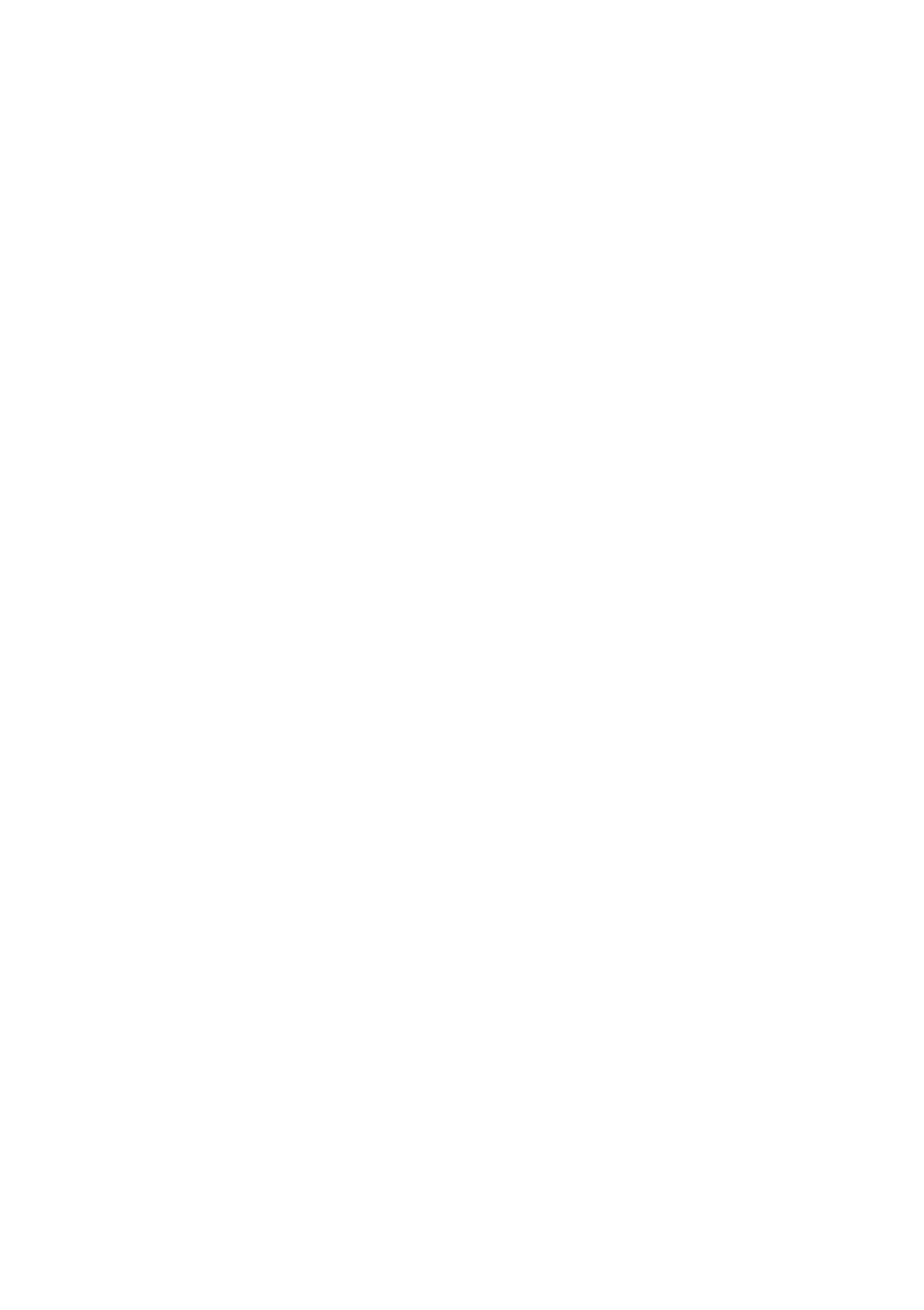




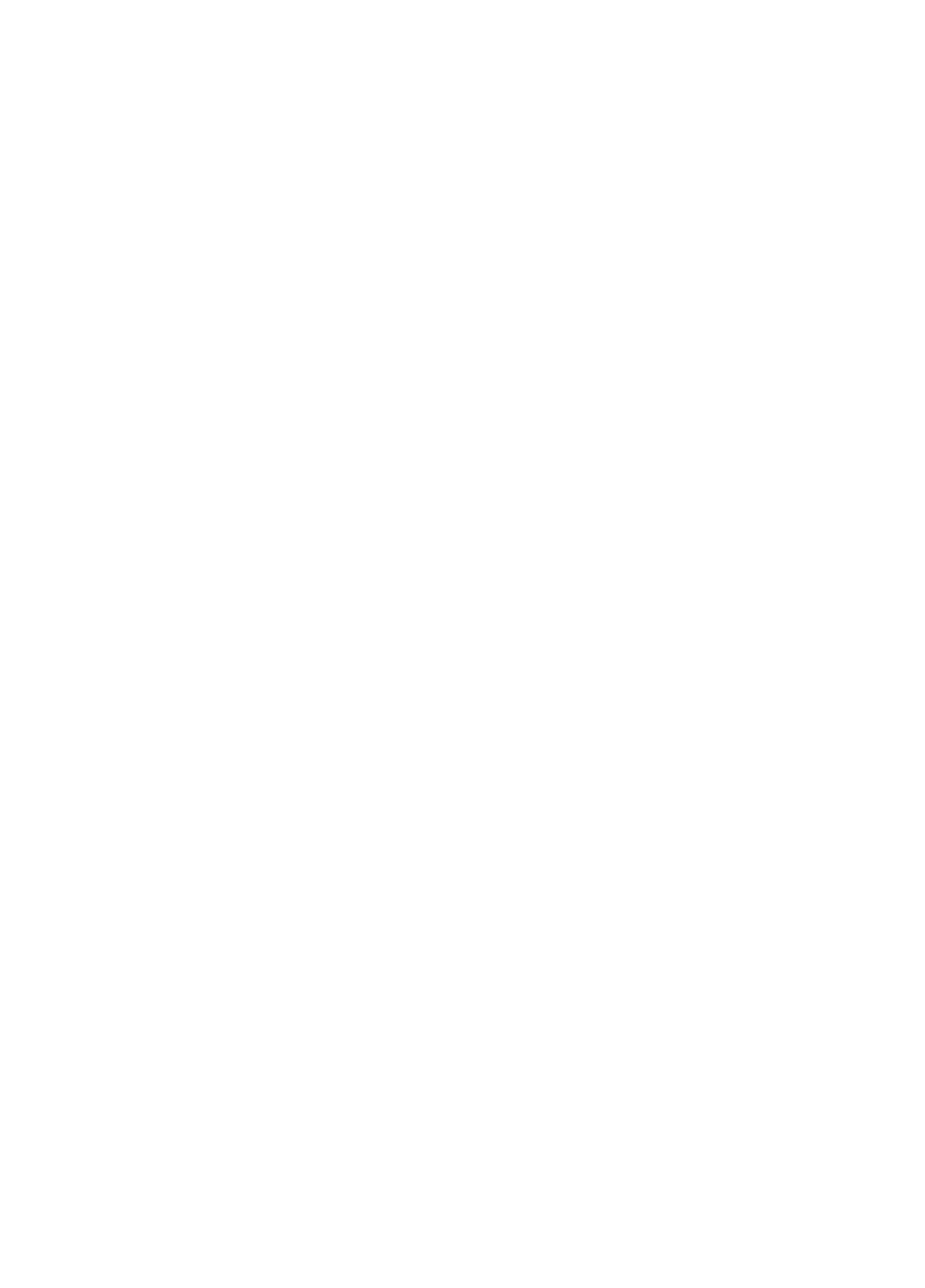



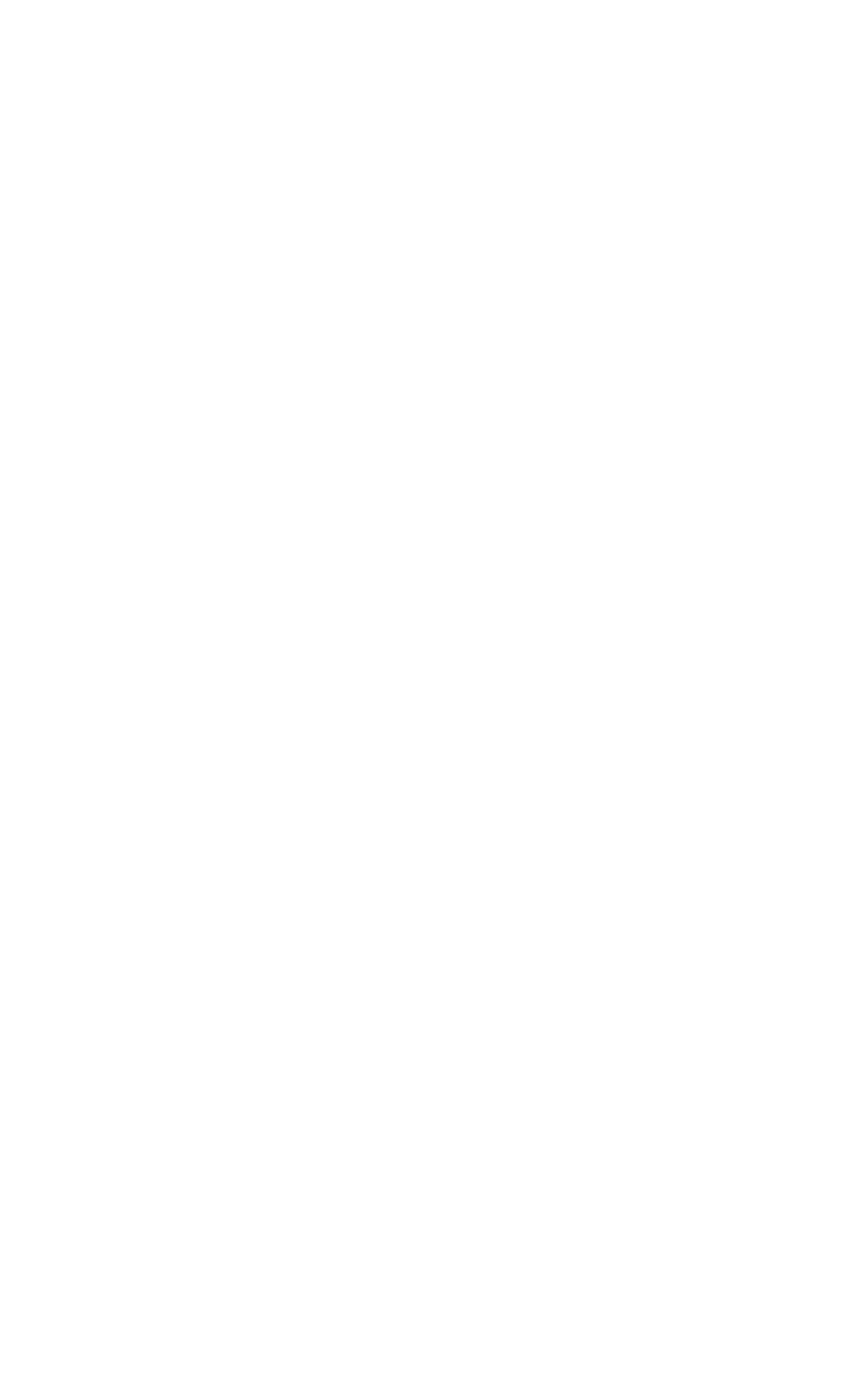
STREAMS TRIBUTARY TO LAKE MICHIGAN--Continued

4-0624. MICHIGAMME RIVER NEAR WITCH LAKE, MICH.--Continued

Suspended sediment, water year October 1966 to September 1967

\begin{tabular}{|c|c|c|c|c|c|c|c|c|c|}
\hline \multirow[b]{3}{*}{ Day } & \multicolumn{3}{|c|}{ OCTOBER } & \multicolumn{3}{|c|}{ NOVEMBER } & \multicolumn{3}{|c|}{ DECEMBER } \\
\hline & \multirow[b]{2}{*}{$\begin{array}{c}\text { Mean } \\
\text { dis- } \\
\text { charge } \\
\text { (cfs) }\end{array}$} & \multicolumn{2}{|c|}{ Suspended sediment } & \multirow[b]{2}{*}{$\begin{array}{c}\text { Mean } \\
\text { dis- } \\
\text { charge } \\
\text { (cfs) }\end{array}$} & \multicolumn{2}{|c|}{\begin{tabular}{|l} 
Suspended sodiment \\
\end{tabular}} & \multirow[b]{2}{*}{$\begin{array}{c}\text { Mean } \\
\text { dis- } \\
\text { charge } \\
\text { (cfg) }\end{array}$} & \multicolumn{2}{|c|}{ Suspended sediment } \\
\hline & & $\begin{array}{c}\text { Mean } \\
\text { concen- } \\
\text { tration } \\
(\text { ppm) }\end{array}$ & $\begin{array}{l}\text { Tons } \\
\text { per } \\
\text { day }\end{array}$ & & $\begin{array}{c}\text { Mean } \\
\text { concen- } \\
\text { tration } \\
\text { (ppm) }\end{array}$ & $\begin{array}{l}\text { Tons } \\
\text { per } \\
\text { day }\end{array}$ & & $\begin{array}{c}\text { Mean } \\
\text { concen- } \\
\text { tration } \\
\text { (ppm) }\end{array}$ & $\begin{array}{l}\text { Tons } \\
\text { per } \\
\text { day }\end{array}$ \\
\hline $\begin{array}{l}1 \ldots \\
2 \ldots \\
3 \ldots \\
4 \ldots \\
5 \ldots\end{array}$ & $\begin{array}{l}140 \\
138 \\
136 \\
149 \\
156\end{array}$ & $\begin{array}{r}15 \\
4 \\
3 \\
7 \\
3\end{array}$ & $\begin{array}{l}5.7 \\
1.5 \\
1.1 \\
2.8 \\
1.3\end{array}$ & $\begin{array}{l}383 \\
380 \\
376 \\
406 \\
296\end{array}$ & $\begin{array}{l}3 \\
3 \\
2 \\
2 \\
3\end{array}$ & $\begin{array}{l}3.1 \\
3.1 \\
2.0 \\
2.2 \\
2.4\end{array}$ & $\begin{array}{l}400 \\
410 \\
400 \\
350 \\
325\end{array}$ & $\begin{array}{l}3 \\
3 \\
3 \\
2 \\
2\end{array}$ & $\begin{array}{l}3.2 \\
3.3 \\
3.2 \\
1.9 \\
1.8\end{array}$ \\
\hline $\begin{array}{r}6 \ldots \\
7 \ldots \\
9 \\
10\end{array}$ & $\begin{array}{l}156 \\
176 \\
189 \\
187 \\
183\end{array}$ & $\begin{array}{l}3 \\
4 \\
4 \\
3 \\
2\end{array}$ & $\begin{array}{l}1.3 \\
1.9 \\
2.0 \\
1.5 \\
1.0\end{array}$ & $\begin{array}{l}285 \\
288 \\
299 \\
302 \\
306\end{array}$ & $\begin{array}{r}2 \\
6 \\
12 \\
3 \\
2\end{array}$ & $\begin{array}{l}1.5 \\
4.7 \\
9.7 \\
2.4 \\
1.7\end{array}$ & $\begin{array}{l}335 \\
350 \\
355 \\
360 \\
360\end{array}$ & $\begin{array}{l}2 \\
2 \\
3 \\
4 \\
3\end{array}$ & $\begin{array}{l}1.8 \\
1.9 \\
2.9 \\
3.9 \\
2.9\end{array}$ \\
\hline $\begin{array}{l}11 \ldots \\
12 \ldots \\
13 \ldots \\
140 \\
15 \ldots\end{array}$ & $\begin{array}{l}181 \\
220 \\
232 \\
170 \\
247\end{array}$ & $\begin{array}{l}2 \\
2 \\
2 \\
4 \\
4\end{array}$ & $\begin{array}{l}1.0 \\
1.2 \\
1.3 \\
1.8 \\
2.7\end{array}$ & $\begin{array}{l}313 \\
313 \\
355 \\
366 \\
302\end{array}$ & $\begin{array}{l}2 \\
2 \\
2 \\
2 \\
2\end{array}$ & $\begin{array}{l}1.7 \\
1.7 \\
1.9 \\
2.0 \\
1.6\end{array}$ & $\begin{array}{l}355 \\
355 \\
350 \\
345 \\
345\end{array}$ & $\begin{array}{l}3 \\
2 \\
4 \\
5 \\
4\end{array}$ & $\begin{array}{l}2.9 \\
1.9 \\
3.8 \\
4.7 \\
3.7\end{array}$ \\
\hline $\begin{array}{l}16 \ldots \\
17 \ldots \\
18 \ldots \\
19 \ldots \\
20 \ldots\end{array}$ & $\begin{array}{l}566 \\
742 \\
662 \\
630 \\
622\end{array}$ & $\begin{array}{r}9 \\
15 \\
7 \\
5 \\
7\end{array}$ & $\begin{array}{l}14 \\
30 \\
13 \\
8.5 \\
12\end{array}$ & $\begin{array}{l}302 \\
302 \\
306 \\
302 \\
299\end{array}$ & $\begin{array}{l}2 \\
2 \\
2 \\
2 \\
2\end{array}$ & $\begin{array}{l}1.6 \\
1.6 \\
1.7 \\
1.6 \\
1.6\end{array}$ & $\begin{array}{l}340 \\
330 \\
325 \\
315 \\
310\end{array}$ & $\begin{array}{l}4 \\
4 \\
4\end{array}$ & $\begin{array}{l}3.7 \\
3.6 \\
2.6 \\
3.4 \\
3.3\end{array}$ \\
\hline $\begin{array}{l}21 \ldots \\
22 \ldots \\
23 \ldots \\
24 \ldots \\
25 \ldots\end{array}$ & $\begin{array}{l}654 \\
670 \\
686 \\
674 \\
614\end{array}$ & $\begin{array}{l}3 \\
4 \\
2 \\
2 \\
3\end{array}$ & $\begin{array}{l}5.3 \\
7.2 \\
3.7 \\
3.6 \\
5.0\end{array}$ & $\begin{array}{l}292 \\
292 \\
264 \\
254 \\
264\end{array}$ & $\begin{array}{l}2 \\
2 \\
2 \\
2 \\
2\end{array}$ & $\begin{array}{l}1.6 \\
1.6 \\
1.4 \\
1.4 \\
1.4\end{array}$ & $\begin{array}{l}305 \\
300 \\
290 \\
280 \\
275\end{array}$ & $\begin{array}{l}3 \\
3 \\
3 \\
3 \\
3\end{array}$ & $\begin{array}{l}2 \cdot 5 \\
2 \cdot 4 \\
2 \cdot 3 \\
2.3 \\
2.2\end{array}$ \\
\hline $\begin{array}{l}26 \ldots \\
27 \ldots \\
28 \ldots \\
29 \ldots \\
30 \ldots \\
31 \ldots \\
\end{array}$ & $\begin{array}{l}506 \\
490 \\
490 \\
486 \\
470 \\
406\end{array}$ & $\begin{array}{l}5 \\
2 \\
4 \\
7 \\
4 \\
4\end{array}$ & $\begin{array}{l}6.8 \\
2.6 \\
5.3 \\
9.2 \\
5.1 \\
4.4\end{array}$ & $\begin{array}{r}274 \\
282 \\
320 \\
360 \\
390 \\
-- \\
\end{array}$ & $\begin{array}{r}2 \\
2 \\
10 \\
6 \\
3 \\
- \\
\end{array}$ & $\begin{array}{l}1.5 \\
1.5 \\
8.6 \\
5.8 \\
3.2 \\
\end{array}$ & $\begin{array}{l}265 \\
255 \\
245 \\
235 \\
230 \\
215 \\
\end{array}$ & $\begin{array}{l}2 \\
2 \\
2 \\
2 \\
3 \\
2 \\
\end{array}$ & $\begin{array}{l}1.4 \\
1.4 \\
1.3 \\
1.3 \\
1.9 \\
1.2\end{array}$ \\
\hline \multirow[t]{2}{*}{ Total } & 12028 & - & 163.8 & 9473 & - & 77.8 & 9910 & - & 80.6 \\
\hline & \multicolumn{3}{|c|}{ JANUARY } & \multicolumn{3}{|c|}{ FEBRUARY } & \multicolumn{3}{|c|}{ MARCH } \\
\hline $\begin{array}{l}1 \ldots \\
2 \ldots \\
3 \ldots \\
4 \ldots \\
5 \ldots\end{array}$ & $\begin{array}{l}205 \\
190 \\
185 \\
175 \\
170\end{array}$ & $\begin{array}{l}2 \\
2 \\
2 \\
9 \\
8\end{array}$ & $\begin{array}{l}1.1 \\
1.0 \\
1.0 \\
4.3 \\
3.7\end{array}$ & $\begin{array}{l}200 \\
198 \\
197 \\
194 \\
192\end{array}$ & $\begin{array}{l}2 \\
2 \\
2 \\
2 \\
3\end{array}$ & $\begin{array}{l}1.1 \\
1.1 \\
1.1 \\
1.0 \\
1.6\end{array}$ & $\begin{array}{l}181 \\
181 \\
181 \\
181 \\
181\end{array}$ & $\begin{array}{l}5 \\
6 \\
3 \\
2 \\
2\end{array}$ & $\begin{array}{l}2.4 \\
2.9 \\
1.5 \\
1.0 \\
1.0\end{array}$ \\
\hline $\begin{array}{r}6 \ldots \\
7 \ldots \\
9 \cdots \\
10 \ldots\end{array}$ & $\begin{array}{l}170 \\
165 \\
165 \\
165 \\
165\end{array}$ & $\begin{array}{l}3 \\
2 \\
1 \\
1 \\
1\end{array}$ & $\begin{array}{r}1.4 \\
.9 \\
.4 \\
.4\end{array}$ & $\begin{array}{l}192 \\
192 \\
192 \\
190 \\
190\end{array}$ & $\begin{array}{l}2 \\
2 \\
2 \\
2 \\
2\end{array}$ & $\begin{array}{l}1.0 \\
1.0 \\
1.0 \\
1.0 \\
1.0\end{array}$ & $\begin{array}{l}180 \\
180 \\
180 \\
179 \\
178\end{array}$ & $\begin{array}{l}2 \\
2 \\
3 \\
3 \\
4\end{array}$ & $\begin{array}{l}1.0 \\
1.0 \\
1.5 \\
1.4 \\
1.9\end{array}$ \\
\hline $\begin{array}{l}11 \ldots \\
12 \ldots \\
13 \ldots \\
14 \ldots \\
15 \ldots\end{array}$ & $\begin{array}{l}165 \\
168 \\
170 \\
170 \\
172\end{array}$ & $\begin{array}{l}2 \\
2 \\
5 \\
2 \\
2\end{array}$ & $\begin{array}{r}: 9 \\
: 99 \\
: 99\end{array}$ & $\begin{array}{l}190 \\
190 \\
190 \\
189 \\
188\end{array}$ & $\begin{array}{l}2 \\
2 \\
2 \\
1 \\
1\end{array}$ & $\begin{array}{r}1.0 \\
1.0 \\
1.0 \\
.5 \\
.5\end{array}$ & $\begin{array}{l}178 \\
177 \\
177 \\
176 \\
176\end{array}$ & $\begin{array}{l}3 \\
5 \\
5 \\
5 \\
5\end{array}$ & $\begin{array}{l}1.4 \\
2.4 \\
2.4 \\
2.4 \\
2.4\end{array}$ \\
\hline $\begin{array}{l}16 \ldots \\
17 \ldots \\
18 \ldots \\
19 \ldots \\
20 \ldots\end{array}$ & $\begin{array}{l}173 \\
175 \\
176 \\
180 \\
182\end{array}$ & $\begin{array}{r}2 \\
2 \\
3 \\
4 \\
14\end{array}$ & $\begin{array}{r}.9 \\
1.9 \\
1.9 \\
6.9\end{array}$ & $\begin{array}{l}188 \\
188 \\
187 \\
187 \\
187\end{array}$ & $\begin{array}{l}1 \\
1 \\
2 \\
2 \\
1\end{array}$ & $\begin{array}{r}.5 \\
.5 \\
1.0 \\
1.0 \\
.5\end{array}$ & $\begin{array}{l}176 \\
175 \\
175 \\
174 \\
174\end{array}$ & $\begin{array}{l}5 \\
6 \\
6 \\
7 \\
3\end{array}$ & $\begin{array}{l}2.4 \\
2.8 \\
2.8 \\
3.3 \\
1.4\end{array}$ \\
\hline $\begin{array}{l}21 \ldots \\
22 \ldots \\
23 \ldots \\
24 \ldots \\
25 \ldots\end{array}$ & $\begin{array}{l}185 \\
190 \\
195 \\
198 \\
199\end{array}$ & $\begin{array}{l}3 \\
2 \\
3 \\
4 \\
7\end{array}$ & $\begin{array}{l}1.5 \\
1.0 \\
1.6 \\
2.1 \\
3.8\end{array}$ & $\begin{array}{l}186 \\
185 \\
184 \\
183 \\
182\end{array}$ & $\begin{array}{l}3 \\
4 \\
7 \\
6 \\
5\end{array}$ & $\begin{array}{l}1.5 \\
2.0 \\
3.5 \\
3.0 \\
2.5\end{array}$ & $\begin{array}{l}172 \\
170 \\
155 \\
142 \\
138\end{array}$ & $\begin{array}{l}3 \\
4 \\
6 \\
7 \\
7\end{array}$ & $\begin{array}{l}1.4 \\
1.8 \\
2.5 \\
2.7 \\
2.6\end{array}$ \\
\hline $\begin{array}{l}26 \ldots \\
27 \ldots \\
28 \ldots \\
29 \ldots \\
30 \ldots \\
31 \ldots\end{array}$ & $\begin{array}{l}200 \\
201 \\
200 \\
200 \\
200 \\
200\end{array}$ & $\begin{array}{r}20 \\
14 \\
3 \\
2 \\
2 \\
2\end{array}$ & $\begin{array}{l}11 \\
7.6 \\
1.6 \\
1.1 \\
1.1 \\
1.1\end{array}$ & $\begin{array}{r}182 \\
181 \\
181 \\
= \\
=\end{array}$ & $\begin{array}{r}4 \\
5 \\
-- \\
- \\
\end{array}$ & $\begin{array}{r}2.0 \\
2.0 \\
2.4 \\
= \\
=\end{array}$ & $\begin{array}{l}140 \\
155 \\
194 \\
288 \\
352 \\
606 \\
\end{array}$ & $\begin{array}{r}7 \\
11 \\
9 \\
7 \\
9 \\
17 \\
\end{array}$ & $\begin{array}{l}2.6 \\
4.6 \\
4.7 \\
5.4 \\
8.6 \\
28\end{array}$ \\
\hline Total & 5654 & -- & 66.0 & 5285 & - & 37.3 & 6072 & -- & 104.2 \\
\hline
\end{tabular}


STREAYS TRIBUTARY TO LAKE MICHIGAN---Continued

4-0624. MICHIGANE RIVER NEAR WITCH LAKE, MICH,--Continued

Suspended sediment, water year October 1966 to September 1967--Continued

\begin{tabular}{|c|c|c|c|c|c|c|c|c|c|}
\hline \multirow[b]{3}{*}{ Day } & \multicolumn{3}{|c|}{ APRIL } & \multicolumn{3}{|c|}{ MaY } & \multicolumn{3}{|c|}{ JUHE } \\
\hline & \multirow[b]{2}{*}{$\begin{array}{c}\text { Mean } \\
\text { dis- } \\
\text { charge } \\
\text { (cfs) }\end{array}$} & \multicolumn{2}{|c|}{ Suspended sediment } & \multirow[b]{2}{*}{$\begin{array}{l}\text { Mean } \\
\text { dis- } \\
\text { charge } \\
\text { (cfs) }\end{array}$} & \multicolumn{2}{|c|}{ Suspended sediment } & \multirow[b]{2}{*}{$\begin{array}{l}\text { Mean } \\
\text { dis- } \\
\text { charge } \\
\text { (cfs) }\end{array}$} & \multicolumn{2}{|c|}{ Suspended sediment } \\
\hline & & $\begin{array}{c}\text { Mean } \\
\text { concen- } \\
\text { tration } \\
\text { (ppm) }\end{array}$ & $\begin{array}{l}\text { Tons } \\
\text { per } \\
\text { day }\end{array}$ & & $\begin{array}{c}\text { Mean } \\
\text { concen- } \\
\text { tration } \\
\text { (ppm) }\end{array}$ & $\begin{array}{l}\text { Tons } \\
\text { per } \\
\text { day }\end{array}$ & & $\begin{array}{c}\text { Mean } \\
\text { concen- } \\
\text { tration } \\
\text { (ppm) }\end{array}$ & $\begin{array}{l}\text { Tons } \\
\text { per } \\
\text { day }\end{array}$ \\
\hline $\begin{array}{l}1 \ldots \\
2 \ldots \\
3 \ldots \\
4 \ldots \\
5 \ldots\end{array}$ & $\begin{array}{r}694 \\
814 \\
934 \\
950 \\
1110\end{array}$ & $\begin{array}{l}18 \\
20 \\
22 \\
32 \\
42\end{array}$ & $\begin{array}{r}34 \\
44 \\
35 \\
82 \\
126\end{array}$ & $\begin{array}{l}1150 \\
1270 \\
1330 \\
1220 \\
1110\end{array}$ & $\begin{array}{l}18 \\
27 \\
20 \\
24 \\
15\end{array}$ & $\begin{array}{l}56 \\
93 \\
72 \\
79 \\
43\end{array}$ & $\begin{array}{l}341 \\
316 \\
344 \\
348 \\
316\end{array}$ & $\begin{array}{l}3 \\
2 \\
2 \\
1 \\
1\end{array}$ & $\begin{array}{r}2.8 \\
1.7 \\
1.9 \\
.9 \\
.9\end{array}$ \\
\hline $\begin{array}{r}6 \ldots \\
7 \ldots \\
8 \ldots \\
9 \ldots\end{array}$ & $\begin{array}{l}1290 \\
1330 \\
1420 \\
1450 \\
1420\end{array}$ & $\begin{array}{l}54 \\
52 \\
38 \\
33 \\
44\end{array}$ & $\begin{array}{l}188 \\
187 \\
146 \\
129 \\
192\end{array}$ & $\begin{array}{r}1060 \\
966 \\
922 \\
830 \\
806\end{array}$ & $\begin{array}{r}17 \\
14 \\
13 \\
9 \\
12\end{array}$ & $\begin{array}{l}49 \\
37 \\
32 \\
20 \\
26\end{array}$ & $\begin{array}{l}274 \\
295 \\
366 \\
398 \\
390\end{array}$ & $\begin{array}{l}2 \\
2 \\
2 \\
2 \\
4\end{array}$ & $\begin{array}{l}1.5 \\
1.6 \\
2.0 \\
2.1 \\
4.2\end{array}$ \\
\hline $\begin{array}{l}11 \ldots \\
12 \ldots \\
13 \ldots \\
14 \ldots \\
15 \ldots\end{array}$ & $\begin{array}{l}1670 \\
1650 \\
1650 \\
1640 \\
1730\end{array}$ & $\begin{array}{l}44 \\
40 \\
25 \\
28 \\
19\end{array}$ & $\begin{array}{r}198 \\
178 \\
111 \\
124 \\
89\end{array}$ & $\begin{array}{l}694 \\
714 \\
722 \\
718 \\
702\end{array}$ & $\begin{array}{r}9 \\
11 \\
9 \\
3 \\
4\end{array}$ & $\begin{array}{l}17 \\
21 \\
18 \\
5.8 \\
7.6\end{array}$ & $\begin{array}{l}410 \\
534 \\
534 \\
646 \\
746\end{array}$ & $\begin{array}{l}5 \\
4 \\
7 \\
6 \\
7\end{array}$ & $\begin{array}{l}5.5 \\
5.8 \\
10 \\
10 \\
14\end{array}$ \\
\hline $\begin{array}{l}16 \ldots \\
17 \ldots \\
18 \ldots \\
19 \ldots \\
20 \ldots\end{array}$ & $\begin{array}{l}2020 \\
2320 \\
2880 \\
3280 \\
3210\end{array}$ & $\begin{array}{l}27 \\
38 \\
42 \\
49 \\
32\end{array}$ & $\begin{array}{l}147 \\
238 \\
327 \\
434 \\
277\end{array}$ & $\begin{array}{l}682 \\
606 \\
518 \\
514 \\
514\end{array}$ & $\begin{array}{l}5 \\
5 \\
3 \\
3 \\
7\end{array}$ & $\begin{array}{l}9.2 \\
8.2 \\
4.2 \\
4.2 \\
9.7\end{array}$ & $\begin{array}{r}978 \\
1180 \\
1490 \\
1450 \\
1390\end{array}$ & $\begin{array}{l}18 \\
34 \\
50 \\
28 \\
25\end{array}$ & $\begin{array}{r}48 \\
108 \\
201 \\
110 \\
94\end{array}$ \\
\hline $\begin{array}{l}21 \ldots \\
22 \ldots \\
23 \ldots \\
24 \ldots \\
25 \ldots\end{array}$ & $\begin{array}{l}2960 \\
2620 \\
2340 \\
2110 \\
1880\end{array}$ & $\begin{array}{l}27 \\
27 \\
18 \\
17 \\
13\end{array}$ & $\begin{array}{r}216 \\
191 \\
114 \\
97 \\
66\end{array}$ & $\begin{array}{l}514 \\
506 \\
474 \\
526 \\
566\end{array}$ & $\begin{array}{r}7 \\
7 \\
5 \\
6 \\
12\end{array}$ & $\begin{array}{l}9.7 \\
9.8 \\
6.4 \\
8.5 \\
18\end{array}$ & $\begin{array}{l}1310 \\
1230 \\
1160 \\
1090 \\
.020\end{array}$ & $\begin{array}{l}16 \\
19 \\
22 \\
16 \\
11\end{array}$ & $\begin{array}{l}57 \\
63 \\
69 \\
47 \\
30\end{array}$ \\
\hline $\begin{array}{l}26 \ldots \\
27 \ldots \\
28 \ldots \\
29 \ldots \\
30 \ldots \\
31 \ldots\end{array}$ & $\begin{array}{r}1630 \\
1520 \\
1370 \\
1190 \\
1110 \\
-0\end{array}$ & $\begin{array}{l}17 \\
25 \\
21 \\
10 \\
10 \\
-\end{array}$ & $\begin{array}{r}75 \\
103 \\
78 \\
32 \\
30 \\
-\end{array}$ & $\begin{array}{l}606 \\
594 \\
566 \\
542 \\
522 \\
494\end{array}$ & $\begin{array}{l}8 \\
6 \\
6 \\
7 \\
7 \\
5 \\
\end{array}$ & $\begin{array}{c}13 \\
9.6 \\
9.2 \\
10 \\
9.9 \\
6.7\end{array}$ & $\begin{array}{l}922 \\
808 \\
906 \\
934 \\
918 \\
\end{array}$ & $\begin{array}{r}14 \\
14 \\
10 \\
8 \\
7 \\
- \\
\end{array}$ & $\begin{array}{l}35 \\
30 \\
24 \\
20 \\
17 \\
\end{array}$ \\
\hline \multirow[t]{2}{*}{ Total } & 52392 & - & 4308 & 22958 & - & 724.5 & 23066 & - & 1017.9 \\
\hline & \multicolumn{3}{|c|}{ JULY } & \multicolumn{3}{|c|}{ AUGUST } & \multicolumn{3}{|c|}{ STPTEMBER } \\
\hline $\begin{array}{l}1 \ldots \\
2 \ldots \\
3 \ldots \\
5 \ldots \\
5 \ldots\end{array}$ & $\begin{array}{l}886 \\
854 \\
850 \\
726 \\
694\end{array}$ & $\begin{array}{r}11 \\
12 \\
11 \\
8 \\
9\end{array}$ & $\begin{array}{l}26 \\
28 \\
25 \\
16 \\
17\end{array}$ & $\begin{array}{l}226 \\
192 \\
169 \\
226 \\
229\end{array}$ & $\begin{array}{l}3 \\
3 \\
2 \\
4 \\
3\end{array}$ & $\begin{array}{l}1.8 \\
1.6 \\
1.0 \\
2.4 \\
1.9\end{array}$ & $\begin{array}{l}145 \\
122 \\
122 \\
122 \\
120\end{array}$ & $\begin{array}{l}6 \\
7 \\
7 \\
7 \\
7\end{array}$ & $\begin{array}{l}2 \cdot 3 \\
2 \cdot 3 \\
2 \cdot 3 \\
2 \cdot 3 \\
2 \cdot 3\end{array}$ \\
\hline $\begin{array}{r}6 \ldots \\
7 \ldots \\
8 \ldots \\
9 \ldots \\
10 \ldots\end{array}$ & $\begin{array}{l}630 \\
566 \\
550 \\
562 \\
574\end{array}$ & $\begin{array}{l}6 \\
4 \\
4 \\
7\end{array}$ & $\begin{array}{c}10 \\
6.1 \\
5.9 \\
7.6 \\
11\end{array}$ & $\begin{array}{l}229 \\
238 \\
274 \\
264 \\
241\end{array}$ & $\begin{array}{l}3 \\
4 \\
4 \\
5 \\
5\end{array}$ & $\begin{array}{l}1.9 \\
2.6 \\
3.0 \\
3.6 \\
3.3\end{array}$ & $\begin{array}{l}118 \\
118 \\
118 \\
118 \\
118\end{array}$ & $\begin{array}{l}7 \\
7 \\
6 \\
7 \\
5\end{array}$ & $\begin{array}{l}2.2 \\
2.2 \\
1.9 \\
2.2 \\
1.6\end{array}$ \\
\hline $\begin{array}{l}11 \ldots \\
12 \ldots \\
13 \ldots \\
14 \ldots \\
15 \ldots\end{array}$ & $\begin{array}{l}642 \\
722 \\
594 \\
466 \\
426\end{array}$ & $\begin{array}{r}10 \\
7 \\
5 \\
3 \\
2\end{array}$ & $\begin{array}{l}17 \\
14 \\
8.0 \\
3.8 \\
2.3\end{array}$ & $\begin{array}{l}226 \\
220 \\
169 \\
178 \\
138\end{array}$ & $\begin{array}{l}5 \\
4 \\
5 \\
5 \\
5\end{array}$ & $\begin{array}{l}3.1 \\
2.4 \\
2.6 \\
2.4 \\
2.1\end{array}$ & $\begin{array}{l}118 \\
118 \\
116 \\
120 \\
127\end{array}$ & $\begin{array}{l}3 \\
5 \\
3 \\
4 \\
4\end{array}$ & $\begin{array}{r}1.0 \\
1.6 \\
1.9 \\
1.3\end{array}$ \\
\hline $\begin{array}{l}16 \ldots \\
17 \ldots \\
18 \ldots \\
19 \ldots \\
20 \ldots\end{array}$ & $\begin{array}{l}362 \\
369 \\
362 \\
390 \\
410\end{array}$ & $\begin{array}{l}2 \\
6 \\
4 \\
3 \\
2\end{array}$ & $\begin{array}{l}2.0 \\
6.0 \\
3.9 \\
3.2 \\
2.2\end{array}$ & $\begin{array}{l}149 \\
147 \\
164 \\
183 \\
183\end{array}$ & $\begin{array}{l}5 \\
6 \\
5 \\
4 \\
5\end{array}$ & $\begin{array}{l}2.0 \\
2.4 \\
2.2 \\
2.0 \\
2.5\end{array}$ & $\begin{array}{l}141 \\
136 \\
132 \\
129 \\
109\end{array}$ & $\begin{array}{l}3 \\
4 \\
5 \\
5 \\
5\end{array}$ & $\begin{array}{l}1.1 \\
1.5 \\
1.6 \\
1.7 \\
1.5\end{array}$ \\
\hline $\begin{array}{l}21 \ldots \\
22 \ldots \\
23 \ldots \\
24 \ldots \\
25 \ldots\end{array}$ & $\begin{array}{l}372 \\
362 \\
348 \\
330 \\
324\end{array}$ & $\begin{array}{l}1 \\
1 \\
1 \\
2 \\
2\end{array}$ & $\begin{array}{r}1.0 \\
1.0 \\
.9 \\
1.8 \\
1.7\end{array}$ & $\begin{array}{l}181 \\
178 \\
154 \\
127 \\
120\end{array}$ & $\begin{array}{l}6 \\
7 \\
5 \\
3 \\
3\end{array}$ & $\begin{array}{l}2.9 \\
3.4 \\
2.1 \\
1.0 \\
1.0\end{array}$ & $\begin{array}{r}95 \\
89 \\
89 \\
111 \\
129\end{array}$ & $\begin{array}{l}5 \\
6 \\
6 \\
6 \\
6\end{array}$ & $\begin{array}{l}1.3 \\
1.4 \\
1.4 \\
1.8 \\
2.1\end{array}$ \\
\hline $\begin{array}{l}26 \ldots \\
27 \ldots \\
28 \ldots \\
29 \ldots \\
30 \ldots \\
31 \ldots\end{array}$ & $\begin{array}{l}316 \\
306 \\
257 \\
244 \\
241 \\
238\end{array}$ & $\begin{array}{l}2 \\
2 \\
2 \\
2 \\
3 \\
3\end{array}$ & $\begin{array}{l}1.7 \\
1.7 \\
1.4 \\
1.3 \\
2.0 \\
1.9\end{array}$ & $\begin{array}{l}123 \\
136 \\
156 \\
181 \\
181 \\
176\end{array}$ & $\begin{array}{l}5 \\
6 \\
6 \\
6 \\
6 \\
6\end{array}$ & $\begin{array}{l}2.7 \\
2.2 \\
2.5 \\
2.9 \\
2.9 \\
2.9\end{array}$ & $\begin{array}{r}118 \\
109 \\
93 \\
77 \\
79 \\
--\end{array}$ & $\begin{array}{r}6 \\
4 \\
4 \\
2 \\
3 \\
-\end{array}$ & $\begin{array}{l}1.9 \\
1.2 \\
1.0 \\
.4 \\
=6\end{array}$ \\
\hline Total & 14973 & - & 231.4 & 5818 & - & $72 \cdot 3$ & 3458 & - & 48.5 \\
\hline $\begin{array}{l}\text { Tota } \\
\text { Tota } \\
\end{array}$ & $\begin{array}{l}\text { dischar } \\
\text { load fo }\end{array}$ & $\begin{array}{l}\text { or ye } \\
\text { a.r } 6 t\end{array}$ & $\ldots \ldots$ & $\cdots$ & & & & 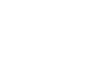 & $\begin{array}{r}171087 \\
6932.3\end{array}$ \\
\hline
\end{tabular}




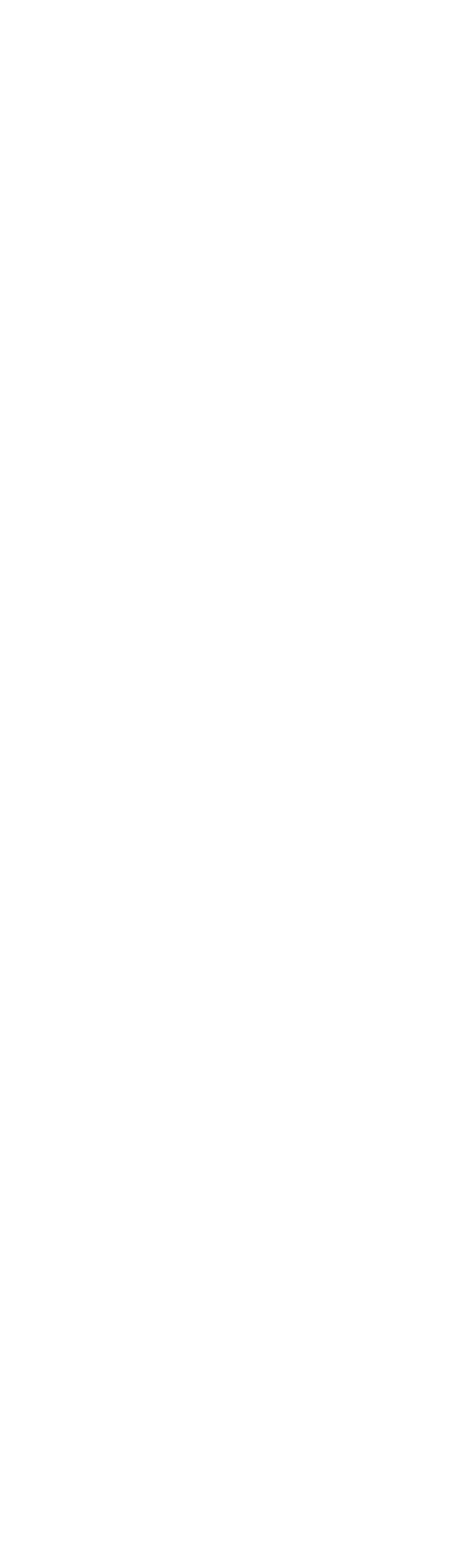




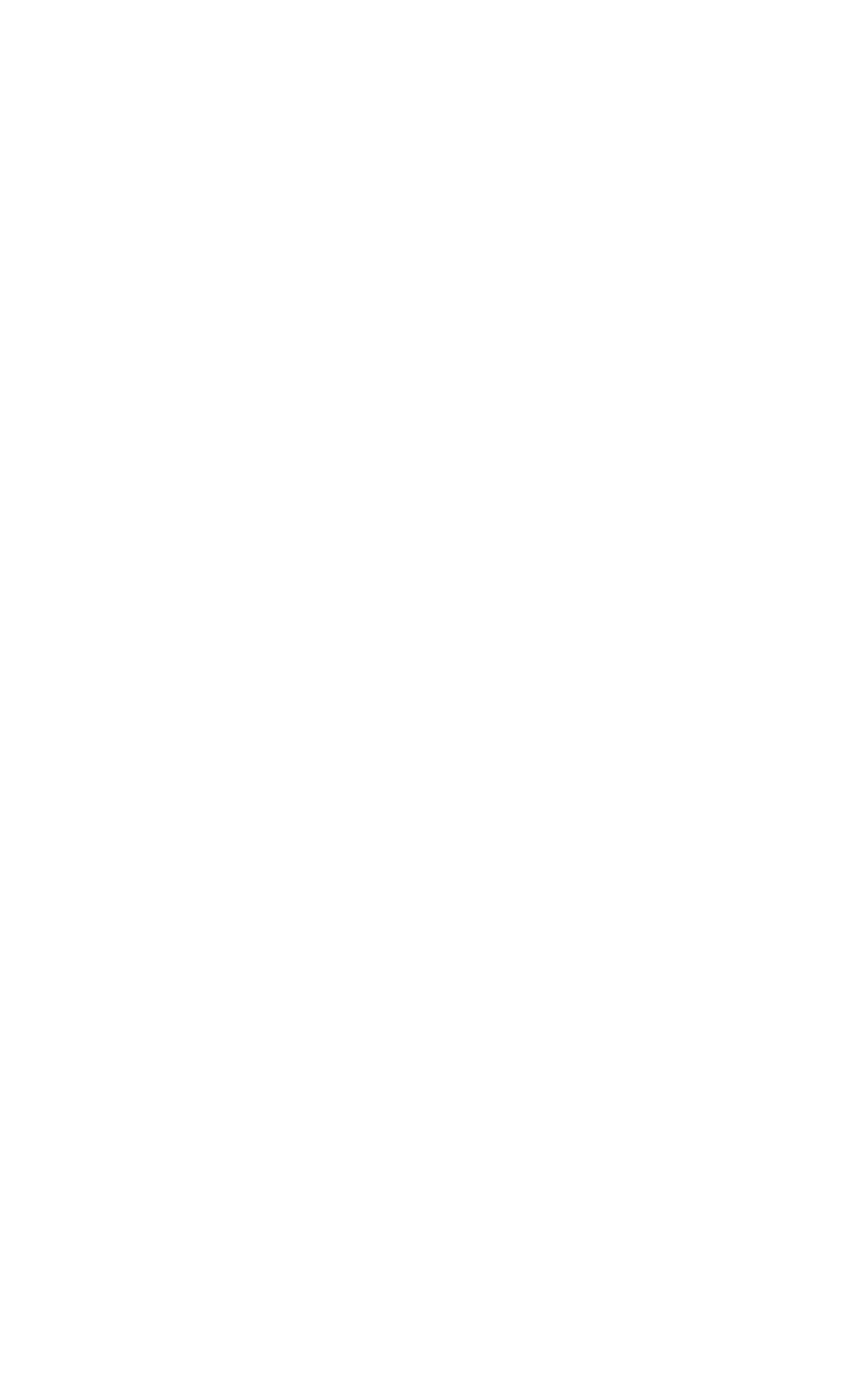




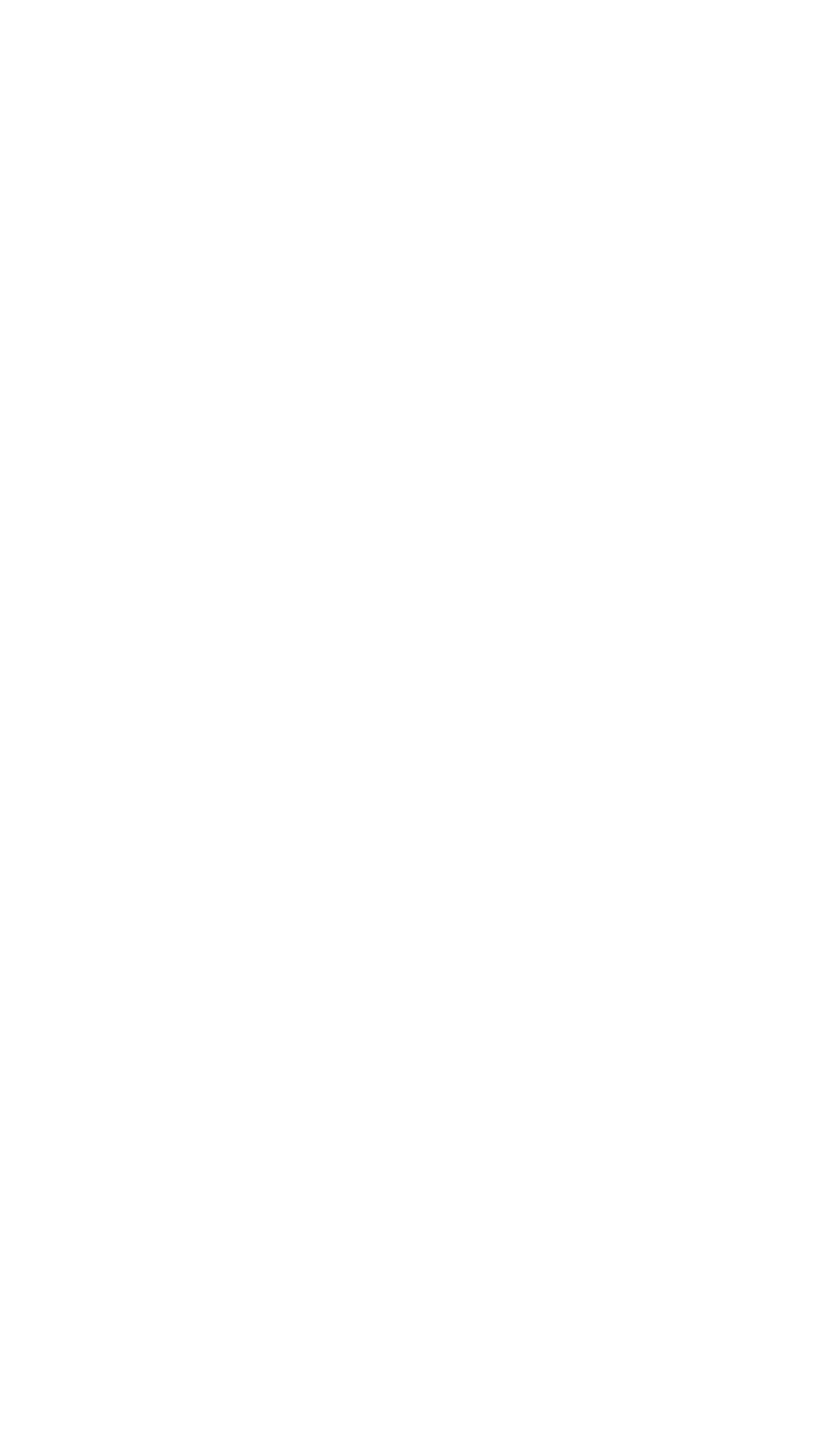




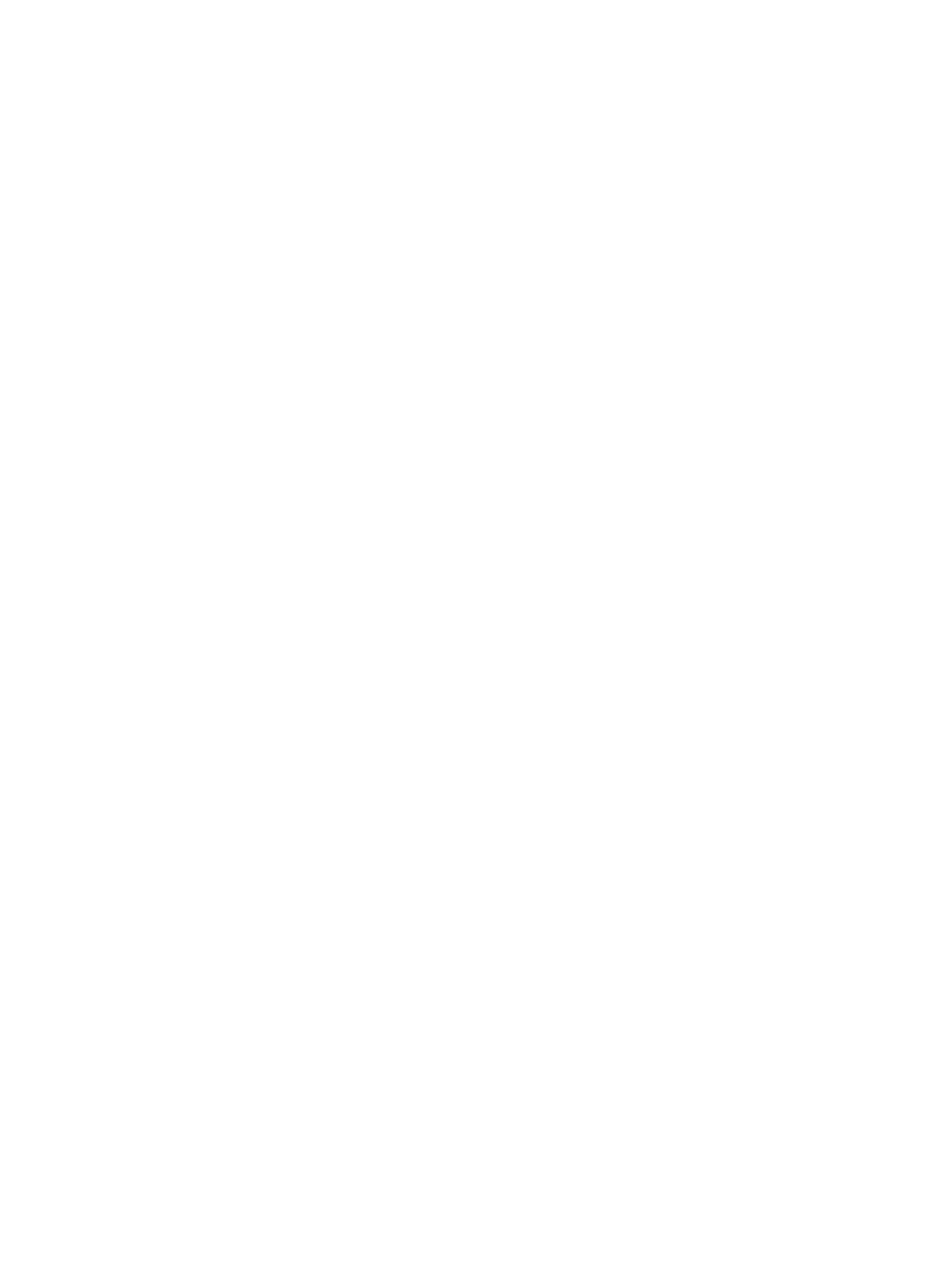




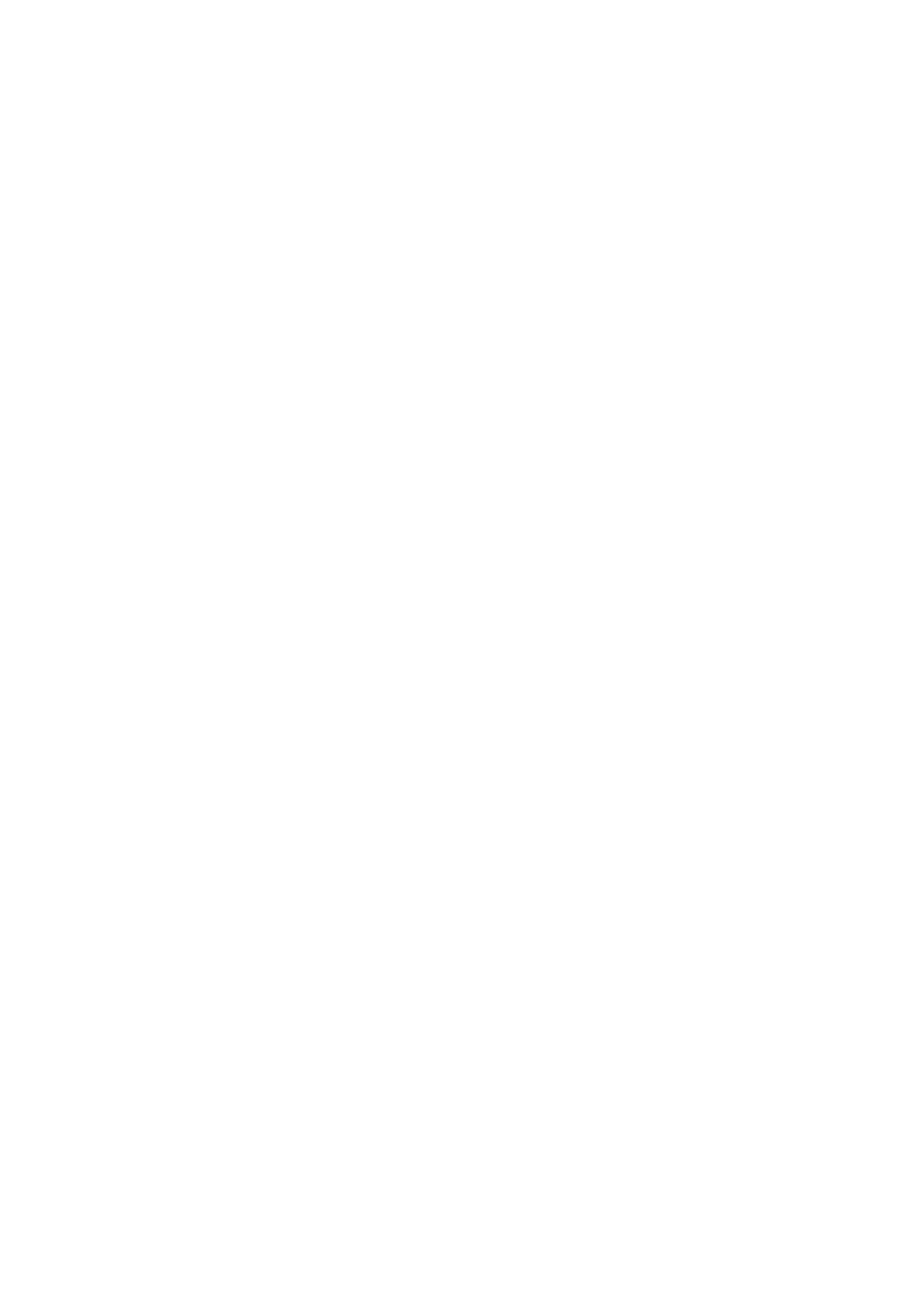




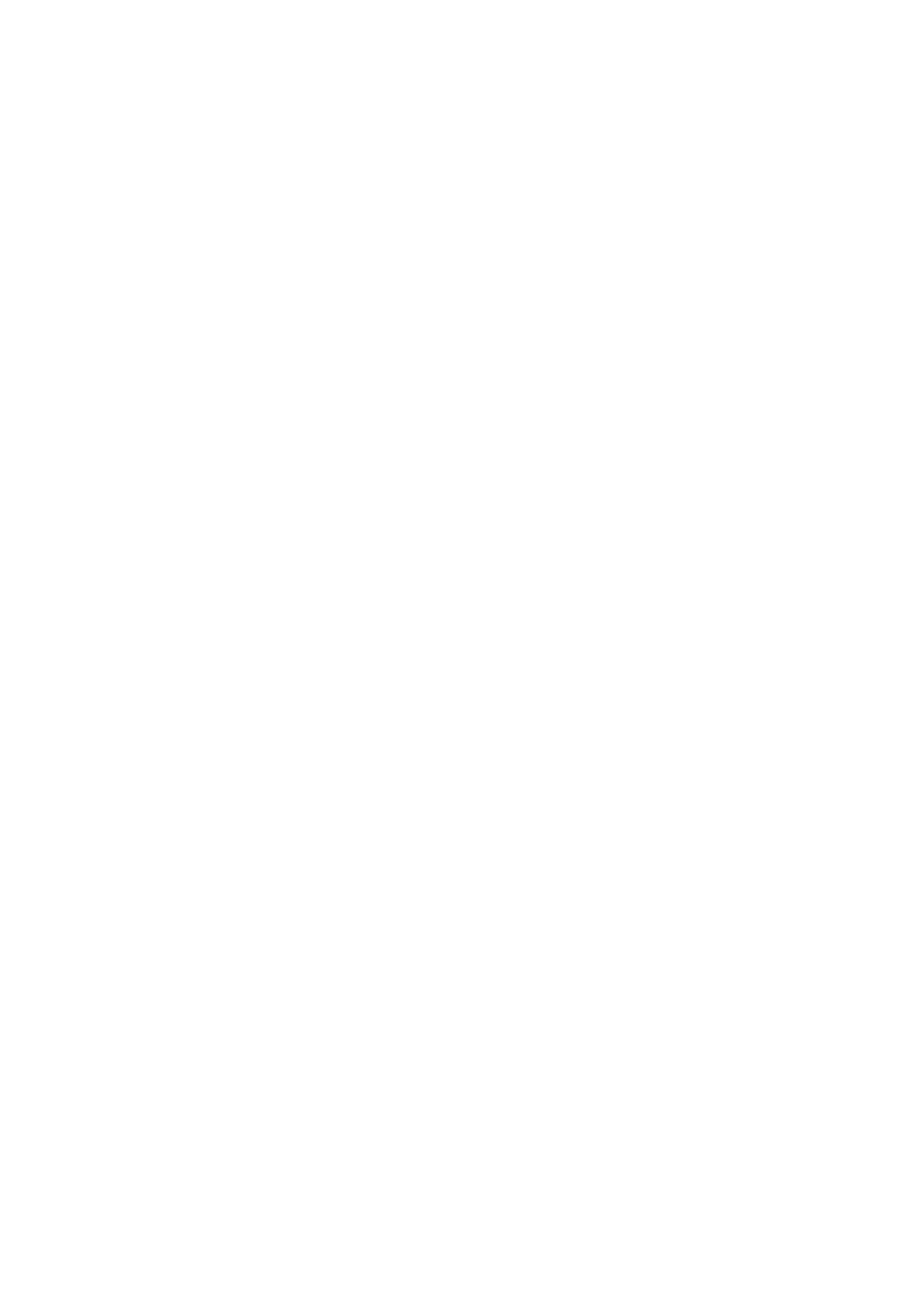




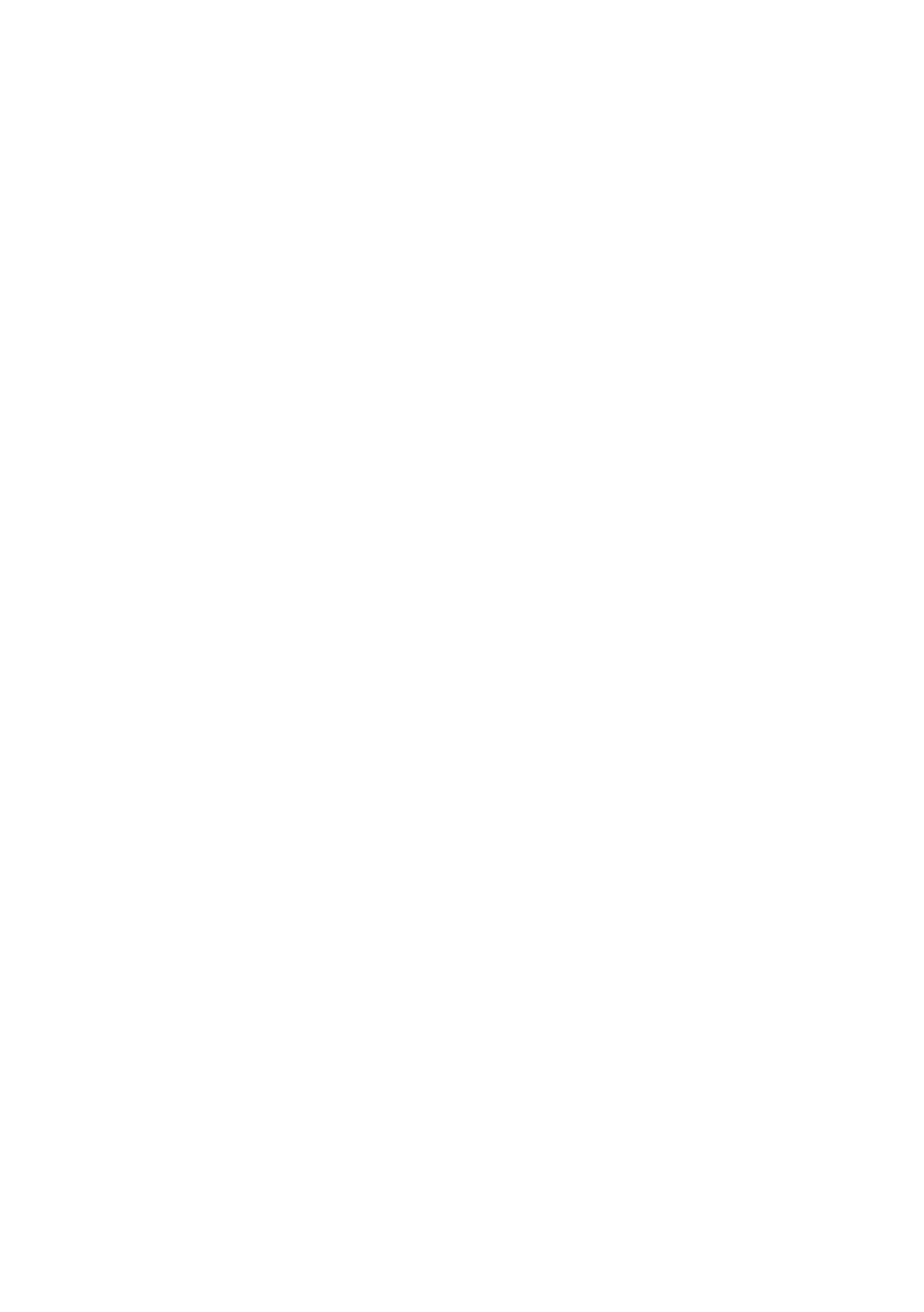




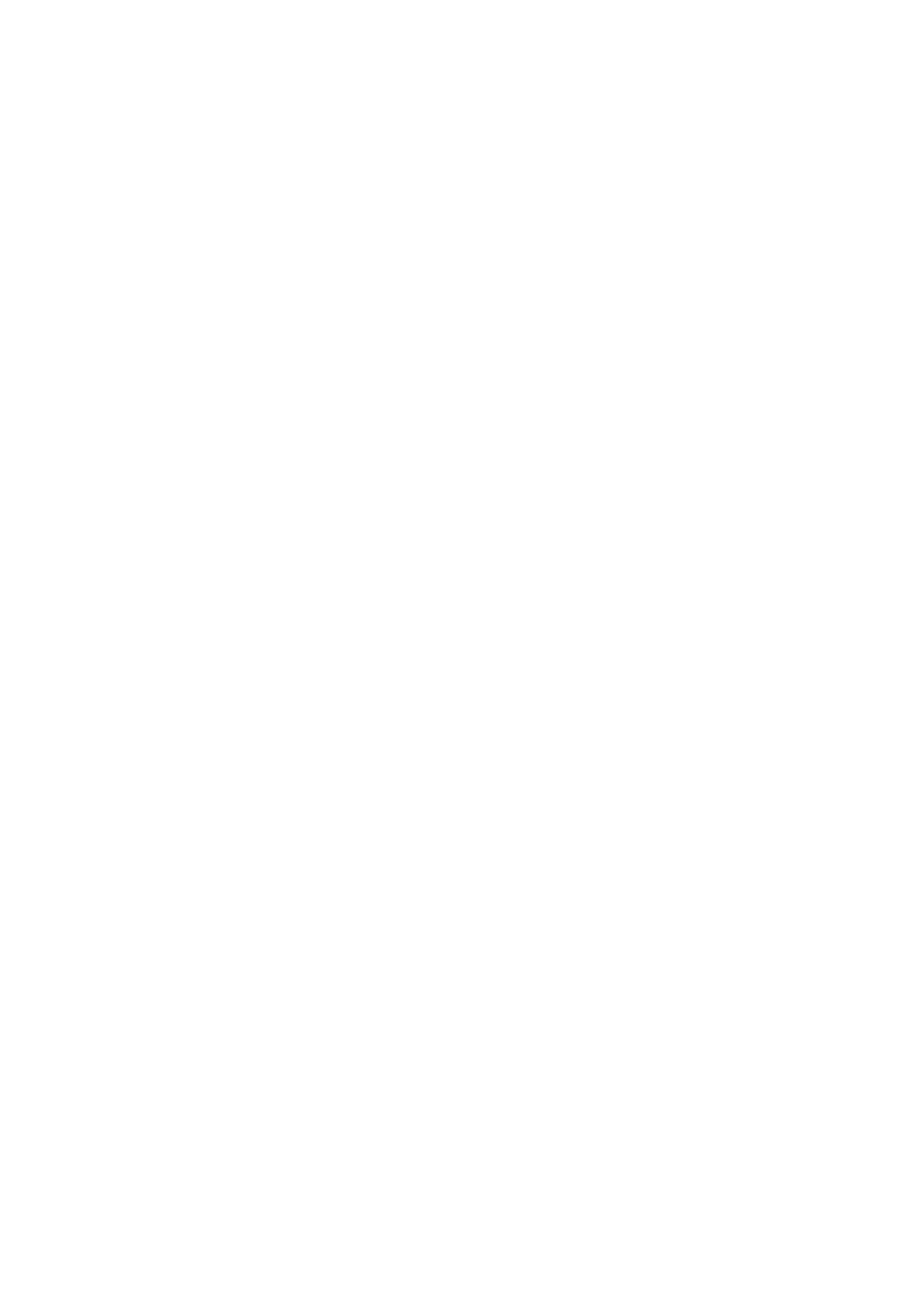




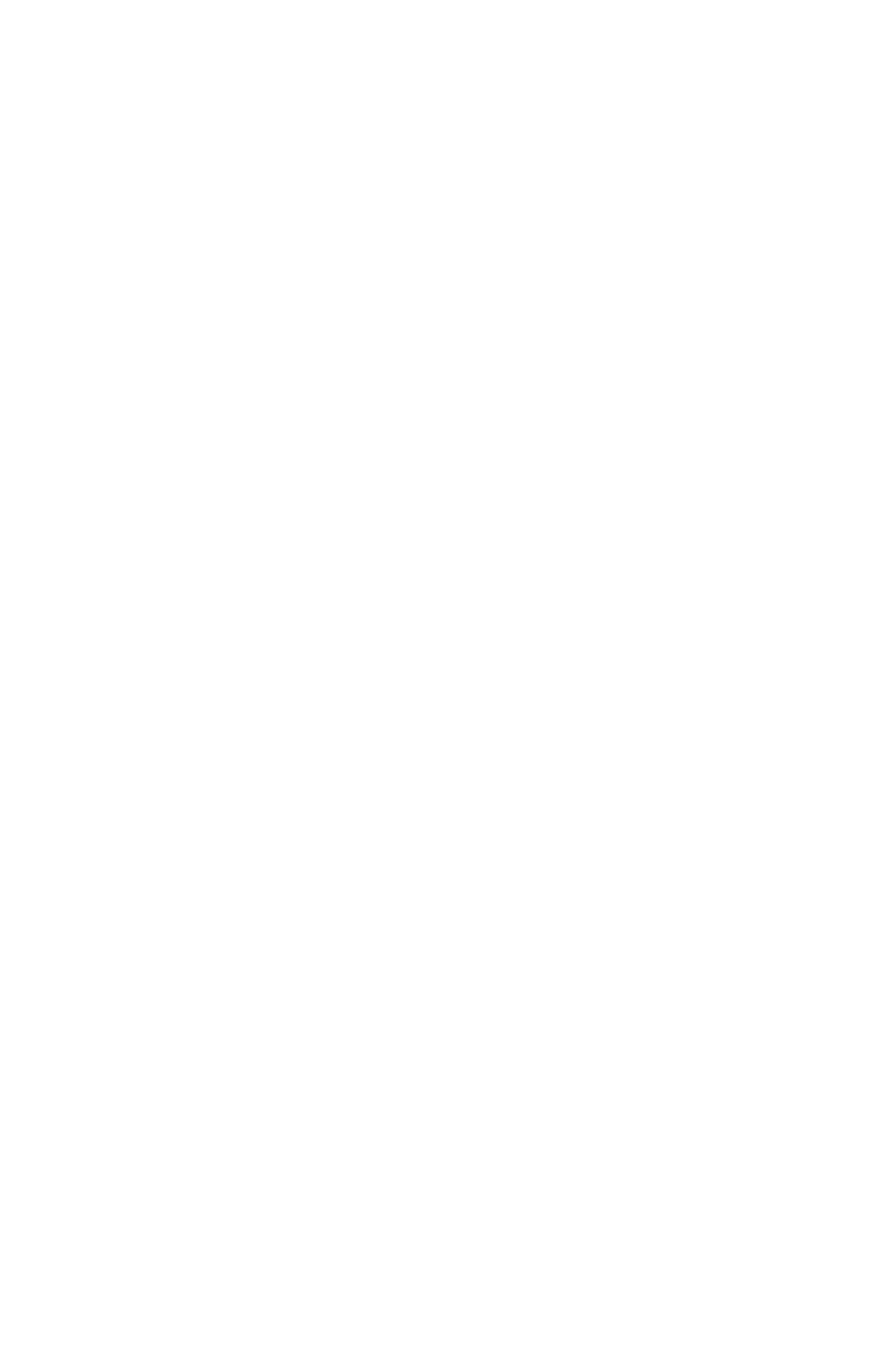




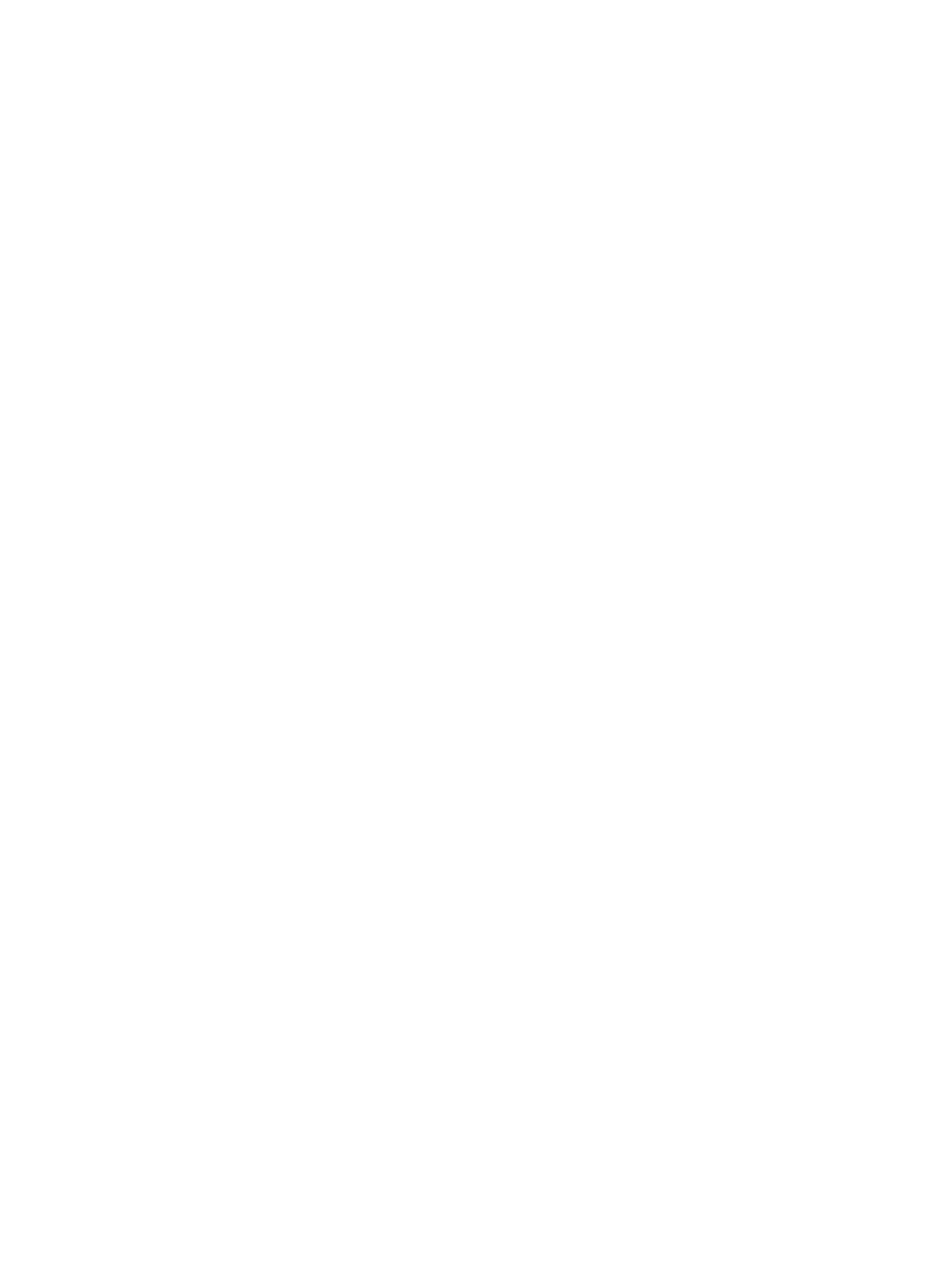


STREAUS TRIBUTARY TO LAKE UICHIGAN--Contınued

4-1252. PINE RIVER NEAR LUTHER, MICH.

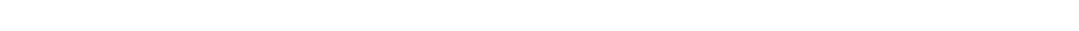
5 miles north of Luther, Lake County.

RECOROS AVAILABLE.-Sediment records: December 1966 to September 1967.

EXTREMES, December 1966 to September 1967.--Sediment concentrations: Haximum datly, $253 \mathrm{ppm}$ Apr. 22 , Mar. 27; młn1mum dał1y, 2 ppm Sept. 23-26.

Sediment loads: Maximum datly, 650 tons Dec. 9; minimum da1ly, 0.7 ton Sept. 23-26.

REMARXS.--Data analyzed and compiled by the Foregt Service, U.S. Dept. of Agriculture, North Cen ${ }^{+}$ral Forest Experiment Station, Cadillac, Hichigan.

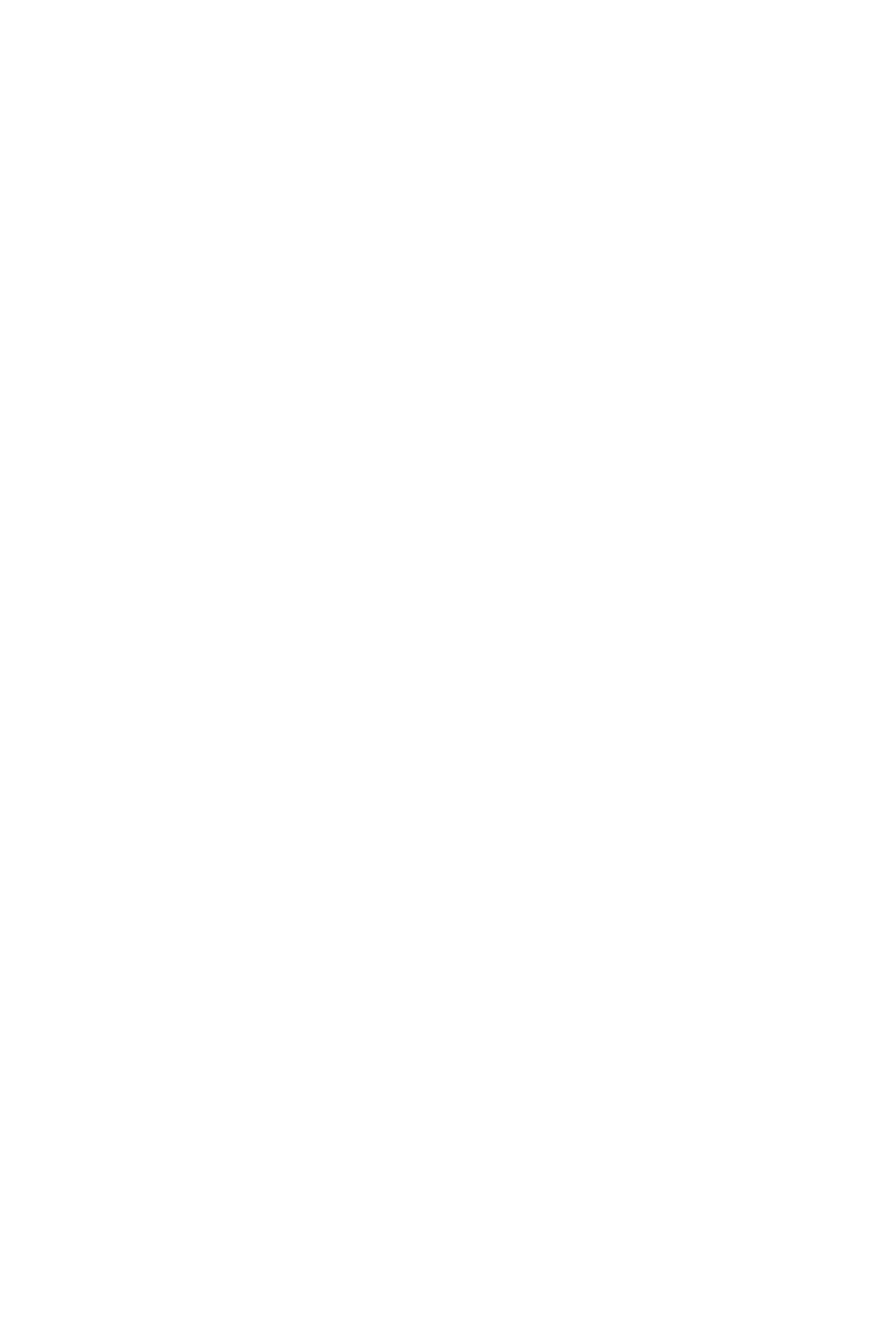


STREAMS TRIBUTARY TO LAKE MICHIGAN--COnt1 nued

4-1252. PINE RIVER NEAR LUTHER, HICH.--Cont1 nued

Total sediment load, December 1966 to September 1967 -Contirued

\begin{tabular}{|c|c|c|c|c|c|c|c|c|c|}
\hline \multirow[b]{3}{*}{ Day } & \multicolumn{3}{|c|}{ APRIL } & \multicolumn{3}{|c|}{ MAY } & \multicolumn{3}{|c|}{ JUNE } \\
\hline & \multirow[b]{2}{*}{$\begin{array}{c}\text { Mean } \\
\text { dis- } \\
\text { charge } \\
\text { (cfs) }\end{array}$} & \multicolumn{2}{|c|}{ Suspended sediment } & \multirow[b]{2}{*}{$\begin{array}{c}\text { Mean } \\
\text { dis- } \\
\text { charge } \\
\text { (cfs) }\end{array}$} & \multicolumn{2}{|c|}{ Suspended sediment } & \multirow[b]{2}{*}{$\begin{array}{c}\text { Mean } \\
\text { dis- } \\
\text { charge } \\
\text { (cfs) }\end{array}$} & \multicolumn{2}{|c|}{ Suspended sediment } \\
\hline & & $\begin{array}{c}\text { Mean } \\
\text { concen- } \\
\text { tration } \\
(\mathrm{ppm})\end{array}$ & $\begin{array}{l}\text { Tons } \\
\text { per } \\
\text { day }\end{array}$ & & $\begin{array}{c}\text { Mean } \\
\text { concen- } \\
\text { tration } \\
\text { (ppm) }\end{array}$ & $\begin{array}{l}\text { Tons } \\
\text { per } \\
\text { day }\end{array}$ & & $\begin{array}{c}\text { Mean } \\
\text { concen- } \\
\text { tration } \\
(\mathrm{ppm})\end{array}$ & $\begin{array}{l}\text { Tons } \\
\text { per } \\
\text { day }\end{array}$ \\
\hline $\begin{array}{l}1 \\
2 \\
3 \\
4 \\
5\end{array}$ & $\begin{array}{l}850 \\
738 \\
625 \\
464 \\
349\end{array}$ & $\begin{array}{l}156 \\
130 \\
120 \\
107 \\
100\end{array}$ & $\begin{array}{r}358 \\
250 \\
202 \\
134 \\
94\end{array}$ & $\begin{array}{l}214 \\
210 \\
206 \\
202 \\
190\end{array}$ & $\begin{array}{l}46 \\
46 \\
46 \\
46 \\
46\end{array}$ & $\begin{array}{l}27 \\
26 \\
26 \\
25 \\
24\end{array}$ & $\begin{array}{l}158 \\
154 \\
150 \\
146 \\
146\end{array}$ & $\begin{array}{r}16 \\
14 \\
12 \\
10 \\
8\end{array}$ & $\begin{array}{l}6.8 \\
5.8 \\
4.9 \\
3.9 \\
3.2\end{array}$ \\
\hline $\begin{array}{r}6 \\
7 \\
8 \\
9 \\
10\end{array}$ & $\begin{array}{l}441 \\
505 \\
402 \\
360 \\
371\end{array}$ & $\begin{array}{r}135 \\
165 \\
102 \\
98 \\
98\end{array}$ & $\begin{array}{r}161 \\
225 \\
111 \\
95 \\
98\end{array}$ & $\begin{array}{l}186 \\
182 \\
202 \\
238 \\
218\end{array}$ & $\begin{array}{l}46 \\
46 \\
46 \\
46 \\
46\end{array}$ & $\begin{array}{l}23 \\
23 \\
25 \\
30 \\
27\end{array}$ & $\begin{array}{l}146 \\
154 \\
408 \\
392 \\
307\end{array}$ & $\begin{array}{r}8 \\
14 \\
157 \\
154 \\
93\end{array}$ & $\begin{array}{c}3.2 \\
5.8 \\
173 \\
163 \\
77\end{array}$ \\
\hline $\begin{array}{l}11 \\
12 \\
13 \\
14 \\
15\end{array}$ & $\begin{array}{l}317 \\
269 \\
242 \\
234 \\
226\end{array}$ & $\begin{array}{l}93 \\
67 \\
55 \\
51 \\
47\end{array}$ & $\begin{array}{l}80 \\
49 \\
36 \\
32 \\
29\end{array}$ & $\begin{array}{l}222 \\
264 \\
230 \\
206 \\
190\end{array}$ & $\begin{array}{l}53 \\
70 \\
31 \\
31 \\
31\end{array}$ & $\begin{array}{l}32 \\
50 \\
19 \\
17 \\
16\end{array}$ & $\begin{array}{l}608 \\
586 \\
495 \\
408 \\
292\end{array}$ & $\begin{array}{r}247 \\
85 \\
82 \\
95 \\
122\end{array}$ & $\begin{array}{r}405 \\
134 \\
110 \\
105 \\
93\end{array}$ \\
\hline $\begin{array}{l}16 \\
17 \\
18 \\
19 \\
20\end{array}$ & $\begin{array}{l}218 \\
543 \\
630 \\
418 \\
302\end{array}$ & $\begin{array}{r}42 \\
178 \\
166 \\
123 \\
99\end{array}$ & $\begin{array}{r}25 \\
261 \\
282 \\
139 \\
81\end{array}$ & $\begin{array}{l}186 \\
182 \\
174 \\
206 \\
226\end{array}$ & $\begin{array}{l}31 \\
31 \\
31 \\
37 \\
47\end{array}$ & $\begin{array}{l}16 \\
15 \\
15 \\
21 \\
29\end{array}$ & $\begin{array}{l}297 \\
297 \\
264 \\
226 \\
206\end{array}$ & $\begin{array}{r}125 \\
125 \\
102 \\
71 \\
58\end{array}$ & $\begin{array}{r}100 \\
100 \\
73 \\
43 \\
32\end{array}$ \\
\hline $\begin{array}{l}21 \\
22 \\
23 \\
24 \\
25\end{array}$ & $\begin{array}{l}381 \\
716 \\
668 \\
441 \\
317\end{array}$ & $\begin{array}{r}142 \\
253 \\
120 \\
82 \\
64\end{array}$ & $\begin{array}{r}146 \\
489 \\
216 \\
98 \\
55\end{array}$ & $\begin{array}{l}210 \\
264 \\
242 \\
242 \\
214\end{array}$ & $\begin{array}{l}31 \\
80 \\
43 \\
25 \\
25\end{array}$ & $\begin{array}{l}18 \\
57 \\
28 \\
16 \\
14\end{array}$ & $\begin{array}{l}206 \\
194 \\
182 \\
178 \\
182\end{array}$ & $\begin{array}{l}58 \\
45 \\
38 \\
30 \\
38\end{array}$ & $\begin{array}{l}32 \\
24 \\
19 \\
14 \\
19\end{array}$ \\
\hline $\begin{array}{l}26 \\
27 \\
28 \\
29 \\
30 \\
31\end{array}$ & $\begin{array}{r}269 \\
246 \\
238 \\
222 \\
218 \\
--\end{array}$ & $\begin{array}{l}57 \\
53 \\
52 \\
50 \\
46 \\
-- \\
\end{array}$ & $\begin{array}{l}41 \\
35 \\
33 \\
30 \\
27 \\
-- \\
\end{array}$ & $\begin{array}{l}198 \\
186 \\
174 \\
170 \\
166 \\
162 \\
\end{array}$ & $\begin{array}{l}24 \\
23 \\
22 \\
21 \\
20 \\
18 \\
\end{array}$ & $\begin{array}{c}13 \\
12 \\
10 \\
9.6 \\
9.0 \\
7.9\end{array}$ & $\begin{array}{r}182 \\
166 \\
166 \\
166 \\
162 \\
-- \\
\end{array}$ & $\begin{array}{l}38 \\
21 \\
21 \\
21 \\
19 \\
-- \\
\end{array}$ & $\begin{array}{r}19 \\
9.4 \\
9.4 \\
9.4 \\
8.3 \\
--\end{array}$ \\
\hline \multirow[t]{2}{*}{ Total } & 12220 & -- & 3912 & 6362 & -- & 680.5 & 7624 & - & 1805.1 \\
\hline & \multicolumn{3}{|c|}{ JULY } & \multicolumn{3}{|c|}{ AUGUST } & \multicolumn{3}{|c|}{ SEPTELIBER } \\
\hline $\begin{array}{l}1 \\
2 \\
3 \\
4 \\
5\end{array}$ & $\begin{array}{l}162 \\
166 \\
166 \\
162 \\
158\end{array}$ & $\begin{array}{l}19 \\
21 \\
21 \\
20 \\
18\end{array}$ & $\begin{array}{l}8.3 \\
9.4 \\
9.4 \\
8.7 \\
7.7\end{array}$ & $\begin{array}{l}134 \\
134 \\
134 \\
134 \\
134\end{array}$ & $\begin{array}{l}7 \\
7 \\
7 \\
7 \\
7\end{array}$ & $\begin{array}{l}2.5 \\
2.5 \\
2.5 \\
2.5 \\
2.5\end{array}$ & $\begin{array}{l}130 \\
126 \\
122 \\
122 \\
122\end{array}$ & $\begin{array}{l}16 \\
16 \\
16 \\
16 \\
16\end{array}$ & $\begin{array}{l}5.6 \\
5.4 \\
5.3 \\
5.3 \\
5.3\end{array}$ \\
\hline $\begin{array}{r}6 \\
7 \\
8 \\
9 \\
10\end{array}$ & $\begin{array}{l}150 \\
146 \\
146 \\
146 \\
146\end{array}$ & $\begin{array}{l}16 \\
14 \\
14 \\
14 \\
14\end{array}$ & $\begin{array}{l}6.5 \\
5.5 \\
5.5 \\
5.5 \\
5.5\end{array}$ & $\begin{array}{l}134 \\
174 \\
202 \\
170 \\
158\end{array}$ & $\begin{array}{r}7 \\
12 \\
42 \\
24 \\
18\end{array}$ & $\begin{array}{c}2.5 \\
5.6 \\
23 \\
11 \\
7.7\end{array}$ & $\begin{array}{l}122 \\
122 \\
122 \\
122 \\
122\end{array}$ & $\begin{array}{l}16 \\
16 \\
16 \\
19 \\
19\end{array}$ & $\begin{array}{l}5.3 \\
5.3 \\
5.3 \\
6.3 \\
6.3\end{array}$ \\
\hline $\begin{array}{l}11 \\
12 \\
13 \\
14 \\
15\end{array}$ & $\begin{array}{l}162 \\
162 \\
162 \\
162 \\
154\end{array}$ & $\begin{array}{l}21 \\
21 \\
21 \\
21 \\
17\end{array}$ & $\begin{array}{l}9.2 \\
9.2 \\
9.2 \\
9.2 \\
7.1\end{array}$ & $\begin{array}{l}150 \\
138 \\
134 \\
138 \\
138\end{array}$ & $\begin{array}{l}18 \\
18 \\
18 \\
18 \\
18\end{array}$ & $\begin{array}{l}7.3 \\
6.7 \\
6.5 \\
6.7 \\
6.7\end{array}$ & $\begin{array}{l}122 \\
122 \\
122 \\
122 \\
118\end{array}$ & $\begin{array}{r}19 \\
19 \\
19 \\
19 \\
4\end{array}$ & $\begin{array}{l}6.3 \\
6.3 \\
6.3 \\
6.3 \\
1.3\end{array}$ \\
\hline $\begin{array}{l}16 \\
17 \\
18 \\
19 \\
20\end{array}$ & $\begin{array}{l}142 \\
142 \\
146 \\
166 \\
158\end{array}$ & $\begin{array}{l}14 \\
14 \\
20 \\
22 \\
23\end{array}$ & $\begin{array}{r}5.4 \\
5.4 \\
7.9 \\
13 \\
9.8\end{array}$ & $\begin{array}{l}138 \\
138 \\
138 \\
134 \\
134\end{array}$ & $\begin{array}{l}18 \\
18 \\
11 \\
11 \\
11\end{array}$ & $\begin{array}{l}6.7 \\
6.7 \\
4.1 \\
4.0 \\
4.0\end{array}$ & $\begin{array}{l}118 \\
118 \\
126 \\
130 \\
130\end{array}$ & $\begin{array}{l}4 \\
4 \\
4 \\
4 \\
4\end{array}$ & $\begin{array}{l}1.3 \\
1.3 \\
1.4 \\
1.4 \\
1.4\end{array}$ \\
\hline $\begin{array}{l}21 \\
22 \\
23 \\
24 \\
25\end{array}$ & $\begin{array}{l}146 \\
142 \\
142 \\
142 \\
138\end{array}$ & $\begin{array}{l}23 \\
23 \\
23 \\
23 \\
15\end{array}$ & $\begin{array}{l}9.1 \\
8.8 \\
8.8 \\
8.8 \\
5.6\end{array}$ & $\begin{array}{l}134 \\
142 \\
138 \\
134 \\
126\end{array}$ & $\begin{array}{l}11 \\
11 \\
11 \\
11 \\
15\end{array}$ & $\begin{array}{l}4.0 \\
4.2 \\
4.1 \\
4.0 \\
5.1\end{array}$ & $\begin{array}{l}142 \\
142 \\
130 \\
130 \\
134\end{array}$ & $\begin{array}{l}4 \\
4 \\
2 \\
2 \\
2 \\
2\end{array}$ & $\begin{array}{r}1.5 \\
1.5 \\
.7 \\
.7 \\
.7\end{array}$ \\
\hline $\begin{array}{l}26 \\
27 \\
28 \\
29 \\
30 \\
31\end{array}$ & $\begin{array}{l}138 \\
142 \\
138 \\
134 \\
134 \\
134\end{array}$ & $\begin{array}{r}15 \\
23 \\
15 \\
7 \\
7 \\
7\end{array}$ & $\begin{array}{l}5.6 \\
8.8 \\
5.6 \\
2.5 \\
2.5 \\
2.5\end{array}$ & $\begin{array}{l}126 \\
130 \\
134 \\
130 \\
142 \\
138\end{array}$ & $\begin{array}{l}15 \\
15 \\
15 \\
15 \\
15 \\
15\end{array}$ & $\begin{array}{l}5.1 \\
5.3 \\
5.4 \\
5.3 \\
5.8 \\
5.6\end{array}$ & $\begin{array}{c}134 \\
158 \\
150 \\
146 \\
166 \\
--\end{array}$ & $\begin{array}{r}2 \\
36 \\
25 \\
15 \\
50 \\
-\end{array}$ & $\begin{array}{c}15^{.7} \\
10 \\
5.9 \\
22^{--}\end{array}$ \\
\hline Total & 4634 & -- & 226.0 & 4362 & -- & 175.6 & 3892 & -- & 147.4 \\
\hline
\end{tabular}

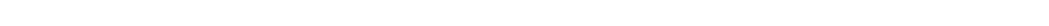

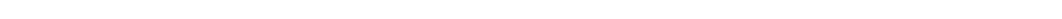




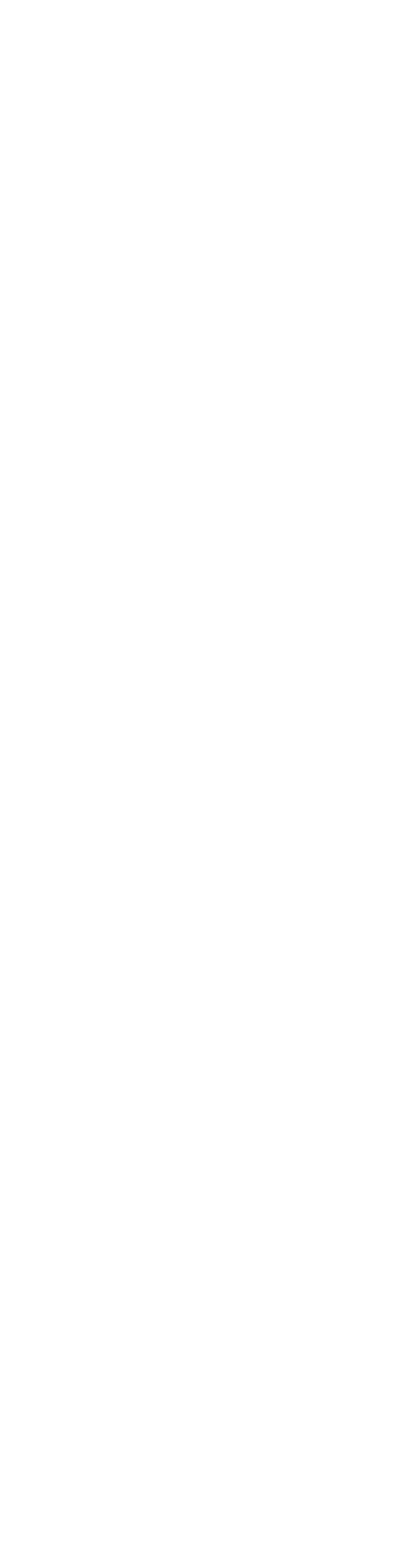




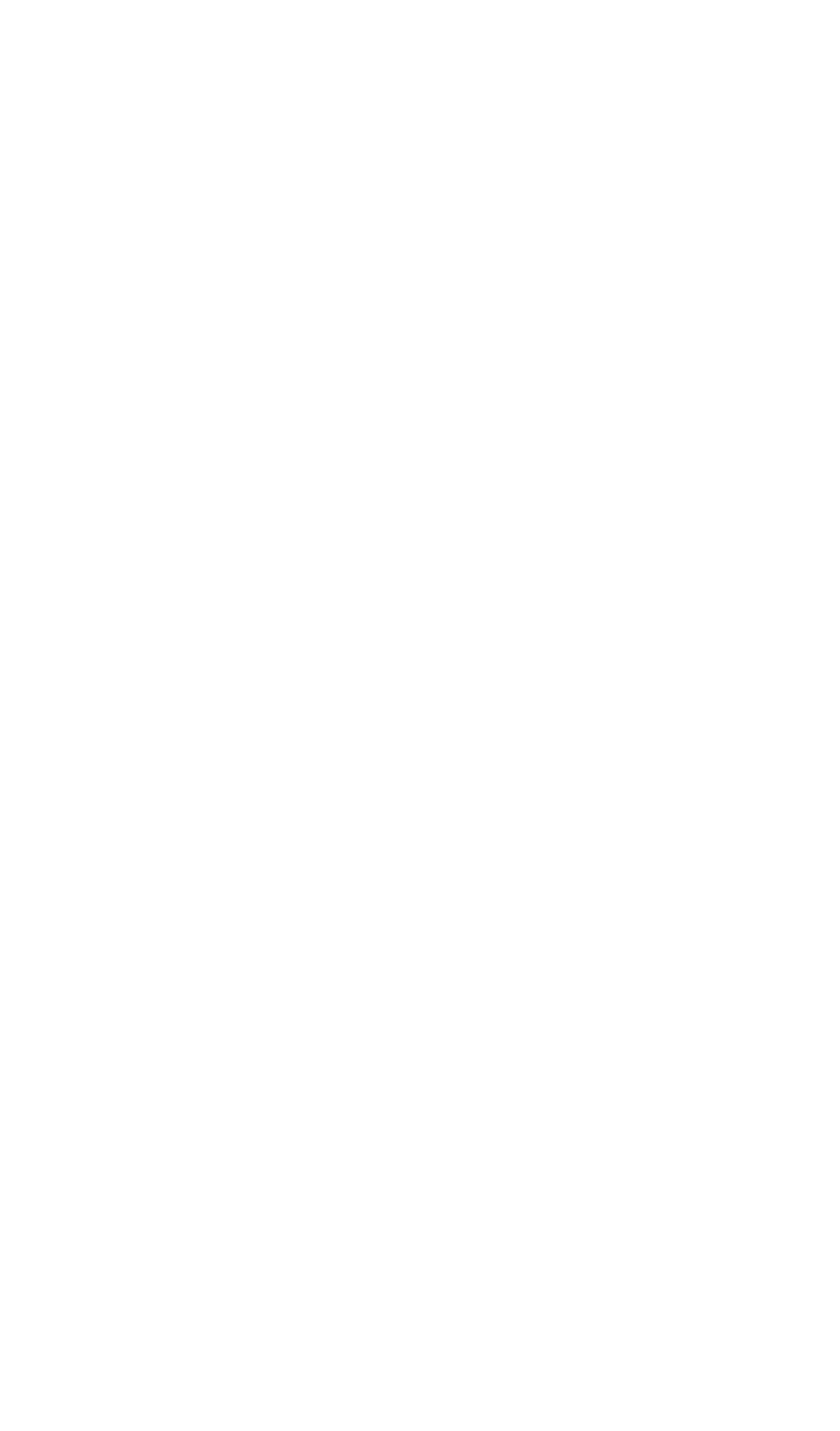




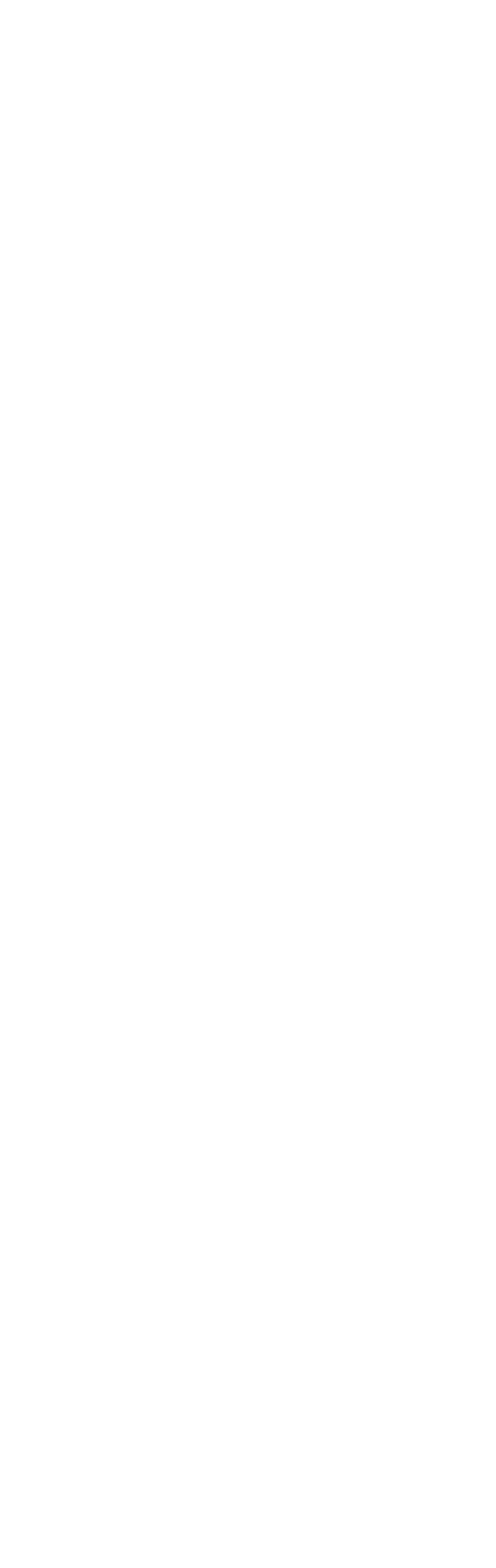


STREANS TRIBUTARY TO LAKE MICHIGAN--COnt1nued

4-1255.1. PINE RIVER NEAR WELLSTON, MICH.

LOCATION.-Lat 44'12'47", long $85^{\circ} 53^{\prime} 47^{\prime \prime}$, SE SWW $\frac{2}{4}$ SW sec. 16, T. 21 N., R. 13 W., at Stronach Dam,

3 miles east of Wellston, Hanistee County.
RECORDS AVAILABLE. --Sediment records: October 1966 to September 1967.

EXTREMES, October 1966 to September 1967.--Sediment concentrations: Haximum daily, 710 ppm Dec. 9; minimum daily, 45 ppm on several days during October and November.

Sediment loads: Maximum dally, 2,400 tons Dec. 9; minimum dally, 32 tons oct. 24, Nov, 5. REMARKS.--Data analyzed and compiled by the Forest Service, U.S. Dept. of Agriculture, North Central Forest Experiment Station, Cadillac, Michigan.

\begin{tabular}{|c|c|c|c|c|c|c|c|c|c|}
\hline \multirow[b]{3}{*}{ Day } & \multicolumn{3}{|c|}{ OCTOBER } & \multicolumn{3}{|c|}{ NOVEMBER } & \multicolumn{3}{|c|}{ DECEMBER } \\
\hline & \multirow[b]{2}{*}{$\begin{array}{l}\text { Mean } \\
\text { dis- } \\
\text { charge } \\
\text { (cfs) }\end{array}$} & \multicolumn{2}{|c|}{ Suspended sediment } & \multirow[b]{2}{*}{$\begin{array}{c}\text { Mean } \\
\text { dis- } \\
\text { charge } \\
(\mathrm{cfs})\end{array}$} & \multicolumn{2}{|c|}{ Suspended aediment } & \multirow[b]{2}{*}{$\begin{array}{c}\text { Mean } \\
\text { dis- } \\
\text { charge } \\
\text { (cfs) }\end{array}$} & \multicolumn{2}{|c|}{ Suspended sediment } \\
\hline & & $\begin{array}{c}\text { Mean } \\
\text { concen- } \\
\text { tration } \\
(\mathbf{p p m})\end{array}$ & $\begin{array}{l}\text { Tons } \\
\text { per } \\
\text { day }\end{array}$ & & $\begin{array}{c}\text { Mean } \\
\text { concen- } \\
\text { tration } \\
(\mathrm{ppm})\end{array}$ & $\begin{array}{l}\text { Tons } \\
\text { per } \\
\text { day }\end{array}$ & & $\begin{array}{l}\text { Mean } \\
\text { concen- } \\
\text { tration } \\
\text { (ppm) }\end{array}$ & $\begin{array}{l}\text { Tons } \\
\text { per } \\
\text { day }\end{array}$ \\
\hline $\begin{array}{l}1 \\
2 \\
3 \\
4 \\
5\end{array}$ & $\begin{array}{l}282 \\
266 \\
266 \\
266 \\
266\end{array}$ & $\begin{array}{l}51 \\
51 \\
51 \\
51 \\
51\end{array}$ & $\begin{array}{l}\mathbf{3 9} \\
\mathbf{3 7} \\
\mathbf{3 7} \\
\mathbf{3 7} \\
\mathbf{3 7}\end{array}$ & $\begin{array}{l}266 \\
266 \\
274 \\
274 \\
266\end{array}$ & $\begin{array}{l}\mathbf{7 1} \\
71 \\
71 \\
\mathbf{4 5} \\
\mathbf{4 5}\end{array}$ & $\begin{array}{l}51 \\
51 \\
53 \\
33 \\
32\end{array}$ & $\begin{array}{l}545 \\
430 \\
401 \\
391 \\
380\end{array}$ & $\begin{array}{r}165 \\
82 \\
63 \\
62 \\
61\end{array}$ & $\begin{array}{r}243 \\
95 \\
68 \\
65 \\
63\end{array}$ \\
\hline $\begin{array}{r}6 \\
7 \\
8 \\
9 \\
10\end{array}$ & $\begin{array}{l}266 \\
258 \\
258 \\
258 \\
258\end{array}$ & $\begin{array}{l}51 \\
51 \\
51 \\
51 \\
51\end{array}$ & $\begin{array}{l}37 \\
36 \\
36 \\
36 \\
36\end{array}$ & $\begin{array}{l}274 \\
282 \\
322 \\
372 \\
401\end{array}$ & $\begin{array}{r}45 \\
45 \\
82 \\
120 \\
132\end{array}$ & $\begin{array}{r}33 \\
34 \\
71 \\
121 \\
143\end{array}$ & $\begin{array}{r}391 \\
634 \\
940 \\
1250 \\
1190\end{array}$ & $\begin{array}{l}100 \\
294 \\
602 \\
710 \\
690\end{array}$ & $\begin{array}{r}106 \\
503 \\
1530 \\
2400 \\
2210\end{array}$ \\
\hline $\begin{array}{l}11 \\
12 \\
13 \\
14 \\
15\end{array}$ & $\begin{array}{l}258 \\
258 \\
258 \\
266 \\
355\end{array}$ & $\begin{array}{r}51 \\
51 \\
51 \\
51 \\
145\end{array}$ & $\begin{array}{r}\mathbf{3 6} \\
\mathbf{3 6} \\
\mathbf{3 6} \\
\mathbf{3 7} \\
\mathbf{1 3 9}\end{array}$ & $\begin{array}{l}3.91 \\
347 \\
330 \\
314 \\
305\end{array}$ & $\begin{array}{r}130 \\
75 \\
63 \\
49 \\
49\end{array}$ & $\begin{array}{r}137 \\
70 \\
56 \\
42 \\
40\end{array}$ & $\begin{array}{l}858 \\
620 \\
480 \\
460 \\
420\end{array}$ & $\begin{array}{l}430 \\
267 \\
200 \\
181 \\
140\end{array}$ & $\begin{array}{l}996 \\
447 \\
259 \\
225 \\
159\end{array}$ \\
\hline $\begin{array}{l}16 \\
17 \\
18 \\
19 \\
20\end{array}$ & $\begin{array}{l}430 \\
391 \\
330 \\
305 \\
297\end{array}$ & $\begin{array}{r}145 \\
120 \\
65 \\
45 \\
45\end{array}$ & $\begin{array}{r}168 \\
127 \\
58 \\
37 \\
36\end{array}$ & $\begin{array}{l}297 \\
297 \\
289 \\
289 \\
282\end{array}$ & $\begin{array}{l}49 \\
49 \\
49 \\
49 \\
49\end{array}$ & $\begin{array}{l}\mathbf{3 9} \\
\mathbf{3 9} \\
\mathbf{3 8} \\
\mathbf{3 8} \\
\mathbf{3 7}\end{array}$ & $\begin{array}{l}401 \\
391 \\
381 \\
364 \\
330\end{array}$ & $\begin{array}{r}125 \\
115 \\
110 \\
96 \\
96\end{array}$ & $\begin{array}{r}135 \\
121 \\
113 \\
94 \\
86\end{array}$ \\
\hline $\begin{array}{l}21 \\
22 \\
23 \\
24 \\
25\end{array}$ & $\begin{array}{l}289 \\
282 \\
274 \\
266 \\
266\end{array}$ & $\begin{array}{l}45 \\
45 \\
45 \\
45 \\
71\end{array}$ & $\begin{array}{l}\mathbf{3 5} \\
\mathbf{3 4} \\
\mathbf{3 3} \\
\mathbf{3 2} \\
\mathbf{5 1}\end{array}$ & $\begin{array}{l}282 \\
282 \\
282 \\
314 \\
411\end{array}$ & $\begin{array}{r}49 \\
49 \\
49 \\
65 \\
140\end{array}$ & $\begin{array}{r}\mathbf{3 7} \\
\mathbf{3 7} \\
\mathbf{3 7} \\
\mathbf{5 5} \\
\mathbf{1 5 5}\end{array}$ & $\begin{array}{l}\mathbf{3 4 7} \\
\mathbf{3 4 7} \\
\mathbf{3 3 9} \\
\mathbf{3 3 0} \\
\mathbf{3 3 0}\end{array}$ & $\begin{array}{r}96 \\
96 \\
96 \\
123 \\
123\end{array}$ & $\begin{array}{r}90 \\
90 \\
88 \\
110 \\
110\end{array}$ \\
\hline $\begin{array}{l}26 \\
27 \\
28 \\
29 \\
30 \\
31\end{array}$ & $\begin{array}{l}266 \\
266 \\
266 \\
266 \\
258 \\
266\end{array}$ & $\begin{array}{l}\mathbf{7 1} \\
\mathbf{7 1} \\
\mathbf{7 1} \\
\mathbf{7 1} \\
\mathbf{7 1} \\
\mathbf{7 1}\end{array}$ & $\begin{array}{l}\mathbf{5 1} \\
\mathbf{5 1} \\
\mathbf{5 1} \\
\mathbf{5 1} \\
\mathbf{5 1} \\
\mathbf{5 1}\end{array}$ & $\begin{array}{r}480 \\
523 \\
881 \\
952 \\
710 \\
--\end{array}$ & $\begin{array}{r}190 \\
220 \\
450 \\
580 \\
335 \\
--\end{array}$ & $\begin{array}{r}246 \\
311 \\
1070 \\
1490 \\
642 \\
--\end{array}$ & $\begin{array}{l}\mathbf{3 3 0} \\
\mathbf{3 2 2} \\
\mathbf{3 2 2} \\
\mathbf{3 2 2} \\
\mathbf{3 2 2} \\
\mathbf{3 3 0}\end{array}$ & $\begin{array}{l}123 \\
123 \\
123 \\
123 \\
123 \\
123\end{array}$ & $\begin{array}{l}110 \\
107 \\
107 \\
107 \\
107 \\
110\end{array}$ \\
\hline \multirow[t]{2}{*}{ Total } & 8757 & -- & 1569 & 11255 & - & 5238 & 14898 & -- & 11054 \\
\hline & \multicolumn{3}{|c|}{ JANUARY } & \multicolumn{3}{|c|}{ FEBRUARY } & \multicolumn{3}{|c|}{ MARCH } \\
\hline $\begin{array}{l}1 \\
2 \\
3 \\
4 \\
5\end{array}$ & $\begin{array}{l}330 \\
330 \\
330 \\
322 \\
\mathbf{3 1 4}\end{array}$ & $\begin{array}{l}123 \\
123 \\
123 \\
123 \\
123\end{array}$ & $\begin{array}{l}110 \\
110 \\
110 \\
107 \\
104\end{array}$ & $\begin{array}{l}\mathbf{3 7 2} \\
\mathbf{3 6 4} \\
\mathbf{3 4 7} \\
\mathbf{3 4 7} \\
\mathbf{3 4 7}\end{array}$ & $\begin{array}{r}100 \\
90 \\
80 \\
80 \\
80\end{array}$ & $\begin{array}{r}100 \\
88 \\
75 \\
75 \\
75\end{array}$ & $\begin{array}{l}297 \\
297 \\
297 \\
289 \\
289\end{array}$ & $\begin{array}{l}\mathbf{5 5} \\
\mathbf{5 5} \\
\mathbf{5 5} \\
\mathbf{5 5} \\
\mathbf{5 5}\end{array}$ & $\begin{array}{l}44 \\
44 \\
44 \\
43 \\
43\end{array}$ \\
\hline $\begin{array}{r}6 \\
7 \\
8 \\
9 \\
10\end{array}$ & $\begin{array}{l}314 \\
322 \\
314 \\
314 \\
314\end{array}$ & $\begin{array}{l}123 \\
123 \\
123 \\
123 \\
123\end{array}$ & $\begin{array}{l}104 \\
107 \\
104 \\
104 \\
104\end{array}$ & $\begin{array}{l}330 \\
305 \\
305 \\
314 \\
314\end{array}$ & $\begin{array}{l}46 \\
58 \\
58 \\
70 \\
70\end{array}$ & $\begin{array}{l}41 \\
48 \\
48 \\
59 \\
59\end{array}$ & $\begin{array}{l}289 \\
289 \\
282 \\
282 \\
289\end{array}$ & $\begin{array}{l}\mathbf{5 5} \\
\mathbf{5 5} \\
\mathbf{5 5} \\
\mathbf{5 5} \\
\mathbf{5 5}\end{array}$ & $\begin{array}{l}43 \\
43 \\
42 \\
42 \\
43\end{array}$ \\
\hline $\begin{array}{l}11 \\
12 \\
13 \\
14 \\
15\end{array}$ & $\begin{array}{l}314 \\
314 \\
314 \\
314 \\
314\end{array}$ & $\begin{array}{l}123 \\
123 \\
123 \\
112 \\
112\end{array}$ & $\begin{array}{r}104 \\
104 \\
104 \\
95 \\
95\end{array}$ & $\begin{array}{l}322 \\
322 \\
330 \\
322 \\
322\end{array}$ & $\begin{array}{l}82 \\
82 \\
82 \\
82 \\
82\end{array}$ & $\begin{array}{l}71 \\
71 \\
73 \\
71 \\
71\end{array}$ & $\begin{array}{l}\mathbf{3 1 4} \\
\mathbf{3 3 9} \\
\mathbf{3 4 7} \\
\mathbf{3 4 7} \\
\mathbf{3 4 7}\end{array}$ & $\begin{array}{r}88 \\
140 \\
169 \\
169 \\
169\end{array}$ & $\begin{array}{r}75 \\
128 \\
158 \\
158 \\
158\end{array}$ \\
\hline $\begin{array}{l}16 \\
17 \\
18 \\
19 \\
20\end{array}$ & $\begin{array}{l}\mathbf{3 1 4} \\
\mathbf{3 1 4} \\
\mathbf{3 1 4} \\
\mathbf{3 1 4} \\
\mathbf{3 1 4}\end{array}$ & $\begin{array}{l}112 \\
112 \\
112 \\
112 \\
112\end{array}$ & $\begin{array}{l}95 \\
95 \\
95 \\
95 \\
95\end{array}$ & $\begin{array}{l}322 \\
322 \\
314 \\
314 \\
305\end{array}$ & $\begin{array}{l}82 \\
82 \\
70 \\
70 \\
\mathbf{5 4}\end{array}$ & $\begin{array}{l}71 \\
71 \\
59 \\
59 \\
44\end{array}$ & $\begin{array}{l}347 \\
339 \\
339 \\
322 \\
314\end{array}$ & $\begin{array}{r}152 \\
130 \\
120 \\
96 \\
56\end{array}$ & $\begin{array}{r}142 \\
119 \\
110 \\
83 \\
47\end{array}$ \\
\hline $\begin{array}{l}21 \\
22 \\
23 \\
24 \\
25\end{array}$ & $\begin{array}{l}314 \\
314 \\
330 \\
430 \\
658\end{array}$ & $\begin{array}{l}112 \\
112 \\
112 \\
210 \\
411\end{array}$ & $\begin{array}{r}95 \\
95 \\
100 \\
244 \\
730\end{array}$ & $\begin{array}{l}305 \\
305 \\
305 \\
297 \\
297\end{array}$ & $\begin{array}{l}54 \\
54 \\
54 \\
54 \\
54\end{array}$ & $\begin{array}{l}44 \\
44 \\
44 \\
43 \\
43\end{array}$ & $\begin{array}{l}314 \\
314 \\
314 \\
314 \\
339\end{array}$ & $\begin{array}{l}64 \\
64 \\
64 \\
64 \\
90\end{array}$ & $\begin{array}{l}\mathbf{5 4} \\
54 \\
54 \\
54 \\
82\end{array}$ \\
\hline $\begin{array}{l}26 \\
27 \\
28 \\
29 \\
30 \\
31\end{array}$ & $\begin{array}{l}\mathbf{7 4 0} \\
\mathbf{5 5 6} \\
\mathbf{4 5 0} \\
\mathbf{4 2 1} \\
\mathbf{4 0 1} \\
\mathbf{3 9 1}\end{array}$ & $\begin{array}{l}371 \\
235 \\
165 \\
140 \\
125 \\
120\end{array}$ & $\begin{array}{l}741 \\
353 \\
200 \\
159 \\
135 \\
127\end{array}$ & $\begin{array}{r}297 \\
297 \\
297 \\
-- \\
-- \\
--\end{array}$ & $\begin{array}{l}55 \\
55 \\
55 \\
-- \\
-- \\
--\end{array}$ & $\begin{array}{l}44 \\
44 \\
44 \\
-- \\
-- \\
--\end{array}$ & $\begin{array}{r}470 \\
870 \\
1040 \\
952 \\
905 \\
905\end{array}$ & $\begin{array}{l}220 \\
630 \\
610 \\
390 \\
403 \\
341\end{array}$ & $\begin{array}{r}279 \\
1480 \\
1710 \\
1000 \\
985 \\
833\end{array}$ \\
\hline Total & 11349 & -- & 5020 & 8940 & -- & 1679 & 12992 & -- & 8194 \\
\hline
\end{tabular}


STREAMS TRIBUTARY TO LAKE MICHIGAN--COnt inued

4-1255.1. PINE RIVER NEAR WELLSTON, MICH.--Continued

Total sediment load, water, year october 1966 to September 1967--Continued

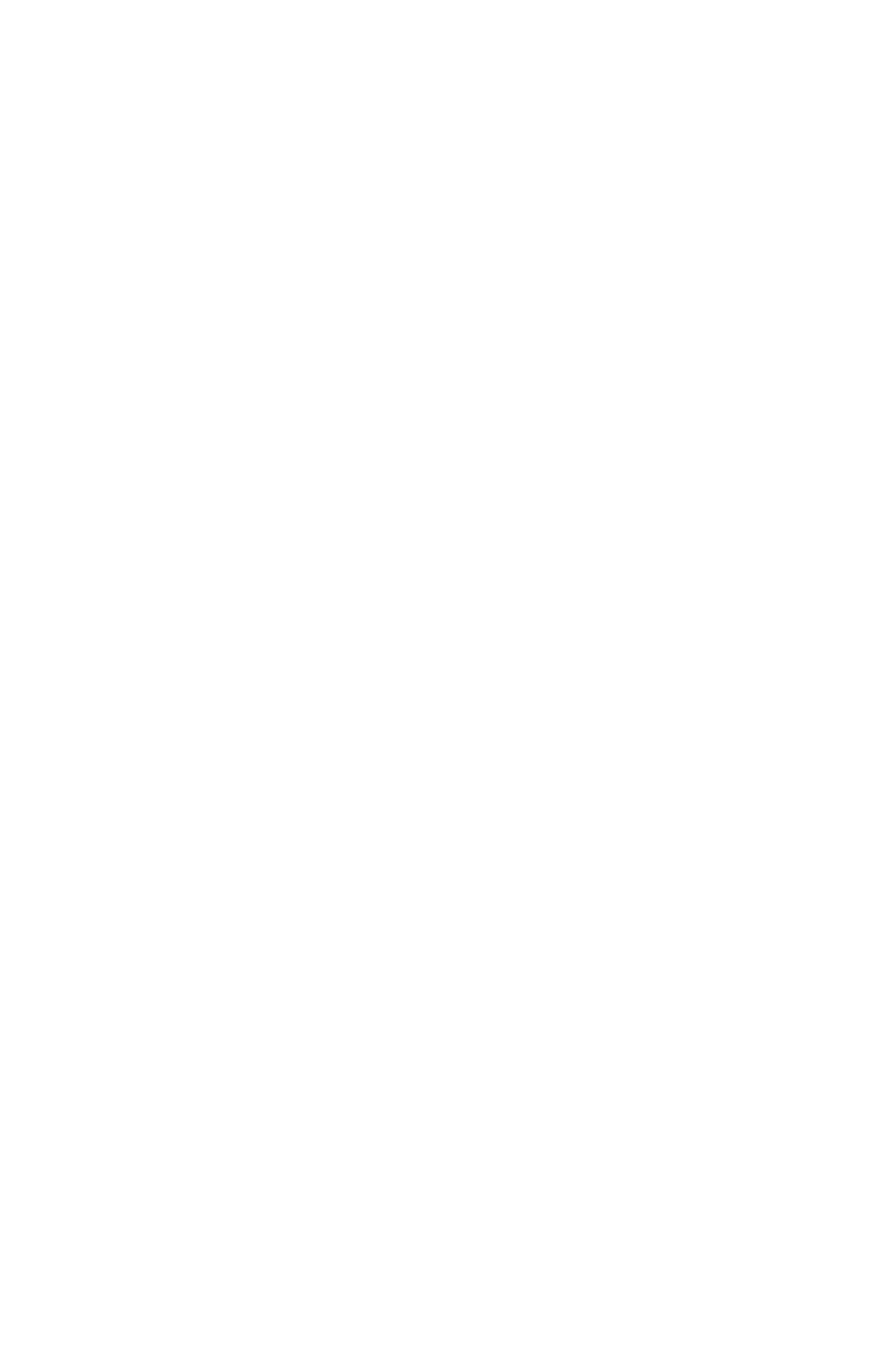




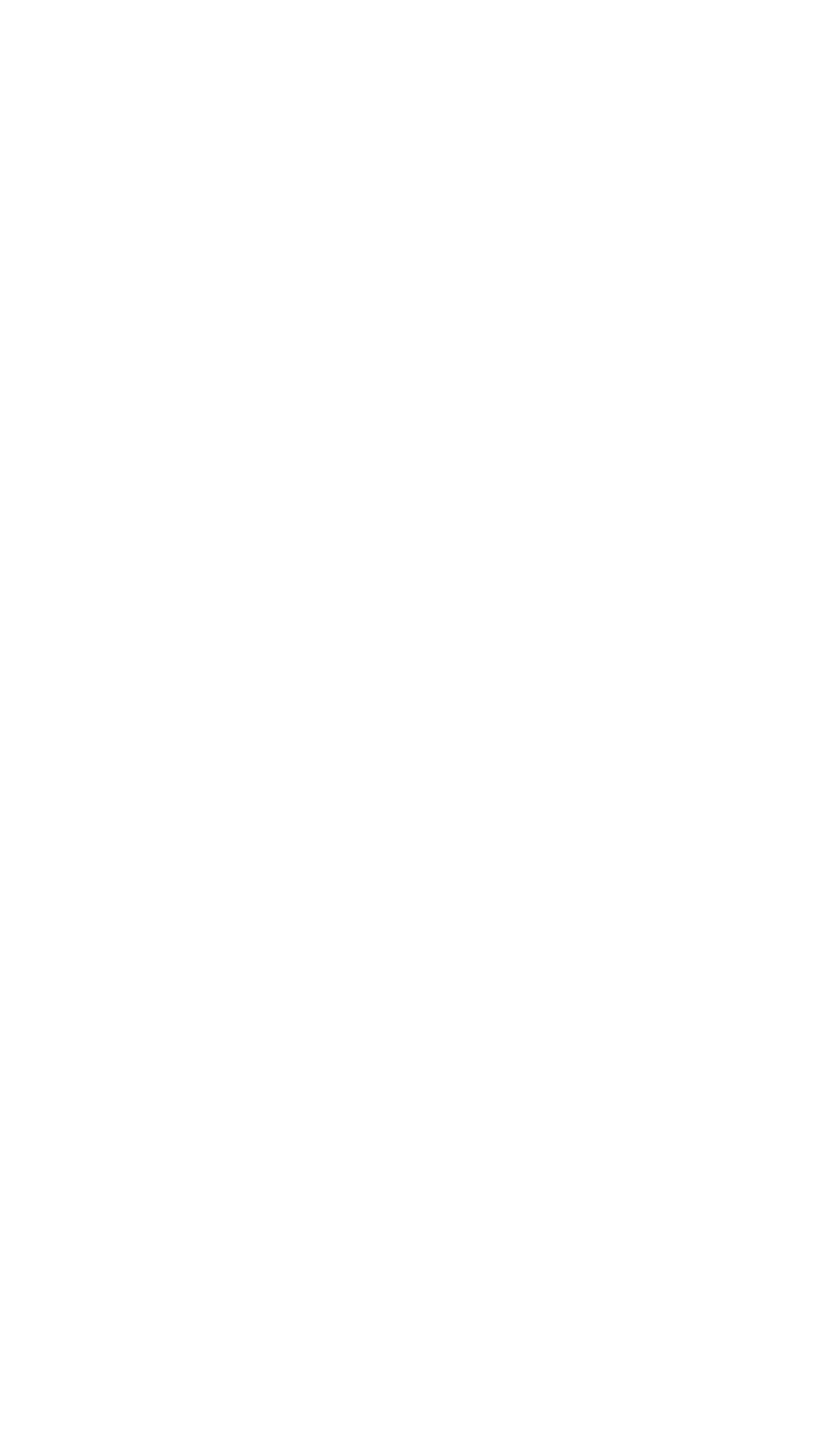




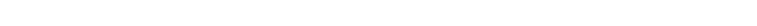

18्वा8क

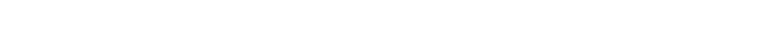

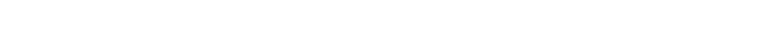

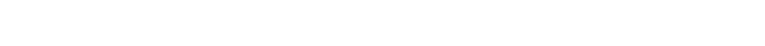

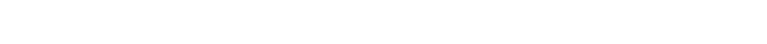

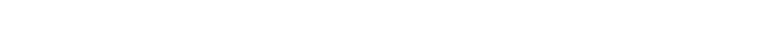

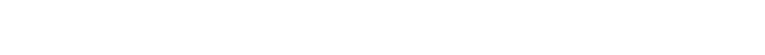

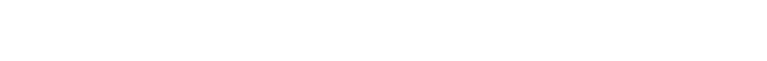

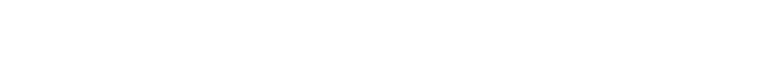

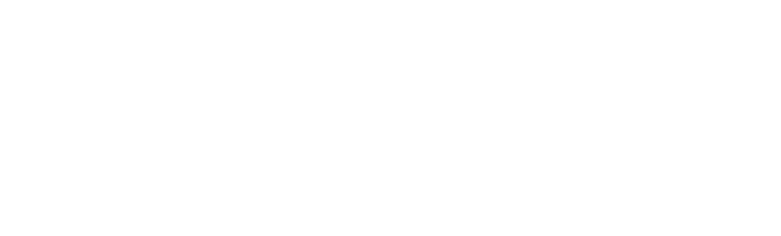




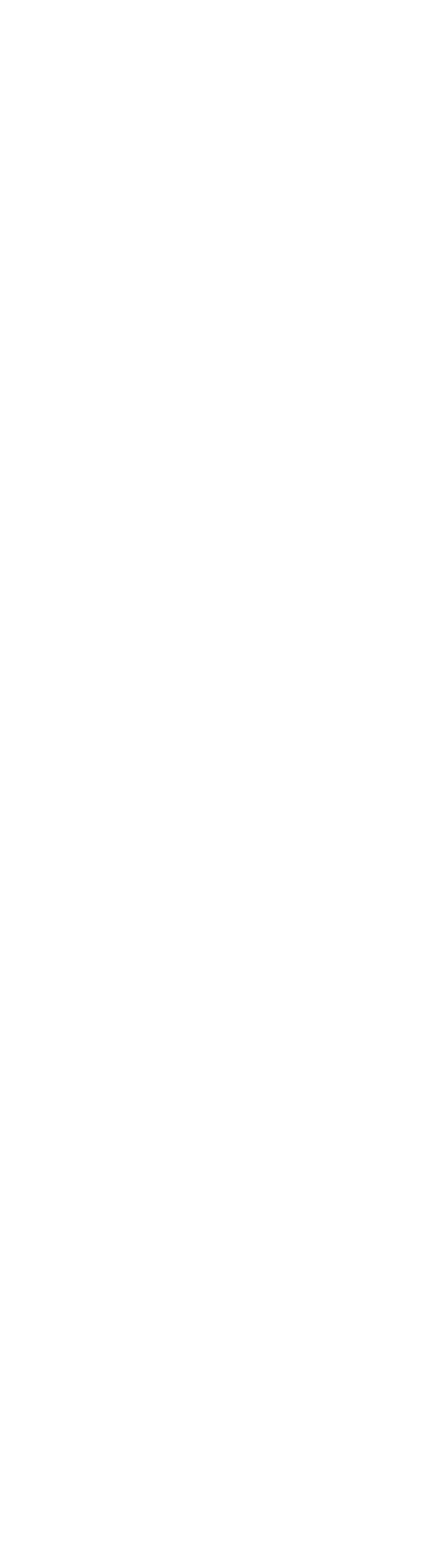




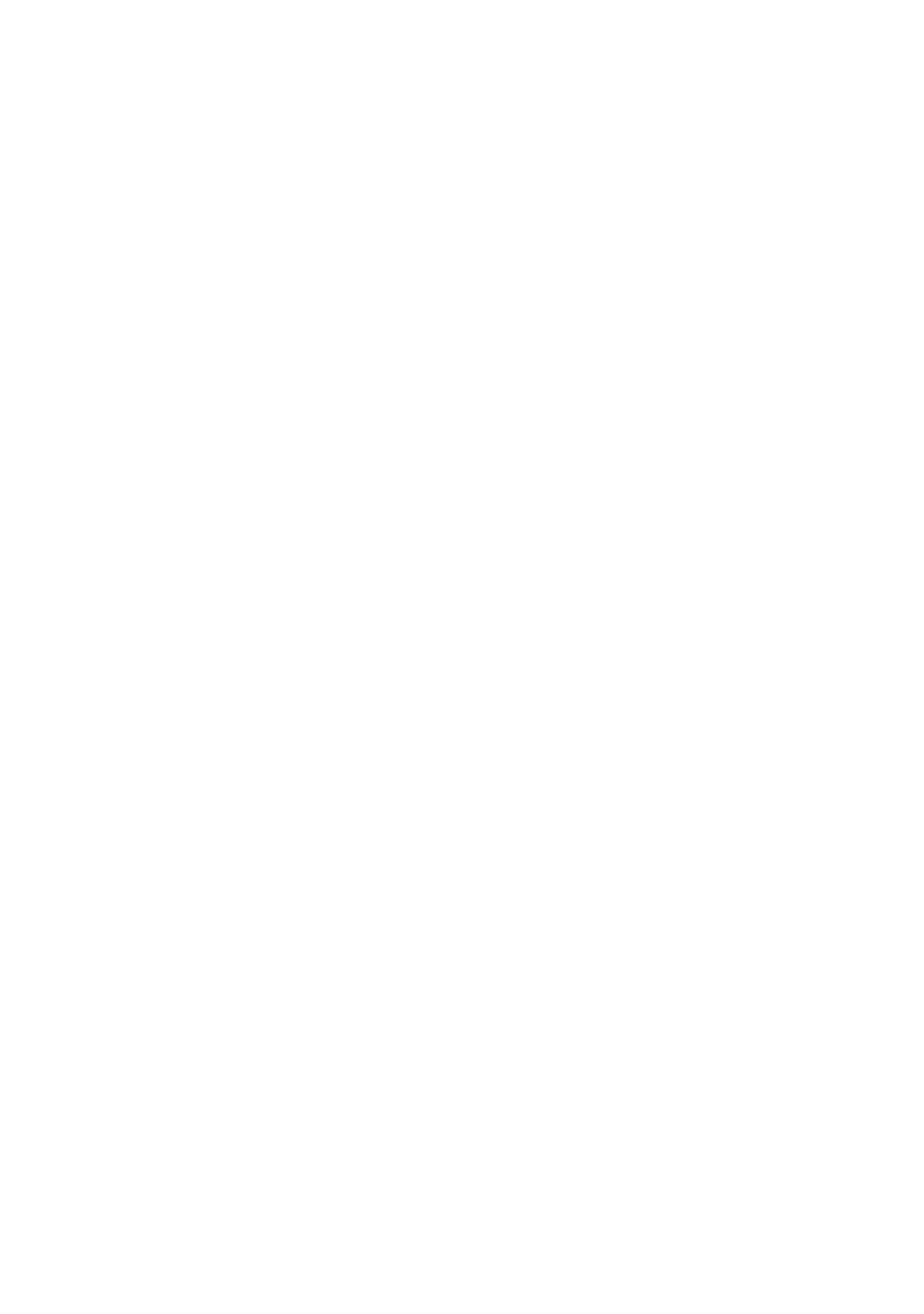




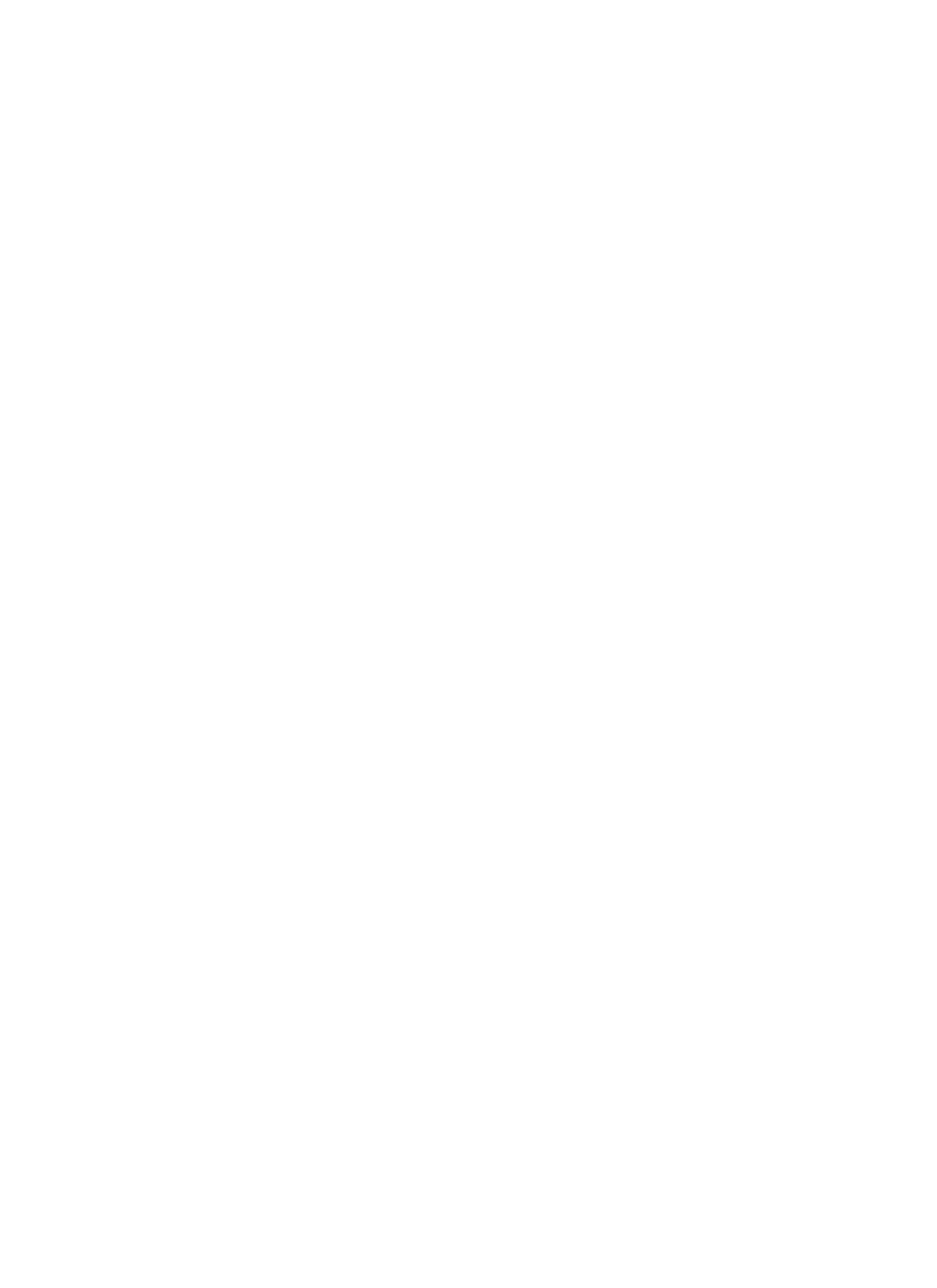




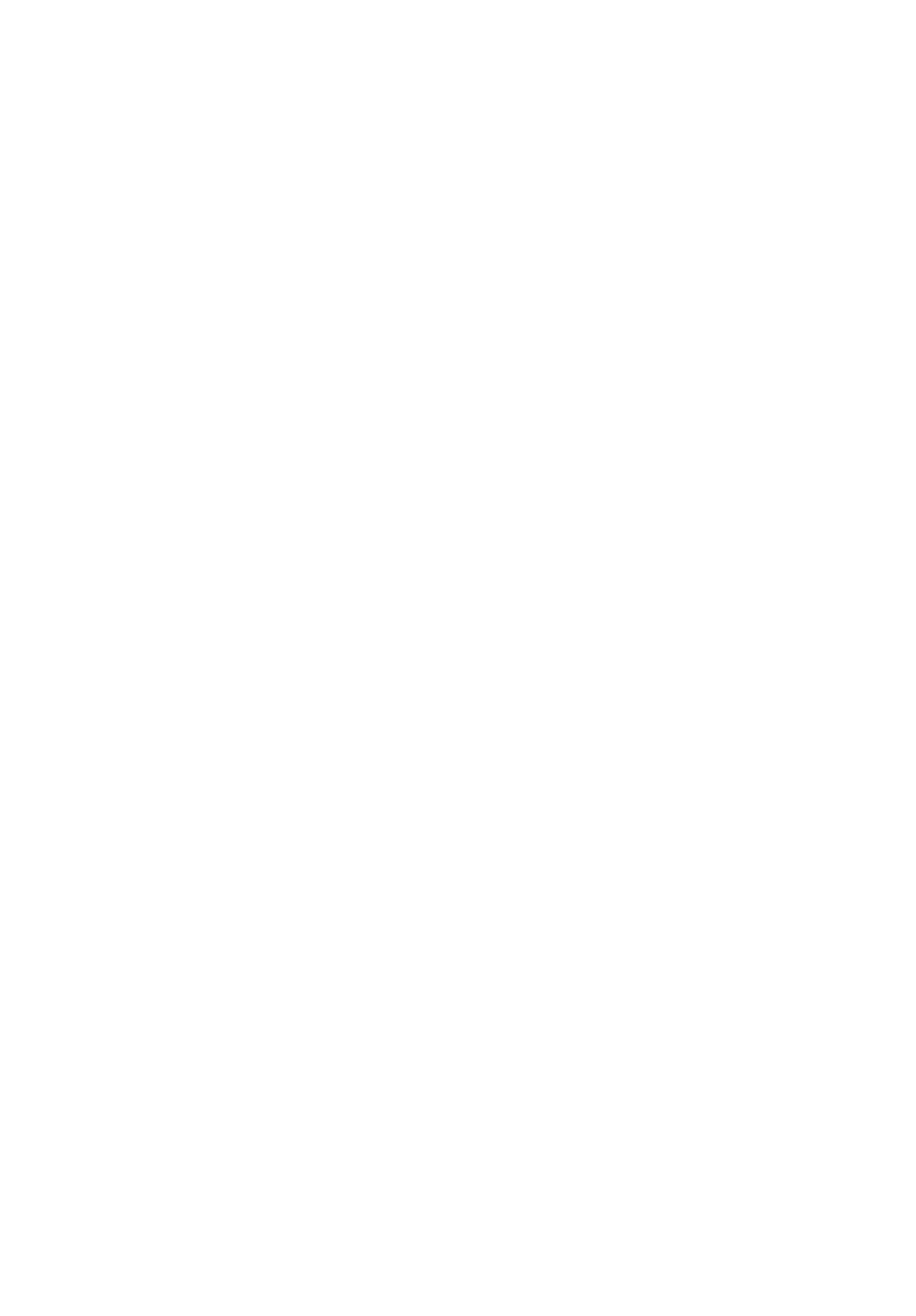




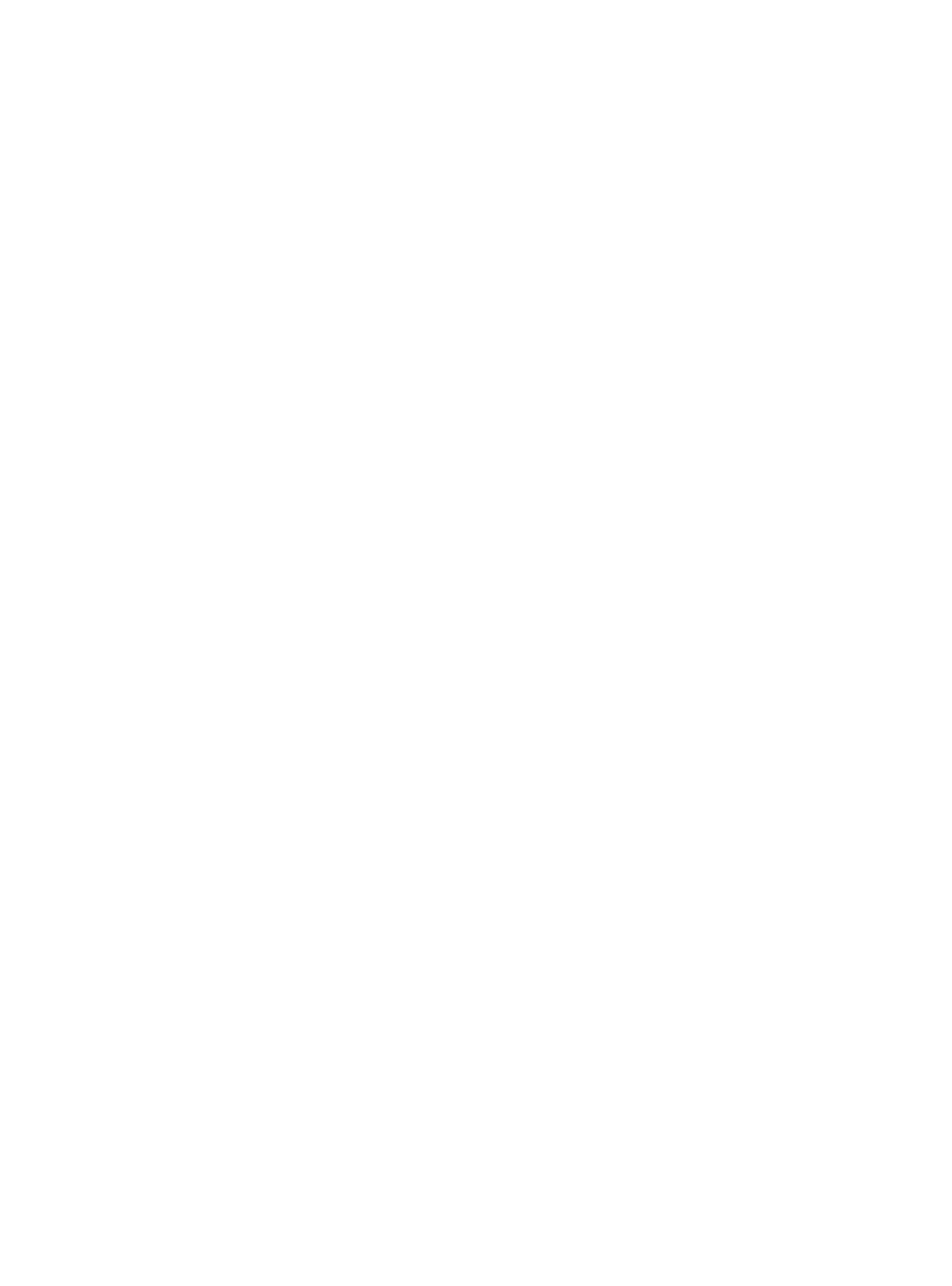




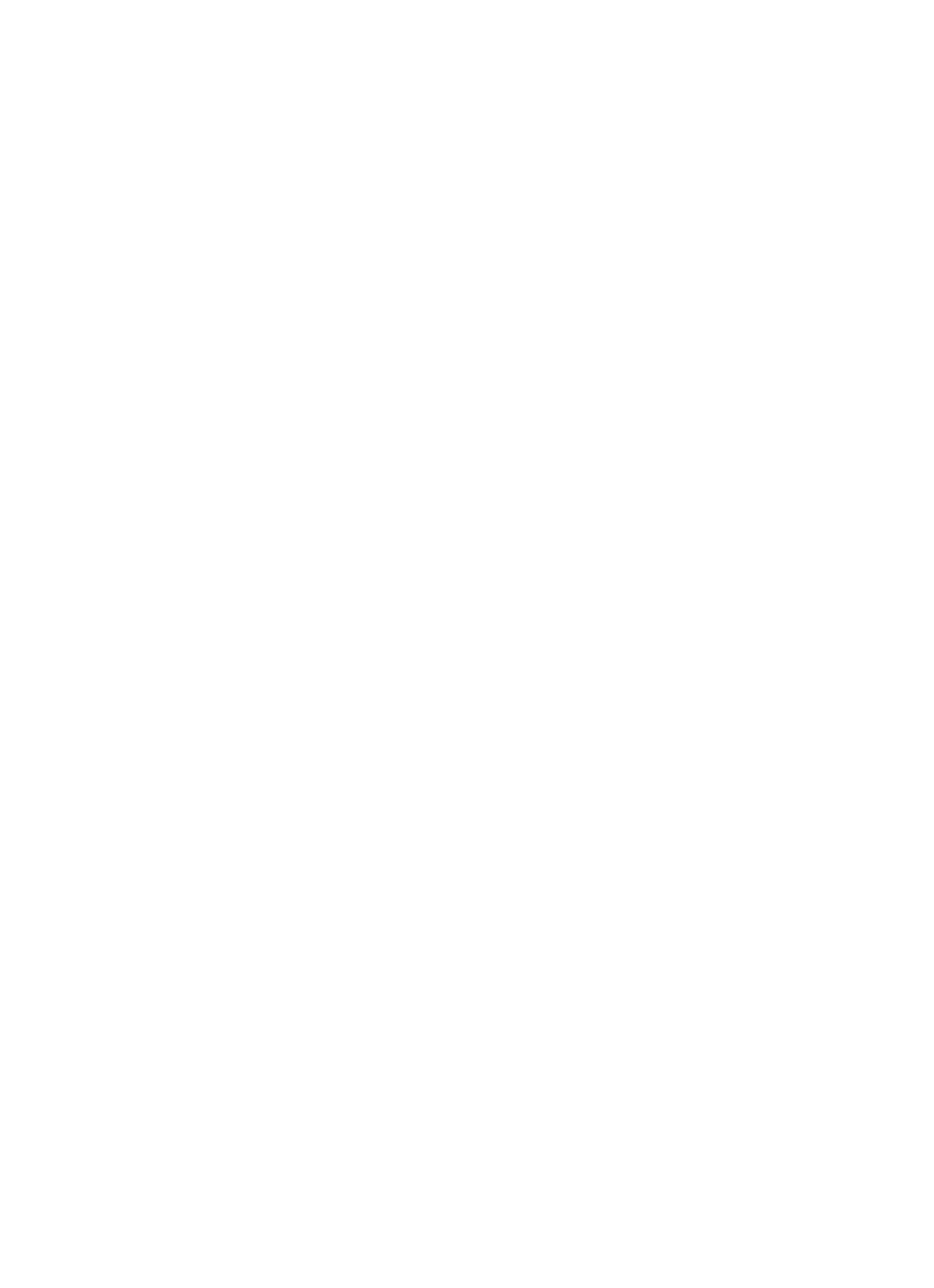




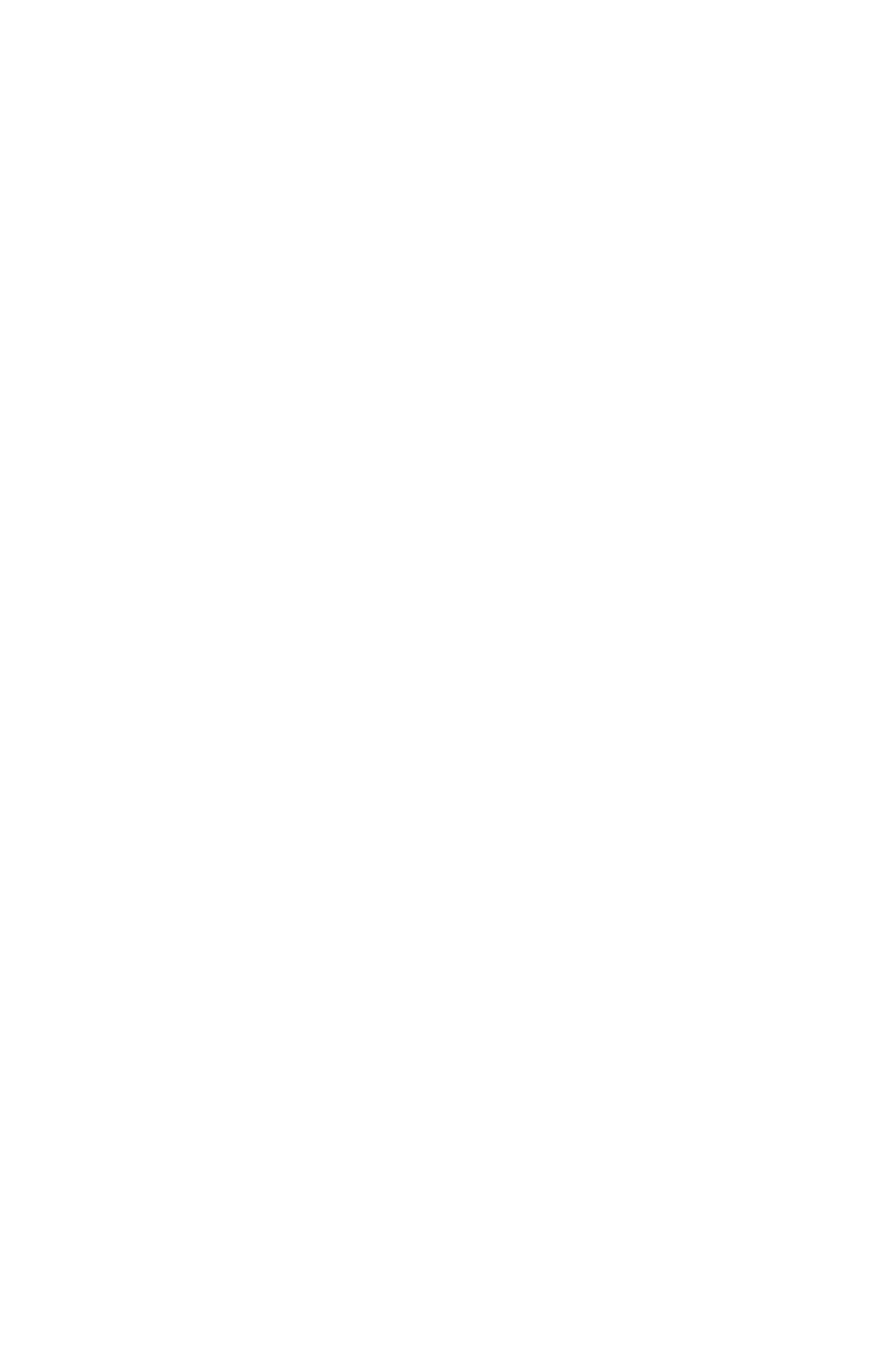




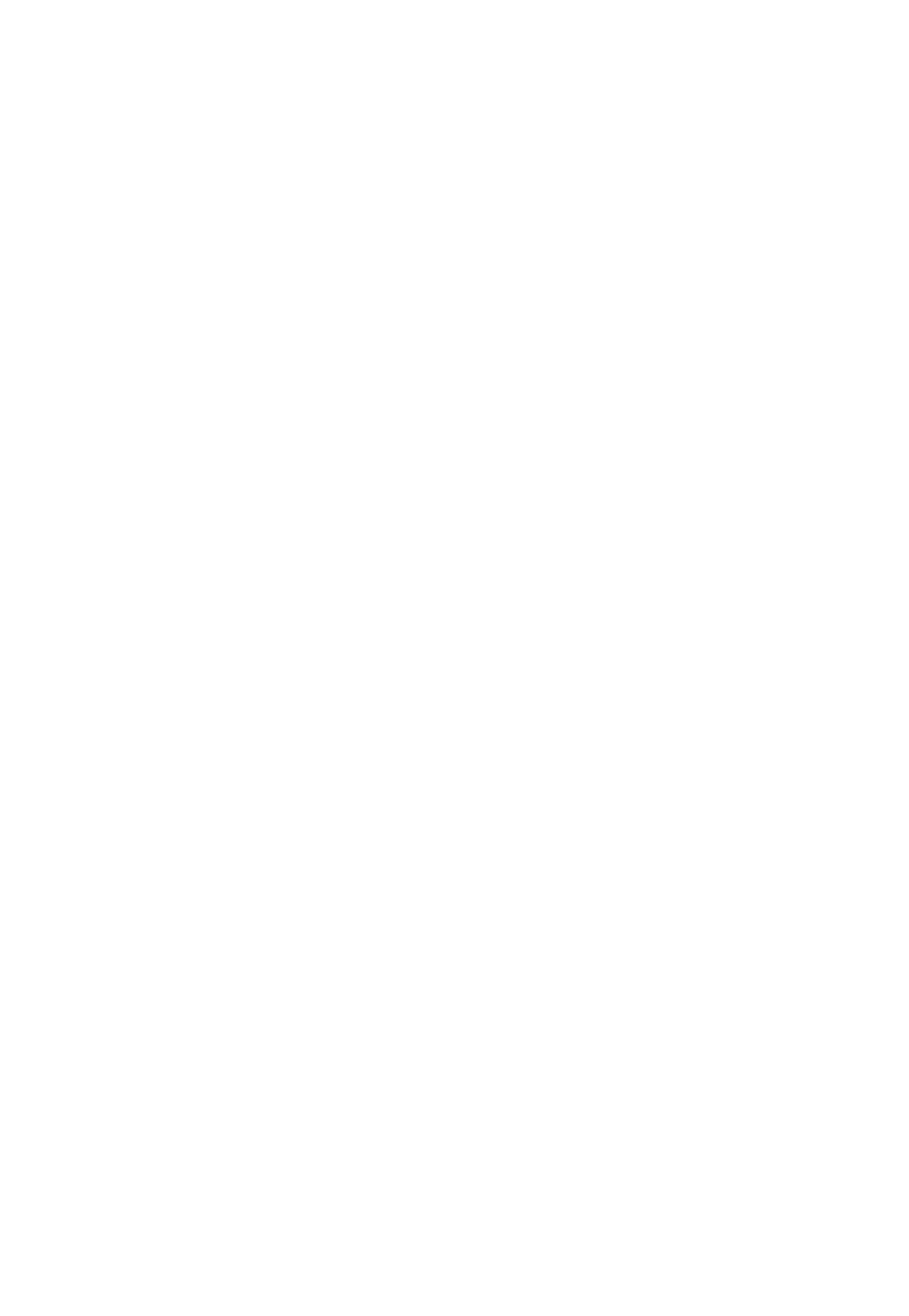




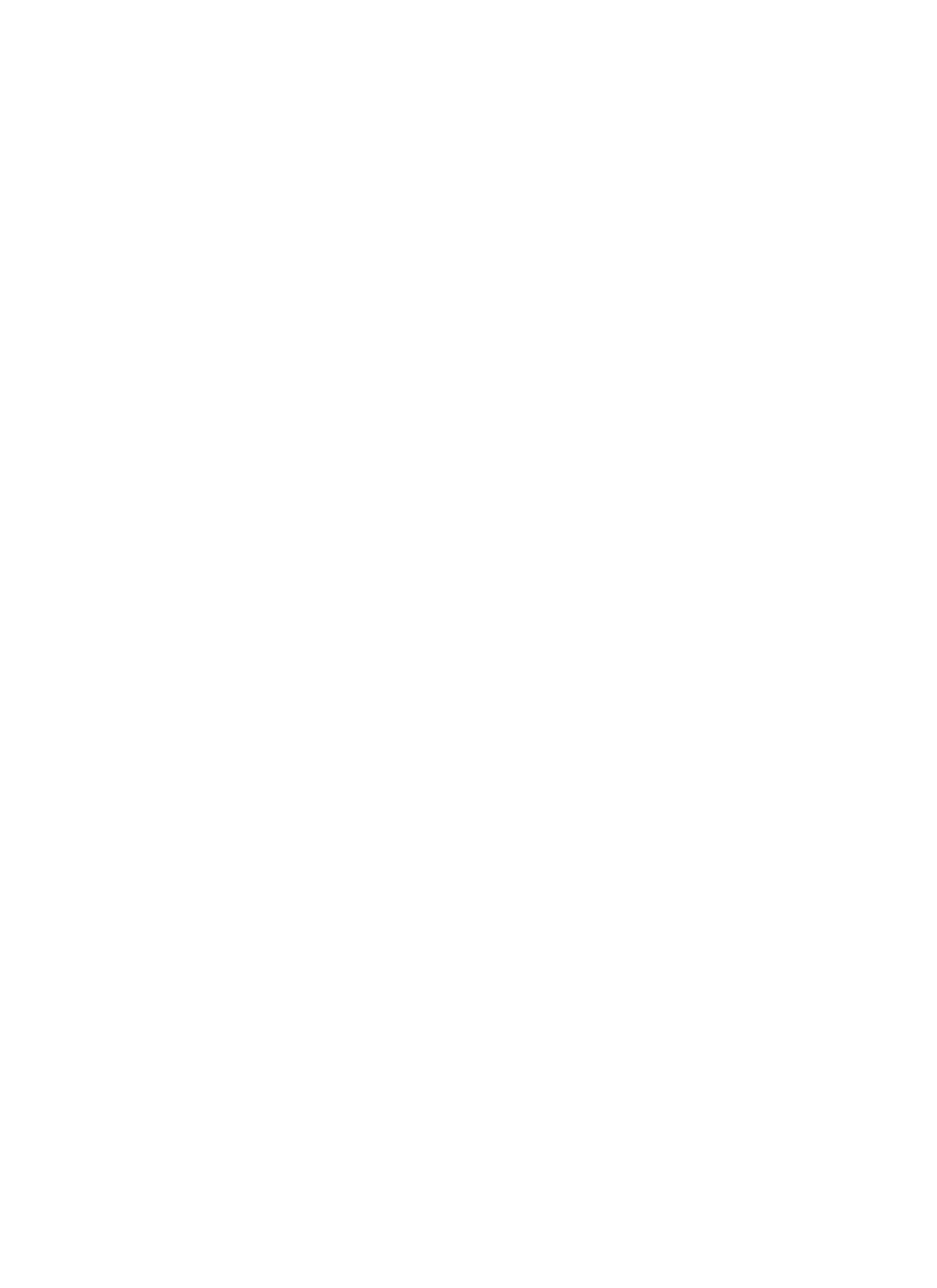




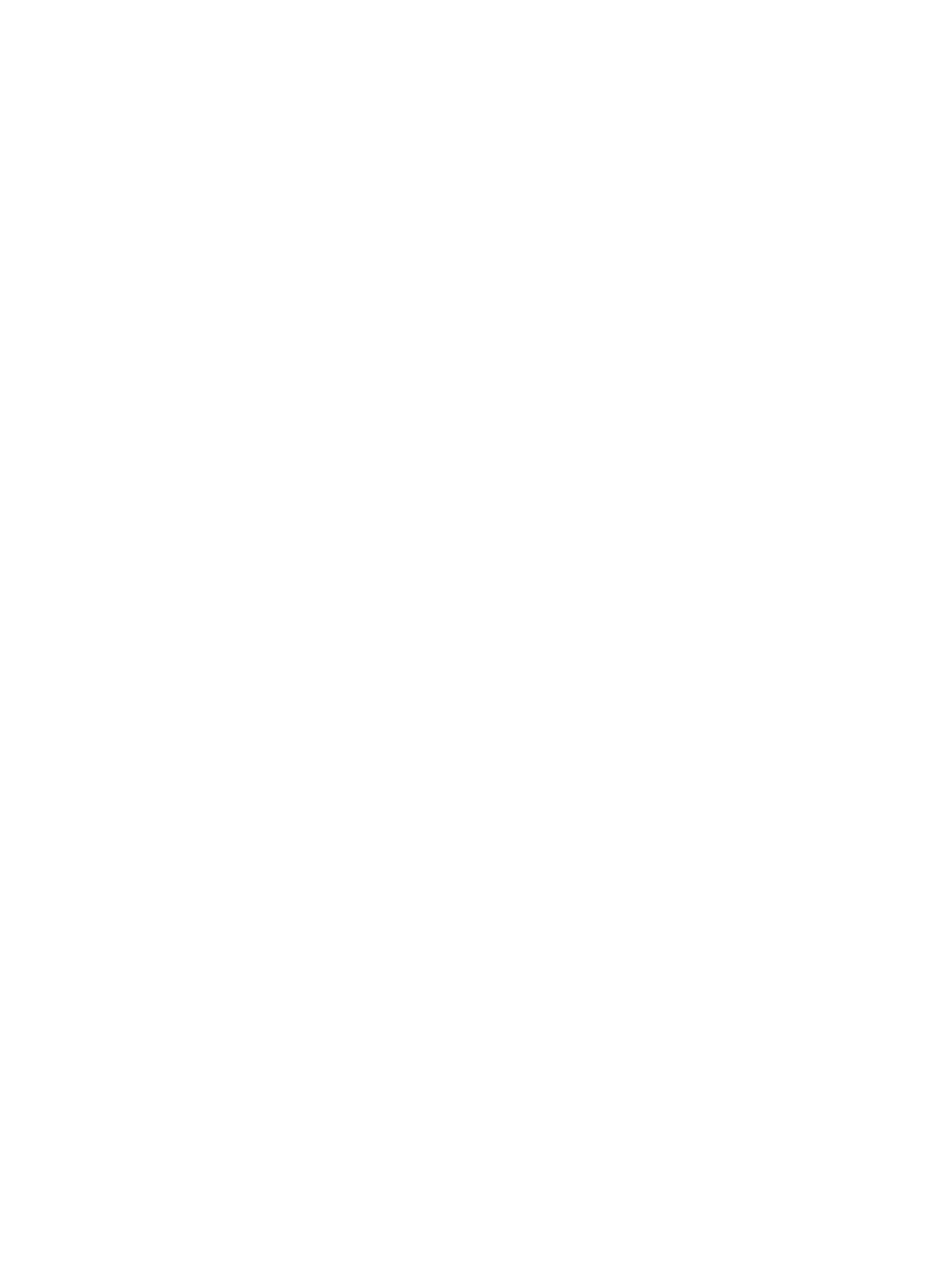




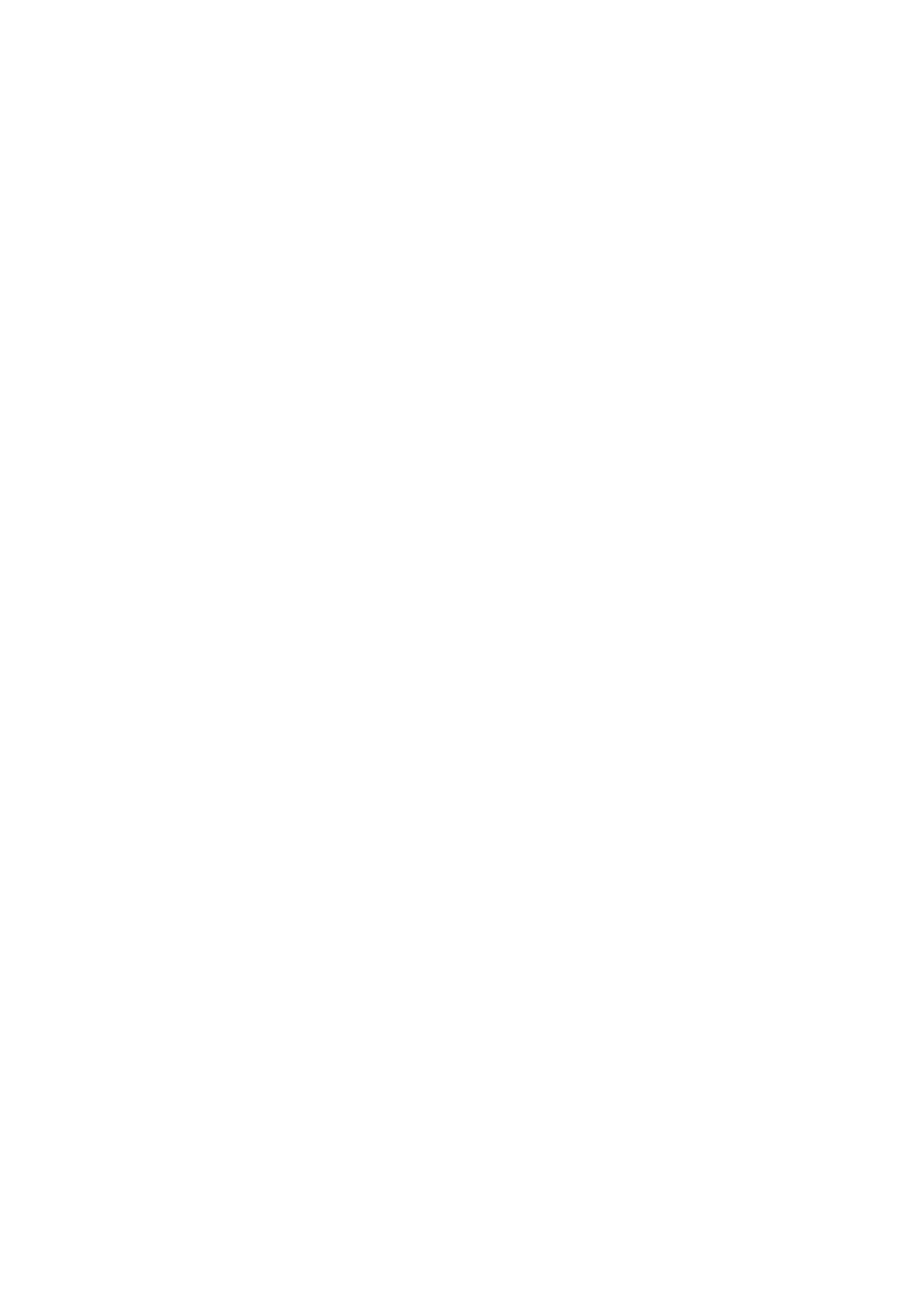




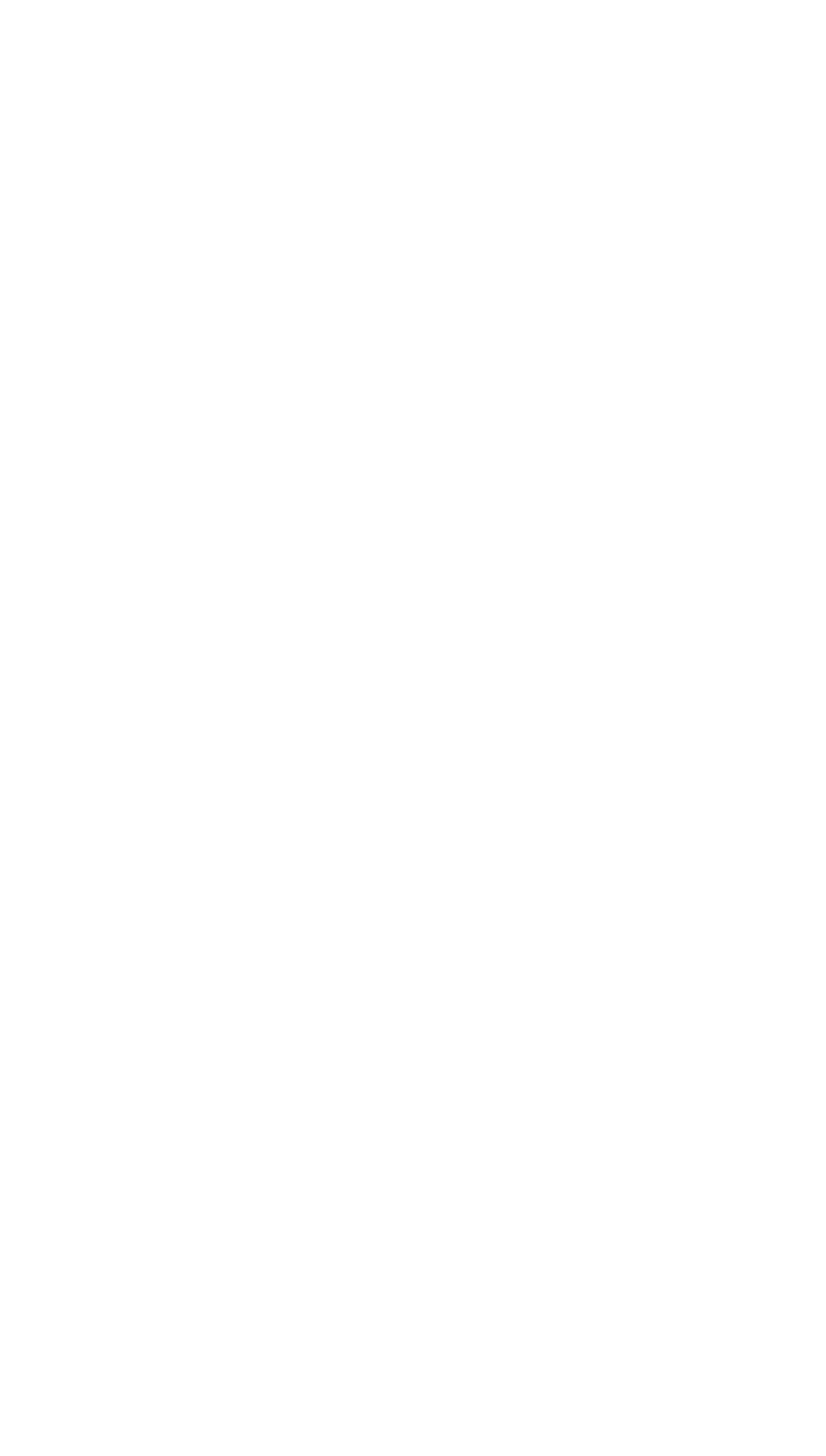




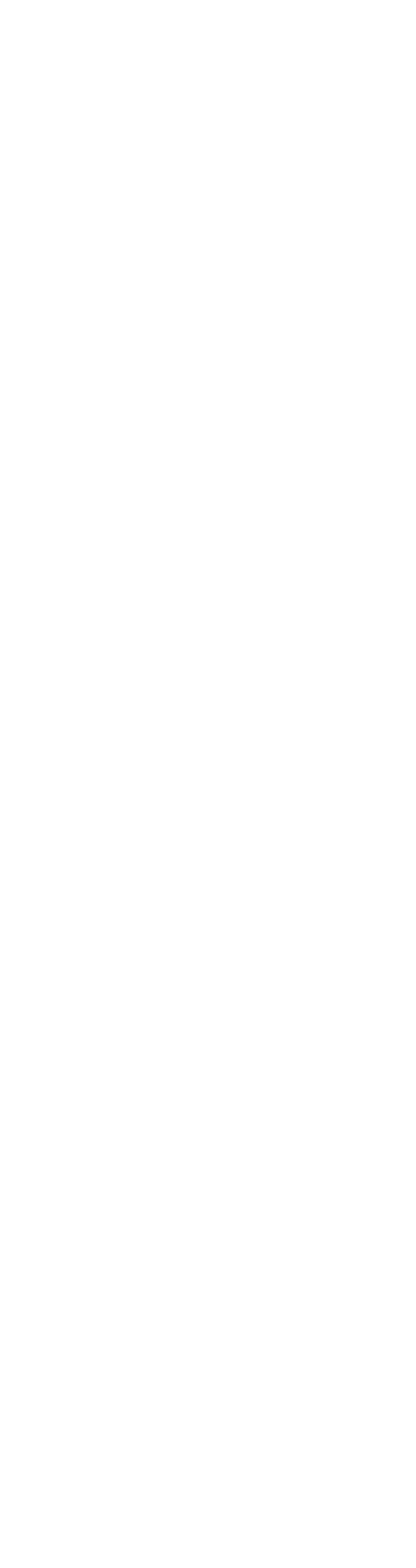




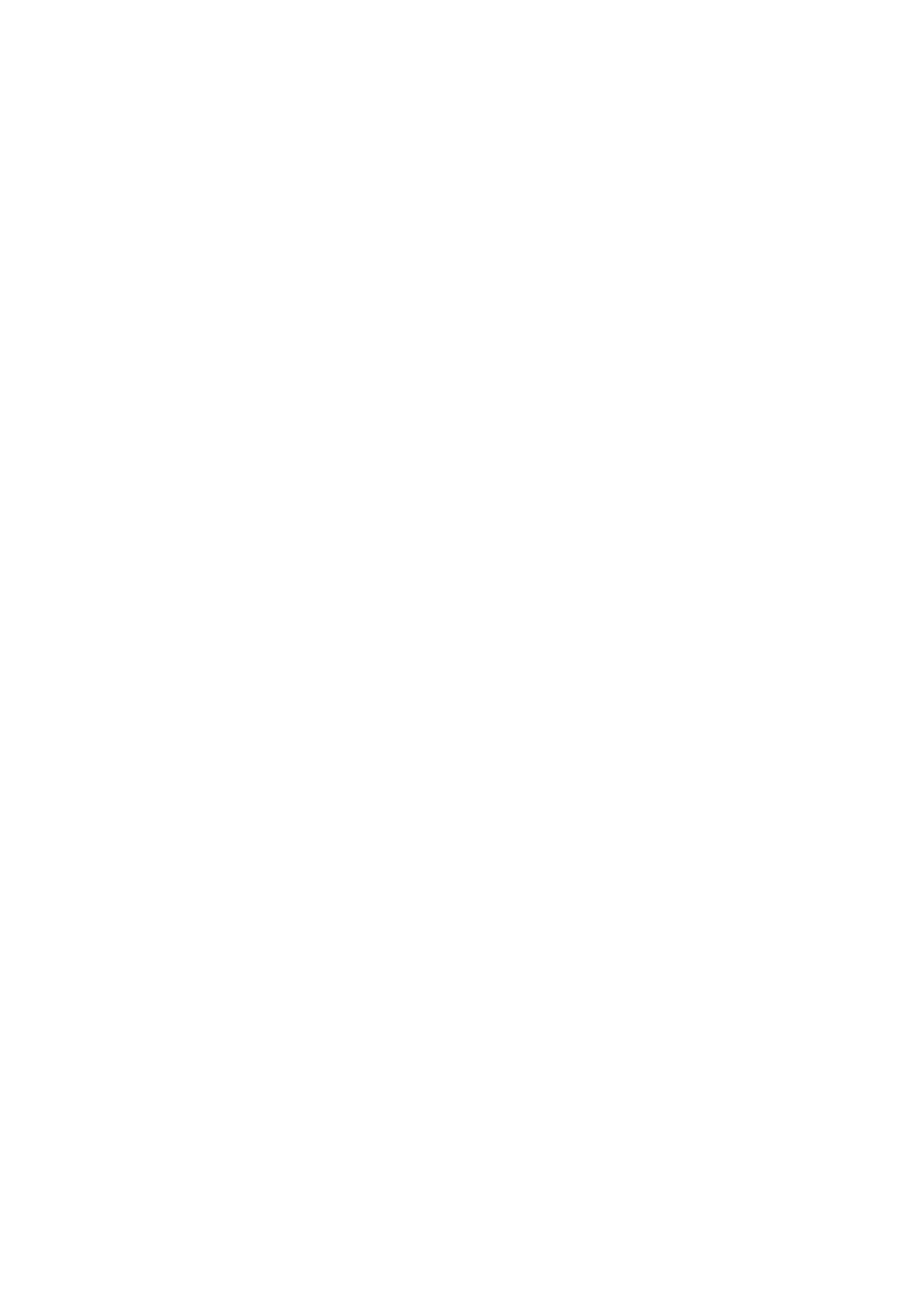




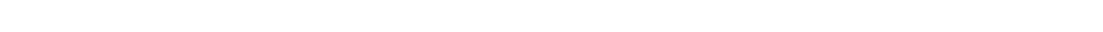
$1.0 \mathrm{mile}$ upstream from gaging station.

DRAINAGE AREA. --538 square miles.

RECORDS AVAILABLE. --Sediment records: Way 1966 to september 1967.

EXTREMES, 1966-67,--Sediment concentrations: Maximum daily, 520 ppm Apr. 17; minjmum daily, 4 ppm Oct. 1 .

Sediment loads: Maximum daily, 3,460 tons Apr. 17; minimum daily, 0.4 ton Oct. 1.

EXTREMES, May 1966 to September 1967.--Sediment concentrations: Maximum daily, 520 ppm Apr. 17, 1967; minimum daily, 1 ppm Sept. 8-11, 1966

Sediment loads: Maximum daily, 3,460 tons Apr, 17, 1967; minimum daily, 0.1 tor Sept. 8-11, 1966 .

REMARKS, --Flow affected by tce Dec, 25 to Jan 23 , Feb, 3-13, Feb, 15 to Mar 9 . Daily loads were

computed by subdivision on Nov. $4,5,9,21$, Apr. 2,17 , June 8, 24, Aug. 9, Sept. 13 .

Suspended sediment, water year October 1966 to Septemer 1967

\begin{tabular}{|c|c|c|c|c|c|c|c|c|c|}
\hline \multirow[b]{3}{*}{ Day } & \multicolumn{3}{|c|}{ OCTOBER } & \multicolumn{3}{|c|}{ MOVEMBER } & \multicolumn{3}{|c|}{ OE :EMBER } \\
\hline & \multirow[b]{2}{*}{$\begin{array}{c}\text { Mean } \\
\text { dis- } \\
\text { charge } \\
\text { (cfs) }\end{array}$} & \multicolumn{2}{|c|}{ Suspended sediment } & \multirow[b]{2}{*}{$\begin{array}{c}\text { Mean } \\
\text { dis- } \\
\text { charge } \\
\text { (cfs) }\end{array}$} & \multicolumn{2}{|c|}{ Suspended sediment } & \multirow[b]{2}{*}{$\begin{array}{c}\text { Mean } \\
\text { dis- } \\
\text { charge } \\
\text { (cfs) }\end{array}$} & \multicolumn{2}{|c|}{ Suspended sediment } \\
\hline & & $\begin{array}{l}\text { Mean } \\
\text { concen- } \\
\text { tration } \\
\text { (ppm) }\end{array}$ & $\begin{array}{l}\text { Tons } \\
\text { per } \\
\text { day }\end{array}$ & & $\begin{array}{c}\text { Mean } \\
\text { concen- } \\
\text { tration } \\
\text { (ppm) }\end{array}$ & $\begin{array}{l}\text { Tons } \\
\text { per } \\
\text { day }\end{array}$ & & $\begin{array}{c}\text { Mean } \\
\text { concen- } \\
\text { tration } \\
(\mathrm{ppm})\end{array}$ & $\begin{array}{l}\text { Tons } \\
\text { per } \\
\text { day }\end{array}$ \\
\hline $\begin{array}{l}1.0 \\
2 \ldots \\
30 . \\
4 \ldots \\
5 \ldots\end{array}$ & $\begin{array}{l}39 \\
49 \\
64 \\
62 \\
59\end{array}$ & $\begin{array}{l}4 \\
5 \\
5 \\
5 \\
5\end{array}$ & $\begin{array}{l}0.4 \\
.7 \\
.9 \\
.8 \\
.8\end{array}$ & $\begin{array}{r}68 \\
80 \\
126 \\
165\end{array}$ & $\begin{array}{r}8 \\
8 \\
11 \\
21 \\
47\end{array}$ & $\begin{array}{l}1.5 \\
1.4 \\
2.4 \\
12 \\
24\end{array}$ & $\begin{array}{l}219 \\
160 \\
160 \\
170 \\
254\end{array}$ & $\begin{array}{l}12 \\
11 \\
11 \\
11 \\
23\end{array}$ & $\begin{array}{l}7.1 \\
4.8 \\
4.8 \\
5.0 \\
17\end{array}$ \\
\hline $\begin{array}{r}6 \ldots \\
7 \ldots \\
8 \ldots \\
9 \ldots \\
10 \ldots\end{array}$ & $\begin{array}{l}59 \\
57 \\
54 \\
52 \\
52\end{array}$ & $\begin{array}{l}5 \\
5 \\
5 \\
5 \\
5\end{array}$ & $\begin{array}{l}.8 \\
.8 \\
.7 \\
.7 \\
.7\end{array}$ & $\begin{array}{l}106 \\
126 \\
134 \\
170 \\
246\end{array}$ & $\begin{array}{l}11 \\
10 \\
11 \\
43 \\
26\end{array}$ & $\begin{array}{l}3.1 \\
3.4 \\
4.0 \\
23 \\
17\end{array}$ & $\begin{array}{l}286 \\
476 \\
694 \\
646 \\
634\end{array}$ & $\begin{array}{l}45 \\
65 \\
87 \\
52 \\
35\end{array}$ & $\begin{array}{r}35 \\
84 \\
149 \\
91 \\
60\end{array}$ \\
\hline $\begin{array}{l}11 \ldots \\
12 \ldots \\
13 \ldots \\
14 \ldots \\
15 \ldots\end{array}$ & $\begin{array}{l}47 \\
43 \\
41 \\
41 \\
59\end{array}$ & $\begin{array}{r}5 \\
5 \\
5 \\
5 \\
12\end{array}$ & $\begin{array}{r}.6 \\
.6 \\
.6 \\
.6 \\
1.9\end{array}$ & $\begin{array}{l}291 \\
231 \\
233 \\
211 \\
109\end{array}$ & $\begin{array}{r}12 \\
10 \\
7 \\
6 \\
6\end{array}$ & $\begin{array}{l}7.5 \\
6.2 \\
4.4 \\
3.4 \\
3.1\end{array}$ & $\begin{array}{l}666 \\
662 \\
566 \\
549 \\
482\end{array}$ & $\begin{array}{l}30 \\
28 \\
28 \\
22 \\
15\end{array}$ & $\begin{array}{l}54 \\
50 \\
43 \\
33 \\
20\end{array}$ \\
\hline $\begin{array}{l}16 \ldots \\
17 \ldots \\
18 \ldots \\
19 \ldots \\
20 \ldots\end{array}$ & $\begin{array}{l}54 \\
56 \\
56 \\
56 \\
57\end{array}$ & $\begin{array}{l}12 \\
12 \\
11 \\
10 \\
10\end{array}$ & $\begin{array}{l}1.7 \\
1.8 \\
1.7 \\
1.5 \\
1.5\end{array}$ & $\begin{array}{l}187 \\
184 \\
176 \\
160 \\
152\end{array}$ & $\begin{array}{l}5 \\
5 \\
5 \\
5 \\
5\end{array}$ & $\begin{array}{l}2.5 \\
2.5 \\
2.4 \\
2.2 \\
2.1\end{array}$ & $\begin{array}{l}438 \\
426 \\
423 \\
409 \\
362\end{array}$ & $\begin{array}{l}17 \\
23 \\
24 \\
22 \\
33\end{array}$ & $\begin{array}{l}21 \\
26 \\
27 \\
24 \\
32\end{array}$ \\
\hline $\begin{array}{l}21 \ldots \\
22 \ldots \\
23 \ldots \\
24 \ldots \\
25 \ldots\end{array}$ & $\begin{array}{l}61 \\
80 \\
66 \\
64 \\
64\end{array}$ & $\begin{array}{l}10 \\
10 \\
10 \\
10 \\
10\end{array}$ & $\begin{array}{l}2.6 \\
2.2 \\
1.8 \\
1.7 \\
1.7\end{array}$ & $\begin{array}{l}170 \\
152 \\
147 \\
160 \\
173\end{array}$ & $\begin{array}{r}12 \\
8 \\
6 \\
5 \\
5\end{array}$ & $\begin{array}{l}6.1 \\
3.3 \\
2.4 \\
2.2 \\
2.3\end{array}$ & $\begin{array}{l}406 \\
333 \\
225 \\
233 \\
220\end{array}$ & $\begin{array}{l}28 \\
18 \\
18 \\
28 \\
27\end{array}$ & $\begin{array}{l}31 \\
16 \\
11 \\
11 \\
10\end{array}$ \\
\hline $\begin{array}{l}26 \ldots \\
27 \ldots \\
21 \ldots \\
29 \ldots \\
30 \ldots \\
31 \ldots\end{array}$ & $\begin{array}{l}57 \\
57 \\
57 \\
61 \\
62 \\
68\end{array}$ & $\begin{array}{l}10 \\
20 \\
10 \\
\\
8\end{array}$ & $\begin{array}{l}2.5 \\
2.5 \\
2.5 \\
1.3 \\
2.3 \\
1.5\end{array}$ & $\begin{array}{r}270 \\
214 \\
222 \\
222 \\
225 \\
-\end{array}$ & $\begin{array}{l}3 \\
17 \\
14 \\
13 \\
12 \\
-\end{array}$ & $\begin{array}{l}2.3 \\
9.8 \\
8.4 \\
7.8 \\
7.3 \\
--\end{array}$ & $\begin{array}{l}200 \\
190 \\
170 \\
180 \\
180 \\
180\end{array}$ & $\begin{array}{l}27 \\
27 \\
17 \\
27 \\
27 \\
27\end{array}$ & $\begin{array}{l}9.2 \\
8.7 \\
7.8 \\
6.3 \\
8.3 \\
0.3\end{array}$ \\
\hline Total & 2754 & - & 37.4 & 5096 & - & 180.0 & 21259 & - & $917 \cdot 3$ \\
\hline
\end{tabular}


STREAKS TRIBUTARY TO LAKE HURON--COntinued

4-1445. SHIAWASSEE RIVER AT OWOSSO, MICH.--Continued

Suspended sediment, water year October 1966 to September 1967--Continued

\begin{tabular}{|c|c|c|c|c|c|c|c|c|c|}
\hline \multirow[b]{3}{*}{ Day } & \multicolumn{3}{|c|}{ JANUARY } & \multicolumn{3}{|c|}{ FEBRUARY } & \multicolumn{3}{|c|}{ MARCH } \\
\hline & \multirow[b]{2}{*}{$\begin{array}{c}\text { Mean } \\
\text { dis- } \\
\text { charge } \\
(c f s)\end{array}$} & \multicolumn{2}{|c|}{ Suspended sediment } & \multirow[b]{2}{*}{$\begin{array}{l}\text { Mean } \\
\text { dis- } \\
\text { charge } \\
\text { (cfs) }\end{array}$} & \multicolumn{2}{|c|}{ Suspended sediment } & \multirow[b]{2}{*}{$\begin{array}{c}\text { Mean } \\
\text { dis- } \\
\text { charge } \\
\text { (cfs) }\end{array}$} & \multicolumn{2}{|c|}{ Suspended sediment } \\
\hline & & $\begin{array}{c}\text { Mean } \\
\text { concen- } \\
\text { tration } \\
\text { (ppm) }\end{array}$ & $\begin{array}{l}\text { Tons } \\
\text { per } \\
\text { day }\end{array}$ & & $\begin{array}{c}\text { Mean } \\
\text { concen- } \\
\text { tration } \\
\text { (ppm) }\end{array}$ & $\begin{array}{l}\text { Tons } \\
\text { per } \\
\text { day }\end{array}$ & & $\begin{array}{c}\text { Mean } \\
\text { concen- } \\
\text { tration } \\
\text { (ppm) }\end{array}$ & $\begin{array}{l}\text { Tons } \\
\text { per } \\
\text { day }\end{array}$ \\
\hline $\begin{array}{l}1 \ldots \\
200 \\
30 \\
40 \\
50\end{array}$ & $\begin{array}{l}170 \\
160 \\
150 \\
150 \\
150\end{array}$ & $\begin{array}{l}17 \\
17 \\
17 \\
17 \\
16\end{array}$ & $\begin{array}{l}7.8 \\
7.3 \\
6.9 \\
6.9 \\
6.5\end{array}$ & $\begin{array}{l}385 \\
409 \\
420 \\
450 \\
500\end{array}$ & $\begin{array}{l}15 \\
15 \\
15 \\
15 \\
15\end{array}$ & $\begin{array}{l}16 \\
17 \\
17 \\
18 \\
20\end{array}$ & $\begin{array}{l}250 \\
240 \\
240 \\
250 \\
260\end{array}$ & $\begin{array}{l}13 \\
15 \\
17 \\
18 \\
19\end{array}$ & $\begin{array}{l}8.8 \\
5.7 \\
12 \\
12 \\
13\end{array}$ \\
\hline $\begin{array}{r}6 \ldots \\
7 \ldots \\
9 \\
10 \ldots\end{array}$ & $\begin{array}{l}150 \\
150 \\
170 \\
200 \\
200\end{array}$ & $\begin{array}{l}15 \\
15 \\
14 \\
13 \\
12\end{array}$ & $\begin{array}{l}6.1 \\
6.1 \\
6.4 \\
7.0 \\
6.5\end{array}$ & $\begin{array}{l}540 \\
500 \\
400 \\
350 \\
320\end{array}$ & $\begin{array}{l}15 \\
15 \\
15 \\
15 \\
15\end{array}$ & $\begin{array}{l}22 \\
20 \\
16 \\
14 \\
13\end{array}$ & $\begin{array}{l}270 \\
270 \\
270 \\
250 \\
256\end{array}$ & $\begin{array}{l}19 \\
20 \\
20 \\
20 \\
21\end{array}$ & $\begin{array}{l}14 \\
15 \\
15 \\
24 \\
15\end{array}$ \\
\hline $\begin{array}{l}11 \ldots \\
12 \ldots \\
13 \ldots \\
14 \ldots \\
15 \ldots\end{array}$ & $\begin{array}{l}190 \\
190 \\
190 \\
190 \\
180\end{array}$ & $\begin{array}{r}11 \\
10 \\
9 \\
8 \\
9\end{array}$ & $\begin{array}{l}5.6 \\
5.1 \\
4.6 \\
4.1 \\
4.4\end{array}$ & $\begin{array}{l}300 \\
300 \\
300 \\
292 \\
300\end{array}$ & $\begin{array}{l}15 \\
15 \\
15 \\
15 \\
15\end{array}$ & $\begin{array}{l}12 \\
12 \\
12 \\
12 \\
12\end{array}$ & $\begin{array}{r}420 \\
739 \\
945 \\
1200 \\
1400\end{array}$ & $\begin{array}{r}32 \\
85 \\
89 \\
174 \\
89\end{array}$ & $\begin{array}{r}36 \\
170 \\
227 \\
564 \\
334\end{array}$ \\
\hline $\begin{array}{l}16 \ldots \\
17 \ldots \\
18 \ldots \\
19 \ldots \\
20 \ldots\end{array}$ & $\begin{array}{l}180 \\
170 \\
160 \\
150 \\
140\end{array}$ & $\begin{array}{l}11 \\
13 \\
15 \\
15 \\
15\end{array}$ & $\begin{array}{l}5.3 \\
6.0 \\
6.5 \\
6.1 \\
5.7\end{array}$ & $\begin{array}{l}350 \\
400 \\
400 \\
400 \\
400\end{array}$ & $\begin{array}{l}15 \\
20 \\
43 \\
39 \\
20\end{array}$ & $\begin{array}{l}14 \\
22 \\
46 \\
42 \\
22\end{array}$ & $\begin{array}{r}1280 \\
1080 \\
950 \\
852 \\
752\end{array}$ & $\begin{array}{l}48 \\
31 \\
22 \\
14 \\
11\end{array}$ & $\begin{array}{r}168 \\
91 \\
58 \\
32 \\
22\end{array}$ \\
\hline $\begin{array}{l}21 \ldots \\
22 \ldots \\
23 \ldots \\
24 \ldots \\
25 \ldots\end{array}$ & $\begin{array}{l}140 \\
140 \\
150 \\
346 \\
479\end{array}$ & $\begin{array}{l}15 \\
15 \\
22 \\
17 \\
44\end{array}$ & $\begin{array}{l}5.7 \\
5.7 \\
8.9 \\
16 \\
57\end{array}$ & $\begin{array}{l}400 \\
400 \\
370 \\
350 \\
300\end{array}$ & $\begin{array}{l}14 \\
13 \\
12 \\
11 \\
10\end{array}$ & $\begin{array}{l}15 \\
14 \\
12 \\
10 \\
8.1\end{array}$ & $\begin{array}{r}670 \\
698 \\
915 \\
1240 \\
1660\end{array}$ & $\begin{array}{l}11 \\
18 \\
37 \\
55 \\
78\end{array}$ & $\begin{array}{r}29 \\
39 \\
91 \\
18 \\
359\end{array}$ \\
\hline $\begin{array}{l}26 \ldots 0 \\
27 \ldots \\
28 \ldots \\
29 \ldots \\
30 \ldots \\
31 \ldots \\
\end{array}$ & $\begin{array}{l}412 \\
170 \\
219 \\
308 \\
392 \\
416\end{array}$ & $\begin{array}{l}28 \\
16 \\
15 \\
15 \\
15 \\
15 \\
\end{array}$ & $\begin{array}{l}31 \\
7.3 \\
8.9 \\
12 \\
16 \\
17\end{array}$ & $\begin{array}{l}280 \\
270 \\
260 \\
= \\
=\end{array}$ & $\begin{array}{r}9 \\
12 \\
= \\
=\end{array}$ & $\begin{array}{l}6.8 \\
7.3 \\
8.4 \\
= \\
=\end{array}$ & $\begin{array}{l}1940 \\
1770 \\
1450 \\
1280 \\
1180 \\
1020\end{array}$ & $\begin{array}{r}106 \\
52 \\
30 \\
28 \\
25 \\
22 \\
\end{array}$ & $\begin{array}{r}555 \\
249 \\
117 \\
97 \\
83 \\
61\end{array}$ \\
\hline \multirow[t]{2}{*}{ Total } & 6562 & - & 306.4 & 10346 & - & 460.6 & 25997 & - & 3664.5 \\
\hline & \multicolumn{3}{|c|}{ APRIL } & \multicolumn{3}{|c|}{ MAY } & \multicolumn{3}{|c|}{ JUNE } \\
\hline $\begin{array}{l}1 \ldots \\
2 \ldots \\
3 \ldots \\
5 \ldots\end{array}$ & $\begin{array}{r}910 \\
1060 \\
1830 \\
1680 \\
1350\end{array}$ & $\begin{array}{r}20 \\
61 \\
300 \\
207 \\
102\end{array}$ & $\begin{array}{r}49 \\
197 \\
1460 \\
939 \\
372\end{array}$ & $\begin{array}{l}549 \\
521 \\
482 \\
454 \\
409\end{array}$ & $\begin{array}{l}18 \\
18 \\
17 \\
15 \\
15\end{array}$ & $\begin{array}{l}27 \\
25 \\
22 \\
18 \\
17\end{array}$ & $\begin{array}{l}134 \\
106 \\
118 \\
111 \\
102\end{array}$ & $\begin{array}{l}13 \\
14 \\
15 \\
15 \\
15\end{array}$ & $\begin{array}{l}4.7 \\
4.0 \\
4.8 \\
4.5 \\
4.1\end{array}$ \\
\hline $\begin{array}{r}6 \ldots \\
7 \ldots \\
8 \ldots \\
20 \ldots\end{array}$ & $\begin{array}{r}1560 \\
1370 \\
1140 \\
1060 \\
985\end{array}$ & $\begin{array}{l}95 \\
45 \\
33 \\
30 \\
27\end{array}$ & $\begin{array}{r}400 \\
166 \\
102 \\
86 \\
72\end{array}$ & $\begin{array}{l}343 \\
349 \\
339 \\
314 \\
286\end{array}$ & $\begin{array}{l}15 \\
15 \\
15 \\
15 \\
15\end{array}$ & $\begin{array}{l}14 \\
14 \\
13 \\
13 \\
12\end{array}$ & $\begin{array}{r}95 \\
99 \\
131 \\
111 \\
126\end{array}$ & $\begin{array}{l}15 \\
15 \\
23 \\
15 \\
15\end{array}$ & $\begin{array}{l}3.8 \\
4.0 \\
9.8 \\
4.5 \\
5.1\end{array}$ \\
\hline $\begin{array}{l}11 \ldots \\
12 \ldots \\
23 \ldots \\
14 \ldots \\
15 \ldots\end{array}$ & $\begin{array}{l}852 \\
775 \\
670 \\
614 \\
642\end{array}$ & $\begin{array}{l}25 \\
23 \\
21 \\
20 \\
20\end{array}$ & $\begin{array}{l}58 \\
48 \\
38 \\
33 \\
35\end{array}$ & $\begin{array}{l}320 \\
343 \\
324 \\
311 \\
298\end{array}$ & $\begin{array}{l}36 \\
21 \\
36 \\
35 \\
33\end{array}$ & $\begin{array}{l}31 \\
19 \\
31 \\
29 \\
27\end{array}$ & $\begin{array}{l}160 \\
134 \\
152 \\
147 \\
160\end{array}$ & $\begin{array}{l}22 \\
15 \\
22 \\
15 \\
15\end{array}$ & $\begin{array}{l}9.5 \\
5.4 \\
9.0 \\
6.0 \\
6.5\end{array}$ \\
\hline $\begin{array}{l}16 \ldots \\
17 \ldots \\
18 \ldots \\
19 \ldots \\
20 \ldots\end{array}$ & $\begin{array}{r}610 \\
2170 \\
2010 \\
1530 \\
1210\end{array}$ & $\begin{array}{r}18 \\
520 \\
330 \\
179 \\
101\end{array}$ & $\begin{array}{r}30 \\
3460 \\
1790 \\
739 \\
330\end{array}$ & $\begin{array}{l}262 \\
262 \\
239 \\
208 \\
189\end{array}$ & $\begin{array}{l}31 \\
30 \\
29 \\
28 \\
28\end{array}$ & $\begin{array}{l}22 \\
21 \\
19 \\
16 \\
14\end{array}$ & $\begin{array}{r}165 \\
173 \\
157 \\
147 \\
97\end{array}$ & $\begin{array}{l}19 \\
15 \\
15 \\
15 \\
15\end{array}$ & $\begin{array}{l}8.5 \\
7.0 \\
6.4 \\
6.0 \\
3.9\end{array}$ \\
\hline $\begin{array}{l}21 \ldots \\
22 \ldots \\
23 \ldots \\
24 \ldots \\
25 \ldots\end{array}$ & $\begin{array}{r}1190 \\
1340 \\
1100 \\
950 \\
829\end{array}$ & $\begin{array}{r}87 \\
119 \\
58 \\
37 \\
33\end{array}$ & $\begin{array}{r}280 \\
431 \\
172 \\
95 \\
74\end{array}$ & $\begin{array}{l}173 \\
176 \\
173 \\
170 \\
173\end{array}$ & $\begin{array}{l}27 \\
26 \\
24 \\
22 \\
20\end{array}$ & $\begin{array}{l}13 \\
12 \\
11 \\
10 \\
9.3\end{array}$ & $\begin{array}{l}157 \\
217 \\
206 \\
283 \\
586\end{array}$ & $\begin{array}{r}23 \\
17 \\
17 \\
46 \\
134\end{array}$ & $\begin{array}{r}9.7 \\
10 \\
9.5 \\
43 \\
212\end{array}$ \\
\hline $\begin{array}{l}26 \ldots \\
27 \ldots \\
28 \ldots \\
29 \ldots \\
30 \ldots \\
31 \ldots\end{array}$ & $\begin{array}{l}739 \\
690 \\
638 \\
590 \\
563 \\
-\end{array}$ & $\begin{array}{l}28 \\
24 \\
23 \\
21 \\
20 \\
-\end{array}$ & $\begin{array}{l}56 \\
45 \\
40 \\
33 \\
30 \\
-\end{array}$ & $\begin{array}{l}176 \\
170 \\
176 \\
165 \\
154 \\
147\end{array}$ & $\begin{array}{l}18 \\
16 \\
15 \\
13 \\
12 \\
12\end{array}$ & $\begin{array}{l}8.6 \\
7.3 \\
7.1 \\
5.8 \\
5.0 \\
4.8\end{array}$ & $\begin{array}{l}444 \\
451 \\
440 \\
423 \\
398 \\
\end{array}$ & $\begin{array}{l}75 \\
52 \\
33 \\
20 \\
17 \\
-\end{array}$ & $\begin{array}{l}90 \\
63 \\
39 \\
23 \\
18\end{array}$ \\
\hline Total & 32657 & - & 11680 & Buses & - & 497.9 & 6230 & - & 634.7 \\
\hline
\end{tabular}


STREAMS TRIBUTARY TO LAKE HURON--COntinued

4-1445. SHIAWASSEE RIVER AT OWOSSO, MICH.--Continued

Suspended sediment, water year October 1966 to September 1967--Continued

\begin{tabular}{|c|c|c|c|c|c|c|c|c|c|}
\hline \multirow[b]{3}{*}{ Day } & \multicolumn{3}{|c|}{ JULY } & \multicolumn{3}{|c|}{ AUGUST } & \multicolumn{3}{|c|}{ SEPTEMBER } \\
\hline & \multirow[b]{2}{*}{$\begin{array}{l}\text { Mean } \\
\text { dis- } \\
\text { charge } \\
\text { (cfs) }\end{array}$} & \multicolumn{2}{|c|}{ Suspended sediment } & \multirow[b]{2}{*}{$\begin{array}{c}\text { Mean } \\
\text { dis- } \\
\text { charge } \\
\text { (cfs) }\end{array}$} & \multicolumn{2}{|c|}{ Suspended sediment } & \multirow[b]{2}{*}{$\begin{array}{c}\text { Mean } \\
\text { dis- } \\
\text { charge } \\
\text { (cfs) }\end{array}$} & \multicolumn{2}{|c|}{ Suspended sediment } \\
\hline & & $\begin{array}{l}\text { Mean } \\
\text { concen- } \\
\text { tration } \\
\text { (ppm) }\end{array}$ & $\begin{array}{l}\text { Tons } \\
\text { per } \\
\text { day }\end{array}$ & & $\begin{array}{c}\text { Mean } \\
\text { concen- } \\
\text { tration } \\
\text { (ppm) }\end{array}$ & $\begin{array}{l}\text { Tons } \\
\text { per } \\
\text { day }\end{array}$ & & $\begin{array}{l}\text { Mean } \\
\text { concen- } \\
\text { tration } \\
\text { (ppm) }\end{array}$ & $\begin{array}{l}\text { Tons } \\
\text { per } \\
\text { day }\end{array}$ \\
\hline $\begin{array}{l}1 \ldots \\
2 \ldots \\
3 \ldots \\
4 \ldots \\
5 \ldots\end{array}$ & $\begin{array}{l}385 \\
375 \\
356 \\
295 \\
256\end{array}$ & $\begin{array}{l}15 \\
15 \\
15 \\
15 \\
15\end{array}$ & $\begin{array}{l}16 \\
15 \\
14 \\
12 \\
10\end{array}$ & $\begin{array}{r}124 \\
111 \\
106 \\
97 \\
74\end{array}$ & $\begin{array}{l}15 \\
15 \\
15 \\
21 \\
18\end{array}$ & $\begin{array}{l}5.0 \\
4.5 \\
4.3 \\
5.5 \\
3.6\end{array}$ & $\begin{array}{l}76 \\
78 \\
80 \\
72 \\
72\end{array}$ & $\begin{array}{l}15 \\
15 \\
15 \\
15 \\
14\end{array}$ & $\begin{array}{l}3.1 \\
3.2 \\
3.2 \\
2.9 \\
2.7\end{array}$ \\
\hline $\begin{array}{r}6 \ldots \\
7 \ldots \\
9 \ldots \\
10 \ldots\end{array}$ & $\begin{array}{l}222 \\
206 \\
192 \\
184 \\
173\end{array}$ & $\begin{array}{l}15 \\
15 \\
15 \\
15 \\
19\end{array}$ & $\begin{array}{l}9.0 \\
8.3 \\
7.8 \\
7.5 \\
0.9\end{array}$ & $\begin{array}{l}74 \\
76 \\
76 \\
84 \\
64\end{array}$ & $\begin{array}{l}18 \\
17 \\
17 \\
31 \\
19\end{array}$ & $\begin{array}{l}3.6 \\
3.5 \\
3.5 \\
7.6 \\
3.3\end{array}$ & $\begin{array}{l}72 \\
68 \\
62 \\
64 \\
18\end{array}$ & $\begin{array}{l}13 \\
11 \\
10 \\
9 \\
7\end{array}$ & $\begin{array}{l}2.5 \\
2.0 \\
1.7 \\
1.6 \\
1.5\end{array}$ \\
\hline $\begin{array}{l}11 \ldots \\
12 \ldots \\
130 \\
14 \ldots \\
150\end{array}$ & $\begin{array}{r}173 \\
168 \\
168 \\
152 \\
99\end{array}$ & $\begin{array}{l}20 \\
15 \\
15 \\
15 \\
15\end{array}$ & $\begin{array}{l}9.3 \\
6.8 \\
6.8 \\
6.2 \\
4.0\end{array}$ & $\begin{array}{l}64 \\
64 \\
70 \\
62 \\
43\end{array}$ & $\begin{array}{l}17 \\
15 \\
15 \\
34 \\
20\end{array}$ & $\begin{array}{l}2.9 \\
2.6 \\
2.8 \\
5.7 \\
2.3\end{array}$ & $\begin{array}{r}80 \\
76 \\
131 \\
72 \\
66\end{array}$ & $\begin{array}{r}6 \\
5 \\
66 \\
36 \\
25\end{array}$ & $\begin{array}{l}1.3 \\
1.0 \\
37 \\
7.0 \\
4.5\end{array}$ \\
\hline $\begin{array}{l}16 \ldots \\
17 \ldots \\
18 \ldots \\
19 . \ldots \\
20 \ldots\end{array}$ & $\begin{array}{l}128 \\
126 \\
124 \\
121 \\
121\end{array}$ & $\begin{array}{l}15 \\
15 \\
15 \\
15 \\
15\end{array}$ & $\begin{array}{l}5.2 \\
5.1 \\
5.0 \\
4.9 \\
4.9\end{array}$ & $\begin{array}{l}49 \\
49 \\
52 \\
93 \\
91\end{array}$ & $\begin{array}{l}20 \\
20 \\
24 \\
45 \\
26\end{array}$ & $\begin{array}{r}2.6 \\
2.6 \\
3.4 \\
11 \\
6.4\end{array}$ & $\begin{array}{l}47 \\
56 \\
20 \\
59 \\
59\end{array}$ & $\begin{array}{l}23 \\
23 \\
23 \\
20 \\
19\end{array}$ & $\begin{array}{l}2.9 \\
3.5 \\
1.2 \\
3.2 \\
3.0\end{array}$ \\
\hline $\begin{array}{l}21 \ldots \\
22 \ldots \\
230 \\
240 \\
25 \ldots\end{array}$ & $\begin{array}{l}138 \\
139 \\
134 \\
134 \\
131\end{array}$ & $\begin{array}{l}15 \\
15 \\
15 \\
15 \\
15\end{array}$ & $\begin{array}{l}4.8 \\
5.6 \\
5.4 \\
5.4 \\
5.3\end{array}$ & $\begin{array}{l}80 \\
68 \\
64 \\
62 \\
62\end{array}$ & $\begin{array}{l}22 \\
20 \\
18 \\
17 \\
15\end{array}$ & $\begin{array}{l}4.8 \\
3.7 \\
3.1 \\
2.8 \\
2.5\end{array}$ & $\begin{array}{l}72 \\
68 \\
61 \\
64 \\
64\end{array}$ & $\begin{array}{l}17 \\
15 \\
14 \\
11 \\
8\end{array}$ & $\begin{array}{l}3.3 \\
2.0 \\
2.3 \\
1.9 \\
1.4\end{array}$ \\
\hline $\begin{array}{l}26 \ldots \\
27 \ldots \\
28 \ldots \\
29 \ldots \\
30 \ldots \\
32 \ldots\end{array}$ & $\begin{array}{l}134 \\
139 \\
131 \\
128 \\
144 \\
147\end{array}$ & $\begin{array}{l}15 \\
15 \\
15 \\
15 \\
23 \\
15\end{array}$ & $\begin{array}{l}5.4 \\
5.6 \\
5.3 \\
5.2 \\
8.9 \\
6.0\end{array}$ & $\begin{array}{r}80 \\
88 \\
102 \\
97 \\
84 \\
80 \\
\end{array}$ & $\begin{array}{l}26 \\
20 \\
17 \\
15 \\
15 \\
15\end{array}$ & $\begin{array}{l}3.6 \\
4.8 \\
4.7 \\
3.9 \\
3.4 \\
3.2\end{array}$ & $\begin{array}{l}62 \\
76 \\
59 \\
61 \\
78 \\
\end{array}$ & $\begin{array}{r}7 \\
7 \\
6 \\
6 \\
5 \\
\end{array}$ & $\begin{array}{l}1.2 \\
1.4 \\
100 \\
3 \circ 0 \\
1.1 \\
-\end{array}$ \\
\hline Total & 5503 & - & 229.6 & 2390 & - & 329.2 & 2053 & - & $106 \cdot 4$ \\
\hline
\end{tabular}


STREAMS TRIBUTARY TO LAKE HUDON--COntInUed

4-1515. CASS RIVER AT FRANKBNUTH, MICH.

LOCATION.--Lat $43^{\circ} 19^{\prime} 50^{\prime \prime}$, long $83^{\circ} 45^{\prime} 25^{\prime \prime}$, at bridge on Debmel Road, 1.1 miles downstream from da in Frankenmuth, Saginaw County, $0.7 \mathrm{mtle}$ downstream from gaging station, and 2.7 miles upstream from Dead Creek.

DRAINAGE AREA. --848 square miles.

RECORDS AVAI LABLE. - -Sediment records: May 1966 to September 1967.

EXTREMES, 1966-67.--Sediment concentrations: Maximum daliy, 535 ppm Mar 28; minimum daily, 4 ppm on many days during December to March.

Sediment loads: Maximum daily, 13,800 tons Mar. 28; minimua daily, leas than 0.50 ton on several days during October.

EXTREMES, May 1966 to September 1967.--Sediment concentrations: Maximum daily, 535 ppm Mar. 28, 1967; minimum daily, 4 ppm on many days during December 1966 to Ma rch 1967

Sediment loads: Maximum daily, 13,800 tons Mar. 28, 1967; minimuin daily, lese than 0.50 ton on several days during October 1966 .

REMARKS. - F low affected by 1ce Dec. 4, 5, 14, 15, Dec. 18 to Mar. 26, Daily loads were computed by subdivision on Dec. 8 , Jan. 24,25, Apr. 17, 22, June 17, and July 12. Occasional regulation by dams above station.

\begin{tabular}{|c|c|c|c|c|c|c|c|c|c|}
\hline \multirow[b]{3}{*}{ Day } & \multicolumn{3}{|c|}{ OCTOBER } & \multicolumn{3}{|c|}{ NOVEMBER } & \multicolumn{3}{|c|}{ DECEMBER } \\
\hline & \multirow[b]{2}{*}{$\begin{array}{c}\text { Mean } \\
\text { dis- } \\
\text { charge } \\
\text { (cfs) }\end{array}$} & \multicolumn{2}{|c|}{ Suspended sediment } & \multirow[b]{2}{*}{$\begin{array}{l}\text { Mean } \\
\text { dis- } \\
\text { charge } \\
\text { (cfs) }\end{array}$} & \multicolumn{2}{|c|}{ Suspended sediment } & \multirow[b]{2}{*}{$\begin{array}{c}\text { Mean } \\
\text { dis- } \\
\text { charge } \\
\text { (cfs) }\end{array}$} & \multicolumn{2}{|c|}{ Suspended sedinsent } \\
\hline & & $\begin{array}{c}\text { Mean } \\
\text { concen- } \\
\text { tration } \\
(\mathrm{ppm})\end{array}$ & $\begin{array}{c}\text { Tons } \\
\text { per } \\
\text { day }\end{array}$ & & $\begin{array}{c}\text { Mean } \\
\text { concen- } \\
\text { tration } \\
(\mathrm{ppm})\end{array}$ & $\begin{array}{c}\text { Tons } \\
\text { per } \\
\text { day }\end{array}$ & & $\begin{array}{c}\text { Mean } \\
\text { concen- } \\
\text { tration } \\
(\mathrm{ppm})\end{array}$ & $\begin{array}{c}\text { Tors } \\
\text { per } \\
\text { day }\end{array}$ \\
\hline $\begin{array}{l}1 \ldots \\
2 \ldots \\
3 \ldots \\
4 \ldots\end{array}$ & $\begin{array}{l}35 \\
34 \\
33 \\
31 \\
32\end{array}$ & $\begin{array}{l}5 \\
5 \\
5 \\
5 \\
5\end{array}$ & $\begin{array}{l}T \\
T \\
T \\
T \\
T\end{array}$ & $\begin{array}{l}37 \\
39 \\
50 \\
53 \\
53\end{array}$ & $\begin{array}{r}8 \\
8 \\
9 \\
10 \\
11\end{array}$ & $\begin{array}{l}1 \\
1 \\
1 \\
1 \\
2\end{array}$ & $\begin{array}{l}160 \\
114 \\
107 \\
105 \\
115\end{array}$ & $\begin{array}{l}8 \\
8 \\
8 \\
8 \\
8\end{array}$ & $\begin{array}{l}3 \\
2 \\
2 \\
2 \\
2\end{array}$ \\
\hline $\begin{array}{r}6 \ldots \\
7 \ldots \\
8 \ldots \\
10 \ldots\end{array}$ & $\begin{array}{l}32 \\
31 \\
31 \\
30 \\
30\end{array}$ & $\begin{array}{l}5 \\
5 \\
5 \\
5 \\
5\end{array}$ & $\begin{array}{l}T \\
T \\
T \\
T \\
T\end{array}$ & $\begin{array}{r}56 \\
69 \\
91 \\
114 \\
157\end{array}$ & $\begin{array}{l}12 \\
12 \\
12 \\
14 \\
23\end{array}$ & $\begin{array}{r}2 \\
2 \\
3 \\
4 \\
10\end{array}$ & $\begin{array}{l}141 \\
336 \\
1000 \\
2090 \\
1850\end{array}$ & $\begin{array}{r}8 \\
8 \\
32 \\
106 \\
68\end{array}$ & $\begin{array}{r}3 \\
7 \\
99 \\
598 \\
340\end{array}$ \\
\hline $\begin{array}{l}11 \ldots \\
12 \ldots \\
13 \ldots \\
14 \ldots \\
15 \ldots\end{array}$ & $\begin{array}{l}28 \\
28 \\
29 \\
30 \\
34\end{array}$ & $\begin{array}{l}5 \\
5 \\
5 \\
5 \\
5\end{array}$ & $\begin{array}{l}T \\
T \\
T \\
T \\
T\end{array}$ & $\begin{array}{l}169 \\
153 \\
147 \\
130 \\
117\end{array}$ & $\begin{array}{r}22 \\
17 \\
14 \\
10 \\
8\end{array}$ & $\begin{array}{r}10 \\
7 \\
6 \\
4 \\
3\end{array}$ & $\begin{array}{r}1360 \\
992 \\
640 \\
500 \\
450\end{array}$ & $\begin{array}{r}34 \\
18 \\
13 \\
8 \\
4\end{array}$ & $\begin{array}{r}125 \\
48 \\
22 \\
11 \\
5\end{array}$ \\
\hline $\begin{array}{l}16 \ldots \\
17 \ldots \\
18 \ldots \\
19 . . \\
20 \ldots\end{array}$ & $\begin{array}{l}38 \\
31 \\
31 \\
34 \\
34\end{array}$ & $\begin{array}{r}8 \\
13 \\
15 \\
13 \\
12\end{array}$ & $\begin{array}{l}1 \\
1 \\
1 \\
1 \\
1\end{array}$ & $\begin{array}{r}105 \\
98 \\
91 \\
84 \\
77\end{array}$ & $\begin{array}{l}7 \\
7 \\
7 \\
7 \\
7\end{array}$ & $\begin{array}{l}2 \\
2 \\
2 \\
2 \\
1\end{array}$ & $\begin{array}{l}405 \\
374 \\
340 \\
310 \\
300\end{array}$ & $\begin{array}{l}4 \\
4 \\
4 \\
4 \\
4\end{array}$ & $\begin{array}{l}4 \\
4 \\
4 \\
3 \\
3\end{array}$ \\
\hline $\begin{array}{l}21 \ldots \\
22 \ldots \\
23 \ldots \\
24 \ldots \\
25 \ldots\end{array}$ & $\begin{array}{l}33 \\
31 \\
34 \\
34 \\
38\end{array}$ & $\begin{array}{r}12 \\
11 \\
10 \\
10 \\
9\end{array}$ & $\begin{array}{l}1 \\
1 \\
1 \\
1 \\
1\end{array}$ & $\begin{array}{l}71 \\
70 \\
68 \\
72 \\
90\end{array}$ & $\begin{array}{l}7 \\
7 \\
8 \\
9 \\
9\end{array}$ & $\begin{array}{l}1 \\
1 \\
1 \\
2 \\
2\end{array}$ & $\begin{array}{l}280 \\
250 \\
230 \\
215 \\
210\end{array}$ & $\begin{array}{l}4 \\
4 \\
4 \\
4 \\
4\end{array}$ & $\begin{array}{l}3 \\
3 \\
2 \\
2 \\
2\end{array}$ \\
\hline $\begin{array}{l}26 \ldots \\
27 \ldots \\
28 \ldots \\
29 \ldots \\
30 \ldots \\
31 \ldots\end{array}$ & $\begin{array}{l}41 \\
39 \\
38 \\
39 \\
38 \\
36\end{array}$ & $\begin{array}{l}8 \\
7 \\
7 \\
7 \\
7 \\
7\end{array}$ & $\begin{array}{l}1 \\
1 \\
1 \\
1 \\
1 \\
1\end{array}$ & $\begin{array}{r}106 \\
109 \\
121 \\
144 \\
163 \\
-\end{array}$ & $\begin{array}{r}11 \\
15 \\
17 \\
10 \\
7 \\
-2\end{array}$ & $\begin{array}{r}3 \\
4 \\
6 \\
4 \\
3 \\
--\end{array}$ & $\begin{array}{l}200 \\
190 \\
180 \\
180 \\
170 \\
170\end{array}$ & $\begin{array}{l}4 \\
4 \\
4 \\
4 \\
4 \\
4\end{array}$ & $\begin{array}{l}2 \\
2 \\
2 \\
2 \\
2 \\
2\end{array}$ \\
\hline Total & 1037 & $-\infty$ & 22 & 2904 & - & 93 & 23964 & -- & 1311 \\
\hline
\end{tabular}

$T$ Less than 0.50 ton. 
STREAMS TRIBUTARY TO LAKE HURON--COnt Inued

4-1515. CASS RIVER AT FRANKENMUTH, MICH.--Continued

Suspended sediment, water year October 1966 to September 1967--Continued

\begin{tabular}{|c|c|c|c|c|c|c|c|c|c|}
\hline \multirow[b]{3}{*}{ Day } & \multicolumn{3}{|c|}{ JANUARY } & \multicolumn{3}{|c|}{ FEBRUARY } & \multicolumn{3}{|c|}{ MARCH } \\
\hline & \multirow[b]{2}{*}{$\begin{array}{c}\text { Mean } \\
\text { dis- } \\
\text { charge } \\
(\text { cfs) }\end{array}$} & \multicolumn{2}{|c|}{ Suspended sediment } & \multirow[b]{2}{*}{$\begin{array}{c}\text { Mean } \\
\text { dis- } \\
\text { charge } \\
\text { (cfs) }\end{array}$} & \multicolumn{2}{|c|}{ Suspended sediment } & \multirow[b]{2}{*}{$\begin{array}{c}\text { Mean } \\
\text { dis- } \\
\text { charge } \\
(\mathrm{cfs})\end{array}$} & \multicolumn{2}{|c|}{ Suspended sediment } \\
\hline & & $\begin{array}{c}\text { Mean } \\
\text { concen- } \\
\text { tration } \\
\text { (ppm) }\end{array}$ & $\begin{array}{l}\text { Tons } \\
\text { per } \\
\text { day }\end{array}$ & & $\begin{array}{c}\text { Mean } \\
\text { concen- } \\
\text { tration } \\
\text { (ppm) }\end{array}$ & $\begin{array}{l}\text { Tons } \\
\text { per } \\
\text { day }\end{array}$ & & $\begin{array}{c}\text { Mean } \\
\text { concen- } \\
\text { tration } \\
(\text { ppm) }\end{array}$ & $\begin{array}{l}\text { Tons } \\
\text { per } \\
\text { day }\end{array}$ \\
\hline $\begin{array}{l}1 \ldots \\
2 \ldots \\
3 \ldots \\
4 \ldots \\
5 \ldots\end{array}$ & $\begin{array}{l}165 \\
160 \\
155 \\
150 \\
150\end{array}$ & $\begin{array}{l}4 \\
4 \\
4 \\
4 \\
4\end{array}$ & $\begin{array}{l}2 \\
2 \\
2 \\
2 \\
2\end{array}$ & $\begin{array}{l}370 \\
360 \\
350 \\
350 \\
340\end{array}$ & $\begin{array}{l}4 \\
4 \\
4 \\
4 \\
4\end{array}$ & $\begin{array}{l}4 \\
4 \\
4 \\
4 \\
4\end{array}$ & $\begin{array}{l}285 \\
285 \\
280 \\
280 \\
275\end{array}$ & $\begin{array}{l}4 \\
4 \\
4 \\
4 \\
4\end{array}$ & $\begin{array}{l}3 \\
3 \\
3 \\
3 \\
3\end{array}$ \\
\hline $\begin{array}{r}6 \ldots \\
7 \ldots \\
8 \ldots \\
10 \ldots\end{array}$ & $\begin{array}{l}145 \\
140 \\
135 \\
135 \\
130\end{array}$ & $\begin{array}{l}4 \\
4 \\
4 \\
4 \\
4\end{array}$ & $\begin{array}{l}2 \\
2 \\
1 \\
1 \\
1\end{array}$ & $\begin{array}{l}340 \\
330 \\
330 \\
325 \\
320\end{array}$ & $\begin{array}{l}4 \\
4 \\
4 \\
4 \\
4\end{array}$ & $\begin{array}{l}4 \\
4 \\
4 \\
4 \\
3\end{array}$ & $\begin{array}{l}275 \\
270 \\
270 \\
270 \\
275\end{array}$ & $\begin{array}{l}4 \\
4 \\
4 \\
4 \\
5\end{array}$ & $\begin{array}{l}3 \\
3 \\
3 \\
3 \\
4\end{array}$ \\
\hline $\begin{array}{l}11 \ldots \\
12 \ldots \\
13 \ldots \\
14 \ldots \\
15 \ldots\end{array}$ & $\begin{array}{l}125 \\
125 \\
120 \\
115 \\
115\end{array}$ & $\begin{array}{l}4 \\
4 \\
4 \\
4 \\
4\end{array}$ & $\begin{array}{l}1 \\
1 \\
1 \\
1 \\
1\end{array}$ & $\begin{array}{l}320 \\
320 \\
320 \\
320 \\
330\end{array}$ & $\begin{array}{l}4 \\
4 \\
4 \\
4 \\
4\end{array}$ & $\begin{array}{l}3 \\
3 \\
3 \\
3 \\
4\end{array}$ & $\begin{array}{l}380 \\
500 \\
700 \\
850 \\
970\end{array}$ & $\begin{array}{r}7 \\
11 \\
13 \\
14 \\
14\end{array}$ & $\begin{array}{r}7 \\
15 \\
25 \\
32 \\
37\end{array}$ \\
\hline $\begin{array}{l}16 \ldots \\
17 \ldots \\
18 \ldots \\
19 \ldots \\
20 \ldots\end{array}$ & $\begin{array}{l}115 \\
115 \\
115 \\
115 \\
120\end{array}$ & $\begin{array}{l}4 \\
4 \\
4 \\
4 \\
4\end{array}$ & $\begin{array}{l}1 \\
1 \\
1 \\
1 \\
1\end{array}$ & $\begin{array}{l}330 \\
330 \\
325 \\
325 \\
320\end{array}$ & $\begin{array}{l}4 \\
4 \\
4 \\
4 \\
4\end{array}$ & $\begin{array}{l}4 \\
4 \\
4 \\
4 \\
3\end{array}$ & $\begin{array}{l}1050 \\
1050 \\
1000 \\
950 \\
900\end{array}$ & $\begin{array}{r}10 \\
5 \\
4 \\
4 \\
4\end{array}$ & $\begin{array}{l}28 \\
14 \\
11 \\
10 \\
10\end{array}$ \\
\hline $\begin{array}{l}21 \ldots \\
22 \ldots \\
23 \ldots \\
24 \ldots \\
25 \ldots\end{array}$ & $\begin{array}{r}125 \\
135 \\
150 \\
300 \\
2100\end{array}$ & $\begin{array}{r}5 \\
5 \\
7 \\
12 \\
75\end{array}$ & $\begin{array}{r}2 \\
2 \\
2 \\
11 \\
237\end{array}$ & $\begin{array}{l}315 \\
310 \\
305 \\
300 \\
300\end{array}$ & $\begin{array}{l}4 \\
4 \\
4 \\
4 \\
4\end{array}$ & $\begin{array}{l}3 \\
3 \\
3 \\
3 \\
3\end{array}$ & $\begin{array}{r}800 \\
800 \\
900 \\
1050 \\
1600\end{array}$ & $\begin{array}{r}4 \\
5 \\
12 \\
32 \\
87\end{array}$ & $\begin{array}{r}9 \\
11 \\
29 \\
91 \\
376\end{array}$ \\
\hline $\begin{array}{l}26 \ldots \\
27 \ldots \\
28 \ldots \\
29 \ldots \\
30 \ldots \\
31 \ldots\end{array}$ & $\begin{array}{r}1500 \\
1100 \\
800 \\
550 \\
450 \\
400\end{array}$ & $\begin{array}{r}68 \\
34 \\
18 \\
13 \\
8 \\
4\end{array}$ & $\begin{array}{r}275 \\
101 \\
39 \\
19 \\
10 \\
4\end{array}$ & $\begin{array}{r}300 \\
290 \\
290 \\
= \\
=\end{array}$ & $\begin{array}{r}4 \\
4 \\
4 \\
-- \\
--\end{array}$ & $\begin{array}{r}3 \\
3 \\
3 \\
-- \\
-- \\
--\end{array}$ & $\begin{array}{r}3000 \\
5680 \\
9540 \\
10500 \\
7910 \\
5660\end{array}$ & $\begin{array}{r}182 \\
350 \\
535 \\
300 \\
140 \\
65\end{array}$ & $\begin{array}{r}1470 \\
5370 \\
13800 \\
8500 \\
2990 \\
993\end{array}$ \\
\hline \multirow[t]{2}{*}{ Total } & 9255 & -- & 729 & 9065 & -- & 98 & 58555 & -- & 33859 \\
\hline & \multicolumn{3}{|c|}{ APRIL } & \multicolumn{3}{|c|}{ MAY } & \multicolumn{3}{|c|}{ JUNE } \\
\hline $\begin{array}{l}1 \ldots \\
2 \ldots \\
3 \ldots \\
4 \ldots \\
5 \ldots\end{array}$ & $\begin{array}{l}3970 \\
3210 \\
3680 \\
4360 \\
2730\end{array}$ & $\begin{array}{l}40 \\
32 \\
60 \\
88 \\
74\end{array}$ & $\begin{array}{r}429 \\
277 \\
596 \\
1040 \\
545\end{array}$ & $\begin{array}{l}547 \\
518 \\
473 \\
429 \\
408\end{array}$ & $\begin{array}{l}17 \\
17 \\
16 \\
15 \\
15\end{array}$ & $\begin{array}{l}25 \\
24 \\
20 \\
17 \\
17\end{array}$ & $\begin{array}{l}135 \\
127 \\
124 \\
117 \\
113\end{array}$ & $\begin{array}{l}35 \\
34 \\
32 \\
30 \\
28\end{array}$ & $\begin{array}{r}13 \\
12 \\
11 \\
9 \\
9\end{array}$ \\
\hline $\begin{array}{r}6 \ldots \\
7 \ldots \\
8 \ldots \\
90 . .\end{array}$ & $\begin{array}{l}1990 \\
2770 \\
2680 \\
2140 \\
2000\end{array}$ & $\begin{array}{l}61 \\
58 \\
77 \\
47 \\
40\end{array}$ & $\begin{array}{l}328 \\
434 \\
557 \\
272 \\
216\end{array}$ & $\begin{array}{l}387 \\
363 \\
353 \\
403 \\
422\end{array}$ & $\begin{array}{l}14 \\
14 \\
13 \\
13 \\
13\end{array}$ & $\begin{array}{l}15 \\
14 \\
12 \\
14 \\
15\end{array}$ & $\begin{array}{l}120 \\
128 \\
258 \\
877 \\
695\end{array}$ & $\begin{array}{l}26 \\
24 \\
23 \\
22 \\
17\end{array}$ & $\begin{array}{r}8 \\
8 \\
16 \\
52 \\
32\end{array}$ \\
\hline $\begin{array}{l}11 \ldots \\
12 \ldots \\
13 \ldots \\
14 \ldots \\
15 \ldots\end{array}$ & $\begin{array}{r}1710 \\
1280 \\
1050 \\
899 \\
865\end{array}$ & $\begin{array}{l}32 \\
27 \\
18 \\
14 \\
17\end{array}$ & $\begin{array}{r}148 \\
93 \\
51 \\
34 \\
40\end{array}$ & $\begin{array}{l}442 \\
646 \\
713 \\
587 \\
502\end{array}$ & $\begin{array}{l}12 \\
12 \\
13 \\
14 \\
14\end{array}$ & $\begin{array}{l}14 \\
21 \\
25 \\
22 \\
19\end{array}$ & $\begin{array}{l}511 \\
498 \\
435 \\
348 \\
276\end{array}$ & $\begin{array}{l}16 \\
23 \\
33 \\
20 \\
23\end{array}$ & $\begin{array}{l}22 \\
31 \\
39 \\
19 \\
17\end{array}$ \\
\hline $\begin{array}{l}16 \ldots \\
17 \ldots \\
18 \ldots \\
19 \ldots \\
20 \ldots\end{array}$ & $\begin{array}{r}823 \\
2000 \\
5580 \\
4750 \\
2530\end{array}$ & $\begin{array}{r}15 \\
142 \\
281 \\
162 \\
74\end{array}$ & $\begin{array}{r}33 \\
948 \\
4230 \\
2080 \\
505\end{array}$ & $\begin{array}{l}431 \\
374 \\
333 \\
304 \\
273\end{array}$ & $\begin{array}{l}12 \\
120 \\
12 \\
13 \\
18\end{array}$ & $\begin{array}{l}14 \\
10 \\
11 \\
11 \\
13\end{array}$ & $\begin{array}{r}223 \\
834 \\
2460 \\
3020 \\
1750\end{array}$ & $\begin{array}{r}21 \\
104 \\
193 \\
126 \\
70\end{array}$ & $\begin{array}{r}13 \\
282 \\
1280 \\
1030 \\
331\end{array}$ \\
\hline $\begin{array}{l}21 \ldots \\
22 \ldots \\
23 \ldots \\
24 \ldots \\
25 \ldots\end{array}$ & $\begin{array}{l}1660 \\
2650 \\
3630 \\
2350 \\
1630\end{array}$ & $\begin{array}{r}45 \\
142 \\
190 \\
94 \\
46\end{array}$ & $\begin{array}{r}202 \\
1020 \\
2860 \\
596 \\
202\end{array}$ & $\begin{array}{l}244 \\
251 \\
248 \\
237 \\
225\end{array}$ & $\begin{array}{l}27 \\
35 \\
38 \\
39 \\
40\end{array}$ & $\begin{array}{l}18 \\
24 \\
25 \\
25 \\
24\end{array}$ & $\begin{array}{l}1180 \\
1120 \\
1920 \\
1550 \\
1360\end{array}$ & $\begin{array}{l}40 \\
35 \\
78 \\
64 \\
56\end{array}$ & $\begin{array}{l}127 \\
106 \\
404 \\
268 \\
206\end{array}$ \\
\hline $\begin{array}{l}26 \ldots \\
27 \ldots \\
28 \ldots \\
29 \ldots \\
30 \ldots \\
31 \ldots\end{array}$ & $\begin{array}{r}1230 \\
965 \\
785 \\
658 \\
590 \\
--\end{array}$ & $\begin{array}{l}28 \\
23 \\
22 \\
23 \\
23 \\
--\end{array}$ & $\begin{array}{l}93 \\
60 \\
47 \\
41 \\
37 \\
--\end{array}$ & $\begin{array}{l}203 \\
185 \\
174 \\
168 \\
156 \\
145\end{array}$ & $\begin{array}{l}40 \\
39 \\
38 \\
37 \\
37 \\
36\end{array}$ & $\begin{array}{l}22 \\
19 \\
18 \\
17 \\
16 \\
14\end{array}$ & $\begin{array}{r}1740 \\
1480 \\
953 \\
992 \\
2410 \\
-2\end{array}$ & $\begin{array}{l}74 \\
66 \\
47 \\
42 \\
95 \\
--\end{array}$ & $\begin{array}{r}348 \\
264 \\
121 \\
112 \\
618 \\
--\end{array}$ \\
\hline Total & 67165 & -- & 17014 & 11144 & -- & 555 & 27754 & -- & 5808 \\
\hline
\end{tabular}


STREAMS TRIBUTARY TO LAKE HURON--COntinued

4-1515. CASS RIVER AT FRANKENLUTH, MICH,--ContInued

\begin{tabular}{|c|c|c|c|c|c|c|c|c|c|}
\hline \multirow[b]{3}{*}{ Day } & \multicolumn{3}{|c|}{ JULY } & \multicolumn{3}{|c|}{ AUGUST } & \multicolumn{3}{|c|}{ SEPTEMBER } \\
\hline & \multirow[b]{2}{*}{$\begin{array}{c}\text { Mean } \\
\text { dis- } \\
\text { charge } \\
\text { (cfs) }\end{array}$} & \multicolumn{2}{|c|}{ Suspended sediment } & \multirow[b]{2}{*}{$\begin{array}{c}\text { Mean } \\
\text { dis- } \\
\text { charge } \\
\text { (cfs) }\end{array}$} & \multicolumn{2}{|c|}{ Suspended sediment } & \multirow[b]{2}{*}{$\begin{array}{c}\text { Mean } \\
\text { dis- } \\
\text { charge } \\
(c f s)\end{array}$} & \multicolumn{2}{|c|}{ Suspended sediment } \\
\hline & & $\begin{array}{l}\text { Mean } \\
\text { concen- } \\
\text { tration } \\
(\text { ppm) }\end{array}$ & $\begin{array}{l}\text { Tons } \\
\text { per } \\
\text { day }\end{array}$ & & $\begin{array}{c}\text { Mean } \\
\text { concen- } \\
\text { tration } \\
(\mathrm{ppm})\end{array}$ & $\begin{array}{l}\text { Tons } \\
\text { per } \\
\text { day }\end{array}$ & & $\begin{array}{c}\text { Mean } \\
\text { concen- } \\
\text { tration } \\
(\mathrm{ppm})\end{array}$ & $\begin{array}{l}\text { Tons } \\
\text { per } \\
\text { dxy }\end{array}$ \\
\hline $\begin{array}{l}1 \ldots \\
2 \ldots \\
3 \ldots \\
4 \ldots\end{array}$ & $\begin{array}{r}1830 \\
1240 \\
960 \\
728 \\
584\end{array}$ & $\begin{array}{l}55 \\
40 \\
35 \\
30 \\
25\end{array}$ & $\begin{array}{r}272 \\
134 \\
91 \\
59 \\
39\end{array}$ & $\begin{array}{l}150 \\
149 \\
140 \\
140 \\
210\end{array}$ & $\begin{array}{l}29 \\
27 \\
26 \\
24 \\
23\end{array}$ & $\begin{array}{r}12 \\
11 \\
10 \\
9 \\
13\end{array}$ & $\begin{array}{l}94 \\
85 \\
80 \\
75 \\
72\end{array}$ & $\begin{array}{l}16 \\
16 \\
16 \\
16 \\
16\end{array}$ & $\begin{array}{l}4 \\
4 \\
3 \\
3 \\
3\end{array}$ \\
\hline $\begin{array}{r}6 \ldots \\
7 \ldots \\
8 \ldots \\
10 \ldots\end{array}$ & $\begin{array}{l}520 \\
423 \\
349 \\
295 \\
255\end{array}$ & $\begin{array}{l}25 \\
25 \\
20 \\
20 \\
19\end{array}$ & $\begin{array}{l}35 \\
29 \\
19 \\
16 \\
13\end{array}$ & $\begin{array}{l}164 \\
137 \\
125 \\
118 \\
116\end{array}$ & $\begin{array}{l}23 \\
23 \\
24 \\
26 \\
27\end{array}$ & $\begin{array}{r}10 \\
9 \\
8 \\
8 \\
8\end{array}$ & $\begin{array}{l}68 \\
65 \\
63 \\
61 \\
59\end{array}$ & $\begin{array}{l}15 \\
15 \\
15 \\
15 \\
14\end{array}$ & $\begin{array}{l}3 \\
3 \\
3 \\
2 \\
2\end{array}$ \\
\hline $\begin{array}{l}11 \ldots \\
12 \ldots \\
13 \ldots \\
14 \ldots \\
15 \ldots\end{array}$ & $\begin{array}{r}264 \\
1210 \\
1490 \\
1030 \\
662\end{array}$ & $\begin{array}{r}19 \\
82 \\
147 \\
84 \\
55\end{array}$ & $\begin{array}{r}14 \\
296 \\
591 \\
234 \\
98\end{array}$ & $\begin{array}{r}108 \\
110 \\
106 \\
96 \\
88\end{array}$ & $\begin{array}{l}29 \\
30 \\
30 \\
31 \\
30\end{array}$ & $\begin{array}{l}8 \\
9 \\
9 \\
8 \\
7\end{array}$ & $\begin{array}{l}58 \\
61 \\
60 \\
58 \\
56\end{array}$ & $\begin{array}{l}14 \\
15 \\
16 \\
17 \\
17\end{array}$ & $\begin{array}{l}2 \\
2 \\
3 \\
3 \\
3\end{array}$ \\
\hline $\begin{array}{l}16 \ldots \\
17 \ldots \\
18 \ldots \\
19 . . \\
20 . .\end{array}$ & $\begin{array}{l}475 \\
370 \\
324 \\
338 \\
668\end{array}$ & $\begin{array}{l}47 \\
38 \\
42 \\
46 \\
40\end{array}$ & $\begin{array}{l}60 \\
38 \\
37 \\
42 \\
72\end{array}$ & $\begin{array}{r}83 \\
82 \\
88 \\
101 \\
116\end{array}$ & $\begin{array}{l}29 \\
28 \\
26 \\
24 \\
21\end{array}$ & $\begin{array}{l}6 \\
6 \\
6 \\
7 \\
7\end{array}$ & $\begin{array}{l}55 \\
55 \\
54 \\
54 \\
54\end{array}$ & $\begin{array}{l}17 \\
18 \\
18 \\
18 \\
19\end{array}$ & $\begin{array}{l}3 \\
3 \\
3 \\
3 \\
3\end{array}$ \\
\hline $\begin{array}{l}21 \ldots \\
22 \ldots \\
23 \ldots \\
24 \ldots \\
25 \ldots\end{array}$ & $\begin{array}{r}1180 \\
922 \\
578 \\
402 \\
312\end{array}$ & $\begin{array}{l}46 \\
46 \\
44 \\
41 \\
39\end{array}$ & $\begin{array}{r}147 \\
115 \\
69 \\
45 \\
33\end{array}$ & $\begin{array}{r}114 \\
111 \\
100 \\
89 \\
83\end{array}$ & $\begin{array}{l}18 \\
19 \\
20 \\
20 \\
19\end{array}$ & $\begin{array}{l}6 \\
6 \\
5 \\
5 \\
4\end{array}$ & $\begin{array}{l}60 \\
62 \\
59 \\
58 \\
59\end{array}$ & $\begin{array}{l}20 \\
21 \\
21 \\
21 \\
22\end{array}$ & $\begin{array}{l}3 \\
4 \\
3 \\
3 \\
4\end{array}$ \\
\hline $\begin{array}{l}26 \ldots \\
27 \ldots \\
28 \ldots \\
29 \ldots \\
30 \ldots \\
31 \ldots\end{array}$ & $\begin{array}{l}252 \\
207 \\
182 \\
162 \\
152 \\
142\end{array}$ & $\begin{array}{l}37 \\
35 \\
34 \\
33 \\
32 \\
30\end{array}$ & $\begin{array}{l}25 \\
20 \\
17 \\
14 \\
13 \\
12\end{array}$ & $\begin{array}{l}78 \\
78 \\
85 \\
93 \\
96 \\
99\end{array}$ & $\begin{array}{l}18 \\
17 \\
17 \\
17 \\
17 \\
16\end{array}$ & $\begin{array}{l}4 \\
4 \\
4 \\
4 \\
4 \\
4\end{array}$ & $\begin{array}{r}63 \\
96 \\
118 \\
121 \\
139 \\
--\end{array}$ & $\begin{array}{l}23 \\
24 \\
25 \\
25 \\
25 \\
--\end{array}$ & $\begin{array}{r}4 \\
6 \\
8 \\
8 \\
9 \\
--\end{array}$ \\
\hline Total & 18506 & -- & 2699 & 3453 & -- & 221 & 2122 & -- & 110 \\
\hline $\begin{array}{l}\text { Total } \\
\text { Total }\end{array}$ & $\begin{array}{l}\text { discharg } \\
\text { load for }\end{array}$ & $\begin{array}{l}\text { or year } \\
\text { ar (ton }\end{array}$ & $\ldots \ldots$ & $\cdots$ & $\cdots$ & 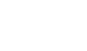 & $\cdots$ & $\cdots$ & $\begin{array}{r}221924 \\
6 ? 519\end{array}$ \\
\hline
\end{tabular}




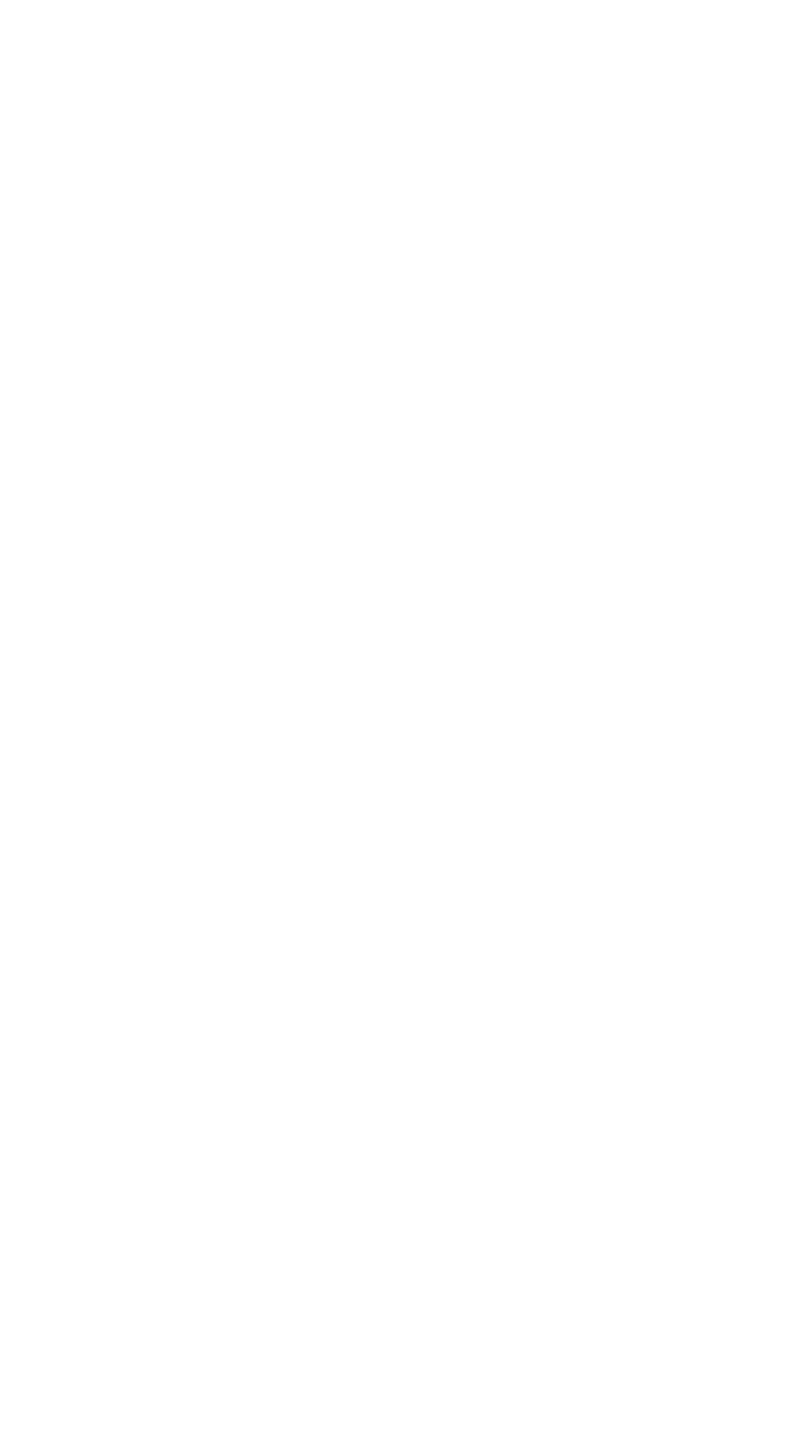




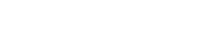

11111111

$1111: 11111$

1111110111

111111,111

1 1 1 1 1 1 1 1

111111111

111111 111

111111 11:

$11111\} 111$

$\circ$. HOM

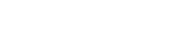

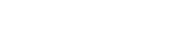

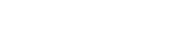

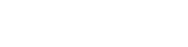

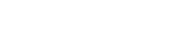

:

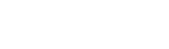

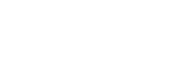

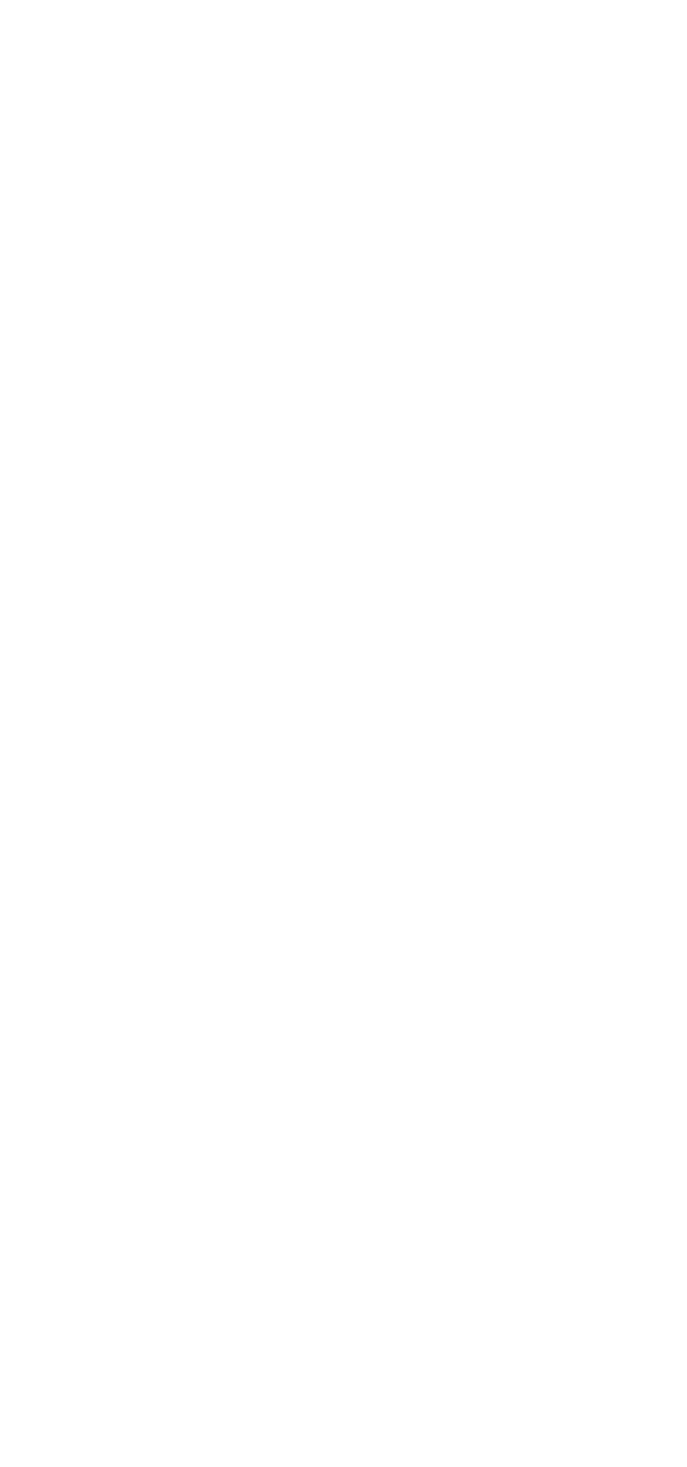




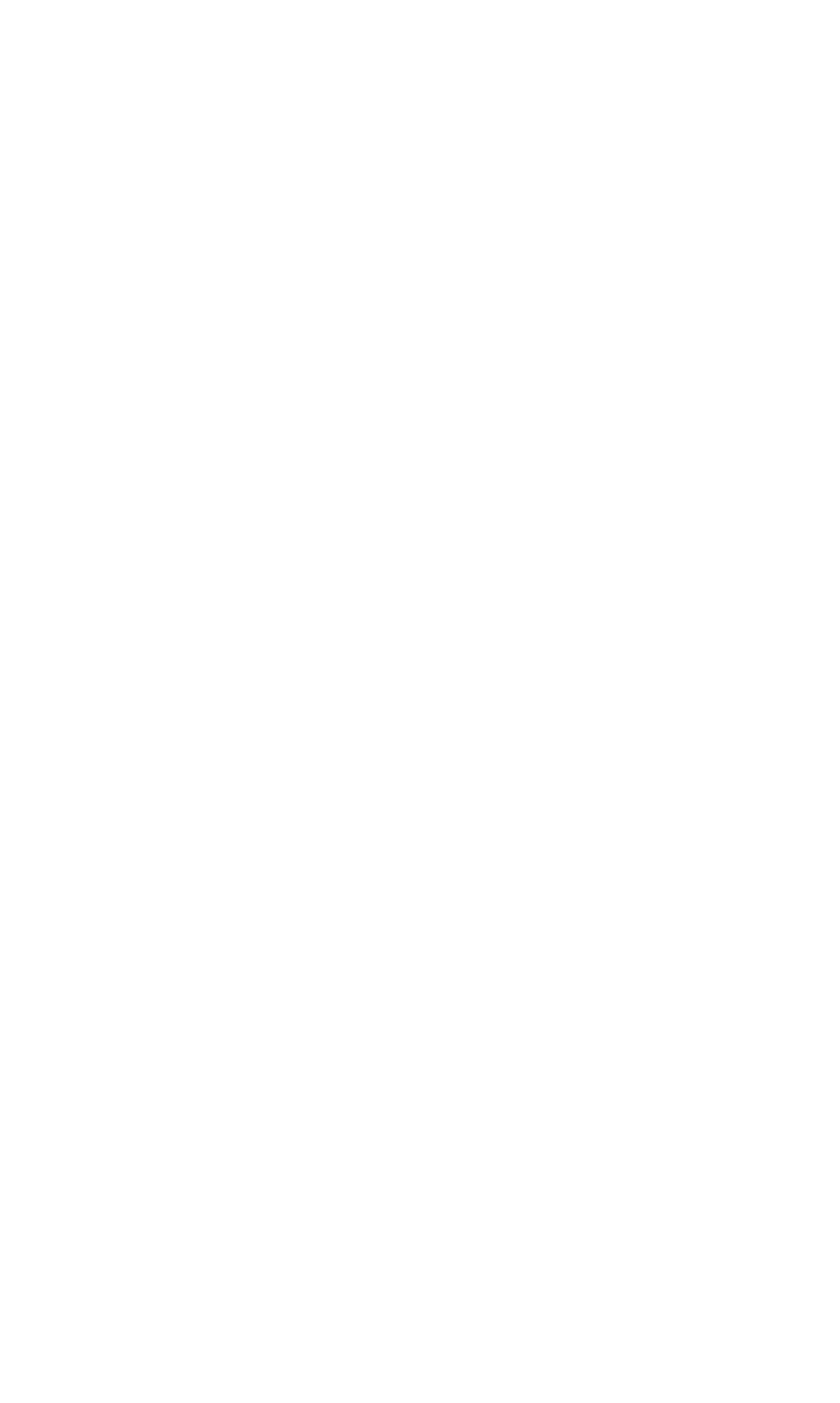



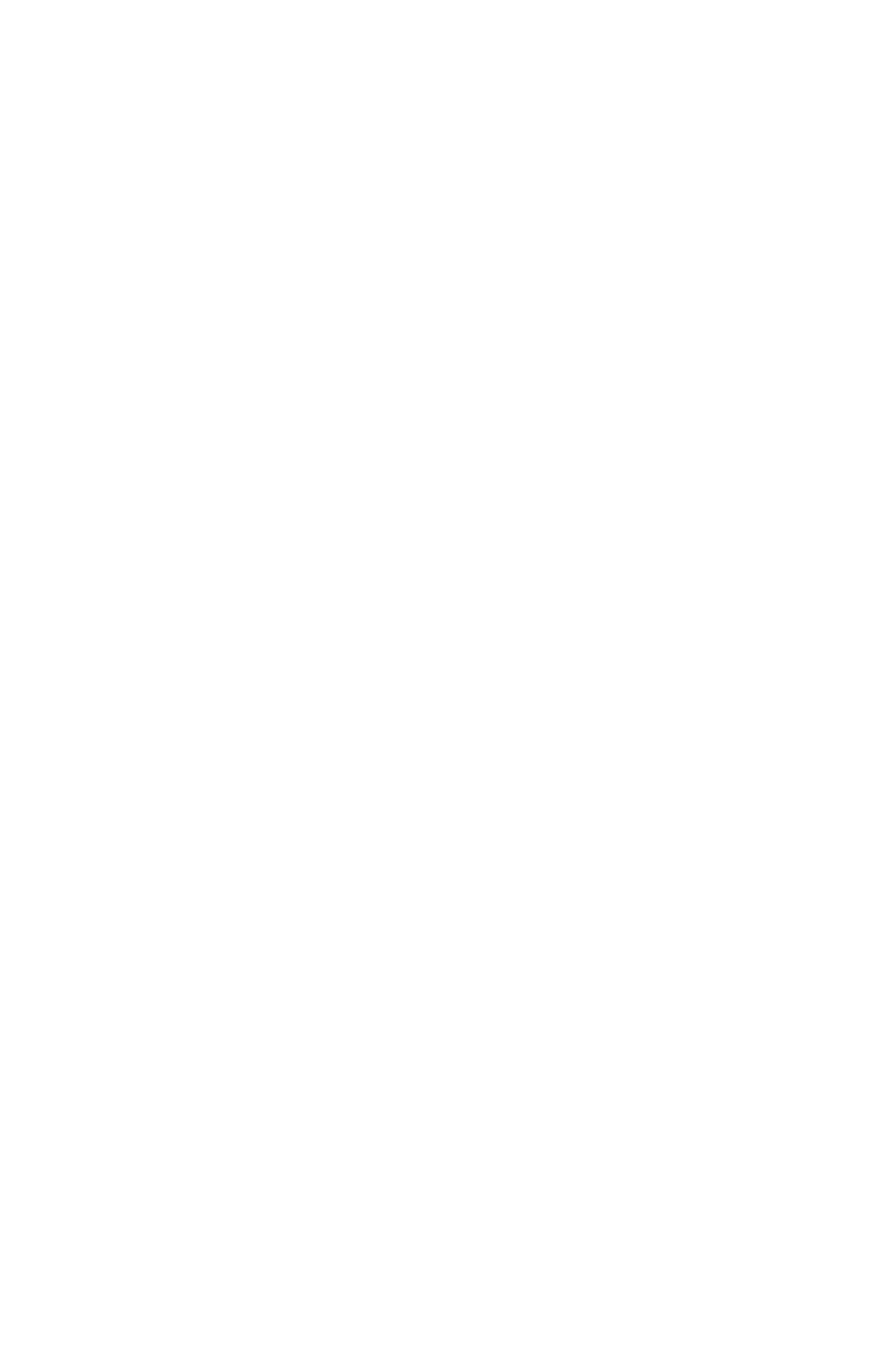
STREAMS TRIBUTARY TO LAKE ERIE--Continued

4-1765. RIVER RAISIN NEAR MONROE, MICH.--Continued

Suspended sediment, water year Octobex 1966 to september 1967

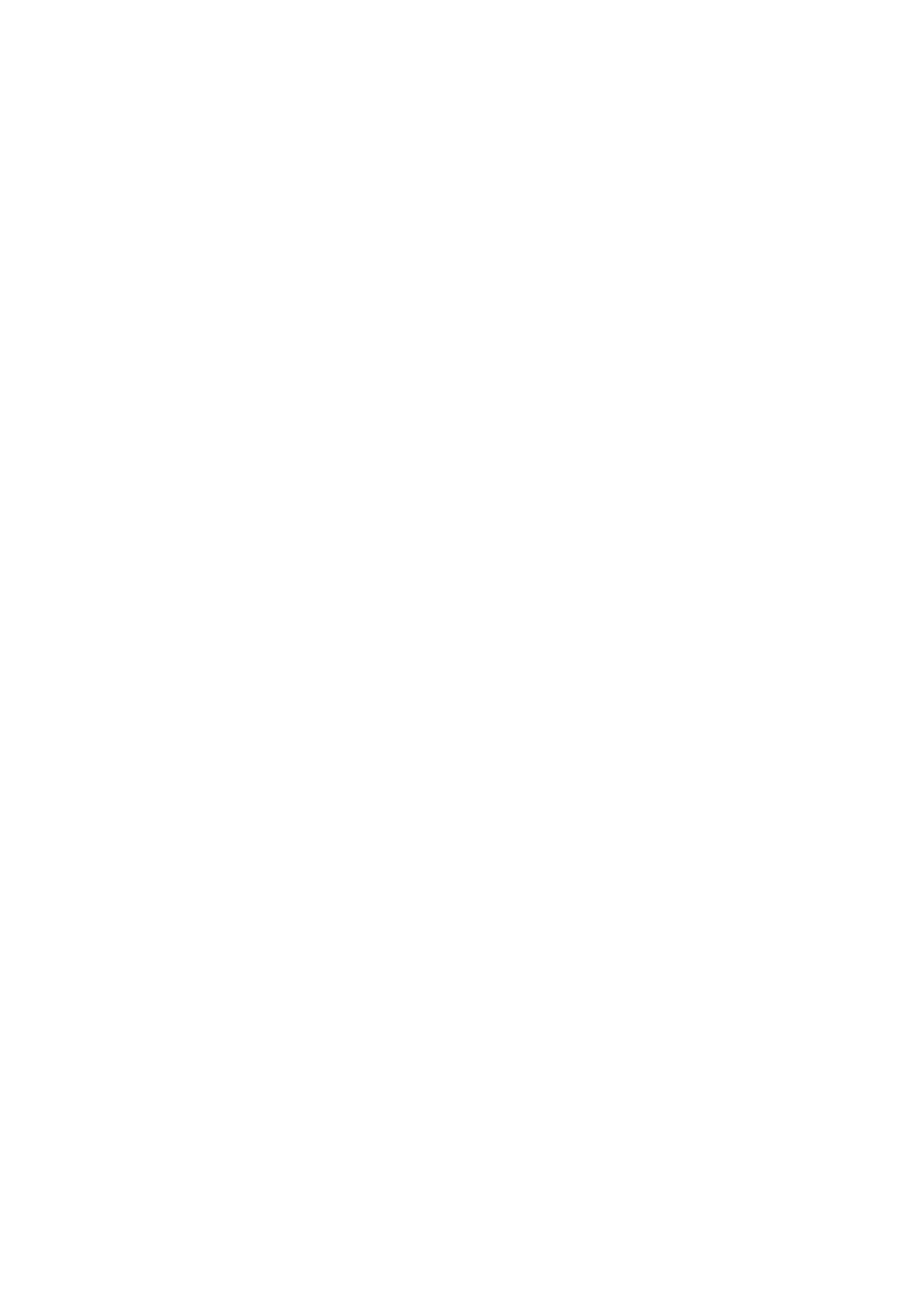


STREAMS TRIBUTARY TO LAKE ERIE--COntinued

4-1765. RIVER RAISIN NEAR MONROE, MICH.--Continued

Suspended sediment, water year October 1966 to September 1967--Continued

\begin{tabular}{|c|c|c|c|c|c|c|c|c|c|}
\hline \multirow[b]{3}{*}{ Day } & \multicolumn{3}{|c|}{ APRIL } & \multicolumn{3}{|c|}{ MAY } & \multicolumn{3}{|c|}{ JUNE } \\
\hline & \multirow[b]{2}{*}{$\begin{array}{l}\text { Mean } \\
\text { dis- } \\
\text { charge } \\
\text { (cfs) }\end{array}$} & \multicolumn{2}{|c|}{ Suspended sediment } & \multirow[b]{2}{*}{$\begin{array}{c}\text { Mean } \\
\text { dis- } \\
\text { charge } \\
\text { (cfs) }\end{array}$} & \multicolumn{2}{|c|}{ Suspended sediment } & \multirow[b]{2}{*}{$\begin{array}{l}\text { Mean } \\
\text { dis- } \\
\text { charge } \\
(\text { cfs })\end{array}$} & \multicolumn{2}{|c|}{ Suspended sediment } \\
\hline & & $\begin{array}{c}\text { Mean } \\
\text { concen- } \\
\text { tration } \\
(p p m)\end{array}$ & $\begin{array}{c}\text { Tons } \\
\text { per } \\
\text { day }\end{array}$ & & $\begin{array}{c}\text { Mean } \\
\text { concen- } \\
\text { tration } \\
\text { (ppm) }\end{array}$ & $\begin{array}{l}\text { Tons } \\
\text { per } \\
\text { day }\end{array}$ & & $\begin{array}{c}\text { Mean } \\
\text { concen- } \\
\text { tration } \\
(p p m)\end{array}$ & $\begin{array}{l}\text { Tons } \\
\text { per } \\
\text { day }\end{array}$ \\
\hline $\begin{array}{l}1 \ldots \\
2 \ldots \\
3 \ldots \\
4 \ldots \\
5 \ldots\end{array}$ & $\begin{array}{l}1470 \\
2590 \\
3360 \\
3120 \\
2950\end{array}$ & $\begin{array}{l}53 \\
332 \\
312 \\
134 \\
101\end{array}$ & $\begin{array}{r}210 \\
2400 \\
2830 \\
1130 \\
804\end{array}$ & $\begin{array}{l}628 \\
634 \\
604 \\
580 \\
592\end{array}$ & \begin{tabular}{l|}
30 \\
29 \\
28 \\
27 \\
26
\end{tabular} & $\begin{array}{l}51 \\
50 \\
46 \\
42 \\
42\end{array}$ & $\begin{array}{l}236 \\
218 \\
208 \\
208 \\
174\end{array}$ & $\begin{array}{l}43 \\
37 \\
40 \\
36 \\
32\end{array}$ & $\begin{array}{l}27 \\
22 \\
22 \\
20 \\
15\end{array}$ \\
\hline $\begin{array}{r}6 \ldots \\
7 \ldots \\
8 \ldots \\
10 \ldots\end{array}$ & $\begin{array}{l}3160 \\
3130 \\
2920 \\
2680 \\
2570\end{array}$ & $\begin{array}{l}94 \\
88 \\
81 \\
78 \\
77\end{array}$ & $\begin{array}{l}802 \\
744 \\
639 \\
564 \\
534\end{array}$ & $\begin{array}{l}532 \\
514 \\
520 \\
532 \\
526\end{array}$ & $\begin{array}{l}26 \\
26 \\
28 \\
30 \\
30\end{array}$ & $\begin{array}{l}37 \\
36 \\
39 \\
43 \\
43\end{array}$ & $\begin{array}{l}165 \\
180 \\
180 \\
218 \\
232\end{array}$ & $\begin{array}{l}32 \\
42 \\
40 \\
35 \\
33\end{array}$ & $\begin{array}{l}14 \\
20 \\
19 \\
21 \\
21\end{array}$ \\
\hline $\begin{array}{l}11 \ldots \\
12 \ldots \\
13 \ldots \\
14 \ldots \\
15 \ldots\end{array}$ & $\begin{array}{l}2230 \\
1920 \\
1690 \\
1490 \\
1530\end{array}$ & $\begin{array}{l}64 \\
63 \\
63 \\
49 \\
64\end{array}$ & $\begin{array}{l}385 \\
327 \\
287 \\
197 \\
264\end{array}$ & $\begin{array}{l}598 \\
742 \\
790 \\
778 \\
712\end{array}$ & $\begin{array}{l}38 \\
45 \\
51 \\
64 \\
58\end{array}$ & $\begin{array}{r}61 \\
90 \\
109 \\
134 \\
111\end{array}$ & $\begin{array}{l}243 \\
226 \\
201 \\
171 \\
132\end{array}$ & $\begin{array}{l}31 \\
34 \\
30 \\
23 \\
22\end{array}$ & $\begin{array}{l}20 \\
21 \\
16 \\
11 \\
7.8\end{array}$ \\
\hline $\begin{array}{l}16 \ldots \\
17 \ldots \\
18 \ldots \\
19 \ldots \\
20 \ldots\end{array}$ & $\begin{array}{r}1580 \\
1540 \\
1360 \\
1110 \\
955\end{array}$ & $\begin{array}{l}43 \\
27 \\
25 \\
27 \\
28\end{array}$ & $\begin{array}{r}183 \\
112 \\
92 \\
81 \\
72\end{array}$ & $\begin{array}{l}622 \\
568 \\
532 \\
462 \\
425\end{array}$ & $\begin{array}{l}68 \\
47 \\
38 \\
35 \\
44\end{array}$ & $\begin{array}{r}114 \\
72 \\
55 \\
44 \\
50\end{array}$ & $\begin{array}{r}135 \\
1310 \\
913 \\
700 \\
468\end{array}$ & $\begin{array}{r}24 \\
116 \\
101 \\
98 \\
85\end{array}$ & $\begin{array}{l}8.7 \\
410 \\
249 \\
185 \\
107\end{array}$ \\
\hline $\begin{array}{l}21 \ldots \\
22 \ldots \\
23 \ldots \\
24 \ldots \\
25 \ldots\end{array}$ & $\begin{array}{r}878 \\
948 \\
983 \\
1030 \\
1010\end{array}$ & $\begin{array}{l}27 \\
27 \\
27 \\
30 \\
27\end{array}$ & $\begin{array}{l}64 \\
69 \\
72 \\
83 \\
74\end{array}$ & $\begin{array}{l}410 \\
385 \\
367 \\
354 \\
349\end{array}$ & $\begin{array}{l}52 \\
52 \\
43 \\
38 \\
33\end{array}$ & $\begin{array}{l}58 \\
54 \\
43 \\
36 \\
31\end{array}$ & $\begin{array}{l}318 \\
295 \\
390 \\
435 \\
367\end{array}$ & $\begin{array}{l}64 \\
53 \\
42 \\
44 \\
45\end{array}$ & $\begin{array}{l}55 \\
42 \\
44 \\
52 \\
45\end{array}$ \\
\hline $\begin{array}{l}26 \ldots \\
27 \ldots \\
28 \ldots \\
29 \ldots \\
30 \ldots \\
31 \ldots\end{array}$ & $\begin{array}{c}941 \\
878 \\
808 \\
742 \\
700 \\
--\end{array}$ & $\begin{array}{l}28 \\
30 \\
28 \\
29 \\
30 \\
--\end{array}$ & $\begin{array}{l}71 \\
71 \\
61 \\
58 \\
57 \\
--\end{array}$ & $\begin{array}{l}336 \\
326 \\
313 \\
295 \\
268 \\
250\end{array}$ & $\begin{array}{l}31 \\
32 \\
39 \\
35 \\
37 \\
41\end{array}$ & $\begin{array}{l}28 \\
28 \\
33 \\
28 \\
27 \\
28\end{array}$ & $\begin{array}{c}282 \\
236 \\
201 \\
171 \\
153 \\
=-\end{array}$ & $\begin{array}{l}49 \\
53 \\
55 \\
50 \\
47 \\
--\end{array}$ & $\begin{array}{l}37 \\
34 \\
30 \\
23 \\
19 \\
-\end{array}$ \\
\hline \multirow[t]{2}{*}{ Total } & 52273 & -- & 23337 & 15544 & -- & 1663 & 9366 & -- & 1617.5 \\
\hline & \multicolumn{3}{|c|}{ JULY } & \multicolumn{3}{|c|}{ AUGUST } & \multicolumn{3}{|c|}{ SEPTEMBER } \\
\hline $\begin{array}{l}1 \ldots \\
2 \ldots \\
3 \ldots \\
4 \ldots \\
5 \ldots\end{array}$ & $\begin{array}{r}135 \\
126 \\
115 \\
100 \\
95\end{array}$ & $\begin{array}{l}46 \\
47 \\
63 \\
82 \\
78\end{array}$ & $\begin{array}{l}17 \\
16 \\
20 \\
22 \\
20\end{array}$ & $\begin{array}{l}315 \\
748 \\
490 \\
259 \\
215\end{array}$ & $\begin{array}{l}22 \\
87 \\
73 \\
57 \\
37\end{array}$ & $\begin{array}{r}25 \\
176 \\
97 \\
40 \\
21\end{array}$ & $\begin{array}{l}87 \\
93 \\
85 \\
75 \\
65\end{array}$ & $\begin{array}{l}17 \\
15 \\
13 \\
13 \\
16\end{array}$ & $\begin{array}{l}4.0 \\
3.8 \\
3.0 \\
2.6 \\
2.8\end{array}$ \\
\hline $\begin{array}{r}6 \ldots \\
7 \ldots \\
8 \ldots \\
10 \ldots\end{array}$ & $\begin{array}{l}89 \\
87 \\
55 \\
75 \\
81\end{array}$ & $\begin{array}{l}28 \\
23 \\
26 \\
30 \\
32\end{array}$ & $\begin{array}{l}6.7 \\
5.4 \\
3.9 \\
6.1 \\
7.0\end{array}$ & $\begin{array}{r}194 \\
165 \\
138 \\
118 \\
89\end{array}$ & $\begin{array}{l}15 \\
15 \\
15 \\
12 \\
34\end{array}$ & $\begin{array}{l}7.9 \\
6.7 \\
5.6 \\
3.8 \\
8.2\end{array}$ & $\begin{array}{l}57 \\
61 \\
69 \\
61 \\
57\end{array}$ & $\begin{array}{l}19 \\
19 \\
18 \\
17 \\
16\end{array}$ & $\begin{array}{l}2 \cdot 9 \\
3 \cdot 1 \\
3 \cdot 4 \\
2.8 \\
2 \cdot 5\end{array}$ \\
\hline $\begin{array}{l}11 \ldots \\
12 \ldots \\
13 \ldots \\
14 \ldots \\
15 \ldots\end{array}$ & $\begin{array}{r}95 \\
81 \\
98 \\
180 \\
147\end{array}$ & $\begin{array}{l}32 \\
32 \\
33 \\
71 \\
47\end{array}$ & $\begin{array}{r}8.2 \\
7.0 \\
8.7 \\
35 \\
19\end{array}$ & $\begin{array}{l}61 \\
98 \\
85 \\
81 \\
75\end{array}$ & $\begin{array}{r}48 \\
23 \\
9 \\
10 \\
20\end{array}$ & $\begin{array}{l}7.9 \\
6.1 \\
2.1 \\
2.2 \\
4.0\end{array}$ & $\begin{array}{l}55 \\
52 \\
50 \\
49 \\
48\end{array}$ & $\begin{array}{l}19 \\
25 \\
25 \\
25 \\
21\end{array}$ & $\begin{array}{l}2.8 \\
3.5 \\
3.4 \\
3.3 \\
2.7\end{array}$ \\
\hline $\begin{array}{l}16 \ldots \\
17 \ldots \\
18 \ldots \\
19 \ldots \\
20 \ldots\end{array}$ & $\begin{array}{r}112 \\
98 \\
87 \\
95 \\
110\end{array}$ & $\begin{array}{l}30 \\
30 \\
30 \\
30 \\
30\end{array}$ & $\begin{array}{l}9.1 \\
7.9 \\
7.0 \\
7.7 \\
8.9\end{array}$ & $\begin{array}{l}67 \\
67 \\
73 \\
69 \\
81\end{array}$ & $\begin{array}{r}13 \\
8 \\
9 \\
10 \\
8\end{array}$ & $\begin{array}{l}2.4 \\
1.4 \\
1.8 \\
1.9 \\
1.7\end{array}$ & $\begin{array}{l}50 \\
54 \\
65 \\
65 \\
49\end{array}$ & $\begin{array}{l}19 \\
18 \\
25 \\
26 \\
27\end{array}$ & $\begin{array}{l}2.6 \\
2.6 \\
4.4 \\
4.6 \\
3.6\end{array}$ \\
\hline $\begin{array}{l}21 \ldots \\
22 \ldots \\
23 \ldots \\
24 \ldots \\
25 \ldots\end{array}$ & $\begin{array}{l}171 \\
282 \\
168 \\
118 \\
100\end{array}$ & $\begin{array}{r}99 \\
198 \\
145 \\
88 \\
72\end{array}$ & $\begin{array}{r}46 \\
151 \\
66 \\
28 \\
19\end{array}$ & $\begin{array}{l}83 \\
91 \\
93 \\
75 \\
71\end{array}$ & $\begin{array}{r}7 \\
8 \\
11 \\
12 \\
36\end{array}$ & $\begin{array}{l}1.6 \\
2.0 \\
2.8 \\
2.4 \\
6.9\end{array}$ & $\begin{array}{r}79 \\
85 \\
85 \\
112 \\
100\end{array}$ & $\begin{array}{l}30 \\
32 \\
34 \\
32 \\
32\end{array}$ & $\begin{array}{l}6.4 \\
7.3 \\
7.8 \\
9.7 \\
8.6\end{array}$ \\
\hline $\begin{array}{l}26 \ldots \\
27 \ldots \\
28 \ldots \\
29 \ldots \\
30 \ldots \\
31 \ldots\end{array}$ & $\begin{array}{r}91 \\
83 \\
77 \\
75 \\
75 \\
268\end{array}$ & $\begin{array}{l}64 \\
55 \\
47 \\
38 \\
30 \\
49\end{array}$ & $\begin{array}{c}16 \\
12 \\
9.8 \\
7.7 \\
6.1 \\
38\end{array}$ & $\begin{array}{l}73 \\
77 \\
75 \\
85 \\
98 \\
85\end{array}$ & $\begin{array}{l}47 \\
43 \\
27 \\
20 \\
17 \\
17\end{array}$ & $\begin{array}{l}9.3 \\
8.9 \\
5.5 \\
4.6 \\
4.5 \\
3.9\end{array}$ & $\begin{array}{l}83 \\
75 \\
77 \\
83 \\
75 \\
-- \\
\end{array}$ & $\begin{array}{l}35 \\
36 \\
37 \\
37 \\
35 \\
--\end{array}$ & $\begin{array}{r}7.8 \\
7.3 \\
7.7 \\
8.3 \\
7.1 \\
--.\end{array}$ \\
\hline Total & 3569 & - & 642.2 & 4394 & -- & $475 \cdot 1$ & 2101 & -- & $142 \cdot 4$ \\
\hline $\begin{array}{l}\text { Total } \\
\text { Tota I } \\
\end{array}$ & $\begin{array}{l}\text { scharge } \\
\text { ad for }\end{array}$ & $\begin{array}{l}x \text { year } \\
\text { ir (tons }\end{array}$ & $\begin{array}{l}- \text { days). } \\
\because \ldots \ldots\end{array}$ & & & $\cdots \cdots$ & $\ldots \ldots$ & $\cdots$ & $\begin{array}{r}255247 \\
59155.0 \\
\end{array}$ \\
\hline
\end{tabular}



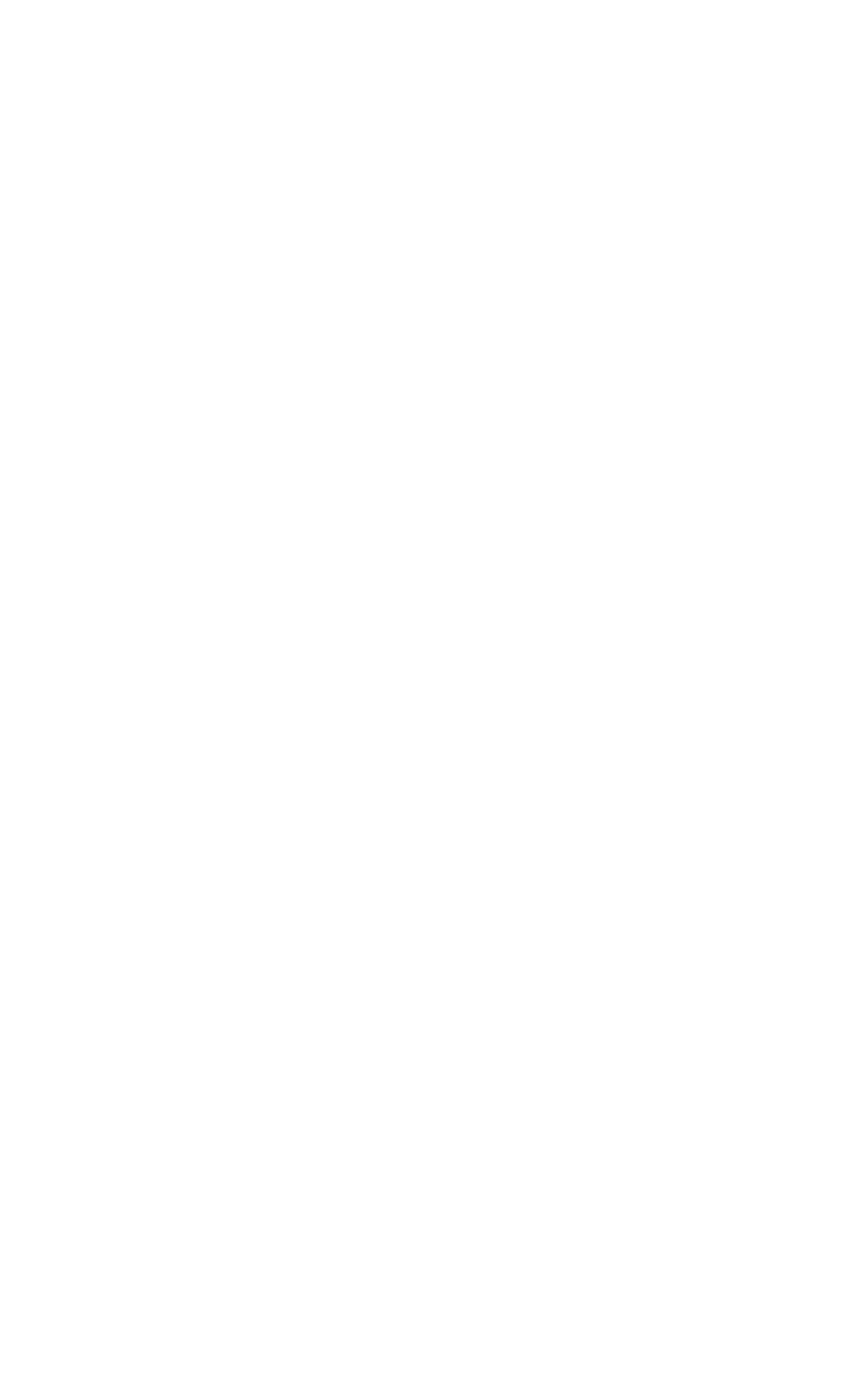
STREAMS TRIBUTARY TO LAKE ERIE--COntınued

4-1820. ST. MARYS RIVER NEAR FORT WAYNE, IND,--Continued

\begin{tabular}{|c|c|c|c|c|c|c|c|c|c|}
\hline \multirow[b]{3}{*}{ Day } & \multicolumn{3}{|c|}{ OCTOBER } & \multicolumn{3}{|c|}{ NOVEMBER } & \multicolumn{3}{|c|}{ DECEMBER } \\
\hline & \multirow[b]{2}{*}{$\begin{array}{c}\text { Mean } \\
\text { dis- } \\
\text { charge } \\
\text { (cfs) }\end{array}$} & \multicolumn{2}{|c|}{ Suspended sediment } & \multirow[b]{2}{*}{$\begin{array}{c}\text { Mean } \\
\text { dis- } \\
\text { charge } \\
\text { (cfa) }\end{array}$} & \multicolumn{2}{|c|}{ Suspended sediment } & \multirow[b]{2}{*}{$\begin{array}{c}\text { Mean } \\
\text { dis- } \\
\text { charge } \\
\text { (cfs) }\end{array}$} & \multicolumn{2}{|c|}{ Suspended serliment } \\
\hline & & $\begin{array}{c}\text { Mean } \\
\text { concen- } \\
\text { tration } \\
(p p m)\end{array}$ & $\begin{array}{l}\text { Tons } \\
\text { per } \\
\text { day }\end{array}$ & & $\begin{array}{c}\text { Mean } \\
\text { concen- } \\
\text { tration } \\
(\text { ppm) }\end{array}$ & $\begin{array}{l}\text { Tons } \\
\text { per } \\
\text { day }\end{array}$ & & $\begin{array}{c}\text { Mean } \\
\text { concen- } \\
\text { tration } \\
(p p m)\end{array}$ & $\begin{array}{l}\text { Tons } \\
\text { per } \\
\text { day }\end{array}$ \\
\hline $\begin{array}{l}1 \ldots \\
2 \ldots \\
3 \ldots \\
4 \ldots \\
5 . .\end{array}$ & $\begin{array}{l}21 \\
18 \\
14 \\
12 \\
14\end{array}$ & $\begin{array}{l}50 \\
43 \\
66 \\
72 \\
60\end{array}$ & $\begin{array}{l}3 \\
2 \\
2 \\
2 \\
2 \\
2\end{array}$ & $\begin{array}{l}15 \\
16 \\
19 \\
18 \\
27\end{array}$ & $\begin{array}{l}\mathbf{2 7} \\
32 \\
\mathbf{3 7} \\
\mathbf{3 0} \\
\mathbf{1 5}\end{array}$ & $\begin{array}{l}1 \\
1 \\
2 \\
1 \\
1\end{array}$ & $\begin{array}{l}613 \\
577 \\
463 \\
578 \\
715\end{array}$ & $\begin{array}{l}52 \\
48 \\
42 \\
47 \\
49\end{array}$ & $\begin{array}{l}86 \\
75 \\
53 \\
73 \\
95\end{array}$ \\
\hline $\begin{array}{r}6 \ldots \\
7 \ldots \\
8 \ldots \\
9 \ldots \\
10 \ldots\end{array}$ & $\begin{array}{l}14 \\
14 \\
14 \\
14 \\
15\end{array}$ & $\begin{array}{l}\mathbf{4 7} \\
\mathbf{5 0} \\
\mathbf{6 0} \\
59 \\
\mathbf{5 3}\end{array}$ & $\begin{array}{l}2 \\
2 \\
2 \\
2 \\
2\end{array}$ & $\begin{array}{r}24 \\
52 \\
318 \\
814 \\
1620\end{array}$ & $\begin{array}{r}17 \\
28 \\
103 \\
186 \\
255\end{array}$ & $\begin{array}{r}1 \\
4 \\
88 \\
450 \\
1190\end{array}$ & $\begin{array}{l}1700 \\
3290 \\
5020 \\
6210 \\
7140\end{array}$ & $\begin{array}{l}142 \\
240 \\
318 \\
466 \\
437\end{array}$ & $\begin{array}{r}652 \\
2130 \\
4310 \\
7810 \\
8420\end{array}$ \\
\hline $\begin{array}{l}11 \ldots \\
12 \ldots \\
13 \ldots \\
14 \ldots \\
15 \ldots\end{array}$ & $\begin{array}{l}18 \\
17 \\
16 \\
16 \\
17\end{array}$ & $\begin{array}{l}47 \\
37 \\
43 \\
55 \\
62\end{array}$ & $\begin{array}{l}2 \\
2 \\
2 \\
2 \\
3\end{array}$ & $\begin{array}{r}1350 \\
697 \\
445 \\
347 \\
293\end{array}$ & $\begin{array}{r}149 \\
84 \\
57 \\
44 \\
32\end{array}$ & $\begin{array}{r}543 \\
158 \\
68 \\
41 \\
25\end{array}$ & $\begin{array}{l}7570 \\
7740 \\
7230 \\
6040 \\
4730\end{array}$ & \begin{tabular}{r|}
248 \\
167 \\
128 \\
112 \\
91
\end{tabular} & $\begin{array}{l}5070 \\
3490 \\
2500 \\
1830 \\
1160\end{array}$ \\
\hline $\begin{array}{l}16 \ldots \\
17 \ldots \\
18 \ldots \\
19 \ldots \\
20 \ldots\end{array}$ & $\begin{array}{l}14 \\
15 \\
18 \\
20 \\
19\end{array}$ & $\begin{array}{l}48 \\
40 \\
37 \\
37 \\
36\end{array}$ & $\begin{array}{l}2 \\
2 \\
2 \\
2 \\
2\end{array}$ & $\begin{array}{r}243 \\
182 \\
135 \\
103 \\
82\end{array}$ & $\begin{array}{l}29 \\
30 \\
43 \\
38 \\
32\end{array}$ & $\begin{array}{r}19 \\
15 \\
16 \\
11 \\
7\end{array}$ & $\begin{array}{r}3370 \\
1970 \\
1310 \\
980 \\
778\end{array}$ & $\begin{array}{l}71 \\
60 \\
50 \\
41 \\
32\end{array}$ & $\begin{array}{r}646 \\
319 \\
177 \\
108 \\
67\end{array}$ \\
\hline $\begin{array}{l}21 \ldots \\
22 \ldots \\
23 \ldots \\
24 \ldots \\
25 \ldots\end{array}$ & $\begin{array}{l}18 \\
17 \\
17 \\
15 \\
14\end{array}$ & $\begin{array}{l}37 \\
49 \\
42 \\
37 \\
36\end{array}$ & $\begin{array}{l}2 \\
2 \\
2 \\
1 \\
1\end{array}$ & $\begin{array}{l}70 \\
62 \\
56 \\
52 \\
51\end{array}$ & $\begin{array}{l}27 \\
23 \\
33 \\
44 \\
55\end{array}$ & $\begin{array}{l}5 \\
4 \\
5 \\
6 \\
8\end{array}$ & $\begin{array}{l}628 \\
497 \\
392 \\
321 \\
270\end{array}$ & $\begin{array}{l}28 \\
26 \\
19 \\
15 \\
11\end{array}$ & $\begin{array}{r}47 \\
35 \\
20 \\
13 \\
8\end{array}$ \\
\hline $\begin{array}{l}26 \ldots \\
27 \ldots \\
28 \ldots \\
29 \ldots \\
30 \ldots \\
31 \ldots\end{array}$ & $\begin{array}{l}15 \\
15 \\
14 \\
14 \\
15 \\
15 \\
\end{array}$ & $\begin{array}{l}39 \\
36 \\
42 \\
42 \\
40 \\
34 \\
\end{array}$ & $\begin{array}{l}2 \\
1 \\
2 \\
2 \\
2 \\
1 \\
\end{array}$ & $\begin{array}{r}51 \\
167 \\
781 \\
581 \\
461 \\
-- \\
\end{array}$ & $\begin{array}{r}44 \\
110 \\
220 \\
95 \\
63 \\
-- \\
\end{array}$ & $\begin{array}{r}6 \\
70 \\
460 \\
149 \\
78 \\
-- \\
\end{array}$ & $\begin{array}{l}250 \\
222 \\
242 \\
240 \\
218 \\
188 \\
\end{array}$ & $\begin{array}{r}11 \\
11 \\
8 \\
5 \\
5 \\
5\end{array}$ & $\begin{array}{l}7 \\
7 \\
5 \\
3 \\
3 \\
3 \\
\end{array}$ \\
\hline \multirow[t]{2}{*}{ Total } & 489 & -- & 60 & 9132 & - & 3433 & 71492 & -- & 39222 \\
\hline & \multicolumn{3}{|c|}{ JANUARY } & \multicolumn{3}{|c|}{ FEBRUARY } & \multicolumn{3}{|c|}{ MARCH } \\
\hline $\begin{array}{l}1 \ldots \\
2 \ldots \\
3 \ldots \\
4 \ldots \\
5 \ldots\end{array}$ & $\begin{array}{l}164 \\
147 \\
120 \\
113 \\
108\end{array}$ & \begin{tabular}{|l|}
5 \\
5 \\
7 \\
6 \\
5
\end{tabular} & $\begin{array}{l}2 \\
2 \\
2 \\
2 \\
1\end{array}$ & $\begin{array}{l}1380 \\
3430 \\
3930 \\
3150 \\
1930\end{array}$ & \begin{tabular}{|r|}
48 \\
182 \\
214 \\
132 \\
81 \\
\end{tabular} & $\begin{array}{r}179 \\
1690 \\
2270 \\
1120 \\
422\end{array}$ & $\begin{array}{l}185 \\
194 \\
278 \\
697 \\
600\end{array}$ & $\begin{array}{l}17 \\
17 \\
20 \\
60 \\
46\end{array}$ & $\begin{array}{r}8 \\
9 \\
15 \\
113 \\
75\end{array}$ \\
\hline $\begin{array}{r}6 \ldots \\
7 \ldots \\
8 \ldots \\
9 . \\
10 .\end{array}$ & $\begin{array}{l}116 \\
147 \\
175 \\
135 \\
118\end{array}$ & $\begin{array}{r}6 \\
42 \\
29 \\
24 \\
22\end{array}$ & $\begin{array}{r}2 \\
17 \\
14 \\
9 \\
7\end{array}$ & $\begin{array}{r}\mathbf{1 2 8 0} \\
\mathbf{8 5 0} \\
\mathbf{6 5 0} \\
\mathbf{5 8 0} \\
\mathbf{5 4 0}\end{array}$ & $\begin{array}{l}84 \\
63 \\
40 \\
91\end{array}$ & $\begin{array}{r}290 \\
400 \\
111 \\
63 \\
133\end{array}$ & $\begin{array}{r}745 \\
1100 \\
720 \\
720 \\
1340\end{array}$ & $\begin{array}{r}63 \\
115 \\
58 \\
38 \\
148\end{array}$ & $\begin{array}{r}127 \\
342 \\
113 \\
74 \\
608\end{array}$ \\
\hline $\begin{array}{l}11 \ldots \\
12 \ldots \\
13 \ldots \\
14 \ldots \\
15 \ldots\end{array}$ & $\begin{array}{r}106 \\
97 \\
92 \\
86 \\
85\end{array}$ & $\begin{array}{r}15 \\
13 \\
11 \\
7 \\
9\end{array}$ & $\begin{array}{l}4 \\
3 \\
3 \\
2 \\
2\end{array}$ & $\begin{array}{r}500 \\
460 \\
437 \\
429 \\
1450\end{array}$ & $\begin{array}{r}49 \\
23 \\
17 \\
16 \\
201\end{array}$ & $\begin{array}{r}66 \\
29 \\
20 \\
19 \\
982\end{array}$ & $\begin{array}{l}3090 \\
3820 \\
3790 \\
3600 \\
3430\end{array}$ & $\begin{array}{r}362 \\
234 \\
109 \\
92 \\
200\end{array}$ & $\begin{array}{r}3020 \\
2410 \\
1120 \\
894 \\
1850\end{array}$ \\
\hline $\begin{array}{l}16 \ldots \\
17 \ldots \\
18 \ldots \\
19 \ldots \\
20 \ldots\end{array}$ & $\begin{array}{l}83 \\
80 \\
76 \\
76 \\
70\end{array}$ & $\begin{array}{l}7 \\
7 \\
8 \\
7 \\
5\end{array}$ & $\begin{array}{l}2 \\
2 \\
2 \\
1 \\
1\end{array}$ & $\begin{array}{r}2890 \\
1960 \\
940 \\
702 \\
620\end{array}$ & $\begin{array}{r}610 \\
407 \\
132 \\
89 \\
77\end{array}$ & $\begin{array}{r}4760 \\
2150 \\
335 \\
169 \\
129\end{array}$ & $\begin{array}{l}3090 \\
2490 \\
1980 \\
1560 \\
1540\end{array}$ & $\begin{array}{l}132 \\
148 \\
162 \\
132 \\
186\end{array}$ & $\begin{array}{r}1100 \\
995 \\
866 \\
556 \\
893\end{array}$ \\
\hline $\begin{array}{l}21 \ldots \\
22 \ldots \\
23 \ldots \\
24 \ldots \\
25 \ldots\end{array}$ & $\begin{array}{r}68 \\
70 \\
80 \\
100 \\
140\end{array}$ & $\begin{array}{r}6 \\
5 \\
4 \\
7 \\
32\end{array}$ & $\begin{array}{r}1 \\
1 \\
1 \\
2 \\
12\end{array}$ & $\begin{array}{l}550 \\
460 \\
408 \\
350 \\
280\end{array}$ & $\begin{array}{l}63 \\
49 \\
35 \\
27 \\
24\end{array}$ & $\begin{array}{l}94 \\
61 \\
39 \\
26 \\
18\end{array}$ & $\begin{array}{l}3730 \\
3570 \\
3270 \\
2400 \\
2050\end{array}$ & $\begin{array}{r}373 \\
252 \\
133 \\
101 \\
91\end{array}$ & $\begin{array}{r}3760 \\
2430 \\
1170 \\
654 \\
504\end{array}$ \\
\hline $\begin{array}{l}26 \ldots \\
27 \ldots \\
28 \ldots \\
29 \ldots \\
30 \ldots \\
31 \ldots\end{array}$ & $\begin{array}{r}213 \\
1420 \\
2420 \\
1840 \\
1071 \\
910 \\
\end{array}$ & $\begin{array}{r}25 \\
124 \\
204 \\
82 \\
46 \\
38 \\
\end{array}$ & $\begin{array}{r}14 \\
569 \\
1330 \\
407 \\
133 \\
93\end{array}$ & $\begin{array}{c}230 \\
200 \\
185 \\
-- \\
-- \\
--\end{array}$ & $\begin{array}{l}20 \\
17 \\
17 \\
-- \\
-- \\
--\end{array}$ & $\begin{array}{r}12 \\
9 \\
8 \\
-- \\
-- \\
-- \\
\end{array}$ & $\begin{array}{l}1750 \\
1360 \\
2640 \\
4050 \\
4290 \\
3990 \\
\end{array}$ & $\begin{array}{r}75 \\
71 \\
319 \\
649 \\
363 \\
273 \\
\end{array}$ & $\begin{array}{r}354 \\
261 \\
2750 \\
7100 \\
4200 \\
2940\end{array}$ \\
\hline Total & 10525 & -- & 2643 & 30771 & -- & 15604 & 68069 & -- & 41311 \\
\hline
\end{tabular}

E Estimated.

A Computed from partly estimated-concentration graph. 
STREAMS TRIBUTARY TO LAKE ERIE--Cont1nued

4-1820. ST, MARYS RIVER NEAR FORT WAYNE, IND.--Cont1nued

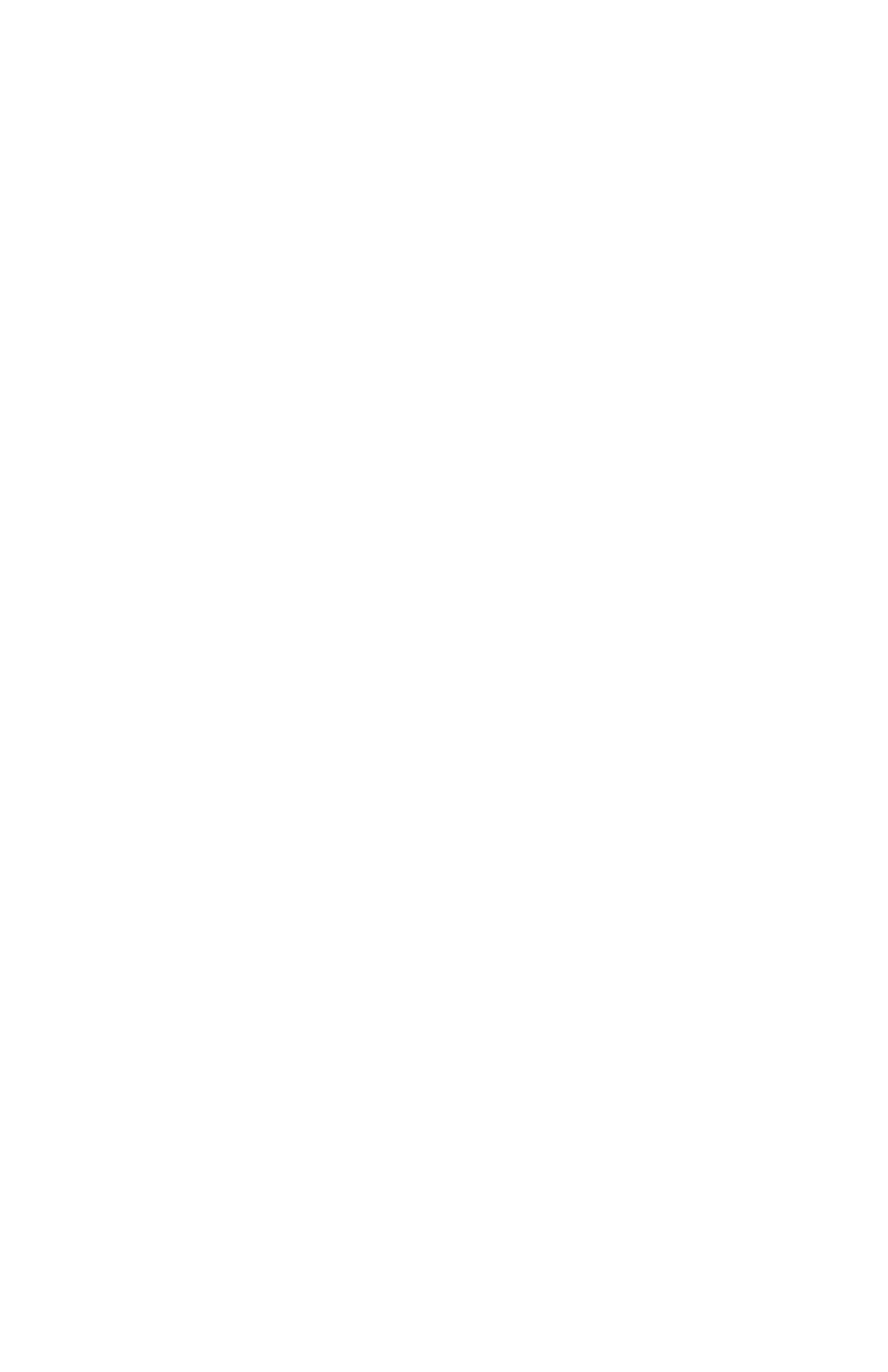

Form 9-265-a Rev

(January 1964) 


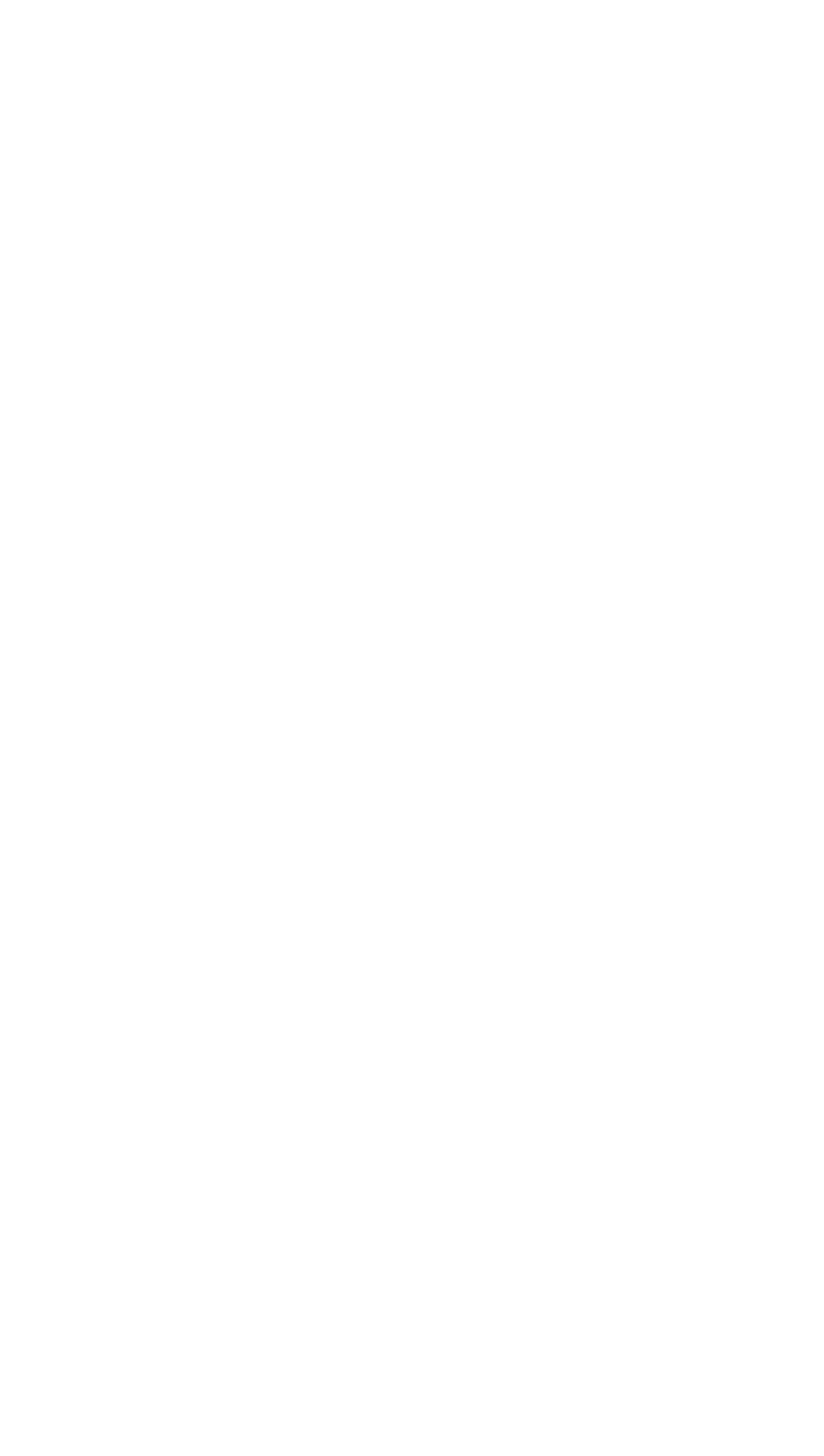


STREAMS TRIBUTARY TO LAKE ERIE--Cont1nued

4-1856. MAUMEE RIVER AT DEFIANCE, OHIO--Continued

Data from continuous recorder, water year October 1966 to September 1967

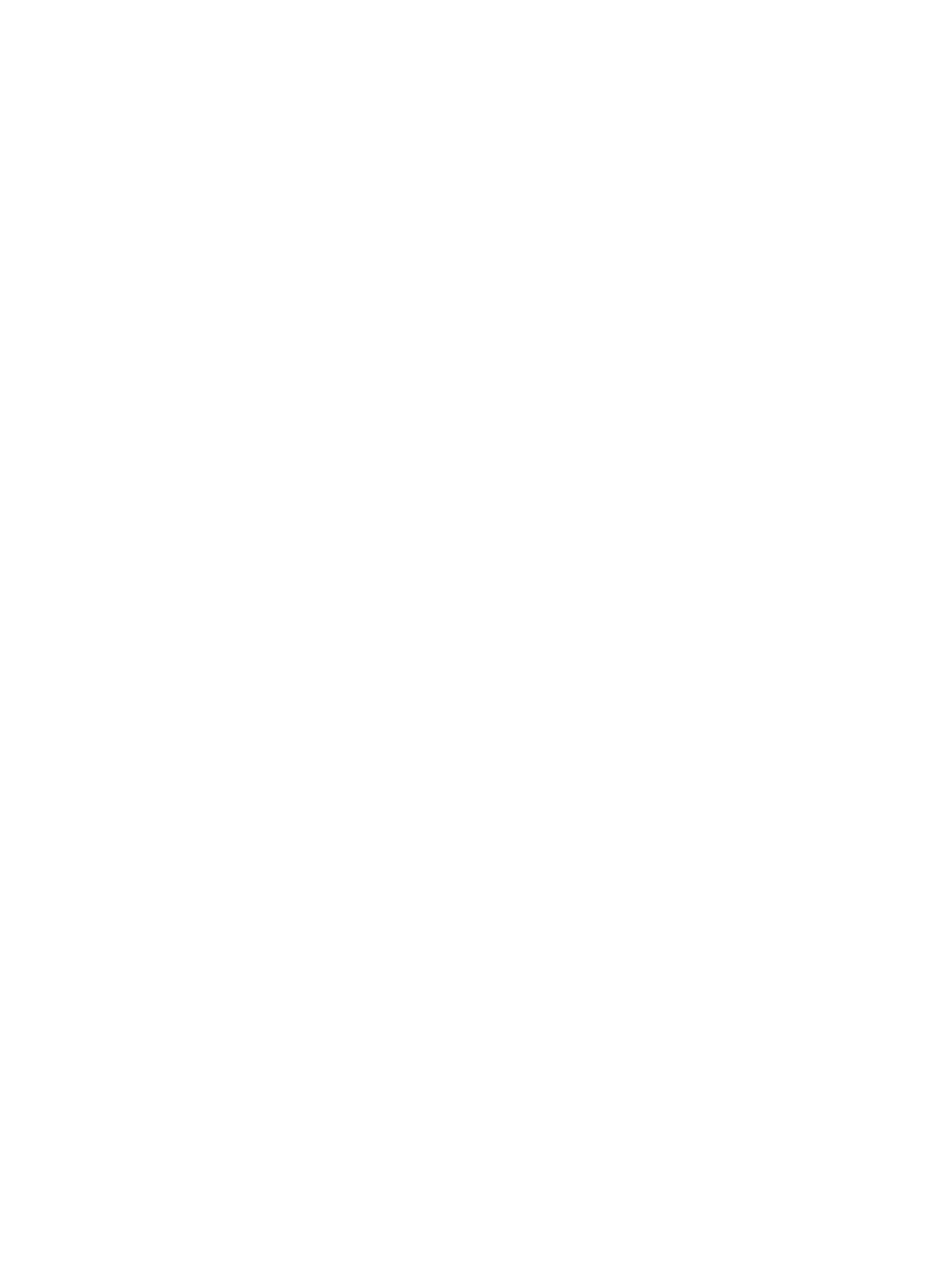


STREAHS TRIBUTARY TO LAKE ERIE--Continued

4-1856. MAUMEE RIVER AT DEFIANCE, OHIO--Continued

Data from continuous recorder, water year october 1966 to September 1967--Continued

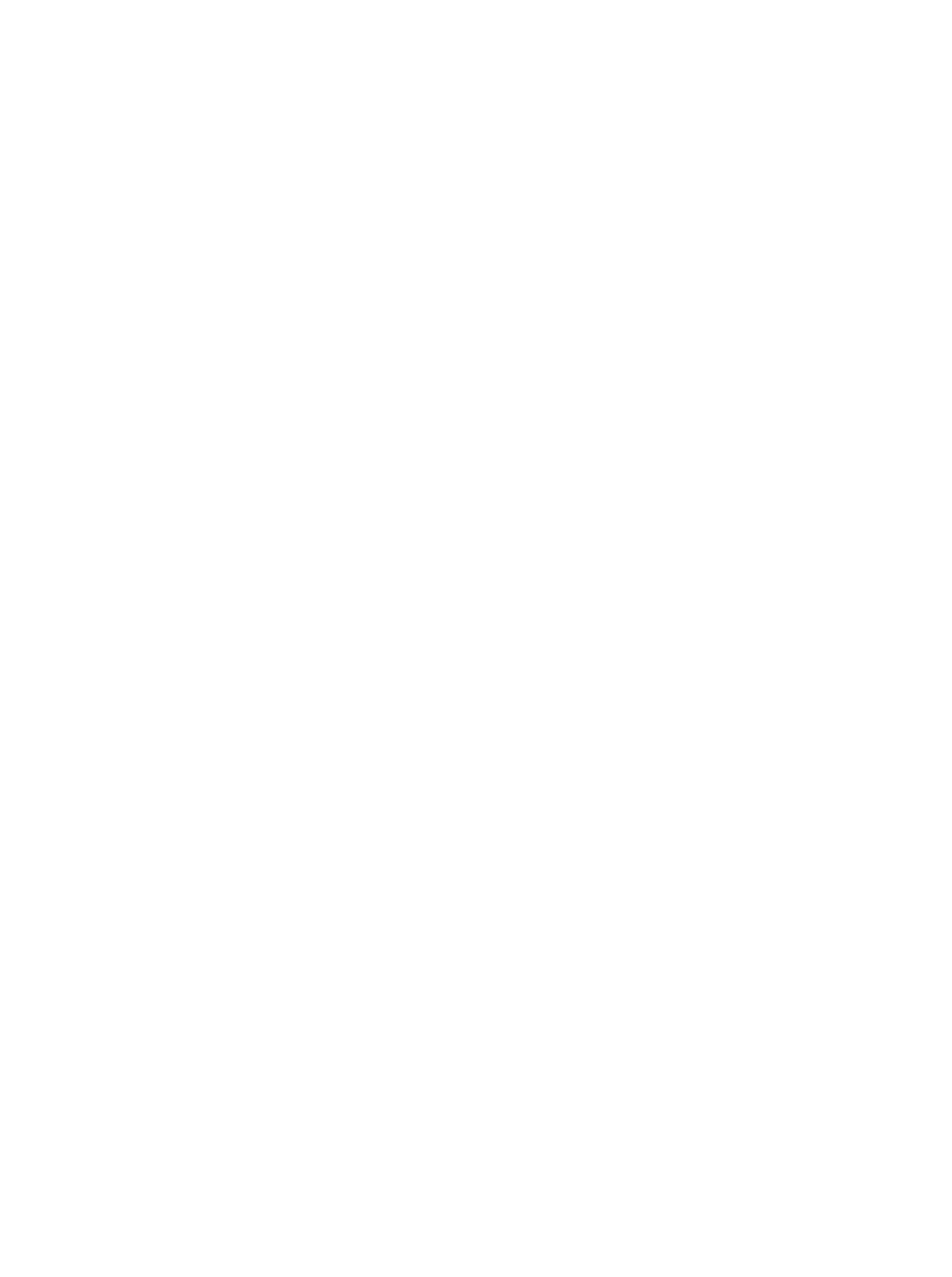




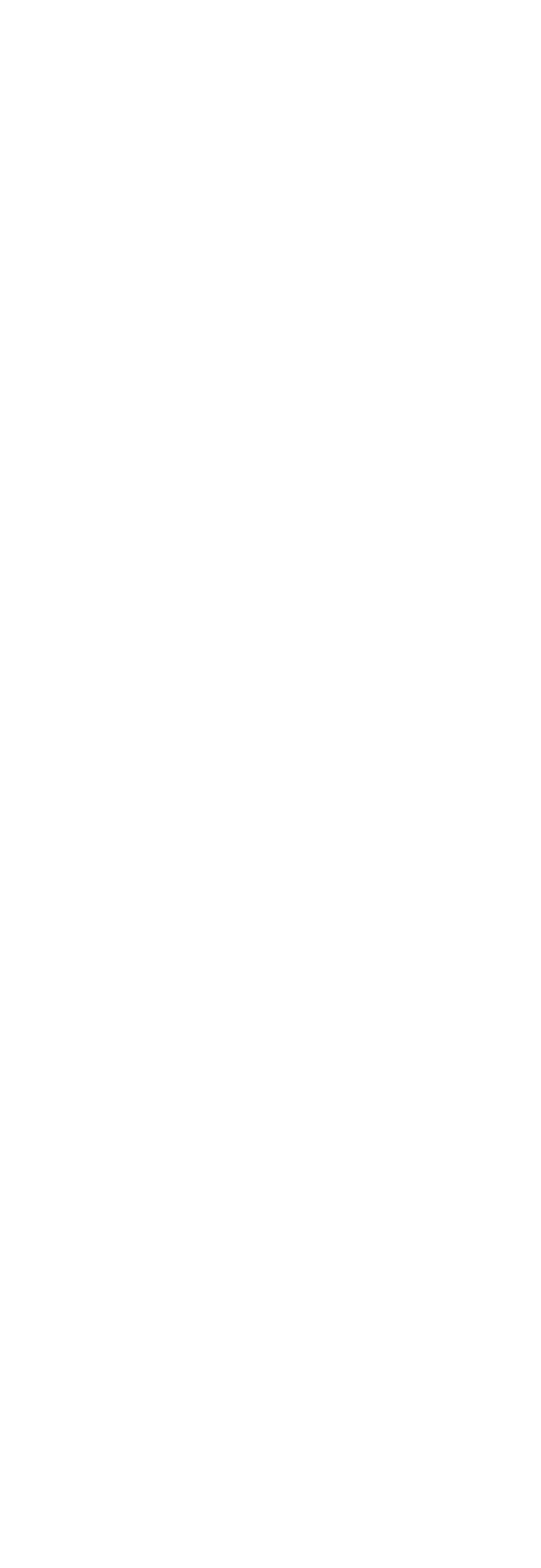


STREAMS TRIBUTARY TO LAKE ERIE--Continued

4-1882. AUGLAIZE RIVER AT CLOVERDALE, OHIO--Cont1nued

Data from continuous recorder, June to September 1967

\begin{tabular}{|c|c|c|c|c|c|c|c|c|c|c|c|c|c|c|c|c|}
\hline \multirow{3}{*}{ Day } & \multicolumn{8}{|c|}{ JUNE } & \multicolumn{8}{|c|}{$J U L Y$} \\
\hline & \multicolumn{2}{|c|}{$\begin{array}{c}\text { Specific } \\
\text { conductance } \\
\text { (micromhos } \\
\text { at } 25^{\circ} \mathrm{C} \text { ) }\end{array}$} & \multicolumn{2}{|c|}{ pH } & \multicolumn{2}{|c|}{$\begin{array}{l}\text { Dissolved } \\
\text { oxygen } \\
\text { (ppm) }\end{array}$} & \multicolumn{2}{|c|}{$\begin{array}{c}\text { Temper- } \\
\text { ature } \\
\left({ }^{\circ} \mathbf{F}\right)\end{array}$} & \multicolumn{2}{|c|}{$\begin{array}{c}\text { Specific } \\
\text { conductance } \\
\text { (micromhos } \\
\text { at } 25^{\circ} \mathrm{C} \text { ) }\end{array}$} & \multicolumn{2}{|c|}{$\mathbf{p H}$} & \multicolumn{2}{|c|}{$\begin{array}{l}\text { Dissolved } \\
\text { oxygen } \\
\text { (ppm) }\end{array}$} & \multicolumn{2}{|c|}{$\begin{array}{c}\text { Temper- } \\
\text { ature } \\
\left({ }^{\circ} \mathrm{F}\right)\end{array}$} \\
\hline & Max & Min & Max & Min & $\operatorname{Max}$ & Min & Max & Min & $\operatorname{Max}$ & Min & Max & Min & Max & Min & $N^{\prime} \times x$ & Min \\
\hline $\begin{array}{l}1 \ldots \\
2 \ldots \\
4 \ldots \\
5 \ldots\end{array}$ & $\begin{array}{l}= \\
=- \\
= \\
=\end{array}$ & $\begin{array}{l}=- \\
\overline{--} \\
=-\end{array}$ & $\begin{array}{l}-- \\
-- \\
--\end{array}$ & $\begin{array}{l}- \\
-- \\
-- \\
-\end{array}$ & & & $\begin{array}{l}-- \\
=- \\
--\end{array}$ & $\begin{array}{l}=- \\
=- \\
=- \\
=-\end{array}$ & $\begin{array}{l}660 \\
680 \\
700 \\
710 \\
700\end{array}$ & $\begin{array}{l}590 \\
620 \\
680 \\
680 \\
680\end{array}$ & $\begin{array}{l}8.6 \\
8.5 \\
8.1 \\
8.4 \\
8.5\end{array}$ & $\begin{array}{l}7.6 \\
7.6 \\
7.5 \\
7.7 \\
8.0\end{array}$ & & & $\begin{array}{l}80 \\
79 \\
78 \\
76 \\
75\end{array}$ & $\begin{array}{l}74 \\
76 \\
75 \\
73 \\
71\end{array}$ \\
\hline $\begin{array}{r}6 \ldots \\
7 \ldots \\
8 \ldots \\
9 \cdots \\
10 \cdots\end{array}$ & $\begin{array}{l}=- \\
=- \\
=- \\
=-\end{array}$ & $\begin{array}{l}=- \\
=- \\
--\end{array}$ & $\begin{array}{l}=- \\
\overline{-} \\
=- \\
--\end{array}$ & $\begin{array}{l}m \\
m \\
m \\
m\end{array}$ & & & $\begin{array}{l}=- \\
=- \\
=-\end{array}$ & $\begin{array}{l}=- \\
=- \\
=- \\
--\end{array}$ & $\begin{array}{l}820 \\
890 \\
770 \\
840 \\
850\end{array}$ & $\begin{array}{l}700 \\
760 \\
730 \\
770 \\
770\end{array}$ & $\begin{array}{l}8.6 \\
8.6 \\
8.4 \\
8.6 \\
8.6\end{array}$ & $\begin{array}{l}7.9 \\
7.9 \\
8.0 \\
7.7 \\
7.7\end{array}$ & & & $\begin{array}{l}76 \\
77 \\
80 \\
83 \\
81\end{array}$ & $\begin{array}{l}71 \\
73 \\
75 \\
77 \\
79\end{array}$ \\
\hline $\begin{array}{l}11 \ldots \\
12 \ldots \\
13 . \\
14 \ldots \\
15 \ldots\end{array}$ & $\begin{array}{l}= \\
\ddot{-} \\
=\end{array}$ & $\begin{array}{l}-- \\
=- \\
--\end{array}$ & $\begin{array}{l}=- \\
=- \\
=-\end{array}$ & $\begin{array}{l}m \\
= \\
m\end{array}$ & & & $\begin{array}{l}= \\
=- \\
=\end{array}$ & $\begin{array}{l}= \\
=- \\
=-\end{array}$ & $\begin{array}{r}820 \\
810 \\
980 \\
1030 \\
1020\end{array}$ & $\begin{array}{l}710 \\
710 \\
800 \\
970 \\
980\end{array}$ & $\begin{array}{l}8.0 \\
8.4 \\
8.0 \\
7.8 \\
7.9\end{array}$ & $\begin{array}{l}7.6 \\
7.6 \\
7.6 \\
7.6 \\
7.6\end{array}$ & & & $\begin{array}{l}83 \\
83 \\
79 \\
75 \\
71\end{array}$ & $\begin{array}{l}78 \\
78 \\
74 \\
71 \\
68\end{array}$ \\
\hline $\begin{array}{l}16 \ldots \\
17 \ldots \\
18 \ldots \\
19 \ldots \\
20 \ldots\end{array}$ & $\begin{array}{r}= \\
= \\
- \\
1050\end{array}$ & $\begin{array}{r}=- \\
=- \\
=- \\
1030\end{array}$ & $\begin{array}{c}-- \\
-- \\
-- \\
-- \\
8.0\end{array}$ & $\begin{array}{l}-- \\
-- \\
7.7\end{array}$ & & & $\begin{array}{l}-- \\
-- \\
-- \\
78\end{array}$ & $\begin{array}{l}-- \\
-- \\
-- \\
77\end{array}$ & $\begin{array}{r}1020 \\
1050 \\
990 \\
950 \\
970\end{array}$ & $\begin{array}{r}1000 \\
970 \\
940 \\
880 \\
890\end{array}$ & $\begin{array}{l}8.6 \\
9.0 \\
9.1 \\
9.3 \\
9.3\end{array}$ & $\begin{array}{l}7.6 \\
8.2 \\
8.6 \\
8.6 \\
8.9\end{array}$ & & & $\begin{array}{l}73 \\
73 \\
76 \\
78 \\
78\end{array}$ & $\begin{array}{l}69 \\
67 \\
69 \\
71 \\
73\end{array}$ \\
\hline $\begin{array}{l}21 \cdots \\
22 \ldots \\
23 \ldots \\
24 \cdots \\
25 \cdots\end{array}$ & $\begin{array}{r}1060 \\
= \\
= \\
=\end{array}$ & $\begin{array}{r}1040 \\
=- \\
= \\
=-\end{array}$ & $\begin{array}{l}9.6 \\
9.4 \\
8.6 \\
8.6 \\
7.5\end{array}$ & $\begin{array}{l}7.7 \\
7.6 \\
7.4 \\
7.3 \\
7.0\end{array}$ & & & $\begin{array}{l}77 \\
80 \\
81 \\
82 \\
77\end{array}$ & $\begin{array}{l}75 \\
74 \\
74 \\
76 \\
73\end{array}$ & $\begin{array}{l}1090 \\
1100 \\
1120 \\
1140 \\
1180\end{array}$ & $\begin{array}{r}970 \\
1040 \\
1060 \\
1090 \\
1110\end{array}$ & $\begin{array}{l}9.0 \\
8.7 \\
8.3 \\
8.0 \\
7.7\end{array}$ & $\begin{array}{l}8.6 \\
8.2 \\
7.8 \\
7.6 \\
7.5\end{array}$ & & & $\begin{array}{l}79 \\
82 \\
82 \\
83 \\
83\end{array}$ & $\begin{array}{l}74 \\
76 \\
78 \\
78 \\
78\end{array}$ \\
\hline $\begin{array}{l}26 \ldots \\
27 \ldots \\
28 \ldots \\
29 \ldots \\
30 \ldots \\
31 \ldots\end{array}$ & $\begin{array}{r}-- \\
710 \\
940 \\
980 \\
-- \\
\end{array}$ & $\begin{array}{r}-- \\
640 \\
-- \\
=-\end{array}$ & $\begin{array}{r}8.4 \\
8.2 \\
8.2 \\
8.2 \\
8.4 \\
-- \\
\end{array}$ & $\begin{array}{r}7.1 \\
7.0 \\
7.0 \\
7.6 \\
7.7 \\
-. \\
\end{array}$ & 7.0 & $4 \cdot 7$ & $\begin{array}{l}78 \\
81 \\
76 \\
74 \\
76 \\
-- \\
\end{array}$ & $\begin{array}{l}71 \\
74 \\
72 \\
71 \\
71 \\
-- \\
\end{array}$ & $\begin{array}{r}1120 \\
980 \\
1040 \\
1130 \\
1160 \\
990\end{array}$ & $\begin{array}{l}910 \\
890 \\
950 \\
940 \\
970 \\
600\end{array}$ & $\begin{array}{l}7.8 \\
8.3 \\
8.1 \\
8.3 \\
7.5 \\
7.4\end{array}$ & $\begin{array}{l}7.4 \\
7.5 \\
7.6 \\
7.5 \\
7.4 \\
7.1\end{array}$ & & & $\begin{array}{l}83 \\
78 \\
78 \\
78 \\
78 \\
74 \\
\end{array}$ & $\begin{array}{l}77 \\
76 \\
75 \\
75 \\
74 \\
71 \\
\end{array}$ \\
\hline \multicolumn{9}{|c|}{ AUGUST } & \multicolumn{8}{|c|}{ SEPTEMBER } \\
\hline $\begin{array}{l}1 \ldots \\
2 \ldots \\
4 \ldots \\
5 \ldots\end{array}$ & $\begin{array}{l}= \\
z- \\
z\end{array}$ & $\begin{array}{l}-- \\
-- \\
-- \\
--\end{array}$ & $\begin{array}{l}7.7 \\
8.4 \\
7.3 \\
7.3 \\
7.3\end{array}$ & $\begin{array}{l}6.8 \\
7.0 \\
7.2 \\
7.2 \\
7.2\end{array}$ & & & $\begin{array}{l}73 \\
75 \\
78 \\
77 \\
77\end{array}$ & $\begin{array}{l}71 \\
72 \\
75 \\
75 \\
75\end{array}$ & $\begin{array}{r}960 \\
880 \\
=- \\
--\end{array}$ & $\begin{array}{r}800 \\
750 \\
\approx- \\
\simeq-\end{array}$ & $\begin{array}{l}7.7 \\
7.9 \\
8.1 \\
8.2 \\
7.8\end{array}$ & $\begin{array}{l}7.1 \\
7.0 \\
7.1 \\
7.3 \\
7.0\end{array}$ & $\begin{array}{l}= \\
= \\
=-\end{array}$ & $\begin{array}{l}=- \\
=- \\
=- \\
=-\end{array}$ & $\begin{array}{l}71 \\
72 \\
72 \\
73 \\
75\end{array}$ & $\begin{array}{l}67 \\
67 \\
68 \\
68 \\
69\end{array}$ \\
\hline $\begin{array}{c}6 \ldots \\
7 \ldots \\
8 \ldots \\
9 \ldots \\
10 \ldots\end{array}$ & $\begin{array}{r}530 \\
530 \\
530 \\
590 \\
--\end{array}$ & $\begin{array}{r}450 \\
500 \\
490 \\
500 \\
--\end{array}$ & $\begin{array}{l}7.5 \\
7.6 \\
7.8 \\
8.9 \\
8.4\end{array}$ & $\begin{array}{l}7.2 \\
7.3 \\
7.4 \\
7.4 \\
7.0\end{array}$ & & & $\begin{array}{l}76 \\
77 \\
78 \\
79 \\
76\end{array}$ & $\begin{array}{l}74 \\
74 \\
74 \\
76 \\
71\end{array}$ & $\begin{array}{l}-- \\
=- \\
=- \\
=-\end{array}$ & $\begin{array}{l}\approx \\
\approx \\
=\end{array}$ & $\begin{array}{l}7.7 \\
7.8 \\
7.6 \\
7.0 \\
7.1\end{array}$ & $\begin{array}{l}7.0 \\
7.0 \\
6.9 \\
6.8 \\
6.8\end{array}$ & $\begin{array}{l}=- \\
=- \\
=-\end{array}$ & $\begin{array}{l}-- \\
=- \\
--\end{array}$ & $\begin{array}{l}75 \\
75 \\
75 \\
73 \\
71\end{array}$ & $\begin{array}{l}70 \\
69 \\
70 \\
70 \\
66\end{array}$ \\
\hline $\begin{array}{l}11 \ldots \\
12 \ldots \\
13 \ldots \\
14 \ldots \\
15 \ldots\end{array}$ & $\begin{array}{l}820 \\
930 \\
950 \\
890 \\
900\end{array}$ & $\begin{array}{l}700 \\
780 \\
840 \\
800 \\
790\end{array}$ & $\begin{array}{l}8.2 \\
8.5 \\
8.9 \\
9.2 \\
9.3\end{array}$ & $\begin{array}{l}7.4 \\
7.5 \\
7.8 \\
7.6 \\
8.8\end{array}$ & & & $\begin{array}{l}73 \\
73 \\
73 \\
75 \\
76\end{array}$ & $\begin{array}{l}69 \\
69 \\
68 \\
69 \\
69\end{array}$ & $\begin{array}{l}= \\
=- \\
=-\end{array}$ & $=$ & $\begin{array}{l}7.0 \\
7.0 \\
7.0 \\
7.0 \\
7.0\end{array}$ & $\begin{array}{l}6.8 \\
6.8 \\
6.7 \\
6.7 \\
6.8\end{array}$ & $\begin{array}{l}z- \\
=- \\
=- \\
=-\end{array}$ & $\begin{array}{l}=- \\
=- \\
=- \\
=-\end{array}$ & $\begin{array}{l}68 \\
68 \\
71 \\
71 \\
72\end{array}$ & $\begin{array}{l}65 \\
64 \\
66 \\
66 \\
66\end{array}$ \\
\hline $\begin{array}{l}16 \ldots \\
17 \ldots \\
18 \ldots \\
19 . \ldots \\
20 \ldots\end{array}$ & $\begin{array}{r}930 \\
900 \\
960 \\
960 \\
1040\end{array}$ & $\begin{array}{l}810 \\
850 \\
890 \\
890 \\
960\end{array}$ & $\begin{array}{l}9.2 \\
8.8 \\
8.4 \\
7.8 \\
7.5\end{array}$ & $\begin{array}{l}8.4 \\
8.4 \\
7.8 \\
7.4 \\
7.3\end{array}$ & & & $\begin{array}{l}77 \\
78 \\
79 \\
76 \\
75\end{array}$ & $\begin{array}{l}71 \\
73 \\
74 \\
73 \\
72\end{array}$ & $\begin{array}{l}=- \\
=- \\
=-\end{array}$ & $\begin{array}{l}-- \\
-- \\
--\end{array}$ & $\begin{array}{l}7.0 \\
6.9 \\
6.9 \\
6.9 \\
7.0\end{array}$ & $\begin{array}{l}6.8 \\
6.8 \\
6.8 \\
6.7 \\
6.7\end{array}$ & $\begin{array}{l}=- \\
=- \\
=- \\
-\end{array}$ & $\begin{array}{l}-m \\
-- \\
-- \\
--\end{array}$ & $\begin{array}{l}73 \\
71 \\
72 \\
73 \\
75\end{array}$ & $\begin{array}{l}67 \\
68 \\
68 \\
69 \\
69\end{array}$ \\
\hline $\begin{array}{l}21 \ldots \\
22 \ldots \\
23 . \\
24 \ldots \\
25 \ldots\end{array}$ & $\begin{array}{l}1200 \\
1190 \\
1210 \\
1230 \\
1290\end{array}$ & $\begin{array}{r}1020 \\
1100 \\
1160 \\
1150 \\
950\end{array}$ & $\begin{array}{l}7.3 \\
7.4 \\
7.4 \\
7.1 \\
6.9\end{array}$ & $\begin{array}{l}7.1 \\
7.0 \\
7.1 \\
6.6 \\
6.1\end{array}$ & & & $\begin{array}{l}75 \\
74 \\
74 \\
75 \\
77\end{array}$ & $\begin{array}{l}70 \\
71 \\
69 \\
69 \\
71\end{array}$ & $\begin{array}{r}1200 \\
=- \\
=- \\
=-\end{array}$ & $\begin{array}{r}1110 \\
= \\
= \\
=\end{array}$ & $\begin{array}{l}7.4 \\
7.0 \\
7.8 \\
8.4 \\
8.4\end{array}$ & $\begin{array}{l}6.8 \\
6.9 \\
7.0 \\
6.2 \\
8.1\end{array}$ & $\begin{array}{l}6.0 \\
6.2 \\
7.2 \\
7.0 \\
6.4\end{array}$ & $\begin{array}{l}4.2 \\
3.4 \\
4.6 \\
6.2 \\
5.9\end{array}$ & $\begin{array}{l}71 \\
68 \\
72 \\
70 \\
70\end{array}$ & $\begin{array}{l}66 \\
64 \\
62 \\
62 \\
69\end{array}$ \\
\hline $\begin{array}{l}26 \ldots \\
27 \ldots \\
28 \ldots \\
29 \ldots \\
30 \ldots \\
31 \ldots\end{array}$ & $\begin{array}{r}960 \\
1010 \\
- \\
-- \\
1130 \\
1230\end{array}$ & $\begin{array}{r}910 \\
910 \\
-- \\
-- \\
1110 \\
960\end{array}$ & $\begin{array}{l}7.2 \\
7.2 \\
7.3 \\
7.3 \\
7.3 \\
7.3\end{array}$ & $\begin{array}{l}5.9 \\
7.1 \\
7.1 \\
7.1 \\
7.1 \\
7.0\end{array}$ & & & $\begin{array}{l}77 \\
73 \\
70 \\
73 \\
76 \\
73\end{array}$ & $\begin{array}{l}72 \\
68 \\
67 \\
68 \\
71 \\
70\end{array}$ & $\begin{array}{l}=- \\
=- \\
=- \\
=-\end{array}$ & $\begin{array}{l}-- \\
=- \\
=- \\
=-\end{array}$ & $\begin{array}{l}8.2 \\
7.8 \\
6.8 \\
6.9 \\
7.5 \\
--2\end{array}$ & $\begin{array}{l}7.5 \\
6.7 \\
6.7 \\
6.4 \\
6.4 \\
-.\end{array}$ & $\begin{array}{l}5.5 \\
5.2 \\
5.8 \\
5.3 \\
5.3 \\
-.\end{array}$ & $\begin{array}{r}5.9 \\
5.8 \\
5.3 \\
4.9 \\
4.7 \\
--\end{array}$ & $\begin{array}{l}70 \\
70 \\
70 \\
72 \\
72 \\
--\end{array}$ & $\begin{array}{l}68 \\
68 \\
68 \\
70 \\
70 \\
-- \\
\end{array}$ \\
\hline
\end{tabular}




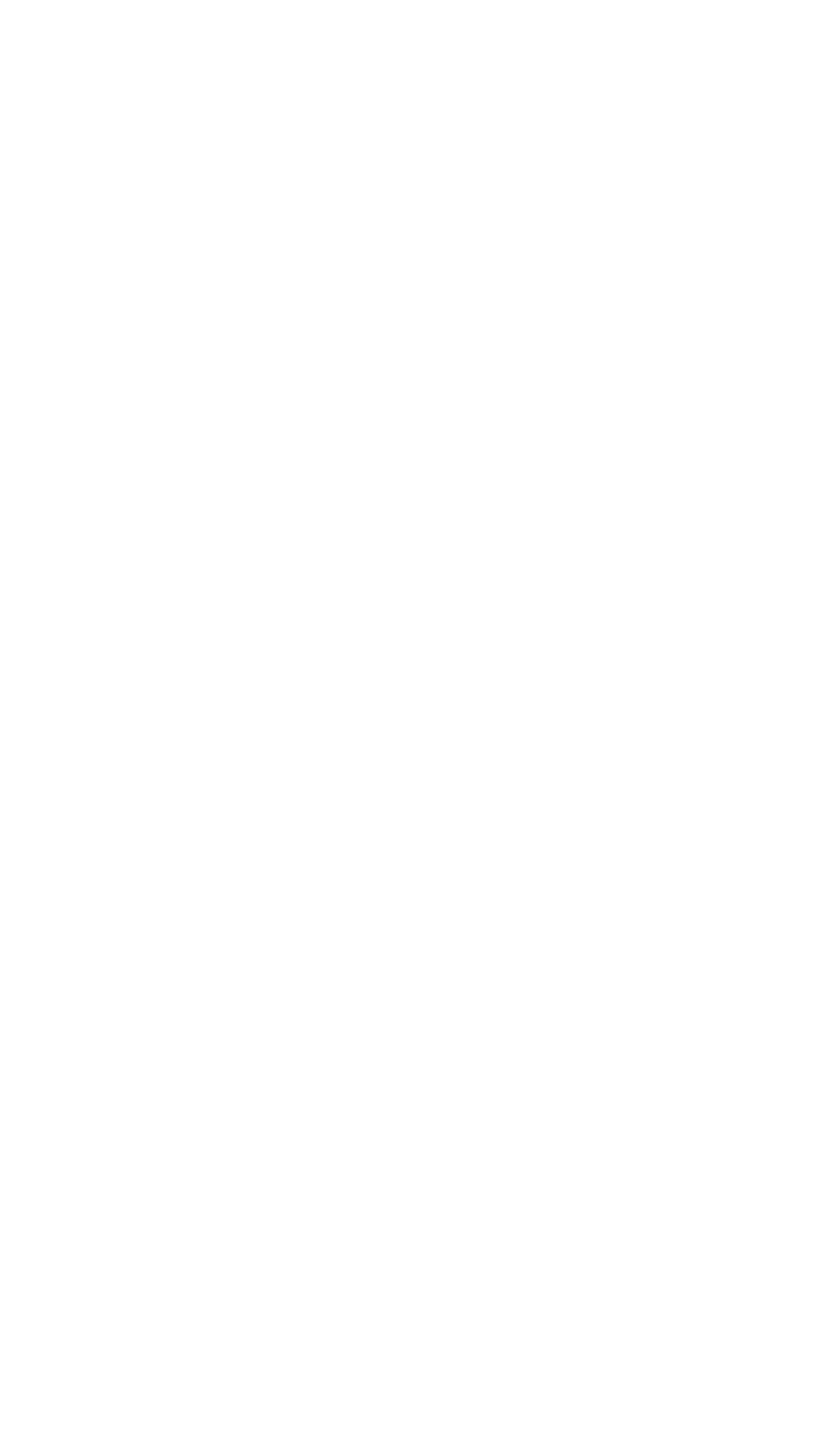


STREAMS TRIBUTARY TO LAKE ERIE--Continued

4-1915. AUGLAIZE RIVER NEAR DEFIANCE, OHIO--Continued

Data from continuous recorder, water year Octobex 1966 to september 1967

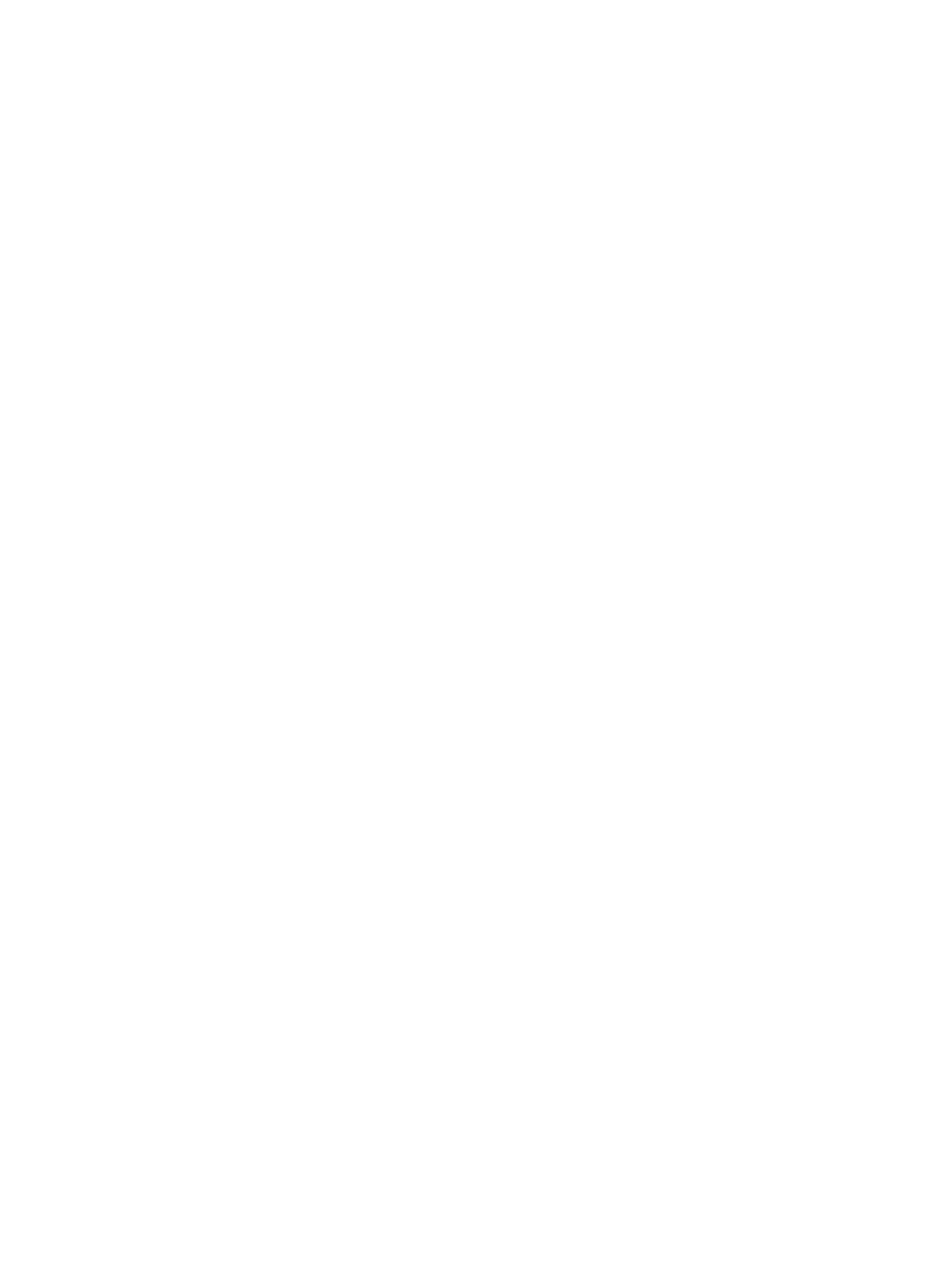


STREAMS TRIBUTARY TO LAKE ERIE--Continued

4-1915. AUGLAIZE RIVER NEAR DEFIANCE, OHIO--Cont Inued

Data from continuous recorder, water year october 1966 to september 1967--Cont1nued

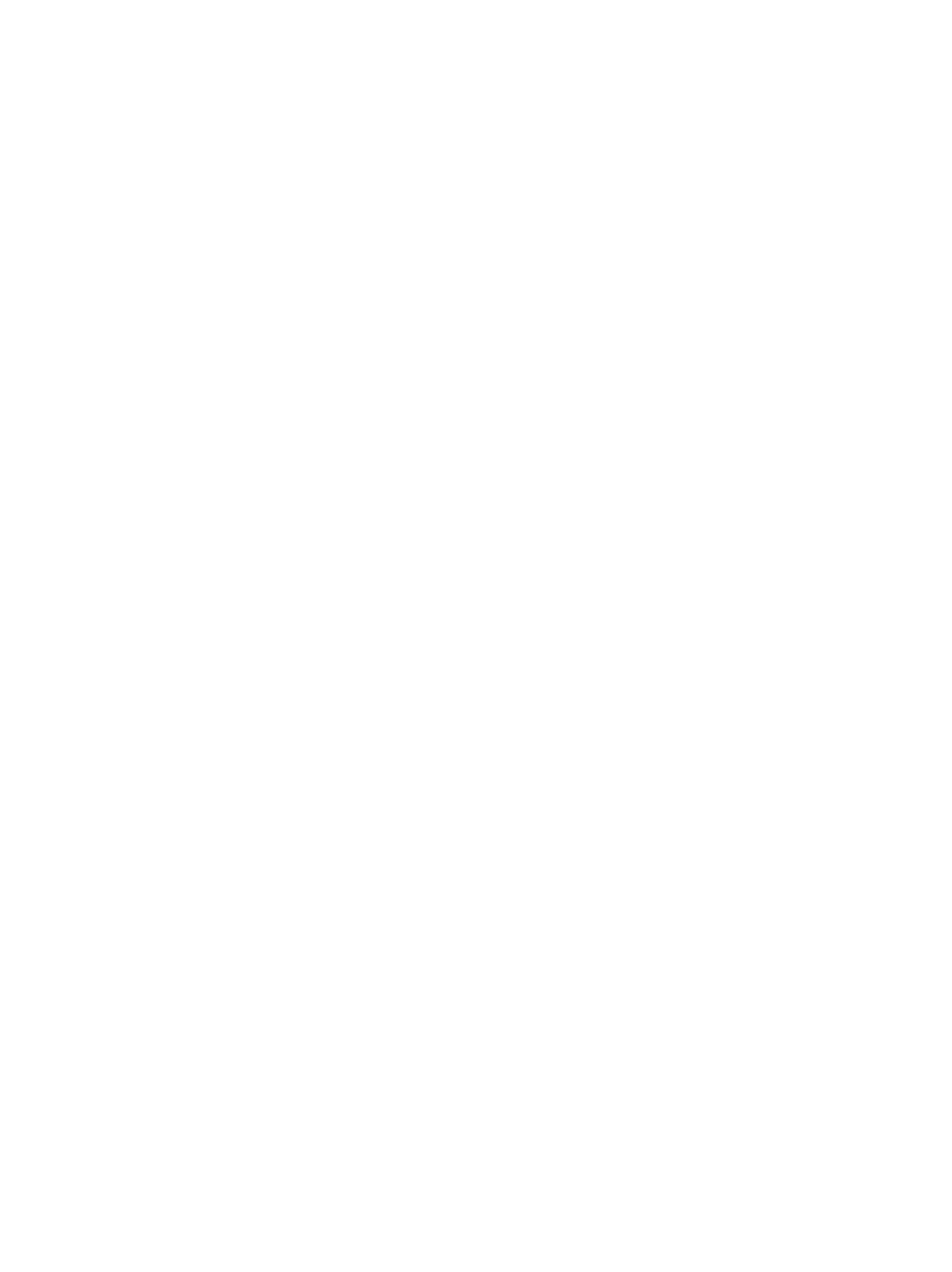




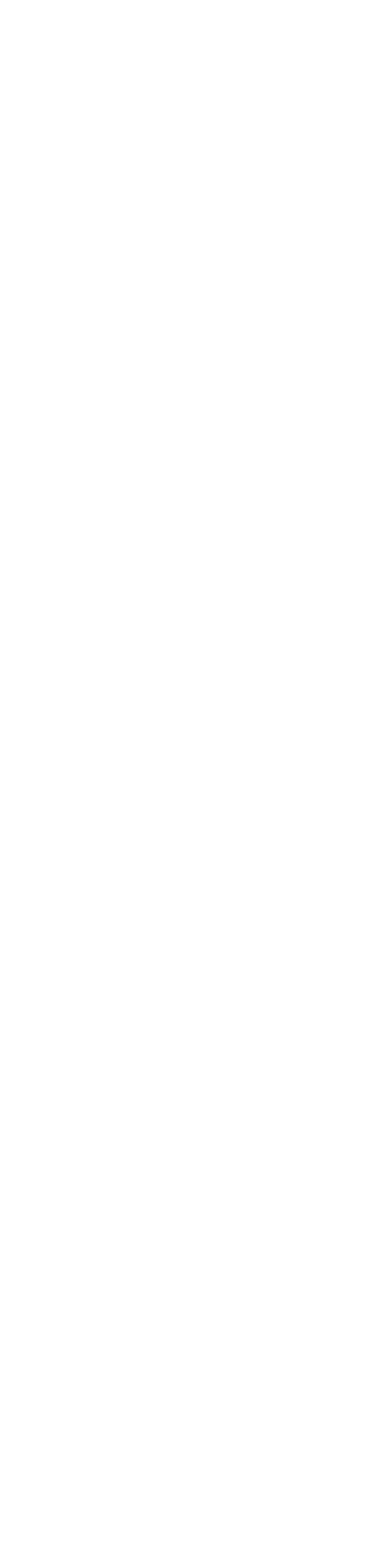

\begin{tabular}{|c|c|}
\hline 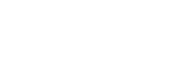 & \\
\hline 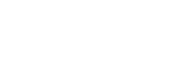 & \\
\hline 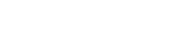 & \\
\hline$\frac{m}{2}$ & 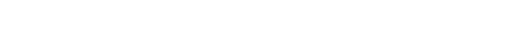 \\
\hline 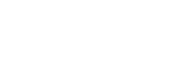 & 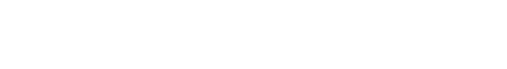 \\
\hline 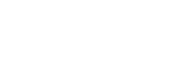 & \\
\hline 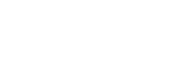 & 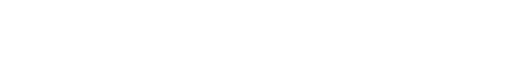 \\
\hline 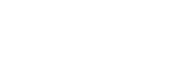 & 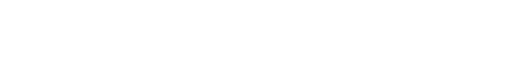 \\
\hline 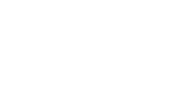 & 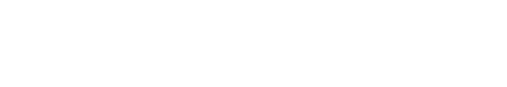 \\
\hline 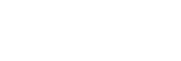 & \\
\hline 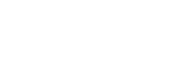 & 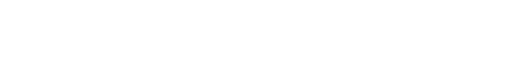 \\
\hline 产善馬 & in \\
\hline 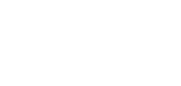 & 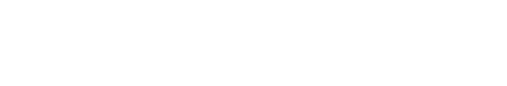 \\
\hline 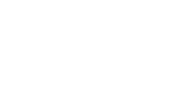 & 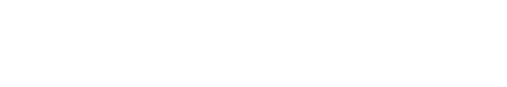 \\
\hline$\frac{3}{8}=\frac{8}{2}$ & $0000000000000 \times 000000 \times 000000$ \\
\hline 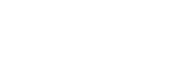 & 疍 \\
\hline 章是金 & \\
\hline 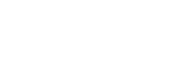 & \\
\hline 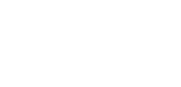 & \\
\hline 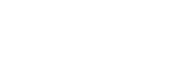 & \\
\hline 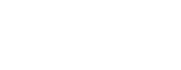 & \\
\hline 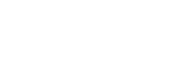 & \\
\hline 窎嘼 & \\
\hline 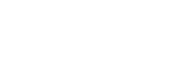 & \\
\hline 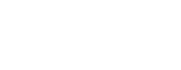 & \\
\hline 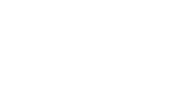 & 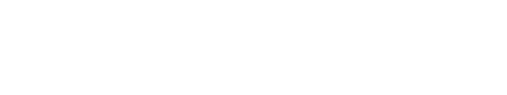 \\
\hline 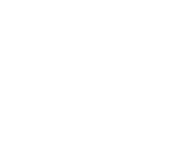 & 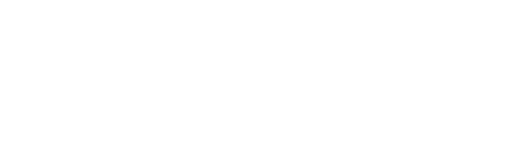 \\
\hline
\end{tabular}


STREAMS TRIBUTARY TO LAKE ERIE--COntInued

4-1935. MAUMEE RIVER AT FATERVILLE, OHIO--COntinued

Data from continuous recorder, water year october 1966 to September 1967

\begin{tabular}{|c|c|c|c|c|c|c|c|c|c|c|c|c|c|c|c|c|}
\hline \multirow{3}{*}{ Day } & \multicolumn{8}{|c|}{ OCTOBER } & \multicolumn{8}{|c|}{ MOVEMAER } \\
\hline & \multicolumn{2}{|c|}{$\begin{array}{c}\text { Specific } \\
\text { conductance } \\
\text { (micromhos } \\
\text { at } 25^{\circ} \mathrm{C} \text { ) }\end{array}$} & \multicolumn{2}{|c|}{ pH } & \multicolumn{2}{|c|}{$\begin{array}{l}\text { Dissolved } \\
\text { oxygen } \\
\text { (ppm) }\end{array}$} & \multicolumn{2}{|c|}{$\begin{array}{c}\text { Temper- } \\
\text { ature } \\
\left({ }^{\circ} \mathrm{F}\right)\end{array}$} & \multicolumn{2}{|c|}{$\begin{array}{c}\text { Specific } \\
\text { conductance } \\
\text { (micromhos } \\
\text { at } 25^{\circ} \mathrm{C} \text { ) }\end{array}$} & \multicolumn{2}{|c|}{ pH } & \multicolumn{2}{|c|}{$\begin{array}{l}\text { Dissolved } \\
\text { oxygen } \\
\text { (ppm) }\end{array}$} & \multicolumn{2}{|c|}{$\begin{array}{c}\text { Temper- } \\
\text { ature } \\
\left({ }^{\circ} \mathrm{F}\right)\end{array}$} \\
\hline & $\operatorname{Max}$ & Min & $\operatorname{Max}$ & Min & $\operatorname{Max}$ & Min & $\operatorname{Max}$ & Min & $\operatorname{Max}$ & Min & Max & Min & Max & Min & Max & Min \\
\hline $\begin{array}{l}1 \ldots \\
2 \ldots \\
3 \ldots \\
4 \ldots \\
5 \ldots\end{array}$ & $\begin{array}{l}760 \\
710 \\
760 \\
740 \\
680\end{array}$ & $\begin{array}{l}620 \\
580 \\
610 \\
600 \\
570\end{array}$ & $\begin{array}{l}8.9 \\
9.0 \\
8.9 \\
8.7 \\
8.8\end{array}$ & $\begin{array}{l}7.9 \\
7.9 \\
7.8 \\
8.1 \\
7.9\end{array}$ & $\begin{array}{l}13.8 \\
14.2 \\
14.1 \\
15.0 \\
-\end{array}$ & $\begin{array}{l}8.4 \\
8.5 \\
8.2 \\
8.2 \\
-.2\end{array}$ & $\begin{array}{l}61 \\
63 \\
65 \\
65 \\
63\end{array}$ & $\begin{array}{l}49 \\
49 \\
51 \\
55 \\
52\end{array}$ & $\begin{array}{l}740 \\
750 \\
710 \\
850 \\
860\end{array}$ & $\begin{array}{l}700 \\
560 \\
580 \\
620 \\
640\end{array}$ & $\begin{array}{l}8.1 \\
8.5 \\
8.5 \\
8.2 \\
8.2\end{array}$ & $\begin{array}{l}7.5 \\
7.5 \\
7.9 \\
7.7 \\
7.7\end{array}$ & $\begin{array}{l}10.9 \\
11.4 \\
11.4 \\
12.4 \\
12.7\end{array}$ & $\begin{array}{r}8.3 \\
8.5 \\
10.0 \\
10.8 \\
10.8\end{array}$ & $\begin{array}{l}50 \\
48 \\
40 \\
42 \\
42\end{array}$ & $\begin{array}{l}46 \\
33 \\
33 \\
33 \\
36\end{array}$ \\
\hline \begin{tabular}{r|}
$6 \ldots$ \\
$7 \ldots$ \\
$8 \ldots$ \\
$9 \ldots$ \\
$10 \ldots$
\end{tabular} & $\begin{array}{l}660 \\
640 \\
650 \\
670 \\
660\end{array}$ & $\begin{array}{l}550 \\
560 \\
580 \\
580 \\
590\end{array}$ & $\begin{array}{l}8.8 \\
8.7 \\
8.7 \\
8.6 \\
8.7\end{array}$ & $\begin{array}{l}7.8 \\
7.7 \\
7.6 \\
7.6 \\
7.4\end{array}$ & $=$ & $\begin{array}{l}=- \\
=- \\
=-\end{array}$ & $\begin{array}{l}62 \\
63 \\
64 \\
65 \\
62\end{array}$ & $\begin{array}{l}48 \\
48 \\
50 \\
52 \\
54\end{array}$ & $\begin{array}{l}710 \\
860 \\
830 \\
800 \\
810\end{array}$ & $\begin{array}{l}640 \\
870 \\
650 \\
660 \\
540\end{array}$ & $\begin{array}{l}9.4 \\
11.1 \\
10.4 \\
10.4 \\
9.3\end{array}$ & $\begin{array}{l}7.8 \\
8.7 \\
9.7 \\
7.9 \\
7.0\end{array}$ & $\begin{array}{l}13.0 \\
12.6 \\
12.2 \\
11.0 \\
10.1\end{array}$ & $\begin{array}{r}11.0 \\
10.8 \\
9.5 \\
9.2 \\
5.0\end{array}$ & $\begin{array}{l}45 \\
49 \\
51 \\
51 \\
60\end{array}$ & $\begin{array}{l}36 \\
40 \\
46 \\
49 \\
49\end{array}$ \\
\hline $\begin{array}{l}11 \ldots \\
12 \ldots \\
13 \ldots \\
14 \ldots \\
15 \ldots\end{array}$ & $\begin{array}{l}680 \\
680 \\
700 \\
710 \\
750\end{array}$ & $\begin{array}{l}600 \\
580 \\
630 \\
640 \\
640\end{array}$ & $\begin{array}{l}8.7 \\
8.8 \\
9.2 \\
9.0 \\
8.6\end{array}$ & $\begin{array}{l}7.1 \\
8.0 \\
8.1 \\
7.8 \\
7.7\end{array}$ & $\begin{array}{r}- \\
12.8 \\
11.8 \\
7.3\end{array}$ & $\begin{array}{l}=- \\
5.0 \\
4.2 \\
4.4\end{array}$ & $\begin{array}{l}59 \\
65 \\
65 \\
67 \\
63\end{array}$ & $\begin{array}{l}51 \\
49 \\
51 \\
59 \\
54\end{array}$ & $\begin{array}{l}370 \\
450 \\
460 \\
460 \\
470\end{array}$ & $\begin{array}{l}360 \\
360 \\
390 \\
410 \\
420\end{array}$ & $\begin{array}{l}7.1 \\
7.2 \\
7.1 \\
7.2 \\
7.2\end{array}$ & $\begin{array}{l}6.5 \\
6.5 \\
6.6 \\
6.6 \\
6.9\end{array}$ & $\begin{array}{l}5.2 \\
5.8 \\
5.9 \\
6.2 \\
6.5\end{array}$ & $\begin{array}{l}3.9 \\
3.4 \\
3.9 \\
3.9 \\
4.4\end{array}$ & $\begin{array}{l}53 \\
53 \\
52 \\
53 \\
51\end{array}$ & $\begin{array}{l}51 \\
50 \\
49 \\
48 \\
47\end{array}$ \\
\hline $\begin{array}{l}16 \ldots \\
17 \ldots \\
18 \ldots \\
19 \ldots \\
20 \ldots\end{array}$ & $\begin{array}{l}720 \\
720 \\
710 \\
710 \\
840\end{array}$ & $\begin{array}{l}640 \\
640 \\
620 \\
630 \\
650\end{array}$ & $\begin{array}{l}8.6 \\
8.7 \\
8.6 \\
8.5 \\
8.7\end{array}$ & $\begin{array}{l}8.0 \\
7.6 \\
7.9 \\
7.9 \\
7.8\end{array}$ & $\begin{array}{r}8.8 \\
10.7 \\
10.2 \\
9.4 \\
10.2\end{array}$ & $\begin{array}{l}6.5 \\
6.9 \\
6.8 \\
7.2 \\
7.5\end{array}$ & $\begin{array}{l}57 \\
57 \\
52 \\
55 \\
59\end{array}$ & $\begin{array}{l}51 \\
49 \\
48 \\
49 \\
46\end{array}$ & $\begin{array}{l}500 \\
500 \\
520 \\
530 \\
530\end{array}$ & $\begin{array}{l}450 \\
460 \\
480 \\
500 \\
500\end{array}$ & $\begin{array}{r}8.6 \\
8.5 \\
= \\
=\end{array}$ & $\begin{array}{l}6.7 \\
7.4 \\
= \\
=\end{array}$ & $\begin{array}{l}8.1 \\
8.2 \\
8.2 \\
8.6 \\
8.8\end{array}$ & $\begin{array}{l}5.1 \\
6.9 \\
6.7 \\
7.1 \\
7.7\end{array}$ & $\begin{array}{l}49 \\
49 \\
46 \\
45\end{array}$ & $\begin{array}{l}45 \\
46 \\
46 \\
43 \\
42\end{array}$ \\
\hline $\begin{array}{l}21 \ldots \\
22 \ldots \\
23 \ldots \\
24 \ldots \\
25 \ldots\end{array}$ & $\begin{array}{r}900 \\
= \\
=\end{array}$ & $\begin{array}{c}830 \\
=- \\
=-\end{array}$ & $\begin{array}{c}8.4 \\
= \\
=\end{array}$ & $\begin{array}{l}7.9 \\
= \\
=-\end{array}$ & $\begin{array}{l}7.8 \\
= \\
=\end{array}$ & $\begin{array}{c}5.2 \\
= \\
= \\
=\end{array}$ & $=$ & $\begin{array}{l}47 \\
= \\
=\end{array}$ & $\begin{array}{l}570 \\
610 \\
630 \\
590 \\
650\end{array}$ & $\begin{array}{l}520 \\
540 \\
550 \\
560 \\
570\end{array}$ & $\bar{\Xi}$ & $\begin{array}{l}= \\
=\end{array}$ & $\begin{array}{l}8.9 \\
9.5 \\
9.2 \\
9.1 \\
8.7\end{array}$ & $\begin{array}{l}7.5 \\
8.0 \\
7.7 \\
7.3 \\
7.0\end{array}$ & $\begin{array}{l}45 \\
46 \\
48 \\
49 \\
50\end{array}$ & $\begin{array}{l}41 \\
41 \\
43 \\
45 \\
48\end{array}$ \\
\hline $\begin{array}{l}26 \ldots \\
27 \ldots \\
28 \ldots \\
29 \ldots \\
30 \ldots \\
31 \ldots\end{array}$ & $\begin{array}{l}-- \\
710 \\
710 \\
740 \\
770\end{array}$ & $\begin{array}{l}- \\
670 \\
650 \\
700 \\
700\end{array}$ & $\begin{array}{l}-- \\
-- \\
8.2 \\
8.0 \\
8.2 \\
0.2\end{array}$ & $\begin{array}{l}-- \\
7.8 \\
7.6 \\
7.6 \\
7.4\end{array}$ & $\begin{array}{r}- \\
-.8 \\
10.5 \\
10.8 \\
10.8\end{array}$ & $\begin{array}{r}- \\
-- \\
7.3 \\
6.8 \\
8.6 \\
7.6\end{array}$ & $\begin{array}{l}- \\
59 \\
56 \\
53 \\
54\end{array}$ & $\begin{array}{l}-- \\
47 \\
47 \\
47 \\
43\end{array}$ & $\begin{array}{r}600 \\
630 \\
630 \\
660 \\
690 \\
\end{array}$ & $\begin{array}{l}580 \\
570 \\
580 \\
570 \\
610 \\
-\end{array}$ & $\begin{array}{l}= \\
= \\
=\end{array}$ & $=$ & $\begin{array}{r}9.3 \\
8.4 \\
8.5 \\
9.1 \\
11.0 \\
\end{array}$ & $\begin{array}{l}7.0 \\
6.6 \\
6.8 \\
8.0 \\
8.2 \\
\end{array}$ & $\begin{array}{l}51 \\
51 \\
48 \\
44 \\
43 \\
\end{array}$ & $\begin{array}{l}46 \\
48 \\
44 \\
40 \\
40 \\
\end{array}$ \\
\hline \multicolumn{9}{|c|}{ DECEMBER } & \multicolumn{8}{|c|}{ JANUARY } \\
\hline $\begin{array}{l}1 \ldots \\
2 \ldots \\
3 \ldots \\
5 \ldots \\
5 \ldots\end{array}$ & $=$ & $\bar{z}=$ & $\begin{array}{l}7.5 \\
7.9 \\
8.0 \\
7.9 \\
8.0\end{array}$ & $\begin{array}{l}6.6 \\
6.3 \\
7.0 \\
7.0 \\
6.5\end{array}$ & $\begin{array}{l}12.0 \\
11.6 \\
11.4 \\
12.3\end{array}$ & $\begin{array}{l}10.3 \\
10.3 \\
10.4 \\
10.2\end{array}$ & $\begin{array}{l}43 \\
40 \\
38 \\
37 \\
36\end{array}$ & $\begin{array}{l}38 \\
35 \\
33 \\
33 \\
33\end{array}$ & $\begin{array}{l}720 \\
730 \\
770 \\
780 \\
780\end{array}$ & $\begin{array}{l}670 \\
680 \\
680 \\
700 \\
720\end{array}$ & $\begin{array}{l}8.9 \\
8.7 \\
8.6 \\
0.2 \\
8.5\end{array}$ & $\begin{array}{l}8.2 \\
7.9 \\
7.7 \\
7.5 \\
6.5\end{array}$ & $\begin{array}{l}7.2 \\
15.0 \\
12.7 \\
12.0 \\
13.9\end{array}$ & $\begin{array}{r}6.6 \\
6.6 \\
10.5 \\
10.9 \\
7.3\end{array}$ & $\begin{array}{l}36 \\
35 \\
35 \\
35 \\
35\end{array}$ & $\begin{array}{l}32 \\
33 \\
32 \\
32 \\
32\end{array}$ \\
\hline $\begin{array}{r}6 \ldots \\
7 \ldots \\
8 \ldots \\
9 \ldots \\
10 \ldots\end{array}$ & $\begin{array}{l}5 \overline{80} \\
490 \\
320 \\
320\end{array}$ & $\begin{array}{l}4 \overline{90} \\
240 \\
240 \\
300\end{array}$ & $\begin{array}{l}7.6 \\
9.8 \\
8.2 \\
8.2 \\
8.2\end{array}$ & $\begin{array}{l}6.6 \\
7.5 \\
7.6 \\
7.5 \\
7.5\end{array}$ & $\begin{array}{r}10.9 \\
11.2 \\
7.7 \\
5.6 \\
9.1\end{array}$ & $\begin{array}{r}10.2 \\
7.7 \\
5.6 \\
4.7 \\
5.2\end{array}$ & $\begin{array}{l}37 \\
40 \\
51 \\
51 \\
51\end{array}$ & $\begin{array}{l}34 \\
37 \\
41 \\
50 \\
47\end{array}$ & $\begin{array}{l}800 \\
790 \\
790 \\
830 \\
850\end{array}$ & $\begin{array}{l}750 \\
720 \\
700 \\
710 \\
790\end{array}$ & $\begin{array}{l}7 . \overline{4} \\
7.2 \\
7.3 \\
8.1\end{array}$ & $\begin{array}{l}-\overline{6} \\
6.5 \\
6.4 \\
6.5\end{array}$ & $\begin{array}{l}15.0 \\
13.1 \\
12.9 \\
14.2 \\
13.7\end{array}$ & $\begin{array}{r}7.6 \\
11.7 \\
9.8 \\
11.9 \\
11.8\end{array}$ & $\begin{array}{l}35 \\
35 \\
37 \\
35 \\
37\end{array}$ & $\begin{array}{l}32 \\
32 \\
32 \\
32 \\
32\end{array}$ \\
\hline $\begin{array}{l}11 \ldots \\
12 \ldots \\
13 \ldots \\
14 \ldots \\
15 \ldots\end{array}$ & $\begin{array}{l}310 \\
310 \\
320 \\
360 \\
380\end{array}$ & $\begin{array}{l}290 \\
300 \\
310 \\
320 \\
360\end{array}$ & $\begin{array}{l}8.6 \\
8.1 \\
8.2 \\
8.2 \\
8.4\end{array}$ & $\begin{array}{l}7.6 \\
7.6 \\
7.6 \\
7.5 \\
7.6\end{array}$ & $\begin{array}{l}5.6 \\
6.2 \\
6.5 \\
6.8 \\
7.0\end{array}$ & $\begin{array}{l}4.7 \\
5.0 \\
5.7 \\
6.0 \\
6.3\end{array}$ & $\begin{array}{l}47 \\
44 \\
42 \\
41 \\
40\end{array}$ & $\begin{array}{l}43 \\
41 \\
39 \\
38 \\
37\end{array}$ & $\begin{array}{l}860 \\
870 \\
850 \\
840 \\
850\end{array}$ & $\begin{array}{l}790 \\
800 \\
790 \\
780 \\
780\end{array}$ & $\begin{array}{l}8.3 \\
8,0 \\
8.0 \\
8.0 \\
8.0\end{array}$ & $\begin{array}{l}7.0 \\
7.7 \\
7.9 \\
7.9 \\
7.9\end{array}$ & $\begin{array}{l}13.1 \\
13.1 \\
13.0 \\
12.5 \\
12.4\end{array}$ & $\begin{array}{l}11.06 \\
11.04 \\
11.07 \\
11.4 \\
11.3\end{array}$ & $\begin{array}{l}35 \\
35 \\
35 \\
35 \\
35\end{array}$ & $\begin{array}{l}32 \\
32 \\
32 \\
32 \\
32\end{array}$ \\
\hline $\begin{array}{l}16 \ldots \\
17 \ldots \\
18 \ldots \\
19 \ldots \\
20 \ldots\end{array}$ & $\begin{array}{l}440 \\
-10 \\
510 \\
530 \\
560\end{array}$ & $\begin{array}{l}380 \\
460 \\
500 \\
520\end{array}$ & $\begin{array}{l}8.4 \\
8.5 \\
8.8 \\
8.9\end{array}$ & $\begin{array}{r}7.6 \\
-.0 \\
7.8 \\
8.0 \\
8.0\end{array}$ & $\begin{array}{r}7.0 \\
14.8 \\
14.8 \\
12.4\end{array}$ & $\begin{array}{r}6.1 \\
7.8 \\
70.8 \\
11.5\end{array}$ & $\begin{array}{l}39 \\
40 \\
39 \\
39\end{array}$ & $\begin{array}{l}36 \\
-2 \\
37 \\
36 \\
36\end{array}$ & $\begin{array}{l}880 \\
900 \\
930 \\
920 \\
920\end{array}$ & $\begin{array}{l}780 \\
800 \\
800 \\
800 \\
800\end{array}$ & $\begin{array}{l}8.0 \\
8.0 \\
8.0 \\
8.0 \\
8.0\end{array}$ & $\begin{array}{l}7.9 \\
7.9 \\
7.9 \\
7.8 \\
7.9\end{array}$ & $\begin{array}{l}12.9 \\
13.0 \\
13.4 \\
13.5 \\
13.6\end{array}$ & $\begin{array}{l}11.2 \\
11.4 \\
11.3 \\
11.4 \\
11.2\end{array}$ & $\begin{array}{l}35 \\
34 \\
35 \\
35 \\
35\end{array}$ & $\begin{array}{l}32 \\
32 \\
32 \\
32 \\
32\end{array}$ \\
\hline $\begin{array}{l}21 \ldots \\
22 \ldots \\
23 \ldots \\
24 \ldots \\
25 \ldots\end{array}$ & $\begin{array}{l}590 \\
590 \\
600 \\
630 \\
640\end{array}$ & $\begin{array}{l}550 \\
560 \\
570 \\
580 \\
600\end{array}$ & $\begin{array}{l}8.9 \\
9.1 \\
9.1 \\
9.2 \\
9.0\end{array}$ & $\begin{array}{l}8.1 \\
8.2 \\
8.5 \\
8.4 \\
8.2\end{array}$ & $\begin{array}{r}12.4 \\
12.2 \\
11.9 \\
6.7 \\
7.0\end{array}$ & $\begin{array}{r}11.3 \\
11.6 \\
6.2 \\
6.2 \\
6.5\end{array}$ & $\begin{array}{l}40 \\
39 \\
38 \\
38 \\
37\end{array}$ & $\begin{array}{l}37 \\
35 \\
35 \\
33 \\
33\end{array}$ & $\begin{array}{l}890 \\
890 \\
880 \\
860 \\
880\end{array}$ & $\begin{array}{l}790 \\
810 \\
770 \\
760 \\
820\end{array}$ & $\begin{array}{l}8.0 \\
8.0 \\
8.0 \\
8.0 \\
8.0\end{array}$ & $\begin{array}{l}7.9 \\
7.9 \\
7.9 \\
7.9 \\
7.9\end{array}$ & $\begin{array}{l}12.9 \\
13.1 \\
14.3 \\
13.8 \\
13.3\end{array}$ & $\begin{array}{l}11.1 \\
11.1 \\
11.1 \\
11.5 \\
10.6\end{array}$ & $\begin{array}{l}34 \\
35 \\
40 \\
39 \\
42\end{array}$ & $\begin{array}{l}32 \\
32 \\
34 \\
34 \\
39\end{array}$ \\
\hline $\begin{array}{l}26 \ldots \\
27 \ldots \\
28 \ldots \\
29 \ldots \\
30 \ldots \\
31 \ldots\end{array}$ & $\begin{array}{l}640 \\
690 \\
680 \\
700 \\
700 \\
690\end{array}$ & $\begin{array}{l}600 \\
630 \\
640 \\
650 \\
650 \\
670\end{array}$ & $\begin{array}{l}9.0 \\
9.4 \\
9.3 \\
9.5 \\
9.2 \\
9.0\end{array}$ & $\begin{array}{l}8.3 \\
8.5 \\
8.4 \\
8.4 \\
8.4 \\
8.2\end{array}$ & $\begin{array}{l}7.0 \\
7.3 \\
6.9 \\
7.2 \\
7.1 \\
7.1\end{array}$ & $\begin{array}{l}6.5 \\
6.7 \\
6.3 \\
6.5 \\
6.4 \\
6.8\end{array}$ & $\begin{array}{l}36 \\
36 \\
35 \\
35 \\
35 \\
35\end{array}$ & $\begin{array}{l}33 \\
33 \\
33 \\
33 \\
33 \\
33 \\
\end{array}$ & $\begin{array}{l}880 \\
800 \\
820 \\
820 \\
780 \\
630\end{array}$ & $\begin{array}{l}740 \\
720 \\
740 \\
680 \\
590 \\
540\end{array}$ & $\begin{array}{l}8.0 \\
8.0 \\
8.0 \\
8.0 \\
8.0 \\
8.0\end{array}$ & $\begin{array}{l}7.9 \\
7.9 \\
7.8 \\
7.8 \\
7.8 \\
7.8\end{array}$ & $\begin{array}{l}11.5 \\
11.1 \\
11.3 \\
11.2 \\
11.1 \\
11.3\end{array}$ & $\begin{array}{l}10.1 \\
10.2 \\
10.1 \\
10.5 \\
10.3 \\
10.7\end{array}$ & $\begin{array}{l}41 \\
37 \\
36 \\
35 \\
36 \\
34\end{array}$ & $\begin{array}{l}35 \\
33 \\
33 \\
33 \\
32 \\
32 \\
\end{array}$ \\
\hline
\end{tabular}


STREAMS TRIBUTARY TO LAKE ERIE--COntinued

4-1935. MAUMEE RIVER AT WATERVILLE, OHIO--Continued

Data from continuous recorder, water year October 1966 to September 1967--Continued

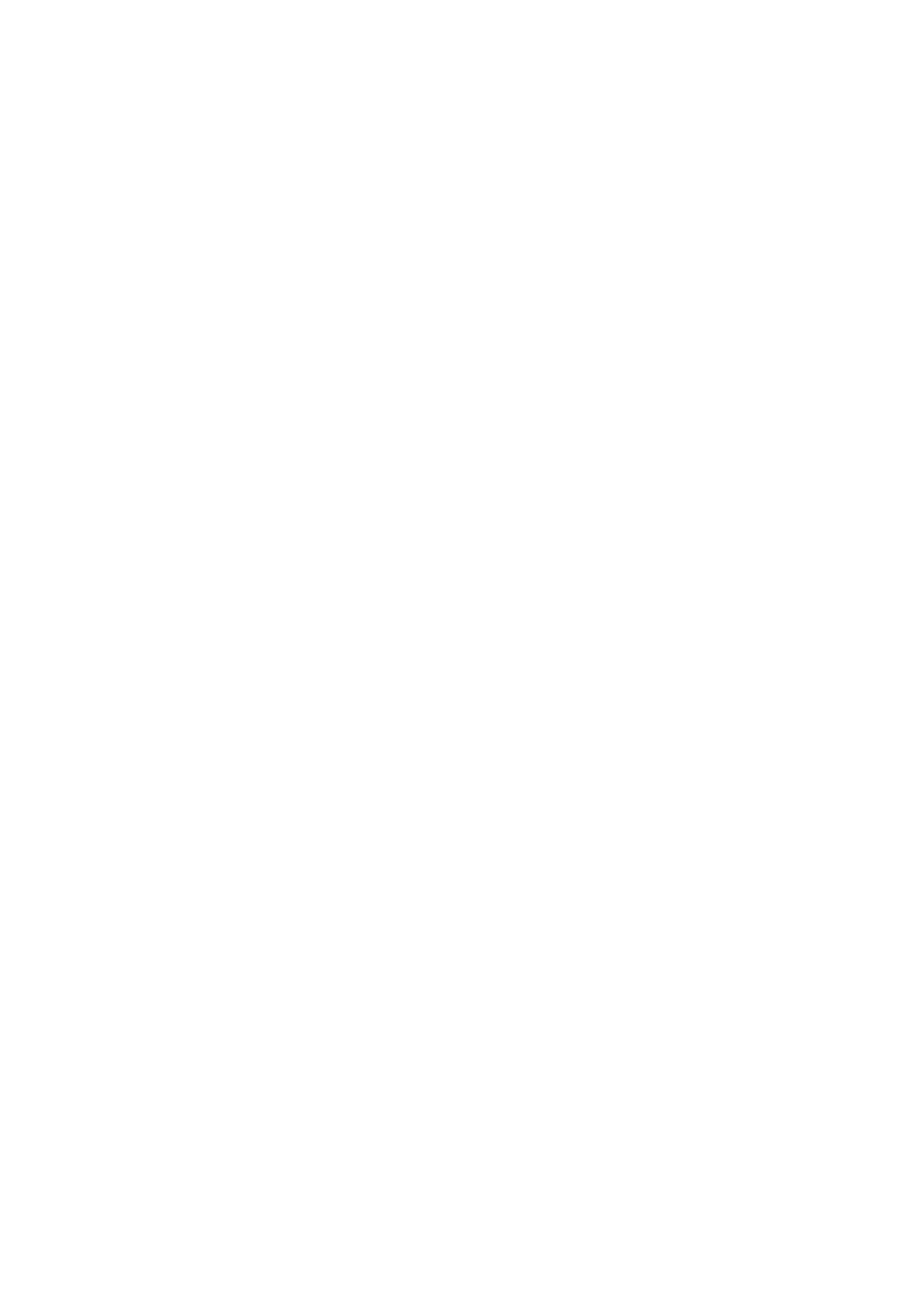


STREAMS TRIBUTARY TO LAKE ERIE--Continued

4-1935. MAUMEE RIVER AT MATERVILLE, OHIO--ContInUed

Data from continuous recorder, water year october 1966 to September 1967--Continued

\begin{tabular}{|c|c|c|c|c|c|c|c|c|c|c|c|c|c|c|c|c|}
\hline \multirow{3}{*}{ Day } & \multicolumn{8}{|c|}{ JUNE } & \multicolumn{8}{|c|}{ NULY } \\
\hline & \multicolumn{2}{|c|}{$\begin{array}{c}\text { Specific } \\
\text { conductance } \\
\text { (micromhos } \\
\text { at } 25^{\circ} \mathrm{C} \text { ) }\end{array}$} & \multicolumn{2}{|c|}{$\mathbf{p H}$} & \multicolumn{2}{|c|}{$\begin{array}{c}\text { Dissolved } \\
\text { oxygen } \\
\text { (ppm) }\end{array}$} & \multicolumn{2}{|c|}{$\begin{array}{c}\text { Temper- } \\
\text { ature } \\
\left({ }^{\circ} \mathrm{F}\right)\end{array}$} & \multicolumn{2}{|c|}{$\begin{array}{c}\text { Specific } \\
\text { conductance } \\
\text { (micromhos } \\
\text { at } 25^{\circ} \mathrm{C} \text { ) }\end{array}$} & \multicolumn{2}{|c|}{$\mathbf{p H}$} & \multicolumn{2}{|c|}{$\begin{array}{l}\text { Nissolved } \\
\text { oxygen } \\
\text { (ppm) }\end{array}$} & \multicolumn{2}{|c|}{$\begin{array}{c}\text { Temper- } \\
\text { ature } \\
\left({ }^{\circ} \mathrm{F}\right)\end{array}$} \\
\hline & Max & Min & $\operatorname{Max}$ & Min & $\operatorname{Max}$ & Min & Max & Min & $\operatorname{Max}$ & Min & $\operatorname{Max}$ & Min & $\mathbf{M} \cdot \mathbf{x}$ & Min & Max & Min \\
\hline $\begin{array}{l}1 \ldots \\
2 \ldots \\
3 \ldots \\
5 \ldots \\
5 \cdots\end{array}$ & $\begin{array}{l}670 \\
690 \\
700 \\
670 \\
690\end{array}$ & $\begin{array}{l}580 \\
610 \\
570 \\
560 \\
600\end{array}$ & $\begin{array}{l}8.9 \\
8.7 \\
8.5 \\
8.6 \\
8.9\end{array}$ & $\begin{array}{l}8.1 \\
8.0 \\
8.0 \\
7.9 \\
7.8\end{array}$ & $\begin{array}{l}8.0 \\
8.0 \\
7.9 \\
7.8 \\
7.8\end{array}$ & $\begin{array}{l}6.4 \\
6.5 \\
6.1 \\
5.7 \\
5.7\end{array}$ & $\begin{array}{l}67 \\
69 \\
73 \\
75 \\
78\end{array}$ & $\begin{array}{l}60 \\
62 \\
63 \\
65 \\
67\end{array}$ & & & $\begin{array}{l}8.8 \\
8.7 \\
8.7 \\
8.6 \\
9.0\end{array}$ & $\begin{array}{l}7.7 \\
7.9 \\
7.8 \\
7.8 \\
7.9\end{array}$ & $\begin{array}{l}9.5 \\
9.1 \\
9.2 \\
9.3 \\
9.9\end{array}$ & $\begin{array}{l}6.8 \\
6.9 \\
6.9 \\
7.0 \\
7.1\end{array}$ & $\begin{array}{l}83 \\
84 \\
81 \\
78 \\
77\end{array}$ & $\begin{array}{l}73 \\
75 \\
73 \\
72 \\
70\end{array}$ \\
\hline $\begin{array}{r}6 \ldots \\
7 \bullet \\
8 \ldots \\
9 \cdots \\
10\end{array}$ & $=$ & $\begin{array}{l}- \\
\overline{-} \\
-\end{array}$ & $\begin{array}{l}9.3 \\
9.3 \\
9.2 \\
9.2 \\
9.1\end{array}$ & $\begin{array}{l}8.1 \\
8.4 \\
8.5 \\
8.6 \\
8.4\end{array}$ & $\begin{array}{l}8.0 \\
7.9 \\
7.5 \\
7.7 \\
7.5\end{array}$ & $\begin{array}{l}5.7 \\
5.4 \\
5.3 \\
5.1 \\
5.1\end{array}$ & $\begin{array}{l}76 \\
79 \\
79 \\
83 \\
82\end{array}$ & $\begin{array}{l}69 \\
69 \\
70 \\
70 \\
71\end{array}$ & & & $\begin{array}{l}9.0 \\
8.9 \\
8.9 \\
9.0 \\
9.0\end{array}$ & $\begin{array}{l}8.3 \\
7.9 \\
8.0 \\
8.3 \\
8.2\end{array}$ & $\begin{array}{r}10.4 \\
9.9 \\
10.5 \\
10.4 \\
9.6\end{array}$ & $\begin{array}{l}7.5 \\
7.0 \\
7.9 \\
7.2 \\
6.7\end{array}$ & $\begin{array}{l}79 \\
80 \\
86 \\
87 \\
82\end{array}$ & $\begin{array}{l}68 \\
70 \\
72 \\
75 \\
77\end{array}$ \\
\hline $\begin{array}{l}11 \ldots \\
12 \ldots \\
13 \ldots \\
14 \ldots \\
15 \ldots\end{array}$ & $=$ & $=$ & $\begin{array}{l}9.0 \\
9.0 \\
8.8 \\
8.7 \\
8.9\end{array}$ & $\begin{array}{l}8.2 \\
8.2 \\
8.1 \\
8.2 \\
8.1\end{array}$ & $\begin{array}{l}7.3 \\
7.2 \\
6.8 \\
6.8 \\
6.5\end{array}$ & $\begin{array}{l}5.1 \\
5.3 \\
5.2 \\
5.0 \\
4.8\end{array}$ & $\begin{array}{l}83 \\
86 \\
86 \\
89 \\
89\end{array}$ & $\begin{array}{l}72 \\
72 \\
74 \\
77 \\
77\end{array}$ & & & $\begin{array}{l}9.0 \\
8.9 \\
8.7 \\
8.6 \\
9.0\end{array}$ & $\begin{array}{l}8.2 \\
8.0 \\
7.9 \\
7.8 \\
7.5\end{array}$ & $\begin{array}{l}9.2 \\
9.5 \\
9.9 \\
9.1 \\
8.0\end{array}$ & $\begin{array}{l}6.2 \\
6.4 \\
6.2 \\
6.5 \\
6.2\end{array}$ & $\begin{array}{l}89 \\
88 \\
84 \\
76 \\
72\end{array}$ & $\begin{array}{l}75 \\
77 \\
74 \\
69 \\
69\end{array}$ \\
\hline $\begin{array}{l}16 \bullet \\
17 \bullet \\
18 \\
19 . \\
20\end{array}$ & $=$ & $=$ & $\begin{array}{l}8.9 \\
9.1 \\
8.9 \\
8.8 \\
8.8\end{array}$ & $\begin{array}{l}8.2 \\
8.0 \\
8.1 \\
7.6 \\
8.1\end{array}$ & $\begin{array}{l}6.6 \\
6.7 \\
5.9 \\
6.3 \\
6.4\end{array}$ & $\begin{array}{l}4.6 \\
4.7 \\
4.5 \\
4.8 \\
5.1\end{array}$ & $\begin{array}{l}88 \\
86 \\
79 \\
79 \\
81\end{array}$ & $\begin{array}{l}79 \\
76 \\
73 \\
71 \\
70\end{array}$ & & & $\begin{array}{l}9.2 \\
9.2 \\
9.1 \\
9.2 \\
8.9\end{array}$ & $\begin{array}{l}8.0 \\
8.4 \\
8.0 \\
8.3 \\
8.2\end{array}$ & $\begin{array}{r}6.7 \\
8.8 \\
10.2 \\
11.4 \\
8.7\end{array}$ & $\begin{array}{l}6.4 \\
6.7 \\
6.4 \\
7.2 \\
6.4\end{array}$ & $\begin{array}{l}78 \\
83 \\
81 \\
85 \\
83\end{array}$ & $\begin{array}{l}68 \\
67 \\
70 \\
71 \\
71\end{array}$ \\
\hline $\begin{array}{l}21 \bullet \\
22 \bullet \\
23 \cdots \\
24 \cdots \\
25 \bullet\end{array}$ & $=$ & $=$ & $\begin{array}{r}8.5 \\
8.8 \\
9.1 \\
-- \\
=-\end{array}$ & $\begin{array}{r}8.0 \\
7.8 \\
8.0 \\
-.-\end{array}$ & $\begin{array}{l}6.0 \\
6.2 \\
6.8 \\
-. \\
-\end{array}$ & $\begin{array}{l}5.0 \\
4.7 \\
5.1 \\
=\end{array}$ & $\begin{array}{l}78 \\
84 \\
86 \\
- \\
-\end{array}$ & $\begin{array}{l}72 \\
72 \\
74 \\
-\end{array}$ & & & $\begin{array}{l}9.2 \\
9.2 \\
9.0 \\
9.3 \\
9.5\end{array}$ & $\begin{array}{l}7.9 \\
8.0 \\
8.3 \\
8.5 \\
8.9\end{array}$ & $\begin{array}{l}8.4 \\
8.3 \\
7.9 \\
7.2 \\
7.3\end{array}$ & $\begin{array}{l}6.1 \\
5.8 \\
5.8 \\
5.3 \\
5.4\end{array}$ & $\begin{array}{l}84 \\
85 \\
83 \\
85 \\
83\end{array}$ & $\begin{array}{l}71 \\
76 \\
75 \\
74 \\
76\end{array}$ \\
\hline $\begin{array}{l}26 \ldots \\
27 \ldots \\
28 \ldots \\
29 \ldots \\
30 \ldots \\
31 \ldots\end{array}$ & $\begin{array}{l}= \\
= \\
=\end{array}$ & $\begin{array}{l}= \\
= \\
=\end{array}$ & $\begin{array}{r}-- \\
-- \\
8.6 \\
8.7 \\
-- \\
\end{array}$ & $\begin{array}{r}\square- \\
=- \\
8.0 \\
7.7 \\
-\end{array}$ & $\begin{array}{r}= \\
\overline{-5} \\
9.3 \\
--\end{array}$ & $\begin{array}{r}-- \\
\overline{-} \\
7.1 \\
7.1 \\
--\end{array}$ & $\begin{array}{l}\overline{-} \\
\overline{77} \\
81\end{array}$ & $\begin{array}{l}- \\
-- \\
72 \\
70 \\
-\end{array}$ & & & $\begin{array}{l}9.3 \\
9.4 \\
9.3 \\
9.4 \\
9.2 \\
9.1\end{array}$ & $\begin{array}{l}8.8 \\
8.7 \\
8.6 \\
6.6 \\
8.1 \\
8.2 \\
\end{array}$ & $\begin{array}{l}7.1 \\
7.2 \\
7.3 \\
7.7 \\
7.6 \\
7.2\end{array}$ & $\begin{array}{l}5.2 \\
5.5 \\
5.5 \\
5.7 \\
5.5 \\
5.7\end{array}$ & $\begin{array}{l}83 \\
81 \\
84 \\
87 \\
81 \\
80 \\
\end{array}$ & $\begin{array}{l}78 \\
77 \\
77 \\
76 \\
75 \\
73 \\
\end{array}$ \\
\hline \multicolumn{9}{|c|}{ AUGUST } & \multicolumn{8}{|c|}{ SEPTEMBER } \\
\hline $\begin{array}{l}1 \% \\
2 \because \\
3 \bullet \\
4 \cdots \\
5 \bullet\end{array}$ & $=$ & $=$ & $\begin{array}{l}9.0 \\
8.7 \\
8.8 \\
8.8 \\
8.7\end{array}$ & $\begin{array}{l}8.3 \\
8.0 \\
7.2 \\
8.2 \\
8.2\end{array}$ & $\begin{array}{l}6.9 \\
5.6 \\
6.4 \\
6.8 \\
9.0\end{array}$ & $\begin{array}{l}5.5 \\
5.4 \\
5.2 \\
5.3 \\
5.2\end{array}$ & $\begin{array}{l}82 \\
80 \\
82 \\
84 \\
84\end{array}$ & $\begin{array}{l}76 \\
78 \\
80 \\
81 \\
78\end{array}$ & $\begin{array}{l}760 \\
750 \\
720 \\
700 \\
690\end{array}$ & $\begin{array}{l}660 \\
630 \\
610 \\
600 \\
580\end{array}$ & $\begin{array}{l}9.0 \\
9.1 \\
9.1 \\
9.0 \\
9.0\end{array}$ & $\begin{array}{l}8.22 \\
8.2 \\
8.3 \\
8.2 \\
8.2\end{array}$ & $\begin{array}{l}7.8 \\
8.0 \\
8.9 \\
8.3 \\
8.4\end{array}$ & $\begin{array}{l}6.1 \\
6.0 \\
6.1 \\
5.9 \\
5.8\end{array}$ & $\begin{array}{l}78 \\
80 \\
77 \\
80 \\
83\end{array}$ & $\begin{array}{l}65 \\
67 \\
68 \\
68 \\
67\end{array}$ \\
\hline $\begin{array}{r}6 \ldots \\
7 \ldots \\
0 \ldots \\
9 \ldots\end{array}$ & $=$ & $\bar{z}=$ & $\begin{array}{l}8.9 \\
8.6 \\
8.7 \\
8.7 \\
9.3\end{array}$ & $\begin{array}{l}8.0 \\
8.3 \\
8.2 \\
8.3 \\
8.1\end{array}$ & $\begin{array}{l}8.3 \\
7.8 \\
8.0 \\
7.2 \\
7.8\end{array}$ & $\begin{array}{l}6.1 \\
6.1 \\
5.5 \\
5.6 \\
5.6\end{array}$ & $\begin{array}{l}84 \\
82 \\
84 \\
86 \\
78\end{array}$ & $\begin{array}{l}75 \\
73 \\
73 \\
76 \\
72\end{array}$ & $\begin{array}{l}740 \\
730 \\
730 \\
700 \\
690\end{array}$ & $\begin{array}{l}640 \\
640 \\
640 \\
650 \\
600\end{array}$ & $\begin{array}{l}8.7 \\
9.2 \\
9.2 \\
8.9 \\
9.4\end{array}$ & $\begin{array}{l}8.0 \\
7.9 \\
7.8 \\
7.7 \\
7.8\end{array}$ & $\begin{array}{l}6.1 \\
7.6 \\
7.7 \\
6.9 \\
7.5\end{array}$ & $\begin{array}{l}5.4 \\
5.1 \\
5.0 \\
5.1 \\
6.3\end{array}$ & $\begin{array}{l}82 \\
81 \\
83 \\
81 \\
75\end{array}$ & $\begin{array}{l}70 \\
69 \\
73 \\
71 \\
65\end{array}$ \\
\hline $\begin{array}{l}11 \ldots \\
12 \ldots \\
13 \ldots \\
14 \ldots \\
15 \ldots\end{array}$ & $=$ & $\begin{array}{l}= \\
= \\
=\end{array}$ & $\begin{array}{l}8.9 \\
8.9 \\
8.8 \\
8.8 \\
8.8\end{array}$ & $\begin{array}{l}8.5 \\
8.0 \\
8.4 \\
8.3 \\
8.3\end{array}$ & $\begin{array}{l}8.3 \\
8.3 \\
8.5 \\
9.1 \\
9.0\end{array}$ & $\begin{array}{l}5.9 \\
6.1 \\
6.1 \\
6.0 \\
5.9\end{array}$ & $\begin{array}{l}78 \\
78 \\
81 \\
82 \\
81\end{array}$ & $\begin{array}{l}66 \\
67 \\
69 \\
68 \\
70\end{array}$ & $\begin{array}{l}680 \\
720 \\
720 \\
730 \\
710\end{array}$ & $\begin{array}{l}630 \\
650 \\
650 \\
640 \\
640\end{array}$ & $\begin{array}{l}9.2 \\
9.1 \\
9.1 \\
9.2 \\
9.3\end{array}$ & $\begin{array}{l}8.2 \\
8.1 \\
8.0 \\
7.9 \\
8.0\end{array}$ & $\begin{array}{r}7.9 \\
9.5 \\
9.7 \\
13.9 \\
14.7\end{array}$ & $\begin{array}{l}6.5 \\
6.3 \\
6.2 \\
8.4 \\
8.0\end{array}$ & $\begin{array}{l}71 \\
74 \\
72 \\
74 \\
76\end{array}$ & $\begin{array}{l}62 \\
62 \\
64 \\
62 \\
62\end{array}$ \\
\hline $\begin{array}{l}16 \bullet \\
17 \bullet \\
18 \\
19 \\
20\end{array}$ & $=$ & $\begin{array}{l}-- \\
=- \\
--\end{array}$ & $\begin{array}{l}8.5 \\
8.5 \\
8.5 \\
8.6 \\
8.4\end{array}$ & $\begin{array}{l}8.2 \\
8.1 \\
8.0 \\
8.0 \\
8.0\end{array}$ & $\begin{array}{l}9.2 \\
7.5 \\
7.4 \\
7.6 \\
7.5\end{array}$ & $\begin{array}{l}5.5 \\
4.9 \\
5.2 \\
5.2 \\
5.3\end{array}$ & $\begin{array}{l}85 \\
84 \\
80 \\
80 \\
84\end{array}$ & $\begin{array}{l}71 \\
73 \\
72 \\
73 \\
75\end{array}$ & $\begin{array}{l}710 \\
680 \\
700 \\
720 \\
720\end{array}$ & $\begin{array}{l}640 \\
620 \\
640 \\
640 \\
600\end{array}$ & $\begin{array}{l}9.3 \\
9.2 \\
9.2 \\
9.3 \\
9.1\end{array}$ & $\begin{array}{l}\text { B.1 } \\
\text { B.1 } \\
\text { B.1 } \\
\text { B.3 } \\
8.3\end{array}$ & $\begin{array}{l}14.5 \\
14.5 \\
14.8 \\
14.5 \\
13.9\end{array}$ & $\begin{array}{l}7.7 \\
8.1 \\
7.6 \\
7.6 \\
7.6\end{array}$ & $\begin{array}{l}76 \\
71 \\
76 \\
75 \\
78\end{array}$ & $\begin{array}{l}64 \\
65 \\
66 \\
67 \\
70\end{array}$ \\
\hline $\begin{array}{l}21 \ldots \\
22 \ldots \\
23 \ldots \\
24 \ldots \\
25 \ldots\end{array}$ & $=$ & $=$ & $\begin{array}{l}8.6 \\
8.6 \\
8.7 \\
8.7 \\
8.8\end{array}$ & $\begin{array}{l}7.5 \\
7.5 \\
7.5 \\
7.7 \\
7.7\end{array}$ & $\begin{array}{l}6.5 \\
6.8 \\
6.9 \\
7.3 \\
7.7\end{array}$ & $\begin{array}{l}4.8 \\
4.6 \\
4.8 \\
5.1 \\
5.3\end{array}$ & $\begin{array}{l}84 \\
84 \\
77 \\
78 \\
84\end{array}$ & $\begin{array}{l}83 \\
76 \\
69 \\
68 \\
73\end{array}$ & $\begin{array}{r}690 \\
690 \\
=- \\
=\end{array}$ & $\begin{array}{r}600 \\
620 \\
= \\
=\end{array}$ & $\begin{array}{r}9.1 \\
9.4 \\
= \\
=\end{array}$ & $\begin{array}{r}8.2 \\
B .4 \\
=- \\
=\end{array}$ & $\begin{array}{r}12.8 \\
13.4 \\
= \\
=\end{array}$ & $\begin{array}{r}7.6 \\
6.6 \\
= \\
=\end{array}$ & $\begin{array}{l}75 \\
75 \\
- \\
-\end{array}$ & $\begin{array}{l}71 \\
66 \\
= \\
=\end{array}$ \\
\hline $\begin{array}{l}26 \ldots \\
27 \ldots \\
28 \ldots \\
29 \ldots \\
30 \ldots \\
31 \ldots\end{array}$ & $\begin{array}{l}- \\
- \\
-0 \\
740 \\
760\end{array}$ & $\begin{array}{l}\overline{-} \\
\overline{-5} \\
680 \\
670\end{array}$ & $\begin{array}{l}8.9 \\
8.8 \\
8.6 \\
8.6 \\
8.9 \\
9.1\end{array}$ & $\begin{array}{l}7.8 \\
7.5 \\
7.5 \\
7.8 \\
7.5 \\
8.0\end{array}$ & $\begin{array}{l}7.8 \\
7.3 \\
7.8 \\
8.0 \\
7.2 \\
7.3\end{array}$ & $\begin{array}{l}5.4 \\
5.2 \\
5.3 \\
5.6 \\
5.3 \\
5.9\end{array}$ & $\begin{array}{l}81 \\
81 \\
81 \\
81 \\
79 \\
73 \\
\end{array}$ & $\begin{array}{l}76 \\
73 \\
70 \\
70 \\
73 \\
69 \\
\end{array}$ & $\begin{array}{l}= \\
= \\
= \\
=\end{array}$ & $\begin{array}{l}= \\
=- \\
=- \\
=\end{array}$ & $\begin{array}{l}= \\
= \\
=\end{array}$ & $\begin{array}{l}= \\
= \\
= \\
=\end{array}$ & $=$ & $=$ & $=$ & $=$ \\
\hline
\end{tabular}


STREAMS TRIBUTARY TO LAKE ERIE--COnt1nued

4-1935. MAUHEE RIVER AT WATERVILLE, OHIO--ContInued Suspended sediment, water year October 1966 to September 1967

\begin{tabular}{|c|c|c|c|c|c|c|c|c|c|}
\hline \multirow[b]{3}{*}{ Day } & \multicolumn{3}{|c|}{ OCTOBER } & \multicolumn{3}{|c|}{ NOVEMBER } & \multicolumn{3}{|c|}{ DECEMBER } \\
\hline & \multirow[b]{2}{*}{$\begin{array}{c}\text { Mean } \\
\text { dis- } \\
\text { charge } \\
\text { (cfs) }\end{array}$} & \multicolumn{2}{|c|}{ Suspended sediment } & \multirow[b]{2}{*}{$\begin{array}{c}\text { Mean } \\
\text { dis- } \\
\text { charge } \\
\text { (cfs) }\end{array}$} & \multicolumn{2}{|c|}{ Suspended sediment } & \multirow[b]{2}{*}{$\begin{array}{l}\text { Mean } \\
\text { dis- } \\
\text { charge } \\
\text { (cfs) }\end{array}$} & \multicolumn{2}{|c|}{ Suspended sediment } \\
\hline & & $\begin{array}{c}\text { Mean } \\
\text { concen- } \\
\text { tration } \\
(\mathrm{ppm})\end{array}$ & $\begin{array}{l}\text { Tons } \\
\text { per } \\
\text { day }\end{array}$ & & $\begin{array}{c}\text { Mean } \\
\text { concen- } \\
\text { tration } \\
(\text { ppm) }\end{array}$ & $\begin{array}{l}\text { Tons } \\
\text { per } \\
\text { day }\end{array}$ & & $\begin{array}{l}\text { Mean } \\
\text { concen- } \\
\text { tration } \\
\text { (ppm) }\end{array}$ & $\begin{array}{l}\text { Tons } \\
\text { rer } \\
\text { day }\end{array}$ \\
\hline $\begin{array}{l}1 \ldots \\
2 \ldots \\
3 \ldots \\
5 \ldots\end{array}$ & $\begin{array}{l}205 \\
183 \\
190 \\
311 \\
183\end{array}$ & $\begin{array}{l}20 \\
22 \\
20 \\
17 \\
15\end{array}$ & $\begin{array}{r}11 \\
11 \\
10 \\
14 \\
7\end{array}$ & $\begin{array}{l}205 \\
205 \\
745 \\
343 \\
272\end{array}$ & $\begin{array}{l}8 \\
8 \\
8 \\
9 \\
9\end{array}$ & $\begin{array}{r}4 \\
4 \\
16 \\
8 \\
7\end{array}$ & $\begin{array}{l}6120 \\
5310 \\
4350 \\
3480 \\
3510\end{array}$ & $\begin{array}{l}45 \\
44 \\
44 \\
44 \\
44\end{array}$ & $\begin{array}{l}744 \\
631 \\
517 \\
413 \\
417\end{array}$ \\
\hline $\begin{array}{r}6 \ldots \\
7 \ldots \\
8 \ldots \\
9 \ldots \\
10 \ldots\end{array}$ & $\begin{array}{l}147 \\
122 \\
169 \\
183 \\
420\end{array}$ & $\begin{array}{r}12 \\
9 \\
7 \\
5 \\
6\end{array}$ & $\begin{array}{l}5 \\
3 \\
3 \\
2 \\
7\end{array}$ & $\begin{array}{r}354 \\
431 \\
800 \\
10100 \\
26900\end{array}$ & $\begin{array}{r}9 \\
8 \\
14 \\
120 \\
353\end{array}$ & $\begin{array}{r}9 \\
9 \\
30 \\
3880 \\
5600\end{array}$ & $\begin{array}{r}8190 \\
27800 \\
68800 \\
74000 \\
78700\end{array}$ & $\begin{array}{r}65 \\
194 \\
847 \\
690 \\
555\end{array}$ & $\begin{array}{r}1440 \\
17200 \\
157000 \\
139000 \\
11 ? 000\end{array}$ \\
\hline $\begin{array}{l}11 \ldots \\
12 \ldots \\
13 \ldots \\
14 \ldots \\
15 \ldots\end{array}$ & $\begin{array}{l}322 \\
224 \\
120 \\
170 \\
365\end{array}$ & $\begin{array}{l}7 \\
8 \\
9 \\
9 \\
9\end{array}$ & $\begin{array}{l}6 \\
5 \\
3 \\
4 \\
9\end{array}$ & $\begin{array}{r}30200 \\
23300 \\
15400 \\
10300 \\
5270\end{array}$ & $\begin{array}{r}419 \\
317 \\
210 \\
112 \\
88\end{array}$ & $\begin{array}{r}34200 \\
19900 \\
8730 \\
3110 \\
1250\end{array}$ & $\begin{array}{l}79000 \\
72400 \\
69600 \\
54900 \\
39300\end{array}$ & $\begin{array}{l}42 \\
31 \\
213 \\
231 \\
166 \\
128\end{array}$ & $\begin{array}{l}97400 \\
61200 \\
43400 \\
24600 \\
13600\end{array}$ \\
\hline $\begin{array}{l}16 \ldots \\
17 \ldots \\
18 \ldots \\
19 \ldots \\
20 \ldots\end{array}$ & $\begin{array}{l}467 \\
169 \\
176 \\
343 \\
365\end{array}$ & $\begin{array}{l}9 \\
9 \\
9 \\
9 \\
9\end{array}$ & $\begin{array}{r}11 \\
4 \\
4 \\
6 \\
9\end{array}$ & $\begin{array}{l}4660 \\
3270 \\
2610 \\
1830 \\
1550\end{array}$ & $\begin{array}{l}89 \\
83 \\
73 \\
63 \\
54\end{array}$ & $\begin{array}{r}1120 \\
733 \\
514 \\
311 \\
226\end{array}$ & $\begin{array}{l}27100 \\
22000 \\
16700 \\
13300 \\
11400\end{array}$ & $\begin{array}{r}105 \\
99 \\
81 \\
65 \\
56\end{array}$ & $\begin{array}{l}7680 \\
5880 \\
3650 \\
2330 \\
1720\end{array}$ \\
\hline $\begin{array}{l}21 \ldots \\
22 \ldots \\
23 \ldots \\
24 \ldots \\
25 \ldots\end{array}$ & $\begin{array}{l}262 \\
322 \\
234 \\
205 \\
190\end{array}$ & $\begin{array}{r}10 \\
9 \\
9 \\
9 \\
9\end{array}$ & $\begin{array}{l}7 \\
8 \\
6 \\
5 \\
5\end{array}$ & $\begin{array}{r}1260 \\
1120 \\
986 \\
890 \\
935\end{array}$ & $\begin{array}{l}49 \\
47 \\
45 \\
43 \\
41\end{array}$ & $\begin{array}{l}167 \\
142 \\
120 \\
103 \\
104\end{array}$ & $\begin{array}{l}9550 \\
8200 \\
6960 \\
5840 \\
4860\end{array}$ & $\begin{array}{l}47 \\
40 \\
35 \\
34 \\
30\end{array}$ & $\begin{array}{r}1210 \\
886 \\
658 \\
536 \\
394\end{array}$ \\
\hline $\begin{array}{l}26 \ldots \\
27 \ldots \\
28 \ldots \\
29 \ldots \\
30 \ldots \\
31 \ldots\end{array}$ & $\begin{array}{l}176 \\
183 \\
234 \\
262 \\
234 \\
262\end{array}$ & $\begin{array}{l}9 \\
9 \\
9 \\
9 \\
9 \\
8 \\
8\end{array}$ & $\begin{array}{l}4 \\
4 \\
6 \\
6 \\
5 \\
6\end{array}$ & $\begin{array}{r}750 \\
1430 \\
4380 \\
6680 \\
6950 \\
0\end{array}$ & $\begin{array}{l}39 \\
53 \\
69 \\
59 \\
45 \\
--\end{array}$ & $\begin{array}{r}80 \\
205 \\
816 \\
1060 \\
844 \\
-0\end{array}$ & $\begin{array}{l}3920 \\
3310 \\
2700 \\
2700 \\
2400 \\
2200\end{array}$ & $\begin{array}{l}27 \\
23 \\
21 \\
20 \\
18 \\
16\end{array}$ & $\begin{array}{r}286 \\
206 \\
153 \\
146 \\
117 \\
95\end{array}$ \\
\hline \multirow[t]{2}{*}{ Total } & 7398 & -- & 198 & 164134 & -- & 103302 & 730600 & $\cdots$ & 653509 \\
\hline & \multicolumn{3}{|c|}{ JANUARY } & \multicolumn{3}{|c|}{ FEBRUARY } & \multicolumn{3}{|c|}{ MARCH } \\
\hline $\begin{array}{l}1 \ldots \\
2 \ldots \\
3 \ldots \\
5 \ldots\end{array}$ & $\begin{array}{l}2300 \\
2100 \\
2000 \\
2000 \\
1800\end{array}$ & $\begin{array}{r}14 \\
12 \\
10 \\
10 \\
9\end{array}$ & $\begin{array}{l}87 \\
68 \\
54 \\
54 \\
44\end{array}$ & $\begin{array}{r}6410 \\
11900 \\
23000 \\
25900 \\
20000\end{array}$ & $\begin{array}{r}33 \\
40 \\
130 \\
240 \\
182\end{array}$ & $\begin{array}{r}571 \\
1370 \\
8070 \\
16800 \\
10200\end{array}$ & $\begin{array}{l}2120 \\
2310 \\
2030 \\
2530 \\
4100\end{array}$ & $\begin{array}{l}28 \\
26 \\
24 \\
20 \\
15\end{array}$ & $\begin{array}{l}160 \\
162 \\
132 \\
137 \\
166\end{array}$ \\
\hline $\begin{array}{r}6 \ldots \\
7 \ldots \\
8 \ldots \\
10 \ldots\end{array}$ & $\begin{array}{l}1500 \\
1390 \\
1690 \\
1750 \\
1920\end{array}$ & \begin{tabular}{l|l}
8 & \\
7 & \\
7 & \\
7 &
\end{tabular} & $\begin{array}{l}32 \\
26 \\
32 \\
33 \\
36\end{array}$ & $\begin{array}{r}13100 \\
6000 \\
3000 \\
2600 \\
3490\end{array}$ & $\begin{array}{r}143 \\
119 \\
102 \\
80 \\
58\end{array}$ & $\begin{array}{r}5060 \\
1930 \\
826 \\
562 \\
547\end{array}$ & $\begin{array}{l}5020 \\
5840 \\
6580 \\
6700 \\
5520\end{array}$ & $\begin{array}{l}15 \\
15 \\
15 \\
16 \\
16\end{array}$ & $\begin{array}{l}203 \\
237 \\
266 \\
289 \\
238\end{array}$ \\
\hline $\begin{array}{l}11 \ldots \\
12 \ldots \\
13 \ldots \\
14 \ldots \\
15 \ldots\end{array}$ & $\begin{array}{l}1640 \\
1410 \\
1140 \\
1270 \\
1140\end{array}$ & $\begin{array}{l}7 \\
6 \\
6 \\
6 \\
5\end{array}$ & $\begin{array}{l}31 \\
23 \\
18 \\
21 \\
15\end{array}$ & $\begin{array}{l}3990 \\
4250 \\
3700 \\
2820 \\
4670\end{array}$ & $\begin{array}{l}42 \\
30 \\
25 \\
27 \\
32\end{array}$ & $\begin{array}{l}452 \\
344 \\
250 \\
206 \\
403\end{array}$ & $\begin{array}{l}12600 \\
24000 \\
28900 \\
28400 \\
25300\end{array}$ & $\begin{array}{r}35 \\
193 \\
252 \\
194 \\
135\end{array}$ & $\begin{array}{r}1290 \\
12500 \\
19700 \\
14900 \\
9220\end{array}$ \\
\hline $\begin{array}{l}16 \ldots \\
17 \ldots \\
18 \ldots \\
19 \ldots \\
20 \ldots\end{array}$ & $\begin{array}{r}1120 \\
1010 \\
840 \\
750 \\
700\end{array}$ & $\begin{array}{l}5 \\
5 \\
4 \\
4 \\
4\end{array}$ & $\begin{array}{r}15 \\
14 \\
9 \\
8 \\
8\end{array}$ & $\begin{array}{l}15900 \\
24400 \\
21600 \\
15400 \\
10700\end{array}$ & $\begin{array}{r}62 \\
236 \\
253 \\
194 \\
170\end{array}$ & $\begin{array}{r}2660 \\
15500 \\
14800 \\
8070 \\
4910\end{array}$ & $\begin{array}{l}22600 \\
18300 \\
15500 \\
13100 \\
12400\end{array}$ & $\begin{array}{r}99 \\
90 \\
100 \\
73 \\
48\end{array}$ & $\begin{array}{l}6040 \\
4450 \\
4180 \\
2580 \\
1610\end{array}$ \\
\hline $\begin{array}{l}21 \ldots \\
22 \ldots \\
23 \ldots \\
24 \ldots \\
25 \ldots\end{array}$ & $\begin{array}{r}750 \\
780 \\
870 \\
1010 \\
1390\end{array}$ & $\begin{array}{l}3 \\
3 \\
3 \\
4 \\
4\end{array}$ & $\begin{array}{r}6 \\
6 \\
7 \\
11 \\
15\end{array}$ & $\begin{array}{l}8400 \\
7130 \\
5720 \\
4250 \\
2500\end{array}$ & $\begin{array}{r}137 \\
93 \\
64 \\
46 \\
37\end{array}$ & $\begin{array}{r}3110 \\
1790 \\
988 \\
528 \\
250\end{array}$ & $\begin{array}{l}20500 \\
31900 \\
31800 \\
25900 \\
20800\end{array}$ & $\begin{array}{r}92 \\
231 \\
244 \\
178 \\
124\end{array}$ & $\begin{array}{r}5500 \\
19900 \\
20900 \\
12400 \\
6960\end{array}$ \\
\hline $\begin{array}{l}26 \ldots \\
27 \ldots \\
20 \ldots \\
29 \ldots \\
30 \ldots \\
31 \ldots\end{array}$ & $\begin{array}{r}1690 \\
4210 \\
7770 \\
11800 \\
10900 \\
7960\end{array}$ & $\begin{array}{r}4 \\
6 \\
17 \\
35 \\
43 \\
41\end{array}$ & $\begin{array}{r}18 \\
68 \\
357 \\
1120 \\
1270 \\
801\end{array}$ & $\begin{array}{r}1800 \\
2000 \\
2090 \\
-- \\
-- \\
--\end{array}$ & $\begin{array}{l}32 \\
30 \\
29 \\
-- \\
--\end{array}$ & $\begin{array}{r}156 \\
162 \\
164 \\
-- \\
-- \\
--\end{array}$ & $\begin{array}{l}16200 \\
13000 \\
13500 \\
22600 \\
28900 \\
27700\end{array}$ & $\begin{array}{r}92 \\
68 \\
70 \\
122 \\
449 \\
381\end{array}$ & $\begin{array}{r}4000 \\
2390 \\
2550 \\
7950 \\
35000 \\
28500\end{array}$ \\
\hline Total & 78600 & $=$ & 4387 & 257520 & $\cdots$ & 100679 & 496550 & -- & 224510 \\
\hline
\end{tabular}


STREAYS TRIBUTARY TO LAKE ERIE--Continued

4-1935. MAUMEE RIVER AT WATERVILLE, OHIO--Cont1 nued

Suspended sediment, water year October 1966 to September 1967--Continued

\begin{tabular}{|c|c|c|c|c|c|c|c|c|c|}
\hline \multirow[b]{3}{*}{ Day } & \multicolumn{3}{|c|}{ APRIL } & \multicolumn{3}{|c|}{ MAY } & \multicolumn{3}{|c|}{ JUNE } \\
\hline & \multirow[b]{2}{*}{$\begin{array}{l}\text { Mean } \\
\text { dis- } \\
\text { charge } \\
(\mathrm{cfs})\end{array}$} & \multicolumn{2}{|c|}{ Suspended sediment } & \multirow[b]{2}{*}{$\begin{array}{c}\text { Mean } \\
\text { dis- } \\
\text { charge } \\
(\mathrm{cfs})\end{array}$} & \multicolumn{2}{|c|}{ Suspended sediment } & \multirow[b]{2}{*}{$\begin{array}{c}\text { Mean } \\
\text { dis- } \\
\text { charge } \\
\text { (cfs) }\end{array}$} & \multicolumn{2}{|c|}{ Suspended sediment } \\
\hline & & $\begin{array}{c}\text { Mean } \\
\text { concen- } \\
\text { tration } \\
(\text { ppm })\end{array}$ & $\begin{array}{l}\text { Tons } \\
\text { per } \\
\text { day }\end{array}$ & & $\begin{array}{c}\text { Mean } \\
\text { concen- } \\
\text { tration } \\
(\mathrm{ppm})\end{array}$ & $\begin{array}{l}\text { Tons } \\
\text { per } \\
\text { day }\end{array}$ & & $\begin{array}{c}\text { Mean } \\
\text { concen- } \\
\text { tration } \\
(\text { ppm) }\end{array}$ & $\begin{array}{c}\text { Tons } \\
\text { per } \\
\text { day }\end{array}$ \\
\hline $\begin{array}{l}1 \ldots \\
2 \ldots \\
3 \ldots \\
5 \ldots\end{array}$ & $\begin{array}{r}22400 \\
16300 \\
12100 \\
8300 \\
7870\end{array}$ & $\begin{array}{l}321 \\
253 \\
198 \\
157 \\
123\end{array}$ & $\begin{array}{r}19400 \\
11100 \\
6470 \\
3520 \\
2610\end{array}$ & $\begin{array}{l}2820 \\
2850 \\
2430 \\
2400 \\
2280\end{array}$ & $\begin{array}{l}54 \\
52 \\
50 \\
49 \\
47\end{array}$ & $\begin{array}{l}411 \\
400 \\
328 \\
318 \\
289\end{array}$ & $\begin{array}{l}2060 \\
1830 \\
1430 \\
1310 \\
1190\end{array}$ & $\begin{array}{l}27 \\
23 \\
19 \\
18 \\
19\end{array}$ & $\begin{array}{r}150 \\
114 \\
73 \\
64 \\
61\end{array}$ \\
\hline $\begin{array}{r}6 \ldots \\
7 \ldots \\
8 \ldots \\
10 \ldots\end{array}$ & $\begin{array}{r}6960 \\
7490 \\
8750 \\
9650 \\
11700\end{array}$ & $\begin{array}{r}106 \\
85 \\
70 \\
75 \\
84\end{array}$ & $\begin{array}{l}1990 \\
1720 \\
1650 \\
1950 \\
2650\end{array}$ & $\begin{array}{r}2210 \\
2940 \\
9150 \\
19400 \\
23400\end{array}$ & $\begin{array}{r}46 \\
48 \\
73 \\
150 \\
166\end{array}$ & $\begin{array}{r}274 \\
381 \\
1800 \\
7860 \\
10500\end{array}$ & $\begin{array}{l}1140 \\
1190 \\
1250 \\
1210 \\
1210\end{array}$ & $\begin{array}{l}20 \\
21 \\
23 \\
25 \\
28\end{array}$ & $\begin{array}{l}62 \\
67 \\
78 \\
82 \\
91\end{array}$ \\
\hline $\begin{array}{l}11 \ldots \\
12 \ldots \\
13 \ldots \\
14 \ldots \\
15 \ldots\end{array}$ & $\begin{array}{r}12300 \\
9700 \\
7870 \\
7820 \\
11300\end{array}$ & $\begin{array}{l}192 \\
287 \\
151 \\
120 \\
125\end{array}$ & $\begin{array}{l}6380 \\
7520 \\
3210 \\
2530 \\
3810\end{array}$ & $\begin{array}{l}22700 \\
26500 \\
24100 \\
19800 \\
15700\end{array}$ & $\begin{array}{l}332 \\
356 \\
334 \\
273 \\
223\end{array}$ & $\begin{array}{r}20300 \\
25500 \\
21700 \\
14600 \\
9450\end{array}$ & $\begin{array}{r}1340 \\
1270 \\
1340 \\
1030 \\
900\end{array}$ & $\begin{array}{l}32 \\
34 \\
33 \\
32 \\
31\end{array}$ & $\begin{array}{r}116 \\
117 \\
119 \\
89 \\
75\end{array}$ \\
\hline $\begin{array}{l}16 \ldots \\
17 \ldots \\
18 \ldots \\
19 \ldots \\
20 \ldots\end{array}$ & $\begin{array}{r}11800 \\
9860 \\
6910 \\
5960 \\
5020\end{array}$ & $\begin{array}{r}148 \\
117 \\
118 \\
104 \\
92\end{array}$ & $\begin{array}{l}4720 \\
3110 \\
2200 \\
1670 \\
1250\end{array}$ & $\begin{array}{r}11800 \\
8500 \\
7000 \\
5200 \\
4400\end{array}$ & $\begin{array}{r}193 \\
143 \\
105 \\
95 \\
84\end{array}$ & $\begin{array}{r}6150 \\
3280 \\
1980 \\
1330 \\
998\end{array}$ & $\begin{array}{r}795 \\
1010 \\
810 \\
954 \\
1010\end{array}$ & $\begin{array}{l}33 \\
35 \\
37 \\
37 \\
38\end{array}$ & $\begin{array}{r}71 \\
95 \\
81 \\
95 \\
104\end{array}$ \\
\hline $\begin{array}{l}21 \ldots \\
22 \ldots \\
23 \ldots \\
24 \ldots \\
25 \ldots\end{array}$ & $\begin{array}{r}4290 \\
7090 \\
10600 \\
10200 \\
7720\end{array}$ & $\begin{array}{r}79 \\
112 \\
173 \\
166 \\
118\end{array}$ & $\begin{array}{r}915 \\
2140 \\
4950 \\
4570 \\
2460\end{array}$ & $\begin{array}{l}3600 \\
3000 \\
2400 \\
2100 \\
1900\end{array}$ & $\begin{array}{l}70 \\
65 \\
62 \\
58 \\
54\end{array}$ & $\begin{array}{l}680 \\
526 \\
402 \\
329 \\
277\end{array}$ & $\begin{array}{l}795 \\
750 \\
696 \\
723 \\
918\end{array}$ & $\begin{array}{l}38 \\
39 \\
37 \\
36 \\
35\end{array}$ & $\begin{array}{l}82 \\
79 \\
70 \\
70 \\
87\end{array}$ \\
\hline $\begin{array}{l}26 \ldots \\
27 \ldots \\
28 \ldots \\
29 \ldots \\
30 \ldots \\
31 \ldots\end{array}$ & $\begin{array}{c}5840 \\
5090 \\
4180 \\
3560 \\
3070 \\
--\end{array}$ & $\begin{array}{r}128 \\
117 \\
97 \\
73 \\
58 \\
--\end{array}$ & $\begin{array}{r}2020 \\
1610 \\
1090 \\
702 \\
481 \\
-\end{array}$ & $\begin{array}{l}2300 \\
2600 \\
2100 \\
2200 \\
2700 \\
2400\end{array}$ & $\begin{array}{l}51 \\
47 \\
43 \\
39 \\
35 \\
31\end{array}$ & $\begin{array}{l}317 \\
330 \\
244 \\
232 \\
255 \\
201\end{array}$ & $\begin{array}{r}885 \\
1360 \\
1270 \\
1100 \\
900 \\
--\end{array}$ & $\begin{array}{l}34 \\
32 \\
32 \\
32 \\
33 \\
--\end{array}$ & $\begin{array}{r}81 \\
118 \\
110 \\
95 \\
80 \\
--\end{array}$ \\
\hline \multirow[t]{2}{*}{ Total } & 261700 & -- & 110398 & 242880 & - & 131642 & 33676 & -- & 2676 \\
\hline & \multicolumn{3}{|c|}{ JULY } & \multicolumn{3}{|c|}{ AUGUST } & \multicolumn{3}{|c|}{ SEPTEMBER } \\
\hline $\begin{array}{l}1 \ldots \\
2 \ldots \\
3 \ldots \\
4 \ldots \\
5 \ldots\end{array}$ & $\begin{array}{r}1040 \\
1230 \\
1120 \\
1030 \\
840\end{array}$ & $\begin{array}{l}33 \\
33 \\
35 \\
37 \\
38\end{array}$ & $\begin{array}{r}93 \\
110 \\
106 \\
103 \\
86\end{array}$ & $\begin{array}{l}1530 \\
2530 \\
2430 \\
1610 \\
1010\end{array}$ & $\begin{array}{l}88 \\
71 \\
55 \\
47 \\
48\end{array}$ & $\begin{array}{l}364 \\
485 \\
361 \\
204 \\
131\end{array}$ & $\begin{array}{l}235 \\
222 \\
209 \\
242 \\
265\end{array}$ & $\begin{array}{l}27 \\
22 \\
18 \\
15 \\
13\end{array}$ & $\begin{array}{r}17 \\
14 \\
10 \\
10 \\
9\end{array}$ \\
\hline $\begin{array}{r}6 \ldots \\
7 \ldots \\
8 \ldots \\
9 \ldots\end{array}$ & $\begin{array}{l}656 \\
723 \\
683 \\
603 \\
528\end{array}$ & $\begin{array}{l}40 \\
41 \\
40 \\
40 \\
40\end{array}$ & $\begin{array}{l}71 \\
80 \\
74 \\
65 \\
57\end{array}$ & $\begin{array}{l}759 \\
603 \\
479 \\
490 \\
344\end{array}$ & $\begin{array}{l}44 \\
41 \\
39 \\
37 \\
35\end{array}$ & $\begin{array}{l}89 \\
67 \\
50 \\
49 \\
33\end{array}$ & $\begin{array}{l}228 \\
176 \\
170 \\
176 \\
154\end{array}$ & $\begin{array}{l}13 \\
11 \\
10 \\
10 \\
10\end{array}$ & $\begin{array}{l}8 \\
5 \\
5 \\
5 \\
4\end{array}$ \\
\hline $\begin{array}{l}11 \ldots \\
12 \ldots \\
13 \ldots \\
14 \ldots \\
15 \ldots\end{array}$ & $\begin{array}{l}515 \\
528 \\
398 \\
515 \\
553\end{array}$ & $\begin{array}{l}39 \\
38 \\
37 \\
35 \\
35\end{array}$ & $\begin{array}{l}54 \\
54 \\
40 \\
49 \\
52\end{array}$ & $\begin{array}{l}234 \\
243 \\
270 \\
270 \\
243\end{array}$ & $\begin{array}{l}32 \\
29 \\
25 \\
22 \\
20\end{array}$ & $\begin{array}{l}20 \\
19 \\
18 \\
16 \\
13\end{array}$ & $\begin{array}{l}142 \\
170 \\
272 \\
190 \\
176\end{array}$ & $\begin{array}{l}13 \\
12 \\
14 \\
16 \\
18\end{array}$ & $\begin{array}{l}4 \\
6 \\
8 \\
8 \\
9\end{array}$ \\
\hline $\begin{array}{l}16 \ldots \\
17 \ldots \\
18 \ldots \\
19 \ldots \\
20 \ldots\end{array}$ & $\begin{array}{l}578 \\
467 \\
456 \\
410 \\
444\end{array}$ & $\begin{array}{l}35 \\
35 \\
42 \\
42 \\
38\end{array}$ & $\begin{array}{l}55 \\
44 \\
52 \\
46 \\
46\end{array}$ & $\begin{array}{l}225 \\
198 \\
207 \\
234 \\
234\end{array}$ & $\begin{array}{l}20 \\
21 \\
22 \\
23 \\
23\end{array}$ & $\begin{array}{l}12 \\
11 \\
12 \\
15 \\
15\end{array}$ & $\begin{array}{l}164 \\
159 \\
176 \\
176 \\
196\end{array}$ & $\begin{array}{l}18 \\
18 \\
19 \\
21 \\
24\end{array}$ & $\begin{array}{r}8 \\
8 \\
9 \\
10 \\
13\end{array}$ \\
\hline $\begin{array}{l}21 \ldots \\
22 \ldots \\
23 \ldots \\
24 \ldots \\
25 \ldots\end{array}$ & $\begin{array}{r}410 \\
479 \\
553 \\
490 \\
1360\end{array}$ & $\begin{array}{l}34 \\
31 \\
36 \\
41 \\
74\end{array}$ & $\begin{array}{r}38 \\
40 \\
54 \\
54 \\
295\end{array}$ & $\begin{array}{l}225 \\
171 \\
183 \\
209 \\
216\end{array}$ & $\begin{array}{l}22 \\
21 \\
24 \\
27 \\
30\end{array}$ & $\begin{array}{l}13 \\
10 \\
12 \\
15 \\
17\end{array}$ & $\begin{array}{l}280 \\
265 \\
239 \\
228 \\
272\end{array}$ & $\begin{array}{l}26 \\
28 \\
39 \\
32 \\
33\end{array}$ & $\begin{array}{l}20 \\
20 \\
17 \\
20 \\
24\end{array}$ \\
\hline $\begin{array}{l}26 \ldots \\
27 \ldots \\
28 \ldots \\
29 \ldots \\
30 \ldots \\
31 \ldots\end{array}$ & $\begin{array}{r}1120 \\
590 \\
467 \\
387 \\
456 \\
972\end{array}$ & $\begin{array}{l}46 \\
39 \\
38 \\
36 \\
38 \\
70\end{array}$ & $\begin{array}{r}139 \\
62 \\
48 \\
38 \\
47 \\
184\end{array}$ & $\begin{array}{l}216 \\
272 \\
242 \\
216 \\
288 \\
288\end{array}$ & $\begin{array}{l}33 \\
35 \\
37 \\
37 \\
35 \\
31\end{array}$ & $\begin{array}{l}19 \\
26 \\
24 \\
22 \\
27 \\
24\end{array}$ & $\begin{array}{c}352 \\
287 \\
272 \\
344 \\
344 \\
--\end{array}$ & $\begin{array}{l}32 ! \\
27 \\
23 \\
18 \\
14 \\
--;\end{array}$ & $\begin{array}{l}30 \\
20 \\
17 \\
17 \\
13 \\
\cdots\end{array}$ \\
\hline Total & 20601 & -- & 2336 & 16663 & -- & 2193 & 6674 & --1 & 368 \\
\hline
\end{tabular}




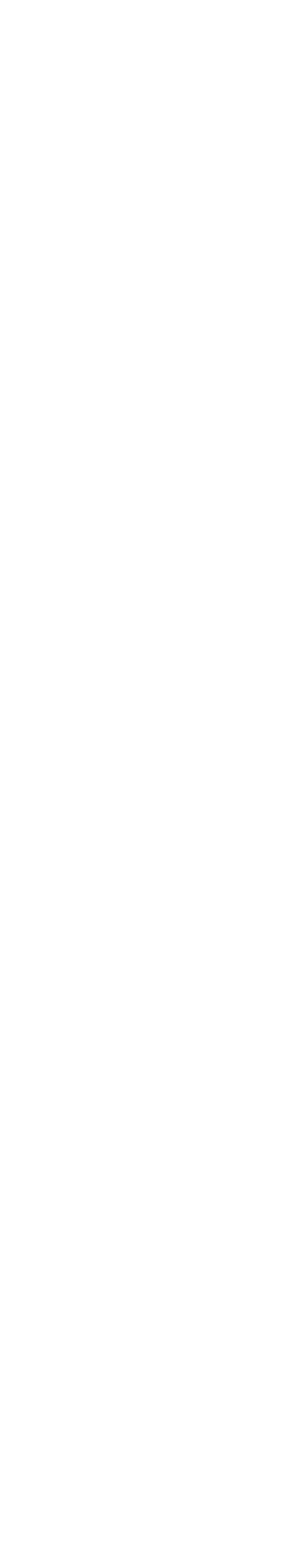




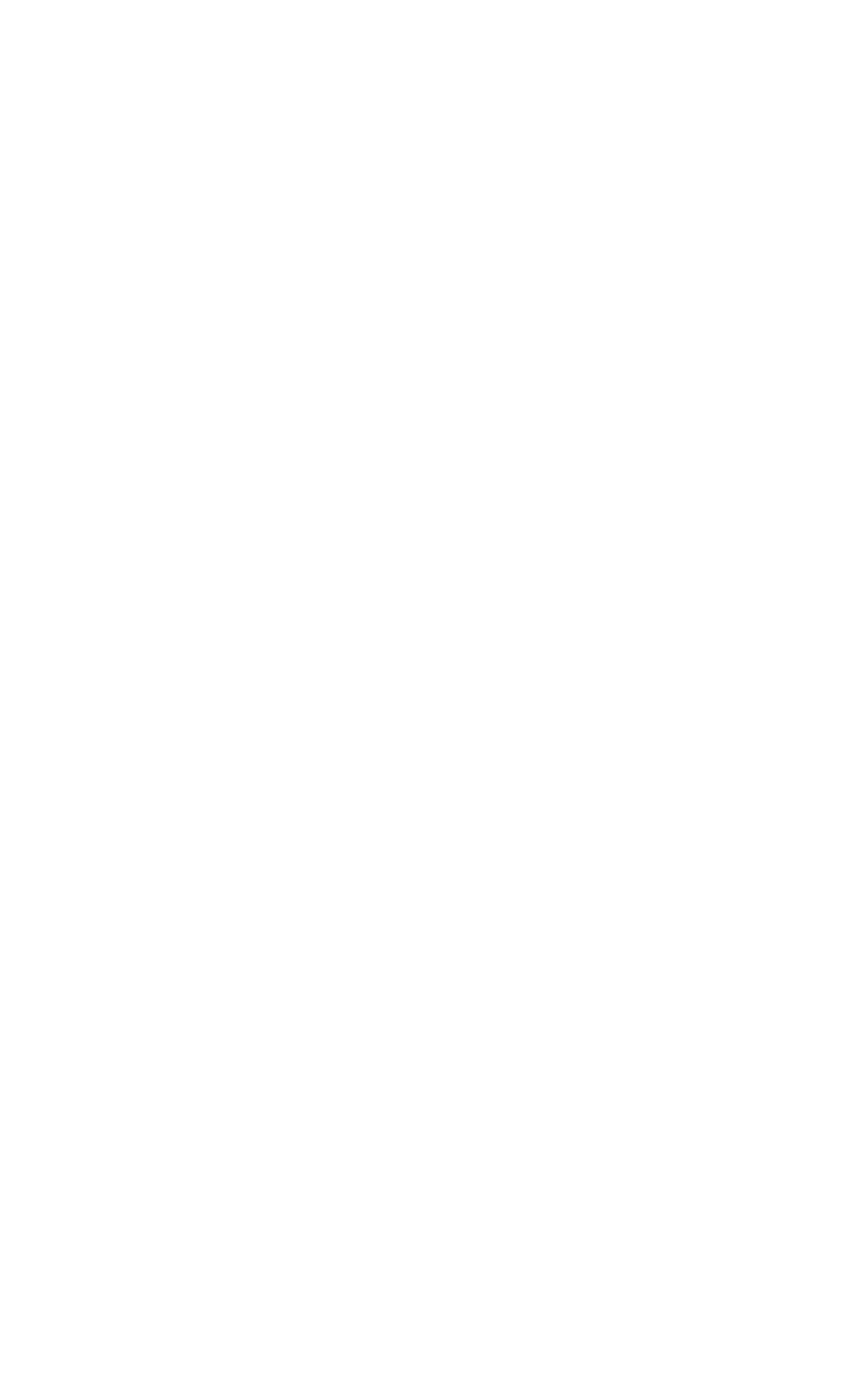


11111

거육유뮤거

ठततकळ $\infty \dot{\infty} \infty \dot{0}:$

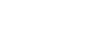

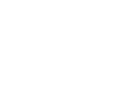

ลิส สํํำลั

1111

111兽

11101 $\frac{1119}{119}$

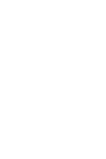

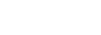

00000

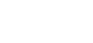
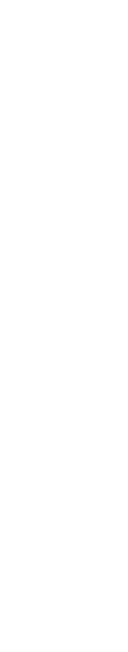

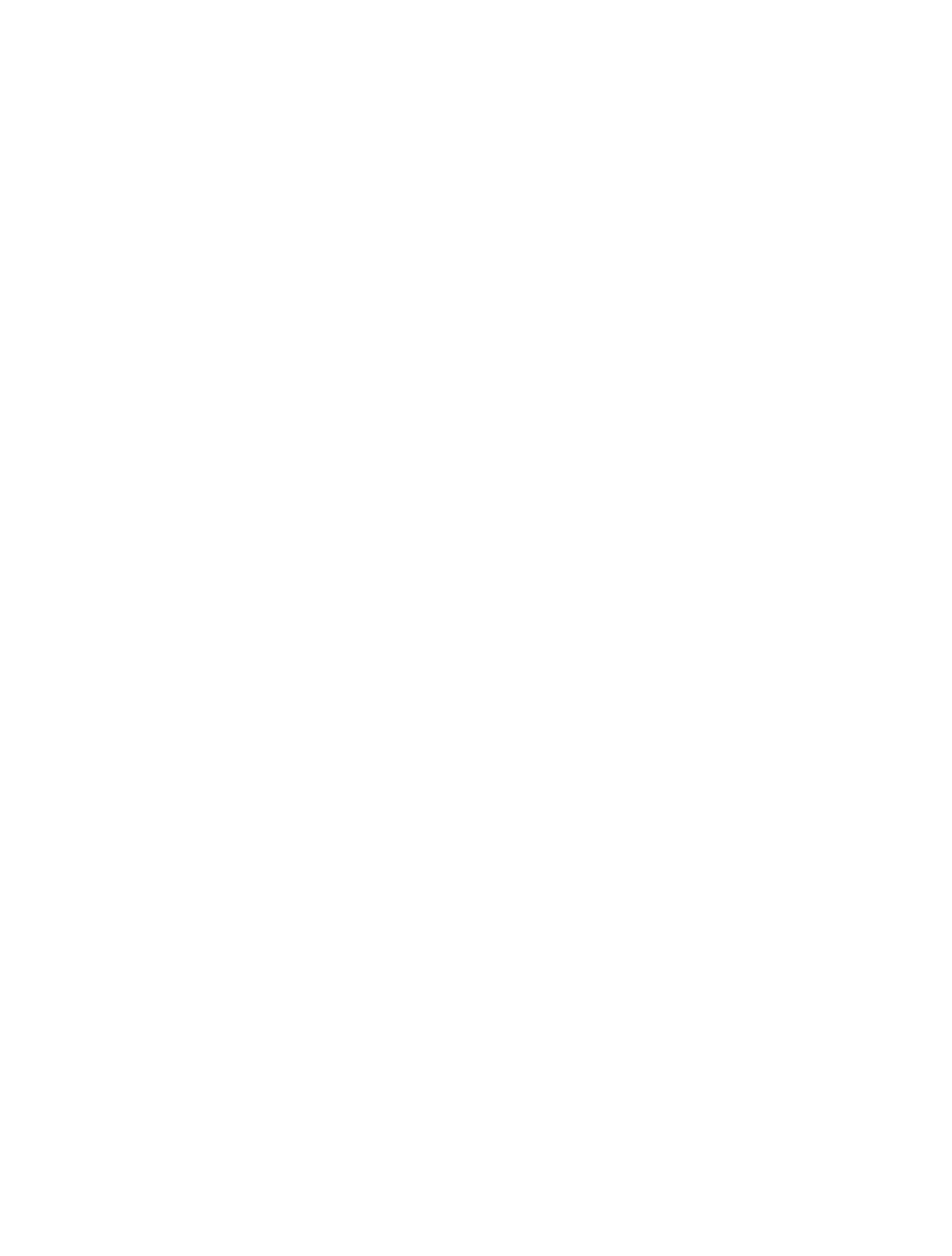


STREAUS TRIBUTARY TO LAKE ERIE--Contınued

4-1940.23. MAUMEE RIVER AT MOUTH, AT U.S, COAST GUARD STATION, AT TOLFDO, OHIO

LOCATION.--Lat $41^{\circ} 41^{\prime} 35^{\prime \prime}$, long $83^{\circ} 28^{\prime} 20^{\prime \prime}$, on left bank at entrance of channel to U.S. Coast Guard and Toledo Yacht Club, in'Bay View Park, across the river from C. \& 0 . docks, and 2,500 feet downstream from Toledo Sewage Disposal plant.

DRAINAGE AREA. --16,608 square miles.

RECORDS AVAILABLE.--Chemical ana1yses: February to September 1967.

Water temperatures: February to September 1967

EXTREMES, February to September 1967.-Specific conductance: Maximum daily, 800 micromhos Mar. 10;

minimum dally, 340 micromhos Apr. 2, 4 . Dissolved oxyg

to September.

REMARKS. industrial pollution caused from upstream and Toledo sources and from sewage disposal plant. No discharge records available.

\begin{tabular}{|c|c|c|c|c|c|c|c|c|c|c|c|c|c|c|c|c|}
\hline \multirow{3}{*}{ Day } & \multicolumn{8}{|c|}{ FEBRUARY } & \multicolumn{8}{|c|}{ MARCH } \\
\hline & \multicolumn{2}{|c|}{$\begin{array}{c}\text { Specific } \\
\text { conductance } \\
\text { (micromhos } \\
\text { at } 25^{\circ} \mathrm{C} \text { ) } \\
\end{array}$} & \multicolumn{2}{|c|}{$\mathbf{p H}$} & \multicolumn{2}{|c|}{$\begin{array}{c}\text { Dissolved } \\
\text { oxygen } \\
\text { (ppm) }\end{array}$} & \multicolumn{2}{|c|}{$\begin{array}{c}\text { Temper- } \\
\text { ature } \\
\left({ }^{c} F\right)\end{array}$} & \multicolumn{2}{|c|}{$\begin{array}{c}\text { Specific } \\
\text { conductance } \\
\text { (micromhos } \\
\text { at } 25^{\circ} \mathrm{C} \text { ) }\end{array}$} & \multicolumn{2}{|c|}{ pH } & \multicolumn{2}{|c|}{$\begin{array}{c}\text { Dissolved } \\
\text { oxygen } \\
\text { (ppm) }\end{array}$} & \multicolumn{2}{|c|}{$\begin{array}{c}\text { Temper- } \\
\text { ature } \\
\left({ }^{\circ} \mathrm{F}\right)\end{array}$} \\
\hline & Max & Min & Max & Min & Max & Min & Max & Min & Max & Min & Max & Min & Max & Min & Max & Min \\
\hline $\begin{array}{l}1 \ldots \\
2 \cdots \\
3 \ldots \\
5 \cdots\end{array}$ & $=$ & $\begin{array}{l}= \\
= \\
=\end{array}$ & $\begin{array}{l}= \\
= \\
=\end{array}$ & $\overline{-}$ & $=$ & $=$ & $\begin{array}{l}=- \\
= \\
=\end{array}$ & $\overline{=}$ & $\begin{array}{l}700 \\
740 \\
660 \\
640 \\
630\end{array}$ & $\begin{array}{l}540 \\
600 \\
600 \\
600 \\
610\end{array}$ & $\begin{array}{l}7.5 \\
7.5 \\
7.5 \\
7.5 \\
7.6\end{array}$ & $\begin{array}{l}7 \cdot 4 \\
7.3 \\
7 \cdot 3 \\
7 \cdot 3 \\
7.3\end{array}$ & $\begin{array}{l}12.3 \\
12.0 \\
11.8 \\
11.6 \\
11.6\end{array}$ & $\begin{array}{l}11.03 \\
11.0 \\
11.2 \\
11.0 \\
10.4\end{array}$ & $\begin{array}{l}38 \\
39 \\
38 \\
38 \\
36\end{array}$ & $\begin{array}{l}36 \\
35 \\
36 \\
34 \\
33\end{array}$ \\
\hline $\begin{array}{r}6 \ldots \\
7 \ldots \\
9 \ldots \\
9 \ldots \\
10 \ldots\end{array}$ & $=$ & $\begin{array}{l}\overline{-} \\
\overline{-} \\
=\end{array}$ & $\begin{array}{l}=- \\
= \\
=\end{array}$ & $\overline{=}$ & $=$ & $\begin{array}{l}=- \\
= \\
=\end{array}$ & $=$ & $=$ & $\begin{array}{l}640 \\
740 \\
710 \\
770 \\
800\end{array}$ & $\begin{array}{l}620 \\
630 \\
670 \\
660 \\
710\end{array}$ & $\begin{array}{l}7.6 \\
7.7 \\
7.7 \\
7.6 \\
7.6\end{array}$ & $\begin{array}{l}7 \cdot 3 \\
7 \cdot 4 \\
7 \cdot 4 \\
7 \cdot 4 \\
7 \cdot 3\end{array}$ & $\begin{array}{l}11.5 \\
12.3 \\
12.1 \\
12.2 \\
12.2\end{array}$ & $\begin{array}{l}10.7 \\
10.6 \\
11.0 \\
10.9 \\
10.5\end{array}$ & $\begin{array}{l}36 \\
35 \\
35 \\
37 \\
40\end{array}$ & $\begin{array}{l}33 \\
33 \\
33 \\
33 \\
35\end{array}$ \\
\hline $\begin{array}{l}11 \ldots \\
12 \ldots \\
13 \ldots \\
14 \ldots \\
15 \ldots\end{array}$ & $=$ & $\begin{array}{l}=- \\
\overline{-} \\
=-\end{array}$ & $=$ & $\begin{array}{l}= \\
= \\
=\end{array}$ & $\begin{array}{l}= \\
=- \\
=\end{array}$ & $\begin{array}{l}= \\
= \\
=\end{array}$ & $\begin{array}{l}\bar{z} \\
\overline{-}\end{array}$ & $\begin{array}{l}= \\
=\end{array}$ & $\begin{array}{l}760 \\
740 \\
650 \\
530 \\
520\end{array}$ & $\begin{array}{l}720 \\
630 \\
470 \\
430 \\
410\end{array}$ & $\begin{array}{l}7.7 \\
7.7 \\
7.6 \\
7.5 \\
7.5\end{array}$ & $\begin{array}{l}7.04 \\
7.5 \\
7.4 \\
7.3 \\
7.1\end{array}$ & $\begin{array}{l}12.7 \\
12.7 \\
12.0 \\
11.8 \\
11.8\end{array}$ & $\begin{array}{l}10.6 \\
11.6 \\
11.1 \\
11.0 \\
11.0\end{array}$ & $\begin{array}{l}37 \\
36 \\
37 \\
39 \\
40\end{array}$ & $\begin{array}{l}35 \\
33 \\
34 \\
37 \\
37\end{array}$ \\
\hline $\begin{array}{l}16.0 \\
17 \ldots \\
18 \ldots \\
19 \ldots \\
20.0\end{array}$ & $\begin{array}{l}-\overline{590} \\
580 \\
510 \\
550\end{array}$ & $\begin{array}{l}580 \\
470 \\
440 \\
460\end{array}$ & $\begin{array}{l}7.5 \\
7.6 \\
7.6 \\
7.4 \\
7.4\end{array}$ & $\begin{array}{l}-7.5 \\
7.5 \\
7.4 \\
7.4 \\
7.3\end{array}$ & $\begin{array}{l}--5 \\
12.5 \\
12.7 \\
12.5 \\
12.5\end{array}$ & $\begin{array}{l}12 . \overline{3} \\
11.9 \\
11.7 \\
11.1\end{array}$ & $\begin{array}{l}-- \\
33 \\
33 \\
33 \\
34\end{array}$ & $\begin{array}{l}\overline{32} \\
32 \\
32 \\
32\end{array}$ & $\begin{array}{l}520 \\
490 \\
550 \\
540 \\
510\end{array}$ & $\begin{array}{l}400 \\
430 \\
460 \\
460 \\
480\end{array}$ & $\begin{array}{l}7.4 \\
7.4 \\
7.5 \\
7.5 \\
7.5\end{array}$ & $\begin{array}{l}7 \cdot 1 \\
7 \cdot 2 \\
7.3 \\
7 \cdot 2 \\
7.3\end{array}$ & $\begin{array}{l}12.0 \\
12.3 \\
12.4 \\
12.5 \\
12.5\end{array}$ & $\begin{array}{l}10.9 \\
10.4 \\
11.0 \\
11.4 \\
11.9\end{array}$ & $\begin{array}{l}41 \\
39 \\
38 \\
39 \\
38\end{array}$ & $\begin{array}{l}37 \\
36 \\
35 \\
34 \\
37\end{array}$ \\
\hline $\begin{array}{l}21 \ldots \\
22 \ldots \\
23 \ldots \\
24 \ldots \\
25 \ldots\end{array}$ & $\begin{array}{l}570 \\
570 \\
550 \\
520 \\
540\end{array}$ & $\begin{array}{l}460 \\
480 \\
470 \\
490 \\
500\end{array}$ & $\begin{array}{l}7.5 \\
7.6 \\
7.6 \\
7.6 \\
7.6\end{array}$ & $\begin{array}{l}7.3 \\
7.4 \\
7.4 \\
7.4 \\
7.5\end{array}$ & $\begin{array}{l}12.6 \\
12.6 \\
12.7 \\
12.7 \\
12.9\end{array}$ & $\begin{array}{l}11.6 \\
11.5 \\
11.7 \\
11.2 \\
11.8\end{array}$ & $\begin{array}{l}35 \\
36 \\
36 \\
34 \\
35\end{array}$ & $\begin{array}{l}33 \\
33 \\
33 \\
33 \\
34\end{array}$ & $\begin{array}{l}580 \\
550 \\
520 \\
460 \\
450\end{array}$ & $\begin{array}{l}480 \\
470 \\
440 \\
430 \\
420\end{array}$ & $\begin{array}{l}7.5 \\
7.5 \\
7.5 \\
7.4 \\
7.4\end{array}$ & $\begin{array}{l}7.2 \\
7.4 \\
7.3 \\
7.3 \\
7.3\end{array}$ & $\begin{array}{l}12.5 \\
12.5 \\
12.5 \\
12.0 \\
12.0\end{array}$ & $\begin{array}{l}11.0 \\
11.8 \\
11.7 \\
11.4 \\
11.1\end{array}$ & $\begin{array}{l}39 \\
38 \\
39 \\
40 \\
41\end{array}$ & $\begin{array}{l}37 \\
36 \\
37 \\
38 \\
39\end{array}$ \\
\hline $\begin{array}{l}26 \ldots \\
27 \ldots \\
28 \ldots \\
29 \ldots \\
30 \ldots \\
31 \ldots\end{array}$ & $\begin{array}{r}640 \\
700 \\
650 \\
= \\
=\end{array}$ & $\begin{array}{r}520 \\
520 \\
550 \\
-- \\
-- \\
--\end{array}$ & $\begin{array}{r}7.6 \\
7.5 \\
7.5 \\
-- \\
-- \\
-\end{array}$ & $\begin{array}{r}7.3 \\
7.4 \\
7.4 \\
- \\
- \\
-\end{array}$ & $\begin{array}{r}12.5 \\
12.3 \\
12.1 \\
= \\
= \\
-\end{array}$ & $\begin{array}{r}11.6 \\
11.6 \\
11.5 \\
=- \\
=-\end{array}$ & $\begin{array}{l}37 \\
38 \\
37 \\
-- \\
-- \\
--\end{array}$ & $\begin{array}{l}34 \\
35 \\
35 \\
= \\
- \\
-\end{array}$ & $\begin{array}{l}450 \\
520 \\
520 \\
480 \\
520 \\
450\end{array}$ & $\begin{array}{l}410 \\
430 \\
450 \\
450 \\
450 \\
420 \\
\end{array}$ & $\begin{array}{l}7.3 \\
7.3 \\
7.3 \\
7.3 \\
7.3 \\
7.1\end{array}$ & $\begin{array}{l}7.2 \\
7.1 \\
7.2 \\
7.1 \\
7.0 \\
7.0\end{array}$ & $\begin{array}{l}12.0 \\
11.4 \\
10.9 \\
10.9 \\
10.9 \\
10.3\end{array}$ & $\begin{array}{r}11.0 \\
10.2 \\
9.0 \\
9.9 \\
9.5 \\
9.9\end{array}$ & $\begin{array}{l}44 \\
47 \\
48 \\
47 \\
50 \\
50 \\
\end{array}$ & $\begin{array}{l}40 \\
42 \\
45 \\
45 \\
46 \\
48 \\
\end{array}$ \\
\hline \multicolumn{9}{|c|}{ APR IL } & \multicolumn{8}{|c|}{ MAY } \\
\hline $\begin{array}{l}1 \ldots \\
2 \ldots \\
3 \ldots \\
5 \ldots\end{array}$ & $\begin{array}{l}490 \\
450 \\
430 \\
430 \\
490\end{array}$ & $\begin{array}{l}370 \\
340 \\
360 \\
340 \\
360\end{array}$ & $\begin{array}{l}7.1 \\
7: 0 \\
7.0 \\
7.0 \\
7.0\end{array}$ & $\begin{array}{l}6.9 \\
6.9 \\
6.9 \\
6.9 \\
7.0\end{array}$ & $\begin{array}{r}10.2 \\
9.9 \\
9.2 \\
9.5 \\
9.0\end{array}$ & $\begin{array}{l}9.1 \\
8.7 \\
7.2 \\
8.2 \\
7.4\end{array}$ & $\begin{array}{l}53 \\
53 \\
58 \\
58 \\
58\end{array}$ & $\begin{array}{l}49 \\
51 \\
53 \\
56 \\
56\end{array}$ & $\begin{array}{l}630 \\
630 \\
660 \\
660 \\
650\end{array}$ & $\begin{array}{l}560 \\
560 \\
580 \\
600 \\
590\end{array}$ & $\begin{array}{l}7.7 \\
- \\
- \\
-\end{array}$ & $\begin{array}{l}7.5 \\
=\end{array}$ & $\bar{z}$ & $\begin{array}{l}= \\
= \\
=\end{array}$ & $\begin{array}{l}58 \\
58 \\
57 \\
58 \\
59\end{array}$ & $\begin{array}{l}54 \\
55 \\
54 \\
56 \\
56\end{array}$ \\
\hline $\begin{array}{r}6 \ldots \\
7 \ldots \\
8 \ldots \\
10\end{array}$ & $\begin{array}{l}530 \\
450 \\
500 \\
520 \\
510\end{array}$ & $\begin{array}{l}410 \\
430 \\
440 \\
450 \\
460\end{array}$ & $\begin{array}{l}7.1 \\
7.2 \\
7.3 \\
7.2 \\
7.2\end{array}$ & $\begin{array}{l}7.0 \\
7.1 \\
7.1 \\
7.0 \\
7.1\end{array}$ & $\begin{array}{l}8.9 \\
8.6 \\
8.5 \\
9.2 \\
9.1\end{array}$ & $\begin{array}{l}7.1 \\
6.5 \\
6.8 \\
7.1 \\
7.8\end{array}$ & $\begin{array}{l}58 \\
56 \\
58 \\
57 \\
57\end{array}$ & $\begin{array}{l}54 \\
55 \\
54 \\
54 \\
53\end{array}$ & $\begin{array}{l}650 \\
640 \\
650 \\
650 \\
680\end{array}$ & $\begin{array}{l}590 \\
590 \\
600 \\
620 \\
600\end{array}$ & $\begin{array}{l}= \\
- \\
-\end{array}$ & $\begin{array}{l}= \\
= \\
=\end{array}$ & $\bar{I}=$ & $\begin{array}{l}= \\
= \\
=\end{array}$ & $\begin{array}{l}58 \\
58 \\
58 \\
56 \\
56\end{array}$ & $\begin{array}{l}56 \\
53 \\
55 \\
55 \\
55\end{array}$ \\
\hline $\begin{array}{l}11 \ldots \\
12 \ldots \\
13 \ldots \\
14 \ldots \\
15 \ldots\end{array}$ & $\begin{array}{l}490 \\
520 \\
530 \\
570 \\
540\end{array}$ & $\begin{array}{l}460 \\
440 \\
490 \\
480 \\
490\end{array}$ & $\begin{array}{l}7.2 \\
7.2 \\
7.2 \\
7.2 \\
7.2\end{array}$ & $\begin{array}{l}7.1 \\
7.1 \\
7.1 \\
7.1 \\
7.0\end{array}$ & $\begin{array}{r}9.4 \\
10.1 \\
9.8 \\
9.4 \\
9.4\end{array}$ & $\begin{array}{l}7.7 \\
8.6 \\
8.2 \\
7.4 \\
7.5\end{array}$ & $\begin{array}{l}56 \\
54 \\
53 \\
56 \\
57\end{array}$ & $\begin{array}{l}53 \\
51 \\
50 \\
52 \\
54\end{array}$ & $\begin{array}{l}620 \\
490 \\
490 \\
520 \\
530\end{array}$ & $\begin{array}{l}450 \\
440 \\
460 \\
480 \\
500\end{array}$ & $\begin{array}{l}= \\
= \\
=\end{array}$ & $=$ & $\bar{I}$ & $\begin{array}{l}= \\
\overline{-} \\
=-\end{array}$ & $\begin{array}{l}55 \\
55 \\
56 \\
55 \\
54\end{array}$ & $\begin{array}{l}54 \\
54 \\
54 \\
54 \\
53\end{array}$ \\
\hline $\begin{array}{l}16 \ldots \\
17 \ldots \\
18 \ldots \\
19 \ldots \\
20 \ldots\end{array}$ & $\begin{array}{l}530 \\
570 \\
560 \\
540 \\
530\end{array}$ & $\begin{array}{l}480 \\
490 \\
480 \\
510 \\
500\end{array}$ & $\begin{array}{l}7.3 \\
7.1 \\
7.3 \\
7.4 \\
7.3\end{array}$ & $\begin{array}{l}7.1 \\
7.0 \\
7.1 \\
7.1 \\
6.9\end{array}$ & $\begin{array}{l}8.7 \\
8.6 \\
9.1 \\
7.5 \\
8.5\end{array}$ & $\begin{array}{l}7.3 \\
7.2 \\
5.5 \\
6.2 \\
6.0\end{array}$ & $\begin{array}{l}60 \\
63 \\
60 \\
62 \\
60\end{array}$ & $\begin{array}{l}56 \\
59 \\
56 \\
59 \\
57\end{array}$ & $\begin{array}{l}550 \\
580 \\
610 \\
630 \\
640\end{array}$ & $\begin{array}{l}530 \\
530 \\
520 \\
510 \\
520\end{array}$ & $\begin{array}{l}7.8 \\
-\end{array}$ & $\overline{7.5}$ & $\begin{array}{r}10.7 \\
8.9 \\
9.0 \\
8.6\end{array}$ & $\begin{array}{r}-- \\
8.3 \\
7.2 \\
7.4 \\
6.7\end{array}$ & $\begin{array}{l}56 \\
57 \\
60 \\
60 \\
60\end{array}$ & $\begin{array}{l}53 \\
54 \\
56 \\
58 \\
59\end{array}$ \\
\hline $\begin{array}{l}21 \ldots \\
22 \ldots \\
23 \ldots \\
24 \ldots \\
25 \ldots\end{array}$ & $\begin{array}{l}570 \\
540 \\
550 \\
560 \\
560\end{array}$ & $\begin{array}{l}510 \\
480 \\
500 \\
520 \\
530\end{array}$ & $\begin{array}{l}7.4 \\
7.2 \\
7.2 \\
7.4 \\
7.5\end{array}$ & $\begin{array}{l}7.0 \\
6.8 \\
6.9 \\
7.1 \\
7.3\end{array}$ & $\begin{array}{l}7.6 \\
8.3 \\
8.0 \\
8.8 \\
8.5\end{array}$ & $\begin{array}{l}6.1 \\
6.6 \\
6.9 \\
6.8 \\
6.5\end{array}$ & $\begin{array}{l}59 \\
59 \\
58 \\
57 \\
57\end{array}$ & $\begin{array}{l}57 \\
56 \\
55 \\
53 \\
53\end{array}$ & $\begin{array}{l}640 \\
560 \\
560 \\
580 \\
590\end{array}$ & $\begin{array}{l}540 \\
530 \\
540 \\
540 \\
530\end{array}$ & $\begin{array}{l}-- \\
-- \\
-- \\
--\end{array}$ & $=$ & $\begin{array}{l}8.2 \\
8.6 \\
8.1 \\
8.3 \\
9.1\end{array}$ & $\begin{array}{l}6.6 \\
6.4 \\
6.3 \\
5.6 \\
5.6\end{array}$ & $\begin{array}{l}62 \\
62 \\
61 \\
63 \\
65\end{array}$ & $\begin{array}{l}60 \\
59 \\
60 \\
60 \\
60\end{array}$ \\
\hline $\begin{array}{l}26 \ldots \\
27 \bullet \\
28 \ldots \\
29 \bullet \\
30 \ldots \\
31 \cdots\end{array}$ & $\begin{array}{r}540 \\
540 \\
610 \\
670 \\
650 \\
-\end{array}$ & $\begin{array}{c}510 \\
520 \\
530 \\
580 \\
550 \\
--\end{array}$ & $\begin{array}{r}7.6 \\
7.6 \\
7.7 \\
7.7 \\
7.7 \\
-\end{array}$ & $\begin{array}{r}7.4 \\
7.5 \\
7.6 \\
7.5 \\
7.5 \\
- \\
\end{array}$ & $\begin{array}{r}9.2 \\
8.5 \\
9.0 \\
8.7 \\
-\end{array}$ & $\begin{array}{r}6.5 \\
7.6 \\
7.3 \\
7.0 \\
-. \\
\end{array}$ & $\begin{array}{l}56 \\
54 \\
56 \\
55 \\
55 \\
--\end{array}$ & $\begin{array}{l}52 \\
50 \\
53 \\
53 \\
53 \\
- \\
\end{array}$ & $\begin{array}{l}560 \\
650 \\
600 \\
640 \\
650 \\
640\end{array}$ & $\begin{array}{l}520 \\
550 \\
550 \\
560 \\
580 \\
580\end{array}$ & $\begin{array}{l}- \\
- \\
- \\
- \\
-\end{array}$ & $=$ & $\begin{array}{r}9.4 \\
7.3 \\
10.4 \\
9.2 \\
10.7 \\
10.2\end{array}$ & $\begin{array}{l}5.5 \\
3.7 \\
4.4 \\
6.3 \\
6.0 \\
6.6\end{array}$ & $\begin{array}{l}65 \\
66 \\
67 \\
65 \\
67 \\
65\end{array}$ & $\begin{array}{l}62 \\
62 \\
64 \\
62 \\
63 \\
61\end{array}$ \\
\hline
\end{tabular}


STREAMS TRIBUTARY TO LAKE ERIE--COntinued

4-1940.23. MAUMEE RIVER AT MOUTH, AT U.S. COAST GUARD STATION, AT TOLEDO, OHIO--CONtinued

Data from continuous recorder, February to September 1967--Continued

\begin{tabular}{|c|c|c|c|c|c|c|c|c|c|c|c|c|c|c|c|c|}
\hline \multirow{3}{*}{ Day } & \multicolumn{8}{|c|}{ JUNE } & \multicolumn{8}{|c|}{ JULY } \\
\hline & \multicolumn{2}{|c|}{$\begin{array}{c}\text { Specific } \\
\text { conductance } \\
\text { (micromhos } \\
\text { at } 25^{\circ} \mathrm{C} \text { ) } \\
\end{array}$} & \multicolumn{2}{|c|}{ pH } & \multicolumn{2}{|c|}{$\begin{array}{c}\text { Dissolved } \\
\text { oxygen } \\
\text { (ppm) }\end{array}$} & \multicolumn{2}{|c|}{$\begin{array}{c}\text { Temper- } \\
\text { ature } \\
\left({ }^{\circ} \mathrm{F}\right)\end{array}$} & \multicolumn{2}{|c|}{$\begin{array}{c}\text { Specific } \\
\text { conductance } \\
\text { (micromhos } \\
\text { at } 25^{\circ} \mathrm{C} \text { ) }\end{array}$} & \multicolumn{2}{|c|}{ pH } & \multicolumn{2}{|c|}{$\begin{array}{c}\text { Dissolved } \\
\text { oxygen } \\
(\mathrm{ppm})\end{array}$} & \multicolumn{2}{|c|}{$\begin{array}{c}\text { Temper- } \\
\text { ature } \\
\left({ }^{\circ} \mathrm{F}\right)\end{array}$} \\
\hline & Max & Min & $\operatorname{Max}$ & Min & Max & Min & Max & Min & Max & Min & Max & Min & $\operatorname{Max}$ & Min & Max & Min \\
\hline $\begin{array}{l}1 \ldots \\
2 \ldots \\
3 \ldots \\
4 \ldots \\
5 \ldots\end{array}$ & $\begin{array}{l}640 \\
680 \\
670 \\
680 \\
650\end{array}$ & $\begin{array}{l}580 \\
620 \\
580 \\
610 \\
610\end{array}$ & & & $\begin{array}{r}11.2 \\
9.0 \\
8.8 \\
8.0 \\
8.1\end{array}$ & $\begin{array}{l}6.9 \\
5.6 \\
4.2 \\
3.1 \\
3.0\end{array}$ & $\begin{array}{l}66 \\
68 \\
70 \\
71 \\
72\end{array}$ & $\begin{array}{l}61 \\
64 \\
66 \\
67 \\
68\end{array}$ & $\begin{array}{l}640 \\
640 \\
610 \\
610 \\
640\end{array}$ & $\begin{array}{l}570 \\
570 \\
550 \\
540 \\
560\end{array}$ & & & $\begin{array}{l}2.4 \\
2.9 \\
2.1 \\
4.0 \\
2.9\end{array}$ & $\begin{array}{l}.0 \\
.0 \\
.0 \\
.0 \\
.0\end{array}$ & $\begin{array}{l}77 \\
77 \\
77 \\
76 \\
76\end{array}$ & $\begin{array}{l}75 \\
75 \\
75 \\
74 \\
73\end{array}$ \\
\hline $\begin{array}{r}6 \\
7 \ldots \\
8 \ldots \\
9 \bullet \\
10\end{array}$ & $\begin{array}{l}690 \\
690 \\
690 \\
700 \\
670\end{array}$ & $\begin{array}{l}640 \\
620 \\
640 \\
580 \\
610\end{array}$ & & & $\mid \begin{array}{r}3.4 \\
2.3 \\
1.6 \\
1.7 \\
.9\end{array}$ & $\begin{array}{l}.1 \\
: 1 \\
: 1 \\
.0 \\
.0\end{array}$ & $\begin{array}{l}71 \\
72 \\
73 \\
76 \\
75\end{array}$ & $\begin{array}{l}69 \\
70 \\
71 \\
72 \\
73\end{array}$ & $\begin{array}{l}610 \\
620 \\
640 \\
650 \\
650\end{array}$ & $\begin{array}{l}530 \\
570 \\
580 \\
590 \\
590\end{array}$ & & & $\begin{array}{l}6.5 \\
5.4 \\
4.0 \\
2.8 \\
4.2\end{array}$ & $\begin{array}{l}.0 \\
.0 \\
.0 \\
.0 \\
.0\end{array}$ & $\begin{array}{l}76 \\
76 \\
77 \\
79 \\
79\end{array}$ & $\begin{array}{l}74 \\
74 \\
75 \\
76 \\
77\end{array}$ \\
\hline $\begin{array}{l}11 \ldots \\
12 \cdots \\
13 \ldots \\
14 \ldots \\
15 \ldots\end{array}$ & $\begin{array}{l}640 \\
620 \\
620 \\
620 \\
640\end{array}$ & $\begin{array}{l}570 \\
560 \\
580 \\
590 \\
590\end{array}$ & & & $\begin{array}{l}1.1 \\
1.6 \\
1.3 \\
1.3 \\
1.4\end{array}$ & $\begin{array}{l}.1 \\
.0 \\
.0 \\
.0 \\
.0\end{array}$ & $\begin{array}{l}76 \\
77 \\
78 \\
80 \\
80\end{array}$ & $\begin{array}{l}73 \\
73 \\
75 \\
76 \\
78\end{array}$ & $\begin{array}{l}640 \\
650 \\
650 \\
660 \\
-\end{array}$ & $\begin{array}{l}570 \\
620 \\
580 \\
610 \\
--\end{array}$ & & & $\begin{array}{r}2.7 \\
1.7 \\
1.8 \\
.7 \\
-\end{array}$ & $\begin{array}{l}.0 \\
.0 \\
.0 \\
.0 \\
.0\end{array}$ & $\begin{array}{l}79 \\
79 \\
79 \\
78 \\
-\end{array}$ & $\begin{array}{l}77 \\
78 \\
78 \\
76 \\
-\end{array}$ \\
\hline $\begin{array}{l}16 \ldots \\
17 \ldots \\
18 \ldots \\
19 \ldots \\
20 \ldots\end{array}$ & $\begin{array}{l}650 \\
600 \\
560 \\
560 \\
820\end{array}$ & $\begin{array}{l}600 \\
560 \\
490 \\
500 \\
530\end{array}$ & & & $\begin{array}{r}.9 \\
2.5 \\
3.9 \\
4.0 \\
1.7\end{array}$ & $\begin{array}{l}.1 \\
.0 \\
.1 \\
.3 \\
.1\end{array}$ & $\begin{array}{l}81 \\
B 1 \\
80 \\
78 \\
78\end{array}$ & $\begin{array}{l}79 \\
78 \\
75 \\
73 \\
76\end{array}$ & $=$ & $\begin{array}{l}=- \\
\overline{50}\end{array}$ & & & $\begin{array}{l}\overline{-} \\
\overline{6.5}\end{array}$ & $\bar{z}$ & $\begin{array}{l}\bar{z} \\
\overline{78}\end{array}$ & $\overline{=}$ \\
\hline $\begin{array}{l}21 \ldots \\
22 \ldots \\
23 \ldots \\
24 \ldots \\
25 \ldots\end{array}$ & $\begin{array}{l}610 \\
610 \\
600 \\
640 \\
640\end{array}$ & $\begin{array}{l}550 \\
550 \\
520 \\
560 \\
560\end{array}$ & & & $\begin{array}{r}.8 \\
.7 \\
.9 \\
1.1 \\
.9\end{array}$ & $\begin{array}{l}.0 \\
.0 \\
.0 \\
.0 \\
.1\end{array}$ & $\begin{array}{l}79 \\
78 \\
79 \\
80 \\
79\end{array}$ & $\begin{array}{l}76 \\
76 \\
77 \\
78 \\
77\end{array}$ & $\begin{array}{l}580 \\
700 \\
760 \\
740 \\
640\end{array}$ & $\begin{array}{l}520 \\
560 \\
520 \\
470 \\
490\end{array}$ & & & $\begin{array}{l}4.2 \\
2.8 \\
1.8 \\
3.8 \\
2.5\end{array}$ & $\begin{array}{l}.4 \\
.0 \\
.0 \\
.5 \\
.1\end{array}$ & $\begin{array}{l}78 \\
78 \\
79 \\
78 \\
79\end{array}$ & $\begin{array}{l}75 \\
76 \\
77 \\
76 \\
77\end{array}$ \\
\hline $\begin{array}{l}26 \ldots \\
27 \ldots \\
28 \ldots \\
29 \ldots \\
30 \ldots \\
31 \ldots\end{array}$ & $\begin{array}{l}610 \\
610 \\
650 \\
660 \\
660 \\
-\end{array}$ & $\begin{array}{r}570 \\
540 \\
550 \\
600 \\
570 \\
--\end{array}$ & & & $\begin{array}{r}.4 \\
1.6 \\
.5 \\
.4 \\
.9 \\
- \\
\end{array}$ & $\begin{array}{l}.1 \\
.0 \\
.0 \\
.0 \\
.0 \\
-0 \\
\end{array}$ & $\begin{array}{l}79 \\
80 \\
79 \\
77 \\
76 \\
- \\
\end{array}$ & $\begin{array}{l}77 \\
78 \\
76 \\
75 \\
74 \\
-\end{array}$ & $\begin{array}{l}700 \\
690 \\
700 \\
700 \\
710 \\
690\end{array}$ & $\begin{array}{l}550 \\
630 \\
550 \\
510 \\
630 \\
560\end{array}$ & & & $\begin{array}{r}1.2 \\
1.7 \\
1.9 \\
2.9 \\
1.1 \\
7.3\end{array}$ & $\begin{array}{l}.0 \\
.0 \\
.0 \\
.0 \\
.0 \\
.1\end{array}$ & $\begin{array}{l}80 \\
80 \\
79 \\
80 \\
79 \\
80 \\
\end{array}$ & $\begin{array}{l}78 \\
78 \\
77 \\
78 \\
77 \\
78 \\
\end{array}$ \\
\hline \multicolumn{9}{|c|}{ AUGUST } & \multicolumn{8}{|c|}{ SEPTEMBER } \\
\hline $\begin{array}{l}1 \ldots \\
2 \ldots \\
3 \cdots \\
4 \ldots \\
5 \ldots\end{array}$ & $\begin{array}{l}760 \\
760 \\
750 \\
740 \\
740\end{array}$ & $\begin{array}{l}650 \\
730 \\
700 \\
700 \\
710\end{array}$ & & & $\begin{array}{r}1.4 \\
1.5 \\
1.6 \\
3.0 \\
2.7\end{array}$ & $\begin{array}{l}.0 \\
: 0 \\
.0 \\
.0 \\
.0\end{array}$ & $\begin{array}{l}80 \\
80 \\
80 \\
80 \\
B 0\end{array}$ & $\begin{array}{l}78 \\
79 \\
78 \\
78 \\
77\end{array}$ & $\begin{array}{l}620 \\
640 \\
600 \\
580 \\
610\end{array}$ & $\begin{array}{l}540 \\
550 \\
510 \\
450 \\
510\end{array}$ & & & $\begin{array}{r}6.6 \\
7.9 \\
8.9 \\
14.4 \\
9.9\end{array}$ & $\begin{array}{l}.0 \\
.0 \\
.0 \\
.5 \\
.3\end{array}$ & $\begin{array}{l}75 \\
75 \\
74 \\
75 \\
78\end{array}$ & $\begin{array}{l}69 \\
71 \\
70 \\
71 \\
72\end{array}$ \\
\hline \begin{tabular}{r|}
$6 \ldots$ \\
$7 \ldots$ \\
$8 \cdots$ \\
$9 \cdots$ \\
$10 \cdots$
\end{tabular} & $\begin{array}{l}720 \\
710 \\
690 \\
680 \\
650\end{array}$ & $\begin{array}{l}690 \\
620 \\
570 \\
560 \\
600\end{array}$ & & & $\begin{array}{r}.99 \\
2.9 \\
109 \\
1.0\end{array}$ & $\begin{array}{l}.0 \\
.0 \\
.0 \\
.0 \\
.0\end{array}$ & $\begin{array}{l}79 \\
80 \\
80 \\
79 \\
77\end{array}$ & $\begin{array}{l}78 \\
77 \\
79 \\
75 \\
76\end{array}$ & $\begin{array}{l}600 \\
590 \\
670 \\
660 \\
310\end{array}$ & $\begin{array}{l}530 \\
530 \\
510 \\
440 \\
410\end{array}$ & & & $\begin{array}{l}6.4 \\
7.4 \\
8.3 \\
5.2 \\
7.7\end{array}$ & $\begin{array}{r}.0 \\
.0 \\
.0 \\
10 \\
1.0\end{array}$ & $\begin{array}{l}77 \\
76 \\
78 \\
76 \\
71\end{array}$ & $\begin{array}{l}73 \\
74 \\
74 \\
68 \\
66\end{array}$ \\
\hline $\begin{array}{l}11 \ldots \\
12 \ldots \\
13 \ldots \\
14 \ldots \\
15 \ldots\end{array}$ & $\begin{array}{l}650 \\
650 \\
690 \\
660 \\
670\end{array}$ & $\begin{array}{l}600 \\
610 \\
600 \\
570 \\
590\end{array}$ & & & $\begin{array}{r}2.4 \\
3.3 \\
.6 \\
.4 \\
.0\end{array}$ & $\begin{array}{l}.0 \\
.0 \\
.0 \\
.0 \\
.0\end{array}$ & $\begin{array}{l}77 \\
77 \\
77 \\
77 \\
77\end{array}$ & $\begin{array}{l}75 \\
75 \\
75 \\
76 \\
76\end{array}$ & $\begin{array}{l}530 \\
660 \\
630 \\
610 \\
630\end{array}$ & $\begin{array}{l}490 \\
520 \\
540 \\
510 \\
510\end{array}$ & & & $\begin{array}{l}5.6 \\
6.8 \\
6.0 \\
6.5 \\
6.6\end{array}$ & $\begin{array}{l}.7 \\
.0 \\
.0 \\
.0 \\
.0\end{array}$ & $\begin{array}{l}70 \\
71 \\
71 \\
73 \\
73\end{array}$ & $\begin{array}{l}68 \\
69 \\
69 \\
70 \\
70\end{array}$ \\
\hline $\begin{array}{l}16 \ldots \\
17 \ldots \\
18 \ldots \\
19 \ldots \\
20 \ldots\end{array}$ & $\begin{array}{l}660 \\
680 \\
640 \\
640 \\
650\end{array}$ & $\begin{array}{l}600 \\
480 \\
520 \\
520 \\
510\end{array}$ & & & $=0$ & $\begin{array}{l}.0 \\
.0 \\
.0 \\
.0 \\
.0\end{array}$ & $\begin{array}{l}79 \\
79 \\
78 \\
77 \\
77\end{array}$ & $\begin{array}{l}77 \\
77 \\
77 \\
76 \\
75\end{array}$ & $\begin{array}{l}580 \\
600 \\
580 \\
580 \\
670\end{array}$ & $\begin{array}{l}470 \\
480 \\
500 \\
530 \\
540\end{array}$ & & & $\begin{array}{r}8.7 \\
5.8 \\
3.2 \\
.9 \\
.0\end{array}$ & $\begin{array}{l}.0 \\
.0 \\
.0 \\
.0 \\
.0\end{array}$ & $\begin{array}{l}74 \\
74 \\
76 \\
76 \\
74\end{array}$ & $\begin{array}{l}70 \\
71 \\
71 \\
71 \\
72\end{array}$ \\
\hline $\begin{array}{l}21 \ldots \\
22 \ldots \\
23 \ldots \\
24 \ldots \\
25 \ldots\end{array}$ & $\begin{array}{l}510 \\
520 \\
560 \\
560 \\
650\end{array}$ & $\begin{array}{l}470 \\
430 \\
470 \\
500 \\
500\end{array}$ & & & $=$ & $\begin{array}{l}0 \\
-- \\
--\end{array}$ & $\begin{array}{l}76 \\
74 \\
75 \\
76 \\
77\end{array}$ & $\begin{array}{l}72 \\
71 \\
71 \\
74 \\
74\end{array}$ & $\begin{array}{l}690 \\
650 \\
720 \\
680 \\
630\end{array}$ & $\begin{array}{l}620 \\
500 \\
580 \\
500 \\
500\end{array}$ & & & $\begin{array}{l}.0 \\
.9 \\
.0 \\
.3 \\
.1\end{array}$ & $\begin{array}{l}.0 \\
.0 \\
.0 \\
.0 \\
.0\end{array}$ & $\begin{array}{l}73 \\
72 \\
72 \\
70 \\
69\end{array}$ & $\begin{array}{l}72 \\
69 \\
68 \\
67 \\
66\end{array}$ \\
\hline $\begin{array}{l}26 \ldots \mid \\
27 \ldots \\
28 \ldots \\
29 \ldots \\
30 \ldots \\
31 \ldots\end{array}$ & $\begin{array}{l}640 \\
600 \\
580 \\
-150 \\
570\end{array}$ & $\begin{array}{l}570 \\
440 \\
500 \\
-- \\
470 \\
470\end{array}$ & & & $\begin{array}{l}= \\
= \\
3.6 \\
6.4\end{array}$ & $\begin{array}{l}.0 \\
.0 \\
-\because 0 \\
.0\end{array}$ & $\begin{array}{l}76 \\
74 \\
74 \\
74 \\
72\end{array}$ & $\begin{array}{l}74 \\
71 \\
72 \\
70 \\
68\end{array}$ & $\begin{array}{r}700 \\
700 \\
460 \\
640 \\
660 \\
-\end{array}$ & $\begin{array}{r}460 \\
400 \\
380 \\
460 \\
460 \\
-\end{array}$ & & & $\begin{array}{r}.3 \\
2.2 \\
3.4 \\
.0 \\
.0 \\
--\end{array}$ & $\begin{array}{l}.0 \\
.0 \\
.0 \\
.0 \\
.0 \\
--\end{array}$ & $\begin{array}{l}69 \\
68 \\
63 \\
63 \\
62 \\
-\end{array}$ & $\begin{array}{l}65 \\
63 \\
61 \\
61 \\
58 \\
--\end{array}$ \\
\hline
\end{tabular}




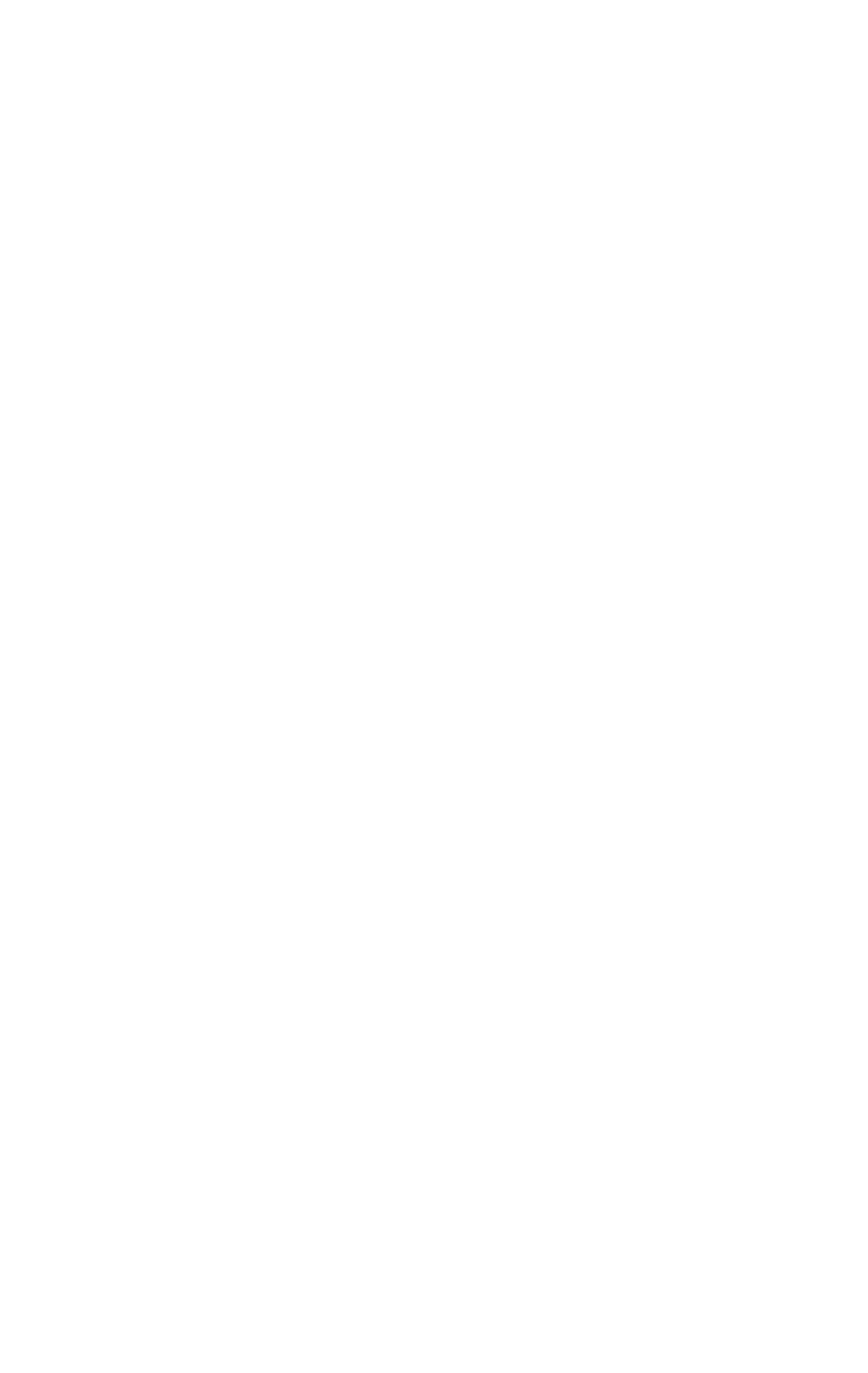




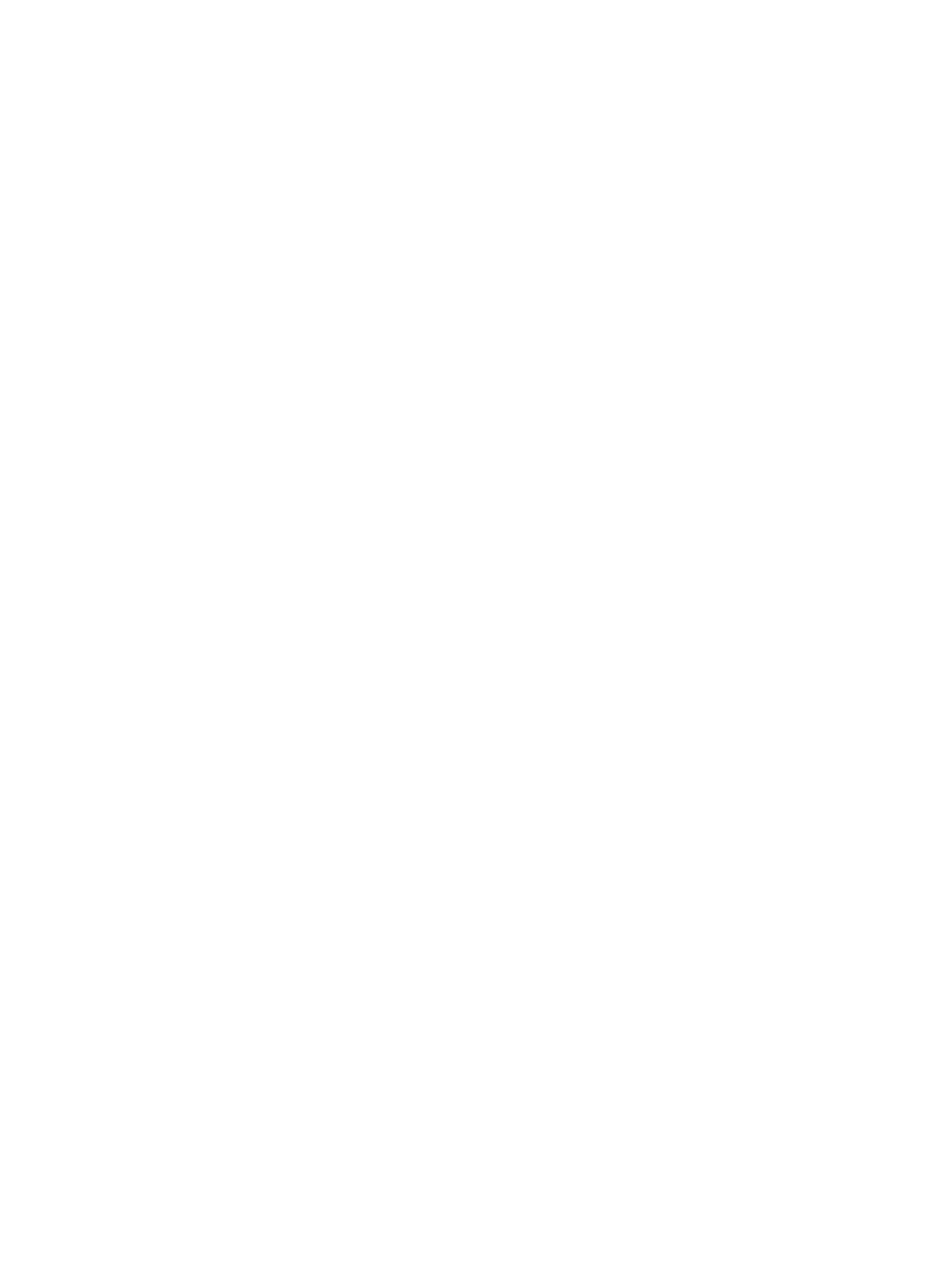

ङ

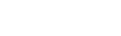

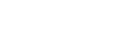




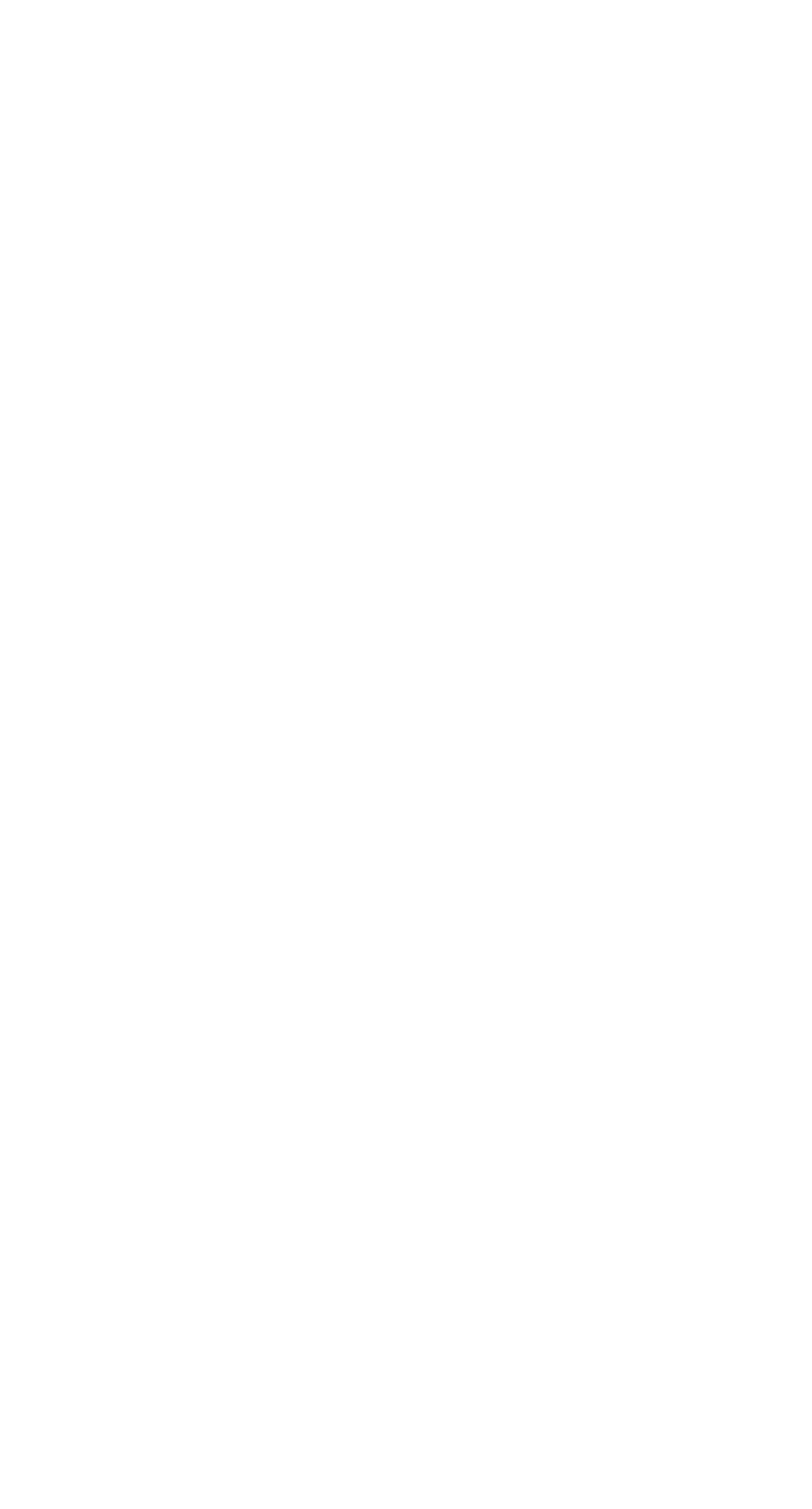


STREAMS TRIBUTARY TO LAKE ERIE--COntinued

4-1980.05. SANDUSKY RIVER BELOW FREWONT, OHIO--COntinued

Data from continuous recorder, water year October 1966 to September 1967

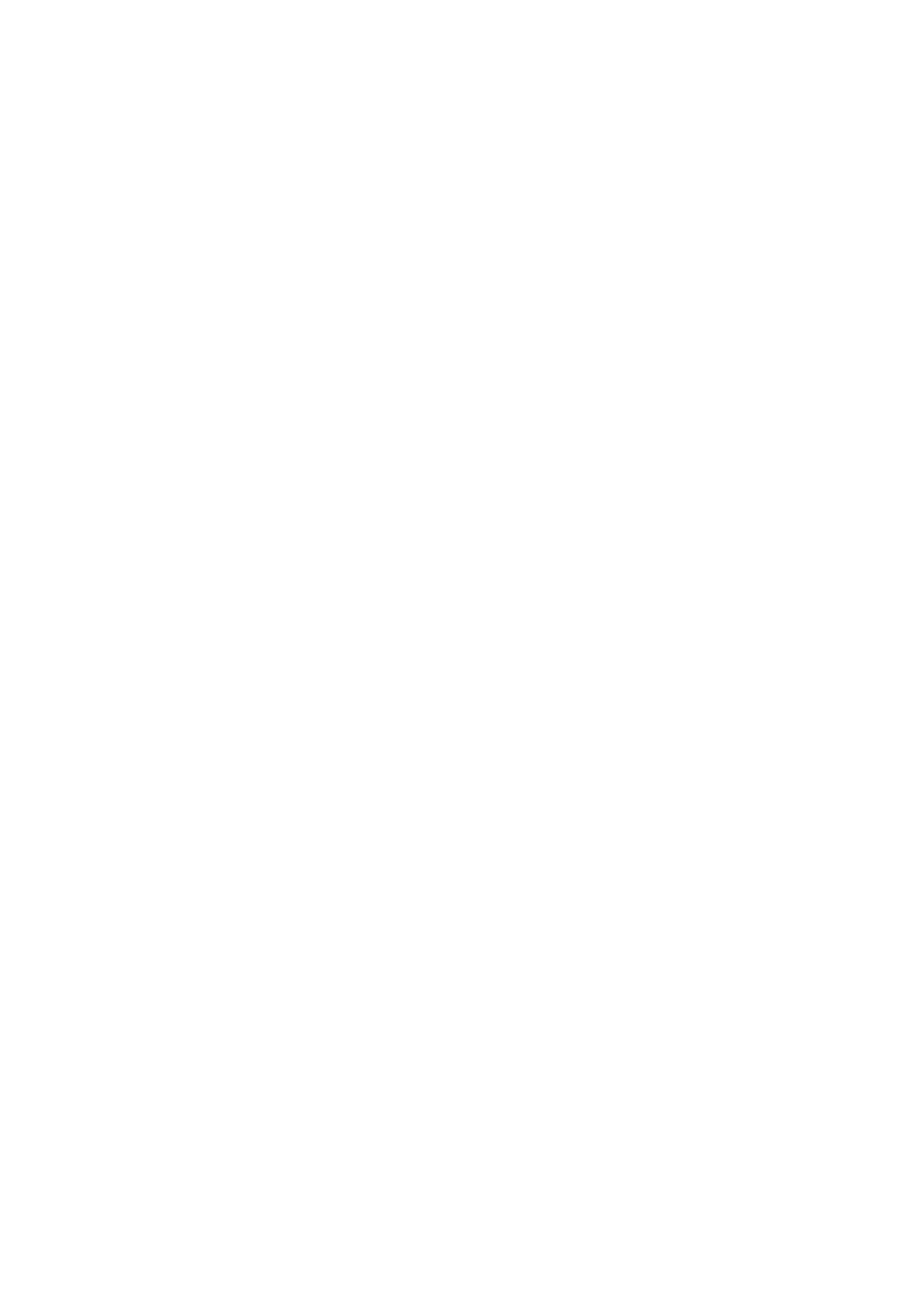


STREAMS TRIBUTARY TO LAKE ERIE--Continued

4-1980.05. SANDUSKY RIVER BELOW FREMONT, OHIO--Continued

Data from continuous recorder, water year October 1966 to September $1967--$ Continued

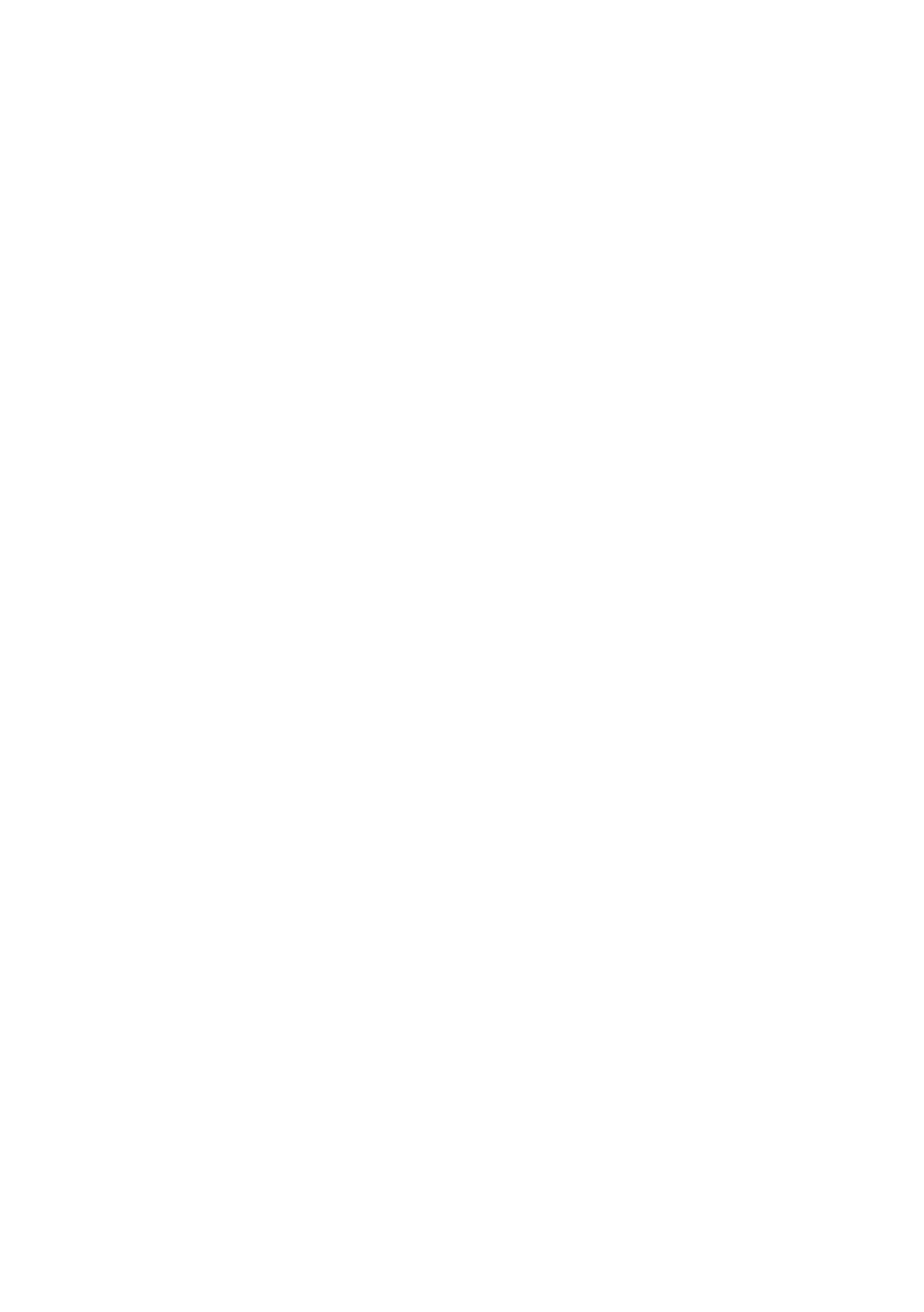


STREAKS TRIBUTARY TO LAKE ERIE--COntinued

4-1980.05. SANDUSKY RIVER BELOW FREWONT, OHIO--COntinued

Data from continuous recorder, water year October 1966 to September 1967--Continued

\begin{tabular}{|c|c|c|c|c|c|c|c|c|c|c|c|c|c|c|c|c|}
\hline \multirow{3}{*}{ Day } & \multicolumn{8}{|c|}{ JUNE } & \multicolumn{8}{|c|}{ JULY } \\
\hline & \multicolumn{2}{|c|}{$\begin{array}{c}\text { Specific } \\
\text { conductance } \\
\text { (micromhos } \\
\text { at } 25^{\circ} \mathrm{C} \text { ) }\end{array}$} & \multicolumn{2}{|c|}{$\mathrm{pH}$} & \multicolumn{2}{|c|}{$\begin{array}{l}\text { Dissolved } \\
\text { oxygen } \\
\text { (ppm) }\end{array}$} & \multicolumn{2}{|c|}{$\begin{array}{c}\text { Temper- } \\
\text { ature } \\
\left({ }^{\circ} \mathbf{F}\right)\end{array}$} & \multicolumn{2}{|c|}{$\begin{array}{c}\text { Specific } \\
\text { conductance } \\
\text { (micromhos } \\
\text { at } 25^{\circ} \mathrm{C} \text { ) }\end{array}$} & \multicolumn{2}{|c|}{$\mathbf{p H}$} & \multicolumn{2}{|c|}{$\begin{array}{c}\text { Dissolved } \\
\text { oxygen } \\
\text { (ppm) }\end{array}$} & \multicolumn{2}{|c|}{$\begin{array}{c}\text { Temper- } \\
\text { ature } \\
\left({ }^{\circ} \mathbf{F}\right)\end{array}$} \\
\hline & Max & Min & Max & Min & $\operatorname{Max}$ & Min & Max & Min & Max & Min & $\operatorname{Max}$ & Min & Max & Min & $A^{4} \times x$ & Min \\
\hline $\begin{array}{l}1 \ldots \\
2 \ldots \\
3 \ldots \\
4 \ldots \\
5 \ldots\end{array}$ & $\begin{array}{l}660 \\
660 \\
660 \\
650 \\
660\end{array}$ & $\begin{array}{l}620 \\
620 \\
590 \\
590 \\
620\end{array}$ & & & $\begin{array}{r}13.4 \\
15.0 \\
+15.0 \\
14.7 \\
11.4\end{array}$ & $\begin{array}{r}8.3 \\
10.3 \\
12.9 \\
11.0 \\
6.5\end{array}$ & $\begin{array}{l}67 \\
68 \\
73 \\
73 \\
73\end{array}$ & $\begin{array}{l}64 \\
64 \\
67 \\
69 \\
69\end{array}$ & $\begin{array}{l}710 \\
640 \\
610 \\
640 \\
630\end{array}$ & $\begin{array}{l}630 \\
570 \\
540 \\
570 \\
600\end{array}$ & & & $\begin{array}{l}>15.0 \\
>15.0 \\
>15.0 \\
15.0 \\
12.9\end{array}$ & $\begin{array}{r}8.2 \\
13.5 \\
14.2 \\
10.0 \\
7.3\end{array}$ & $\begin{array}{l}79 \\
79 \\
78 \\
76 \\
74\end{array}$ & $\begin{array}{l}72 \\
76 \\
75 \\
74 \\
71\end{array}$ \\
\hline $\begin{array}{r}6 \ldots \\
7 \ldots \\
8 \ldots \\
90\end{array}$ & $\begin{array}{l}570 \\
680 \\
690 \\
710 \\
720\end{array}$ & $\begin{array}{l}620 \\
630 \\
630 \\
650 \\
650\end{array}$ & & & $\begin{array}{r}7.7 \\
6.7 \\
4.2 \\
3.7 \\
10.8\end{array}$ & $\begin{array}{l}4.7 \\
3.2 \\
2.9 \\
1.1 \\
1.5\end{array}$ & $\begin{array}{l}73 \\
74 \\
75 \\
77 \\
80\end{array}$ & $\begin{array}{l}70 \\
71 \\
72 \\
73 \\
74\end{array}$ & $\begin{array}{l}560 \\
670 \\
640 \\
590 \\
590\end{array}$ & $\begin{array}{l}610 \\
600 \\
560 \\
500 \\
530\end{array}$ & & & $\begin{array}{l}14.3 \\
13.5 \\
-15.0 \\
P 15.0 \\
12.8\end{array}$ & $\begin{array}{r}8.3 \\
9.7 \\
10.5 \\
9.2 \\
6.6\end{array}$ & $\begin{array}{l}75 \\
75 \\
77 \\
80 \\
78\end{array}$ & $\begin{array}{l}71 \\
72 \\
73 \\
74 \\
75\end{array}$ \\
\hline $\begin{array}{l}11 \ldots \\
12 \ldots \\
13 \ldots \\
14 \ldots \\
15 \ldots\end{array}$ & $\begin{array}{l}720 \\
740 \\
750 \\
770 \\
790\end{array}$ & $\begin{array}{l}680 \\
680 \\
690 \\
700 \\
720\end{array}$ & & & $\begin{array}{r}11.7 \\
10.5 \\
7.5 \\
5.8 \\
5.8\end{array}$ & $\begin{array}{l}3.3 \\
4.9 \\
2.3 \\
1.8 \\
1.9\end{array}$ & $\begin{array}{l}79 \\
79 \\
81 \\
80 \\
81\end{array}$ & $\begin{array}{l}75 \\
75 \\
76 \\
77 \\
78\end{array}$ & $\begin{array}{l}510 \\
570 \\
540 \\
560 \\
570\end{array}$ & $\begin{array}{l}500 \\
500 \\
510 \\
510 \\
520\end{array}$ & & & $\begin{array}{r}11.0 \\
11.5 \\
8.7 \\
5.0 \\
2.9\end{array}$ & $\begin{array}{l}4.1 \\
2.9 \\
3.9 \\
1.7 \\
1.0\end{array}$ & $\begin{array}{l}79 \\
79 \\
78 \\
76 \\
73\end{array}$ & $\begin{array}{l}75 \\
76 \\
76 \\
73 \\
72\end{array}$ \\
\hline $\begin{array}{l}16 \ldots \\
17 \ldots \\
18 \ldots \\
20 \ldots \\
20.0\end{array}$ & $\begin{array}{l}800 \\
810 \\
810 \\
820 \\
790\end{array}$ & $\begin{array}{l}750 \\
760 \\
760 \\
760 \\
730\end{array}$ & & & $\begin{array}{r}9.3 \\
13.0 \\
6.5 \\
9.2 \\
10.9\end{array}$ & $\begin{array}{r}1.9 \\
2.7 \\
.8 \\
1.0 \\
5.6\end{array}$ & $\begin{array}{l}82 \\
82 \\
79 \\
76 \\
76\end{array}$ & $\begin{array}{l}79 \\
78 \\
76 \\
73 \\
71\end{array}$ & $\begin{array}{l}580 \\
590 \\
600 \\
600 \\
620\end{array}$ & $\begin{array}{l}540 \\
540 \\
540 \\
540 \\
560\end{array}$ & & & $\begin{array}{r}4.4 \\
6.0 \\
10.0 \\
9.0 \\
7.5\end{array}$ & $\begin{array}{r}.7 \\
2.2 \\
4.0 \\
3.0 \\
.6\end{array}$ & $\begin{array}{l}73 \\
73 \\
74 \\
74 \\
76\end{array}$ & $\begin{array}{l}70 \\
70 \\
71 \\
71 \\
71\end{array}$ \\
\hline $\begin{array}{l}21 \cdots \\
22 \bullet \\
23 \ldots\end{array}$ & $\begin{array}{l}790 \\
790 \\
750\end{array}$ & $\begin{array}{l}740 \\
700 \\
660\end{array}$ & & & $\begin{array}{r}10.5 \\
5.2 \\
8.2\end{array}$ & $\begin{array}{l}3.3 \\
1.5 \\
2.0\end{array}$ & $\begin{array}{l}76 \\
76 \\
78\end{array}$ & $\begin{array}{l}73 \\
72 \\
73\end{array}$ & $\begin{array}{l}760 \\
840 \\
710\end{array}$ & $\begin{array}{l}620 \\
710 \\
420\end{array}$ & & & $\begin{array}{r}9.0 \\
6.8 \\
--\end{array}$ & $\begin{array}{r}1.8 \\
2.7 \\
--\end{array}$ & $\begin{array}{l}76 \\
78 \\
77\end{array}$ & $\begin{array}{l}72 \\
73 \\
74\end{array}$ \\
\hline $\begin{array}{l}24 \ldots \\
25 \ldots\end{array}$ & $\begin{array}{l}680 \\
690\end{array}$ & $\begin{array}{l}650 \\
650\end{array}$ & & & $\begin{array}{l}7.7 \\
3.8\end{array}$ & $\begin{array}{l}2.2 \\
1.2\end{array}$ & $\begin{array}{l}77 \\
76\end{array}$ & $\begin{array}{l}74 \\
73\end{array}$ & $\begin{array}{l}510 \\
520\end{array}$ & $\begin{array}{l}420 \\
460\end{array}$ & & & $\overline{--}$ & $=$ & $\begin{array}{l}78 \\
79\end{array}$ & $\begin{array}{l}75 \\
75\end{array}$ \\
\hline $\begin{array}{l}26 \ldots \\
27 \ldots \\
28 \ldots \\
29 \ldots \\
30 \ldots \\
31 \ldots\end{array}$ & $\begin{array}{l}690 \\
690 \\
660 \\
650 \\
660 \\
--\end{array}$ & $\begin{array}{l}650 \\
600 \\
590 \\
500 \\
610 \\
--\end{array}$ & & & $\begin{array}{r}5.6 \\
10.8 \\
15.0 \\
13.2 \\
13.4 \\
-- \\
\end{array}$ & $\begin{array}{r}3.8 \\
4.9 \\
10.0 \\
10.0 \\
10.9 \\
--\end{array}$ & $\begin{array}{l}74 \\
78 \\
76 \\
75 \\
75 \\
--\end{array}$ & $\begin{array}{l}72 \\
73 \\
74 \\
72 \\
71 \\
-- \\
\end{array}$ & $\begin{array}{l}510 \\
520 \\
520 \\
530 \\
570 \\
580\end{array}$ & $\begin{array}{l}460 \\
460 \\
480 \\
490 \\
500 \\
540\end{array}$ & & & $\begin{array}{l}=- \\
=- \\
=- \\
=-\end{array}$ & $\begin{array}{l}-- \\
-- \\
-- \\
-- \\
--\end{array}$ & $\begin{array}{l}79 \\
77 \\
76 \\
79 \\
78 \\
75 \\
\end{array}$ & $\begin{array}{l}76 \\
75 \\
74 \\
74 \\
73 \\
72 \\
\end{array}$ \\
\hline \multicolumn{9}{|c|}{ AUGUST } & \multicolumn{8}{|c|}{ SEPTEMBER } \\
\hline $\begin{array}{l}1 \cdots \\
2 \ldots \\
3 \ldots \\
5 \ldots\end{array}$ & $\begin{array}{l}630 \\
640 \\
640 \\
630 \\
620\end{array}$ & $\begin{array}{l}550 \\
560 \\
590 \\
580 \\
580\end{array}$ & & & & & $\begin{array}{l}78 \\
78 \\
79 \\
78 \\
79\end{array}$ & $\begin{array}{l}72 \\
74 \\
74 \\
76 \\
75\end{array}$ & $\begin{array}{l}770 \\
770 \\
770 \\
780 \\
770\end{array}$ & $\begin{array}{l}710 \\
710 \\
710 \\
700 \\
700\end{array}$ & & & $\begin{array}{l}=- \\
=- \\
=- \\
--\end{array}$ & $\begin{array}{l}=- \\
=- \\
=-\end{array}$ & $\begin{array}{l}73 \\
74 \\
73 \\
74 \\
74\end{array}$ & $\begin{array}{l}59 \\
69 \\
70 \\
70 \\
70\end{array}$ \\
\hline $\begin{array}{l}6 \ldots \\
7 \ldots \\
8 \ldots\end{array}$ & $\begin{array}{l}610 \\
620 \\
640\end{array}$ & $\begin{array}{l}580 \\
570 \\
580\end{array}$ & & & & & $\begin{array}{l}79 \\
78 \\
78\end{array}$ & $\begin{array}{l}75 \\
76 \\
75\end{array}$ & $\begin{array}{l}750 \\
750 \\
770\end{array}$ & $\begin{array}{l}690 \\
690 \\
690\end{array}$ & & & $\begin{array}{l}=- \\
=-\end{array}$ & $\begin{array}{l}z- \\
z-\end{array}$ & $\begin{array}{l}75 \\
75 \\
75\end{array}$ & $\begin{array}{l}71 \\
71 \\
72\end{array}$ \\
\hline $10 \ldots$ & $\begin{array}{l}650 \\
640\end{array}$ & $\begin{array}{l}580 \\
600\end{array}$ & & & & & $\begin{array}{l}78 \\
76\end{array}$ & $\begin{array}{l}75 \\
73\end{array}$ & $\begin{array}{l}750 \\
710\end{array}$ & $\begin{array}{l}690 \\
650\end{array}$ & & & 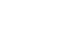 & $=-$ & $\begin{array}{l}74 \\
71\end{array}$ & $\begin{array}{l}71 \\
69\end{array}$ \\
\hline $\begin{array}{l}11 \ldots \\
12 \ldots \\
13 \ldots \\
14 \ldots \\
15 \ldots\end{array}$ & $\begin{array}{l}640 \\
650 \\
640 \\
660 \\
670\end{array}$ & $\begin{array}{l}610 \\
610 \\
600 \\
600 \\
610\end{array}$ & & & & & $\begin{array}{l}75 \\
74 \\
75 \\
74 \\
74\end{array}$ & $\begin{array}{l}72 \\
71 \\
71 \\
71 \\
71\end{array}$ & $\begin{array}{l}790 \\
780 \\
780 \\
780 \\
780\end{array}$ & $\begin{array}{l}710 \\
720 \\
720 \\
730 \\
730\end{array}$ & & & $\begin{array}{l}>15.0 \\
>15.0 \\
>15.0 \\
>15.0 \\
>15.0\end{array}$ & $\begin{array}{r}5.7 \\
12.0 \\
10.8 \\
10.5 \\
11.9\end{array}$ & $\begin{array}{l}71 \\
71 \\
73 \\
72 \\
72\end{array}$ & $\begin{array}{l}68 \\
68 \\
68 \\
68 \\
59\end{array}$ \\
\hline $\begin{array}{l}16 \ldots \\
17 \ldots \\
18 \ldots \\
19 \ldots \\
20 \ldots\end{array}$ & $\begin{array}{r}690 \\
-- \\
-- \\
--\end{array}$ & $\begin{array}{r}620 \\
=- \\
=-\end{array}$ & & & & & $\begin{array}{l}74 \\
-- \\
=- \\
--\end{array}$ & $\begin{array}{l}72 \\
=- \\
=- \\
=-\end{array}$ & $\begin{array}{l}790 \\
770 \\
780 \\
790 \\
780\end{array}$ & $\begin{array}{l}720 \\
710 \\
710 \\
720 \\
660\end{array}$ & & & $\begin{array}{r}\$ 15.0 \\
\$ 15.0 \\
\$ 15.0 \\
\$ 15.0 \\
13.6\end{array}$ & $\begin{array}{r}12.1 \\
13.1 \\
10.9 \\
10.0 \\
7.3\end{array}$ & $\begin{array}{l}72 \\
72 \\
74 \\
73 \\
74\end{array}$ & $\begin{array}{l}70 \\
70 \\
70 \\
71 \\
71\end{array}$ \\
\hline $\begin{array}{l}21 \ldots \\
22 \ldots \\
23 \ldots \\
24 \ldots \\
25 \ldots\end{array}$ & $\begin{array}{l}-- \\
670 \\
690 \\
680\end{array}$ & $\begin{array}{l}-- \\
630 \\
630 \\
610\end{array}$ & & & & & $\begin{array}{l}-- \\
74 \\
75 \\
75\end{array}$ & $\begin{array}{l}-- \\
-- \\
72 \\
72 \\
72\end{array}$ & $\begin{array}{l}800 \\
790 \\
820 \\
790 \\
830\end{array}$ & $\begin{array}{l}740 \\
730 \\
700 \\
730 \\
750\end{array}$ & & & $\begin{array}{l}7.3 \\
3.4 \\
3.3 \\
3.8 \\
7.1\end{array}$ & $\begin{array}{l}3 \cdot 3 \\
2 \cdot 3 \\
2 \cdot 2 \\
1 \cdot 6 \\
2.8\end{array}$ & $\begin{array}{l}72 \\
70 \\
59 \\
67 \\
66\end{array}$ & $\begin{array}{l}70 \\
68 \\
67 \\
65 \\
64\end{array}$ \\
\hline $\begin{array}{l}26 \ldots \\
27 \ldots \\
28 \ldots \\
29 \ldots \\
30 \ldots \\
31 \ldots\end{array}$ & $\begin{array}{l}690 \\
700 \\
720 \\
690 \\
740 \\
760\end{array}$ & $\begin{array}{l}620 \\
660 \\
650 \\
640 \\
630 \\
690\end{array}$ & & & & & $\begin{array}{l}75 \\
74 \\
74 \\
73 \\
74 \\
72\end{array}$ & $\begin{array}{l}72 \\
71 \\
70 \\
70 \\
71 \\
70\end{array}$ & $\begin{array}{l}870 \\
880 \\
870 \\
890 \\
890 \\
--\end{array}$ & $\begin{array}{r}790 \\
810 \\
770 \\
830 \\
800 \\
--\end{array}$ & & & $\begin{array}{l}9.9 \\
7.2 \\
5.7 \\
5.5 \\
7.1 \\
-.-\end{array}$ & $\begin{array}{r}4.8 \\
5.3 \\
5.1 \\
4.8 \\
4.6 \\
--\end{array}$ & $\begin{array}{l}66 \\
65 \\
63 \\
60 \\
55 \\
-\end{array}$ & $\begin{array}{l}63 \\
63 \\
60 \\
55 \\
53 \\
-\end{array}$ \\
\hline
\end{tabular}




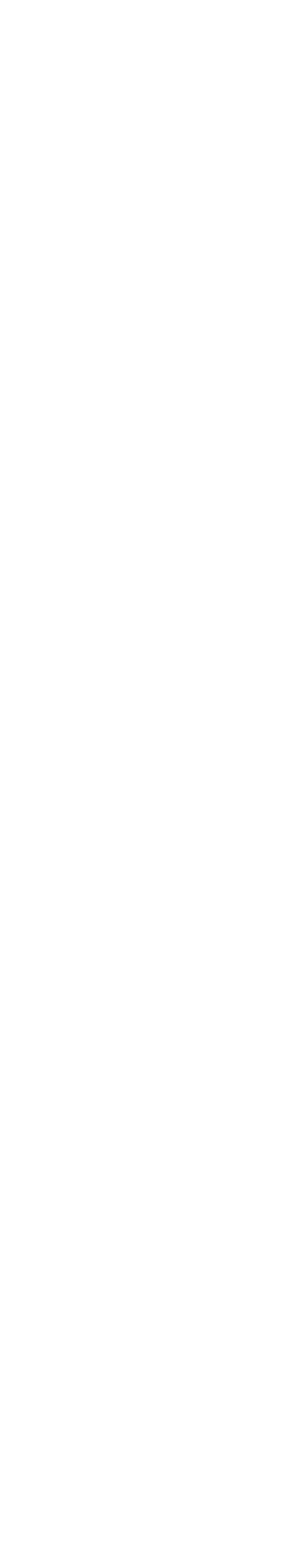

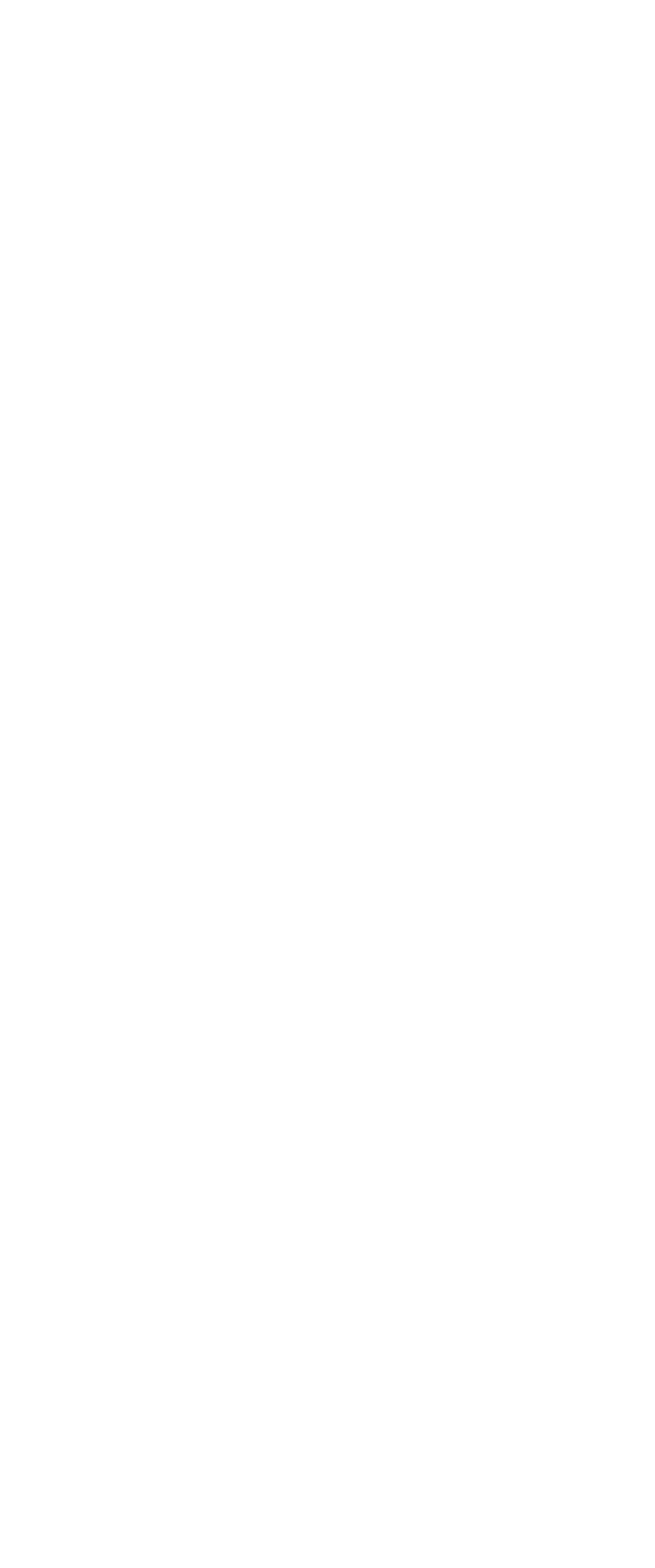




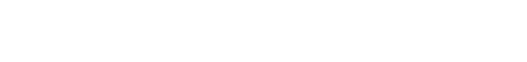

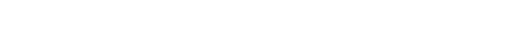
Tा是|

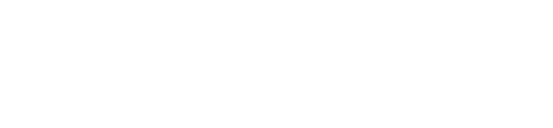

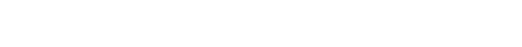

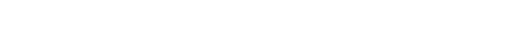

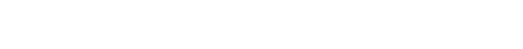

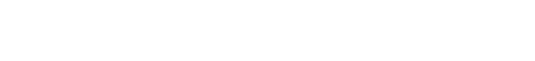

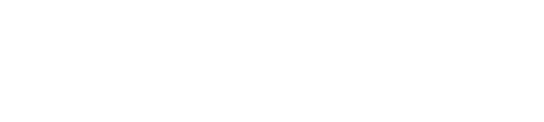

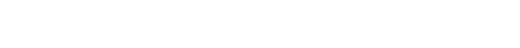

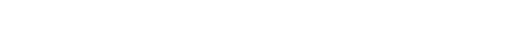
$00,10000,1000,0000,100,100$

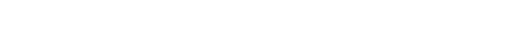

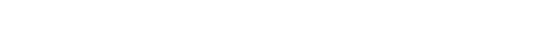

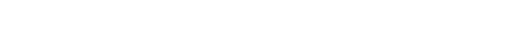

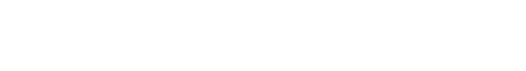

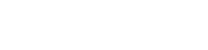

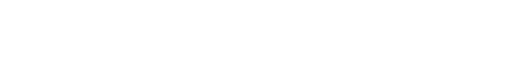

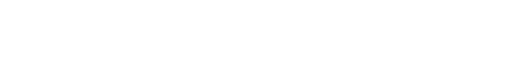

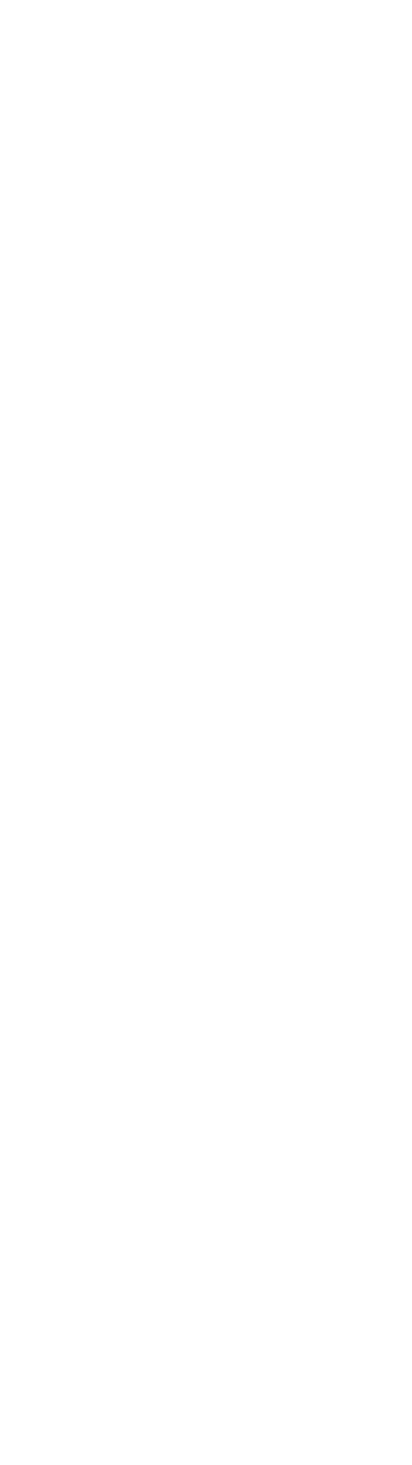




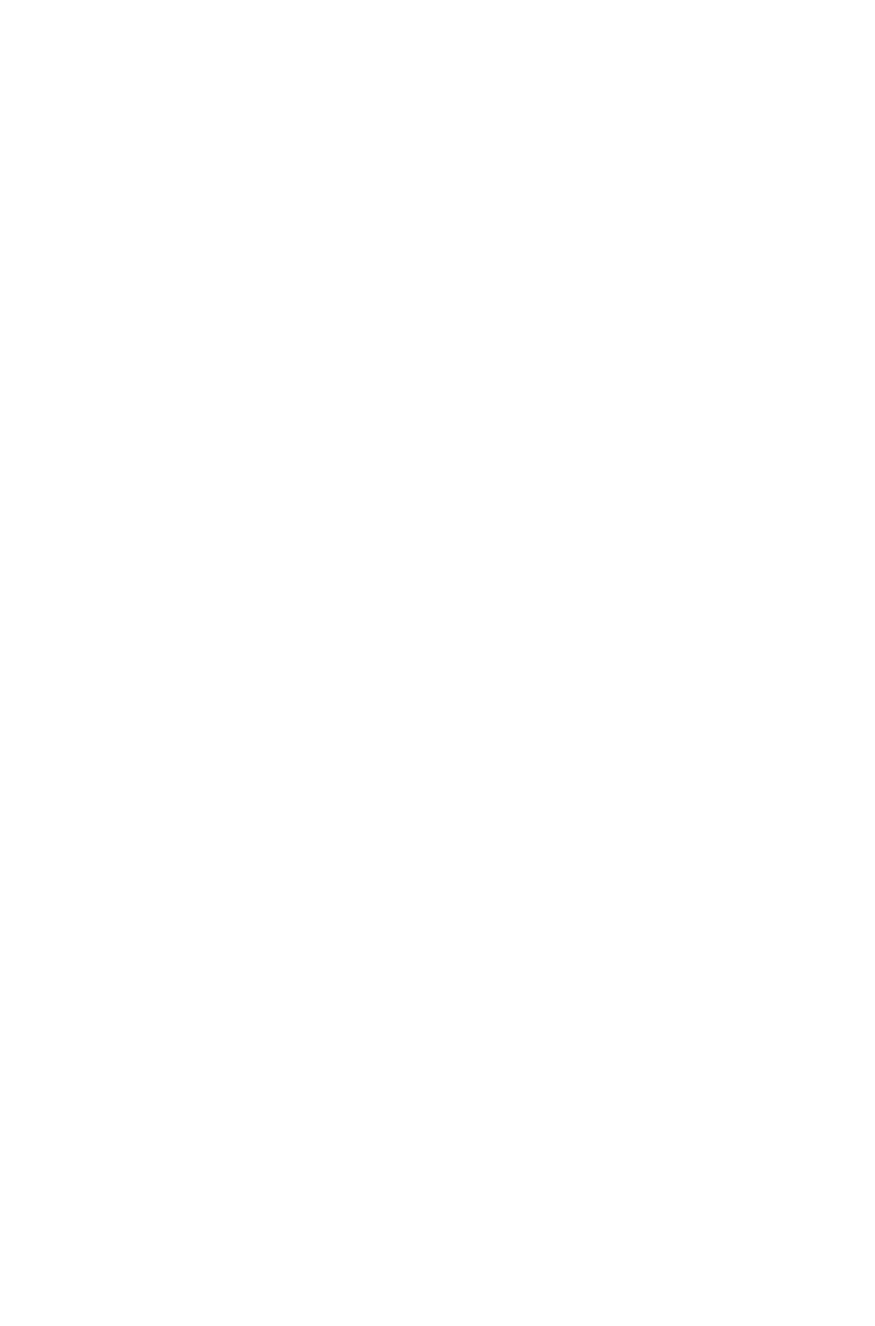


STREAMS TRIBUTARY TO LAKE ERIE--COntinued

4-2005.5. BLACK RIVER BELOW ELYRIA, OHIO

LOCATION.--Lat $41^{\circ} 24^{\prime} 42^{\prime \prime}$, long $82^{\circ} 05^{\prime} 45^{\prime \prime}$, at Ford Road bridge on north edge of Elyria, Lorain County, $0.7 \mathrm{mile}$ downstream from Elyria sewage disposal plant, and $5.2 \mathrm{miles}$ downstream from gaging station at Elyria.

DRAINAGE AREA. - -412 square miles.

RECORDS AVAILABLE.--Chemical analyses: January 1966 to September 1967.

Nater temperatures: January 1966 to September 1967.

EXTREMES, 1966-67. - Water temperatures: Maximum, $84^{\circ} \dot{\mathrm{F}}$ June 15 ; minimum, freezing point on many days during January to March.

EXTREMES, January 1966 to September 1967.--Specific conductance (January to September 1966): Maximum daily, >1,500 micromhos on many days during July to September 1966; minimum daily, 220 micrombos Feb. 11 , 1966 .

Disso1ved oxygen (January to September 1966): Maximum da11y, >15.0 ppm May 2, 31, June 1, 2, 1966; minimum daily, $0.0 \mathrm{ppm}$ June $3,5,6$, July $3,4,1966$

Water temperatures: Maximum, $84^{\circ} \mathrm{F}$ July 3,1966 , June 15,1967 ; minimum, f reezing point on many days during winter months,

REMARKS. --A monitor pas installed at this site on Dec, 30,1965 . The quality of the water is affected by sewage disposal and industrial waste. The recorder was out of operation for much of the year due to repairs.

Data from continuous recorder, water year October 1966 to september 1967

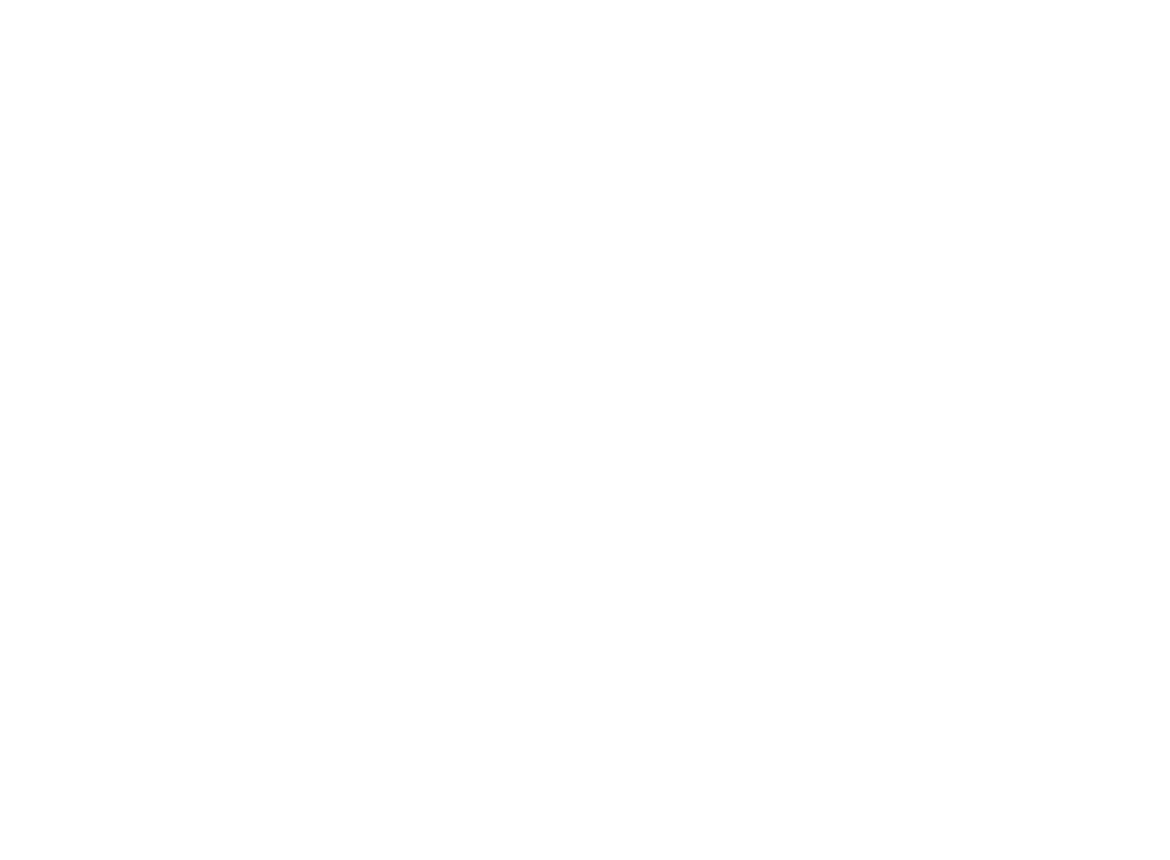


STREAMS TRIBUTARY TO LAKE ERIE--COntinued

4-2005.5. BLACK RIVER BELOW ELYRIA, OHIO--COntinued

Data from continuous recorder, water year October 1966 to september 1967--continued

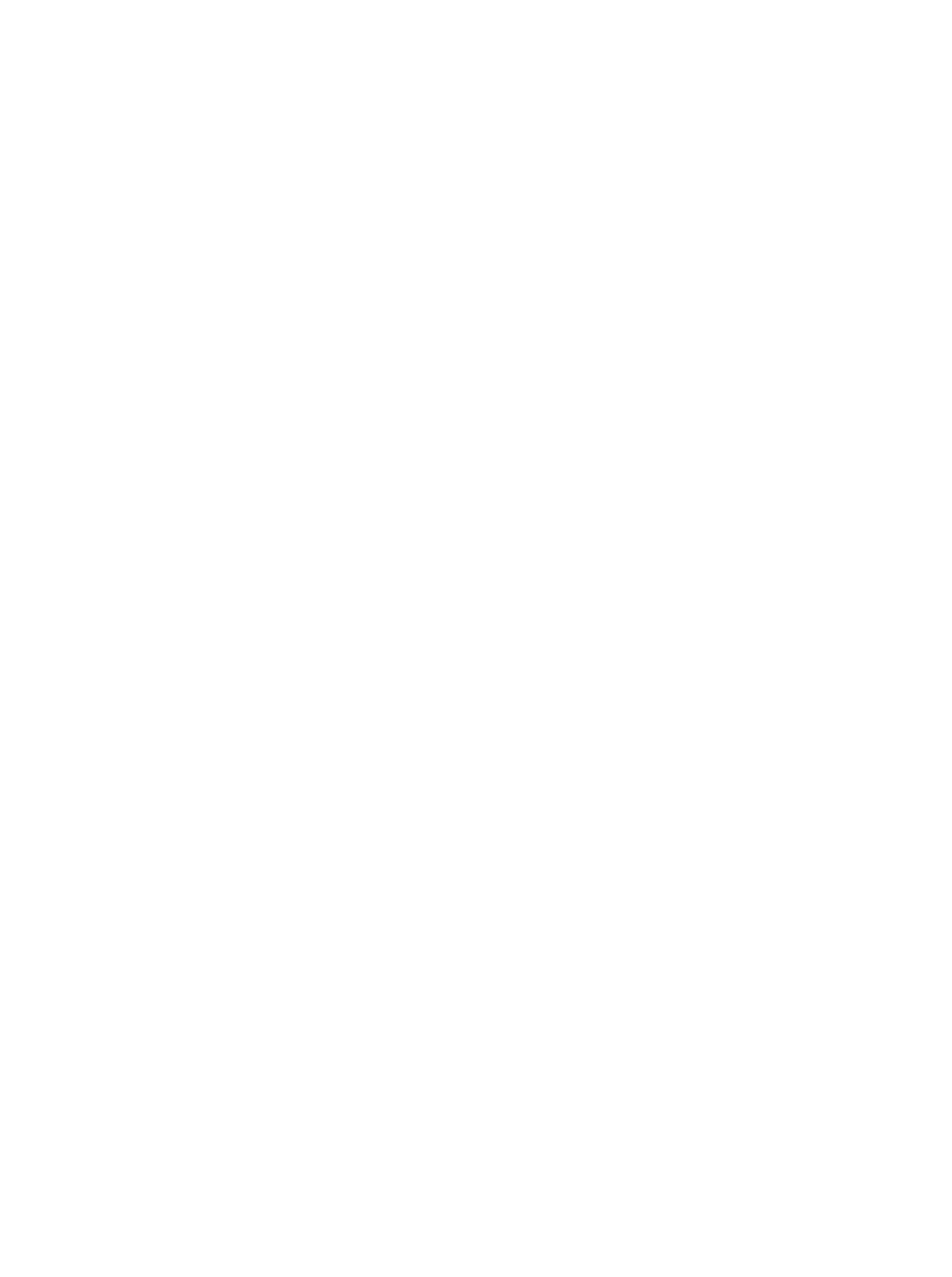


STREAMS TRIBUTARY TO LAKE ERIE--COntinued

4-2005,5. BLACK RIVER BELOW ELYRIA, OHIO--Continued

Data from continuous recorder, water year October 1966 to september 1967--Continued

\begin{tabular}{|c|c|c|c|c|c|c|c|c|c|c|c|c|c|c|c|c|c|c|}
\hline \multirow[t]{2}{*}{ Day } & \multicolumn{2}{|c|}{$\begin{array}{c}\text { Specific } \\
\text { conductance } \\
\text { (micromhos } \\
\text { at } 25^{\circ} \mathrm{C} \text { ) }\end{array}$} & \multicolumn{2}{|c|}{$\begin{array}{c}\text { Dissolved } \\
\text { oxygen } \\
\text { (ppm) }\end{array}$} & \multicolumn{2}{|c|}{$\begin{array}{c}\text { Temper- } \\
\text { ature } \\
\left({ }^{\prime} \mathbf{F}\right)\end{array}$} & \multicolumn{2}{|c|}{$\begin{array}{c}\text { Specific } \\
\text { conductance } \\
(\text { micromhos } \\
\left.\text { at } 25^{\circ} \mathrm{C}\right)\end{array}$} & \multicolumn{2}{|c|}{$\begin{array}{c}\text { Dissolved } \\
\text { oxygen } \\
\text { (ppm) }\end{array}$} & \multicolumn{2}{|c|}{$\begin{array}{c}\text { Temper- } \\
\text { ature } \\
\left({ }^{\circ} \mathbf{F}\right)\end{array}$} & \multicolumn{2}{|c|}{$\begin{array}{c}\text { Specific } \\
\text { conductance } \\
\text { (micromhos } \\
\text { at } 25^{\circ} \mathrm{C} \text { ) }\end{array}$} & \multicolumn{2}{|c|}{$\begin{array}{l}\text { Dissolved } \\
\text { oxygen } \\
\text { (ppm) }\end{array}$} & \multicolumn{2}{|c|}{$\begin{array}{c}\text { Temper- } \\
\text { ature } \\
\left({ }^{\circ} \mathrm{F}\right)\end{array}$} \\
\hline & Max & Min & $\operatorname{Max}$ & Min & Max & Min & $\operatorname{Max}$ & Min & $\operatorname{Max}$ & Min & Max & Min & $\operatorname{Max}$ & Min & Max & Min & $\mathbf{M} \mathbf{~ x ~}$ & Min \\
\hline $\begin{array}{l}1 \\
2 \\
3 \\
4 \\
5\end{array}$ & & & & & & & $\begin{array}{l}-- \\
- \\
- \\
- \\
--\end{array}$ & $\begin{array}{l}-- \\
-- \\
-- \\
-\end{array}$ & $\begin{array}{l}- \\
- \\
-\end{array}$ & $\begin{array}{l}-- \\
- \\
-\end{array}$ & $\mid \begin{array}{l}-- \\
-- \\
-\end{array}$ & $\begin{array}{l}-- \\
-- \\
--\end{array}$ & $\begin{array}{r}1 \text { Ao } \\
1110 \\
1030 \\
1010 \\
940\end{array}$ & $\begin{array}{r}1050 \\
1010 \\
920 \\
880 \\
850\end{array}$ & $\begin{array}{l}9.6 \\
8.8 \\
8.5 \\
8.5 \\
8.6\end{array}$ & $\begin{array}{l}6.4 \\
6.0 \\
6.1 \\
6.2 \\
5.8\end{array}$ & $\begin{array}{l}72 \\
73 \\
73 \\
73 \\
74\end{array}$ & $\begin{array}{l}64 \\
64 \\
65 \\
65 \\
66\end{array}$ \\
\hline $\begin{array}{r}6 \\
7 \\
8 \\
9 \\
10\end{array}$ & & & & & & & $\begin{array}{l}-- \\
-- \\
- \\
--\end{array}$ & $\begin{array}{l}- \\
-- \\
- \\
-\end{array}$ & $\begin{array}{l}- \\
- \\
-\end{array}$ & $\begin{array}{l}-- \\
- \\
--\end{array}$ & $\begin{array}{l}=- \\
=- \\
=-\end{array}$ & $\begin{array}{l}-- \\
-\overline{-} \\
-\end{array}$ & $\begin{array}{r}1000 \\
1170 \\
940 \\
860 \\
\end{array}$ & $\begin{array}{l}840 \\
900 \\
770 \\
820 \\
-\end{array}$ & $\begin{array}{l}8.8 \\
8.5 \\
7.7 \\
6.0 \\
7.3\end{array}$ & $\begin{array}{l}5.6 \\
5.9 \\
5.1 \\
2.1 \\
4.1\end{array}$ & $\begin{array}{l}74 \\
74 \\
74 \\
72 \\
69\end{array}$ & $\begin{array}{l}67 \\
67 \\
68 \\
69 \\
65\end{array}$ \\
\hline $\begin{array}{l}11 \\
12 \\
13 \\
14 \\
15\end{array}$ & & & & & & & $\begin{array}{l}- \\
- \\
- \\
-\end{array}$ & $\begin{array}{l}-- \\
= \\
= \\
-\end{array}$ & $=$ & $\begin{array}{l}-- \\
-- \\
--\end{array}$ & $\begin{array}{l}=- \\
=- \\
=-\end{array}$ & $\begin{array}{l}- \\
- \\
-- \\
-\end{array}$ & $\begin{array}{l}1 \overline{0} \\
1160 \\
1200 \\
1290\end{array}$ & $\begin{array}{r}-- \\
990 \\
1010 \\
1150 \\
990\end{array}$ & $\begin{array}{l}7.1 \\
7.4 \\
6.5 \\
6.5 \\
6.5\end{array}$ & $\begin{array}{l}5.4 \\
5.6 \\
5.5 \\
4.8 \\
4.4\end{array}$ & $\begin{array}{l}70 \\
70 \\
72 \\
71 \\
72\end{array}$ & $\begin{array}{l}60 \\
60 \\
63 \\
63 \\
64\end{array}$ \\
\hline $\begin{array}{l}16 \\
17 \\
18 \\
19 \\
20\end{array}$ & & & & & & & $\begin{array}{l}= \\
= \\
= \\
-\end{array}$ & $\begin{array}{l}- \\
=- \\
-- \\
-- \\
-\end{array}$ & $\begin{array}{l}= \\
=\end{array}$ & $\begin{array}{l}-- \\
-- \\
-- \\
--\end{array}$ & $\begin{array}{l}- \\
z \\
z\end{array}$ & $\begin{array}{l}-- \\
z- \\
= \\
-\end{array}$ & $\begin{array}{l}1150 \\
1270 \\
1130 \\
1310 \\
1340\end{array}$ & $\begin{array}{r}950 \\
980 \\
920 \\
1050 \\
1240\end{array}$ & $\begin{array}{l}6.8 \\
\epsilon .7 \\
\epsilon .5 \\
6.2 \\
5.0\end{array}$ & $\begin{array}{l}4.6 \\
4.8 \\
4.8 \\
4.4 \\
3.7\end{array}$ & $\begin{array}{l}72 \\
71 \\
72 \\
70 \\
72\end{array}$ & $\begin{array}{l}63 \\
66 \\
67 \\
65 \\
67\end{array}$ \\
\hline $\begin{array}{l}21 \\
22 \\
23 \\
24 \\
25\end{array}$ & & & & & & & $\begin{array}{l}--1 \\
- \\
-- \\
- \\
--\end{array}$ & $\begin{array}{l}-- \\
- \\
- \\
-\end{array}$ & $\begin{array}{l}= \\
=- \\
--\end{array}$ & $\begin{array}{l}-- \\
-- \\
-- \\
--\end{array}$ & $\begin{array}{l}-- \\
z \\
z\end{array}$ & $\begin{array}{l}-- \\
-- \\
-- \\
--\end{array}$ & $\begin{array}{l}1280 \\
1190 \\
1250 \\
1240 \\
1270\end{array}$ & $\begin{array}{l}1100 \\
1100 \\
1190 \\
1180 \\
1180\end{array}$ & $\begin{array}{l}3.5 \\
4.5 \\
4.5 \\
4.9 \\
4.5\end{array}$ & $\begin{array}{r}.8 \\
1.8 \\
3.7 \\
3.7 \\
3.8\end{array}$ & $\begin{array}{l}70 \\
67 \\
67 \\
64 \\
65\end{array}$ & $\begin{array}{l}67 \\
63 \\
00 \\
61 \\
57\end{array}$ \\
\hline $\begin{array}{l}26 \\
27 \\
28 \\
29 \\
30 \\
31\end{array}$ & & & & & & & $\begin{array}{r}-1 \\
-1 \\
1180 \\
1070 \\
1150\end{array}$ & $\begin{array}{r}-- \\
-- \\
-- \\
1000 \\
91 \mathrm{C} \\
920\end{array}$ & $\begin{array}{r}- \\
- \\
-- \\
6.6 \\
7.2 \\
8.1\end{array}$ & $\begin{array}{r}-- \\
-- \\
2.5 \\
3.5 \\
4.2\end{array}$ & $\begin{array}{l}-2 \\
-2 \\
73 \\
73 \\
71\end{array}$ & $\begin{array}{l}-- \\
-- \\
-- \\
71 \\
69 \\
67\end{array}$ & $\begin{array}{r}1310 \\
1250 \\
1090 \\
1130 \\
1160 \\
--\end{array}$ & $\begin{array}{r}1200 \\
1090 \\
990 \\
1020 \\
1060 \\
-\end{array}$ & $\begin{array}{c}3.9 \\
3.1 \\
3.5 \\
3.8 \\
3.8 \\
--\end{array}$ & $\begin{array}{r}2.7 \\
1.7 \\
3.1 \\
3.3 \\
3.5 \\
-\end{array}$ & $\begin{array}{l}67 \\
67 \\
62 \\
59 \\
57 \\
--\end{array}$ & $\begin{array}{l}59 \\
02 \\
58 \\
50 \\
54 \\
-\end{array}$ \\
\hline
\end{tabular}


STREAMS TRIBUTARY TO LAKE ERIE--CONtinued

4-2080. CUYAHOGA RIVER AT INDEPENDENCE, OHIO

LOCATION. --Lat $41^{\circ} 23^{\prime} 44^{\prime \prime}$, long $81^{\circ} 37^{\prime} 45^{\prime \prime}$, at gaging station on right bank 140 feet dovnstream from highway bridge on Old' Rockside Road, $i$ mile northeast of Independence, Cuyahoga Co'snty, and 3 miles downstream from Tinkers Creek.

DRAINAGE AREA. -707 square miles.

RECORDS AVAILABLE. --Chemical anaiyses: October 1948 to September 1949, July 1965 to September 1967. Water temperatures: October 1948 to September 1949, October 1952 to September 1967. Sediment records: October 1950 to September 1967

EXTREMES, 1966-67.--Water temperatures: Maximum, $83^{\circ} \mathrm{F}$ Aug. 11 ; minimum, $33^{\circ} \mathrm{F}$ Jan, $19, \mathrm{Feb} .8$. Sediment concentrations: Maximum daily, $1,130 \mathrm{ppm}$ Nov. 9 ; minimum daily, $4 \mathrm{ppm} \mathrm{Jun} ; 23,24$. Sediment loads: Maximum dally, 13,400 tons May 7; minimum dally, 2 tons June 18-20, 24.

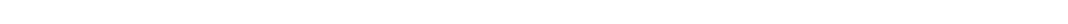
minimum, freezing point on many days during winter months.

Sediment concentrations (1950-67): Maximum daily, 4,800 ppm Aug, 21, 1960; minimum daily, 1 ppm Sept. 4, 10, 1955 .

Sediment loads (1950-67): Maximum daily, 51,400 tons Mar. 5, 1964; minimum daily, less than 0.50 ton on several days during August and September 1954, and September 1955 .

REMARKS. -Continuous recorder installed in gage house. Diurnal fluctuations caused b powerplants above station. Water diverted into ohio Canal at Brecksille, 6 miles upstream from station, bypasses station.

Data from continuous recorder. water year October 1966 to September 1967

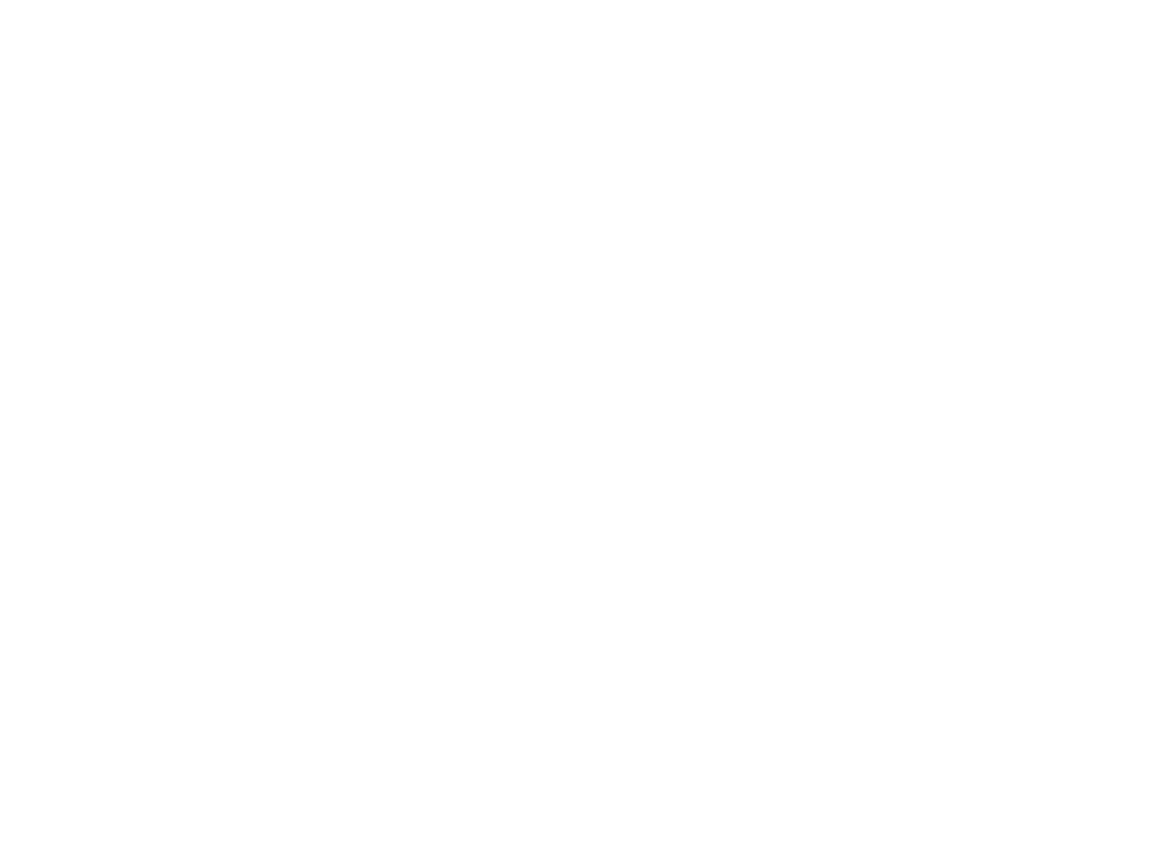


STREAMS TRIBUTARY TO LAKE ERIE- CONtInued

4-2080. CUYAHOGA RIVER AT INDEPENDENCE, OHIO--Continued

Data from continuous recorder, water year October 1966 to September 1967--Continued

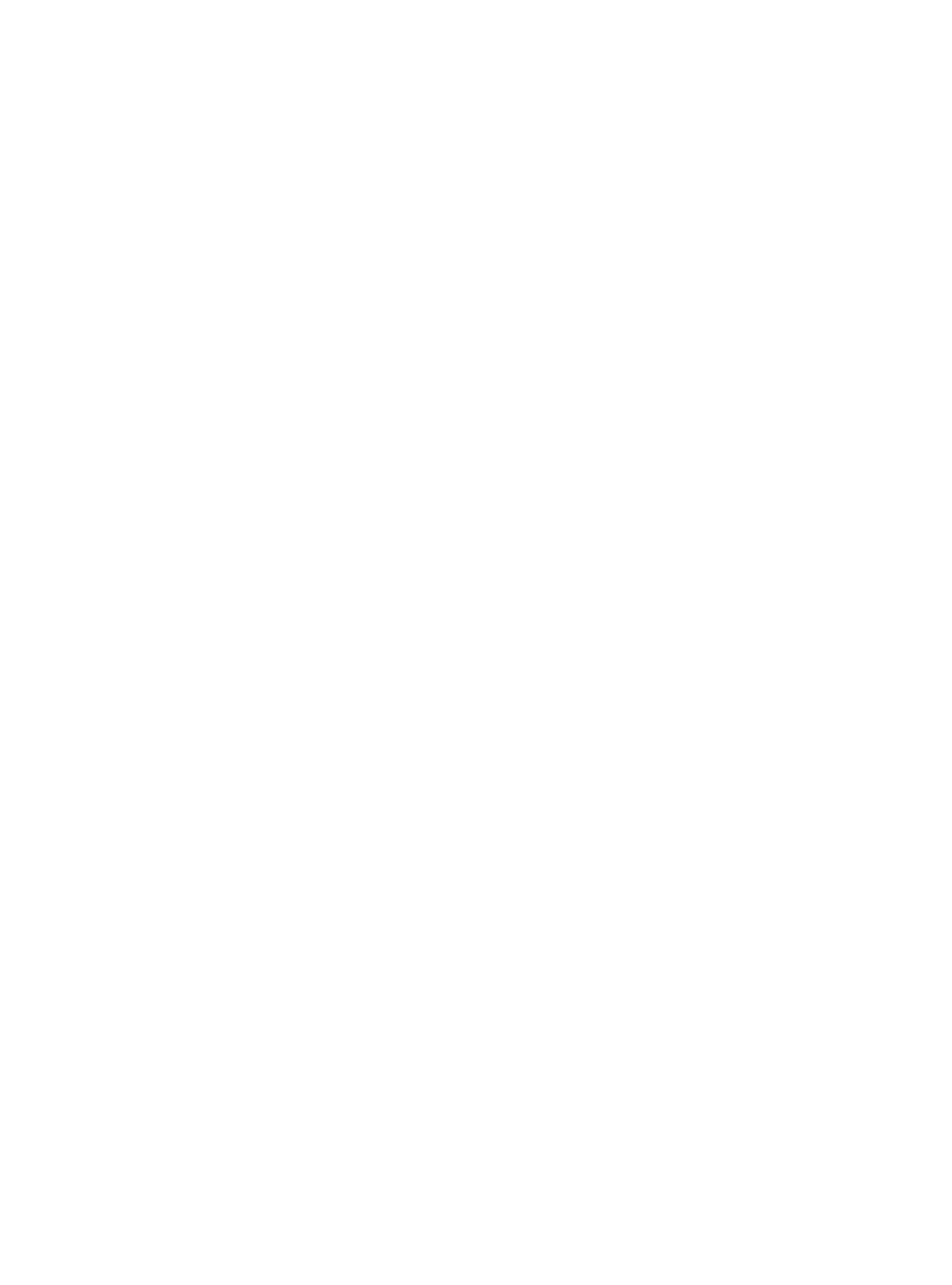


STREAMS TRIBUTARY TO LAKE ERIE--Continued

4-2080. CUYAHOGA RIVER AT INDEPENDENCE, OHIO--Continued

\begin{tabular}{|c|c|c|c|c|c|c|c|c|c|c|c|c|c|c|c|c|c|c|}
\hline \multirow[t]{2}{*}{ Day } & \multicolumn{2}{|c|}{$\begin{array}{c}\text { Specific } \\
\text { conductance } \\
\text { (micromhos } \\
\text { at } 25^{\circ} \mathrm{C} \text { ) }\end{array}$} & \multicolumn{2}{|c|}{$\begin{array}{l}\text { Dissolved } \\
\text { oxygen } \\
\text { (ppm) }\end{array}$} & \multicolumn{2}{|c|}{$\begin{array}{c}\text { Temper- } \\
\text { ature } \\
\left({ }^{\circ} \mathbf{F}\right)\end{array}$} & \multicolumn{2}{|c|}{$\begin{array}{c}\text { Specific } \\
\text { conductance } \\
\text { (micromhos } \\
\text { at } 25^{\circ} \mathrm{C} \text { ) }\end{array}$} & \multicolumn{2}{|c|}{$\begin{array}{l}\text { Dissolved } \\
\text { oxygen } \\
\text { (ppm) }\end{array}$} & \multicolumn{2}{|c|}{$\begin{array}{c}\text { Temper- } \\
\text { ature } \\
\left({ }^{\circ} \mathbf{F}\right)\end{array}$} & \multicolumn{2}{|c|}{$\begin{array}{c}\text { Specific } \\
\text { conductance } \\
\text { (micromhos } \\
\text { at } 25^{\circ} \mathrm{C} \text { ) }\end{array}$} & \multicolumn{2}{|c|}{$\begin{array}{l}\text { Dissolved } \\
\text { oxygen } \\
\text { (ppm) }\end{array}$} & \multicolumn{2}{|c|}{$\begin{array}{c}\text { Temper- } \\
\text { ature } \\
\left({ }^{\circ} \mathrm{F}\right)\end{array}$} \\
\hline & Max & Min & Max & Min & Max & Min & Max & Min & Max & Min & Max & Min & $\operatorname{Max}$ & Min & Max & Min & Max & Min \\
\hline $\begin{array}{l}1 \\
2 \\
3 \\
4 \\
5\end{array}$ & $\begin{array}{l}1440 \\
1280 \\
1310 \\
1230 \\
1410\end{array}$ & $\begin{array}{l}1160 \\
1090 \\
1100 \\
1070 \\
1080\end{array}$ & $\begin{array}{l}4.9 \\
4.7 \\
5.0 \\
5.3 \\
5.6\end{array}$ & $\begin{array}{l}3.9 \\
3.8 \\
3.9 \\
3.9 \\
4.5\end{array}$ & $\begin{array}{l}79 \\
78 \\
76 \\
74 \\
70\end{array}$ & $\begin{array}{l}73 \\
75 \\
72 \\
70 \\
67\end{array}$ & $\begin{array}{r}>1500 \\
>1500 \\
1350 \\
1320 \\
1280\end{array}$ & $\begin{array}{l}1190 \\
1350 \\
1130 \\
1010 \\
1000\end{array}$ & $\begin{array}{l}3.0 \\
3.2 \\
3.2 \\
2.6 \\
1.7\end{array}$ & $\begin{array}{l}2.2 \\
1.7 \\
2.1 \\
1.7 \\
1.4\end{array}$ & $\begin{array}{l}76 \\
76 \\
77 \\
77 \\
75\end{array}$ & $\begin{array}{l}71 \\
71 \\
73 \\
73 \\
72\end{array}$ & $\begin{array}{l}1000 \\
1140 \\
1340 \\
1250 \\
1270\end{array}$ & $\begin{array}{r}820 \\
910 \\
1140 \\
1150 \\
1140\end{array}$ & $\begin{array}{l}4.3 \\
4.2 \\
4.4 \\
4.2 \\
4.0\end{array}$ & $\begin{array}{l}3.3 \\
3.0 \\
3.7 \\
3.6 \\
3.2\end{array}$ & $\begin{array}{l}70 \\
70 \\
70 \\
71 \\
72\end{array}$ & $\begin{array}{l}67 \\
66 \\
67 \\
67 \\
69\end{array}$ \\
\hline $\begin{array}{r}6 \\
7 \\
8 \\
9 \\
10\end{array}$ & $\begin{array}{l}1230 \\
1290 \\
1380 \\
1390 \\
1310\end{array}$ & $\begin{array}{l}1050 \\
1150 \\
1160 \\
1230 \\
1040\end{array}$ & $\begin{array}{l}6.2 \\
5.7 \\
6.1 \\
6.0 \\
4.6\end{array}$ & $\begin{array}{l}4.5 \\
4.2 \\
3.8 \\
3.8 \\
3.4\end{array}$ & $\begin{array}{l}72 \\
74 \\
76 \\
78 \\
78\end{array}$ & $\begin{array}{l}66 \\
69 \\
71 \\
73 \\
75\end{array}$ & $\begin{array}{r}>1500 \\
>1500 \\
1400 \\
>1500 \\
>1500\end{array}$ & $\begin{array}{l}1200 \\
1320 \\
1250 \\
1330 \\
1190\end{array}$ & $\begin{array}{l}2.3 \\
3.4 \\
5.0 \\
4.4 \\
4.0\end{array}$ & $\begin{array}{l}1.4 \\
2.0 \\
2.6 \\
2.9 \\
2.7\end{array}$ & $\begin{array}{l}73 \\
72 \\
76 \\
78 \\
77\end{array}$ & $\begin{array}{l}70 \\
69 \\
72 \\
76 \\
73\end{array}$ & $\begin{array}{r}1420 \\
1400 \\
1390 \\
>1500 \\
1300\end{array}$ & $\begin{array}{r}1190 \\
1260 \\
1260 \\
970 \\
1000\end{array}$ & $\begin{array}{l}4.3 \\
4.2 \\
3.6 \\
3.8 \\
4.1\end{array}$ & $\begin{array}{l}3.6 \\
3.5 \\
3.1 \\
2.9 \\
3.8\end{array}$ & $\begin{array}{l}72 \\
72 \\
72 \\
72 \\
69\end{array}$ & $\begin{array}{l}69 \\
69 \\
70 \\
69 \\
68\end{array}$ \\
\hline $\begin{array}{l}11 \\
12 \\
13 \\
14 \\
15\end{array}$ & $\begin{array}{r}1310 \\
1330 \\
1330 \\
>1500 \\
>1500\end{array}$ & $\begin{array}{l}1080 \\
1110 \\
1160 \\
1150 \\
1150\end{array}$ & $\begin{array}{l}4.7 \\
4.9 \\
4.5 \\
4.7 \\
4.8\end{array}$ & $\begin{array}{l}4.3 \\
3.5 \\
3.3 \\
3.0 \\
3.8\end{array}$ & $\begin{array}{l}79 \\
79 \\
77 \\
73 \\
69\end{array}$ & $\begin{array}{l}76 \\
74 \\
73 \\
69 \\
67\end{array}$ & $\begin{array}{r}1320 \\
>1500 \\
>1500 \\
1430 \\
1430\end{array}$ & $\begin{array}{l}1170 \\
1090 \\
1430 \\
1280 \\
1320\end{array}$ & $\begin{array}{l}5.7 \\
5.4 \\
5.5 \\
5.2 \\
5.1\end{array}$ & $\begin{array}{l}3.4 \\
3.8 \\
3.7 \\
3.8 \\
3.8\end{array}$ & $\begin{array}{l}83 \\
72 \\
76 \\
78 \\
81\end{array}$ & $\begin{array}{l}71 \\
68 \\
68 \\
70 \\
71\end{array}$ & $\begin{array}{l}1240 \\
1310 \\
1390 \\
1390 \\
1410\end{array}$ & $\begin{array}{r}720 \\
930 \\
1230 \\
1240 \\
1250\end{array}$ & $\begin{array}{l}4.6 \\
4.6 \\
4.4 \\
4.2 \\
4.1\end{array}$ & $\begin{array}{l}4.0 \\
4.1 \\
3.7 \\
3.6 \\
3.4\end{array}$ & $\begin{array}{l}68 \\
68 \\
69 \\
70 \\
70\end{array}$ & $\begin{array}{l}05 \\
64 \\
06 \\
67 \\
68\end{array}$ \\
\hline $\begin{array}{l}16 \\
17 \\
18 \\
19 \\
20\end{array}$ & $\begin{array}{r}>1500 \\
>1500 \\
>1500 \\
1240 \\
1190\end{array}$ & $\begin{array}{r}1110 \\
1290 \\
980 \\
900 \\
810\end{array}$ & $\begin{array}{l}5.0 \\
5.3 \\
5.2 \\
4.7 \\
5.1\end{array}$ & $\begin{array}{l}4.2 \\
4.3 \\
4.1 \\
3.9 \\
3.3\end{array}$ & $\begin{array}{l}68 \\
69 \\
71 \\
72 \\
74\end{array}$ & $\begin{array}{l}65 \\
66 \\
67 \\
68 \\
69\end{array}$ & $\begin{array}{r}1450 \\
1380 \\
>1500 \\
>1500 \\
1260\end{array}$ & $\begin{array}{l}1370 \\
1290 \\
1210 \\
1160 \\
1050\end{array}$ & $\begin{array}{l}4.3 \\
3.8 \\
3.8 \\
4.1 \\
4.0\end{array}$ & $\begin{array}{l}3.2 \\
3.0 \\
2.6 \\
2.8 \\
3.1\end{array}$ & $\begin{array}{l}72 \\
77 \\
74 \\
74 \\
72\end{array}$ & $\begin{array}{l}69 \\
70 \\
71 \\
71 \\
70\end{array}$ & $\mid \begin{array}{r}> \\
>1500 \\
1500 \\
1390 \\
1430 \\
1410\end{array}$ & $\begin{array}{l}1380 \\
1360 \\
1270 \\
1310 \\
1330\end{array}$ & $\begin{array}{l}4.0 \\
4.3 \\
4.4 \\
4.6 \\
4.6\end{array}$ & $\begin{array}{l}3.7 \\
3.6 \\
3.9 \\
3.9 \\
3.1\end{array}$ & $\begin{array}{l}71 \\
72 \\
73 \\
72 \\
73\end{array}$ & $\begin{array}{l}68 \\
70 \\
70 \\
70 \\
71\end{array}$ \\
\hline $\begin{array}{l}21 \\
22 \\
23 \\
24 \\
25\end{array}$ & $\begin{array}{r}1420 \\
1210 \\
>1500 \\
>1500 \\
1200\end{array}$ & $\begin{array}{r}810 \\
1060 \\
1030 \\
1130 \\
1070\end{array}$ & $\begin{array}{l}5.8 \\
6.6 \\
6.3 \\
5.8 \\
6.8\end{array}$ & $\begin{array}{l}3.3 \\
3.3 \\
3.1 \\
3.4 \\
3.3\end{array}$ & $\begin{array}{l}75 \\
76 \\
77 \\
78 \\
79\end{array}$ & $\begin{array}{l}70 \\
71 \\
73 \\
75 \\
74\end{array}$ & $\begin{array}{r}1050 \\
1480 \\
1500 \\
>1500 \\
>1500\end{array}$ & $\begin{array}{r}900 \\
1000 \\
1260 \\
1180 \\
1370\end{array}$ & $\begin{array}{l}4.4 \\
4.6 \\
4.6 \\
4.8 \\
4.0\end{array}$ & $\begin{array}{l}3.3 \\
3.4 \\
3.6 \\
3.7 \\
2.6\end{array}$ & $\begin{array}{l}-- \\
=- \\
-- \\
-\overline{72}\end{array}$ & $\begin{array}{l}-- \\
-- \\
-- \\
\overline{71}\end{array}$ & $\begin{array}{l}=- \\
=- \\
=- \\
--\end{array}$ & $\begin{array}{l}=- \\
=- \\
--\end{array}$ & $\begin{array}{l}-- \\
\overline{-} \\
--\end{array}$ & $\bar{z}=$ & $\begin{array}{l}-- \\
\ddot{--} \\
--\end{array}$ & $\begin{array}{l}- \\
-- \\
--\end{array}$ \\
\hline $\begin{array}{l}26 \\
27 \\
28 \\
29 \\
30 \\
31\end{array}$ & $\begin{array}{r}>1500 \\
1260 \\
1360 \\
1250 \\
1280 \\
>1500\end{array}$ & $\begin{array}{l}1160 \\
1120 \\
1000 \\
1060 \\
1170 \\
1220\end{array}$ & $\begin{array}{l}6.4 \\
4.5 \\
4.9 \\
5.0 \\
4.4 \\
3.3\end{array}$ & $\begin{array}{l}3.4 \\
3.4 \\
3.2 \\
3.4 \\
2.9 \\
2.6\end{array}$ & $\begin{array}{l}77 \\
76 \\
73 \\
73 \\
74 \\
74\end{array}$ & $\begin{array}{l}73 \\
73 \\
71 \\
70 \\
70 \\
70\end{array}$ & $\begin{array}{r}>1500 \\
1170 \\
1210 \\
1180 \\
1160 \\
1240\end{array}$ & $\begin{array}{r}1160 \\
1050 \\
1020 \\
1010 \\
870 \\
920\end{array}$ & $\begin{array}{l}3.1 \\
3.0 \\
3.9 \\
3.8 \\
3.5 \\
3.8\end{array}$ & $\begin{array}{l}2.4 \\
2.7 \\
2.5 \\
3.0 \\
2.5 \\
1.5\end{array}$ & $\begin{array}{l}72 \\
73 \\
72 \\
72 \\
72 \\
71\end{array}$ & $\begin{array}{l}71 \\
71 \\
70 \\
68 \\
68 \\
69\end{array}$ & $\begin{array}{l}-- \\
=- \\
=- \\
--\end{array}$ & $\begin{array}{l}-- \\
-- \\
-- \\
--\end{array}$ & $=$ & $\begin{array}{l}= \\
= \\
= \\
=\end{array}$ & $\begin{array}{l}-- \\
-- \\
=-\end{array}$ & $\begin{array}{l}-- \\
-- \\
-- \\
-\end{array}$ \\
\hline
\end{tabular}


STREAMS TRIBUTARY TO LAKE ERIE--COnt1nued

4-2080. CUYAHOGA RIVER AT INDEPENDENCE, OHIO--COntinued

Suspended sediment, water year October 1966 to September 1967

\begin{tabular}{|c|c|c|c|c|c|c|c|c|c|}
\hline \multirow[b]{3}{*}{ Day } & \multicolumn{3}{|c|}{ OCTOBER } & \multicolumn{3}{|c|}{ NOVEMBER } & \multicolumn{3}{|c|}{ DECEMBER } \\
\hline & \multirow[b]{2}{*}{$\begin{array}{l}\text { Mean } \\
\text { dis- } \\
\text { charge } \\
\text { (cfs) }\end{array}$} & \multicolumn{2}{|c|}{ Suspended sediment } & \multirow[b]{2}{*}{$\begin{array}{l}\text { Mean } \\
\text { dis- } \\
\text { charge } \\
\text { (cfs) }\end{array}$} & \multicolumn{2}{|c|}{ Suspended sediment } & \multirow[b]{2}{*}{$\begin{array}{c}\text { Mean } \\
\text { dia- } \\
\text { charge } \\
(\mathrm{cfs})\end{array}$} & \multicolumn{2}{|c|}{ Suspended sediment } \\
\hline & & $\begin{array}{c}\text { Mean } \\
\text { concen- } \\
\text { tration } \\
(\mathrm{ppm})\end{array}$ & $\begin{array}{l}\text { Tons } \\
\text { per } \\
\text { day }\end{array}$ & & $\begin{array}{c}\text { Mean } \\
\text { concen- } \\
\text { tration } \\
(\mathrm{ppm})\end{array}$ & $\begin{array}{l}\text { Tons } \\
\text { per } \\
\text { day }\end{array}$ & & $\begin{array}{c}\text { Mean } \\
\text { concen- } \\
\text { tration } \\
\text { (ppm) }\end{array}$ & $\begin{array}{l}\text { Tons } \\
\text { per } \\
\text { day }\end{array}$ \\
\hline $\begin{array}{l}1 \ldots \\
2 \ldots \\
3 \ldots \\
4 \ldots \\
5 \ldots\end{array}$ & $\begin{array}{l}153 \\
125 \\
107 \\
223 \\
127\end{array}$ & $\begin{array}{l}12 \\
11 \\
12 \\
20 \\
15\end{array}$ & $\begin{array}{l}5 \\
4 \\
3 \\
7 \\
5\end{array}$ & $\begin{array}{r}125 \\
522 \\
1450 \\
522 \\
348\end{array}$ & $\begin{array}{r}52 \\
967 \\
1090 \\
72 \\
48\end{array}$ & $\begin{array}{r}20 \\
1590 \\
5050 \\
201 \\
45\end{array}$ & $\begin{array}{l}376 \\
336 \\
303 \\
278 \\
344\end{array}$ & $\begin{array}{l}35 \\
34 \\
27 \\
28 \\
71\end{array}$ & $\begin{array}{l}36 \\
31 \\
22 \\
21 \\
80\end{array}$ \\
\hline $\begin{array}{r}6 \ldots \\
7 \ldots \\
9 \ldots \\
10 \ldots\end{array}$ & $\begin{array}{l}118 \\
110 \\
108 \\
104 \\
171\end{array}$ & $\begin{array}{l}13 \\
18 \\
20 \\
17 \\
21\end{array}$ & $\begin{array}{r}4 \\
5 \\
6 \\
5 \\
10\end{array}$ & $\begin{array}{r}392 \\
725 \\
763 \\
2550 \\
1940\end{array}$ & $\begin{array}{r}49 \\
379 \\
249 \\
1130 \\
386\end{array}$ & $\begin{array}{r}52 \\
860 \\
513 \\
8390 \\
2390\end{array}$ & $\begin{array}{r}962 \\
2880 \\
2530 \\
2010 \\
4690\end{array}$ & $\begin{array}{l}384 \\
385 \\
242 \\
138 \\
499\end{array}$ & $\begin{array}{r}997 \\
4550 \\
1790 \\
749 \\
6320\end{array}$ \\
\hline $\begin{array}{l}11 \ldots \\
12 \ldots \\
13 \ldots \\
14 \ldots \\
15 \ldots\end{array}$ & $\begin{array}{l}149 \\
127 \\
123 \\
118 \\
140\end{array}$ & $\begin{array}{l}18 \\
15 \\
22 \\
21 \\
18\end{array}$ & $\begin{array}{l}7 \\
5 \\
7 \\
7 \\
7\end{array}$ & $\begin{array}{r}2170 \\
1140 \\
824 \\
675 \\
615\end{array}$ & $\begin{array}{r}401 \\
126 \\
78 \\
58 \\
50\end{array}$ & $\begin{array}{r}2810 \\
388 \\
174 \\
106 \\
83\end{array}$ & $\begin{array}{l}4110 \\
2780 \\
2150 \\
1700 \\
1370\end{array}$ & $\begin{array}{r}303 \\
198 \\
147 \\
125 \\
90\end{array}$ & $\begin{array}{r}3360 \\
1490 \\
853 \\
528 \\
333\end{array}$ \\
\hline $\begin{array}{l}16 \ldots \\
17 \ldots \\
18 \ldots \\
19 \ldots \\
20 \ldots\end{array}$ & $\begin{array}{l}240 \\
132 \\
129 \\
123 \\
166\end{array}$ & $\begin{array}{r}148 \\
23 \\
22 \\
20 \\
40\end{array}$ & $\begin{array}{r}112 \\
8 \\
8 \\
7 \\
18\end{array}$ & $\begin{array}{l}553 \\
495 \\
432 \\
372 \\
320\end{array}$ & $\begin{array}{l}43 \\
36 \\
32 \\
32 \\
28\end{array}$ & $\begin{array}{l}64 \\
48 \\
37 \\
32 \\
24\end{array}$ & $\begin{array}{r}1080 \\
873 \\
715 \\
620 \\
585\end{array}$ & $\begin{array}{l}78 \\
67 \\
73 \\
45 \\
48\end{array}$ & $\begin{array}{r}227 \\
158 \\
141 \\
75 \\
76\end{array}$ \\
\hline $\begin{array}{l}21 \ldots \\
22 \ldots \\
23 \ldots \\
24 \ldots \\
25 \ldots\end{array}$ & $\begin{array}{l}147 \\
127 \\
113 \\
101 \\
115\end{array}$ & $\begin{array}{l}21 \\
16 \\
28 \\
16 \\
25\end{array}$ & $\begin{array}{l}8 \\
5 \\
9 \\
4 \\
8\end{array}$ & $\begin{array}{l}282 \\
268 \\
244 \\
226 \\
229\end{array}$ & $\begin{array}{l}23 \\
23 \\
24 \\
30 \\
32\end{array}$ & $\begin{array}{l}18 \\
17 \\
16 \\
18 \\
20\end{array}$ & $\begin{array}{l}526 \\
459 \\
409 \\
364 \\
328\end{array}$ & $\begin{array}{l}48 \\
45 \\
18 \\
15 \\
17\end{array}$ & $\begin{array}{l}68 \\
56 \\
20 \\
15 \\
15\end{array}$ \\
\hline $\begin{array}{l}26 \ldots \\
27 \ldots \\
28 \ldots \\
29 \ldots \\
30 \ldots \\
31 \ldots\end{array}$ & $\begin{array}{r}116 \\
113 \\
115 \\
113 \\
110 \\
99\end{array}$ & $\begin{array}{l}26 \\
24 \\
19 \\
19 \\
20 \\
20\end{array}$ & $\begin{array}{l}8 \\
7 \\
6 \\
6 \\
6 \\
5\end{array}$ & $\begin{array}{r}257 \\
303 \\
289 \\
310 \\
352 \\
-\end{array}$ & $\begin{array}{l}33 \\
47 \\
28 \\
47 \\
42 \\
--\end{array}$ & $\begin{array}{l}23 \\
38 \\
22 \\
39 \\
40 \\
--\end{array}$ & $\begin{array}{l}299 \\
296 \\
275 \\
418 \\
340 \\
292\end{array}$ & $\begin{array}{l}18 \\
28 \\
84 \\
68 \\
38 \\
32\end{array}$ & $\begin{array}{l}15 \\
22 \\
62 \\
77 \\
35 \\
25 \\
\end{array}$ \\
\hline \multirow[t]{2}{*}{ Total } & 3962 & -- & 312 & 19693 & -- & 23228 & 34698 & - & 22247 \\
\hline & \multicolumn{3}{|c|}{ JANUARY } & \multicolumn{3}{|c|}{ FEBRUARY } & \multicolumn{3}{|c|}{ MARCH } \\
\hline $\begin{array}{l}1 \ldots \\
2 \ldots \\
3 \ldots \\
4 \ldots \\
5 \ldots\end{array}$ & $\begin{array}{l}299 \\
320 \\
317 \\
313 \\
268\end{array}$ & $\begin{array}{l}25 \\
23 \\
54 \\
48 \\
29\end{array}$ & $\begin{array}{l}20 \\
20 \\
46 \\
41 \\
21\end{array}$ & $\begin{array}{l}1110 \\
2980 \\
1890 \\
1500 \\
1240\end{array}$ & $\begin{array}{r}196 \\
877 \\
151 \\
92 \\
52\end{array}$ & $\begin{array}{r}387 \\
7620 \\
771 \\
373 \\
174\end{array}$ & $\begin{array}{r}383 \\
399 \\
915 \\
1420 \\
1270\end{array}$ & $\begin{array}{r}43 \\
45 \\
273 \\
325 \\
122\end{array}$ & $\begin{array}{r}44 \\
48 \\
878 \\
1250 \\
418\end{array}$ \\
\hline $\begin{array}{r}6 \ldots \\
7 \ldots \\
8 \ldots \\
9 \ldots \\
10 \ldots\end{array}$ & $\begin{array}{l}241 \\
271 \\
380 \\
296 \\
275\end{array}$ & $\begin{array}{l}33 \\
42 \\
51 \\
31 \\
25\end{array}$ & $\begin{array}{l}21 \\
31 \\
52 \\
25 \\
19\end{array}$ & $\begin{array}{r}1110 \\
937 \\
750 \\
720 \\
680\end{array}$ & $\begin{array}{l}31 \\
46 \\
41 \\
28 \\
25\end{array}$ & $\begin{array}{r}93 \\
116 \\
83 \\
54 \\
46\end{array}$ & $\begin{array}{l}1900 \\
1600 \\
1460 \\
1310 \\
1800\end{array}$ & $\begin{array}{r}228 \\
101 \\
120 \\
52 \\
183\end{array}$ & $\begin{array}{r}1170 \\
436 \\
473 \\
184 \\
1120\end{array}$ \\
\hline $\begin{array}{l}11 \ldots \\
12 \ldots \\
13 \ldots \\
14 \ldots \\
15 \ldots\end{array}$ & $\begin{array}{l}268 \\
271 \\
268 \\
261 \\
271\end{array}$ & $\begin{array}{l}28 \\
28 \\
30 \\
34 \\
32\end{array}$ & $\begin{array}{l}20 \\
20 \\
22 \\
24 \\
23\end{array}$ & $\begin{array}{r}660 \\
535 \\
487 \\
625 \\
1390\end{array}$ & $\begin{array}{r}26 \\
28 \\
35 \\
121 \\
370\end{array}$ & $\begin{array}{r}46 \\
40 \\
46 \\
248 \\
1390\end{array}$ & $\begin{array}{r}2920 \\
2460 \\
997 \\
1900 \\
1850\end{array}$ & $\begin{array}{r}231 \\
118 \\
95 \\
100 \\
78\end{array}$ & $\begin{array}{r}1820 \\
784 \\
256 \\
513 \\
390\end{array}$ \\
\hline $\begin{array}{l}16 \ldots \\
17 \ldots \\
18 \ldots \\
19 \ldots \\
20 \ldots\end{array}$ & $\begin{array}{l}241 \\
238 \\
196 \\
180 \\
178\end{array}$ & $\begin{array}{l}32 \\
30 \\
37 \\
42 \\
44\end{array}$ & $\begin{array}{l}21 \\
19 \\
20 \\
20 \\
21\end{array}$ & $\begin{array}{r}1960 \\
1260 \\
1090 \\
937 \\
1000\end{array}$ & $\begin{array}{r}521 \\
132 \\
56 \\
40 \\
39\end{array}$ & $\begin{array}{r}2760 \\
449 \\
165 \\
101 \\
105\end{array}$ & $\begin{array}{l}1710 \\
1650 \\
1360 \\
1160 \\
1130\end{array}$ & $\begin{array}{l}89 \\
83 \\
75 \\
68 \\
55\end{array}$ & $\begin{array}{l}411 \\
370 \\
275 \\
213 \\
168\end{array}$ \\
\hline $\begin{array}{l}21 \ldots \\
22 \ldots \\
23 \ldots \\
24 \ldots \\
25 \ldots\end{array}$ & $\begin{array}{l}180 \\
196 \\
254 \\
324 \\
340\end{array}$ & $\begin{array}{l}42 \\
41 \\
41 \\
40 \\
39\end{array}$ & $\begin{array}{l}20 \\
22 \\
28 \\
35 \\
36\end{array}$ & $\begin{array}{l}970 \\
805 \\
740 \\
625 \\
496\end{array}$ & $\begin{array}{l}36 \\
38 \\
42 \\
43 \\
43\end{array}$ & $\begin{array}{l}94 \\
83 \\
84 \\
73 \\
58\end{array}$ & $\begin{array}{l}2870 \\
2470 \\
2070 \\
1810 \\
1720\end{array}$ & $\begin{array}{r}488 \\
248 \\
128 \\
92 \\
78\end{array}$ & $\begin{array}{r}4060 \\
1650 \\
715 \\
450 \\
362\end{array}$ \\
\hline $\begin{array}{l}26 \ldots \\
27 \ldots \\
28 \ldots \\
29 \ldots \\
30 \ldots \\
31 \ldots\end{array}$ & $\begin{array}{l}368 \\
950 \\
934 \\
774 \\
640 \\
670\end{array}$ & $\begin{array}{r}51 \\
186 \\
105 \\
52 \\
44 \\
82\end{array}$ & $\begin{array}{r}51 \\
598 \\
265 \\
109 \\
76 \\
165\end{array}$ & $\begin{array}{r}447 \\
415 \\
424 \\
-- \\
--\end{array}$ & $\begin{array}{l}43 \\
80 \\
90 \\
-- \\
--\end{array}$ & $\begin{array}{r}52 \\
90 \\
103 \\
-- \\
=-\end{array}$ & $\begin{array}{l}1560 \\
1370 \\
2590 \\
2890 \\
2170 \\
1730\end{array}$ & $\begin{array}{r}53 \\
30 \\
512 \\
340 \\
155 \\
107\end{array}$ & $\begin{array}{r}223 \\
111 \\
4540 \\
2650 \\
908 \\
500\end{array}$ \\
\hline Total & 10982 & -- & 1911 & 27783 & -- & 15904 & 52844 & -- & 27390 \\
\hline
\end{tabular}


STREAMS TRIBUTARY TO LAKE ERIE--Continued

4-2080. CUYAHOGA RIVER AT INDEPENDENCE, OHIO--Continued

\begin{tabular}{|c|c|c|c|c|c|c|c|c|c|}
\hline \multirow[b]{3}{*}{ Day } & \multicolumn{3}{|c|}{ APRIL } & \multicolumn{3}{|c|}{ MAY } & \multicolumn{3}{|c|}{ JUNE } \\
\hline & \multirow[b]{2}{*}{$\begin{array}{l}\text { Mean } \\
\text { dis- } \\
\text { charge } \\
\text { (cfs) }\end{array}$} & \multicolumn{2}{|c|}{ Suspended sediment } & \multirow[b]{2}{*}{$\begin{array}{c}\text { Mean } \\
\text { dis- } \\
\text { charge } \\
(\mathbf{c f s})\end{array}$} & \multicolumn{2}{|c|}{ Suspended sediment } & \multirow[b]{2}{*}{$\begin{array}{c}\text { Mean } \\
\text { dis- } \\
\text { charge } \\
\text { (cfs) }\end{array}$} & \multicolumn{2}{|c|}{ Suspended sediment } \\
\hline & & $\begin{array}{l}\text { Mean } \\
\text { concen- } \\
\text { tration } \\
\text { (ppm) }\end{array}$ & $\begin{array}{l}\text { Tons } \\
\text { per } \\
\text { day }\end{array}$ & & $\begin{array}{c}\text { Mean } \\
\text { concen- } \\
\text { tration } \\
(\mathrm{ppm})\end{array}$ & $\begin{array}{l}\text { Tons } \\
\text { per } \\
\text { day }\end{array}$ & & $\begin{array}{c}\text { Mean } \\
\text { concen- } \\
\text { tration } \\
(\mathrm{pFm})\end{array}$ & $\begin{array}{c}\text { Tons } \\
\text { per } \\
\text { day }\end{array}$ \\
\hline $\begin{array}{l}1 \ldots \\
2 \ldots \\
3 \ldots \\
5 \ldots\end{array}$ & $\begin{array}{l}1530 \\
1370 \\
1430 \\
1160 \\
1010\end{array}$ & $\begin{array}{r}80 \\
62 \\
144 \\
82 \\
84\end{array}$ & $\begin{array}{l}330 \\
229 \\
556 \\
257 \\
229\end{array}$ & $\begin{array}{r}821 \\
1040 \\
1340 \\
1050 \\
904\end{array}$ & $\begin{array}{r}150 \\
230 \\
170 \\
58 \\
59\end{array}$ & $\begin{array}{l}365 \\
646 \\
615 \\
164 \\
144\end{array}$ & $\begin{array}{l}270 \\
243 \\
231 \\
210 \\
202\end{array}$ & $\begin{array}{r}14 \\
14 \\
11 \\
5 \\
5\end{array}$ & $\begin{array}{r}10 \\
9 \\
7 \\
3 \\
3\end{array}$ \\
\hline $\begin{array}{r}6 \ldots \\
7 \ldots \\
8 \ldots \\
10 \ldots\end{array}$ & $\begin{array}{l}1130 \\
1800 \\
1160 \\
1070 \\
1230\end{array}$ & $\begin{array}{r}153 \\
441 \\
51 \\
38 \\
38\end{array}$ & $\begin{array}{r}520 \\
2510 \\
160 \\
110 \\
126\end{array}$ & $\begin{array}{l}1040 \\
3540 \\
3280 \\
3000 \\
2110\end{array}$ & $\begin{array}{r}88 \\
1060 \\
561 \\
347 \\
120\end{array}$ & $\begin{array}{r}247 \\
13400 \\
4970 \\
2810 \\
684\end{array}$ & $\begin{array}{l}202 \\
202 \\
207 \\
210 \\
204\end{array}$ & $\begin{array}{r}5 \\
6 \\
10 \\
10 \\
11\end{array}$ & $\begin{array}{l}3 \\
3 \\
6 \\
6 \\
6\end{array}$ \\
\hline $\begin{array}{l}11 \ldots \\
12 \ldots \\
13 \ldots \\
14 \ldots \\
15 \ldots\end{array}$ & $\begin{array}{r}1130 \\
1000 \\
1020 \\
1070 \\
904\end{array}$ & $\begin{array}{l}38 \\
44 \\
45 \\
44 \\
44\end{array}$ & $\begin{array}{l}116 \\
119 \\
124 \\
127 \\
107\end{array}$ & $\begin{array}{l}4170 \\
3930 \\
2640 \\
2170 \\
2280\end{array}$ & $\begin{array}{l}220 \\
255 \\
128 \\
118 \\
177\end{array}$ & $\begin{array}{r}3280 \\
2910 \\
912 \\
691 \\
1090\end{array}$ & $\begin{array}{l}180 \\
165 \\
177 \\
165 \\
175\end{array}$ & \begin{tabular}{r|}
6 \\
10 \\
11 \\
11 \\
11
\end{tabular} & $\begin{array}{l}3 \\
4 \\
5 \\
5 \\
5\end{array}$ \\
\hline $\begin{array}{l}16 \ldots \\
17 \ldots \\
18 \ldots \\
19 \ldots \\
20 \ldots\end{array}$ & $\begin{array}{l}788 \\
725 \\
705 \\
645 \\
595\end{array}$ & $\begin{array}{l}44 \\
45 \\
45 \\
49 \\
51\end{array}$ & $\begin{array}{l}94 \\
88 \\
86 \\
85 \\
82\end{array}$ & $\begin{array}{l}2150 \\
1730 \\
1590 \\
1310 \\
1100\end{array}$ & $\begin{array}{r}163 \\
98 \\
122 \\
90 \\
58\end{array}$ & $\begin{array}{l}946 \\
458 \\
524 \\
318 \\
172\end{array}$ & $\begin{array}{l}175 \\
210 \\
170 \\
131 \\
131\end{array}$ & $\begin{array}{l}8 \\
7 \\
5 \\
5 \\
5\end{array}$ & $\begin{array}{l}4 \\
4 \\
2 \\
2 \\
2\end{array}$ \\
\hline $\begin{array}{l}21 \ldots \\
22 \ldots \\
23 \ldots \\
24 \ldots \\
25 \ldots\end{array}$ & $\begin{array}{r}745 \\
1890 \\
1070 \\
1040 \\
1080\end{array}$ & $\begin{array}{r}136 \\
498 \\
110 \\
58 \\
42\end{array}$ & $\begin{array}{r}326 \\
2810 \\
318 \\
163 \\
122\end{array}$ & $\begin{array}{l}904 \\
777 \\
670 \\
565 \\
505\end{array}$ & $\begin{array}{l}48 \\
42 \\
30 \\
22 \\
23\end{array}$ & $\begin{array}{r}117 \\
88 \\
54 \\
34 \\
31\end{array}$ & $\begin{array}{l}234 \\
766 \\
243 \\
199 \\
172\end{array}$ & $\begin{array}{r}7 \\
68 \\
4 \\
4 \\
6\end{array}$ & $\begin{array}{r}4 \\
191 \\
3 \\
2 \\
3\end{array}$ \\
\hline $\begin{array}{l}26 \ldots \\
27 \ldots \\
28 \ldots \\
29 \ldots \\
30 \ldots \\
31 \ldots\end{array}$ & $\begin{array}{c}981 \\
959 \\
854 \\
730 \\
665 \\
--\end{array}$ & $\begin{array}{l}45 \\
44 \\
41 \\
37 \\
33 \\
--\end{array}$ & $\begin{array}{r}119 \\
114 \\
95 \\
73 \\
59 \\
--\end{array}$ & $\begin{array}{l}478 \\
407 \\
387 \\
399 \\
347 \\
297\end{array}$ & $\begin{array}{r}18 \\
18 \\
17 \\
30 \\
11 \\
6\end{array}$ & $\begin{array}{r}23 \\
20 \\
18 \\
32 \\
10 \\
5 \\
\end{array}$ & $\begin{array}{c}180 \\
199 \\
177 \\
515 \\
264 \\
--\end{array}$ & $\begin{array}{r}6 \\
6 \\
8 \\
1110 \\
182 \\
--\end{array}$ & $\begin{array}{r}3 \\
3 \\
4 \\
1790 \\
130 \\
\end{array}$ \\
\hline \multirow[t]{2}{*}{ Total } & 31486 & -- & 10254 & 46931 & -- & 35778 & 6809 & -- & 2225 \\
\hline & \multicolumn{3}{|c|}{ JULY } & \multicolumn{3}{|c|}{ AUGUST } & \multicolumn{3}{|c|}{ SEPTEMGER } \\
\hline $\begin{array}{l}1 \ldots \\
2 \ldots \\
3 \ldots \\
40 \\
5 \ldots\end{array}$ & $\begin{array}{l}202 \\
162 \\
144 \\
167 \\
153\end{array}$ & $\begin{array}{r}112 \\
47 \\
20 \\
15 \\
14\end{array}$ & $\begin{array}{r}61 \\
21 \\
8 \\
7 \\
6\end{array}$ & $\begin{array}{l}160 \\
146 \\
199 \\
160 \\
131\end{array}$ & $\begin{array}{l}16 \\
20 \\
70 \\
23 \\
18\end{array}$ & $\begin{array}{r}7 \\
8 \\
38 \\
10 \\
6\end{array}$ & $\begin{array}{l}188 \\
153 \\
127 \\
102 \\
100\end{array}$ & $\begin{array}{l}27 \\
22 \\
20 \\
20 \\
20\end{array}$ & $\begin{array}{r}14 \\
9 \\
7 \\
6 \\
5\end{array}$ \\
\hline $\begin{array}{c}6 \ldots \\
7 \ldots \\
8 \ldots \\
9 \ldots \\
10 \ldots\end{array}$ & $\begin{array}{l}139 \\
137 \\
133 \\
137 \\
175\end{array}$ & $\begin{array}{l}12 \\
12 \\
10 \\
10 \\
28\end{array}$ & $\begin{array}{r}5 \\
4 \\
4 \\
4 \\
13\end{array}$ & $\begin{array}{r}115 \\
96 \\
111 \\
127 \\
170\end{array}$ & $\begin{array}{l}18 \\
14 \\
15 \\
15 \\
14\end{array}$ & $\begin{array}{l}6 \\
4 \\
4 \\
5 \\
6\end{array}$ & $\begin{array}{l}117 \\
111 \\
113 \\
153 \\
270\end{array}$ & $\begin{array}{r}20 \\
20 \\
20 \\
40 \\
100\end{array}$ & $\begin{array}{r}6 \\
6 \\
6 \\
20 \\
77\end{array}$ \\
\hline $\begin{array}{l}11 \ldots \\
12 \ldots \\
13 \ldots \\
14 \ldots \\
15 \ldots\end{array}$ & $\begin{array}{l}155 \\
142 \\
148 \\
182 \\
125\end{array}$ & $\begin{array}{l}18 \\
12 \\
12 \\
18 \\
13\end{array}$ & $\begin{array}{l}8 \\
5 \\
5 \\
9 \\
4\end{array}$ & $\begin{array}{r}127 \\
113 \\
104 \\
93 \\
107\end{array}$ & $\begin{array}{l}16 \\
15 \\
14 \\
15 \\
14\end{array}$ & $\begin{array}{l}5 \\
5 \\
4 \\
4 \\
4\end{array}$ & $\begin{array}{l}148 \\
137 \\
123 \\
119 \\
117\end{array}$ & $\begin{array}{l}35 \\
22 \\
20 \\
20 \\
19\end{array}$ & $\begin{array}{r}14 \\
8 \\
7 \\
6 \\
6\end{array}$ \\
\hline $\begin{array}{l}16 \ldots \\
17 \ldots \\
18 \ldots \\
19 \ldots \\
20 \ldots\end{array}$ & $\begin{array}{l}109 \\
104 \\
139 \\
258 \\
167\end{array}$ & $\begin{array}{l}12 \\
11 \\
18 \\
46 \\
15\end{array}$ & $\begin{array}{r}4 \\
3 \\
7 \\
32 \\
7\end{array}$ & $\begin{array}{l}106 \\
104 \\
106 \\
210 \\
162\end{array}$ & $\begin{array}{l}12 \\
13 \\
16 \\
77 \\
40\end{array}$ & $\begin{array}{r}3 \\
4 \\
5 \\
47 \\
17\end{array}$ & $\begin{array}{r}111 \\
106 \\
94 \\
109 \\
109\end{array}$ & $\begin{array}{l}19 \\
18 \\
18 \\
18 \\
18\end{array}$ & $\begin{array}{l}6 \\
5 \\
5 \\
5 \\
5\end{array}$ \\
\hline $\begin{array}{l}21 \ldots \\
22 \ldots \\
23 \ldots \\
24 \ldots \\
25 \ldots\end{array}$ & $\begin{array}{l}153 \\
127 \\
121 \\
135 \\
199\end{array}$ & $\begin{array}{l}15 \\
15 \\
15 \\
18 \\
50\end{array}$ & $\begin{array}{r}6 \\
5 \\
5 \\
7 \\
27\end{array}$ & $\begin{array}{l}146 \\
123 \\
115 \\
109 \\
113\end{array}$ & $\begin{array}{l}28 \\
22 \\
20 \\
21 \\
20\end{array}$ & $\begin{array}{r}11 \\
7 \\
6 \\
6 \\
6\end{array}$ & $\begin{array}{l}153 \\
279 \\
177 \\
155 \\
153\end{array}$ & $\begin{array}{l}47 \\
86 \\
26 \\
20 \\
19\end{array}$ & $\begin{array}{r}20 \\
65 \\
12 \\
8 \\
8\end{array}$ \\
\hline $\begin{array}{l}26 \ldots \\
27 \ldots \\
28 \ldots \\
29 \ldots \\
30 \ldots \\
31 \ldots\end{array}$ & $\begin{array}{l}153 \\
137 \\
172 \\
170 \\
144 \\
139\end{array}$ & $\begin{array}{l}22 \\
15 \\
18 \\
37 \\
28 \\
19\end{array}$ & $\begin{array}{r}9 \\
6 \\
8 \\
17 \\
11 \\
7\end{array}$ & $\begin{array}{l}119 \\
131 \\
146 \\
182 \\
177 \\
328\end{array}$ & $\begin{array}{l}22 \\
19 \\
20 \\
20 \\
32 \\
78\end{array}$ & $\begin{array}{r}7 \\
7 \\
8 \\
10 \\
16 \\
78\end{array}$ & $\begin{array}{c}165 \\
150 \\
720 \\
515 \\
279 \\
--\end{array}$ & $\begin{array}{r}19 \\
20 \\
372 \\
250 \\
127 \\
-- \\
\end{array}$ & $\begin{array}{r}8 \\
8 \\
779 \\
348 \\
96 \\
--\end{array}$ \\
\hline Total & 4728 & -- & 325 & 4336 & -- & 354 & 5353 & -- & 1575 \\
\hline $\begin{array}{l}\text { Total } \\
\text { Total }\end{array}$ & $\begin{array}{l}\text { lischarg } \\
\text { oad for }\end{array}$ & $\begin{array}{l}\text { or year } \\
\text { ar (ton }\end{array}$ & $\begin{array}{l}\text { (s-days) } \\
\ldots \ldots \ldots\end{array}$ & . . . . . & $\ldots \ldots$ & $\ldots \ldots$ & $\cdots \cdots$ & $\cdots \cdots$ & $\begin{array}{l}249605 \\
141503 \\
\end{array}$ \\
\hline
\end{tabular}




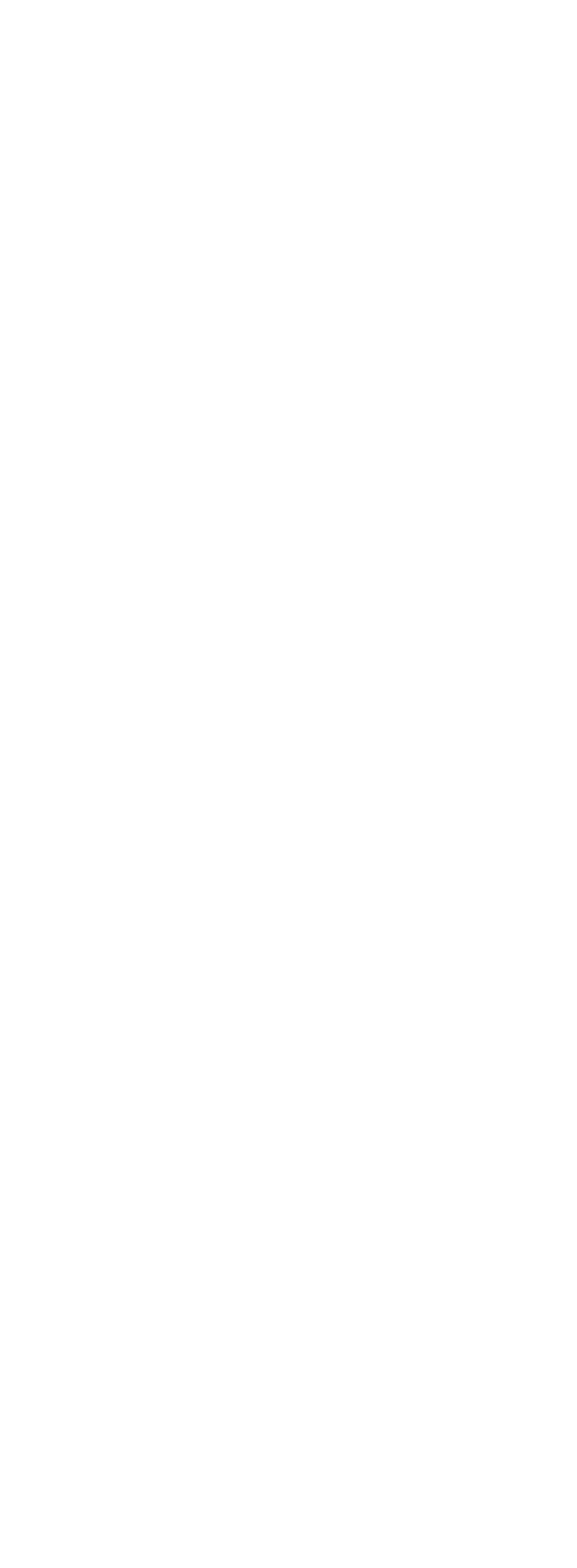




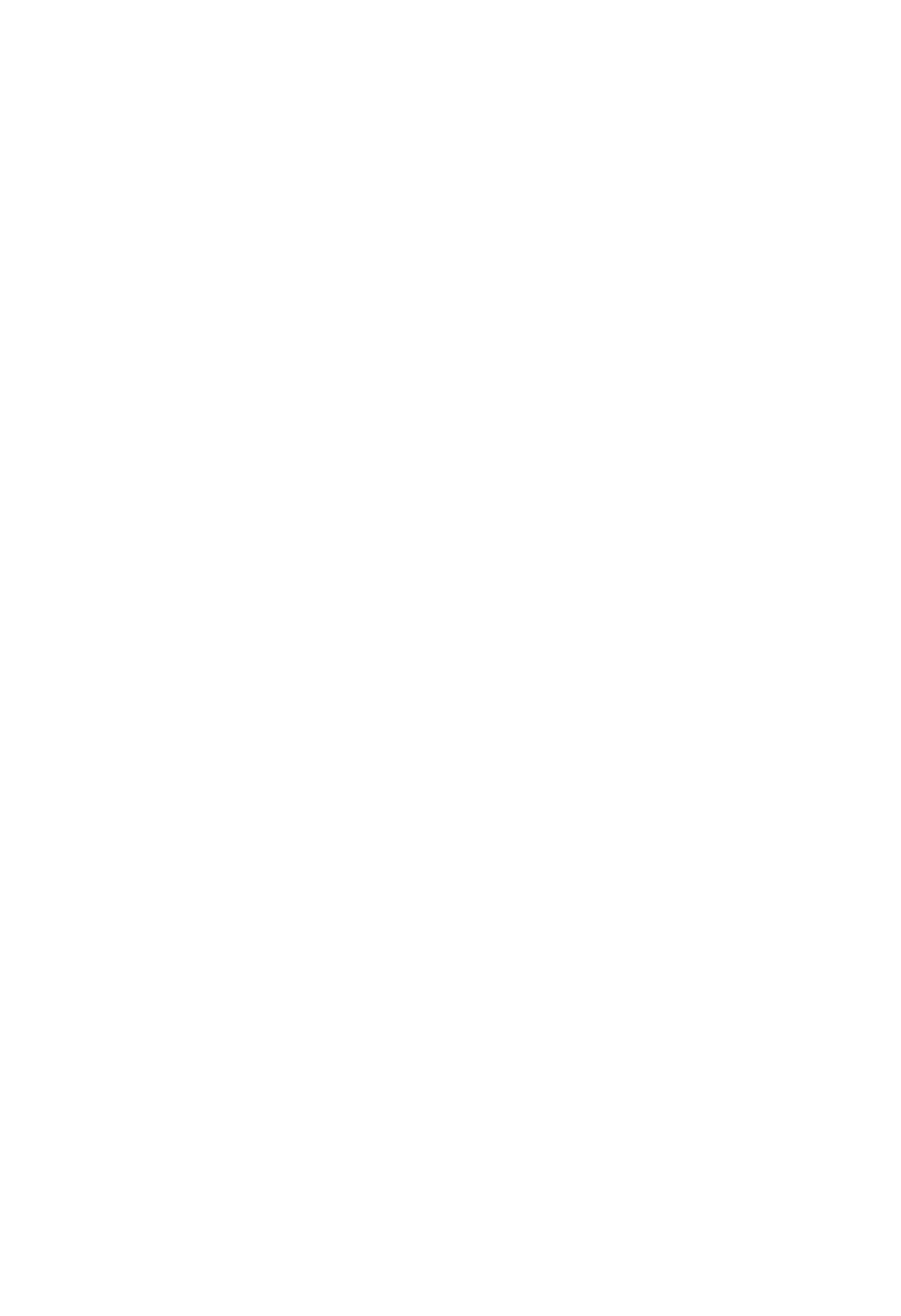




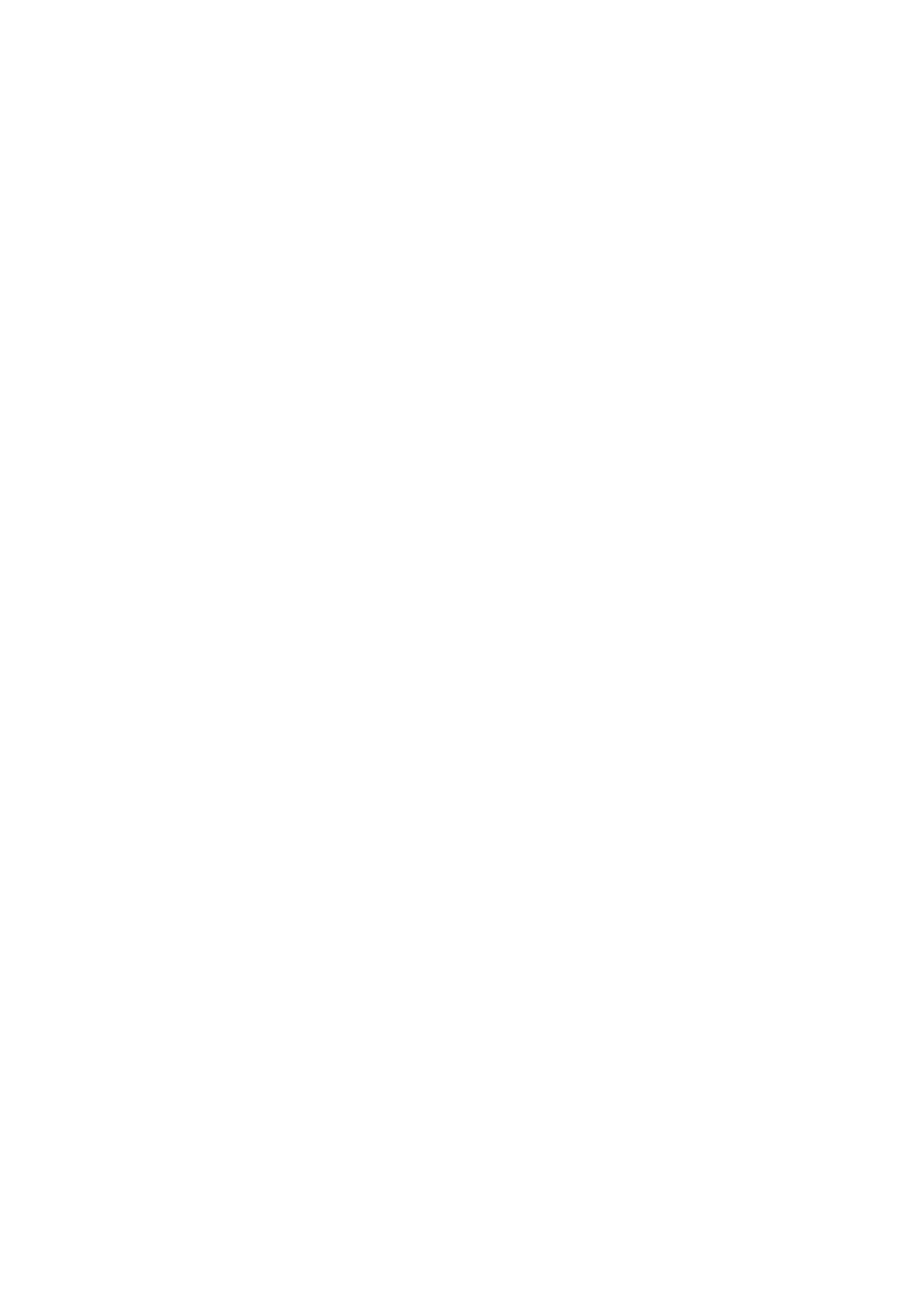




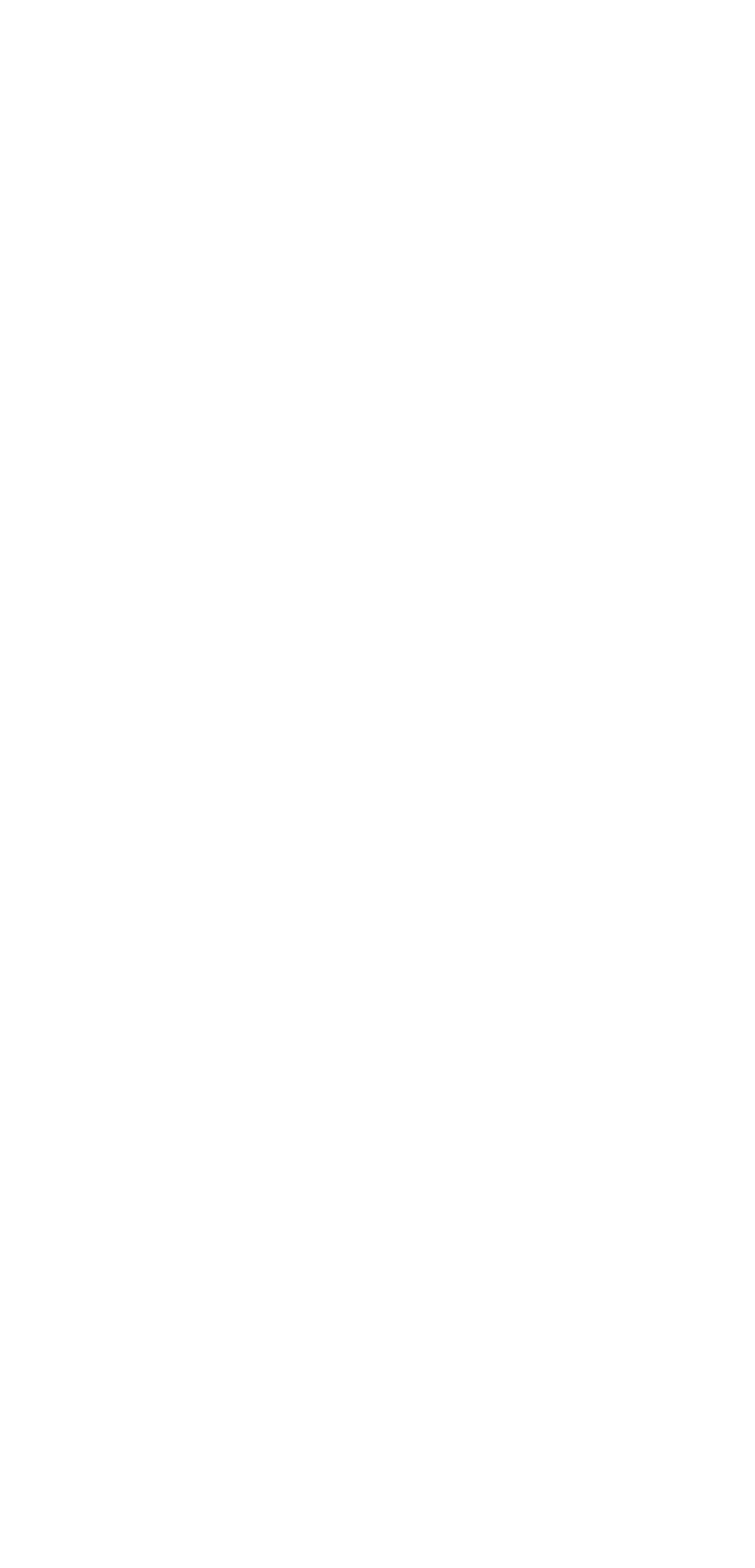


STREAYS TRIBUTARY TO LAKE ERIE--Cont1 nued

4-2085.06. CUYAHOGA RIVER AT WEST FIIRD STREET BRIDGE, IN CLEVFLAND, OHIO--Cont1mWed Data fron continuous recorder, November 1966 to September 1967

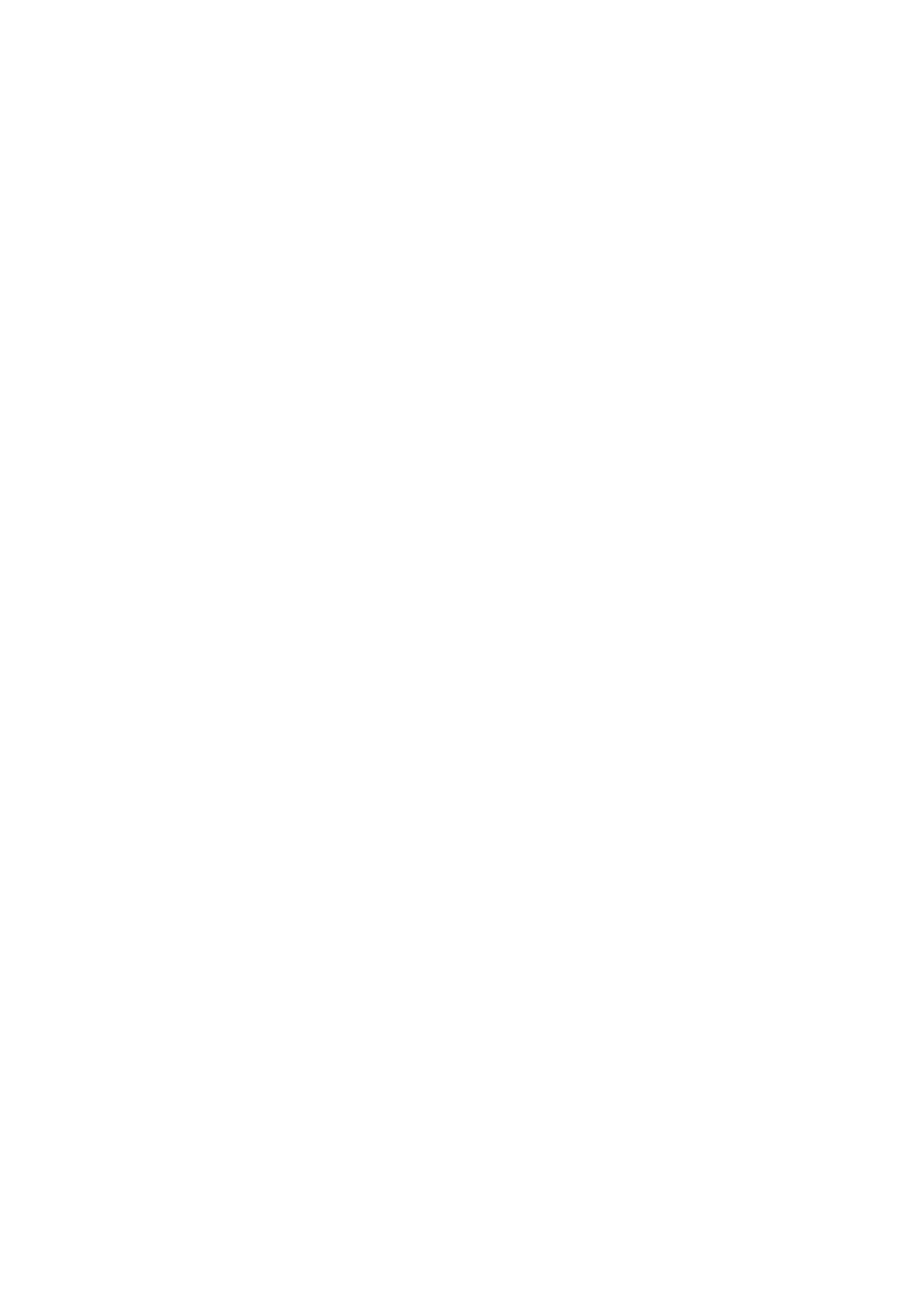


STREAMS TRIBUTARY TO LAKE ERIE--COntinued

4-2085.06. CUYAHOGA RIVER AT WEST THIRD STREET BRIDGE, IN CLEVELAND, OHI3--ContInued

\begin{tabular}{|c|c|c|c|c|c|c|c|c|c|c|c|c|c|c|c|c|}
\hline \multirow{3}{*}{ Day } & \multicolumn{8}{|c|}{ FEBRUARY } & \multicolumn{8}{|c|}{ MARCH } \\
\hline & \multicolumn{2}{|c|}{$\begin{array}{c}\text { Specific } \\
\text { conductance } \\
\text { (micromhos } \\
\text { at } 25^{\circ} \mathrm{C} \text { ) }\end{array}$} & \multicolumn{2}{|c|}{ pH } & \multicolumn{2}{|c|}{$\begin{array}{l}\text { Dtessolved } \\
\text { oxygen } \\
\text { (ppm) }\end{array}$} & \multicolumn{2}{|c|}{$\begin{array}{c}\text { Temper- } \\
\text { ature } \\
\left({ }^{\circ} \mathbf{F}\right)\end{array}$} & \multicolumn{2}{|c|}{$\begin{array}{c}\text { Specific } \\
\text { conductance } \\
\text { (micromhos } \\
\text { at } 25^{\circ} \mathrm{C} \text { ) }\end{array}$} & \multicolumn{2}{|c|}{ pH } & \multicolumn{2}{|c|}{$\begin{array}{l}\text { Dissolved } \\
\text { oxygen } \\
\text { (ppm) }\end{array}$} & \multicolumn{2}{|c|}{$\begin{array}{c}\text { Temper- } \\
\text { ature } \\
\left({ }^{\circ} \mathbf{F}\right)\end{array}$} \\
\hline & $\operatorname{Max}$ & Min & Max & Min & $\operatorname{Max}$ & Min & Max & Min & Max & Min & Max & Min & Max & Min & $\operatorname{Max}$ & Min \\
\hline $\begin{array}{l}1 \ldots \\
2 \ldots \\
3 \ldots \\
4 \ldots \\
5 \ldots\end{array}$ & $\begin{array}{r}1030 \\
680 \\
690 \\
700\end{array}$ & $\begin{array}{l}-- \\
500 \\
550 \\
650 \\
620\end{array}$ & & & $\begin{array}{l}9.2 \\
8.2 \\
8.4 \\
8.1\end{array}$ & $\begin{array}{l}-.7 \\
7.7 \\
8.1 \\
7.9 \\
7.4\end{array}$ & $\begin{array}{l}-72 \\
40 \\
42 \\
43\end{array}$ & $\begin{array}{l}-- \\
37 \\
36 \\
37 \\
37\end{array}$ & $\begin{array}{r}-- \\
1580 \\
1750 \\
--\end{array}$ & $\begin{array}{r}1450 \\
1450 \\
=- \\
--\end{array}$ & $\begin{array}{l}-- \\
7.3 \\
7.4 \\
7.6 \\
8.0\end{array}$ & $\begin{array}{l}--- \\
7 \cdot 2 \\
7 \cdot 2 \\
7.2 \\
7.4\end{array}$ & $\begin{array}{l}6.4 \\
6.6 \\
8.1 \\
7.7\end{array}$ & $\begin{array}{l}--- \\
5.9 \\
5.7 \\
5.5 \\
7.2\end{array}$ & $\begin{array}{l}-- \\
53 \\
51 \\
49 \\
44\end{array}$ & $\begin{array}{l}-- \\
50 \\
48 \\
44 \\
41\end{array}$ \\
\hline $\begin{array}{r}6 \ldots \\
7 \ldots \\
8 \cdots \\
10 \cdots\end{array}$ & $\begin{array}{r}710 \\
810 \\
1000 \\
1035 \\
1110\end{array}$ & $\begin{array}{l}660 \\
710 \\
780 \\
910 \\
960\end{array}$ & & . & $\begin{array}{l}7.8 \\
7.5 \\
7.3 \\
6.8 \\
6.6\end{array}$ & $\begin{array}{l}6.9 \\
6.8 \\
6.6 \\
6.3 \\
5.5\end{array}$ & $\begin{array}{l}44 \\
43 \\
43 \\
47 \\
50\end{array}$ & $\begin{array}{l}40 \\
37 \\
39 \\
43 \\
44\end{array}$ & $\begin{array}{l}-- \\
-- \\
--\end{array}$ & $\begin{array}{l}-- \\
-- \\
--\end{array}$ & $\begin{array}{l}7.9 \\
7.8 \\
7.7 \\
7.6 \\
7.5\end{array}$ & $\begin{array}{l}7 \cdot 3 \\
7 \cdot 2 \\
7 \cdot 3 \\
7 \cdot 3 \\
7 \cdot 1\end{array}$ & $\begin{array}{l}7.7 \\
7.4 \\
7.4 \\
7.2 \\
7.2\end{array}$ & $\begin{array}{l}6.9 \\
6.9 \\
6.8 \\
6.6 \\
6.5\end{array}$ & $\begin{array}{l}42 \\
44 \\
47 \\
46 \\
48\end{array}$ & $\begin{array}{l}39 \\
40 \\
44 \\
44 \\
46\end{array}$ \\
\hline $\begin{array}{l}11 \ldots \\
12 \ldots \\
13 \ldots \\
14 \ldots \\
15 \ldots\end{array}$ & $\begin{array}{l}-- \\
--\end{array}$ & $\begin{array}{l}\overline{-} \\
\overline{--} \\
\overline{--}\end{array}$ & & & $\begin{array}{l}= \\
= \\
=\end{array}$ & $\begin{array}{l}-- \\
\overline{--} \\
--\end{array}$ & $\begin{array}{l}-- \\
=- \\
=- \\
--\end{array}$ & $\begin{array}{l}=- \\
=- \\
=- \\
--\end{array}$ & $\begin{array}{l}-- \\
-- \\
--\end{array}$ & $\begin{array}{l}=- \\
=- \\
=-\end{array}$ & $\begin{array}{r}8.2 \\
8.1 \\
8.1 \\
=-\end{array}$ & $\begin{array}{r}7.3 \\
7.9 \\
7.5 \\
-= \\
=-\end{array}$ & $\begin{array}{r}7.0 \\
7.3 \\
-- \\
-\end{array}$ & $\begin{array}{r}6.6 \\
6.8 \\
-- \\
--\end{array}$ & $\begin{array}{l}=- \\
=- \\
=-\end{array}$ & $=$ \\
\hline $\begin{array}{l}16 \ldots \\
17 \ldots \\
18 \ldots \\
19 \ldots \\
20 \ldots\end{array}$ & $\begin{array}{l}-- \\
-- \\
--\end{array}$ & $\begin{array}{l}-- \\
\overline{-} \\
-- \\
--\end{array}$ & & & $\begin{array}{l}= \\
= \\
=\end{array}$ & $\begin{array}{l}=- \\
=- \\
=-\end{array}$ & $\begin{array}{l}=- \\
=- \\
--\end{array}$ & $\begin{array}{l}=- \\
=- \\
=- \\
=-\end{array}$ & $\begin{array}{l}-- \\
-- \\
--\end{array}$ & $\begin{array}{l}- \\
-- \\
-- \\
--\end{array}$ & $\begin{array}{l}-- \\
-- \\
--\end{array}$ & $\begin{array}{l}-- \\
-- \\
-- \\
--\end{array}$ & $=$ & $=$ & $\begin{array}{l}=- \\
=- \\
=- \\
--\end{array}$ & $\begin{array}{l}=- \\
=- \\
=-\end{array}$ \\
\hline $\begin{array}{l}21 \ldots \\
22 \ldots \\
23 \ldots \\
24 \ldots \\
25 \ldots\end{array}$ & $\begin{array}{l}= \\
= \\
= \\
-\end{array}$ & $\begin{array}{l}-- \\
-- \\
--\end{array}$ & & & $\begin{array}{l}= \\
= \\
=\end{array}$ & $\begin{array}{l}-- \\
-- \\
--\end{array}$ & $\begin{array}{l}-- \\
-\overline{-} \\
-- \\
--\end{array}$ & $\begin{array}{l}-- \\
=- \\
-- \\
--\end{array}$ & $\begin{array}{l}-- \\
z- \\
- \\
-\end{array}$ & $\begin{array}{l}=- \\
- \\
- \\
--\end{array}$ & $\begin{array}{l}-- \\
7.6 \\
7.6 \\
7.8\end{array}$ & $\begin{array}{r}-- \\
7 .-3 \\
7.2 \\
7.3\end{array}$ & $\begin{array}{l}-- \\
-- \\
8.8 \\
8.9 \\
8.6\end{array}$ & $\begin{array}{r}-2 \\
7.6 \\
7.4 \\
7.6\end{array}$ & $\begin{array}{l}=- \\
=- \\
=\end{array}$ & $\begin{array}{l}= \\
= \\
=\end{array}$ \\
\hline $\begin{array}{l}26 \ldots \\
27 \ldots \\
28 \ldots \\
29 \ldots \\
30 \ldots \\
31 \ldots\end{array}$ & $\begin{array}{l}-- \\
-- \\
- \\
-\end{array}$ & $\begin{array}{l}-- \\
-- \\
-- \\
--\end{array}$ & & & $\begin{array}{l}- \\
\because- \\
\because \\
-\end{array}$ & $\begin{array}{l}=- \\
=- \\
=- \\
=-\end{array}$ & $\begin{array}{l}-- \\
=- \\
=- \\
=- \\
--\end{array}$ & $\begin{array}{l}=- \\
=- \\
=- \\
=-\end{array}$ & $\begin{array}{r}-- \\
-- \\
560 \\
580 \\
730\end{array}$ & $\begin{array}{r}-- \\
-- \\
510 \\
480 \\
530\end{array}$ & $\begin{array}{l}7.9 \\
7.8 \\
7.5 \\
7.6 \\
7.6 \\
7.4\end{array}$ & $\begin{array}{l}7.7 \\
7.3 \\
7.1 \\
7.2 \\
7.2 \\
7.2\end{array}$ & $\begin{array}{r}8.6 \\
6.8 \\
4.1 \\
-\ldots \\
--\end{array}$ & $\begin{array}{r}6.5 \\
3.7 \\
3.0 \\
=- \\
=-\end{array}$ & $\begin{array}{l}- \\
=- \\
50 \\
51 \\
56\end{array}$ & $\begin{array}{l}- \\
-- \\
-- \\
48 \\
50\end{array}$ \\
\hline
\end{tabular}

\begin{tabular}{|c|c|c|c|c|c|c|c|c|c|c|c|c|c|c|c|c|}
\hline \multicolumn{9}{|c|}{ APRIL } & \multicolumn{8}{|c|}{ MAY } \\
\hline $1 \ldots$ & $\sim-$ & -- & 7.6 & 7.1 & - & -- & 57 & 53 & -- & - & -- & -- & $\cdots$ & -- & - & -- \\
\hline $2 \cdots$ & -- & -- & 7.7 & 7.5 & - & -- & 59 & 55 & -- & -- & -- & -- & - & -- & - & -- \\
\hline & - & -- & 7.8 & 7.3 & - & -- & 59 & 55 & - & -- & - & -- & - & -- & $\sim$ & - \\
\hline $4 \ldots$ & -- & -- & 7.4 & 7.1 & $\cdots$ & -- & 55 & 51 & -- & $\cdots$ & -- & - & - & $-\infty$ & - & -- \\
\hline $5 \ldots$ & -- & -- & 7.2 & 6.9 & - & -- & 57 & 51 & - & - & -- & -- & - & -- & -- & $-\infty$ \\
\hline 6.0 & -- & - & 7.1 & 6.8 & $=$ & - & 59 & 55 & - & - & -- & - & - & -- & -- & - \\
\hline $7 .$. & -- & -- & 7.5 & 6.7 & $\cdots$ & -- & 57 & 48 & -- & -- & - & -- & $\ldots$ & -. & -- & - \\
\hline $8 .$. & - & -- & 7.4 & 7.0 & $\cdots$ & -- & 56 & 51 & -- & -- & -- & -- & -. & -- & - & $=$ \\
\hline $9 \ldots$ & -- & -- & 7.5 & 6.2 & - & -- & 59 & 55 & -- & -- & $-\infty$ & -- & - & - & - & -- \\
\hline $10 \ldots$ & $\cdots$ & -- & 7.4 & 7.1 & $=$ & -- & 63 & 59 & $-m$ & - & - & -- & - & -- & - & -- \\
\hline $11 \ldots$ & - & -- & 7.1 & 6.8 & -- & -- & 60 & 56 & $\rightarrow$ & -- & -- & -- & - & -- & - & -- \\
\hline $12 \ldots$ & -- & -. & 7.1 & 6.9 & $-\infty$ & -- & 62 & 57 & 520 & 400 & -- & - & 7.0 & 5.5 & 55 & 54 \\
\hline $13 \ldots$ & -- & -- & 7.0 & 6.8 & - & -- & 60 & 57 & 590 & 520 & - & -- & 6.9 & 5.6 & 56 & 54 \\
\hline $14 \ldots$ & - & -- & 7.1 & 6.8 & $\cdots$ & -- & 63 & 60 & 590 & 500 & - & - & - & $=$ & 56 & 55 \\
\hline $15 \ldots$ & -- & -- & 7.0 & 6.8 & - & -- & 69 & 61 & -- & -- & -- & $\rightarrow$ & - & -- & - & - \\
\hline $16 \ldots$ & -- & -- & 7.3 & 6.9 & -- & -- & 73 & 67 & 650 & 550 & 7.0 & 6.8 & 6.4 & 4.8 & 57 & 56 \\
\hline $17 \ldots$ & - & -- & - & -- & $\cdots$ & -- & -- & -- & 710 & 590 & 6.9 & 6.8 & 5.8 & 4.0 & 60 & 59 \\
\hline $18 \ldots$ & -- & -- & -- & - & - & -- & - & -- & 800 & 660 & 7.0 & 6.8 & 4.8 & 4.1 & 63 & 60 \\
\hline $19 .$. & -- & -- & -- & -- & -- & -- & -- & -- & - & -- & 6.9 & 6.6 & 4.2 & 3.4 & - & - \\
\hline $20 \ldots$ & 980 & 910 & 7.0 & 6.7 & .4 & .2 & -- & - & $\cdots$ & -- & 7.0 & 6.5 & 3.8 & 1.9 & - & - \\
\hline $21 \ldots$ & 1000 & 940 & 7.1 & 6.7 & .4 & .2 & -- & - & -- & -- & 7.2 & 7.0 & 3.7 & 2.2 & - & - \\
\hline $22 .$. & -- & -- & 7.3 & 6.9 & $\cdots$ & -- & -- & -- & - & - & 7.3 & 7.0 & 3.9 & 2.8 & -- & -- \\
\hline $23 \ldots$ & -- & -- & 7.3 & 7.1 & - & -- & -- & -- & -- & -- & 7.0 & 6.8 & 3.3 & .7 & - & - \\
\hline $24 \ldots$ & -- & -- & 7.3 & 7.0 & $\cdots$ & - & 61 & 57 & -- & - & 6.9 & 6.7 & 2.4 & .6 & - & -- \\
\hline $25 \ldots$ & - & - & 7.1 & 6.9 & - & -- & 58 & 56 & -- & -- & 6.8 & 6.6 & 1.1 & $\cdot 3$ & - & -- \\
\hline $26 \ldots$ & -- & $\cdots$ & 7.0 & 6.7 & - & -- & 61 & 57 & -- & - & 6.8 & 6.5 & .8 & .3 & - & - \\
\hline 27. & -- & -- & 6.8 & 6.6 & $\cdots$ & - & 60 & 57 & -- & - & 6.7 & 6.5 & 1,1 & .8 & - & -- \\
\hline $28 \ldots$ & - & -- & -- & -- & - & -- & - & -- & -- & -- & 6.6 & 6.4 & 1.1 & .8 & - & -- \\
\hline $29 \ldots$ & $=$ & -- & -- & $\cdots$ & $\cdots$ & -- & -- & -- & - & -- & 6.7 & 6.6 & .9 & .8 & - & -- \\
\hline $30 \ldots$ & -- & -- & -- & -- & $\cdots$ & -- & -- & - & $\cdots$ & - & 6.6 & 5.9 & 1.4 & .8 & -- & - \\
\hline $31 \ldots$ & $\cdots$ & -- & -- & - & $\cdots$ & -- & -- & -- & -- & - & 6.6 & 5.9 & 1.4 & 1.2 & -- & -- \\
\hline
\end{tabular}


STREAMS TRIBUTARY TO LAKE ERIE--Continued

4-2085.06. CUYAHOGA RIVER AT WEST THIRD STREET BRIDGE, IN CLEVELAND, OHIO--Continued

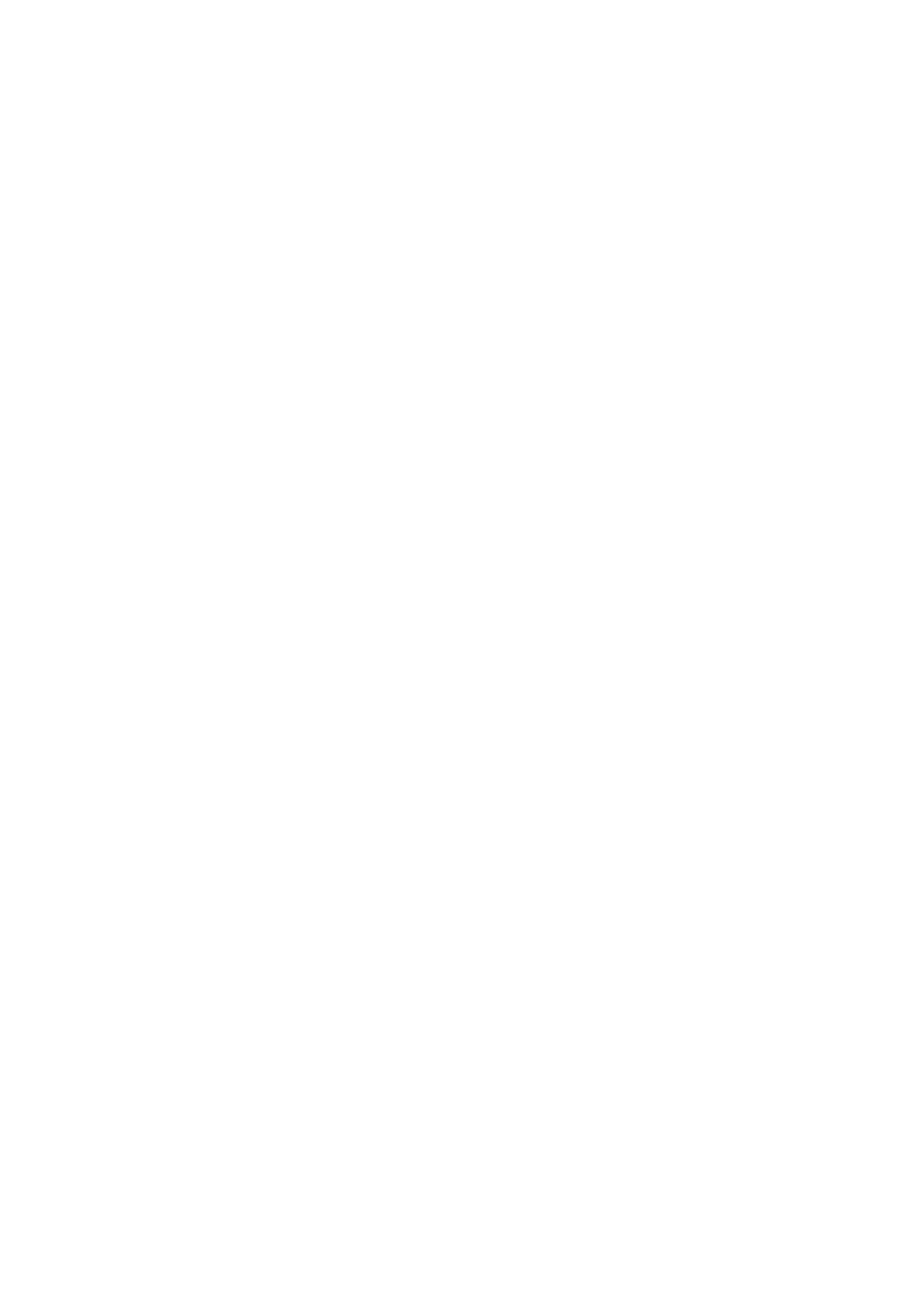




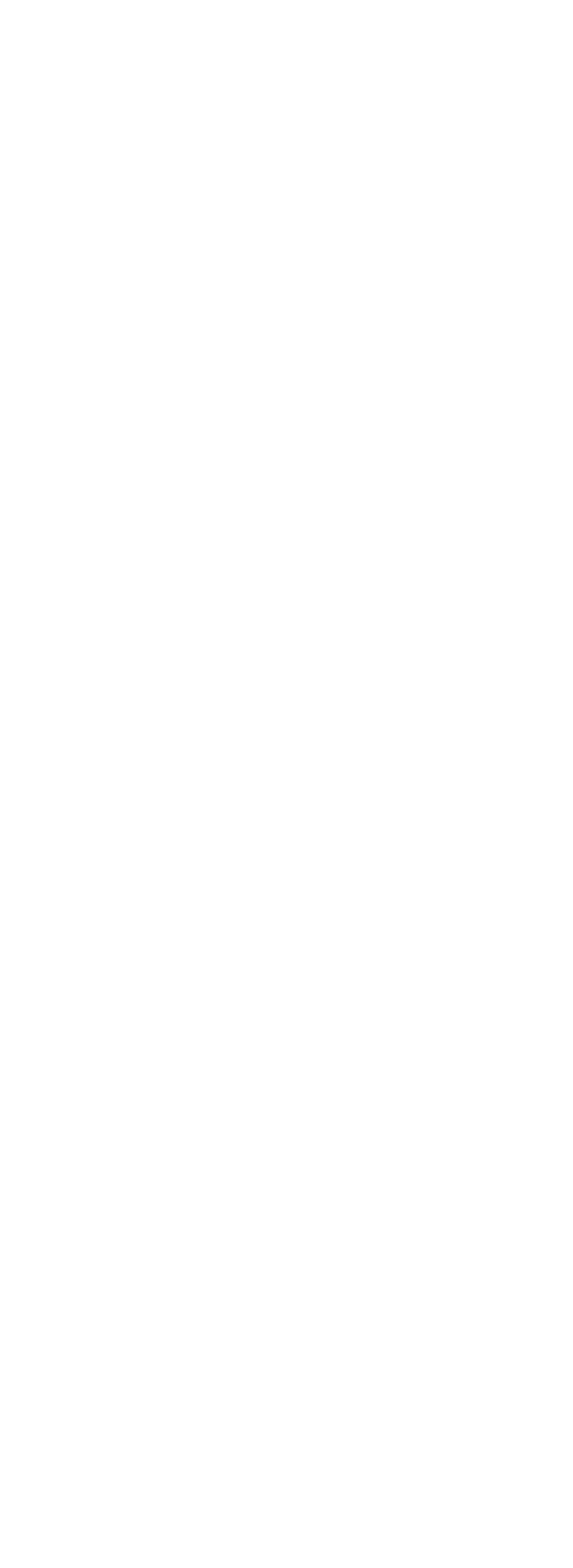


STREAMS TRIBUTARY TO LAKE ERIE--COntinued

4-2085.1. CUYAHOGA RIVER AT CENTER STREET BRIDGE IN CLEVELAND, OHIO--Continued

Data from continuous recorder, October and November 1966

\begin{tabular}{|c|c|c|c|c|c|c|c|c|c|c|c|c|c|c|c|c|}
\hline \multirow{3}{*}{ Day } & \multicolumn{8}{|c|}{ OCTOBER } & \multicolumn{8}{|c|}{ NOVEMBER } \\
\hline & \multicolumn{2}{|c|}{$\begin{array}{c}\text { Specific } \\
\text { conductance } \\
\text { (micromhos } \\
\text { at } 25-\mathrm{C} \text { ) }\end{array}$} & \multicolumn{2}{|c|}{ pH } & \multicolumn{2}{|c|}{$\begin{array}{c}\text { Dissolved } \\
\text { oxygen } \\
\text { (ppm) }\end{array}$} & \multicolumn{2}{|c|}{$\begin{array}{l}\text { Temper- } \\
\text { ature } \\
(\mathrm{F})\end{array}$} & \multicolumn{2}{|c|}{$\begin{array}{c}\text { Specific } \\
\text { conductance } \\
\text { (micromhos } \\
\text { at } 25^{\circ} \mathrm{C} \text { ) }\end{array}$} & \multicolumn{2}{|c|}{$\mathrm{pH}$} & \multicolumn{2}{|c|}{$\begin{array}{c}\text { Dissolved } \\
\text { oxygen } \\
\text { (ppm) }\end{array}$} & \multicolumn{2}{|c|}{$\begin{array}{c}\text { Temper- } \\
\text { ature } \\
\left({ }^{\circ} \mathbf{F}\right)\end{array}$} \\
\hline & $\operatorname{Max}$ & Min & $\operatorname{Max}$ & Min & $\operatorname{Max}$ & Min & Max & Min & Max & Min & Max & Min & Max & Min & Max & Min \\
\hline $\begin{array}{l}1 \cdots \\
2 \cdots \\
3 \cdots \\
4 \cdots\end{array}$ & $\begin{array}{l}1480 \\
1480 \\
1400 \\
1360 \\
1360\end{array}$ & $\begin{array}{r}750 \\
1170 \\
1050 \\
1100 \\
880\end{array}$ & $\begin{array}{l}7.2 \\
7.0 \\
7.0 \\
7.1 \\
7.2\end{array}$ & $\begin{array}{l}6.7 \\
6.8 \\
6.9 \\
7.0 \\
6.9\end{array}$ & $\begin{array}{l}.2 \\
: 2 \\
: 2 \\
.1 \\
.5\end{array}$ & $\begin{array}{l}.0 \\
.0 \\
.0 \\
.0 \\
.1\end{array}$ & $\begin{array}{l}79 \\
78 \\
77 \\
77 \\
77\end{array}$ & $\begin{array}{l}72 \\
73 \\
73 \\
74 \\
74\end{array}$ & $\begin{array}{r}1470 \\
1540 \\
890 \\
780 \\
750\end{array}$ & $\begin{array}{r}1260 \\
880 \\
600 \\
710 \\
700\end{array}$ & $\begin{array}{l}7.2 \\
7.4 \\
7.7 \\
7.7 \\
7.5\end{array}$ & $\begin{array}{l}7: 1 \\
7: 0 \\
7.3 \\
7.5 \\
7.1\end{array}$ & $\begin{array}{r}.9 \\
.8 \\
1.5 \\
1.6 \\
1.5\end{array}$ & $\begin{array}{l}: 3 \\
: 3 \\
: 9 \\
: 9\end{array}$ & $\begin{array}{l}65 \\
72 \\
58 \\
52 \\
54\end{array}$ & $\begin{array}{l}65 \\
58 \\
51 \\
51 \\
51\end{array}$ \\
\hline $\begin{array}{r}6 \\
7 \ldots \\
6 \\
9 \bullet \\
10\end{array}$ & $\begin{array}{l}1280 \\
1200 \\
1230 \\
1280 \\
1260\end{array}$ & $\begin{array}{l}1140 \\
1030 \\
1130 \\
1050 \\
1030\end{array}$ & $\begin{array}{l}7.3 \\
7.3 \\
7.2 \\
7.1 \\
7.1\end{array}$ & $\begin{array}{l}7.1 \\
7.1 \\
7.0 \\
6.9 \\
6.9\end{array}$ & $\begin{array}{l}.2 \\
.4 \\
.3 \\
.3 \\
.3\end{array}$ & $\begin{array}{l}.0 \\
.0 \\
.0 \\
.1 \\
.1\end{array}$ & $\begin{array}{l}78 \\
76 \\
76 \\
78 \\
77\end{array}$ & $\begin{array}{l}73 \\
71 \\
72 \\
73 \\
72\end{array}$ & $\begin{array}{r}930 \\
1080 \\
1110 \\
940 \\
680\end{array}$ & $\begin{array}{l}750 \\
930 \\
940 \\
600 \\
590\end{array}$ & $\begin{array}{l}7.3 \\
7.7 \\
7.7 \\
7.9 \\
7.6\end{array}$ & $\begin{array}{l}7.2 \\
7.2 \\
7.2 \\
7.2 \\
7.3\end{array}$ & $\begin{array}{l}1.3 \\
1.3 \\
2.6 \\
2.1 \\
1.8\end{array}$ & $\begin{array}{r}.5 \\
.4 \\
.5 \\
1.1 \\
1.1\end{array}$ & $\begin{array}{l}57 \\
61 \\
61 \\
60 \\
60\end{array}$ & $\begin{array}{l}54 \\
57 \\
57 \\
56 \\
57\end{array}$ \\
\hline $\begin{array}{l}11 \bullet \bullet \\
12 \bullet \bullet \\
13 \bullet \\
14 \bullet \bullet \\
15 \bullet \bullet\end{array}$ & $\begin{array}{l}1340 \\
1330 \\
1240 \\
1210 \\
1190\end{array}$ & $\begin{array}{r}1170 \\
1110 \\
820 \\
990 \\
990\end{array}$ & $\begin{array}{l}7.1 \\
7.2 \\
7.2 \\
7.1 \\
7.0\end{array}$ & $\begin{array}{l}7.0 \\
7.0 \\
7.1 \\
6.9 \\
6.7\end{array}$ & $\begin{array}{l}.2 \\
.2 \\
.6 \\
.2 \\
.3\end{array}$ & $\begin{array}{l}.1 \\
: 1 \\
: 0 \\
11 \\
: 1\end{array}$ & $\begin{array}{l}78 \\
77 \\
76 \\
75 \\
76\end{array}$ & $\begin{array}{l}72 \\
73 \\
69 \\
69 \\
69\end{array}$ & $\begin{array}{l}700 \\
660 \\
770 \\
760 \\
800\end{array}$ & $\begin{array}{l}570 \\
600 \\
660 \\
750 \\
750\end{array}$ & $\begin{array}{l}7.7 \\
7.5 \\
7.6 \\
8.2 \\
8.1\end{array}$ & $\begin{array}{l}7.3 \\
7.2 \\
7.4 \\
7.5 \\
7.9\end{array}$ & $\begin{array}{l}4.0 \\
5.0 \\
= \\
=\end{array}$ & $\begin{array}{r}1.4 \\
3.0 \\
- \\
-\end{array}$ & $\begin{array}{l}60 \\
58 \\
58 \\
58 \\
58\end{array}$ & $\begin{array}{l}57 \\
57 \\
56 \\
57 \\
57\end{array}$ \\
\hline $\begin{array}{l}16 \ldots \\
17 \bullet \\
18 \bullet \\
19 \bullet \\
20 \cdots\end{array}$ & $\begin{array}{l}1280 \\
1220 \\
1250 \\
1250 \\
1270\end{array}$ & $\begin{array}{r}1130 \\
1070 \\
1170 \\
940 \\
1150\end{array}$ & $\begin{array}{l}6.8 \\
6.9 \\
7.1 \\
7.4 \\
7.4\end{array}$ & $\begin{array}{l}6.7 \\
6.7 \\
6.8 \\
7.1 \\
7.1\end{array}$ & $\begin{array}{l}.2 \\
.3 \\
.3 \\
.5 \\
.4\end{array}$ & $\begin{array}{r}.1 \\
.2 \\
.2 \\
.3 \\
.2\end{array}$ & $\begin{array}{l}78 \\
75 \\
74 \\
73 \\
71\end{array}$ & $\begin{array}{l}72 \\
70 \\
70 \\
66 \\
69\end{array}$ & $\begin{array}{l}580 \\
=\end{array}$ & $\begin{array}{c}000 \\
= \\
=\end{array}$ & $\begin{array}{r}7.9 \\
\therefore \\
-\end{array}$ & $\begin{array}{l}7.1 \\
= \\
=\end{array}$ & $\begin{array}{l}2.6 \\
3.4 \\
2.5 \\
2.1 \\
2.6\end{array}$ & $\begin{array}{l}1.8 \\
2.1 \\
1.5 \\
1.5 \\
1.9\end{array}$ & $\begin{array}{l}58 \\
59 \\
60 \\
61 \\
6 ?\end{array}$ & $\begin{array}{l}57 \\
57 \\
58 \\
60 \\
61\end{array}$ \\
\hline $\begin{array}{l}21 \bullet \\
22 \cdots \\
23 \cdots \\
24 \bullet \\
25 \cdots\end{array}$ & $\begin{array}{l}1300 \\
1190 \\
1160 \\
1160 \\
1240\end{array}$ & $\begin{array}{r}1030 \\
970 \\
970 \\
820 \\
1050\end{array}$ & $\begin{array}{l}7.1 \\
7.3 \\
7.3 \\
7.3 \\
7.4\end{array}$ & $\begin{array}{l}7.0 \\
7.1 \\
7.1 \\
7.2 \\
7.2\end{array}$ & $\begin{array}{l}.4 \\
.5 \\
.4 \\
.7 \\
.4\end{array}$ & $\begin{array}{r}.3 \\
.3 \\
.3 \\
.2 \\
.2\end{array}$ & $\begin{array}{l}72 \\
68 \\
68 \\
68 \\
69\end{array}$ & $\begin{array}{l}67 \\
64 \\
64 \\
62 \\
64\end{array}$ & $\begin{array}{l}= \\
= \\
=\end{array}$ & $=$ & $=$ & $\begin{array}{l}= \\
= \\
=\end{array}$ & $\begin{array}{r}2.3 \\
= \\
=\end{array}$ & $\begin{array}{l}=0 \\
= \\
=\end{array}$ & $\begin{array}{l}63 \\
- \\
- \\
-\end{array}$ & $\begin{array}{l}61 \\
= \\
=\end{array}$ \\
\hline $\begin{array}{l}26 \ldots \\
27 \ldots \\
28 \ldots \\
29 \ldots \\
30 \ldots \\
31 \ldots\end{array}$ & $\begin{array}{l}1260 \\
1270 \\
1350 \\
1350 \\
1480 \\
1500\end{array}$ & $\begin{array}{l}1160 \\
1070 \\
1070 \\
1110 \\
1210 \\
1150\end{array}$ & $\begin{array}{l}7.4 \\
7.4 \\
7.3 \\
7.2 \\
7.2 \\
7.2\end{array}$ & $\begin{array}{l}7.2 \\
7.1 \\
7.0 \\
7.0 \\
7.0 \\
7.0\end{array}$ & $\begin{array}{r}.5 \\
.4 \\
.5 \\
.5 \\
.9 \\
1.0\end{array}$ & $\begin{array}{l}.2 \\
.3 \\
.3 \\
.3 \\
.3 \\
.3\end{array}$ & $\begin{array}{l}70 \\
71 \\
72 \\
71 \\
71 \\
70\end{array}$ & $\begin{array}{l}67 \\
67 \\
66 \\
66 \\
66 \\
63\end{array}$ & $\begin{array}{l}= \\
=\end{array}$ & $=$ & $=$ & $=$ & $=$ & $\begin{array}{l}- \\
- \\
-\end{array}$ & $=$ & $=$ \\
\hline
\end{tabular}




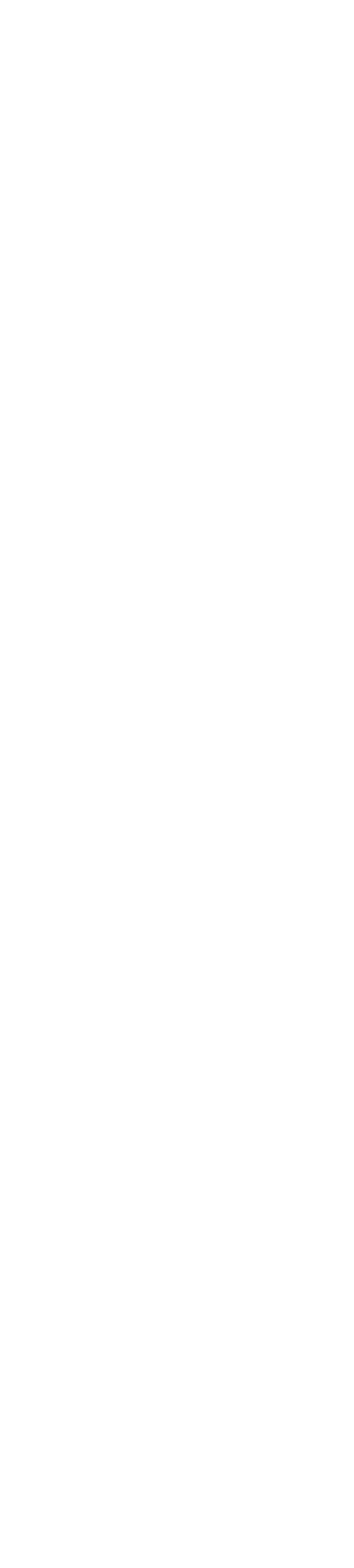

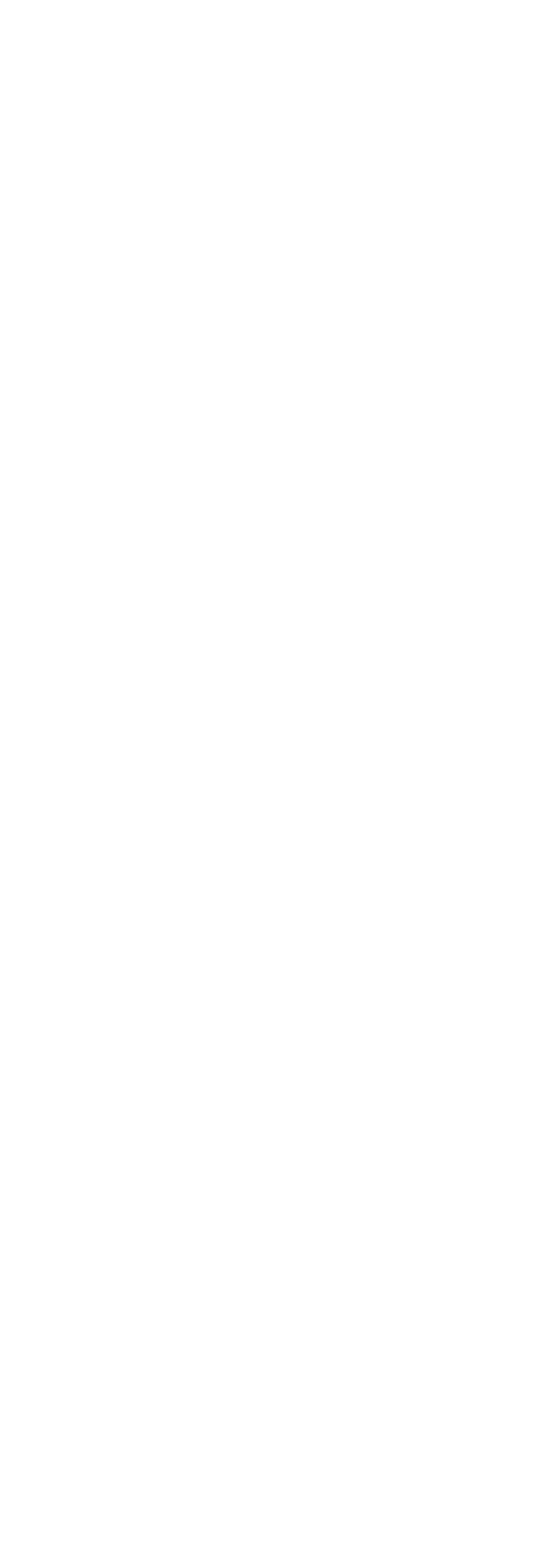



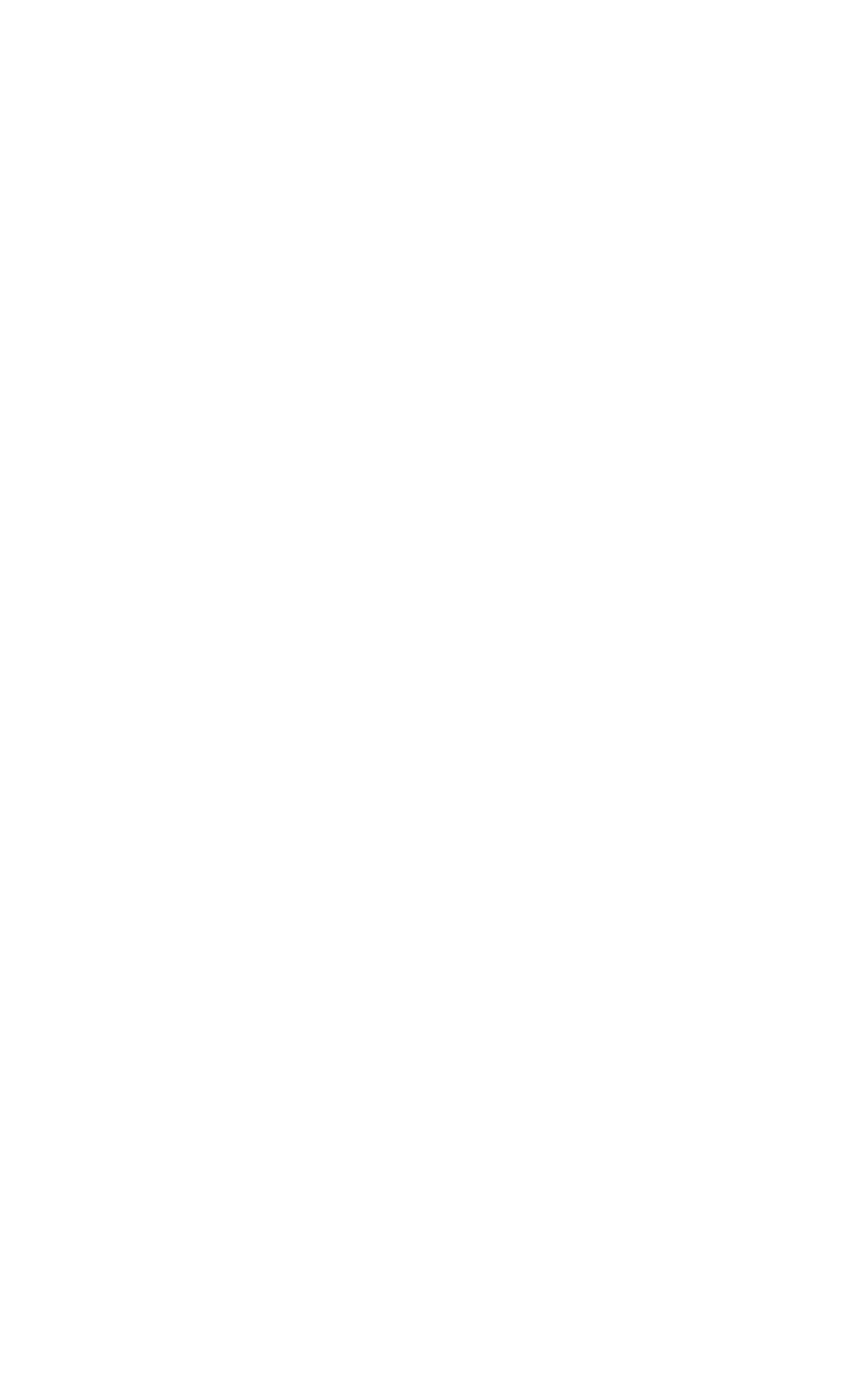
STREAMS TRIBUTARY TO LAKE ERIE--Continued

4-2122. GRAND RIVER AT PAINESVILLE, OHIO--Continued

Data from continuous recorder, December 1966 to September 1967

\begin{tabular}{|c|c|c|c|c|c|c|c|c|c|c|c|c|c|c|c|c|}
\hline \multirow{3}{*}{ Day } & \multicolumn{8}{|c|}{ DECEMBER } & \multicolumn{8}{|c|}{ JAMUARY } \\
\hline & \multicolumn{2}{|c|}{$\begin{array}{c}\text { Specific } \\
\text { conductance } \\
\text { (micromhos } \\
\text { at } 25^{\circ} \mathrm{C} \text { ) }\end{array}$} & \multicolumn{2}{|c|}{$\mathrm{pH}$} & \multicolumn{2}{|c|}{$\begin{array}{l}\text { Dissolved } \\
\text { oxygen } \\
\text { (ppm) }\end{array}$} & \multicolumn{2}{|c|}{$\begin{array}{c}\text { Temper- } \\
\text { ature } \\
\left({ }^{\circ} \mathrm{F}\right)\end{array}$} & \multicolumn{2}{|c|}{$\begin{array}{c}\text { Specific } \\
\text { conductance } \\
\text { (micromhos } \\
\left.\text { at } 25^{\circ} \mathrm{C}\right)\end{array}$} & \multicolumn{2}{|c|}{$\mathbf{p H}$} & \multicolumn{2}{|c|}{$\begin{array}{c}\text { Dissolved } \\
\text { oxygen } \\
(\text { ppm) }\end{array}$} & \multicolumn{2}{|c|}{$\begin{array}{c}\text { Temper- } \\
\text { ature } \\
\left({ }^{\circ} \mathbf{F}\right)\end{array}$} \\
\hline & Max & Min & Max & Min & Max & Min & Max & Min & Max & $\operatorname{Min}$ & Max & Min & Max & Min & Max & Min \\
\hline $\begin{array}{l}1 \ldots \\
2 \cdots \\
3 \cdots \\
4 \cdots \\
5 \cdots\end{array}$ & $\begin{array}{l}= \\
= \\
=\end{array}$ & $\begin{array}{l}= \\
= \\
=\end{array}$ & $\begin{array}{l}= \\
= \\
=\end{array}$ & $=$ & $=$ & $\begin{array}{l}= \\
=- \\
--\end{array}$ & $\begin{array}{l}= \\
= \\
=\end{array}$ & $\overline{=}$ & $\begin{array}{l}4900 \\
5000 \\
5100 \\
4600 \\
-\end{array}$ & $\begin{array}{r}4200 \\
4200 \\
4100 \\
3900 \\
-\end{array}$ & $\begin{array}{l}7.3 \\
9.1 \\
9.2 \\
8.8 \\
-.\end{array}$ & $\begin{array}{l}6.6 \\
6.6 \\
6.7 \\
6.4 \\
-.-\end{array}$ & $\begin{array}{r}12.5 \\
12.5 \\
12.7 \\
12.9 \\
-.\end{array}$ & $\begin{array}{l}12.3 \\
12.4 \\
12.5 \\
12.7 \\
-.\end{array}$ & $\begin{array}{l}39 \\
39 \\
40 \\
38 \\
-\end{array}$ & $\begin{array}{l}38 \\
38 \\
38 \\
37 \\
--\end{array}$ \\
\hline \begin{tabular}{r|}
$6 \ldots$ \\
$7 \ldots$ \\
$8 \ldots$ \\
$9 \ldots$ \\
$10 \ldots$
\end{tabular} & $=$ & $=$ & $\begin{array}{l}= \\
= \\
=\end{array}$ & $=$ & $\begin{array}{l}= \\
= \\
=\end{array}$ & $=$ & $\begin{array}{l}= \\
=\end{array}$ & $\begin{array}{l}\bar{z} \\
\bar{z}\end{array}$ & $\begin{array}{l}7000 \\
5100 \\
3900 \\
6100\end{array}$ & $\begin{array}{l}4800 \\
3500 \\
3100 \\
3300\end{array}$ & $\begin{array}{r}9.9 \\
10.2 \\
9.6 \\
9.7\end{array}$ & $\begin{array}{l}7.2 \\
7.2 \\
8.7 \\
7.7\end{array}$ & $\begin{array}{l}12.7 \\
14.1 \\
14.1 \\
13.9\end{array}$ & $\begin{array}{l}11 .- \\
12.7 \\
13.8 \\
13.7\end{array}$ & $\begin{array}{l}-2 \\
42 \\
37 \\
36\end{array}$ & $\begin{array}{l}-7 \\
37 \\
34 \\
34\end{array}$ \\
\hline $\begin{array}{l}11 \bullet \\
12 \bullet \\
13 \bullet \\
14 \ldots \\
15 \bullet\end{array}$ & $\begin{array}{l}\overline{-} \\
=\end{array}$ & $=$ & $\begin{array}{l}= \\
\bar{z} \\
=\end{array}$ & $\begin{array}{l}= \\
= \\
=\end{array}$ & $=$ & $\begin{array}{l}= \\
= \\
=\end{array}$ & $=$ & $=$ & $\begin{array}{l}6900 \\
7100 \\
7200 \\
7900 \\
7700\end{array}$ & $\begin{array}{l}4600 \\
5000 \\
5200 \\
5800 \\
6000\end{array}$ & $\begin{array}{r}10.0 \\
9.7 \\
10.0 \\
9.9 \\
9.7\end{array}$ & $\begin{array}{l}6.6 \\
7.2 \\
6.7 \\
7.4 \\
7.3\end{array}$ & $\begin{array}{l}13.8 \\
13.4 \\
12.3 \\
12.8 \\
12.1\end{array}$ & $\begin{array}{l}13.4 \\
12.2 \\
11.6 \\
11.5 \\
11.6\end{array}$ & $\begin{array}{l}37 \\
40 \\
42 \\
43 \\
41\end{array}$ & $\begin{array}{l}35 \\
37 \\
38 \\
39 \\
38\end{array}$ \\
\hline $\begin{array}{l}16 \ldots \\
17 \ldots \\
18 \ldots \\
19 . \\
20 \ldots\end{array}$ & $=$ & $=$ & $=$ & $\begin{array}{l}= \\
= \\
=\end{array}$ & $\begin{array}{l}= \\
= \\
=\end{array}$ & $=$ & $\begin{array}{l}= \\
= \\
=\end{array}$ & $=$ & $\begin{array}{l}7500 \\
7400 \\
7500 \\
7900 \\
8500\end{array}$ & $\begin{array}{l}5300 \\
5100 \\
4800 \\
5900 \\
5900\end{array}$ & $\begin{array}{r}9.8 \\
9.8 \\
10.3 \\
8.1 \\
7.8\end{array}$ & $\begin{array}{l}6.6 \\
6.5 \\
6.3 \\
6.2 \\
6.0\end{array}$ & $\begin{array}{l}12.1 \\
12.5 \\
12.5 \\
12.3 \\
12.3\end{array}$ & $\begin{array}{l}11.8 \\
11.9 \\
12.2 \\
11.6 \\
11.6\end{array}$ & $\begin{array}{l}39 \\
39 \\
38 \\
40 \\
41\end{array}$ & $\begin{array}{l}37 \\
36 \\
35 \\
37 \\
39\end{array}$ \\
\hline $\begin{array}{l}21 \ldots \\
22 \ldots \\
23 \ldots \\
24 \cdots \\
25 \cdots\end{array}$ & $\begin{array}{r}6800 \\
7200 \\
7100 \\
7700\end{array}$ & $\begin{array}{r}6000 \\
5800 \\
5600 \\
6300\end{array}$ & $\begin{array}{r}9.2 \\
10.1 \\
9.1 \\
9.8\end{array}$ & $\begin{array}{l}-. \\
8.0 \\
7.9 \\
7.7 \\
8.2\end{array}$ & $\begin{array}{r}= \\
= \\
12.9 \\
12.3\end{array}$ & $\frac{-}{12.2}$ & $\begin{array}{l}\overline{43} \\
42 \\
42 \\
41\end{array}$ & $\begin{array}{l}41 \\
40 \\
40 \\
39\end{array}$ & $\begin{array}{l}8200 \\
8500 \\
5700 \\
3100 \\
4200\end{array}$ & $\begin{array}{l}6400 \\
5700 \\
3000 \\
2400 \\
2300\end{array}$ & $\begin{array}{r}9.8 \\
10.1 \\
10.1 \\
8.4 \\
10.1\end{array}$ & $\begin{array}{l}6.2 \\
7.0 \\
7.1 \\
7.6 \\
6.5\end{array}$ & $\begin{array}{l}12.2 \\
12.2 \\
12.7 \\
12.6 \\
12.2\end{array}$ & $\begin{array}{l}11.9 \\
11.7 \\
12.1 \\
12.2 \\
11.5\end{array}$ & $\begin{array}{l}42 \\
43 \\
41 \\
39 \\
43\end{array}$ & $\begin{array}{l}39 \\
41 \\
36 \\
37 \\
39\end{array}$ \\
\hline $\begin{array}{l}26 \ldots \\
27 \ldots \\
28 \ldots \\
29 \ldots \\
30 \ldots \\
31 \ldots\end{array}$ & $\begin{array}{l}8400 \\
7800 \\
7000 \\
7500 \\
7400 \\
5700\end{array}$ & $\begin{array}{l}6600 \\
5500 \\
5200 \\
6100 \\
5300 \\
4300\end{array}$ & $\begin{array}{l}9.9 \\
9.7 \\
8.9 \\
9.4 \\
9.8 \\
9.0\end{array}$ & $\begin{array}{l}8.0 \\
7.6 \\
7.5 \\
5.8 \\
6.2 \\
6.3\end{array}$ & $\begin{array}{l}12.4 \\
12.5 \\
12.5 \\
12.3 \\
12.4 \\
12.5\end{array}$ & $\begin{array}{l}12.1 \\
12.3 \\
11.9 \\
11.8 \\
12.2 \\
12.3\end{array}$ & $\begin{array}{l}41 \\
42 \\
42 \\
42 \\
39 \\
40\end{array}$ & $\begin{array}{l}39 \\
39 \\
39 \\
38 \\
38 \\
38\end{array}$ & $\begin{array}{l}4200 \\
3800 \\
1500 \\
1900 \\
2000 \\
2300\end{array}$ & $\begin{array}{l}2700 \\
1200 \\
1300 \\
1500 \\
1600 \\
1800\end{array}$ & $\begin{array}{r}10.1 \\
9.9 \\
9.7 \\
9.7 \\
9.9 \\
10.3\end{array}$ & $\begin{array}{l}8.2 \\
8.1 \\
8.7 \\
8.7 \\
7.1 \\
8.5\end{array}$ & $\begin{array}{l}11.9 \\
12.8 \\
14.4 \\
12.2 \\
12.3 \\
12.4\end{array}$ & $\begin{array}{l}11.6 \\
11.00 \\
12.0 \\
11.9 \\
12.1 \\
12.0\end{array}$ & $\begin{array}{l}43 \\
42 \\
41 \\
38 \\
37 \\
36\end{array}$ & $\begin{array}{l}41 \\
39 \\
38 \\
36 \\
35 \\
34\end{array}$ \\
\hline \multicolumn{9}{|c|}{ FEBRUARY } & \multicolumn{8}{|c|}{ MARCH } \\
\hline $\begin{array}{l}1 \ldots \\
2 \cdots \\
3 \bullet \\
4 \cdots \\
5 \bullet\end{array}$ & $\begin{array}{l}2500 \\
1900 \\
1100 \\
1300 \\
2100\end{array}$ & $\begin{array}{r}1700 \\
900 \\
500 \\
900 \\
1300\end{array}$ & $\begin{array}{l}11.0 \\
11.2 \\
10.9 \\
11.0 \\
11.1\end{array}$ & $\begin{array}{l}9.1 \\
8.8 \\
9.0 \\
9.6 \\
9.7\end{array}$ & $\begin{array}{l}12.1 \\
13.5 \\
13.0 \\
12.5 \\
12.2\end{array}$ & $\begin{array}{r}10.3 \\
9.4 \\
12.0 \\
12.0 \\
11.9\end{array}$ & $\begin{array}{l}36 \\
36 \\
35 \\
36 \\
36\end{array}$ & $\begin{array}{r}35 \\
34 \\
34 \\
34 \\
34 \\
34\end{array}$ & $\begin{array}{l}9800 \\
9000 \\
8600 \\
7600 \\
4000\end{array}$ & $\begin{array}{l}7200 \\
4800 \\
4000 \\
2800 \\
2700\end{array}$ & $\begin{array}{l}11.7 \\
11.3 \\
11.0 \\
11.1 \\
10.7\end{array}$ & $\begin{array}{l}8.8 \\
8.2 \\
7.6 \\
8.8 \\
9.2\end{array}$ & $\begin{array}{r}9.1 \\
9.6 \\
11.4 \\
12.7 \\
12.4\end{array}$ & $\begin{array}{r}7.7 \\
7.8 \\
7.9 \\
10.5 \\
10.4\end{array}$ & $\begin{array}{l}45 \\
43 \\
44 \\
39 \\
37\end{array}$ & $\begin{array}{l}40 \\
41 \\
39 \\
36 \\
35\end{array}$ \\
\hline $\begin{array}{r}6 \ldots \\
7 \ldots \\
8 \ldots \\
9 \ldots \\
10 \ldots\end{array}$ & $\begin{array}{l}2700 \\
3600 \\
5300 \\
5300 \\
5700\end{array}$ & $\begin{array}{l}1900 \\
2400 \\
3100 \\
3900 \\
3300\end{array}$ & $\begin{array}{l}11.3 \\
11.5 \\
11.4 \\
11.5 \\
11.3\end{array}$ & $\begin{array}{l}9.9 \\
9.2 \\
9.4 \\
9.0 \\
9.2\end{array}$ & $\begin{array}{l}12.3 \\
11.9 \\
10.5 \\
10.8 \\
11.0\end{array}$ & $\begin{array}{r}10.3 \\
9.5 \\
8.8 \\
8.2 \\
7.8\end{array}$ & $\begin{array}{l}34 \\
35 \\
38 \\
40 \\
39\end{array}$ & $\begin{array}{l}34 \\
34 \\
34 \\
37 \\
37\end{array}$ & $\begin{array}{l}2800 \\
2500 \\
2100 \\
2400 \\
2400\end{array}$ & $\begin{array}{l}1800 \\
1560 \\
1600 \\
1800 \\
1000\end{array}$ & $\begin{array}{l}10.4 \\
11.2 \\
10.7 \\
11.2 \\
10.4\end{array}$ & $\begin{array}{l}8.9 \\
9.3 \\
8.8 \\
9.1 \\
8.7\end{array}$ & $\begin{array}{l}12.8 \\
13.1 \\
13.1 \\
13.0 \\
12.7\end{array}$ & $\begin{array}{l}10.9 \\
11.6 \\
12.7 \\
12.4 \\
10.4\end{array}$ & $\begin{array}{l}36 \\
37 \\
36 \\
38 \\
38\end{array}$ & $\begin{array}{l}34 \\
35 \\
35 \\
35 \\
35\end{array}$ \\
\hline $\begin{array}{l}12 \ldots \\
13 \ldots \\
14 \ldots \\
15 \ldots\end{array}$ & $\begin{array}{l}6500 \\
5600 \\
6000 \\
5900 \\
5200\end{array}$ & $\begin{array}{l}4700 \\
4600 \\
4600 \\
4400 \\
2800\end{array}$ & $\begin{array}{r}11.7 \\
10.6 \\
9.6 \\
10.2 \\
11.2\end{array}$ & $\begin{array}{l}9.2 \\
9.0 \\
8.4 \\
8.4 \\
8.8\end{array}$ & $\begin{array}{l}10.8 \\
10.4 \\
10.2 \\
10.9 \\
11.7\end{array}$ & $\begin{array}{l}9.0 \\
8.8 \\
9.4 \\
8.4 \\
9.2\end{array}$ & $\begin{array}{l}39 \\
43 \\
42 \\
43 \\
40\end{array}$ & $\begin{array}{l}38 \\
37 \\
1 \\
39 \\
39 \\
136 \\
\end{array}$ & $\begin{array}{l}1400 \\
1050 \\
1200 \\
1250 \\
1700\end{array}$ & $\begin{array}{l}900 \\
550 \\
700 \\
900 \\
900\end{array}$ & $\begin{array}{l}10.4 \\
10.8 \\
10.8 \\
10.2 \\
10.7\end{array}$ & $\begin{array}{l}8.8 \\
8.7 \\
8.6 \\
0.8 \\
8.9\end{array}$ & $\begin{array}{l}12.1 \\
12.2 \\
11.9 \\
11.5 \\
11.9\end{array}$ & $\begin{array}{r}10.3 \\
10.4 \\
10.9 \\
10.7 \\
9.9\end{array}$ & $\begin{array}{l}38 \\
44 \\
41 \\
41 \\
41\end{array}$ & $\begin{array}{l}37 \\
36 \\
37 \\
39 \\
38\end{array}$ \\
\hline $\begin{array}{l}16 \ldots \\
17 \ldots \\
18 \ldots \\
19 \ldots \\
20 \ldots\end{array}$ & $\begin{array}{l}2800 \\
1400 \\
2100 \\
2600 \\
3500\end{array}$ & $\begin{array}{l}1200 \\
1200 \\
1200 \\
1700 \\
2100\end{array}$ & $\begin{array}{l}10.6 \\
10.4 \\
10.7 \\
10.9 \\
10.3\end{array}$ & $\begin{array}{l}9.4 \\
8.8 \\
9.2 \\
9.2 \\
9.1\end{array}$ & $\begin{array}{l}12.3 \\
12.4 \\
12.4 \\
12.4 \\
12.2\end{array}$ & $\begin{array}{l}11.0 \\
11.5 \\
12.1 \\
12.1 \\
11.9\end{array}$ & $\begin{array}{l}37 \\
35 \\
36 \\
36 \\
37\end{array}$ & $\begin{array}{l}33 \\
34 \\
34 \\
35 \\
36\end{array}$ & $\begin{array}{l}2200 \\
3200 \\
3500 \\
4400 \\
4300\end{array}$ & $\begin{array}{l}1600 \\
2000 \\
2400 \\
2700 \\
1800\end{array}$ & $\begin{array}{l}11.3 \\
11.0 \\
10.7 \\
10.2 \\
10.2\end{array}$ & $\begin{array}{l}8.6 \\
8.8 \\
8.4 \\
8.2 \\
7.9\end{array}$ & $\begin{array}{l}12.2 \\
11.9 \\
12.5 \\
12.2 \\
11.9\end{array}$ & $\begin{array}{r}9.0 \\
9.2 \\
9.5 \\
10.1 \\
9.6\end{array}$ & $\begin{array}{l}41 \\
40 \\
40 \\
40 \\
42\end{array}$ & $\begin{array}{l}37 \\
37 \\
35 \\
36 \\
38\end{array}$ \\
\hline $\begin{array}{l}21 \ldots \\
22 \cdots \\
23 \cdots \\
24 \ldots \\
25 \ldots\end{array}$ & $\begin{array}{l}4800 \\
5600 \\
5600 \\
6600 \\
8600\end{array}$ & $\begin{array}{l}2400 \\
4200 \\
4400 \\
4600 \\
4500\end{array}$ & $\begin{array}{l}11.1 \\
11.4 \\
11.3 \\
11.5 \\
11.8\end{array}$ & $\begin{array}{l}9.3 \\
9.2 \\
9.3 \\
9.1 \\
9.7\end{array}$ & $\begin{array}{l}12.0 \\
12.0 \\
11.6 \\
11.6 \\
10.3\end{array}$ & $\begin{array}{r}10.5 \\
7.4 \\
8.4 \\
7.9 \\
7.8\end{array}$ & $\begin{array}{l}37 \\
39 \\
38 \\
40 \\
42\end{array}$ & $\begin{array}{l}35 \\
36 \\
36 \\
38 \\
37\end{array}$ & $\begin{array}{l}7200 \\
3000 \\
1700 \\
1750 \\
1800\end{array}$ & $\begin{array}{r}2000 \\
1200 \\
1200 \\
1400 \\
700\end{array}$ & $\begin{array}{l}9.5 \\
9.3 \\
9.3 \\
9.3 \\
9.2\end{array}$ & $\begin{array}{l}7.8 \\
7.6 \\
7.3 \\
7.7 \\
7.6\end{array}$ & $\begin{array}{r}12.0 \\
12.2 \\
14 \cdot 0 \\
8.9 \\
10.1\end{array}$ & $\begin{array}{l}9.9 \\
9.9 \\
7.0 \\
6.7 \\
6.3\end{array}$ & $\begin{array}{l}41 \\
38 \\
37 \\
40 \\
42\end{array}$ & $\begin{array}{l}37 \\
36 \\
36 \\
36 \\
37\end{array}$ \\
\hline $\begin{array}{l}26 \ldots \\
27 \ldots \\
28 \ldots \\
29 \ldots \\
30 \ldots \\
31 \ldots\end{array}$ & $\begin{array}{r}8800 \\
7200 \\
14400 \\
= \\
=\end{array}$ & $\begin{array}{r}6000 \\
5000 \\
4700 \\
-- \\
-\end{array}$ & $\begin{array}{r}11.4 \\
11.3 \\
11.6 \\
- \\
- \\
-\end{array}$ & $\begin{array}{r}8.9 \\
8.5 \\
8.7 \\
-- \\
=-\end{array}$ & $\begin{array}{r}10.1 \\
10.8 \\
10.8 \\
-- \\
--\end{array}$ & $\begin{array}{r}7.7 \\
8.0 \\
7.6 \\
= \\
=-\end{array}$ & $\begin{array}{l}41 \\
42 \\
43 \\
-- \\
--\end{array}$ & $\begin{array}{l}30 \\
39 \\
40 \\
-- \\
-\end{array}$ & $\begin{array}{l}1200 \\
2100 \\
2400 \\
1600 \\
1800 \\
2400\end{array}$ & $\begin{array}{r}1000 \\
1000 \\
1400 \\
800 \\
900 \\
1800\end{array}$ & $\begin{array}{r}8.6 \\
10.0 \\
9.2 \\
9.1 \\
8.9 \\
11.0\end{array}$ & $\begin{array}{l}7.6 \\
7.7 \\
7.7 \\
7.7 \\
7.3 \\
7.7\end{array}$ & $\begin{array}{r}9.1 \\
= \\
= \\
=\end{array}$ & $\begin{array}{r}5.9 \\
= \\
= \\
=\end{array}$ & $\begin{array}{l}46 \\
48 \\
48 \\
48 \\
51 \\
54\end{array}$ & $\begin{array}{l}40 \\
44 \\
46 \\
45 \\
44 \\
49\end{array}$ \\
\hline
\end{tabular}


STREAMS TRIBUTARY TO LAKE ERIE--COntinued

4-2122. GRAND RIVER AT PAINESVILLE, OHIO--Continued

Data from continuous recorder, December 1966 to september 1967--Continued

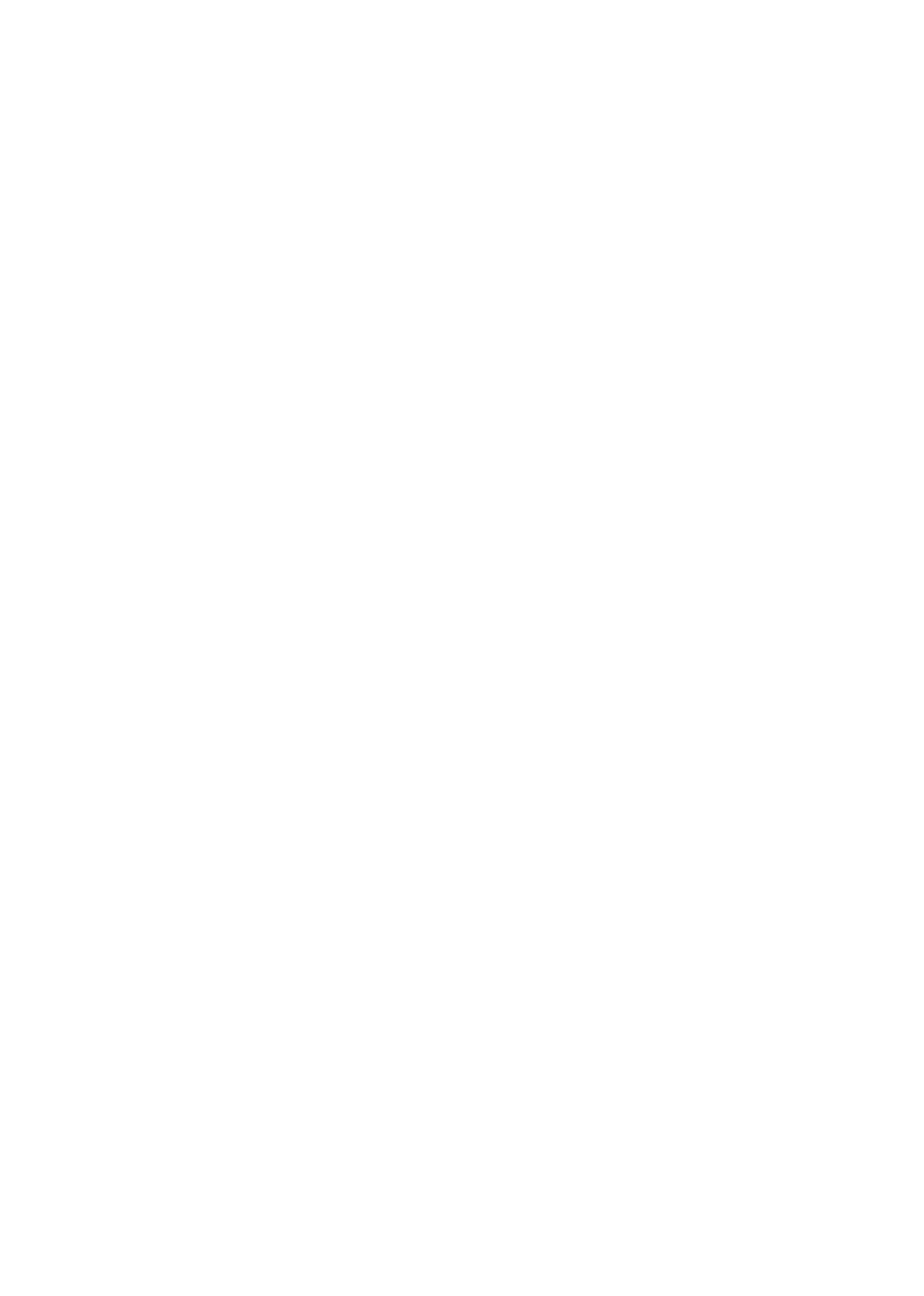


STREAMS TRIBUTARY TO LAKE ERIE--ContInued

4-2122. GRAND RIVER AT PAINESVILLE, OHIO--Continued

Data from continuous recorder, December 1966 to September 1967--Continued

\begin{tabular}{|c|c|c|c|c|c|c|c|c|c|c|c|c|c|c|c|c|}
\hline \multirow{3}{*}{ Day } & \multicolumn{8}{|c|}{ AUGUST } & \multicolumn{8}{|c|}{ SEPTEMEER } \\
\hline & \multicolumn{2}{|c|}{$\begin{array}{c}\text { Specific } \\
\text { conductance } \\
\text { (micromhos } \\
\text { at } 25^{\circ} \mathrm{C} \text { ) }\end{array}$} & \multicolumn{2}{|c|}{ pH } & \multicolumn{2}{|c|}{$\begin{array}{c}\text { Dissolved } \\
\text { oxygen } \\
\text { (ppm) }\end{array}$} & \multicolumn{2}{|c|}{$\begin{array}{c}\text { Temper- } \\
\text { ature } \\
\left({ }^{\circ} \mathbf{F}\right)\end{array}$} & \multicolumn{2}{|c|}{$\begin{array}{c}\text { Specific } \\
\text { conductance } \\
\text { (micromhos } \\
\text { at } 25^{\circ} \mathrm{C} \text { ) }\end{array}$} & \multicolumn{2}{|c|}{ pH } & \multicolumn{2}{|c|}{$\begin{array}{l}\text { Dissolved } \\
\text { oxygen } \\
\text { (ppm) }\end{array}$} & \multicolumn{2}{|c|}{$\begin{array}{c}\text { Temper- } \\
\text { ature } \\
\left({ }^{\circ} \mathrm{F}\right)\end{array}$} \\
\hline & Max & $\operatorname{Min}$ & Max & Min & $\operatorname{Max}$ & Min & $\operatorname{Max}$ & Min & Max & Min & $\operatorname{Max}$ & Min & Mav & Min & $\operatorname{Max}$ & Min \\
\hline $\begin{array}{l}1 \ldots \\
2 \cdots \\
3 \cdots \\
5 \cdots \\
5 \cdots\end{array}$ & $\bar{z}$ & $=$ & $\bar{z}$ & $\vec{m}=$ & $=$ & $\bar{z}$ & $=$ & $\bar{z}$ & $\begin{array}{r}10600 \\
8200 \\
9300 \\
9700\end{array}$ & $\begin{array}{l}8500 \\
-- \\
5000 \\
7900 \\
0400\end{array}$ & $=$ & $=$ & $\begin{array}{l}1.9 \\
3.3 \\
3.1 \\
3.6 \\
4.5\end{array}$ & $\begin{array}{l}: 0 \\
1.7 \\
2.0 \\
2.1 \\
1.4\end{array}$ & $\begin{array}{l}82 \\
82 \\
82 \\
84 \\
84\end{array}$ & $\begin{array}{l}79 \\
78 \\
79 \\
80 \\
81\end{array}$ \\
\hline $\begin{array}{r}6 \ldots \\
7 \ldots \\
8 \ldots \\
9 \ldots \\
10 \ldots\end{array}$ & $\begin{array}{r}= \\
10400 \\
20500\end{array}$ & $\begin{array}{r}= \\
= \\
9000 \\
10400\end{array}$ & $\begin{array}{l}\overline{-} \\
0.2 \\
8.4\end{array}$ & $\begin{array}{l}\bar{z} \\
7.9 \\
8.0\end{array}$ & $\begin{array}{l}\bar{z} \\
6.0 \\
6.1\end{array}$ & $\begin{array}{l}= \\
4.5 \\
4.3\end{array}$ & $\begin{array}{l}\overline{-} \\
\frac{83}{85}\end{array}$ & $\bar{z}=$ & $\begin{array}{r}700 \\
8800 \\
10000 \\
-\end{array}$ & $\begin{array}{r}6000 \\
6800 \\
7900 \\
= \\
=\end{array}$ & $=$ & $=$ & $\begin{array}{l}4.4 \\
3.3 \\
1.9 \\
2.6 \\
2.1\end{array}$ & $\begin{array}{l}2.5 \\
1.7 \\
1.5 \\
1.6 \\
1.8\end{array}$ & $\begin{array}{l}84 \\
85 \\
89 \\
87 \\
81\end{array}$ & $\begin{array}{l}81 \\
81 \\
84 \\
81 \\
77\end{array}$ \\
\hline $\begin{array}{l}11 \ldots \\
12 \ldots \\
13 \ldots \\
14 \ldots \\
15 \ldots\end{array}$ & $\begin{array}{r}19100 \\
8600 \\
9900 \\
12000 \\
12400\end{array}$ & $\begin{array}{r}7400 \\
7400 \\
7900 \\
9800 \\
10400\end{array}$ & $\begin{array}{l}8.4 \\
8.3 \\
8.1 \\
8.0 \\
8.1\end{array}$ & $\begin{array}{l}8.2 \\
8.1 \\
7.7 \\
4.5 \\
7.7\end{array}$ & $\begin{array}{l}6.6 \\
6.3 \\
5.2 \\
=\end{array}$ & $\begin{array}{l}6.0 \\
4.2 \\
2.0 \\
=\end{array}$ & $\begin{array}{l}83 \\
84 \\
85 \\
85 \\
87\end{array}$ & $\begin{array}{l}78 \\
80 \\
81 \\
82 \\
82\end{array}$ & $\begin{array}{r}9900 \\
12200 \\
13600 \\
14100 \\
13200\end{array}$ & $\begin{array}{l}5900 \\
9800 \\
9000 \\
9400 \\
9600\end{array}$ & $=$ & $=$ & $\begin{array}{l}2.1 \\
5.3 \\
3.7 \\
2.4 \\
8.3\end{array}$ & $\begin{array}{l}1.8 \\
2.0 \\
2.1 \\
2.1 \\
2.2\end{array}$ & $\begin{array}{l}81 \\
82 \\
81 \\
81 \\
83\end{array}$ & $\begin{array}{l}77 \\
76 \\
73 \\
76 \\
77\end{array}$ \\
\hline $\begin{array}{l}16 \bullet \\
17 \bullet \\
18 \cdots \\
19 \bullet \\
20 \cdots\end{array}$ & $\begin{array}{r}14500 \\
= \\
16000 \\
17700\end{array}$ & $\begin{array}{r}10900 \\
12800 \\
9500\end{array}$ & $\begin{array}{l}8.1 \\
8.2 \\
7.9 \\
8.1 \\
8.1\end{array}$ & $\begin{array}{l}7.7 \\
7.7 \\
7.6 \\
7.7 \\
7.7\end{array}$ & $\bar{z}$ & $\bar{z}$ & $\begin{array}{l}87 \\
87 \\
88 \\
87 \\
87\end{array}$ & $\begin{array}{l}83 \\
84 \\
85 \\
84 \\
81\end{array}$ & $\begin{array}{l}13800 \\
13500 \\
13400 \\
13300 \\
12300\end{array}$ & $\begin{array}{r}9200 \\
10000 \\
9400 \\
7500 \\
9400\end{array}$ & $\overline{=}$ & $\bar{E}$ & $\begin{array}{l}7.9 \\
5.8 \\
4.7 \\
5.2 \\
5.9\end{array}$ & $\begin{array}{l}2.3 \\
3.6 \\
2.7 \\
2.9 \\
3.1\end{array}$ & $\begin{array}{l}83 \\
83 \\
83 \\
83 \\
85\end{array}$ & $\begin{array}{l}76 \\
79 \\
79 \\
79 \\
82\end{array}$ \\
\hline $\begin{array}{l}21 \ldots \\
22 \ldots \\
23 \cdots \\
24 \ldots \\
25 \cdots\end{array}$ & $\begin{array}{r}9900 \\
9300 \\
= \\
9600\end{array}$ & $\begin{array}{r}8300 \\
7900 \\
= \\
1600\end{array}$ & $\begin{array}{l}8.1 \\
8.4 \\
8.2 \\
8.3 \\
8.2\end{array}$ & $\begin{array}{l}8.0 \\
8.0 \\
8.0 \\
8.0 \\
8.0\end{array}$ & $\bar{z}$ & $=$ & $\begin{array}{l}83 \\
82 \\
81 \\
82 \\
83\end{array}$ & $\begin{array}{l}79 \\
78 \\
78 \\
79 \\
81\end{array}$ & $\begin{array}{r}15900 \\
19300 \\
11100\end{array}$ & $\begin{array}{r}11800 \\
14000 \\
= \\
7800\end{array}$ & $\begin{array}{l}10.3 \\
10.4 \\
10.3 \\
10.2 \\
10.3\end{array}$ & $\begin{array}{r}10.1 \\
10.2 \\
9.9 \\
10.1 \\
9.8\end{array}$ & $\begin{array}{l}4.2 \\
5.1 \\
5.1 \\
=\end{array}$ & $\begin{array}{l}2.0 \\
2.4 \\
2.3 \\
=\end{array}$ & $\begin{array}{l}84 \\
79 \\
76 \\
75 \\
76\end{array}$ & $\begin{array}{l}77 \\
72 \\
70 \\
73 \\
72\end{array}$ \\
\hline $\begin{array}{l}26 \cdots \\
27 \cdots \\
28 \cdots \\
29 \cdots \\
30 \cdots \\
31 \cdots\end{array}$ & $\begin{array}{r}11700 \\
14000 \\
13700 \\
13000 \\
10400\end{array}$ & $\begin{array}{r}9400 \\
10100 \\
11000 \\
8600 \\
5100\end{array}$ & $\begin{array}{l}8.4 \\
= \\
=\end{array}$ & $\begin{array}{l}8.1 \\
= \\
= \\
=\end{array}$ & $\begin{array}{l}5.6 \\
4.3 \\
3.3 \\
1.9 \\
2.1 \\
3.1\end{array}$ & $\begin{array}{r}3.3 \\
2.5 \\
1.4 \\
.7 \\
.7 \\
.8\end{array}$ & $\begin{array}{l}84 \\
84 \\
81 \\
84 \\
83 \\
81\end{array}$ & $\begin{array}{l}81 \\
81 \\
78 \\
78 \\
81 \\
77\end{array}$ & $\begin{array}{r}9700 \\
11000 \\
15400 \\
15400 \\
3900 \\
-\end{array}$ & $\begin{array}{r}7700 \\
9600 \\
9700 \\
3400 \\
3000 \\
-0\end{array}$ & $\begin{array}{r}10.4 \\
10.4 \\
8.8 \\
8.9 \\
8.8 \\
-\end{array}$ & $\begin{array}{l}9.7 \\
8.6 \\
8.6 \\
8.6 \\
8.6 \\
\end{array}$ & $\begin{array}{l}4.5 \\
4.2 \\
6.8 \\
7.0 \\
-.0\end{array}$ & $\begin{array}{l}3.5 \\
3.3 \\
4.2 \\
6.6 \\
-\end{array}$ & $\begin{array}{l}79 \\
79 \\
75 \\
69 \\
59 \\
-\end{array}$ & $\begin{array}{l}73 \\
74 \\
69 \\
58 \\
57 \\
\end{array}$ \\
\hline
\end{tabular}



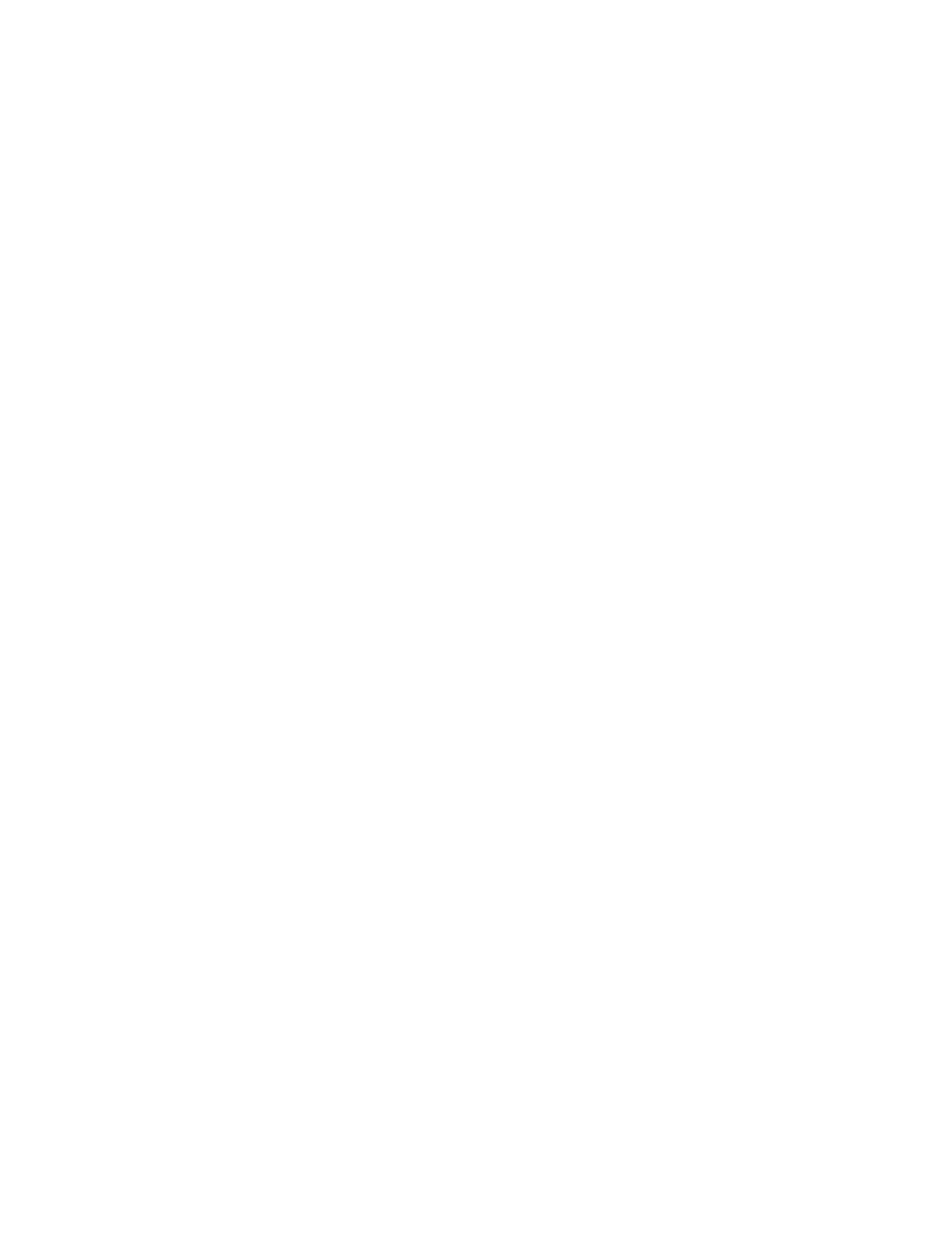


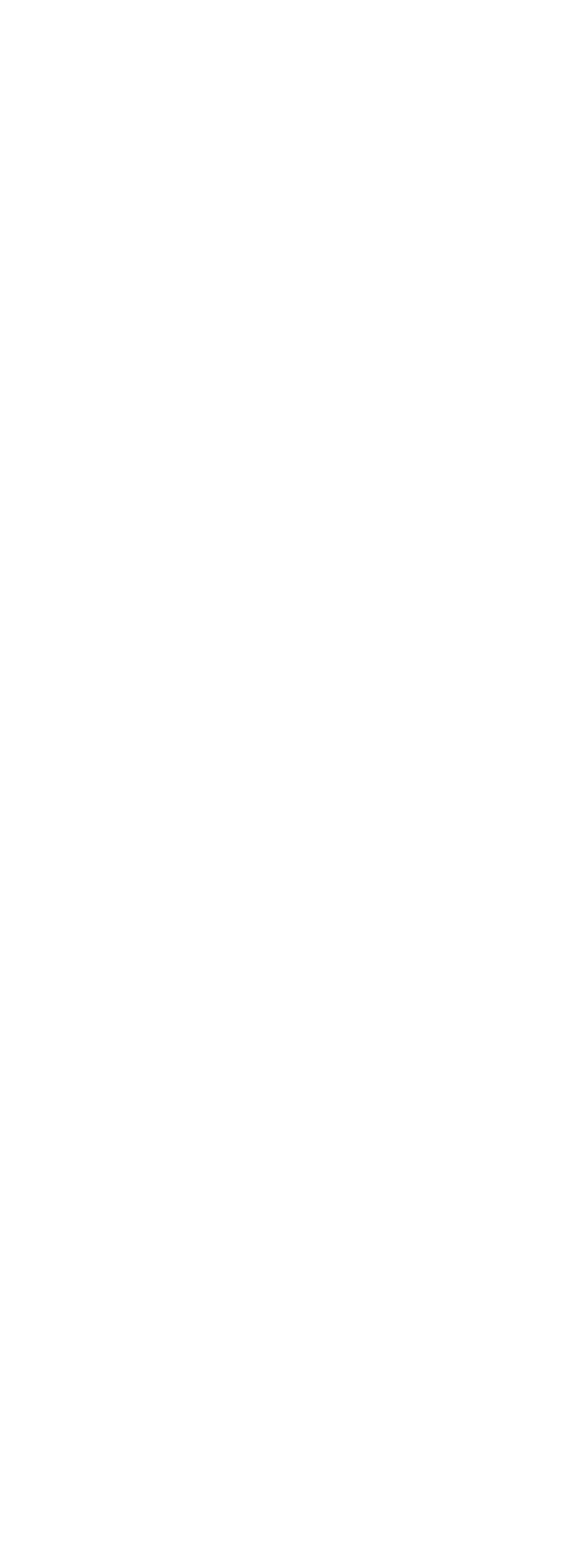




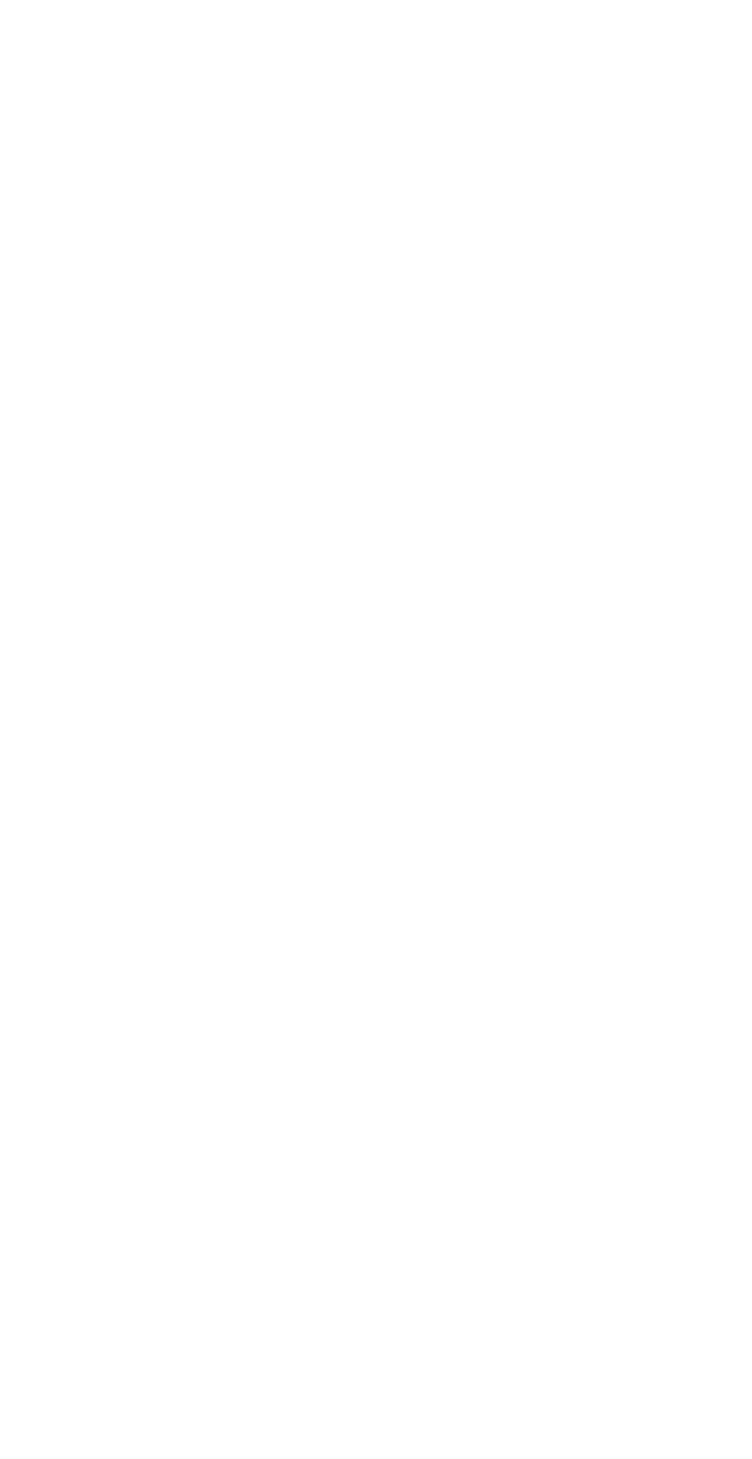




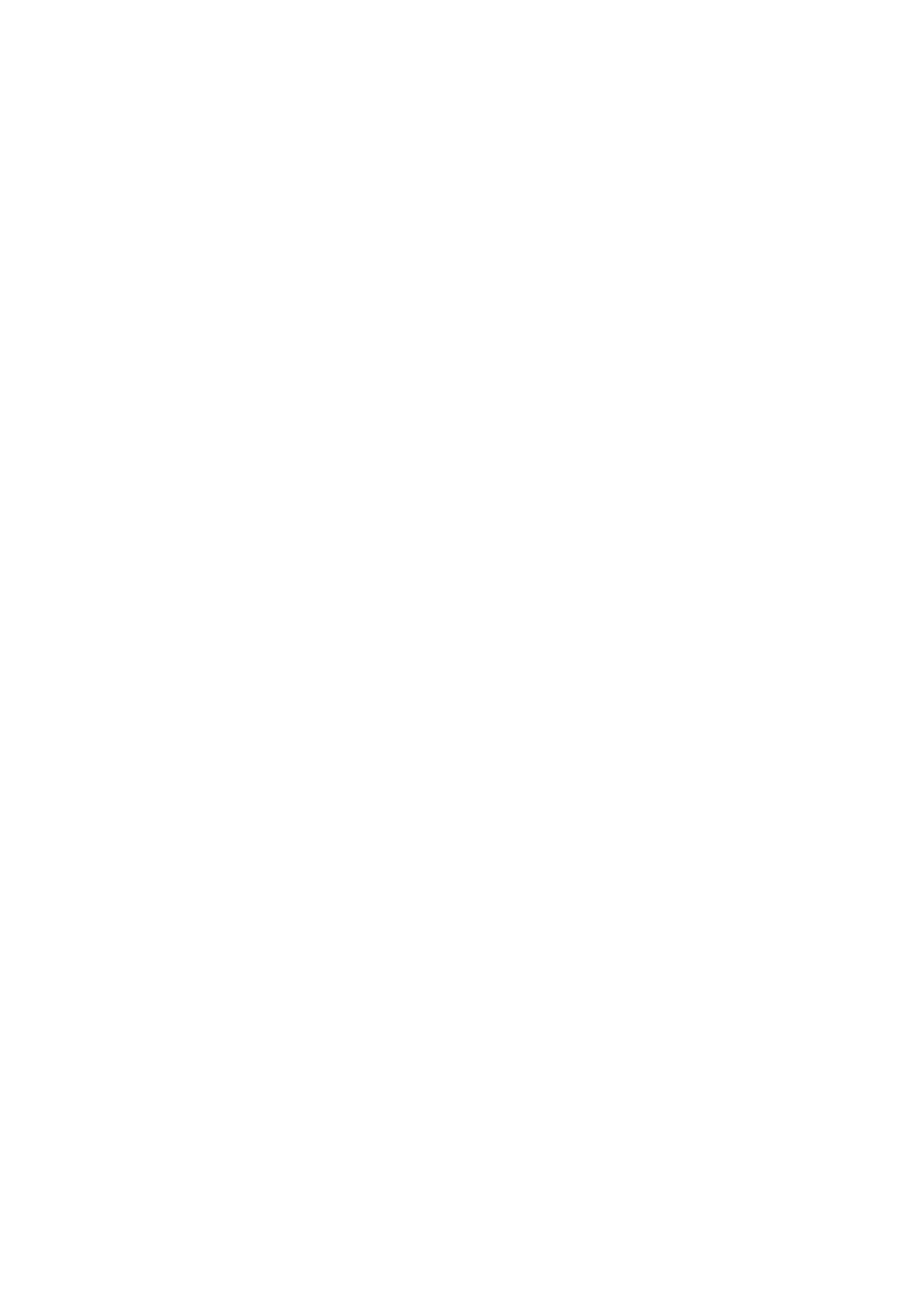




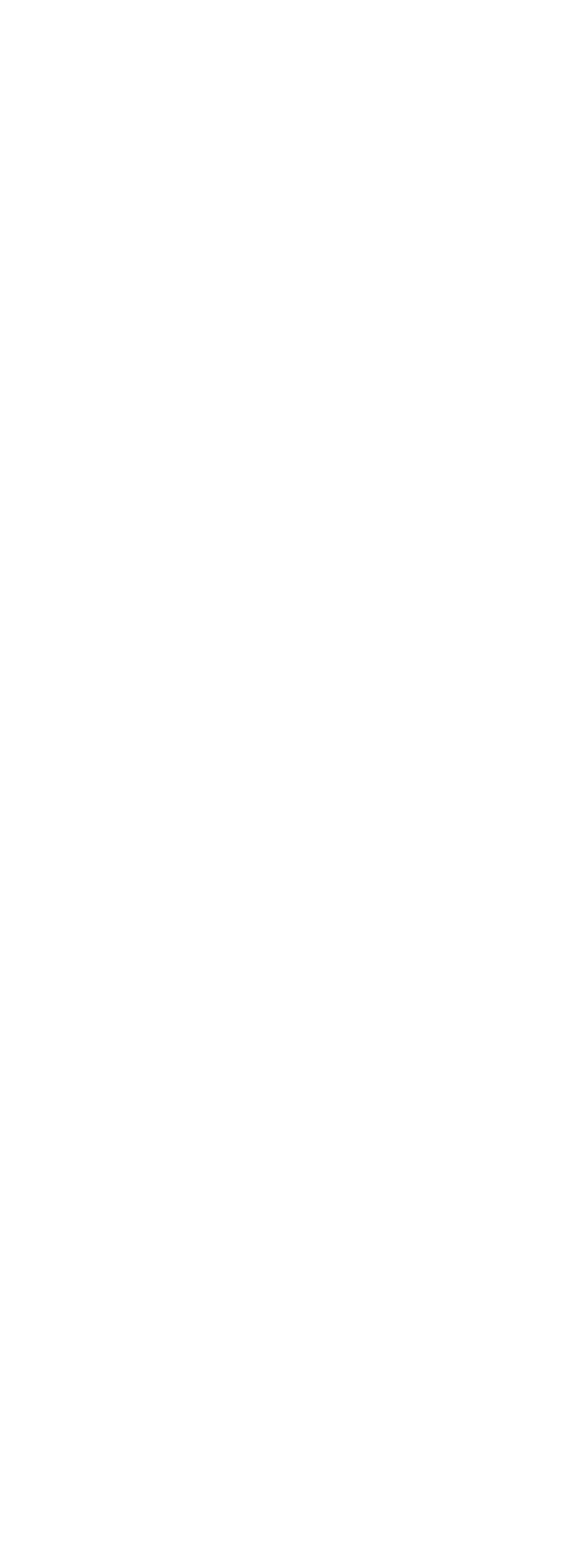




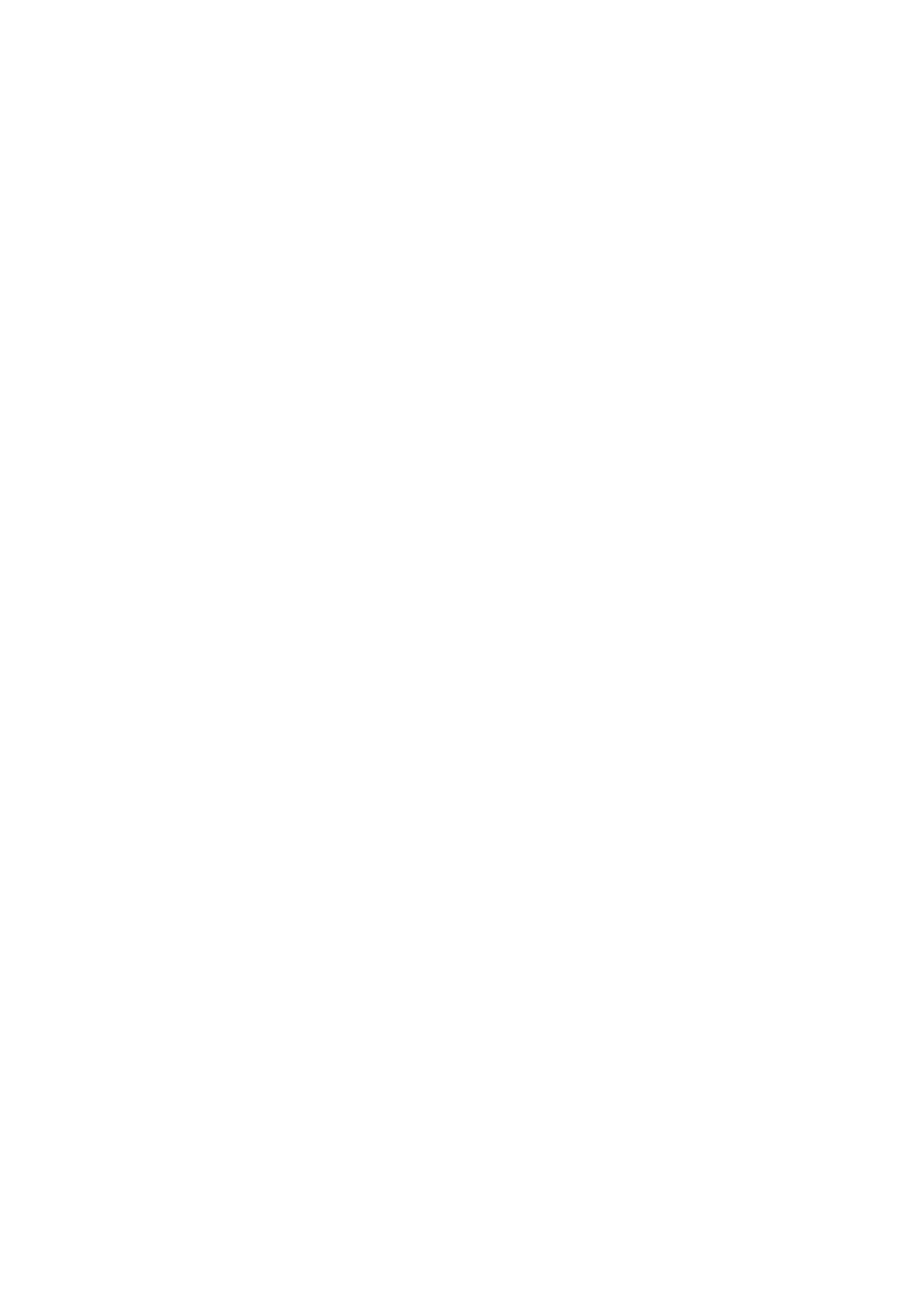




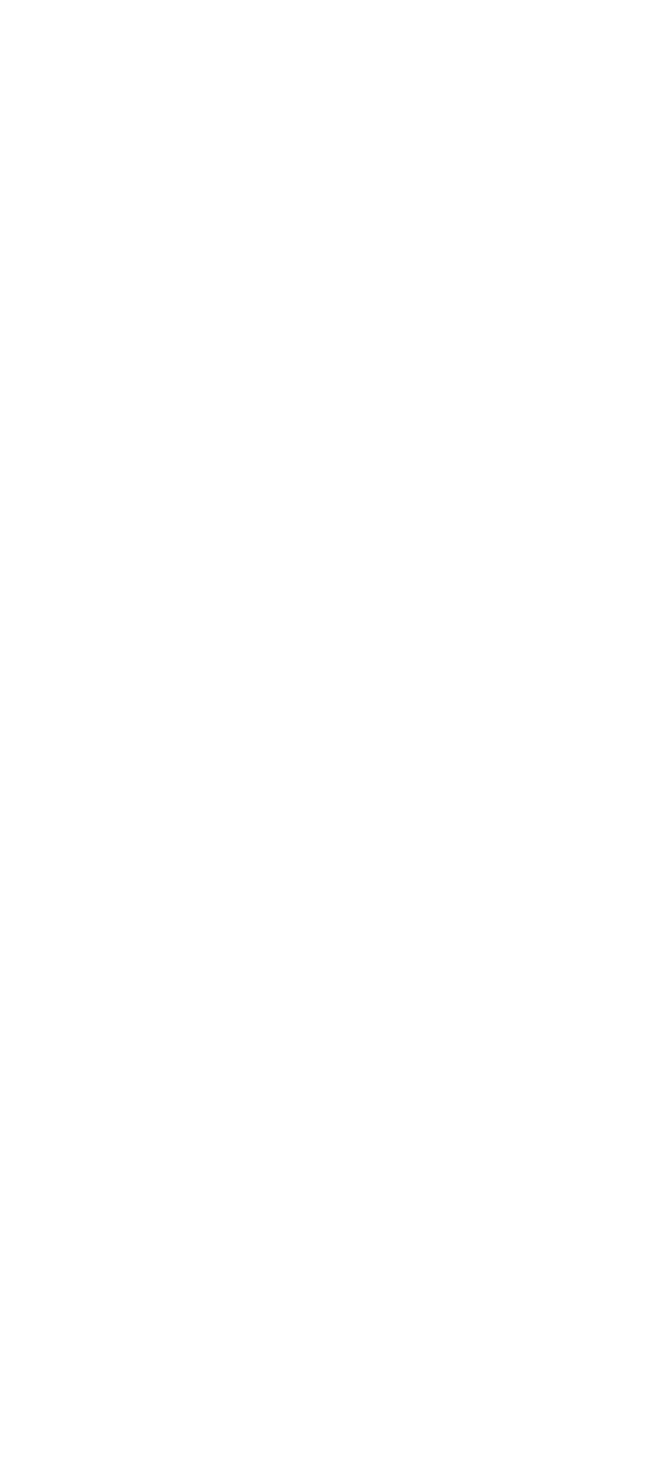




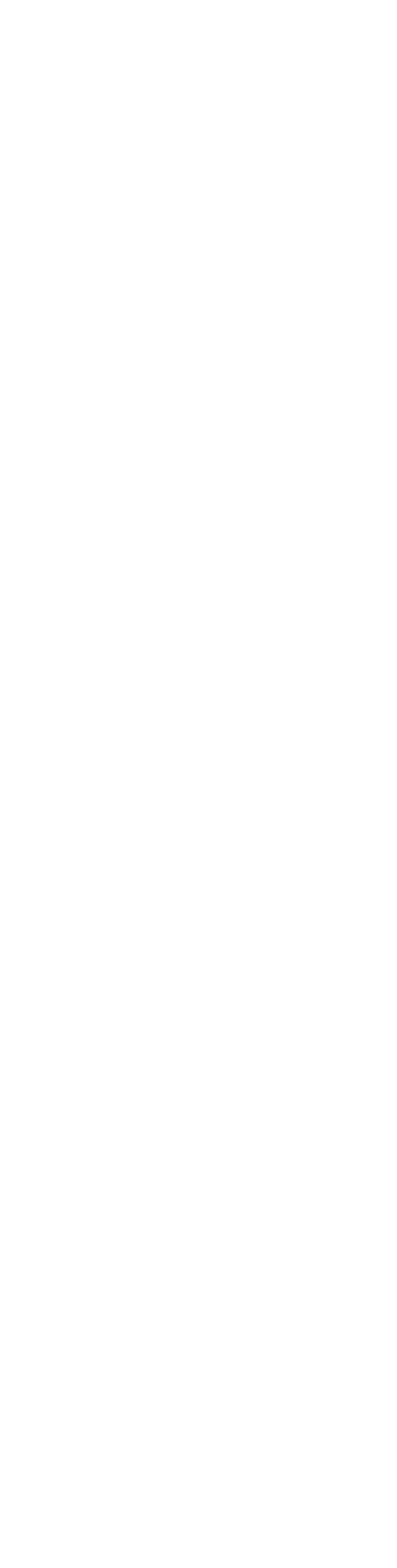




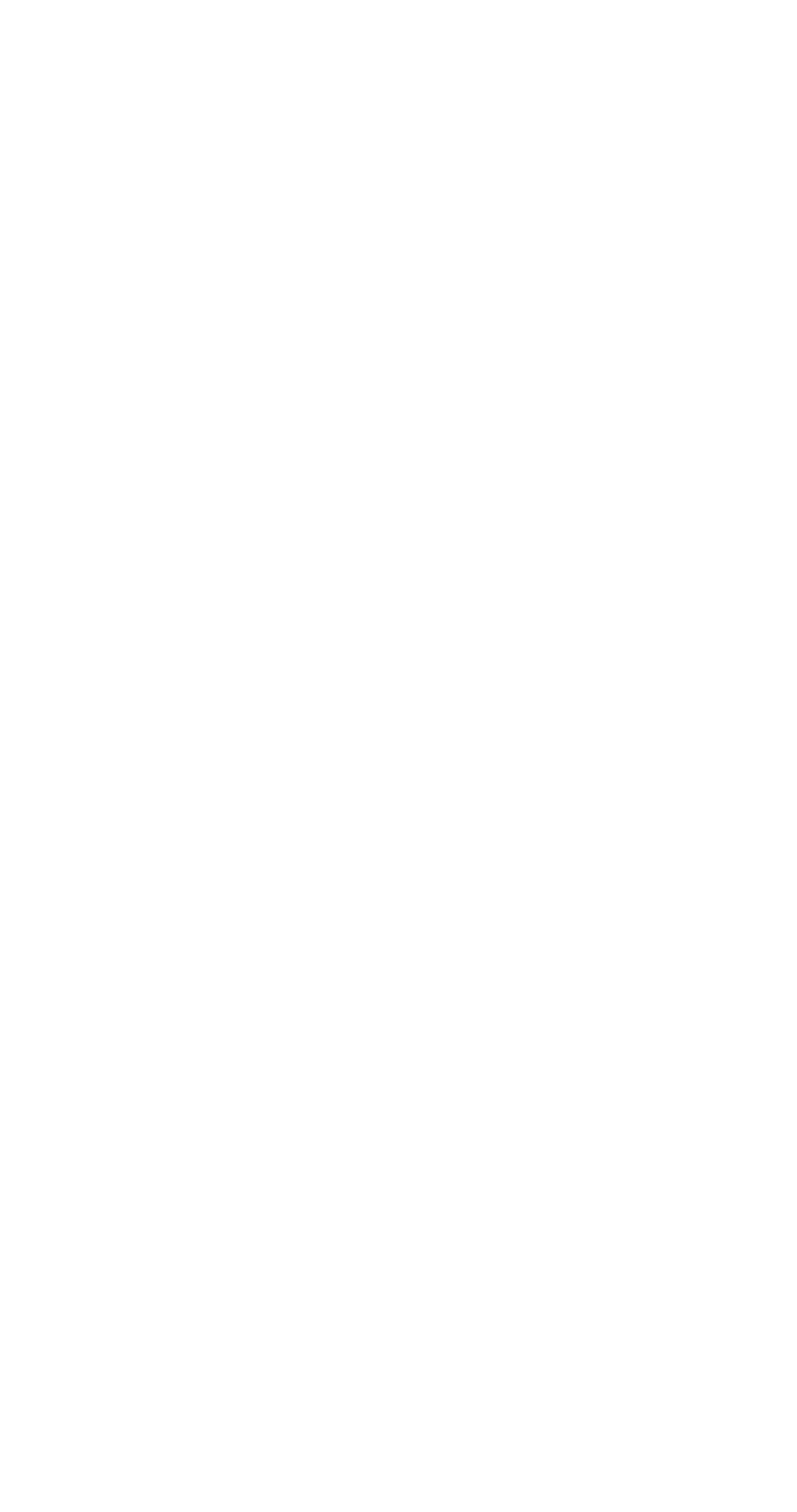




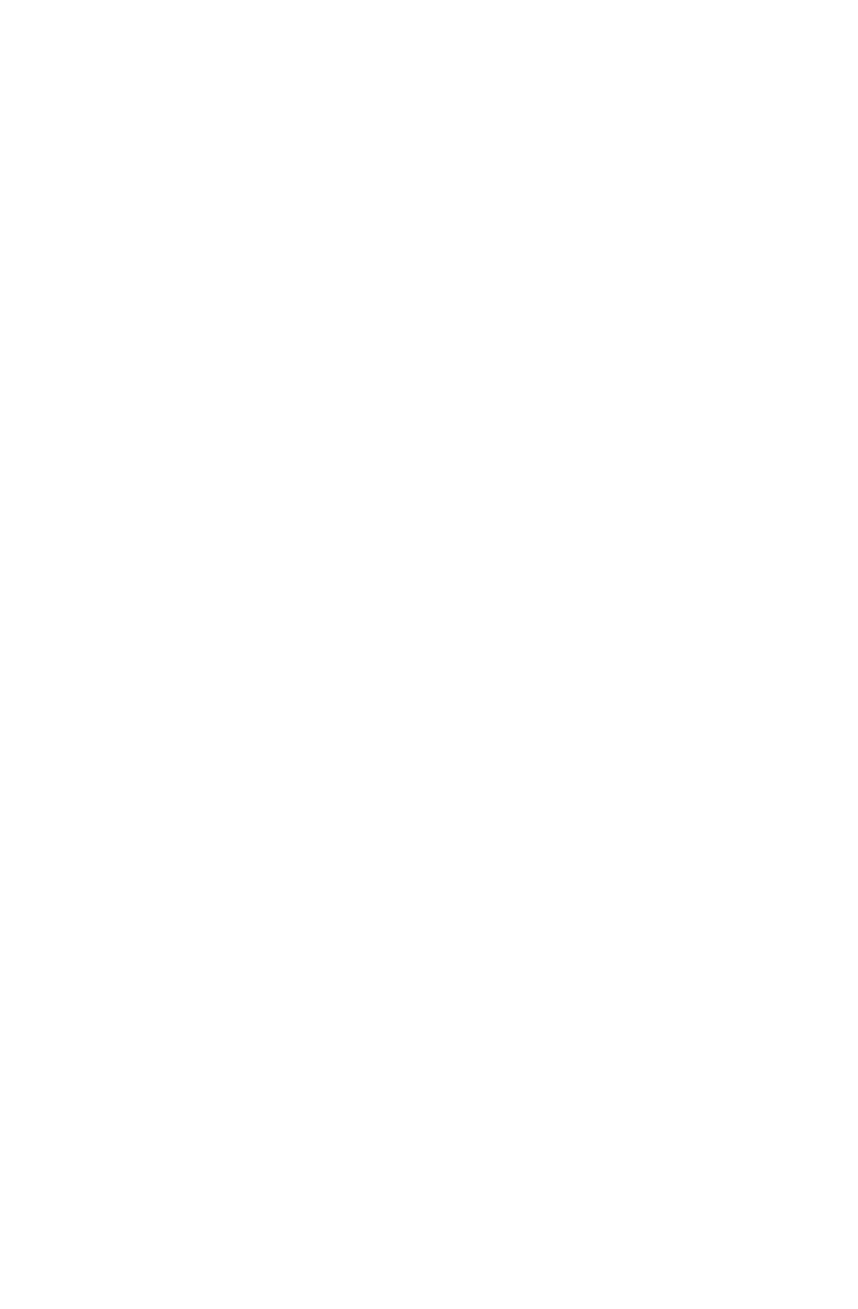




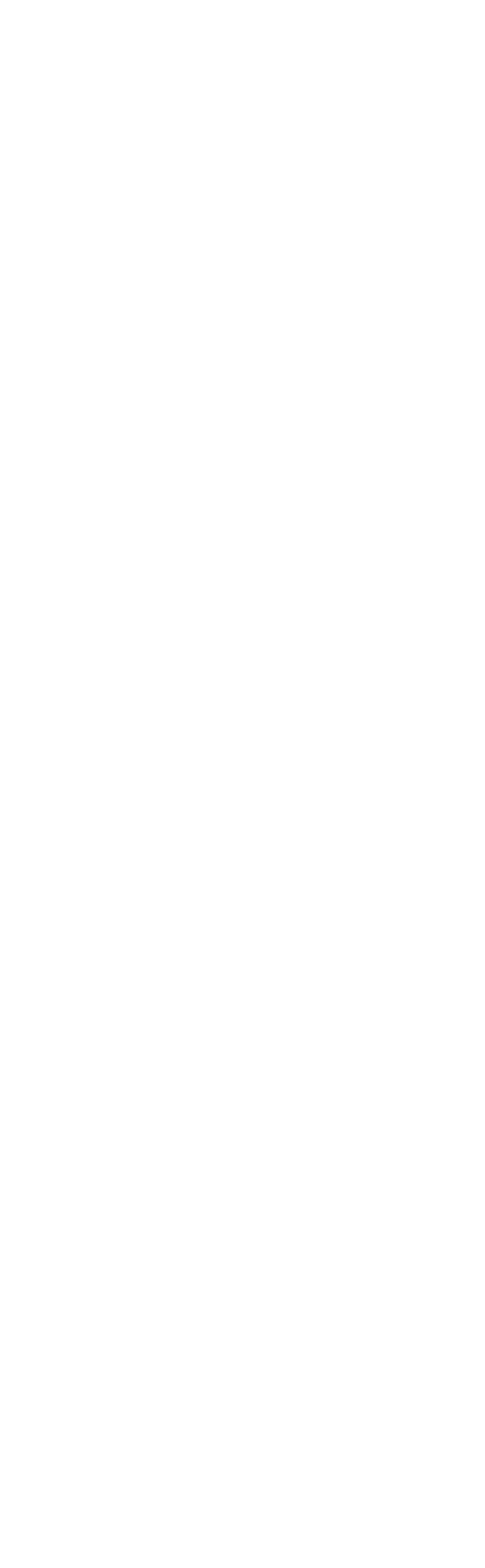




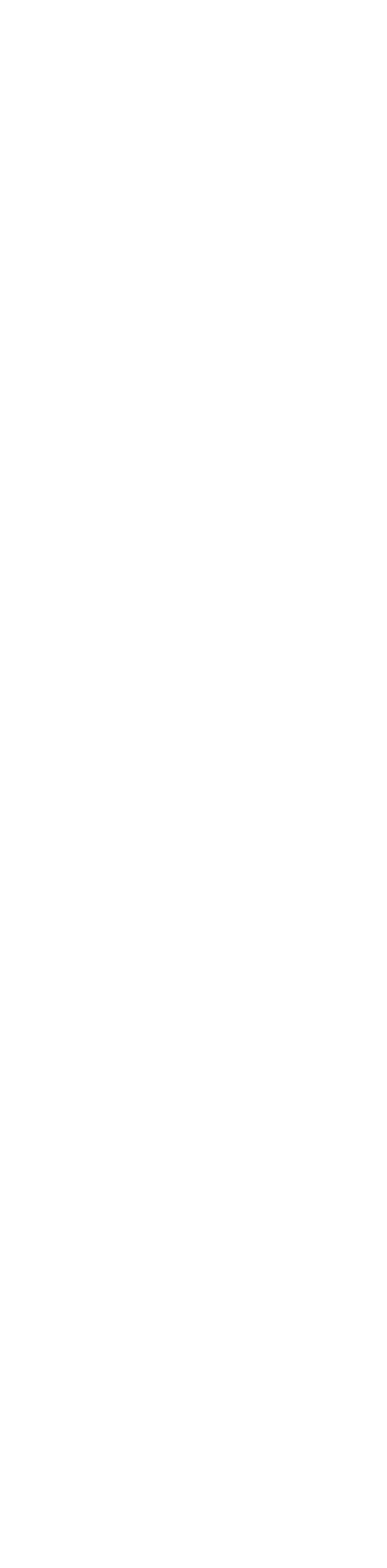




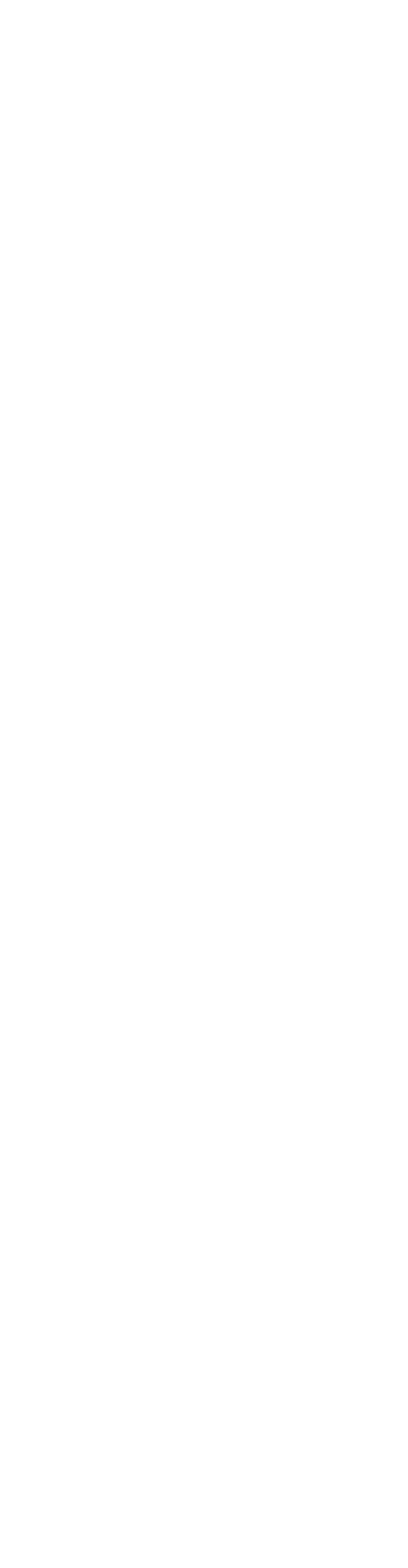




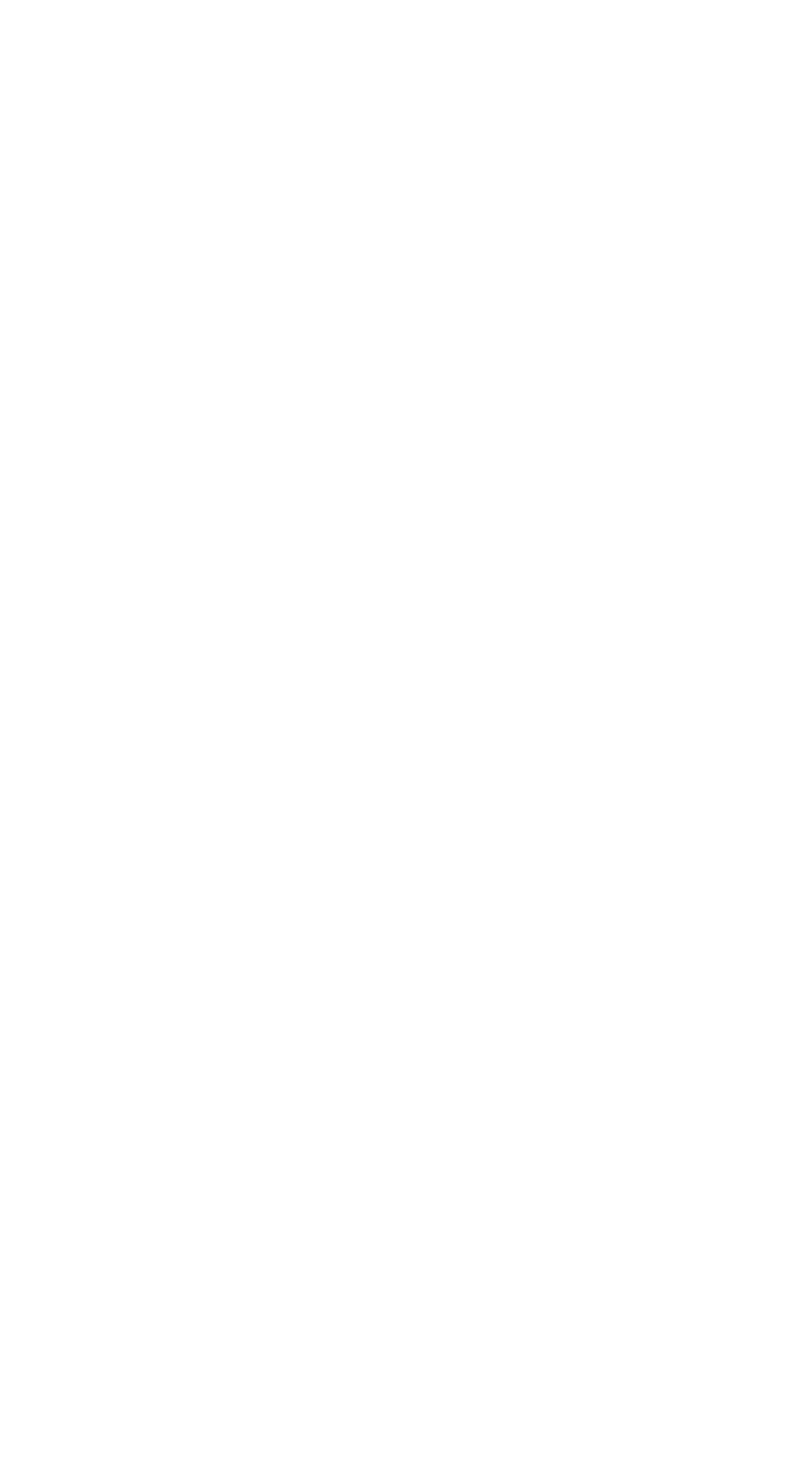




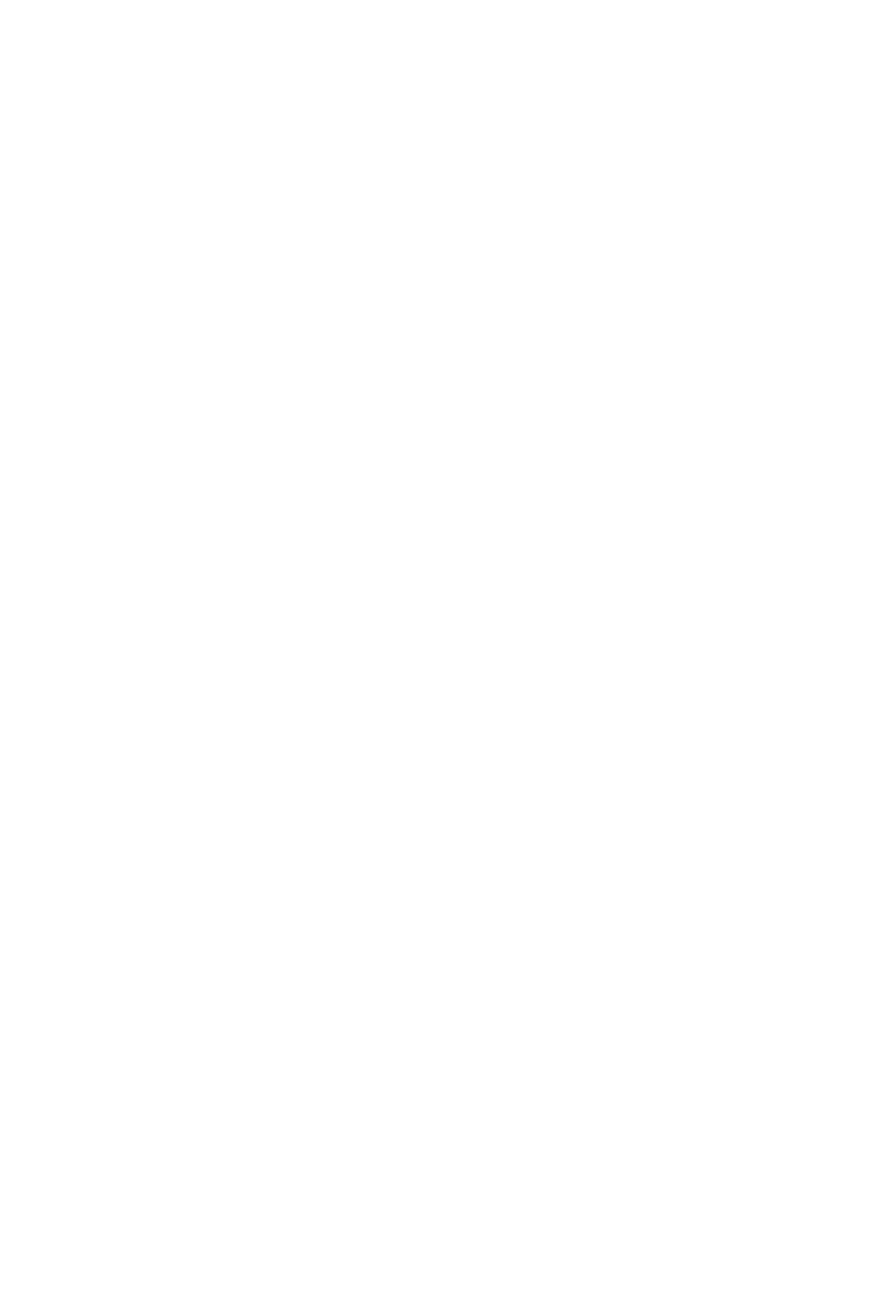




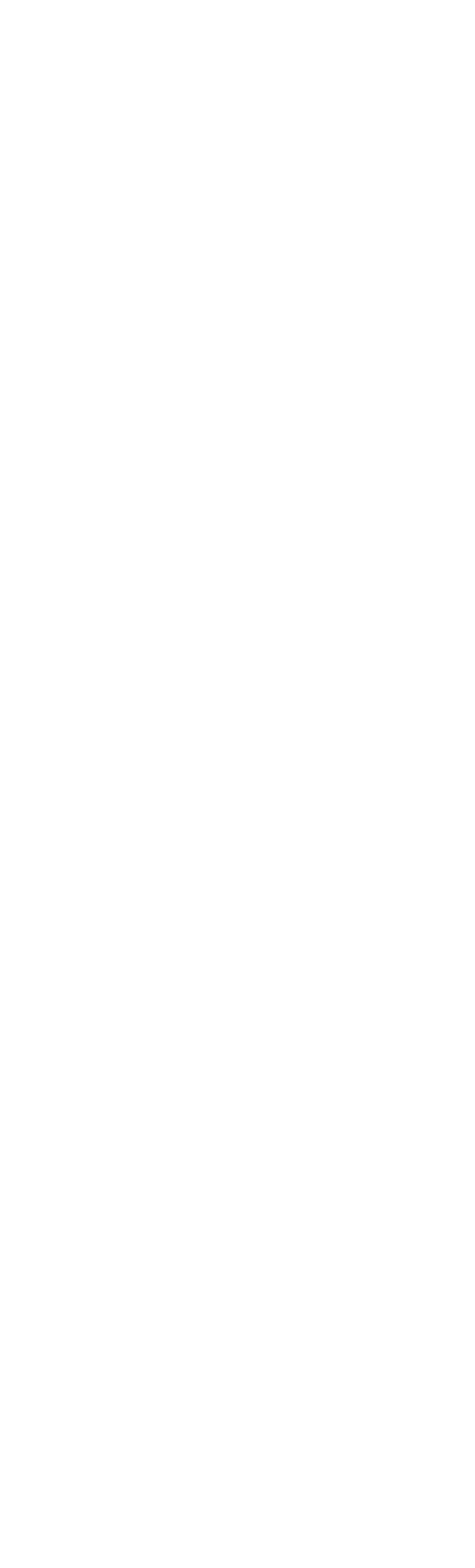




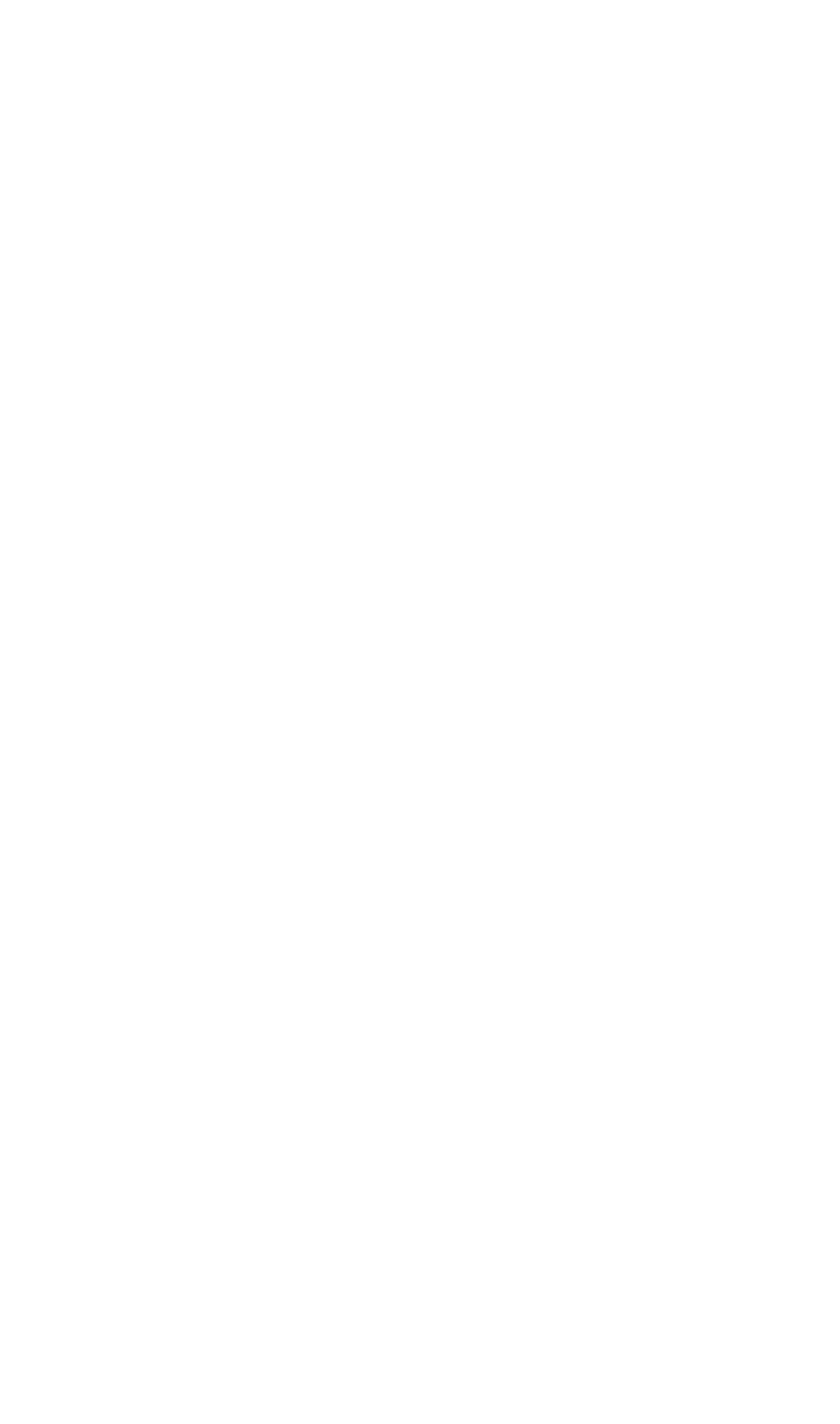




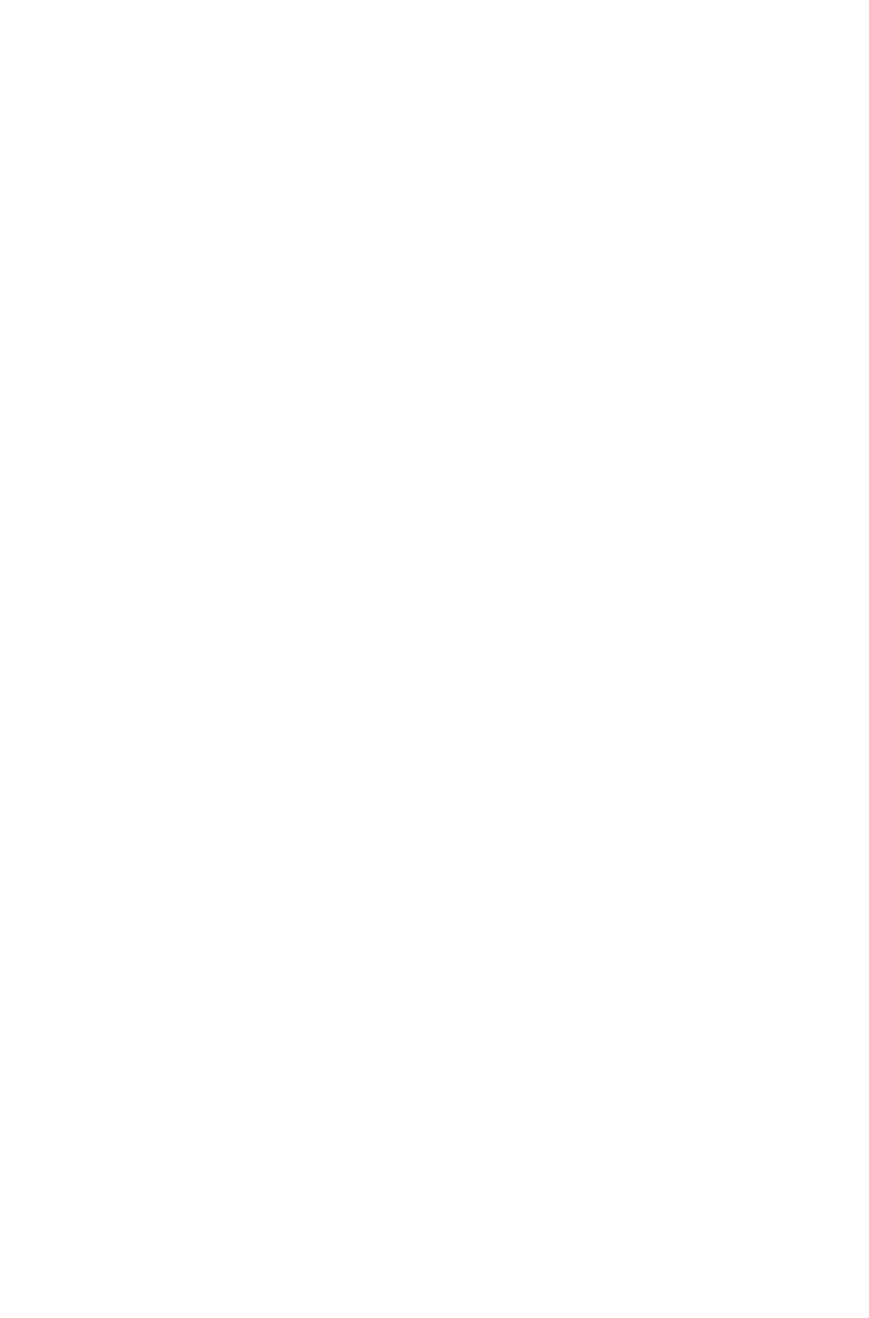




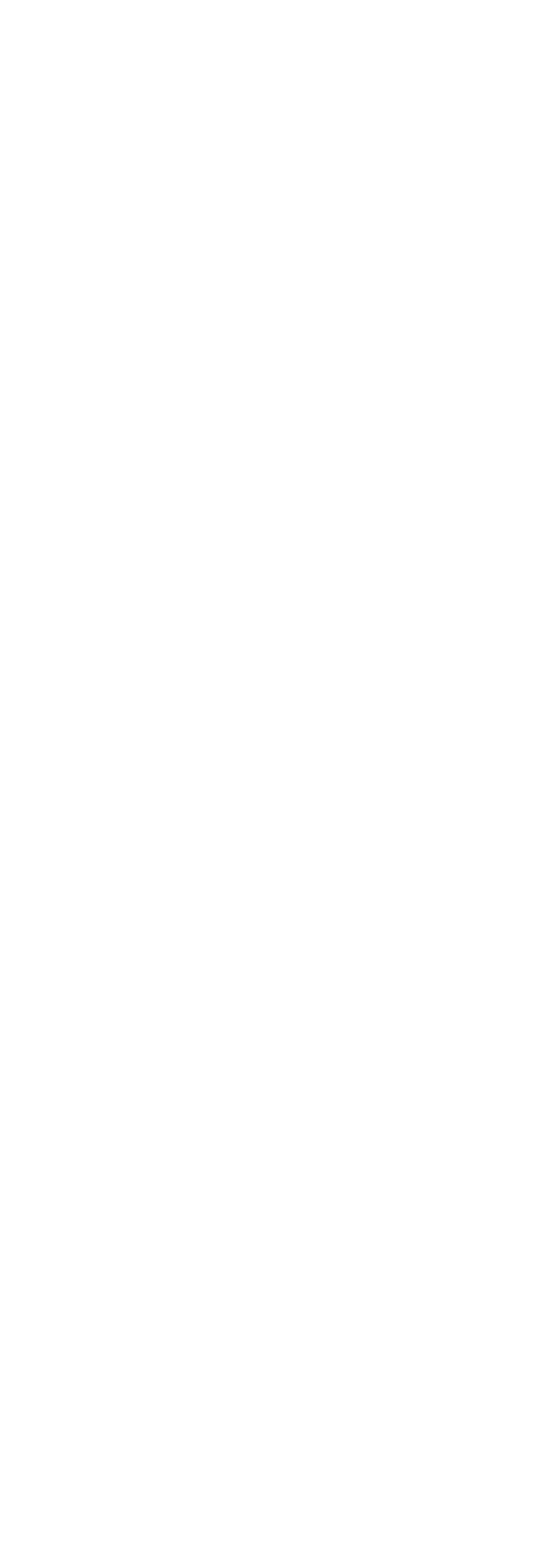




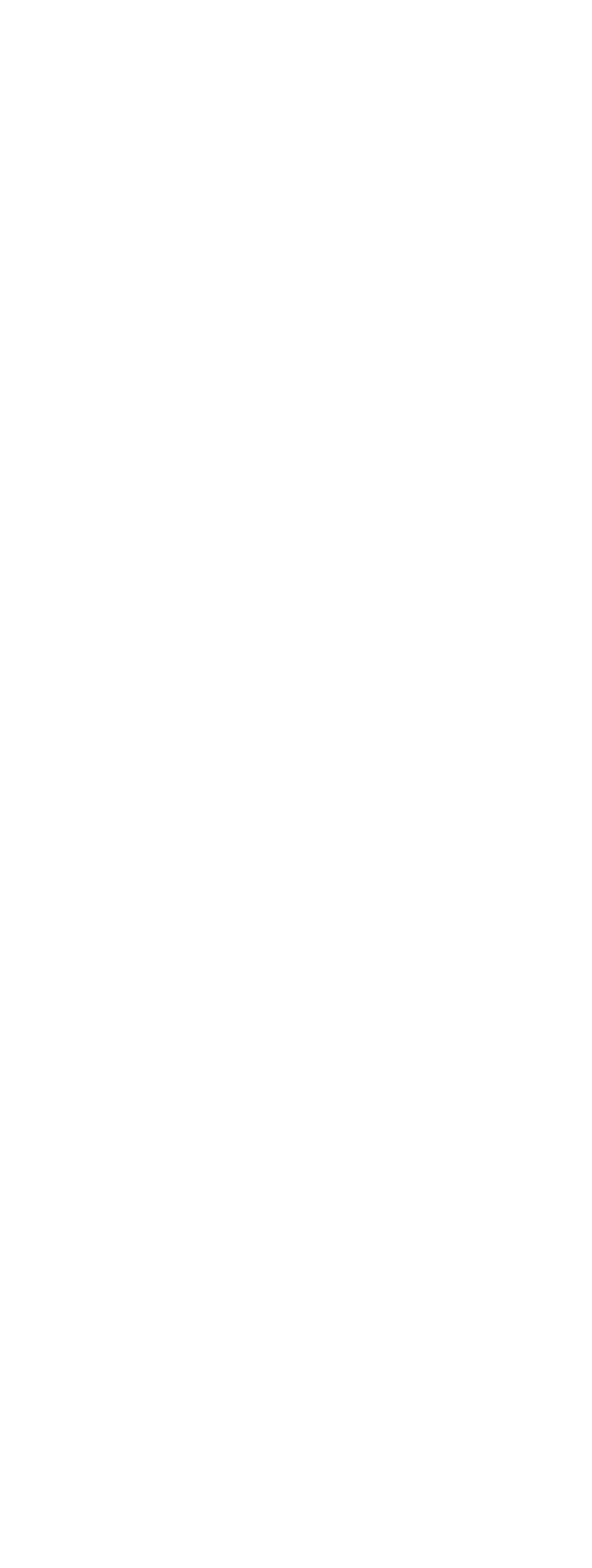




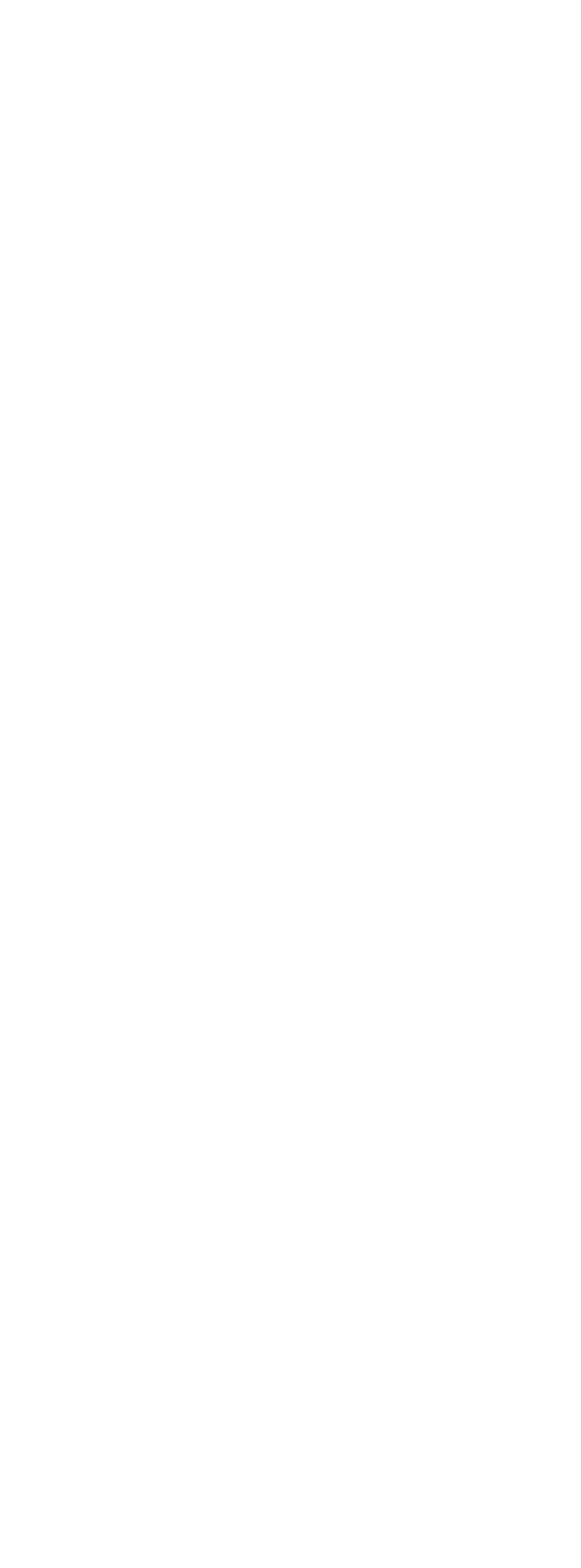




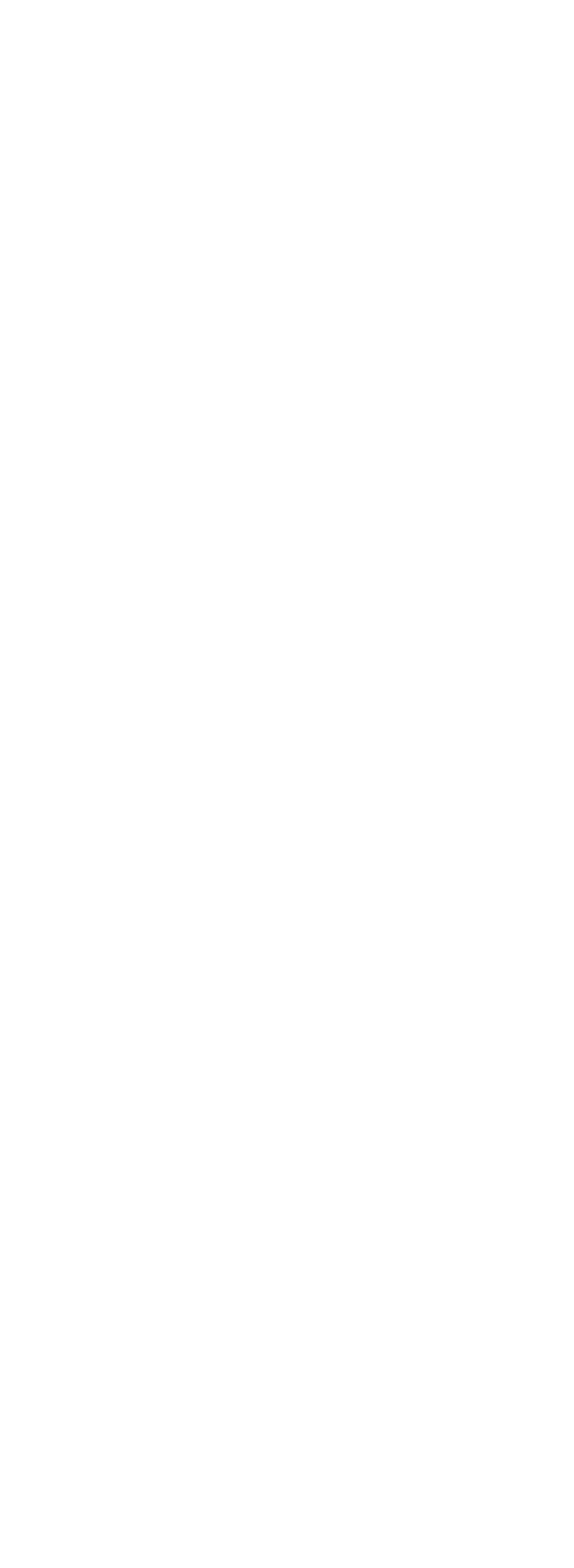




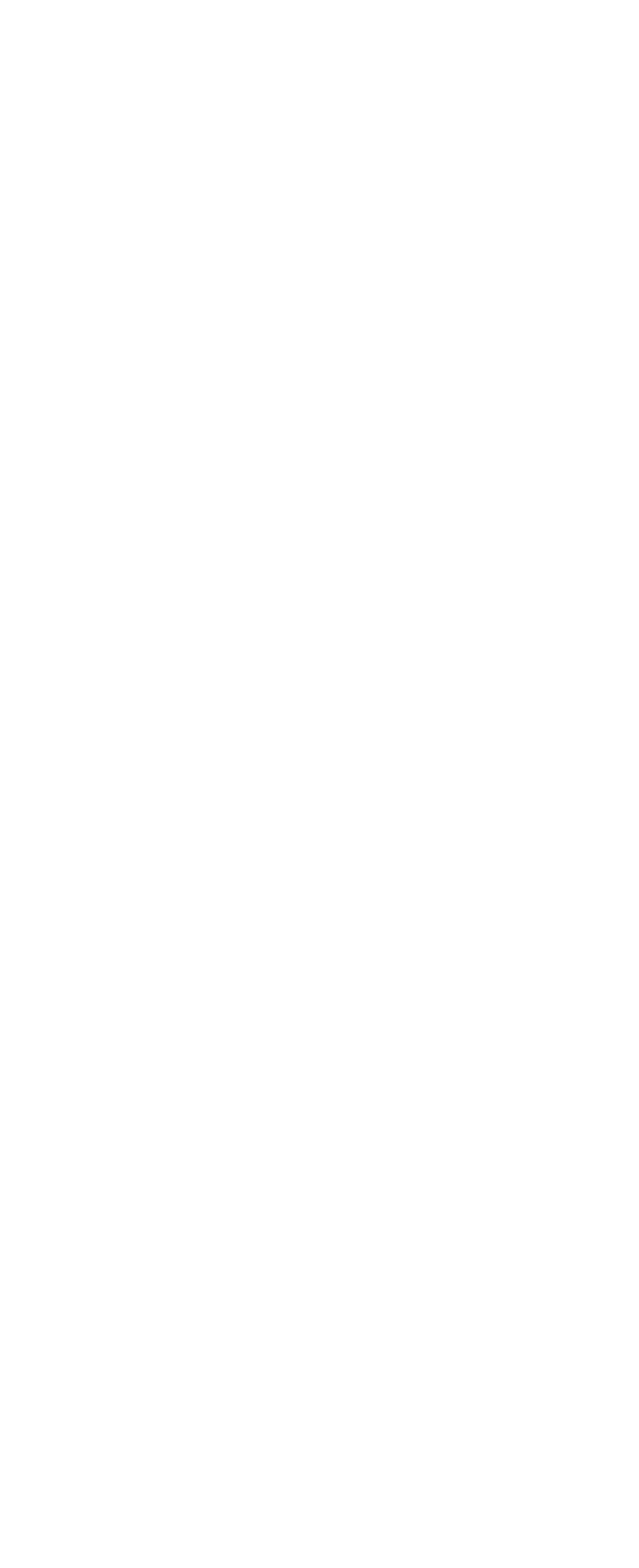




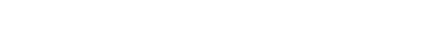

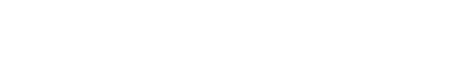

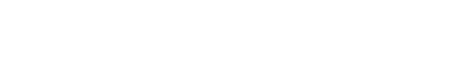
蛋 自

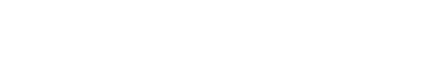
南然离

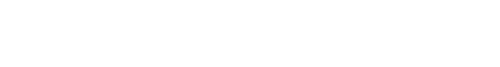

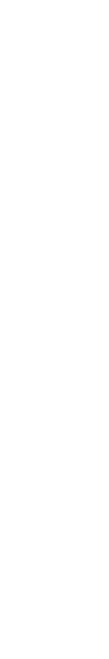

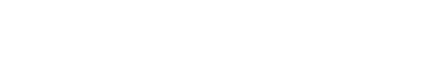

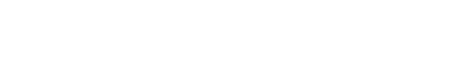
光采

com 自焉

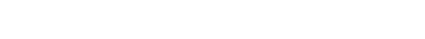

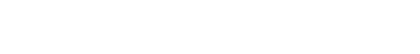

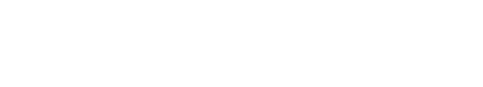

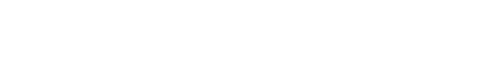

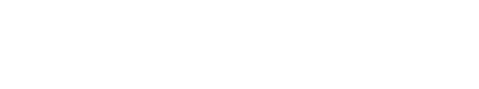

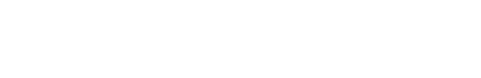
d

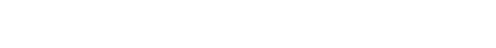

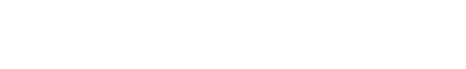
鼻㫷

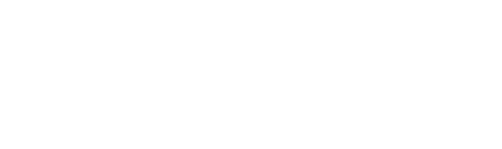




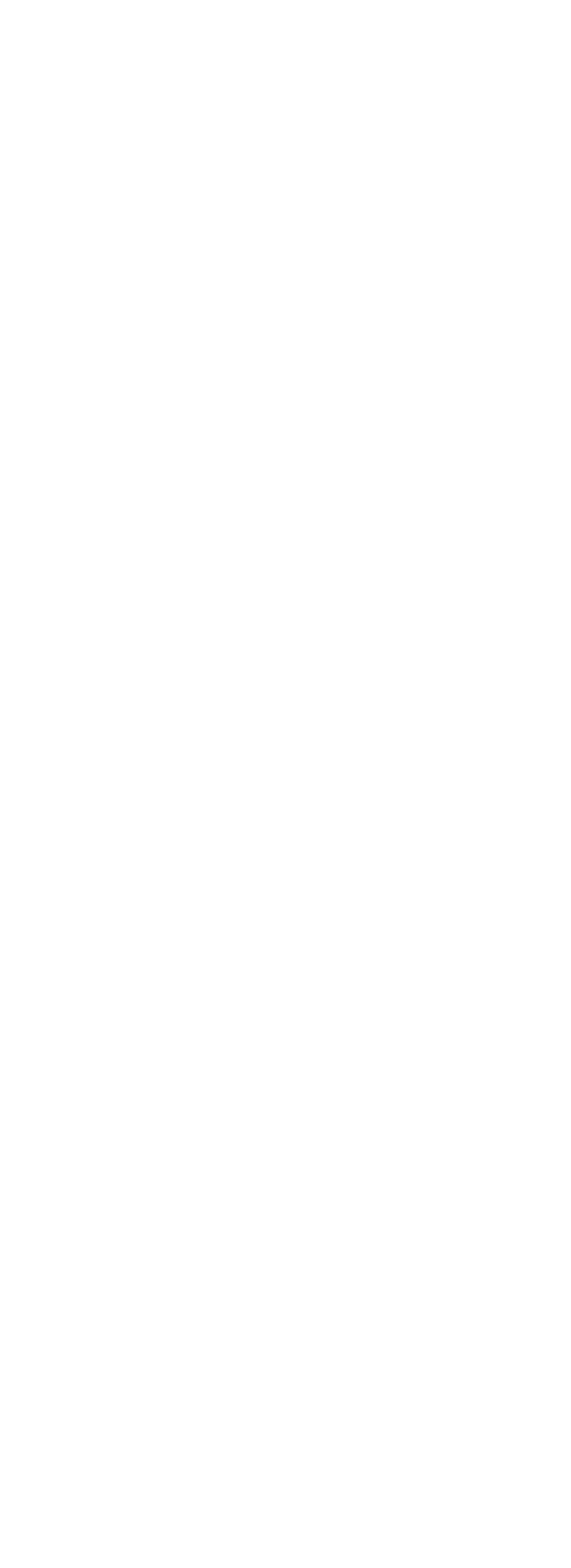




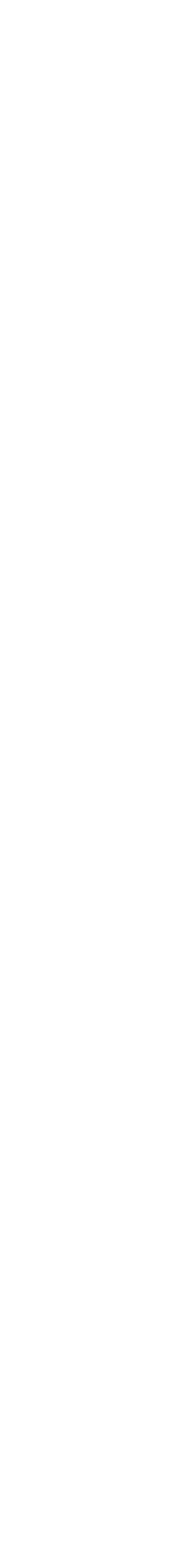

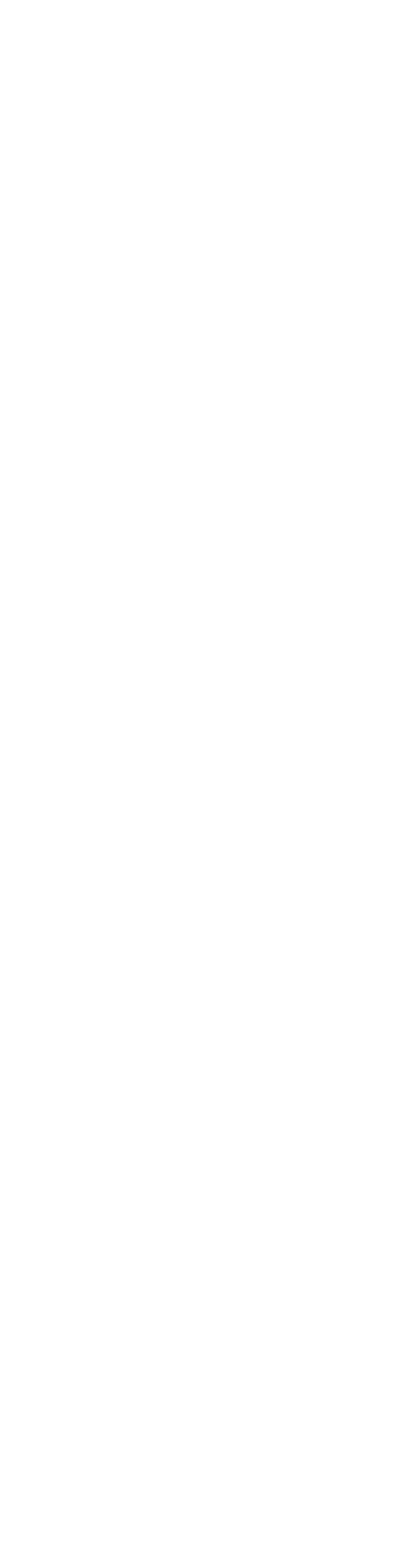




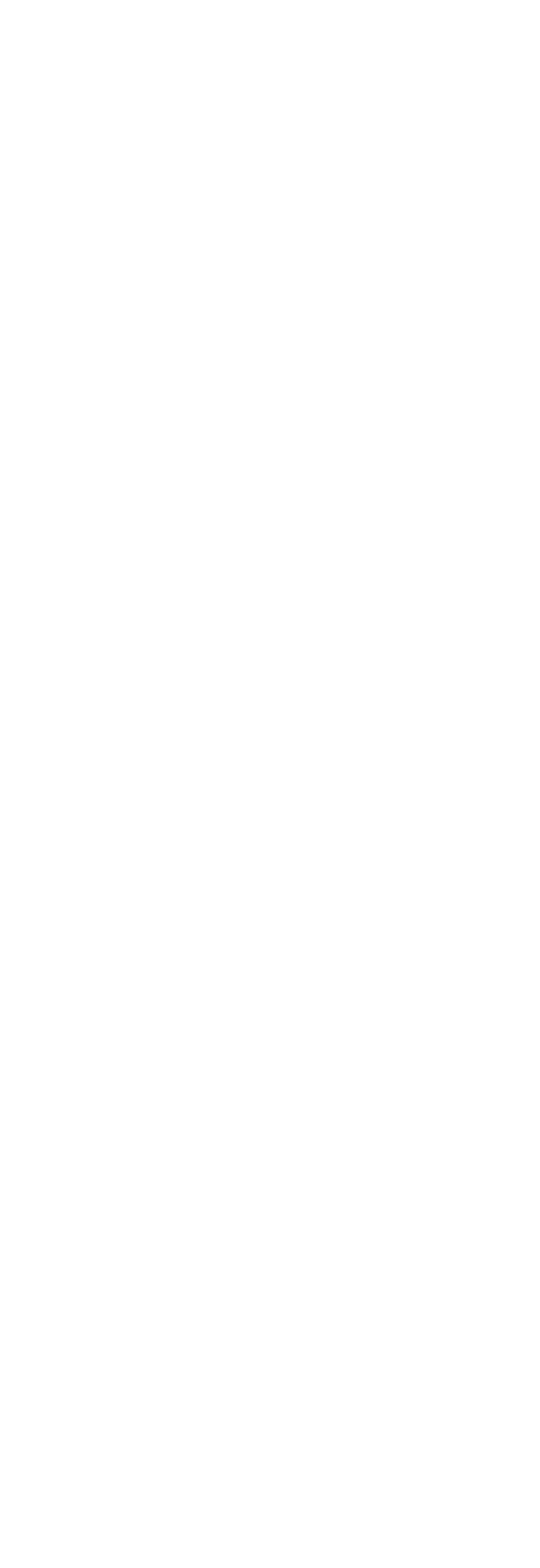




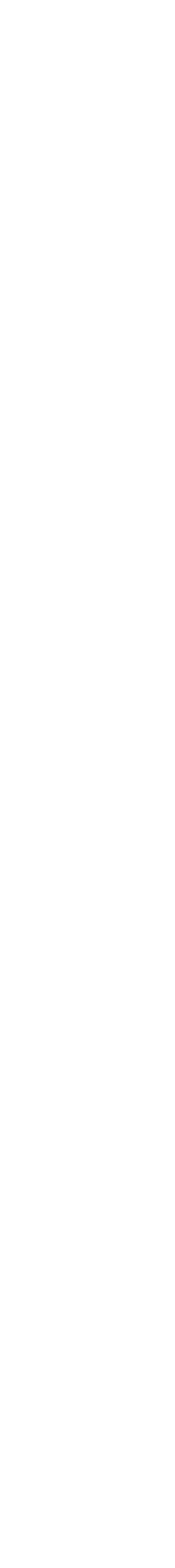

\begin{tabular}{|c|c|c|c|}
\hline & 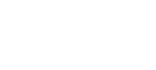 & 0050008 & $: 8850 \%$ \\
\hline & 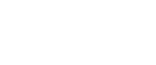 & 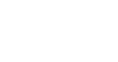 & 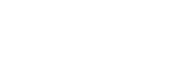 \\
\hline & 官台 & & \\
\hline & 吾 & 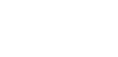 & 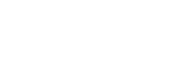 \\
\hline & 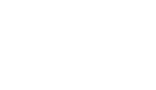 & 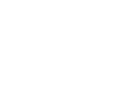 & 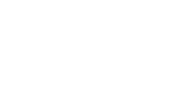 \\
\hline & 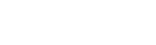 & 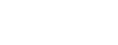 & ํํำะ ำ \\
\hline & 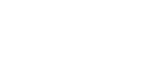 & ஸ゙ณ & 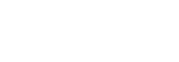 \\
\hline & 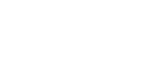 & 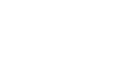 & 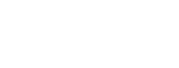 \\
\hline & 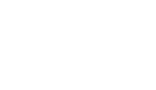 & & \\
\hline & 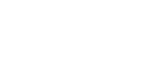 & 舟 & 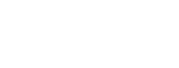 \\
\hline & $\frac{1}{2} \stackrel{g}{g}_{g}^{3}$ & 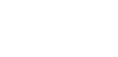 & Мก \\
\hline & 高峦闰 & 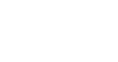 & $\because \because \because \because \because 90$ \\
\hline & 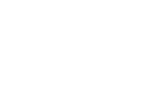 & 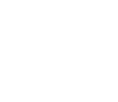 & 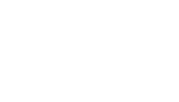 \\
\hline & 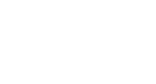 & หื่ & 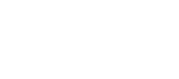 \\
\hline & है है क्ट & 000000 & $000000 \mathrm{No}$ \\
\hline & 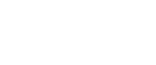 & 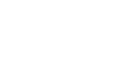 & 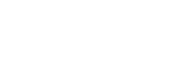 \\
\hline & 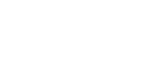 & 111111 & $111111 \stackrel{8}{0}$ \\
\hline & 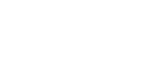 & $\overbrace{}^{-\infty} 0^{\infty}, \infty .00$ & .0.000.0. \\
\hline & 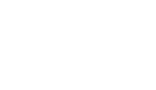 & $\begin{array}{l}\text { moonno } \\
\text { ministivin }\end{array}$ & 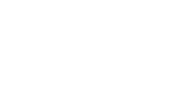 \\
\hline & 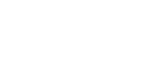 & 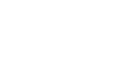 & 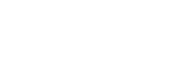 \\
\hline & 㐫焉无 & 운요우유국 & 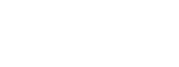 \\
\hline & 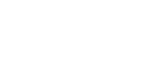 & & \\
\hline & 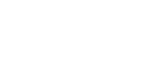 & Sisinisin & |⿰彳士⿻尸丨 \\
\hline & 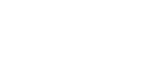 & 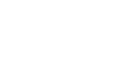 & 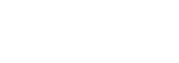 \\
\hline & 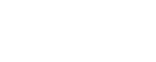 & 유요 & 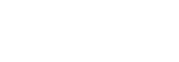 \\
\hline & 急咅 & 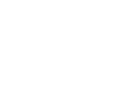 & 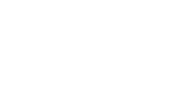 \\
\hline & 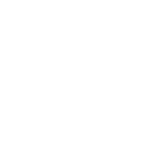 & 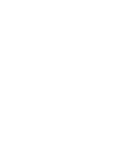 & 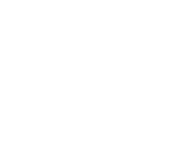 \\
\hline
\end{tabular}




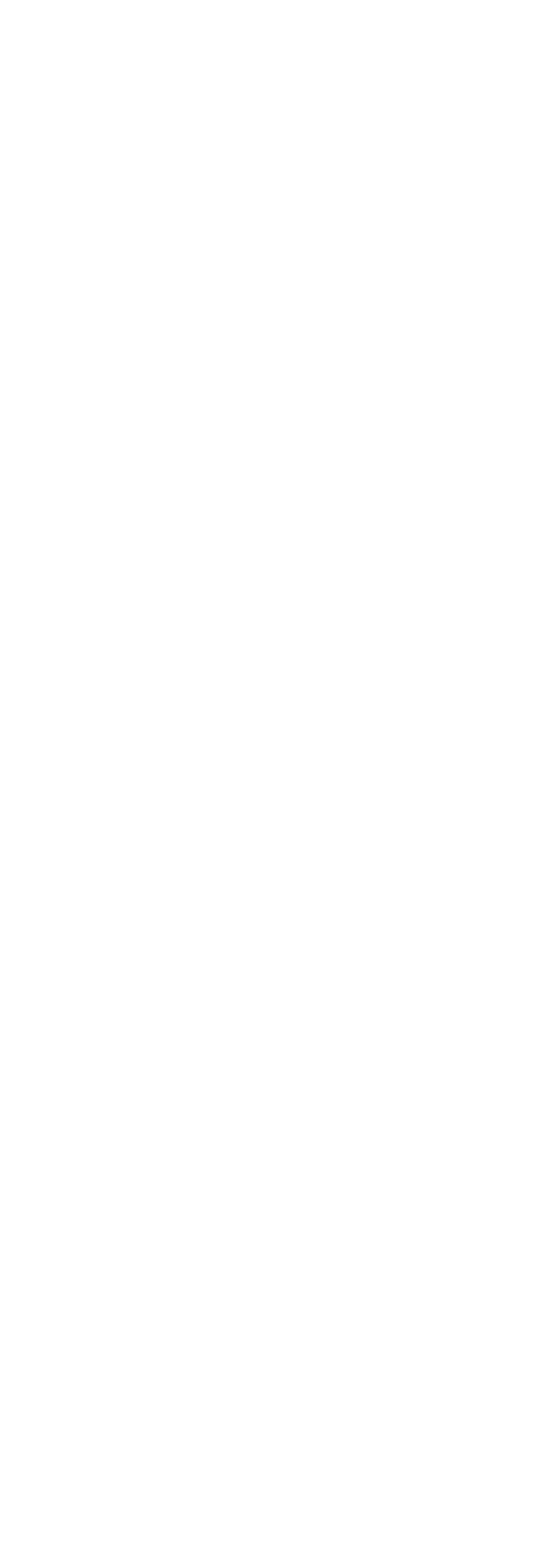




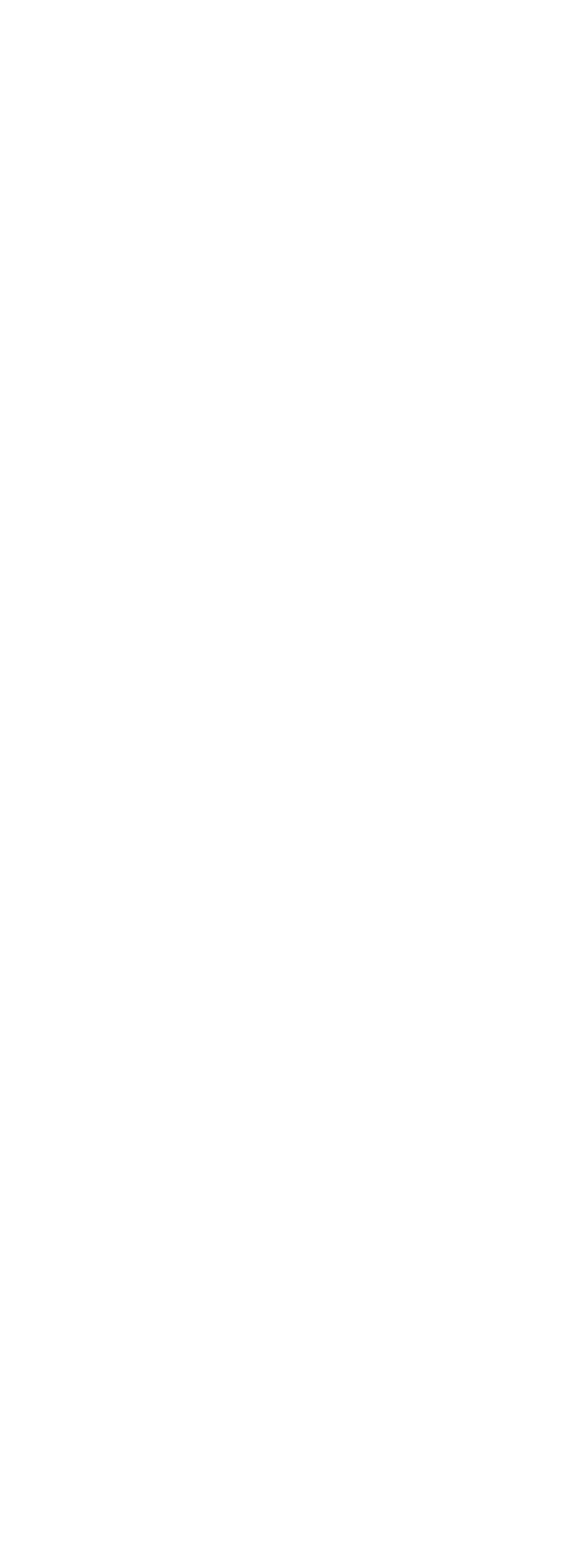




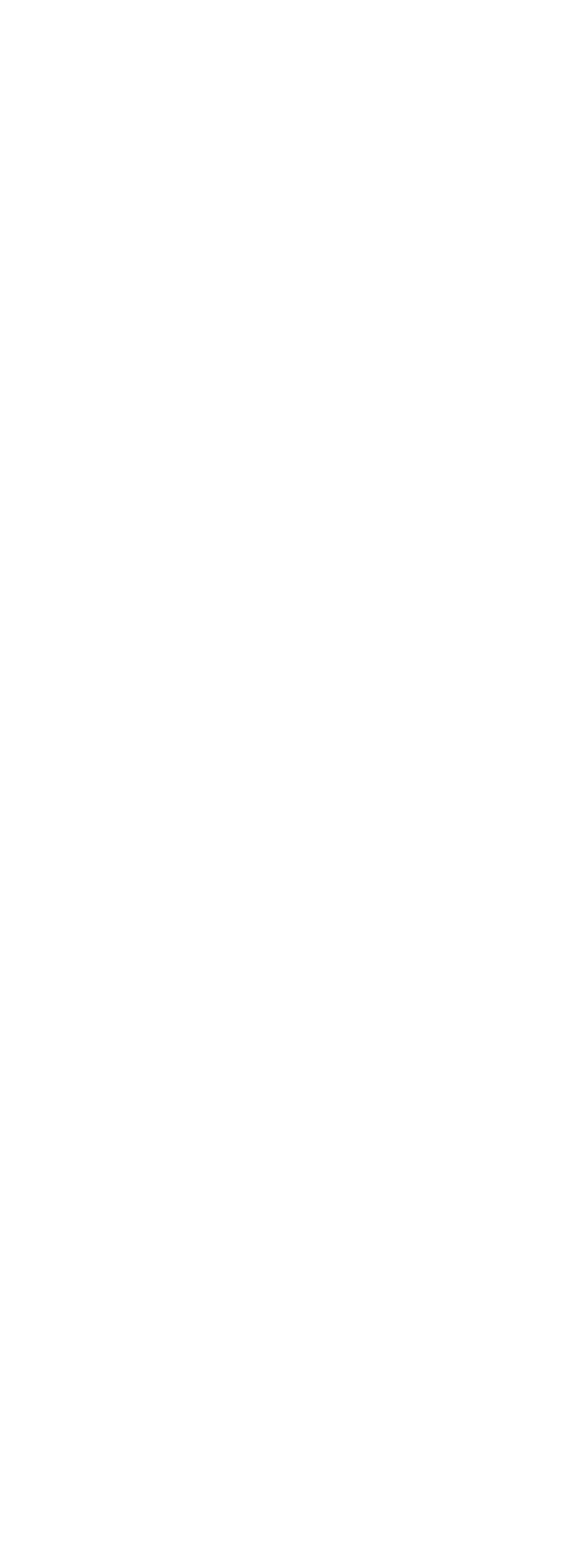




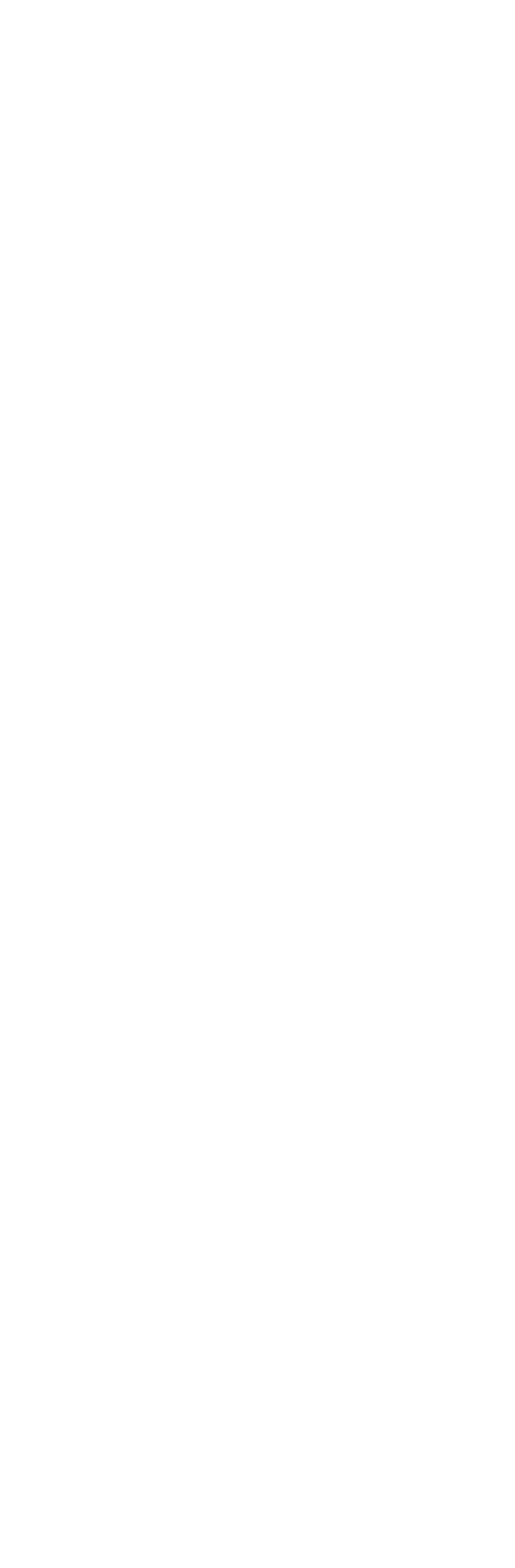




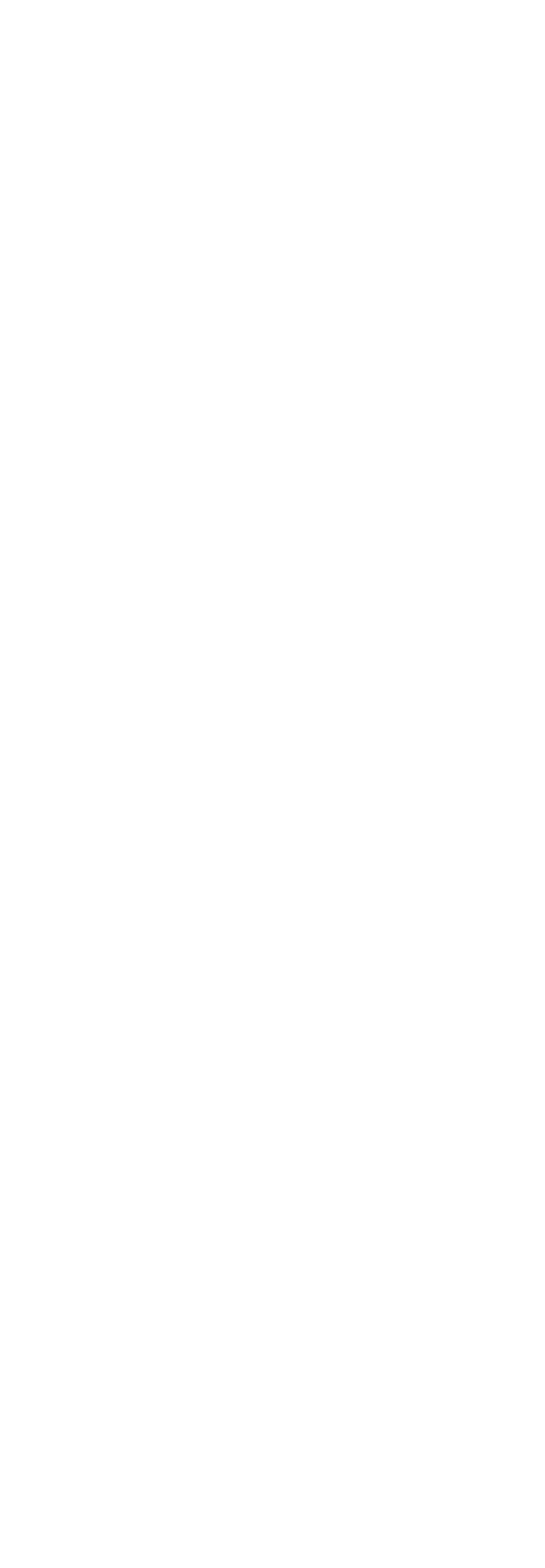




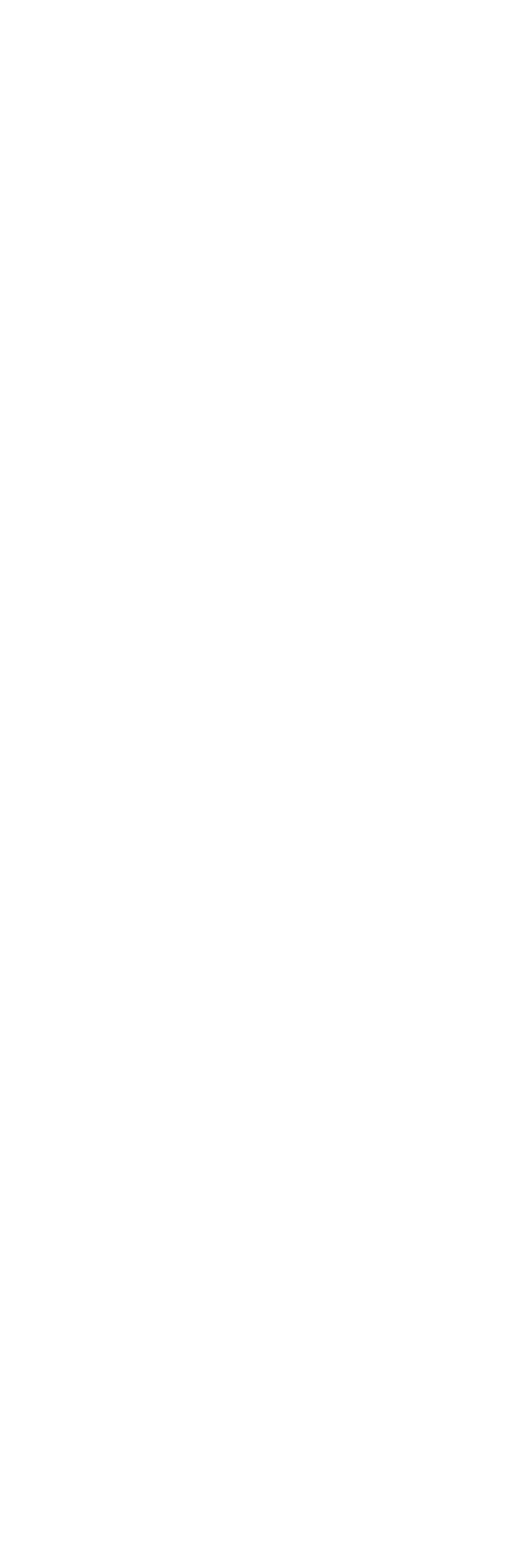

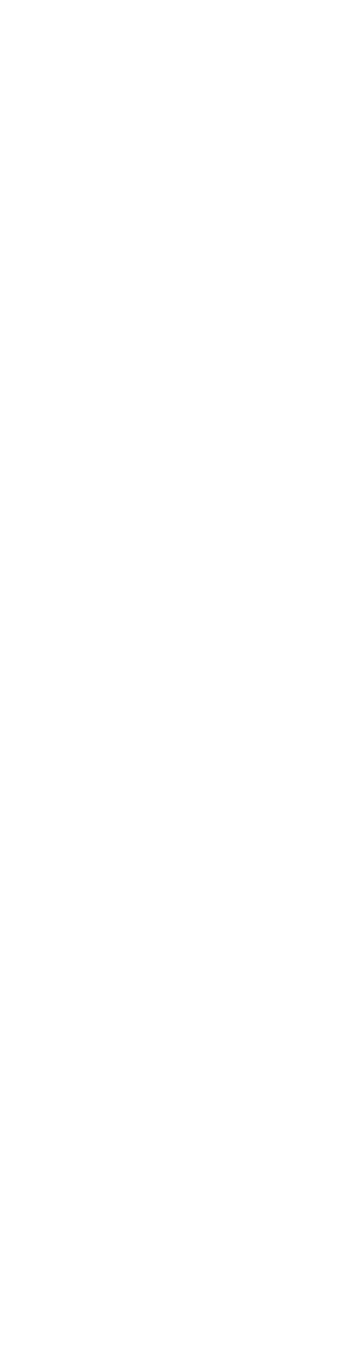




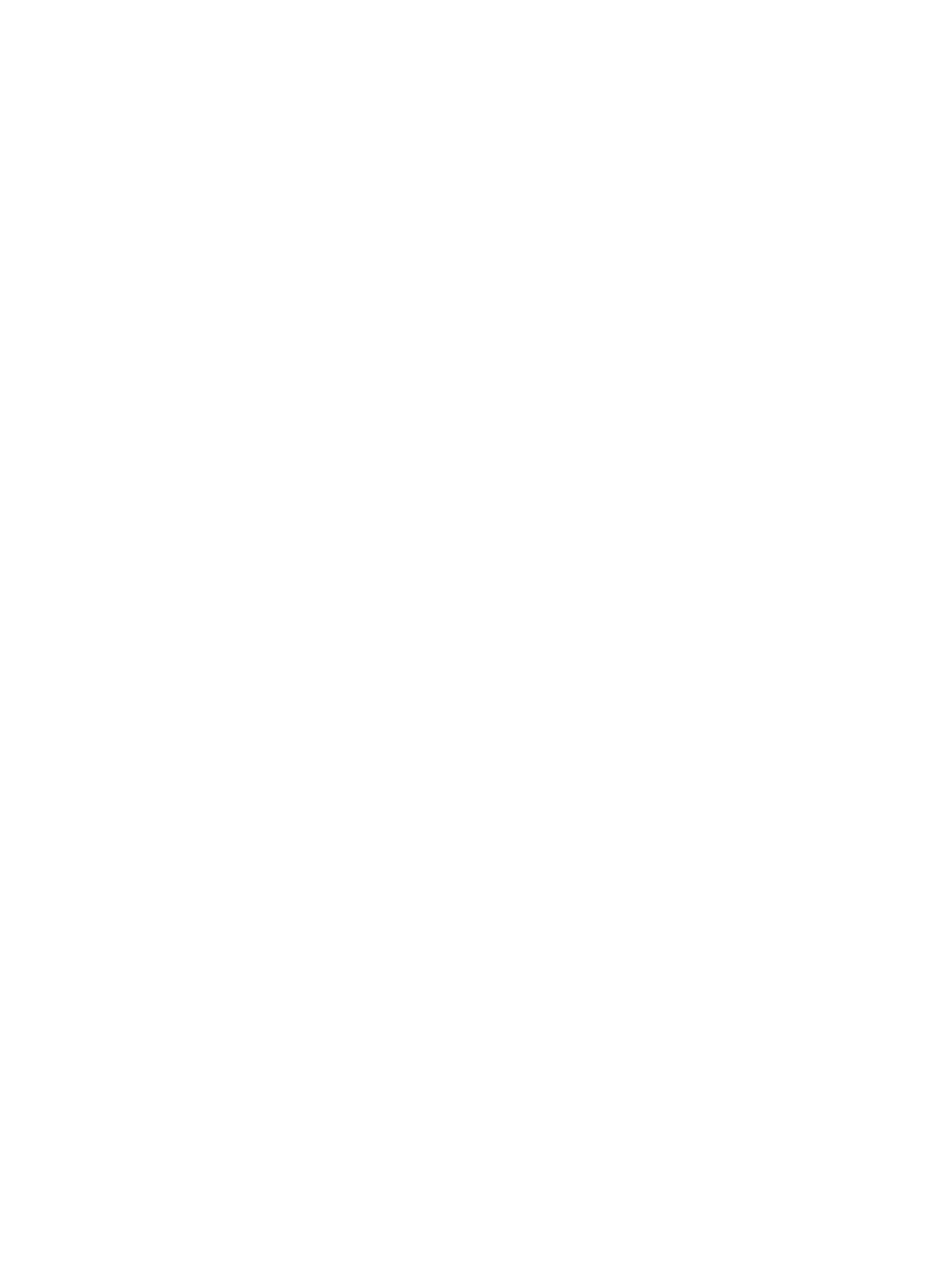




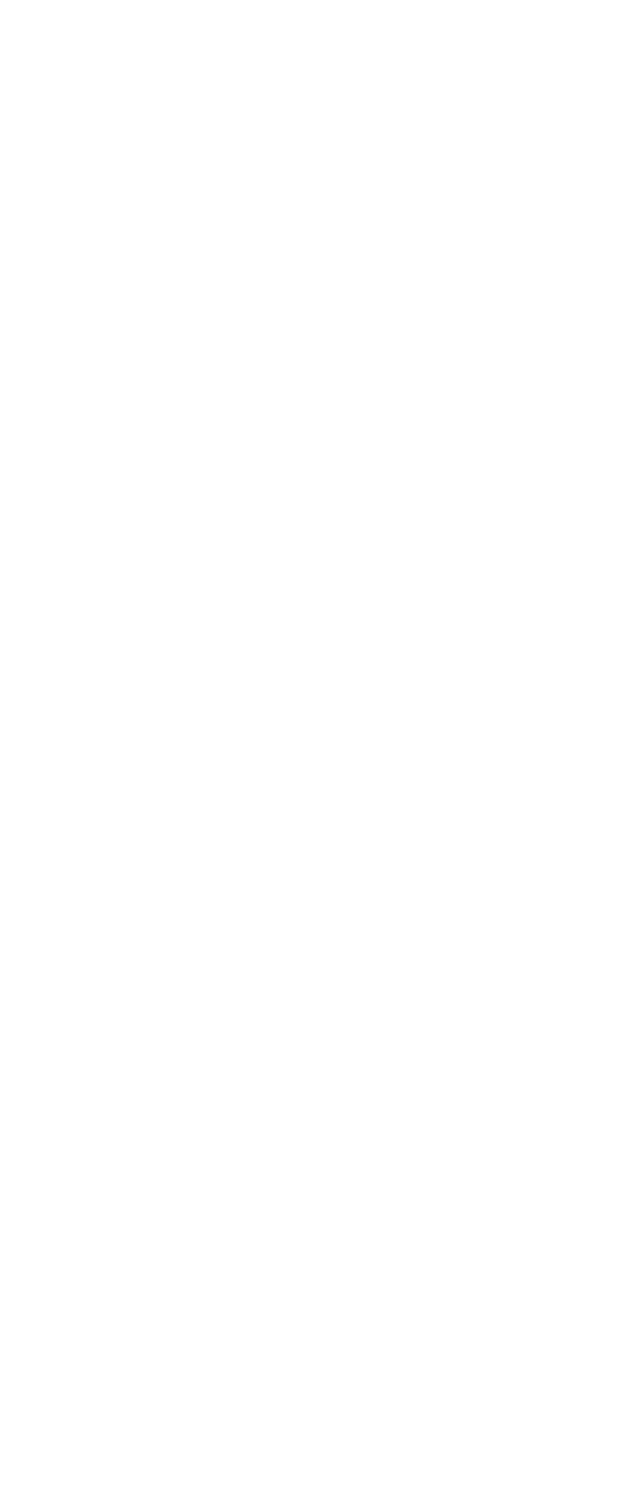




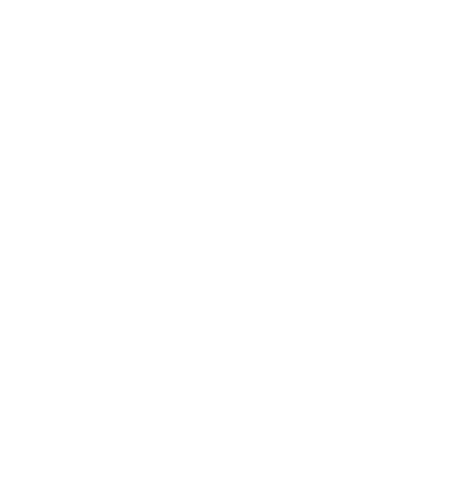

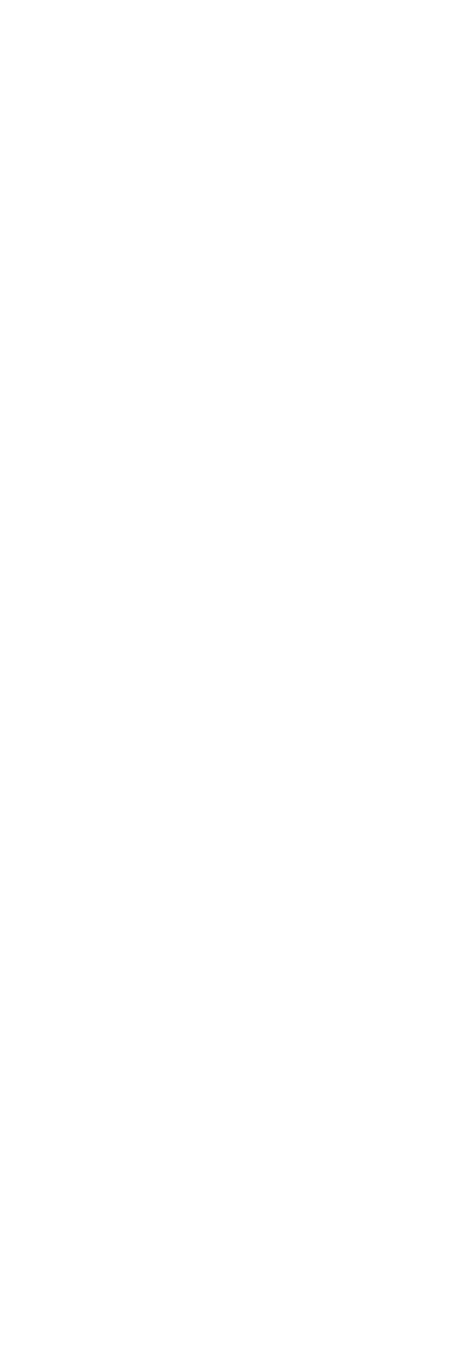




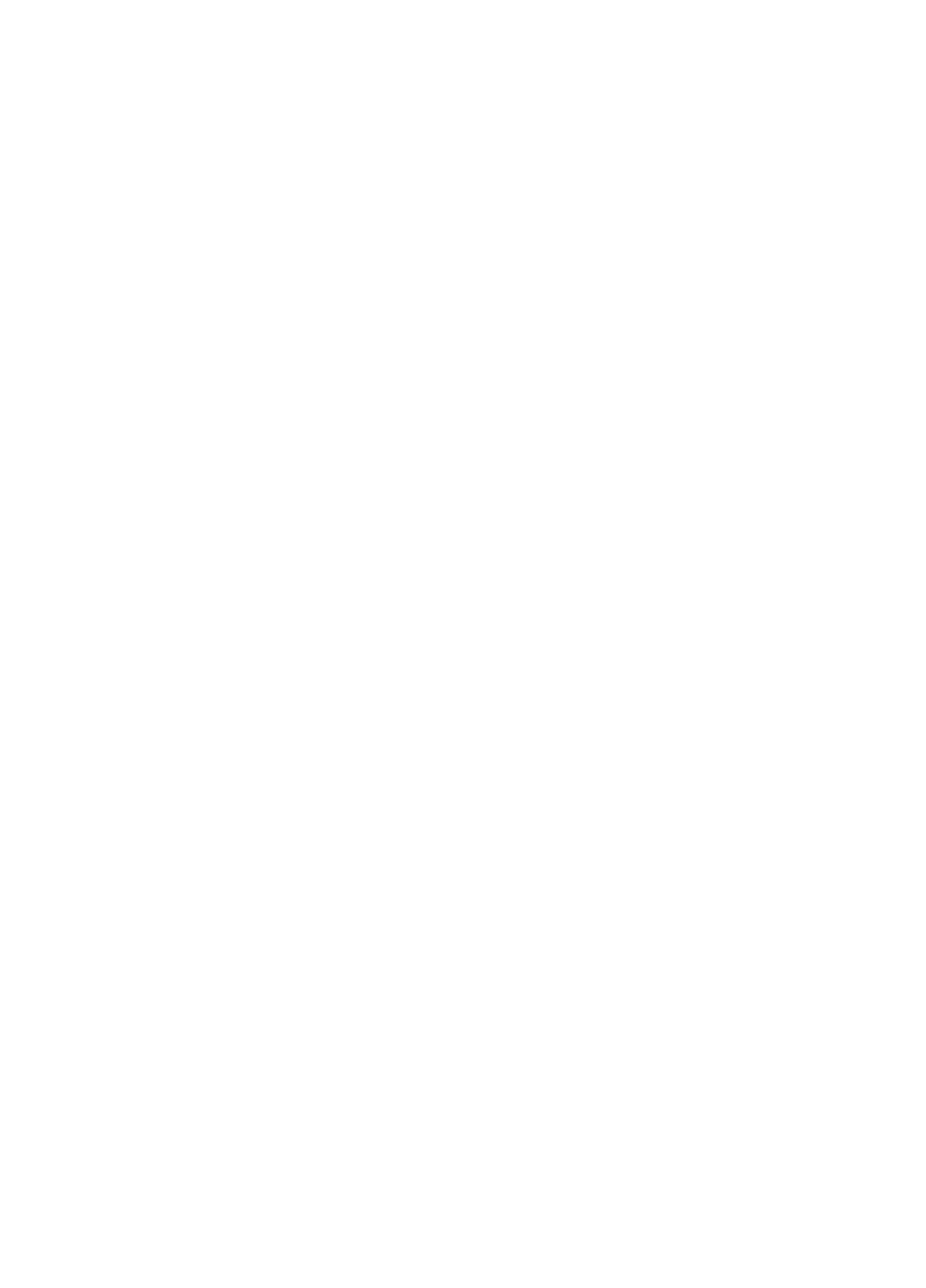




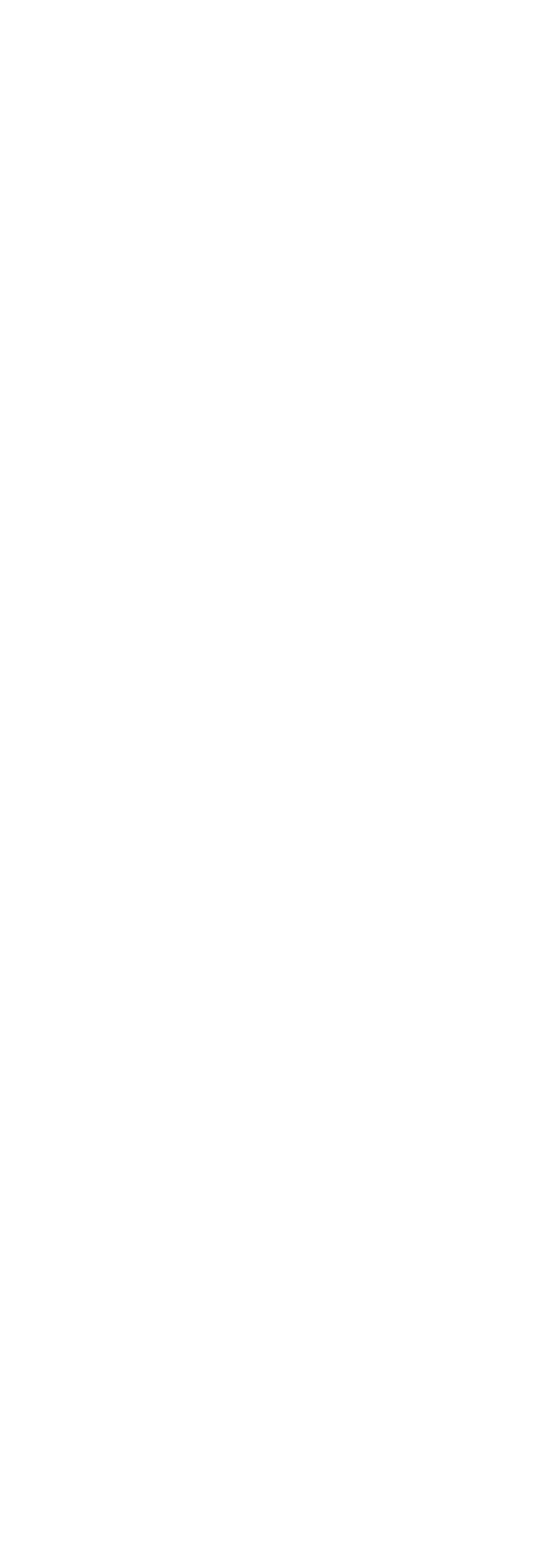




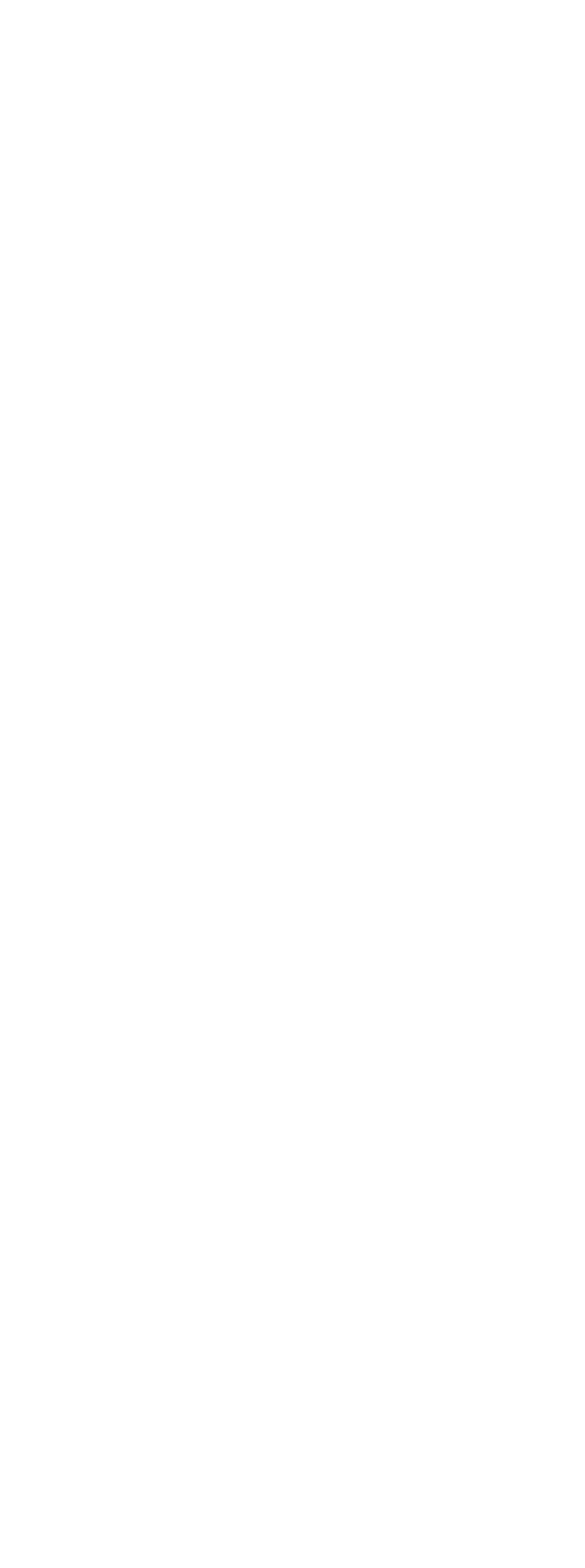




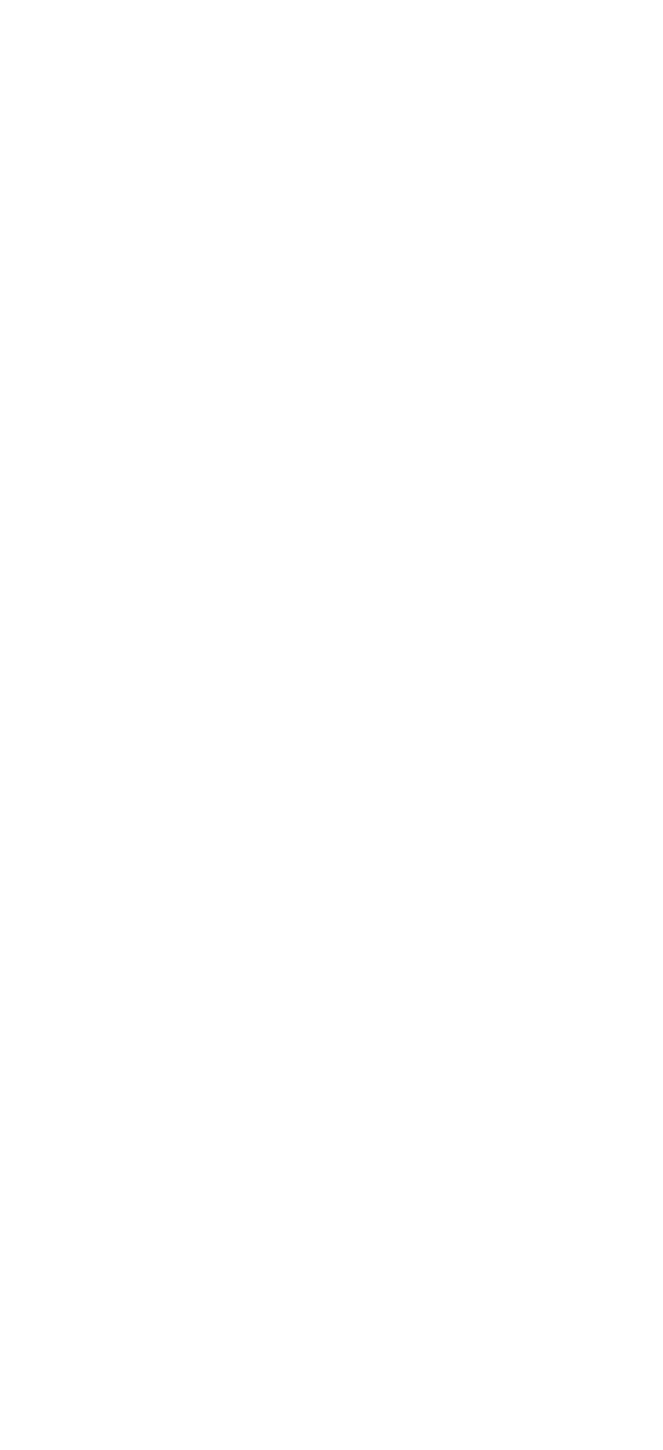




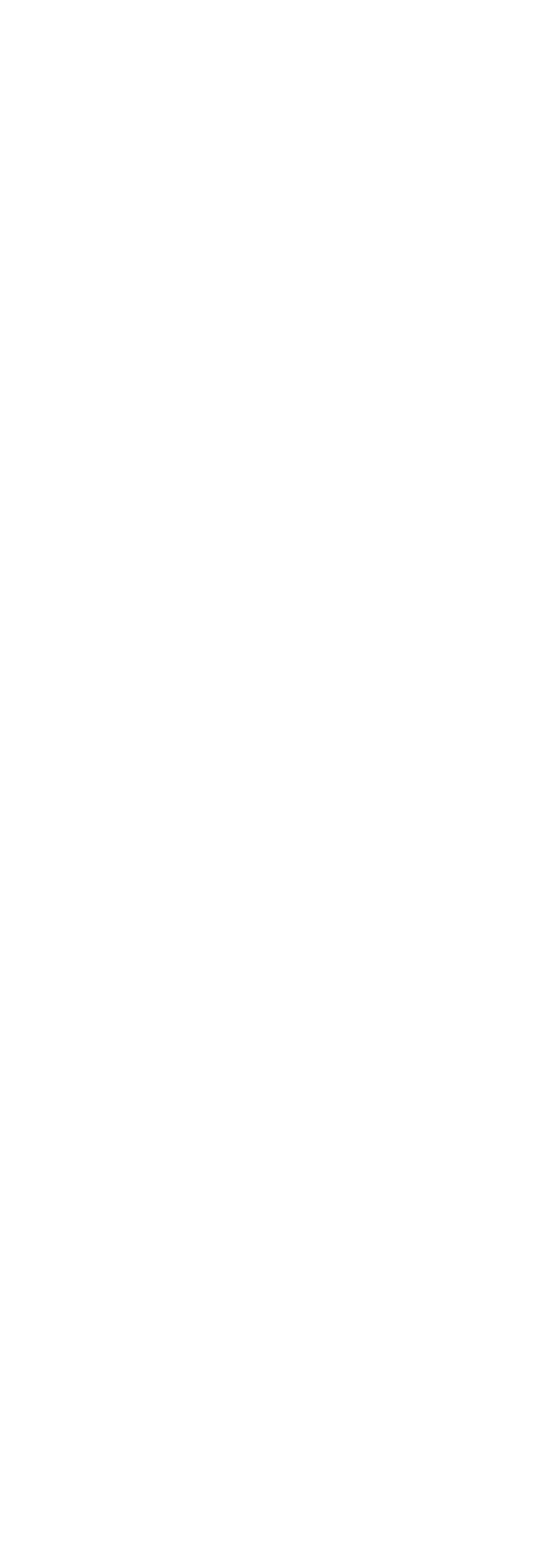




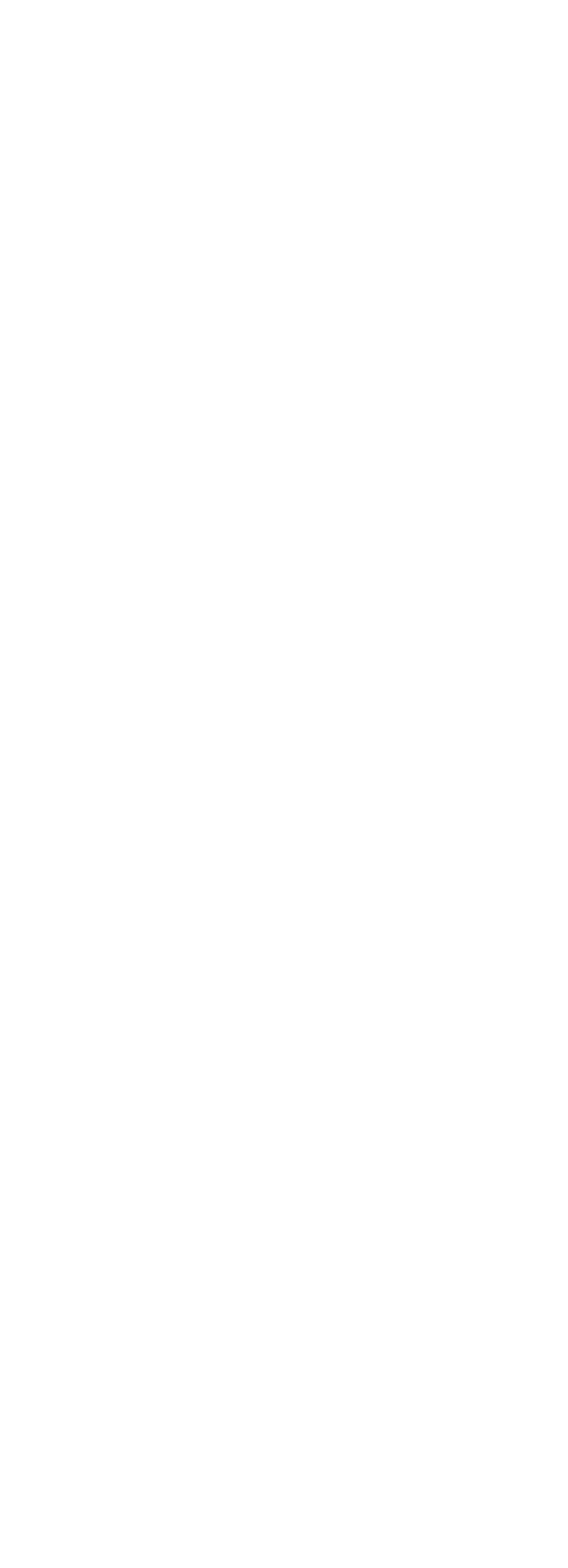




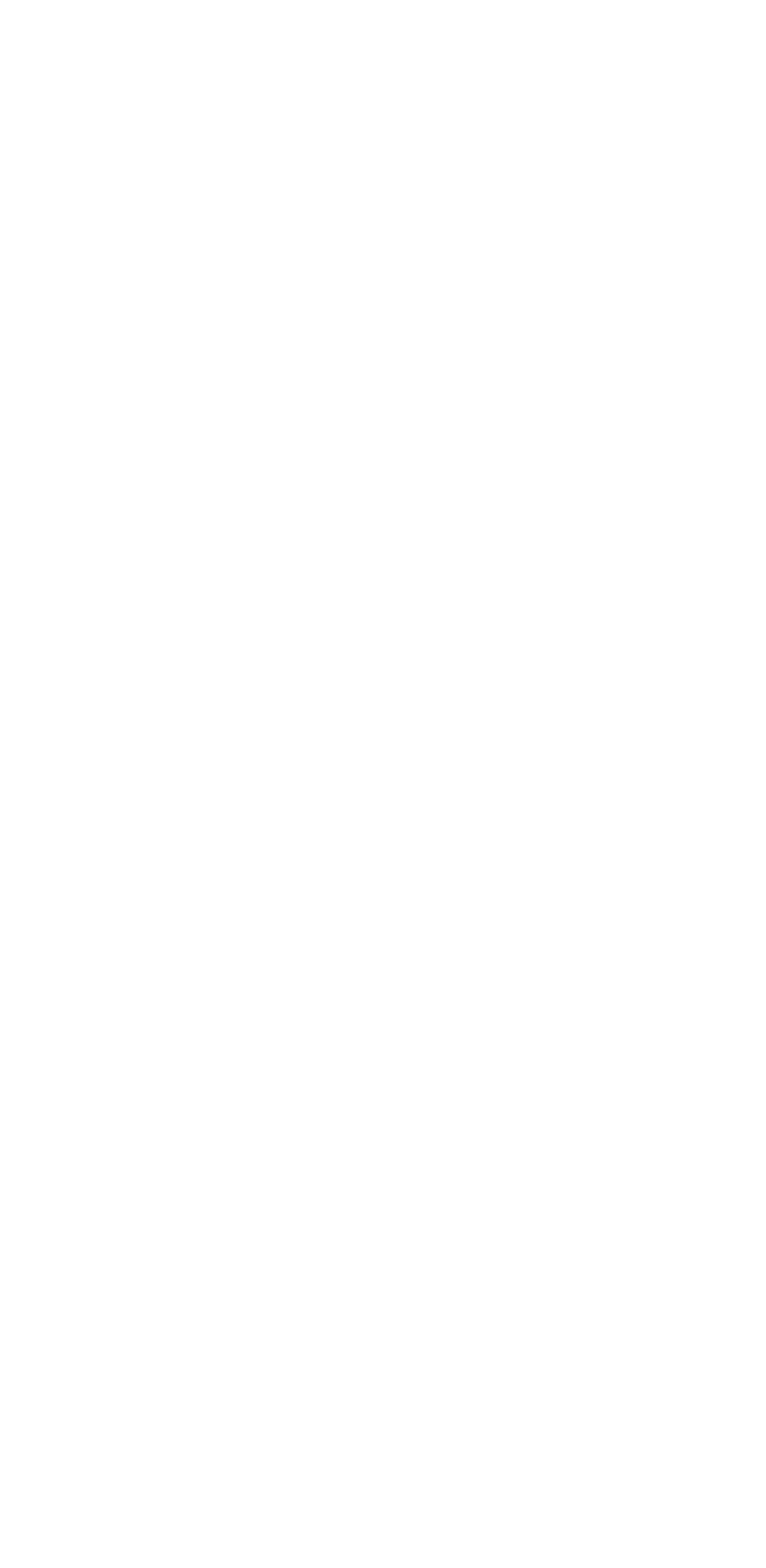


CHEMICAL-QUALITY INVESTIGATIONS OF COLD WATER STREAMS IN MICHIGAN

A series of specific conductance measurements was obtained as part of a water-resources investigation of the cold-water streams of Michigan in cooperation with the Michigan State Department of Conservation. The purpcse of these measurements is to determine the range in specific conductance under various streamflow conditions. The results, together with continuous thermograph records, ground-water records, streamflow records, and other hydrologic data wili be used to determine the relationship of hydroiogtc factors to recreational values.

Specific conductance (micromhos at $25^{\circ} \mathrm{C}$ ), October 1965 to September 1967

Date $\quad$\begin{tabular}{c|c|c|c} 
Water & & Time & tem- \\
per- & Discharge \\
ature & $($ cfs) & $\begin{array}{c}\text { Specific } \\
\text { conductance } \\
\text { (micrombs } \\
\text { at } \\
(24 \mathrm{hr})\end{array}$ & $\left.25^{\circ} \mathrm{C}\right)$ \\
\hline
\end{tabular}

STREAMS TRIBUTARY TO LAKE SUPERIOR

4-0310. BLACK RIVER NEAR BESSEMER (LAT 46 $30^{\prime} 41^{\prime \prime}$, LONG $90^{\circ} 04^{\prime} 28^{\prime}$ )

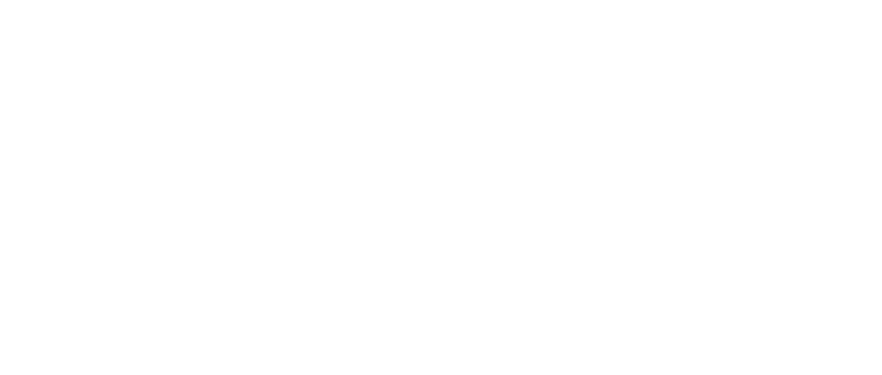

4-0330. MIDDLE BRANCH ONTONAGON RIVER NEAR PAULDING

(LAT $46^{\circ} 21^{\prime} 25^{\prime \prime}$, LONG $89^{\circ} 04^{\prime} 38^{\prime \prime}$ )

\begin{tabular}{|c|c|c|c|c|}
\hline & & & & \\
\hline Oct, $5,1965 \ldots \ldots \ldots \ldots \ldots \ldots \ldots$ & 1355 & $\mathbf{4 4}$ & 118 & 145 \\
\hline Nov. $3, \ldots \ldots \ldots \ldots \ldots$ & 1400 & 43 & 111 & 150 \\
\hline Nov. $30 \ldots \ldots \ldots \ldots \ldots \ldots \ldots \ldots$ & 1400 & 32 & 194 & 125 \\
\hline Dec. $31, \ldots \ldots \ldots \ldots \ldots \ldots \ldots$, & 1130 & 32 & 145 & 135 \\
\hline Mar. 2, i $966 \ldots \ldots$ & 1145 & 32 & 90.0 & 150 \\
\hline $\mathrm{Apr}, 20, \ldots \ldots \ldots \ldots \ldots \ldots \ldots \ldots$ & 1030 & 39 & 651 & 60 \\
\hline 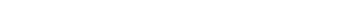 & 0930 & 61 & 130 & 145 \\
\hline 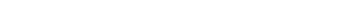 & 1830 & 70 & 143 & 150 \\
\hline 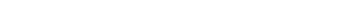 & 1700 & 70 & 99.2 & 185 \\
\hline$\ldots \ldots \ldots \ldots$ & 1430 & 72 & 132 & 140 \\
\hline oct. 7.. & 0930 & 46 & 135 & 140 \\
\hline .......... & 1445 & 34 & 139 & 140 \\
\hline$\ldots \ldots \ldots \ldots \ldots \ldots$ & 1650 & 32 & 142 & 145 \\
\hline Jan. $12,1967, \ldots \ldots \ldots \ldots \ldots \ldots$ & 1500 & 32 & 133 & 145 \\
\hline Feb. $13, \ldots \ldots$ & 1630 & 32 & 128 & 160 \\
\hline May $4 \ldots \ldots \ldots \ldots \ldots \ldots \ldots$ & 0930 & 38 & 330 & 80 \\
\hline June $7 \ldots \ldots \ldots \ldots \ldots \ldots \ldots \ldots \ldots$ & 1145 & 60 & 164 & 130 \\
\hline
\end{tabular}

STREAMS TRIBUTARY TO LAKE MICHIGAN

4-0495. MANISTIQUE RIVER AT GERMFASK (LAT $46^{\circ} 14^{\circ} 00^{\prime \prime}$, LONG $85^{\circ} 55^{\prime} 40^{\prime \prime}$ )

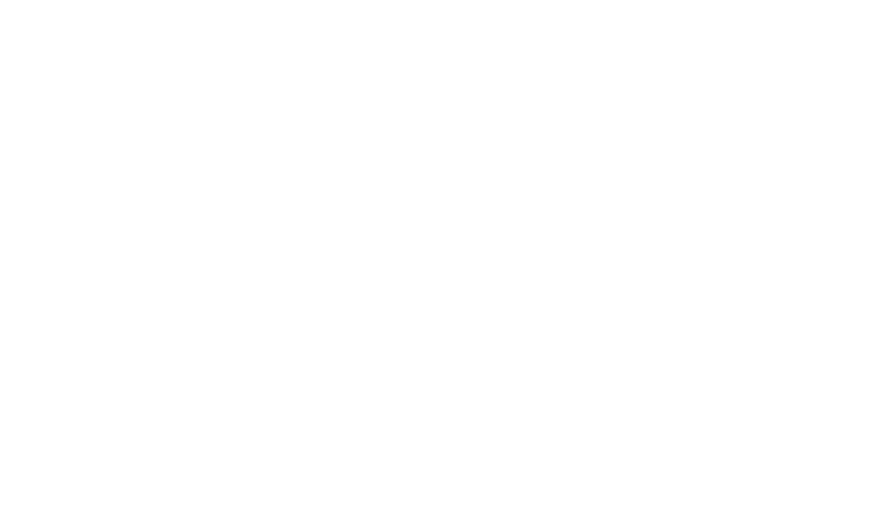


CHEMICAL-QUALITY INVESTIGATIONS OF COLD WATER STREAMS IN MICHIGAN--Continued

Specific conductance (micromhos at $25^{\circ} \mathrm{C}$ ),

October 1965 to September 1967--Continued

\begin{tabular}{c|c|c|c|c}
\hline \multicolumn{2}{c}{ October 1965 to September 1967--Continued } & $\begin{array}{c}\text { Specific } \\
\text { conductance } \\
\text { (micromhos } \\
\text { at } \\
255^{\circ} \mathrm{C} \text { ) }\end{array}$ \\
\hline
\end{tabular}

STREAMS TRIBUTARY TO LAKE MICHIGAN--Continued

4-0580. MIDDLE BRANCH ESCANABA RIVER NEAR I SHPEMING--Continued

\begin{tabular}{|c|c|c|c|c|}
\hline 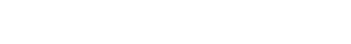 & $\begin{array}{l}1020 \\
1030\end{array}$ & $\begin{array}{l}63 \\
65\end{array}$ & $\begin{array}{l}22.2 \\
46.3\end{array}$ & $\begin{array}{l}100 \\
105\end{array}$ \\
\hline 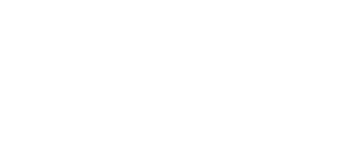 & $\begin{array}{l}1550 \\
1015 \\
1130 \\
1240 \\
1400 \\
1730 \\
1300 \\
0930\end{array}$ & $\begin{array}{l}51 \\
34 \\
32 \\
48 \\
63 \\
68 \\
67 \\
47\end{array}$ & $\begin{array}{r}57.6 \\
92.3 \\
110 \\
260 \\
286 \\
90.0 \\
46.3 \\
35.0\end{array}$ & $\begin{array}{r}110 \\
80 \\
75 \\
55 \\
60 \\
80 \\
90 \\
110\end{array}$ \\
\hline
\end{tabular}

4-1225. PERE MARQUETTE RIVER AT SCOTTVILLE (LAT 43 $56^{\prime} 40^{\prime \prime}$, LONG 86 $16^{\prime} 45^{\prime \prime}$ )

\begin{tabular}{|c|c|c|c|c|}
\hline 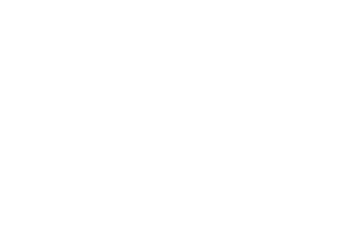 & $\begin{array}{l}1705 \\
0925 \\
1210 \\
0955 \\
1225 \\
1405 \\
0840 \\
0730 \\
1530 \\
1520 \\
1130 \\
1605\end{array}$ & $\begin{array}{l}48 \\
42 \\
33 \\
33 \\
32 \\
33 \\
42 \\
47 \\
65 \\
72 \\
66 \\
58\end{array}$ & $\begin{array}{r}865 \\
715 \\
942 \\
1140 \\
1070 \\
1010 \\
795 \\
680 \\
572 \\
414 \\
458 \\
486\end{array}$ & $\begin{array}{l}325 \\
295 \\
300 \\
265 \\
260 \\
275 \\
310 \\
320 \\
360 \\
345 \\
350 \\
335\end{array}$ \\
\hline 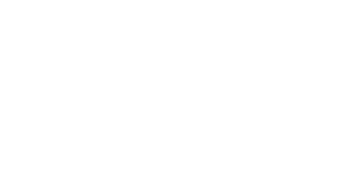 & $\begin{array}{l}0900 \\
1330 \\
0950 \\
1400 \\
1000 \\
1730 \\
1635 \\
1430 \\
1300 \\
1315\end{array}$ & $\begin{array}{l}46 \\
43 \\
32 \\
32 \\
32 \\
51 \\
67 \\
60 \\
67 \\
59\end{array}$ & $\begin{array}{r}395 \\
529 \\
1260 \\
700 \\
671 \\
925 \\
643 \\
684 \\
556 \\
495\end{array}$ & $\begin{array}{l}360 \\
350 \\
280 \\
320 \\
300 \\
330 \\
355 \\
355 \\
360 \\
360\end{array}$ \\
\hline
\end{tabular}

4-1235. MANISTEE RIVER NEAR GRAYLING (LAT 44 $41^{\prime} 35^{\prime \prime}$, LONG $84^{\circ} 50^{\prime} 50^{\prime \prime}$ )

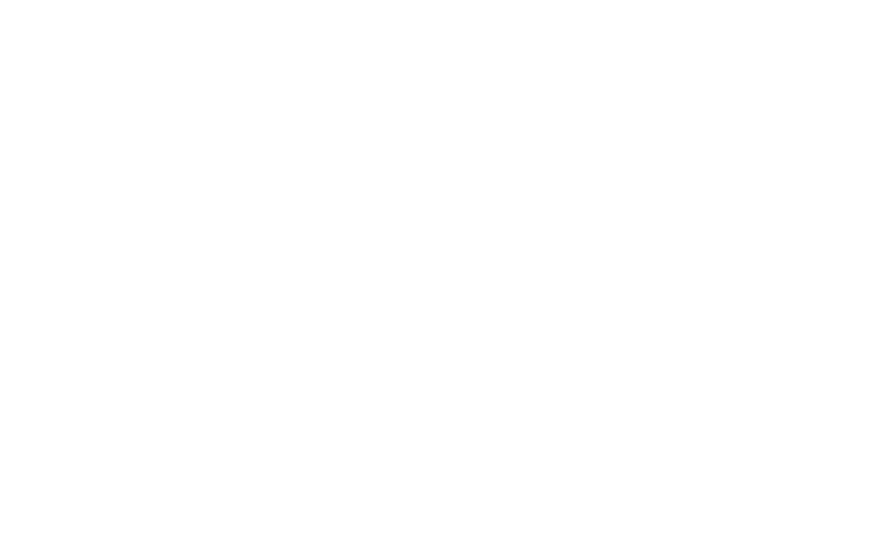

STREAMS TRIBUTARY TO LAKE HURON

4-1280. STURGEON RIVER NEAR WOLVERINE (LAT $45^{\circ} 17^{\prime} 55^{\prime \prime}$, LONG $84^{\circ} 36^{\circ} 40^{\prime \prime}$ )

\begin{tabular}{|c|c|c|c|c|}
\hline 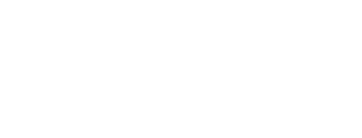 & $\begin{array}{l}1230 \\
1255 \\
1310 \\
1310 \\
0935 \\
1020 \\
1015\end{array}$ & $\begin{array}{l}42 \\
41 \\
38 \\
32 \\
32 \\
34 \\
37\end{array}$ & $\begin{array}{l}193 \\
222 \\
449 \\
208 \\
210 \\
195 \\
249\end{array}$ & $\begin{array}{l}375 \\
370 \\
330 \\
360 \\
355 \\
360 \\
350\end{array}$ \\
\hline
\end{tabular}

A Daily mean discharge. 
CHEUICAL-QUALITY INVESTIGATIONS OF COLD WATER STREAES IN MICHIGAN--CONTInUed Specific conductance (micromhos at $25^{\circ} \mathrm{C}$ ), October 1965 to September 1967--Continued

\begin{tabular}{l|c|c|c|c}
\hline \multicolumn{3}{c}{ October 1965 to September 1967--Continued } \\
Date & $\begin{array}{c}\text { Water } \\
\text { tem- } \\
\text { per- } \\
\text { ature } \\
\left({ }^{\circ} \mathrm{F}\right)\end{array}$ & $\begin{array}{c}\text { Discharge } \\
\text { (cfs) }\end{array}$ & $\begin{array}{c}\text { Specific } \\
\text { conductance } \\
\text { (micrombos) } \\
\text { at } \\
\left.24{ }^{\circ} \mathrm{C}\right)\end{array}$ \\
\hline
\end{tabular}

STREAUS TRIBUTARY TO LAKE HURON--Continued

4-1280. Sturgeon River near Wolverine--Continued

\begin{tabular}{|c|c|c|c|c|}
\hline 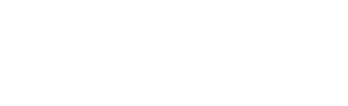 & $\begin{array}{l}1000 \\
0920 \\
1030 \\
0950 \\
1405\end{array}$ & $\begin{array}{l}48 \\
56 \\
62 \\
58 \\
59\end{array}$ & $\begin{array}{r}267 \\
185 \\
149 \\
155 \\
\mathbf{A 1 5 5}\end{array}$ & $\begin{array}{l}350 \\
400 \\
360 \\
380 \\
345\end{array}$ \\
\hline 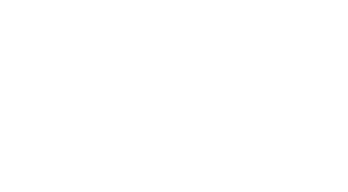 & $\begin{array}{l}1010 \\
1400 \\
0945 \\
1015 \\
1330 \\
1125 \\
1350 \\
1335 \\
0905 \\
0915\end{array}$ & $\begin{array}{l}48 \\
38 \\
32 \\
34 \\
32 \\
51 \\
58 \\
58 \\
59 \\
54\end{array}$ & $\begin{array}{r}181 \\
\mathbf{A} 207 \\
173 \\
200 \\
220 \\
264 \\
177 \\
177 \\
205 \\
163\end{array}$ & $\begin{array}{l}350 \\
350 \\
360 \\
360 \\
350 \\
325 \\
380 \\
360 \\
380 \\
385\end{array}$ \\
\hline
\end{tabular}

4-1290. PIGEON RIVER NEAR VANDERBILT (LAT $45^{\circ} 10^{\prime} 15^{\prime \prime}$, LONG $84^{\circ} 26^{\prime} 20^{\prime \prime}$ )

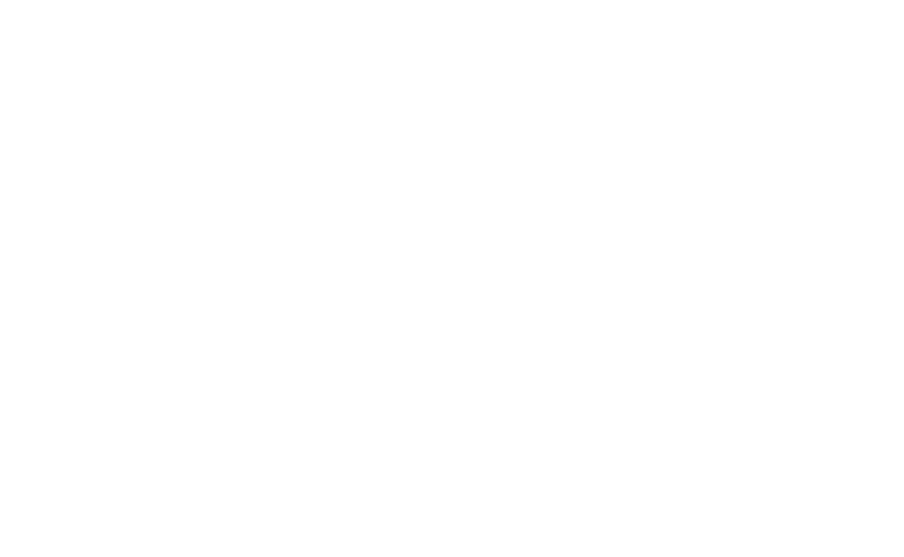

4-1355. AU SABLE RIVER AT GRAYLING (LAT $44^{\circ} 39^{\prime} 35^{\prime \prime}$, LONG $84^{\circ} 42^{\prime} 45^{\prime \prime}$ )

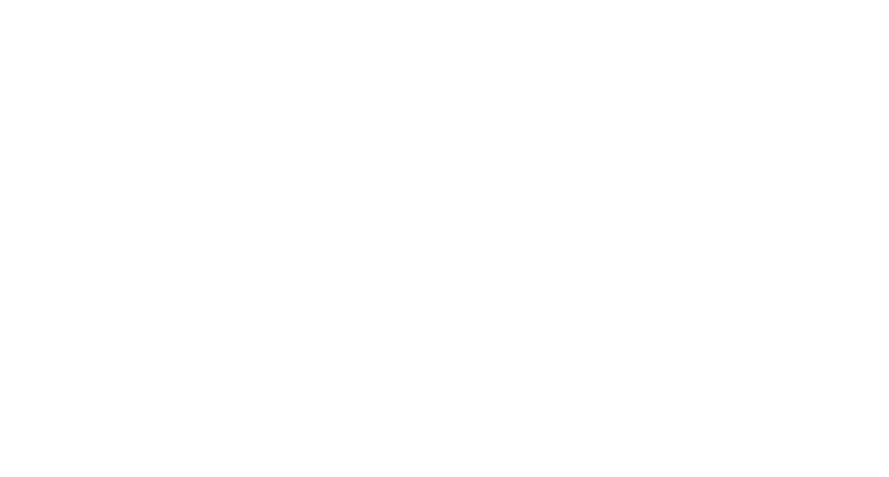

A Daily mean discharge. 
CHEMICAL-QUALITY INVESTIGATIONS OF COLD WATER STREAMS IN MICHIGAN--COntInUEd

Specific conductance (micromhos at $25^{\circ} \mathrm{C}$ ), October 1965 to September 1967--Continued

\begin{tabular}{c|c|c|c|c}
\hline \multicolumn{3}{c}{ October 1965 to September 1967--Continued } & $\begin{array}{c}\text { Specific } \\
\text { conductance } \\
\text { (micromhos } \\
\text { at } \\
\left.25^{\circ} \mathrm{C}\right)\end{array}$ \\
\hline
\end{tabular}

STREAMS TRIBUTARY TO LAKE HURON--COntinued

4-1385. AU GRES RIVER NEAR NATIONAL CITY (LAT $44^{\circ} 10^{\prime} 45^{\prime \prime}$, LONG $83^{\circ} 44^{\prime} 15^{\prime \prime}$ )

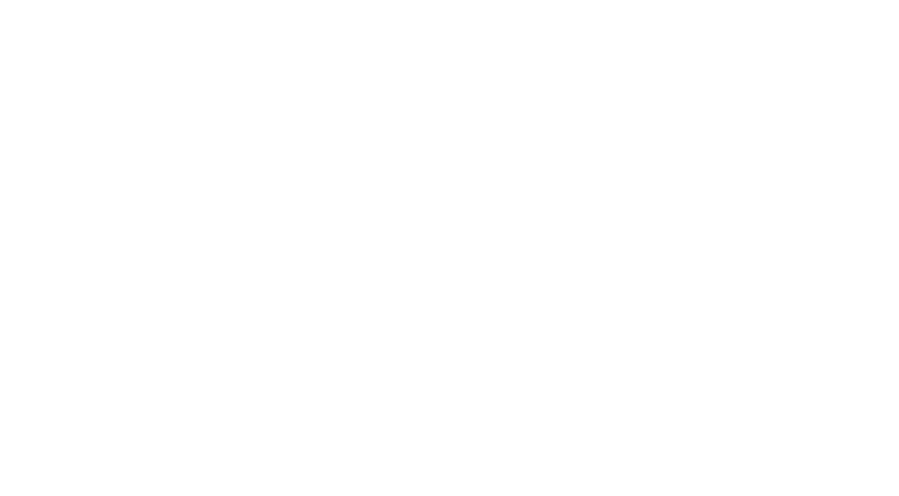

4-1405. RIFLE RIVER AT SELKIRK (LAT 44 $18^{\circ} 50^{\prime \prime}$, LONG $84^{\circ} 04^{\prime} 00^{\prime \prime}$ )

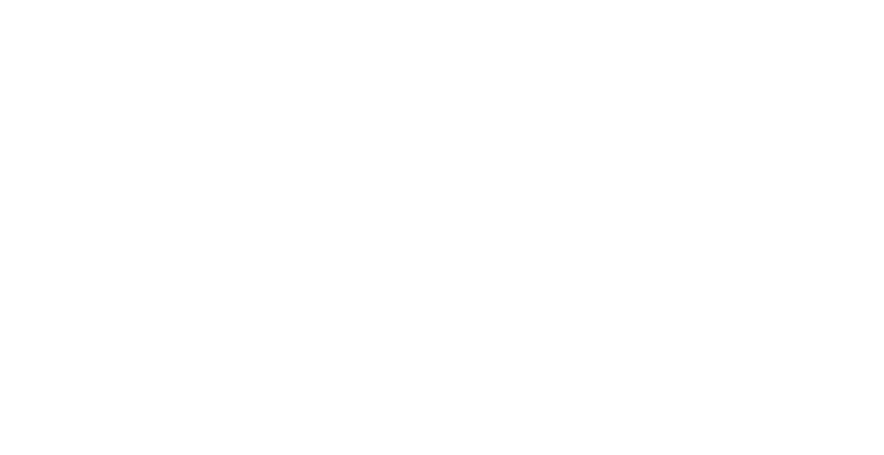

4-1525. TOBACCO RIVER AT BEAVERTON (LAT $43^{\circ} 52^{\prime} 45^{\prime \prime}$, LONG $84^{\circ} 28^{\prime} 25^{\prime \prime}$ )

\begin{tabular}{|c|c|c|c|c|}
\hline 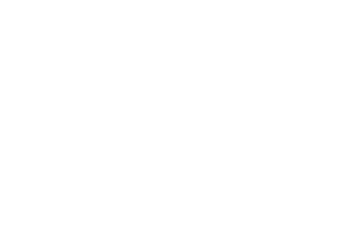 & $\begin{array}{l}1410 \\
1300 \\
1005 \\
1150 \\
1250 \\
1210 \\
1400 \\
0955 \\
1130 \\
0815 \\
1020 \\
1030\end{array}$ & $\begin{array}{l}55 \\
44 \\
34 \\
33 \\
33 \\
34 \\
39 \\
51 \\
59 \\
77 \\
72 \\
67\end{array}$ & $\begin{array}{l}249 \\
247 \\
301 \\
557 \\
242 \\
481 \\
437 \\
423 \\
199 \\
157 \\
179 \\
185\end{array}$ & $\begin{array}{l}475 \\
485 \\
445 \\
395 \\
475 \\
450 \\
425 \\
425 \\
480 \\
445 \\
415 \\
400\end{array}$ \\
\hline 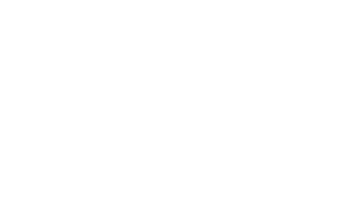 & $\begin{array}{l}0945 \\
1300 \\
1355 \\
1350 \\
1220 \\
1655 \\
1235 \\
1210 \\
0915 \\
0900 \\
0925\end{array}$ & $\begin{array}{l}53 \\
38 \\
34 \\
32 \\
33 \\
46 \\
52 \\
73 \\
72 \\
70 \\
63\end{array}$ & $\begin{array}{l}154 \\
132 \\
397 \\
208 \\
240 \\
340 \\
459 \\
130 \\
130 \\
220 \\
159 \\
\end{array}$ & $\begin{array}{l}440 \\
380 \\
465 \\
480 \\
430 \\
340 \\
395 \\
425 \\
445 \\
455 \\
430\end{array}$ \\
\hline
\end{tabular}

A Daily mean discharge. 


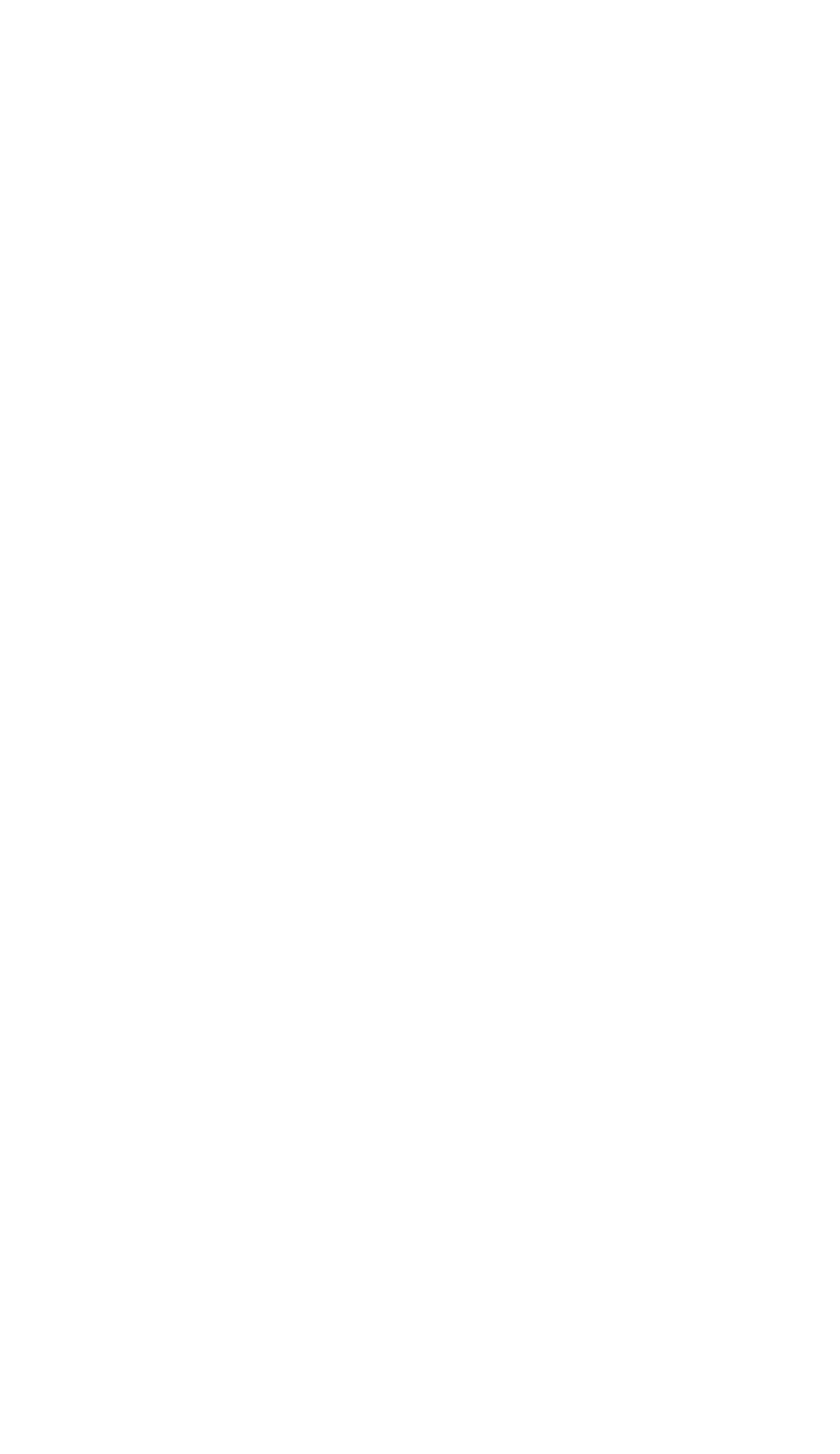




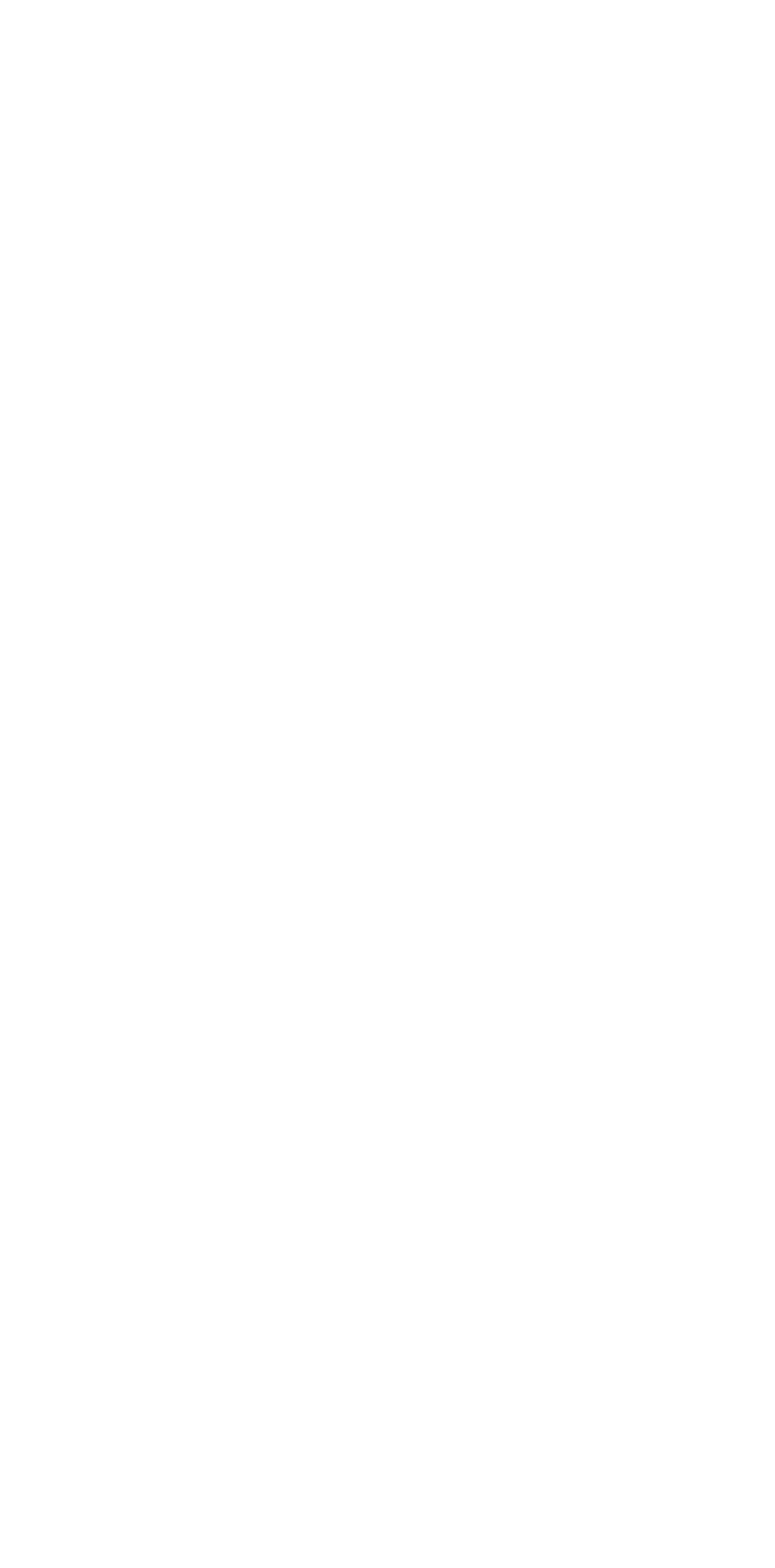




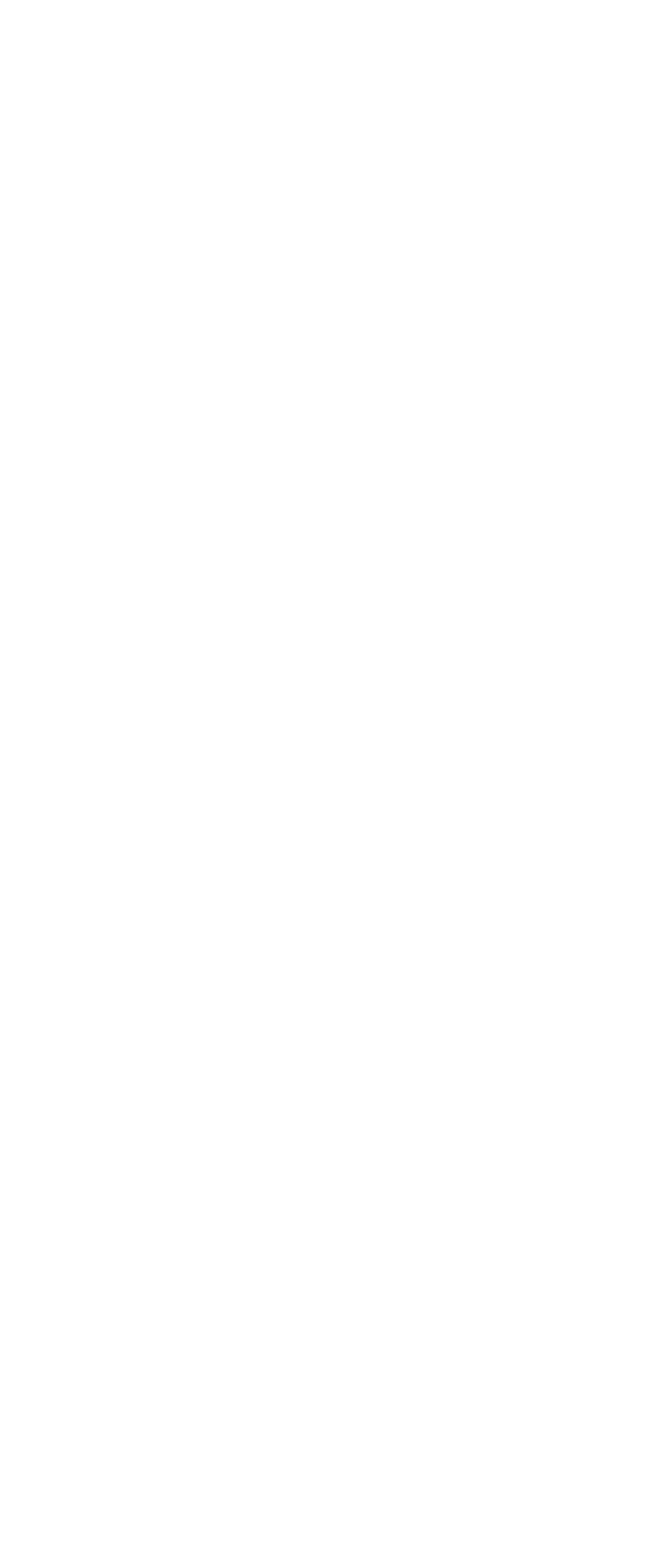




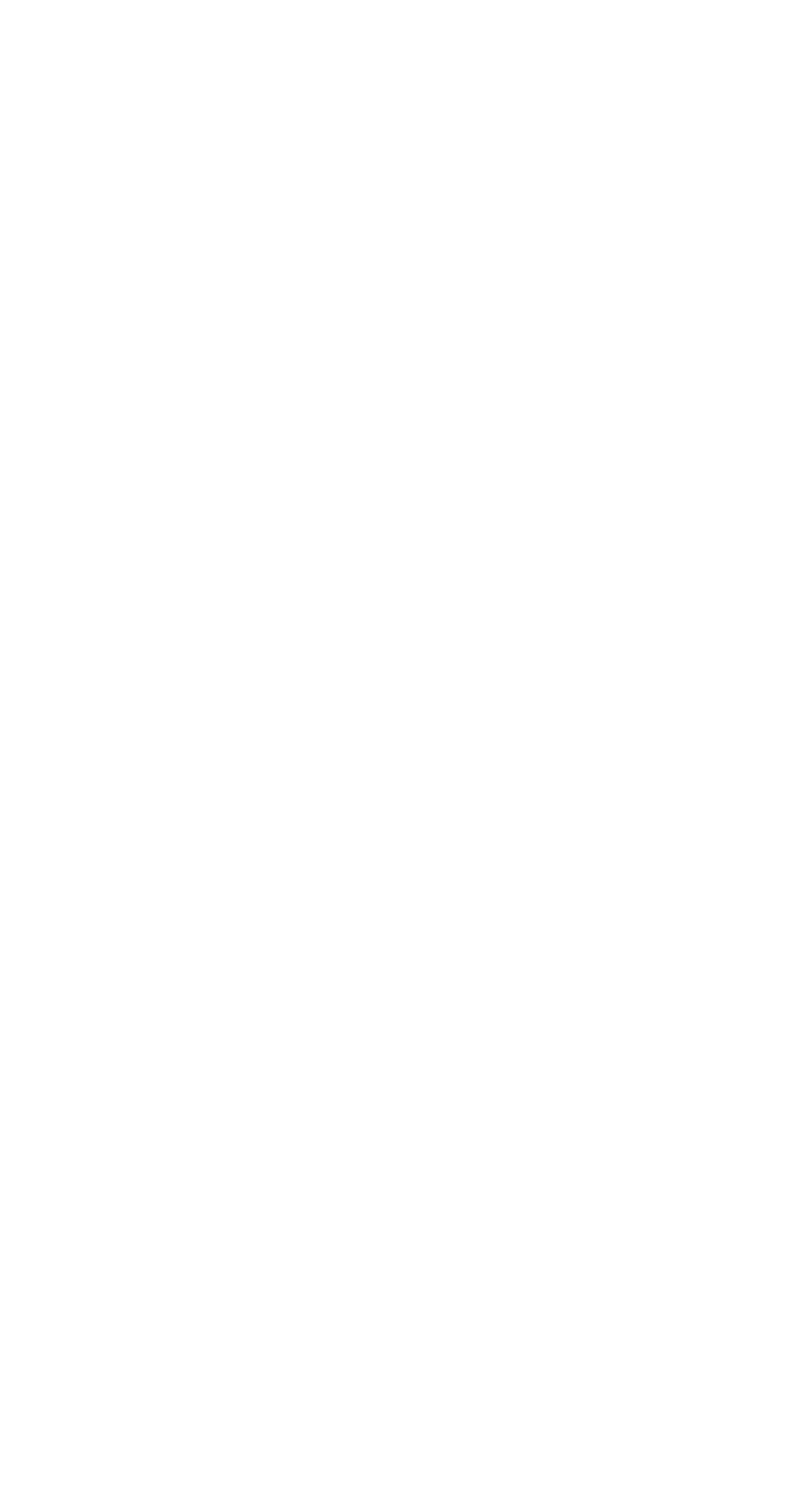




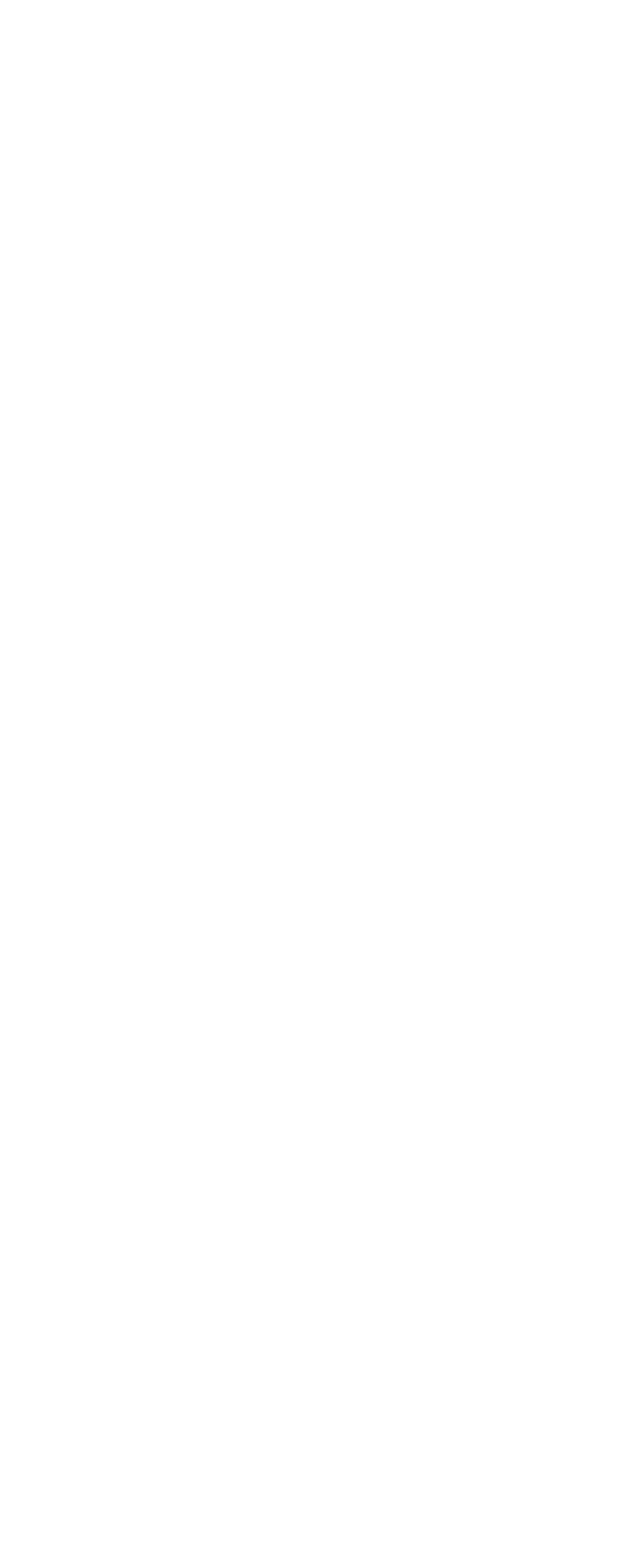




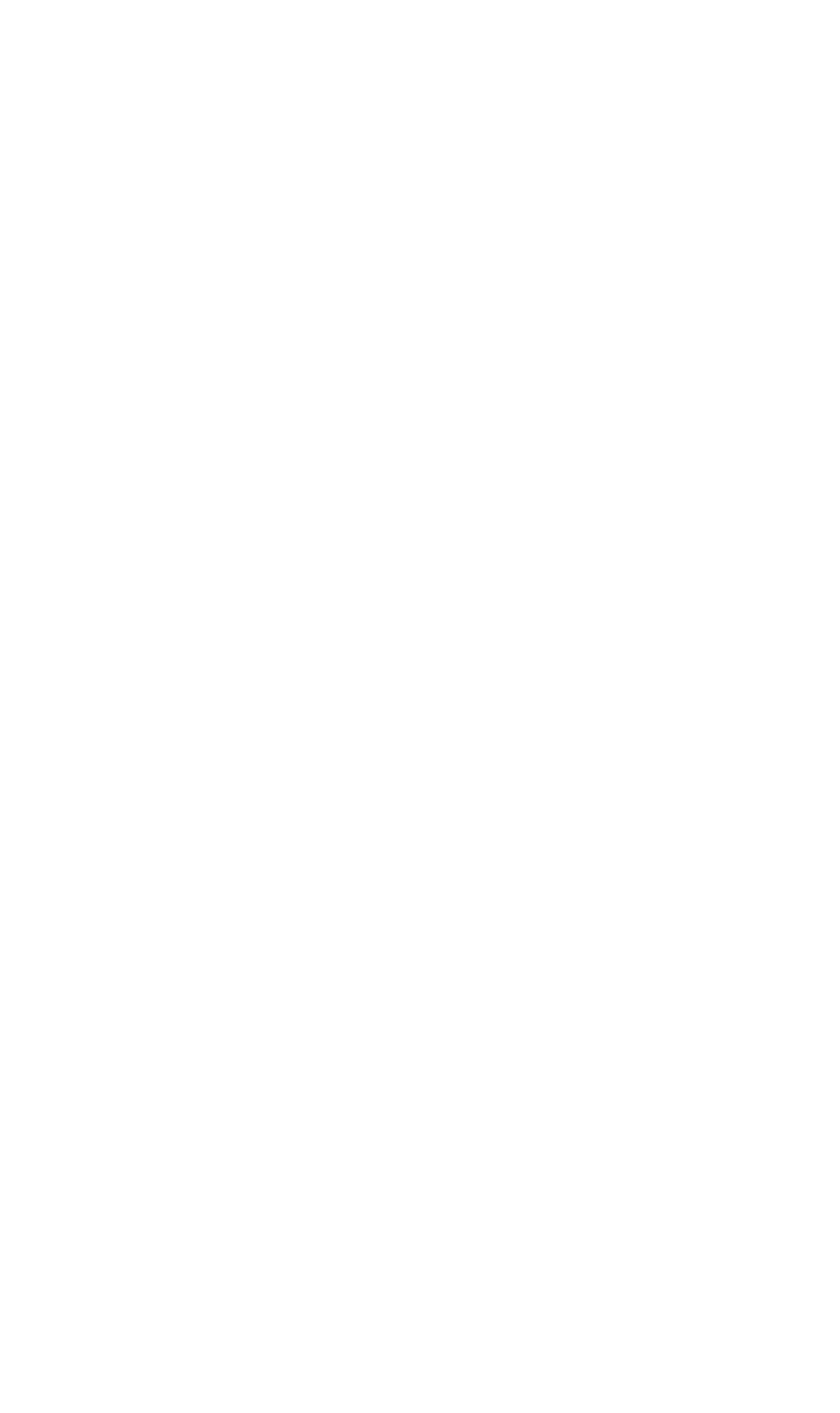




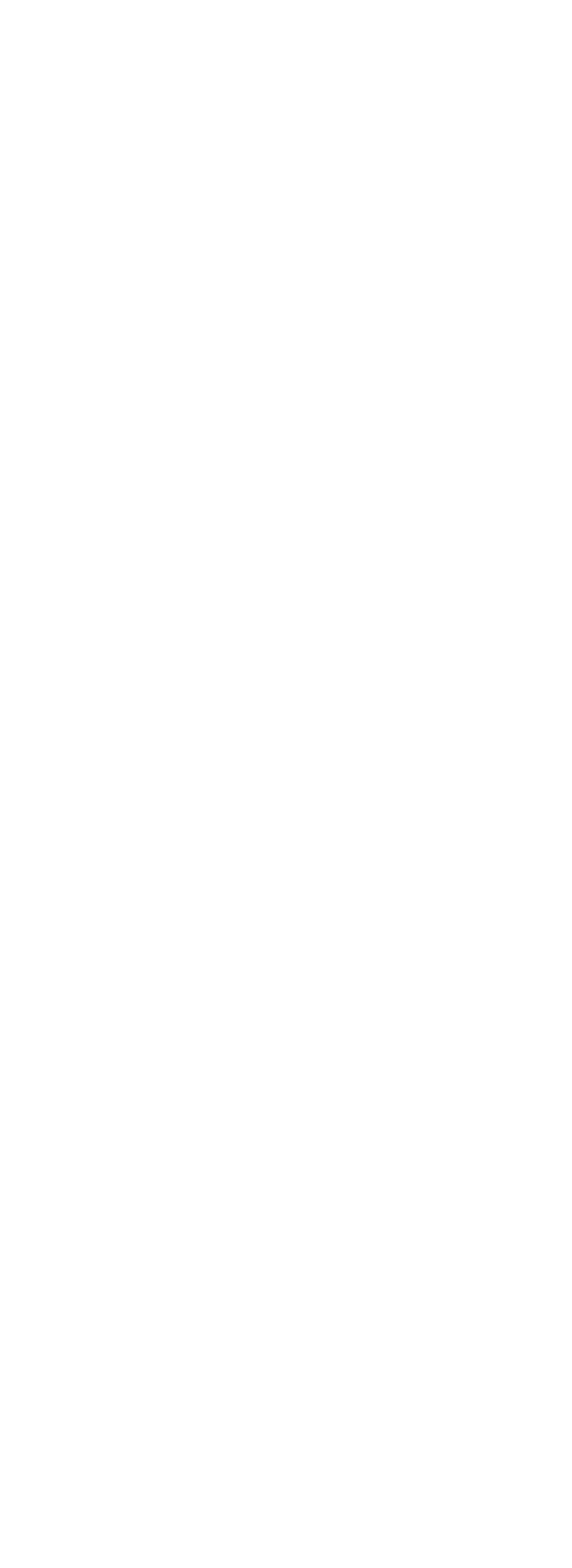




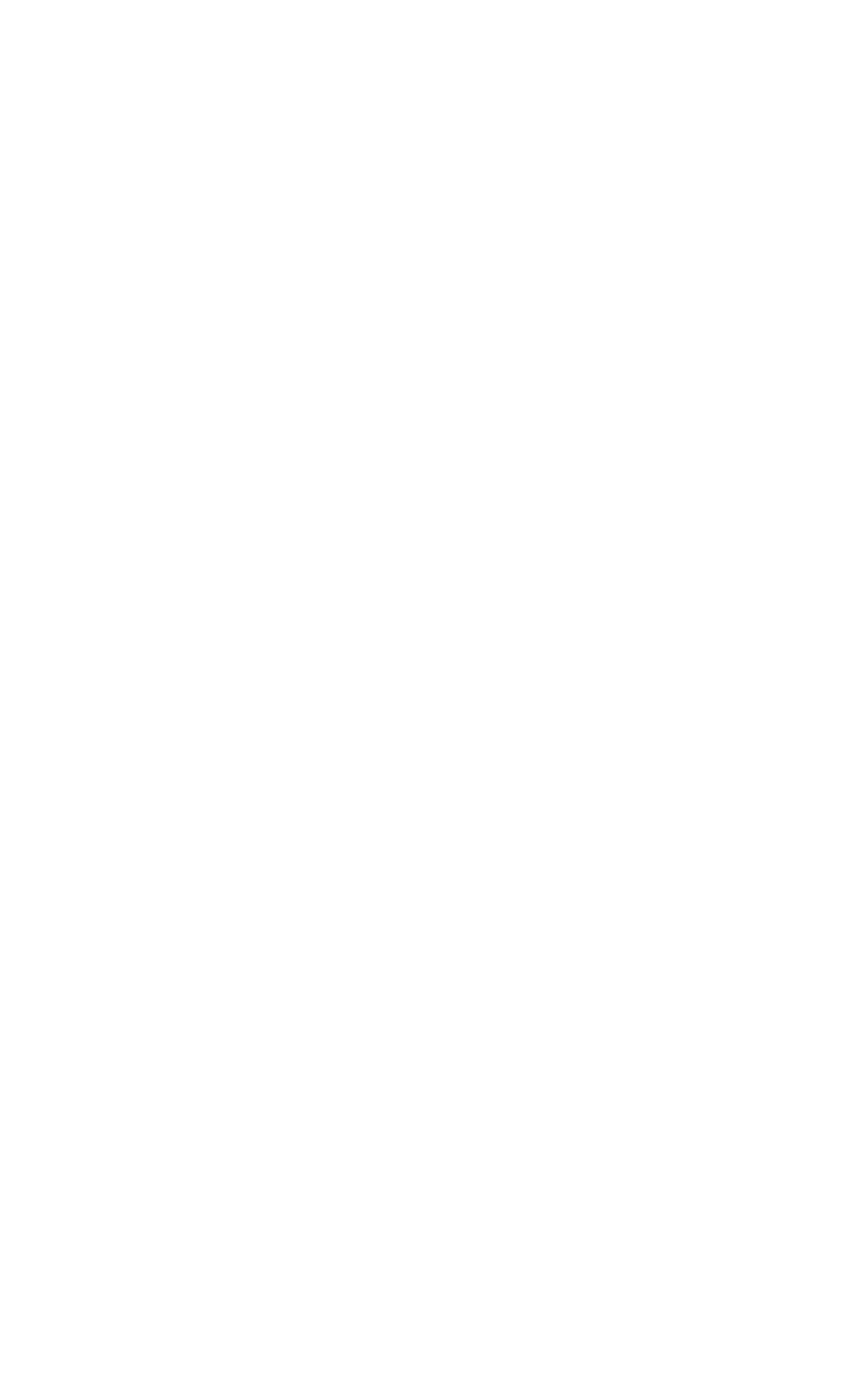




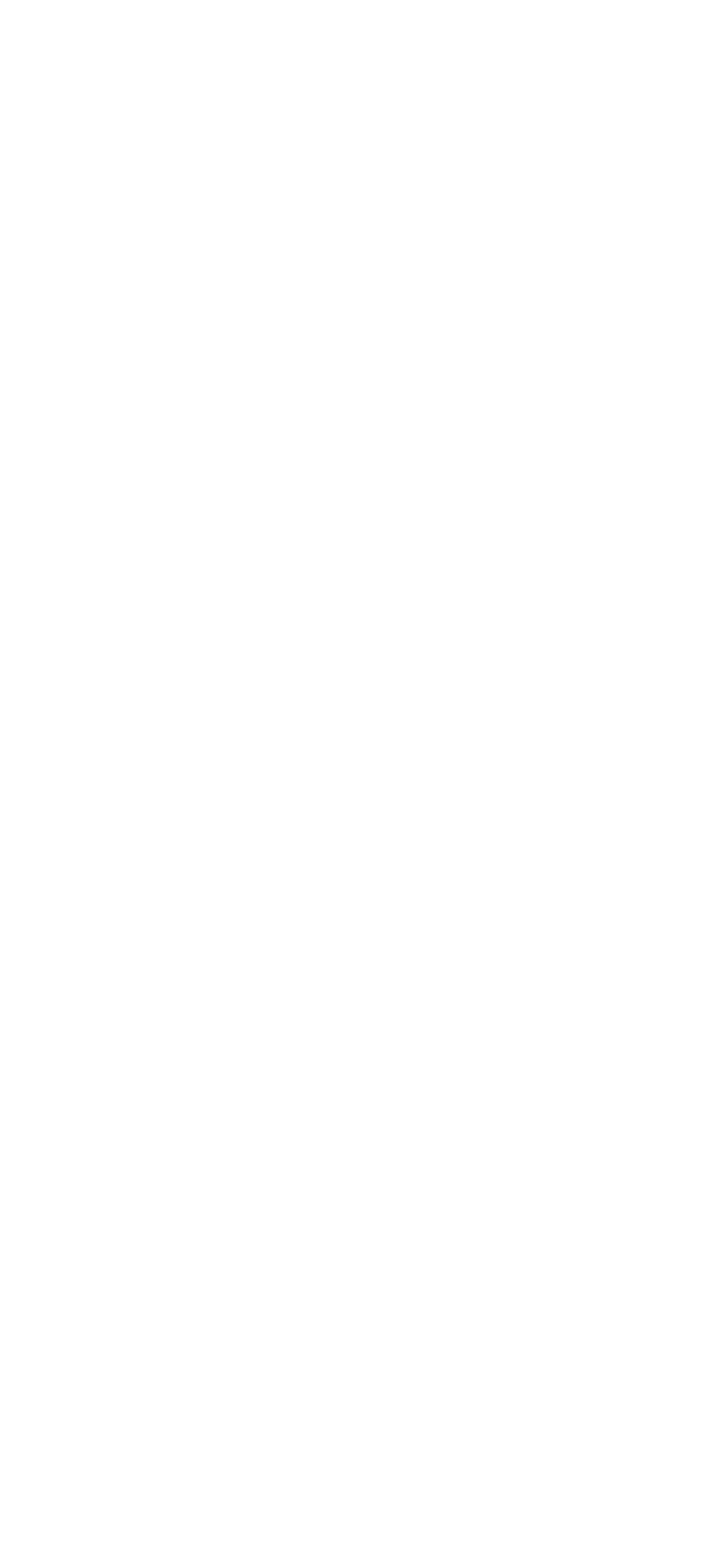




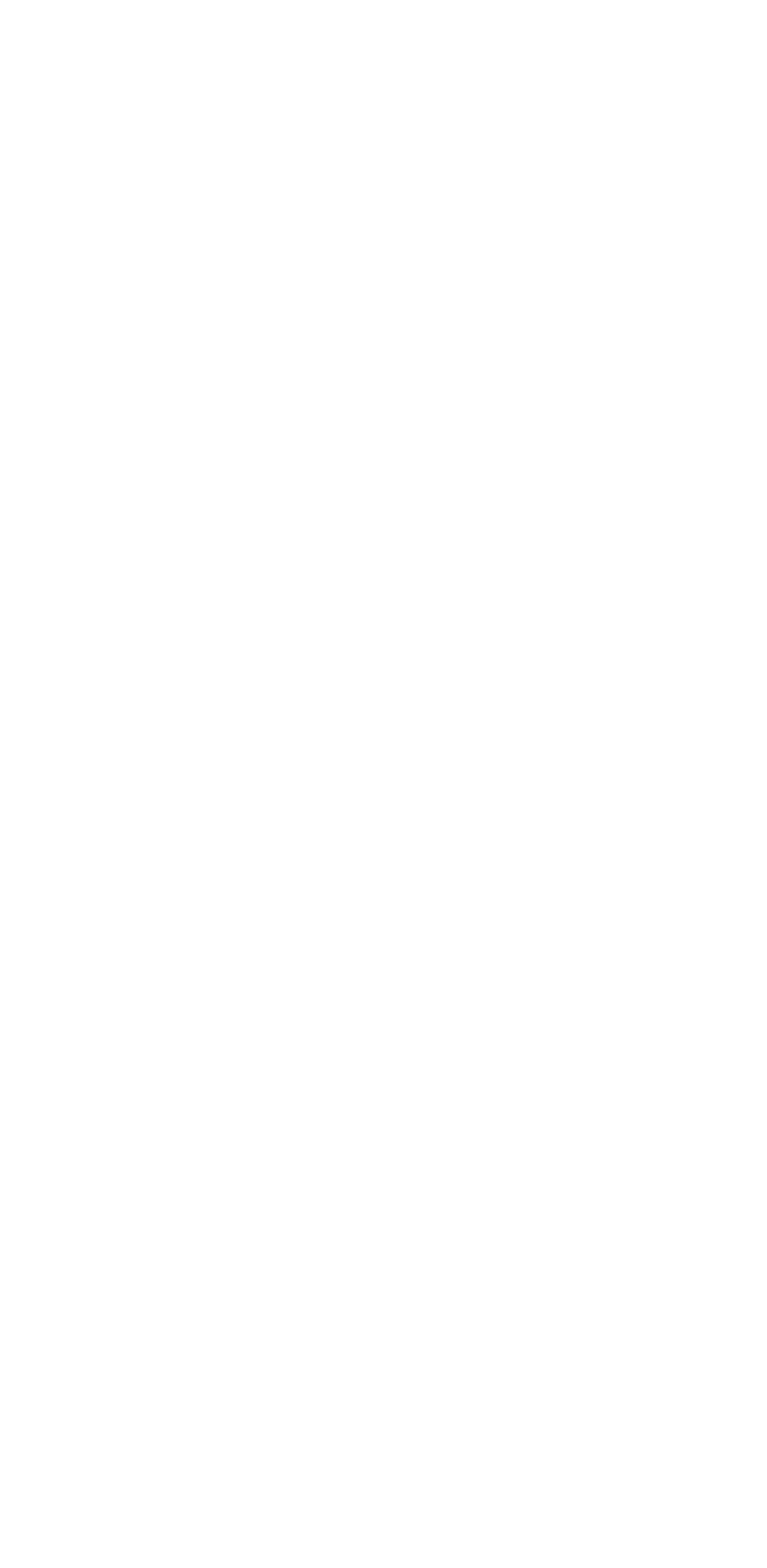




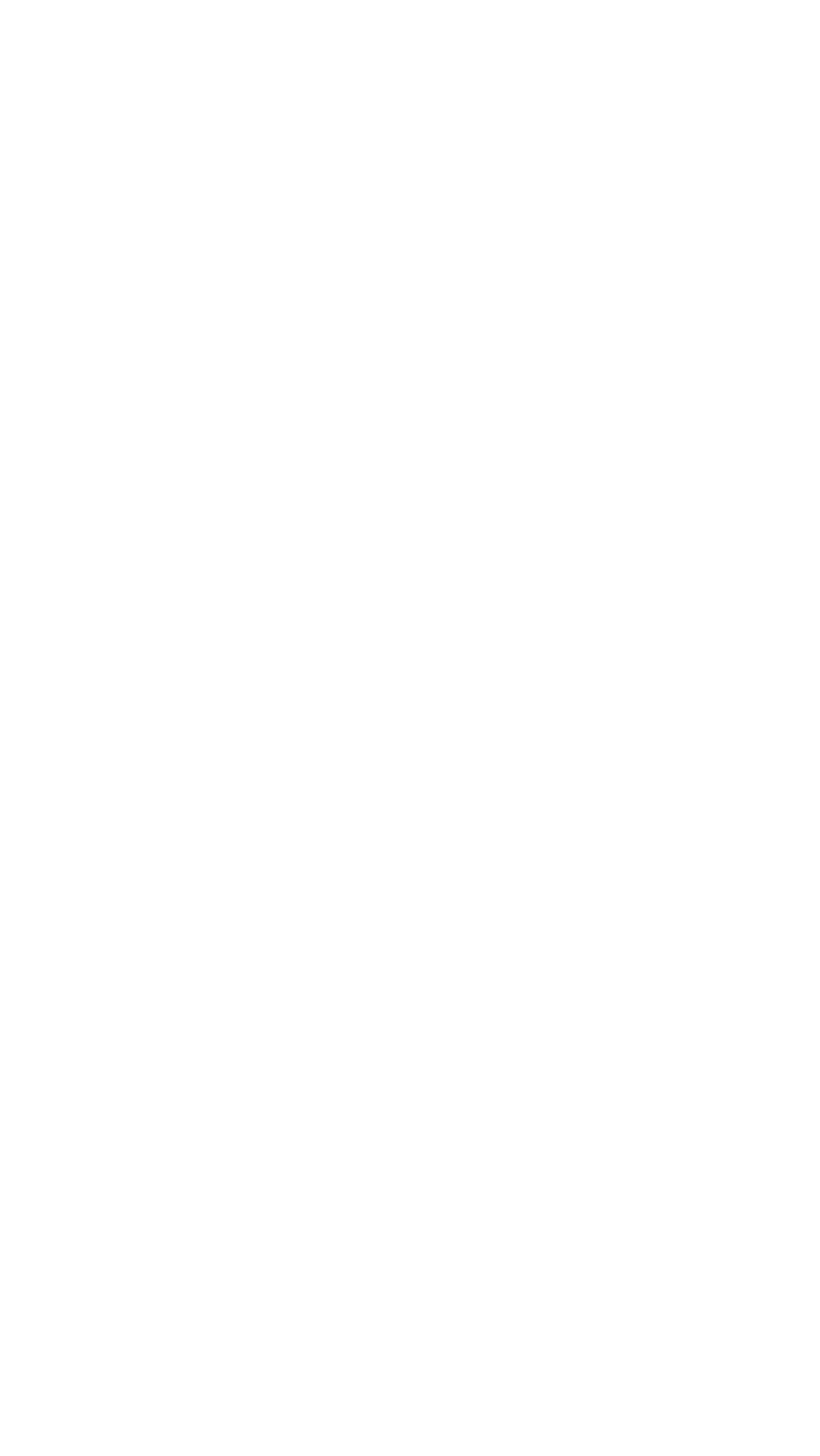




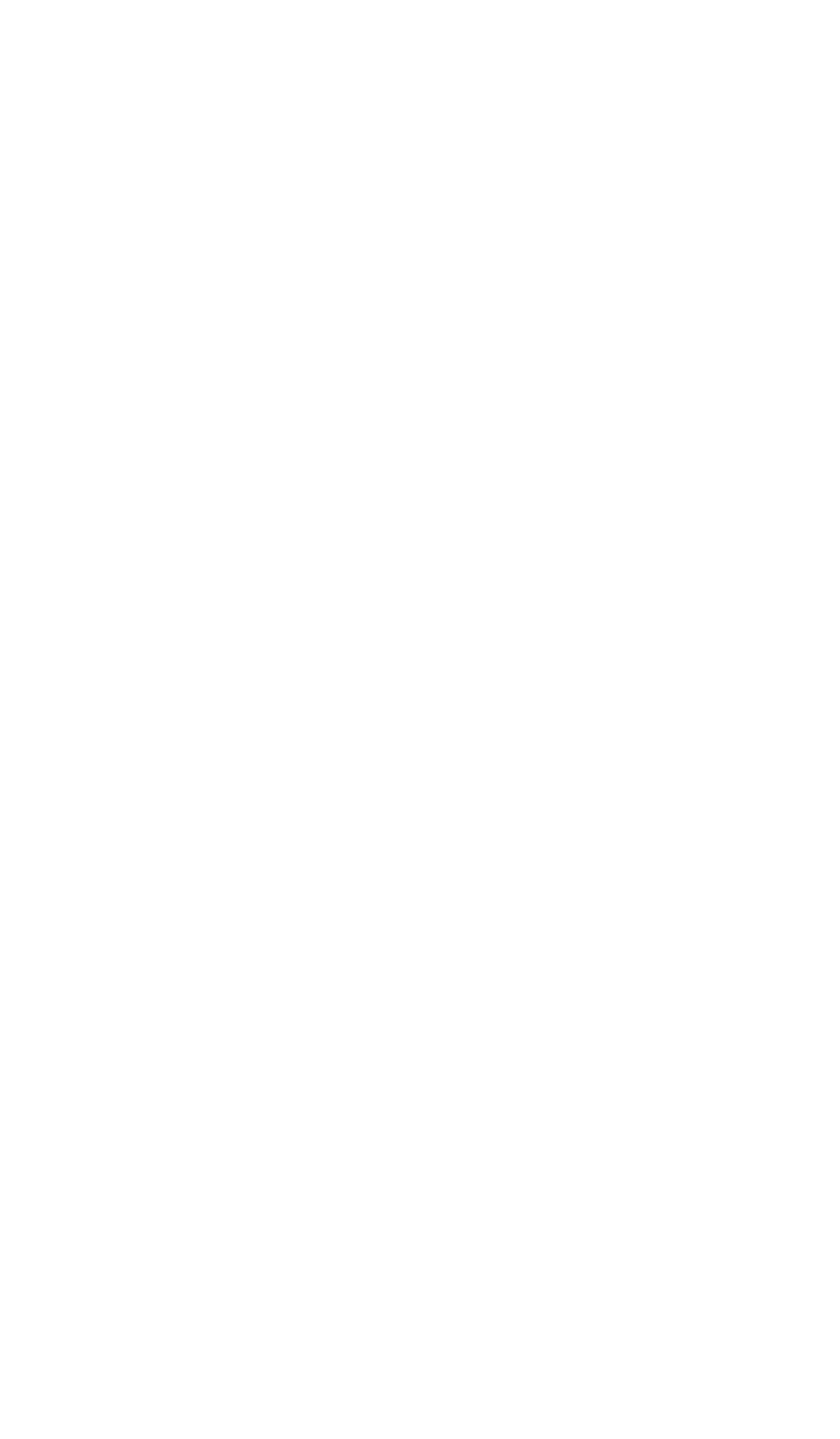




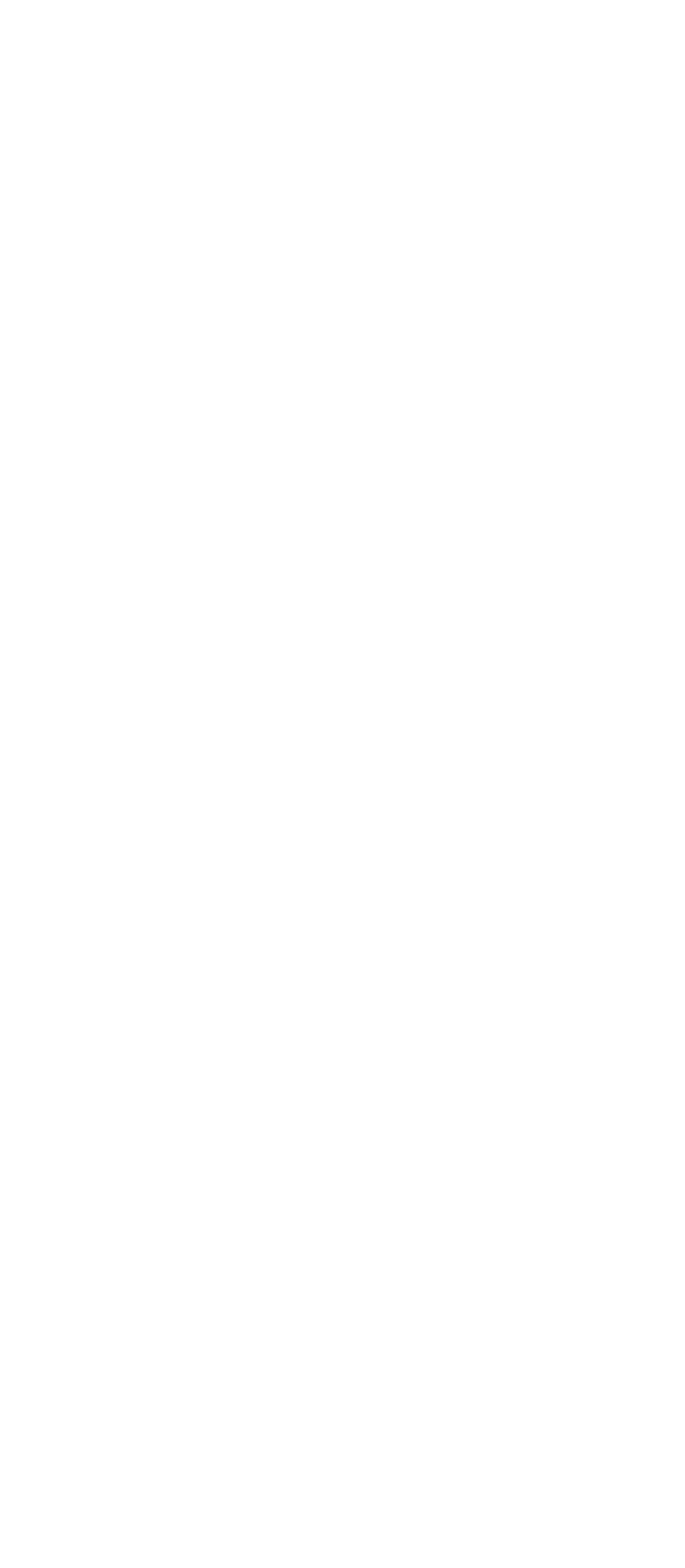




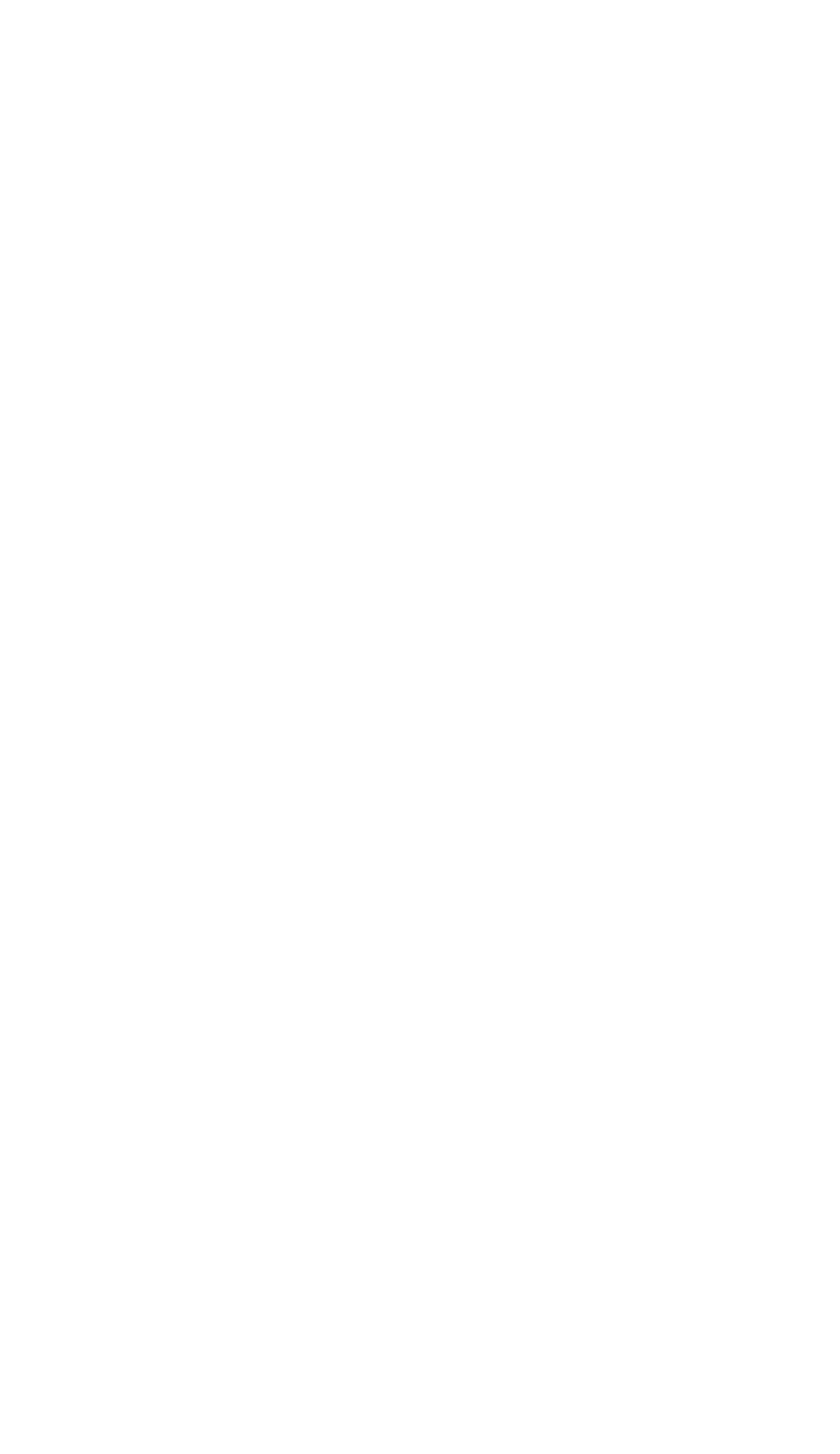




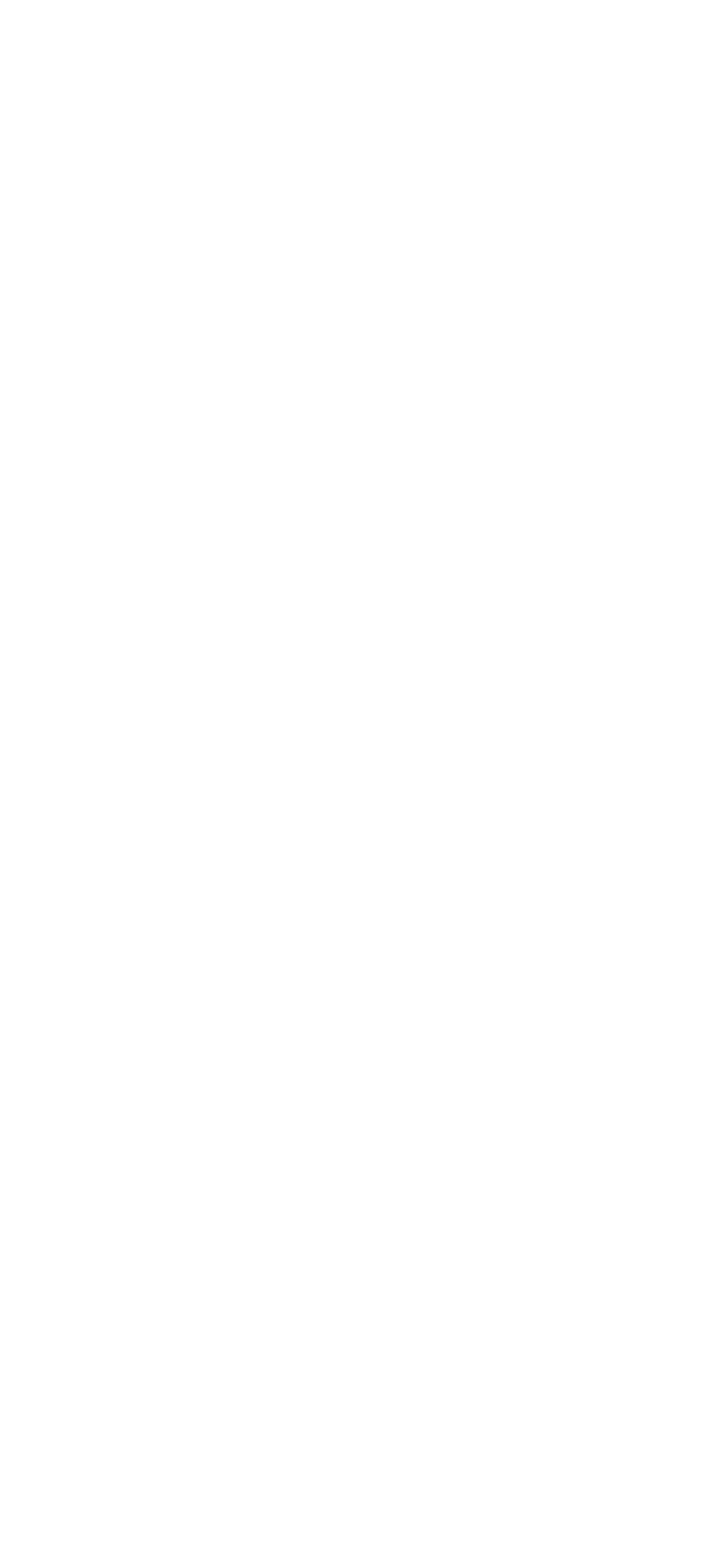




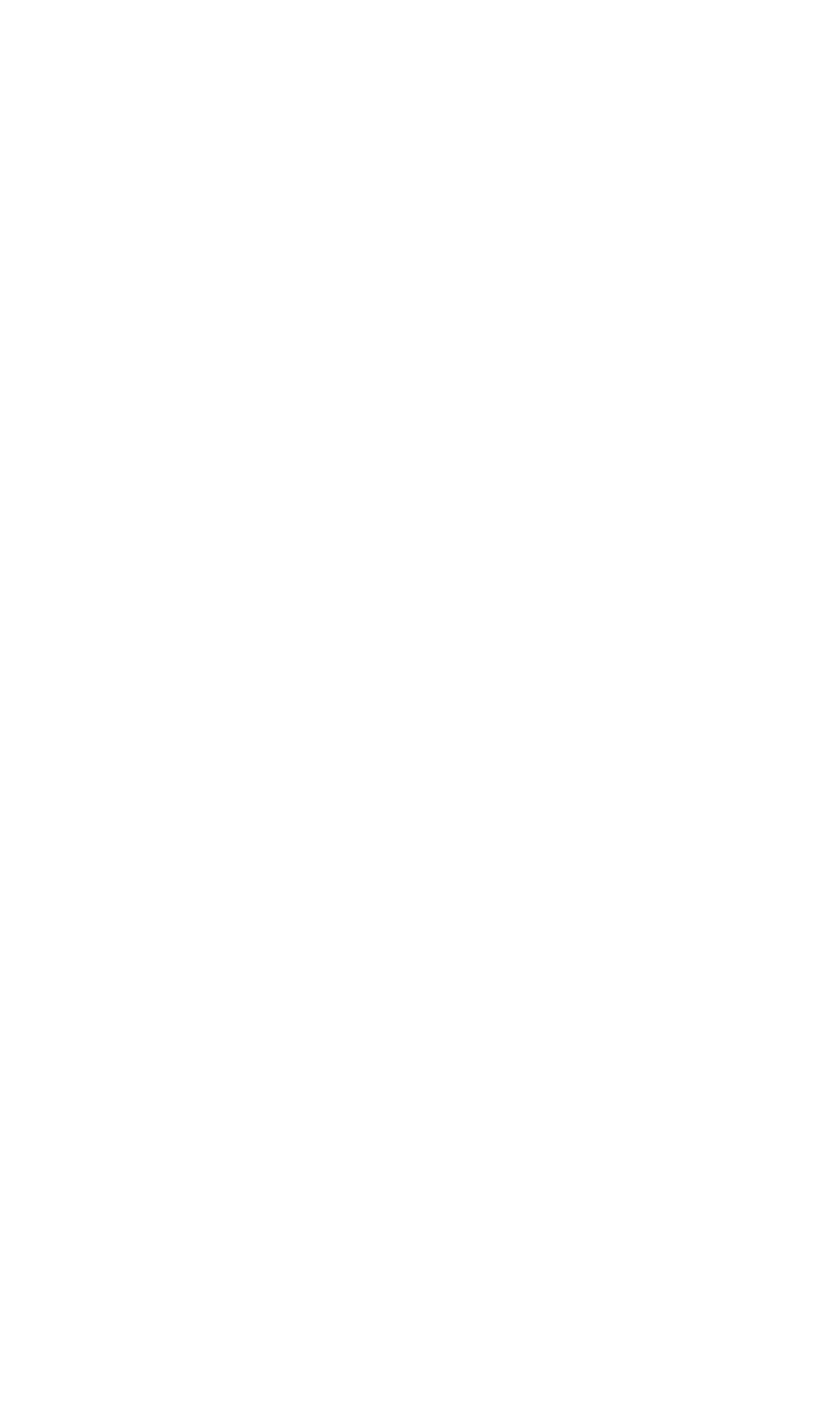




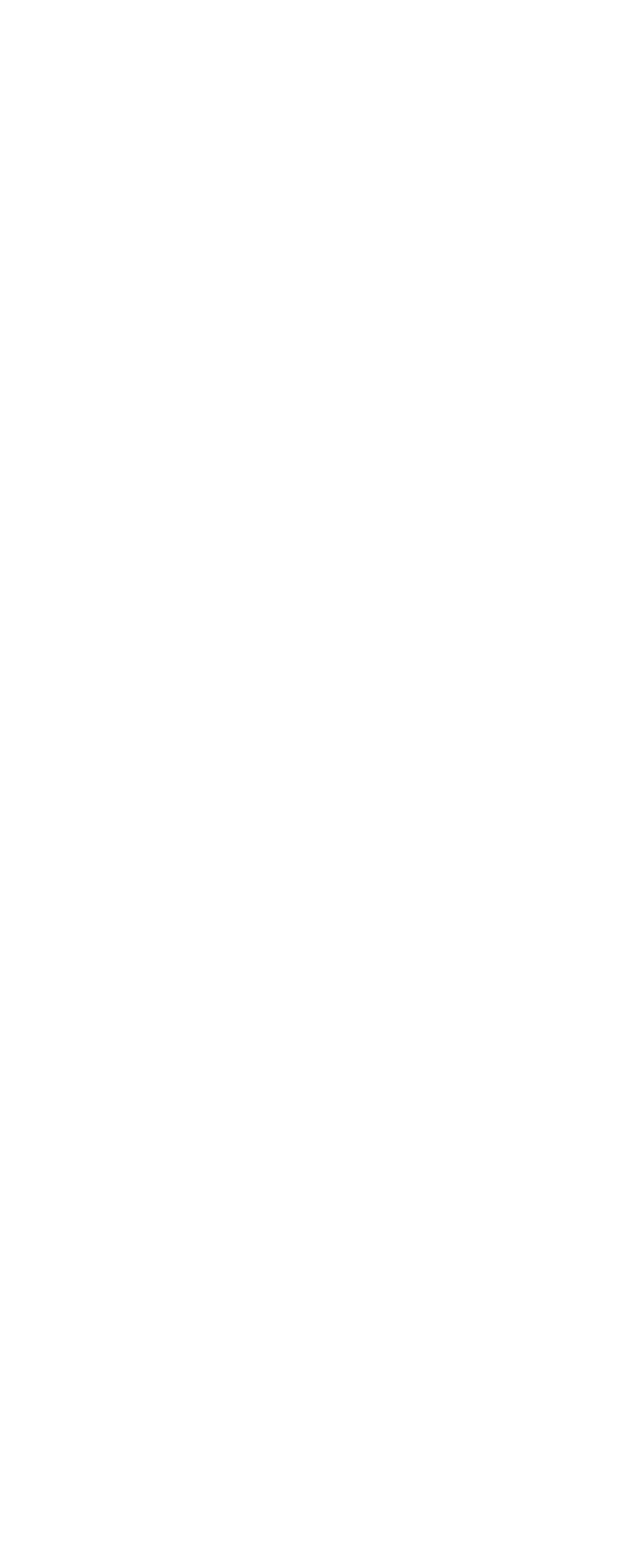




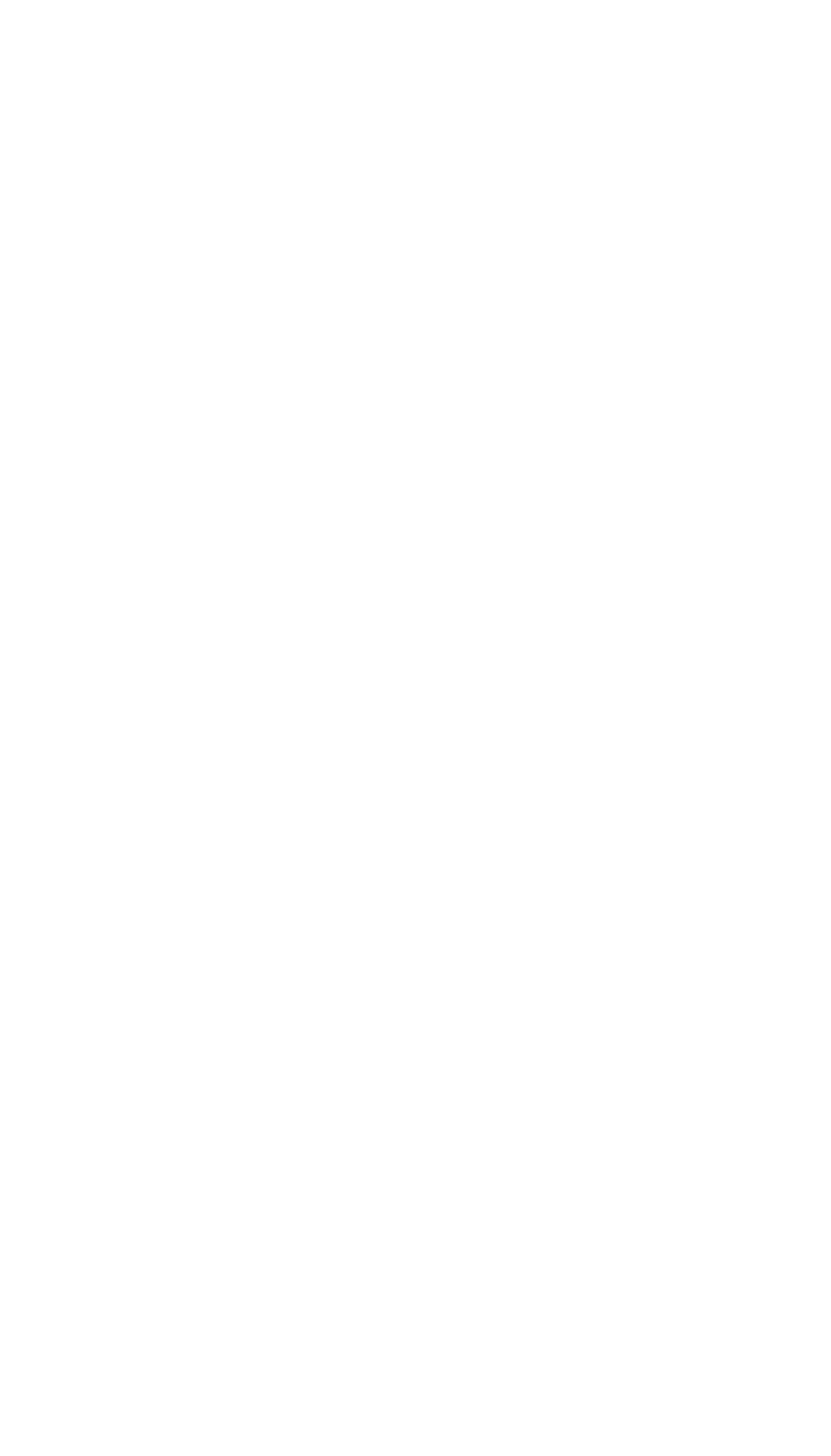




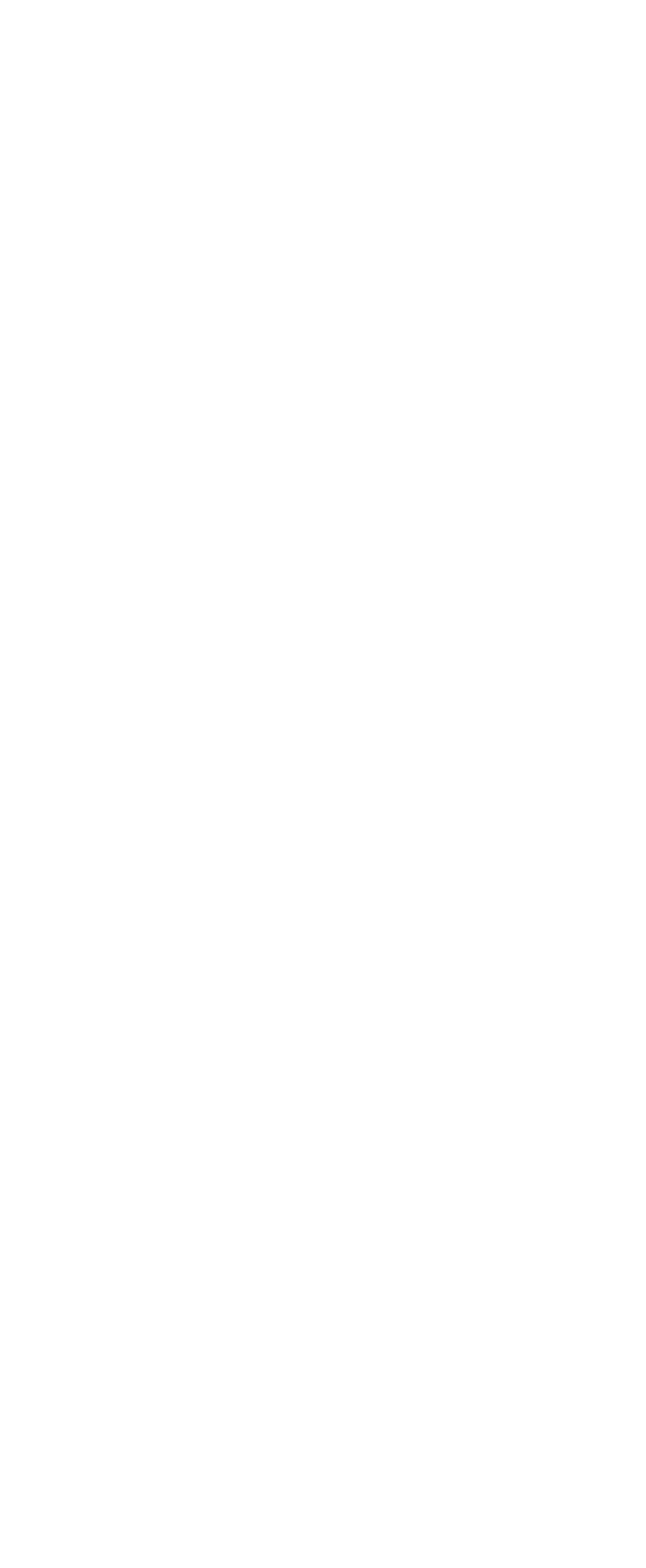




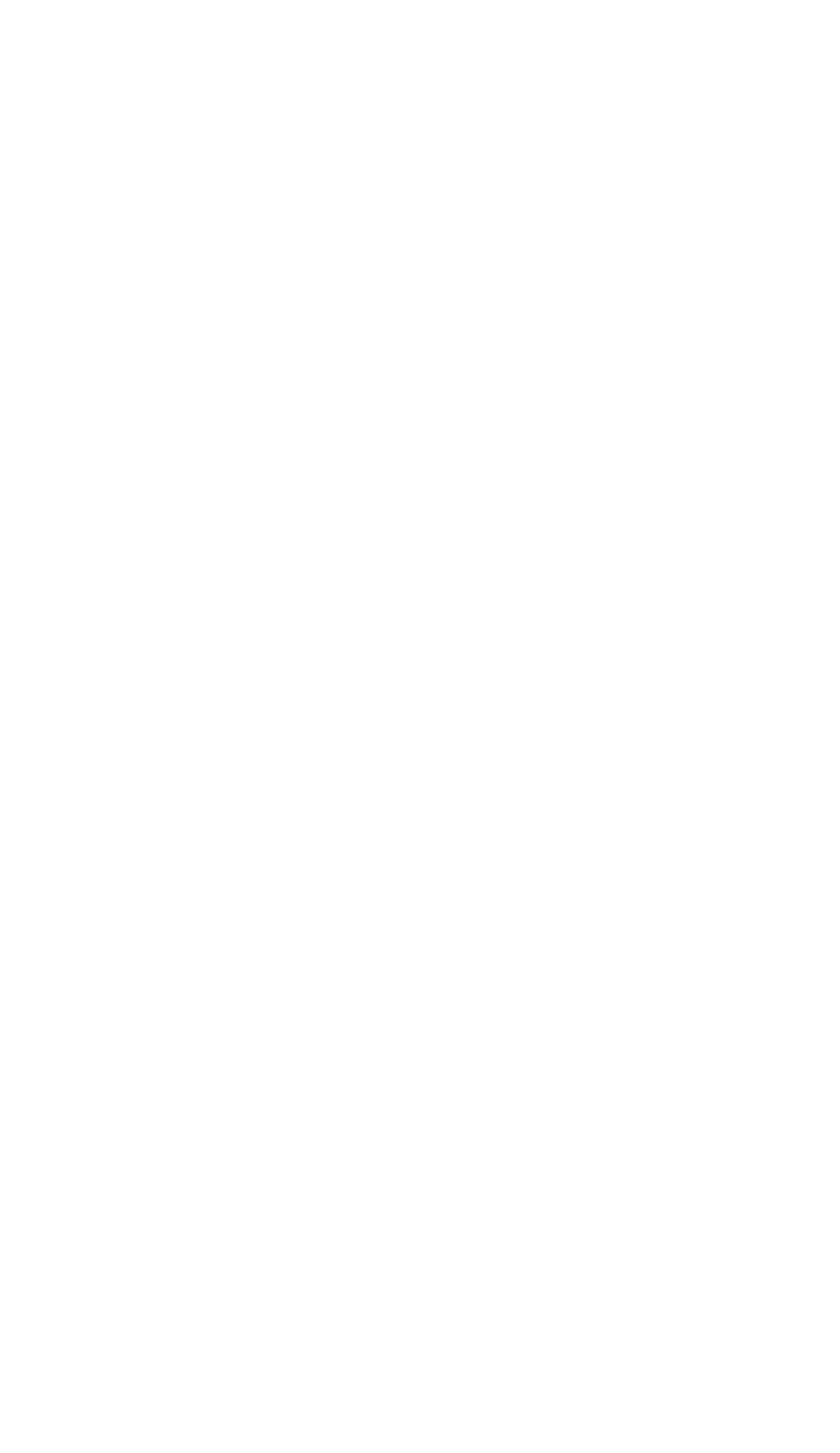




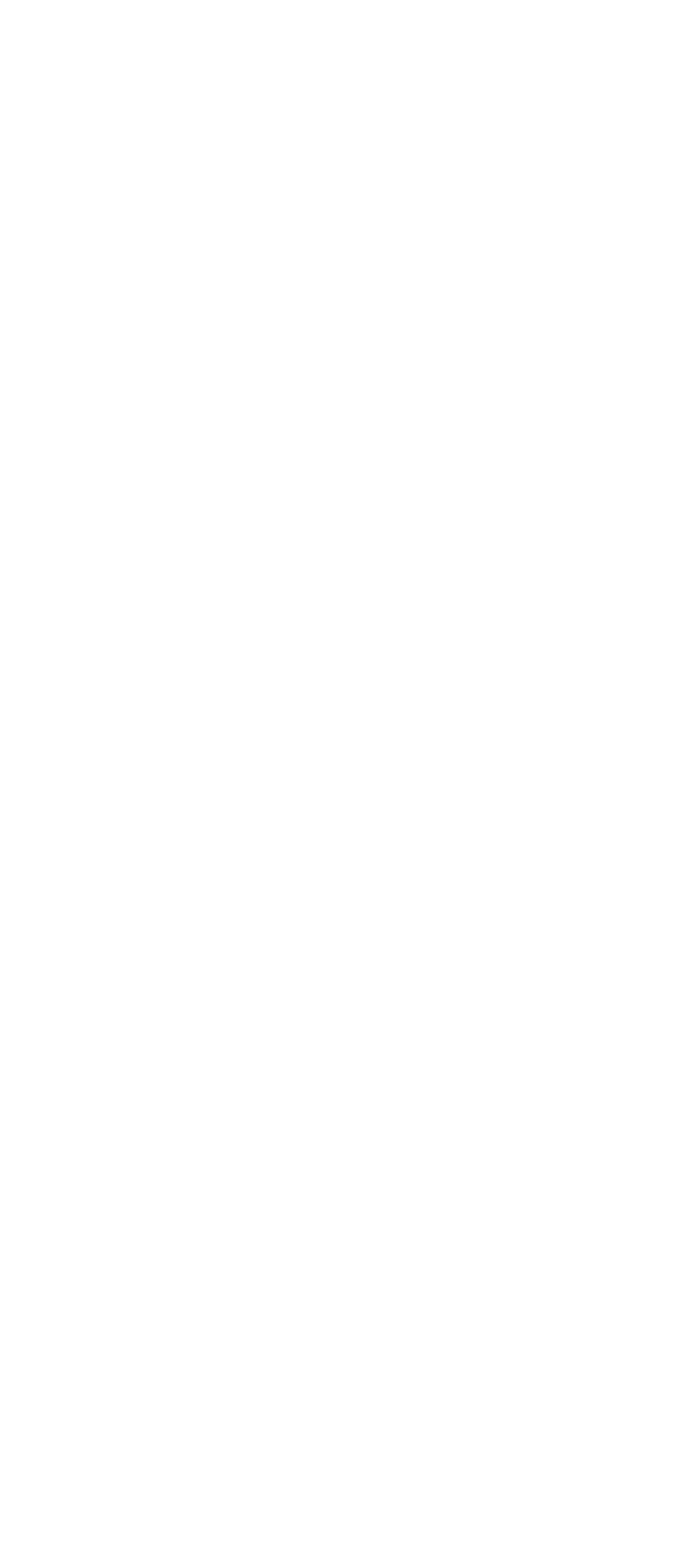




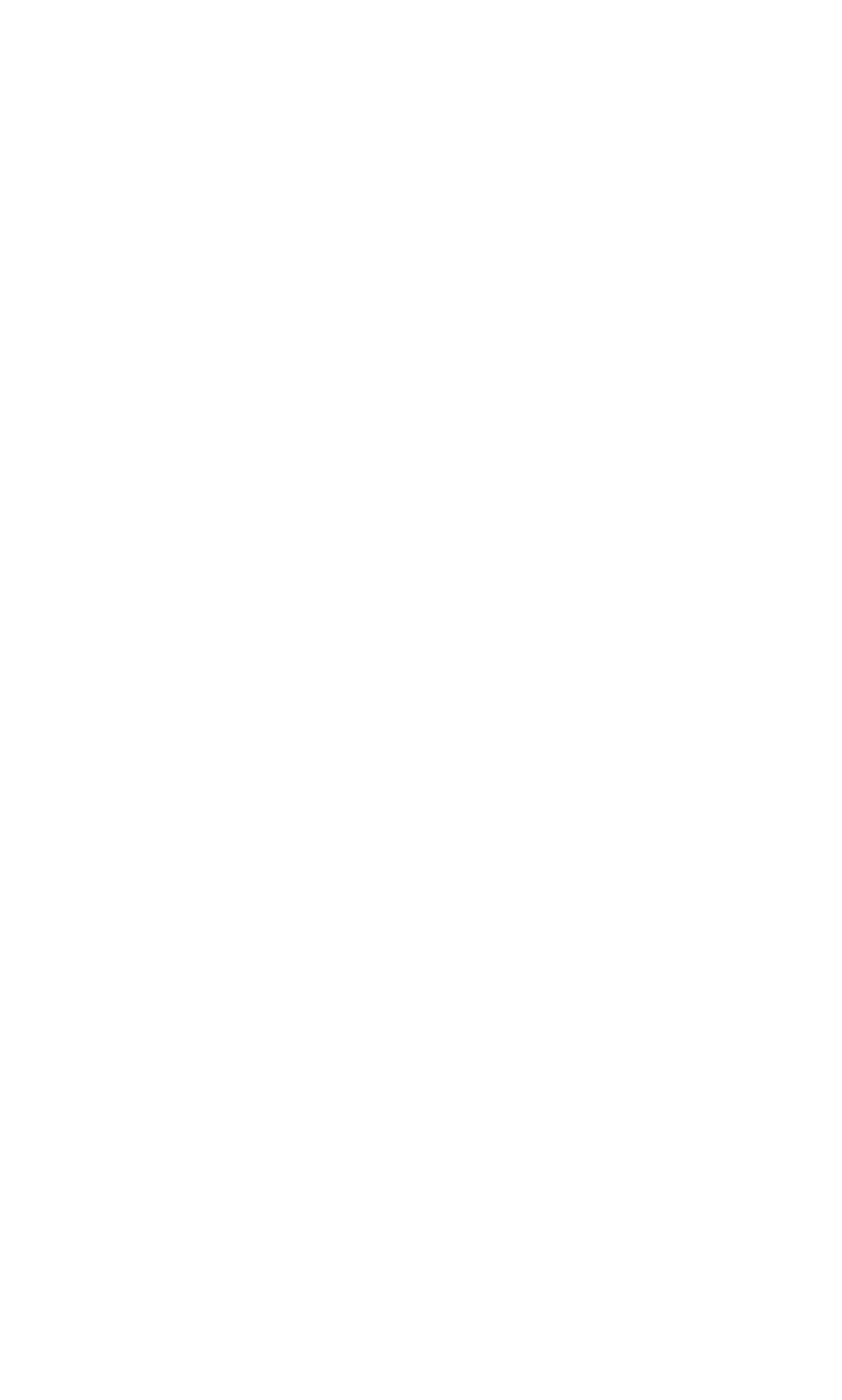




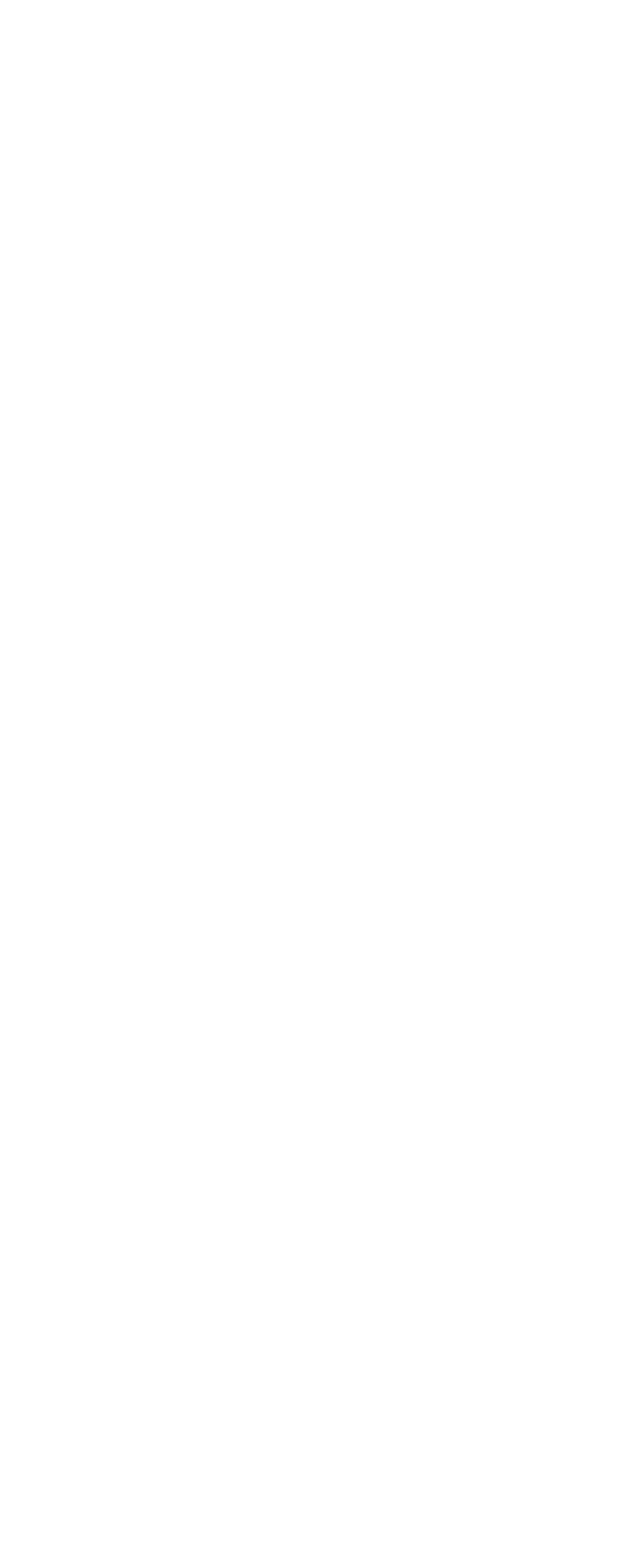




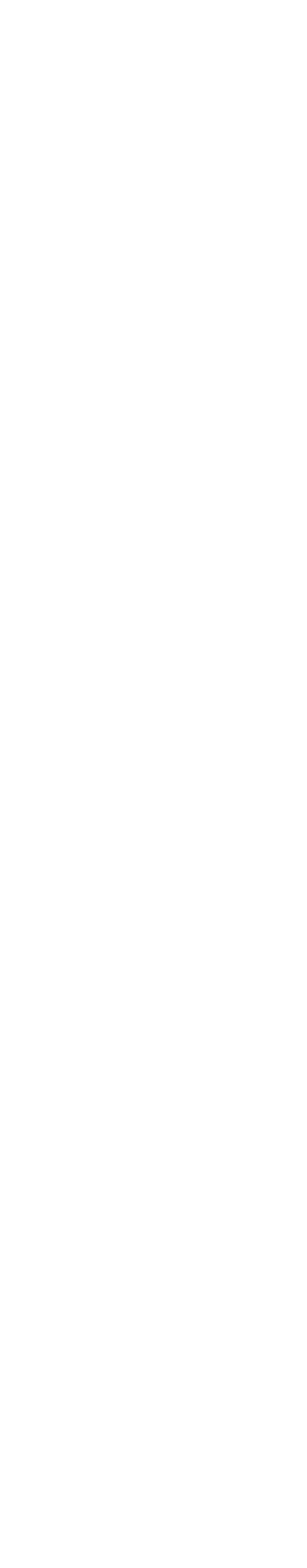




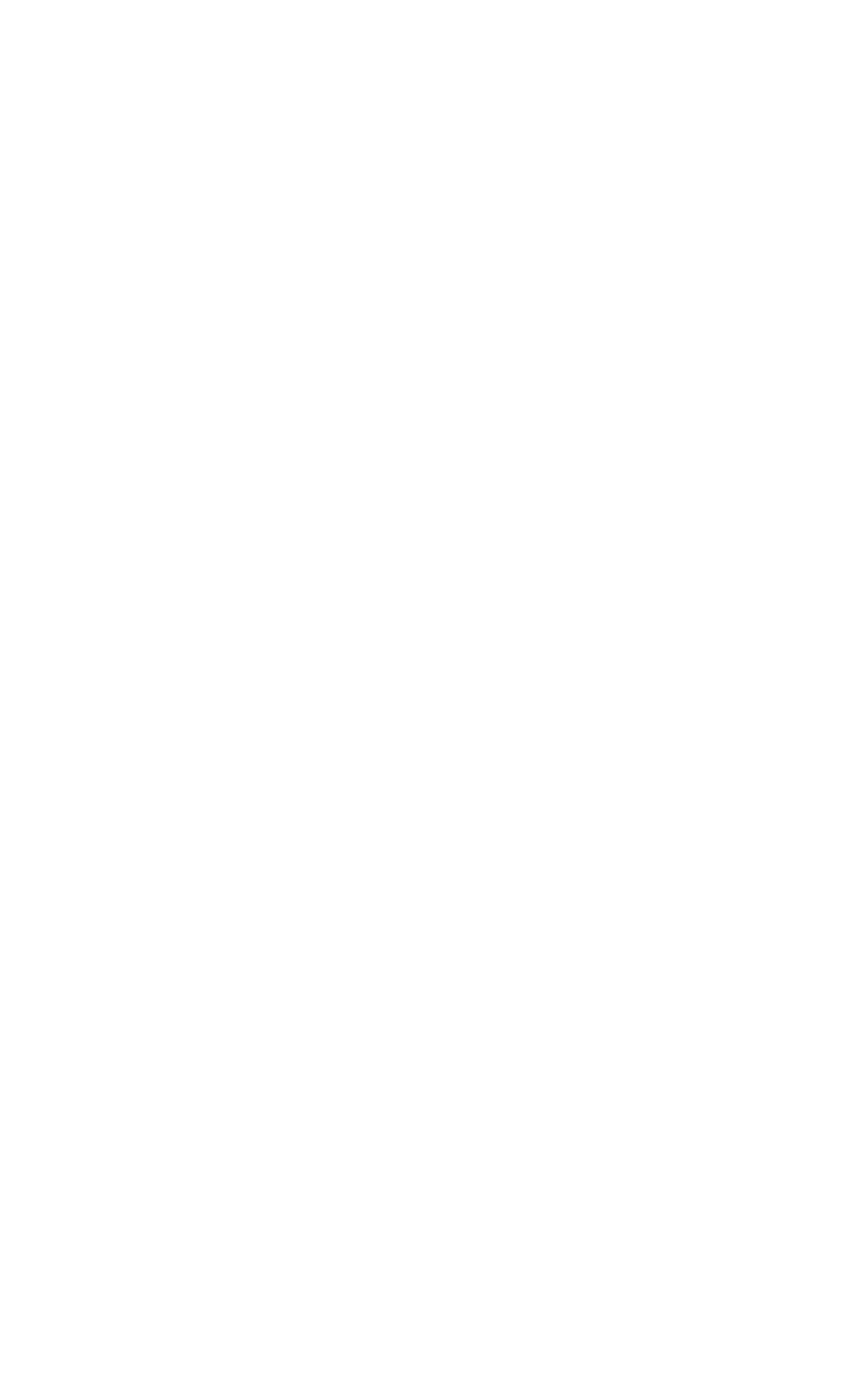




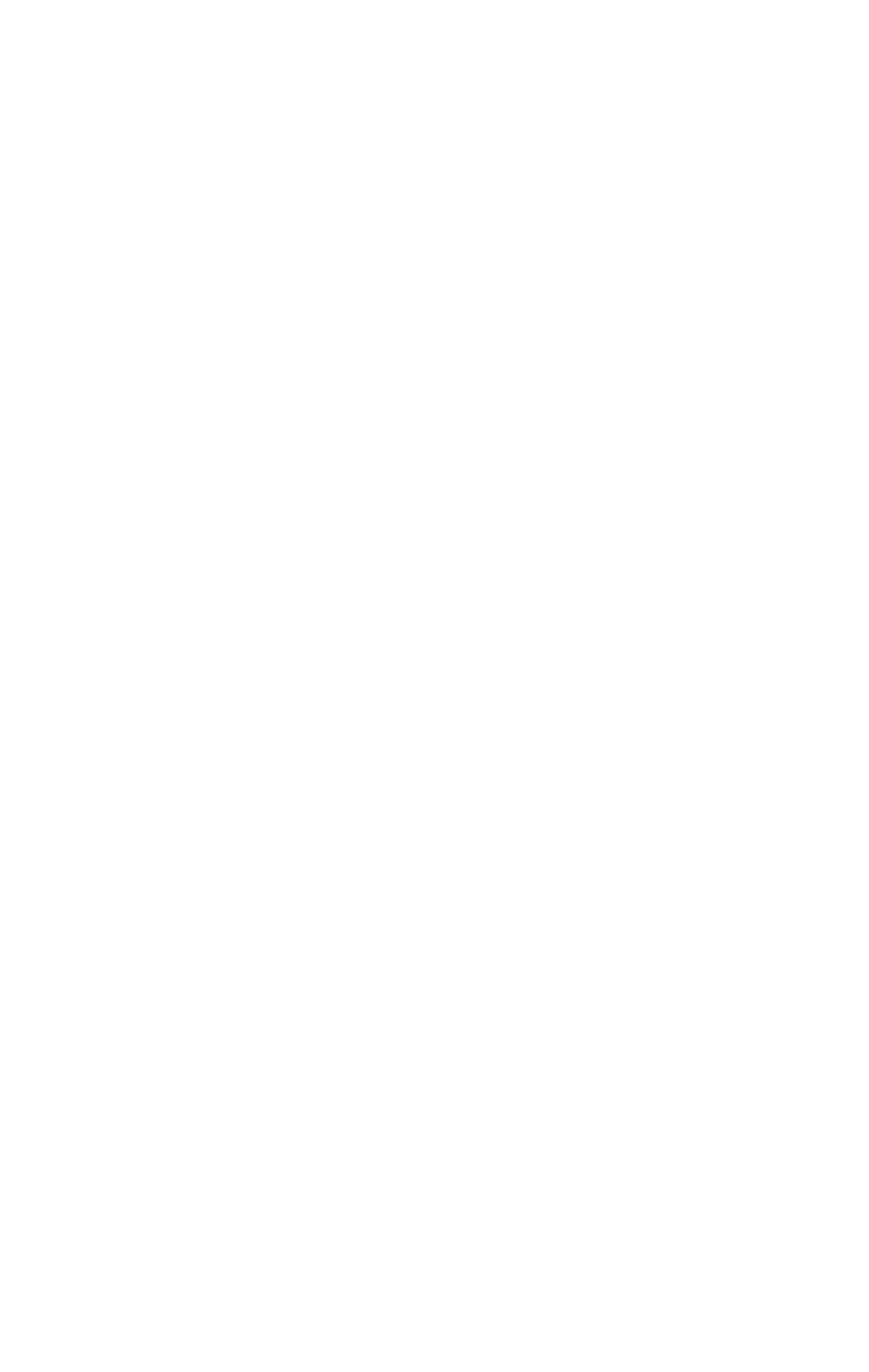




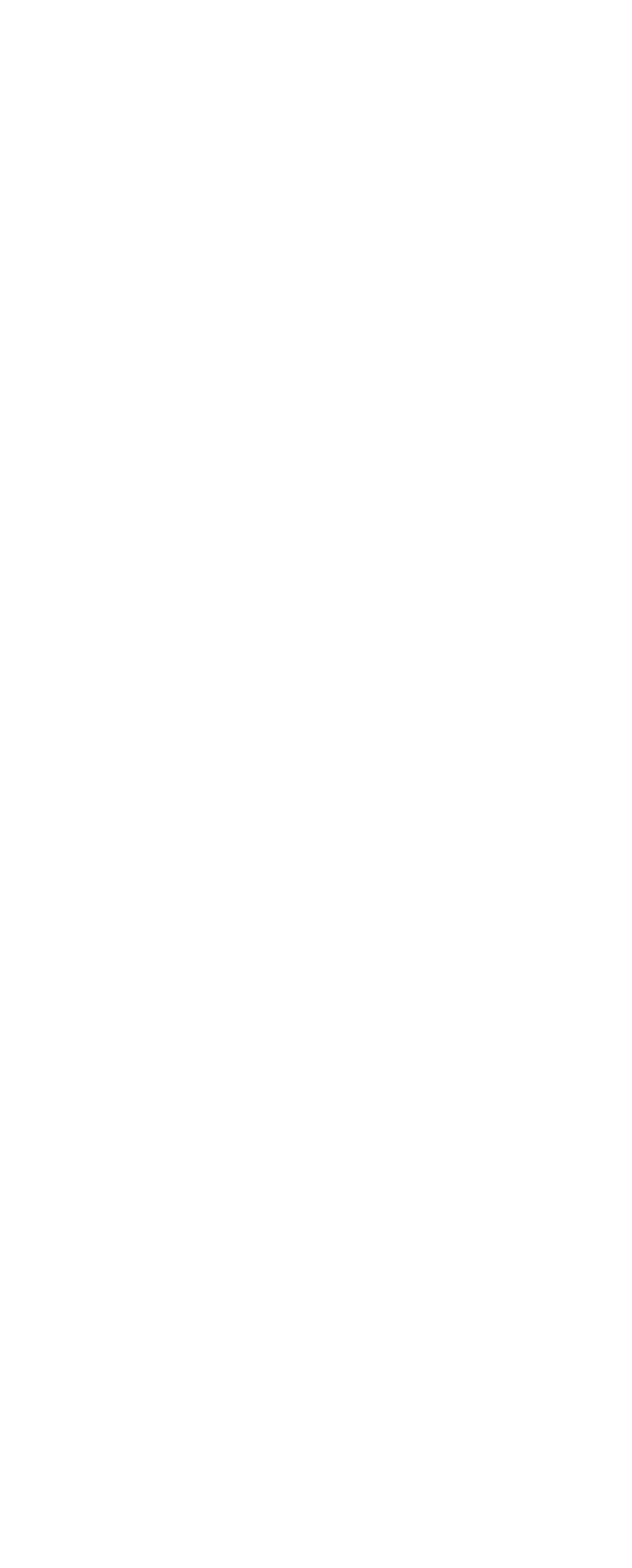




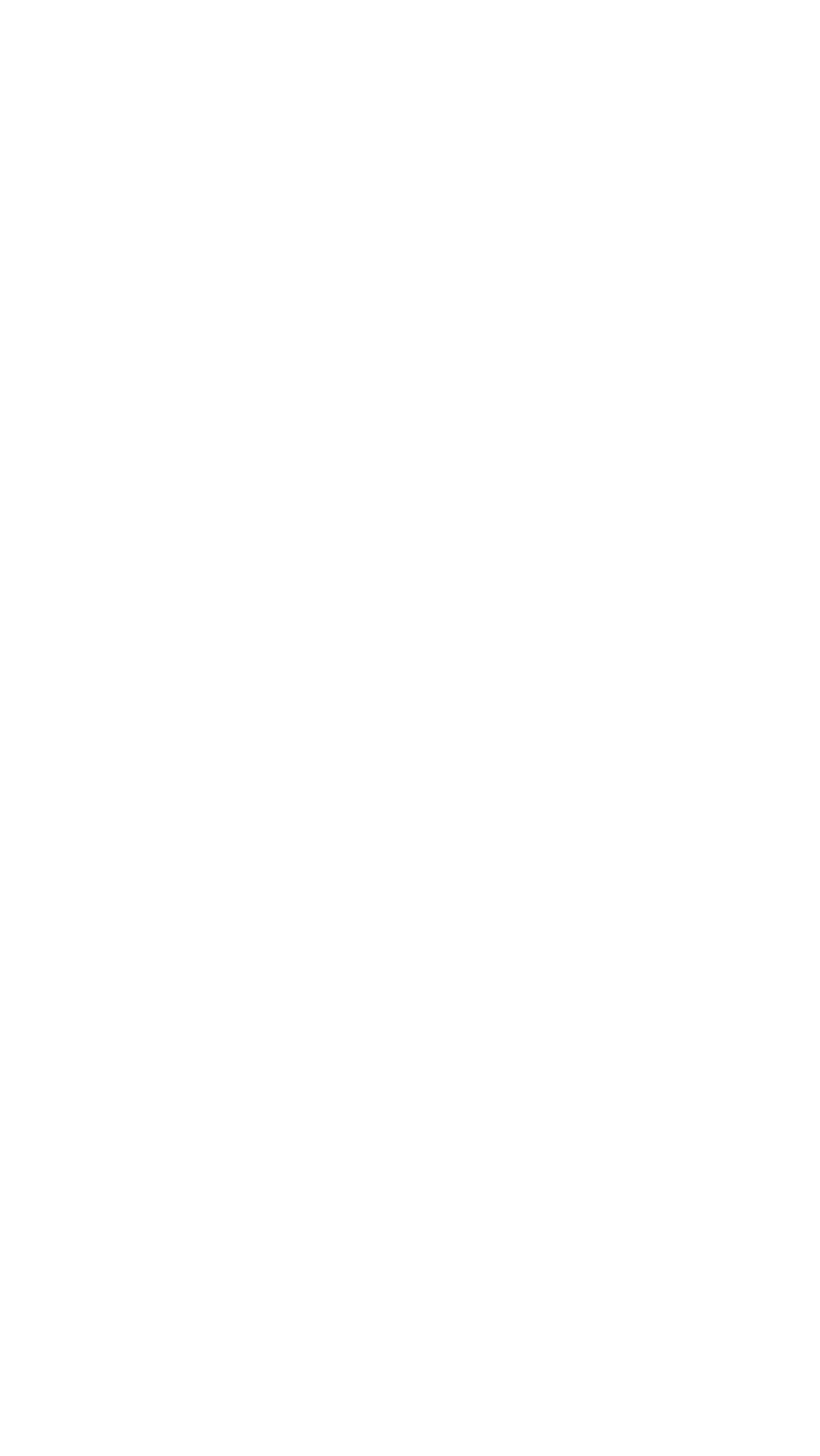




\section{$\underline{\text { INDEX }}$}

Acidity $\ldots \ldots \ldots \ldots \ldots \ldots \ldots \ldots \ldots \ldots$ 19-20 Adamsvilie, Ohio, Raccoon Creek at.. 112-117 Alexandria Bay, N.Y., St. Lawrence River at..................

Allegheny River, at Ki Kïanning, Pa...

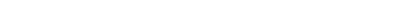
bel ow reservol $\mathrm{r}$, near Kinzua, $\mathrm{Pa}$... near Kinzua, Pa.................

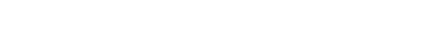

Analyses of sampies coilected at low flow on streams in the Ohio River basin in Ohio.... in the St. Lawrence River basin

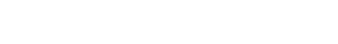

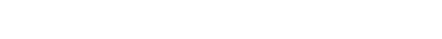
Ashley, Ohio, Whetstone Creek near..
Asheville, N.C., French Broad River

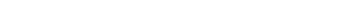
Athens, Ohio, Hocking River below... Au Sable River at Grayling, Mich.... South Branch, near Luzerne, Mich.. Auglaize River, at Cloverdale, Ohio. near Defiance, Ohio..............

Baldwinsville, N.Y., Seneca River at Barbourville, $\mathrm{Ky}_{\text {. , Columbia River at }}$

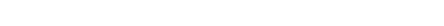

Barren River at Bowling Green, Ky... near Finney, Ky................

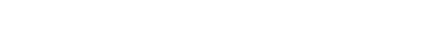
near Hackleburg, Ala ................... Beaver River at Moshier Falis, N.Y.

Beaver Bent Creek, N.C., French Broad

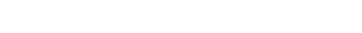
Bessemer, Mich., Black River near... Beverly, Ohio, Muskingum River near. Bicarbonate, carbonate and hydroxide..................

Big Raccoon Creek near Fincastie, Ind.....................249-251 Big Sandy River basin............ iis 123,348 Biochemical oxygen demand............ Bishop, Ala., Bear Creek at.......... Black Creek at Churchville, N.Y.....

Black River, at Elyria, Ohio......... at Watertown, N.Y................ below Elyria, Ohio.................. near Bessemer, Mich.............. near Fargo, Mich.................. near Garnet, Mich................... near Garnet, Mich.................. Blantyre, N.C., French Broad River

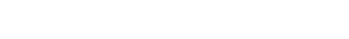

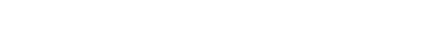
Boardman River near Mayfield, Mich.:

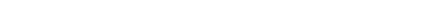

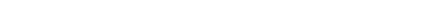
Bouquet River at Willsboro, N.Y..... Bourneville, Ohio, Paint Creek near. Bowling Green, Ky., Barren River at. 243-244 Brasher Iron Works, N.Y., Deer River at........................

Bridgeport, N.Y., Chittenango Creek

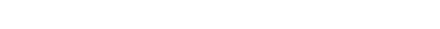

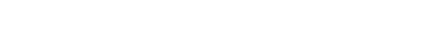
Bryson $\mathrm{C} i \mathrm{t} y, \ldots .$. . . . Tuckasegee River at....................

Buffalo Creek at Gardenvi ile, N.....

Wet Prong, near Mammoth Cave, $\mathrm{Ky}, 238-239$ Buffalo River near Flat Woods, Tenn.........................

Bullrun Creek near Haijs crossroads,

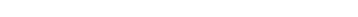

Burgin, Ky., Dix River near.......... Burkesville, Ky., Cumberland River near..................... 274-275 Butternut Creek near Jamesville, N. Y.................. 508-509

\section{Cabin Creek, w. Va., Kanawha River}

$$
\text { at..................... }
$$

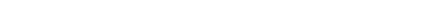

Cambridge, ohio, Salt Fork near......

Campbellsville, Ky., Green River near................... 228

Canaseraga Creek near Canaseraga,

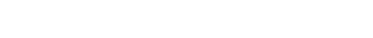

Canton, N.C., Pigeon River at.......... 283

Carr Fork near Sassafras, Ky........ 211-212

Cass River at Frankenmuth, Mich..... 433-435

Casselman River at Grantsville, Md... 63

Cataloochee Creek near Cataloochee,

N.C.................... 285-286

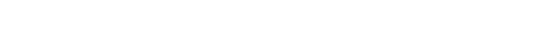

Cedar Creek near'pleasant Site, Ala. $\quad 312$

Celo, N.C., South Toe River near.... 287-288

Centertion, Ind., White River near... 255-256

Champion, Mich., Peshekee River near 393

Charleston, W. Va., Kanawha River at 108

Chase, Ala, , Flint River near....... 307

Cheat River at Lake Lynn, Pa......... 61

Chemical analyses of lakes in $\ldots \ldots . . .538$

Chemical oxygen demand............ 21-22

Chemical quality ..................... Cold Water Streams in Michigan 539-542 Chilhowee Dam, Tenn., Little Tennessee River below......... 295

Chillicothe, Ohio, Scioto River at... 139-141 Chittenango Creek at Bridgeport, N.Y.................. 510

Chloride.................. 14

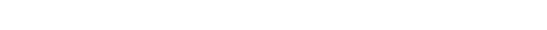

Clarion River basin............33-42,342

Clay, w. Va., Elk River at........... 106

Cleveland, Ohio, Cuyahoga River at... 484-487

Cuyahoga River in.......481-483; 488-489

Clinch River at Speers Ferry, Va.... 297

Clinton

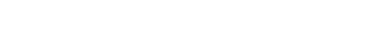

Cloverdale, Ohio, Auglaize $\ddot{R}$ iver at. $448-449$

Cold Spring Creek basin........... 338

Cold Water streams in Michican, Chemical-quality

Investigations of .......... 539-542

Collection and examination of data...

Color......................... 20-21

Composition of

$\begin{array}{llr}\text { Conemaugh River at Seward, Pa...... } & 42-43 \\ \text { Conewango Creek at Waterboro, } \mathrm{N}, \dot{\mathrm{Y}} \ldots & 38\end{array}$

Constantia, N.Y., Scriba Creek near. 511-512

Cooksburg, $\mathrm{Pa}$. , Torns Run at........ 39

Cooperation.................. 27-29

Copper...................... 16

Cowaseion $\mathrm{Creek}$ at oniontown, N. Y...

Crab Orchard Creek near Deermont,

Cumberland River, at Bäbourvilie, Ky...................

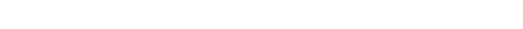

Cumberland River bas in... $2723-275,357-360,383$

Cuyahoga River at Center street Bridge, in Cleveland, Ohio....488-489 at Dupont intake, in Cleveland, Ohio.............481-483

at Independence, ôhio................... 476-480 at West Third Street Bridge, Cleveland, Ohio.......... 484-487 
Cynthiana, Ky., South Fork Licking River at. South Fork ticking D

Dayton, Ohio, Mad River near....... 181-182 Deer Creek at Williamsport, Ohio.... 136-138 Deer River at Brasher Iron Horks,

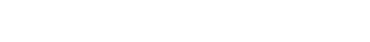

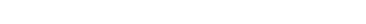
Defiance, Ohio, Auglaize River near.

Maumee River at............... 445-447

Dial, Ga., Toccoa River near......... Dillon Fails, Ohio, Licking River

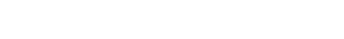

Dillsboro, N.C., Tuckasegee River

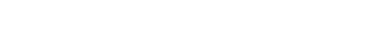

Dissolved oxygen $\ldots \ldots \ldots \ldots \ldots \ldots \ldots \ldots \ldots \ldots$
Dissolved solids $\ldots \ldots \ldots \ldots \ldots \ldots \ldots \ldots \ldots$

Dissolved solids

Dix River at Dix Dam near Bur

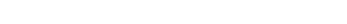

Donnattsburg, N.Y. $_{\text {. }}$ Independence River at................ Drayton Plains, Mich., Clinton River near................. Dresden, Ohio, Muskingum River at... Dundee, Ky., Rough River at.........

\section{E}

Eagle City, Ohio, Mad River at...... 178-180 Eagle Creek at Glencoe, Ky ......... 222-225 East Branch Fish Creek at Taberg, N.Y...................... 503-504 East Fork Litile Miami River at Perintown, Ohio.........................

East Fork Poplar Creek near Oak

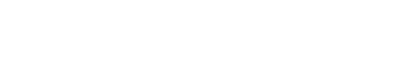

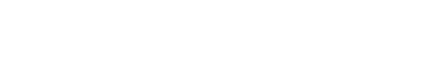

Eaton Rapids, Mich., Grand River

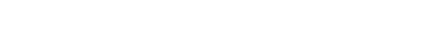

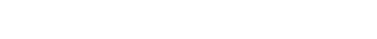

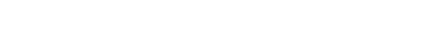

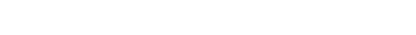

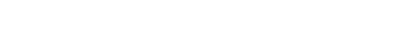
Elkhorn City, ky., Russeii Fork at... Elkins, W. Va., Tygart Valley River

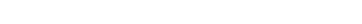

Elyria, Ohio, Biack River at..........

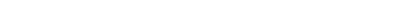

Englewood, ohio, stiliwater River

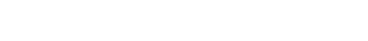

Evart, Mich., Muskegon River at......

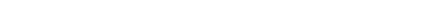

$$
\text { F }
$$

Falls of Rough, Ky, Rough River

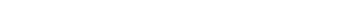

Fargo, Mich., Bl ack River near...... 436-437 Farmers, Ky., Licking River at....... 159-162 Fence, Wis., popple River near....... 397-399 Fincastle, Ind., Big Raccoon Creek near......................

Finney, Ky., Barren River near.....

Fish Creek, East Branch, at Taberg, N, Y

West Branch, at Blossvaie, $\ddot{N}, \mathrm{Y}_{\ldots} \ldots$. Flat Woods, Tenn., Buffalo River

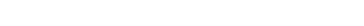

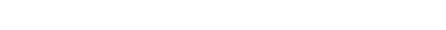

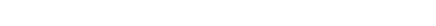
Ford River near Hyde, Mich.......... Fort Wayne, Ind., St. Marys River

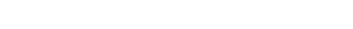

Foster C1ty, Mich., sturgeon $\mathrm{kiver}$

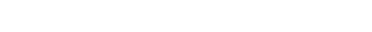

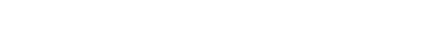
Frankenmuth, Mich., Cass River at... 433-435 Frankfort, Ky. , Kentucky River at... 217-221 Fraser, Mich., Clinton River near... Freesoil, Mich, Little Manistee

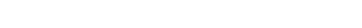

Fremont, ohio, Sandusky River bëlow. 466-469
French Broad River, at Asheville,

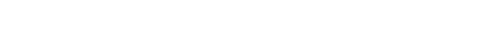

at Blantyre,, . C...................

at Hot Springs, N.C............. 282

at Marsha11, N.C................. 280-282

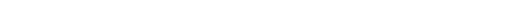

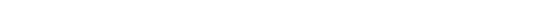

Friendship, N.Y., Vä Campen Cre ek

Friendsviile, Md., Youghioghèny

River at.................

G
89

293

21

$29-30$

216

529

437
$85-87$

246

156-158

300-301

25 7-260

419

401

01-204

106
107

104

105
118

118

$470-472$ 176-177

317-318

307
14

14
392

442-444

100

5

438

417
Gardenville, N.Y, Buffalo Creek at

Garnet, Mich., Black River near.....

Genesee River at Driving Park

Avenue, Rochester, N.Y........

500

Germantown, Ohio, Twin Creek at..... 190

Glen Lyn, Va., New River at......... 100

Glencoe, Ky., Eagle Creek at........ 222-225

Grand Chain, I11., ohio River near... 321-324

Grand River, at Lansing, Mich....... 402

at painesville, Ohio............ 490-495

at Portland, Mich................. 403

near Eaton Rapids, Mich........... 401

Grantsville, Md., Casselman River

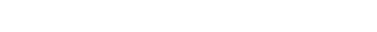

Grassy Run at Norton, W. Va....... 55-57

Grayling, Mich., Au Sable River at..

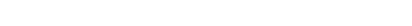

Great Miami River, at Elizabethtown,

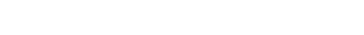

at New Baltimore, ohio.............. 198-200

at Troy, ohio................... 169

at West Carroliton, Ohio.......... 183-184

near Hamilton, Ohio............... 196-197

near Miamisburg, ohio.............. 185-189

near Middletown, ohio............. 193-194

near Taylorsvilie Dam, at

Taylorsville, ohio.........170-171

Great Miami River basin. 169-234,332-333, 379

Great Valley Creek Basin.......... 337

Green River, at Mammoth Cave, Ky.... 237-238 at Munfordville, Ky............ 231-236

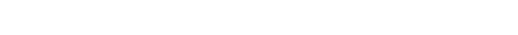

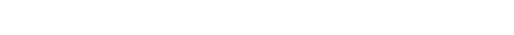

Green River basin. ............ $228-246,350$

$\begin{array}{lr}\text { Greensburg, Ky ., Green River near... } & 229 \\ \text { Greenup, Ky., Týgarts Creek neər.... 124-126 }\end{array}$

\section{$\mathrm{H}$}

Hackleburg, Ala., Bear Creek near... 310-311 Halls Crossroads, Tenn., Bullrin Creek near . $¥ \ldots \ldots \ldots \ldots \ldots \ldots$. Halltown, Ala., Littie Bear Creek

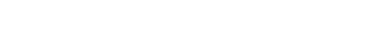

Hamilton, ohio, Great Miami River àt

Hardness.................... 196.197

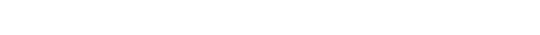

Hazard, Ky., North Fork Kentucky River at...............213-215

Hepco, N. C., Pigeon River near....... 284

Heuvelton, N.Y., Oswegatchie River

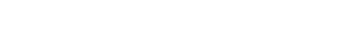

Higby, ohio, sicioto River at............

Hocking River below Athens, ơio.... 146-151

Holston River near Rogersville,

Tenn..................... 291

River at................. 282

Houghton Creek near Lupton, Mich....

Huntington, Ind., Wabash River at... 247

Hyde, Mich., Ford River near........ 392

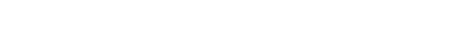

Independence, Ohio, Cuyahoga Rjver at...................476-480

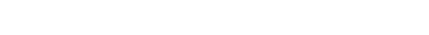

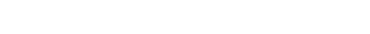

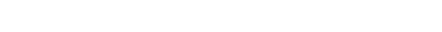

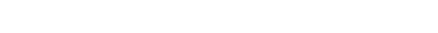

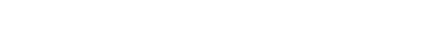

Ishpeming, Mich., Middle Branch Escanaba River

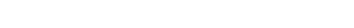


Jamesville, N.Y., Butternut Creek near................... Johns Creek near Van Lear, Ky...... Jonesville, Va, Powell River near. Jordan River near East Jordan, Mich.

K

Kanawha River, at Cabin Creek,

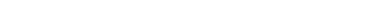

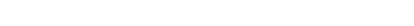
at Winfield Dam, at Winfield, W. Va................. 109-111

Kanawha River basin......... 100-1i1, 346-347 Kentucky River at 1 ock 4 , at Frankfort, Ky........... 217-221 Nor th Fork, at Hazard, Ky .........213-215 Kentucky River basin.... $211-225,348-349,383$ Kepler, Tenn, , Beech Creek at....... 289-290 Kermit, $w$. Va, , Tug Fork at.........

Killbuck Creek at Killbuck, Ohio.....

Kinzua, Pa, Allegheny River near............... 33-35,36-38 Kiskiminetas River at Leechburg (Vandergrift), $\mathrm{Pa}, \ldots \ldots \ldots . . .44-46$

Kiskiminetas River basin......... 42-46,343 Kittanning, $\mathrm{Pa}$. , Allegheny River at. $40-42$ Knapp Creek at Marlinton, w. Va..... 102 Kyrock, $\mathrm{Ky}$. , Nolin River at........ 240-241

$$
\text { L }
$$

Lafayet te, Ind, Wabash River at.... Lake Lynn, Pa., Cheat River at...... Lake port, N.Y., Canaseraga Creek

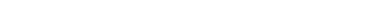

Lansing, Mich., Grand River at.......

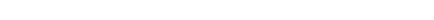

Leavitisburg, Ohio, Mahoning River Leechburg, Pa... Kiskiminetas River

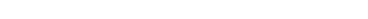

Levisa Fork at Paintsvilie, Ky .... 120 Licking River at Farmers, Ky ...... 159-162 at McKinney sburg, Ky.............. 163-167 below Dillon Dam, near Dilion

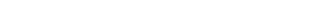

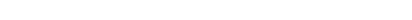

South Fork at Cynthiana, Ky........

Licking River basin................ 159-168 downstream order, for which records are published........ VII-XIV

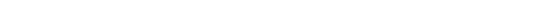

Lithium

Little Barren River near Monrö, $\mathrm{Ky}$.

Little Bear Creek near Halltown, Mla.......................... Merint inn

Little Manistee River near Freesoil,

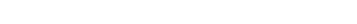

Little Muskegon River near Morley,

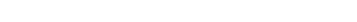

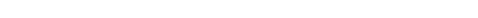

Little Tennessee River below Chilhowee Dam, Tenn.........

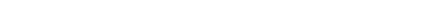
Lowellville, Ohio, Mahoning River

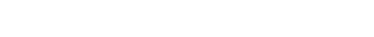

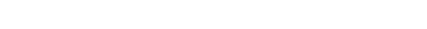
Lucasville, Ohio, Scioto River at... Lupton, Mich., Houghton Creek near...

Luther, Mich., Pine River near......

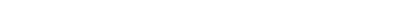

Luzerne, Mich., South Branch Au Sable River near............

McGaw, Ohio, Upper Twin Creek at... McKinneysburg, Ky., Licking River at ..................... 163-167

Mad River at Eagle City, Ohio....... 178-180

near Dayton, Ohio.............. 181-182

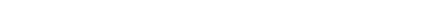

Mahoning River, at Leavitusurg,

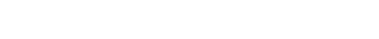

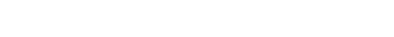
below Lowellville, Ohio.......
Mahoning River, West Branch, near Ravenna Ohio......................

Mammoth Cave, Ky., Green River at... 237-238

Wet Prong Buffalo Creek near..... 238-239

Manganese ................... 11-12

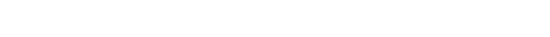

Marlinton $W$. Va., Knapp Creek at... 102

Marshall, N.C., French Broad River

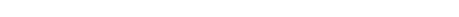

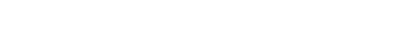

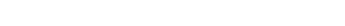

Maumee River, at $\ddot{\text { Center }} \mathrm{C}$ and $\ddot{o}$.

Railroad dock, at Toledo, Ohio 464-465

at Defiance, Ohio.............445-447

at mouth, at U.S. Coast Guard Station, at Toledo, Ohio...

at Toledo Overseas Terminal Dock, at Toledo, Ohio..........4 460-461

at Waterville, ohio...............453-459

Mayfield, Mich., Boardman River

near................ 418

Metropolis, iii... ohio River at..... 320

Miamisburg, Ohio, Great Miami River near.................... 185-189

Michigamme River near Witch Lake,

Mich. ..................394-396

Michigan, Chemicai-Quality

Investigations of Cold Water

Streams in.............. 539-542

Middle Branch Escanaba $\ddot{R} i v e r$ near

Ishpeming, Mich,.......... 390

Middlesboro, Ky, Yellow Creek near, $\quad 272$

Middletown, Ohio Great Miami River

at ..................... 191-192

Great Miami River near................. 193-194

Mineral constituents in solution.... 11-18

Miscellaneous analyses of lakes ard streams, in Ohio River basir.. 335-368

in St. Lawrence River basin...... 538-570

in St. Lawrence River basin,..... 8 , at Point Marion, Pa...... 58-60

at South Pittsburg, $\mathrm{Pa} \ldots \ldots \ldots \ldots \ldots, 64-67$

Monong ahe la River basin...... 51-67,343-344

Monroe, Ky, , Little Barren River

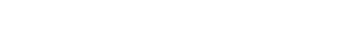

Monroe, Mich, . River Raisin near.... 439-441

Morley, Mich., Little Muskegon River 405

Moshier Faiis, $\mathrm{N}, \ddot{Y}$ Beaver River at 530

Munfordville, $\mathrm{Ky}_{\text {. }}$, Green River at... 231-236

Muskeg on River at Evart, Mich....... 404

Muskingum River, at Dresden, Ohio... $85-87$

at Philo, Ohio............... 90.93

near Beverly, ohio............. 94-96

Muskingum River basin........ $8 \dot{8} \dot{1}-\dot{9} \dot{6}, 326-329$

$$
\mathrm{N}
$$

New Baltimore, Ohio, Great Miami Rjver at 198-200

New River at Bluestone Dam, W. Va... 101 at Glen Lyn, Va................. 100 Newark, Ohio, Licking River near.... 88 Nickel and cobalt.............. 15-16 Nitrate....................... 14 Noblesviile, ind., White River at.... White River near.............. 252 Nolin River at Kyrock, Ky............ 240-241 Nora, Ind., White River near......... 254 North Fork Kentucky River at Hazard, Ky............... 213-215 Norton, w. Va., Grassy Run at ..... 55.57 Roaring Creek at............... 52.54

$$
0
$$

Oak Ridge, Tenn., East Fork Poplar Creek near.............300-301 Oakmont, Pa., Al legheny River at.... 40.50 Ogdensburg, N.Y., St. Lawrence

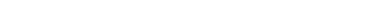

Ohio River at $\mathrm{lock}$ and dam 53 , near Grand Chain, I11...... 321-324

at Markland Dam, near Warsaw, Ky... 205-210 at Metropolis, ill........... 320 at stratton, ohio............. 77-80 Ohio River basin, records available for water temperatures in.... 383 Spectrographic analyses of lakes

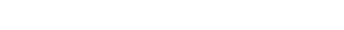
of samples collected at low flow on streams in........... 
Ohio River basin in Ohio, pesticide analyses of streams in........

Ohio River basin................

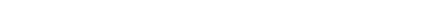

olean Creek basin.................

olentangy River near worthington,

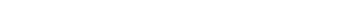

Olney, Ky., Tradewater River at .....

Oneida Lake, USGS Station Nos. $8-22$,

Oneida River below dam, at

$5 \ldots \ldots 528$

Caughden oy N,Y,

Oniontown, N.Y., Cowasei on Creek

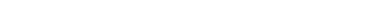

organics .......................

Oswago Creek basin .......................

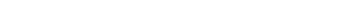

Owasso Mich Shiawassee River at. 43053

Oxygen consumed.................

\section{$\mathbf{P}$}

Paducah, Ky., Tennessee River near..

Painesville, Ohio, Grand River at. 490 319

Paint Creek near Bourneville, ohio.. 142-145

Paintsville, Ky., Levisa Fork at.... 120-123

Palmer, Mich., S'chweitzer Creek near

Per 1 town, Ohto, East Fork Little

Miami River at.............. 156-158

Peshekee River near Champion, Mich..

Pesticide analyses of streams in, Ohio River basin in Ohio......

st. Lawrence River basin in ohio... Petersburg, Ind., White River at.... Philo, ohio, Muskingum River at.....

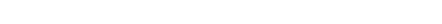

Pigeon River, at Canton, $_{\mathrm{N}}, \ldots \ldots \ldots \ldots$

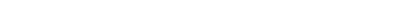

near Hepco, N.C.................

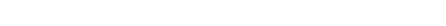

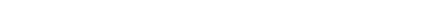

Piney River at Vernon, Tenn.............. 315-316

pleasant H1ll, Ohio, stillwater

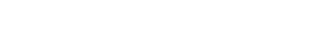

Pleasant Site, Ala., Cedar Creek

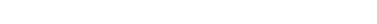

Point Marion, Pa., Monongaheia

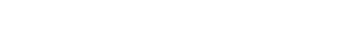

Poplar Creek, East Fork, near Oäk

Ridge, Tenn...................300-301

Popple Creek near Fence, Wis........ 397-399

Portland, Mich., Grand River at......

Powell River near Jonesville, Va....

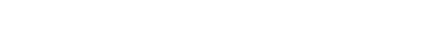

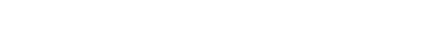

Properties and characteristics of water.....................

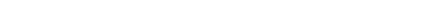

Pulaski, Tenn., Richiand $\ddot{\text { Creek }}$

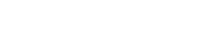

Q

Queen Shoals, W. Va., Elk River at.. R

Raccoon Creek at Adamsville, Ohio... 112-117 Raccoon Creek basin...... 112-ii , 329,345 Ravenna, Ohio, West Branch Mahoning River near.................. Records available for water

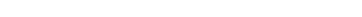

Republic, Mich, Biäk River near... 388-389 Richland River near Pulaski, Tenn... 308-309 Rifle River, at Selkirk, Mich....... at "The Ranch," near Lupton, Mich.....................

near Sterling, Mich .......... 427-428

River Raisin near Monroe, Mich...... 439-441

Roaring Creek at Norton, w. Va...... 5 52-54

Rochester, N.Y., Genesee River at...

Rogersvilie, Tenn., Holston River

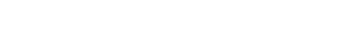

Rolling Fork near Boston,

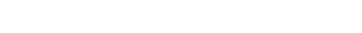

Rough River, at Dundee, Ky......... at Rough River Dam, near Fai is of Rough, $\mathrm{ky}, \ldots \ldots \ldots \ldots \ldots \ldots \ldots$

291

227

276

246

245
Russel 1 Fork at Elkhorn City, Ky....

St. Lawrence River, at Alexandria Bay, N.Y.................. 532

at Ogdensburg, $N, Y \ldots \ldots \ldots \ldots \ldots \ldots \ldots . \ldots \ldots$

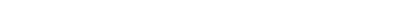

t. Lawrence River basin in öhic, Analyses of Samples Collected at Low Flow on Streams in..... St. Lawrence River bas in ..... 584-570 $\mathrm{St}$. Marys River near Fort Wayne,

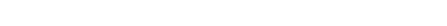

Salt Creek near Harrodsburg, Ind.... 261

Salt Fork at mouth, near Cambridge, ohio.................... 84

Salt River at Shepherdsvilie, Ky.... 226

Salt River basin.............226-227,383

Sandusky River below Fremont, ohio.................... 466-469

Sassafrass, Ky . Carr Fork near...... 211-212

Schweitzer Creek near palmer, Mich.. 391

Scioto River, at Chillicothe, Ohio.. 139-141

at Higby, ohio.............. 146-151

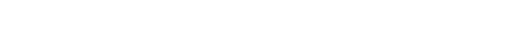

below Shadehili, Ohio.................. 134-135 Scioto River basin.......... 127-154,329-330 Scriba Creek near Constantia, N.Y... 511-512

Sediment...................6-7,24-25

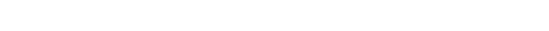

Rifle River at................ 426

Seneca River at Baidwinsviile, $\mathrm{N}_{.} \mathrm{Y}_{\ldots}$.

Sequatchie River near Whitwell, Tenn 306

Seward, $\mathrm{Pa}$. , Conemaugh $\mathrm{River}$ at..... $42-43$

Seymour, Ind., East Fork White River at. ............... 257-260

Shadehil1, ohio, Scioto River below. 134-135

Sheperdsville, Ky., Salt River at... 226

Shiawassee River, at Byron, Mich.... 429

at Owosso, Mich............... 430-432

silica.........................

Silver Creek near Luther, Mich....... 411

Sodium adsorption ratio........... 19

Sodium and potassium............. 12-13

South Branch Au Sable River near .... Luzerne, Mich............. 422

South Fork Licking River at

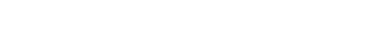

South Pittsburg, Pa., Monongaheia River at................ 64-67

South Toe River near $\mathrm{Cel}$

Specific conductance.............. 20

Spectrographic analyses of lakes and streams in, Ohio River

basin................ 378

st, Lawrence River basin $\ldots \ldots \ldots . \ldots . . .56$

Speers Ferry, Va., Clinch River

sterling, Mich... Rifie River ......

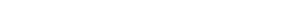

Stillwater River, at Englewood, Ohio.................... 176-177

at Pleasant Hiij, ohto............... 172-175

Stratton, Ohio, ohio River at....... $77-80$

Streamflow..................... 25

Streams tributary to, Lake

Erie.... 439-496,543-544,545,552-554

Lake Huron..............420 42-435,540-542

Lake Michigan,.............. 378-419,539-540 $378-419,539-540$
$546-552,567-570$

Lake Ontario........... $497-531,554-565$

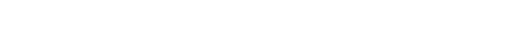

St. Lawrence River........ 532-537,565,570

strontium..................... 12

Sturgeon River, near Foster City,

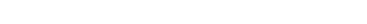

Sulfate.......................... 13

Sutton, w. va... E⿺辶巛 River at.........
$\mathrm{T}$

Taberg, N.Y., East Branch Fish Creek at .................. 503-504 Taylorsviile, ohio, Great Miani

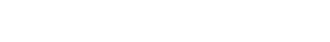
Tenn.................... 
Temperature................. 5-6,22-23 Tennessee River at Kentucky Dam near Paducah, Ky........... 319

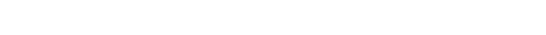
$380-381,382,383$

Toccoa River near Dia1, Ga.........

Toledo, Ohio, Maumee River at.... 460-461,462-463,464-465

Tomotla, N.C., Vailey River at..... 303-304

Toms Run at Cooksburg, Pa...........

Townsend, Tenn., Little River above. 292-293

Tradewater River at Olney, Ky...... 263-271

Tradewater River basin..... 263-271,354-357

Troy, Ohio, Great Miami River at.... 169

Tuckasagee River, at Bryson City,

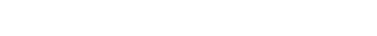

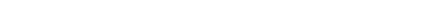

Tug Fork at Kermit, $w$. Va...........

Turbidity....................

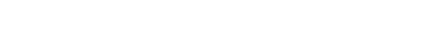

Tygart Valley River at Elkins,

Tygarts Creek near Greenup, Ky.......

Upper Twin Creek at McGaw, Ohio.....

Upper Twin Creek basin......... 155,331

USGS Station Nos, $8-22, N . Y$. Oneida Lake............... 513-528

$\mathrm{V}$

Valley River at Tomotla, N.C....... 303-304

Van Campen Creek at Friendship, N.Y................... 497

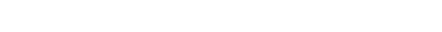

Vernon, Tenn, , piney River at...... 315-316

W

Wabash River, at Huntington, Ind.... at Lafayette, Ind.

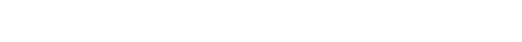

Warsaw, Ky., Ohio River near........ 205-210

Washington Creek at Windigo, Mich... 384-335
Water temperatures, records available for Ohio River basin.................. 383 Waterboro, N.Y., Conewango Creek at. $\quad 38$ Watertown, N.Y., Black River at..... 531 Waterville, N.C., Pigeon River at.... 287 Waterville, Ohio, Maumee River at ... 453-459 Weliston, Mich., Pine River near.... 412-416 West Branch Fish Creek at Blossvale, N.Y.............. 502

West Branch Mahoning River near Ravenna, Ohio 68

West Carrollton, Ohio, Great Miami River at ................. 183-184 Wet Prong Buffaio $\ddot{\text { Creek near }}$ Mammoth Cave, Ky........... 238-239

Whetstone Creek near Ashley, Ohio... 127-128 White River, at Noblesville, Ind... 253

at Petersburg, Ind............. 262 East Fork, at'seymour, Ind........ 257-260 near centerton, Ind............. 255-256 near Noblesville, Ind............ 252

near Nora, Ind................. 254 Whitwel1, Tenn., Sequatchie River near.................. 306

williamsport, ohio, Deer Creek at... 136-138 Willsboro, N.Y., Bouquet River at... 537 Windigo, Mich, Washingt on Creek at. 3\%4-385 Winfield, W. Va., Kanawha River at.. 109-111

Witch Lake, Mich., Michigame River

Witch Lake, Mich., Michigamme River $394-396$

Wolverine, Mich., sturgeon River near................. 420

Worthington, Ohio, olentangy River near.................... 129

$\mathrm{Y}$

Ye1low Creek near Middlesboro, кy..................... 272

Youghiogheny River at Friendsvilie, Md..................... 62 
, 